NUREG/CR-0200, Rev. 5

ORNL/NUREG/CSD-2/R5

Vol. 2, Part 3

\title{
SCALE
}

\section{A Modular Code System for Performing Standardized Computer Analyses for Licensing Evaluation}

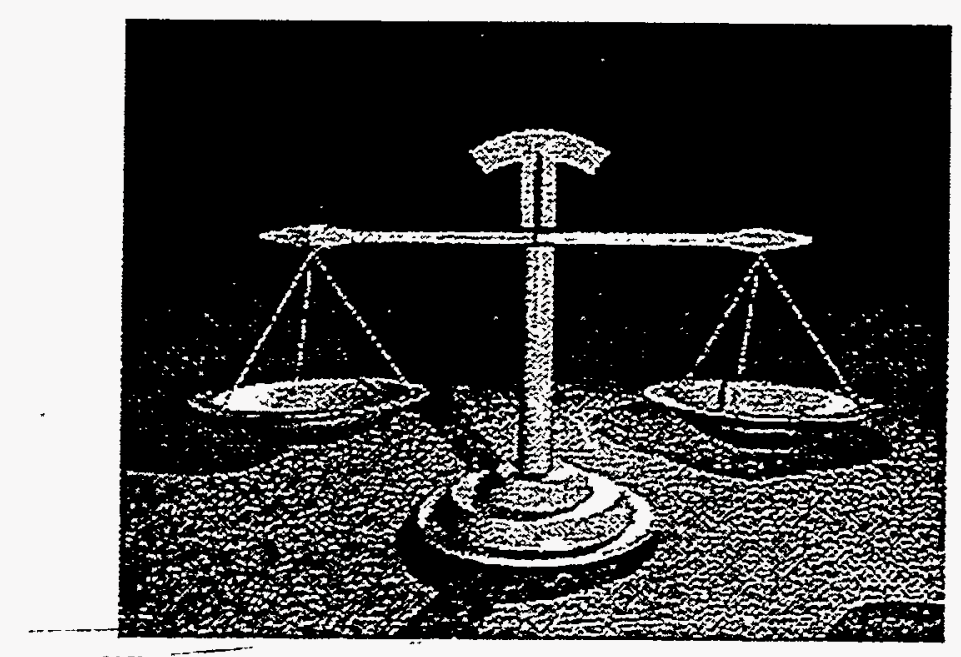

Functional Modules, Part 3

Oak Ridge National Laboratory

Prepared for

U.S. Nuclear Regulatory Commission
RECEIVED

MAY $O>1997$

OSTI

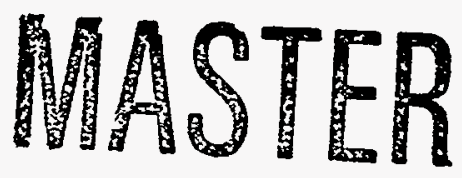

DISTRIEUTION OF THS DOCUNENT is UMERED 


\section{DISCLAIMER}

This report was prepared as an account of work sponsored by an agency of the United States Government. Neither the United States Government nor any agency thereof, nor any of their employees, make any warranty, express or implied, or assumes any legal liability or responsibility for the accuracy, completeness, or usefulness of any information, apparatus, product, or process disclosed, or represents that its use would not infringe privately owned rights. Reference herein to any specific commercial product, process, or service by trade name, trademark, manufacturer, or otherwise does not necessarily constitute or imply its endorsement, recommendation, or favoring by the United States Government or any agency thereof. The views and opinions of authors expressed herein do not necessarily state or reflect those of the United States Government or any agency thereof. 


\section{DISCLAMMER}

Portions of this document may be illegible in electronic image products. Images are produced from the best available original document. 
NUREG/CR-0200, Rev. 5

ORNL/NUREG/CSD-2/R5

Vol. 2, Part 3

\section{SCALE: A Modular Code System for Performing Standardized \\ Computer Analyses for \\ Licensing Evaluation}

Functional Modules

F16-F17

Manuscript Completed: December 1996

Date Published: March 1997

Oak Ridge National Laboratory

Managed by Lockheed Martin Energy Research Corp.

Oak Ridge National Laboratory

Oak Ridge, TN 37831

Prepared for

Spent Fuel Project Office

Office of Nuclear Material Safety and Safeguards

U.S. Nuclear Regulatory Commission

Washington, DC 20555-0001

NRC Job Code B0009 


\section{AVAILABILITY NOTICE}

Availability of Reference Materials Cited in NRC Publications

Most documents cited in NRC publications will be available from one of the following sources:

1. The NRC Public Document Room, 2120 L Street, NW., Lower Level, Washington, DC 20555-0001

2. The Superintendent of Documents, U.S. Government Printing Office, P. O. Box 37082, Washington. DC 20402-9328

3. The National Technical Information Service, Springfield, VA 22161-0002

Although the listing that follows represents the majority of documents cited in NRC publications, it is not intended to be exhaustive.

Referenced documents available for inspection and copying for a fee from the NRC Public Document Room include NRC correspondence and internal NRC memoranda; NRC bulletins, circulars, information notices, inspection and investigation notices; licensee event reports; vendor reports and correspondence; Commission papers; and applicant and license日 documents and correspondence.

The following documents in the NUREG serles are available for purchase from the Government Printing Office: formal NRC staff and contractor reports, NRC-sponsored conference proceedings, international agreement reports, grantee reports, and NRC booklets and brochures. Also available are regulatory guides, NRC regulations In the Code of Federal Regulations, and Nuclear Regulatory Commission Issuances.

Documents avallable from the National Technical Information Service include NUREG-series reports and technical reports prepared by other Federal agencies and reports prepared by the Atomic Energy Commission. forerunner agency to the Nuclear Regulatory Commission.

Documents available from public and special technical libraries include all open literature items, such as books, journal articles, and transactions. Federal Register notices. Federal and State legislation. and congressional reports can usually be obtained from these libraries.

Documents such as theses, dissertations, foreign reports and translations, and non-NRC conference proceedings are available for purchase from the organization sponsoring the publication cited.

Single coples of NRC draft reports are available free. to the extent of supply. upon written request to the Office of Administration, Distribution and Mail Services Section, U.S. Nuclear Regulatory Commission, Washington, DC 20555-0001.

Copies of industry codes and standards used in a substantive manner in the NRC regulatory process are maintained at the NRC Library. Two White Flint North. 11545 Rockville Pike. Rockville. MD 20852-2738, for use by the public. Codes and standards are usually copyrighted and may be purchased from the originating organization or, if they are American National Standards. from the American National Standards institute. 1430 Broadway, New York, NY 10018-3308.

\section{DISCLAIMER NOTICE}

This report was prepared as an account of work sponsored by an agency of the United States Govemment. Neither the United States Govemment nor any agency thereof, nor any of their employees, makes any warranty, expressed or implied, or assumes any legal liability or responsibility for any third party's use, or the results of such use, of any information, apparatus, product, or process disclosed in this report, or represents that its use by such third party would not infringe privately owned rights. 


\section{CONTENTS}

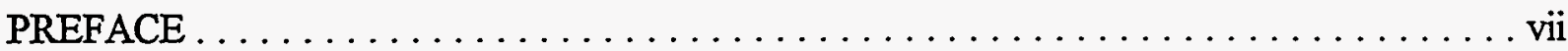

Volume 1, Part 1: Control Modules

C1* CSAS1: A ONE-DIMENSIONAL CRITICALITY SAFETY ANALYSIS MODULE

C2* CSAS2: A MULTIDIMENSIONAL CRITICALITY SAFETY ANALYSIS MODULE

C3*** CSAS3: AN OPTIMUM CONCENTRATION CRITICALITY SAFETY ANALYSIS MODULE

C4 CSAS: AN ENHANCED CRITICALITY SAFETY ANALYSIS MODULE WITH SEARCH OPTIONS (N. F. Landers, L. M. Petrie)

C6 CSAS6: CONTROL MODULE FOR ENHANCED CRITICALITY SAFETY ANALYSIS WITH KENO VI (D. F. Hollenbach, L. M. Petrie)

\section{Volume 1, Part 2: Control Modules}

S1 SAS1: A ONE-DIMENSIONAL SHIELDING ANALYSIS MODULE (J. R. Knight, C. V. Parks, S. M. Bowman, L. M. Petrie, J. A. Bucholz)

S2 SAS2H: A COUPLED ONE-DIMENSIONAL DEPLETION AND SHIELDING ANALYSIS MODULE (O. W. Hermann, C. V. Parks)

S3 SAS3: AN AUTOMATED MONTE CARLO SHIELDING ANALYSIS MODULE (M. B. Emmett, J. T. West)

S4 SAS4: A MONTE CARLO CASK SHIELDING ANALYSIS MODULE USING AN AUTOMATED BIASING PROCEDURE (J. S. Tang)

S5 QADS: A MULTIDIMENSIONAL POINT-KERNEL ANALYSIS MODULE (B. L. Broadhead)

H1 HTAS1: A TWO-DIMENSIONAL HEAT TRANSFER ANALYSIS OF FUEL CASKS, VERSION 4.0 (G. E. Giles)

\footnotetext{
*Obsolete with SCALE-4.0 release.

**Not included in SCALE-4.3 release.

***Cancelled. Included in Section C4.
} 


\section{Volume 2, Part 1: Functional Modules}

F1 BONAMI: RESONANCE SELF-SHIELDING BY THE BONDARENKO METHOD (N. M. Greene)

F2 NITAWL-II: SCALE SYSTEM MODULE FOR PERFORMING RESONANCE SHIELDING AND WORKING IIBRARY PRODUCTION (N. M. Greene, L. M. Petrie, R. M. Westfall)

F3 XSDRNPM: A ONE-DIMENSIONAL DISCRETE-ORDINATES CODE FOR TRANSPORT ANALYSIS (N. M. Greene, L. M. Petrie)

F4 XSDOSE: A MODULE FOR CALCULATING FLUXES AND DOSE RATES AT POINTS OUTSIDE A SHIELD (J. A. Bucholz)

F5* KENO IV/S: AN IMPROVED MONTE CARLO CRITICALITY PROGRAM

F6 COUPLE: SCALE SYSTEM MODULE TO PROCESS PROBLEMDEPENDENT CROSS SECTIONS AND NEUTRON SPECTRAL DATA FOR ORIGEN-S DATA ANALYSES (O. W. Hermann)

F7 ORIGEN-S: SCALE SYSTEM MODULE TO CALCULATE FUEL DEPLETION, ACTINIDE TRANSMUTATION, FISSION PRODUCT BUILDUP AND DECAY, AND ASSOCIATED RADIATION SOURCE TERMS (O. W. Hermann, R. M. Westfall)

F8 ICE: MODULE TO MIX MULTIGROUP CROSS SECTIONS (N. M. Greene, L. M. Petrie, S. K. Fraley)

\section{Volume 2, Part 2: Functional Modules}

F9 MORSE-SGC FOR THE SCALE SYSTEM (J. T. West, T. J. Hoffman, M. B. Emmett)

F10 HEATING 7.2 USER'S MANUAL (K. W. Childs)

F11 KENO V.a: AN IMPROVED MONTE CARLO CRITICALITY PROGRAM WITH SUPERGROUPING (L. M. Petrie, N. F. Landers)

F12* JUNEBUG-II: A THREE-DIMENSIONAL GEOMETRY PLOTTING CODE

F13* HEATPLOT-S: A TEMPERATURE DISTRIBUTION PLOTTING PROGRAM FOR HEATING

*Obsolete with SCALE-4.0 release.

**Not included in SCALE-4.3 release. 
Volume 2, Part 3: Functional Modules

F14* REGPLOT6: A PLOTTING PROGRAM TO VERIFY HEATING INPUT DATA

F15** PLORIGEN: A PLOTTING PROGRAM FOR ORIGEN-S OUTPUT (O. W. Hermann)

F16 OCULAR: A RADIATION EXCHANGE FACTOR COMPUTER PROGRAM (C. B. Bryan, G. E. Giles)

F17 KENO-VI: A GENERAL QUADRATIC VERSION OF THE KENO PROGRAM (D. F. Hollenbach, L. M. Petrie, N. F. Landers)

\section{Volume 3: Miscellaneous}

M1 SCALE SYSTEM DRIVER (L. M. Petrie)

M2 SCALE SUBROUTINE LIBRARY (L. M. Petrie)

M3 SCALE FREE-FORM READING ROUTINES (L. M. Petrie)

M4 SCALE CROSS-SECTION LIBRARIES (W. C. Jordan)

M5 THERMAL MATERIAL PROPERTIES LIBRARY (A. L. Edwards, P. T. Williams)

M6 ORIGEN-S DATA LIBRARIES (J. C. Ryman, O. W. Hermann)

M7 THE MATERIAL INFORMATION PROCESSOR FOR SCALE (N. F. Landers, L. M. Petrie, J. A. Bucholz)

M8 STANDARD COMPOSITION LIBRARY (J. A. Bucholz, J. R. Knight, C. V. Parks, L. M. Petrie, J. C. Turner, R. M. Westfall)

M9 MARS: A MULTIPLE ARRAY SYSTEM USING COMBINATORIAL GEOMETRY (J. T. West, M. B. Emmett)

M10 FIDO INPUT SYSTEM (L. M. Petrie)

M11* SCALE INTERACTIVE INPUT PROCESSOR

M12* CESAR: A CRITICALITY EXPERIMENT STORAGE AND RETRIEVAL PROGRAM

\footnotetext{
*Obsolete with SCALE-4.0 release.

**Not included in SCALE-4.3 release.
} 
Volume 3: Miscellaneous (continued)

M13 PICTURE: A. PRINTER PLOT PACKAGE FOR MAKING 2-D PICTURES OF MARS GEOMETRIES (M. B. Emmett)

M14 COMPOZ DATA GUIDE (J. R. Knight, L. M. Petrie)

M15 USER'S GUIDE FOR UTILITY MODULES (N. M. Greene)

M16 COMMENT DATA GUIDE (L. M. Petrie)

${ }^{*}$ Obsolete with SCALE-4.0 release. 


\section{PREFACE}

\section{Background}

This Manual represents Revision 5 of the user documentation for the modular code system referred to as SCALE. The history of the SCALE code system dates back to 1969 when the current Computational Physics and Engineering Division at Oak Ridge National Laboratory (ORNL) began providing the transportation package certification staff at the U.S. Atomic Energy Commission with computational support in the use of the new KENO code for performing criticality safety assessments with the statistical Monte Carlo method. From 1969 to 1976 the certification staff relied on the ORNL staff to assist them in the correct use of codes and data for criticality, shielding, and heat transfer analyses of transportation packages. However, the certification staff learned that, with only occasional use of the codes, it was difficult to become proficient in performing the calculations often needed for an independent safety review. Thus, shortly after the move of the certification staff to the U.S. Nuclear Regulatory Commission (NRC), the NRC staff proposed the development of an easy-touse analysis system that provided the technical capabilities of the individual modules with which they were familiar. With this proposal, the concept of the Standardized Computer Analyses for Licensing Evaluation (SCALE) code system was born.

The NRC staff provided ORNL with some general development criteria for SCALE: (1) focus on applications related to nuclear fuel facilities and package designs, (2) use well-established computer codes and data libraries, (3) design an input format for the occasional or novice user, (4) prepare "standard" analysis sequences (control modules) that will automate the use of multiple codes (functional modules) and data to perform a system analysis, and (5) provide complete documentation and public availability. With these criteria the ORNL staff laid out the framework for the SCALE system and began development efforts. The initial version (Version 0) of the SCALE Manual was published in July 1980. Then, as now, the Manual is divided into three volumes - Volume 1 for the control module documentation (Sections $\mathrm{C} 4, \mathrm{C} 6, \mathrm{~S} 1-\mathrm{S} 4$, and $\mathrm{H1}$ ), Volume 2 for the functional module documentation (Sections F1-F17), and Volume 3 for the documentation of the data libraries and subroutine libraries (Sections M1-M16).

\section{System Overview}

The original concept of SCALE was to provide "standardized" sequences where the user had very few analysis options in addition to the geometry model and materials. Input for the control modules has been designed to be free-form with extensive use of keywords and engineering-type input requirements. The more flexible functional modules have a more difficult input logic and require the user to interface the data sets necessary to run the modules in a stand-alone fashion. As the system has grown in popularity over the years and additional options have been requested, the control modules have been improved to allow sophisticated users additional access to the numerous capabilities within the functional modules. However, the most important feature of the SCALE system remains the capability to simplify the user knowledge and effort required to prepare material mixtures and to perform adequate problem-dependent cross-section processing.

The modules available in Version 0 of SCALE were for criticality safety analysis sequences (CSAS) that provided automated material and cross-section processing prior to a one-dimensional (1-D) or multidimensional criticality analysis. Since that time the capabilities of the system have been 
significantly expanded to provide additional CSAS capabilities, new shielding analysis sequences (SAS) that also include depletion/decay capabilities for spent fuel characterization, and a heat transfer analysis sequence (HTAS). At the center of the CSAS and SAS sequences is the library of subroutines referred to as the Material Information Processor or MIPLIB (see Section M7). The purpose of MIPLIB is to allow users to specify problem materials using easily remembered and easily recognizable keywords that are associated with mixtures, elements, and nuclides provided in the Standard Composition Library (see Section M8). MIPLIB also uses other keywords and simple geometry input specifications to prepare input for the modules that perform the problem-dependent cross-section processing: BONAMI, NITAWL-II, and XSDRNPM. A keyword supplied by the user selects the cross-section library from a standard set provided in SCALE (see Section M4) or designates the reference to a user-supplied library. Several utility modules from AMPX ${ }^{1}$ have been included to provide users with the capability to edit the cross-section data and reformat user-supplied libraries for use in SCALE.

Over the history of the project several modules have been removed from the system because they are no longer supported by the development staff at ORNL. Tables 1 and 2 provide a summary of the major applications of each of the control modules and functional modules currently in the SCALE code system. The control modules were designed to provide the system analysis capability originally requested by the NRC staff. The CSAS module (sometimes denoted as the CSAS4 module and documented in Section C4) is the primary control module designed for the calculation of the neutron multiplication factor of a system. Eight sequences enable general analysis of a 1-D system model or a multidimensional system model, capabilities to search on geometry spacing, and problemdependent cross-section processing for use in executing stand-alone functional modules. CSAS6 is a new criticality control module to provide automated problem-dependent cross-section processing and criticality calculations via the new KENO-VI functional module. The SAS1 and SAS3 modules (see Sections S1 and S3, respectively) provide general 1-D deterministic and 3-D Monte Carlo analysis capabilities. The SAS2 module (see Section S2) was originally developed to perform a depletion/decay calculation to obtain spent fuel radiation source terms that were subsequently input automatically to a 1-D, radial shielding analysis in a cylindrical geometry. Over time the depletion/decay portion of the SAS2 module has been significantly enhanced and interfacing to the other shielding modules has been provided. The SAS4 module (see Section S4) enables automated particle biasing for a Monte Carlo analysis of a transportation package-type geometry. The HTAS1 module (see Section H1) is the only heat transfer control module and uses the various capabilities of the HEATING code to perform different sequences of steady-state and transient analysis that enable the normal and accident conditions of a transportation package to be evaluated. Like SAS4, the HTAS1 module is limited to a package-type geometry.

The capability to perform a point-kernel shielding analysis within the SCALE system has been developed in the QADS control module which has been added in this release of the software package.

A 238-energy-group neutron cross-section library based on ENDF/B-V has recently been prepared for the SCALE system. ${ }^{5}$ All the nuclides that are available in ENDF/B-V are in the library. A 44-group library has been collapsed from this 238-group library and validated against numerous critical measurements. ${ }^{6}$ These libraries are available in this version of SCALE or as a separate data package from the software distribution centers. 


\section{Major Enhancements in SCALE-4.3}

\section{New ENDF/B-V libraries}

SCALE-4.3 includes 238GROUPNDF5, a 238-group, AMPX master-format neutron crosssection library that contains data for all the nuclides available in ENDF/B-V. The library has Bondarenko shielding factors included for nuclides with unresolved resonances, nuclides with AdlerAdler resonance data (U-233 and Pu-241), and the nonresonance nuclides Li-7, F-19, Al-27, and Si14. Bondarenko factors are used for the latter nuclides because they exhibit resonance structure in the point data. The initial development of this library included only s-wave resonance data in the resonance parameters that are passed to the Nordheim treatment in NITAWL. Although demonstrated sufficient for thermal systems, it was found that $p$-wave and perhaps $d$-wave resonances can have a significant effect on the results for shielding applications and for unmoderated, intermediate energy problems. Thus, p-wave and d-wave data were added to the library. Users, however, will not be able to readily access the p-and d-wave resonance data until SCALE-4.3 has been made available to RSIC in 1995.

Several spectra suitable for collapsing this fine-group library to a broad-group structure are included as part of the library. A 44-group derivative of the 238-group library, 44GROUPNDF5, collapsed using a spectrum for a pressurized-water-reactor fuel pin lattice, is also included in the package. This broad-group library has a similar group structure as that provided in the SCALE 27group ENDF/B-IV library, except that additional groups were added to ensure more accurate treatment of the $0.3-\mathrm{eV}$ resonance of ${ }^{239} \mathrm{Pu}$. Based on an analysis of a set of 93 thermal and fast critical experiments, the ENDF/B-V 44-group library has demonstrated markedly improved performance over similar analyses performed with the ENDF/B-IV 27-group library ("Validation of SCALE-4 Criticality Sequences Using ENDF/B-V Data," Proceedings of the Topical Meeting on Physics and Methods in Criticality Safety, September 19-23, 1993). In addition, by comparing SAS2H/ORIGEN-S results with measured isotopic data, the library has demonstrated improved results in the prediction of spent fuel isotopics (Validation of the SCALE System for PWR Spent Fuel Isotopic Composition Analyses, ORNL/TM-12667, March 1995).

\section{KENO-VI}

KENO-VI is a new version of the KENO Monte Carlo Criticality Safety Code developed at Oak Ridge National Laboratory. It constructs and processes geometry data as sets of quadratic equations. A lengthy set of simple, easy-to-use geometric functions, similar to those provided in KENO-V.a, and the ability to build more complex geometric shapes (represented by sets of quadratic equations) are the heart of the geometry package in KENO-VI. The code's flexibility is increased by allowing the following features: intersecting geometry regions; hexagonal as well as cuboidal arrays; regions, holes, arrays, and units rotated to any angle and truncated to any position; and the use of an array boundary that intersects the array.

KENO-VI maintains all the flexibility and options of KENO-V.a plus a variety of new options. In KENO-VI, units can be constructed using both the simple geometric shapes provided and the tailored geometric shapes constructed using quadratic equations. It includes the new 2-D color plotting capability that has been added to KENO-V.a (see "Improvements to KENO-V.a Include 2-D 
Color Plot Capability"). A new SCALE Criticality Safety Analysis Sequence, CSAS6, has been added for running KENO-VI.

Users should be aware that the added geometry features in KENO-VI can result in significantly longer run times than KENO-V.a. A KENO-VI problem that can also be modeled with KENO-V.a will typically run twice as long as the same problem using KENO-V.a. Thus, the new version $\mathrm{VI}$ is not a replacement for the existing version V.a, but an additional version for complex geometries that could not be modeled previously.

\section{New criticality search on material concentrations}

A new search feature has been added to the criticality search sequences in SCALE. Searches may now be done on the concentration of standard compositions in one or more mixtures in the problem. During a concentration search, if the search convergence criteria have not been met, the atom densities of the specified standard compositions are updated, problem-dependent resonance processing is performed using BONAMI, NITAWL, and applicable sections of the material information processor, and a new $\mathrm{k}_{\mathrm{eff}}$ is calculated using KENO-V.a. Concentration searches cannot be performed on materials contained in cell-weighted mixtures.

In all search sequences (both geometry and concentration), problem-dependent resonance processing of the cross sections is now performed for each iteration prior to the execution of KENO. Heterogeneous effects, Dancoff factors, and self-shielding are now accounted for between iterations. Prior to the addition of concentration searches, a search sequence would update only the specified geometry, but not the cross sections, prior to calculating a new $\mathrm{k}_{\text {eff }}$ using KENO-V.a. Previously, to ensure that the converged result was acceptable, the problem needed to be rerun with the converged geometry data. The recent changes to the search sequences eliminate the need to rerun a converged problem to account for changes in cross sections.

\section{Enhanced graphical capabilities}

The graphical display of KENO-V.a and KENO-VI geometry models has been dramatically improved by the new capability to produce high-resolution 2-D color plot files that can be viewed onscreen using appropriate viewer software or printed on a color printer. This new option is activated by using the parameter scr-yes in the KENO plot data. A plot file using up to 256 colors is generated. The plot data parameter "clr=" can be used to override the default color assignments. These plots can be generated only on UNIX workstations and MS-DOS-based personal computers (PC).

In addition to the 2-D color plots, fractional values are now valid for the lpi= parameter in the plot data, which will make it easier to print circles on laser printers.

\section{KENO-V.a enhancements}

Enhancements to KENO-V.a fall into one of three categories: removed limitations, editing changes, or added capabilities.

Two independent limitations to KENO-V.a were removed. The first limitation involved HOLE boundaries touching other HOLE or adjacent geometry region boundaries. Significant errors 
in $\mathrm{k}_{\text {eff }}$ (as much as 1\%) occurred when HOLE boundaries touched with no indication of a problem. HOLE boundaries may now touch other HOLE or adjacent geometry region boundaries.

The second limitation involved the number of scattering angles allowed. Although the parameter sct= (number of scattering angles) was limited to 13, no check was made to avoid overstoring data. Any number of scattering angles are now allowed.

The mixing table edit has been changed to sort mixture data by mixture number. The mixture number and density make up the first line of the data for each mixture. The following lines, which represent the nuclides in the mixture, are sorted by nuclide number. Each line contains a nuclide number, atom density, weight fraction, ZA number, atomic weight, and nuclide title. This provides the user a concise table of the components that make up the mixtures used in the problem.

Three new capabilities were also added to KENO-V.a which provide the user with useful information for analyzing and checking the problem.

The energy corresponding to the average lethargy causing fission is now calculated and the printing of this information (i.e., $\mathrm{NUB}=\mathrm{YES}$ ) is now a default parameter. This is useful for determining trends in $\mathrm{k}_{\text {eff }}$ as a function of neutron energy to look for problem-type biases.

System total fissions and absorptions by region are now calculated. A parameter to suppress printing fissions and absorptions by region for each group has been added. Set GAS=NO to print only the system totals by group. These values have several uses, such as helping to verify proper problem sampling and determining region importance.

Finally, the total mass of each mixture in the problem is now calculated and printed. These values can be used to help verify the geometry and material masses of the problem.

\section{New cross-section processing features}

The cross-section processing portion of the SCALE system has been upgraded to add major improvements to the NITAWL-II code. NITAWL-II has been modified to perform the resonance calculation in double precision. The mesh generation for a resonance has been modified to better span higher energy resonances and to reduce excessive numbers of mesh points.

In addition, this new version of NITAWL-II is able to interpolate the available thermalscattering matrices to obtain data for the temperature requested by user input (via direct input to NITAWL-II or via the SCALE Standard Composition data). Previously, NITAWL-II had no such capability and selected the thermal-scattering data that was closest to the requested temperature. Thermal-scattering data for moderator materials, such as hydrogen and graphite, are available at many more temperatures in the new ENDF/B-V SCALE libraries than in the older ENDF/B-IV SCALE libraries. However, even with the new ENDF/B-V libraries, the interpolation should better determine the effect that a change in moderator temperature will have on the system multiplication factor.

The CSAS and SAS1-SAS4 modules also have been modified via MIPLIB to provide two new parameters in the optional MORE DATA input:

$M L V=$ maximum $L$ value for which resonance calculation will be done $(L=0$ is s-wave, $L=1$ includes p-wave, $L=2$ includes d-wave). The default value is $L=2$.

$\mathrm{MSH}=$ maximum number of mesh points per resonance. The default value is 2001 .

Note that if NITAWL-II is run stand-alone, the default values for MLV and MSH are 0 and 501, respectively. 


\section{New KENO-V.a sample problems}

The KENO-V.a sample problems have been updated to improve the range of functionality testing and provide more flexibility in using other cross-section libraries. The SCALE-4.2 sample problems used the 27-group ENDF/B-IV cross-section library. The cross sections were processed by NITAWL-II prior to the execution of KENO-V.a. The new sample problems use BONAMI, which is not necessary for the 27-group library, as well as NITAWL-II for resonance processing of cross sections so that the sample problems can easily be run with other cross-section libraries that require the use of BONAMI. The NITAWL-II input data were updated to specify 2001 mesh points per resonance and the highest resonance $\mathrm{L}$-value of 2 . The previous input data used the default values of 501 mesh points and an L-value of 0.

Eight new problems were added to the existing 25 sample problems. Sample problems 26 through 28 are variations of sample problem 1, modeled as hemicylinders with chords and origins, and are extensions of sample problems 23 through 25 , which are modeled using chords without origins. Sample problem 29 is a bare critical sphere, and sample problems 30 through 32 are the same critical system modeled using hemispheres with origins. Sample problem 33 is a critical triangular pitched array of partially flooded cylindrical annuli of low-enriched-uranium metal.

\section{Standard Composition Library updated for ENDF/B-VI compatibility}

The Standard Composition Library has been expanded for compatibility with ENDF/B-VI cross-section libraries. In addition, the Material Information Processor Library (MIPLIB) has also been updated so that all the control modules can use ENDF/B-VI cross-section libraries via the new expanded Standard Composition Library. The changes were necessary because the cross sections for the natural-element identifiers such as FE for iron are no longer available in the ENDF/B-VI data. Most problems set up to use other cross-section libraries should now run without any changes using ENDF/B-VI libraries.

The changes to the Standard Composition Library were very extensive and fall into several categories. Additions were made so that nearly all the elements are given by both their full name and by their chemical symbol. The full-name elements are all given as naturally occurring abundance nuclides, while a few of the chemical symbol nuclides are given as the principal isotope. For instance, HYDROGEN would include trace amounts of deuterium, while $\mathbf{H}$ would be $100 \%{ }^{1} \mathrm{H}$.

The isotopic distribution table was changed to include most of the elements. Arbitrary materials may now contain more than one multiple-isotope nuclide. In addition, the specially weighted elements in stainless steel and in Inconel were added, specifying the natural abundance of each.

Atomic masses for isotopes were taken from ENDF/B-VI, if available. Atomic masses for naturally occurring elements were taken from ENDF/B-V, if available. Remaining atomic masses were taken from GE Chart of the Nuclides or the CRC Handbook of Chemistry and Physics.

\section{QAD-CGGP and QADS}

The 3-D point-kernel shielding code, QAD-CGGP, and its associated SCALE control module have been added. QADS performs multidimensional point-kernel estimation of gamma transport through practically any type of shielding materials using a simplified input scheme that follows the 
general input philosophy of the SCALE shielding sequences. QADS was designed to capture the flexibility and power of the QAD technique for problems amenable to point-kernel solution while allowing for an easy-to-use input interface. The QADS module is called via the SCALE driver and preprocesses the actual input for the QAD-CGGP code. The driver then calls and executes QADCGGP automatically. The SCALE standard composition library is used to allow simplified input of materials. The problem geometry is coded using the well-known MORSE combinatorial geometry package. Finally, the dose portion of the input follows the XSDOSE input data format in SAS1. The combined use of the SCALE standard compositions and free-form input with the multidimensional geometry capabilities and generally short running time of point-kemel techniques produces a very powerful procedure for shielding analysis of a wide variety of problems.

\section{SCALE-4.3 minor modifications}

In addition to the major enhancements noted above, SCALE-4.3 contains many minor modifications, including corrections to errors in SCALE-4.2 and changes to improve portability to other computing platforms.

SCALE driver: The driver was modified to improve portability to other types of workstations. Modifications to accept upper or lower case input files were also added.

KENO-V.a: (1) Corrected error that sometimes occurred when the boundary of a HOLE touched another HOLE or adjacent geometry region. The error can produce erroneous results, either conservative or nonconservative, without triggering waming or error messages. The effect on $\mathrm{k}_{\text {eff }}$ can be very significant in some cases ( $1 \%$ ). (2) Fixed to allow more than 13 scattering angles. Although the parameter "sct=" was limited to 13 , no check was made to avoid overstoring data. (3) Corrected error causing core dump on some workstations when a global unit wasn't explicitly defined. (4) Corrected error that permitted a case with a negative radius to run. (5) Added calculation of the energy corresponding to the average lethargy causing fission and made the printing of this information (i.e., NUB=YES) a default parameter. (6) Corrected errors in the starting points edit obtained when PSP=YES. (7) Corrected an error that occurred when a history encountered an edge where differential albedos were used. Other minor fixes were made for (8) printing densities of mixtures that have other mixtures added in and (9) printing plot coordinates for problems ending in a bare array. (10) Output was enhanced to print information on start and plot input parameters that were previously omitted.

NITAWL: (1) Corrected the grayness correction to self-shielding in annular regions. (2) Corrected an error passing a variable of the wrong type that resulted in incorrect self-shielding of thermal groups below $0.5 \mathrm{eV}$.

All Control Modules (MIPLIB): (1) Added checks to avoid the use of negative number densities when solutions with physically unrealistic parameters are entered. (2) Corrected an error that caused CSAS to loop if the collapse option was specified and an input nuclide ID was not found in the cross-section library. (3) Modified MIPLIB to check for resonance data on the cross-section library used to determine whether to perform resonance corrections for a nuclide. Previously, a flag in the Standard Composition Library was used to make this determination. (4) Corrected calculated thickness ("lbar") of cylindrical and spherical annuli for input to BONAMI. (5) Modified reading of Dancoff factor keywords in MORE DATA to detect and prevent erroneous keyword input. (6) Changed the label "lbar" printed by CSAS in PARM=CHECK output to "abar." (7) Replaced the 123GROUP and 218GROUP cross-section-library keywords with 44GROUP and 
238GROUP. The former libraries, which were the least used of the standard SCALE libraries, were removed as defaults so the new ENDF/B-V libraries, which give more accurate results, could be accessed directly via keyword input.

CSAS/MODIFY: Added an option in the CSAS4 and CSAS4X sequences to perform a criticality search on nuclide concentration. Modified the search sequences to update unit cell data or number densities (depending on the type of search) and execute BONAMI and NITAWL prior to every KENO-V.a calculation.

SAS2: (1) Modified for compatibility with recent MIPLIB changes. (2) Corrected the soluble boron concentration to change linearly when NLIB/CYC $>1$. (3) Modified to allow use of the SYMMSLABCELL geometry in MIPLIB and more than one fuel zone. (4) Automated model setup when burnable poison rods occupy some but not all guide tubes in a fuel assembly. (5) Added THERM, RES, FAST, and the two energy boundaries for converting cross sections to the total flux normalization. (6) Modified the AMPX cross-section library defaults to match MIPLIB, including the use of unit 70 for unrecognized libraries. (7) Corrected an error that occurred if light element nuclides are in both the ORIGEN-S light element and fission product libraries and are input as individual nuclides in the MIPLIB input.

ORIGEN-S : (1) Replaced call to INQOPN with call to OPNFIL for standard input (unit 5) to improve portability to other computers. (2) Initialize arrays only within the array boundaries for better portability. (3) Added EXTERNAL statements for BLOCK DATA files to improve portability. (4) Improved coding for the integral option using the actinide library. (5) Program was corrected to execute a continuation subcase when using the integral option. (6) Corrected call to subroutine STOP.

ORIGEN-S Libraries: (1) Corrected Cf-249 data in lowest energy group in Master Photon Library. It was high by factor of 100. (2) Corrected the half-life of Se-79. It was low by factor of 10 . (3) Corrected $\mathrm{Br}-86 \mathrm{~m}$ decay data that was erroneously changed in ENDF/B-VI update.

COUPLE: (1) Added check for correct ordering of fission product nuclides by atomic weight in input library. (2) Added EXTERNAL statement for BLOCK DATA files to improve portability to other computers. (3) Modified output format for THERM, RES, and FAST from floating point (F) to exponential (E). (4) Corrected an error that occurred when only fission product yield data were being updated. Note that this error did not occur when using COUPLE in the SAS2 sequence.

Standard Composition Library: (1) Revised the resonance energy scattering and/or total cross sections for 197 materials based on the 44-group ENDF/B-V cross-section library. Consistent values were specified for both the natural element and individual isotopes $\mathrm{B}, \mathrm{Zr}, \mathrm{Eu}, \mathrm{Hf}$, and $\mathrm{W}$. (2) Added new composition ZIRC2 for Zircaloy-2 when using ENDF/B-V cross-section libraries. (3) Replaced $\sigma_{s}$ and $\sigma_{t}$ values in Nuclide Information Table with average values calculated from ENDF/B-V or ENDF/B-VI libraries. (4) Density for ZIRCALLOY and ZIRC2 was corrected from 6.506 to $6.56 \mathrm{~g} / \mathrm{cc}$.

All Cross-Section Libraries: The atomic masses of nuclides were modified to all be in terms of neutron mass for consistency.

XSDRNPM: (1) Modified to scale the weighting flux so that minimum value is $1 \mathrm{E}-20$. This modification was made to reduce the likelihood that an underflow would occur when creating a weighted cross-section library for problems where there are large variations in the flux (many orders of magnitude). (2) Corrected an error that caused broad-group-flux edits to print bad values. (3) Corrected an error that would occur when creating a gamma-only broad-group library. 
XSDRNPM/SAS4: Adjoint calculation in XSDRNPM for SAS4 was corrected. Only affects fixed-source calculations with upscatter on machines whose single- and double-precision formats are different (includes IBM workstations). Any such calculations should be rerun to determine impact of correction.

SAS4: (1) Increased the number of mesh intervals for both neutrons and gammas in the XSDRN adjoint calculation to improve the likelihood of convergence. Made additional minor changes to improve portability. (2) Updated for consistency with new nuclide ID numbering scheme in MIPLIB.

MORSE: Corrected a problem caused by the use of an incorrect normalization factor on standard deviations at the end of each batch. This occurred when NMOST was equal to NSTRT.

BONAMI: (1) Restored Bondarenko factor printout that was inadvertently deleted in July 1990 modification. Results were not impacted. (2) Corrected so that calculations with more than one nuclide specified with a zero number density will run.

SAS1: (1) Modified to force the pointer for the double-precision flux array to start on a double word boundary. This change improves performance significantly on some workstations other than IBM. (2) Corrected setting of termination flag so that SCALE driver can run other modules when cases are stacked in an input file.

AIM: Corrected error that created a bad magic word in a binary library if a magic word position occurred as the last position of a transfer array in the BCD data.

HEATING: A coding flaw was found and corrected in HEATING that prevented the proper application of the unit system conversion factors for the material properties database. This option allows the user to select a material from the database and convert the property values to the user's unit system. Due to the flaw, the material property values were not converted and values were used in the calculations that were not correct for the unit system. This flaw would affect only HEATING or HTAS1 problems that specify unit conversion factors for the material properties database.

HTAS1: A coding flaw was found and corrected in HTAS1 that prevented the building and the use of enclosure radiation connectors for models that replace the material in the neutron shield with a void (no material). A normal (and the default) analysis would replace the material in the neutron shield with air. Any other material or a void can be placed in the neutron shield volume. As long as any type of material (not a void) is in the neutron shield then the thermal radiation connectors are built in OCULAR and the analysis procedures correctly. However, if a void volume is modeled in HTAS1 then the flaw prevented the building and use of the connectors. Thus, no heat would be transferred across the neutron shield, which could significantly and potentially nonconservatively alter the thermal history of the shipping cask.

All modules (UNIXIIB): Modified subroutine DATIM to read the date and time from the file "datetime.std" if it exists. This option will be useful for comparing sample problem output files.

KENO-V.a, SAS2 (SUBLIB): Modified subroutine YREAD to correctly read an array of numbers separated by commas.

\section{Portability}

Version 4.3 of the SCALE system has been developed to ensure portability among various computing platforms. The system is maintained and enhanced at ORNL under quality assurance and configuration management plans. The system has been routinely tested on IBM and DEC 
workstations. In addition, the system has been applied by ORNL on SUN and HP workstations. Information needed to install SCALE on each of these systems is included with the software package distributed by the code centers. A separate SCALE software package, designated SCALE-PC, is available for the execution of the SCALE system, except heat transfer modules, on a MS-DOS personal computer.

\section{Related developments}

The definition of "easy-to-use" has changed considerably since the late 1970s. As funding has allowed, the ORNL development staff has sought to develop user interfaces that provide a distinct aid to novice or occasional users of the system. These full-screen input processors were developed to work on a MS-DOS personal computer and provide interactive help to the user in preparing accurate input for a SCALE module. Currently, input processors are available only for the criticality control sequences ${ }^{2}$ and the ORIGEN-S functional module. ${ }^{3}$ The SCALE-PC version includes an updated version of the ORIGEN-S processor coupled with the ARP code, which interpolates on standard LWR ORIGEN-S binary libraries, in the ORIGEN-ARP system (Section F7.A).

\section{Availability}

The SCALE code system and the other software designated under Related Developments have been packaged by the Radiation Shielding Information Center (RSIC). The SCALE system and the related software may be obtained by contacting

Radiation Shielding Information Center

Oak Ridge National Laboratory

P.O. Box 2008

Oak Ridge, TN 37831-6362

Telephone: (615) 574-6176

FAX: (615) 574-6182

E-mail: pdc@ornl.gov

\section{Acknowledgments}

The SCALE system is maintained at ORNL and enhanced to keep pace with normal technical advancements in the analysis areas of interest. Although the NRC continues its role as the controlling sponsor of the SCALE system, the U.S. Department of Energy (DOE) began assisting in the maintenance of the SCALE system in 1987. Over the years numerous individuals within these sponsoring organizations have played key roles in ensuring that the SCALE system remained a readily available, reliable system for the analysis of nuclear fuel facilities and packages. The individuals who have worked with the ORNL staff to coordinate maintenance and development activities include R. H. Odegaarden (NRC, ret.), G. H. Bidinger (NRC, ret.), C. Mauck (DOE, ret.), E. P. Easton (NRC), W. H. Lake (NRC and DOE), M. E. Wangler (DOE), and M. G. Bailey (NRC).

As demonstrated by this Manual, there are also numerous individuals from the ORNL staff who have contributed significantly to the development and enhancement of the SCALE system. Most 
are credited by their authorship of the sections in this Manual that correspond to their work. A few individuals have been essential to the development and maintenance of SCALE but are not credited by authorship. These individuals include: S. K. Martin, who is responsible for implementing and controlling software system changes; $\mathrm{C}$. $\mathrm{H}$. Shappert, who provided the editorial review of this Manual; and L. F. Norris, who prepared the entire manuscript. Special acknowledgement is also due to R. M. Westfall and G. E. Whitesides who, together with $R$. Odegaarden of the NRC, developed the concept and long-range goals of the SCALE system in the late 1970s. Finally, this Project Leader will always be grateful to C. V. Parks, who has served as the SCALE Project Leader for the past 15 years, and L. M. Petrie, who for nearly 20 years has consistently provided consultation and advice on the technical direction that should be taken in development of nearly every module and crosssection library that are in the present system.

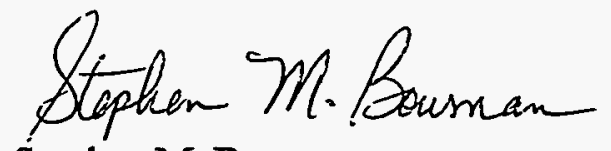

Stephen M. Bowman

SCALE Project Leader

January 1997

\section{References}

1. Greene, N. M., Ford, W. E., III, Petrie, L. M., and Arwood, J. W., AMPX-77: $A$ Modular Code System for Generating Coupled Multigroup Neutron-Gamma Cross-Section Libraries from ENDF/B-IV and/or ENDF/B-V, ORNL/CSD/TM-283, Martin Marietta Energy Systems, Inc., Oak Ridge Natl. Lab., October 1992.

2. S. M. Bowman OFFSCALE: A PC Input Processor for the SCALE Code System - The CSASIN Processor for the Criticality Sequences, NUREG/CR-6182, Vol. 1 (ORNL/TM12263/V1), U.S. Nuclear Regulatory Commission, November 1994.

3. S. M. Bowman OFFSCALE: A PC Input Processor for the SCALE Code System - The ORIGNATE Processor for ORIGEN-S, NUREG/CR-6182, Vol. 2 (ORNL/TM-12263/V2), U.S. Nuclear Regulatory Commission, November 1994.

4. Broadhead, B.L., QADS: A Multidimensional Point Kernel Analysis Module, NUREG/CR5468 (ORNL/CSD/TM-270), U.S. Nuclear Regulatory Commission, May 1990.

5. N. M. Greene, J. W. Arwood, R. Q. Wright, C. V. Parks, The LAW Library-A Multigroup Cross-Section Library for Use in Radioactive Waste Analysis Calculations, ORNL/TM-12370, Martin Marietta Energy Systems, Inc., Oak Ridge Natl. Lab., August 1994.

6. M. D. DeHart and S. M. Bowman, Validation of the SCALE Broad Structure 44-Group ENDF/B-V Cross-Section Library for Use in Criticality Safety Analyses, NUREG/CR-6102 (ORNL/TM-12460), U.S. Nuclear Regulatory Commission, September 1994. 
Table 1 Analysis capabilities summary of the SCALE control modules

\begin{tabular}{|c|c|c|c|}
\hline $\begin{array}{l}\text { Control } \\
\text { module }\end{array}$ & Analysis function(s) & $\begin{array}{l}\text { Functional modules } \\
\text { executed }\end{array}$ & $\begin{array}{l}\text { Section } \\
\text { reference }\end{array}$ \\
\hline CSAS & $\begin{array}{l}\text { 1-D deterministic calculation of neutron multiplication } \\
\text { 3-D Monte Carlo calculation of neutron multiplication } \\
\text { Problem-dependent cross-section processing } \\
\text { Multiplication search or spacing }\end{array}$ & $\begin{array}{l}\text { BONAMI } \\
\text { NITAWL-II } \\
\text { XSDRNPM } \\
\text { KENO V.a } \\
\text { ICE }\end{array}$ & $\mathrm{C} 4$ \\
\hline CSAS6 & 3-D Monte Carlo calculation of neutron multiplication & $\begin{array}{l}\text { BONAMI } \\
\text { NITAWL-II } \\
\text { XSDRNPM } \\
\text { KENO-VI }\end{array}$ & C6 \\
\hline SAS1 & $\begin{array}{l}\text { 1-D deterministic calculation of radiation transport through } \\
\text { shield and dose evaluation at a point } \\
\text { Calculation of dose at detector based on leakage from } \\
\text { critical volume }\end{array}$ & $\begin{array}{l}\text { BONAMI } \\
\text { NITAWL-II } \\
\text { XSDRNPM } \\
\text { XSDOSE }\end{array}$ & $\mathrm{S} 1$ \\
\hline SAS2 & $\begin{array}{l}\text { Point depletion/decay of nuclear fuel } \\
\text { 1-D radial shielding analysis in cylindrical geometry }\end{array}$ & $\begin{array}{l}\text { BONAMI } \\
\text { NITAWL-II } \\
\text { XSDRNPM } \\
\text { COUPLE } \\
\text { ORIGEN-S } \\
\text { XSDOSE }\end{array}$ & S2 \\
\hline SAS3 & Dose evaluation using MORSE Monte Carlo code & $\begin{array}{l}\text { BONAMI } \\
\text { NITAWL-II } \\
\text { XSDRNPM } \\
\text { MORSE-SGC }\end{array}$ & S3 \\
\hline SAS4 & $\begin{array}{l}\text { Calculation of dose outside of transportation package using } \\
\text { MORSE code and automated biasing techniques }\end{array}$ & $\begin{array}{l}\text { BONAMI } \\
\text { NITAWL-II } \\
\text { XSDRNPM } \\
\text { MORSE-SGC }\end{array}$ & S4 \\
\hline QADS & 3-D point-kernel gamma-ray shielding analysis & QAD-CGGP & S5 \\
\hline HTAS1 & $\begin{array}{l}\mathrm{R}-Z \text { steady-state and transient analyses of a transportation } \\
\text { package }\end{array}$ & $\begin{array}{l}\text { OCULAR } \\
\text { HEATING }\end{array}$ & $\mathrm{H1}$ \\
\hline
\end{tabular}


Table 2 Analysis capabilities summary of the SCALE functional modules

\begin{tabular}{|c|c|c|}
\hline Module & Function & $\begin{array}{l}\text { Section } \\
\text { reference }\end{array}$ \\
\hline BONAMI & Resonance self-shielding of cross sections with Bondarenko factors & F1 \\
\hline NITAWL-II & Resonance self-shielding of cross sections with resolved resonance data & F2 \\
\hline XSDRNPM & $\begin{array}{l}\text { General 1-D, discrete-ordinates code for: } \\
\text { - zone-weighting of cross sections } \\
\text { - eigenvalue calculations for neutron multiplication } \\
\text { - fixed-source calculation for shielding analysis } \\
\text { - adjoint calculation for determining importance functions }\end{array}$ & F3 \\
\hline XSDOSE & $\begin{array}{l}\text { Module for calculation of dose at a point based on the 1-D leakage flux } \\
\text { from a finite shield }\end{array}$ & F4 \\
\hline COUPLE & $\begin{array}{l}\text { Interface module for preparation of cross-section and spectral data for } \\
\text { ORIGEN-S }\end{array}$ & F6 \\
\hline ORIGEN-S & $\begin{array}{l}\text { General-purpose point-depletion and decay code to calculate isotopic, } \\
\text { decay heat, radiation source terms, and curie levels }\end{array}$ & F7 \\
\hline ICE & Cross-section utility module for mixing cross sections & F8 \\
\hline MORSE-SGC & $\begin{array}{l}\text { Monte Carlo code with combinatorial and array geometry features used to } \\
\text { perform radiation shielding analysis }\end{array}$ & F9 \\
\hline HEATING7.2 & $\begin{array}{l}\text { Finite-volume, multidimensional code for conduction and radiation heat } \\
\text { transfer }\end{array}$ & F10 \\
\hline KENO V.a & Monte Carlo code for calculation of neutron multiplication factors & F11 \\
\hline OCULAR & Calculation of radiation exchange factors & F16 \\
\hline KENO-VI & $\begin{array}{l}\text { Monte Carlo code for calculation of neutron multiplication factors for } \\
\text { complex geometries }\end{array}$ & F17 \\
\hline
\end{tabular}


NUREG/CR-0200

Revision 5

Volume 2, Section F16

ORNL/NUREG/CSD-2/V2/R5

Computational Physics and Engineering Division

\section{OCULAR: A RADIATION EXCHANGE FACTOR COMPUTER PROGRAM}

C. B. Bryan

G. E. Giles

Date Published: March 1997

Prepared for the

Office of Nuclear Material Safety and Safeguards

U.S. Nuclear Regulatory Commission

Washington, DC 20555

Under Interagency Agreement DOE 1886-C000-9B

NRC JCN No. B0009

Prepared by the

OAK RIDGE NATIONAL LABORATORY

Oak Ridge, Tennessee 37831

managed by

LOCKHEED MARTIN ENERGY RESEARCH CORP.

for the

U.S. DEPARTMENT OF ENERGY

under Contract No. DE-AC05-960R22464 


\begin{abstract}
OCULAR is a radiation exchange factor computer code compatible with the axisymmetric $\mathrm{r}-\mathrm{z}$ geometry of HEATING. The code may be used to generate graybody exchange factors, as well as geometric configuration factors, which describe the radiative exchange in the cylindrical or annular enclosures that are characteristic of an axisymmetric geometry.
\end{abstract}




\section{CONTENTS}

Page

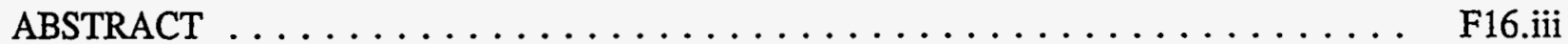

LIST OF FIGURES $\ldots \ldots \ldots \ldots \ldots \ldots \ldots \ldots \ldots \ldots \ldots \ldots \ldots \ldots$ F16.vii

LIST OF TABLES $\ldots \ldots \ldots \ldots \ldots \ldots \ldots \ldots \ldots \ldots \ldots \ldots \ldots \ldots \ldots \ldots$ F16.vii

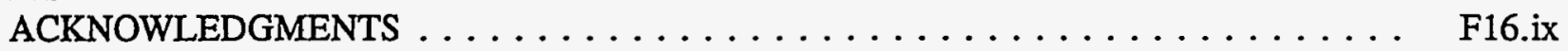

F16.1 INTRODUCTION $\ldots \ldots \ldots \ldots \ldots \ldots \ldots \ldots \ldots \ldots \ldots \ldots \ldots \ldots \ldots \ldots$

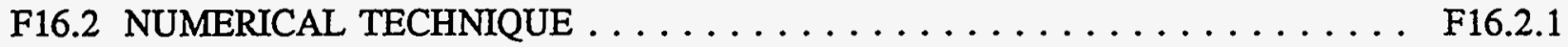

F16.2.1. Statement of the Problem . . . . . . . . . . . . F16.2.1

F16.2.2. Enclosure Definition . . . . . . . . . . . . . F F16.2.2

F16.2.3. Annular Geometric Configuration Factors . . . . . . . . . . . . . F16.2.4

F16.2.3.1. Cylinder-to-ring factors . . . . . . . . . . . F16.2.4

F16.2.3.2. Cylinder-to-shell factors . . . . . . . . . . . F16.2.5

F16.2.3.3. Ring-to-shell factors . . . . . . . . . . . F F16.2.7

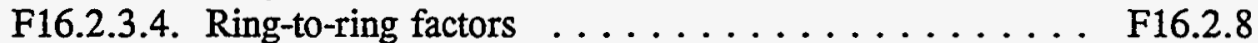

F16.2.3.5. Shell-to-shell factors . . . . . . . . . . . . F F16.2.9

F16.2.4. Cylindrical Geometric Configuration Factors . . . . . . . . . . F16.2.10

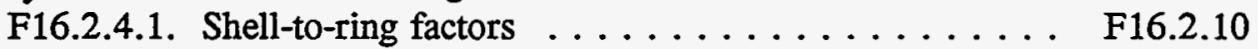

F16.2.4.2. Ring-to-ring factors $\ldots \ldots \ldots \ldots \ldots \ldots$ F16.2.11

F16.2.4.3. Shell-to-shell factors . . . . . . . . . . F16.2.13

F16.2.5. Exchange Factors . . . . . . . . . . . . . F16.2.13

F16.3 PROGRAM LOGIC FLOW AND SUBROUTINE DESCRIPTION $\ldots \ldots \ldots \ldots$. . F16.3.1

F16.3.1. Description of Subroutines Used by OCULAR . . . . . . . . . F16.3.1

F16.4 INPUT DESCRIPTION FOR OCULAR $\ldots \ldots \ldots \ldots \ldots \ldots \ldots \ldots \ldots \ldots$. . . F16.4.1

F16.4.1. General . . . . . . . . . . . . . . . F F16.4.1

F16.4.2. OPTION Data Block . . . . . . . . . . . . . F16.4.3

F16.4.3. Problem Control Parameters . . . . . . . . . . . . F16.4.4

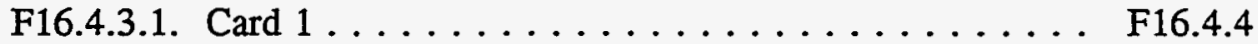

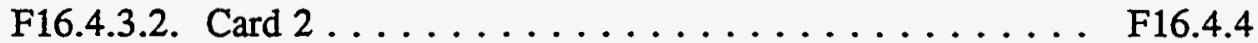

F16.4.3.2.1. Entry $1 \ldots \ldots \ldots \ldots$ F16.4.4

F16.4.3.2.2. Entry 2 - geometry type . . . . . F F16.4.4

F16.4.4. Region Data Block (Cards R1 and R2) . . . . . . . . . F F16.4.4

F16.4.4.1. Block indicator card . . . . . . . . . . F F16.4.4

F16.4.4.2. Card R1 . . . . . . . . . . . . F F16.4.5

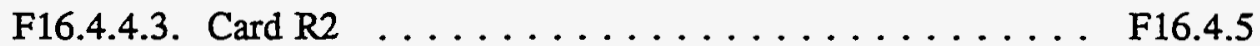

F16.4.5. Material Data Block (Cards $M$ and $P C) \ldots \ldots \ldots \ldots \ldots$. . . . F16.4.5

F16.4.5.1. Block indicator card . . . . . . . . . . F F16.4.6

F16.4.5.2. Card $M \ldots \ldots \ldots \ldots \ldots \ldots$ F16.4.6

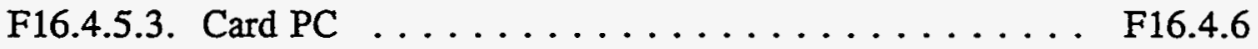

F16.v

NUREG/CR-0200,

Vol. 2, Rev. 5 
F16.4.6. X (or R) Grid Data Block (Cards L1 and N1) . . . . . F16.4.6

F16.4.6.1. Block indicator card . . . . . . . . . F F16.4.7

F16.4.6.2. Card L1 . . . . . . . . . . . . . . F F16.4.7

F16.4.6.3. Card $N 1 \ldots \ldots \ldots \ldots \ldots \ldots$ F16.4.7

F16.4.7. Z (or $\phi$ ) Grid Data Block (Cards L3 and N3) $\ldots \ldots \ldots \ldots \ldots \ldots$ F16.4.7

F16.4.7.1. Block indicator card ............. F16.4.7

F16.4.7.2. Card L3 . . . . . . . . . . . . . . F16.4.7

F16.4.7.3. Card N3 . . . . . . . . . . . F F16.4.7

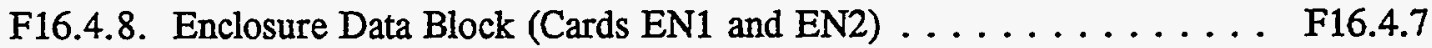

F16.4.8.1. Block indicator card . . . . . . . . . F F16.4.8

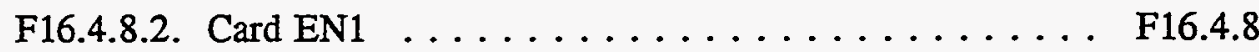

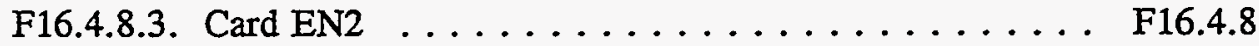

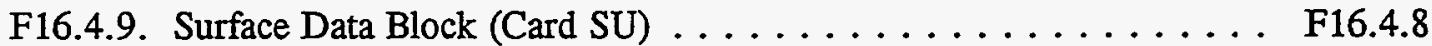

F16.4.9.1. Block indicator card . . . . . . . . . F F16.4.8

F16.4.9.2. Card SU . . . . . . . . . . . . . . F16.4.89

F16.4.10. Emissivity Data Block (Card EM) . . . . . . . . . . . . F F16.4.9

F16.4.10.1. Block indicator card . . . . . . . . . F F16.4.9

F16.4.10.2. Card EM ... . . . . . . . . . . . . F F16.4.9

F16.4.11. Analytical Function Data Block (Cards A1 and A2) . . . . . F F16.4.10

F16.4.11.1. Block indicator card ............. F16.4.10

F16.4.11.2. Card A1 . . . . . . . . . . . . F F16.4.10

F16.4.11.3. Card A2 ................. F16.4.10

F16.4.11.4. User-supplied subroutine EMSSVY . . . . . . F F16.4.11

F16.4.12. Tabular Function Data Block (Cards T1 and T2) . . . . . . F F16.4.11

F16.4.12.1. Block indicator card ............. F16.4.11

F16.4.12.2. Card T1 . . . . . . . . . . . . F16.4.11

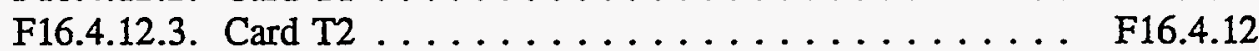

F16.4.13. Data Block Termination Card . . . . . . . . . . F F16.4.13

F16.4.14. Summary and Format of Input . . . . . . . . . . F F16.4.13

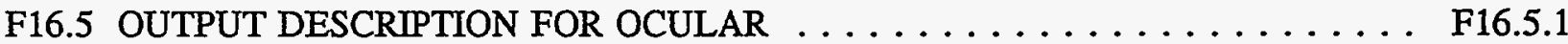

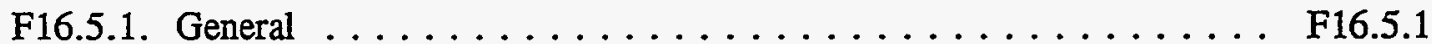

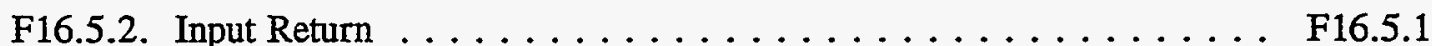

F16.5.3. Exchange Factors . . . . . . . . . . . . . . . F16.5.1

F16.5.4. HEATING Input $\ldots \ldots \ldots \ldots \ldots \ldots \ldots \ldots$ F16.5.2 . . . . . . . . . .

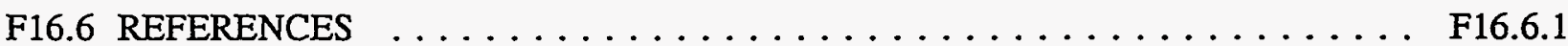

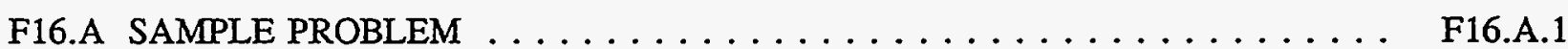

NUREG/CR-0200,

Vol. 2, Rev. 5

F16.vi 


\section{LIST OF FIGURES}

Figure

Page

F16.2.1 OCULAR axisymmetric geometry $\ldots \ldots \ldots \ldots \ldots \ldots \ldots \ldots \ldots \ldots \ldots$ F16.2.1

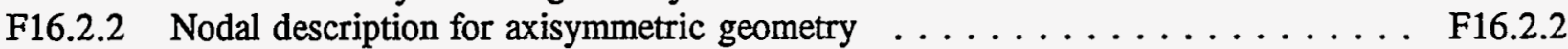

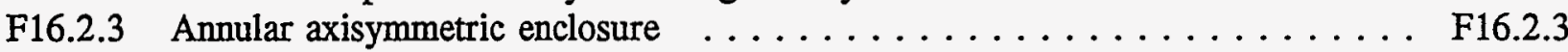

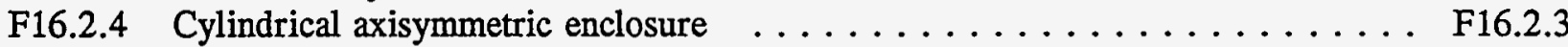

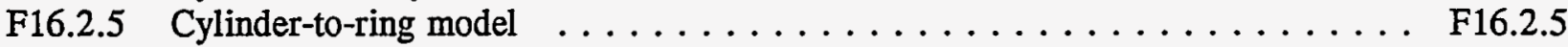

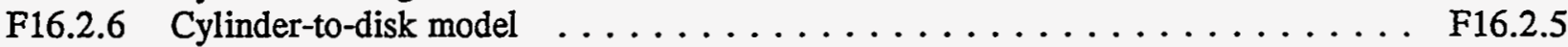

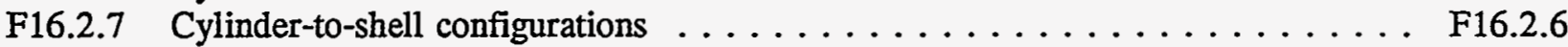

F16.2.8 Annular ring-to-shell model $\ldots \ldots \ldots \ldots \ldots \ldots \ldots \ldots \ldots \ldots \ldots \ldots \ldots . \ldots \ldots$

F16.2.9 Annular ring-to-ring model $\ldots \ldots \ldots \ldots \ldots \ldots \ldots \ldots \ldots \ldots \ldots \ldots \ldots$

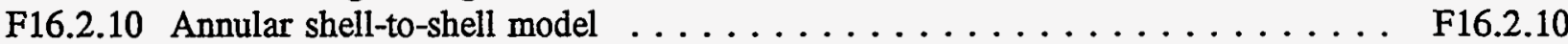

F16.2.11 Cylindrical shell-to-ring model $\ldots \ldots \ldots \ldots \ldots \ldots \ldots \ldots \ldots \ldots \ldots \ldots$ F16.2.11

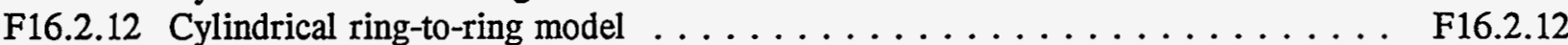

F16.2.13 Disk-to-disk model . . . . . . . . . . . . . . . . . . . . . . F16.2.12

F16.2.14 Shell-to-shell model $\ldots \ldots \ldots \ldots \ldots \ldots \ldots \ldots \ldots \ldots \ldots \ldots$. . . . . . . F16.2.13

F16.3.1 Calling sequence of routines $\ldots \ldots \ldots \ldots \ldots \ldots \ldots \ldots \ldots \ldots . \ldots \ldots \ldots$

F16.4.1 User-supplied subroutine EMSSVY $\ldots \ldots \ldots \ldots \ldots \ldots \ldots \ldots \ldots \ldots$. . . . . F16.4.12

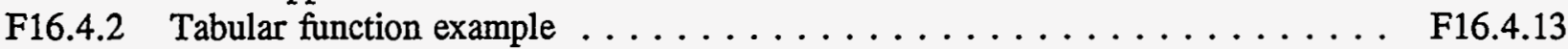

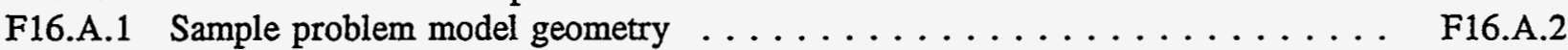




\section{LIST OF TABLES}

\section{Table}

F16.3.1 Summary of subroutines and entries $\ldots \ldots \ldots \ldots \ldots \ldots \ldots \ldots \ldots \ldots \ldots$ F16.3.2

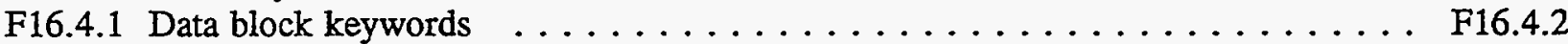

F16.4.2 List of OCULAR variables whose default value may be modified through the

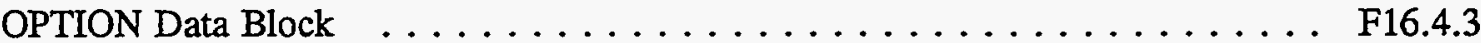

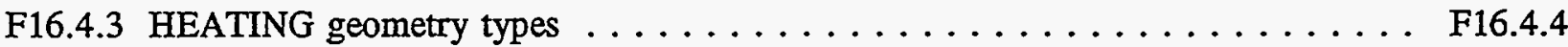

F16.4.4 A1 and A2 cards necessary to describe the function $100.0 \sin (5 x)+e^{-3 x} \ldots \ldots$ F16.4.11

F16.4.5 $\mathrm{T} 1$ and $\mathrm{T} 2$ cards necessary to describe the tabular function depicted in

Fig. F16.17 . . . . . . . . . . . . . . . . . . . . F16.4.13

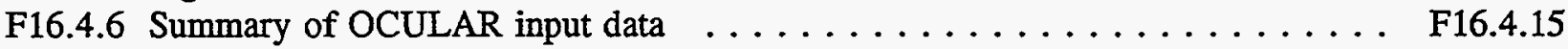

F16.A.1 Hemispherical total emissive property data $\ldots \ldots \ldots \ldots \ldots \ldots \ldots \ldots$ F16.A.1

F16.A.2 OCULAR sample problem output $\ldots \ldots \ldots \ldots \ldots \ldots \ldots \ldots$ F16.6.

NUREG/CR-0200, 


\section{ACKNOWLEDGMENTS}

Funding for this project was provided by the Storage and Transport Systems Branch, Nuclear Material Safety and Safeguards, of the U.S. Nuclear Regulatory Commission. A portion of this work, the capability to model cylindrical enclosures, was funded by A. A. Khan of the Y-12 Development Division.

The author (C. B. Bryan) is indebted to L. M. Petrie for the use of the SCALE free-form reading routines. Gratitude is extended to C. V. Parks for his constructive reviews of the manuscript.

Special gratitude is extended to R. V. Arimilli of the University of Tennessee for providing insight into the phenomenon of thermal radiation heat transfer. 


\section{F16.1 INTRODUCTION}

The radiative exchange factor computer program OCULAR was developed for the U.S. Nuclear Regulatory Commission (NRC) as part of their efforts to develop standardized methods for performing safety analyses of nuclear fuel shipping containers. The program is a functional module within the SCALE system.

Frequently, nuclear fuel shipping containers are modeled as an assembly of right circular cylinders. Historically, standardized thermal analyses of these containers have been performed using the axisymmetric geometry (type R-Z) capability of HEATING (see Sect. F10).

Version 6.0 of the HEATING code provided the analyst with the capability of modeling onedimensional (1-D) radiant heat transfer. Radiation is present in the cylindrical and annular enclosures characteristic of the axisymmetric geometry. The HEATING program was enhanced with the release of version 6.1 to provide the capability of modeling multidimensional radiant heat transfer. Exchange factors defining the radiative interaction between enclosure surfaces must be supplied to HEATING as input.

OCULAR is designed to calculate graybody exchange factors for the cylindrical and annular enclosures characteristic of an axisymmetric geometry. The geometric configuration factor (view factor) is the fraction of energy leaving blackbody surface $i$, which arrives at blackbody surface $j$ directly. For any blackbody surface $i$ in the enclosure, conservation of energy requires that the sum of the configuration factors from surface $i$ to itself and the remaining enclosure surfaces equal 1.0. The exchange factor is the fraction of the energy emitted by graybody surface $i$ that is absorbed by graybody surface $j$ directly and by all reflections. Similarly, for any graybody surface $i$ in the enclosure, conservation of energy requires that the sum of the exchange factors from surface $i$ to itself and the remaining enclosure surfaces equal the emissivity of surface $i$. OCULAR calculates the configuration factor between the two surfaces analytically. The exchange factors are calculated using Hottel's Matrix Method (Ref. 1).

The input data have been designed to be compatible with that of the other functional modules within SCALE. OCULAR uses SCALE's free-form reading subroutines (see Sect. M3). The input data are subdivided into data blocks that are identifiable by keywords.

The OCULAR input data have been developed with the intention that OCULAR can read and process the HEATING input data. OCULAR is geometrically compatible with the axisymmetric geometry of HEATING, and its output may be directly input to HEATING. The OCULAR input data contain additional data blocks required to describe the enclosure of interest. Thus, a user may develop the HEATING input data to model a heat transfer problem, include the additional data blocks required to perform the exchange-factor calculations, execute OCULAR, and then use the data set coupled with the exchange factors for the HEATING thermal analysis.

Essentially every array whose size is a function of the input data is variably dimensioned. The default values used to compute these variable dimensions may be overridden using input data, and thus the code does not have to be recompiled each time a change in array size is specified. OCULAR uses the SCALE computer memory allocation feature (see Sect. M2).

OCULAR will read the input for a case until it encounters an end-of-case indicator. The program checks the input data for errors and inconsistencies and issues messages identifying any data problems that may have been encountered. Input processing is continued but the problem is not executed. This procedure results in the code identifying all or most of the input data errors with one execution. If no input data errors are encountered, OCULAR will proceed with the specific calculations for the case.

OCULAR solves for the graybody exchange factors (or blackbody configuration factors) for the nodal mesh employed by HEATING. The emissivity of the enclosure surfaces may be positionally dependent. The positional dependence may be specified through the use of analytical functions, tabular 
functions, or a user-supplied subroutine. Multiple surfaces and materials may be used to define an enclosure. The surface definitions must be consistent with the axisymmetric geometry. Calculations may be performed for multiple enclosures. Nodal spacing need not be equal.

OCULAR output includes the node numbers $i$ and $j$, the exchange (or configuration) factor between $i$ and $j$, and the sum of the factors for each emitting node $i$. This output is provided for verification purposes. Additional binary output is generated which will serve as unformatted input to HEATING through the CONNECTOR data block.

OCULAR has been developed for the axisymmetric geometry. In the course of the development, efforts have been made to make the code easily adaptable to the other HEATING geometry types.

NUREG/CR-0200,

Vol. 2, Rev. 5

F16.1.2 


\section{F16.2 NUMERICAL TECHNIQUE}

\section{F16.2.1. Statement of the Problem}

The HEATING program offers twelve possible geometries and currently OCULAR is designed to analytically calculate graybody exchange factors for the annular and cylindrical enclosures characteristic of an $\mathrm{r}-\mathrm{z}$ axisymmetric geometry. The code has been developed with a general format to facilitate future inclusion of the other two-dimensional (2-D) and three-dimensional (3-D) geometries.

As stated previously, OCULAR is geometrically compatible with the $\mathrm{r}-\mathrm{z}$ axisymmetric geometry of HEATING. The nodal mesh developed by OCULAR is identical to that of HEATING. Thus, OCULAR solves for the radiative exchange factors for nodes that lie on enclosure surfaces using HEATING's node-numbering convention.

HEATING employs a finite-difference mesh generation technique to develop an approximation to the physical problem. In order to define the nodal mesh, a system of orthogonal curvilinear coordinate surfaces is superimposed on the problem. The surfaces may be unevenly spaced, but must extend to the outer boundaries of the problem. A typical node is defined at the intersection of any three surfaces. For an $\mathrm{r}-\mathrm{z}$ axisymmetric geometry, a node may lie at the intersection of four different materials. The axisymmetric geometry of interest is illustrated in Fig. F16.2.1.

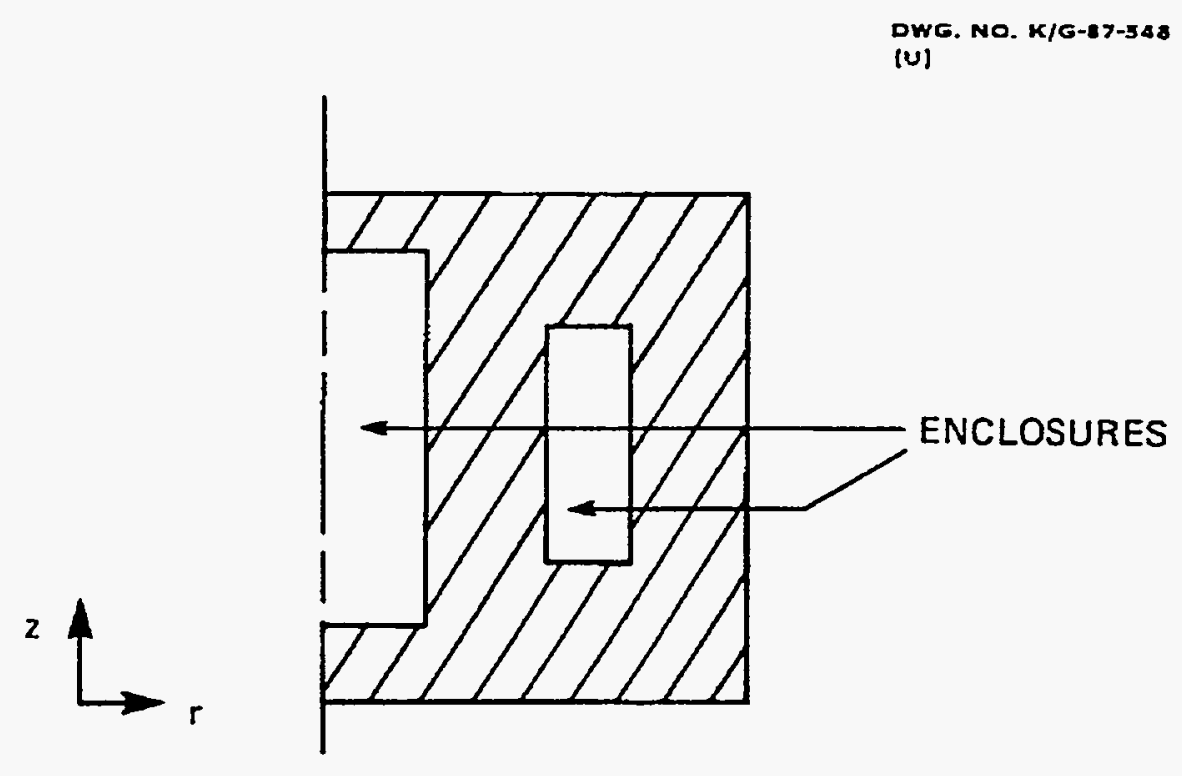

Figure F16.2.1 OCULAR axisymmetric geometry

The enclosure within the finite-difference mesh may be characterized for an axisymmetric geometry as a series of finite-length cylindrical surfaces or annular rings. Each node has an associated area in the radial and axial directions. With reference to Fig. F16.2.2, these nodal areas are defined by: 


$$
\begin{gathered}
A_{r}(i, k)=\pi\left[\left(\frac{r(i+1)+r(i)}{2}\right)^{2}-\left(\frac{r(i)+r(i-1)}{2}\right)^{2}\right], \\
A_{z}(i, k)=\pi r(i)(z(k+1)-z(k-1)) .
\end{gathered}
$$

OCULAR calculates exchange factors between areas associated with nodes that lie on defined enclosure surfaces.

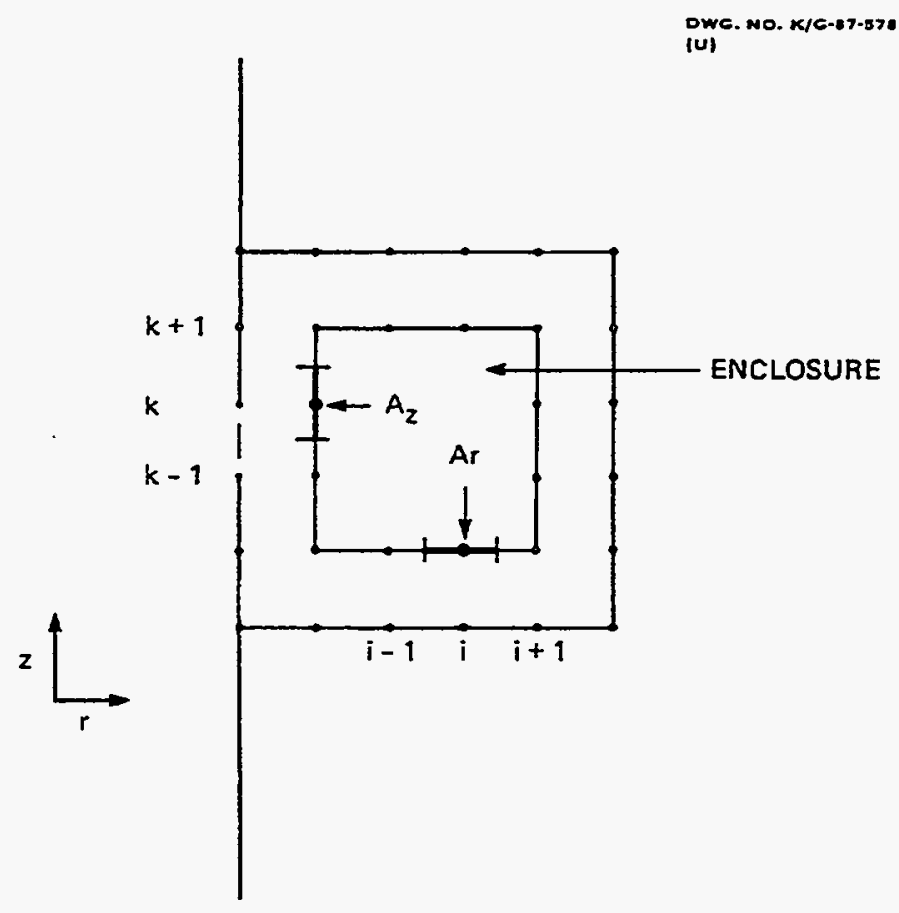

Figure F16.2.2 Nodal description for axisymmetric geometry

\section{F16.2.2. Enclosure Definition}

An enclosure is defined as a closed set of surfaces that lie within the model boundaries. OCULAR has been developed to model enclosures characteristic of the $\mathrm{r}-\mathrm{z}$ axisymmetric geometry, with the capability of extension to other geometries based on this enclosure definition. A general OCULAR model is illustrated in Fig. F16.2.1.

The following conventions are incorporated into the program:

1. multiple enclosures may be present in a model,

NUREG/CR-0200,

Vol. 2, Rev. 5
F16.2.2 
2. each enclosure is defined by surfaces that must be parallel to the coordinates axes,

3. each enclosure may be composed of multiple surfaces,

4. the nodal areas on parallel surfaces need not be equal,

5. surface boundaries must correspond to fine gridline locations,

6. the emissivity of a surface may vary with position,

7. the emissivity of a nodal area must be constant across the area,

8. the emissivity of a nodal area composed of different enclosure surfaces is an area-weighted emissivity, and

9. the enclosure may be bounded by multiple materials.

The annular and cylindrical enclosures modeled by OCULAR are illustrated in Figs. F16.2.3 and F16.2.4. The components of these enclosures may be described as a cylinder, lower ring, upper ring, and shell. Each component may be subdivided into smaller components through the use of the variable spacing capabilities of the mesh generator.

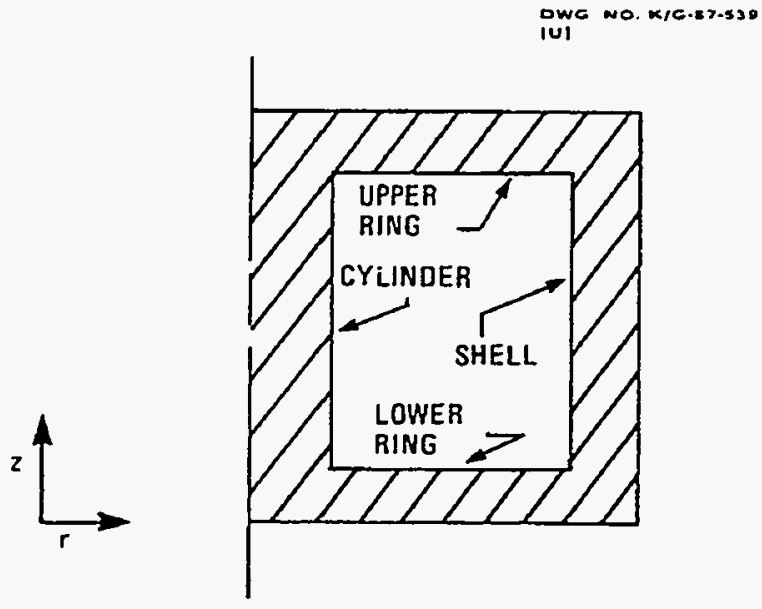

Figure F16.2.3 Annular axisymmetric enclosure

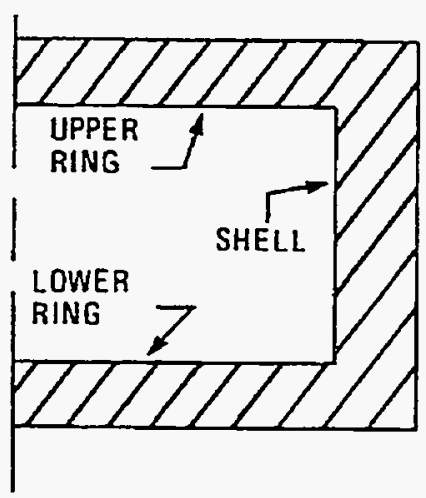

Figure F16.2.4 Cylindrical axisymmetric enclosure

Direct radiant exchange in the annulus is described by interaction between the following:

1. the cylinder and the lower ring,

2. the cylinder and the upper ring,

3. the cylinder and the shell, 
4. the lower ring and the shell,

5. the upper ring and the shell,

6. the lower ring and the upper ring, and

7. the shell and itself.

The analytic expressions for the geometric configuration factors for this enclosure are described in Sect. F16.2.3. Note that these expressions account for the shading effects in the enclosure which result from the presence of the cylinder.

Direct radiant exchange in the cylindrical enclosure may be described by interaction between:

1. the lower ring and the shell,

2. the upper ring and the shell,

3. the lower ring and the upper ring, and

4. the shell and itself.

The analytic expressions for the geometric configuration factors for this enclosure are described in Sect. F16.2.4.

\section{F16.2.3. Annular Geometric Configuration Factors}

The annular enclosure may be described as consisting of a cylindrical surface, two ring surfaces, and a shell surface, as illustrated in Fig. F16.2.3. The analytic expressions for the configuration factor between nodal areas that lie on these major surfaces are described in the following sections. The view factor algebra necessary to calculate reciprocal factors is not presented.

\section{F16.2.3.1. Cylinder-to-ring factors}

The configuration factor from cylindrical area 1 to ring area $2, F_{1-2}$, illustrated in Fig. F16.2.5, is a function of the cylinder-to-disk configuration factor $F_{(a-b)}$, illustrated in Fig. F16.2.6 (Ref. 2). The factor $F_{1-2}$ may be expressed as:

$$
\begin{aligned}
F_{1-2} & =\frac{A_{1}+A_{4}}{A_{1}}\left(F_{((1+4)-(2+3))}-F_{((1+4)-(3))}\right) \\
& -\frac{A_{4}}{A_{1}}\left(F_{(4)-(2+3))}-F_{((4)-\beta))}\right),
\end{aligned}
$$

where

NUREG/CR-0200,

Vol. 2, Rev. 5

F16.2.4 


$$
\begin{gathered}
F_{(a-b)}=\frac{1}{2 \pi}\left\{\cos ^{-1}\left(\frac{h^{2}-r_{d}^{2}+r_{c}^{2}}{h^{2}+r_{d}^{2}-r_{c}^{2}}\right)-\left(\frac{r_{c}}{2 h}\right)\left[\frac{\left(h^{2}+r_{d}^{2}+r_{c}^{2}\right)^{2}}{r_{c}^{4}}-4\left(\frac{r_{d}}{r_{c}}\right)^{2}\right]^{12}\right. \\
\cdot \cos ^{-1} \frac{r_{d}\left(h^{2}-r_{d}^{2}+r_{c}^{2}\right)}{r_{d}\left(h^{2}+r_{d}^{2}-r_{c}^{2}\right)}+\left[\frac{\left.h^{2}-r_{d}^{2}+r_{c}^{2}\right]}{r_{c}^{2}}\right] \sin ^{-1}\left(\frac{r_{c}}{r_{d}}\right) \\
\left.-\left(\frac{\pi}{2}\right)\left[\frac{h^{2}+r_{d}^{2}-r_{c}^{2}}{r_{c}^{2}}\right]\right\} .
\end{gathered}
$$

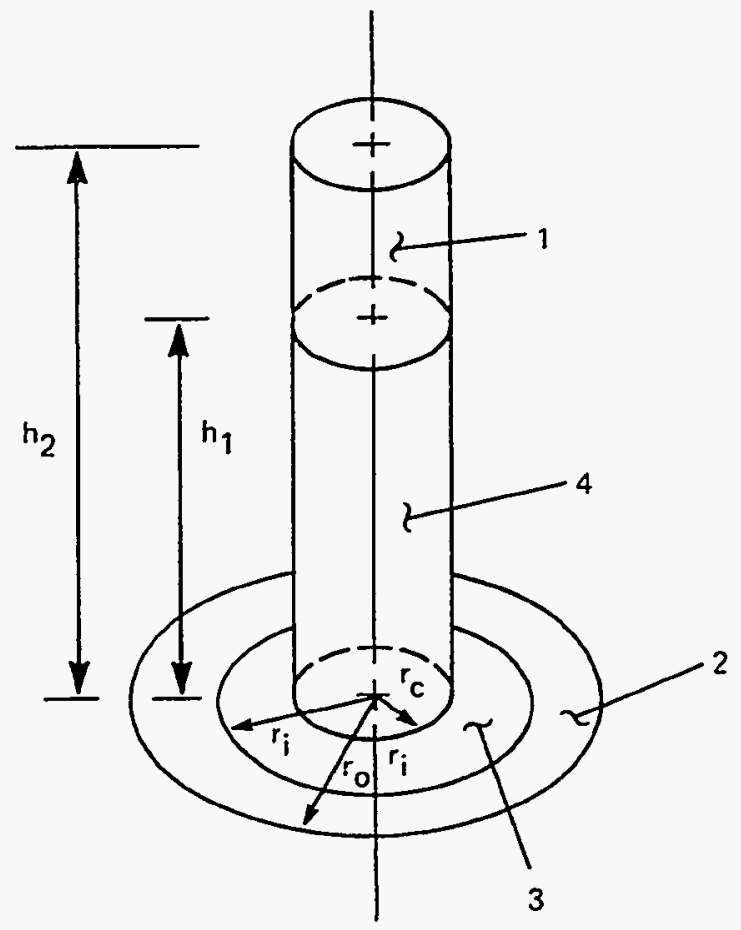

Figure F16.2.5 Cylinder-to-ring model

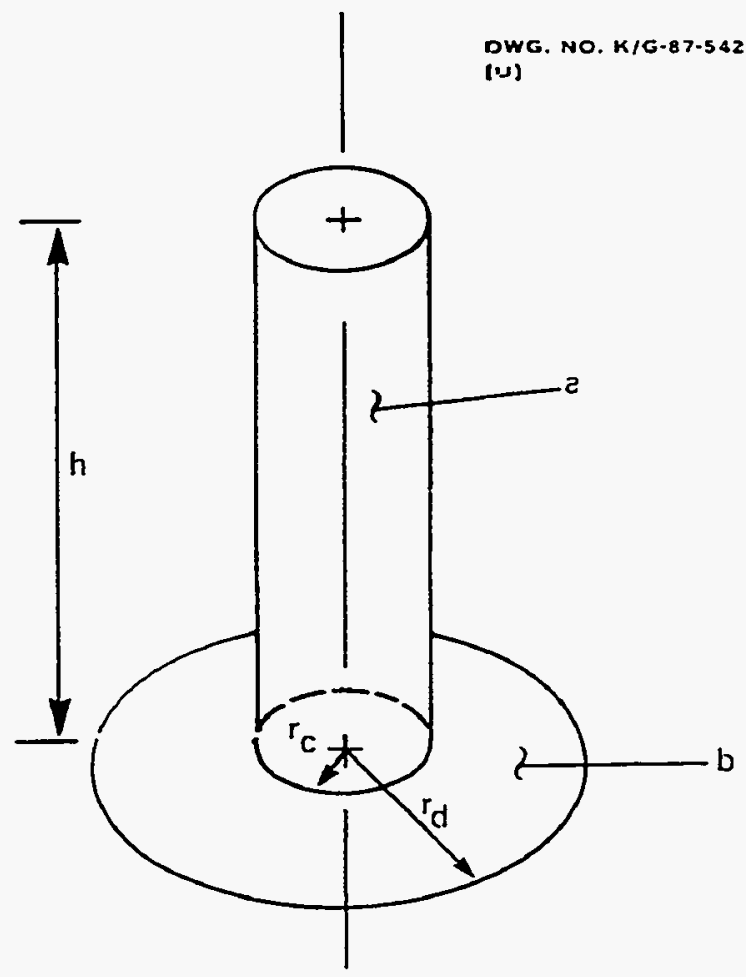

Figure F16.2.6 Cylinder-to-disk model

\section{F16.2.3.2. Cylinder-to-shell factors}

The configuration factor from cylindrical area 1 to shell area $2, F_{1-2}$, is a function of the cylinderto-disk configuration factor, defined in Sect. F16.2.3.1, and the relative position of area 2 with respect to area 1 (Ref. 2). The four configurations are illustrated in Fig. F16.2.7 and will be referred to as I, II, III, and IV. In each case, the radius of the cylinder is $r_{c}$ and the shell is $r_{0}$. A shorthand notation is used 
where $F_{\left(h_{1}-h_{2}\right.}$, represents the cylinder-to-disk factor $F_{(a-b)}$, with $h=h_{1}-h_{2}$. The factors for each configuration are as follows:

(a) Configuration I

$$
F_{1-2}=\frac{1}{h_{1}}\left[h_{3}+h_{2} F_{\left(h_{2}\right)}+h_{4} F_{\left(h_{4}\right)}-\left(h_{2}+h_{3}\right) F_{\left(h_{2}+h_{3}\right)}-\left(h_{3}+h_{4}\right) F_{\left(h_{3}+h_{4}\right)}\right]
$$

(b) Configuration II

$$
F_{1-2}=\frac{1}{h_{1}}\left[h_{2} F_{\left(h_{2}\right)}+h_{4}\left(1-F_{\left(h_{4}\right)}\right)+\left(h_{3}-h_{4}\right) F_{\left(h_{3}-h_{4}\right)}-\left(h_{2}+h_{3}\right) F_{\left(h_{2}+h_{3}\right)}\right],
$$

(c) Configuration III

$$
F_{1-2}=\frac{1}{h_{3}}\left[h_{3}+h_{2} F_{\left(h_{2}\right)}+h_{4} F_{\left(h_{2}\right)}-\left(h_{2}+h_{3}\right) F_{\left(h_{2}+h_{3}\right)}-\left(h_{3}+h_{4}\right) F_{\left(h_{3}+h_{4}\right)}\right] \text {, }
$$

(d) Configuration IV

$$
F_{1-2}=\frac{1}{h_{1}}\left[\left(h_{1}+h_{2}\right) F_{\left(h_{1}+h_{2}\right)}+\left(h_{2}+h_{3}\right) F_{\left(h_{2}+h_{3}\right)}-h_{2} F_{\left(h_{2}\right)}-\left(h_{1}+h_{2}+h_{3}\right) F_{\left(h_{1}+h_{2}+h_{3}\right)}\right] .
$$
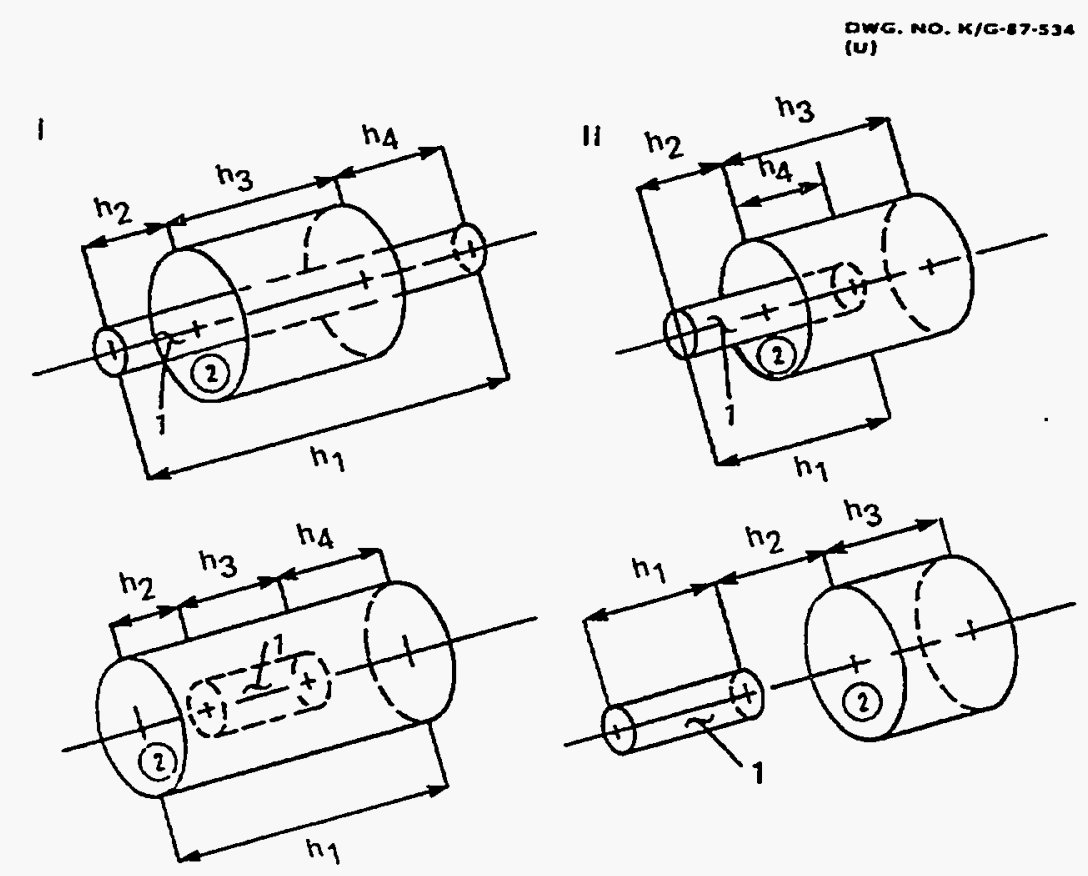

III

IV

Figure F16.2.7 Cylinder-to-shell configurations

NUREG/CR-0200,

Vol. 2, Rev. 5
F16.2.6 


\section{F16.2.3.3. Ring-to-shell factors}

The configuration factor from ring area 1 to shell area $2, F_{1-2}$, illustrated in Fig. F16.2.8 may be expressed as (Ref. 3):

$$
F_{1-2}=\frac{2}{\rho_{o}^{2}-\rho_{i}^{2}} \int_{\rho_{l}}^{\rho_{o}} r F_{d A_{1}-A_{2}} d r
$$

where

$$
\begin{aligned}
F_{d A_{1}-A_{2}}= & \frac{1}{\pi} \tan ^{-1}\left[\frac{r_{s}+r}{r_{s}-r} \tan \left(\frac{\omega}{2}\right)\right]-\frac{\left(r_{s}^{2}-r^{2}-h^{2}\right)}{\pi \sqrt{\left(r_{s}^{2}+r^{2}+h^{2}\right)^{2}-\left(4 r^{2} r_{s}^{2}\right)}} \\
& \tan ^{-1}\left[\frac{\sqrt{\left(r_{s}^{2}+r^{2}+h^{2}\right)^{2}-4\left(r^{2} r_{s}^{2}\right)}}{r_{s}^{2}+r^{2}+h^{2}-2 r r_{s}} \tan \left(\frac{\omega}{2}\right)\right],
\end{aligned}
$$

for

$$
\omega=\cos ^{-1}\left(\frac{r_{c}}{r}\right)+\cos ^{-1}\left(\frac{r_{c}}{r_{s}}\right) .
$$

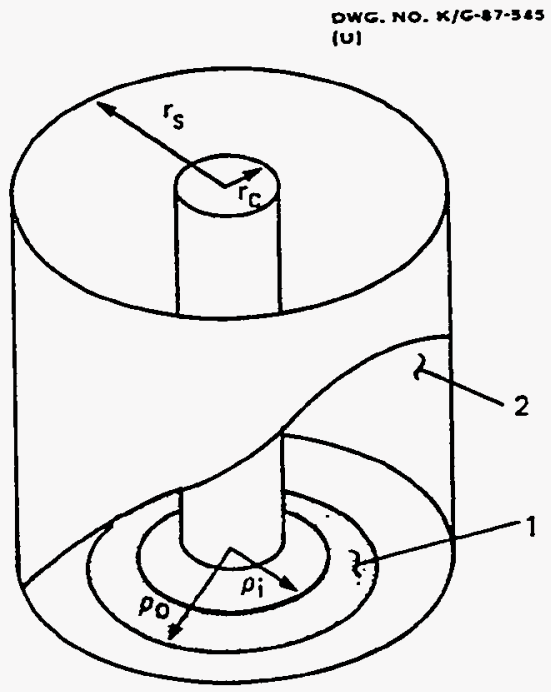

Figure F16.2.8 Annular ring-to-shell model

F16.2.7 


\section{F16.2.3.4. Ring-to-ring factors}

The configuration factor from ring 1 to ring 2 separated by a solid coaxial cylinder (Ref. 4), as shown in Fig. F16.2.9, may be expressed as

$$
F_{1-2}=\frac{2}{\left(\rho_{o}^{2}-\rho_{i}^{2}\right)} \int_{\rho_{i}}^{\rho_{0}} \rho F_{d A_{1}-A_{2}} d \rho,
$$

where

$$
\begin{aligned}
F_{d A_{1}-A_{1}} & =\frac{\omega-\phi}{2 \pi}+\frac{r_{o}^{2}-\rho^{2}-h^{2}}{\pi \sqrt{\left(r_{o}^{2}+\rho^{2}+h^{2}\right)^{2}-4 \rho^{2} r_{o}^{2}}} \tan ^{-1}\left(\frac{\sqrt{r_{o}^{2}+\rho^{2}+h^{2}+2 \rho r_{o}} \tan \frac{\omega}{2}}{\sqrt{r_{o}^{2}+\rho^{2}+h^{2}-2 \rho r_{o}}}\right) \\
& -\frac{\left(r_{i}^{2}-\rho^{2}-h^{2}\right)}{\pi \sqrt{\left(r_{i}^{2}+\rho^{2}+h^{2}\right)^{2}-4 \rho^{2} r_{i}^{2}}} \tan ^{-1}\left(\frac{\sqrt{r_{i}^{2}+\rho^{2}+h^{2}+2 \rho r_{i}} \tan \frac{\phi}{2}}{\sqrt{r_{i}^{2}+\rho^{2}+h^{2}-2 \rho r_{i}}}\right),
\end{aligned}
$$

for

$$
\begin{aligned}
& \omega=\cos ^{-1}\left(\frac{r_{c}}{\rho}\right)+\cos ^{-1}\left(\frac{r_{c}}{r_{o}}\right), \\
& \phi=\cos ^{-1}\left(\frac{r_{c}}{\rho}\right)+\cos ^{-1}\left(\frac{r_{c}}{r_{i}}\right) .
\end{aligned}
$$




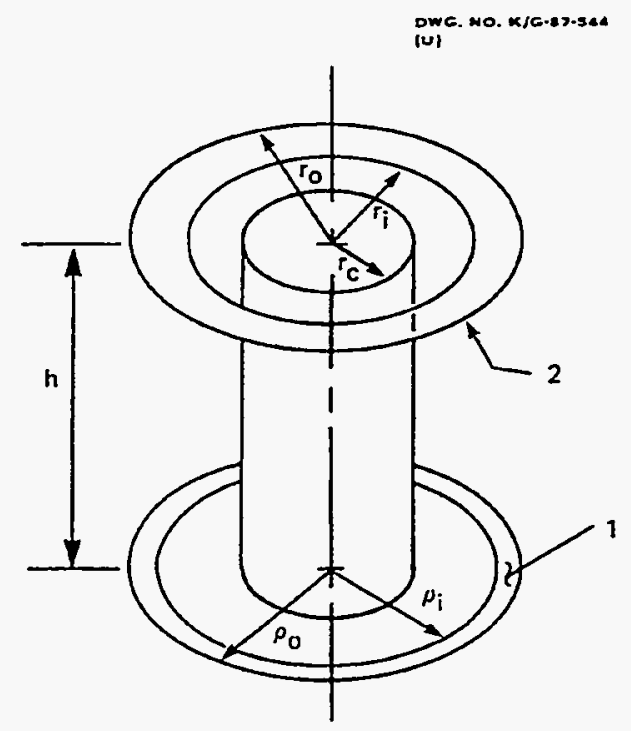

Figure F16.2.9 Annular ring-to-ring model

\section{F16.2.3.5. Shell-to-shell factors}

The configuration factor from the interior of a shell to itself for an annular enclosure (Ref. 5), as illustrated in Fig. F16.2.10, may be expressed as

$$
\begin{gathered}
F_{1-1}=1-\frac{1}{R}+\frac{2}{\pi R} \tan ^{-1} \frac{2 \sqrt{R^{2}-1}}{L} \\
-\frac{L}{2 \pi R}\left[\frac{\sqrt{4 R^{2}+L^{2}}}{L} \sin ^{-1} \frac{4\left(R^{2}-1\right)+\left(\frac{L^{2}}{R^{2}}\right)\left(R^{2}-2\right)}{L^{2}+4\left(R^{2}-1\right)}\right] \\
-\sin ^{-1} \frac{\left(R^{2}-2\right)}{R^{2}}+\frac{\pi}{2}\left(\frac{\sqrt{4 R^{2}+L^{2}}}{L}-1\right),
\end{gathered}
$$

where

$$
\begin{aligned}
& R=\frac{r_{s}}{r_{c}}, \\
& L=\frac{h}{r_{c}} .
\end{aligned}
$$




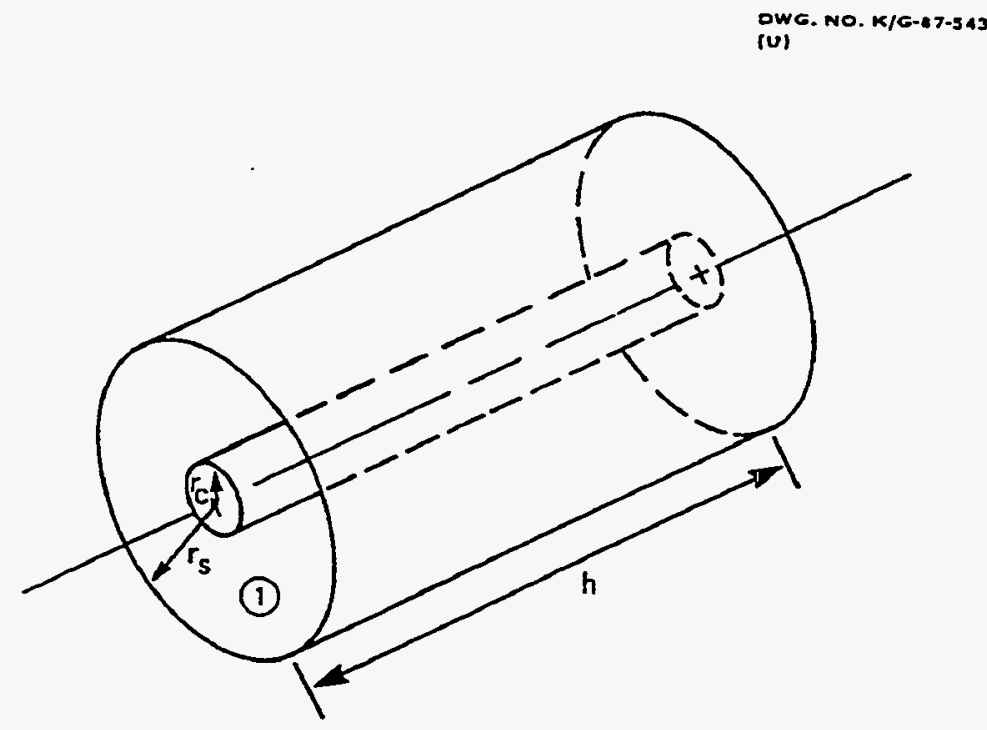

Figure F16.2.10 Annular shell-to-shell model

\section{F16.2.4. Cylindrical Geometric Configuration Factors}

The cylindrical enclosure consists of two ring surfaces and a shell surface, as illustrated in Fig. F16.2.4. In the model generation process, the program treats the centerline of the enclosure as a window. Thus, the centerline is a pseudosurface that must be included in the input to completely define the enclosure. Although this surface is used to define the enclosure, it is not included in the solution technique. The analytic expressions for the configuration factor between nodal areas that lie on these major surfaces are described in the following sections. The view factor algebra necessary to calculate reciprocal factors is not presented.

\section{F16.2.4.1. Shell-to-ring factors}

The configuration factor from the interior of shell area 1 to ring area $2, F_{1-2}$, as illustrated in Fig. F16.2.11, may be expressed as (Ref. 6):

$$
\begin{aligned}
F_{1-2}= & \frac{1}{4\left(L_{2}-L_{1}\right)}\left[\sqrt{L_{2}^{4}+2 L_{2}^{2}\left(1+R_{2}\right)^{2}+\left(1-R_{2}^{2}\right)^{2}}-\sqrt{L_{2}^{4}+2 L_{2}^{2}\left(1+R_{1}^{2}\right)+\left(1-R_{1}^{2}\right)^{2}}\right. \\
& \left.+\sqrt{L_{1}^{4}+2 L_{1}^{2}\left(1+R_{1}^{2}\right)+\left(1-R_{1}^{2}\right)^{2}}-\sqrt{L_{1}^{4}+2 L_{1}^{2}\left(1+R_{2}^{2}\right)+\left(1-R_{2}^{2}\right)^{2}}\right],
\end{aligned}
$$


where

$$
\begin{aligned}
& L_{1}=\frac{h_{1}}{r_{s}}, \\
& L_{2}=\frac{h_{2}}{r_{s}}, \\
& R_{1}=\frac{r_{i}}{r_{s}}, \\
& R_{2}=\frac{r_{0}}{r_{s}} .
\end{aligned}
$$

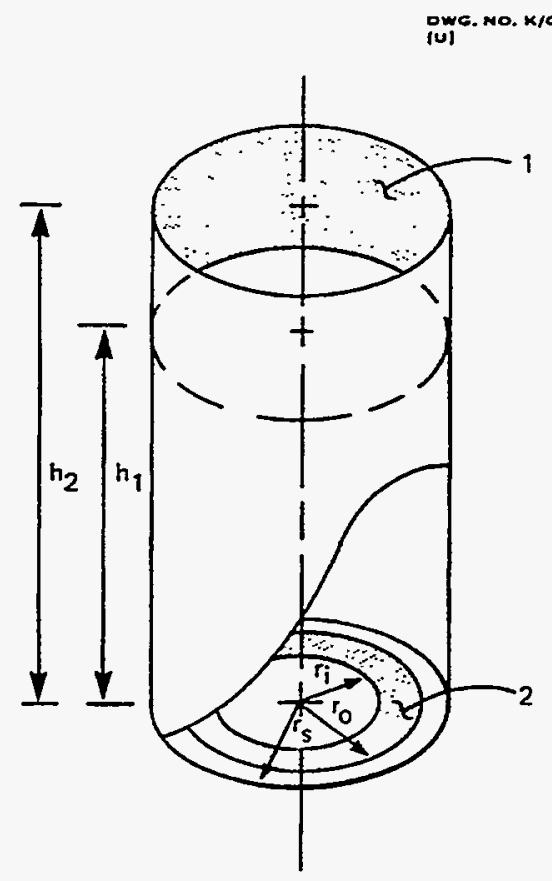

Figure F16.2.11 Cylindrical shell-to-ring model 


\section{F16.2.4.2. Ring-to-ring factors}

For two coaxial rings, the configuration factor from ring 1 to ring $2, F_{1-2}$, is a function of the configuration factor between two coaxial disks, $F_{(\mathrm{a}-\mathrm{b})}$ (Ref. 5). The ring-to-ring configuration is illustrated in Fig. F16.2.12, the disk-to-disk configuration in Fig. F16.2.13.

$$
F_{1-2}=\frac{A_{1}+A_{4}}{A_{1}}\left(F_{((1+4)-(2+3))}-F_{((1+4)-3)}\right)-\frac{A_{4}}{A_{1}}\left(F_{(4-(2+3))} F_{(4-3)}\right),
$$

where

$$
\begin{gathered}
F_{(a-b)}=\frac{1}{2}\left[1+\frac{1+R_{b}^{2}}{R_{a}^{2}}-\left(\left(1+\left(\frac{1+R_{b}^{2}}{R_{a}^{2}}\right)\right)^{2}-4\left(\frac{R_{b}}{R_{a}}\right)^{2}\right)^{1 / 2}\right] \\
R_{a}=\frac{a}{h}, \\
R_{b}=\frac{b}{h} .
\end{gathered}
$$
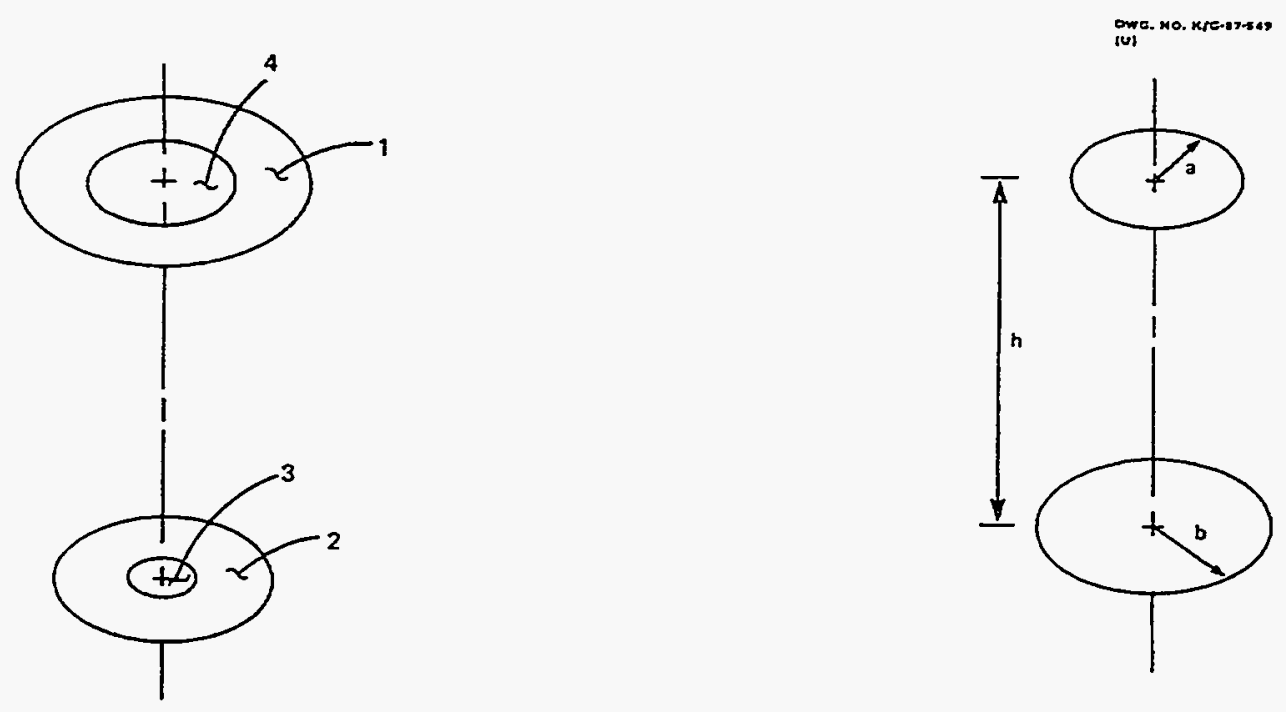

Figure F16.2.12 Cylindrical ring-to-ring model

Figure F16.2.13 Disk-to-disk model

NUREG/CR-0200,

Vol. 2, Rev. 5

F16.2.12 


\section{F16.2.4.3. Shell-to-shell factors}

The configuration factor from the interior of a shell to itself, $F_{1-1}$, as illustrated in Fig. F16.2.14, may be expressed as (Ref. 6):

$$
F_{1-1}=\left(1+\frac{h}{2 r_{s}}\right)-\left(1+\left(\frac{h}{2 r_{s}}\right)^{2}\right)^{1 / 2} .
$$

\section{F16.2.5. Exchange Factors}

The exchange factor is defined as the fraction of energy emitted by surface $i$ (if it is assumed to be a black surface) absorbed by surface $j$ (Ref. 1). The exchange factor depends on the geometric arrangement of all surfaces in the enclosure and their emittances. OCULAR solves for the exchange factors using Hottel's Matrix Method. This portion of the code is modeled upon an earlier computer program, HOTTEL (Ref. 7). OCULAR outputs the factor between two nodal areas and the sum of the factors for each emitting node. This sum should equal the emittance of the emitting nodal area. Since OCULAR employs exact solutions for configuration factor computations, any differences that do exist are a result of numerical integration over a finite surface area. The magnitude of the configuration factor asymptotically approaches the exact solution for the annular ring-to-ring and ring-to-shell factors as the finite surface area approaches zero. These solutions are presented as Eqs. (F16.9) and (F16.12). Experience has shown that the configuration factor for the innermost ring contains this error. Thus, care should be exercised when defining the mesh spacing for the annular enclosure in this region. If the difference due to discretization error is unacceptable, the mesh should be refined in this region and the problem repeated.

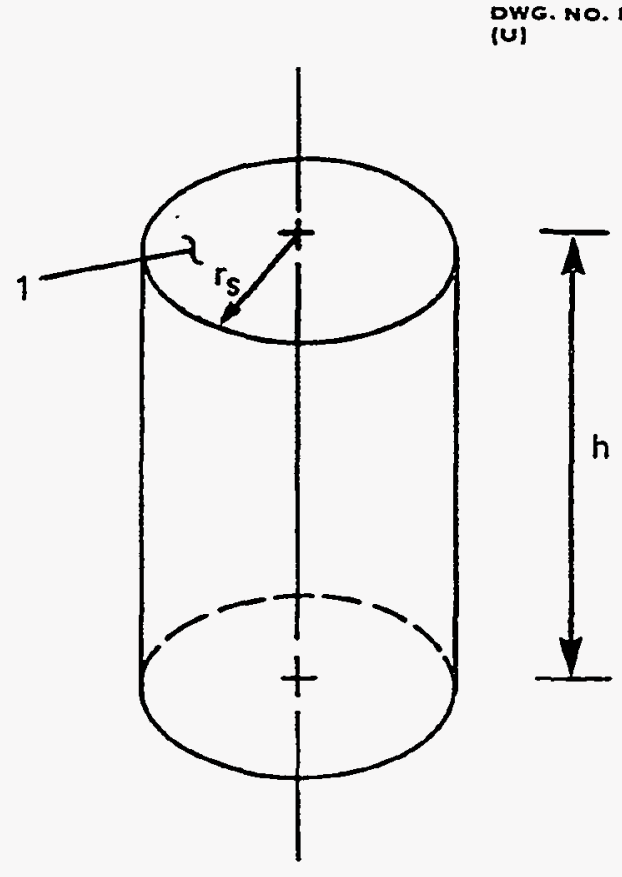

Figure F16.2.14 Shell-to-shell model

F16.2.13

NUREG/CR-0200, Vol. 2, Rev. 5 
The exchange factors are calculated assuming that the following restrictions in the heat transfer analysis will be met:

1. the temperature is uniform across a nodal area,

2. the directional spectral emissivity and the directional spectral absorptivity are equal and independent of either angle or wavelength,

3. all energy is emitted and reflected diffusely, and

4. the incident and reflected energy flux is uniform over each nodal area. 


\section{F16.3 PROGRAM LOGIC FLOW AND SUBROUTINE DESCRIPTION}

OCULAR reads input data for one case per computer run. Execution is halted after the input data are read and the exchange factors are generated. The calling sequence of routines is depicted in Fig. F16.3.1.

\section{F16.3.1. Description of Subroutines Used by OCULAR}

Descriptions of subroutines and entry points that comprise OCULAR are presented in Table F16.3.1.

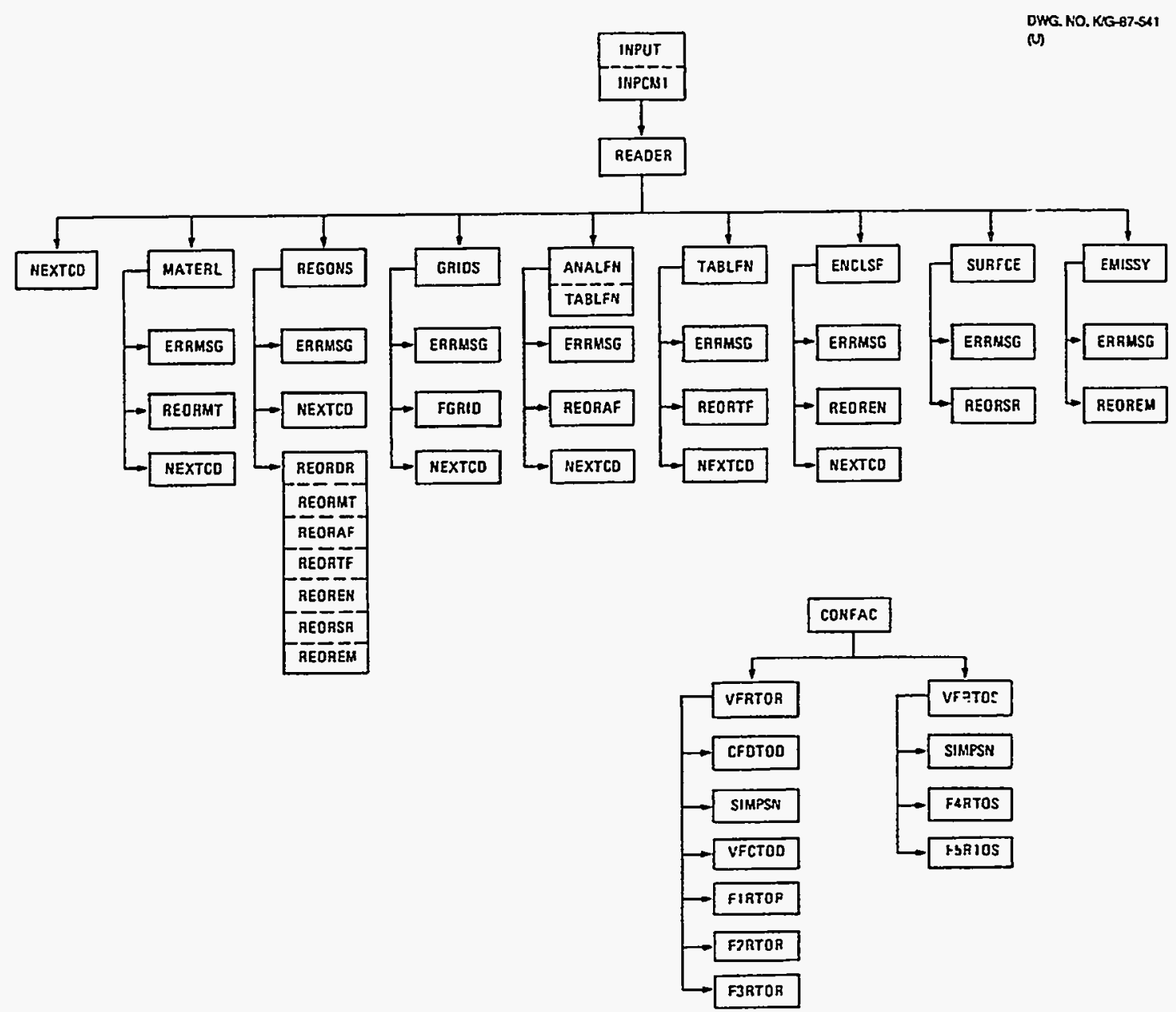

Figure F16.3.1 Calling sequence of routines

F16.3.1

NUREG/CR-0200,

Vol. 2, Rev. 5 
Table F16.3.1 Summary of subroutines and entries

BLOCK DATA Initializes data in labeled commons /ARYLNG/ and /IOUNIT/

MAIN OCULRA Directs ALOCAT to call subroutine ALCROR and opens buffers.

ALCROR Serves as an interface between the OCULAR main routine and subroutines. Determines the maximum dimension of the array that holds all variably dimensioned arrays.

ANALFN Reads card images for one analytical function from the analytical function data block for each call. Checks the data to determine if they are compatible and writes error messages if they are not. Called from READER Calls ERRMSG, NEXTCD, REORAF, and REORTF. Calls SCALE free-form reading routines DREAD and IREAD.

ANALYT Entry in PREANA. Evaluates the referenced analytical function or calls the specified user-supplied subroutine. Called from FUNCTN. Calls EMSSVY.

BLDENC Builds the general-enclosure mesh that overlays the problem mesh. Called from OCULST.

CFDTOD Calculates the view factor from one radial disk to another coaxial radial disk. Called from VFRTOR.

CFSTOS Calculates the view factor from the interior of a right circular cylinder to itself for an annular or cylindrical enclosure. Called from VFSTOS.

CHKATF Checks the external reference number (input data) to an analytical or tabular function to determine whether or not it has been defined. Calculates internal reference numbers to defined functions. Writes error messages for undefined functions. Called from ERRCK.

CONFAC Serves as a driver for the calculation of the analytic geometric view factors and exchange factors. Called from OCULST. Calls EXCHNG, FUNCTN, VFCTOR, VFCTOS, VFRTOR, VFRTOS, and VFSTOS.

DECOMP Decomposes a real matrix by Gaussian elimination and estimates the condition of the matrix. Called from EXCHNG. Calls SOLVE (Ref. 8).

DIFFER Calculates the fine lattice lines that bound a region and a surface. Called from WRITER. Calls REGION.

ECHO Reads remaining standard input data card images from unit IECHO, lists input data card images on unit IO, blanks out columns 73 through 80 except for title cards, comments, and end of data indicators, and writes the resulting input data images on unit IN. Assumes card image with "@" in column 1 is a continuation of the previous card image. Replaces "@" in column 1 with a blank. Called from MAIN.

NUREG/CR-0200,

Vol. 2, Rev. 5

F16.3.2 
Table F16.3.1 (continued)

EMISSY $\quad$ Reads card images for one emissivity function from the emissivity function data block for each call. Checks the data to determine if they are compatible and writes error messages if they are not. Called from READER. Calls ERRMSG and REOREM. Calls SCALE free-form reading routines DREAD and IREAD.

EMSSVY Evaluates the user-supplied function defining the emissivity for the portion of the node whose properties are being evaluated. Writes an error message and stops when called unless the user-supplied algorithm has been added. Called from ANALYT.

ENCLSE Reads card images for one enclosure function from the enclosure function data block for each call. Checks the data to determine if it is compatible and writes error messages if it is not. Called from READER Calls ERRMSG and REOREN. Calls SCALE free-form reading routine IREAD.

ENREGN Entry in REGION. Writes error message if the fine grid matching a surface boundary cannot be located. Called from DIFFER.

ERRCK Checks references by the region, material, enclosure, surface, and emissivity input data to determine whether or not the referenced parameters have been defined. Called from INPUT. Calls CHKATF.

ERRMSG Called when the number of parameters defined by the input data exceeds the maximum allowed by the code. Writes error message and sets flag indicating number of errors encountered. Called from ANALFN, EMISSY, ENCLSE, GRIDS, MATERL, REGONS, and SURFCE. Calls SCALE free-form reading routine AREAD.

EXCHNG Uses Hottel's matrix solution to calculate the exchange factor terms. Called by CONFAC. Calls DECOMP and SOLVE.

F1RTOR Function representing an integrand of the function in the $F_{d A_{1}-A_{2}}$ ring-to-ring configuration factor calculations. Accessed by VFRTOR through SIMPSN.

F2RTOR Function representing an integrand of the function in the $F_{d A_{1}-A_{2}}$ ring-to-ring configuration factor calculations. Accessed by VFRTOR through SIMPSN.

F3RTOR Function representing an integrand of the $F_{d A_{1}-A_{2}}$ function in the ring-to-ring configuration factor calculations. Accessed by VFRTOR through SIMPSN.

F4RTOS Function representing an integrand of the $F_{d A_{1}-A_{2}}$ function in the ring to dA, shell configuration factor calculations. Accessed by VFRTOS through SIMPSN.

F5RTOS Function representing an integrand of the $F_{d A_{1}-A_{2}}$ function in the ring-to-shell configuration factor calculations. Accessed by VFRTOS through SIMPSN. 
Table F16.3.1 (continued)

FGRID

Calculates the fine gridlines along each axis based on the respective set of gross gridlines and their related divisions. Called from GRIDS.

FUNCTN Computes the value of an emissivity which can be positional-dependent. Value of the emissivity is a function of the independent variables $X$ (or $R$ ), $Y$ (or $\theta$ ), and $Z$ (or $\phi$ ). Called from CONFAC. Calls entries ANALYT and TABLE.

GRIDS Reads the card images from the XGRID, YGRD, and ZGRID data blocks. Called from READER. Calls ERRMSG, FGRID, and NEXTCD.

INITIL Initializes variables and arrays to zero. Called from INPUT.

INPUT Reads the first four input cards and calls routines to read and write the remaining input data. Job information and parameters are output. Called from OCULST. Calls ERRCK, INITIL, NEXTCD, OUTPUT, PREANA, PRETAB, READER, SETTYP, and WRITER Calls SCALE free-form reading routines AREAD, DREAD, IREAD, and SCANON.

MATERL Reads card images for one material from the material data block for each call. Checks the data to determine if they are compatible and writes error messages if they are not. Called from READER. Calls ERRMSG, NEXTCD, and REORMT. Calls SCALE free-form reading routines $C R E A D, D R E A D$, and IREAD.

NEXTCD Reads the first word of the next card image. Writes message to include last card image successfully read if "end-of-file" or "end-of-data" is encountered and sets appropriate flag. Writes out entire card image if it is a comment and looks at next card image. Otherwise, resets flag so that the next read is from first word of this card image and returns to the calling subroutine. Called from ANALFN, ENCLSE, GRIDS, INPUT, MATERL, READER, REGONS, SURFCE, and TABLFN. Calls SCALE routine AREAD.

OCULST Sets the size of the variably dimensioned arrays and initializes the parameters for the run. Called from ALCROR. Calls entries INPUT, NEXTCD, PLANES, POINTS, BLDENC, CONFAC, and PRINTR. Calls SCALE routine IONUMS.

OPTION Reads the OPTION data block and writes out the values of the parameters that can be reset with this data block. Called from MAIN.

OUTPUT Writes out the parameters from Card 2, checks the parameters for errors, and writes error messages if errors are encountered. Called from INPUT.

PLANES Performs error checking to determine whether the surface data are properly defined and whether enclosures are defined by prescribed surfaces. Called from OCULST.

POINTR Sets the size of the variably dimensioned arrays. Called from MAIN.

NUREG/CR-0200,

Vol. 2, Rev. 5

F16.3.4 
Table F16.3.1 (continued)

POINTS Generates the nodal configuration and the arrays defining the fine lattice lines passing through each node. Called from OCULST.

PREANA Serves as initial entry for passing variably dimensioned arrays for later use by entry ANALYT. Called from INPUT.

PRETAB Serves as initial entry for passing variably dimensioned arrays for later use by entry TABLE. Checks tabular data for consistency and writes messages if errors are detected. Called from INPUT.

PRINTR Writes out the exchange factor data and the HEATING CONNECTOR input data. Called from OCULST.

READER Reads each card image in the standard input data beginning with the data immediately following the title card and card 2. Checks for keywords defining a data block and branches to associated subroutine where related input data from the block are read. Assumes card image belongs to currently open data block if a keyword is not found. Writes error message and continues with next card image if keyword is not found on first card image. Returns to INPUT upon encountering an "end-of-file" or an "end-of-data." Called from INPUT. Calls MATERL, NEXTCD, REGONS, GRIDS, ANALFN, ENCLSE, SURFCE, and EMISSY. Calls entry TABLFN.

REGION Checks input data to ensure that the boundary of each region corresponds to a fine gridline. Called from DIFFER.

REGONS Reads card images for one region from the region data block for each call. Checks the data to determine if they are compatible and writes error messages if they are not. Called from READER. Calls ERRMSG, NEXTCD, and REORDR. Calls SCALE free-form reading routines DREAD and IREAD.

REORDR Reorders arrays containing the input data associated with the region data block when a region is deleted by the input data. Entries REORMT, REORAF, REORTF, REOREN, REORSR, and REOREM are independent sections of coding and perform similar tasks on other input data items. Called from REGONS.

REORAF Reorders arrays containing the input data associated with the analytical function data block when an analytical function is deleted by the input data. Called from ANALFN.

REOREM Reorders arrays containing the input data associated with the emissivity function data block when an emissivity function is deleted by the input data. Called from EMISSY.

REOREN Reorders arrays containing the input data associated with the enclosure function data block when an enclosure function is deleted by the input data. Called from ENCLSE.

REORMT Reorders arrays containing the input data associated with the material function data block when a material function is deleted by the input data. Called from MATERL. 
Table F16.3.1 (continued)

REORSR $\quad$ Reorders arrays containing the input data associated with the surface function data block when a surface function is deleted by the input data. Called from SURFCE.

REORTF Reorders arrays containing the input data associated with the tabular function data block when a tabular function is deleted by the input data. Called from entry TABLFN.

SETTYP Initializes flags and parameters that are a function of the geometry type. Called from INPUT.

SIMPSN Integrates a specified function using Simpson's Rule. Called by VFRTOR and VFRTOS. Accesses functions F1RTOR, F2RTOR, F3RTOR, F4RTOS, and F5RTOS.

SOLVE Solves the linear system $A A * X=C K$. Called from EXCHNG. Calls DECOMP (Ref. 8).

SURFCE Reads card images for one surface from the surface data block for each call. Checks the data to determine if they are compatible and writes error messages if they are not. Called from READER Calls ERRMSG, NEXTCD, and REORSR. Calls SCALE free-form reading routines $\mathrm{DREAD}$ and $\mathrm{READ}$.

TABLE Entry in PRETAB. Performs checking to ensure tabular function values bound the argument values. Writes warning message. Called from FUNCTN.

TABLFN Entry in ANALFN. Reads card images for one tabular function from the tabular function data block for each call. Checks the data to determine if they are compatible and writes error messages if they are not. Called from READER. Calls ERRMSG, NEXTCD, and REORTF. Calls SCALE free-form reading routines DREAD and IREAD.

VFCTOD Computes the configuration factor from the outside surface of a cylinder to a disk. Called from VFCTOR and VFCTOS.

VFCTOR Calculates the configuration factor from the outer surface of a cylinder to a ring at the base of the cylinder for an annular enclosure. Called from CONFAC. Calls VFCTOD.

VFCTOS Calculates the configuration factor from the exterior of an inner-right circular cylinder of finite length to the interior of an outer-right circular cylinder (shell) using cylinderto-disk configuration factors and view factor algebra for an annular enclosure. Called from CONFAC. Calls VFCTOD.

VFRTOR Calculates the configuration factor between coaxial rings. Called from CONFAC. Calls CFDTOD, SIMPSN, and VFCTOD. Accesses functions F1RTOR, F2RTOR, and F3RTOR.

NUREG/CR-0200,

Vol. 2, Rev. 5

F16.3.6 
Table F16.3.1 (continued)

VFRTOS Calculates the configuration factor between a ring in the enclosure and the inner surface of the outer shell. Calls SIMPSN. Accesses F4RTOS and F5RTOS.

VFSTOS Calculates the configuration factor from the interior of a right circular cylindrical shell of finite length to itself and from the interior of a right circular cylindrical shell to the interior of a coaxial shell. Called from CONFAC, calls CFSTOS.

WRITER Writes out the input data values, except for the title card, card 2 and comment cards. Checks for errors and outputs messages if errors are detected. Called from INPUT. Calls DIFFER. 


\section{F16.4 INPUT DESCRIPTION FOR OCULAR}

\section{F16.4.1. General}

A detailed discussion of the input data cards is presented, followed by a brief outline of the input data for the benefit of the user who is familiar with the data preparation. In preparing the input data, any consistent set of units may be used in the OCULAR program. The units associated with the algorithms which appear in the user-supplied subroutine EMSSVY must be consistent with those of the input data.

The input data set for OCULAR is derived from the HEATING input data set with the intention that OCULAR can read and process the HEATING input data. Thus, a user may develop a HEATING input deck to model a heat transfer problem, include the additional enclosure, surface, and emissivity information required by OCULAR, and use the same data set that will be used for the thermal analysis to produce the necessary exchange factors. OCULAR will read only the data needed from the HEATING input deck. By necessity, OCULAR data assume the same format as HEATING data. If a user chooses not to use a HEATING input data set, zeros should be supplied in appropriate HEATING data entries. The input description assumes that a HEATING data set is not being used.

Formatted input data are read from logical unit No. 4 and unformatted input data are read from logical unit No. 95. Formatted output is written to logical unit No. 6 and unformatted node-to-node connector data are written to logical unit No. 12.

The input data for OCULAR are read using the SCALE free-form reading routines (see Sect. M2). When OCULAR is executed within the SCALE system, =OCULAR or \#OCULAR must be the first record in the data set. An input data set is terminated with a percent (\%) sign. When executed within the SCALE system, an END card must be supplied as the last card of the data deck to signify the end of the input data to the SCALE driver.

Data are entered in an unformatted manner by separating each data item by one or more blanks or by a comma. With a few exceptions noted, the data items may be entered anywhere in columns 1 through 72. If the data that are to appear on a card will not fit on one card, an "@" must appear in column 1 of each continuation card. Otherwise, the code will read the remaining data for that card image as either zero or blank. There is no limit to the number of continuation cards. However, a continuation card may not immediately follow a title card, an end-of-data card, a comment card, or a keyword indicator card. Columns 73 through 80 of each card are reserved for identification to aid the user in the preparation and handling of data. Decimal data may be entered as FORTRAN input. For example, $1.733 \times 10^{-4}$ may be entered as $1.733-4,1.733 \mathrm{E}-4,1.733 \mathrm{D}-4$, or 0.0001733 . Note that imbedded blanks are not allowed within a given number representation. SCALE free-form reading routines have provisions for multiple entries of the same data value. This step is done by entering the number of repeats, followed by either $R, *$, or $\$$, followed by the data value to be repeated. For example, $5 \mathrm{R} 2$ or $5 * 2$ enters five successive 2 's in the input data. No blanks should be inserted between the multiplier and the repeat flag, but each multiple entry must be separated from the rest of the data by one or more blanks or by a comma. Because blanks are ignored, an embedded zero must be specified in the input data either as 0 followed by one or more blanks, as $\mathbf{0}$ followed by a comma, or as one or more blanks followed by a comma. However trailing blanks may be omitted. Multiple zeros may be specified as $\mathrm{NZ}$, where $\mathrm{N}$ is the number of zeros to be repeated. Again, there must not be any blanks between the $N$ and the $Z$, but the NZ must be separated from the rest of the data by one or more blanks or by a comma. All literal data fields, such as material names, must be delineated by a blank, they must not be delineated by a comma.

F16.4.1

NUREG/CR-0200, Vol. 2, Rev. 5 
The input data for an execution of OCULAR consist of data defining the size of the variably dimensioned arrays and the options that will be in effect during the computer run. Case parameters that dictate the required size of the variably dimensioned arrays are input with the OPTIONS data block. This data block contains variables whose default values may be modified and it is placed at the beginning of an OCULAR data set.

This data block is followed by case data. A case consists of a title card, one parameter card, and the data blocks necessary to define the problem being modeled. The user may wish to add comment cards to the input data for documentation purposes. Any number of comment cards may appear anywhere in the input data following the title card, except a comment card may not precede a continuation card. The comment cards are identified by an asterisk $\left(^{*}\right)$ in column 1 . The comments will be written on the standard output unit as they are encountered.

Ten different data blocks may be used in describing the model to the computer code. A data block consists of a block indicator card containing the keyword followed by the data for that block. No embedded blanks can be present in the first four characters of the keyword. The keyword for each data block is contained in Table F16.4.1.

Table F16.4.1 Data block keywords

\begin{tabular}{l}
\hline REGIONS \\
MATERIALS \\
XGRID \\
YGRID \\
ZGRID \\
ANALYTICAL FUNCTIONS \\
TABULAR FUNCTIONS \\
ENCLOSURES \\
SURFACES \\
EMISSIVITIES
\end{tabular}

The data reference number blocks may appear in any order within the block and may have any positive integer value accepted by the machine. If a data reference number appears more than once within a data block, the last data read with that reference number are used.

The final data card in a data deck for a case is an end-of-data card and must contain a percent $\%$ in column 1 and a blank in column 2. This card signifies the end of data for a problem. As OCULAR reads the input data, it sets a flag when an error is encountered and continues to read additional data unless the error was fatal. When the end of data indicator (\%) is encountered, OCULAR terminates reading and commences processing the input data. After processing is completed, the code performs the specified calculations unless an error was encountered.

In the sections that follow, the characters $(A),(I)$, or $(R)$ may appear after the heading for the entries to indicate that the entry is alphanumeric, integer, or real, respectively. Suggested data card labels follow each data block section heading. These labels may be entered in columns 73 through 80 of the related data cards to aid in identifying the data.

NUREG/CR-0200,

Vol. 2, Rev. 5

F16.4.2 


\section{F16.4.2. OPTION Data Block}

The variables labeled in commons /ARYLNG/ and /IOUNIT/ are initialized in a BLOCK DATA subprogram. In general, it is advantageous to tailor OCULAR to a specific problem by overriding the default values specified in the BLOCK DATA with values appropriate for the problem. This adaptation is accomplished through the use of the OPTION data block input feature described below. Each of the variables in the two common blocks whose default value can be modified appears in this data block.

The first record read by OCULAR contains data for the OPTION data block. This feature allows the user to change the default value of any or all variables in the data block by including the variable name and its desired value. The variables are input beginning with OPTION and ending with END. These parameters apply to OCULAR for the entire run. Table F16.4.2 contains each variable name and its default value.

Table F16.4.2 List of OCULAR variables whose default value may be modified through the OPTION data block

\begin{tabular}{lrl}
\hline MAXANA & 5 & Maximum number of analytical functions \\
MAXCON & 1 & Maximum number of connectors \\
MAXEMS & 5 & Maximum number of emissivity functions \\
MAXENC & 5 & Maximum number of enclosures \\
MAXGGL & 10 & Maximum number of gross gridlines along any axis \\
MAXMAT & 5 & Maximum number of materials \\
MAXNEA & 8 & Maximum number of nodal areas in an enclosure \\
MAXPRS & 10 & Maximum number of pairs in each tabular function \\
MAXPTS & 50 & Maximum number of lattice points (nodes) \\
MAXREG & 5 & Maximum number of regions \\
MAXRFG & 50 & Maximum number of X (or R) fine gridlines \\
MAXSRF & 5 & Maximum number of enclosure surfaces \\
MAXTBL & 5 & Maximum number of tabular functions \\
MAXTFG & 50 & Maximum number of $Y$ (or 0 ) fine gridlines \\
MAXZFG & 50 & Maximum number of $Z$ (or 0) fine gridlines \\
\hline & & \\
\hline
\end{tabular}

F16.4.3

NUREG/CR-0200, Vol. 2, Rev. 5 


\section{F16.4.3. Problem Control Parameters}

\section{F16.4.3.1. Card 1}

This card, which can contain alphanumeric characters in the first 72 columns, contains a descriptive title for the problem and must be the first card in the data deck. The card itself cannot be omitted, although it may be left blank. This title serves to identify the output associated with a problem, and it appears at the top of a number of the tables generated by the program. It is also included in messages output by the code.

\section{F16.4.3.2. Card 2}

\section{F16.4.3.2.1. Entry 1}

The first entry on card 2 is not processed by OCULAR. The entry itself cannot be omitted and should be set to zero if the user is not using a HEATING input data deck.

\section{F16.4.3.2.2. Entry 2 - geometry type}

The HEATING program offers twelve possible geometries (seven and eight are functionally the same) which are members of either the cylindrical, Cartesian, or the spherical coordinate system. The geometry types are listed in Table F16.4.3 below.

Table F16.4.3 HEATING geometry types

\begin{tabular}{lll}
\hline Cylindrical & Rectangular & Spherical \\
\hline I R- $\theta-Z$ & $6 \mathrm{X}-\mathrm{Y}-\mathrm{Z}$ & $10 \mathrm{R}$ \\
$2 \mathrm{R}-\theta$ & $7 \mathrm{X}-\mathrm{Y}$ & $11 \mathrm{R}-\theta$ \\
$3 \mathrm{R}-\mathrm{Z}$ & $8 \mathrm{X}-\mathrm{Z}$ & $12 \mathrm{R}-\theta-\phi$ \\
$4 \mathrm{R}$ & $9 \mathrm{X}$ & \\
$5 \mathrm{Z}$ & & \\
\hline
\end{tabular}

Currently OCULAR is designed to model enclosures for the R-Z geometry type. Thus, entry 2 on card 2 should be 3 .

\section{F16.4.4. Region Data Block (Cards R1 and R2)}

Each region is described by two cards that must appear in pairs. The cards are repeated for each region. There must be at least one region specified. The maximum number of regions is MAXREG.

\section{F16.4.4.1. Block indicator card}

\section{REGIONS}

NUREG/CR-0200,

Vol. 2, Rev. 5

F16.4.4 


\section{F16.4.4.2. Card R1}

a. Region Number (I)

This entry contains the number of the region to be described. The region numbering system does not require that a region occupy any particular zone in the overall configuration.

b. Region Material Number (I)

The second entry of this card defines the material which occupies the region. The integer entry is the function number of the material listed in the material data block.

c. Region Dimensions ( $R$ )

Dimensions of the region boundaries are entered as floating-point numbers and are arranged in the following order:

1. smaller dimension of $\mathrm{X}$ or $\mathrm{R}$ region boundary,

2. larger dimension of $\mathrm{X}$ or $\mathrm{R}$ region boundary,

3. smaller dimension of $Y$ or $\theta$ region boundary,

4. larger dimension of $\mathrm{Y}$ or $\theta$ region boundary,

5. smaller dimension of $Z$ or $\phi$ region boundary, and

6. larger dimension of $Z$ or $\phi$ region boundary.

These dimensions constitute the third through eighth entries, respectively. If the problem is $1-$ or 2-D, then the region boundary dimensions for the remaining unnecessary coordinate should be zero. For the $\mathrm{R}-Z$ geometry type, the fifth and sixth entries should be zero. The region volume must be nonnegative. Although it is usually more convenient to place the overall configuration at the origin, it is not necessary to do so; however, all region boundary dimensions are entered as their distance from the origin. For the axisymmetric geometry, the minimum inner radial dimension is zero. The axial region boundary dimensions need not be positive, but must extend in the positive $\mathrm{Z}$ direction.

\section{F16.4.4.3. Card R2}

This card must be included with the appropriate $R l$ card even if it is blank for an OCULAR run. The HEATING data contained on this card are not utilized.

\section{F16.4.5. Material Data Block (Cards $M$ and PC)}

A group of cards, consisting of an $\mathrm{M}$ card and possibly a $\mathrm{PC}$ card, is required to describe each material for a HEATING model. A subset of the HEATING data is processed and used by OCULAR, and only this subset is described below. 


\section{F16.4.5.1. Block indicator card}

\section{MATERIALS}

\section{F16.4.5.2. Card M}

a. Material Number (I)

The first entry, an integer, contains the number of the material which is to be described. This entry corresponds to the material specified as entry 2 on card R1. Each different material has a unique number.

b. Material Name (A)

The second entry contains the name of the material. The name, which may consist of up to eight alphanumeric characters, is used to aid in identification of output data. It cannot contain any embedded-blanks and must be terminated by one or more blanks. Note that OCULAR does not access the material properties library of SCALE. However, an asterisk is acceptable as the first character of the material name.

c. HEATING Data

Entries $3,4,5,6,7$, and 8 are HEATING data that are not processed for use by OCULAR. If OCULAR is being used in a stand-alone fashion, these entries should be blank.

d. Phase Change Flag (1)

When employing a HEATING input deck, the ninth entry on the $M$ card is a positive integer indicating that a material can undergo a change-of-phase. OCULAR uses this entry as a flag to indicate that a PC card immediately follows the $M$ card. The entry should be blank for a stand-alone OCULAR run and for materials that do not undergo a phase change.

\section{F16.4.5.3. Card PC}

Information on this card is not processed for use by OCULAR. This card must be present if the ninth entry on card $M$ is nonzero.

\section{F16.4.6. X (or R) Grid Data Block (Cards L1 and N1)}

Gross lattice data for the $X$ (or $R$ ) axis are entered on two sets of cards: the first set specifies the lattice dimensions, and the second indicates the mesh divisions between gross lattice lines. All numbers on the first set ( $\mathrm{L} 1$ cards) are of the floating-point type and are entered by specifying all of the gross lattice dimensions along the $X$ (or R) axis sequentially on one or more cards. The second set (N1 cards) specify the number (an integer greater than or equal to 1) of equal increments which are between the gross lattice lines whose dimensions are given on the first set of cards. In particular, an entry on an NI card specifies the number of equal increments between the gross lattice line in the corresponding entry on the 
$\mathrm{L} 1$ card and the gross lattice line immediately following it. Any L1 or N1 card that is a continuation card must contain an "@" in column 1.

F16.4.6.1. Block indicator card

XGRID

\section{F16.4.6.2. Card L1}

The Ll cards correspond to the $\mathrm{X}$ (or R) coordinate. The total number of entries must not exceed MAXGGL.

\section{F16.4.6.3. Card N1}

The N1 cards correspond to the X (or R) coordinate and have one less entry than the $\mathrm{L} 1$ cards. The total number of fine lattice lines along the $\mathrm{X}$ (or $\mathrm{R}$ ) axis or the sum of the entries on the $\mathrm{N} 1$ card plus 1 must not exceed MAXRFG.

\section{F16.4.7. Z (or $\phi$ ) Grid Data Block (Cards L3 and N3)}

The gross lattice data for the $Z$ (or $\phi$ ) axis are formed in the same manner as for the data along the X (or R) axis. Any L3 or N3 card that is a continuation card must contain an "@" in column 1.

\section{F16.4.7.1. Block indicator card}

\section{ZGRID}

\section{F16.4.7.2. Card L3}

The L3 cards correspond to the $\mathrm{Z}$ (or $\phi$ ) coordinate. The total number of entries must not exceed MAXGGL.

\section{F16.4.7.3. Card N3}

The N3 cards correspond to the $\mathrm{Z}$ (or $\phi$ ) coordinate and have one less entry than the L3 card. The total number of fine lattice lines along the $Z$ (or $\phi$ ) axis or the sum of the entries on the N3 card plus 1 must not exceed MAXZFG.

\section{F16.4.8. Enclosure Data Block (Cards EN1 and EN2)}

Each enclosure is described by two cards that must appear in pairs. The cards are repeated for each enclosure. There must be at least one enclosure for each problem. Each different enclosure is assigned a unique positive integer. Enclosures may be defined to exist in voided regions or in regions containing nonparticipating materials such as air. The surfaces that comprise the enclosure must be defined such that a complete enclosure is formed. For input purposes, the program treats the centerline of a cylindrical enclosure as a window. Thus, the centerline is a pseudosurface that must be input. This 
surface is used to define the enclosure, but it is not included in the solution technique. The maximum number of enclosures is MAXENC.

\section{F16.4.8.1. Block indicator card}

\section{ENCLOSURES}

\section{F16.4.8.2. Card EN1}

a. Enclosure Number (I)

The first entry on card EN1 is an integer that contains the number of the enclosure to be defined.

b. Boundary Number (I)

The second entry on the EN1 card contains the boundary number defining the HEATING boundary condition number which will be used to model the radiant heat transfer within the enclosure.

c. Number of Surfaces (I)

The third entry contains the number of surfaces that comprise the enclosure.

\section{F16.4.8.3. Card EN2}

The entries on the EN2 card define the surfaces that comprise the enclosure. The total number of entries must correspond to the number specified by the third entry on card EN1. The surface numbers must correspond to surfaces defined in the Surface Data Block.

\section{F16.4.9. Surface Data Block (Card SU)}

Surface data are described in a manner similar to regions. The location of the surface is defined by specifying where its endpoints lie in the model. A 2-D surface may be visualized as a line; a 3-D surface as an area. The surface dimension will always be one dimension less than the model's dimension. The input data have been generalized to provide for future implementation HEATING geometries. The number of surfaces cannot exceed MAXSRF.

\section{F16.4.9.1. Block indicator card}

\section{SURFACES}

\section{F16.4.9.2. Card $\mathrm{SU}$}

a. Surface Number (I)

This entry contains the number of the surface to be described.

NUREG/CR-0200,

Vol. 2, Rev. 5

F16.4.8 


\section{b. Emissivity of Surface (I)}

The second entry of this card indicates the emissivity function number that describes the hemispherical total emissivity of the surface.

c. Surface Dimensions (R)

Dimensions of the surface boundaries are entered as floating-point numbers and are arranged in the following order:

1. smaller dimension of $X$ (or $R$ ) surface boundary,

2. larger dimension of $X$ (or $R$ ) surface boundary,

3. smaller dimension of $Y$ (or $\theta$ ) surface boundary,

4. larger dimension of $Y($ or $\theta)$ surface boundary,

5. smaller dimension of $Z$ (or $\phi$ ) surface boundary, and

6. larger dimension of $Z$ (or $\phi$ ) surface boundary.

For the axisymmetric geometry, the $\mathrm{Y}$ (or $\theta$ ) boundary is set to zero by OCULAR. The two $\mathrm{X}$ (or R) boundaries must be equal or the two $Z$ (or $\phi$ ) entries must be equal. For a 3-D model, either the $X$, the $Y$, or the $Z$ surface boundary dimensions must be equal.

\section{F16.4.10. Emissivity Data Block (Card EM)}

Total hemispherical emissive property data are entered on the EM cards. At least one emissivity function must be defined for each problem. The total number of emissivity functions cannot exceed MAXEMS. An area-weighted average emissivity is used for nodal areas comprised of two different enclosure surfaces.

\section{F16.4.10.1. Block indicator card}

\section{EMISSIVITIES}

\section{F16.4.10.2. Card EM}

Each different emissivity function is assigned a unique positive integer. The emissivity function may be expressed as:

$$
\epsilon(x, y, z)=\epsilon_{c} F_{i}(x) F_{j}(y) F_{K}(z),
$$

where $\epsilon(x, y, z)$ is a total hemispherical emissivity at a location $(x, y, z)$ in the model. Since the emissivity associated with a surface may be a function of position, the data card consists of five entries. All of them 
are integers except the second, which is a floating-point number. The first entry contains the emissivity function number. The second entry contains the constant factor describing the emissivity function. This term corresponds to $\epsilon_{c s}$ in Eq. (F16.29). The remaining entries, which identify analytical or tabular functions $F(x), F(y), F(z)$, contain the $x$ - (or $r$-), $y$ - (or $\theta$ ), and $z$ - (or $\phi$-) dependent function parameters corresponding to the $\mathrm{i}, \mathrm{j}$, and $\mathrm{k}$, respectively, in Eq. F16.29. If the emissivity does not vary along a particular axis of the surface, then the position-dependent function parameter associated with the coordinate must be zero, and the corresponding function value will be set to 1.0 by the code. The emissivity function value may not be set to zero. To model a surface with an emissivity of zero, a small value, such as $1.0 \times 10^{-6}$ is suggested. A value of 1.0 is recommended to model black surfaces such as holes in the enclosure.

\section{F16.4.11. Analytical Function Data Block (Cards A1 and A2)}

Each analytical function, defined as

$$
\begin{aligned}
F(v) & =A_{1}+A_{2} v+A_{3} v^{2}+A_{4} \cos \left(A_{5} v\right) \\
& +A_{6} e^{A, v}+A_{8} \sin \left(A_{9} v\right)+A_{10} \ln \left(A_{11} v\right)
\end{aligned}
$$

is described by an A1 card and one or more A2 cards. The total number of analytical functions must not exceed MAXANA.

\section{F16.4.11.1. Block indicator card}

\section{ANALYTICAL FUNCTIONS}

\section{F16.4.11.2. Card A1}

The first entry on Card Al is a unique analytical function number, an integer. The second entry, also an integer, is the number of coefficients, $A_{i}$, which are on the $\mathrm{A} 2$ cards. If the second entry is blank or zero, then the code assumes that a user-supplied subroutine will be supplied for the emissivity. The second entry cannot exceed MAXPAR which is currently 11.

\section{F16.4.11.3. Card A2}

The A2 cards contain up to MAXPAR (currently set to 11) ordered pairs, where each ordered pair is defined as follows: the first element of an ordered pair consists of an integer $i$; the second element consists of the value of the coefficient $A_{i}$. The integer i must not exceed MAXPAR. The A2 cards will be continued until each coefficient in the analytical function is defined. If the second entry on Card A1 is blank or zero, then the related A2 card is omitted. A continuation card must contain an "@" in column 1.

As an example, the cards which are necessary to describe

$$
f(x)=100.0 \sin (5 x)+e^{-3 x}
$$

are presented in Table F16.4.4.

NUREG/CR-0200, 
Table F16.4.4 $\mathrm{Al}$ and $\mathrm{A} 2$ cards necessary to describe the function $100.0 \sin (5 \mathrm{x})+e^{-3 \mathrm{x}}$

\begin{tabular}{lccccccccc}
\hline Entry & 1 & 2 & 3 & 4 & 5 & 6 & 7 & 8 & Card \\
\hline & 1 & 4 & & & & & & & A1 \\
& 8 & 100.0 & 9 & 5.0 & 6 & 1.0 & 7 & -3.0 & A2 \\
\hline
\end{tabular}

\section{F16.4.11.4. User-supplied subroutine EMSSVY}

The dummy FORTRAN subroutine, EMSSVY, incorporated in OCULAR to model the emissivity of an enclosure surface is presented in Fig. F16.4.1. The user must overwrite this dummy routine with FORTRAN coding designed to describe the emissivity behavior.

\section{F16.4.12. Tabular Function Data Block (Cards T1 and T2)}

The tabular function is assumed to be a set of linearly connected points. The function is described by specifying a set of ordered pairs $v$ and $F(v)$. Each ordered pair contains an independent variable and its functional value. A maximum of MAXPRS points is allowed, and linear interpolation is performed between the points. The function is evaluated according to

$$
F(v)=\left[\begin{array}{ll}
F\left(v_{1}\right) & v<v_{i} \\
F\left(v_{n}\right) & v>v_{n}
\end{array}\right.
$$

for points outside the defined domain. The total number of tabular functions must not exceed MAXTBL.

\section{F16.4.12.1. Block indicator card}

TABULAR FUNCTIONS

\section{F16.4.12.2. Card T1}

The first entry on the $\mathrm{T} 1$ card (an integer) is a unique tabular function number. The number of points (an integer) is the second entry. 
SUBROUT INE EMSSVY (RVALUE, $R, T H, Z, V A L U E$, NUMBER)

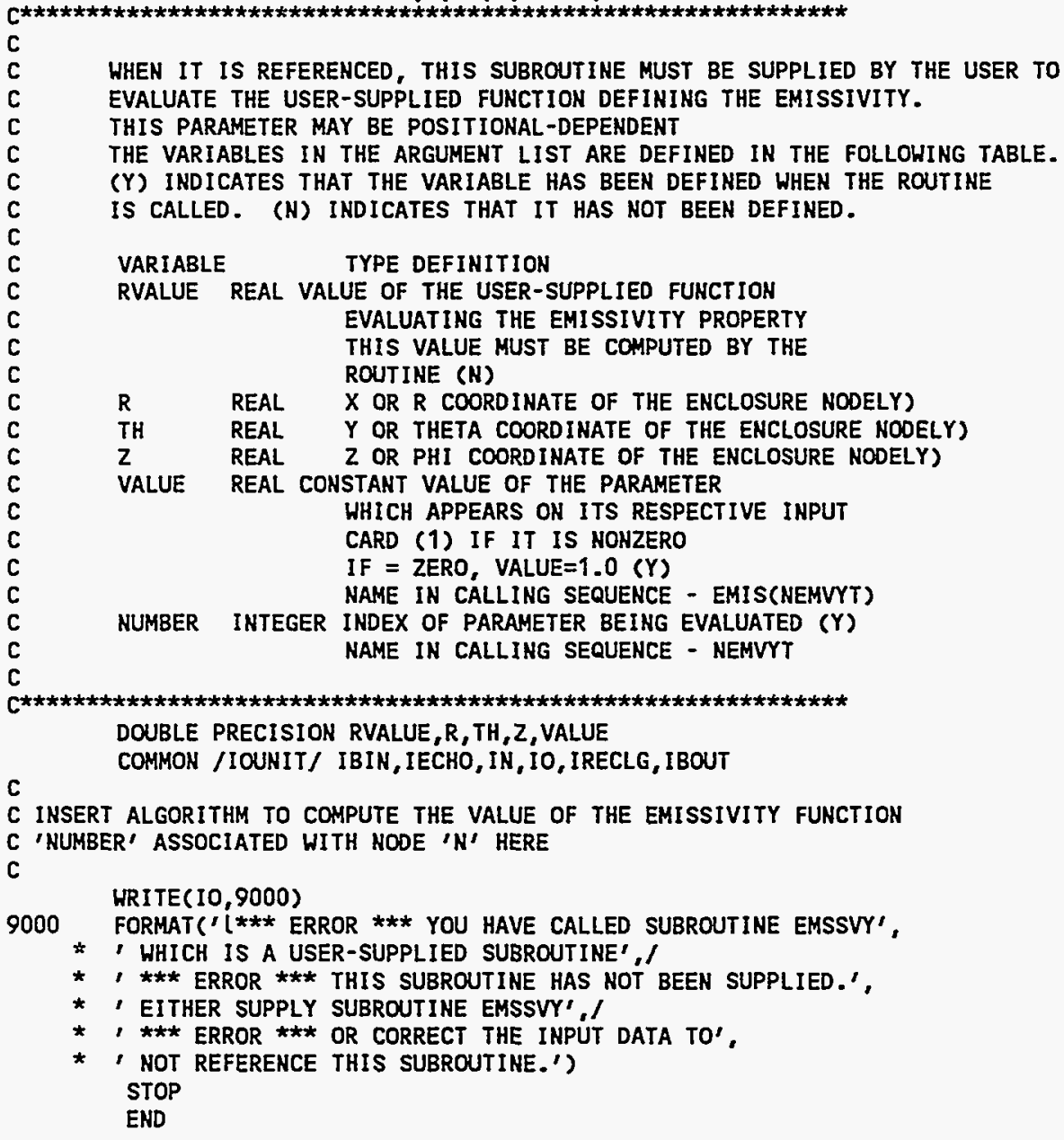

Figure F16.4.1 User-supplied subroutine EMSSVY

\section{F16.4.12.3. Card T2}

The T2 cards contain the ordered pairs, all floating-point numbers. The first member of the pair is the independent variable; the second, the function value. A continuation card must contain an "@" in column 1 .

An example of an acceptable tabular function is presented in Fig. F16.4.2. The input for this example is presented in Table F16.4.5.

NUREG/CR-0200,

Vol. 2, Rev. 5

F16.4.12 


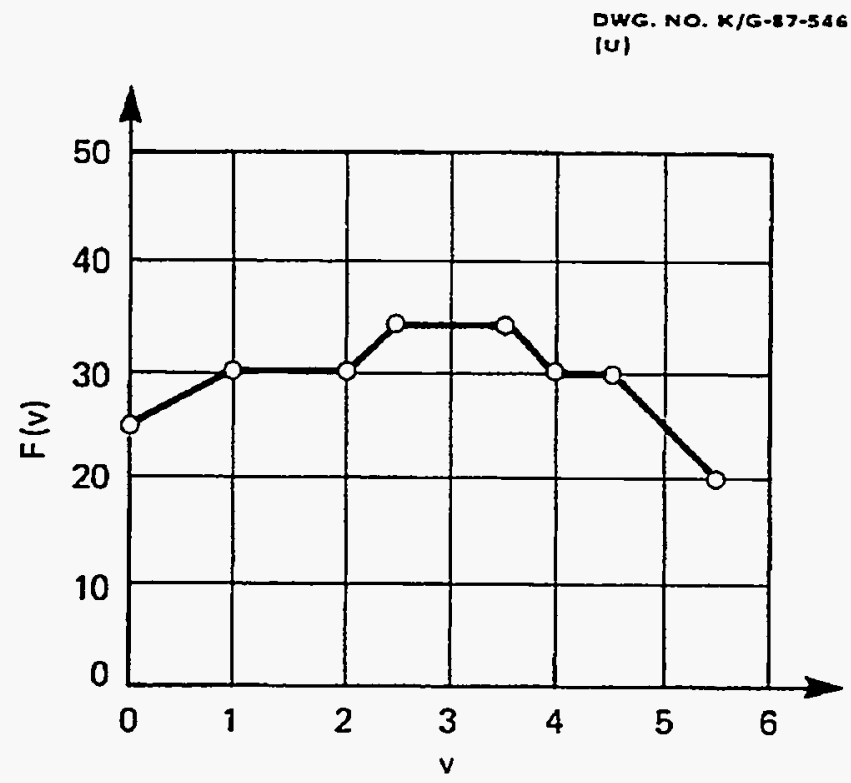

Figure F16.4.2 Tabular function example

Table F16.4.5 T1 and T2 cards necessary to describe the tabular function depicted in Fig. F16.4.2

\begin{tabular}{rrrrrrrrrr}
\hline Entry & 1 & 2 & 3 & 4 & 5 & 6 & 7 & 8 & Card \\
\hline 1 & 8 & & & & & & & T1 \\
& 0.0 & 25.0 & 1.0 & 30.0 & 2.0 & 30.0 & 2.5 & 35.0 & T2 \\
& 03.5 & 35.0 & 4.0 & 30.0 & 4.5 & 30.0 & 5.5 & 20.0 & T2 \\
\hline
\end{tabular}

\section{F16.4.13. Data Block Termination Card}

Each problem (or case) must be terminated with a data block termination card. This card consists of a percent sign (\%) in column 1 , followed by a blank in column 2.

\section{F16.4.14. Summary and Format of Input}

A summary of the format and information needed to prepare the input data deck is presented in Table F16.4.6. Columns 73 through 80 of each card are reserved for identification. This input format assumes that an OCULAR input data deck is not being enhanced for use as a HEATING input data deck. 
Thus all HEATING dependent input data are reflected as blank entries. The user should supply zeros in these entries when OCULAR is used in a stand-alone fashion. The table provides proposed identification names for the cards, and parenthetically, the section of the report where more information can be found. The first line in each format box includes the variable name actually used in the program, and in the parentheses, the variable type. The rest of the box includes a short explanation of the input in that box. 
Table F16.4.6 Summary of OCULAR input data

\begin{tabular}{|c|c|c|c|c|c|c|c|c|c|}
\hline Entry 1 & Entry 2 & Entry 3 & Entry 4 & Entry 5 & Entry 6 & Entry 7 & Entry 8 & Entry 9 & Cand \\
\hline \multicolumn{9}{|c|}{ JOBDES - Job Description - Up to 72 Alphenumeric Cheracters } & $\begin{array}{c}\text { Cand 1 } \\
\text { (F16.4.3.1) }\end{array}$ \\
\hline & 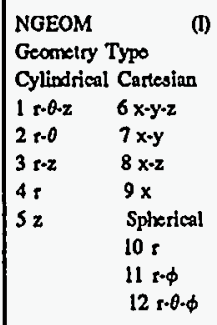 & & & & & & & & $\begin{array}{c}\text { Card 2 } \\
\text { (F16.4.3.2) }\end{array}$ \\
\hline \multicolumn{10}{|l|}{ REGIONS } \\
\hline \multirow[t]{2}{*}{$\begin{array}{l}\text { NOREG(I) } \\
\text { Region number }\end{array}$} & $\begin{array}{l}\quad \text { MATL(I) } \\
\text { Region material } \\
\text { number. (Cand } M \text { ) } \\
\text { Enter zero for gap } \\
\text { region }\end{array}$ & $\begin{array}{l}\text { RRIN(R) } \\
\text { Smaller } X \text { or } R \text { region } \\
\text { dimension }\end{array}$ & \begin{tabular}{|l}
\multicolumn{1}{c}{ RROT(R) } \\
Larger X or R region \\
dimension
\end{tabular} & $\begin{array}{l}\quad \operatorname{THLT}(\mathrm{R}) \\
\text { Smaller } \mathrm{Y} \text { of } \theta \text { region } \\
\text { dimension }\end{array}$ & \begin{tabular}{l}
\multicolumn{1}{c}{ THRT(R) } \\
Larger $Y$ or $\theta$ region \\
dimension
\end{tabular} & \begin{tabular}{|l}
\multicolumn{1}{|c}{ ZZBK(R) } \\
Smaller $Z$ or $\phi$ region \\
dimension
\end{tabular} & \begin{tabular}{|l}
\multicolumn{1}{c}{$\quad$ ZZFR(R) } \\
Larger $Z$ or $\theta$ region \\
dimension
\end{tabular} & & $\begin{array}{c}\text { Card RI } \\
\text { (F16.4.4.2) } \\
\text { Maximum MAXREG }\end{array}$ \\
\hline & \multicolumn{8}{|c|}{ NOTE: Although not usod, this card camnot bo omittod. } & $\begin{array}{c}\text { Card R2 } \\
\text { (F16.4.4.3) }\end{array}$ \\
\hline \multicolumn{10}{|l|}{ MATERIALS } \\
\hline \multirow[t]{2}{*}{$\begin{array}{c}\text { MAT(M) } \\
\text { Material number }\end{array}$} & $\underset{\text { Matcrial namo }}{\text { MATNAM(A) }}$ & & & & & & & \begin{tabular}{l}
\multicolumn{1}{c}{ MCP(I) } \\
Phase change flag. \\
Zero implites to phaso \\
changes
\end{tabular} & $\begin{array}{c}\text { Card M } \\
\text { (F16.4.5.2) } \\
\text { Maxlmum MAXMAT }\end{array}$ \\
\hline & \multicolumn{8}{|c|}{ NOTE: This cand is only present for materials with chango of phase capabilities. Thero can only bo MAXCP such materials. } & $\begin{array}{c}\text { Card PC } \\
\text { (F16.4.5.3) }\end{array}$ \\
\hline
\end{tabular}


Table F16.4.6 (continued)

\begin{tabular}{|c|c|c|c|c|c|c|c|c|c|}
\hline Entry $!$ & Enlry 2 & Entry 3 & Entry 4 & Entry 5 & Entry 6 & Entry 7 & Entry 8 & Entry 9 & Card \\
\hline \multicolumn{10}{|l|}{ XGRID } \\
\hline $\begin{array}{c}\mathrm{RG}(\mathrm{R}) \\
\text { Smallest } \mathrm{X} \text { or } \mathrm{R} \text { gross } \\
\text { Latlios lino dimension }\end{array}$ & $\begin{array}{c}R G(R) \\
\text { Next X or } R \text { groess } \\
\text { lallioe line dimenstion }\end{array}$ & \begin{tabular}{|l}
\multicolumn{1}{|c}{$\mathbf{R G}(\mathbf{R})$} \\
Next X or $\mathbf{R}$ gross \\
lattice lino dimension
\end{tabular} & \multicolumn{6}{|c|}{ NOTE: Maximum of MAXGGL. } & Cand LI \\
\hline $\begin{array}{l}\text { NDRG() } \\
\text { Number of divisions } \\
\text { between corre. } \\
\text { sponding } X \text { or } R \text { groess } \\
\text { lino and the following } \\
\text { line }\end{array}$ & NDRG(I) & NDRG(n) & \multicolumn{6}{|c|}{ NOTE: Must have ono less entry than in L1 carda. Maximum of MAXRFG. } & $\begin{array}{c}\text { Cand NI } \\
\text { (F16.4.6.3) }\end{array}$ \\
\hline \multicolumn{10}{|l|}{ ZGRID } \\
\hline ZG(R) & \multicolumn{8}{|c|}{ NOTE: Same as LI cards except for $Z$ or $\phi$ direction. Maximum of MAXGGL. } & $\begin{array}{c}\text { Cand L3 } \\
(\text { F16.4.7.2) }\end{array}$ \\
\hline NDZO(D) & \multicolumn{8}{|c|}{ NOTE: Samo as N1 cands exoept for $Z$ or $\phi$ direction. Maximum of MAXZFG. } & $\begin{array}{c}\text { Cand N3 } \\
\text { (F16.4.7.3) }\end{array}$ \\
\hline \multicolumn{10}{|l|}{ ENCLOSURES } \\
\hline $\begin{array}{l}\text { NENCLT(I) } \\
\text { Encolosure nutmber }\end{array}$ & \begin{tabular}{l}
\multicolumn{1}{c}{ NENBCT(I) } \\
Boundary condition \\
number describing \\
heal transfer. Mech. \\
anism in enclosure
\end{tabular} & \begin{tabular}{|l}
\multicolumn{1}{c}{ NSRF(I) } \\
Number of surfaces \\
defining enclosuro
\end{tabular} & & & & & & & $\begin{array}{c}\text { Card EN1 } \\
\text { (F16.4.8.2) } \\
\text { Maximum MAXENC }\end{array}$ \\
\hline $\begin{array}{l}\text { NSUURFT(D) } \\
\text { Surfaco number } \\
\text { comprising enclosure. }\end{array}$ & $\begin{array}{c}\text { NSURFT(D) } \\
\text { Next surface number. }\end{array}$ & $\begin{array}{c}\text { NSURFT(1) } \\
\text { Next surface number. }\end{array}$ & & & & & & & $\begin{array}{l}\text { Cand EN2 } \\
\text { (F16.4.8.3) }\end{array}$ \\
\hline \multicolumn{10}{|l|}{ SURFACES } \\
\hline $\begin{array}{c}\text { NENSRT(I) } \\
\text { Surfaco number }\end{array}$ & $\begin{array}{c}\text { NEMST(1) } \\
\text { Surfaco emissivity } \\
\text { function number }\end{array}$ & \begin{tabular}{|l}
$\quad$ ENRRIN(R) \\
Smalles $X$ or $R$ \\
surfaco dimension
\end{tabular} & \begin{tabular}{|l|}
\multicolumn{1}{c|}{ ENRROT(R) } \\
Larger $X$ or $R$ surfaco \\
dimension
\end{tabular} & $\begin{array}{l}\text { ENTHLT(R) } \\
\text { Smalles } Y \text { or } \theta \text { eurfaco } \\
\text { dimension }\end{array}$ & $\begin{array}{l}\quad \text { ENTHRT(R) } \\
\text { Larger } Y \text { or } \theta \text { surfaco } \\
\text { dimension }\end{array}$ & $\begin{array}{l}\quad \text { ENZZBK(R) } \\
\text { Smaller Z or } \phi \\
\text { surfaco dimenstion }\end{array}$ & $\begin{array}{l}\quad \text { ENZZFK(R) } \\
\text { Larger Z or } \theta \text { surfaco } \\
\text { dimension }\end{array}$ & & $\begin{array}{c}\text { Card SU } \\
\text { (F16.4.9.2) } \\
\text { Maximum MAXSRF }\end{array}$ \\
\hline \multicolumn{10}{|l|}{ EMISSIVITIES } \\
\hline $\begin{array}{c}\text { NEMVYT(I) } \\
\text { Emissivity number }\end{array}$ & $\begin{array}{c}\text { EMIS(R) } \\
\text { Emissivily if constant }\end{array}$ & $\begin{array}{l}\text { NEMR(I) } \\
\text { X- or R-dependent } \\
\text { function number }\end{array}$ & $\begin{array}{c}\text { NEMTH() } \\
\text { Y- or O-dependent } \\
\text { funetion number }\end{array}$ & $\begin{array}{l}\text { NEMZ(I) } \\
\text { Z- or } \phi \text {-dependent } \\
\text { function numaber }\end{array}$ & & & & & $\begin{array}{c}\text { Card EM } \\
\text { (F16.4.10.2) } \\
\text { Maximum MAXEMS }\end{array}$ \\
\hline
\end{tabular}


Table F16.4.6 (continued)

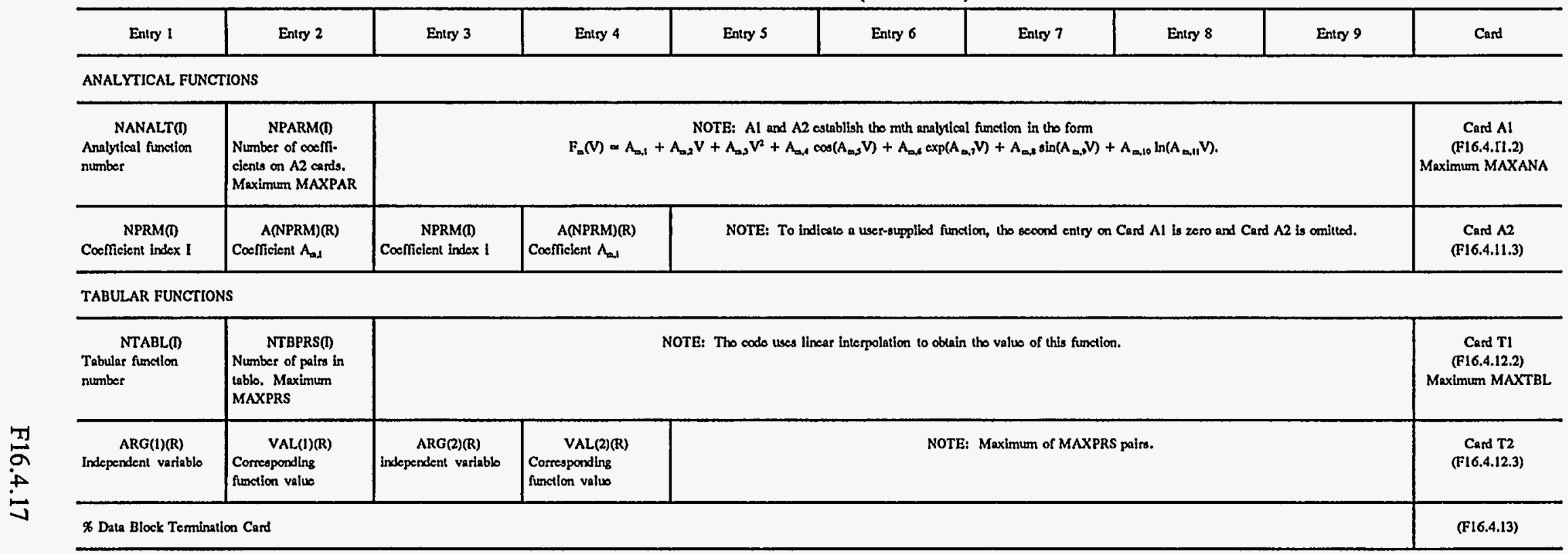




\section{F16.5 OUTPUT DESCRIPTION FOR OCULAR}

\section{F16.5.1. General}

The output generated by the OCULAR program is best illustrated by an example, thus the reader is referred to Appendix F16.A for an example of the actual output. The code automatically lists the input data card images, tabulates the input data with descriptive headings, and lists model information generated by the code from the input data. If the problem runs to completion, the code prints the emitting node number, the absorbing node number, the exchange (configuration) factor between the emitting and the absorbing node and the sum of the factors for each emitting node. The sum of the factors should equal the emissivity of the emitting node. If the difference due to discretization error is unacceptable, the mesh should be refined and the problem rerun.

In addition to the exchange factor results, the code writes the data necessary for input to HEATING. These data consist of an emitting (base) node number, the number of exchange factor connections made to this node, the boundary condition number describing the heat transfer mechanism present in the enclosure, a reciprocity flag, the absorbing node numbers, and the connector value. The connector is defined as the product of the emitting node's area and the exchange factor between the two nodes. In addition to including this information as standard output, the code writes a binary data set to unit No. 12 to be read as input by HEATING. Any errors encountered in the input data which cause problem termination are included as program output.

\section{F16.5.2. Input Return}

If the input data are read in card image form, OCULAR automatically lists the card images with the card columns indicated every tenth card and with each card image numbered. Since this capability serves to document the input data exactly as these data were supplied to the code, this feature assists the user in the location of input data errors identified by the program.

The standard output contains a summary of the capabilities of the current version of OCULAR, along with a heading identifying the version of the code, the date and time of the run, and the computer on which the job was executed. This summary is followed by tables indicating the maximum number of parameters that may be utilized during the run. These values are obtained from the BLOCK DATA subprogram and any data entered through the OPTION data block. The values of parameters from the first three data cards are then tabulated along with the input/output logical unit numbers available for the program. The code then tabulates data it generates from the input data. These data include the fine lattice lines along each axis, the orientation of the enclosure surfaces, the total number of nodes in the problem, and the enclosure nodes. Additionally, the code writes a summary of the dimensional characteristics of the enclosure nodes.

\section{F16.5.3. Exchange Factors}

The user-oriented output from OCULAR lists the emitting node, the absorbing node, and the exchange factor between the two nodes. Additionally, the code prints the sum of the exchange factors from each emitting node to all absorbing nodes. This sum should equal the emissivity of the emitting node. If the difference due to discretization error is unacceptable, the mesh should be refined and the problem should be rerun. OCULAR reports the total number of connectors produced. This value may be used as the value for MAXCON in the HEATING data set. 


\section{F16.5.4. HEATING Input}

OCULAR output data are written on a binary data set to unit 12 for input into HEATING as unformatted input through the CONNECTOR data block. This data set contains the emitting node number, the number of absorbing nodes to which the emitting node has connections, the boundary condition number describing the heat transfer mechanism present, a reciprocity flag, the absorbing node numbers, and the connector value. The connector is defined as the product of the exchange factor and the emitting node's area.

NUREG/CR-0200,

Vol. 2, Rev. 5

F16.5.2 


\section{F16.6 REFERENCES}

1. J. A. Wiebelt, Engineering Radiation Heat Transfer, Holt, Rinehart, and Winston, New York, 1966.

2. S. N. Rea, "Rapid Method for Determining Concentric Cylinder Radiation View Factors," AlAA Journal 13(8), 1122 (August 1975).

3. C. P. Minning, "Radiation Shape Factors between End Wall and Outer Wall of Concentric Tubular Enclosures," ALAA Journal 17(12), 1407 (December 1979).

4. C. P. Minning, "Shape Factors between Coaxial Annular Disks Separated by a Solid Cylinder," ALAA Journal 17(3), 318 (March 1979).

5. R. Siegel and J. R. Howell, Thermal Radiation Heat Transfer, McGraw-Hill, New York, 1981.

6. J. R. Howell, A Catalog of Radiation Configuration Factors, McGraw-Hill, New York, 1982.

7. P. T. Williams, "Sample Problems for RADFAC/HOTTEL/ TRUMP Radiation Calculations," Union Carbide Corp. Letter Report, Union Carbide Corp., Nucl. Div., Oak Ridge Gaseous Diffusion Plant, January 10, 1983.

8. G. E. Forsythe, M. A. Malcolm, and C. B. Moler, Computer Methods for Mathematical Computations, Prentice-Hall, Inc., 1977. 


\section{F16.A SAMPLE PROBLEM}

The use of the OCULAR program is best illustrated by example. This sample problem is presented for instructive purposes. It is not intended to represent an actual engineering problem, but rather to introduce the novice user to the capabilities of the program. Graybody radiation exchange factors are computed for both an annular and cylindrical axisymmetric enclosure.

The problem of interest is illustrated in Fig. F16.A.1. The OCULAR input data set is presented in Fig. F16.A.2. The user-supplied routine EMSSVY employed in this model is presented in Fig. F16.A.3.

The model consists of three materials - iron, air, and stainless steel. The air is assumed not to participate in the radiant exchange. The surfaces of the steel and the iron are assumed to be treated to exhibit emissive characteristics dependent upon surface orientation. The emissivity for horizontally oriented surfaces present in the enclosure is referred to as the radial emissivity of a material. The emissivity for vertically oriented surfaces is referred to as the axial emissivity of a material. The emissivity data for iron are assumed constant. The emissivity of stainless steel varies as a function of axial position on the enclosure surface. These data are presented in Table F16.A.1 below.

Table F16.A.1 Hemispherical total emissive property data

\begin{tabular}{lcc}
\hline Material & Iron & Stainless steel \\
\hline Radial emissivity & 0.3 & $0.1+\overline{0.01 \mathrm{z}}$ \\
Axial emissivity & 0.8 & 0.
\end{tabular}

Illustrated in Fig. F16.A.1 are the locations of regions, enclosures, and surfaces contained in the OCULAR input. Region numbers are contained in circles, enclosure numbers in squares, and surface numbers in triangles. Regions $1,4,5$, and 7 contain material 1 , defined to be iron. Regions 2 and 6 contain material 2, defined to be air. Regions 3 and 8 contain material 3, defined to be stainless steel.

Multidimensional radiant exchange is present in regions 2 and 6. These regions are defined to be enclosures 1 and 2, respectively.

Enclosure 1 is a cylindrical enclosure composed of four surfaces. Note that one of these surfaces describes the centerline. In the calculation of exchange factors, it is necessary for a complete enclosure to be input to OCULAR. The centerline surface is actually a pseudosurface that must be input in order to describe a complete enclosure, but which is eliminated from the problem solution by the program. The emissivity of the upper- and lower-ring surfaces is constant. The emissivity of the shell surface varies as a function of axial position on the shell. This positional-dependent emissivity is input using the user-supplied routine capability of OCULAR.

Enclosure 2 is an annular enclosure composed of six surfaces. The enclosure consists of a cylinder, lower ring, upper ring, and shell. The cylinder is comprised of three enclosure surfaces which exhibit the different emissive properties of the iron and steel composing the surface. The positional-dependent emissivity present on a portion of the cylinder is input using the analytical 


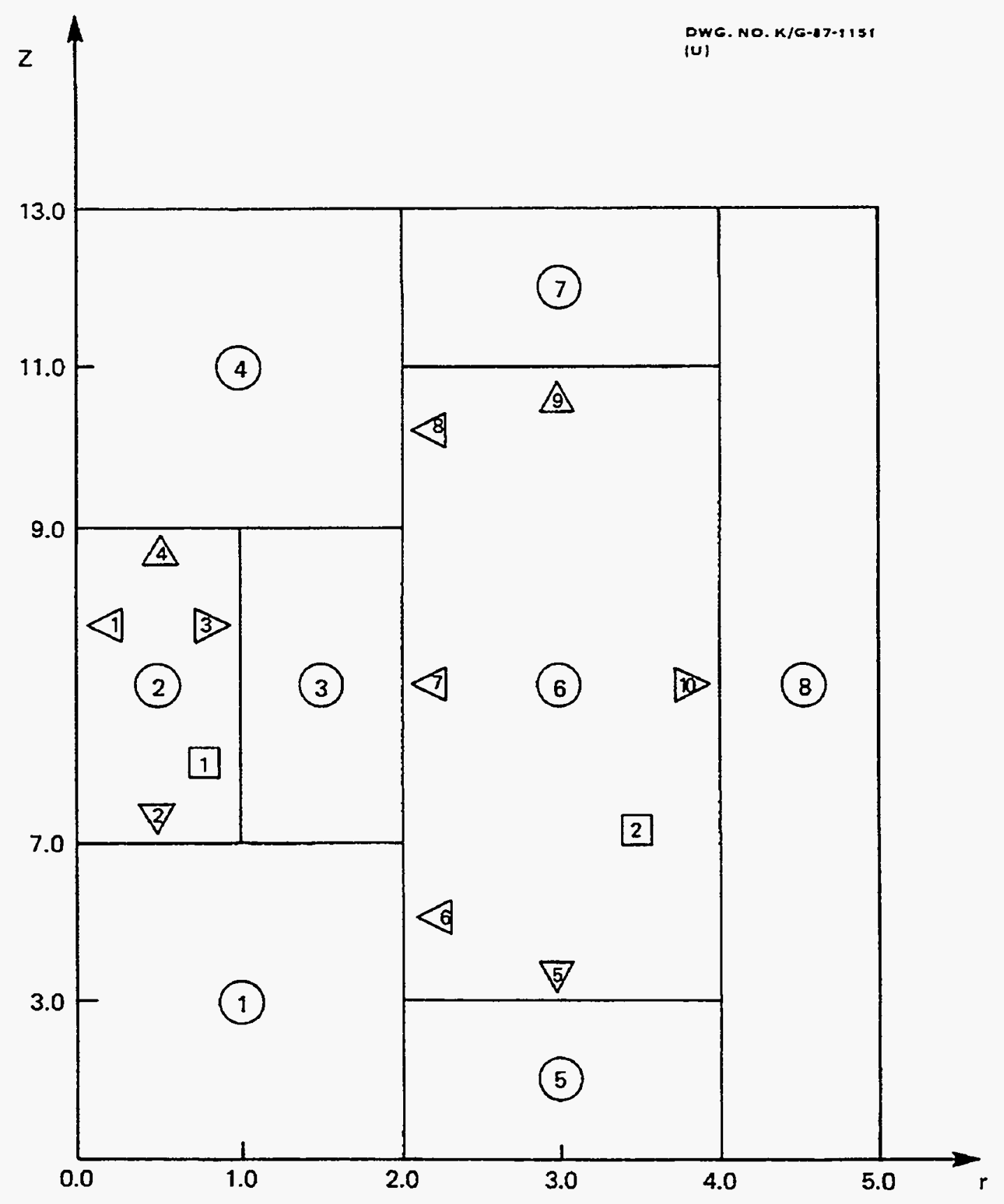

Figure F16.A.1 Sample problem model geometry 
function capability of OCULAR. The emissivity of the lower and upper rings is constant. The emissivity of the shell is positional-dependent and is input using the tabular function capability.

In developing an input data set to produce exchange factors that will later be input to HEATING, it is necessary to define the boundary condition number that will be used by HEATING to describe the heat transfer mechanism which is present between nodes input in the CONNECTOR data block. In this sample problem, it is assumed that boundary condition 1 , input as the second entry on the EN1 card, will be used to describe the radiation heat transfer mechanism present between nodes. As a side note, the Stefan-Boltzmann constant would generally be entered as the coefficient for radiation in the HEATING input data set for boundary condition 1.

The output for this sample problem is presented in Table F16.A.2. The printed output contains an echo of the input, summary tables of the input data, descriptions of each enclosure, and the surfaces composing it. Additional output is provided describing the location and emissivity of each enclosure surface nodal area. This output is provided for the purpose of validation of the model. It is recommended that the user run HEATING to receive a nodal map of the problem. Note that corner nodes appear twice in the enclosure node summary. The area associated with a corner node is composed of a vertical and horizontal area. Exchange factors for these areas are computed and reported separately. Reciprocity is used to reduce the number of connectors input to HEATING. 


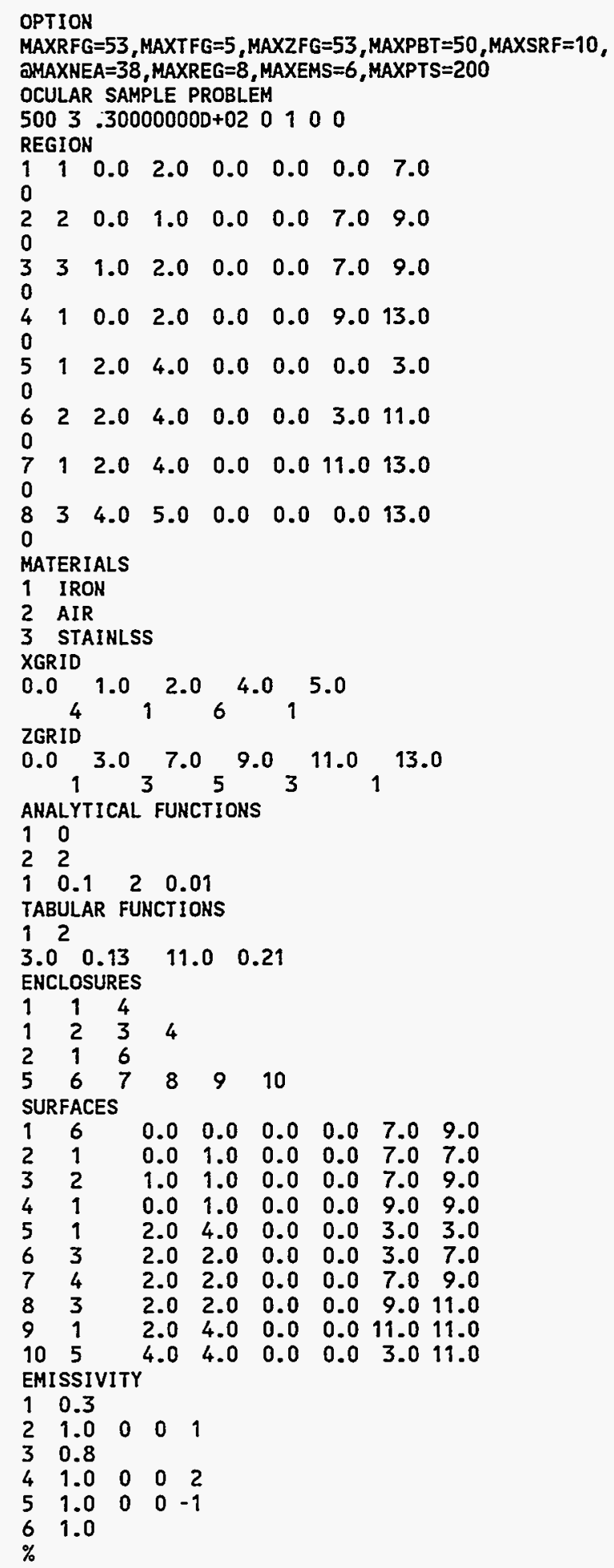

Figure F16.A.2 Sample problem OCULAR input

NUREG/CR-0200,

Vol. 2, Rev. 5

F16.A.4 
SUBROUTINE EHSSVY (RVALUE, $R, T H, Z$, VALUE, NUMBER)

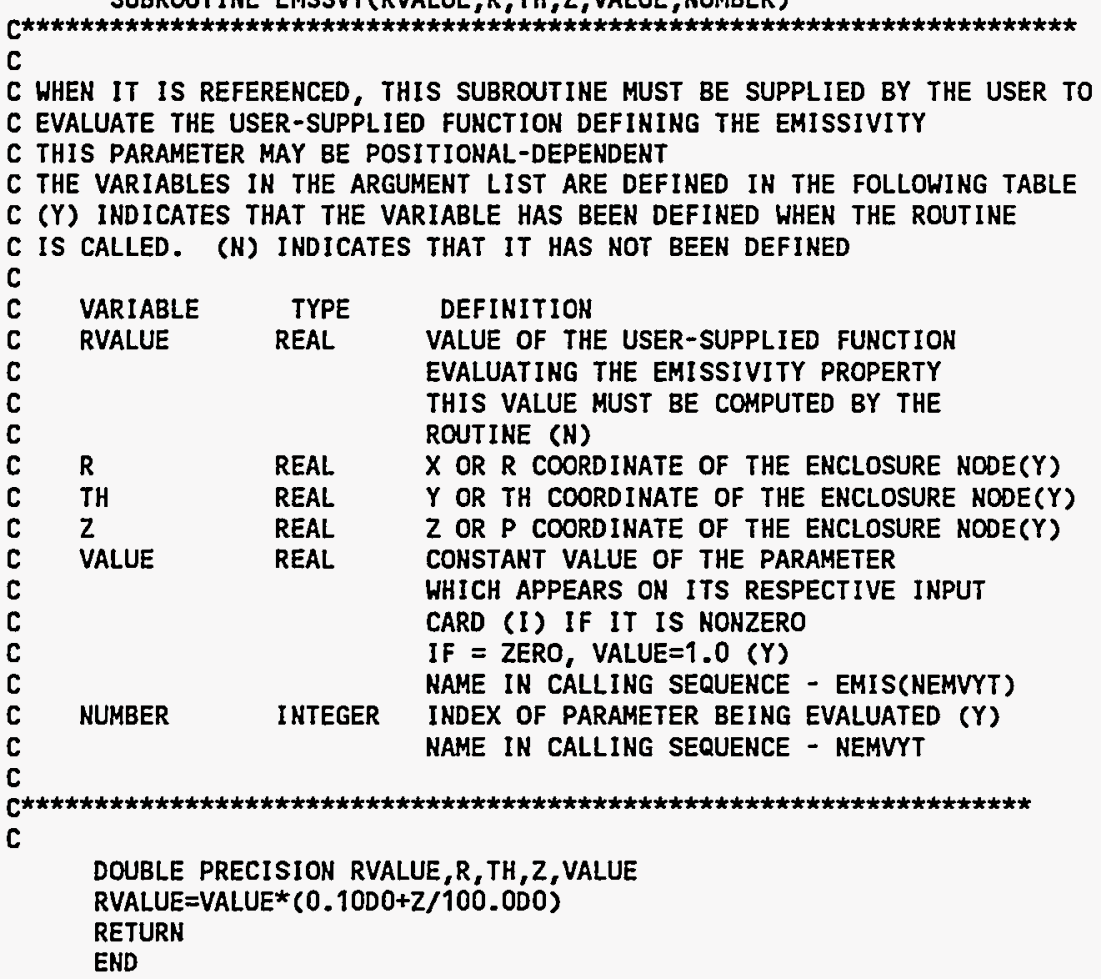

Figure F16.A.3 User-supplied routine EMSSVY 


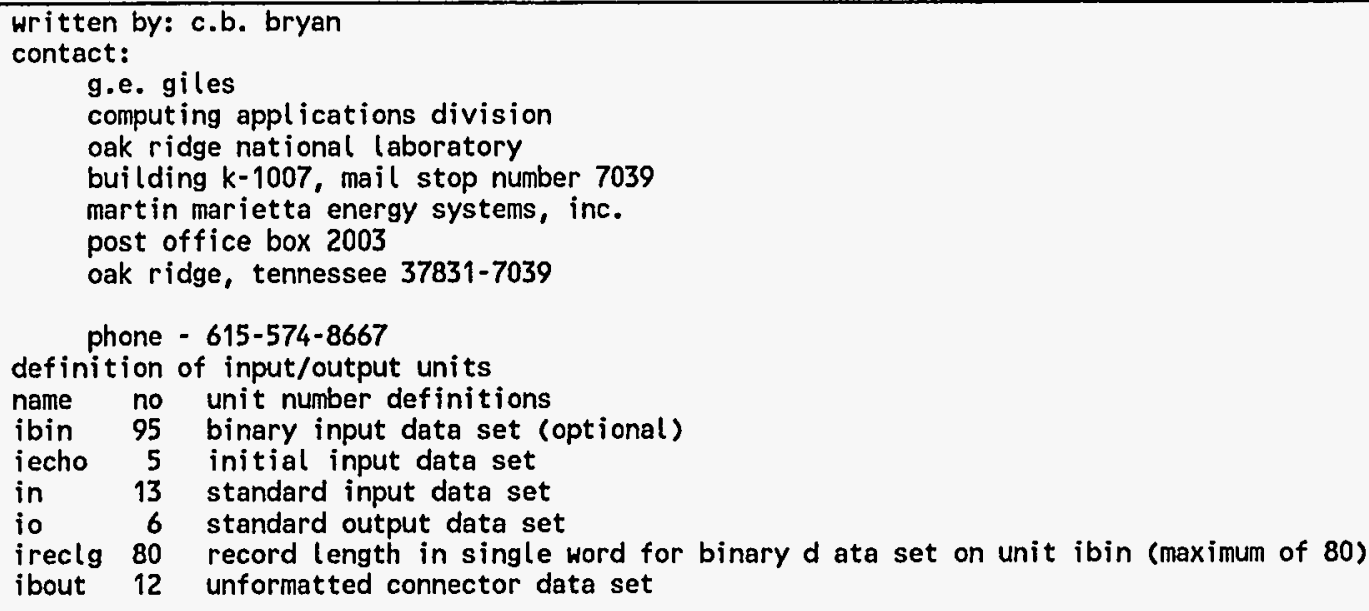

print input card images with card columns indicated every 10 th card--

card

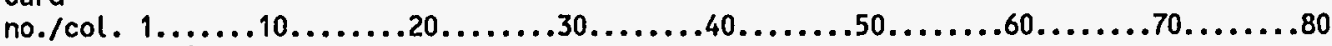

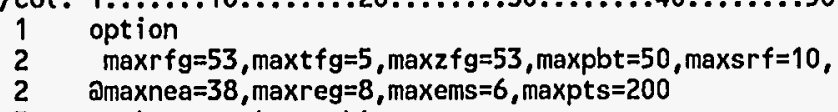

ocular sample problem

$5003.300000000+020100$

region

$\begin{array}{llllllll}1 & 1 & 0.0 & 2.0 & 0.0 & 0.0 & 0.0 & 7.0\end{array}$

$\begin{array}{llllllll}2 & 2 & 0.0 & 1.0 & 0.0 & 0.0 & 7.0 & 9.0\end{array}$

$1 \mathrm{col} .1 \ldots \ldots 10 \ldots \ldots .20 \ldots \ldots 30 \ldots \ldots$

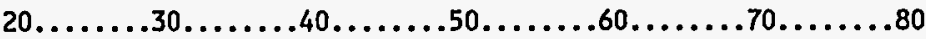

$\begin{array}{lllllllll}10 & 3 & 3 & 1.0 & 2.0 & 0.0 & 0.0 & 7.0 & 9.0\end{array}$

$\begin{array}{llllllllll}11 & 0 & & & & & & & & \\ 12 & 4 & 1 & 0.0 & 2.0 & 0.0 & 0.0 & 9.0 & 13.0\end{array}$

130

$\begin{array}{lllllllll}14 & 5 & 1 & 2.0 & 4.0 & 0.0 & 0.0 & 0.0 & 3.0\end{array}$

$\begin{array}{llllllllll}16 & 6 & 2 & 2.0 & 4.0 & 0.0 & 0.0 & 3.0 & 11.0\end{array}$

170

$\begin{array}{lllllllllll}18 & 7 & 1 & 2.0 & 4.0 & 0.0 & 0.0 & 11.0 & 13.0\end{array}$

$19 \quad 0$

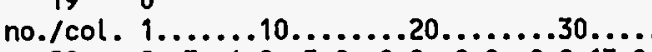

$\begin{array}{llllllllllll}20 & 8 & 3 & 4.0 & 5.0 & 0.0 & 0.0 & 0.0 & 13.0\end{array}$ 


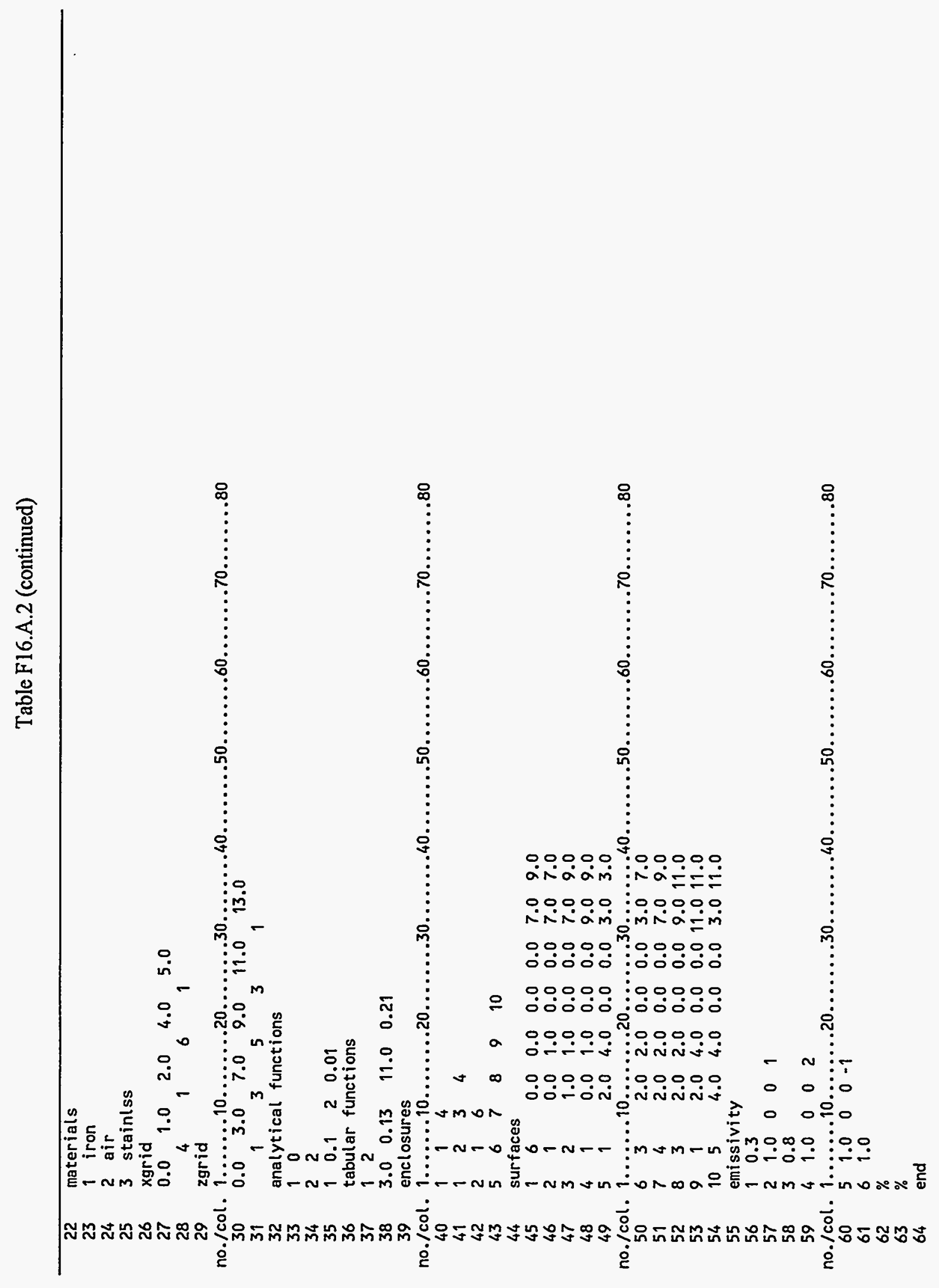

F16.A.7

NUREG/CR-0200,

Vol. 2, Rev. 5 
the variably dimensioned arrays require 82814 single words or $324 \mathrm{k}$ bytes of core.

code: ocular $05 / 12 / 93$

date: $06 / 14 / 93$

time: $14: 53: 5$

jobnam: geg

computer: unix

job description -- ocular sample problem

geometry type number

3 (or $r z$ )

definition of input/output units

iecho 5 initial input data set

in 13 standard input data set

io 6 standard output data set

ibout 12 unformatted connector data set

number of parameters specified by the input data

number of regions

number of materials

number of analytical functions

number of tabular functions

number of points in gross $x$ or $r$ lattice

number of points in gross $y$ of $t$ lattice

number of points in gross $z$ or $p$ lattice

number of enclosures in the model

number of surfaces

number of emissivities

surmary of region data

$\begin{array}{ccccccc}\begin{array}{c}\text { region } \\ \text { number }\end{array} & \begin{array}{c}\text { left-x or } \\ \text { inner-r }\end{array} & \begin{array}{c}\text { right-x or } \\ \text { outer-r }\end{array} & \begin{array}{c}\text { lower-y or } \\ \text { left-theta }\end{array} & \begin{array}{c}\text { upper-y or } \\ \text { right-theta }\end{array} & \begin{array}{c}\text { rear-z or } \\ \text { upper phi }\end{array} & \begin{array}{r}\text { front-z or } \\ \text { lower phi }\end{array} \\ 2 & .0000 & 2.0000 & .0000 & .0000 & .0000 & 7.0000 \\ 3 & .0000 & 1.0000 & .0000 & .0000 & 7.0000 & 9.0000 \\ 4 & 1.0000 & 2.0000 & .0000 & .0000 & 7.0000 & 9.0000 \\ 5 & .0000 & 2.0000 & .0000 & .0000 & 9.0000 & 13.0000 \\ 6 & 2.0000 & 4.0000 & .0000 & .0000 & .0000 & 3.0000 \\ 7 & 2.0000 & 4.0000 & .0000 & .0000 & 3.0000 & 11.0000 \\ 8 & 2.0000 & 4.0000 & .0000 & .0000 & 11.0000 & 13.0000 \\ & 4.0000 & 5.0000 & .0000 & .0000 & .0000 & 13.0000\end{array}$




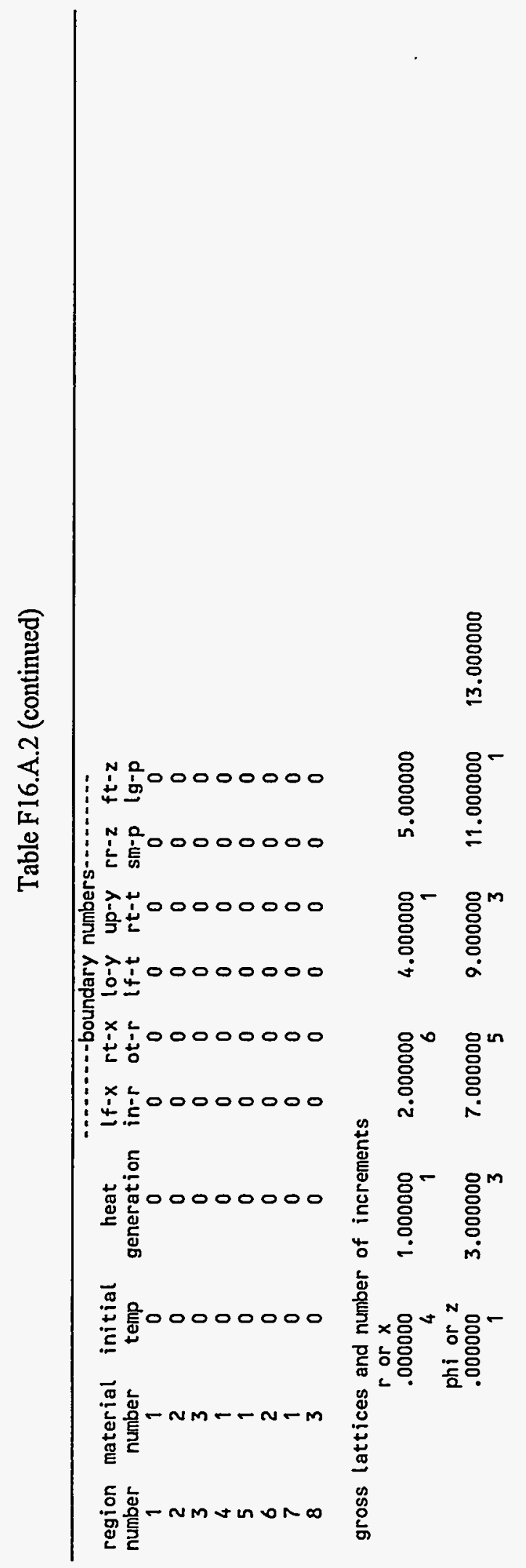

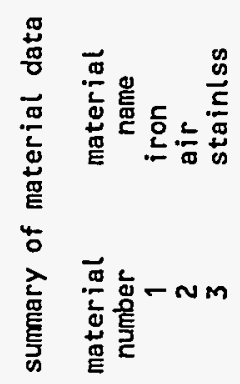

F16.A.9

NUREG/CR-0200,

Vol. 2, Rev. 5 
summary of analytic functions

$f(v)=a(1)+a(2) * v+a(3) * v^{* * 2}+a(4) * \cos (a(5) * v)+a(6) * \exp (a(7) * v)+a(8) * \sin (a(9) * v)+a(10) * \log (a(11) * v)$

no.

$$
\text { a(1) } a(2)
$$

a(3) $\quad$ (3)

a(5) $a(6)$

a(7)

$a(8)$

a(9)

a(10)

a(11)

$\begin{array}{llllllllllll}2 & 1.000 D-01 & 1.000 D-02 & 0.000 D+00 & 0.000 D+00 & 0.000 D+00 & 0.000 D+00 & 0.000 D+00 & 0.000 D+00 & 0.000 D+00 & 0.000 D+00 & 0.000 D+00\end{array}$

summary of tabular functions

table number -

argument

number of pairs -
value

value

$1.30000000 \mathrm{D}-01$
$2.10000000 \mathrm{D}-01$

Ty
0
0
0
0 
Table F16.A.2 (continued)

\begin{tabular}{|c|c|c|c|c|c|c|c|c|c|c|}
\hline \multicolumn{11}{|c|}{ summary of enclosure data } \\
\hline $\begin{array}{l}\text { enclosur } \\
\text { number }\end{array}$ & \multicolumn{2}{|c|}{$\begin{array}{l}\text { boundary condition } \\
\text { describing the heat } \\
\text { transfer mechanism } \\
\text { in the enclosure }\end{array}$} & \multicolumn{4}{|c|}{$\begin{array}{l}\text { surface numbers } \\
\text { comprising the } \\
* * * * \text { enclosure } * * * * *\end{array}$} & & & & \\
\hline $\begin{array}{l}1 \\
2\end{array}$ & & $\begin{array}{l}1 \\
1\end{array}$ & $\begin{array}{l}1 \\
5\end{array}$ & $\begin{array}{l}2 \\
6\end{array}$ & $\begin{array}{l}3 \\
7\end{array}$ & $\begin{array}{l}4 \\
8\end{array}$ & 9 & 10 & & \\
\hline \multicolumn{11}{|c|}{ sumnary of surface data } \\
\hline \multicolumn{11}{|c|}{ 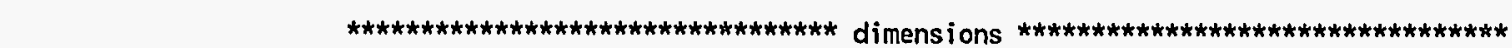 } \\
\hline $\begin{array}{c}\text { surface } \\
\text { number } \\
1 \\
2 \\
3 \\
4 \\
5 \\
6 \\
7 \\
8 \\
9 \\
10\end{array}$ & $\begin{array}{c}\text { emissivity } \\
\text { number } \\
6 \\
1 \\
2 \\
1 \\
1 \\
3 \\
4 \\
3 \\
1 \\
5\end{array}$ & $\begin{array}{l}\text { left-x or } \\
\text { inner-r } \\
.0000 \\
.0000 \\
1.0000 \\
.0000 \\
2.0000 \\
2.0000 \\
2.0000 \\
2.0000 \\
2.0000 \\
4.0000\end{array}$ & $\begin{array}{l}\text { right } \\
\text { oute } \\
.00 \\
1.00 \\
1.00 \\
1.00 \\
4.00 \\
2.00 \\
2.00 \\
2.00 \\
4.00 \\
4.00\end{array}$ & & $\begin{array}{r}\text { lowe } \\
\text { left } \\
\vdots \\
\vdots\end{array}$ & $\begin{array}{l}y \text { or } \\
\text { heta } \\
00 \\
00 \\
00 \\
00 \\
00 \\
00 \\
00 \\
00 \\
00 \\
00\end{array}$ & $\begin{array}{l}\text { uppe } \\
\text { righ }\end{array}$ & $\begin{array}{l}r-y \text { or } \\
\text { tt-theta } \\
.0000 \\
.0000 \\
.0000 \\
.0000 \\
.0000 \\
.0000 \\
.0000 \\
.0000 \\
.0000 \\
.0000\end{array}$ & $\begin{array}{c}\text { rear }-z \text { or } \\
\text { lower phi } \\
7.0000 \\
7.0000 \\
7.0000 \\
9.0000 \\
3.0000 \\
3.0000 \\
7.0000 \\
9.0000 \\
11.0000 \\
3.0000\end{array}$ & $\begin{array}{c}\text { front-z or } \\
\text { upper phi } \\
9.0000 \\
7.0000 \\
9.0000 \\
9.0000 \\
3.0000 \\
7.0000 \\
9.0000 \\
11.0000 \\
11.0000 \\
11.0000\end{array}$ \\
\hline
\end{tabular}

summary of emissivity data

$\begin{array}{ccccc}\text { number } & \text { emissivity } & \begin{array}{c}\text { position-dependent function numbers } \\ x \text { or } r\end{array} & y \text { or th } & \text { or } P \\ 1 & 3.00000 D-01 & 0 & 0 & 0 \\ 2 & 1.00000 D+00 & 0 & 0 & 1 \\ 3 & 8.00000 D-01 & 0 & 0 & 0 \\ 4 & 1.00000 D+00 & 0 & 0 & 2 \\ 5 & 1.00000 D+00 & 0 & 0 & -1 \\ 6 & 1.00000 D+00 & 0 & 0 & 0 \\ \text { summary of fine lattice lines } & & & \end{array}$

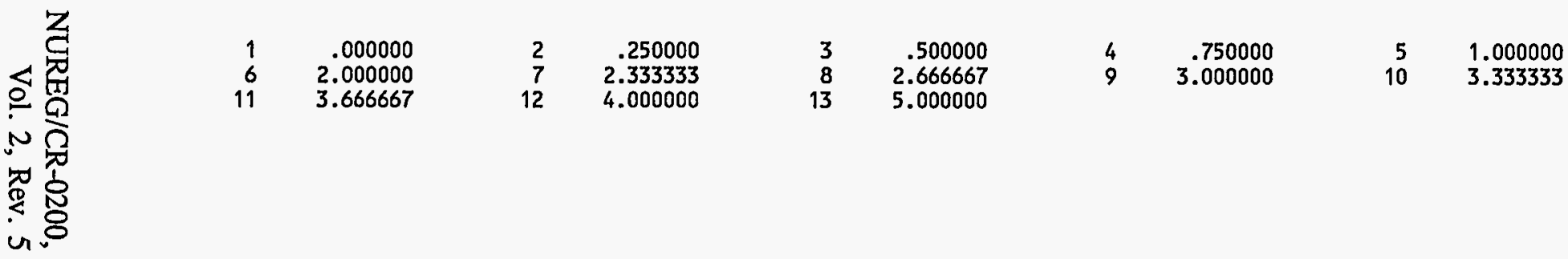


Table F16.A.2 (continued)

$z$ or phi fine lattice lines

$\begin{array}{rrrr}1 & .000000 & 2 & 3.00000 \\ 6 & 7.400000 & 7 & 7.800000 \\ 11 & 9.666667 & 12 & 10.333333\end{array}$

$\begin{array}{rr}3 & 4.333333 \\ 8 & 8.200000\end{array}$

***** job description $* \star * * *$ ocular sample problem

***** the input data for this case have been read and processed

$* * * * *$ number of errors encountered in the input data for this case was .-. 0

**** number of warnings encount

$\begin{array}{lll}\text { sumary of surface orientations } & \\ \text { surface number } & 1 \text { is a } z \text { (or phi) surface } \\ \text { surface number } & 2 \text { is an } x \text { (or } r \text { ) surface } \\ \text { surface number } & 3 \text { is a } z \text { (or phi) surface } \\ \text { surface number } & 4 \text { is an } x \text { (or } r \text { ) surface } \\ \text { surface number } & 5 \text { is an } x \text { (or } r \text { ) surface } \\ \text { surface number } & 6 \text { is a } z \text { (or phi) surface } \\ \text { surface number } & 7 \text { is a } z \text { (or phi) surface } \\ \text { surface number } & 8 \text { is a } z \text { (or phi) surface } \\ \text { surface number } & 9 \text { is an x (or } r \text { ) surface } \\ \text { surface number } & 10 \text { is a } z \text { (or phi) surface }\end{array}$

summary of enclosure surface connections

enclosure number

surface connected to surface

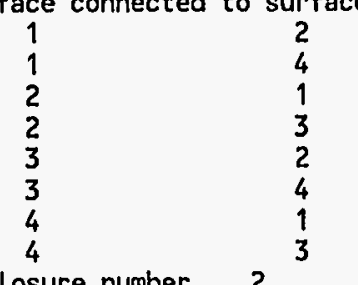

enclosure number 2

surface connected to surface

$\begin{array}{cc}5 & 6 \\ 5 & 10 \\ 6 & 5 \\ 6 & 7 \\ 7 & 6 \\ 7 & 8\end{array}$


Table F16.A.2 (continued)

\begin{tabular}{rr}
\hline 8 & 7 \\
8 & 9 \\
9 & 8 \\
9 & 10 \\
10 & 5 \\
10 & 9
\end{tabular}

this model contains 182 nodes.

summary of enclosure nodes

enclosure number

base surface nodes

node nodal

radial

axial

area boundaries

emissivity

number area

location locetion

7.000000

minimum $r$ maximum $r$

.300000

$\begin{array}{lll}53 & .049087 & .000000\end{array}$

7.000000

maximum $r$

$.392699 \quad .250000$

$\begin{array}{llll}56 & 1.178097 & .500000 & 7.000000\end{array}$

$\begin{array}{lcc} & 57 & .736311 \\ 2 & & \text { upper surface nodes } \\ 2 & \text { node nodal }\end{array}$

7.000000

$\begin{array}{ll}.125000 & .375000 \\ .375000 & .625000\end{array}$

.375000

$.625000 \quad .875000$

.300000

$.000000 \quad 7.000000$

875000

1.000000

.300000

.300000

w

number area

radial

axial

area boundaries

emissivity

ocation location minimum $r$ maximum $r$

.000000

.375000

.300000

9.000000

$375000 \quad .37500$

.300000

50000

$\begin{array}{llll}120 & .785398 & .500000 & 9.000000 \\ 121 & 1.178097 & .750000 & 9.000000\end{array}$

.625000

.300000

875000

1.000000

.300000

shell surface nodes

node nodal

$1.000000 \quad 9.000000$

emissivity

minimum 2 maximum

radial axial

location

maximum $z$

170000

$57 \quad 1.256637 \quad 1.000000$

7.000000

7.000000

7.200000

.174000

7.400000

. 200000

8.600000

.174000

$83-2.513274-1.00000$

8.80000

7.600000

8.000000

$8.000000 \quad 8.400000$

$\begin{array}{rrrr}96 & 2.513274 & 1.000000 & 8.200000 \\ 109 & 2.513274 & 1.000000 & 8.600000\end{array}$

8.400000

8.800000

178000

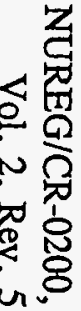

$122 \quad 1.256637 \quad 1.000000$

9.000000

8.800000

9.000000

.190000 


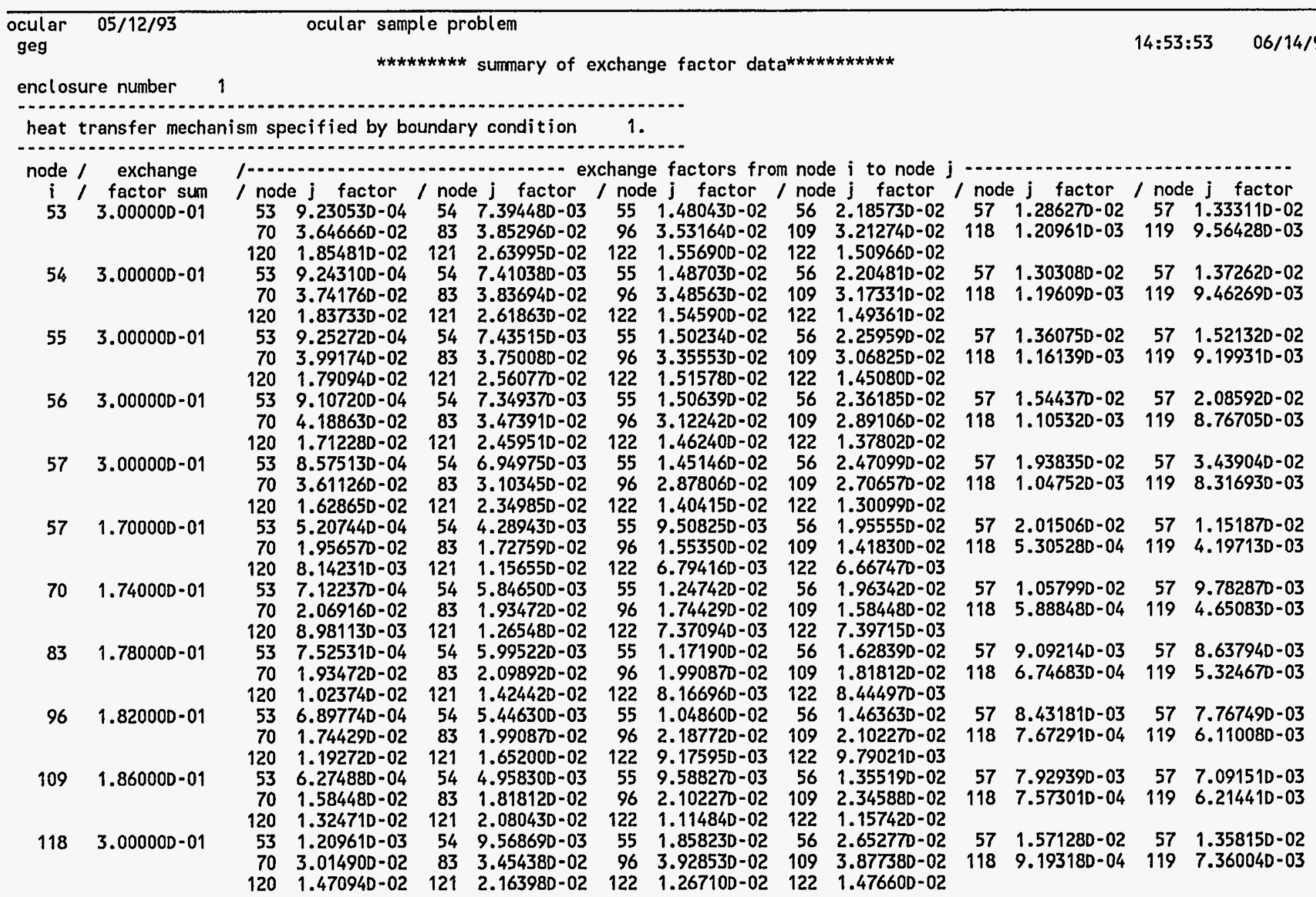


Table F16.A.2 (continued)

\begin{tabular}{|c|c|c|c|c|c|c|c|c|c|c|c|c|c|}
\hline 119 & $3.00000 D-01$ & $\begin{array}{r}53 \\
70 \\
120\end{array}$ & $\begin{array}{l}1.19554 D-03 \\
2.976530-02 \\
1.47656 D-02\end{array}$ & $\begin{array}{r}54 \\
83 \\
121\end{array}$ & $\begin{array}{l}9.462690-03 \\
3.407790-02 \\
2.181450-02\end{array}$ & $\begin{array}{r}55 \\
96 \\
122\end{array}$ & $\begin{array}{l}1.83986 \mathrm{D}-02 \\
3.91045 \mathrm{D}-02 \\
1.28276 \mathrm{D}-02\end{array}$ & $\begin{array}{r}56 \\
109 \\
122\end{array}$ & $\begin{array}{l}2.630110-02 \\
3.977220-02 \\
1.51980 D-02\end{array}$ & $\begin{array}{r}57 \\
118\end{array}$ & $\begin{array}{l}1.559420-02 \\
9.200040-04\end{array}$ & $\begin{array}{r}57 \\
119\end{array}$ & $\begin{array}{l}1.343080-02 \\
7.37130 \mathrm{D}-03\end{array}$ \\
\hline 120 & $3.000000-01$ & $\begin{array}{r}53 \\
70 \\
120\end{array}$ & $\begin{array}{l}1.15926 D-03 \\
2.87396 D-02 \\
1.489070-02\end{array}$ & $\begin{array}{r}54 \\
83 \\
121\end{array}$ & $\begin{array}{l}9.18663 D-03 \\
3.27597 D-02 \\
2.23146 D-02\end{array}$ & $\begin{array}{r}55 \\
96 \\
122\end{array}$ & $\begin{array}{l}1.79094 D-02 \\
3.816710-02 \\
1.33684 D-02\end{array}$ & $\begin{array}{r}56 \\
109 \\
122\end{array}$ & $\begin{array}{l}2.56842 D-02 \\
4.23908 D-02 \\
1.68312 D-02\end{array}$ & $\begin{array}{r}57 \\
118\end{array}$ & $\begin{array}{l}1.526860-02 \\
9.193370-04\end{array}$ & $\begin{array}{r}57 \\
119\end{array}$ & $\begin{array}{l}1.30277 \mathrm{D}-02 \\
7.382810-03\end{array}$ \\
\hline 121 & $3.000000-01$ & $\begin{array}{r}53 \\
70 \\
120\end{array}$ & $\begin{array}{l}1.099980-03 \\
2.699680-02 \\
1.487640-02\end{array}$ & $\begin{array}{r}54 \\
83 \\
121\end{array}$ & $\begin{array}{l}8.728780-03 \\
3.038770-02 \\
2.323430-02\end{array}$ & $\begin{array}{r}55 \\
96 \\
122\end{array}$ & $\begin{array}{l}1.707180-02 \\
3.524280-02 \\
1.511140-02\end{array}$ & $\begin{array}{r}56 \\
109 \\
122\end{array}$ & $\begin{array}{l}2.45951 D-02 \\
4.43825 D-02 \\
2.30761 D-02\end{array}$ & $\begin{array}{r}57 \\
118\end{array}$ & $\begin{array}{l}1.468660-02 \\
9.016580-04\end{array}$ & $\begin{array}{r}57 \\
119\end{array}$ & $\begin{array}{l}1.23365 D-02 \\
7.27150 D-03\end{array}$ \\
\hline 122 & $3.000000-01$ & $\begin{array}{r}53 \\
70 \\
120\end{array}$ & $\begin{array}{l}1.03793 \mathrm{D}-03 \\
2.51595 \mathrm{D}-02 \\
1.42597 \mathrm{D}-02\end{array}$ & $\begin{array}{r}54 \\
83 \\
121\end{array}$ & $\begin{array}{l}8.244810-03 \\
2.787660-02 \\
2.417820-02\end{array}$ & $\begin{array}{r}55 \\
96 \\
122\end{array}$ & $\begin{array}{l}1.61683 D-02 \\
3.13206 D-02 \\
1.88814 D-02\end{array}$ & $\begin{array}{r}56 \\
109 \\
122\end{array}$ & $\begin{array}{l}2.33983 D-02 \\
3.80533 D-02 \\
3.80984 D-02\end{array}$ & $\begin{array}{r}57 \\
118\end{array}$ & $\begin{array}{l}1.40415 D-02 \\
8.44730 D-04\end{array}$ & $\begin{array}{r}57 \\
119\end{array}$ & $\begin{array}{l}1.159540-02 \\
6.841390-03\end{array}$ \\
\hline 122 & $1.900000-01$ & $\begin{array}{r}53 \\
70 \\
120\end{array}$ & $\begin{array}{l}5.897130-04 \\
1.479430-02 \\
1.051950-02\end{array}$ & $\begin{array}{r}54 \\
83 \\
121\end{array}$ & $\begin{array}{l}4.667530-03 \\
1.688990-02 \\
2.163390-02\end{array}$ & $\begin{array}{r}55 \\
96 \\
122\end{array}$ & $\begin{array}{l}9.067520-03 \\
1.958040-02 \\
2.232330-02\end{array}$ & $\begin{array}{r}56 \\
109 \\
122\end{array}$ & $\begin{array}{l}1.291890-02 \\
2.314840-02 \\
1.425000-02\end{array}$ & $\begin{array}{r}57 \\
118\end{array}$ & $\begin{array}{l}7.622970-03 \\
5.76796 D-04\end{array}$ & $\begin{array}{r}57 \\
119\end{array}$ & $\begin{array}{l}6.667470-03 \\
4.74938 D-03\end{array}$ \\
\hline
\end{tabular}

connectors

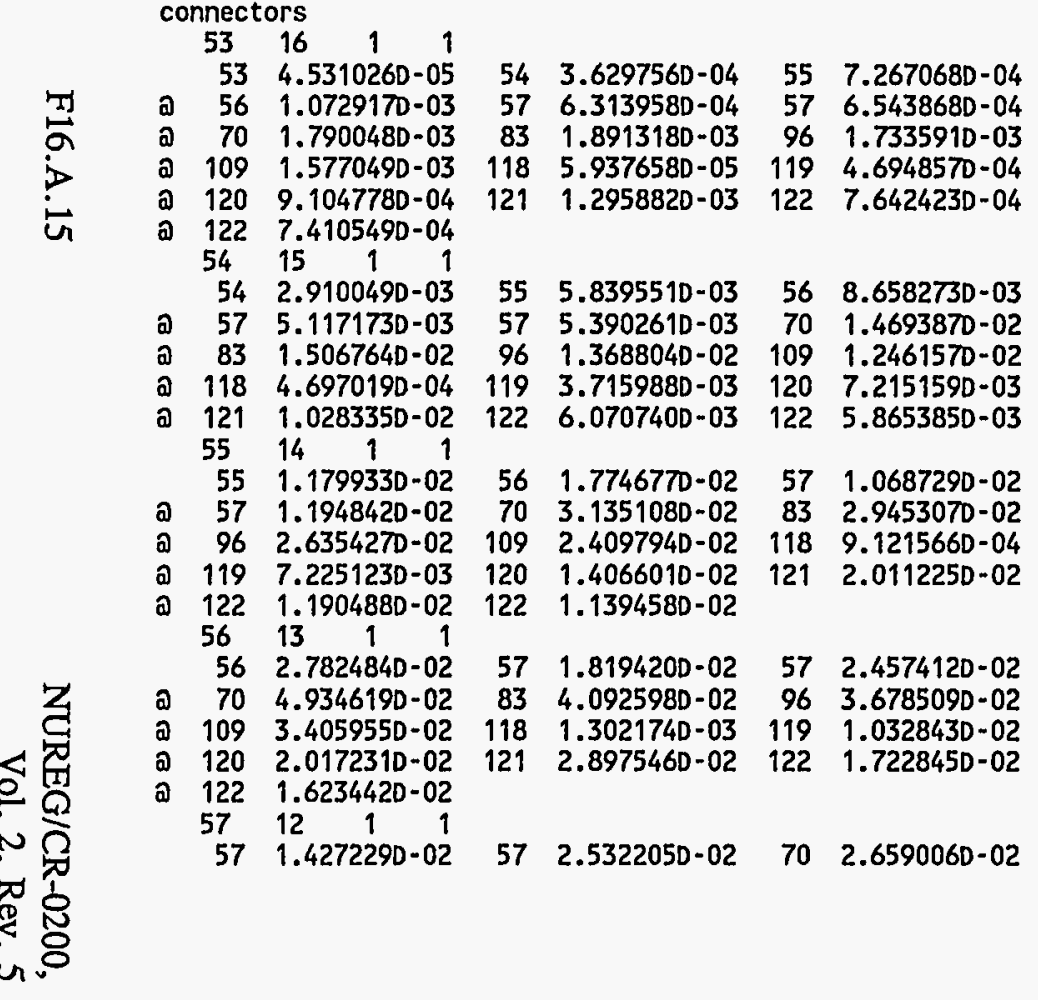


Q $\quad$\begin{tabular}{lllllll}
\hline & 83 & $2.2851040-02$ & 96 & $2.1191460-02$ & 109 & $1.9928740-02$
\end{tabular}

$\begin{array}{lllllll}\text { a } 118 & 7.713006 \mathrm{D}-04 & 119 & 6.123844 \mathrm{D}-03 & 120 & 1.1991940-02\end{array}$

a $121 \quad 1.730223 \mathrm{D}-02 \quad 122 \quad 1.033893 \mathrm{D}-02 \quad 122 \quad 9.579306 \mathrm{D}-03$ $\begin{array}{lllll}57 & 11 & 1 & 1\end{array}$ $571.4474860-02$

$\begin{array}{lll}2.4587030-02 & 83 & 2.1709500-02\end{array}$

$\begin{array}{lllll}-02 & 109 & 1.45822900-02 & 118 & 6.6668170-04\end{array}$

$\begin{array}{lllllll}119 & 5.2742710-03 & 120 & 1.0231930-02 & 121 & 1.4533650-02\end{array}$

a $1228.5377970-03 \quad 122 \quad 8.3785920-03$ $\begin{array}{clrrrrr}70 & 10 & 1 & 1 & & & \\ 70 & 5.2003610-02 & 83 & 4.8624910-02 & 96 & 4.3838770-02\end{array}$

a $109 \quad 3.982222 \mathrm{D}-02 \quad 118 \quad 1.4799380-03 \quad 119 \quad 1.1688800-02$

$\begin{array}{lllllll}\text { a } & 120 & 2.257205 \mathrm{D}-02 & 121 & 3.1804860-02 & 122 & 1.8525190-02\end{array}$

a $1221.8591070-02$ $\begin{array}{llll}83 & 9 & 1 & 1\end{array}$ $\begin{array}{rrrrrr}83 & 5.275164 \mathrm{D}-02 & 96 & 5.003600 \mathrm{D}-02 & 109 & 4.5694210-02 \\ 118 & 1.6956630-03 & 119 & 1.3382350-02 & 120 & 2.5729410-02\end{array}$

a $118 \quad 1.695663 \mathrm{D}-03 \quad 119 \quad 1.3382$ a $121 \quad 3.5799690-02 \quad 122 \quad 2.0525820-02 \quad 122 \quad 2.1224530-02$ $\begin{array}{llll}96 & 8 & 1 & 1\end{array}$ $96 \quad 5.4983460-02 \quad 109 \quad 5.2835710-02 \quad 118 \quad 1.9284130-03$ $\begin{array}{lllllll}\text { a } & 119 & 1.5356310-02 & 120 & 2.9976390-02 & 121 & 4.1519400-02\end{array}$ a $122 \quad 2.3061670-02 \quad 122 \quad 2.4605470-02$

$\begin{array}{llll}109 & 7 & 1 & 1\end{array}$

$\begin{array}{lllllll}109 & 5.8958510-02 & 118 & 1.9033050-03 & 119 & 1.5618510-02\end{array}$

尔
$\vdots$
$\vdots$
0

a $120 \quad 3.3293620-02$

$122 \quad 2.9089120-02$ $\begin{array}{llll}118 & 6 & 1 & 1\end{array}$ $\begin{array}{lllllll}118 & 4.5126900-05 & 119 & 3.6128490-04 & 120 & 7.2204580-04\end{array}$ a $121 \quad 1.062240 \mathrm{D}-03 \quad 122 \quad 6.2198410-04 \quad 122 \quad 7.248237 \mathrm{D}-04$ $\begin{array}{llll}119 & 5 & 1 & 1\end{array}$ $\begin{array}{lllllll}119 & 2.894704 \mathrm{D}-03 & 120 & 5.7984490-03 & 121 & 8.566536 \mathrm{D}-03\end{array}$ $\begin{array}{llll}122 & 5.0373920-03 \quad 122 \quad 5.9682420-03\end{array}$

$\begin{array}{llll}120 & 4 & 1 & 1\end{array}$ $\begin{array}{lllll}1 & 1.7525820-02 & 122 & 1.0499540-02\end{array}$ $1221.3219160-02$

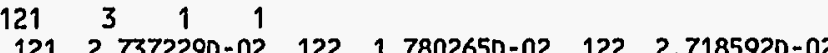
$\begin{array}{llllll}121 & 2.7372290-02 & 122 & 1.7802650-02 & 122 & 2.7185920-02\end{array}$ $\begin{array}{llll}122 & 2 & 1 & 1\end{array}$ $122 \quad 1.3902610-02 \quad 122 \quad 2.8052260-02$

$1221.790710 \mathrm{D}-02$ 
Table F16.A.2 (continued)

\begin{tabular}{|c|c|c|c|c|c|}
\hline & \begin{tabular}{cc}
\multicolumn{2}{c}{ summary of enclosure no } \\
enclosure number 2 \\
cyl inder surface nodes \\
node nodal \\
number & area \\
19 & 8.377580 \\
32 & 16.755161 \\
45 & 16.755161 \\
58 & 10.890855 \\
71 & 5.026548 \\
84 & 5.026548 \\
97 & 5.026548 \\
110 & 5.026548 \\
123 & 6.702064 \\
136 & 8.377580 \\
149 & 8.377580 \\
162 & 4.188790
\end{tabular} & $\begin{array}{l}\text { lodes } \\
\text { radial } \\
\text { location } \\
2.000000 \\
2.000000 \\
2.000000 \\
2.000000 \\
2.000000 \\
2.000000 \\
2.000000 \\
2.000000 \\
2.000000 \\
2.000000 \\
2.000000 \\
2.000000\end{array}$ & $\begin{array}{l}\text { axial } \\
\text { location } \\
3.000000 \\
4.333333 \\
5.666667 \\
7.000000 \\
7.400000 \\
7.800000 \\
8.200000 \\
8.600000 \\
9.000000 \\
9.666667 \\
10.333333 \\
11.000000\end{array}$ & \begin{tabular}{cc}
\multicolumn{2}{c}{ area boundaries } \\
minimum Z & maximum z \\
3.000000 & 3.666667 \\
3.666667 & 5.000000 \\
5.000000 & 6.333333 \\
6.333333 & 7.200000 \\
7.200000 & 7.600000 \\
7.600000 & 8.000000 \\
8.000000 & 8.400000 \\
8.400000 & 8.800000 \\
8.800000 & 9.333333 \\
9.333333 & 10.000000 \\
10.000000 & 10.666667 \\
10.666667 & 11.000000
\end{tabular} & $\begin{array}{l}\text { emissivity } \\
.800000 \\
.800000 \\
.800000 \\
.655077 \\
.174000 \\
.178000 \\
.182000 \\
.186000 \\
.570500 \\
.800000 \\
.800000 \\
.800000\end{array}$ \\
\hline 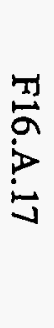 & \begin{tabular}{cl}
\multicolumn{2}{c}{ base surface nodes } \\
node & nodal \\
number & area \\
19 & 2.181662 \\
20 & 4.886922 \\
21 & 5.585054 \\
22 & 6.283185 \\
23 & 6.981317 \\
24 & 7.679449 \\
25 & 4.101524
\end{tabular} & $\begin{array}{c}\text { radial } \\
\text { location } \\
2.000000 \\
2.333333 \\
2.666667 \\
3.000000 \\
3.333333 \\
3.666667 \\
4.000000\end{array}$ & $\begin{array}{l}\text { axial } \\
\text { location } \\
3.000000 \\
3.000000 \\
3.000000 \\
3.000000 \\
3.000000 \\
3.000000 \\
3.000000\end{array}$ & \begin{tabular}{ll}
\multicolumn{2}{c}{ area boundaries } \\
minimum $r$ & maximum $r$ \\
2.000000 & 2.166667 \\
2.166667 & 2.500000 \\
2.500000 & 2.833333 \\
2.833333 & 3.166667 \\
3.166667 & 3.500000 \\
3.500000 & 3.833333 \\
3.833333 & 4.000000
\end{tabular} & $\begin{array}{c}\text { emissivity } \\
.300000 \\
.300000 \\
.300000 \\
.300000 \\
.300000 \\
.300000 \\
.300000\end{array}$ \\
\hline & $\begin{array}{cc}\text { upper } & \text { surface nodes } \\
\text { node } & \text { nodal } \\
\text { number } & \text { area } \\
162 & 2.181662 \\
163 & 4.886922 \\
164 & 5.585054 \\
165 & 6.283185 \\
166 & 6.981317 \\
167 & 7.679449 \\
168 & 4.101524\end{array}$ & $\begin{array}{c}\text { radial } \\
\text { location } \\
2.000000 \\
2.333333 \\
2.666667 \\
3.000000 \\
3.333333 \\
3.666667 \\
4.000000\end{array}$ & $\begin{array}{c}\text { axial } \\
\text { location } \\
11.000000 \\
11.000000 \\
11.000000 \\
11.000000 \\
11.000000 \\
11.000000 \\
11.000000\end{array}$ & \begin{tabular}{ll}
\multicolumn{2}{c}{ area boundaries } \\
minimum $r$ & maximum $r$ \\
2.000000 & 2.166667 \\
2.166667 & 2.500000 \\
2.500000 & 2.833333 \\
2.833333 & 3.166667 \\
3.166667 & 3.500000 \\
3.500000 & 3.833333 \\
3.833333 & 4.000000
\end{tabular} & $\begin{array}{c}\text { emissivity } \\
.300000 \\
.300000 \\
.300000 \\
.300000 \\
.300000 \\
.300000 \\
.300000\end{array}$ \\
\hline 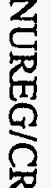 & $\begin{array}{cc}\text { shell } & \text { surface nodes } \\
\text { node } & \text { nodal } \\
\text { number } & \text { area } \\
25 & 16.755161 \\
38 & 33.510322\end{array}$ & $\begin{array}{l}\text { radial } \\
\text { location } \\
4.000000 \\
4.000000\end{array}$ & $\begin{array}{l}\text { axial } \\
\text { location } \\
3.000000 \\
4.333333\end{array}$ & \begin{tabular}{ll}
\multicolumn{2}{c}{ area boundaries } \\
minimum z & maximum z \\
3.000000 & 3.666667 \\
3.666667 & 5.000000
\end{tabular} & $\begin{array}{c}\text { emissivity } \\
.130000 \\
.143333\end{array}$ \\
\hline
\end{tabular}


N 唺

要是

in

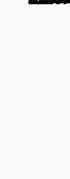

$\begin{array}{rrrrrrr}51 & 33.510322 & 4.000000 & 5.666667 & 5.000000 & 6.333333 & .156667 \\ 64 & 21.781709 & 4.000000 & 7.000000 & 6.333333 & 7.200000 & .165333 \\ 77 & 10.053096 & 4.000000 & 7.400000 & 7.200000 & 7.600000 & .174000 \\ 90 & 10.053096 & 4.000000 & 7.800000 & 7.600000 & 8.000000 & .178000 \\ 103 & 10.053096 & 4.000000 & 8.200000 & 8.000000 & 8.400000 & .182000 \\ 116 & 10.053096 & 4.000000 & 8.600000 & 8.400000 & 8.800000 & .186000 \\ 129 & 13.404129 & 4.000000 & 9.000000 & 8.800000 & 9.333333 & .191333 \\ 142 & 16.755161 & 4.000000 & 9.666667 & 9.333333 & 10.000000 & .196667 \\ 155 & 16.755161 & 4.000000 & 10.333333 & 10.000000 & 10.666667 & .203333 \\ 168 & 8.377580 & 4.000000 & 11.000000 & 10.666667 & 11.000000 & .210000\end{array}$

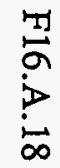


Table F16.A.2 (continued)

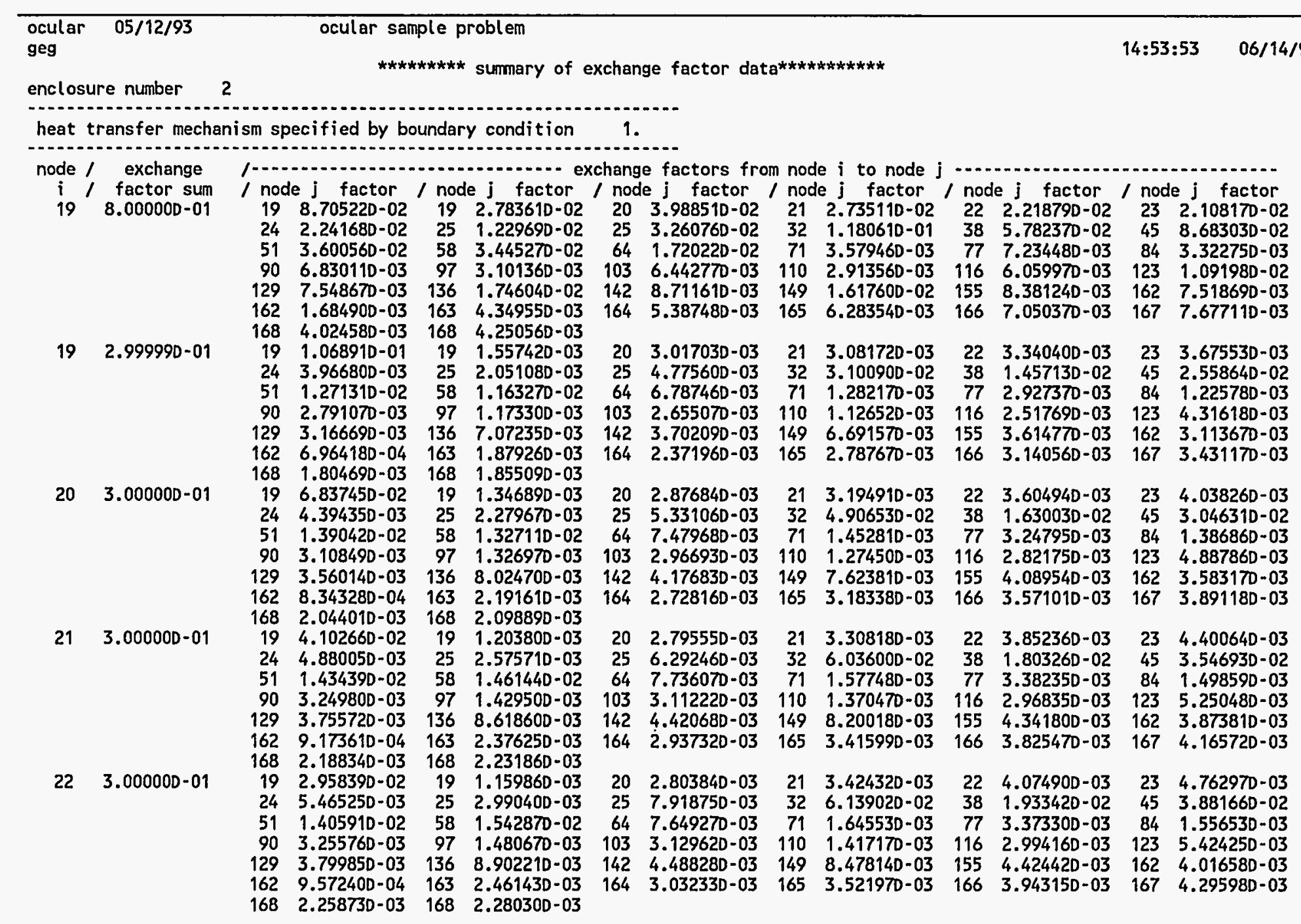


Table F16.A.2 (continued)

\begin{tabular}{|c|c|c|c|c|c|c|c|c|c|c|c|c|c|}
\hline 23 & $3.000000-01$ & $\begin{array}{r}19 \\
24 \\
51 \\
90 \\
129 \\
162 \\
168\end{array}$ & $\begin{array}{l}2.52980 D-02 \\
6.33814 D-03 \\
1.31993 D-02 \\
3.17720 D-03 \\
3.752190-03 \\
9.72890 D-04 \\
2.28842 D-03\end{array}$ & $\begin{array}{r}19 \\
25 \\
58 \\
97 \\
136 \\
163 \\
168\end{array}$ & $\begin{array}{l}1.14860 \mathrm{D}-03 \\
3.696790-03 \\
1.57431 \mathrm{D}-02 \\
1.49444 \mathrm{D}-03 \\
8.988290-03 \\
2.49065 \mathrm{D}-03 \\
2.28005 \mathrm{D}-03\end{array}$ & $\begin{array}{r}20 \\
25 \\
64 \\
103 \\
142 \\
164\end{array}$ & $\begin{array}{l}2.82678 D-03 \\
1.096750-02 \\
7.34022 D-03 \\
3.06780 D-03 \\
4.45086 D-03 \\
3.06301 D-03\end{array}$ & $\begin{array}{r}21 \\
32 \\
71 \\
110 \\
149 \\
165\end{array}$ & $\begin{array}{l}3.520510-03 \\
5.922890-02 \\
1.666970-03 \\
1.42960 \mathrm{D}-03 \\
8.57357 \mathrm{D}-03 \\
3.55667 \mathrm{D}-03\end{array}$ & $\begin{array}{r}22 \\
38 \\
77 \\
116 \\
155 \\
166\end{array}$ & $\begin{array}{l}4.28668 D-03 \\
1.95613 D-02 \\
3.27383 D-03 \\
2.94587 D-03 \\
4.40786 D-03 \\
3.98416 D-03\end{array}$ & $\begin{array}{r}23 \\
45 \\
84 \\
123 \\
162 \\
167\end{array}$ & $\begin{array}{l}5.19333 D-03 \\
4.03240 D-02 \\
1.57306 D-03 \\
5.47224 D-03 \\
4.07105 D-03 \\
4.34604 D-03\end{array}$ \\
\hline 24 & $3.000000-01$ & $\begin{array}{r}19 \\
24 \\
51 \\
90 \\
129 \\
162 \\
168\end{array}$ & $\begin{array}{l}2.445470-02 \\
7.79804 D-03 \\
1.18715 D-02 \\
3.03470 D-03 \\
3.636310-03 \\
9.72080 D-04 \\
2.292050-03\end{array}$ & $\begin{array}{r}19 \\
25 \\
58 \\
97 \\
136 \\
163 \\
168\end{array}$ & $\begin{array}{l}1.12693 \mathrm{D}-03 \\
5.00029 \mathrm{D}-03 \\
1.55191 \mathrm{D}-02 \\
1.47440 \mathrm{D}-03 \\
8.91765 \mathrm{D}-03 \\
2.48185 \mathrm{D}-03 \\
2.24599 \mathrm{D}-03\end{array}$ & $\begin{array}{r}20 \\
25 \\
64 \\
103 \\
142 \\
164\end{array}$ & $\begin{array}{l}2.79640 D-03 \\
1.68746 D-02 \\
6.86558 D-03 \\
2.94615 D-03 \\
4.33688 D-03 \\
3.05011 D-03\end{array}$ & $\begin{array}{r}21 \\
32 \\
71 \\
110 \\
149 \\
165\end{array}$ & $\begin{array}{l}3.54913 \mathrm{D}-03 \\
5.66883 \mathrm{D}-02 \\
1.64206 \mathrm{D}-03 \\
1.41227 \mathrm{D}-03 \\
8.53078 \mathrm{D}-03 \\
3.543390-03\end{array}$ & $\begin{array}{r}22 \\
38 \\
77 \\
116 \\
155 \\
166\end{array}$ & $\begin{array}{l}4.471570-03 \\
1.71876 D-02 \\
3.106270-03 \\
2.84189 D-03 \\
4.320790-03 \\
3.974160-03\end{array}$ & $\begin{array}{r}23 \\
45 \\
84 \\
123 \\
162 \\
167\end{array}$ & $\begin{array}{l}5.76194 D-03 \\
3.99044 D-02 \\
1.550410-03 \\
5.415520-03 \\
4.06048 D-03 \\
4.343690-03\end{array}$ \\
\hline 25 & $3.000000-01$ & $\begin{array}{r}19 \\
24 \\
51 \\
90 \\
129 \\
162 \\
168\end{array}$ & $\begin{array}{l}2.51170 D-02 \\
9.36225 D-03 \\
1.06874 D-02 \\
2.897720-03 \\
3.51698 D-03 \\
9.63990 D-04 \\
2.28369 D-03\end{array}$ & $\begin{array}{r}19 \\
25 \\
58 \\
97 \\
136 \\
163 \\
168\end{array}$ & $\begin{array}{l}1.09100 D-03 \\
6.460970-03 \\
1.50249 D-02 \\
1.440630-03 \\
8.78445 D-03 \\
2.45808 D-03 \\
2.20507 D-03\end{array}$ & $\begin{array}{r}20 \\
25 \\
64 \\
103 \\
142 \\
164\end{array}$ & $\begin{array}{l}2.71620 \mathrm{D}-03 \\
2.36165 \mathrm{D}-02 \\
6.43700 \mathrm{D}-03 \\
2.82644 \mathrm{D}-03 \\
4.21537 \mathrm{D}-03 \\
3.02085 \mathrm{D}-03\end{array}$ & $\begin{array}{r}21 \\
32 \\
71 \\
110 \\
149 \\
165\end{array}$ & $\begin{array}{l}3.50735 D-03 \\
5.49686 D-02 \\
1.596390-03 \\
1.38316 D-03 \\
8.430210-03 \\
3.51204 D-03\end{array}$ & $\begin{array}{r}22 \\
38 \\
77 \\
116 \\
155 \\
166\end{array}$ & $\begin{array}{l}4.58105 D-03 \\
1.31219 D-02 \\
2.94910 D-03 \\
2.73735 D-03 \\
4.22284 D-03 \\
3.94416 D-03\end{array}$ & $\begin{array}{r}23 \\
45 \\
84 \\
123 \\
162 \\
167\end{array}$ & $\begin{array}{l}6.29242 D-03 \\
3.84578 D-02 \\
1.511170-03 \\
5.31768 D-03 \\
4.02096 D-03 \\
4.31920 D-03\end{array}$ \\
\hline 25 & $1.300000-01$ & $\begin{array}{r}19 \\
24 \\
51 \\
90 \\
129 \\
162 \\
168\end{array}$ & $\begin{array}{l}1.63038 D-02 \\
7.73421 D-03 \\
4.19050 D-03 \\
1.01807 D-03 \\
1.17484 D-03 \\
2.90380 D-04 \\
6.42125 D-04\end{array}$ & $\begin{array}{r}19 \\
25 \\
58 \\
97 \\
136 \\
163 \\
168\end{array}$ & $\begin{array}{l}6.21823 D-04 \\
5.78112 D-03 \\
5.46195 D-03 \\
4.879470-04 \\
2.80606 D-03 \\
7.40117 D-04 \\
6.78380 D-04\end{array}$ & $\begin{array}{r}20 \\
25 \\
64 \\
103 \\
142 \\
164\end{array}$ & $\begin{array}{l}1.55489 D-03 \\
3.65743 D-03 \\
2.37528 D-03 \\
9.76820 D-04 \\
1.37432 D-03 \\
9.03325 D-04\end{array}$ & $\begin{array}{r}21 \\
32 \\
71 \\
110 \\
149 \\
165\end{array}$ & $\begin{array}{l}2.097490-03 \\
2.706710-02 \\
5.603160-04 \\
4.608430-04 \\
2.631670-03 \\
1.038930-03\end{array}$ & $\begin{array}{r}22 \\
38 \\
77 \\
116 \\
155 \\
166\end{array}$ & $\begin{array}{l}2.96953 D-03 \\
5.26631 D-03 \\
1.05454 D-03 \\
9.31217 D-04 \\
1.33650 D-03 \\
1.15023 D-03\end{array}$ & $\begin{array}{r}23 \\
45 \\
84 \\
123 \\
162 \\
167\end{array}$ & $\begin{array}{l}4.569810-03 \\
1.53540 D-02 \\
5.20707 D-04 \\
1.73898 D-03 \\
1.24195 D-03 \\
1.23648 D-03\end{array}$ \\
\hline 32 & $8.00000 D-01$ & $\begin{array}{r}19 \\
24 \\
51 \\
90 \\
129 \\
162 \\
168\end{array}$ & $\begin{array}{l}5.90305 D-02 \\
2.59821 D-02 \\
5.09373 D-02 \\
8.24459 D-03 \\
8.68581 D-03 \\
1.84935 D-03 \\
4.30198 D-03\end{array}$ & $\begin{array}{r}19 \\
25 \\
58 \\
97 \\
136 \\
163 \\
168\end{array}$ & $\begin{array}{l}4.03763 D-03 \\
1.34559 D-02 \\
4.27310 D-02 \\
3.74277 D-03 \\
2.01357 D-02 \\
4.73154 D-03 \\
4.67816 D-03\end{array}$ & $\begin{array}{r}20 \\
25 \\
64 \\
103 \\
142 \\
164\end{array}$ & $\begin{array}{l}1.431070-02 \\
2.70671 D-02 \\
2.24513 D-02 \\
7.63463 D-03 \\
9.86154 D-03 \\
5.84059 D-03\end{array}$ & $\begin{array}{r}21 \\
32 \\
71 \\
110 \\
149 \\
165\end{array}$ & $\begin{array}{l}2.01200 \mathrm{D}-02 \\
1.23643 \mathrm{D}-01 \\
4.41326 \mathrm{D}-03 \\
3.47215 \mathrm{D}-03 \\
1.83285 \mathrm{D}-02 \\
6.798890-03\end{array}$ & $\begin{array}{r}22 \\
38 \\
77 \\
116 \\
155 \\
166\end{array}$ & $\begin{array}{l}2.30213 D-02 \\
6.53800 D-02 \\
8.94369 D-03 \\
7.07494 D-03 \\
9.33496 D-03 \\
7.60906 D-03\end{array}$ & $\begin{array}{r}23 \\
45 \\
84 \\
123 \\
162 \\
167\end{array}$ & $\begin{array}{l}2.467870-02 \\
1.03892 D-01 \\
4.05726 D-03 \\
1.28232 D-02 \\
8.44981 D-03 \\
8.249390-03\end{array}$ \\
\hline 38 & $1.433330-01$ & $\begin{array}{r}19 \\
24 \\
51 \\
90 \\
129 \\
162 \\
168\end{array}$ & $\begin{array}{l}1.445590-02 \\
3.938820-03 \\
5.07007 D-03 \\
1.24098 D-03 \\
1.40297 D-03 \\
3.30724 D-04 \\
7.01933 D-04\end{array}$ & $\begin{array}{r}19 \\
25 \\
58 \\
97 \\
136 \\
163 \\
168\end{array}$ & $\begin{array}{l}9.486520-04 \\
1.606070-03 \\
7.63678 D-03 \\
6.13723 D-04 \\
3.340580-03 \\
8.404960-04 \\
7.76221 D-04\end{array}$ & $\begin{array}{r}20 \\
25 \\
64 \\
103 \\
142 \\
164\end{array}$ & $\begin{array}{l}2.37712 D-03 \\
2.63315 D-03 \\
2.91186 D-03 \\
1.18438 D-03 \\
1.62070 D-03 \\
1.02133 D-03\end{array}$ & $\begin{array}{r}21 \\
32 \\
71 \\
110 \\
149 \\
165\end{array}$ & $\begin{array}{l}3.00544 D-03 \\
3.26900 \mathrm{D}-02 \\
7.39998 \mathrm{D}-04 \\
5.69265 \mathrm{D}-04 \\
3.07924 \mathrm{D}-03 \\
1.16784 \mathrm{D}-03\end{array}$ & $\begin{array}{r}22 \\
38 \\
77 \\
116 \\
155 \\
166\end{array}$ & $\begin{array}{l}3.625170-03 \\
5.681220-03 \\
1.290370-03 \\
1.12178 D-03 \\
1.55183 D-03 \\
1.28313 D-03\end{array}$ & $\begin{array}{r}23 \\
45 \\
84 \\
123 \\
162 \\
167\end{array}$ & $\begin{array}{l}4.075270-03 \\
2.321290-02 \\
6.69402 D-04 \\
2.11057 D-03 \\
1.44202 D-03 \\
1.36542 D-03\end{array}$ \\
\hline 45 & $8.000000-01$ & $\begin{array}{l}19 \\
24 \\
51\end{array}$ & $\begin{array}{l}4.341520-02 \\
1.828950-02 \\
6.729650-02\end{array}$ & $\begin{array}{l}19 \\
25 \\
58\end{array}$ & $\begin{array}{l}3.331570-03 \\
9.414140-03 \\
5.459640-02\end{array}$ & $\begin{array}{l}20 \\
25 \\
64\end{array}$ & $\begin{array}{l}8.88508 D-03 \\
1.53540 D-02 \\
3.79485 D-02\end{array}$ & $\begin{array}{l}21 \\
32 \\
71\end{array}$ & $\begin{array}{l}1.18231 \mathrm{D}-02 \\
1.03892 \mathrm{D}-01 \\
5.93951 \mathrm{D}-03\end{array}$ & $\begin{array}{l}22 \\
38 \\
77\end{array}$ & $\begin{array}{l}1.455620-02 \\
4.642580-02 \\
1.445390-02\end{array}$ & $\begin{array}{l}23 \\
45 \\
84\end{array}$ & $\begin{array}{l}1.68017 D-02 \\
1.12355 D-01 \\
5.53380 D-03\end{array}$ \\
\hline
\end{tabular}


Table F16.A.2 (continued)

\begin{tabular}{|c|c|c|c|c|c|c|c|c|c|c|c|c|c|}
\hline & & $\begin{array}{r}90 \\
129 \\
162 \\
168\end{array}$ & $\begin{array}{l}1.266740-02 \\
1.176320-02 \\
2.178080-03 \\
5.044300-03\end{array}$ & $\begin{array}{r}97 \\
136 \\
163 \\
168\end{array}$ & $\begin{array}{l}5.116510-03 \\
2.635790-02 \\
5.56396 D-03 \\
5.76034 D-03\end{array}$ & $\begin{array}{l}103 \\
142 \\
164\end{array}$ & $\begin{array}{l}1.11846 D-02 \\
1.284240-02 \\
6.898410-03\end{array}$ & $\begin{array}{l}110 \\
149 \\
165\end{array}$ & $\begin{array}{l}4.718240-03 \\
2.332490-02 \\
8.061060-03\end{array}$ & $\begin{array}{l}116 \\
155 \\
166\end{array}$ & $\begin{array}{l}9.953670-03 \\
1.17443 D-02 \\
9.02793 D-03\end{array}$ & $\begin{array}{l}123 \\
162 \\
167\end{array}$ & $\begin{array}{l}1.71848 D-02 \\
1.05492 D-02 \\
9.74708 D-03\end{array}$ \\
\hline 51 & $1.56667 D-01$ & $\begin{array}{r}19 \\
24 \\
51 \\
90 \\
129 \\
162 \\
168\end{array}$ & $\begin{array}{l}9.001400-03 \\
2.720560-03 \\
6.173840-03 \\
1.780750-03 \\
1.993190-03 \\
4.485870-04 \\
8.936370-04\end{array}$ & $\begin{array}{r}19 \\
25 \\
58 \\
97 \\
136 \\
163 \\
168\end{array}$ & $\begin{array}{l}8.276770-04 \\
1.30809 D-03 \\
1.43838 D-02 \\
1.01626 D-03 \\
4.89760 D-03 \\
1.13061 D-03 \\
1.04524 D-03\end{array}$ & $\begin{array}{r}20 \\
25 \\
64 \\
103 \\
142 \\
164\end{array}$ & $\begin{array}{l}2.02769 D-03 \\
2.09525 D-03 \\
4.03645 D-03 \\
1.70239 D-03 \\
2.26827 D-03 \\
1.36394 D-03\end{array}$ & $\begin{array}{r}21 \\
32 \\
71 \\
110 \\
149 \\
165\end{array}$ & $\begin{array}{l}2.390660-03 \\
2.546870-02 \\
1.347170-03 \\
9.041390-04 \\
4.368740-03 \\
1.54688 D-03\end{array}$ & $\begin{array}{r}22 \\
38 \\
77 \\
116 \\
155 \\
166\end{array}$ & $\begin{array}{l}2.63609 D-03 \\
5.07007 D-03 \\
1.83737 D-03 \\
1.60713 D-03 \\
2.12954 D-03 \\
1.68160 D-03\end{array}$ & $\begin{array}{r}23 \\
45 \\
84 \\
123 \\
162 \\
167\end{array}$ & $\begin{array}{l}2.749860-03 \\
3.364820-02 \\
1.16219 D-03 \\
3.221260-03 \\
2.017910-03 \\
1.76390 D-03\end{array}$ \\
\hline 58 & $6.550770-01$ & $\begin{array}{r}19 \\
24 \\
51 \\
90 \\
129 \\
162 \\
168\end{array}$ & $\begin{array}{l}2.650210-02 \\
1.094290-02 \\
4.425800-02 \\
1.651690-02 \\
1.397620-02 \\
2.148120-03 \\
5.102810-03\end{array}$ & $\begin{array}{r}19 \\
25 \\
58 \\
97 \\
136 \\
163 \\
168\end{array}$ & $\begin{array}{l}2.33028 D-03 \\
5.65843 D-03 \\
4.90929 D-02 \\
5.47039 D-03 \\
2.88232 D-02 \\
5.51182 D-03 \\
6.07806 D-03\end{array}$ & $\begin{array}{r}20 \\
25 \\
64 \\
103 \\
142 \\
164\end{array}$ & $\begin{array}{l}5.954960-03 \\
8.402990-03 \\
4.02780 D-02 \\
1.437490-02 \\
1.449560-02 \\
6.91812 D-03\end{array}$ & $\begin{array}{r}21 \\
32 \\
71 \\
110 \\
149 \\
165\end{array}$ & $\begin{array}{l}7.49454 D-03 \\
6.57400 D-02 \\
5.88105 D-03 \\
5.141760-03 \\
2.505690-02 \\
8.16924 D-03\end{array}$ & $\begin{array}{r}22 \\
38 \\
77 \\
116 \\
155 \\
166\end{array}$ & $\begin{array}{l}8.90119 D-03 \\
2.34978 D-02 \\
1.83510 D-02 \\
1.23661 D-02 \\
1.26887 D-02 \\
9.20141 D-03\end{array}$ & $\begin{array}{r}23 \\
45 \\
84 \\
123 \\
162 \\
167\end{array}$ & $\begin{array}{l}1.00918 D-02 \\
8.39944 D-02 \\
5.73145 D-03 \\
1.888320-02 \\
1.11249 D-02 \\
9.92496 D-03\end{array}$ \\
\hline 64 & $1.65333 D-01$ & $\begin{array}{r}19 \\
24 \\
51 \\
90 \\
129 \\
162 \\
168\end{array}$ & $\begin{array}{l}6.616210-03 \\
2.42056 D-03 \\
6.20992 D-03 \\
2.50377 D-03 \\
2.84962 D-03 \\
6.24126 D-04 \\
1.17572 D-03\end{array}$ & $\begin{array}{r}19 \\
25 \\
58 \\
97 \\
136 \\
163 \\
168\end{array}$ & $\begin{array}{l}6.79834 D-04 \\
1.21210 D-03 \\
2.01390 D-02 \\
1.76911 D-03 \\
7.51342 D-03 \\
1.56171 D-03 \\
1.43913 D-03\end{array}$ & $\begin{array}{r}20 \\
25 \\
64 \\
103 \\
142 \\
164\end{array}$ & $\begin{array}{l}1.67813 D-03 \\
1.82714 D-03 \\
5.17830 D-03 \\
2.42263 D-03 \\
3.216390-03 \\
1.874410-03\end{array}$ & $\begin{array}{r}21 \\
32 \\
71 \\
110 \\
149 \\
165\end{array}$ & $\begin{array}{l}1.98361 D-03 \\
1.72702 D-02 \\
2.28407 D-03 \\
1.52560 D-03 \\
6.42336 D-03 \\
2.11229 D-03\end{array}$ & $\begin{array}{r}22 \\
38 \\
77 \\
116 \\
155 \\
166\end{array}$ & $\begin{array}{l}2.20652 D-03 \\
4.479790-03 \\
2.53480 D-03 \\
2.299450-03 \\
2.97694 D-03 \\
2.27472 D-03\end{array}$ & $\begin{array}{r}23 \\
45 \\
84 \\
123 \\
162 \\
167\end{array}$ & $\begin{array}{l}2.352640-03 \\
2.919110-02 \\
2.040520-03 \\
5.201450-03 \\
2.911170-03 \\
2.35380 D-03\end{array}$ \\
\hline 7 & $1.740000-$ & $\begin{array}{r}19 \\
24 \\
51 \\
90 \\
129 \\
162 \\
168\end{array}$ & $\begin{array}{l}5.965770-03 \\
2.50871 D-03 \\
8.98110 D-03 \\
5.415630-03 \\
4.83374 D-03 \\
6.37732 D-04 \\
1.57205 D-03\end{array}$ & $\begin{array}{r}19 \\
25 \\
58 \\
97 \\
136 \\
163 \\
168\end{array}$ & $\begin{array}{l}5.56499 D-04 \\
1.30261 D-03 \\
1.27423 D-02 \\
1.63392 D-03 \\
9.12194 D-03 \\
1.64940 D-03 \\
1.92666 D-03\end{array}$ & $\begin{array}{r}20 \\
25 \\
64 \\
103 \\
142 \\
164\end{array}$ & $\begin{array}{l}1.41246 D-03 \\
1.86772 D-03 \\
9.89764 D-03 \\
4.96610 D-03 \\
4.85083 D-03 \\
2.10006 D-03\end{array}$ & $\begin{array}{r}21 \\
32 \\
71 \\
110 \\
149 \\
165\end{array}$ & $\begin{array}{l}1.752750-03 \\
1.471090-02 \\
1.632140-03 \\
1.576720-03 \\
7.913240-03 \\
2.508490-03\end{array}$ & $\begin{array}{r}22 \\
38 \\
77 \\
116 \\
155 \\
166\end{array}$ & $\begin{array}{l}2.056920-03 \\
4.933320-03 \\
5.471190-03 \\
4.333110-03 \\
4.099650-03 \\
2.84440 D-03\end{array}$ & $\begin{array}{r}23 \\
45 \\
84 \\
123 \\
162 \\
167\end{array}$ & $\begin{array}{l}2.31523 D-03 \\
1.97984 D-02 \\
1.65488 D-03 \\
5.90833 D-03 \\
3.47685 D-03 \\
3.07068 D-03\end{array}$ \\
\hline 77 & 1 & $\begin{array}{r}19 \\
24 \\
51 \\
90 \\
129 \\
162 \\
168\end{array}$ & $\begin{array}{l}6.02873 D-03 \\
2.37285 D-03 \\
6.12458 D-03 \\
3.04060 D-03 \\
3.55707 D-03 \\
7.81361 D-04 \\
1.41476 D-03\end{array}$ & $\begin{array}{r}19 \\
25 \\
58 \\
97 \\
136 \\
163 \\
168\end{array}$ & $\begin{array}{l}6.352800-04 \\
1.203190-03 \\
1.98802 D-02 \\
2.46900 D-03 \\
1.01818 D-02 \\
1.94694 D-03 \\
1.77775 D-03\end{array}$ & $\begin{array}{r}20 \\
25 \\
64 \\
103 \\
142 \\
164\end{array}$ & $\begin{array}{l}1.578870-03 \\
1.75756 D-03 \\
5.492070-03 \\
2.97935 D-03 \\
4.02018 D-03 \\
2.33040 D-03\end{array}$ & $\begin{array}{r}21 \\
32 \\
71 \\
110 \\
149 \\
165\end{array}$ & $\begin{array}{l}1.87908 D-03 \\
1.49062 D-02 \\
2.735600-03 \\
2.163520-03 \\
8.412390-03 \\
2.615070-03\end{array}$ & $\begin{array}{r}22 \\
38 \\
77 \\
116 \\
155 \\
166\end{array}$ & $\begin{array}{l}2.10831 D-03 \\
4.30122 D-03 \\
2.99420 D-03 \\
2.85374 D-03 \\
3.70582 D-03 \\
2.79644 D-03\end{array}$ & $\begin{array}{r}23 \\
45 \\
84 \\
123 \\
162 \\
167\end{array}$ & $\begin{array}{l}2.27350 D-03 \\
2.408980-02 \\
2.694910-03 \\
7.284540-03 \\
3.749950-03 \\
2.863250-03\end{array}$ \\
\hline 84 & $1.780000-01$ & $\begin{array}{r}19 \\
24 \\
51 \\
90 \\
129 \\
162\end{array}$ & $\begin{array}{l}5.53792 D-03 \\
2.36868 D-03 \\
7.74794 D-03 \\
5.79833 D-03 \\
5.91005 D-03 \\
6.96180 D-04\end{array}$ & $\begin{array}{r}19 \\
25 \\
58 \\
97 \\
136 \\
163\end{array}$ & $\begin{array}{l}5.320250-04 \\
1.233070-03 \\
1.241810-02 \\
1.748420-03 \\
1.037160-02 \\
1.818310-03\end{array}$ & $\begin{array}{r}20 \\
25 \\
64 \\
103 \\
142 \\
164\end{array}$ & $\begin{array}{l}1.34833 D-03 \\
1.73569 D-03 \\
8.842270-03 \\
5.70989 D-03 \\
5.86767 D-03 \\
2.349130-03\end{array}$ & $\begin{array}{r}21 \\
32 \\
71 \\
110 \\
149 \\
165\end{array}$ & $\begin{array}{l}1.66510 D-03 \\
1.35242 D-02 \\
1.65488 D-03 \\
1.72682 D-03 \\
9.04484 D-03 \\
2.83621 D-03\end{array}$ & $\begin{array}{r}22 \\
38 \\
77 \\
116 \\
155 \\
166\end{array}$ & $\begin{array}{l}1.94566 D-03 \\
4.46268 D-03 \\
5.38983 D-03 \\
5.20925 D-03 \\
4.83747 D-03 \\
3.23522 D-03\end{array}$ & $\begin{array}{r}23 \\
45 \\
84 \\
123 \\
162 \\
167\end{array}$ & $\begin{array}{l}2.184800-03 \\
1.84460 D-02 \\
1.724770-03 \\
6.607870-03 \\
3.951970-03 \\
3.496440-03\end{array}$ \\
\hline
\end{tabular}




\begin{tabular}{|c|c|c|c|c|c|c|c|c|c|c|c|c|c|}
\hline 90 & $1.780000-01$ & $\begin{array}{r}168 \\
19 \\
24 \\
51 \\
90 \\
129 \\
162 \\
168\end{array}$ & $\begin{array}{l}1.78454 D-03 \\
5.69175 D-03 \\
2.31818 D-03 \\
5.93584 D-03 \\
3.27295 D-03 \\
3.97564 D-03 \\
8.89288 D-04 \\
1.55855 D-03\end{array}$ & $\begin{array}{r}168 \\
19 \\
25 \\
58 \\
97 \\
136 \\
163 \\
168\end{array}$ & $\begin{array}{l}2.23782 D-03 \\
6.05700 D-04 \\
1.18223 D-03 \\
1.78933 D-02 \\
2.853950-03 \\
1.235610-02 \\
2.210090-03 \\
1.992610-03\end{array}$ & $\begin{array}{r}20 \\
25 \\
64 \\
103 \\
142 \\
164\end{array}$ & $\begin{array}{l}1.51107 D-03 \\
1.69678 D-03 \\
5.42484 D-03 \\
3.27695 D-03 \\
4.51813 D-03 \\
2.64119 D-03\end{array}$ & $\begin{array}{r}21 \\
32 \\
71 \\
110 \\
149 \\
165\end{array}$ & $\begin{array}{l}1.80544 D-03 \\
1.37410 D-02 \\
2.70782 D-03 \\
2.615240-03 \\
9.956690-03 \\
2.954470-03\end{array}$ & $\begin{array}{r}22 \\
38 \\
77 \\
116 \\
155 \\
166\end{array}$ & $\begin{array}{l}2.03485 D-03 \\
4.13658 D-03 \\
3.04060 D-03 \\
3.165670-03 \\
4.169910-03 \\
3.14050 D-03\end{array}$ & $\begin{array}{r}23 \\
45 \\
84 \\
123 \\
162 \\
167\end{array}$ & $\begin{array}{l}2.206390-03 \\
2.111240-02 \\
2.899170-03 \\
8.948020-03 \\
4.374980-03 \\
3.185160-03\end{array}$ \\
\hline 97 & $1.820000-01$ & $\begin{array}{r}19 \\
24 \\
51 \\
90 \\
129 \\
162 \\
168\end{array}$ & $\begin{array}{l}5.168 \\
2.252 \\
6.775 \\
5.707 \\
7.122 \\
7.535 \\
2.038\end{array}$ & $\begin{array}{r}19 \\
25 \\
58 \\
97 \\
136 \\
163 \\
168\end{array}$ & $\begin{array}{l}5.09 \\
1.17 \\
1.18 \\
1.82 \\
1.16 \\
2.00 \\
2.63\end{array}$ & $\begin{array}{r}20 \\
25 \\
64 \\
103 \\
142 \\
164\end{array}$ & $\begin{array}{l}1.290110-03 \\
1.62649 D-03 \\
7.66616 D-03 \\
6.10385 D-03 \\
7.159810-03 \\
2.637310-03\end{array}$ & $\begin{array}{r}21 \\
32 \\
71 \\
110 \\
149 \\
165\end{array}$ & $\begin{array}{l}1.588 \\
1.247 \\
1.633 \\
1.846 \\
1.028 \\
3.226\end{array}$ & $\begin{array}{r}22 \\
38 \\
77 \\
116 \\
155 \\
166\end{array}$ & $\begin{array}{l}03 \\
03 \\
03 \\
03 \\
03\end{array}$ & $\begin{array}{r}23 \\
45 \\
84 \\
123 \\
162 \\
167\end{array}$ & $\begin{array}{l}.07561 D-03 \\
.70550 D-02 \\
.74842 D-03 \\
.255720-03 \\
.481210-03 \\
.006770-03\end{array}$ \\
\hline 103 & $1.820000-01$ & $\begin{array}{r}19 \\
24 \\
51 \\
90 \\
129 \\
162 \\
168\end{array}$ & $\begin{array}{l}5.36898 D-03 \\
2.25053 D-03 \\
5.67462 D-03 \\
3.27695 D-03 \\
4.34783 D-03 \\
1.00517 D-03 \\
1.69498 D-03\end{array}$ & $\begin{array}{r}19 \\
25 \\
58 \\
97 \\
136 \\
163 \\
168\end{array}$ & $\begin{array}{l}5.761870-04 \\
1.153150-03 \\
1.557290-02 \\
3.051920-03 \\
1.500720-02 \\
2.493090-03 \\
2.20583 D-03\end{array}$ & $\begin{array}{r}20 \\
25 \\
64 \\
103 \\
142 \\
164\end{array}$ & $\begin{array}{l}1.44226 D-03 \\
1.62803 D-03 \\
5.24903 D-03 \\
3.47232 D-03 \\
4.98891 D-03 \\
2.97767 D-03\end{array}$ & $\begin{array}{r}21 \\
32 \\
71 \\
110 \\
149 \\
165\end{array}$ & & $\begin{array}{r}22 \\
38 \\
77 \\
116 \\
155 \\
166\end{array}$ & & $\begin{array}{r}23 \\
45 \\
84 \\
123 \\
162 \\
167\end{array}$ & $\begin{array}{l}2.130420-03 \\
1.86409 D-02 \\
2.85495 D-03 \\
1.07646 D-02 \\
5.11448 D-03 \\
3.51110 D-03\end{array}$ \\
\hline 11 & $1.86000 \mathrm{D}-01$ & $\begin{array}{r}19 \\
24 \\
51 \\
90 \\
129 \\
162 \\
168\end{array}$ & $\begin{array}{l}4.85593 D-03 \\
2.15764 D-03 \\
6.02760 D-03 \\
5.23048 D-03 \\
8.23985 D-03 \\
8.07043 D-04 \\
2.33939 D-03\end{array}$ & $\begin{array}{r}19 \\
25 \\
58 \\
97 \\
136 \\
163 \\
168\end{array}$ & $\begin{array}{l}4.8 \\
1.1 \\
1.1 \\
1.8 \\
1.2 \\
2.2 \\
3.1\end{array}$ & $\begin{array}{r}20 \\
25 \\
64 \\
103 \\
142 \\
164\end{array}$ & $\begin{array}{l}1 . \\
6 . \\
6 . \\
2 .\end{array}$ & $\begin{array}{r}21 \\
32 \\
71 \\
110 \\
149 \\
165\end{array}$ & & $\begin{array}{r}22 \\
38 \\
77 \\
116 \\
155 \\
166\end{array}$ & & $\begin{array}{r}23 \\
45 \\
84 \\
123 \\
162 \\
167\end{array}$ & $\begin{array}{l}-03 \\
-02 \\
-03 \\
-03 \\
-03 \\
-03\end{array}$ \\
\hline 11 & $1.860000-01$ & $\begin{array}{r}19 \\
24 \\
51 \\
90 \\
129 \\
162 \\
168\end{array}$ & $\begin{array}{l}5.04998 D-03 \\
2.17089 D-03 \\
5.35710 D-03 \\
3.16567 D-03 \\
4.65347 D-03 \\
1.12659 D-03 \\
1.82253 D-03\end{array}$ & $\begin{array}{r}19 \\
25 \\
58 \\
97 \\
136 \\
163 \\
168\end{array}$ & $\begin{array}{l}5.46374 D-04 \\
1.11680 D-03 \\
1.33966 D-02 \\
2.99005 D-03 \\
1.80725 D-02 \\
2.79347 D-03 \\
2.41471 D-03\end{array}$ & $\begin{array}{r}20 \\
25 \\
64 \\
103 \\
142 \\
164\end{array}$ & $\begin{array}{l}1.3 \\
1.5 \\
4.9 \\
3.4 \\
5.4 \\
3.3\end{array}$ & $\begin{array}{r}21 \\
32 \\
71 \\
110 \\
149 \\
165\end{array}$ & & $\begin{array}{r}22 \\
38 \\
77 \\
116 \\
155 \\
166\end{array}$ & & $\begin{array}{r}23 \\
45 \\
84 \\
123 \\
162 \\
167\end{array}$ & $\begin{array}{l}D-03 \\
D-02 \\
D-03 \\
D-02 \\
b-03 \\
D-03\end{array}$ \\
\hline 12 & $705000-01$ & $\begin{array}{r}19 \\
24 \\
51 \\
90 \\
129 \\
162\end{array}$ & $\begin{array}{l}1.36497 \mathrm{D}-02 \\
6.20528 \mathrm{D}-03 \\
1.61063 \mathrm{D}-02 \\
1.34220 \mathrm{D}-02 \\
2.675610-02\end{array}$ & $\begin{array}{r}19 \\
25 \\
58 \\
97 \\
136 \\
163\end{array}$ & $\begin{array}{l}1.40501 D-03 \\
3.254310-03 \\
3.06851 D-02 \\
5.44179 D-03 \\
4.25056 D-02 \\
7.46075 D-03\end{array}$ & $\begin{array}{r}20 \\
25 \\
64 \\
103 \\
142 \\
164\end{array}$ & $\begin{array}{l}3.564070-03 \\
4.347460-03 \\
1.690470-02 \\
1.614690-02 \\
3.153850-02 \\
1.056520-02\end{array}$ & $\begin{array}{r}21 \\
32 \\
71 \\
110 \\
149 \\
165\end{array}$ & $\begin{array}{l}540 D-03 \\
5810-02 \\
125 D-03 \\
352 D-03 \\
615 D-02 \\
201 D-02\end{array}$ & $\begin{array}{r}22 \\
38 \\
77 \\
116 \\
155 \\
166\end{array}$ & $\begin{array}{l}523 D-03 \\
5290-02 \\
268 D-02 \\
785 D-02 \\
2590-02 \\
630 D-02\end{array}$ & $\begin{array}{r}23 \\
45 \\
84 \\
123 \\
162 \\
167\end{array}$ & $\begin{array}{l}5.70025 D-03 \\
4.29621 D-02 \\
4.95590 D-03 \\
2.45454 D-02 \\
1.72525 D-02 \\
1.62849 D-02\end{array}$ \\
\hline 129 & 91333D- & & $\begin{array}{l}4.71792 D-03 \\
2.08330 D-03\end{array}$ & 2 & $\begin{array}{l}4120-04 \\
76160-03\end{array}$ & $\begin{array}{l}20 \\
25\end{array}$ & $\begin{array}{l}1.297970-03 \\
1.468550-03\end{array}$ & $\begin{array}{l}21 \\
32\end{array}$ & $\begin{array}{l}1.56488 D-03 \\
1.08573 D-02\end{array}$ & $\begin{array}{l}22 \\
38\end{array}$ & $\begin{array}{l}1.781180-03 \\
3.507420-03\end{array}$ & $\begin{array}{l}23 \\
45\end{array}$ & $\begin{array}{l}1.954270-03 \\
1.470400-02\end{array}$ \\
\hline
\end{tabular}


Table F16.A.2 (continued)

\begin{tabular}{|c|c|c|c|c|c|c|c|c|c|c|c|c|c|}
\hline & & $\begin{array}{r}51 \\
90 \\
129 \\
162 \\
168 \\
10\end{array}$ & $\begin{array}{l}4.982980-03 \\
2.98173 D-03 \\
4.87019 D-03 \\
1.270340-03 \\
1.98041 D-03\end{array}$ & $\begin{array}{r}58 \\
97 \\
136 \\
163 \\
168 \\
10\end{array}$ & $\begin{array}{l}1.135570-02 \\
2.67075 D-03 \\
2.17161 D-02 \\
3.164120-03 \\
2.67488 D-03\end{array}$ & $\begin{array}{r}64 \\
103 \\
142 \\
164\end{array}$ & $\begin{array}{l}4.630640-03 \\
3.260870-03 \\
5.877220-03 \\
3.835340-03\end{array}$ & $\begin{array}{r}71 \\
110 \\
149 \\
165\end{array}$ & $\begin{array}{l}1.81265 D-03 \\
3.08994 D-03 \\
1.76818 D-02 \\
4.32069 D-03\end{array}$ & $\begin{array}{r}77 \\
116 \\
155 \\
166\end{array}$ & $\begin{array}{l}2.66780 D-03 \\
3.490110-03 \\
5.60884 D-03 \\
4.52089 D-03\end{array}$ & $\begin{array}{r}84 \\
123 \\
162 \\
167\end{array}$ & $\begin{array}{l}2.21627 D-03 \\
1.33780 D-02 \\
7.40225 D-03 \\
4.34444 D-03\end{array}$ \\
\hline 136 & $8.00000 D-01$ & $\begin{array}{r}19 \\
24 \\
51 \\
90 \\
129 \\
162 \\
168\end{array}$ & $\begin{array}{l}1.746040-02 \\
8.174510-03 \\
1.95904 D-02 \\
1.482740-02 \\
3.474570-02 \\
3.866540-03 \\
1.326180-02\end{array}$ & $\begin{array}{r}19 \\
25 \\
58 \\
97 \\
136 \\
163 \\
168\end{array}$ & $\begin{array}{l}1.84176 D-03 \\
4.30072 D-03 \\
3.74701 D-02 \\
6.99916 D-03 \\
6.24705 D-02 \\
1.32472 D-02 \\
2.12273 D-02\end{array}$ & $\begin{array}{r}20 \\
25 \\
64 \\
103 \\
142 \\
164\end{array}$ & $\begin{array}{l}4.68108 D-03 \\
5.61212 D-03 \\
1.95349 D-02 \\
1.800870-02 \\
4.87128 D-02 \\
1.94856 D-02\end{array}$ & $\begin{array}{r}21 \\
32 \\
71 \\
110 \\
149 \\
165\end{array}$ & $\begin{array}{l}5.74573 D-03 \\
4.02714 D-02 \\
5.47316 D-03 \\
7.75335 D-03 \\
6.17292 D-02 \\
2.32109 D-02\end{array}$ & $\begin{array}{r}22 \\
38 \\
77 \\
116 \\
155 \\
166\end{array}$ & $\begin{array}{l}6.676660-03 \\
1.33623 D-02 \\
1.22181 D-02 \\
2.16870 D-02 \\
4.69294 D-02 \\
2.52382 D-02\end{array}$ & $\begin{array}{r}23 \\
45 \\
84 \\
123 \\
162 \\
167\end{array}$ & $\begin{array}{l}7.49024 D-C \\
5.27158 D-C \\
6.22294 D-C \\
3.40045 D-C \\
2.74062 D-C \\
2.63463 D-C\end{array}$ \\
\hline 142 & $1.966670-01$ & $\begin{array}{r}19 \\
24 \\
51 \\
90 \\
129 \\
162 \\
168\end{array}$ & $\begin{array}{l}4.355810-03 \\
1.987740-03 \\
4.53653 D-03 \\
2.710880-03 \\
4.70178 D-03 \\
1.38526 D-03 \\
2.255610-03\end{array}$ & $\begin{array}{r}19 \\
25 \\
58 \\
97 \\
136 \\
163 \\
168\end{array}$ & $\begin{array}{l}4.82043 D-04 \\
1.03189 D-03 \\
9.42214 D-03 \\
2.14794 D-03 \\
2.43564 D-02 \\
3.50840 D-03 \\
3.07036 D-03\end{array}$ & $\begin{array}{r}20 \\
25 \\
64 \\
103 \\
142 \\
164\end{array}$ & $\begin{array}{l}1.218240-03 \\
1.374320-03 \\
4.18130 D-03 \\
2.99335 D-03 \\
6.29878 D-03 \\
4.44087 D-03\end{array}$ & $\begin{array}{r}21 \\
32 \\
71 \\
110 \\
149 \\
165\end{array}$ & $\begin{array}{l}1.47356 D-03 \\
9.86154 D-03 \\
1.45525 D-03 \\
2.610710-03 \\
2.263920-02 \\
5.28410 D-03\end{array}$ & $\begin{array}{r}22 \\
38 \\
77 \\
116 \\
155 \\
166\end{array}$ & $\begin{array}{l}-03 \\
-03 \\
-03 \\
-03 \\
-03 \\
-03\end{array}$ & $\begin{array}{r}23 \\
45 \\
84 \\
123 \\
162 \\
167\end{array}$ & $\begin{array}{l}1 . \\
1 . \\
1 . \\
1 . \\
9 .\end{array}$ \\
\hline 149 & $8.00000 D-01$ & $\begin{array}{r}19 \\
24 \\
51 \\
90 \\
129 \\
162 \\
168\end{array}$ & $\begin{array}{l}1.61760 \mathrm{D}-02 \\
7.81988 \mathrm{D}-03 \\
1.74750 \mathrm{D}-02 \\
1.19480 \mathrm{D}-02 \\
2.82909 \mathrm{D}-02 \\
6.51985 \mathrm{D}-03 \\
1.33102 \mathrm{D}-02\end{array}$ & $\begin{array}{r}19 \\
25 \\
58 \\
97 \\
136 \\
163 \\
168\end{array}$ & $\begin{array}{l}1.74260 \mathrm{D}-03 \\
4.127290-03 \\
3.25740 \mathrm{D}-02 \\
6.17725 \mathrm{D}-03 \\
6.17292 \mathrm{D}-02 \\
2.75520 \mathrm{D}-02 \\
2.58570 \mathrm{D}-02\end{array}$ & $\begin{array}{r}20 \\
25 \\
64 \\
103 \\
142 \\
164\end{array}$ & $\begin{array}{l}4.447220-03 \\
5.263330-03 \\
1.670070-02 \\
1.42090 \mathrm{D}-02 \\
4.527850-02 \\
2.94492 \mathrm{D}-02\end{array}$ & $\begin{array}{r}21 \\
32 \\
71 \\
110 \\
149 \\
165\end{array}$ & $\begin{array}{l}5.466790-03 \\
3.66569 D-02 \\
4.74794 D-03 \\
6.97867 D-03 \\
6.783290-02 \\
2.69784 D-02\end{array}$ & $\begin{array}{r}22 \\
38 \\
77 \\
116 \\
155 \\
166\end{array}$ & $\begin{array}{l}-03 \\
-02 \\
-02 \\
-02 \\
-02 \\
-02\end{array}$ & $\begin{array}{r}23 \\
45 \\
84 \\
123 \\
162 \\
167\end{array}$ & $\begin{array}{l}4 \\
5 \\
3 . \\
3 . \\
2 .\end{array}$ \\
\hline 155 & 03 & $\begin{array}{r}19 \\
24 \\
51 \\
90 \\
129 \\
162 \\
168\end{array}$ & $\begin{array}{l}4.19062 D-03 \\
1.98036 D-03 \\
4.25908 D-03 \\
2.50195 D-03 \\
4.48707 D-03 \\
1.25224 D-03 \\
3.43319 D-03\end{array}$ & $\begin{array}{r}19 \\
25 \\
58 \\
97 \\
136 \\
163 \\
168\end{array}$ & $\begin{array}{l}4.70673 D-04 \\
1.033720-03 \\
8.24763 D-03 \\
1.73681 D-03 \\
2.34647 D-02 \\
3.22313 D-03 \\
3.96602 D-03\end{array}$ & $\begin{array}{r}20 \\
25 \\
64 \\
103 \\
142 \\
164\end{array}$ & $\begin{array}{l}8 D-03 \\
0 D-03 \\
3 D-03 \\
1 D-03 \\
0 D-03 \\
10-03\end{array}$ & $\begin{array}{r}21 \\
32 \\
71 \\
110 \\
149 \\
165\end{array}$ & $\begin{array}{l}-03 \\
.03 \\
-03 \\
-03 \\
-02 \\
.03\end{array}$ & $\begin{array}{r}22 \\
38 \\
77 \\
116 \\
155 \\
166\end{array}$ & $\begin{array}{l}-03 \\
-03 \\
-03 \\
-03 \\
.03 \\
.03\end{array}$ & $\begin{array}{r}23 \\
45 \\
84 \\
123 \\
162 \\
167\end{array}$ & $\begin{array}{l}1 . \\
1 . \\
1 . \\
1 .\end{array}$ \\
\hline 16 & 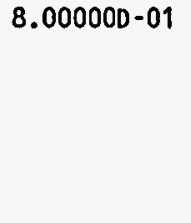 & $\begin{array}{r}19 \\
24 \\
51 \\
90 \\
129 \\
162 \\
168\end{array}$ & $\begin{array}{l}1.50374 D-02 \\
7.44422 D-03 \\
1.61432 D-02 \\
1.05000 D-02 \\
2.36872 D-02 \\
4.74300 D-02 \\
1.07333 D-02\end{array}$ & $\begin{array}{r}19 \\
25 \\
58 \\
97 \\
136 \\
163 \\
168\end{array}$ & $\begin{array}{l}1.62170 D-03 \\
3.93719 D-03 \\
2.892470-02 \\
5.37745 D-03 \\
5.48125 D-02 \\
4.496370-02 \\
2.59705 D-02\end{array}$ & $\begin{array}{r}20 \\
25 \\
64 \\
103 \\
142 \\
164\end{array}$ & $\begin{array}{l}036 D-03 \\
780 D-03 \\
381 D-02 \\
788 D-02 \\
300 D-02 \\
65 D-02\end{array}$ & $\begin{array}{r}21 \\
32 \\
71 \\
110 \\
149 \\
165\end{array}$ & $\begin{array}{l}08 D-03 \\
920-02 \\
220-03 \\
420-03 \\
35 D-02 \\
39 D-02\end{array}$ & $\begin{array}{r}22 \\
38 \\
77 \\
116 \\
155 \\
166\end{array}$ & $\begin{array}{l}6.02487 D-03 \\
1.15361 D-02 \\
8.99988 D-03 \\
1.44402 D-02 \\
4.87553 D-02 \\
1.77019 D-02\end{array}$ & $\begin{array}{r}23 \\
45 \\
84 \\
123 \\
162 \\
167\end{array}$ & $\begin{array}{l}4.219670-0 \\
4.742360-0 \\
2.760390-0 \\
6.240020-0 \\
1.940140-0\end{array}$ \\
\hline 10 & $2.999990-$ & $\begin{array}{r}19 \\
24 \\
51 \\
90 \\
129 \\
162 \\
168\end{array}$ & $\begin{array}{l}6.470020-03 \\
3.421720-03 \\
6.890290-03 \\
4.09784 D-03 \\
7.804980-03 \\
2.015040-03 \\
1.895690-03\end{array}$ & $\begin{array}{r}19 \\
25 \\
58 \\
97 \\
136 \\
163 \\
168\end{array}$ & $\begin{array}{l}6.96418 D-04 \\
1.81230 \mathrm{D}-03 \\
1.07234 \mathrm{D}-02 \\
1.73622 \mathrm{D}-03 \\
1.48475 \mathrm{D}-02 \\
3.15066 \mathrm{D}-03 \\
3.29234 \mathrm{D}-03\end{array}$ & $\begin{array}{r}20 \\
25 \\
64 \\
103 \\
142 \\
164\end{array}$ & $\begin{array}{l}1.86889 D-03 \\
2.23012 D-03 \\
6.231270-03 \\
4.63181 D-03 \\
1.06388 D-02 \\
3.02635 D-03\end{array}$ & $\begin{array}{r}21 \\
32 \\
71 \\
110 \\
149 \\
165\end{array}$ & $\begin{array}{l}2.348440-03 \\
1.42030 D-02 \\
1.46933 D-03 \\
1.85943 D-03 \\
2.503620-02 \\
3.31753 D-03\end{array}$ & $\begin{array}{r}22 \\
38 \\
77 \\
116 \\
155 \\
166\end{array}$ & $\begin{array}{l}5685 D-03 \\
7992 D-03 \\
0051 D-03 \\
9132 D-03 \\
1723 D-03 \\
8030 D-03\end{array}$ & $\begin{array}{r}23 \\
45 \\
84 \\
123 \\
162 \\
167\end{array}$ & $\begin{array}{l}1.67276 \mathrm{D}-0 \\
1.60400 \mathrm{D}-0 \\
7.92948 \mathrm{D}-0 \\
9.10656 \mathrm{D}-0 \\
3.91771 \mathrm{D}-0\end{array}$ \\
\hline
\end{tabular}


Table F16.A.2 (continued)

\begin{tabular}{|c|c|c|c|c|c|c|c|c|c|c|c|c|c|c|}
\hline 163 & $3.000000-01$ & $\begin{array}{r}19 \\
24 \\
51 \\
90 \\
129 \\
162 \\
168\end{array}$ & $\begin{array}{l}7.45638 D-03 \\
3.90005 D-03 \\
7.75274 D-03 \\
4.54648 D-03 \\
8.67872 D-03 \\
1.40654 D-03 \\
2.13877 D-03\end{array}$ & $\begin{array}{r}19 \\
25 \\
58 \\
97 \\
136 \\
163 \\
168\end{array}$ & $\begin{array}{l}8.38955 D-04 \\
2.06303 D-03 \\
1.22835 D-02 \\
2.05716 D-03 \\
2.27095 D-02 \\
2.92671 D-03 \\
3.62778 D-03\end{array}$ & $\begin{array}{r}20 \\
25 \\
64 \\
103 \\
142 \\
164\end{array}$ & $\begin{array}{l}2.19161 D-03 \\
2.53754 D-03 \\
6.96074 D-03 \\
5.12865 D-03 \\
1.20288 D-02 \\
3.27796 D-03\end{array}$ & $\begin{array}{r}21 \\
32 \\
71 \\
110 \\
149 \\
165\end{array}$ & $\begin{array}{l}2.715710-03 \\
1.622240-02 \\
1.696530-03 \\
2.262910-03 \\
4.723210-02 \\
3.726980-03\end{array}$ & $\begin{array}{r}22 \\
38 \\
77 \\
116 \\
155 \\
166\end{array}$ & $\begin{array}{l}3.16470 D-03 \\
5.76340 D-03 \\
4.00514 D-03 \\
5.74656 D-03 \\
1.10507 D-02 \\
4.17496 D-03\end{array}$ & $\begin{array}{r}23 \\
45 \\
84 \\
123 \\
162 \\
167\end{array}$ & $\begin{array}{l}3.558070-03 \\
1.907640-02 \\
1.87026 D-03 \\
1.023190-02 \\
3.854030-02 \\
4.44929 D-03\end{array}$ & \\
\hline 164 & $3.000000-01$ & $\begin{array}{r}19 \\
24 \\
51 \\
90 \\
129 \\
162 \\
168\end{array}$ & $\begin{array}{l}8.08122 D-03 \\
4.19390 D-03 \\
8.18364 D-03 \\
4.75415 D-03 \\
9.20482 D-03 \\
1.18217 D-03 \\
2.40870 D-03\end{array}$ & $\begin{array}{r}19 \\
25 \\
58 \\
97 \\
136 \\
163 \\
168\end{array}$ & $\begin{array}{l}9.265480-04 \\
2.218440-03 \\
1.349030-02 \\
2.373580-03 \\
2.922830-02 \\
2.868220-03 \\
4.195520-03\end{array}$ & $\begin{array}{r}20 \\
25 \\
64 \\
103 \\
142 \\
164\end{array}$ & $\begin{array}{l}2.387140-03 \\
2.70998 D-03 \\
7.31021 D-03 \\
5.35981 D-03 \\
1.33226 D-02 \\
3.464390-03\end{array}$ & $\begin{array}{r}21 \\
32 \\
71 \\
110 \\
149 \\
165\end{array}$ & $\begin{array}{l}2.937320-03 \\
1.75218 D-02 \\
1.89005 D-03 \\
2.685330-03 \\
4.41737 D-02 \\
4.05466 D-03\end{array}$ & $\begin{array}{r}22 \\
38 \\
77 \\
116 \\
155 \\
166\end{array}$ & $\begin{array}{l}3.41137 D-03 \\
6.12798 D-03 \\
4.19472 D-03 \\
6.02025 D-03 \\
1.31280 D-02 \\
4.62289 D-03\end{array}$ & $\begin{array}{r}23 \\
45 \\
84 \\
123 \\
162 \\
167\end{array}$ & $\begin{array}{l}3.828760-03 \\
2.069520-02 \\
2.114220-03 \\
1.267820-02 \\
1.705990-02 \\
4.991890-03\end{array}$ & \\
\hline 165 & $3.00000 D-01$ & $\begin{array}{r}19 \\
24 \\
51 \\
90 \\
129 \\
162 \\
168\end{array}$ & $\begin{array}{l}8.37805 D-03 \\
4.33081 D-03 \\
8.25001 D-03 \\
4.72715 D-03 \\
9.21748 D-03 \\
1.151920-03 \\
2.74583 D-03\end{array}$ & $\begin{array}{r}19 \\
25 \\
58 \\
97 \\
136 \\
163 \\
168\end{array}$ & $\begin{array}{l}9.679410-04 \\
2.292580-03 \\
1.41600 D-02 \\
2.580970-03 \\
3.094780-02 \\
2.898760-03 \\
5.19188 D-03\end{array}$ & $\begin{array}{r}20 \\
25 \\
64 \\
103 \\
142 \\
164\end{array}$ & $\begin{array}{l}2.47596 D-03 \\
2.77048 D-03 \\
7.32259 D-03 \\
5.31454 D-03 \\
1.40909 D-02 \\
3.60415 D-03\end{array}$ & $\begin{array}{r}21 \\
32 \\
71 \\
110 \\
149 \\
165\end{array}$ & $\begin{array}{l}3.03643 D-03 \\
1.81304 D-02 \\
2.00680 D-03 \\
2.960870-03 \\
3.59712 D-02 \\
4.31343 D-03\end{array}$ & $\begin{array}{r}22 \\
38 \\
77 \\
116 \\
155 \\
166\end{array}$ & $\begin{array}{l}3.52197 D-03 \\
6.22847 D-03 \\
4.18412 D-03 \\
5.96772 D-03 \\
1.58941 D-02 \\
5.02935 D-03\end{array}$ & $\begin{array}{r}23 \\
45 \\
84 \\
123 \\
162 \\
167\end{array}$ & $\begin{array}{l}3.951850-03 \\
2.149620-02 \\
2.268960-03 \\
1.410140-02 \\
1.194590-02 \\
5.570940-03\end{array}$ & \\
\hline 166 & $3.000000-01$ & $\begin{array}{r}19 \\
24 \\
51 \\
90 \\
129 \\
162 \\
168\end{array}$ & $\begin{array}{l}8.46044 D-03 \\
4.37157 D-03 \\
8.07166 \mathrm{D}-03 \\
4.52232 D-03 \\
8.68011 D-03 \\
1.15009 \mathrm{D}-03 \\
3.34406 \mathrm{D}-03\end{array}$ & $\begin{array}{l}19 \\
25 \\
58 \\
97 \\
136 \\
163 \\
168\end{array}$ & $\begin{array}{l}9.814240-04 \\
2.31719 D-03 \\
1.43542 D-02 \\
2.66673 D-03 \\
3.02859 D-02 \\
2.922470-03 \\
7.46694 D-03\end{array}$ & $\begin{array}{r}20 \\
25 \\
64 \\
103 \\
142 \\
164\end{array}$ & $\begin{array}{l}2.49971 D-03 \\
2.760560-03 \\
7.09714 D-03 \\
5.04849 D-03 \\
1.38385 D-02 \\
3.69832 D-03\end{array}$ & $\begin{array}{r}21 \\
32 \\
71 \\
110 \\
149 \\
165\end{array}$ & $\begin{array}{l}3.06038 D-03 \\
1.82617 D-02 \\
2.04797 D-03 \\
3.07316 D-03 \\
3.08413 D-02 \\
4.52641 D-03\end{array}$ & $\begin{array}{r}22 \\
38 \\
77 \\
116 \\
155 \\
166\end{array}$ & $\begin{array}{l}3.54883 D-03 \\
6.15902 D-03 \\
4.02688 D-03 \\
5.62992 D-03 \\
1.93438 D-02 \\
5.44414 D-03\end{array}$ & $\begin{array}{r}23 \\
45 \\
84 \\
123 \\
162 \\
167\end{array}$ & $\begin{array}{l}3.984160-03 \\
2.16670 \mathrm{D}-02 \\
2.32936 \mathrm{D}-03 \\
1.45565 \mathrm{D}-02 \\
1.06211 \mathrm{D}-02 \\
6.340490-03\end{array}$ & \\
\hline 167 & $3.000000-01$ & $\begin{array}{r}19 \\
24 \\
51 \\
90 \\
129 \\
162 \\
168\end{array}$ & $\begin{array}{l}8.37503 D-03 \\
4.34369 D-03 \\
7.69702 D-03 \\
4.16966 D-03 \\
7.58301 D-03 \\
1.11299 D-03 \\
4.95112 D-03\end{array}$ & $\begin{array}{r}19 \\
25 \\
58 \\
97 \\
136 \\
163 \\
168\end{array}$ & $\begin{array}{l}9.74765 \mathrm{D}-04 \\
2.30685 \mathrm{D}-03 \\
1.40754 \mathrm{D}-02 \\
2.62261 \mathrm{D}-03 \\
2.87414 \mathrm{D}-02 \\
2.83136 \mathrm{D}-03 \\
1.48404 \mathrm{D}-02\end{array}$ & $\begin{array}{r}20 \\
25 \\
64 \\
103 \\
142 \\
164\end{array}$ & $\begin{array}{l}2.47621 D-03 \\
2.697770-03 \\
6.67622 D-03 \\
4.59635 D-03 \\
1.18493 D-02 \\
3.63046 D-03\end{array}$ & $\begin{array}{r}21 \\
32 \\
71 \\
110 \\
149 \\
165\end{array}$ & $\begin{array}{l}3.02961 D-03 \\
1.79987 D-02 \\
2.00990 D-03 \\
3.020780-03 \\
2.82670 D-02 \\
4.55804 D-03\end{array}$ & $\begin{array}{r}22 \\
38 \\
77 \\
116 \\
155 \\
166\end{array}$ & $\begin{array}{l}3.514890-03 \\
5.958190-03 \\
3.748260-03 \\
5.040870-03 \\
2.062990-02 \\
5.76408 D-03\end{array}$ & $\begin{array}{r}23 \\
45 \\
84 \\
123 \\
162 \\
167\end{array}$ & $\begin{array}{l}3.950950-03 \\
2.12664 D-02 \\
2.28858 D-03 \\
1.421230-02 \\
1.05826 D-02 \\
7.60746 D-03\end{array}$ & \\
\hline 168 & $3.00000 D-01$ & $\begin{array}{r}19 \\
24 \\
51 \\
90 \\
129 \\
162 \\
168\end{array}$ & $\begin{array}{l}8.22042 D-03 \\
4.29150 D-03 \\
7.30121 D-03 \\
3.82011 D-03 \\
6.47216 D-03 \\
1.00835 D-03 \\
8.02297 D-03\end{array}$ & $\begin{array}{r}19 \\
25 \\
58 \\
97 \\
136 \\
163 \\
168\end{array}$ & $\begin{array}{l}9.59942 D-04 \\
2.28369 D-03 \\
1.35496 D-02 \\
2.49792 D-03 \\
2.70878 D-02 \\
2.54832 D-03 \\
3.00443 D-02\end{array}$ & $\begin{array}{r}20 \\
25 \\
64 \\
103 \\
142 \\
164\end{array}$ & $\begin{array}{l}2.435420-03 \\
2.62315 D-03 \\
6.24385 D-03 \\
4.15451 D-03 \\
9.214390-03 \\
3.27993 D-03\end{array}$ & $\begin{array}{r}21 \\
32 \\
71 \\
110 \\
149 \\
165\end{array}$ & $\begin{array}{l}2.979870-03 \\
1.75740 D-02 \\
1.92660 D-03 \\
2.866990-03 \\
2.71868 D-02 \\
4.20638 D-03\end{array}$ & $\begin{array}{r}22 \\
38 \\
77 \\
116 \\
155 \\
166\end{array}$ & $\begin{array}{l}3.46018 D-03 \\
5.73495 D-03 \\
3.46766 D-03 \\
4.46714 D-03 \\
1.40250 D-02 \\
5.69202 D-03\end{array}$ & $\begin{array}{r}23 \\
45 \\
84 \\
123 \\
162 \\
167\end{array}$ & $\begin{array}{l}3.895190-03 \\
2.060650-02 \\
2.187020-03 \\
1.343230-02 \\
1.096170-02 \\
9.270180-03\end{array}$ & \\
\hline 168 & $2.10000 \mathrm{D}-01$ & $\begin{array}{r}19 \\
24 \\
51 \\
90 \\
129 \\
162 \\
168\end{array}$ & $\begin{array}{l}4.25056 D-03 \\
2.05883 D-03 \\
4.18094 D-03 \\
2.39113 D-03 \\
4.27980 D-03 \\
8.57380 D-04 \\
1.47092 D-02\end{array}$ & $\begin{array}{r}19 \\
25 \\
58 \\
97 \\
136 \\
163 \\
168\end{array}$ & $\begin{array}{l}4.830970-04 \\
1.07957 D-03 \\
7.90147 D-03 \\
1.578470-03 \\
2.12273 D-02 \\
2.11620 D-03 \\
6.61985 D-03\end{array}$ & $\begin{array}{r}20 \\
25 \\
64 \\
103 \\
142 \\
164\end{array}$ & $\begin{array}{l}1.22435 D-03 \\
1.35676 D-03 \\
3.74173 D-03 \\
2.64700 D-03 \\
6.14073 D-03 \\
2.79701 D-03\end{array}$ & $\begin{array}{r}21 \\
32 \\
71 \\
110 \\
149 \\
165\end{array}$ & $\begin{array}{l}1.48791 D-03 \\
9.35631 D-03 \\
1.15600 D-03 \\
1.88141 D-03 \\
2.58570 D-02 \\
3.89391 D-03\end{array}$ & $\begin{array}{r}22 \\
38 \\
77 \\
116 \\
155 \\
166\end{array}$ & $\begin{array}{l}1.71022 D-03 \\
3.10489 D-03 \\
2.13330 D-03 \\
2.89765 D-03 \\
7.93204 D-03 \\
6.22245 D-03\end{array}$ & $\begin{array}{r}23 \\
45 \\
84 \\
123 \\
162 \\
167\end{array}$ & $\begin{array}{l}1.90004 D-03 \\
1.152070-02 \\
1.342690-03 \\
9.373210-03 \\
1.29852 D-02 \\
1.360370-02\end{array}$ & \\
\hline
\end{tabular}


Table F16.A.2 (continued)

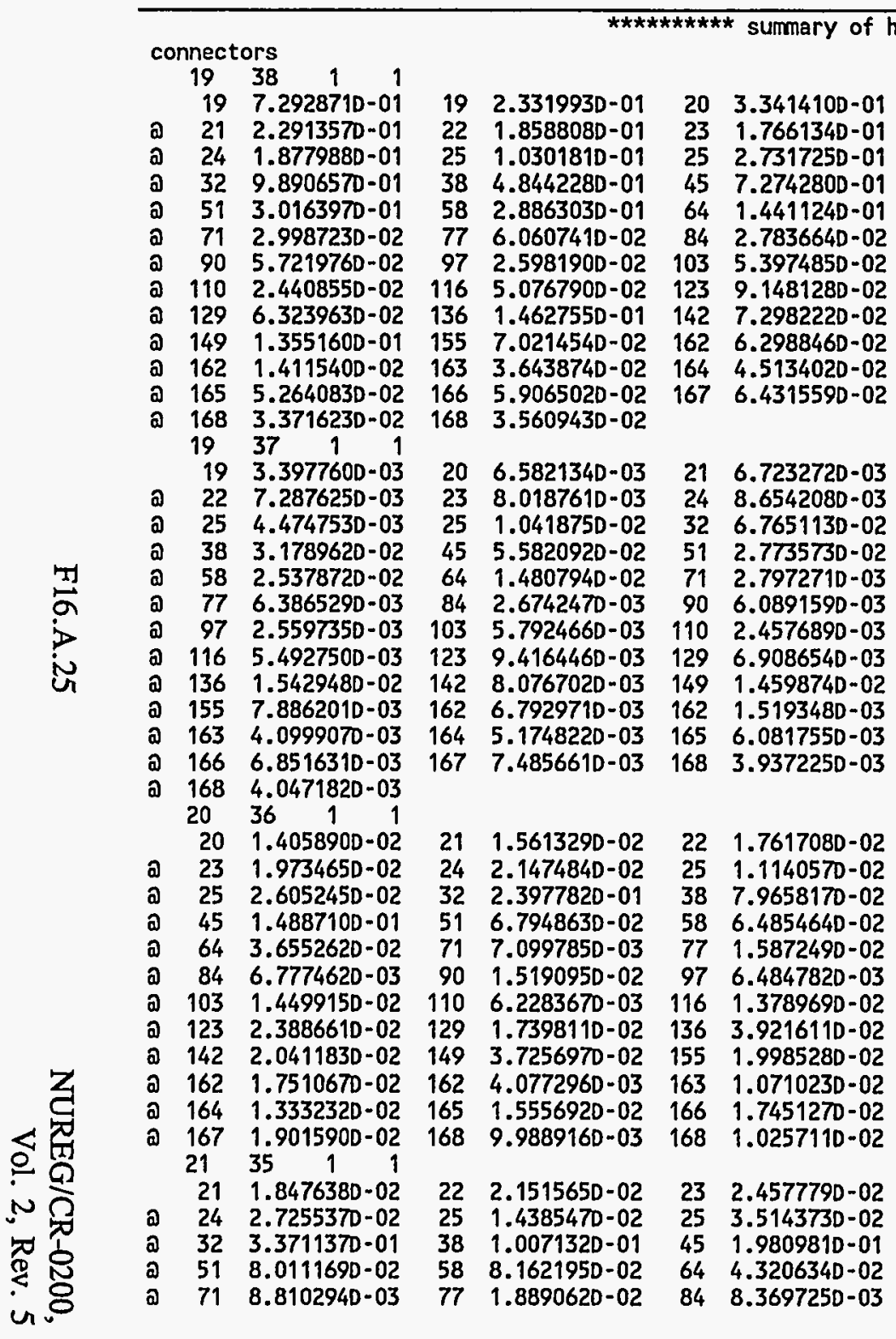


a $90 \begin{array}{llllll}908150310-02 & 97 & 7.9838220-03 & 103 & 1.7381920-02\end{array}$

$\begin{array}{lllllll}\text { a } & 110 & 7.6541640-03 & 116 & 1.6578390-02 & 123 & 2.9324240-02\end{array}$

$\begin{array}{lllllll}\text { a } 129 & 2.0975910-02 & 136 & 4.8135350-02 & 142 & 2.4689730-02\end{array}$

a $149 \quad 4.5798450-02 \quad 155 \quad 2.4249180-02 \quad 162 \quad 2.1635450-02$

$\begin{array}{lllllll}\text { a } & 162 & 5.1235080-03 & 163 & 1.3271460-02 & 164 & 1.6405100-02\end{array}$

$\begin{array}{llllll}165 & 1.9078470-02 & 166 & 2.136546 \mathrm{D}-02 & 167 & 2.326577 \mathrm{D}-02\end{array}$

a $168 \quad 1.2221990-02 \quad 168 \quad 1.2465060-02$

$22 \quad 34 \quad 1 \quad 1$

$\begin{array}{lll}22 & 2.5603350-02 \\ \text { a } 25 & 1.8789270-02\end{array}$

a $25 \quad 1.8789270-02$

a $58 \quad 9.6941530-02$

a $77 \quad 2.1195050-02$

a $979.3033000-03$

a $116 \quad 1.8812880-02$

$23 \quad 2.9926650-02$

$\begin{array}{lll}24 & 3.433918 \mathrm{D}-02\end{array}$

$25 \quad 4.975500 \mathrm{D}-02 \quad 32 \quad 3.857261 \mathrm{D}-01$

$\begin{array}{llll}45 & 2.4389200-01 & 51 & 8.8336140-02\end{array}$

$64 \quad 4.8061800-02 \quad 71 \quad 1.0339190-02$

$84 \quad 9.7799710-03 \quad 90 \quad 2.0456570-02$

$\begin{array}{lllll}-02 & 123 & 3.408155 \mathrm{D}-02 & 129 & 2.3875170-02\end{array}$

$\begin{array}{llllll}136 & 5.5934240-02 & 142 & 2.8200670-02 & 149 & 5.3269710-02\end{array}$

$\begin{array}{lllllll}155 & 2.7799440-02 & 162 & 2.5236930-02 & 162 & 6.0145190-03\end{array}$

$\begin{array}{llllllll}163 & 1.5465640-02 & 164 & 1.9052710-02 & 165 & 2.212918 D-02\end{array}$

$\begin{array}{llllll}166 & 2.4775540-02 & 167 & 2.6992440-02 & 168 & 1.4192010-02\end{array}$

a $1681.4327530-02$

$23 \quad 33 \quad 1 \quad 1$

尔

$23 \quad 3.6256310-02$

ล $257.6567880-02$

a $45 \quad 2.8151480-01$

$24 \quad 4.4248540-02$

32 4.134954D-01

$38 \quad 1.3656370-01$

a $64 \quad 5.1244420-02$

$9.2148640-02$

a $841.0982030-02$

a $103 \quad 2.1417310-02$

อ $123 \quad 3.8203450-02$

$637630-02$

$77 \quad 2.2855670-02$

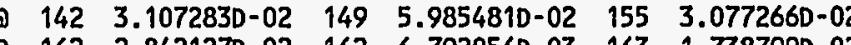

$\begin{array}{llllll}162 & 2.842127 \mathrm{D}-02 & 162 & 6.792056 \mathrm{D}-03 & 163 & 1.7387990-02\end{array}$

\begin{tabular}{lllllll} 
a & 164 & $2.1383820-02$ & 165 & $2.4830210-02$ & 166 & $2.781470 D-02$ \\
\hline & 167 & $3.0341100-02$ & 168 & $1.597620 D-02$ & 168 & $1.5917760-02$
\end{tabular} $\begin{array}{llll}24 & 32 & 1 & 1\end{array}$

$245.9884640-02$

$32.4353470-01$

a $324.3533470-01$

a $51 \quad 9.1166790-02$

a $71 \quad 1.2610140-02$

a $902.3304850-02$

a $1101.0845490-02$

a $129 \quad 2.7924880-02$

a $1496.5511670-02$

a $1627.465036 \mathrm{D}-03$

$25 \quad 3.8399500-02$

a $165 \quad 2.7211290-02$

$38 \quad 1.3199110-01 \quad 45 \quad 3.0644360-01$

$58 \quad 1.1917790-01 \quad 64 \quad 5.2723900-02$

$\begin{array}{llll}77 & 2.3854470-02 & 84 & 1.1906280-02\end{array}$

$97 \quad 1.132260 \mathrm{D}-02 \quad 103 \quad 2.2624780-02$

$\begin{array}{llll}116 & 2.1824170-02 & 123 & 4.1588180-02\end{array}$

$\begin{array}{llll}36 & 6.848260 \mathrm{D}-02 & 142 & 3.330484 \mathrm{D}-02\end{array}$

$\begin{array}{llll}55 & 3.3181260-02 & 162 & 3.1182280-02\end{array}$

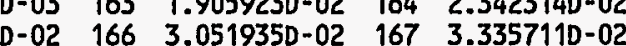

ه 168 1.7601680-02

$25 \quad 31-1$

$25 \quad 2.6499820-02$

a $38 \quad 5.3819910-02$

$\begin{array}{lll}\text { a } & 58 & 6.1625190-02 \\ 0 & 77 & 1.2095820-02\end{array}$

25 9.686361D-02 $32 \quad 2.2545520-01$

$514.3834650-02$

$\begin{array}{llll}64 & 2.6401510-02 & 71 & 6.547618 D-03 \\ 84 & 6.1980830-03 & 90 & 1.1885070-02\end{array}$ 
Table F16.A.2 (continued)

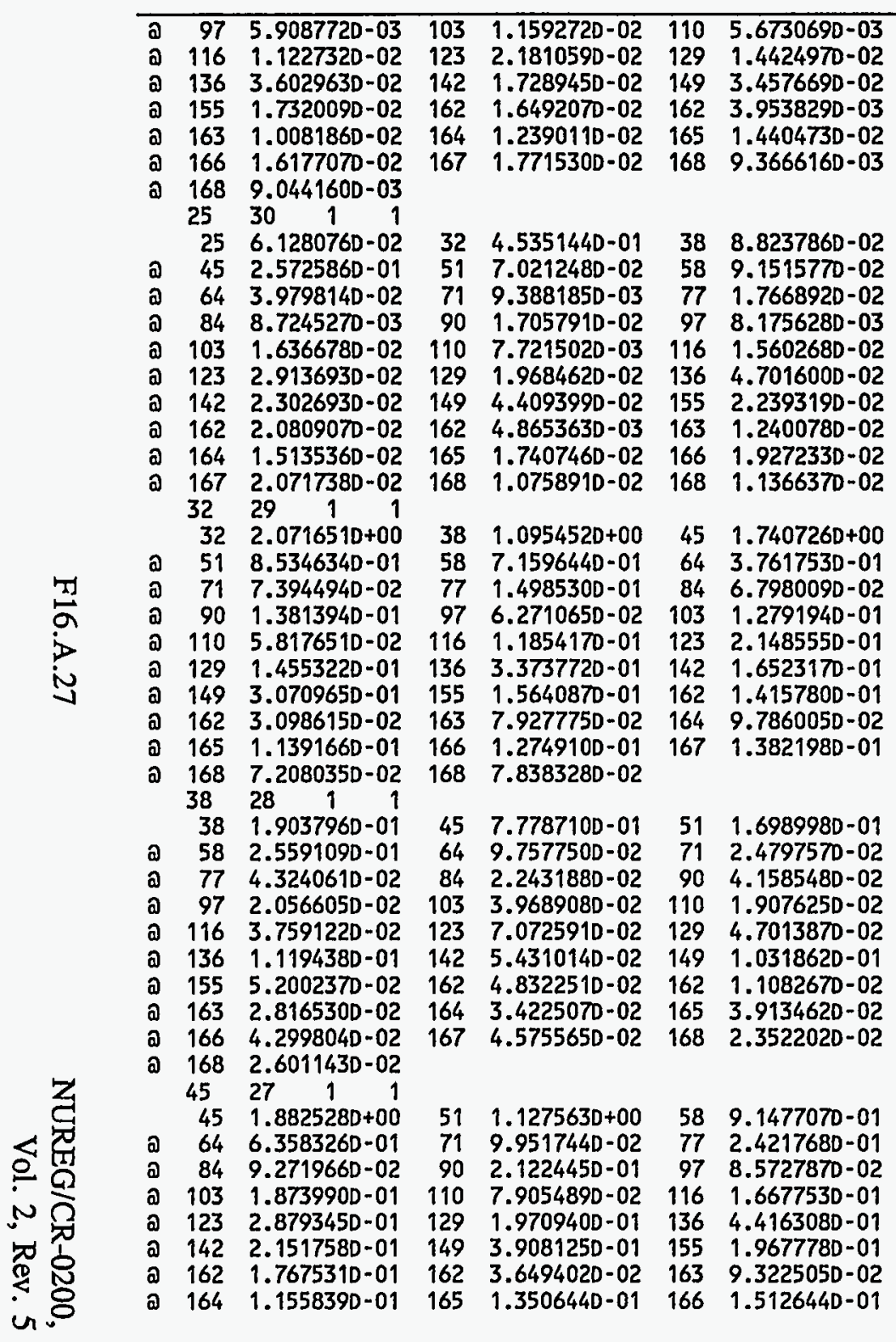




\begin{tabular}{|c|c|c|c|c|c|c|}
\hline \multirow[t]{2}{*}{ a } & $\begin{array}{l}16 \\
51\end{array}$ & $71.6331390-01$ & 168 & $8.4518080-02$ & 168 & $9.6515430-02$ \\
\hline & & & 58 & 01 & 24 & 1.352 \\
\hline a & & & & & & \\
\hline a & 90 & 5.9 & 97 & & 103 & \\
\hline & 110 & & 116 & & 123 & \\
\hline & 12 & & 13 & & 142 & \\
\hline a & 149 & $3979 D-01$ & 155 & 12 & 162 & \\
\hline & 162 & & 163 & & 164 & \\
\hline a & 165 & 5. & 166 & & 167 & \\
\hline & 168 & 02 & & & & \\
\hline & & 01 & 64 & 11 & 71 & $6.404962 D-02$ \\
\hline a & 77 & $1.9985770-01$ & 84 & & 90 & \\
\hline & & $67724 D-02$ & 103 & & 110 & \\
\hline & 116 & & & & 129 & \\
\hline & & & & & & \\
\hline a & 15 & & 16 & & & \\
\hline & 163 & & 164 & & 165 & \\
\hline & 166 & $1.002112 D-01$ & 167 & & 168 & \\
\hline & 168 & $\begin{array}{l}6.6195220-02 \\
24\end{array}$ & & & & \\
\hline & & .01 & 71 & & & \\
\hline & & & & & & \\
\hline & & & & & & \\
\hline & 12 & & & & & \\
\hline al & 14 & & & & 55 & \\
\hline A & 16 & & 6 & & 163 & \\
\hline & 16 & & 165 & & 166 & \\
\hline & 16 & & 168 & & 168 & \\
\hline & & & & & & \\
\hline & & & & & & \\
\hline ค & 110 & & & & & \\
\hline & 129 & & 13 & & & \\
\hline & 14 & & & & & \\
\hline & 16 & & & & 164 & \\
\hline & & & 1 & & 167 & \\
\hline & & & & & & \\
\hline & & & & & & \\
\hline \multirow{6}{*}{ a } & & & & & 1 & \\
\hline & 110 & & & & & \\
\hline & & & 14 & & & \\
\hline & 155 & 3.7 & 16 & & & \\
\hline & 16 & 1.9 & 16 & & 165 & \\
\hline & & & & & & \\
\hline
\end{tabular}


Table F16.A.2 (continued)

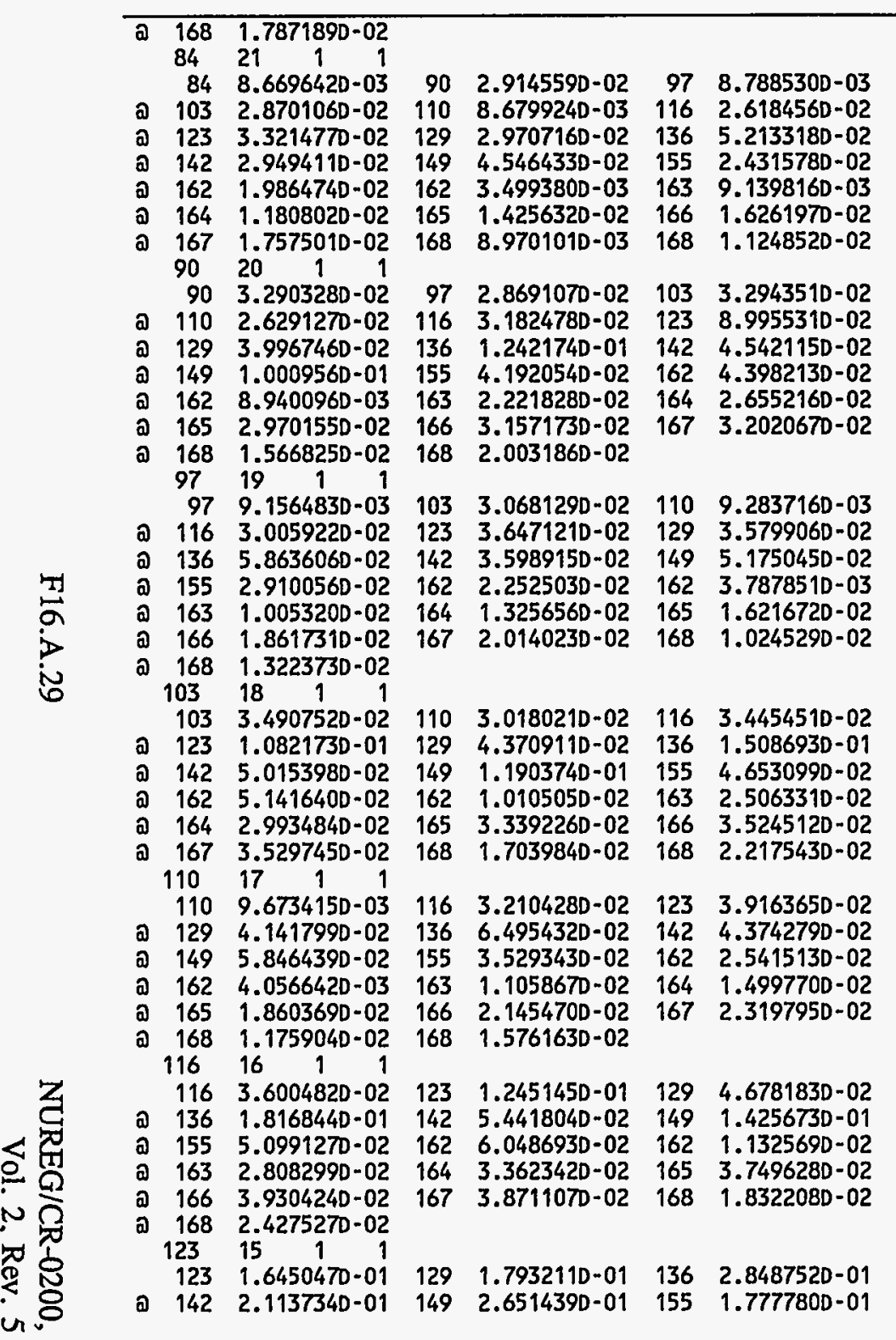




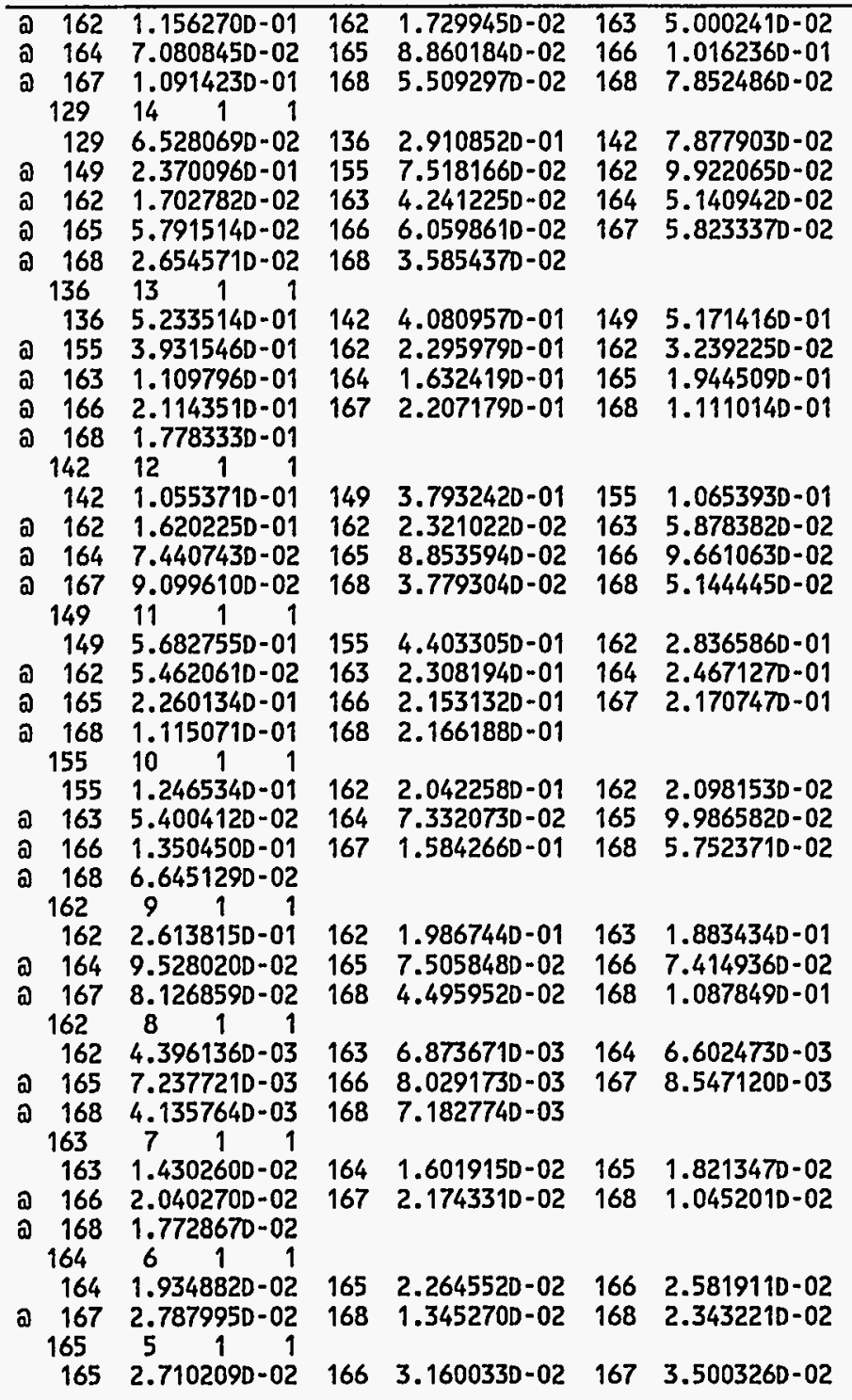


Table F16.A.2 (continued)

\begin{tabular}{cccccccc}
\hline a & 168 & $1.725256 \mathrm{D}-02$ & 168 & $3.2621520-02$ & & \\
166 & 4 & 1 & 1 & & & & \\
166 & $3.800727 D-02$ & 167 & $4.4264950-02$ & 168 & $2.334595 \mathrm{D}-02$ \\
a 168 & $5.212906 \mathrm{D}-02$ & & & & \\
167 & 3 & 1 & 1 & & & & \\
167 & $5.842108 \mathrm{D}-02$ & 168 & $3.802185 \mathrm{D}-02$ & 168 & $1.139661 \mathrm{D}-01$ \\
168 & 2 & 1 & 1 & & & & \\
168 & $3.290641 \mathrm{D}-02$ & 168 & $1.232275 \mathrm{D}-01$ & & \\
168 & 1 & 1 & 1 & & & & \\
168 & $5.545834 \mathrm{D}-02$ & & & &
\end{tabular}

$* * * * *$ job description $* * * * *$ ocular sample problem

***** the calculations for this case have been completed.

***** number of connectors generated for this case was

$\star * * * *$ number of warnings issued for this case was

$\begin{array}{rr}-. & 1700 \\ -. & 0\end{array}$

***** number of errors issued for this case was 
NUREG/CR-0200

Revision 5

Volume 2, Section F17

ORNL/NUREG/CSD-2/V2/R5

Computational Physics and Engineering Division

KENO-VI: A GENERAL QUADRATIC VERSION OF THE KENO PROGRAM

\author{
D. F. Hollenbach \\ L. M. Petrie \\ N. F. Landers*
}

Date Published: March 1997

\author{
Prepared for the \\ U.S. Department of Energy \\ Office of Environmental, Safety, and Health \\ Budget Activity No. HP 0100000 \\ and \\ U.S. Nuclear Regulatory Commission \\ Office of Nuclear Material Safety and Safeguards \\ Washington, DC 20555 \\ Under Interagency Agreement DOE 1886-C000-9B \\ NRC FIN No. B-0009
}

\author{
Prepared by the \\ OAK RIDGE NATIONAL LABORATORY \\ managed by \\ LOCKHEED MARTIN ENERGY RESEARCH CORP. \\ for the \\ U.S. DEPARTMENT OF ENERGY \\ under contract DE-AC05-96OR22464
}

*Formerly with Oak Ridge National Laboratory. 


\begin{abstract}
KENO-VI is an extension of the KENO Monte Carlo criticality program. It was developed for use in the SCALE system. KENO-VI contains all the features currently in KENO-V.a plus a more flexible geometry package. The geometry package in KENO-VI is capable of modeling any volume that can be constructed using quadratic equations. In addition, such features as geometry intersections, body rotation, hexagonal arrays, and array boundaries have been included to make the code more fiexible.

A set of predefined geometry volumes have been incorporated into KENO-VI. Additional volumes can be constructed using the QUADRATIC geometry card that allows the user to specify any volume that can be modeled using quadratic equations. The ability to intersect the volumes makes it possible to exactly model such things as pipe intersections, which was previously impossible in KENO-V.a The ability to rotate bodies means volumes no longer must be positioned parallel to a major axis. Hexagonal arrays were added to simplify the construction of arrays. The use of array boundaries makes it possible to fill a noncuboidal volume with an array, specifying the boundary where a particle leaves and enters the array.

The primary purpose of KENO-VI is to determine k-effective. Other calculated quantities include lifetime, generation time, energy-dependent leakages, energy- and region-dependent absorptions, fissions, fluxed, and fission densities.

KENO-VI retains the KENO-V.a features such as flexible data input, the capability of supergrouping energy-dependent data, $a \mathrm{P}_{\mathrm{n}}$ scattering model in the cross sections, a procedure for matching lethargy boundaries between albedos and cross sections to extend the usefulness of the albedo feature, and restart capabilities.

This advanced user-oriented program features a more complex geometry package, simplified data input, and efficient use of computer storage. These features allow the user to readily solve large geometrically complex problems whose computer storage requirements and geometric complexity preclude solution by previous versions of KENO.
\end{abstract}


$\cdots$ 


\section{CONTENTS}

$\underline{\text { Page }}$

ABSTRACT F17.iii

LIST OF FIGURES F17.ix

LIST OF TABLES F17.xiv

ACKNOWLEDGMENTS F17.xv

F17.1 INTRODUCTION F17.1.1

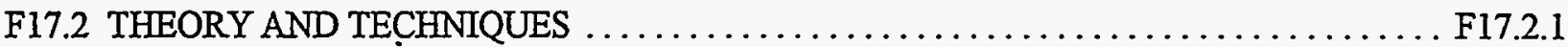

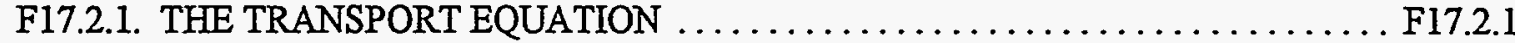

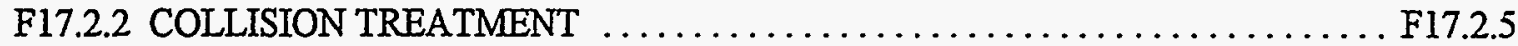

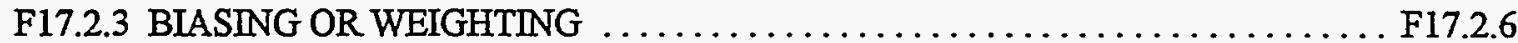

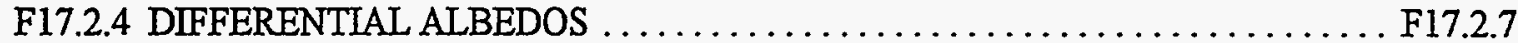

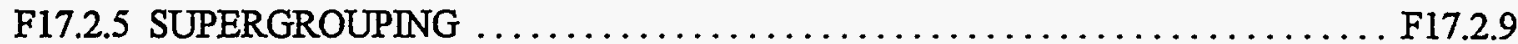

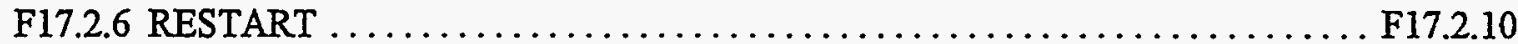

F17.2.7 GEOMETRY ..................................... F17.2.10

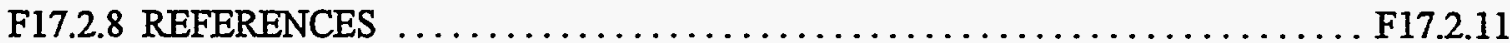

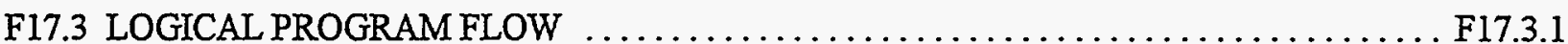

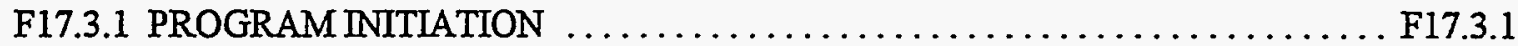

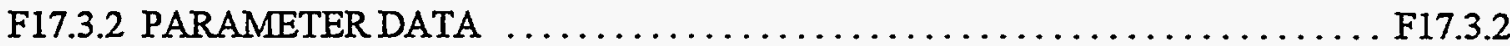

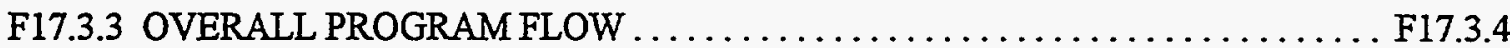

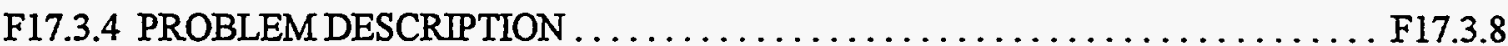

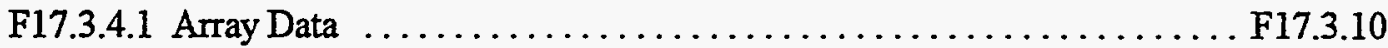

F17.3.4.2 Geometry Data ...............................F17.3.11

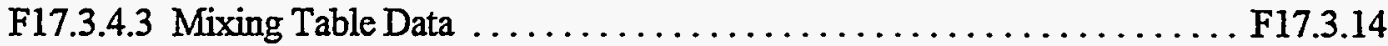

F17.3.4.4 Plot Data . . . . . . . . . . . . . . . . . . . . . . . . . . F 17.3 .15

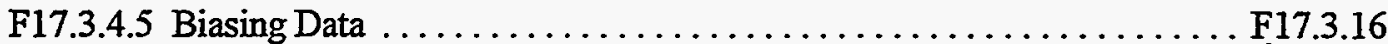

F17.3.4.6 Restart Data .................................... F17.3.17

F17.3.4.7 Generate Remaining Data .......................... F17.3.18

F17.3.5 CREATE A MIXED CROSS-SECTION DATA FILE $\ldots \ldots \ldots \ldots \ldots \ldots \ldots \ldots$ F17.3.20

F17.3.5.1 Cross-Section Mixing . ........................... F17.3.21

F17.3.5.2 Generate Angles and Probabilities ..................... F17.3.23

F17.3.6 WRITE CROSS SECTIONS ON DIRECT-ACCESS FILE . . . . . . . . . . . . . F F17.3.24

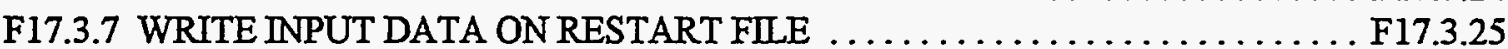

F17.3.8 GENERATE ALBEDO CROSS-SECTION

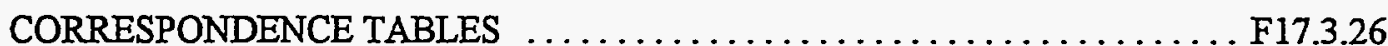

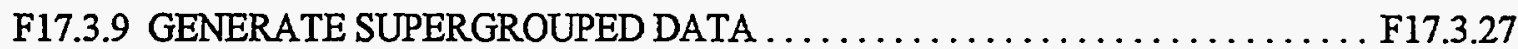

F17.3.9.1 Print Macroscopic Cross Sections ..................... F17.3.28

F17.3.9.2 Write Supergroup Data File ........................ F17.3.29

F17.v

NUREG/CR-0200

Vol. 2, Rev. 5 


\section{CONTENTS (continued)}

Page

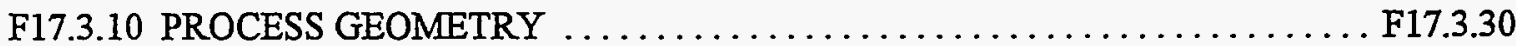

F17.3.10.1 Load Data From the Direct-Access File . . . . . . . . . . . . . . . . F17.3.32

F17.3.10.2 Calculate Volumes . . . . . . . . . . . . . . . . . . F17.3.33

F17.3.11 LOAD BIASING OR WEIGHTING DATA $\ldots \ldots \ldots \ldots \ldots \ldots \ldots \ldots \ldots$ F17.3.34

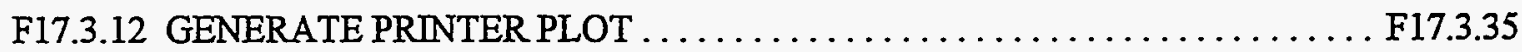

F17.3.13 PROCESS HISTORIES BY SUPERGROUP $\ldots \ldots \ldots \ldots \ldots \ldots \ldots \ldots \ldots$ F17.3.37

F17.3.13.1 Load Calculated Restart Data . . . . . . . . . . . . . . F17.3.40

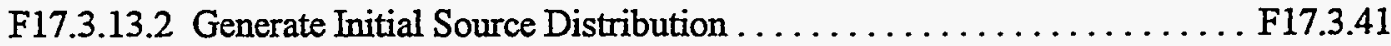

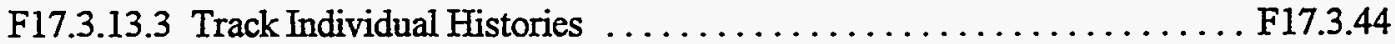

F17.3.13.4 Provide the Next-Generation Source . . . . . . . . . . . . F17.3.52

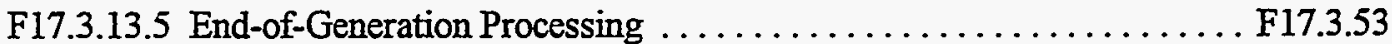

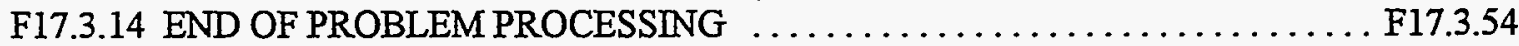

F17.3.15 PRINT FLUXES . . . . . . . . . . . . . . . . . . . . . . . . . F17.3.55

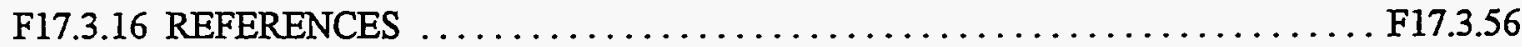

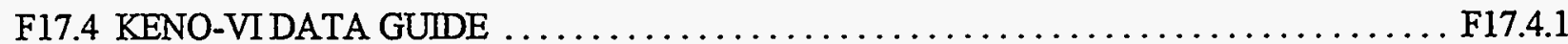

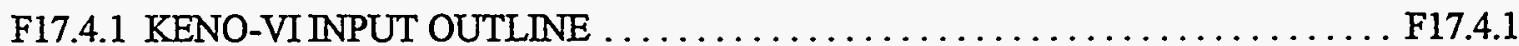

F17.4.2 PROCEDURE FOR DATA INPUT $\ldots \ldots \ldots \ldots \ldots \ldots \ldots \ldots \ldots \ldots \ldots \ldots \ldots \ldots \ldots \ldots . \ldots \ldots \ldots$

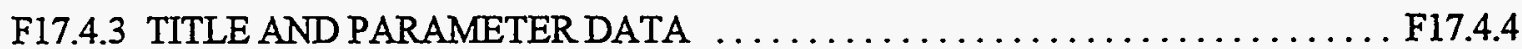

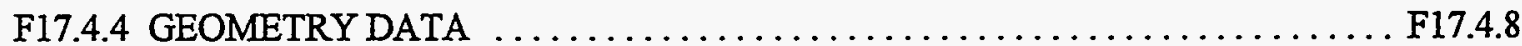

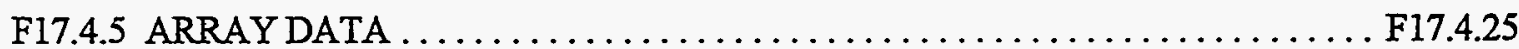

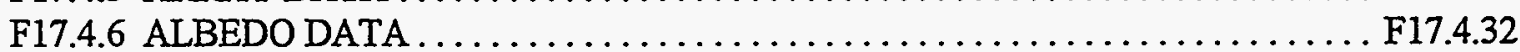

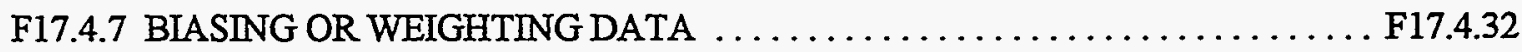

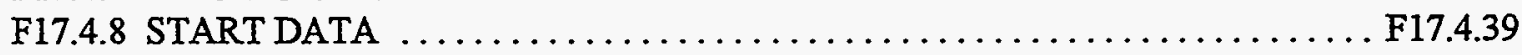

F17.4.9 EXTRA 1-D XSECS IDs DATA $\ldots \ldots \ldots \ldots \ldots \ldots \ldots \ldots \ldots \ldots \ldots \ldots \ldots \ldots \ldots \ldots \ldots . \ldots \ldots .42$

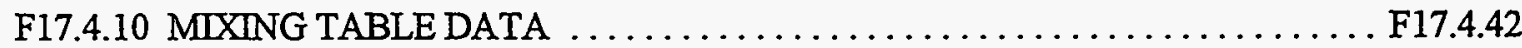

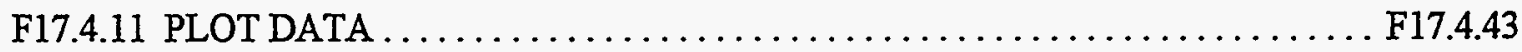

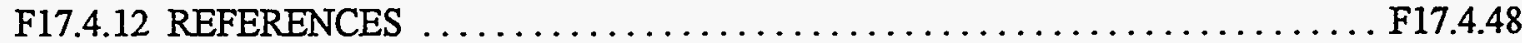

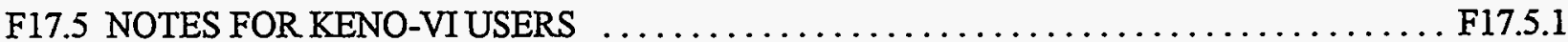

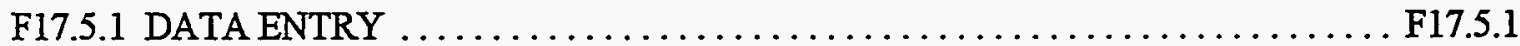

F17.5.1.1 Multiple and Scattered Entries in the Mixing Table ............ F17.5.1

F17.5.1.2 Multiple Entries in Geometry Data ................... F17.5.1

F17.5.2 DEFAULT LOGICAL UNIT NUMBERS FOR KENO-VI . . . . . . . . . . F F17.5.2

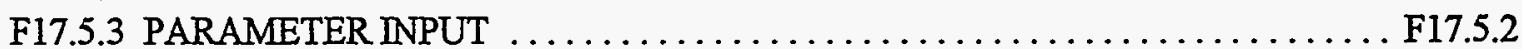

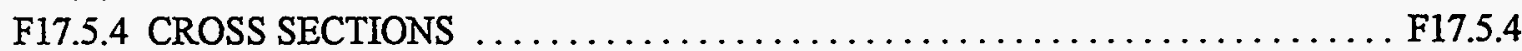

F17.5.4.1 Use an ICE Mixed Cross-Section

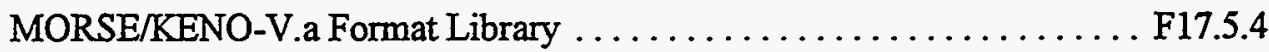

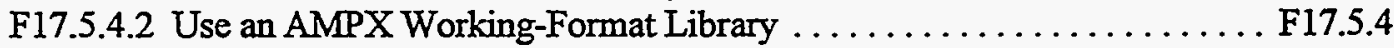

F17.5.4.3 Number of Scattering Angles ........................ F17.5.4

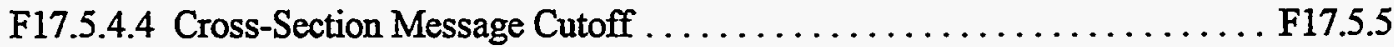

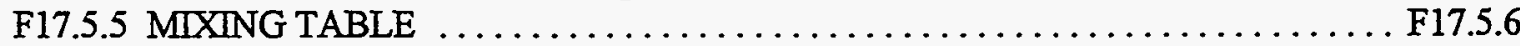

NUREG/CR-0200

Vol. 2, Rev. 5

F17.vi 


\section{CONTENTS (continued)}

Page

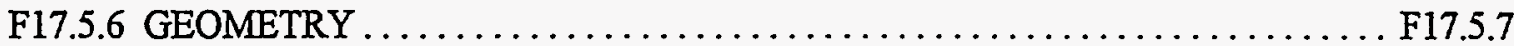

F17.5.6.1 Use of Holes in the Geometry .................... F17.5.30

F17.5.6.2 Nesting Holes . . . . . . . . . . . . . . . . . . . F17.5.32

F17.5.6.3 Multiple Arrays . . . . . . . . . . . . . . . . . . . . . F17.5.39

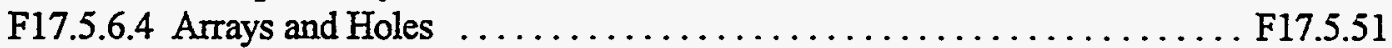

F17.5.6.5 Triangular Pitched Arrays (Sample Problem 20) . . . . . . . . . . F17.5.67

F17.5.7 ALTERNATIVE SAMPLE PROBLEM MOCKUPS . . . . . . . . . . . . . . F17.5.71

F17.5.7.1 Sample Problem 12, First Alternative ................ F17.5.71

F17.5.7.2 Sample Problem 12, Second Alternative ............... F17.5.72

F17.5.7.3 Sample Problem 13, Alternative ...................... F17.5.74

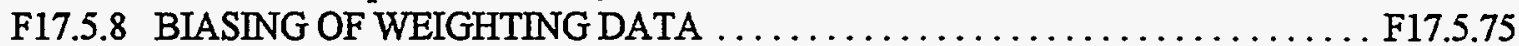

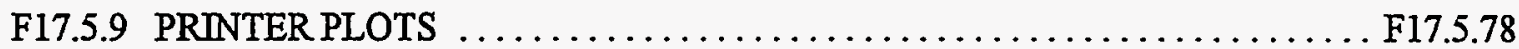

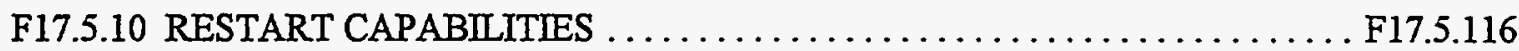

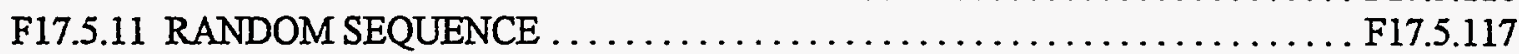

F17.5.12 MATRIXK-EFFECTIVE .......................... F17.5.130

F17.5.13 DEVIATIONS ................................. F17.5.131

F17.5.14 GENERATION TIME AND LIFETMME $\ldots \ldots \ldots \ldots \ldots \ldots \ldots \ldots \ldots \ldots$ F17.5.131

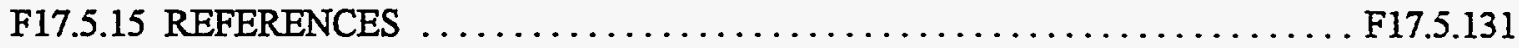

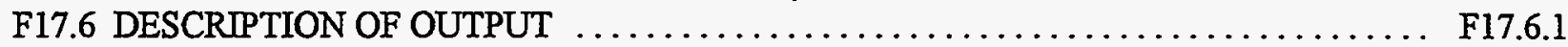

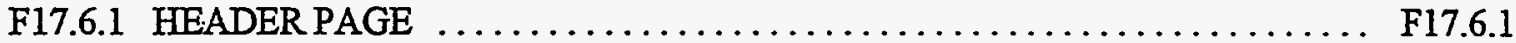

F17.6.2 PROGRAM VERIFICATION INFORMATION $\ldots \ldots \ldots \ldots \ldots \ldots \ldots \ldots \ldots$ F17.6.3

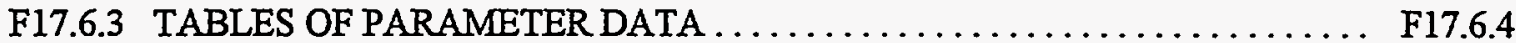

F17.6.4 UNPROCESSED GEOMETRY INPUT DATA $\ldots \ldots \ldots \ldots \ldots \ldots \ldots \ldots \ldots \ldots \ldots \ldots \ldots$

F17.6.5 TABLE OF DATA SETS USED IN THE PROBLEM $\ldots \ldots \ldots \ldots \ldots \ldots \ldots$ F17.6.6

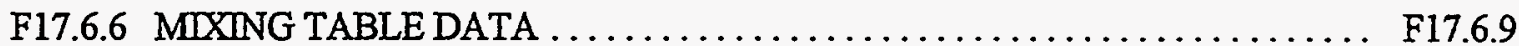

F17.6.7 ALBEDO CROSS-SECTION CORRESPONDENCE . . . . . . . . . . . . . . F F 17.6 .10

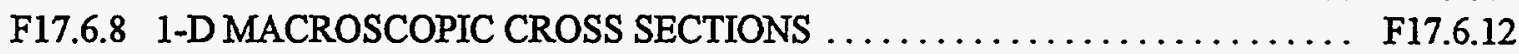

F17.6.9 EXTRA 1-D CROSS SECTIONS .......................... F17.6.12

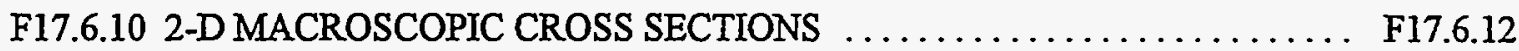

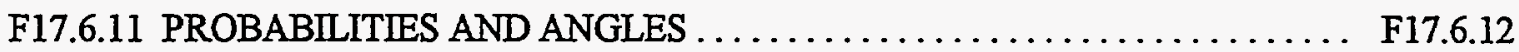

F17.6.12 TABLE OF ADDITIONAL INFORMATION $\ldots \ldots \ldots \ldots \ldots \ldots \ldots \ldots \ldots$ F17.6.15

F17.6.13 TABLE OF SPACE AND SUPERGROUP INFORMATION ........... F17.6.17

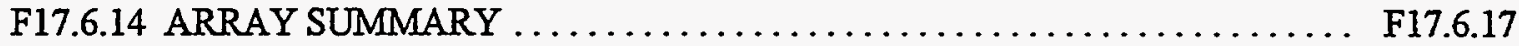

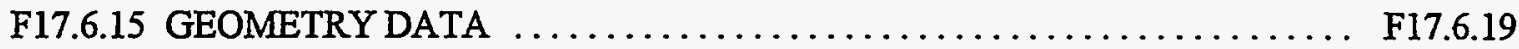

F17.6.16 UNIT ORIENTATION DESCRIPTION ...................... F17.6.19

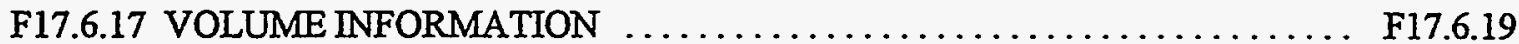

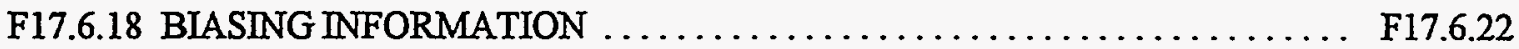

F17.6.19 GROUP-DEPENDENT WEIGHTS ....................... F17.6.22

F17.6.20 PICTURE OR PLOT REPRESENTATION ................... F17.6.23

F17.6.21 CONCLUDE PRETRACKING EDITS ...................... F17.6.25

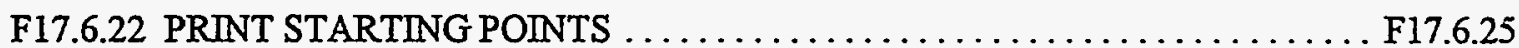




\section{CONTENTS (continued)}

$\underline{\text { Page }}$

F17.6.23 K-EFFECTIVES BY GENERATION

F17.6.27

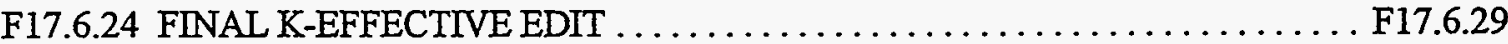

F17.6.25 PLOT OF AVERAGE K-EFFECTIVE BY GENERATION RUN . . . . . . . F F17.6.29

F17.6.26 PLOT OF AVERAGE K-EFFECTIVE BY GENERATION SKIPPED . . . . . . . F17.6.32

F17.6.27 FINAL EDIT OF FISSIONS, ABSORPTIONS,

AND LEAKAGE . . . . . . . . . . . . . . . . . . . . . . F17.6.32

F17.6.28 MATRIX K-EFFECTIVE BY UNIT LOCATION . . . . . . . . . . . . . . . F17.6.32

F17.6.29 FISSION PRODUCTION BY POSITION INDEX MATR $I$ X . . . . . . . F 17.6 .35

F17.6.30 SOURCE VECTOR BY POSITION INDEX . . . . . . . . . . . . . . . F F17.6.36

F17.6.31 COFACTOR K-EFFECTIVE BY POSITION INDEX . . . . . . . . . . . . . F 17.6 .36

F17.6.32 MATRIX K-EFFECTIVE BY UNIT NUMBER . . . . . . . . . . . . . . . F 17.6 .37

F17.6.33 FISSION PRODUCTION BY UNIT NUMBER MATRIX . . . . . . . . . . F17.6.38

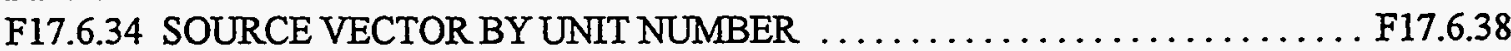

F17.6.35 COFACTOR K-EFFECTIVE BY UNIT NUMBER . . . . . . . . . . . . . . F 17.6 .38

F17.6.36 MATRIX K-EFFECTIVE BY HOLE NUMBER . . . . . . . . . . . . . . . . . F F17.6.39

F17.6.37 FISSION PRODUCTION BY HOLE NUMBER MATRIX . . . . . . . . . . F F 17.6 .40

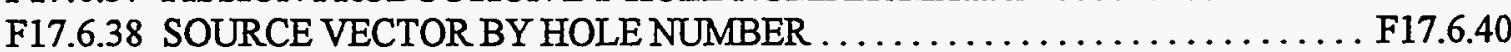

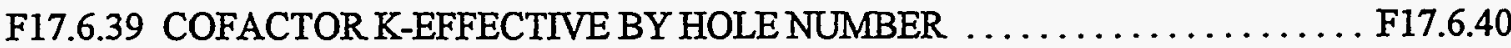

F17.6.40 MATRIXK-EFFECTIVE BY ARRAY NUMBER . . . . . . . . . . . F17.6.41

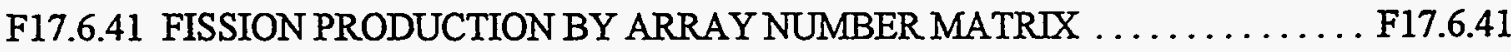

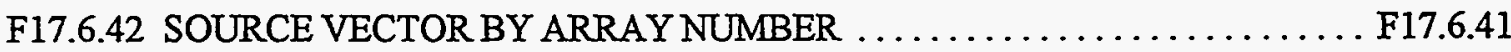

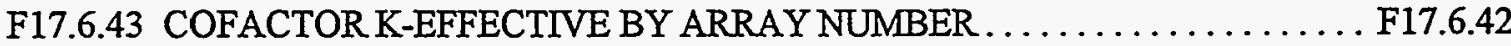

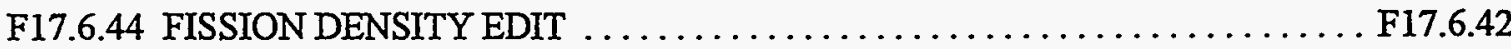

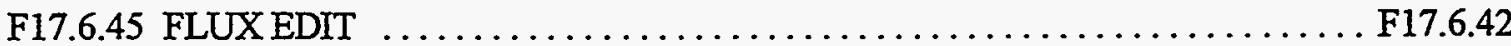

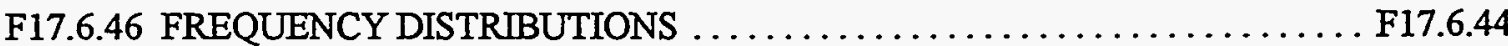

F17.7 WARNING MESSAGES AND ERROR MESSAGES $\ldots \ldots \ldots \ldots \ldots \ldots \ldots \ldots \ldots \ldots \ldots$ F17.7.1

F17.7.1 MESSAGES ........................................ F17.7.1

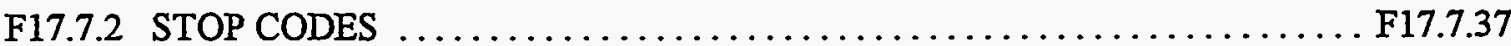

F17.7.3 MESSAGES ASSOCIATED WITH STOP 20 IN KENO VI $\ldots \ldots \ldots \ldots \ldots$ F17.7.39

F17.A ALPHABETICAL INDEX OF SUBROUTINES $\ldots \ldots \ldots \ldots \ldots \ldots \ldots \ldots \ldots \ldots \ldots$ F17.A.1

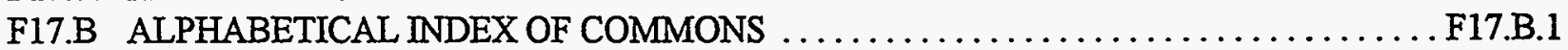

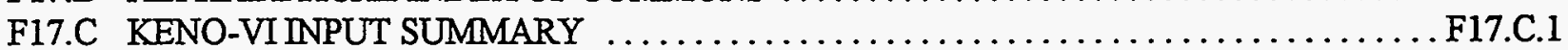

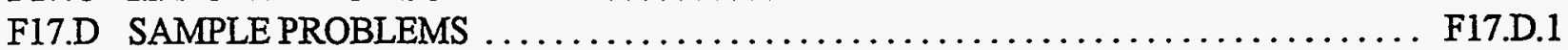

F17.D.1 KENO-VI SAMPLE PROBLEM DATA .................... F17.D.1

F17.D.2 SAMPLE PROBLEM WORKING-FORMAT LIBRARY $\ldots \ldots \ldots \ldots \ldots \ldots$ F17.D.40

F17.D.2.1 CSASN Data ............................... F17.D.40

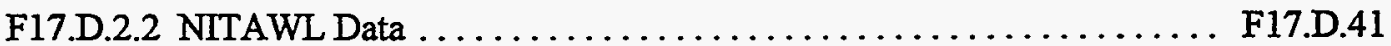

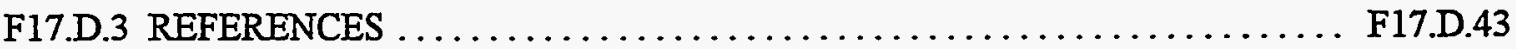

F17.E SELECTED OUTPUT FROM KENO V.a SAMPLE PROBLEMS $\ldots \ldots \ldots \ldots \ldots \ldots \ldots$ F17.E.1

F17.F LIST OF KENO V.a VALIDATION REPORTS $\ldots \ldots \ldots \ldots \ldots \ldots \ldots \ldots \ldots \ldots \ldots$ F17.F.1

NUREG/CR-0200

Vol. 2, Rev. 5

F17.viii 


\section{LIST OF FIGURES}

Figure

Page

F17.2.1 Analytic estimate of the relationship between WTLOW and the variance, $\sigma_{k}^{2}$,

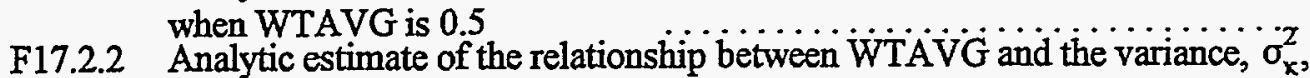

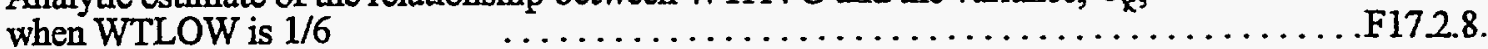

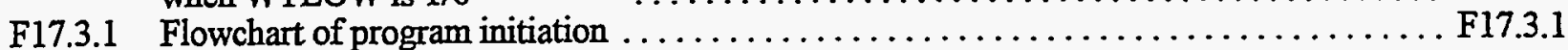

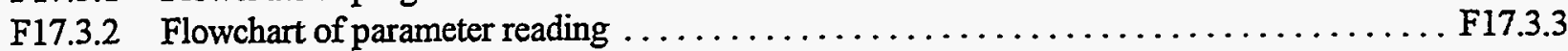

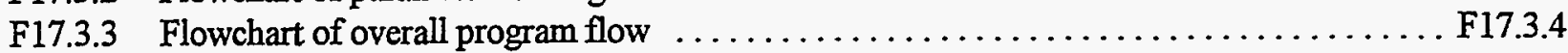

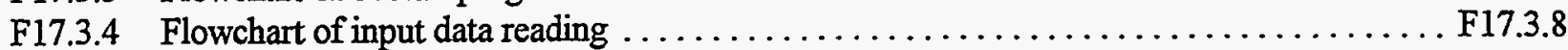

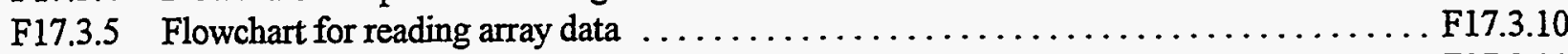

F17.3.6 Flowchart for reading geometry and media keyword data $\ldots \ldots \ldots \ldots \ldots \ldots \ldots \ldots$ F17.3.11

F17.3.7 Flowchart for reading geometry boundary and media data $\ldots \ldots \ldots \ldots \ldots \ldots \ldots \ldots 17.3 .13$

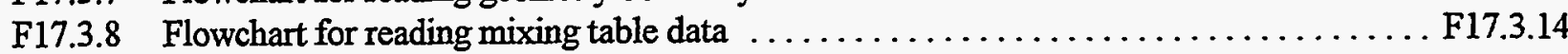

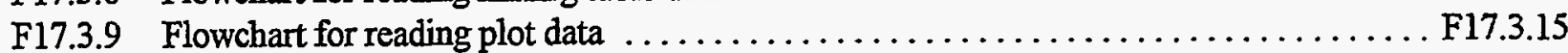

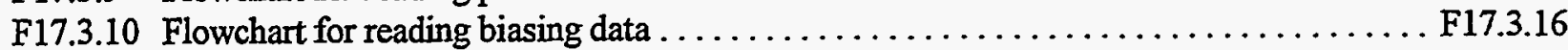

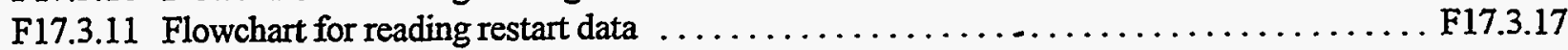

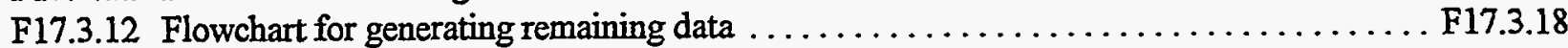

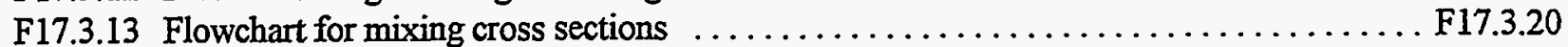

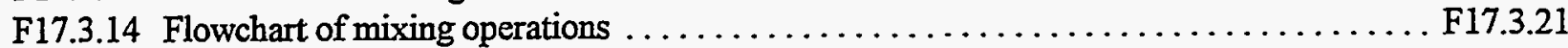

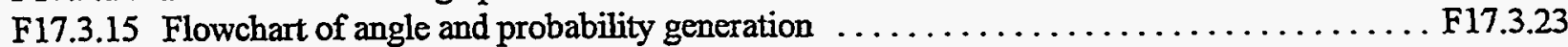

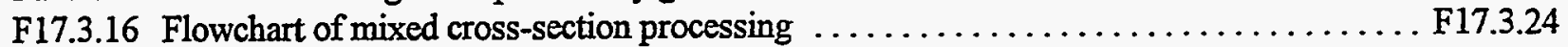

F17.3.17 Flowchart for writing data on the restart data file $\ldots \ldots \ldots \ldots \ldots \ldots \ldots \ldots \ldots \ldots \ldots \ldots \ldots \ldots \ldots . .25$

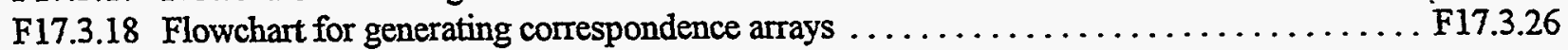

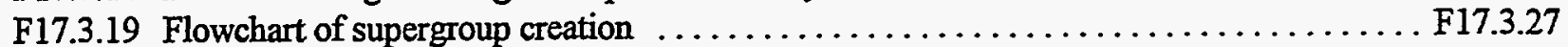

F17.3.20 Flowchart for printing macroscopic cross sections $\ldots \ldots \ldots \ldots \ldots \ldots \ldots \ldots \ldots \ldots \ldots \ldots \ldots \ldots . .28$

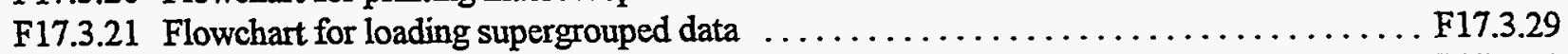

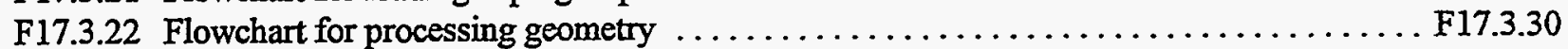

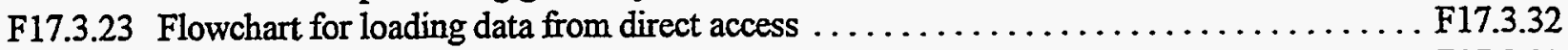

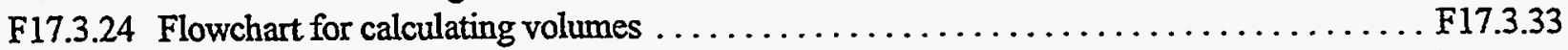

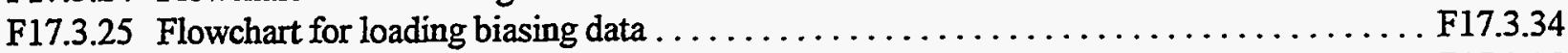

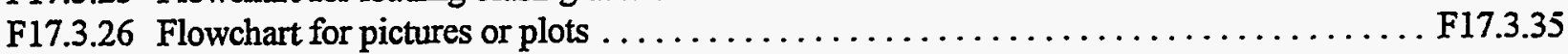

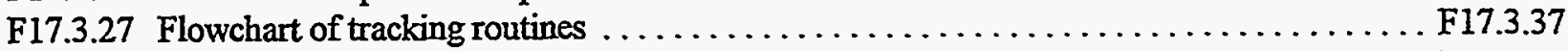

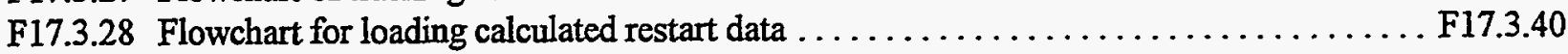

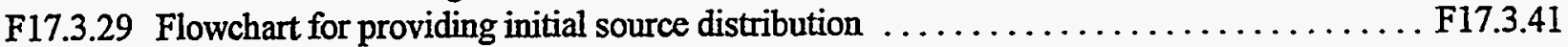

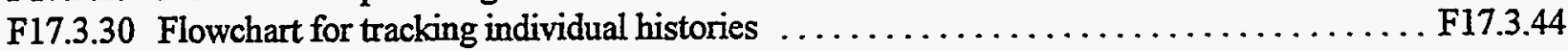

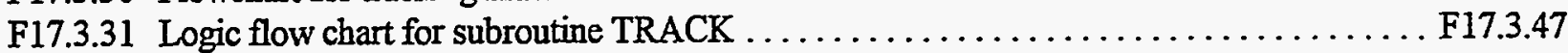

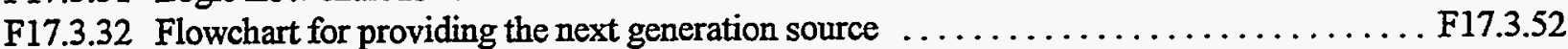

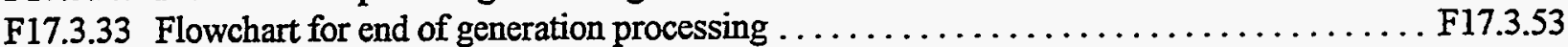

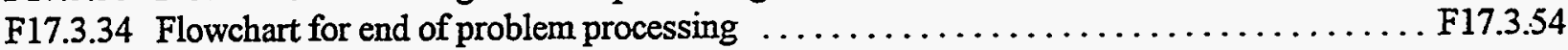

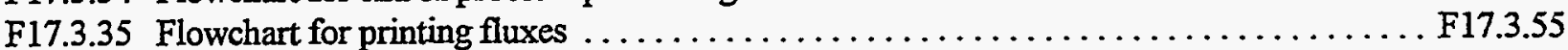

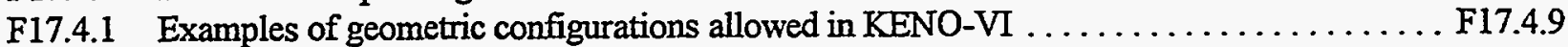

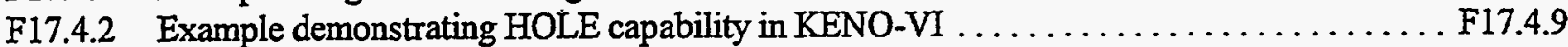

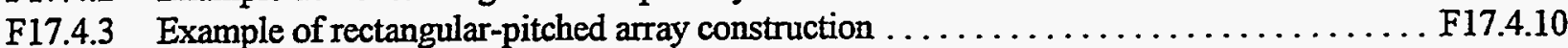

F17.4.4 Example of triangular-pitched array construction $\ldots \ldots \ldots \ldots \ldots \ldots \ldots \ldots \ldots \ldots \ldots \ldots .10 \ldots \ldots$

F17.ix

NUREG/CR-0200

Vol. 2, Rev. 5 


\section{LIST OF FIGURES (continued)}

Figure

$\underline{\text { Page }}$

F17.4.5 Example of an array composed of units containing arrays and holes . . . . . . . . F17.4.11

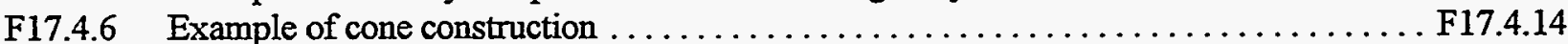

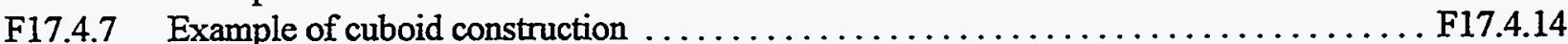

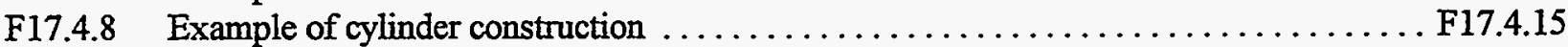

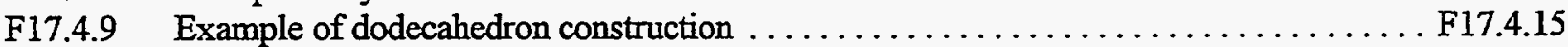

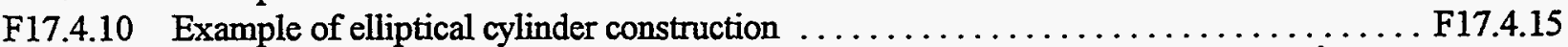

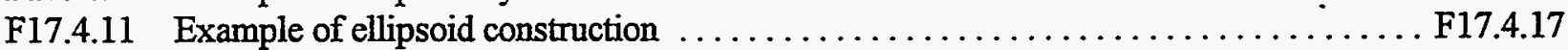

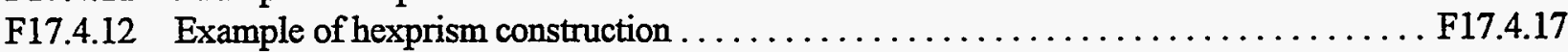

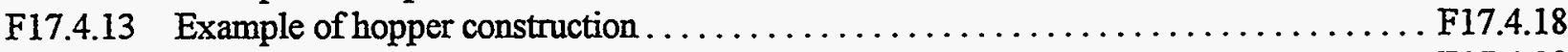

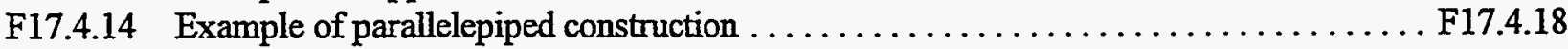

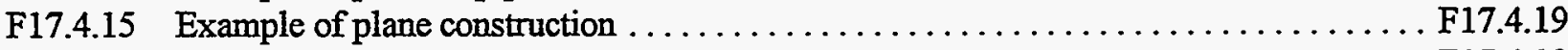

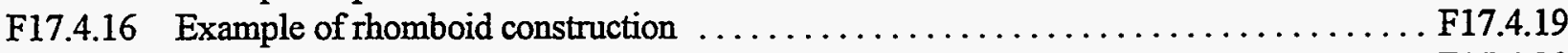

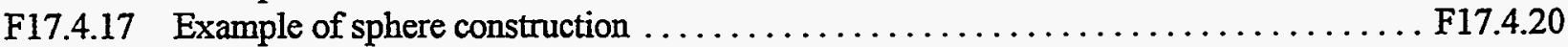

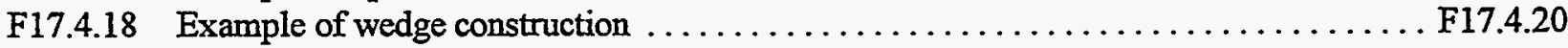

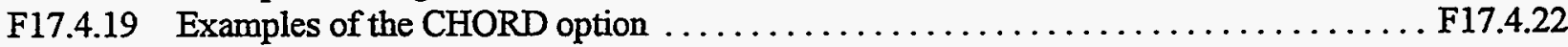

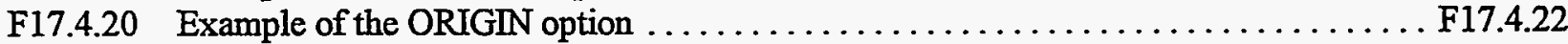

F17.4.21 Explanation of the ROTATE option $\ldots \ldots \ldots \ldots \ldots \ldots \ldots \ldots \ldots \ldots \ldots \ldots \ldots \ldots \ldots \ldots \ldots \ldots \ldots .23$

F17.4.22 Example of the MEDIA record $\ldots \ldots \ldots \ldots \ldots \ldots \ldots \ldots \ldots \ldots \ldots \ldots \ldots \ldots \ldots \ldots \ldots \ldots \ldots \ldots .23$

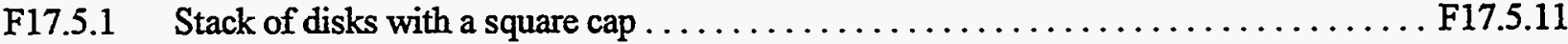

F17.5.2 Two large cylinders joined axially by a small cylinder $\ldots \ldots \ldots \ldots \ldots \ldots \ldots \ldots \ldots$ F17.5.20

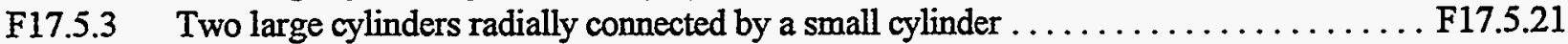

F17.5.4 Two small cylinders joined axially by a large cylinder $\ldots \ldots \ldots \ldots \ldots \ldots \ldots \ldots \ldots$ F17.5.22

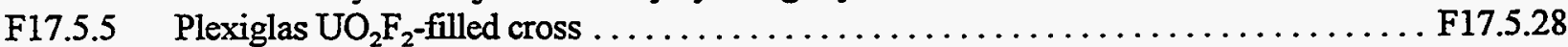

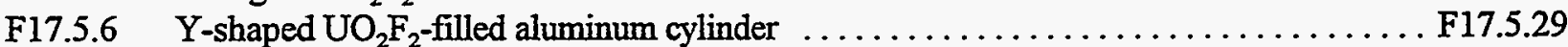

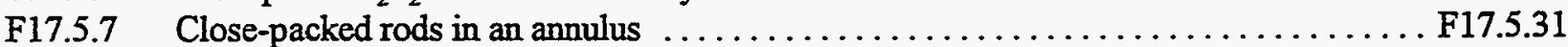

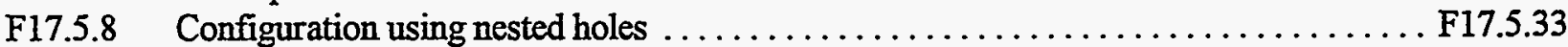

F17.5.9 Complicated geometric arrangement represented by Unit $2 \ldots \ldots \ldots \ldots \ldots \ldots \ldots$ F17.5.33

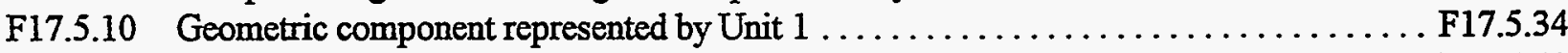

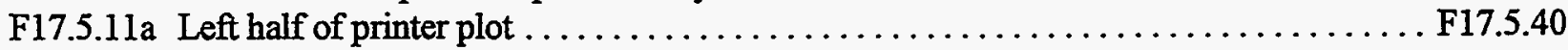

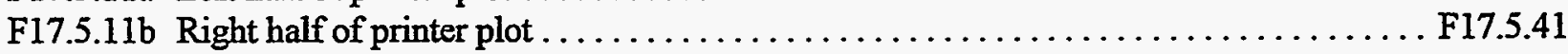

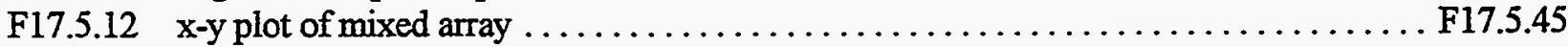

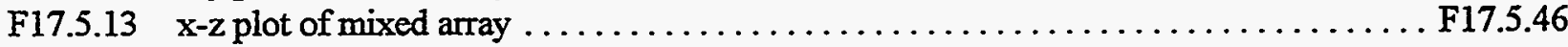

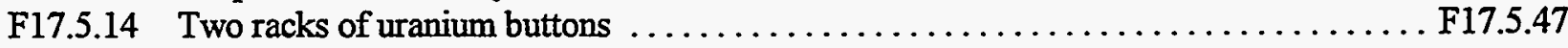

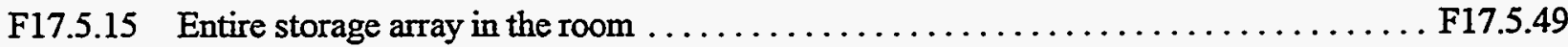

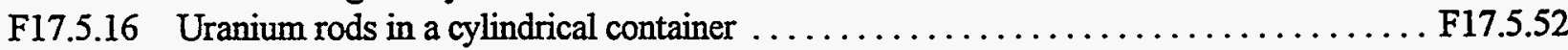

F17.5.16a $10 \times 10$ Array of uranium 32 rods and 68 void cuboids with the array boundary $\ldots \ldots$ F17.5.53

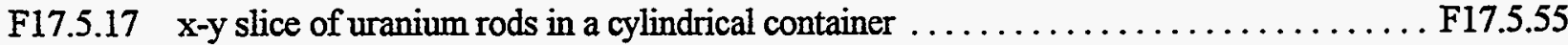

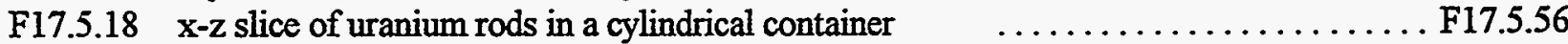

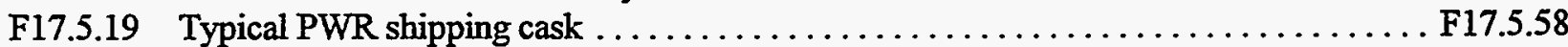

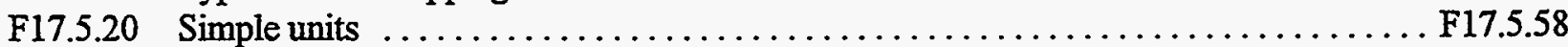

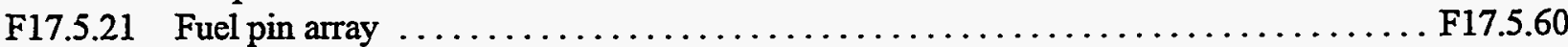

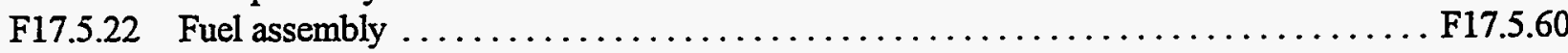

NUREG/CR-0200

Vol. 2, Rev. 5 


\section{LIST OF FIGURES (continued)}

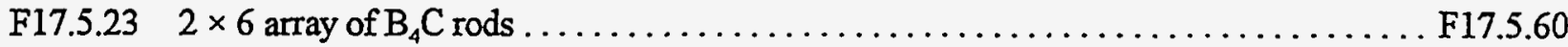

F17.5.24

Central array

F17.5.60

F17.5.25

Long $\mathrm{B}_{4} \mathrm{C}$ rod arrays

F17.5.61

F17.5.26

Central section with long $\mathrm{B}_{4} \mathrm{C}$ arrays

F17.5.62

F17.5.27

Two fuel assemblies and $\mathrm{B}_{4} \mathrm{C}$ rods .

F17.5.63

F17.5.28

Fuel cell and empty cell set up as hexprisms

F17.5.68

F17.5.29

Seven cylinders stacked in a triangular pitched array with a

cylindrical array boundary

F17.5.69

F17.5.30

$\mathrm{X}-\mathrm{Y}$ slice of 7 cylinders in a triangular pitched array

F17.5.70

F17.5.31

Associated data for single unit mixture map

F17.5.81

F17.5.32

Mixture map of single unit with centered origin

F17.5.82

F17.5.33

Associated data for single unit map

F17.5.82

F17.5.34

Unit map printer plot for single unit with centered origin

F17.5.83

F17.5.35

Associated data for mixture map of single unit with offset origin

F17.5.85

F17.5.36

Mixture map of single unit with offset origin

F17.5.85

F17.5.37

Associated data for unit map of single unit with offset origin

F17.5.86

F17.5.38

F17.5.39

$x-y$ plot of $2 \times 2 \times 2$ bare array

F17.5.88

$x-z$ plot of $2 \times 2 \times 2$ bare array

F17.5.89

F17.5.40

Plot data for $x-y$ slice of example 4

F17.5.91

F17.5.41

$x-y$ plot of $2 \times 2 \times 2$ reflected array

F17.5.92

F17.5.42

Plot data for enlarged $x-y$ slice of example 4

F17.5.93

F17.5.43

Enlarged z-y plot of $2 \times 2 \times 2$ reflected array

F17.5.93

F17.5.44

Plot data for $x-z$ slice of example 4

F17.5.94

F17.5.45

F17.5.46

$x-z$ plot of $2 \times 2 \times 2$ reflected array

F17.5.95

Plot data for enlarged $x-z$ slice of example 4

F17.5.96

F17.5.47

F17.5.48

Enlarged $x-z$ plot of $2 \times 2 \times 2$ reflected array

F17.5.97

Plot data for $x-y$ slice of example 5

F17.5.100

F17.5.49

$x-y$ plot of $2 \times 2 \times 2$ reflected array with centered origin

F17.5.101

F17.5.50

Plot data for an enlarged $x-y$ slice of example 5

F17.5.102

F17.5.51

F17.5.52

Enlarged $x-y$ plot of $2 \times 2 \times 2$ reflected array with centered origin

F17.5.103

Plot data for $x-z$ slice of example 5

F17.5.103

F17.5.53

F17.5.54

$x-z$ plot of reflected $2 \times 2 \times 2$ array with centered origin

F17.5.104

Plot data for enlarged $x-z$ slice of example 5

F17.5.105

F17.5.55

F17.5.56

Enlarged $x-z$ plot of reflected $2 \times 2 \times 2$ array with centered origin

F17.5.106

Mixture map of nested holes problem

F17.5.108

F17.5.57

Plot data for unit map of nested holes

F17.5.109

F17.5.58

Unit map of nested holes problem

F17.5.110

F17.5.59

Plot data for $x-z$ slice of storage array

F17.5.113

F17.5.60

$x-z$ plot of storage array

F17.5.114

F17.5.61

Plot data for $x-y$ slice of storage array

F17.5.115

F17.5.62

$x-y$ plot of storage array

F17.5.115 


\section{LIST OF FIGURES (continued)}

Figure

F17.6.1

F17.6.2

F17.6.3

F17.6.4

F17.6.5

F17.6.5a

F17.6.6

F17.6.7

F17.6.8

F17.6.9

F17.6.10

F17.6.11

F17.6.12

F17.6.13

F17.6.14

F17.6.15

F17.6.16

F17.6.17

F17.6.18

F17.6.19

F17.6.20

F17.6.21

F17.6.22

F17.6.23

F17.6.24

F17.6.25

F17.6.26

F17.6.27

F17.6.28

F17.6.29

F17.6.30

F17.6.31

F17.6.32

F17.6.33

F17.6.34

F17.6.35

F17.6.36

F17.6.37

F17.6.38

F17.6.39
Sample KENO-VI header page

Sample program verification table

Sample table of numeric parameter data

Sample table of logical parameter data

Example of unprocessed geometry input data

Sample table of geometry input data

Sample table of data sets used in the problem

Example of mixing table data

Cumulative probabilities for correlating the albedo energy group

to the cross-section energy group

Cumulative probabilities for correlating the cross-section

energy group to the albedo energy group ...

Example of macroscopic 1-D cross sections

Example of 2-D macroscopic cross sections

Example of macroscopic probabilities

Example of macroscopic angles

Sample table of additional information

Sample table of space and supergroup information

Examples of array summary

Example of geometry region data

Example of unit orientation description

Sample volume information

Biasing information

Example of biasing data

Summary of picture symbols and coordinates

Sample plot representation

Pretracking edits

Example of initial source points

Example of $k$-effectives by generation

Example of the final $k$-effective edit

Sample plot of average k-effective by generation run

Sample plot of average k-effective by generation skipped

Sample of the final edit of fissions, absorptions, and leakage

with region-dependent information suppressed

Sample of the final edit of fissions, absorptions, and leakage by region

Example of matrix k-effective by unit location

Sample fission production matrix by position index

Example of source vector by position index

Example of cofactor $k$-effective by position index

Example of matrix k-effective by unit number

An example of the fission probability matrix by unit

Example of the source vector by unit

Example of cofactor k-effective by unit number
F17.6.2

F17.6.3

F17.6.4

F17.6.5

F17.6.7

F17.6.8

F17.6.8

F17.6.10

F17.6.11

F17.6.11

F17.6.13

F17.6.13

F17.6.14

F17.6.14

F17.6.16

F17.6.18

F17.6.18

F17.6.20

F17.6.21

F17.6.22

F17.6.22

F17.6.23

F17.6.23

F17.6.24

F17.6.25

F17.6.26

F17.6.28

F17.6.30

F17.6.31

F17.6.33

F17.6.34

F17.6.34

F17.6.35

F17.6.35

F17.6.36

F17.6.36

F17.6.37

F17.6.38

F17.6.39

F17.6.39
NUREG/CR-0200

Vol. 2, Rev. 5
F17.xii 


\section{LIST OF FIGURES (continued)}

Figure

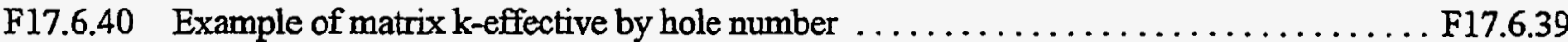

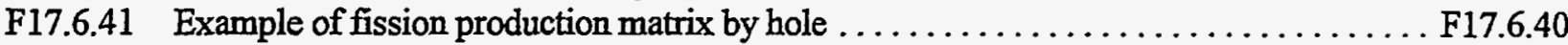

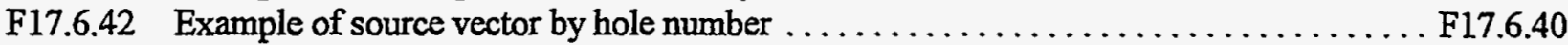

F17.6.43 Example of cofactor k-effective by hole number . . . . . . . . . . . . . . . . F17.6.41

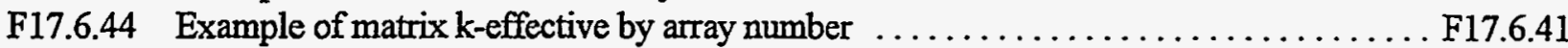

F17.6.45 An example of the fission production matrix by array number $\ldots \ldots \ldots \ldots \ldots \ldots \ldots$ F17.6.41

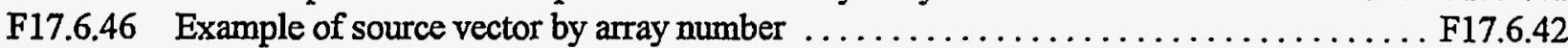

F17.6.47 Example of cofactor k-effective by array number . . . . . . . . . . . . . . . . F17.6.42

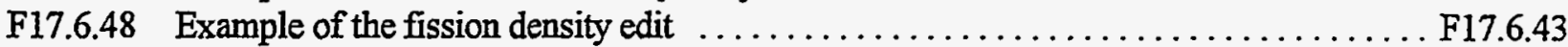

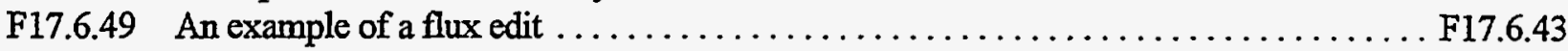

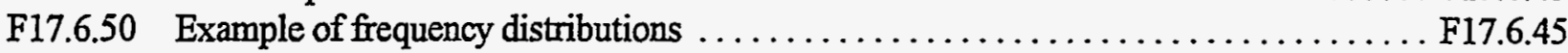

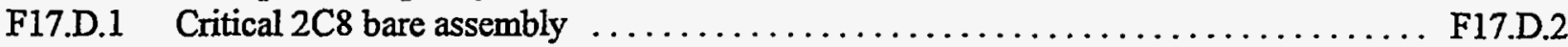

F17.D.2 Half of the paraffin reflected $2 \mathrm{C} 8$ assembly before the top reflector was added ..... F17.D.5

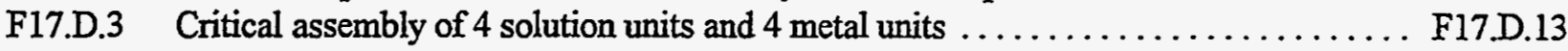

F17.D.4 Drawing of two cuboids in an annulus critical assembly ................. F17.D.16

F17.D.5 Drawing of the cylinder in an annulus critical assembly $\ldots \ldots \ldots \ldots \ldots \ldots \ldots$ F17.D.18

F17.D.6 Drawing of a critical assembly consisting of a uranium sphere

on a Plexiglas collar with a cylindrical water reflector $\ldots \ldots \ldots \ldots \ldots \ldots \ldots$ F17.D. 19

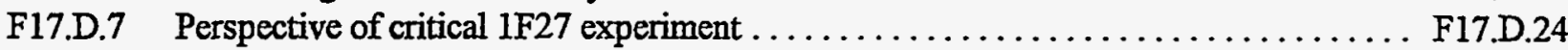

F17.D.8 View of a 27-unit cubic array with 2.54-cm-thick Plexiglas reflector on five sides and a $15.24-\mathrm{cm}$-thick paraffin base ................. F17.D.25

F17.D.9 Typical arrangement for critical experiments with interacting arrays of aluminum cylinders containing enriched ${ }^{235} \mathrm{U}$ solutions $\ldots \ldots \ldots \ldots \ldots \ldots$ F17.D.28

F17.D.10 Schematic of bare partially filled sphere experiment inside a 9.5-ft-diam, 9-ft-high steel tank

F17.D.31 
F17.4.1 Types of input data

F17.4.1

F17.4.2

FIDO-like input for mixed box orientation fill option

F17.4.30

F17.4.3

Face codes for entering boundary (albedo) conditions

F17.4.33

F17.4.4

Albedo names available on the KENO-VI albedo library for

use with the face codes

F17.4.34

F17.4.5 IDs, group structure and incremental thicknesses for weighting

data available on the KENO-VI weighting library

F17.4.36

F17.4.6

Starting distributions available in KENO-VI

F17.4.40

F17.4.7

Summary of parameter data

F17.4.50

F17.4.8

Summary of array data

F17.4.51

F17.4.9

Summary of biasing data

F17.4.52

F17.4.10

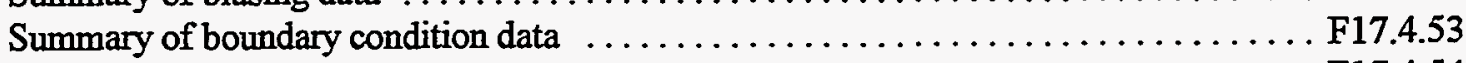

F17.4.11

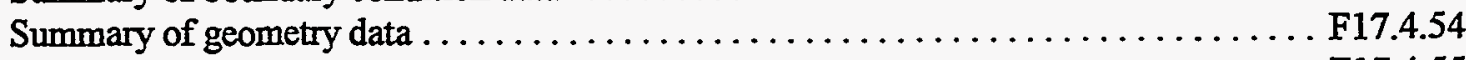

F17.4.12

F17.4.13

Summary of mixing table data.

F17.4.55

F17.4.14

Summary of plot data .

F17.4.56

F17.5.1

F17.5.2

Summary of starting data

F17.4.57

KENO-VI logical unit numbers

F17.5.3

Structure of RESTART file

F17.5.118

F17.5.3

Key of RESTART file variables

F17.5.123

F17.C.1

F17.C. 2

Summary of parameter data

F17.C. 2

F17.C.3

F17.C. 4

Summary of array data

F17.C. 3

Summary of biasing data

F17.C. 4

F17.C.5

Summary boundary condition data .

F17.C.5

F17.C. 6

F17.C.7

Summary of geometry data

F17.C.6

Summary of mixing table data

F17.C.7

F17.C. 8

Summary of plot data

F17.C.8

Summary of starting data

.F17.C.9 


\section{ACKNOWLEDGMENTS}

Many individuals have contributed significantly to the development of KENO-VI. Special recognition is given to G. E. Whitesides, formerly Director, Computing Applications Division, who was responsible for the concept and development of the original KENO code. He has also contributed significantly to some of the techniques utilized in KENO-VI. J. T. Thomas has offered many ideas that have been implemented in the code. R. M. Westfall has provided consultation, encouragement, and benchmarks for validating the code. The special abilities of J. R. Knight contributed substantially to debugging the code. Appreciation is expressed to C. V. Parks for reviewing this document. The efforts of L. F. Norris in preparing this document are gratefully acknowledged. Special appreciation is expressed to the DOENuclear Criticality Methods Resource Center, who with the leadership of program managers Blake Brown, Bill Kinney, Herb Field, Bob Kratzke, Jerry Counts, Sam Rosenblum, and Burton Rothleder provided funding for the development of KENO-VI. 


\section{F17.1 INTRODUCTION}

KENO-VI, a functional module in the SCALE system, is a multigroup Monte Carlo criticality program used to calculate the $k_{\text {eff }}$ of a three-dimensional (3-D) system. Special features include simplified data input, supergrouping of energy-dependent data, the use of quadratic equations to represent geometry input, a $\mathrm{P}_{n}$ scattering treatment, extended use of differential albedo reflection, and an improved restart capability.

The KENO-VI data input features flexibility in the order of input. The single restriction is that the title must be entered first and the parameter data, if any, must immediately follow. A large portion of the data has been assigned default values that have been found to be adequate for many problems. This feature enables the user to run a problem with a minimum of input data.

Blocks of input data are entered in the form:

\section{READ XXXX input data END XXXX}

where XXXX is the keyword for the type of data being entered. The types of data entered include parameters, geometry region data, array definition data, biasing or weighting data, albedo boundary conditions, starting distribution information, the cross-section mixing table, extra one-dimensional (1-D) (reaction rate) cross-section IDs for special applications, and printer plot information.

A block of data can be omitted unless it is needed or desired for the problem. Within the blocks of data, most of the input is activated by using keywords to override the default values.

KENO-VI contains a more flexible geometry package than the one in KENO-V.a. In KENO-VI, geometry regions are constructed and processed as sets of quadratic equations. A set of geometric shapes that include all those used in KENO-V.a plus others and the ability to build more complex geometric shapes using sets of quadratic equations is available in KENO-VI. Unlike KENO-V.a, KENO-VI allows intersections between geometry regions within a unit and the ability to specify an array boundary that intersects the array.

The primary difference between the KENO-V.a and KENO-VI geometry input is the methodology used to represent the geometry/material regions in a unit. KENO-VI uses two geometry records to describe a region. The first record, called the GEOMETRY record, contains the geometry keyword, region boundary definitions, and any geometry modification data: The second record, called the MEDIA record, contains the media keyword, the material, hole, or array $\mathrm{ID}$ number, the bias $\mathrm{I}$ number, and the region definition vector. Using geometry modification data, regions can be rotated and translated to any angle and position within a unit. KENO-VI requires that a global unit be specified in a problem, including single unit problems.

All the options in KENO-V.a pertaining to arrays are present in KENO-VI, plus additional flexibility. In addition to cuboidal arrays, hexagonal arrays can be directly constructed in KENO-VI. Also, the ability to specify an array boundary that intersects the array makes it possible to construct a lattice in a cylinder using one array in KENO-VI instead of multiple arrays and holes that would be required in KENO-VI.

An important feature of KENO-VI is the capability of supergrouping the energy-dependent information such as cross sections and fluxes. This automatic feature is activated when the computer storage is insufficient to hold the entire problem at once. The energy-dependent data are then broken into supergroups that are written on a direct-access device and moved in and out of memory as necessary. Thus larger problems can be run on smaller computers.

Anisotropic scattering is treated by using discrete scattering angles. The angles and associated probabilities are generated in a manner that preserves the moments of the angular scattering distribution for the selected group-to-group transfer. These moments can be derived from the coefficients of a $P_{n}$ Legendre polynomial expansion. All moments through the $2 n-1$ moment are preserved for $n$ discrete scattering angles. A one-to-one correspondence exists such that $n$ Legendre coefficients yield $n$ moments. The cases of zero and one scattering angle are treated in a special manner. KENO-VI can recognize that the distribution is isotropic 
even if the user specifies multiple scattering angles, and therefore selects from a continuous isotropic distribution. If the user specifies one scattering angle, the code performs semicontinuous scattering by picking scattering angle cosines uniformly over some range between -1 and +1 . The probability is zero over the rest of the range.

Differential albedos are available to simulate tracking in a reflector. These albedos were generated using the Hansen-Roach 16-energy-group structure. KENO-VI can extend the use of these albedos to include other energy group structures by matching lethargy boundaries between the albedos and cross sections so the appropriate energy transfers can be made. Lethargy boundary tables are created for both the albedo and cross-section energy group structures, and the lethargy interval corresponding to the desired transfer is determined based on a uniform distribution over the lethargy interval. Approximations must be made when the energy group boundaries of the albedos and cross sections are different. Therefore, the user should scrutinize the results to evaluate the effects of the approximations until an adequate information base is established.

The KENO-VI restart option is easy to activate. Certain changes can be made when a problem is restarted, including the use of a different random sequence and turning off certain print options, such as fluxes or the fissions and absorptions, by region. 


\section{F17.2 THEORY AND TECHNIQUES}

\section{F17.2.1. THE TRANSPORT EQUATION}

The equation KENO-VI solves may be derived in the following manner, starting with the Boltzmann neutron transport equation which may be written as ${ }^{1}$

$$
\begin{gathered}
\frac{1}{\mathrm{v}} \frac{\partial \Phi}{\partial \mathrm{t}}(\mathrm{X}, \mathrm{E}, \Omega, \mathrm{t})+\Omega \cdot \nabla \Phi(\mathrm{X}, \mathrm{E}, \Omega, \mathrm{t})+\Sigma_{\mathrm{t}}(\mathrm{X}, \mathrm{E}, \Omega, \mathrm{t}) \Phi(\mathrm{X}, \mathrm{E}, \Omega, \mathrm{t})=\mathrm{S}(\mathrm{X}, \mathrm{E}, \Omega, \mathrm{t}) \\
+\int_{\mathrm{E}^{\prime}} \int_{\Omega^{\prime}} \Sigma_{\mathrm{s}}\left(\mathrm{X}, \mathrm{E}^{\prime} \rightarrow \mathrm{E}, \Omega^{\prime} \rightarrow \Omega, \mathrm{t}\right) \Phi\left(\mathrm{X}, \mathrm{E}^{\prime}, \Omega^{\prime}, \mathrm{t}\right) \mathrm{d} \Omega^{\prime} \mathrm{dE}^{\prime},
\end{gathered}
$$

where

$$
\begin{aligned}
& \Phi(\mathrm{X}, \mathrm{E}, \Omega, \mathrm{t}) \quad \text { = neutron flux (neutrons } / \mathrm{cm}^{2} / \mathrm{s} \text { ) per unit energy at energy } \mathrm{E} \text { per steradian } \\
& \text { about direction } \Omega \text { at position } \mathrm{X} \text { at time } \mathrm{t} \text { moving at speed } \mathrm{v} \text { corresponding } \\
& \text { to } \mathrm{E} \text {, } \\
& \Sigma_{\mathrm{t}}(\mathrm{X}, \mathrm{E}, \Omega, \mathrm{t}) \quad=\text { macroscopic total cross section of the media }\left(\mathrm{cm}^{-1}\right) \text { at position } \mathrm{X} \text {, energy } \\
& E \text {, direction } \Omega \text { and time } t \text {, } \\
& \Sigma_{s}\left(X, E^{\prime} \rightarrow E_{\rho} \Omega^{\prime} \rightarrow \Omega, t\right)=\text { macroscopic differential cross section of the media }\left(\mathrm{cm}^{-1}\right) \text { per unit energy } \\
& \text { at energy } E^{\prime} \text { per steradian about direction } \Omega^{\prime} \text { at position } X \text {, and time } t \text {, for } \\
& \text { scattering to energy } E \text { and direction } \Omega \text {, } \\
& \mathrm{S}(\mathrm{X}, \mathrm{E}, \Omega, \mathrm{t})=\text { neutrons } / \mathrm{cm}^{3} / \mathrm{s} \text { born at position } \mathrm{X} \text { and time } \mathrm{t} \text { per unit energy at energy } \mathrm{E} \\
& \text { per steradian about direction } \Omega \text { (excludes scatter source). }
\end{aligned}
$$

Defining $q(X, E, \Omega, t)$ as the total source resulting from the external source, scattering, fission and all other contributions, the following relationship can be written:

$$
\mathrm{q}(\mathrm{X}, \mathrm{E}, \Omega, \mathrm{t})=\mathrm{S}(\mathrm{X}, \mathrm{E}, \Omega, \mathrm{t})+\int_{\mathrm{E}^{\prime}} \int_{\Omega^{\prime}} \Sigma_{s}\left(\mathrm{X}, \mathrm{E}^{\prime} \rightarrow \mathrm{E}, \Omega^{\prime} \rightarrow \Omega, \mathrm{t}\right) \Phi\left(\mathrm{X}, \mathrm{E}^{\prime}, \Omega^{\prime}, \mathrm{t}\right) \mathrm{d} \Omega^{\prime} \mathrm{d} E^{\prime} .
$$

Combining Eqs. (F17.2.1) and (F17.2.2), assuming the media to be isotropic, ignoring the time dependence of the cross sections and converting the equation to multigroup form, yields

$$
\frac{1}{v_{g}} \frac{\partial \Phi_{g}}{\partial t}(X, \Omega, t)+\Omega \cdot \nabla \Phi_{g}(X, \Omega, t)+\Sigma_{t_{s}}(X) \Phi_{g}(X, \Omega, t)=q_{g}(X, \Omega, t),
$$

where

$$
\begin{aligned}
& \text { is the energy group of interest, } \\
& v_{g} \quad \text { is the average velocity of the neutrons in group } g \text {, }
\end{aligned}
$$


$\Phi_{g}(X, \Omega, t)$ is the angular flux of neutrons having their energies in group $g$, at position $X$ and time $t$,

$\Sigma_{\mathrm{tg}}(\mathrm{X}) \quad$ is the macroscopic total cross section of the media at position $\mathrm{X}$ for group $\mathrm{g}$, corresponding to

$$
\Sigma_{\mathrm{tg}}(\mathrm{X})=\frac{\int_{\Delta \mathrm{E}_{\mathrm{g}}} \Sigma_{\mathrm{t}}(\mathrm{X}, \mathrm{E}) \Phi(\mathrm{X}, \mathrm{E}, \Omega, \mathrm{t}) \mathrm{dE}}{\int_{\Delta \mathrm{E}_{\mathrm{g}}} \Phi(\mathrm{X}, \mathrm{E}, \Omega, \mathrm{t}) \mathrm{dE}},
$$

where

$\Delta \mathrm{E}_{\mathrm{g}} \quad$ defines group $\mathrm{g}$,

$\mathrm{q}_{8}(\mathrm{X}, \Omega, t)$ is the total source contributing to energy group $\mathrm{g}$ at position $\mathrm{X}$, and time $\mathrm{t}$ in direction $\Omega$.

Utilizing the relationship $\mathrm{X}^{\prime}=\mathrm{X}-\mathrm{R} \Omega$, defining the problem to be time-independent, using an integrating factor ${ }^{2}$ on both sides of Eq. (F17.2.3), and defining

$$
\mathrm{T}(\mathrm{R})=\int_{0}^{\mathrm{R}} \Sigma_{\mathrm{t}_{\mathrm{g}}}\left(\mathrm{X}-\mathrm{R}^{\prime} \Omega\right) \mathrm{d} \mathrm{R}^{\prime},
$$

the following equation can be written:

$$
\Phi_{g}(X, \Omega)=\int_{0}^{\infty} q_{g}(X-R \Omega, \Omega) e^{-T(R)} d R
$$

At this point, the problem becomes an eigenvalue problem. If there is no external source, the source may be defined as

$$
\mathrm{q}_{\mathrm{g}}(\mathrm{X}, \Omega)=\sum_{\mathrm{g}^{\prime}} \int \mathrm{d} \Omega^{\prime} \Phi_{\mathrm{g}^{\prime}}\left(\mathrm{X}, \Omega^{\prime}\right) \Sigma_{\mathrm{s}}\left(\mathrm{X}, \mathrm{g}^{\prime} \rightarrow \mathrm{g}, \Omega^{\prime} \cdot \Omega\right)+\frac{1}{\mathrm{k}} \mathrm{Q}_{\mathrm{g}}^{\prime}(\mathrm{X}, \Omega)
$$

where

$k$ is the largest eigenvalue of the integral equation,

$\mathrm{Q}_{\mathrm{g}}^{\prime}(\mathrm{X}, \Omega) \quad$ is the fission source at position $\mathrm{X}$ for energy group $\mathrm{g}$ and direction $\Omega$ (all fission contributions to group $\mathrm{g}$ from all energy groups in the previous generation),

$\Sigma_{3}\left(\mathrm{X}, \mathrm{g}^{\prime} \rightarrow \mathrm{g}_{3} \Omega^{\prime} \cdot \Omega\right)$ is the scattering cross section for scattering at position $\mathrm{X}$ from group $\mathrm{g}^{\prime}$ and direction $\Omega^{\prime}$ to group $g$ and direction $\Omega$. 
In terms of energy, the scatter can be defined as

$\Sigma_{s}\left(X, g^{\prime} \rightarrow g, \Omega^{\prime} \cdot \Omega\right)=\frac{\int_{\Delta E_{g}} \int_{\Delta E_{g}^{\prime}} \Sigma_{s}\left(X, E^{\prime}-E, \Omega^{\prime} \cdot \Omega\right) \Phi\left(X, E^{\prime}, \Omega^{\prime}\right) d E^{\prime} d E}{\int_{\Delta E_{g^{\prime}}} \Phi\left(X, E^{\prime}, \Omega^{\prime}\right) \mathrm{dE}^{\prime}}$,

where

$\Delta \mathrm{E}_{\mathrm{g}}$ is the energy range defining energy group $\mathrm{g}$

$\Delta E_{g^{\prime}}$ is the energy range defining energy group $g^{\prime}$.

Assuming the fission neutrons to be isotropic, the fission source $Q_{g}(X, \Omega)$ can be written as

$$
Q_{g}^{\prime}(X, \Omega)=\frac{1}{4 \pi} \sum_{g^{\prime}} \int_{\Omega^{\prime}} d \Omega^{\prime} \Phi_{g^{\prime}}\left(X, \Omega^{\prime}\right) \chi\left(X, g^{\prime} \rightarrow g\right) v_{g^{\prime}}(X) \Sigma_{f g^{\prime}}(X)
$$

where

$\chi\left(\mathrm{X}, \mathrm{g}^{\prime} \rightarrow \mathrm{g}\right)$ is the fraction of neutrons born in energy group $\mathrm{g}$ from fission in energy group $\mathrm{g}^{\prime}$ in the media at position $\mathrm{X}$,

$v_{g^{\prime}}(X)$ is the number of neutrons resulting from a fission in group $g^{\prime}$ at position $X$,

$\Sigma_{\mathrm{fg}^{\prime}}(\mathrm{X})$ is the macroscopic fission cross section of the material at position $\mathrm{X}$ for a neutron in energy group $\mathrm{g}^{\prime}$.

Substituting Eq. (F17.2.5) into Eq. (F17.2.4) yields the following equation:

$$
\begin{aligned}
& \Phi_{g}(X, \Omega)=\int_{0}^{\infty} d R e^{-T(R)} \\
& \quad\left\{\frac{1}{k} Q_{g}^{\prime}(X-R \Omega, \Omega)+\sum_{g^{\prime}}\left[\int_{\Omega^{\prime}} d \Omega^{\prime} \Phi_{g^{\prime}}\left(X-R \Omega, \Omega^{\prime}\right) \Sigma_{s}\left(X-R \Omega, g^{\prime} \rightarrow g, \Omega^{\prime} \cdot \Omega\right)\right]\right\} .
\end{aligned}
$$

The definition of $k$ may be given as the ratio of the number of neutrons in the $(n+1)$ th generation to the number of neutrons in the $n$th generation or the largest eigenvalue of the integral equation. Using Eq. (F17.2.7), Eq. (F17.2.8) can be written as 


$$
\begin{aligned}
\Phi_{\mathrm{g}}(\mathrm{X}, \Omega)= & \int_{0}^{\infty} \mathrm{dRe} \mathrm{e}^{-\mathrm{T}(\mathrm{R})}\left\{\sum_{\mathrm{g}^{\prime}} \frac{1}{\mathrm{k}} \int_{\Omega^{\prime}} \mathrm{v}_{\mathrm{g}^{\prime}}(\mathrm{X}-\mathrm{R} \Omega) \Sigma_{\mathrm{fg}}(\mathrm{X}-\mathrm{R} \Omega) \chi\left(\mathrm{X}-\mathrm{R} \Omega, \mathrm{g}^{\prime} \rightarrow \mathrm{g}\right) \Phi_{\mathrm{g}^{\prime}}\left(\mathrm{X}-\mathrm{R} \Omega, \Omega^{\prime}\right) \frac{\mathrm{d} \Omega^{\prime}}{4 \pi}\right. \\
& \left.+\sum_{\mathrm{g}^{\prime}} \int_{\Omega^{\prime}} \mathrm{d} \Omega^{\prime} \Sigma_{\mathrm{tg}}\left(\mathrm{X}-\mathrm{R} \Omega, \Omega^{\prime}\right) \frac{\Sigma_{\mathrm{g}}\left(\mathrm{X}-\mathrm{R} \Omega, \mathrm{g}^{\prime} \rightarrow \mathrm{g}, \Omega^{\prime} \cdot \Omega\right)}{\Sigma_{\mathrm{tg}}(\mathrm{X}-\mathrm{R} \Omega)}\right\} .
\end{aligned}
$$

Writing Eq. (F17.2.9) in "generation notation," multiplying and dividing certain terms by $\Sigma_{\mathrm{t}_{\mathrm{g}}}(\mathrm{X})$ and multiplying both sides of the equation by $v_{\mathrm{g}}(\mathrm{X}) \Sigma_{\mathrm{f}_{\mathrm{g}}}(\mathrm{X})$, yield the following equation, which is solved by KENO-VI.

$$
\begin{gathered}
\frac{v_{\mathrm{g}}(\mathrm{X}) \Sigma_{\mathrm{fg}}(\mathrm{X})}{\Sigma_{\mathrm{tg}}(\mathrm{X})} \Sigma_{\mathrm{tg}}(\mathrm{X}) \Phi_{\mathrm{gg}}(\mathrm{X}, \Omega)=\frac{v_{\mathrm{g}}(\mathrm{X}) \Sigma_{\mathrm{fg}}(\mathrm{X})}{\Sigma_{\mathrm{tg}}(\mathrm{X})} \Sigma_{\mathrm{tg}}(\mathrm{X}) \int_{0}^{\infty} \mathrm{dRe} e^{-\mathrm{T}(\mathrm{R})} \\
\left\{\frac{1}{\mathrm{k}} \sum_{\mathrm{g}^{\prime}} \int_{\Omega^{\prime}} \frac{v_{\mathrm{g}^{\prime}}(\mathrm{X}-\mathrm{R} \Omega) \Sigma_{\mathrm{fg}}(\mathrm{X}-\mathrm{R} \Omega)}{\Sigma_{\mathrm{tg}}(\mathrm{X}-\mathrm{R} \Omega)} \chi\left(\mathrm{X}-\mathrm{R} \Omega, \mathrm{g}^{\prime}-\mathrm{g}\right) \Sigma_{\mathrm{tg}}(\mathrm{X}-\mathrm{R} \Omega) \phi_{\mathrm{g}^{\prime}, \mathrm{n}-1}\left(\mathrm{X}-\mathrm{R} \Omega, \Omega^{\prime}\right) \frac{\mathrm{d} \Omega^{\prime}}{4 \pi}\right. \\
\left.+\sum_{\mathrm{g}^{\prime}} \int_{\Omega^{\prime}} \frac{\Sigma_{\mathrm{s}}\left(\mathrm{X}-\mathrm{R} \Omega, \mathrm{g}^{\prime}-\mathrm{g}, \Omega^{\prime} \cdot \Omega\right)}{\Sigma_{\mathrm{tg}}(\mathrm{X}-\mathrm{R} \Omega)} \Sigma_{\mathrm{tg}}(\mathrm{X}-\mathrm{R} \Omega) \Phi_{\mathrm{g}^{\prime}, \mathrm{n}}\left(\mathrm{X}-\mathrm{R} \Omega, \Omega^{\prime}\right) \mathrm{d} \Omega^{\prime}\right\}
\end{gathered}
$$

where $n$ indicates the $n$th generation and $n-1$ is the $(n-1)$ th generation. Note that the left-hand side of the equation, $v_{\mathrm{g}}(\mathrm{X}) \Sigma_{\mathrm{fg}}(\mathrm{X}) \Phi_{\mathrm{gn}}(\mathrm{X}, \Omega)$ is the fission production for the $n$th generation.

The solution strategy utilized by KENO-VI solves Eq. (F17.2.10) by using an iterative procedure. The fission production at point $\mathrm{X}$ in energy group $\mathrm{g}$ due to neutrons in the $(n-1)$ th generation, normalized to the system multiplication, is

$$
\frac{1}{\mathrm{k}} \sum_{\mathrm{g}^{\prime}} \int_{\Omega^{\prime}} \frac{\mathrm{v}_{\mathrm{g}^{\prime}}(\mathrm{X}) \Sigma_{\mathrm{fg}}(\mathrm{X})}{\Sigma_{\mathrm{tg}}(\mathrm{X})} \chi\left(\mathrm{X}, \mathrm{g}^{\prime} \rightarrow \mathrm{g}\right) \Sigma_{\mathrm{tg}}(\mathrm{X}) \Phi_{\mathrm{g}^{\prime}, \mathrm{n}-1}\left(\mathrm{X}, \Omega^{\prime}\right) \frac{\mathrm{d} \Omega^{\prime}}{4 \pi} .
$$

The collision points used in KENO-VI are chosen by selecting path lengths from the distribution

$$
e^{-T(R) M} \text {, }
$$

which is the probability of transport from any position $X-R \Omega$ to position $X$.

The first collision density of neutrons in group $g$ per unit solid angle about $\Omega$ resulting from the fission source produced by the $(n-1)$ generation, normalized to the system multiplication, is 


$$
\begin{aligned}
& \Sigma_{t g}(X) \int_{0}^{\infty} d R e^{-T(R)} \frac{1}{k} \int_{\Omega^{\prime}} \sum_{g^{\prime}} \frac{v_{g^{\prime}}(X-R \Omega) \Sigma_{f g^{\prime}}(X-R \Omega)}{\Sigma_{t g^{\prime}}(X-R \Omega)} \\
& \chi\left(X-R \Omega, g^{\prime}-g\right) \Sigma_{t g}(X-R \Omega) \Phi_{g^{\prime}, n-1}\left(X-R \Omega, \Omega^{\prime}\right) \frac{d \Omega^{\prime}}{4 \pi} .
\end{aligned}
$$

The scattering source at position X emerging in group $\mathrm{g}$ and direction $\Omega$ resulting from previous collisions in the same generation, is

$$
\sum_{g^{\prime}} \int_{\Omega^{\prime}} \frac{\Sigma_{s}\left(X, g^{\prime}-g, \Omega^{\prime} \cdot \Omega\right)}{\Sigma_{t^{\prime}}(X)} \Sigma_{\mathrm{b}^{\prime}}(X) \Phi_{g^{\prime} \Omega^{\prime}}\left(X, \Omega^{\prime}\right) \mathrm{d} \Omega^{\prime}
$$

The collision density in group $\mathrm{g}$, per solid angle about $\Omega$ is

$$
\Sigma_{\mathrm{tg}} \int_{0}^{\infty} \mathrm{dRe}-\mathrm{T}(\mathrm{R}) \sum_{\mathrm{g}^{\prime}} \int_{\Omega^{\prime}} \frac{\Sigma_{\mathrm{s}}\left(\mathrm{X}-\mathrm{R} \Omega, \mathrm{g}^{\prime}-\mathrm{g}, \Omega^{\prime} \cdot \Omega\right)}{\Sigma_{\mathrm{tg}}(\mathrm{X}-\mathrm{R} \Omega)} \Sigma_{\mathrm{tg}}(\mathrm{X}-\mathrm{R} \Omega) \Phi_{\mathrm{g}^{\prime}, \mathrm{n}}\left(\mathrm{X}-\mathrm{R} \Omega, \Omega^{\prime}\right) \mathrm{d} \Omega^{\prime} .
$$

The total collision density times $\frac{v_{\mathrm{g}}(\mathrm{X}) \Sigma_{\mathrm{fg}}(\mathrm{X})}{\Sigma_{\mathrm{tg}}(\mathrm{X})}$ is the relationship from which KENO-VI picks the source points for the next generation.

\section{F17.2.2 COLLISION TREATMENT}

A collision occurs in a geometrical region when a history exhausts its mean free path length within the boundaries of the region. For each collision, the absorbed weight and the fission weight are tabulated, then the weight is modified by the nonabsorption probability. This new weight is checked for splitting and Russian roulette; if it survives, the history is scattered. A new energy group is selected from the cumulative transfer probability distribution. This group-to-group transfer determines an angular scattering distribution, usually expressed as a Legendre expansion of the cross-section transfer array. A set of discrete angles and probabilities are generated by a generalized Gaussian quadrature procedure, ${ }^{3}$ preserving the moments of the Legendre expansion of the angular scattering distribution. KENO-VI treats $\mathrm{P}_{0}$ and $\mathrm{P}_{1}$ Legendre expansions as special cases. If the scattering distribution is isotropic, a flag is set to randomly select new direction cosines from an isotropic distribution, instead of using discrete scattering angles. If the distribution is a $\mathrm{P}_{1}$ expansion, KENO-VI randomly selects the cosine of the scattering angle according to

(1) $|\bar{\mu}|<\frac{10^{-10}}{3}$ : scattering distribution is isotropic,

(2) $|\bar{\mu}| \leq 1 / 3: \mu=\left(\sqrt{1+6 \zeta \bar{\mu}+(3 \bar{\mu})^{2}}-1\right) / 3 \bar{\mu}$,

or

(3) $|\bar{\mu}|>1 / 3: \mu=\zeta(1-|\bar{\mu}|)+\bar{\mu}$, 
where $\zeta$ is a uniform random variable between -1 and +1 , and $\bar{\mu}$ is the mean cosine of the scattering angle. Otherwise, KENO-VI randomly selects one of the discrete scattering angles $(\mu)$. New direction cosines are then calculated according to the following relationships where $u, v$, and $w$ are the initial direction cosines and $u^{\prime}, v^{\prime}$, and $\mathrm{w}^{\prime}$ are the direction cosines after the collision.

$$
\begin{aligned}
& \mathrm{u}^{\prime}=\mathrm{u} \cos \psi-\sqrt{\mathrm{v}^{2}+\mathrm{w}^{2}} \sin \psi \cos \eta \\
& \mathrm{v}^{\prime}=\mathrm{v} \cos \psi+\frac{\mathrm{uv}}{\sqrt{\mathrm{v}^{2}+\mathrm{w}^{2}}} \cos \eta \sin \psi-\frac{\mathrm{w}}{\sqrt{\mathrm{v}^{2}+\mathrm{w}^{2}}} \sin \psi \sin \eta, \\
& \mathrm{w}^{\prime}=\mathrm{w} \cos \psi+\frac{\mathrm{uw}}{\sqrt{\mathrm{v}^{2}+\mathrm{w}^{2}}} \cos \eta \sin \psi+\frac{\mathrm{v}}{\sqrt{\mathrm{v}^{2}+\mathrm{w}^{2}}} \sin \psi \sin \eta,
\end{aligned}
$$

where

$$
\begin{aligned}
& \sin \psi=\sqrt{1-\mu^{2}}, \\
& \cos \Psi=\mu=\text { cosine of the scattering angle, } \\
& \eta \quad=\text { a random azimuthal angle between } 0 \text { and } 2 \pi .
\end{aligned}
$$

\section{F17.2.3 BIASING OR WEIGHTING}

In order to minimize the statistical deviation of $\mathrm{k}_{\mathrm{eff}}$ per unit computer time, KENO-VI utilizes weighted tracking rather than analog tracking. Weighted tracking accounts for absorption by reducing the neutron weight, rather than allowing the neutron history to be terminated by absorption. To prevent expending excessive computer time tracking low-weight neutrons, Russian roulette is played when the weight of the neutron drops below a preset weight, WTLOW. Neutrons that survive Russian roulette are assigned a weight, WTAVG. The value of WTLOW and WTAVG can be assigned as a function of position and energy. The following values are used by KENO-VI:
DWTAV $=0.5$
WTAVG = DWTAV
is the default value of WTAVG,
WTLOW $=$ WTAVG/3.0
is the weight given a neutron that survives Russian roulette, and
is the value of weight at which Russian roulette is played.

A study ${ }^{4}$ by Hoffman shows these default values to be reasonable for bare critical assemblies. Figure F17.2.1, from this study, shows the analytic relationship between the variance and WTLOW when WTAVG is 0.5 . Note that the default value of 0.167 for WTLOW is very close to the minimum point on the curve. Experimental results of actual Monte Carlo calculations ${ }^{5}$ provide further assurance that 0.167 is an optimum choice for WTLOW when WTAVG is 0.5 .

Figure F17.2.2, also from the Hoffman study, shows the analytic relationship between the variance and the value chosen for WTAVG for a value of WTLOW $=0.167$. Although the KENO-VI default value for WTAVG is not the optimum, a close examination of the data shows the variance to be changing relatively slow as a function of WTAVG. Even though this study shows a value near 0.26 to be optimum for this system, further

NUREG/CR-0200

Vol. 2, Rev. 5

F17.2.6 
studies of other systems are needed before changing the default value of WTAVG from the 0.5 that has been used in previous versions of KENO.

Inside a fissile core, the importance of a neutron is a slowly varying function in terms of energy and position. Hence for many systems, the standard defaults for WTLOW and WTAVG are good values to use. For reflectors, however, the worth of a neutron varies both as a function of distance from the fissile material and as a function of energy. As a neutron in the reflector becomes less important relative to a neutron in the fissile region, it becomes desirable to spend less time tracking it. Therefore a space- and energy-dependent weighting or biasing function is used in KENO-VI to allow the user to minimize the variance in $\mathrm{k}_{\text {eff }}$ per unit tracking time. When a biasing function is used in a reflector, it becomes possible for a neutron to move from one importance region into another whose WTLOW is greater than the weight of the neutron. When this occurs, Russian roulette is played to reduce the number of neutrons tracked. When the reverse occurs, that is, when the neutron moves to a region of higher importance, its weight may be much higher than WTAVG for that region. When the weight of the neutron is greater than a preset value, WTHI, the neutron is split into two neutrons, each having a weight equal to one-half the weight of the original neutron. This procedure is repeated until the weight of the split neutron is less than WTHI. The default value for WTHI is WTAVG*3.0. WTHI is the weight at which splitting occurs.

The weighting or biasing function for a given core material and reflector material can be obtained by using the adjoint solution from $S_{n}$ type programs for a similar (usually simplified) problem. This adjoint flux gives the relative contribution of a neutron at a given energy and position to the total fissions in the system. The weighting function for KENO-VI is thus proportional to the reciprocal of the adjoint flux. Although such a function can be difficult to obtain, the savings gained makes the effort worthwhile for many of the materials that are frequently used as reflectors. Biasing functions ${ }^{6}$ have been prepared for several reflector materials commonly used in KENO-VI calculations. The use of biasing to minimize the variance in $\mathrm{k}_{\mathrm{ef}}$ per unit computer time will usually increase the variance in other parameters such as leakage or absorption in the reflector.

\section{F17.2.4 DIFFERENTIAL ALBEDOS}

Arrays reflected by thick layers of material having a small absoxption to scattering ratio may require large amounts of computer time to determine $k_{\text {eff }}$ because of the relatively long time a history may spend in the reflector. A differential albedo technique ${ }^{7}$ was developed for use with the KENO codes to eliminate tracking in the reflector. This technique involves returning a history at the point it impinges on the reflector and selecting an emergent energy and polar angle from a joint density function dependent upon the incident energy and polar angle. The weight of the history is adjusted by the functional return from the reflector, which is also based on the incident energy and angle.

The characteristics of a differential albedo emulate the attributes of the reflector material and are independent of the material or materials adjacent to the reflector. Thus a differential albedo that is generated for a given reflector material can be used with any array, regardless of the type of fuel or fissile material contained within the array.

For many calculations involving reflected arrays of fissile material, the differential albedo treatment is a powerful tool that can significantly reduce the computing time required to determine $k_{\text {eff. }}$. The savings will vary, depending on the importance of the reflector to the system. A substantial effort is required to generate a differential albedo, but the savings gained are well worth the effort for commonly used reflector materials.

To generate the differential albedo information for a material, a fixed source calculation must be made for each incident energy and angle. The data presently available for use with KENO-VI were generated by 1-D discrete-ordinates calculations for slab geometry, representing infinite slabs. Consequently, for a finite reflector, these data will not correctly treat histories that enter the reflector near an edge. Past experience with differential albedo reflectors indicates that $k_{\text {eff }}$ appears to be conservative for small faces and will tend toward the correct 


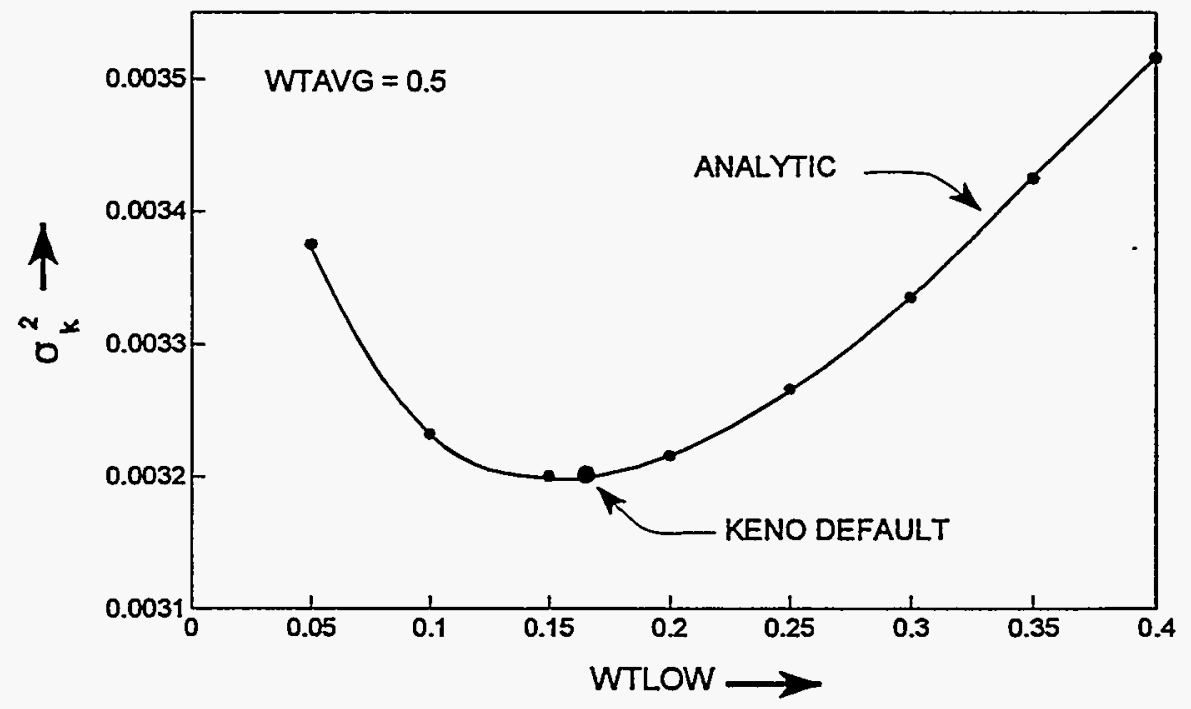

Figure F17.2.1. Analytic estimate of the relationship between WTLOW and the variance, $\sigma_{k}^{2}$, when WTAVG is 0.5

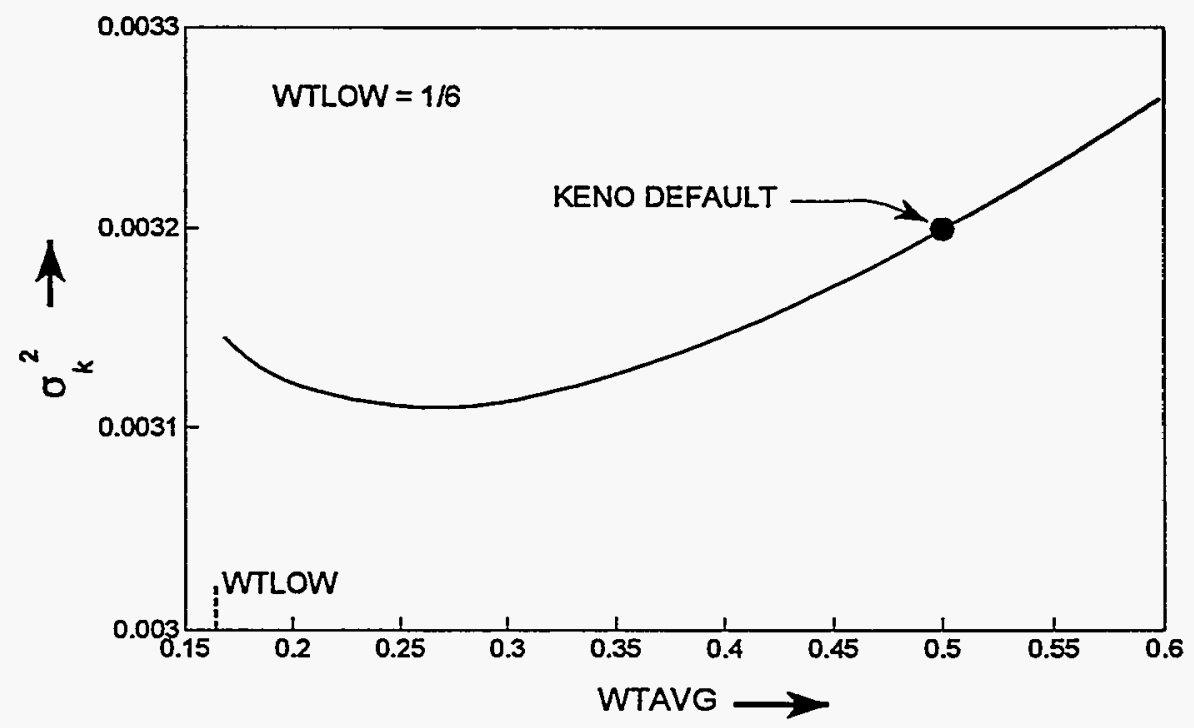

Figure F17.2.2. Analytic estimate of the relationship between WTAVG and the variance, $\sigma_{x}^{2}$, when WTLOW is $1 / 6$ 
result as the face becomes large relative to the area near the corners. Therefore, care must be taken to ensure that any surface to which a differential albedo is applied is large enough that the errors at the edges can be ignored.

Because differential albedos are expensive and time-consuming to generate, those corresponding to the Hansen-Roach 16-energy-group structure are the only differential albedos currently available for use with KENOVI. In the past, their use was limited to problems utilizing cross sections having the Hansen-Roach 16-energygroup structure. KENO-VI extends the use of differential albedos to other energy group structures by allowing appropriate energy transfers. Lethargy boundary tables are created for the albedo group structure and the crosssection group structure and determining the lethargy interval corresponding to the desired transfer (cross section group structure to albedo group structure or vice versa), as based on a uniform lethargy distribution over the interval. When the energy group boundaries of the cross sections and albedos are different, the results should be scrutinized by the user to evaluate the effects of the approximations.

\section{F17.2.5 SUPERGROUPING}

An important feature of KENO-VI is the capability of supergrouping energy-dependent information-cross sections, albedos, pointer arrays, weights, leakages, absorptions, fissions, and fluxes. If the available computer memory is too small to hold all the problem data at once, KENO-VI determines the number of supergroups necessary to allow execution of the problem. A problem cannot be supergrouped if the energy-dependent data associated with any individual energy group are too large to fit in the available memory. If enough memory is available to accommodate all the energy-dependent data at once, only one supergroup is created. Once the number of supergroups has been determined, the energy-dependent data are arranged in supergroups and are written on the direct-access supergroup file. During execution of a problem, the supergrouped data are moved in and out of memory as necessary.

The advantage of supergrouping is that larger problems can be run on smaller computers. This capability is gained at the expense of running time and increased I/Os. The more supergroups, the more I/Os are used, and the slower the problem will run because of the banking, sorting, and use of direct-access devices in the solution of the problem.

In order to reduce the amount of data movement between memory and the direct-access supergroup file, KENO-VI maintains a bank of histories (the neutron bank) and follows all those histories that fall within the current supergroup before going to the next supergroup. Histories that are scattered out of the current supergroup are placed back in the bank. When all the histories in the current supergroup have been processed, the bank is sorted, placing the histories for the most populous supergroup at the top of the bank. All other histories are placed at the bottom of the bank. The data for the most populous supergroup are then brought into memory and tracking proceeds.

\section{F17.2.6 RESTART}

KENO-VI incorporates a versatile and convenient restart capability. The decision to write a restart file requires the user to specify only the number of generations between writing restart data and the unit number where the restart file is to be written. A file definition must be included in the job control language for the restart data file. The input data are the first data written on the restart data file. The group-dependent input data are written a group at a time. This includes the cross sections, albedos, pointer arrays, and weights. The number of records of input data is automatically determined by the code and written on the restart data file. After the input data have been written on the restart data file, the calculated data are written at the end of each specified generation. These data include the generation number, random number, number of histories per generation,

F17.2.9

NUREG/CR-0200

Vol. 2, Rev. 5 
number of energy groups, bank lengths, common information, the $k_{\text {eff }}$ values by generation, the neutron bank, the fission densities, matrix arrays, and the calculated group-dependent data. These group-dependent data are written a group at a time and include leakages, absorptions, fissions and fluxes.

The KENO-VI restart capability allows a problem to be restarted at the first generation with different input because all data input supersedes data from the restart data file.

If a problem is to be restarted at a generation greater than 1 , the only data that can be changed are certain parameter data. Changes in the parameter data that are not allowed include (1) requesting fissions and absorptions by region if they were not requested by the parent case, (2) requesting fission densities and fluxes if they were not requested by the parent case, (3) requesting matrix information that was not requested in the parent case, and (4) changing the configuration of the neutron bank to be different from that of the parent case.

Because restart data are written a group at a time, a problem may be restarted with an entirely different supergroup structure.

If a problem is to be restarted following a generation for which restart data were not written, the code will write a message and restart with the next available generation for which restart data exist. If no such generation is found, the problem is terminated.

\section{F17.2.7 GEOMETRY}

KENO-VI geometry can model any geometric shape that can be described using quadratic equations. These geometric shapes are stacked together forming regions. The set of regions is then used to build units. A set of predefined shapes that include cones, cuboids (rectangular parallelepipeds), cylinders, dodecahedrons, ecylinders (elliptical cylinders), ellipsoids, hexprisms, hoppers, parallelepipeds, planes, thombohedrons, spheres, and wedges is used to construct regions. In addition, the keyword quadratic is provided which allows additional shapes to be constructed by specifying the quadratic equations that describe the shape. These shapes can be rotated and translated to any orientation and position within their respective unit. Hemispheres and hemicylinders can be constructed using spheres and cylinders with a chord. Regions are rotated by providing the nonzero angles associated with the Euler X-convention.

A major improvement in KENO-VI is the ability to intersect regions. Region volumes are no longer calculated due to the complexity involved with intersecting regions. Each set of multiple geometry regions is called a unit. KENO-VI allows multiple sets of geometry regions (i.e., units), with each set having an independent coordinate system. A global unit must be specified for every problem, including single-unit problems. Units having cuboidal outer boundaries where the adjoining faces have the same dimensions can be stacked together in a 3-D rectangular parallelepiped called an array or lattice, just as children's blocks can be stacked. Unlike KENO-V.a, units having hexagonal outer boundaries where the adjoining faces have the same dimensions can also be stacked together in an array. An array boundary must be specified that either coexists with the outermost edge of the array or that is entirely within the array. The array boundary can be any shape that is definable using quadratic equations. An array can be treated as a building block and be used as a unit within another array.

The use of holes in KENO-VI allows a unit to be emplaced within another unit. This feature allows the addition of a complex structure, previously defined as a unit, to be directly placed within another unit. However, a hole is not allowed to intersect other holes and must be completely contained within a specified region. In KENO-VI the use of holes to place complex structures within a unit may actually reduce the CPU time needed for the problem.

Multiple arrays can be described in KENO-VI. A global array must be specified if one is desired. In KENO-VI the outermost boundary is always specified as the global-unit boundary. If the outermost boundary is to be the array boundary, a global unit must still be specified with the global-unit boundary coinciding with the array boundary. Unlike past versions of KENO, KENO-VI cannot run a single unit problem without specifying a global unit.

NUREG/CR-0200

Vol. 2, Rev. 5

F17.2.10 


\section{F17.2.8 REFERENCES}

1. . Robert V. Meghreblian and David K. Holmes, Reactor Analysis, McGraw-Hill, 1960.

2. J. E. Powell and C. P. Wells, Differential Equations, Ginn Company, 1950.

3. E. A. Straker, P.N. Stevens, D. C. Irving, and V. R Cain, The MORSE Code-AMultigroup Neutron and Gamma-Ray Monte Carlo Transport Code, Appendix B, ORNL-4585, Union Carbide Corp., Nucl. Div., Oak Ridge Natl. Lab., 1970.

4. T. J. Hoffman, The Optimization of Russian Roulette Parameters for KENO-V.a, ORNL/TM-7539, Union Carbide Corp., Nucl. Div., Oak Ridge Natl. Lab., 1982.

5. L. M. Petrie and N. F. Cross, KENO IV - An Improved Monte Carlo Criticality Program, ORNL-4938, Union Carbide Corp., Nucl. Div., Oak Ridge Natl. Lab., 1975. Also see "KENO IV/S: An Improved Monte Carlo Criticality Program," Sect. F5 of SCALE: A Modular Code System for Performing Standardized Computer Analyses for Licensing Evaluation, NUREG/CR-0200, Rev. 3.

6. J. R. Knight and L. M. Petrie, 16- and 123-Group Weighting Functions for KENO-V.a, ORNL/TM-4660, Union Carbide Corp., Nucl. Div., Oak Ridge Natl. Lab., 1975.

7. G. E. Whitesides and J. T. Thomas, "The Use of Differential Current Albedos in Monte Carlo Criticality Calculations," Trans. Am. Nucl. Soc. 12, 889 (November 1969). 


\section{F17.3 LOGICAL PROGRAM FLOW}

The general flow of the KENO-VI program during the solution of a problem is given in this section. A formal flowchart is not included because of the voluminous nature of the program. The logical program flow is broken up into small sections. The format of each section includes an abbreviated flowchart, a brief explanation of the purpose of that section of the program, and a brief description of each subroutine involved. The abbreviated flowcharts are drawn with KENO-VI subroutine names contained in boxes and library routines as bare names. An arrow in the flowchart indicates that the subroutine associated with the arrow will be treated in detail later in the section.

\section{F17.3.1 PROGRAM INITLATION}

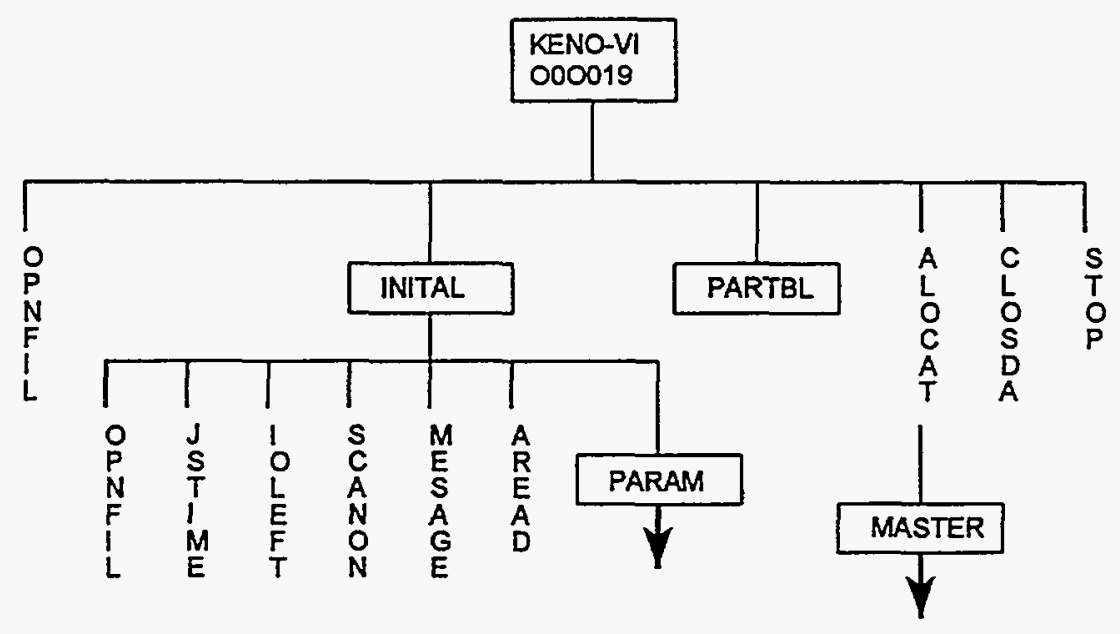

Figure F17.3.1. Flowchart of program initiation

The function of this portion of the program is to initialize information, print a header page, call the parameter reading subroutine PARAM, access subroutine MASTER with the storage space allocated by subroutine ALOCAT, and close out the direct-access files when the problem is completed or terminated (Figure F17.3.1).

KENOVI - These main programs set flags to specify the proper mode of data reading for the stand-alone O00019 - KENO-VI program INITAL is called to perform some initialization. MASTER is then called from ALOCAT with the requested storage allocation. The direct-access files are closed out by CLOSDA when a problem is completed or terminated.

OPNFIL - This library routine is called to initialize the input and output logical units. 
INITAL - This subroutine calls library routines to perform initialization and print a header page. It then reads the problem's title card and parameter read flag and calls subroutine PARAM to do the actual reading of the parameter data.

JSTIME - This call to the library routine JSTIME is for the purpose of storing the initial time in COMMON/FINAL/ for timing purposes.

IOLEFT - This call to the library routine IOLEFT is for the purpose of storing the initial I/O count in COMMON/FINAL/ for future calculations that indicate the number of $I / O$ s used in certain parts of the program.

SCANON - This library routine is called to activate the feature that allows scanning for the word END when reading data.

MESAGE - This library routine is called with two arguments, an eight-character hollerith argument and an output unit. Additional library routines are called from MESAGE to print a header page in block letters. The header page includes the eight-character hollerith argument (KENO-VI), the date, the time execution was begun, and the job name. The library routine LISTQA is called to provide a program verification page for quality assurance purposes.

AREAD - This library routine is used to read alphanumeric data. It is used here to read the title and the parameter reading flag.

PARAM - This subroutine is called to set default values for the parameter input data and to read parameter data. See Sect. F17.3.2 for a more detailed description of PARAM.

PARTBL - This subroutine prints out a table containing the values of all input parameters.

ALOCAT - This subroutine is called with three arguments. The first argument is a subroutine name, and the second argument is the maximum number of words of storage to be allocated. ALOCAT calls subroutine MASTER with two arguments, an array name, and the length of the array. The third argument is prefixed by an asterisk and specifies the statement number to return to if there is not enough storage to run the problem.

MASTER - This subroutine is called by subroutine ALOCAT. It is the controlling subroutine for the bulk of the KENO-VI program flow. See Sect. F17.3.3 for a more-detailed description of subroutine MASTER

CLOSDA - This library routine is called to close out each direct-access file at the normal completion or normal termination of a problem.

STOP - This library routine is called to write a message and terminate execution when there is insufficient storage to run the problem. 


\section{F17.3.2 PARAMETER DATA}

The function of this section of the program is to set default values for the parameters and to read the parameter input data (Figure F17.3.2).

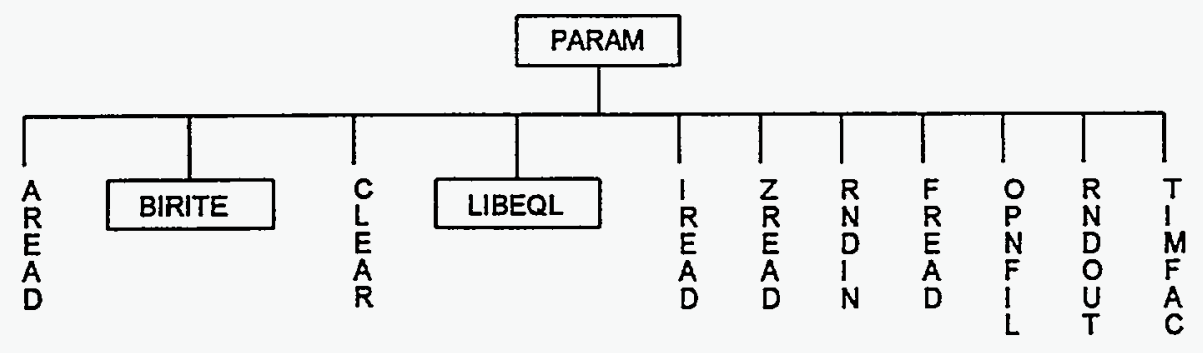

Figure F17.3.2. Flowchart of parameter reading

PARAM - This subroutine is responsible for reading the parameter input data and setting default values for the parameters. The library routine CLEAR is used to zero parameters that are defaulted to zero. The parameter data block is read using AREAD, IREAD, FREAD and ZREAD. Each entry in the parameter data block uses a keyword so the code can store the parameter data in the correct location. If the problem is a restart problem, restart information including the title of the original case, parameter data and some common information is read from the restart data file. The defaulted and input parameter tables are printed by PARAM. Some preliminary data checking is done, and appropriate warning and error messages may be printed.

CLEAR - This library routine is called to zero the parameters that are defaulted to zero.

AREAD - This library routine can be called many times from subroutine PARAM. It is used to read parameter names and alphanumeric parameter data.

IREAD - This library routine can be called many times from subroutine PARAM. It is used to read integer parameter data.

FREAD - This library routine can be called many times from subroutine PARAM. It is used to read floatingpoint data.

-ZREAD - This library routine can be called from subroutine PARAM to read a hexadecimal random number that will be used as a kernel for the random number package.

RNDIN - This library routine is called from subroutine PARAM to transfer the random number read by ZREAD to the random number package. It is called only if a random number was entered as parameter data. 
RNDOUT - This library routine is called from subroutine PARAM to preserve the current random number so it can be written on the restart data set and printed in the parameter data.

TIMFAC - This library routine is called from subroutine PARAM to provide the proper adjustment factor by which the allotted time is multiplied. This factor adjusts the execution time for execution on different computers.

OPNFIL - This library routine is called to initialize the logical unit for the restart data file.

BIRITE - This subroutine writes information to a buffer in CSAS format which could later be used for a restart problem.

LIBEQL - This subroutine reads the library number from ICE type input which contains the cross-section data to be used by the problem.

\section{F17.3.3 OVERALL PROGRAM FLOW}

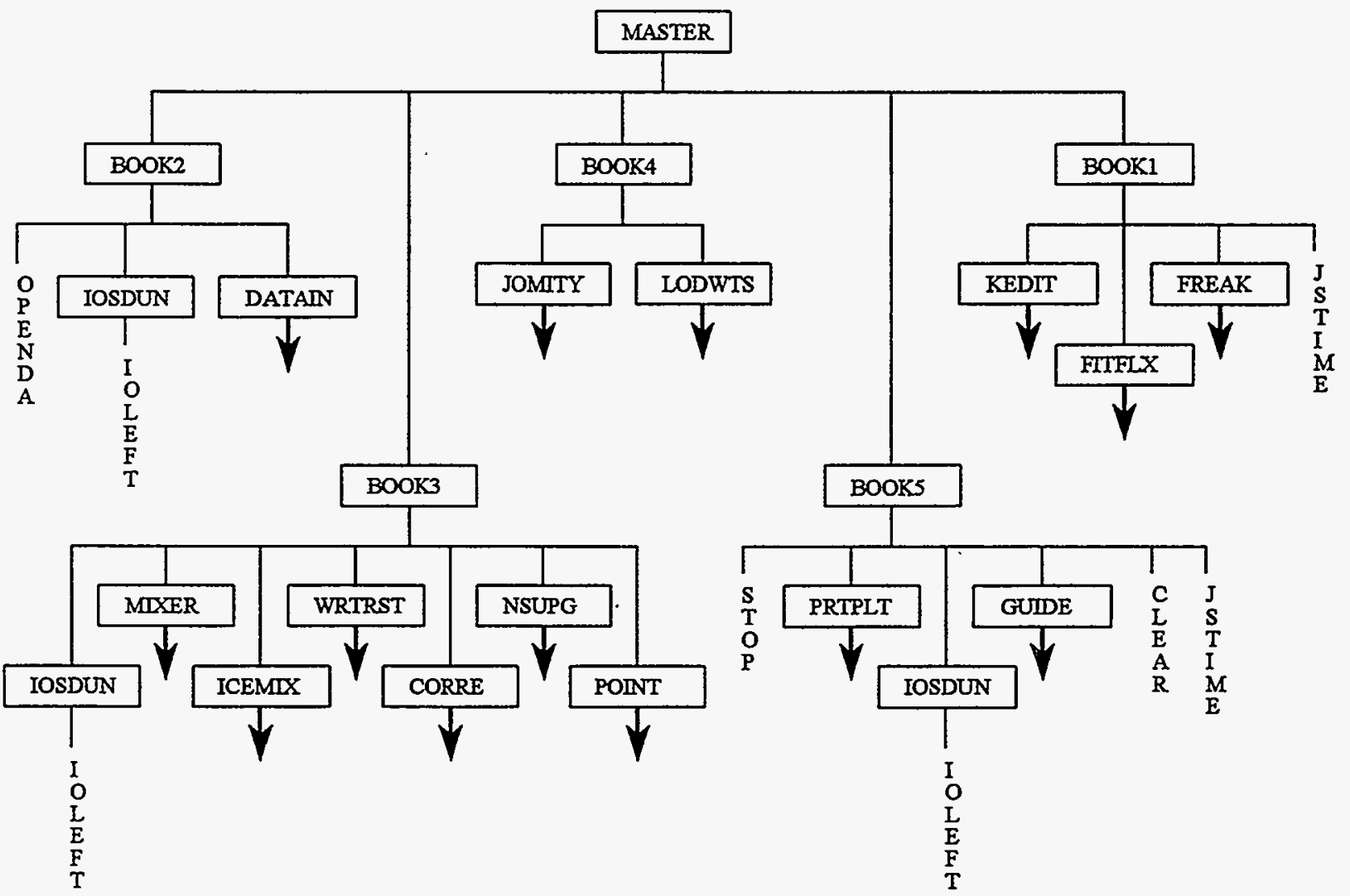

Figure F17.3.3. Flowchart of overall program flow 
The purpose of this section of the program is to direct the primary flow of KENO-VI (Figure F17.3.3). This flowchart covers the complete scope of the program from data reading to editing and printing the results.

MASTER - This subroutine controls the primary flow of KENO-VI. It initializes the direct access files and calls subroutines to read, check and print the input data, calls the tracking routines and prints the calculated results. The number of $\mathrm{I} / \mathrm{O}$ s used during various operations is calculated and printed. The following subroutines are called from MASTER as indicated:

\begin{tabular}{lll} 
Subroutine & \multicolumn{1}{c}{ Function } & \multicolumn{1}{c}{ Condition } \\
\cline { 1 - 2 } OPENDA & Initializes direct access & Always \\
BOOK2 & Controls Inputting of Data & Always \\
BOOK3 & Controls Data Mixing and Organization & Always \\
BOOK4 & Controls Geometry Processing and biasing data & Always \\
BOOK5 & Controls Tracking and Plots & Always \\
BOOK1 & Controls Output & Always \\
IOSDUN & Initializes IOs & Always \\
DATAIN & Reads input data & Always \\
MIXER & Mixes cross sections & If mixing table is read \\
ICEMTX & Reads ICE mixed library & If cross sections are not to be \\
& & used from the restart data file \\
WRTRST & Writes restart information & If a unit is defined for writing \\
& & restart information \\
CORRE & Generates albedo-cross-section information & If differential albedo data are \\
& & used \\
NSUPG & Creates supergrouped data & Always \\
POINT & Calculates pointers & Always \\
JOMITY & Primarily controls geometry processing & Always \\
PRTPLT & Prints specified plots & If a plot data block is entered \\
& & and the plot option is not turned \\
& & off \\
CLEAR & Initializes arrays where calculated data are stored & Always \\
LODWTS & Loads biasing data from direct access into memory & Always \\
GUIDE & Controls tracking & Always \\
KEDIT & Edits calculated results & Always \\
FITFLX & Loads fluxes for printing & If fluxes are calculated \\
FREAK & Prints frequency distribution & Always \\
JSTIME & Timing & Always \\
& &
\end{tabular}

OPENDA - This library routine initializes the direct-access files.

BOOK2 - This subroutine is called once to call the subroutines needed to read the input data.

BOOK3 - This subroutine is called once to call the subroutines that read, mix, or generate the required crosssection data, write restart information, create supergroup data if required, and calculate pointers. 
BOOK4 - This subroutine is called once to call the subroutines that controls geometry data processing and reads required biasing data.

BOOK5 - This subroutine is called once to call the subroutines that print plots and control particle tracking.

BOOKl - This subroutine is called once to call the subroutines that calculate results and print output.

IOSDUN - This subroutine is called several times to indicate the number of I/Os used for various operations.

DATAIN - This subroutine controls the reading of all input data except the title and parameters. It is explained in more detail in Sect. F17.3.4.

MIXER - This subroutine is called only if mixing table information is to be entered as data. It controls the mixing of cross-section information and writes a Monte Carlo formatted mixed cross-section library for use later in the program. More details are contained in Sect. F17.3.5.

ICEMIX - This subroutine reads the Monte Carlo formatted mixed cross-section library and manipulates the cross sections to obtain the cross-section information used by KENO-VI. This information is then written on the direct-access data file. See Sect. F17.3.6 for additional information.

WRTRST - This subroutine is called if a unit has been defined on which to write restart information. The function of WRTRST is to write restart information as explained in Sect. F17.3.7.

CORRE - This subroutine is called only if the albedo data block specifies differential albedo data. It creates lethargy boundary tables and generates albedo cross-section energy group correspondence information. See Sect. F17.3.8 for additional details.

NSUPG - The purpose of this subroutine is to create supergrouped information and write it on the directaccess file as described in Sect. F17.3.9.

POINT - This subroutine calculates pointers to access data in memory.

JOMITY - This subroutine is primarily responsible for generating additional geometry data, checking the geometry data, writing appropriate geometry error messages, and printing the geometry that is used in the problem. Section F17.3.10 contains additional details.

LODWTS - This subroutine reads biasing information data from the direct-access data file, loads it into memory and prints it as described in Sect. F17.3.11.

PRTPLT - This subroutine is called to generate and print 2-D printer plots representing slices through the geometrical representation of the physical problem. See Sect. F17.3.12 for additional details.

CLEAR - This library routine initializes arrays where the calculated data are stored.

GUIDE - This subroutine guides the flow of the program through the actual tracking of each history. See Sect. F17.3.13 for a more detailed explanation.

NUREG/CR-0200

Vol. 2, Rev. 5

F17.3.6 
KEDIT - This subroutine is responsible for editing the $\mathrm{k}_{\mathrm{eff}}$ values and printing the various information calculated by KENO-VI. Section F17.3.14 contains additional details.

FITFLX - This subroutine is called only if fluxes are calculated. Its purpose is to determine the maximum number of regions for which fluxes can be contained in memory and to print the fluxes. A moredetailed description is contained in Sect. F17.3.15.

FREAK - This subroutine is called to generate and print the frequency distribution of the $k_{\text {eff }}$ calculated for each generation. The library routines SQRT and EXP are utilized in these calculations.

JSTIME - This library routine is called at the completion of a problem to compute the total amount of time used.

\section{F17.3.4 PROBLEM DESCRIPTION}

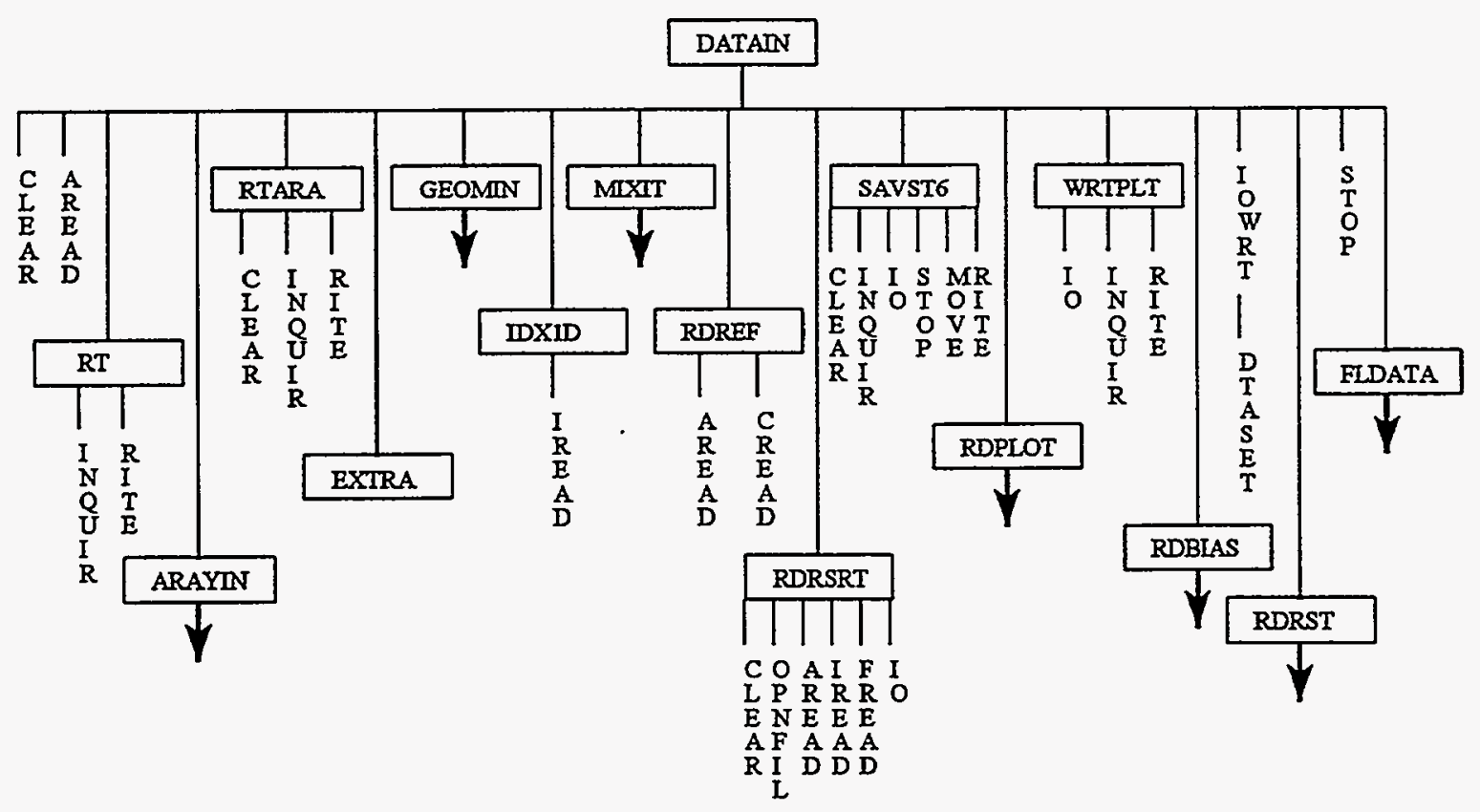

Figure F17.3.4. Flowchart of input data reading

This section of the program controls the reading of the input data (Figure F17.3.4), excluding the title card and parameter data. After the data have been read, they are written on the direct-access data file.

DATAIN - This subroutine controls all the data reading with the exception of the title and parameter data. It initializes COMMON/STDATA/, the common that contains the start data, and initializes the MT array that contains the IDs of the $1-D$ cross sections that are to be utilized in the problem. The data 
reading is accomplished by reading blocks of data, as described in Sect. F17.4. A keyword precedes the data, indicating the type of data to be read. After reading the keyword, the appropriate subroutine is called to read the accompanying data block. After the data block has been read, it is written on the direct-access data file. IOWRT is called several times to generate a table that lists the unit numbers used by KENO-VI, their names, data set names and the volume containing the data set. This table can be valuable for quality assurance applications. The library routine STOP is called to write error messages. Subroutine FLDATA is then called to supply information that was not entered as data.

CLEAR - This library routine is called to initialize COMMON /STDATA/. If biasing data are entered, it is called to clear the space that will contain the biasing data. CLEAR is called with two arguments, a beginning location and a length. It initializes all included locations to zero.

AREAD - This library routine is used to read the READ flag, the keyword for the type of data to be read, the END flag and the keyword for the type of data just completed. It can be called many times from DATAIN.

RT - $\quad$ This subroutine is called to write data on the direct-access data file. It passes information between DATAIN and RITE. INQUIR is called to return the value of the next direct-access record after the geometry data and/or the extra 1-D cross sections are written on a direct-access device.

RITE - This library routine is called from RT to write an array of data on the direct-access data file.

ARAYIN - This subroutine is called to read data defining the array size. It also reads the unit orientation data if any are entered as data. ARAYIN is always called if array data are specified. See Sect. F17.3.4.1 for additional information. Data input for the array data block is described in detail in Sect. F17.4.5.

RTARA - This subroutine is called only if ARAYIN is called. CLEAR is called to zero the array before RTARA reads the array data from the scratch unit and writes them on the direct-access device. INQUIR is called to return the value of the next direct-access record after the array data are written on the direct-access device.

EXTRA - This dummy subroutine is provided to allow the user to input extra data that are not typically processed by KENO-VI. The user must provide the programming to read and utilize the data.

GEOMIN - This subroutine is called to read the geometry region data. See Sect. F17.3.4.2 for additional information. The geometry region data block is described in detail in Sect. F17.4.4.

IDX1D - This subroutine is called if the number of extra 1-D cross sections is greater than zero and an extra 1-D data block is entered. It reads the extra 1-D IDs and loads them into the MT array. The data reading is accomplished using the library routine IREAD. Section F17.4.9 describes the data input for defining extra 1-D data.

MIXIT - This subroutine is called to read the mixing table data block that defines the mixtures that are to be created. Section F17.3.4.3 explains the mixing procedure in more detail. 
RDREF - This subroutine is called to read the boundary conditions (or albedo options) that are to be applied at the outer boundaries of the system described by the geometry data and the unit orientation data. The boundary condition data block is read using the library routine AREAD. The library routine, CREAD, is used to read the albedo names. Some preliminary data checks are made to detect invalid face code names and incompatible boundary conditions. Section F17.4.6 describes the data input for defining the boundary conditions.

RDSTRT - This subroutine is called to read the start data block that is used to define the spatial distribution of the initial generation. The library routine, CLEAR, is called to zero the array that will contain the start data. The library routine AREAD is used to read the keywords associated with the start data. IREAD and FREAD are used to read the integer and floating-point start data, respectively. The library routine $\mathrm{IO}$ is used to write the start data associated with start type 6 on the scratch data file. The library routine, INQUIR, returns the value of the next direct-access record after writing the start data on the direct-access device. Data input for defining the initial source distribution is described in Sect. F17.4.8.

SAVST6 - This subroutine is called to save the data associated with start type 6. SAVST6 is called only if start type 6 was specified in the start type data. See Sect. F17.4.8 for start type information. The library routine CLEAR is called to initialize the array that will contain the start data arrays. The library routine IO is used to read the start data array from the scratch data file and load it into memory. The library routine MOVE is used to move the start data array into the neutron bank. The library routine RITE is called to write the neutron bank data on the direct-access data file. The library routine, INQUIR, returns the value of the next direct-access record after writing the start type 6 data on the direct-access device.

RDPLOT - This subroutine is called to read the plot data block that is used to generate printer plots. Section F17.3.4.4 explains the processing of the plot data in more detail. Section F17.4.11 describes the plot input data in detail.

WRTPLT - This subroutine reads the plot data block from the scratch data file and loads it on direct access. IO reads the data from the scratch data file and loads them in memory. RITE writes the data on the direct-access data file. INQUIR returns the value of the next direct-access record.

RDBIAS - This subroutine is called to read the biasing or weighting data to be used in the problem. See Sect. F17.3.4.5 for more information. The biasing input data block is described in detail in Sect. F17.4.7.

IOWRT - This library routine is called with five arguments. They are, in order, (1) the output unit, (2) a four-character hollerith name representing a unit name, (3) the unit number represented by the second argument, (4) the number of words of hollerith information contained in the fifth argument, and (5) hollerith information to be printed. IOWRT is called several times to generate a table of the unit numbers, their names, the data set names, and the volumes on which each resides.

DTASET - This library routine is called from IOWRT to provide the data set name of the requested I/O unit and the volume on which it resides.

RDRST - After the data reading is complete, this subroutine is called if a unit containing data for restarting the problem has been defined. It loads data from the restart data file as described in Sect. F17.3.4.6. 
FLDATA - This subroutine is called to supply default data for arrays that were not entered as input. Section F17.3.4.7 contains a more-detailed account of the exact procedure.

F17.3.4.1 Array Data

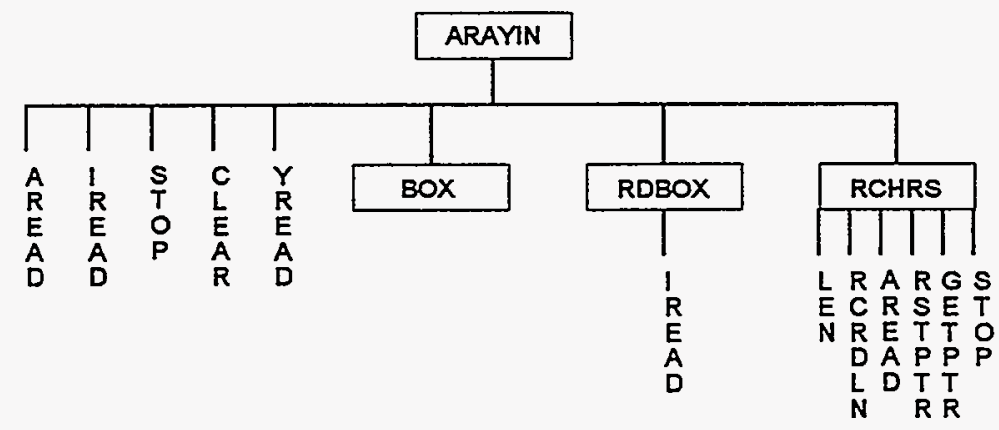

Figure F17.3.5. Flowchart for reading array data

(Figure F17.3.5).

ARAYIN - This subroutine is called from DATAIN when the words READ ARRA are encountered. It is responsible for reading the data parameters that define the size of each unit orientation array. The unit orientation array data block for each array is read by YREAD for the FILL option and by RDBOX for the LOOP option. BOX then writes the array data on the scratch data file. CLEAR is called to zero the unit orientation array and the data reading is done using the library routines AREAD, IREAD, and YREAD. Section F17.4.5 describes the data read by this subroutine.

AREAD - This library routine is used to read the keywords associated with the array data.

IREAD - This library routine is used to read the integer data associated with the array data.

STOP - This library routine is called to write an error message and stop if insufficient memory is available to accommodate the unit orientation array.

CLEAR - This library routine is called to zero the unit orientation array before it is loaded.

YREAD - This library routine is called to read the unit orientation data for the FILL option.

BOX - This subroutine is called to write the array data on the scratch data file. 
RDBOX - This subroutine is called only if the LOOP option is used for entering the unit orientation data. It uses the library routine IREAD to read the unit orientation data. Some data consistency checks are made and appropriate error messages are written if errors are encountered. If the input geometry is to be printed, RDBOX prints the unit orientation for each array.

RCHRS - This subroutine is used to read the comment associated with an array. The intrinsic function LEN determines the length of the comment. GETPTR is used to return the current pointer in the input buffer. RSTPTR resets the pointer. AREAD is used to read the input data and RCRDLN sets the length of the input buffer. STOP is called to write an error message and stop if the array comment is too long (i.e., the ending delimiter is missing).

F17.3.4.2 Geometry Data

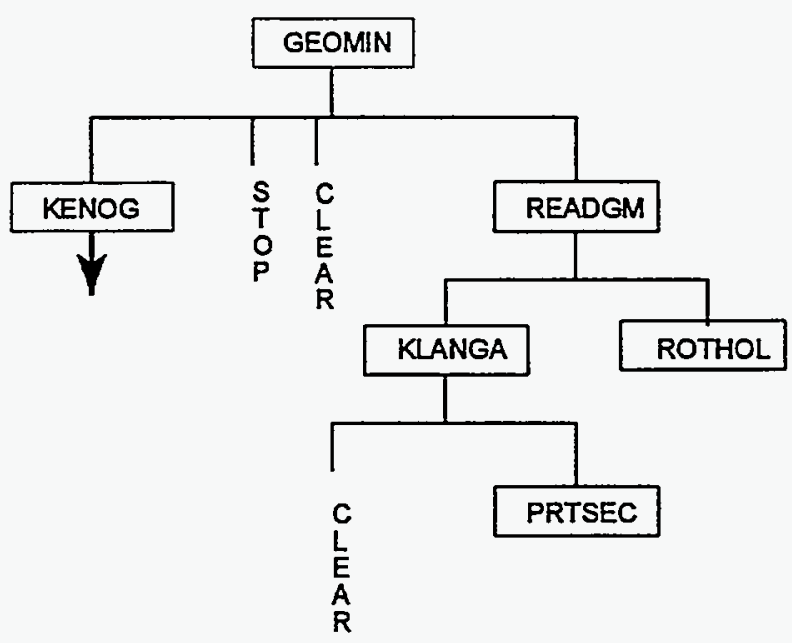

Figure F17.3.6. Flowchart for reading geometry and media keyword data

This section of the program reads the geometry data (Figure F17.3.6).

GEOMIN - This subroutine controls the reading of the geometry data. KENOG is called to read each geometry region specification and write it on the scratch data unit. Pointers for the data arrays are then calculated, and CLEAR is called to initialize the data arrays. READGM is called to read the data from the scratch data unit and load them into the appropriate data arrays. STOP is called to write an error message if more storage is needed. The data block read in this portion of the program is described in Sect. F17.4.4.

KENOG - This subroutine uses AREAD to read the geometry word and IREAD to read the unit number. KENOG then calls the appropriate subroutine, based on the geometry word previously read, to read in the associated geometry data. The necessary geometry data block is written on the scratch data unit. If the input geometry data block is to be printed, KENOG does this as the data are read. 
READGM - This subroutine reads the geometry data from the scratch data unit created in KENOG and loads them into the proper arrays.

KLANGA - This subroutine creates a geometry word sector array that defines how the geometry/material regions relate to the geometric shapes in each unit.

ROTHOL - This subroutine creates a rotation matrix for the holes if required.

PRTSEC - This subroutine writes the sector array to the file.

This section of the program contains the subroutines that read the geometry data for each geometric input shape, as well as holes and arrays, and writes the data to a scratch file.

ROTRNS - This subroutine translates and rotates the location and orientation of a geometric body based on the geometric keyword read in and the data relating to the body read from the subroutines ORIGIN and ROTATE.

SPHERE - This subroutine reads the radius of a sphere using DREAD and generates the coefficients of the quadratic equation that represents the surface of the sphere.

CYLNDR - This subroutine reads the radius and top and bottom surfaces of a cylinder using DREAD and generates the set of quadratic equations that represent the surface of the cylinder.

ECYL - This subroutine reads the $x$-radius, $y$-radius, and top and bottom surfaces of an elliptical cylinder using DREAD and generates the set of quadratic equations that represent the surface of the cylinder.

ELLIPS - This subroutine reads the $x$-radius, $y$-radius, and $z$-radius of an ellipse using DREAD and generates the quadratic equation that represents the surface of the ellipse.

CONE - This subroutine reads the top radius, bottom radius, top surface, and bottom surface using DREAD and generates the set of quadratic equations that represent the surface of the cone section.

CUBOID - This subroutine reads the $+X,-X,+Y,-Y,+Z$, and $-Z$ faces of the cuboid using DREAD and generates the set of quadratic equations that represent the surface of the cuboid.

HXPRSM - This subroutine reads the inscribed radius, the top surface, and the bottom surface of a hexprism using DREAD and generates the set of quadratic equations that represent the surface of the hexprism.

WEDGE - This subroutine reads the $x$-coordinate of the triangular base, the $x$ and $y$ coordinates of the intersection of the other two sides, and the height of the wedge using DREAD and generates the set of quadratic equations that represent the surface of the wedge.

RHOMB - This subroutine reads the length of a side and the angle between the $y$-face and the $y$-axis of the rhomboid using DREAD and generates the set of quadratic equations that represent the surface of the rhomboid. 
CRSPRD - This subroutine generates and returns a unit vector from the cross product of two input vectors.

PPIPED - This subroutine reads the $x$-distance, $y$-distance, $z$-distance, the angle between the $y$-distance and the $y$-axis, the angle between the $z$-distance and the $z$-axis, and the angle between the projection of the $z$-distance on the $x$-y plane and the $x$-axis using DREAD and generates the set of quadratic equations that represent the surface of the parallelepiped.
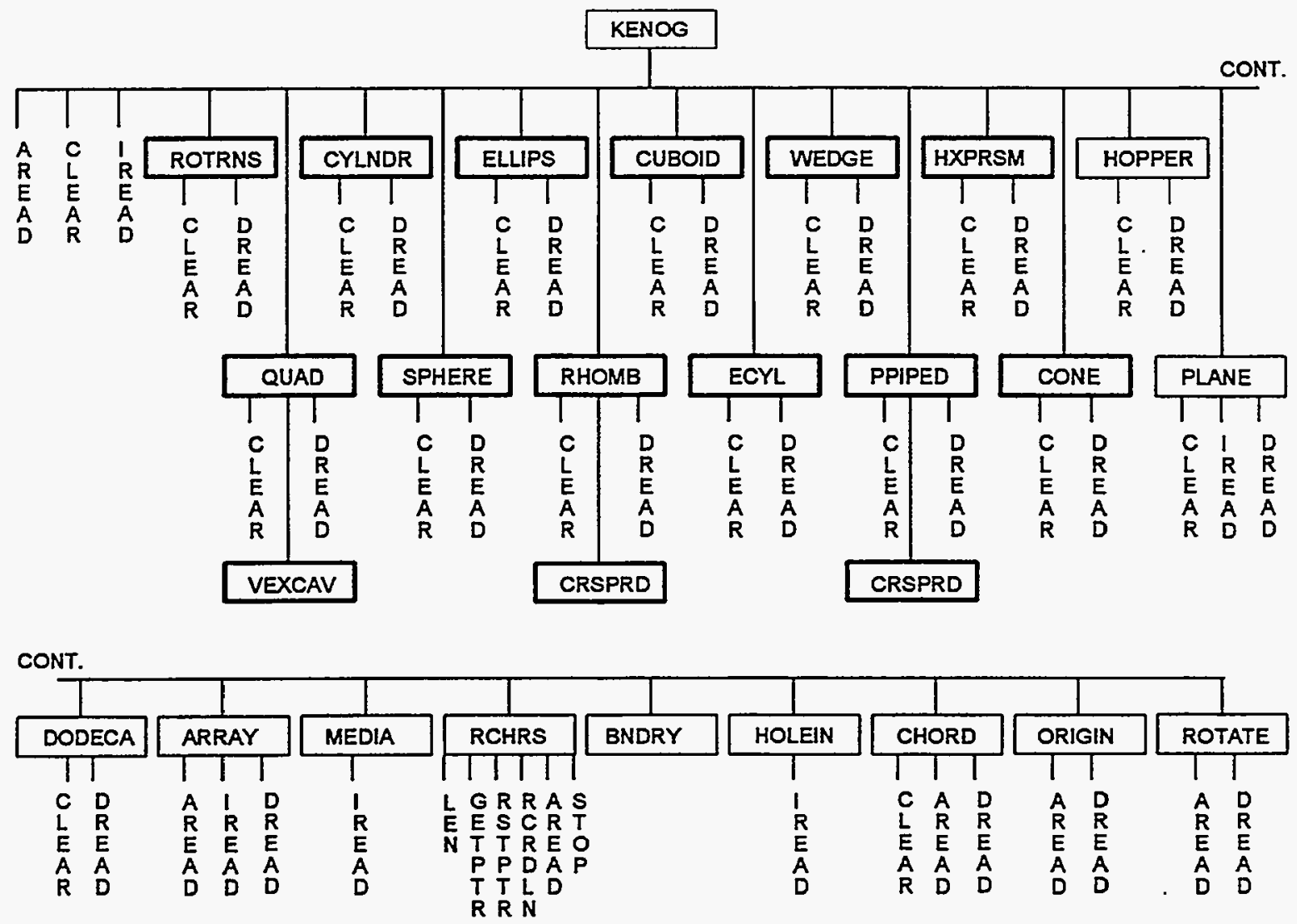

Figure F17.3.7. Flowchart for reading geometry boundary and media data

HOPPER - This subroutine reads the $x$ half-length, $y$ half-length and $z$ surface for the top and the $x$ half-length, $y$ half-length, and $z$ surface for the bottom using DREAD and generates the set of quadratic equations that represent the surface of the hopper.

PLANE - This subroutine reads the keywords and associated dimensions that represent a plane using AREAD and DREAD, respectively, and generates the quadratic equation that represents the planar surface.

QUAD - This subroutine reads the keywords and associated coefficients of a quadratic using AREAD and DREAD respectively. 
VEXCAV - This function determines if the quadratic equation specified using QUAD is convex or concave.

DEDUCE - This subroutine reads the inscribed radius of the dodecahedron using DREAD and generates the quadratic equation that represents the surface of the dodecahedron.

ARRAY - This subroutine reads the array number and definition vector of the region containing the array using IREAD, the keyword for placing the array in the unit using AREAD, and the origin of the unit at the specified array position relative to the origin of the unit containing the array using IREAD and DREAD.

MEDIA - This subroutine reads the media number, the importance region, and the definition vector for the sector using IREAD.

BNDRY - This subroutine reads the definition vector that describes the boundary of a unit.

HOLEIN - This subroutine reads the unit number inserted in the hole and the definition vector of the region containing the hole using IREAD.

CHORD - This subroutine reads the chord orientation keyword using AREAD and the plane location using $\mathrm{DREAD}$, then generates the quadratic equation that represents the surface of the plane and adds it to the set of equations that represents the geometric shape being developed.

ORIGIN - This subroutine reads the set of translation keywords using AREAD and the values associated with each keyword using DREAD. These values are then stored in common block /RTRN/.

ROTATE - This subroutine reads the set of rotation keywords using AREAD and the values associated with each keyword using DREAD. These values are then stored in common block /RTRN/.

F17.3.4.3 Mixing Table Data

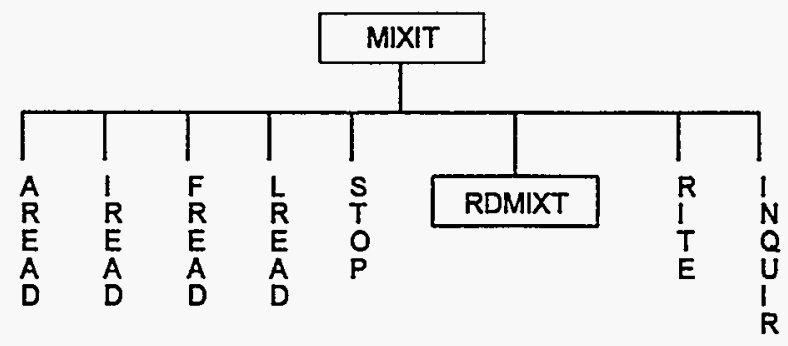

Figure F17.3.8. Flowchart for reading mixing table data

This section deals with reading the mixing table data (Figure F17.3.8).

MIXIT - This subroutine uses AREAD to read the mixture keywords and the scattering keyword. IREAD is used to read the mixture numbers and the number of scattering angles as well as the nuclide IDs. LREAD is used to determine if the next digit is a numeric digit. FREAD reads the number 
densities. The necessary data arrays are written on the scratch data file. Pointers are calculated for the necessary storage arrays and RDMIXT is called to load the data from the scratch file into the storage arrays. RITE is called to write the mixing table information on the direct-access device and INQUIR is called to return the value of the next direct-access record.

LREAD - This library routine returns a value of "true" if the next character is a numeric digit. Otherwise, a value of "false" is returned.

STOP - This library routine is called from MIXIT if the storage space is insufficient to hold the mixing table arrays.

RDMIXT - This subroutine reads the mixing table data arrays from the scratch data file and loads them into the storage arrays.

\section{F17.3.4.4 Plot Data}

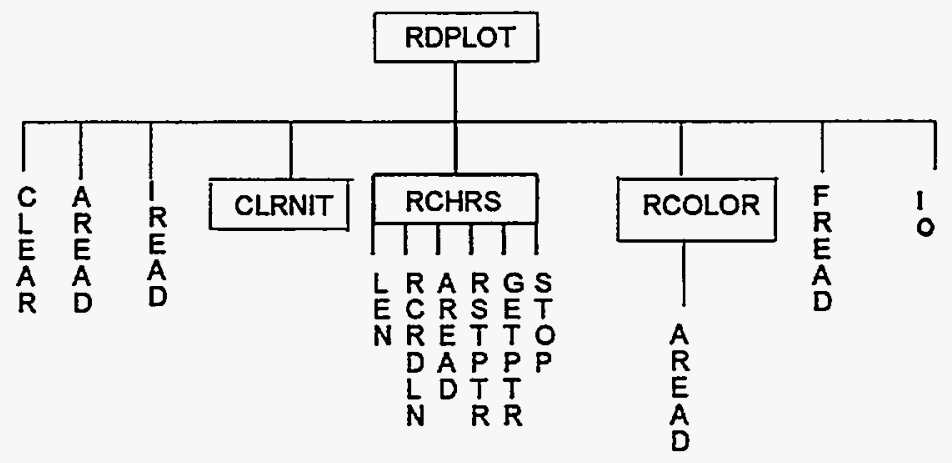

Figure F17.3.9. Flowchart for reading plot data

This section of the program reads the plot or picture data used to generate printer plot maps of the mixtures, units and/or bias IDs used in the problem (Figure F17.3.9). The plot input data block is described in Sect. F17.4.11.

RDPLOT - This subroutine uses CLEAR to initialize the data arrays. RCHRS is used to read the plot title and the character string of symbols to be used in the plot. AREAD, IREAD and FREAD are used to read the plot or picture input data. SQRT is used to determine the normalization factor for the direction cosines, and IO is called to load the plot data on the scratch data file.

RCHRS - This subroutine is used to read the plot title and the character string that defines the symbols to be used in the plot. The intrinsic function LEN is used to determine the length of a character variable. GETPTR is used to return the current pointer in the input buffer. RSTPTR resets the pointer. AREAD is used to read the input data, and RCRDLN sets the length of the input buffer. STOP is called to write an error message if the plot title is too long and terminate the problem. 
CLRNIT - This subroutine initializes the color tables for screen plots.

RCOLOR - This subroutine is used to redefine the red, green, and blue components of the screen plot color tables. AREAD is used to read the color table position and the new red, green, and blue values of that position.

F17.3.4.5 Biasing Data

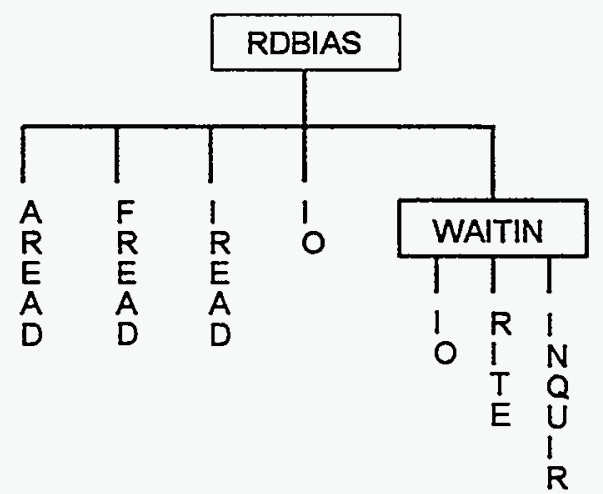

Figure F17.3.10. Flowchart for reading biasing data

This section of the program reads the biasing data used in the problem (Figure F17.3.10). The biasing input data block is described in Sect. F17.4.7.

RDBIAS - This subroutine is responsible for reading the biasing data block and writing it on the scratch data file. AREAD is used to read the keywords used in the biasing data and a title for the biasing material if the energy and space dependent values of the biasing function are entered by the user. IREAD and FREAD are used to read the numerical data. Pointers for the storage arrays needed to process the biasing data are determined, and WAITIN is called to load the data from the scratch data file into the storage arrays and write them on the direct-access data file.

WAITIN - This subroutine reads the biasing data block from the scratch data file and loads it into the storage arrays. IO is used to load the energy- and space-dependent biasing function (wtovg) into the storage arrays. RITE is used to write the biasing data on the direct-access data file. INQUIR is then called to return the value of the next direct-access record. 


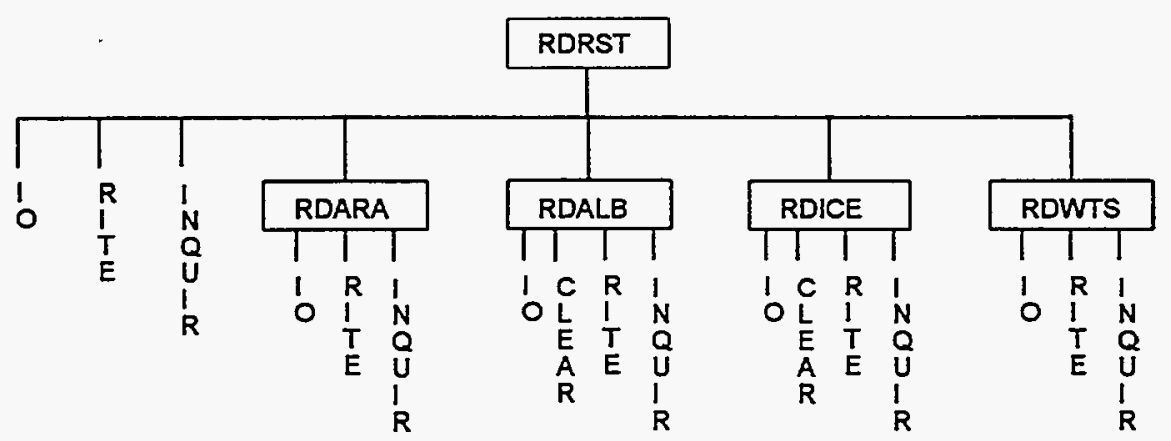

Figure F17.3.11. Flowchart for reading restart data

This section of the program reads restart information from the restart data file (Figure F17.3.11).

RDRST - This subroutine is called only if the problem is to use data from the restart data file. The program recognizes that restart data will be read if the restart unit is defined as a number greater than zero. IO is used to load the array that contains the 1-D IDs from the restart data file. Each type of data is loaded from the restart data file using IO and is written on the direct-access data file by RITE. - All restart data, except the mixed cross-section data, the differential albedo data, the array data, and the biasing data, are processed directly in RDRST. RDICE is called to load the cross-section data on the direct-access data file, RDALB is called to load the differential albedo data on the directaccess data file, RDARA is called to load the array data on the direct-access data file, and RDWTS is called to load the biasing data on the direct-access data file. The library routine INQUIR is called to return the value of the next direct-access record.

RDALB - This subroutine is called from RDRST to read the albedo data block from the restart data file and write it on the direct-access data file. IO is used to load the albedo pointer and length arrays into memory from the restart data file. CLEAR is called to zero the albedo pointer and length arrays and RITE writes them on the direct-access data file. Each record of albedo data is read from the restart data file, loaded into memory using $\mathrm{IO}$, and written on the direct-access data file using RITE. When all the records of albedo data have been processed, the updated pointer and length arrays are rewritten over the initial ones using RITE. INQUIR returns the value of the next directaccess record.

RDICE - This subroutine is called from RDRST to read the cross-section data block from the restart data file and write it on the direct-access data file. CLEAR is called to zero the pointer and length arrays. The length array is then read from the restart data file. RITE is used to write the pointer array and the length array on the direct-access data file. Then IO and RITE are used to load the cross-section data from the restart data file and write them on the direct-access data file. This procedure is repeated for every record of each mixture. The updated pointer and length arrays are then rewritten over the initial ones using RITE. INQUIR returns the value of the next direct-access record. 
RDARA - This subroutine is called from RDRST to read the array data block from the restart data file and write it on the direct-access data file. IO is used to load the data from the restart data file, and RITE is used to write them on the direct-access data file. INQUIR returns the value of the next directaccess record.

RDWTS - This subroutine is called from RDRST to read the biasing data block from the restart data file and write it on the direct-access data file. IO is used to load the data from the restart data file and RITE is used to write them on the direct-access data file. INQUIR returns the value of the next directaccess record.

\section{F17.3.4.7 Generate Remaining Data}

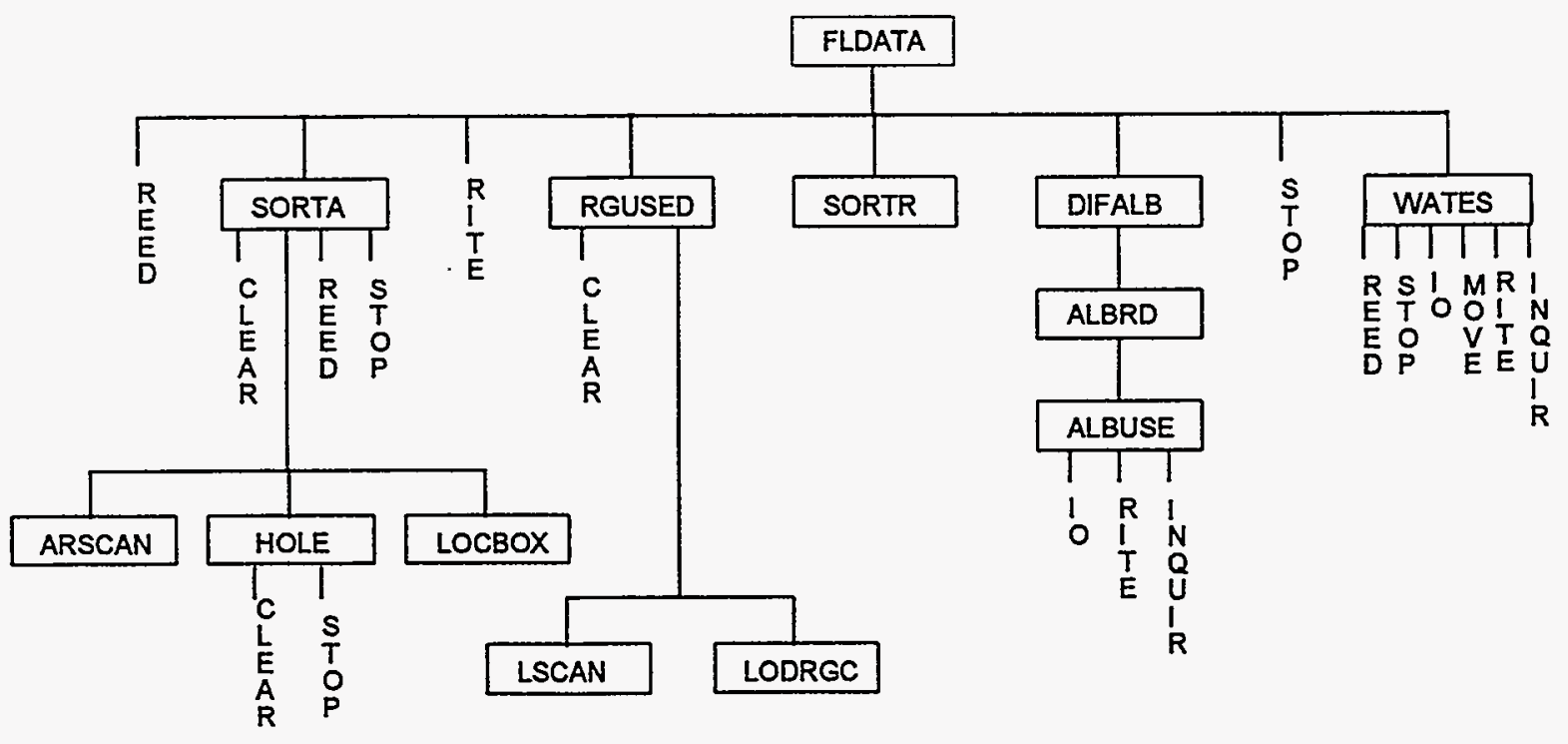

Figure F17.3.12. Flowchart for generating remaining data

This section of the program is responsible for generating data blocks that are required to solve a problem but are not entered directly as data (Figure F17.3.12).

FLDATA - The library routine REED is used to load data arrays from the beginning of the mixtures used in the geometry through the geometry data. The library routine, STOP, may be called to print an error message. SORTA is called to determine which arrays and holes are used as well as the array and hole nesting levels. RITE is called to write the geometry data on the direct-access data file. RGUSED is called to determine which geometry regions are used in the problem. SORTR is called to generate the mixture correspondence array. It is called again to generate the bias region correspondence array. These correspondence arrays are used to avoid storing mixture cross sections and biasing data that were entered as data but are not actually used in the problem. If boundary conditions specify differential albedo data and they are not available from the restart data file, DIFALB is called to read the albedo data block and load the requested data on the direct-access file. 
If the requested biasing data were unavailable from the restart data file, WATES is called to load the energy and position biasing function (wtovg array) on the direct-access data file.

SORTA - This subroutine checks to see that the global array is properly defined. It determines the array correspondence array and the nesting levels for holes and arrays. SORTA uses CLEAR to initialize arrays. REED is used to load the array data and STOP is used to write an error message and terminate if more computer storage is needed for the problem.

ARSCAN - This function, which is called from sorta, is used to determine if array data have been entered if an array was specified.

HOLE - This subroutine is called from SORTA to determine what holes occur at the next nesting level and to adjust the array nesting level for arrays that occur in holes. It also checks to be sure holes are not recursively nested.

LOCBOX - This function subprogram is called from SORTA to determine the unit at a given position in the unit orientation array.

RGUSED - This subroutine determines which geometry regions are used in the problem. The library routine CLEAR is called to zero the space for the region correspondence array. LSCAN determines if a particular unit has been used in the unit orientation array and if it has, LODRGC is called to load the region number into the region correspondence array.

LSCAN - This is a logical function that returns a value of true if the specified unit is used in the unit orientation array. A value of false is returned if the unit was not used in the unit orientation array.

LODRGC - This subroutine loads the region number in the region correspondence array.

SORTR - This subroutine is called twice from FLDATA to create a mixture correspondence array and a biasing correspondence array. These correspondence arrays are used to avoid storing mixture cross sections and biasing information that were defined in the input data but were not referenced in the geometry data utilized in the problem. They are also used throughout the code for accessing the proper mixture cross sections and biasing information.

DIFALB - This subroutine is called if differential albedos are specified as a boundary condition but are not available from the restart data file. It rewinds the albedo data file, reads the header record and calculates pointers. ALBRD is called to load the albedo data.

ALBRD - This subroutine searches through the albedo data file to locate the requested albedo name or boundary condition. If it is not found, an enror message is written. If it is found, the number of different differential albedos that were requested are tabulated and ALBUSE is called.

ALBUSE - This subroutine writes the pointer array on the direct-access data file. IO is used to load data from the albedo data file and RITE is used to write the data on the direct-access data file. Then the pointer and length arrays are rewritten on the direct-access data file. The library routine INQUIR is called after each call to RITE to return the value of the next direct-access record. 
If the requested biasing data were unavailable from the restart data file, WATES is called to load the energy and position biasing function (wtovg array) on the direct-access data file.

SORTA - This subroutine checks to see that the global array is properly defined. It determines the array correspondence array and the nesting levels for holes and arrays. SORTA uses CLEAR to initialize arrays. REED is used to load the array data and STOP is used to write an error message and terminate if more computer storage is needed for the problem.

ARSCAN - This function, which is called from sorta, is used to determine if array data have been entered if an array was specified.

HOLE - This subroutine is called from SORTA to determine what holes occur at the next nesting level and to adjust the array nesting level for arrays that occur in holes. It also checks to be sure holes are not recursively nested.

LOCBOX - This function subprogram is called from SORTA to determine the unit at a given position in the unit orientation array.

RGUSED - This subroutine determines which geometry regions are used in the problem. The library routine CLEAR is called to zero the space for the region correspondence array. LSCAN determines if a particular unit has been used in the unit orientation array and if it has, LODRGC is called to load the region number into the region correspondence array.

LSCAN - This is a logical function that returns a value of true if the specified unit is used in the unit orientation array. A value of false is returned if the unit was not used in the unit orientation array.

LODRGC - This subroutine loads the region number in the region correspondence array.

SORTR - This subroutine is called twice from FLDATA to create a mixture correspondence array and a biasing correspondence array. These correspondence arrays are used to avoid storing mixture cross sections and biasing information that were defined in the input data but were not referenced in the geometry data utilized in the problem. They are also used throughout the code for accessing the proper mixture cross sections and biasing information.

DIFALB - This subroutine is called if differential albedos are specified as a boundary condition but are not available from the restart data file. It rewinds the albedo data file, reads the header record and calculates pointers. ALBRD is called to load the albedo data.

ALBRD - This subroutine searches through the albedo data file to locate the requested albedo name or boundary condition. If it is not found, an error message is written. If it is found, the number of different differential albedos that were requested are tabulated and ALBUSE is called.

ALBUSE - This subroutine writes the pointer array on the direct-access data file. IO is used to load data from the albedo data file and RITE is used to write the data on the direct-access data file. Then the pointer and length arrays are rewritten on the direct-access data file. The library routine INQUIR is called after each call to RITE to return the value of the next direct-access record. 
WATES - This subroutine reads the biasing input data block from the direct-access data file and reads the KENO-VI weights library. STOP is called if the computer storage space is too small to contain the energy- and position-dependent biasing function (wtavg). IO is used to load the biasing function into a temporary storage array. If a specific biasing function is to be used, MOVE is called to load it into the wtovg array. If biasing or weighting data are entered, REED is used to load the data into a temporary storage array. If a specific biasing function that was loaded from cards is to be used in the problem, MOVE is called to load it into the wtovg array. When all the data have been processed, RITE is called to load the biasing input data on the direct-access data file. RITE is called again to load the wtavg array on the direct-access data file. INQUIR returns the value of the next direct-access record after each call to RITE.

\section{F17.3.5 CREATE A MIXED CROSS-SECTION DATA FILE}

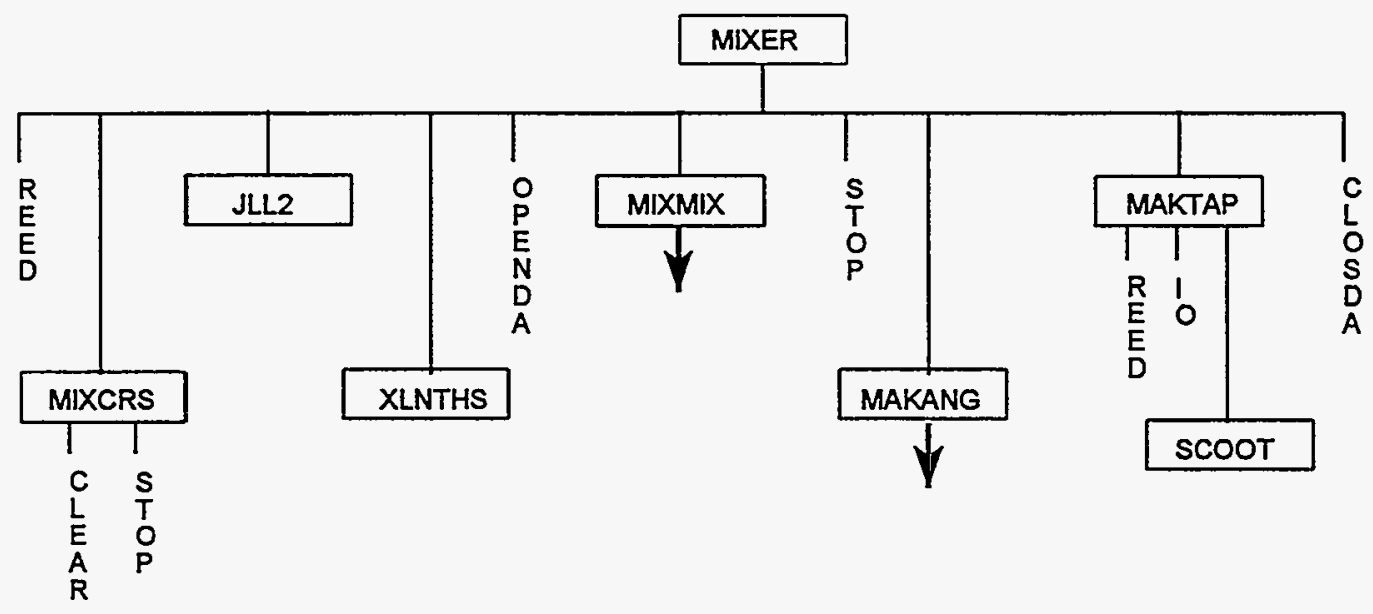

Figure F17.3.13. Flowchart for mixing cross sections

The function of this portion of the program is to utilize the mixing table data and AMPX working format library from the cross-section data file to create a Monte-Carlo-formatted mixed cross-section data file (Figure F17.3.13). This data file has the same format as an ICE mixed cross-section MORSE/KENO-VI library. ${ }^{1}$

MIXER - This subroutine controls the mixing of cross sections and the generation of the angles and probabilities to create a Monte-Carlo-formatted mixed cross-section library. First the mixing table is read from the direct-access data file, MIXCRS is called to generate the mixture correspondence array, and JLL2 is called to generate the array that points to the beginning of each group in the triangularized mixture array. XINTHS is called to calculate the number of direct-access blocks required for the mixtures and MXXMIX is called to do the mixing. MAKANG is called to generate the angles and probabilities from the mixed cross sections, and MAKTAP is called to write the Monte-Carlo-formatted mixture tape. Calls to STOP are made to print error messages if more space is needed to mix the cross sections or to process the angles. 
MIXCRS - The mixture correspondence array is generated by this subroutine. This array relates the mixture number in the mixing table to the mixture index.

JLL2 - This routine generates an array of pointers that point to the beginning location of each energy group in a triangularized mixture transfer array.

XINTHS - This routine computes the number of direct-access blocks necessary to hold the mixtures.

MIXMIX - This subroutine controls the actual mixing of the cross sections. See Sect. F17.3.5.1 for a more detailed description of subroutine MIXMIX.

MAKANG - This subroutine controls the generation of angles and probabilities. See Sect. F17.3.5.2 for a more detailed description of subroutine MAKANG.

MAKTAP - Subroutine MAKTAP is used to write a mixed cross-section library in a format similar to the ICE Monte Carlo library format. MAKTAP calls SCOOT to compress out zero 1-D cross sections.

SCOOT - This subroutine eliminates $1-D$ cross sections that are zero in all groups.

\section{F17.3.5.1 Cross-Section Mixing}

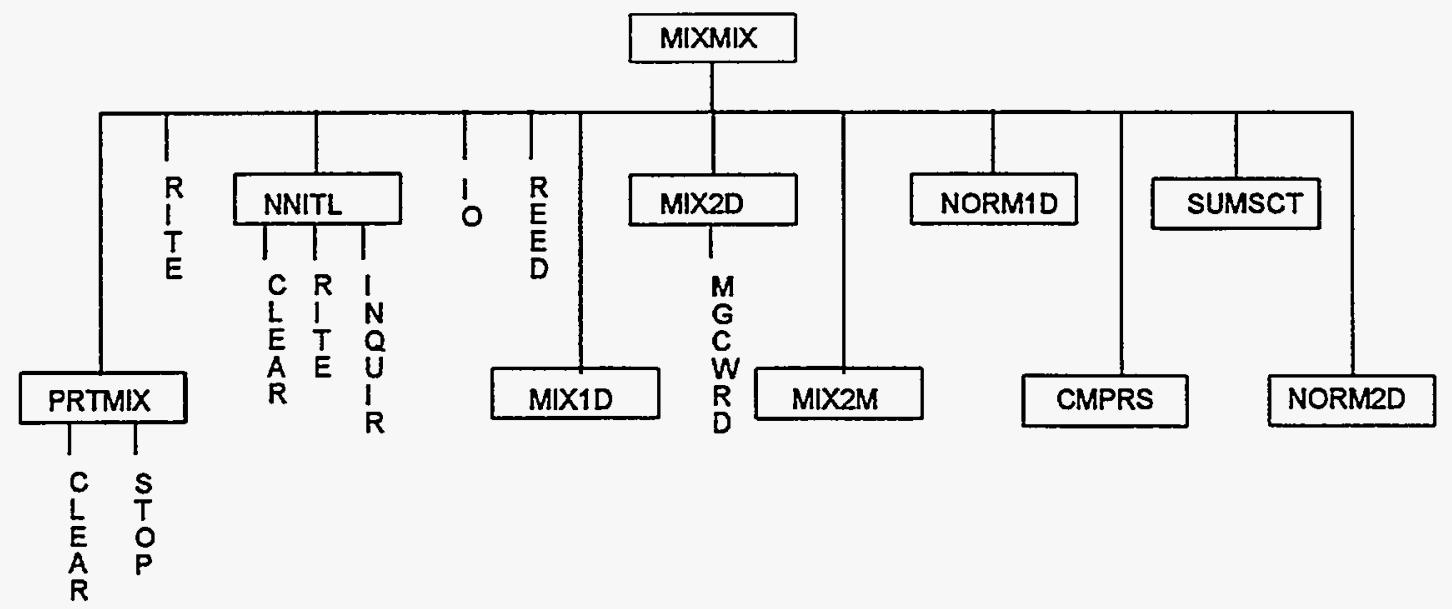

Figure F17.3.14. Flowchart of mixing operations

This section of the program produces mixed cross sections (Figure F17.3.14).

MIXMIX - This subroutine controls the actual mixing of the cross sections. It calls PRTMIX to print the mixing table and calls NNITL to initialize the mixtures. It then reads the input AMPX working library, calls MIXID to mix the 1-D cross sections, and calls MIX2D to mix the 2-D arrays. After all the nuclides selected from the working library have been mixed, the already mixed cross sections may be used as input for further mixing operations using MIX1D to mix the 1-D cross sections and MIX2M to mix the 2-D cross sections. NORM1D is then called to normalize the fission spectrum 
and to prepare the adjoint production cross sections if necessary. CMPRS is called to generate the magic word array and to compress the 2-D arrays. SUMSCT is called to sum the transfer array by group and NORM2D is called to convert the transfer array to a probability density function.

PRTMIX - This subroutine prints the requested number of scattering angles and the mixing table.

NNITL - This subroutine initializes the mixture cross sections to zero on the direct-access storage. CLEAR is called to zero the array, RITE writes the array on the direct-access device, and INQUIR returns the value of the next direct-access record.

MIX1D - This subroutine mixes the 1-D cross sections. It mixes most 1-D cross sections using number densities, but the fission spectrum is mixed based on $v \Sigma_{f} \phi \mathrm{dE}$ for the nuclide being mixed. The flux is the flux used to generate the multigroup cross sections, if it is available. Otherwise a flat flux is used. If the problem is an adjoint case, MIXID prepares the cross sections in adjoint form as they are mixed.

MIX2D - This subroutine mixes the 2-D cross sections from a working library. The mixture cross sections are stored in a triangularized array. The library routine, MGCWRD, is called to create the magic word for accessing the mixture cross sections. If the problem is an adjoint case, MIX2D prepares the cross sections in adjoint form as they are mixed.

MIX2M - This subroutine mixes previously mixed 2-D cross sections into new mixtures using new number densities or volume fractions.

NORM1D - This subroutine is used to normalize the fission spectrum vector. If the problem is an adjoint problem, it also interchanges $v \Sigma_{f}$ and the fission spectrum.

CMPRS - This subroutine compresses out zeros in the 2-D mixture arrays and generates the pointer array used to access data in these arrays.

SUMSCT - This subroutine is used to sum the transfers for each group.

NORM2D - This subroutine normalizes the transfer arrays and divides the $P_{\ell}$ arrays by $\left(2_{\ell}+1\right)$. 


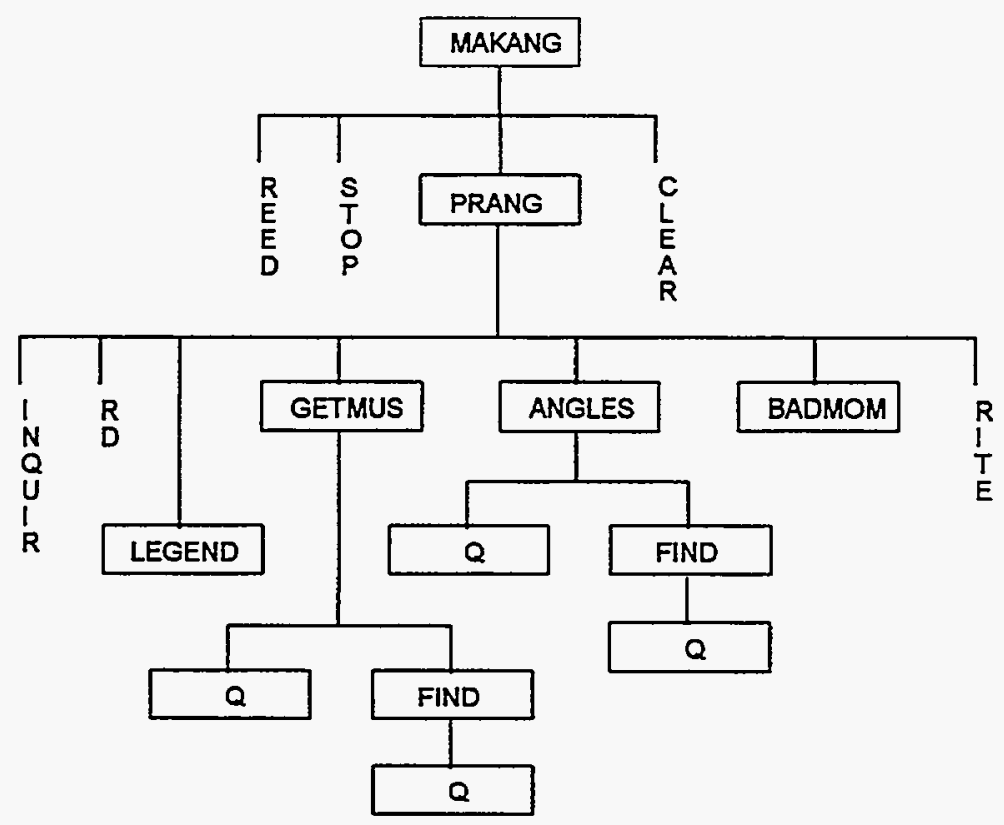

Figure F17.3.15. Flowchart of angle and probability generation

This portion of the program produces the angles and probabilities for each mixture.

MAKANG - This subroutine controls the generation of angles and probabilities. If the available storage is insufficient to generate all the angles and probabilities for one mixture at a time, MAKANG supergroups the data. Subroutine PRANG is called to actually generate the angles and probabilities for a supergroup.

PRANG - This subroutine reads the mixture data for a supergroup and loops through each transfer in the supergroup. It calls LEGEND to convert the Legendre expansion to moments. GETMUS is called to generate the orthogonal polynomials and ANGLES is called to generate the angles and probabilities. If there is an error, BADMOM is called to print the data input and the data corresponding to the angles and probabilities actually used.

LEGEND - This subroutine determines the moments of a function from a Legendre expansion of the function.

GETMUS - This subroutine calculates the $\mu_{i}^{\prime}$ 's and $\sigma_{i}^{\prime}$ 's that determine the orthogonal polynomials, the $Q_{i}^{\prime} s^{2}$

ANGLES - This subroutine determines the angles and probabilities from the $\mathrm{Q}_{i}$ polynomials. ${ }^{2}$ It calls FIND to determine the roots of $Q_{i}$, and calls the function $Q$ to evaluate $Q_{j}$.

FIND - This subroutine finds the roots of a polynomial $Q_{i}$ by using an interval-halving technique.

Q - $\quad$ This function evaluates a polynomial $Q_{i}$ by using the recursion formulas. 


$$
\begin{aligned}
& Q_{i+1}(x)=\left(x-\mu_{i+1}\right) Q_{i}(x)-\sigma_{i}^{2} Q_{i-1}(x) \\
& Q_{0}(x)=1.0, \text { and } \\
& Q_{1}(x)=x-\mu_{1} .
\end{aligned}
$$

BADMOM - This routine is called when an error is detected in generating the angles and probabilities. BADMOM prints the Legendre coefficients that were input to the calculation and the moments corresponding to these coefficients. It then computes the moments corresponding to the angles and probabilities actually generated and the Legendre coefficients corresponding to these moments. BADMOM then prints these moments and coefficients so they may be compared with the original moments and coefficients.

\section{F17.3.6 WRITE CROSS SECTIONS ON DIRECT-ACCESS FILE}

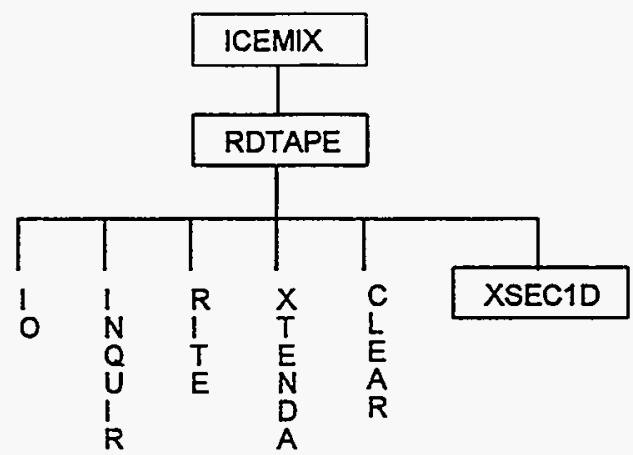

Figure F17.3.16. Flowchart of mixed cross-section processing

This section of the program is responsible for reading the Monte Carlo mixed cross-section library, selecting the desired information, and writing it on the direct-access data file (Figure F17.3.16).

ICEMIX - This subroutine reads information from the Monte Carlo mixed cross-section library, performs preliminary checks for data consistency, calculates pointers for the desired data arrays and calls RDTAPE to actually read the library and write the desired information on the direct-access data file.

RDTAPE - This subroutine reads the Monte Carlo formatted mixed cross-section library, sorts out the data needed by KENO-VI, and writes the data on the direct-access data file. The library routine SQRT is used in calculating the inverse velocities used by KENO-VI. The library routine IO is used repeatedly to read and load data from the Monte Carlo formatted mixed cross-section library. RITE is used to write data required by KENO-VI on the direct-access data file. INQUIR returns the value of the next direct-access record after each call to RITE. XTENDA is a library routine that is called to extend the number of blocks for a direct-access device if too few blocks were initialized. XSEC1D is called to process the 1-D cross sections. RDTAPE manipulates the pointer array and 
writes it on the direct-access data file. The $P_{0}$ cross sections, angles and probabilities are also processed by RDTAPE.

XSECID - This subroutine sorts the 1-D cross sections and loads them in the following order: total cross section, scattering cross section, production cross section, absorption cross section, extra cross sections for special purposes, and the fission spectrum. The extra cross sections require the user to provide programming to utilize them. If one of the required cross sections is not found, it is padded with zeros. The cross sections are normalized by the total cross section and the fission spectrum is summed and normalized to 1.0. The data are transferred back to RDTAPE where they are written on the direct-access data file.

\section{F17.3.7 WRITE INPUT DATA ON RESTART FILE}

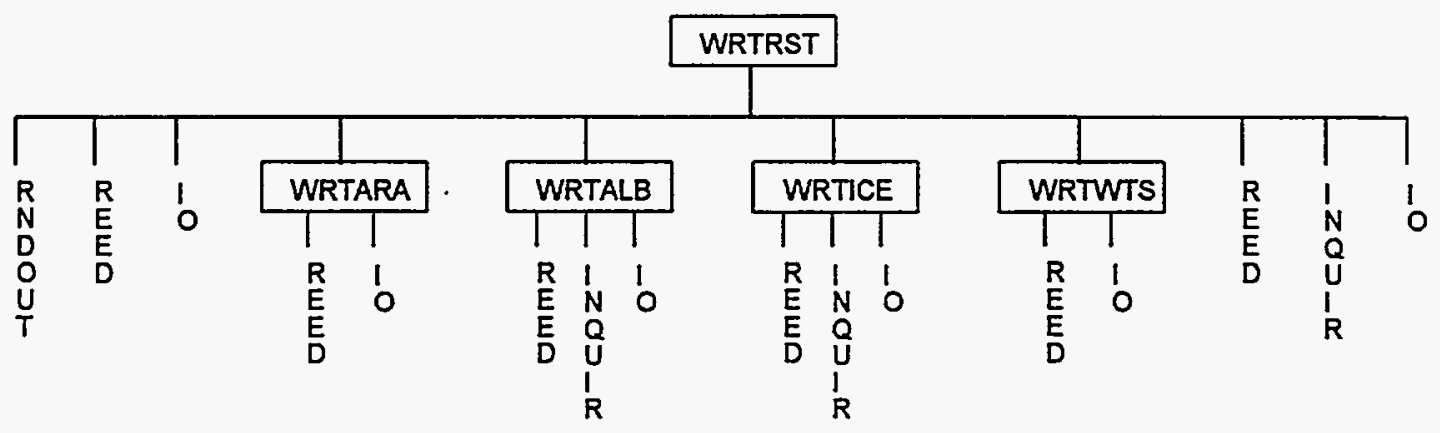

Figure F17.3.17. Flowchart for writing data on the restart data file

This section of the program is responsible for writing all data except the calculated results on the restart data file (Figure F17.3.17). This section of the program is omitted if a unit number has not been assigned for the restart data file. This information is entered as parameter data, WRS=, as described in Sect. F17.4.3. The calculated results are written on the restart data file later in the program. The restart data file is used for restarting a problem.

WRTRST - This subroutine writes the input data on the restart data file. RNDOUT is called to return the seed of the next random number. The problem title and parameter data are in the first record written on the restart data file. The array containing the IDs of the 1-D cross sections is then written. The geometry region data, mixing table data, extra 1-D data, biasing data, start data, plot data, and energy and inverse velocities are written. The unit orientation header record is written and WRTARA is called to write the unit orientation data. The albedo header record is written, and WRTALB is called to write the albedo data. The cross-section header record is written and WRTICE is called to write the cross sections. The header record for user-supplied weighting data is written, and WRTWTS is called to write the user-supplied weighting or biasing data on the restart data file. 
WRTARA - This subroutine is called from WRTRST to write the array number, array size and corresponding unit orientation array on the restart data file for each array that is entered in the problem. The library routine REED is called to load the direct-access pointers for the albedo data blocks. INQUIR is called to return the value of the next direct-access record. REED is used to read the data from the direct-access data file, and IO is used to write the data on the restart data file.

WRTALB - This subroutine is called from WRTRST to write the albedo data on the restart data file. The library routine REED is used to read the albedo data from the direct-access data file, and IO is used to write the data on the restart data file.

WRTICE - This subroutine is called from WRTRST to write the cross-section data block on the restart data file. REED is called to load the direct-access pointers for the cross-section data blocks. INQUIR is called to return the value of the next direct-access record. The library routine REED is used to read the rest of the cross-section information from the direct-access data file, and IO is used to write it on the restart data file.

WRTWTS - This subroutine is called from WRTRST to write the biasing input data block on the restart data file. The library routine REED is used to read the data block from the direct-access data file, and IO is used to write it on the restart data file.

\section{F17.3.8 GENERATE ALBEDO CROSS-SECTION CORRESPONDENCE TABLES}

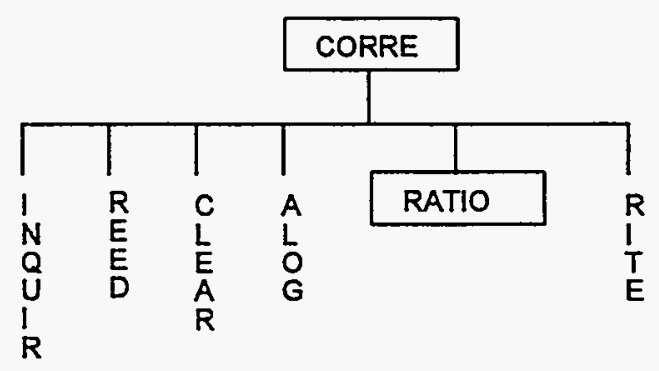

Figure F17.3.18. Flowchart for generating correspondence arrays

This section of the program generates the correspondence tables that are necessary to correlate the energy group structures of the cross sections and albedos (Figure F17.3.18). It is invoked only if differential albedos are used in the problem.

CORRE - This subroutine is called only if differential albedos are used. The library routine REED is called to read arrays. The library routine INQUIR is called to return the value of the next direct-access record. The library routine CLEAR is used to initialize arrays. CORRE reads the energy bounds for the albedos and the cross sections and converts them to lethargies by using the library routine ALOG. RATIO is called to create a probability array relating the cross-section energy bounds to those of the albedos. A second call is made to RATIO to create and print the probability array relating the albedo energy bounds to those of the cross sections. RITE is used to write the correspondence tables on the direct-access data file. 
includes the supergroup and comesponding energy groups, the length of the cross section and albedo data for the supergroups and the total length of each supergroup. FILLSG is then called to construct the supergroups as described in Sect. F17.3.9.2. After the supergrouped data have been written on the direct-access device, the library routine FREECR is called to release the space that is not needed for the problem.

PRTXS - This subroutine prints the cross-section information as described in Sect. F17.3.9.1.

POINT - This subroutine determines the storage requirements of the nonsupergrouped data and creates pointers to access data within the nonsupergrouped storage array.

PRATBL - This subroutine prints the additional information table to the computer output.

RTADJ - This subroutine right adjusts the albedo boundary condition names which are read in as left-adjusted data RTADJ utilizes the FORTRAN-supplied intrinsic function INDEX to locate the first blank character.

XXALB - This function determines the amount of space necessary to contain the albedo data corresponding to a cross-section energy group.

LIMLN - This subroutine is called to calculate and print the supergroup number, the energy groups contained in the supergroup, the length of the cross section and albedo data in the supergroup, and the total length of the supergroup. IXALB is utilized to obtain the amount of space required to contain the albedo data corresponding to a cross-section energy group.

FIILSG - This subroutine constructs supergroups as described in Sect. F17.3.9.2.

\section{F17.3.9.1 Print Macroscopic Cross Sections}

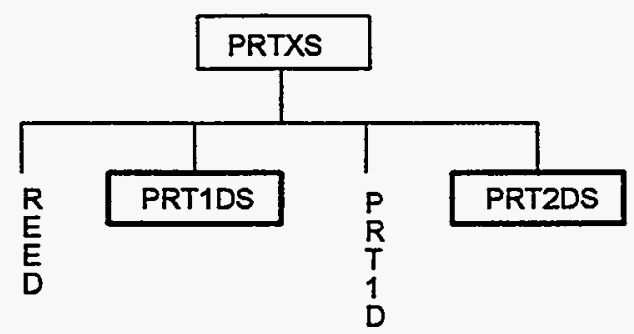

Figure F17.3.20. Flowchart for printing macroscopic cross sections

This portion of the program prints the macroscopic cross-section data for materials used in the problem description (Figure F17.3.20). 
PRTXS - If macroscopic cross sections are not to be printed, a return is executed. PRTXS loops over the number of mixtures that are used in the problem. REED is used to load the data, then pointers into the data arrays are calculated. If the space is insufficient to contain the data, a message is printed. If 1-D mixture cross sections are to be printed, PRT1DS is called to print them. If the extra 1-D cross sections are to be printed, REED is used to load the data and the library routine PRTIDS is called to print them. If the transfer arrays are to be printed, REED is called to load the data and PRT2DS is called to print them. If the number of scattering angles is greater than zero and the mixture probabilities and angles are to be printed, REED is used to load probability data and PRT2DS prints them. Then REED loads angle data and PRT2DS prints them.

PRTIDS - This subroutine prints the macroscopic 1-D cross sections, one energy group at a time.

PRT2DS - This subroutine prints a 2-D variable length array in a compact manner.

F17.3.9.2 Write Supergroup Data File

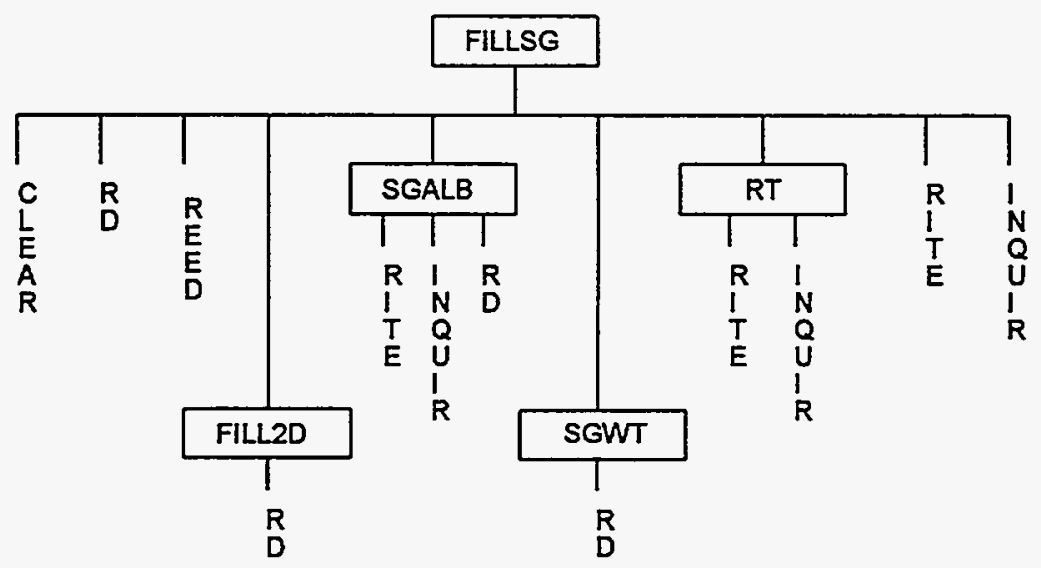

Figure F17.3.21. Flowchart for loading supergrouped data

This portion of the program collects the group-dependent data by supergroup and writes them on the direct-access supergroup data file (Figure F17.3.21).

FILLSG - This subroutine is responsible for filling the supergroups and writing them on the direct-access supergroup data file. For each supergroup, CLEAR is called to initialize the working space. Pointers are calculated for the data arrays and space is allotted for the calculated data such as fluxes that will be supergrouped. The library routines REED and RD are used to load data from the directaccess data file into the proper arrays as follows: For each mixture the inverse velocities are loaded, followed by the pointer array and all the 1-D cross-section arrays. RD and REED are used to load the 2-D arrays from the direct-access data file. FIL2D is called to load them into the supergroup. Pointers are calculated for the albedo data, and SGALB is called to load the albedo data into the 
supergroup. SGWT loads the average weight array (biasing data) into the supergroup. FULLS then calls $\mathrm{RT}$ to write the calculated data for the supergroup on the direct-access supergroup data file. RITE writes the group-dependent data on the direct-access supergroup data file. INQUIR is called as necessary to return the value of the next direct-access record.

FIL2D - This subroutine loops over the number of mixtures. It uses RD to load the 2-D cross-section data for the supergroup from the direct-access data file; first the $P_{0}$ data, then for each scattering angle, the angles and probabilities. The pointer array is redefined so the supergrouped data can be accessed.

SGALB - This subroutine uses REED and RD to load the albedo data for the supergroup from the directaccess data file. INQUIR is used to provide the value of the next direct-access record. It loops over the number of differential albedos used in the problem. Then the pointer array is redefined so the supergrouped data can be accessed.

SGWT - This subroutine loops over the number of biasing regions used in the problem. RD is used to load the average weight array from the direct-access data file. If any average weight entry remains undefined or zero, it is set to the default value of weight average.

RT - $\quad$ This subroutine is called to write the calculated data (fluxes, etc.) on the direct-access supergroup data file using the library routine, RITE. INQUIR is used to return the value of the next directaccess record, after the call to RITE.

RITE - This library routine is used to write the group-dependent data for the supergroup on the directaccess supergroup data file.

\section{F17.3.10. PROCESS GEOMETRY}

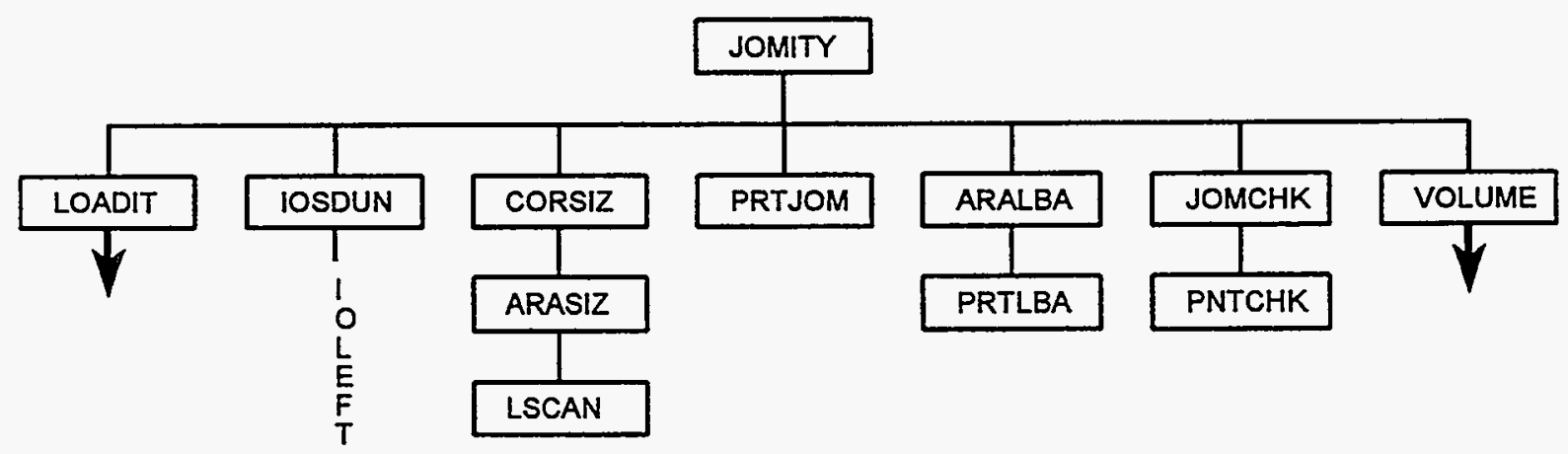

Figure F17.3.22. Flowchart for processing geometry

This portion of the program is primarily responsible for loading the geometry data, generating additional geometry data, checking the geometry for consistency, writing error messages related to the geometry, and printing the geometry that is used in the problem (Figure F17.3.22).

NUREG/CR-0200

Vol. 2, Rev. 5

F17.3.30 
JOMITY - This subroutine is responsible for generating additional geometry data, checking the geometry data, writing geometry error messages, and printing the geometry.

LOADIT - This subroutine loads the geometry data and the nonsupergrouped portion of the albedo data. Section F17.3.10.1 contains a more detailed description of the procedure.

IOSDUN - This subroutine returns the number of IOs used. The library routine IOLEFT returns the number of input/output requests left before the system cancels the job.

CORSIZ - This subroutine sends the appropriate lattice or array information to ARASIZ for each lattice that is used in the problem. Using this information, it calculates the overall positive dimensions of the global array. The library routine, SQRT, is utilized to calculate the maximum chord length of an unreflected array, a reflected array or a single unit problem.

ARASIZ - This subroutine uses the array unit orientation data to calculate the positive dimensions of the core boundary for that array or lattice. The function LSCAN is called to determine if a specified unit has been used in the array. ARASIZ also checks to ensure that the faces of adjacent umits are the same size and shape. Several error messages are written if errors are encountered.

LSCAN - This is a logical function that returns a value of true if the specified unit is used in the unit orientation array. A value of false is returned if the unit was not used in the unit orientation array.

PRTJOM - This subroutine prints the geometry data used in the problem.

ARALBA - This subroutine calls PRTLBA for each array that is used in the problem.

PRTLBA - This subroutine is called to print the unit orientation data for each lattice or array that is used in the problem. It may print a warning message associated with one or more lattices.

VOLUME - This subroutine is responsible for calculating the volume of each geometry region and the cumulative volumes for each unit that is used in the problem. See Sect. F17.3.10.2 for additional details. 


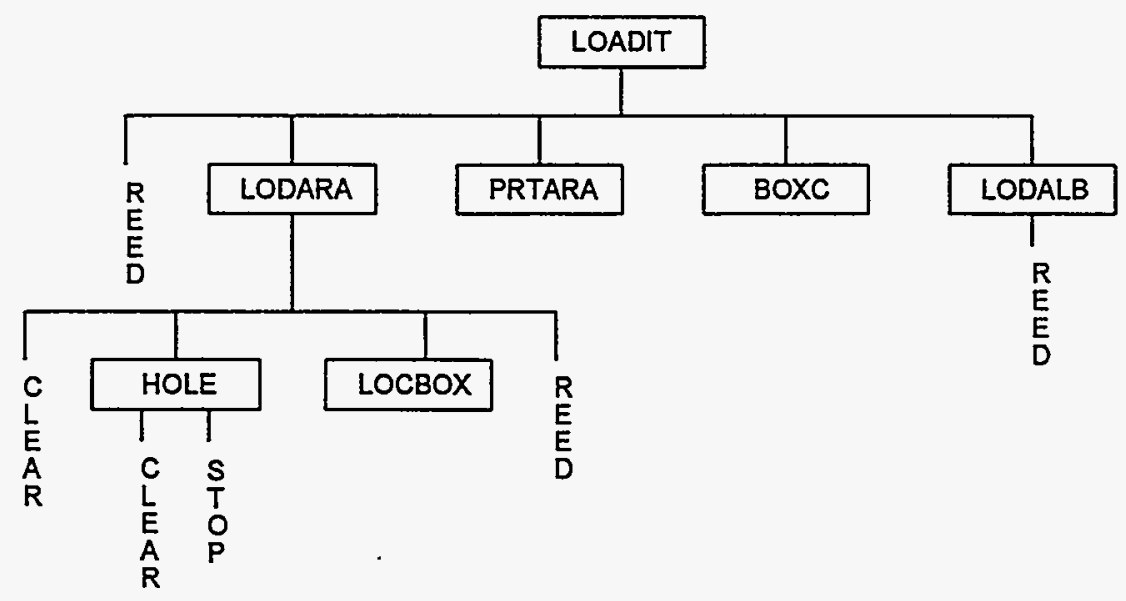

Figure F17.3.23. Flowchart for loading data from direct access

This portion of the program loads data from the direct-access data file into permanent memory (Figure F17.3.23).

LOADIT - This subroutine calls the library routine REED to load the geometry data. If the problem is an array problem (lattice geometry), LODARA is called to load the lattices that are used in the problem and recompute and readjust the array nesting level array and hole nesting level array. If multiple units are used in the problem, PRTARA is called to print the unit orientation array for each lattice used in the problem. BOXC is called to load the unit correspondence array, and LODALB is called to load the nonsupergrouped portion of the albedo data.

LODARA - This subroutine is responsible for loading the lattices (unit orientation arrays) that are used in the problem, computing the hole nesting level array, and computing and adjusting the array nesting level array. CLEAR is used to initialize the arrays and REED is used to load the unit orientation arrays. HOLE and LOCBOX are both called by LODARA.

HOLE - This subroutine is called from LODARA to determine which holes occur at the next nesting level and to adjust the array nesting level for arrays that occur in holes. It also checks to ensure that holes are not recursively nested. CLEAR is used for initialization purposes and STOP is called if holes are recursively nested.

LOCBOX - This function is called from LODARA to return the unit at a given position in the unit orientation array.

PRTARA - This subroutine prints a table of the arrays used in the problem. The array number, the number of units in the $x, y$, and $z$ directions, and the nesting level is printed for each array.

BOXC - This subroutine uses the number of units and the geometry region number corresponding to the first and last geometry region of each unit to generate the unit correspondence array which contains the 
unit number for each geometry region. This information is loaded in the appropriate position as it is generated.

LODALB - This subroutine calls the library routine REED to load the pointer and length arrays for the albedo data from the direct-access data file. REED is used to load the nonsupergrouped albedo data, for each albedo that is used, into a temporary array. A loop over the number of angles is then used to load these data into the appropriate arrays. When all of the albedos used in the problem have been processed, REED is called to load the pointer arrays for the cross sections and albedos as well as the arrays defining the albedo to cross-section energy group correlation.

\section{F17.3.10.2 Calculate Volumes}

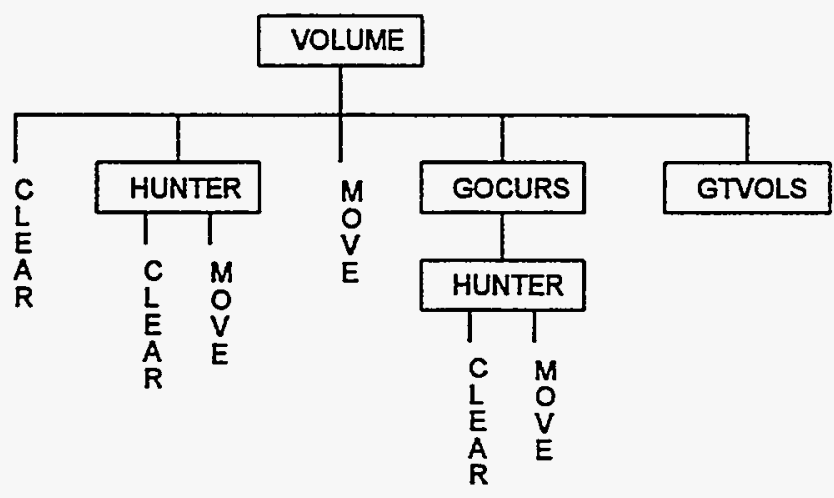

Figure F17.3.24. Flowchart for calculating volumes

This portion of the program is responsible for calculating the volume of each region used in the problem, the cumulative volumes for each unit used in the problem, the number of times each unit was used in the problem, and the total volume of each region summed over all occurrences (Figure F17.3.24).

VOLUME - This subroutine attempts to calculate the volume of each region for every unit that is used in the problem. It then attempts to calculate the cumulative volumes for each unit. CLEAR is used to initialize arrays. If an external reflector is present, HUNTER is called to determine the number of times each array and/or hole is used in the reflector. GOCURS is used to determine the number of times each unit, array and hole is used in the problem. GTVOLS is called to calculate and print the number of occurrences for each unit and the corresponding total volumes for the entire system. CLEAR is called to initialize the array for the total volume of each mixture used in the problem prior to calculating and printing those totals.

HUNTER - This subroutine determines the number of times each unit, array and hole is used. CLEAR is used to initialize storage arrays for the present hole level and the next hole level. MOVE is used to move the storage arrays.

GOCURS - This subroutine loops over the array size and calls HUNTER to determine the number of times each unit, lattice or array, and hole is used in the problem. 
GTVOLS - This subroutine calculates the total volume of each region for the entire problem by multiplying the volume of the region by the number of times the region is used in the problem.

\section{F17.3.11 LOAD BIASING OR WEIGHTING DATA}

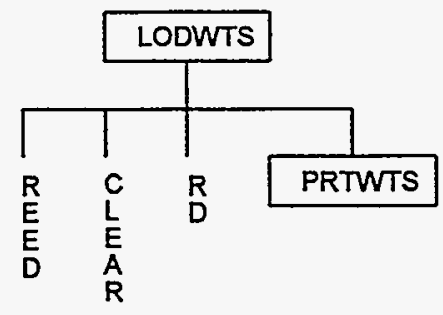

Figure F17.3.25. Flowchart for loading biasing data

This portion of the program is executed only if the input parameter data contain PWT=YES, as described in Sect. F17.4.3. If biasing data are to be printed, the program loads and prints the average weight array (Figure F17.3.25).

LODWTS - This subroutine is responsible for printing the bias IDs vs the material IDs used in the problem and for loading and printing the biasing or weighting data. The library routine REED is called to load the bias IDs used in the problem from the direct-access device. The number of sets of data that will fit in the available memory is calculated. Then the library routine CLEAR is used to initialize that space. RD is used to load the data that will fit, and PRTWTS is called to print them. Then the entire process is repeated until all the biasing or weighting data used in the problem have been loaded and printed.

PRTWTS - This subroutine prints the group-dependent weight-averaged array for each biasing region in a compact fashion. 


\section{F17.3.12 GENERATE PRINTER PLOT}

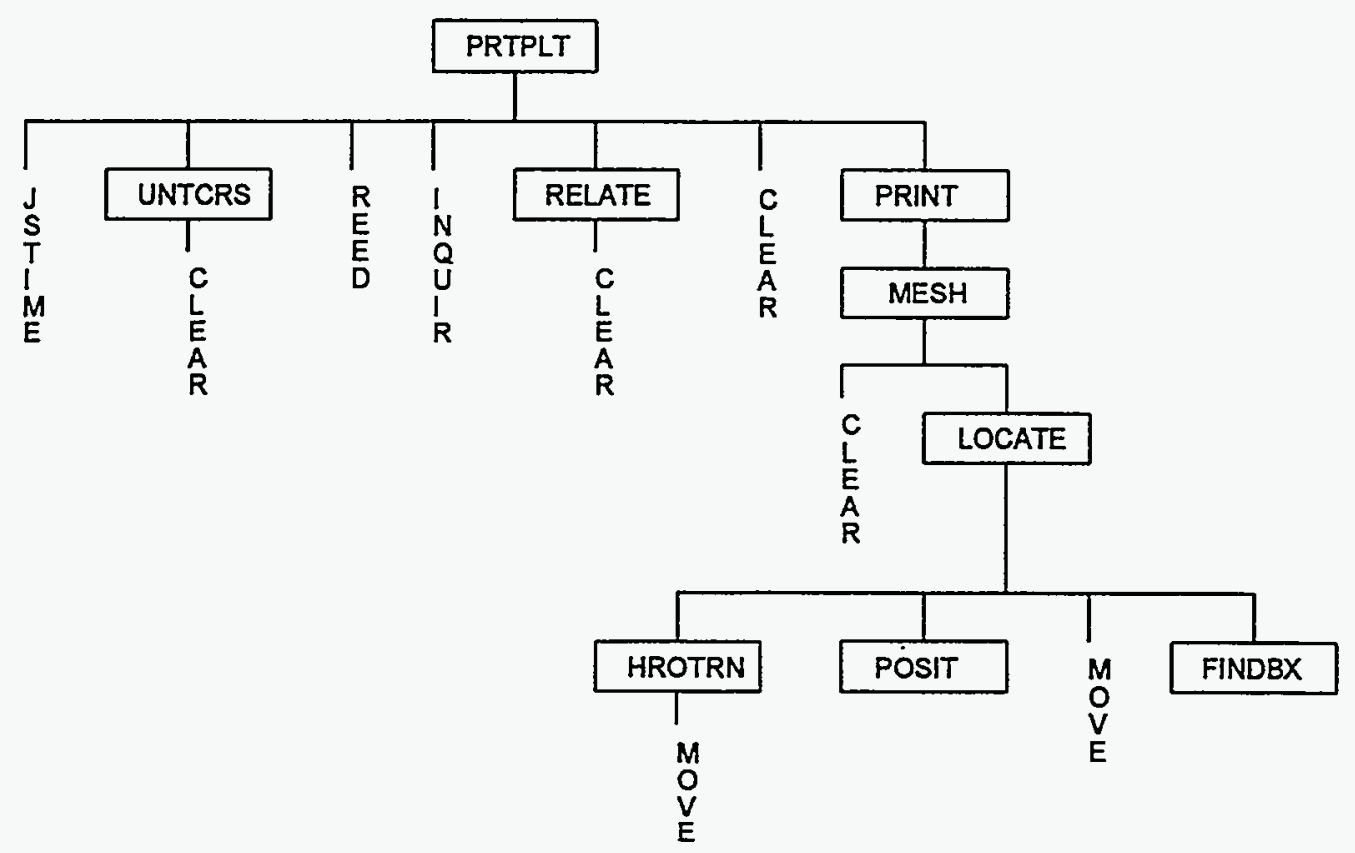

Figure F17.3.26. Flowchart for pictures or plots

This portion of the program generates printer plots of a 2-D slice through the geometry (Figure F17.3.26). As many plots as are desired can be printed.

PRTPLT - This subroutine controls the generation of the printer plots. The library routine CLEAR is called to zero the necessary space. Subroutine UNTCRS is called to generate a unit correspondence array. REED is used to load the picture data from direct access. INQUIR is called to return the value of the next direct-access record. The picture title is printed, and subroutine RELATE is called to print a heading for the symbol map and print the symbol map. The picture coordinates, direction cosines and number of symbols across and down the page as well as the step intervals, are printed. Then subroutine PRINT is called to generate the actual picture.

UNTCRS - This subroutine calls CLEAR to zero the unit correspondence array. It then loads the appropriate unit number in the appropriate position of the array.

RELATE - This subroutine calls CLEAR to zero the reverse correspondence array. It then prints the plot header telling whether a mixture, unit, or bias ID map is to be printed. It loads the array that correlates the symbols to be used in the printer plot with the mixture numbers, bias ID numbers, or unit numbers that were used in the problem. The array is then printed to facilitate user interpretation of the printer plot. 
PRINT - This subroutine determines the number of pages that will be needed to print the printer plot picture. Subroutine MESH is called to load the appropriate mixture numbers, unit numbers or bias ID numbers for each line of print for the picture. Then PRINT prints the line of symbols corresponding to them.

MESH - This subroutine loads an array that contains the appropriate mixture number, unit number or bias ID number for each character in a line. CLEAR is called to initialize arrays if nested holes or nested arrays are present in the problem. LOCATE is called to determine the geometry region and unit that contains each mesh point. MESH then loads the mixture number, unit number, or bias ID number.

LOCATE - This subroutine is responsible for determining the geometry region for each mesh point in the picture. Subroutine POSIT is called to determine the region that contains the specified mesh point. If array data are used, MOVE is called to load the current array data into the array stack. If the mesh point is located within a hole, HROTRN is called to determine the position within the unit contained in the hole that contains the mesh point. If the mesh point is within an array, FINDBX is called to determine the position within the lattice or array that contains the mesh point. LOCBOX is then called to determine the unit that contains the mesh point. POSIT is used to determine the geometry region that contains the mesh point. If the mesh point is in a region that contains a hole, the coordinates of the mesh point are translated to the hole and POSIT is called again.

HROTRN - This subroutine rotates and translates the coordinates to locate the position of a specific point in a hole.

FINDBX - This subroutine locates the position in an array that contains a specified point.

LOCBOX - This function returns the unit at a given position in an array.

POSIT - This subroutine determines the region within a unit that contains a specified point. 


\section{F17.3.13 PROCESS HISTORIES BY SUPERGROUP}

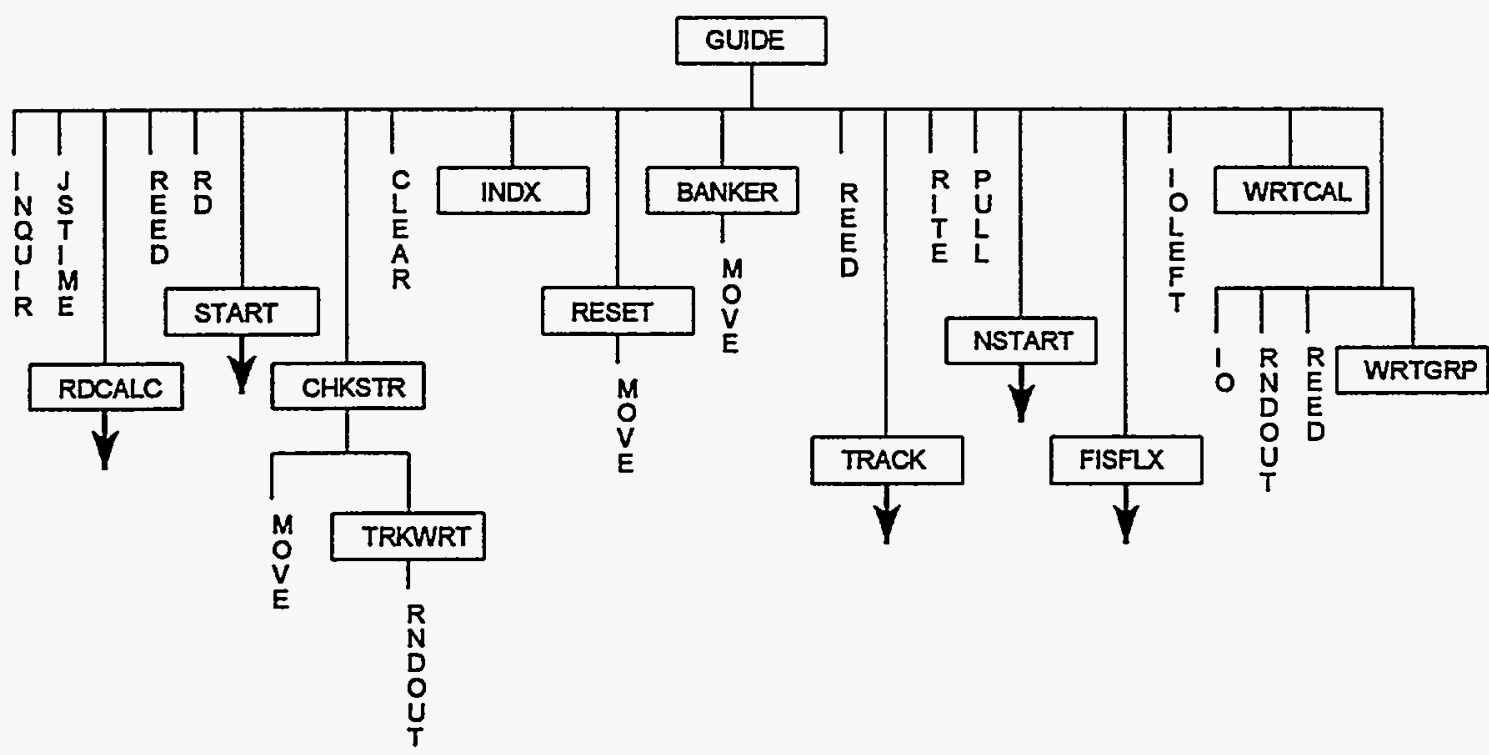

Figure F17.3.27. Flowchart of tracking routines

This section of the program is where the tracking of the individual histories is done, one supergroup at a time (Figure F17.3.27).

GUDE - This subroutine controls the tracking procedure. It loads the calculated data for a restarted problem, calls subroutine START to obtain the initial source distribution, calls CHKSTR to load the initial starting distribution in COMMON /NUTRON/ and prints the starting points as requested by the data. The library routine CLEAR is called several times to initialize arrays. IOLEFT and JSTIME are called to initialize the I/Os and time for the tracking procedure. INQUIR is used to return the value of the next direct-access record. SQRT is used in estimating the lower limit of the $99 \%$ confidence interval of the sample distribution of $k_{\text {eff }}$

The heart of subroutine GUIDE is a loop over generations, from the starting generation to the number of generations requested. Subroutine RESET is called to accumulate the fission source and the source vectors for matrix $\mathrm{k}_{\text {eff. }}$. It also counts the number of histories in each supergroup and determines the supergroup with the largest number of histories. Then subroutine BANKER is called to sort the histories by supergroup, loading the largest supergroup at the top of the bank. GUIDE calculates pointers for the supergrouped data and loads the supergrouped data using the library routine REED. TRACK is called to do the actual tracking. The library routine RITE writes the calculated supergrouped data on the direct-access supergroup data file. When all the supergroups have been processed, NSTART is called to provide the fission source for the next generation. Then FISFLX is called to calculate matrix information and statistics for the calculated data. GUIDE then checks to be sure sufficient time and I/Os remain to ensure that another generation can be processed. If another generation cannot be processed and restart data are to be 
written, WRTCAL is called to write the calculated data on the restart data file. A message is printed by GUIDE stating the reason for terminating the calculation.

GUIDE is a very important subroutine in KENO-VI. The following table is provided to assist in understanding the functions performed by the subroutines called by GUIDE:

\begin{tabular}{|c|c|c|}
\hline Subroutine & Function & Condition \\
\hline INQUIR & Set direct-access pointer & Always \\
\hline JSTIME & Monitor time usage & Always \\
\hline RDCALC & $\begin{array}{l}\text { Load calculated data for } \\
\text { restarting a problem }\end{array}$ & If the problem is restarted \\
\hline REED & $\begin{array}{l}\text { Load data from direct-access } \\
\text { supergroup data file }\end{array}$ & Always \\
\hline $\mathrm{RD}$ & Load data from direct access & Always \\
\hline START & Provide initial source & $\begin{array}{l}\text { If the problem is started with the } \\
\text { first generation }\end{array}$ \\
\hline CHKSTR & Print starting points & Always \\
\hline INDX & Locate cross-section index & Always \\
\hline RESET & Count histories/supergroup & Always \\
\hline BANKER & Sort the neutron bank & Always \\
\hline TRACK & Track individual histories & Always \\
\hline RITE & Write data on direct access & Always \\
\hline NSTART & $\begin{array}{l}\text { Provide fission source for the } \\
\text { next generation }\end{array}$ & Always \\
\hline FISFLX & Calculate statistics & Always \\
\hline IOLEFT & Monitor I/O usage & Always \\
\hline PULL & Terminate problem & If excessive time is used \\
\hline WRTCAL & Write data on restart file & $\begin{array}{l}\text { If a restart data file is to be } \\
\text { created }\end{array}$ \\
\hline
\end{tabular}

INQUIR - This library routine returns the value of the next direct-access record. It is called to obtain the pointer for the cross-section data.

JSTIME - This library routine is called several times from GUIDE for timing purposes.

RDCALC - This subroutine is called only if the problem is being restarted at a generation greater than 1 . Its purpose is to read data from the restart data file and write the supergrouped data on the directaccess data file. See Sect. F17.3.13.1 for additional information.

REED - This library routine is called early in GUIDE if a problem is not being restarted in order to load data that are needed to create the initial source distribution. REED is called to load supergrouped data for the supergroup being processed from the direct-access supergroup file. 
RD - This library routine is called to load the fission spectrum for use in creating the initial source distribution.

START - This subroutine is responsible for creating the initial source distribution. See Sect. F17.3.13.2 for additional details.

CHKSTR - This subroutine calls the library routine MOVE to load the initial source distribution into COMMON /NUTRON/. If the starting points are to be printed, TRKWRT is called to print them using the debug tracking format.

TRKWRT - This subroutine is called from CHKSTR to print information about the current status of the current neutron in the debug tracking format. When TRKWRT is called from CHKSTR, the information of interest is the position at which the neutron was started. RNDOUT is called from TRKWRT to make the current random number available for printing.

CLEAR - This library routine is called to initialize the fission density array and the arrays that hold the matrix $\mathrm{k}_{\mathrm{eff}}$ and associated statistics.

INDX - This subroutine is called only if the average number of neutrons per fission and the average energy at which fission occurs are to be calculated. (See Sect. F17.4.3, NUB=.) INDX determines the position of the fission cross section in the extra 1-D cross-section array. The fission cross section is required for calculating the average energy at which fission occurs.

RESET - This subroutine is called to accumulate the fission source and the source vectors for the matrix $k_{\text {eff }}$ and to count the number of histories in a supergroup.

BANKER - This subroutine is responsible for sorting all the particles in the current supergroup into the top of the neutron bank and all other particles into the bottom of the bank.

TRACK - This subroutine is responsible for the actual tracking of each individual history. See Sect. F17.3.13.3 for a detailed description.

RITE - When the program returns from TRACK, RITE is called to write the calculated supergrouped data on the direct-access supergroup data file.

PULL - This library routine is called from GUDE to set a time interval that results in a nonstandard return if that time interval is exceeded. This step is for the purpose of preventing the program from looping indefinitely. PULL is called later in GUIDE to reset the time interval as appropriate.

NSTART - This subroutine is called from GUIDE to provide the fission source for the next generation. See Sect. F17.3.13.4 for specific details.

FISFLX - This subroutine calculates statistics for $k_{e f f}$ the matrix $k_{e f i f}$ fissions, absorptions, leakages, and fluxes. Section F17.3.13.5 contains additional details.

IOLEFT - This library routine is called to determine if sufficient I/Os remain to allow processing another generation. 
WRTCAL - If a restart data file is to be created, this subroutine writes the calculated information on the restart data file with a frequency specified by the parameter data (Sect. F17.4.3, RES=). RNDOUT is called to preserve the random number. Then the generation number, random number, number of histories per generation, number of energy groups, banked information, some common information and all the $k_{\text {eff }}$ values calculated to this point are written on the restart data file. The neutron bank and if requested, the fission densities are written. If matrix $\mathrm{k}_{\mathrm{eff}}$ information is requested, IO is used to write it on the restart data file. Then WRTCAL loops over the number of supergroups, calculating pointers, using REED to load data from the direct-access supergroup file and calling WRTGRP to write the group-dependent calculated information on the restart data file. When all the data have been written, a message is printed.

WRTGRP - This subroutine writes calculated data (leakages, absorptions, fissions, and if requested, fluxes) for each energy group on the restart data file.

\section{F17.3.13.1 Load Calculated Restart Data}

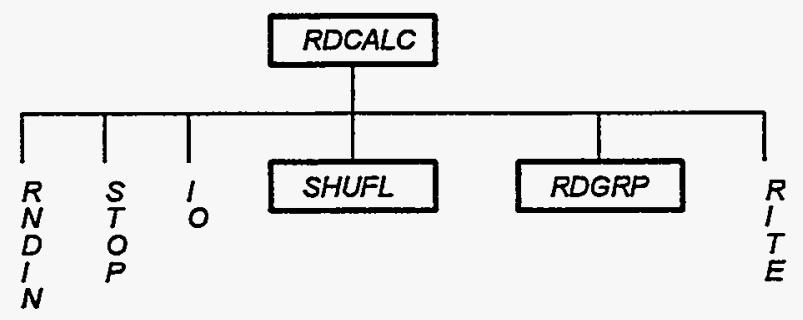

Figure F17.3.28. Flowchart for loading calculated restart data

This section of the program loads the calculated data such as $\mathrm{k}_{\mathrm{eff}}$ values and fluxes from the restart data file if the starting generation number is greater than 1 (Figure F17.3.28).

RDCALC - This subroutine is called from GUIDE if the starting generation number is greater than 1. This indicates that a calculation is to be restarted using the starting generation number as the first generation to be processed. Thus all the results that were calculated in a previous run must be loaded from the restart data file to continue the calculation. RDCALC reads the previously calculated data from the restart data file and checks for consistency against parameters that were entered as input data. Appropriate messages are printed if inconsistencies are encountered. RNDIN may be called to load a new random number. STOP is called if more storage is needed to hold the neutron bank. IO is used to load data from the restart data file and SHUFL is called to sort and store the neutron bank. Pointers are calculated for the supergrouped restart data, and RDGRP is called to read the group-dependent data from the restart data file. RITE is used to write the restart data on the supergroup data file.

RNDIN - This library routine is called to load a new random number for use with the restarted problem if a random number was entered in the parameter input data. 
STOP - This library routine is called to write an error message and stop if the available storage is not large enough to hold the neutron bank.

IO - This library routine is used to load matrix $\mathrm{k}_{\mathrm{eff}}$ information if it is to be calculated.

SHUFL - This subroutine is called to sort and store the neutron bank.

RDGRP - This subroutine is used to load the supergrouped data from the restart data file. This includes leakages, fissions, absorptions and fluxes.

RITE - This library routine is used to write previously calculated results on the direct-access supergroup data file so the problem can be restarted properly.

\section{F17.3.13.2 Generate Initial Source Distribution}

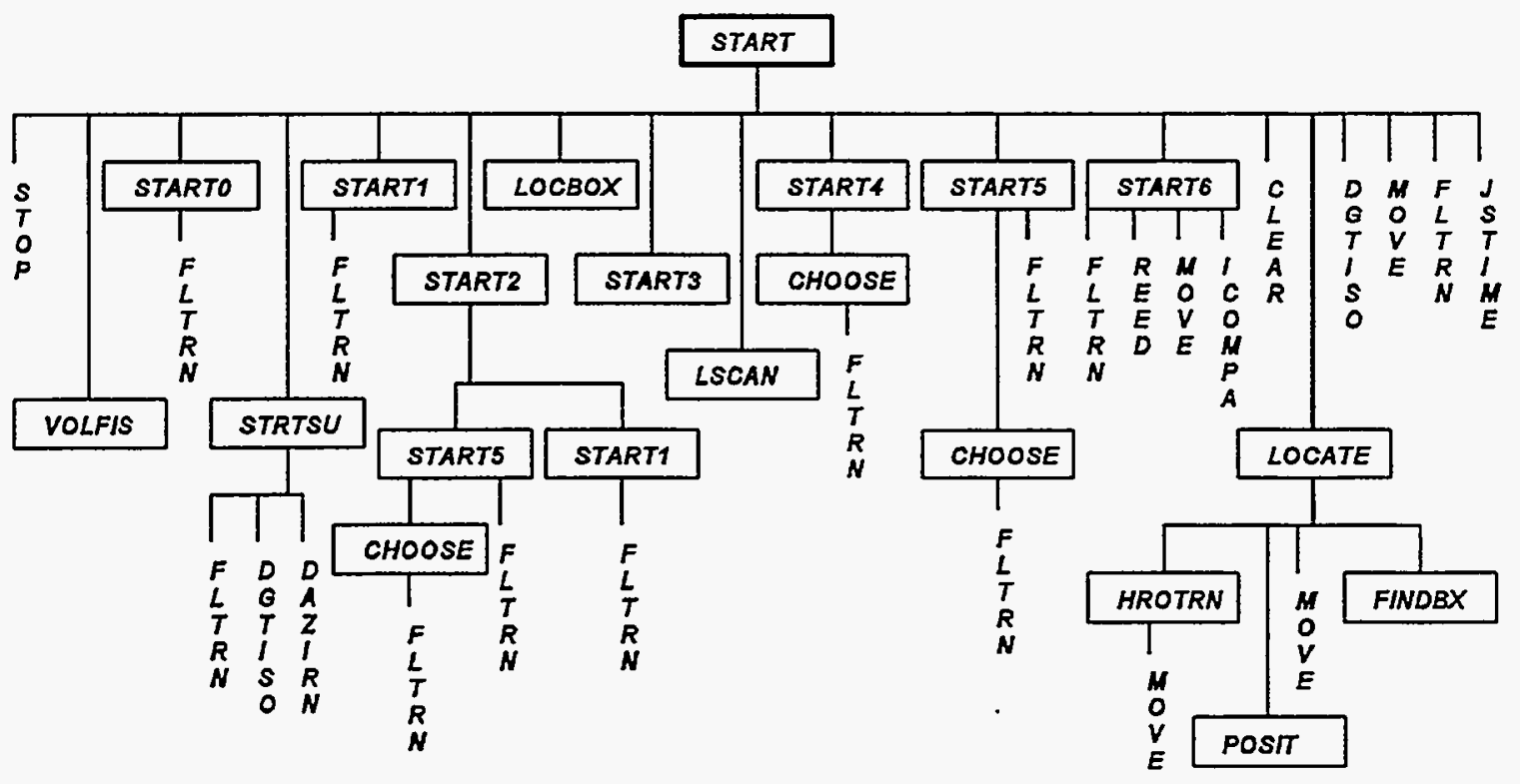

Figure F17.3.29. Flowchart for providing initial source distribution

This portion of the program is responsible for generating the initial source distribution (Figure F17.3.29) in accordance with information specified in the start data (see Sect. F17.4.8).

START - This subroutine is responsible for generating the initial source distribution. If fissile material is not used in the problem, STOP is called to write a message and terminate the problem. Appropriate messages are printed if the specified start type is incompatible with the geometry 
configuration. Subroutine VOLFIS is called to calculate the volume fraction of fissile material. STOP is called to print error messages if the start data are geometrically invalid or the fraction started as a spike is invalid. LSCAN is used to determine if the specified unit is in the global array. Then START0, STRTSU, START1, START2, START3, START4, START5, or START6 is called to generate starting points having the characteristics specified in the start data (see Sect. F17.4.8). Subroutine LOCBOX is called after both START2 and START3 to determine the unit number at the specified position in the array. Subroutine LOCATE then determines the geometry region that contains the specified point by utilizing POSIT, FINDBX and LOCBOX. FINDBX is called to locate the position within the array that contains the starting point. LOCBOX is called to determine the unit number located at that position in the array. The starting point is translated to the coordinate system of the unit and POSIT is called to determine which region within the unit contains the starting point. A check is then made to be sure the region contains fissile material. If it does not, the point is discarded. If the region contains fissile material, DGTISO is called to provide the initial direction cosines. START uses FLTRN to set the initial energy group and MOVE is called to load the initial data for the history into the neutron bank. JSTIME is called to be sure the allowed time is not exceeded. If it is, or if the required number of source neutrons have been generated, the starting is terminated. If too few initial source neutrons exist, FLTRN and MOVE are used to fill the remaining starting positions from those that were generated. A message to that effect is then printed.

STOP - $\quad$ This library routine is called from START to write error messages.

VOLFIS - This subroutine determines the volume fraction of fissile material in an unreflected array or an array whose reflector material is not fissile. It determines the volume fraction of fissile material in the system for single unit problems and reflected problems having fissile reflector material. If the volume fraction of fissile material is found to be zero, an error message is written and execution is terminated.

LSCAN - This logical function returns a value of true if the specified unit is used in the problem.

START0 - This subroutine is called from START to generate a uniform initial source distribution in a cuboidal volume. The source distribution is generated by choosing points uniformly throughout the volume using the library routine FLTRN, and discarding points that do not occur in fissile material. See Sect. F17.4.8 and Table F17.4.6 for assistance in modifying the default boundaries over which the starting points are chosen.

STRTSU - This subroutine is called to generate a uniform initial source distribution for a single unit problem or a reflected problem for which the user has specified that the reflector be included in the starting distribution. FLTRN is used to choose points uniformly throughout a

cuboidal volume. DAZIRN, DGTISO, and FLTRN are used to choose points uniformly throughout a noncuboidal volume.

DAZIRN - This library routine provides the sine and cosine of a random azimuthal angle.

DGTISO - This library routine provides the direction cosines of an isotopically distributed random direction. It is used to generate an isotropic source distribution.

NUREG/CR-0200

Vol. 2, Rev. 5

F17.3.42 
STARTI - This subroutine is used to provide starting points chosen from a cosine distribution. The library routines DARSIN and FLTRN are used to provide the cosine distribution. See Table F17.4.6 for details of the various initial starting distributions.

START2 - This subroutine starts a specified fraction of the initial source distribution uniformly in fissile material in the unit located at a specified position in the global array. The remainder of the initial source is chosen from a cosine distribution as described in Table F17.4.6. START5 is called to determine the source points located in the unit at the specified location, and START1 is called to choose points from a cosine distribution.

LOCBOX - This function is called to return the unit at a given position in a given array.

START3 - This subroutine starts all the initial source neutrons at a specified point within the unit located at a specified position in the global array.

START4 - In this subroutine, a unit type is specified for starting the initial source distribution. A uniform sampling is made over the global unit orientation array to locate units of the specified type, and start the initial source neutrons at a specified positions within these units. CHOOSE is called to determine the positions within the global array that are occupied by the specified unit type.

CHOOSE - This subroutine locates the positions of a specified unit within the global unit orientation array by randomly choosing positions in the array and discarding them if the specified unit was not at that position. The library routine FLTRN is used to randomly choose positions in the unit orientation array.

START5 - This subroutine starts the initial source neutrons uniformly in fissile material within a specified unit type. A uniform sampling is made over the global unit orientation array to locate units of this type by utilizing subroutine CHOOSE.

START6 - This subroutine starts the initial source neutrons at points specified by the user. These points must be specified relative to the origin of the global array. REED is called to load the start type 6 data from the direct-access device. MOVE is called to move the start data into common. FLTRN is used to randomly supply additional starting points from existing ones. ICOMPA is used to determine if the starting point is identical to the previous one. See Table F17.4.6 for start data specifications.

LOCATE - This subroutine determines the geometry region that contains the specified starting point. HROTRN is used to determine the points location in a unit that is contained within a hole. FINDBX is used to determine the point's location in an array and the unit number at that location.

HROTRN - This subroutine locates the position of a specific point in a unit that is contained within a hole.

POSIT - This subroutine determines the region within the unit that contains the specified position.

FINDBX - This subroutine locates the position in an array that contains a specified point.

LOCBOX - This function returns the unit for a specified position in an array. 
MOVE - This library routine is called from START to load data from COMMON /NUTRON/ into the neutron bank. It is also used to pad the neutron bank to provide enough starting positions if too few were initially created.

FLTRN - This library routine is called from various subroutines during creation of the initial source distribution, to return a random number between zero and 1. START calls FLTRN to aid in choosing the initial source neutrons. It is also called if too few starting positions were generated. It is used to randomly choose from the initially created starting positions to pad the neutron bank until sufficient starting points exist.

JSTIME - This library routine is used for timing purposes.

F17.3.13.3 Track Individual Histories

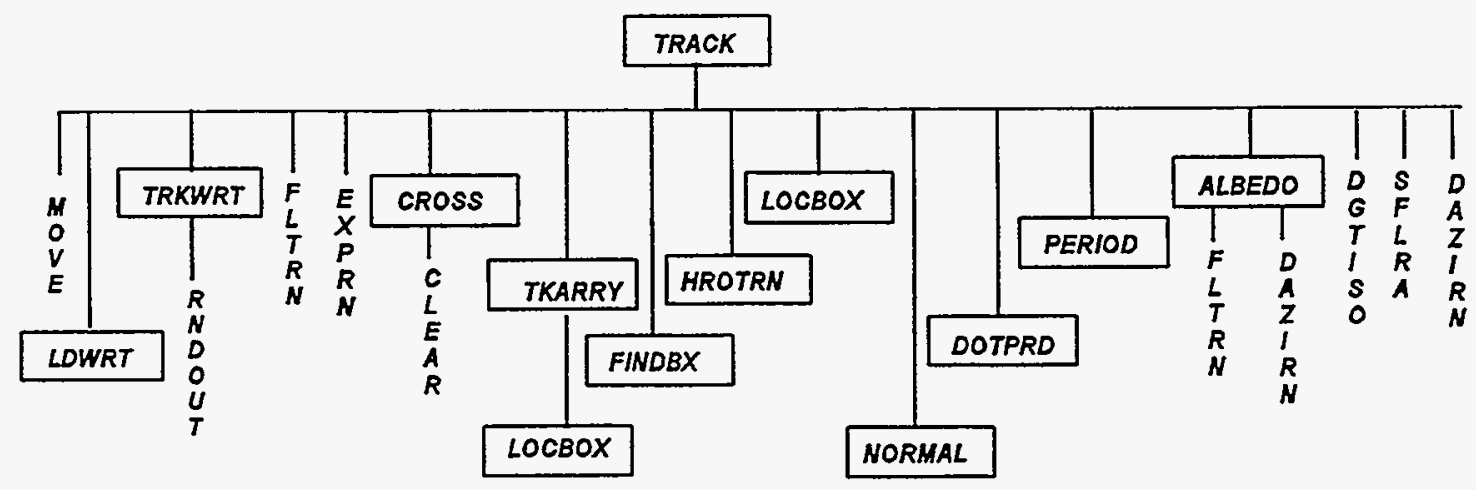

Figure F17.3.30. Flowchart for tracking individual histories

This section of the program does the actual tracking of the individual histories (Figure F17.3.30).

TRACK - This subroutine is called by GUIDE to accomplish the actual tracking of the individual histories. Each history is tracked, and its contributions to the various calculated results are tabulated, until it escapes from the system or is killed via Russian roulette. If a history changes supergroups as a result of a collision or an albedo reflection, it is stored in the neutron bank. In the course of tracking a history, an initialization call is made to subroutine ALBIN if differential albedo boundary conditions are utilized in the problem. LDWRT may be called to print debug information and, if history tracks are to be printed, TRKWRT is called from strategic locations throughout TRACK to provide pertinent information about the history as it moves through the tracking process. The library routine MOVE is utilized throughout the tracking procedure to move data in and out of storage arrays and commons. FLTRN is used to provide random numbers used in playing Russian roulette, processing downscatters, picking fission points, picking

NUREG/CR-0200

Vol. 2, Rev. 5

F17.3.44 
scattering angles and determining the fission energy group. EXPRN provides a random number, selected from an exponential distribution, to be used as the number of mean free paths a history can traverse. CROSS is called to determine if a boundary crossing has occurred. TKARRY is used to track a particle inside an array. FINDBX is used to locate the position of a particle in an array. HROTRN is called to transfer the coordinates of a particle from its current unit to the unit within the hole it is entering or vise versa. LOCBOX is called to determine the unit at a specified location in an array. ALBEDO is called to process differential albedo boundary conditions. The library routine DGTISO is used to provide direction cosines from an isotropic distribution. SFLRA provides a random number between -1.0 and 1.0 for use in processing an isotropic scattering. DAZIRN provides the sine and cosine of a random azimuthal angle for use in the anisotropic scattering treatment of a collision.

DOTPRD - This function returns the dot product of two direction vectors.

PERIOD - This subroutine processes periodic albedos on paired planes. Given a position and direct vector on one plane, it calculates the new position and direct vector on the paired plane.

NORMAL - This subroutine returns the normal to a surface at a given point on the surface.

LDWRT - This subroutine prints debug information that is useful only for a programmer. It is called if BUG=YES is specified in the parameter data (see Sect. F17.4.3). In normal operation, this subroutine should never be called.

MOVE - This library routine is utilized frequently in TRACK to move data in and out of storage arrays and commons.

TRKWRT - This subroutine is called from various locations in TRACK to print information about the current neutron as it is being processed. RNDOUT is called from TRKWRT to make the current random number available for printing.

FLTRN - This library routine provides a random number between zero and 1. TRACK utilizes these random numbers for playing Russian roulette, processing downscatters, picking fission points, determining scattering angles and determining the fission energy group.

CROSS - This important subroutine is responsible for processing crossings (i.e., it determines when a history has moved out of one geometry region into another). It determines if a crossing has actually occurred, and if it has, the coordinates of the crossing are upgraded to give the crossing point. The fraction of the path length used is also determined.

TKARRY - This subroutine is used to track a particle inside an array. It determines if a particle changes position within an array or crosses of the array.

FINDBX - This subroutine locates the position in an array that contains a specified point

HROTRN - This subroutine is used to transfer the coordinate system of a particle when it enters or leaves a hole. Upon entering a hole the particle location is transferred to the coordinate system of the unit within the hole. Upon exiting a hole the particle location is transferred to the coordinate system of the unit surrounding the hole.

F17.3.45

NUREG/CR-0200

Vol. 2, Rev. 5 
LOCBOX - This function returns the unit for a specified position in an array.

ALBEDO - This subroutine is responsible for processing a differential albedo reflection. The direction cosines for the face where the albedo reflection occurs are loaded, and the incident angle and the albedo energy group corresponding to the incident energy group are determined. The position of the albedo energy group within the supergroup, and the first cross-section energy group and the number of cross-section energy groups corresponding to it are determined. This is used to calculate the new cross-section energy group of the history. Then the returning angle and direction cosines are calculated. The history's weight is then corrected for the weight lost in the albedo portion of the problem. The weight lost in the albedo reflection is summed.

FLTRN - This library routine is called from ALBEDO to return a random number between zero and 1 that is used to select (1) the albedo energy group corresponding to the input energy group, (2) the returning albedo energy group, (3) the returning energy group corresponding to the returning albedo energy group, and (4) the returning angle.

EXPRN - This library routine is called from TRACK to provide the number of mean free paths to the next collision. This random number is picked from an exponential distribution.

DGTISO - This library routine is called from TRACK to provide direction cosines from an isotropic distribution. These direction cosines are utilized in processing isotropic scattering.

SFLRA - This library routine is called from TRACK to provide a random number between -1.0 and 1.0 for use in processing anisotropic scattering.

DAZIRN - This library routine is called from ALBEDO to return the sine and cosine of a random azimuthal angle which are used in determining the direction cosines of the returning history.

The remainder of this section is devoted to the logical flow of subroutine TRACK as illustrated by Fig. F17.3.31. The portions of TRACK performing specialized functions are denoted in the text by a descriptive name enclosed in quotes to distinguish them from subroutine names and in the figure by all capital letters. These descriptive names correspond to the functions depicted in the flowchart.

A brief discussion of the logical program flow through subroutine TRACK follows. If differential albedos are used, an initialization call is made to ALBIN. If debug print was specified in the parameter data, LDWRT is called. The library routine MOVE is used to load data from the neutron bank into COMMON INUTRON/ and various flags are set. Then the fission source portion of TRACK, denoted "FSTART," initializes and sets information necessary for processing the history. The "PATH" portion of TRACK sets the path length. The "CROSSING" portion of TRACK calculates the distance required for the neutron to cross each region boundary in the unit it is currently in. If the neutron is in a unit that is part of an array the "ARRAY TRACKING" portion of TRACK calculates the distance required for the neutron to exit the array boundary. The "POSITION" section of TRACK determines which region in the unit the neutron is in. If the neutron is outside its current unit three possibilities exist: (1) it could be changing to a new array position, (2) it could be exiting a hole, or (3) it could be exiting the global unit. If the neutron is changing array positions it calls subroutine TKARRY which transforms the coordinates of the neutron to those of the unit in the array position containing the neutron. If the neutron is exiting a hole or changing array position, the unit number is updated and it returns to "CROSSING." If the neutron is exiting the global unit it can enter an albedo boundary or leak from the system. If it leaks from the system, the history is terminated. If it enters an albedo boundary it enters the "ALBEDO" portion of TRACK which reflects the neutron back into the global unit.

NUREG/CR-0200

Vol. 2, Rev. 5

F17.3.46 


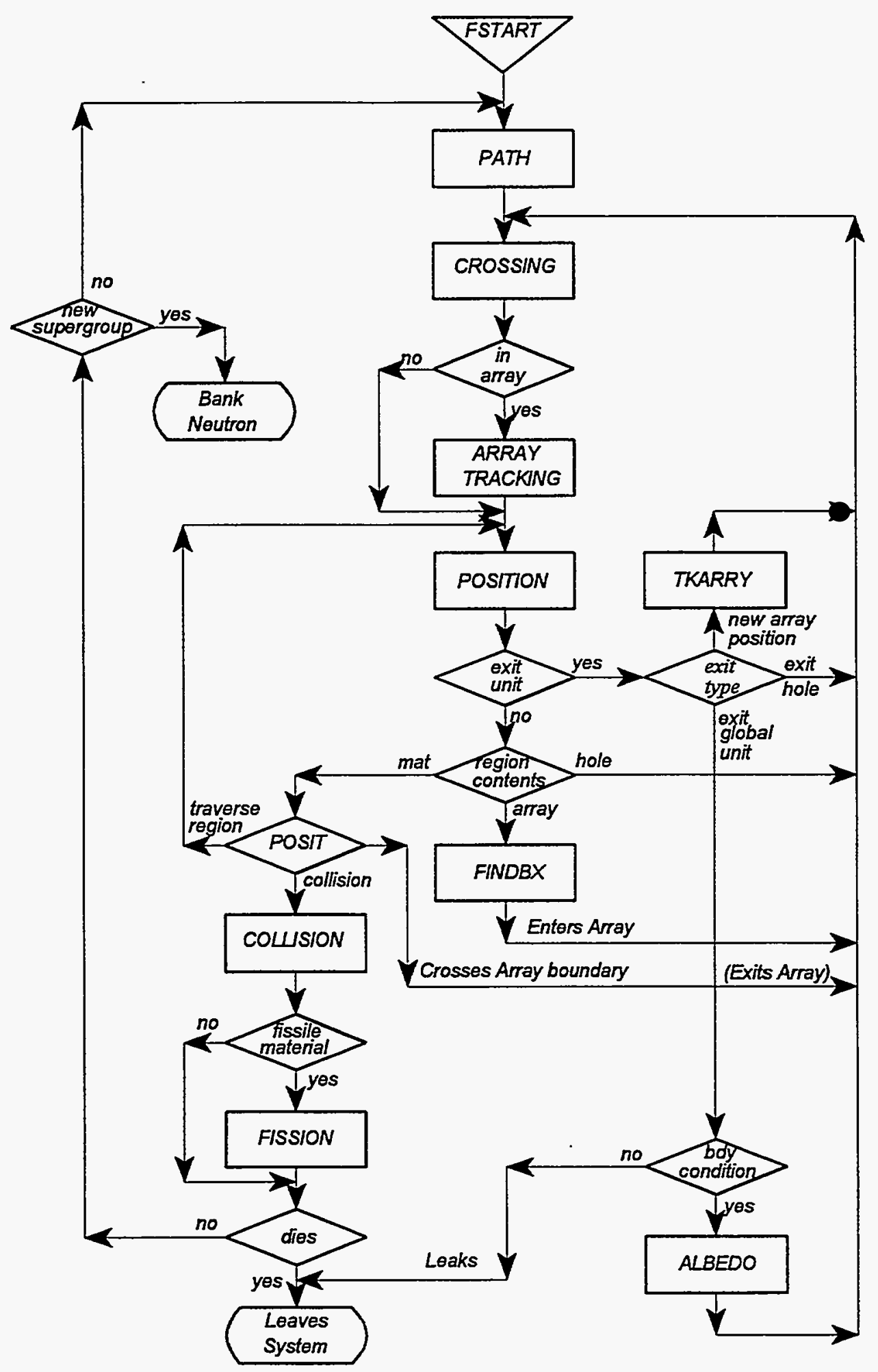

Figure F17.3.31. Logic flowchart for subroutine TRACK 
If the "POSITION" section of TRACK determines the neutron is inside the current unit, the contents of the region containing the neutron is checked. If the region contains a hole, the unit number and coordinate system of the neutron are updated and the code returns to the "CROSSING." If the region contains an array, the subroutine FINDBX is called, which determines the neutron's position relative to the unit it is entering. The neutron then returns to the "CROSSING" section of TRACK.

If the region the neutron is in contains a material, "POSIT" determines if the neutron traverses the region or has a collision in the region. If the neutron traverses the region, it is returned to the "NEUTRON POSITION" section of TRACK; otherwise it enters the "COLUISION" section of TRACK which updates its weights, position, direction, and energy group. If the collision occurs in a region containing fissile material, it enters the "FISSION" section of TRACK. After a collision, the particle can die, move to a new supergroup, in which case it is banked for later, or return to the "PATH" section of TRACK and continue.

"FSTART" - This portion of TRACK calls the library routine MOVE to load information pertaining to the history to be tracked. Then logical flags are set to indicate if the history is in an array and whether or not the history is a split neutron. Variables are initialized and if the history tracks are to be printed, TRKWRT is called to print information about the history. If the history is the result of an albedo reflection that resulted in the history moving to a new supergroup, and the weight is large enough, the history proceeds to the "PATH" portion of TRACK. Otherwise Russian roulette is played. If it survives, the weight is set to the average weight and the history proceeds to the "PATH" portion of TRACK. If the history is a split neutron, variables are initialized and the history proceeds to the "COLLISION" portion of TRACK to undergo the collision process.

"PATH" - This portion of TRACK determines the path length. If all the path length has been exhausted, the library routine EXPRN is used to define a new number of mean-free paths from an exponential distribution. If the region contains a void, the distance traveled is set to the maximum chord length of the system. Otherwise the distance traveled is equal to the remaining path length, divided by the macroscopic total cross section of the mixture contained in the region. The end point of the path is determined from the starting coordinates, the distance traveled and the direction cosines. If the starting and ending coordinates are identical in any given direction, the end point is changed by a very small amount in the proper direction.

"CROSSING"- This portion of TRACK initializes all the pointers and variables for the unit currently containing the neutron and determines which quadratic equations in the $\mathrm{QC}$ array need to be processed. It then checks to see if the current unit is in an array, and, if so, goes to the "ARRAY TRACKING" section of TRACK. Subroutine CROSS is then called to calculate the CA array which contains crossing distances from the current neutron position to the boundary of each region in the unit.

"ARRAY TRACKING"- This portion of TRACK initializes all the pointers and variables for the unit currently containing the array and determines which quadratic equations in the $\mathrm{QC}$ array need to be processed. Subroutine CROSS is then called to calculate the CA array which contains crossing distances from the current neutron position to the boundary of each region in the unit. The distance from the current neutron position needed to cross the array boundary is determined.

"POSITION"- This portion of TRACK determines which region, if any, in the current unit contains the neutron. This section first determines which region in the unit contains the neutron, if any, and sets a flag to .true. if the neutron is inside the unit and false. if it is outside the unit. Error

NUREG/CR-0200

Vol. 2, Rev. 5

F17.3.48 
messages are printed if the neutron is found to be in more than one region. These error messages may be caused by incorrectly specified regions (i.e., specifying the same volume in more than one region) or by not explicitly specifying which region contains the boundary between regions.

If the neutron is found to be inside the unit under consideration, the contents of the region are examined. The contents of the region containing the neutron will fall into one of three categories: (1) material, (2) hole, (3) or array. If the neutron is in a region containing material, it transfers to the "POSIT" section of the code. If the neutron is in a region containing a hole, a flag is set indicating an inward crossing into a hole and subroutine HOLROT is called, which translates and rotates the coordinates of the neutron to those of the unit in the hole. The neutron is then transferred to the "CROSSING" section of TRACK.

If the neutron is in a region containing an array, the array number is determined and the appropriate pointers and variables are initialized. If the neutron is already in an array, subroutine MOVE is used to store the current array location in the array stack. Subroutine FINDBX is then called to determine the array position of the neutron and transform the coordinates of the neutron into those of the unit in the array position it is crossing into. The neutron is then transferred to the "CROSSING" section of TRACK.

If the neutron is found not to be in the unit, there are four possibilities: (1) it has undergone an albedo reflection and roundoff error has put it outside the unit, (2) it has crossed out of the global unit, (3) it has crossed out of a hole, or (4) it has changed positions in an array. If the neutron crossed out of the global unit, it is transferred to the "ALBEDO" section of TRACK which determines if it leaks from the system or is reflected back into the system.

If the neutron has crossed out of a hole, a flag is set indicating an outward crossing out of a hole and subroutine HOLROT is called, which translates and rotates the coordinates of the neutron to those of the unit surrounding the hole. The neutron is then transferred to the "CROSSING" section of TRACK. If tracking information was asked for, subroutine TRKWRT is called to print pertinent information. The neutron is then transferred to the "CROSSING" section of TRACK.

If the neutron has changed position in an array, subroutine TKARRY is called to translate the neutron to the coordinate system of the unit in the new array position. If tracking information was asked for, subroutine TRKWRT is called to print pertinent information. The neutron is then transferred to the "CROSSING" section of TRACK.

"POSIT" - This portion of TRACK determines the material in the region, determines the distance the neutron needs to travel to exit the unit, and computes the amount of mean free paths needed to travel to exit the region. If tracking data were asked for, subroutine TRKWRT is called to print pertinent data. If the number of mean free paths needed to exit the region is greater than the number of mean-free paths assigned in "PATH," the neutron is transferred to the "COLLISION" section of TRACK. Otherwise the distance the neutron has traveled is updated, and the amount of mean-free paths already traveled is computed to exit the region. If tracking data were asked for, subroutine TRKWRT is called to print pertinent data. If the neutron is in an array, the neutron is checked to see if it crosses the array boundary. If it does not, the neutron is transferred to the "POSITION" section of TRACK. If the array boundary is crossed, the region 
number, position, unit number, and distance traveled are updated. If the array was nested, subroutine MOVE is called to restore the unit location in the surrounding array. If tracking information was indicated, subroutine TRKWRT is called to print pertinent information. The neutron is then transferred to the "CROSSING" section of TRACK.

"COLLISION" - When a history has a collision, the processing is done in this portion of TRACK. The number of mean-free paths used, distance traveled, and neutron position are updated. If fluxes are to be calculated, the new contribution is summed in. The age of the history is summed, the remaining path length is set to zero, the absorption weight, fission weight, and the contribution to the average number of neutrons produced per fission and the self-multiplication of the unit are calculated, based on the macroscopic cross-section data and the weight of the history. The weight of the history is then redefined to be the weight times the macroscopic nonabsorption probability. If the history tracks are to be printed, TRKWRT is called to print information pertinent to the collision process. If matrix $k_{\text {eff }}$ values are to be calculated, the fission weight is summed into the proper arrays. If the weight of the history exceeds the weight at which splitting occurs, a check is made to ensure that the neutron bank has adequate space for another history. If it is full, a message is written and a counter incremented. If the counter reaches 50 , the program is terminated and an error message is printed. If the bank can hold another history, the weight of the history is halved and the neutron counter is incremented. If the history tracks are to be printed, TRKWRT is called to print information pertinent to the split neutron. The library routine MOVE is used to store the split neutron in the neutron bank. The history cycles through the checking and splitting process until its weight is less than the weight at which splitting occurs. Then the weight is checked to see if Russian roulette should be played. If it is played and the history survives, the weight is set to the average weight. If Russian roulette is not played, the weight remains unchanged. In both cases, the new energy group is computed and a check is made to determine if the history undergoes anisotropic scattering. If it does, the azimuthal angle is chosen using DAZIRN, and the sine and cosine of that angle are returned to be used for calculating new direction cosines. If the history does not undergo anisotropic scattering, the new direction cosines are chosen from an isotropic distribution using DGTISO. This completes the "COLLISION" portion of TRACK.

"FISSION" - This portion of TRACK is responsible for generating and storing the fission source resulting from a collision. In the "COLLISION" portion of TRACK, the fission weight is defined as the weight of a history times the macroscopic production probability. If the fission weight of a history is greater than zero, the "FISSION" portion of TRACK is executed. To ensure generating enough fission source points to maintain an adequate representation of the true distribution, a minimum production factor is defined at the beginning of each generation to be

$$
\frac{3.0 \bar{k}}{\sqrt{F G}}
$$

where $\bar{k}$ is the running average value of the $\mathrm{k}_{\text {eff }}$ through the current generation and FG is the number of histories per generation. This represents an estimate of the lower limit of the $99 \%$ confidence interval for the distribution of the generation $k_{\text {eff }}$ Experience indicates that using this factor to generate fission source points leads to enough new fission points to fill the neutron bank for most generations. 
When the "FISSION" portion of TRACK is entered, the library routine FLTRN is used to provide a random number that is saved. A pseudo fission weight is defined as the fission weight divided by the random number. If the result is less than the production factor, the history proceeds to "PATH" or is stored in the neutron bank, depending on whether or not it remains in the same supergroup. If the history remained in the "FISSION" section, and its fission weight is greater than the production factor, the pseudo fission weight is redefined to be the production factor divided by the random number. If the fission bank is not full, the fission energy group is determined using FLTRN, the fission point is stored in the bank, and the number of fission points is incremented. The library routine MOVE is used to load information pertaining to the fission point from COMMON $/$ NUTRON/ into the fission bank, and the pseudo fission weight is loaded directly into the fission bank. If the fission bank is full when a new fission source point is generated, the bank is searched for the smallest pseudo fission weight. This is compared with the pseudo fission weight of the new fission point, and the point having the larger pseudo fission weight is stored in the bank.

After the fission point has been banked, the fission weight of the history is decremented by the production factor. If the remaining fission weight is greater than zero, the history returns to the beginning of "FISSION" to continue processing.

"ALBEDO" - If an albedo boundary condition is specified on any face of the problem, this portion of TRACK is utilized to provide the proper treatment. Each face is checked in sequence to determine if the history (1) leaks from the system, (2) undergoes specular or mirror image reflection, (3) undergoes periodic reflection, or (4) proceeds through the differential albedo treatment.

If the history undergoes specular or mirror image reflection, it is returned at the point it exited the face with its energy unchanged and the sign of its direction cosines reversed. If a periodic reflection occurs, the history is moved to the opposing face with its energy and direction cosines unchanged. If the history enters a differential albedo reflector, subroutine ALBEDO is called to determine the new weight of the history and its returning angle and energy. If the history enters a new supergroup, TRKWRT may be called to print the history track information and MOVE is called to bank the history in the neutron bank. When a history remains in the same supergroup, it is returned at the point it exited, and Russian roulette is played if the returning weight is low enough to warrant that action. If the weight is sufficiently high to avoid playing Russian roulette, or if the history survives Russian roulette, the history proceeds to the beginning of "PATH" and tracking continues. 


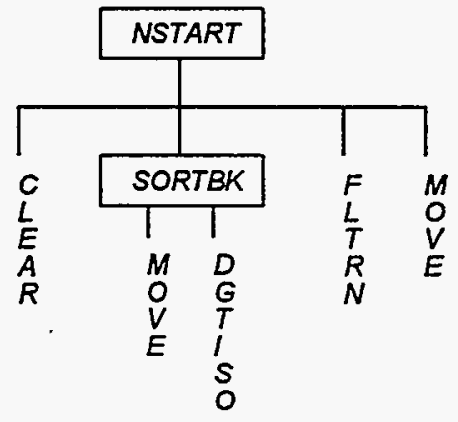

Figure F17.3.32. Flowchart for providing the next-generation source

This section of the program is responsible for providing the source for the next generation from the fission source generated during the tracking procedure (Figure F17.3.32).

NSTART - This subroutine calls CLEAR to initialize the neutron bank and writes an error message if no fission points were generated. Subroutine SORTBK is called to move information from the fission bank containing the fission source generated by the last generation into the neutron bank to be used as the source for the next generation. NSTART then checks to be sure enough source points exist to start the next generation. If too few starting points exist, the library routines MOVE and FLTRN are used to fill the required number of starting positions from the existing fission points.

SORTBK - This subroutine sorts the fission bank so the fission points are loaded in the order of their probability of being picked in a random selection process. For each source history, the library routine MOVE is used to move the fission source generated by the last generation into the neutron bank, and the library routine DGTISO is used to provide direction cosines from an isotropic distribution. Then the neutron number, weight and age are initialized.

F17.3.13.5 End-of-Generation Processing

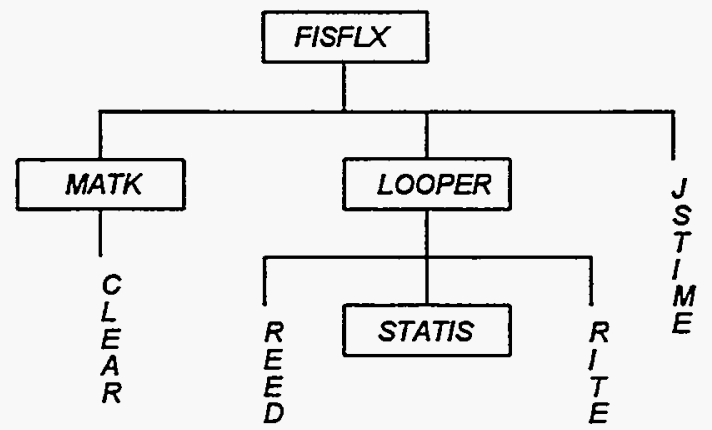

Figure F17.3.33. Flowchart for end of generation processing

NUREG/CR-0200

Vol. 2, Rev. 5

F17.3.52 
This portion of the program is responsible for processing data at the end of each generation.

FISFLX - This subroutine is called at the end of each generation to process data collected for that generation. The generation $k_{\text {eff }}$ the running average value of $k_{\text {eff }}$ and its deviation, and the matrix $\mathrm{k}_{\mathrm{eff}}$ and its deviation are processed and printed. MATK is called to process the matrix $\mathrm{k}_{\mathrm{eff}}(\mathrm{s})$ and associated information. LOOPER is called and, in turn, calls STATIS to collect and process the contribution and statistics for the flux, fissions, and absorptions, as well as the contribution to the leakage.

MATK - This subroutine is called to calculate the matrix $k_{e f f}$ by solving for the principal eigenvalue and eigenvector of a matrix using an iterative technique. The library routine CLEAR is used to initialize arrays and SQRT is used in calculating the deviation of the eigenvalue. MATK may be called to calculate the matrix $k_{\text {eff }}$ by array position, unit type, array number, and/or hole number.

LOOPER - This subroutine is called from FISFLX to load arrays in preparation for calling STATIS. A loop is made over the number of supergroups, within which pointers are calculated, REED is called to load the leakage, absorption, fission and flux arrays from the direct-access supergroup file, STATIS is called to process the data and RITE writes the processed data on the directaccess supergroup file. This procedure is repeated until all supergroups have been processed.

STATIS - This subroutine collects the sum of the contributions and the sum of the square of the contributions for the fluxes, fissions, absorptions and leakages to be used at the end of the problem in calculating their deviations.

\section{F17.3.14 END OF PROBLEM PROCESSING}

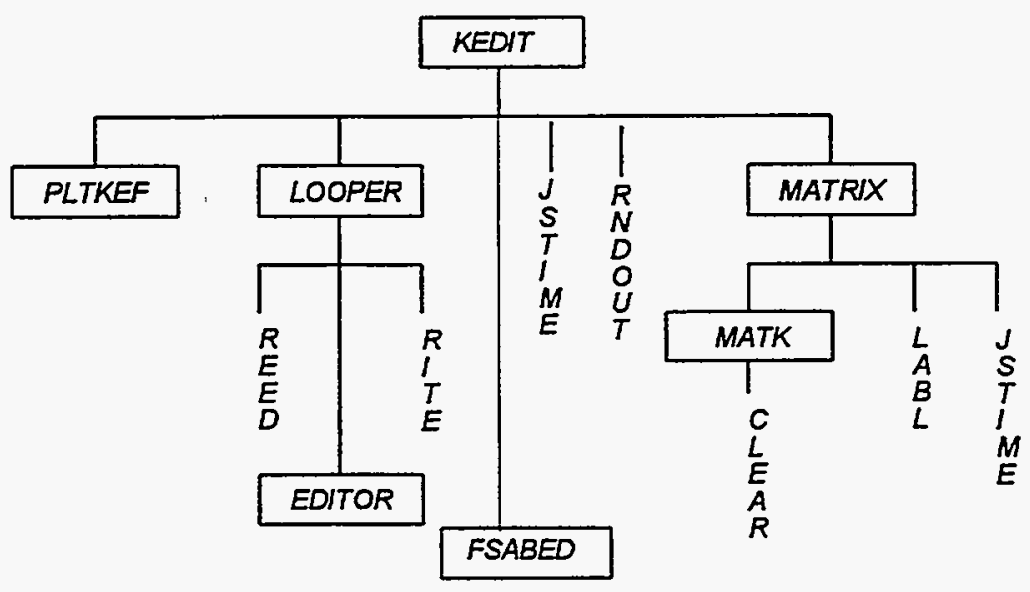

Figure F17.3.34. Flowchart for end-of-problem processing

This portion of the program is responsible for processing data and printing all the results except the fluxes at the completion or termination of a problem. 
KEDIT - This subroutine controls the processing and printing of results at the end of a problem. The life time and generation time are printed and, if the average number of neutrons per fission was calculated, it and the average fission group are printed. KEDIT then calculates and prints the average $k_{\mathrm{eff}}$ and its associated deviation for the 67,95 , and $99 \%$ confidence intervals and the number of histories involved. This is done repeatedly, skipping more generations each time. PLTKEF is called to print a plot of the average value of $k_{\text {eff }}$ as a function of the number of generations. It also prints a plot of the average value of $k_{\text {eff }}$ as a function of the number of generations skipped. LOOPER is called to prepare data for EDITOR which in turn calculates and prints the group-dependent fissions, absorptions and leakages and their deviations. If requested, the fissions and absorptions may also be printed by region. KEDIT then prints the total fissions, absorptions and leakages for the system, and their associated deviations. RNDOUT is called to provide the current random number to be printed. If matrix $k_{\text {eff }}$ data were requested, MATRIX is called to calculate and print matrix information. KEDIT then processes and prints the fission densities.

PLTKEF - This subroutine is called from KEDIT to print a plot of the average value of $k_{\text {eff }}$ vs generation and a plot of the average value of $\mathrm{k}_{\mathrm{eff}}$ vs generations skipped. The library routines MIN, MAX, and SQRT are used to generate the $\mathrm{k}_{\text {eff }}$ axis of the plots. The MOD function is used in labeling the generation axis.

LOOPER - This subroutine is called from KEDIT to load arrays in preparation for calling EDITOR. A loop is made over the number of supergroups. Within the loop, pointers are calculated, REED is called to load the leakage, absorption, fission and flux arrays from the direct-access supergroup file and EDITOR is called to process the data. RITE then writes the processed data for the supergroup on the direct-access supergroup file.

FSABED - This subroutine is called from KEDIT to calculate and print the total fissions and absorptions by region of the problem after all generations have been completed.

EDITOR - This subroutine is called from LOOPER to calculate and print the energy-dependent fissions, absorptions and leakages and their deviations. The fissions and absorptions may be region-dependent as well as energy-dependent.

MATRIX - This subroutine is called from KEDIT to calculate and print various information related to the matrix $k_{\text {eff. }}$ It is called if one or more matrix options were specified in the parameter data (see Sect. F17.4.3). If matrix information was collected, MATK is called to calculate cofactor $k_{\text {eff }}$ values. MATRIX then prints them as they are calculated. MATRIX also prints the fission production matrix if that was specified in the parameter data (see Sect. F17.4.3). The library routine LABL is called to print the source vector. MATRIX then prints the average self-multiplication calculated on the basis of collected data. This procedure is repeated for each type of matrix information specified in the parameter data. JSTIME is called to determine the amount of time used in the problem, which is then printed in MATRIX.

MATK - This subroutine calculates the principal eigenvalue and eigenvector of a matrix using an iterative technique. It also calculates the deviation associated with the eigenvalue, using CLEAR to initialize arrays and SQRT in calculating the deviation. MATK may be called from MATRIX to calculate cofactor $\mathrm{k}_{\mathrm{eff}}$ values.

NUREG/CR-0200

Vol. 2, Rev. 5

F17.3.54 


\section{F17.3.15 PRINT FLUXES}

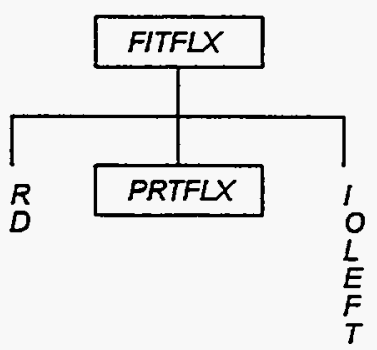

Figure F17.3.35. Flowchart for printing fluxes

This portion of the program is responsible for printing the fluxes at the completion of a problem (Figure F17.3.35).

FITFLX - This subroutine determines the maximum number of regions for which flux data will fit in memory and loads and prints them as they will fit. The library routine IOLEFT is called to determine the number of input/output requests remaining before the system cancels the job. Pointers are calculated and the library routine $\mathrm{RD}$ is used to load the fluxes for those regions from the direct-access supergroup file. PRTFLX is called to calculate the deviations and print the region- and energy-dependent fluxes and their associated deviations. If more fluxes remain to be printed, the process is repeated until all have been printed.

PRTFLX - This subroutine normalizes the fluxes, calculates their deviations and prints them, one supergroup at a time. The library routine SQRT is used when calculating the deviations.

\section{F17.3.16 REFERENCES}

1. S. K. Fraley, Users Guide for ICE-II, ORNL/CSD/TM-9/R1, Union Carbide Corp., Nucl. Div., Oak Ridge Natl. Lab., July 1977. Also see "ICE-S: Module to Mix Multigroup Cross Sections," Sect. F8 of SCALE: AModular Code System for Performing Standardized Computer Analyses for Licensing Evaluation, NUREG/CR-0200, Rev. 4 (ORNL/NUREG/CSD-2/R4), Vols. I, II, and III, February 1995). Available from Radiation Shielding Information Center, Oak Ridge National Laboratory as CCC-545.

2. "Appendix B, Generalized Gaussian Quadrature," The MORSE Code - A Multigroup Neutron and Gamma-Ray Monte Carlo Transport Code, ORNL-4585, Union Carbide Corp., Nucl. Div., Oak Ridge Natl. Lab., 1970. Also see "MORSE-SGC/S for the SCALE System," Sect. F9 of SCALE: AModular Code System for Performing Standardized Computer Analyses for Licensing Evaluation, NUREG/CR0200, Rev. 4 (ORNL/NUREG/CSD-2/R4), Vols. I, II, and II, February 1995). Available from Radiation Shielding Information Center, Oak Ridge National Laboratory as CCC-545. 


\section{F17.4 KENO-VI DATA GUIDE}

KENO-VI may be run."stand alone" or as a part of a SCALE criticality safety sequence. If KENO-VI is run "stand alone," cross-section data can be utilized from an AMPX ${ }^{1}$ working-format library or from an ICE (Sect. F8) mixed cross-section MORSE/KENO-V.a format library, also called a Monte Carlo format cross-section library. If KENO-VI uses an AMPX working- format library, a mixing table data block must be entered. If an ICE mixed cross-section MORSE/KENO-V.a library is used, a mixing table data block is not entered, and the mixtures specified in the KENO-VI geometry description must be consistent with the mixtures created in ICE. These are the entries in the 11\$[MUD] array in the ICE input data.

If KENO-VI is run as part of a SCALE criticality safety sequence, the mixtures are defined in the CSAS data (Sect. C6.4) and a mixing table data block cannot be entered in KENO-VI. Furthermore, the mixture numbers used in the KENO-VI geometry description must correspond to those defined in the standard composition data of the CSAS input. A mixture number of 500 must be used in the KENO-VI geometry description in order to use a cell-weighted mixture. A cell-weighted mixture is available only in SCALE sequences that use XSDRN to perform a cell-weighting calculation.

\section{F17.4.1 KENO-VI INPUT OUTLINE}

The data input for KENO-VI is outlined below. Defaulted data for KENO-VI have been found to be adequate for many problems. These values should be carefully considered when entering data. The information in BOLD TYPE is entered as data.

Blocks of input data are entered in the form:

\section{READ XXXX input data END XXXX}

where XXXX is the keyword for the type of data being entered. The keywords that can be used are listed in Table F17.4.1. A minimum of four characters are required for a keyword. However, the keywords can be up to twelve characters long, the first four of which must be input exactly as listed in the table. Data input is activated by entering the words READ XXXX followed by one or more blanks. All input data pertinent to XXXX are then entered. Data for XXXX are terminated by entering END XXXX followed by two or more blanks.

Table F17.4.1 Types of input data

\begin{tabular}{ll}
\hline \multicolumn{1}{c}{ Type of data } & First four characters \\
\hline Parameters & PARA or PARM \\
Geometry & GEOM \\
Biasing & BIAS \\
Boundary conditions & BOUN or BNDS \\
Start & STAR or STRT \\
Array (unit orientation) & ARRA \\
Extra 1-D cross sections & XIDS \\
Cross-section mixing table & MIXT or MIX \\
Plot or picture & PLOT or PLT or PICT \\
\hline \multicolumn{2}{c}{${ }^{a}$ MIX and PLT must include a trailing blank that is considered part } \\
of the keyword.
\end{tabular}

F17.4.1

NUREG/CR-0200, Vol. 2, Rev. 5 
Two data records must be entered for every problem. The first is the problem title. The second is the END DATA to terminate the problem.

(1) problem title

Enter a problem title (limit 80 characters including blanks). A title must be entered if running "stand alone."

See Sect. F17.4.3.

When used in a CSAS sequence, this title is omitted.

(2) READ PARA parameter data END PARA

Enter parameter input as needed to describe a problem. Default values are assigned to all parameters. A problem can be num without entering any parameter data if the default values are acceptable.

Parameter data must begin with the words READ PARA. Parameter data may be entered in any order. If a parameter is entered more than once, the last value is used. The words END PARA terminate the parameter data. See Sect. F17.4.3.

$\left(\mathrm{n}_{1}\right)$... $\left(\mathrm{n}_{9}\right) \quad$ The following data may be entered in any order. Data not needed to describe the problem may be omitted.

$\left(n_{1}\right)$ READ GEOM all geometry region data END GEOM

Geometry region data must be entered for every problem that is not a restart problem. Geometry data must begin with the words READ GEOM. The words END GEOM terminate the geometry region data. See Sect. F17.4.4.

$\left(\mathrm{n}_{2}\right)$ READ ARRA array definition data END ARRA

Enter array definition data as needed to describe the problem. Array definition data define the array size and position units (defined in the geometry data) in a three-dimensional (3-D) lattice that represents the physical problem being analyzed. Array data must begin with the words READ ARRA. The words END ARRA terminate the array data. See Sect. F17.4.5.

\section{$\left(n_{3}\right)$ READ BIAS biasing information END BIAS}

Biasing information is used to define the weight that is given a neutron surviving Russian roulette. Enter biasing information as needed to describe the problem. Biasing data must begin with the words READ BIAS. The words END BIAS terminate the biasing data. See Sect. F17.4.7. 


\section{$\left(n_{4}\right)$ READ BOUN albedo boundary conditions END BOUN}

Enter albedo boundary conditions as needed to describe the problem. Albedo data must begin with the words READ BOUN and terminate with the words END BOUN. See Sect. F17.4.6.

$\left(\mathrm{n}_{5}\right)$ READ STAR starting distribution information END STAR

Enter starting information data for starting the initial source neutrons only if a uniform starting distribution is undesirable. Start data must begin with the words READ STAR and terminate with the words END STAR. See Sect. F17.4.8.

$\left(\mathrm{n}_{6}\right)$ READ MIXT cross-section mixing table END MTXT

Enter a mixing table to define all the mixtures to be used in the problem. The mixing table must begin with the words READ MIXT and end with the words END MIXT. Do not enter mixing table data if KENO-VI is run as a part of a SCALE criticality safety sequence. See Sect. F17.4.10.

$\left(\mathrm{n}_{7}\right)$ READ X1DS extra 1-D cross-section IDs END X1DS

Enter the IDs of any extra one-dimensional (1-D) cross sections that are to be used in the problem. These must be available on the mixture cross-section library. Extra 1-D cross-section data must begin with the words READ X1DS and terminate with the words END X1DS. See Sect. F17.4.9.

\section{$\left(\mathrm{n}_{8}\right)$ READ PLOT plot data END PLOT}

Enter the data needed to provide a two-dimensional (2-D) printer plot of a slice through a specified portion of the 3-D geometrical representation of the problem. Plot or picture data must begin with the words READ PLOT and terminate with the words END PLOT. See Sect. F17.4.11.

$\left(\mathrm{n}_{\mathrm{g}}\right)$ END DATA must be entered

Terminate the data for the problem.

\section{F17.4.2 PROCEDURE FOR DATA INPUT}

This section is a brief list of the input data for KENO-VI. Additional information concerning KENO-VI data input may be found in Sect. F17.5. The first data record of "stand alone" KENO VI must be the title. The next block of data must be the parameters if they are to be entered. A problem can be run without entering the parameters. The remaining blocks of data can be entered in any order.

BOLD TYPE specifies keywords. A keyword is used to identify the data that follow it. When a keyword is used, it must be entered exactly as shown in the data guide. All keywords, except those ending with an equal sign, must be followed by at least one blank. 
small italics

correlate data with a program variable name. The actual values are entered in place of the program variable name and are terminated by a blank or a comma.

CAPITAL ITALICS identify general data items. General data items are general classes of data including

(1) geometry data such as UNIT INITIALIZATION and UNIT NUMBER DEFINITION, GEOMETRY REGION DEFINITION VECTOR, GEOMETRY WORD, MIXTURE NUMBER, BLASID, and REGION DIMENSIONS,

(2) albedo data such as FACE CODES and $A L B E D O N A M E S$, and

(3) weighting data such as BIAS IDNUMBERS, etc.

\section{F17.4.3 TITLE AND PARAMETER DATA}

TITLE ... A title must be entered if KENO VI is being run "stand alone" (i.e., not part of a CSAS sequence). title length is 80 characters, including blanks.

PARAMETER DATA . . Enter only those parameters whose values you wish to change. The commonly changed parameters are TME, GEN, and $N P G$. Seldom changed parameters are $N B K, N F B, X N B, X F B, W T H$, $W T L, T B A, B U G, T R K$, and $L N G$.

\section{READ PARAM}

Floating-point parameters
$\mathrm{RND}=$ rndnum input hexadecimal random number; a default value is provided. If a random number
is specified, it should be chosen from a previous run.
$\mathrm{TME}=t \max$ execution time (in minutes) for the problem, default $=30$ minutes.
TBA $=t b t c h$ time allotted for each generation (in minutes), default $=0.5$ minutes. If $t b t c h$ is exceeded in any generation, the problem is terminated and final edits are performed.
WTA $=d w t w \quad$ the default average weight given a neutron that survives Russian roulette, $d w t a v$ default $=0.5$.
WTH $=$ wthigh the default value of wthigh is 3.0 and should be changed only if the user has a valid reason to do so. The weight at which splitting occurs is defined to be wthigh $x$ wtavg, where wtavg is the weight given to a neutron that survives Russian roulette.
WTL $=$ wtlow $\quad$ Russian roulette is played when the weight of a neutron is less than wtlow $x$ wtavg. The wtlow default $=1.0$ /wthigh. 
SIG = sigma This is used to terminate a problem when a standard deviation of sigma has been reached. The problem will still terminate when the specified number of generations have been run, even if the standard deviation is still greater than sigma.

NOTE: The default values of $w$ thigh and $w t l o w$ have been determined to minimize the deviation per unit running time for many problems.

Integer parameters
$\mathbf{G E N}=n b a$
number of generations to be run, default $=103$
$\mathbf{N P G}=n p b$
number of neutrons per generation, default $=300$
NSK $=n s k i p$
number of generations ( 1 through nskip) to be omitted when collecting results, default $=3$

RES $=n r s t r t$

number of generations between writing restart data, default $=0$. If RES is zero, restart data are not written. When restarting a problem, RES is defaulted to the value that was used when the restart data block was written. Thus, it must be entered as zero to terminate writing restart data for a restarted problem. (WRS is the logical unit number for writing restart data. See logical unit numbers in the parameter data.)
NBK $=n b a n k$
number of positions in the neutron bank, default $=n p b+25$
$\mathrm{XNB}=n x n b k$
number of extra entries in the neutron bank, default $=0$
$\mathrm{NFB}=n f b n k$
number of positions in the fission bank, default $=n p b$
$\mathrm{XFB}=n x f b k$
number of extra entries in the fission bank, default $=0$
$\mathrm{X1D}=$ numx $1 d$
number of extra 1-D cross sections, default $=0$
$\mathrm{LNG}=\operatorname{lng}$
number of words of storage to be requested by subroutine $A L O C A T$, default = 1000000 . (This value is reduced to fit in the space allotted to the job when the problem is run.)
$\mathrm{BEG}=n b a s$
beginning generation number, default $=1$. If $B E G$ is greater than 1 , restart data must be available. $B E G$ must be 1 greater than the number of generations retrieved from the restart file.
$\mathrm{NB8}=n b 8$
number of blocks allocated for the first direct-access unit, default $=200$
NL8 $=n l 8$
length of blocks allocated for the first direct-access unit, default $=789$ 
Alphanumeric parameter data ... enter YES or NO

RUN = lrun key for determining if the problem is to be executed when data checking is complete, default = YES

Note: The value of RUN set here will be overridden by a value entered in the PLOT data. However, if the problem is restarted, the default value or the value entered here is the value that will be used unless the PLOT data block from the restart unit is overridden by new PLOT data. See Sect. F17.4.11.

$\mathbf{F L X}=n f L x \quad$ key for collecting and printing fluxes, default $=$ NO

FDN $=n f d e n \quad k e y$ for collecting and printing fission densities, default $=\mathrm{NO}$

$\mathrm{ADJ}=$ nadj $\quad$ key for running adjoint calculation, default $=$ NO. Adjoint cross sections must be available to run an adjoint problem. If $L I B=$ is specified, the cross sections will be adjointed by the code. If $\mathrm{XSC}=$ is specified, the cross sections must already be in adjoint order.

$A M X=a m x \quad k e y$ for printing all mixture cross-section data. This is the same as activating $X A P, X S 1, X S 2$, $P K I$, and $u P I D$. If any of these are entered in addition to $A M X$, that portion of $A M X$ will be overridden, default $=$ NO.

$\mathrm{XAP}=$ prtap $\quad$ key for printing discrete scattering angles and probabilities for the mixture cross sections, default $=$ NO

$\mathrm{XS1}=\operatorname{prtp0}$ key for printing mixture $1-\mathrm{D}$ cross sections, default $=$ NO

$\mathrm{XS2}=p r t 1 \quad$ key for printing mixture 2-D cross sections, default $=\mathrm{NO}$

PKI $=$ prtchi $\quad$ print input fission spectrum, default $=\mathrm{NO}$

$\mathbf{P 1 D}=$ prtex $\quad$ print extra $1-\mathrm{D}$ cross sections, default $=$ NO

$\mathbf{F A R}=l f a \quad$ key for printing fissions and absorptions by region, default $=$ NO

MKP $=$ larpos calculate and print matrix $k$-effective by unit location, default $=$ NO.

Unit location may also be referred to as array position or position index.

$\mathbf{C K P}=l c k p \quad$ calculate and print cofactor $\mathrm{k}$-effective by unit location, default is the value of $M K P$. Unit location may also be referred to as array position or position index.

$\mathrm{FMP}=$ pmapos print fission production matrix by array position, default $=\mathrm{NO}$

MKU = lunit calculate and print matrix $k$-effective by unit type, default $=$ NO

$C K U=l c k u \quad$ calculate and print cofactor k-effective by unit type, default is the value of $M K U$

NUREG/CR-0200,

Vol. 2, Rev. 5

F17.4.6 
FMU $=$ pmunit print fission production matrix by unit type, default $=$ NO

MKH $=$ lmhole calculate and print matrix $k$-effective by hole number, default $=$ NO

CKH $=$ lckh calculate and print cofactor $k$-effective by hole number, default is the value of MKH

FMH $=$ pmhole print fission production matrix by hole number, default $=\mathrm{NO}$

HHL $=$ lhhgh $\quad$ collect matrix information by hole number at the highest hole nesting level, default $=$ NO

MKA = lmarry calculate and print matrix $k$-effective by array number, default $=\mathrm{NO}$

A global array must be specified if array matrix data are collected.

$\mathbf{C K A}=$ lcka $\quad$ calculate and print cofactor $\mathrm{k}$-effective by array number, default is the value of MKA

FMA $=$ pmarry print fission production matrix by array number, default $=$ NO

HAL = langh collect matrix information by array number at the highest array nesting level, default $=$ NO

PLT $=$ lplot $\quad$ key for drawing specified pictures of the problem geometry, default $=$ YES

Note: To draw a plot, appropriate plot data must be entered. The value of $P L T$ set here will be overridden by a value entered in the PLOT data. However, if the problem is restarted, the default value or the value entered here is the value that will be used unless the PLOT data block from the restart unit is overridden by new PLOT data. See Sect. F17.4.11. The value of lplot set here is written on the restart unit, and the value of lplot set in the PLOT data is not.

BUG $=$ ldbug print debug information, default $=$ NO

Enter $Y E S$ for code debug purposes only.

TRK $=$ ltrk print tracking information, default $=\mathrm{NO}$

Enter YES for code debug purposes only.

$\mathbf{P W T}=l p w t \quad$ print weight average array, default $=$ NO

$\mathbf{P G M}=$ lgeom print unprocessed geometry as it is read, default $=$ NO

SMU $=$ lmult $\quad$ calculate the average self-multiplication of $a$ unit, default $=$ NO

$\mathrm{NUB}=$ newbar calculate the average number of neutrons per fission and the average energy group at which fission occurred, default $=\mathrm{NO}$

PAX = lcorsp print the arrays defining the correspondence between the cross-section energy group structure and the albedo energy group structure, default $=$ NO 
Logical Unit Numbers

$\mathrm{XSC}=$ xsecs logical unit number for a MORSE/KENO-VI format mixed cross-section library, default = 14
$\mathbf{A L B}=$ albdo $\quad$ logical unit number for albedo data, default $=79$
WTS $=w t s \quad$ logical unit number for weights, default $=80$
LIB $=l i b \quad$ logical unit number for $A M P X$ working format cross-section library, default $=0$
SKT $=s k r t \quad$ logical unit number for scratch space, default $=16$
RST $=$ rstrt $\quad$ logical unit number for reading restart data, default $=0$
Enter a logical unit number to restart if $B E G>1$
WRS $=$ wstrt $\quad$ logical unit number for writing restart data, default $=0$
A nonzero value must be entered if $R E S>0$.

EXAMPLE: READ PARAM NPG=203 FLX=YES END PARAM

\section{F17.4.4 GEOMETRY DATA}

GEOMETRY REGION DATA . . . geometric arrangements in KENO-VI are achieved in a manner similar to using a child's building blocks. Each building block is called a UNIT. An array or lattice is constructed by stacking these units. Once an array or lattice has been constructed, it can be placed in a unit by using the ARRAY specification.

Each UNIT has its own coordinate system. All geometry data used in a problem are correlated to the absolute coordinate system by specifying a global unit. A global unit that encloses the entire system must be specified for every problem including a single unit problem. Units are constructed of combinations from over a dozen predefined shapes plus any other shapes that can be defined using quadratic equations. These geometric shapes are allowed to intersect each other, producing regions that are then described by specifying them as internal or external to the geometric shapes. The geometric shapes can be translated anywhere within the system and rotated to any orientation. Figure 17.4.1 shows some acceptable geometric configurations.

Special options are provided to enhance the basic geometry package. These fall under the heading EXTENDED GEOMETRY DESCRIPTIONS and include ARRAY and HOLE descriptions. The HOLE option allows placing a unit within a geometry/material region (see Fig. F17.4.2). Where a hole record is used, the region boundary must coincide exactly with the boundary of the unit placed in the region. The hole option allows complex units to be constructed separately and then placed in a region on another unit. Since a particle must check every region to determine its location within a unit, using holes to contain complex sections of a problem may decrease the CPU time needed for the problem. An arbitrary number of HOLES can be placed in a unit. 


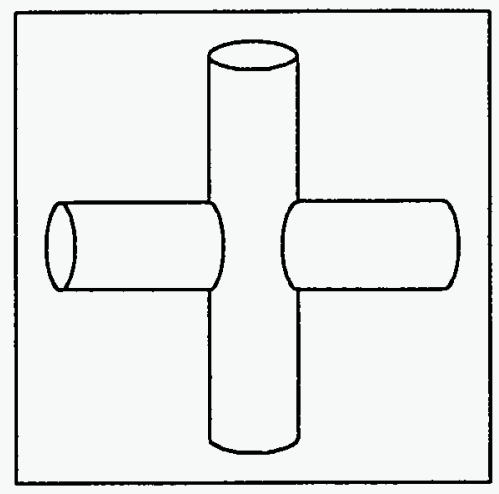

INTERSECTING REGIONS

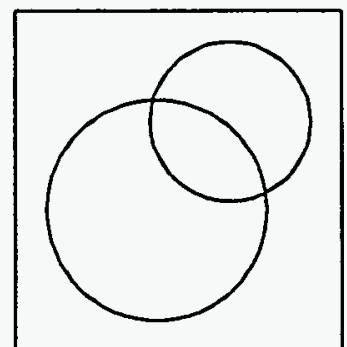

INTERSECTING REGIONS

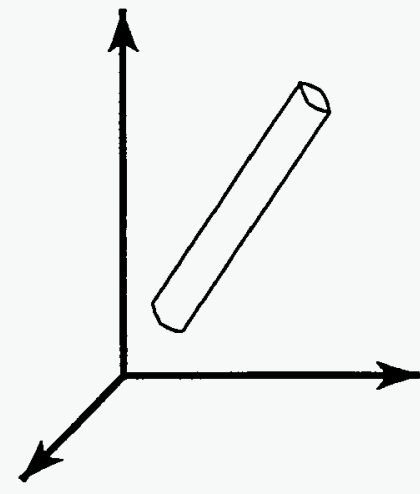

ROTATED REGION

Figure F17.4.1 Examples of geometric configurations allowed in KENO-VI

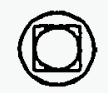

UNIT 1

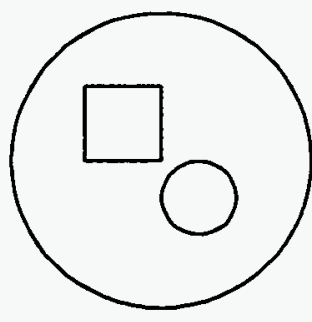

UNIT 2
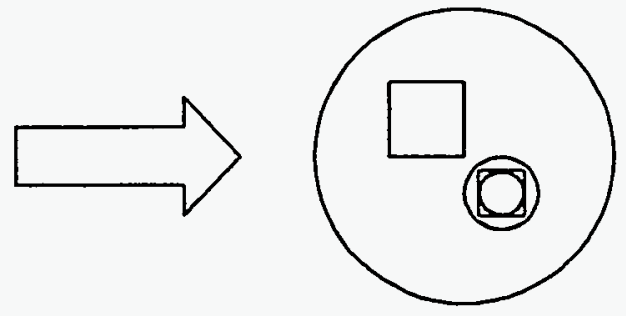

UNIT 2 WITH UNIT 1 PLACED INIT AS A HOLE

Figure F17.4.2 Example demonstrating HOLE capability in KENO-VI

Lattices or arrays are created by stacking UNITS. Units that have a rectangular parallelepiped outer region can be used to construct a rectangular array. Units that have a hexprism outer region can be used to construct a triangular-pitched matrix. In either case, the adjacent faces of adjacent units stacked together must match exactly. See Sect. F17.5.6.4 for additional clarification and Figs. F17.4.3 and 17.4.4 for typical examples. 


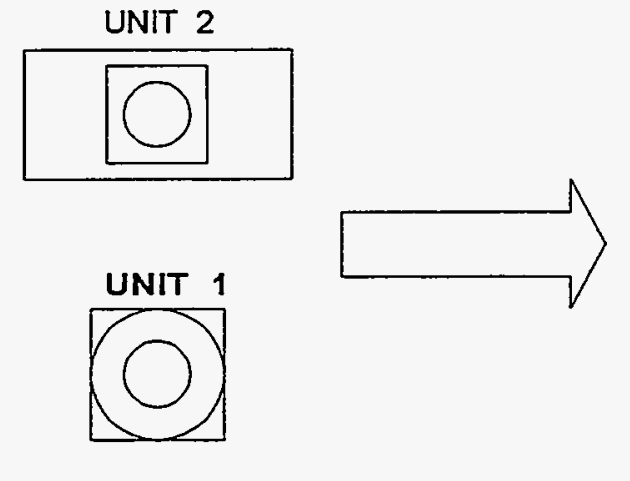

CREATE UNITS

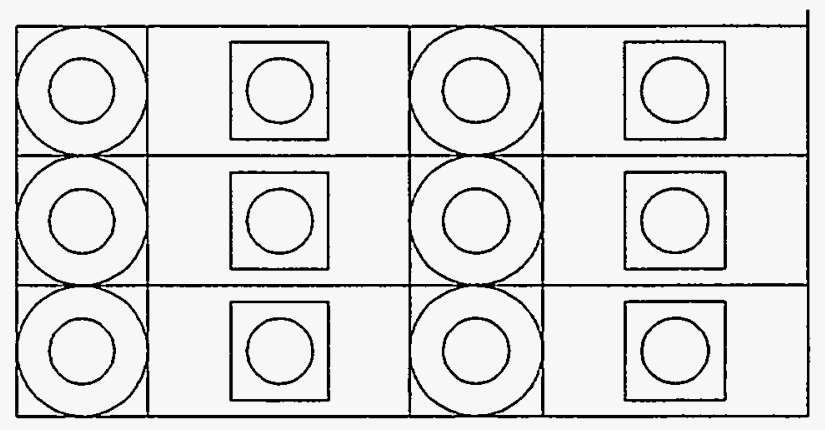

STACK THE UNITS TO FORM AN ARRAY

Figure F17.4.3 Example of rectangular-pitched array construction

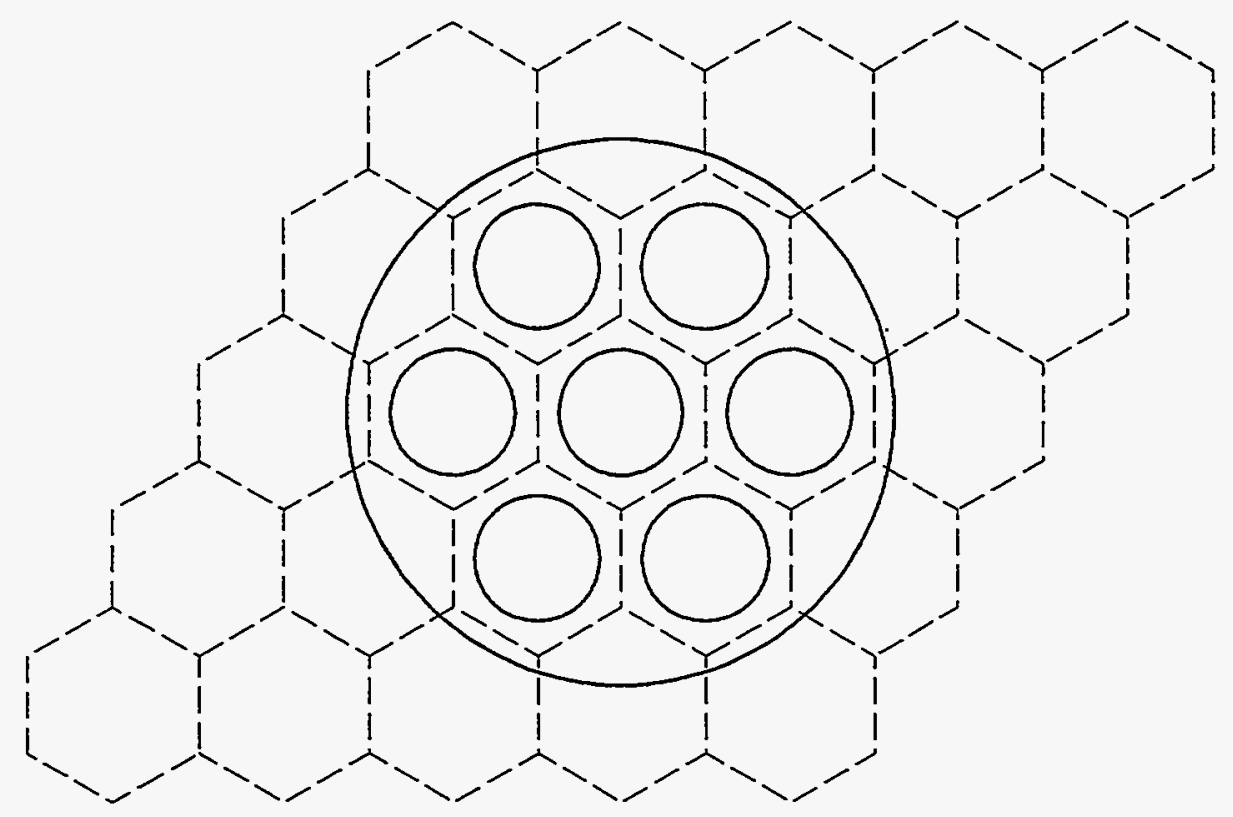

Figure F17.4.4 Example of triangular-pitched array construction 
The ARRAY option is provided to allow placing an array or lattice within a unit. An array is placed in a unit by placing it directly into a geometry/material region. The region boundary containing the array must coincide with or be contained within the array boundary. The region boundary becomes the array boundary. A particle enters or leaves the array when the region boundary is crossed. Multiple array may be placed directly in a UNIT by placing them in separate regions. Arrays can also be placed within a unit using HOLES. When an array is placed in a unit via a HOLE, the unit that contains the array, rather than the array itself, is placed in the unit. Arrays of dissimilar arrays can be created by stacking units that contain arrays. See Fig. F17.4.5 for an example of an array composed of units containing holes and arrays.

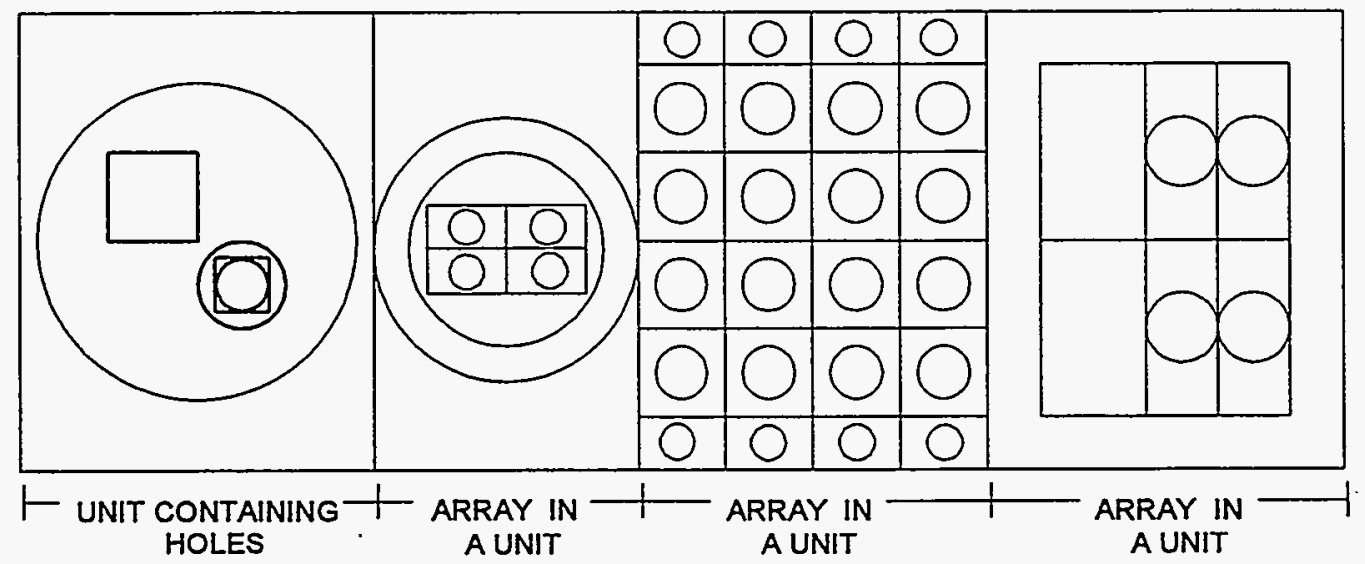

Figure F17.4.5 Example of an array composed of units containing arrays and holes

The method of entering GEOMETRY REGION DATA follows:

\section{READ GEOM GEOMETRY REGION DATA END GEOM}

GEOMETRY REGION DATA must be entered unless the problem is being restarted. A description of all units the user wishes to define must be entered. See Sect. F17.5.6 for detailed examples.

The description of a unit includes all geometry data following a UNIT INITIALIZATION. A unit is terminated by encountering another UNIT INITIALIZATION or an END GEOM.

A GEOMETRY REGION DATA description consists of the following:

(a) UNIT INITIALIZATION

(b) GEOMETRY REGION DESCRIPTION

(c) OPTIONAL GEOMETRY COMMENTS

(a) UNIT INITIALIZATION . . This data sequence signals the beginning of a new geometric coordinate system and assigns the unit number to the geometry regions comprising the unit.

A UNIT INITIALIZATION is invoked when one or more of the following data items are encountered: 
(a1)

GLOBAL SPECIFICATION

fgeom

GLOBAL

The word GLOBAL, when entered, must be followed by one or more blanks, the word UNIT, and a UNIT ID NUMBER. Enter the geometry word GLOBAL immediately prior to the UNIT that defines the overall geometric boundaries of the problem. A global unit must be entered for each problem.

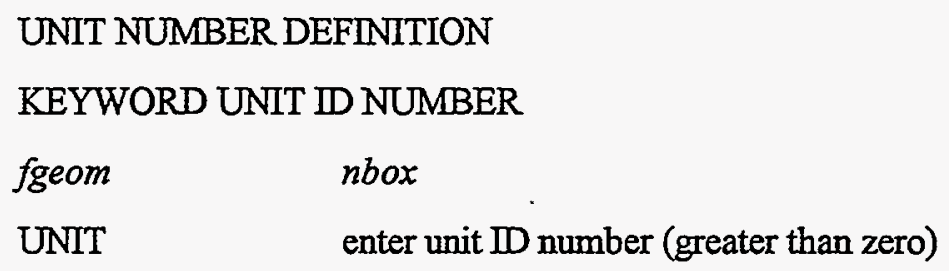

The UNIT NUMBER definition assigns the specified unit number to the geometry data that define the unit.

(b) GEOMETRY REGION DESCRIPTION ... This type of geometry data consists of geometry records, media records, a boundary record and their associated data. Free-form input is used to enter the data. Options $R, *, \$$, and P from Table F17.4.2 can be used. The first record, called the GEOMETRY RECORD, is entered in the form:

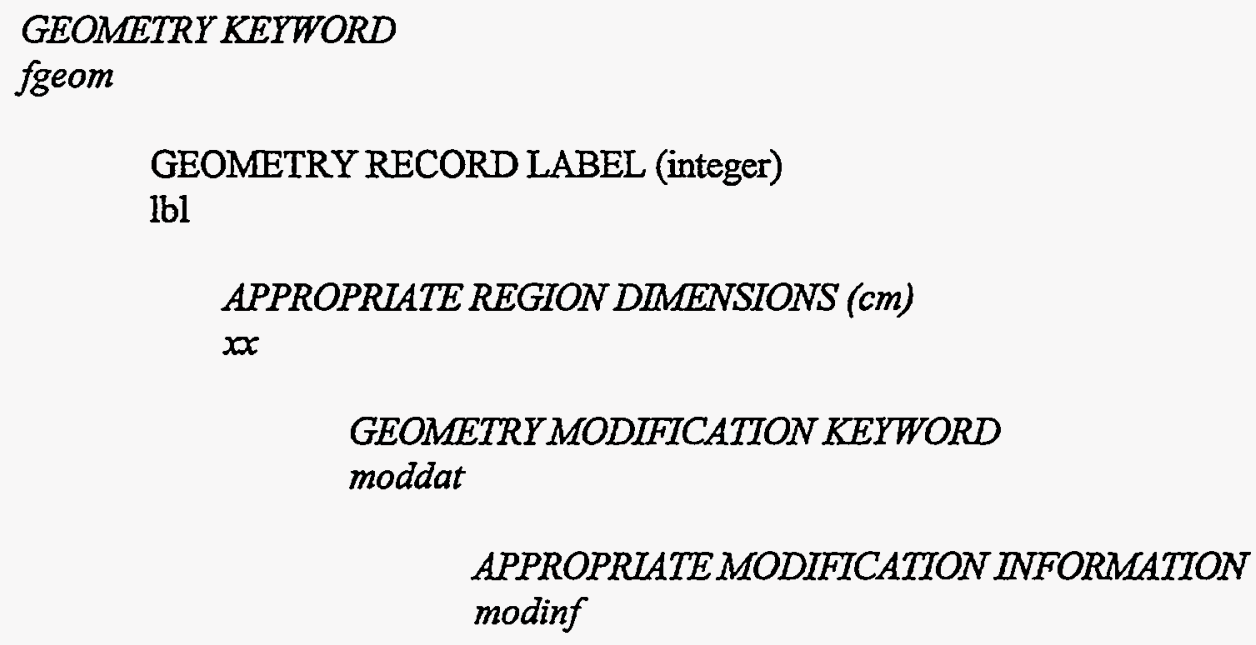

The second record, called the MEDIA RECORD, is entered in the form:

MEDIA KEYWORD

fmed

MAXTURE, HOLE, OR ARRAY ID

mat

NUREG/CR-0200,

Vol. 2, Rev. 5

F17.4.12 
BIAS ID, if appropriate

imp

REGION DEFINITION VECTOR

il i2 i3 i4

The third record, called the BOUNDARY RECORD, is entered in the form:

BOUNDARY KEYWORD

bndry

\section{REGION DEFINITION VECTOR}

il i2 i3 i4

The geometry records contain information describing the dimensions and location of each geometric shape. The media records contain information describing the contents of each region and how the region boundaries relate to the geometric shapes. The geometry and media records can be combined in any order within a unit. The region definition vector in the media and boundary records refer to the geometry record labels. In the region definition vector, a positive label means the media is inside the specified geometric shape and a negative label means the media is outside the specified geometric shape. Each unit must contain one BOUNDARY record which describes the unit boundary. Only that section of the unit geometry contained within the volume specified by the boundary record is considered part of the unit.

The GEOMETRY KEYWORD fgeom is followed by one or more blanks and must be one of the keywords below. A label and the APPROPRIATE REGIONAL DIMENSIONS follow the keywords as described below.

CONE, CUBOID, CYLINDER, DODECAHEDRON, ECYLINDER, ELLIPSOID, HEXPRISM, HOPPER, PARALLELEPIPED, PPIPED, PLANE, QUADRATIC, RHOMBOID, SPHERE, WEDGE

Note: fgeom may be no more than 12 characters long.

CONE specifies a body consisting of one nappe of a right circular cone. It is defined by specifying the - top radius of the cone, $R t$, the $Z$ coordinate of the top face, $Z t$, the bottom radius of the cone, $R b$, and the $Z$ coordinate of the bottom face, $Z b$. Figure 17.4.6 shows the correct input sequence for a cone.

CUBOID specifies a rectangular parallelepiped. It is defined by specifying the $+X$ dimension, $-X$ dimension, $+Y$ dimension, $-Y$ dimension, $+Z$ dimension, $-Z$ dimension. It is perpendicular to the $X, Y$, and $Z$ axes unless otherwise specified by the option geometry modification data. Figure 17.4.7 shows the correct input sequence for a cuboid.

CYLINDER specifies a right circular cylinder. It is defined by specifying the radius of the cylinder, $R$, the $Z$ coordinate of the top face, $\mathrm{Zt}$, and the $\mathrm{Z}$ coordinate of the bottom face, $\mathrm{Zb}$. Its centerline must lie on the $Z$ axis, unless otherwise specified by the optional geometry modification data. Figure 17.4.8 shows the correct input sequence for a cylinder. 


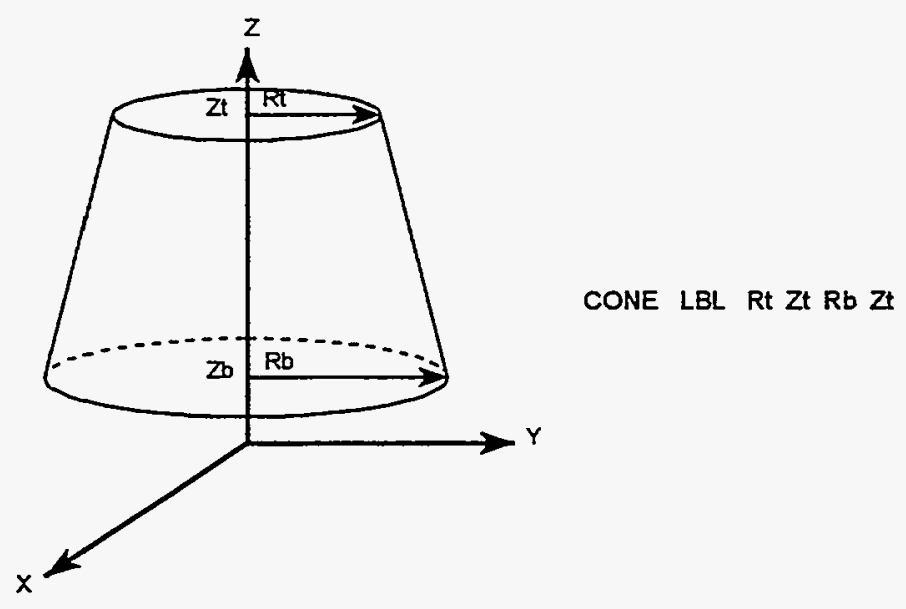

Figure F17.4.6 Example of cone construction

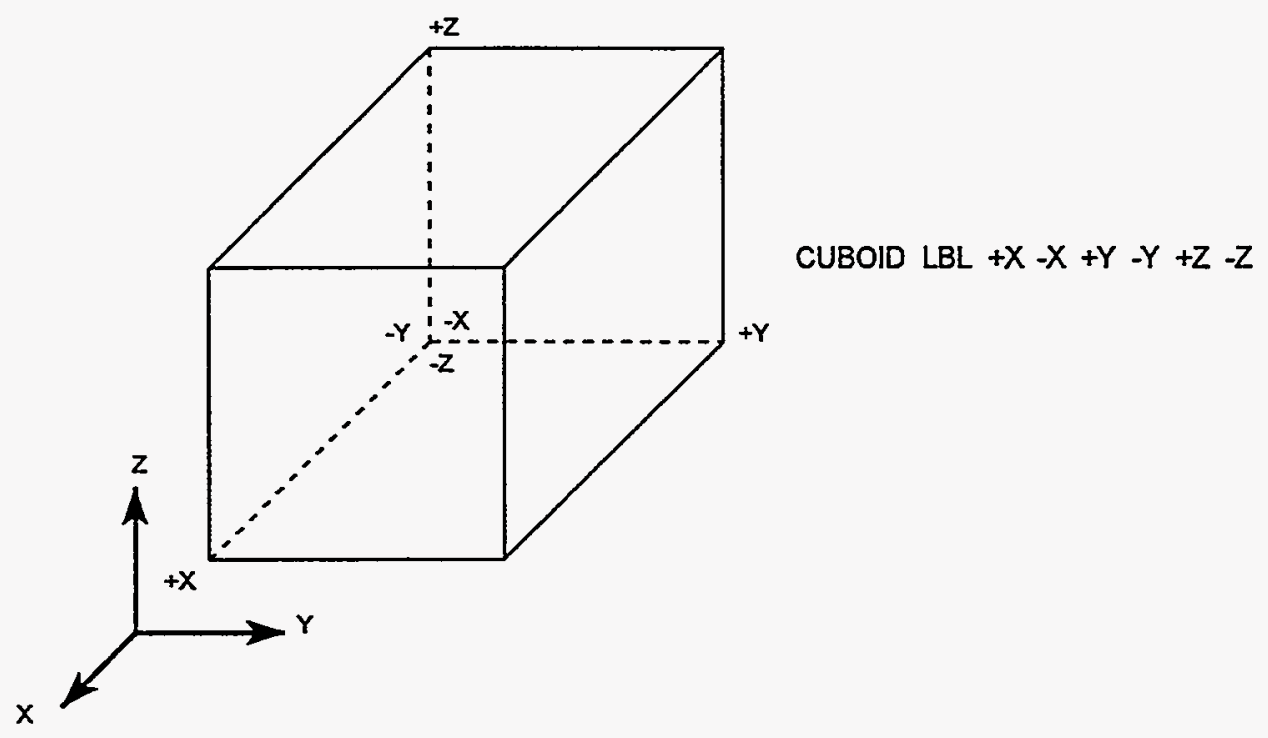

Figure F17.4.7 Example of cuboid construction 


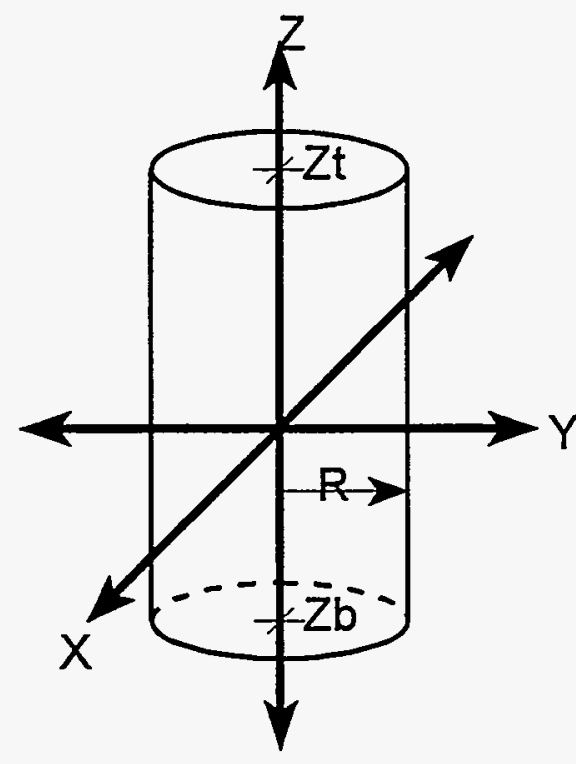

CYLINDER LBLR Zt Zb

Figure F17.4.8 Example of cylinder construction

DODECAHEDRON specifies a body whose surface consists of 12 rhombuses of the same size and shape. It is defined by specifying the radius of the inscribed sphere, $R$. It is centered on the origin in a fixed orientation unless otherwise specified by the optional geometry modification data. Figure 17.4.9 shows the correct input sequence for a dodecahedron.

ECYLINDER specifies a right cylinder with an elliptical cross-section. It is defined by specifying the semiradius along the $x$-axis, $R x$, the semiradius along the $y$-axis, $R y$, the $Z$ coordinate of the top face, $\mathrm{Zt}$, and the $\mathrm{Z}$ coordinate of the bottom face, $\mathrm{Zb}$. Its centerline must lie on the $\mathrm{Z}$ axis, unless otherwise specified by the optional geometry modification data. Figure 17.4.10 shows the correct input sequence for an elliptical cylinder.

ELLIPSOID specifies a body whose cross-section slices parallel to each of the coordinate axes are ellipses. It is defined by specifying the semiradius along the $x$-axis, $R x$, the semiradius along the $y$-axis, $\mathrm{Ry}$, and the semiradius along the $\mathrm{z}$-axis, $\mathrm{Rz}$. It is centered about the origin, unless otherwise specified by the optional geometry modification data. Figure 17.4.11 shows the correct input sequence for an ellipsoid.

HEXPRISM specifies a body whose top and bottom faces are hexagons that have the same orientation and are perpendicular to the $Z$ axis. It is defined by specifying the inscribed radius, $R$, the $Z$ coordinate of the top face, $\mathrm{Zt}$, and the $\mathrm{Z}$ coordinate of the bottom face, $\mathrm{Zb}$. Figure 17.4.12 is an example input for a hexprism. See Fig. F17.4.4 for the default orientation used to stack hexprisms in an array. 

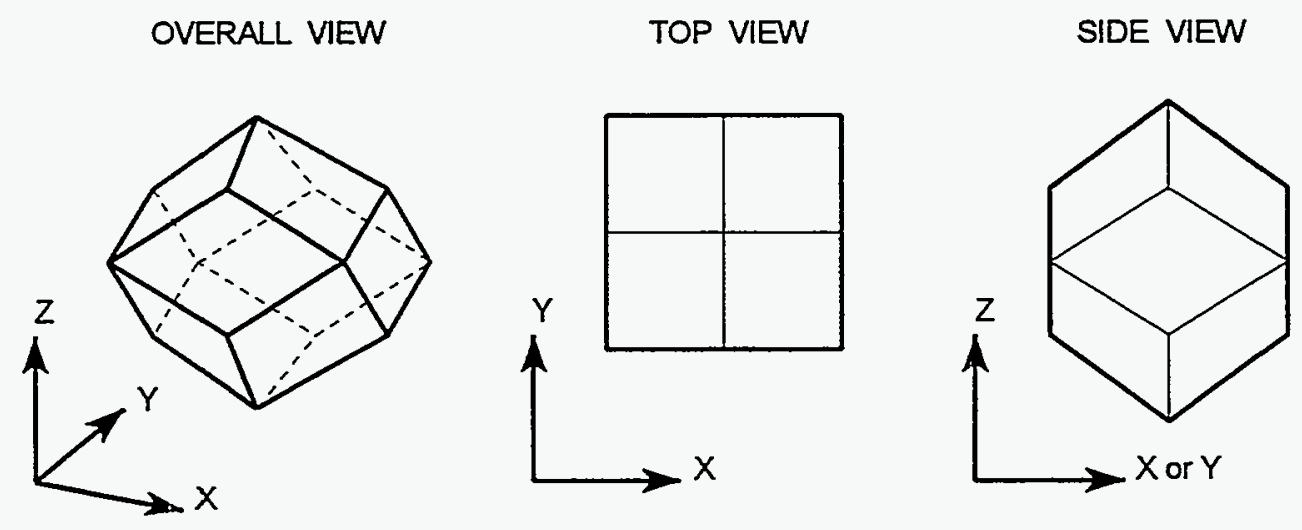

\section{DODECAHEDRON LBL $R$}

( $R$ is the Inscribed Radius)

Figure F17.4.9 Example of dodecahedron construction

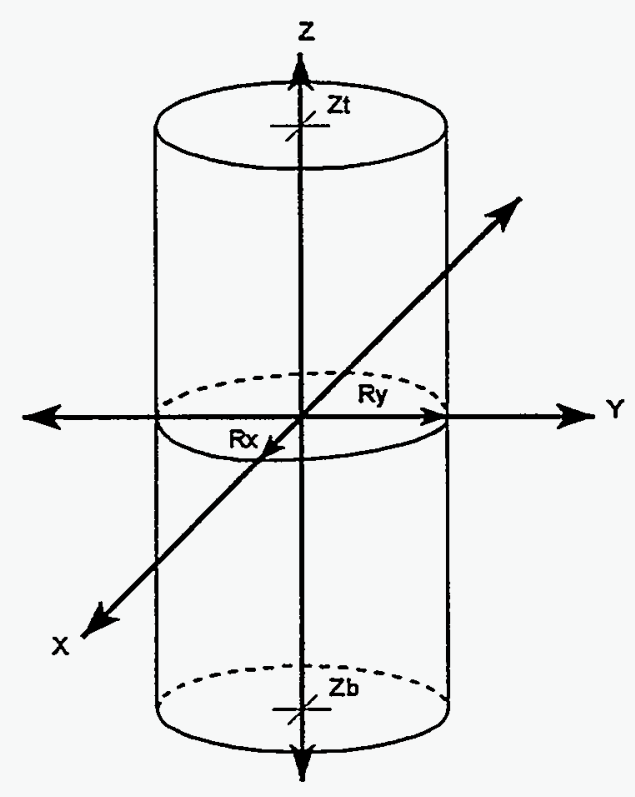

ECYLINDER LBL Rx Ry Zt Zb

Figure F17.4.10 Example of elliptical cylinder construction 


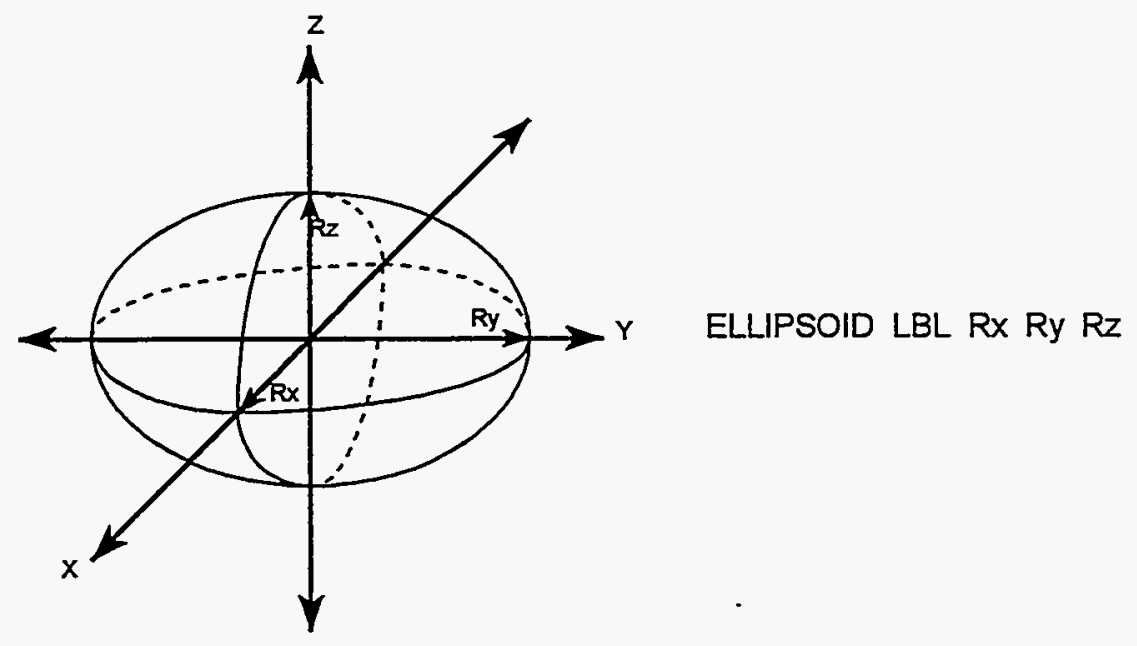

Figure F17.4.11 Example of ellipsoid construction

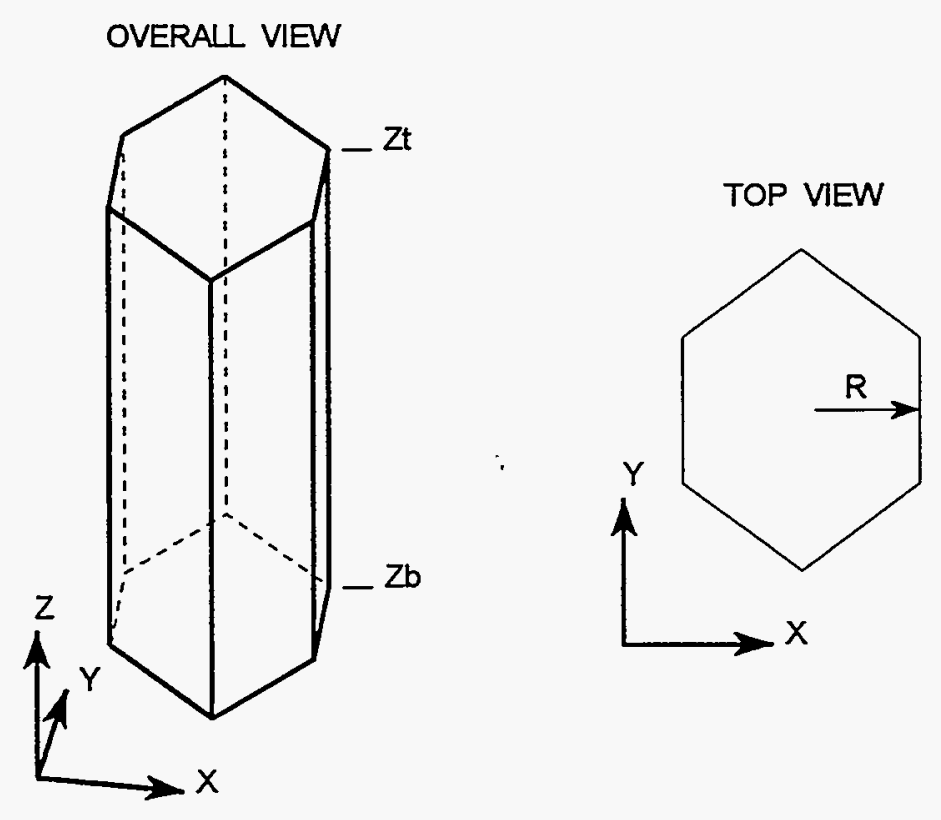

HEXPRISM LBL $R$ Zt Zb

( $R$ is the Inscribed Radius)

Figure F17.4.12 Example of hexprism construction 
HOPPER specifies a body whose top and bottom faces are rectangular parallelograms centered about the $z$-axis and parallel to the $x$ and $y$ axes. It is defined by specifying the half-length of the top face along the $x$-axis, Lxt, the half-length of the top face along the $y$-axis, Lyt, the $Z$ coordinate of the top face, $\mathrm{Zt}$, the half-length of the bottom face along the $\mathrm{x}$-axis, Lxb, the half-length of the bottom face along the $y$-axis, Lyb, and the $Z$ coordinate of the bottom face, $Z b$. Its centerline must lie on the $Z$ axis unless otherwise specified by the optional geometry modification data. Figure 17.4.13 shows the correct input sequence for a hopper.

PARALLELEPIPED is a body with six faces composed of parallelograms, whose opposing faces are or PPIPED parallel. It is defined by specifying the length of the faces in the $x$ direction, XDIST, the length of the faces in the $y$ direction, YDIST, the length of the faces in the $z$ direction, ZDIST, the angle between the $x$-face and the $y$-axis, PSI, the angle between the $y$-face and the $z$-axis, THETA, and the angle between the projection of the top corner nearest the $z$-axis onto the $x-y$ plane and the $x$-axis, $P H I$. The bottom face must lie on the $x-y$ plane at $Z=0$ with a corner at the origin unless otherwise specified by the optional geometry modification data. Figure 17.4.14 shows the correct input sequence for a parallelepiped. The angles psi, theta, and phi must be in the range 0 to $90^{\circ}$.

PLANE is a surface where any two points can be connected by a straight line entirely contained within plane that divides all space into two regions. The positive side of the plane is the side the normal points to or where the equation $a X+b Y+c Z+d>0$. It is defined by specifying the coefficients of the equation $\mathrm{aX}+\mathrm{bY}+\mathrm{cZ}+\mathrm{d}=0$ using the keywords $X P L=a, Y P L=b, Z P L=c$, and $\mathrm{CON}=\mathrm{d}$. Only the nonzero coefficients of the equation need to be specified. Figure 17.4.15 shows the correct input sequence for a plane.

QUADRATIC specifies a surface using a quadratic equation of the form: $a X^{2}+b Y^{2}+c Z^{2}+d X Y+e X Z+f Y Z+g X+h Y+i Z+j=0$.

It is defined by specifying the coefficients of the above equation using the keywords $A Q U=a$, $B Q U=b, C Q U=c, D Q U=d, E Q U=e, F Q U=f, G Q U=g, H Q U=h, I Q U=i$, and JQU=j. Only the nonzero coefficients of the equation need to be specified.

RHOMBOID is a body composed of six identical faces, each one a rhombus. It is defined by specifying the length of the edge of the base along the $x$-axis, DX, and the angle between $y$ edge of the base and the $y$-axis, psi. Its base is in the xy plane at $Z=0$, with a corner at the origin unless otherwise specified by the optional geometry modification data. Figure 17.4.16 shows the correct input sequence for a rhomboid.

SPHERE specifies a sphere. It is defined by specifying the radius, $\mathrm{R}$ It is centered about the origin, unless otherwise specified by the optional geometry modification data. Figure 17.4.17 shows the correct input sequence for a sphere.

WEDGE is a right-triangular prism having five faces. The two ends are triangles, and the three sides are rectangles. It is defined by specifying the length of the base along the $x$-axis, XBASE, the $x$ and $y$ coordinate where the other two sides meet, XPT and YPT, and the length along the $z$-axis, $Z L N G$. One side is in the $X Z$ plane at $Y=0$, and the bottom face is in the $X Y$ plane at $Z=0$,

NUREG/CR-0200, 


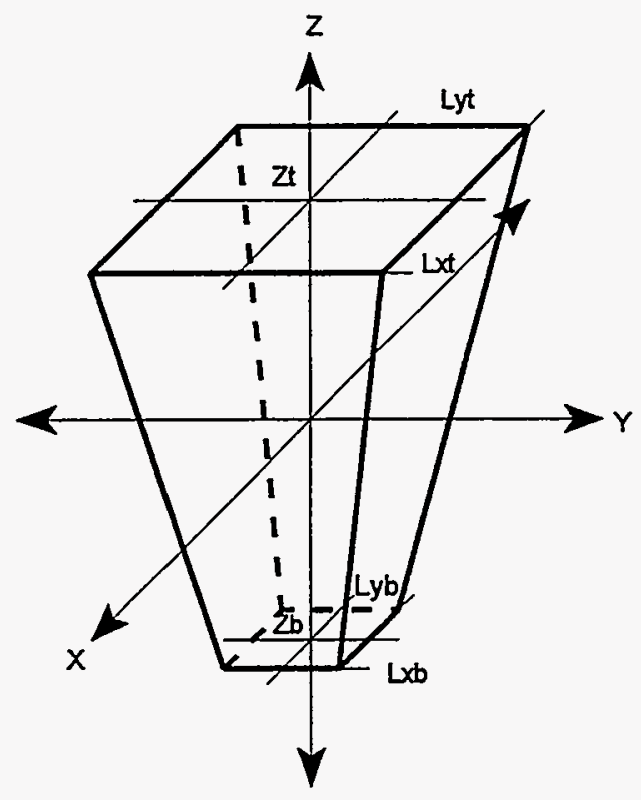

HOPPER LBL Lxt Lyt Zt Lxb Lyb Zb

Figure F17.4.13 Example of hopper construction

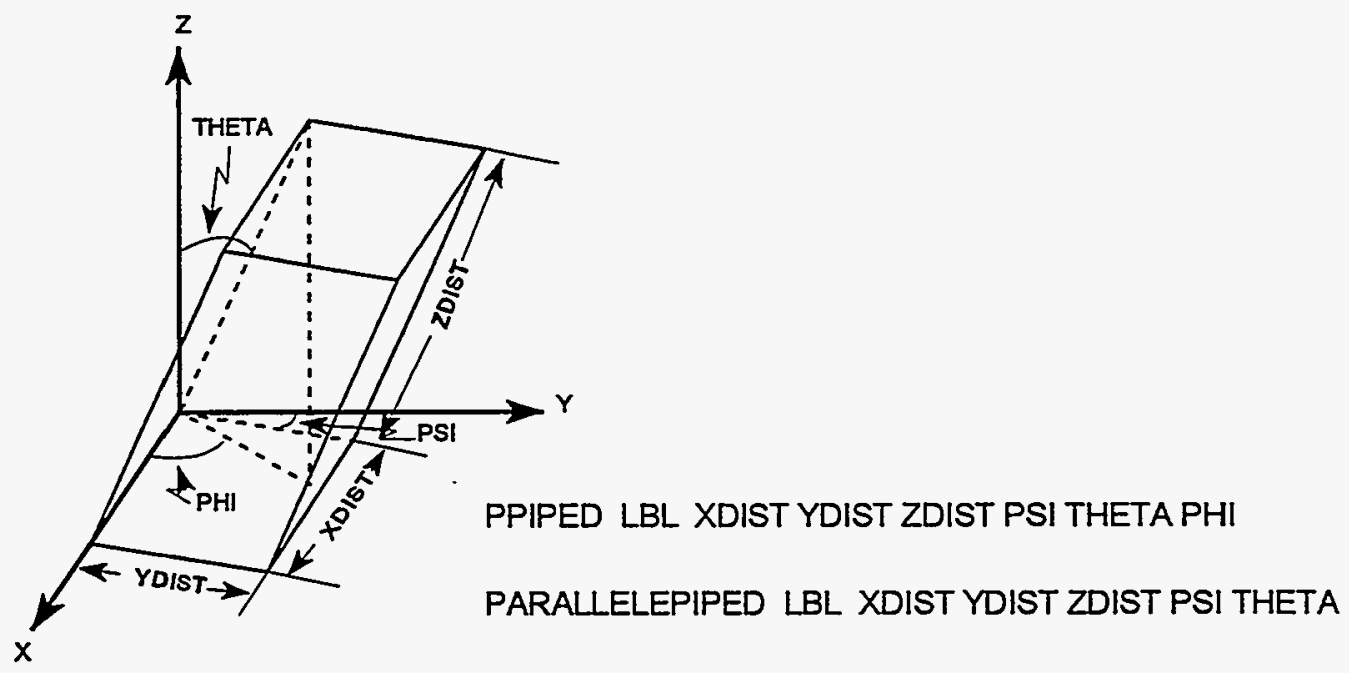

Figure F17.4.14 Example of parallelepiped construction 


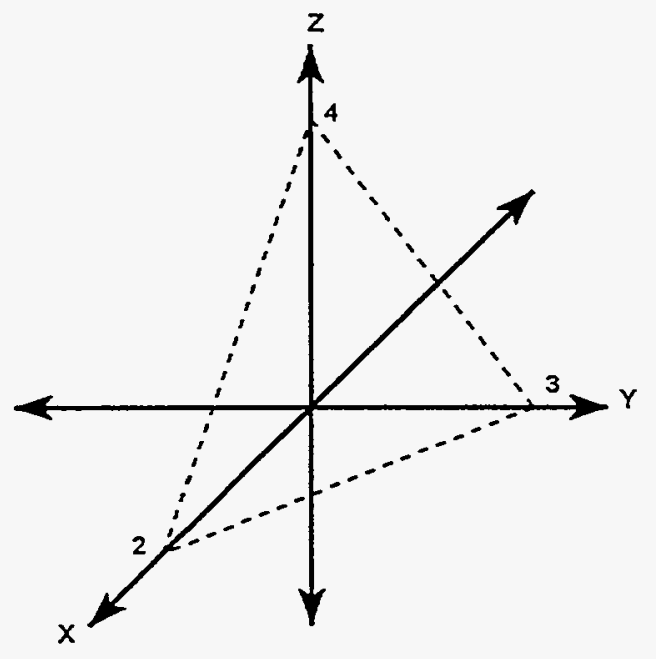

$a X+b Y+c Z+d=0$

PLANE LBL XPL=a YPL=b $Z P L=c \quad C O N=d$

$6 X+4 Y+3 Z-12=0$

Figure F17.4.15 Example of plane construction

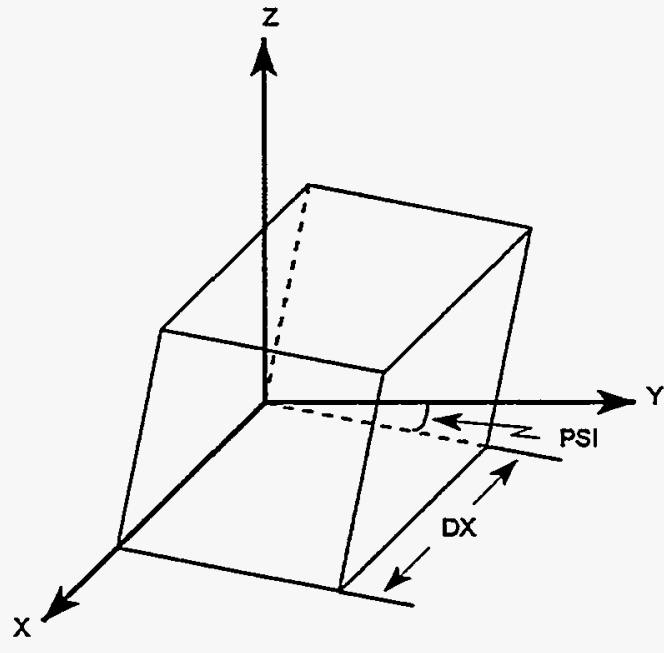

RHOMBOID LBL DX PSI

Figure F17.4.16 Example of rhomboid construction 


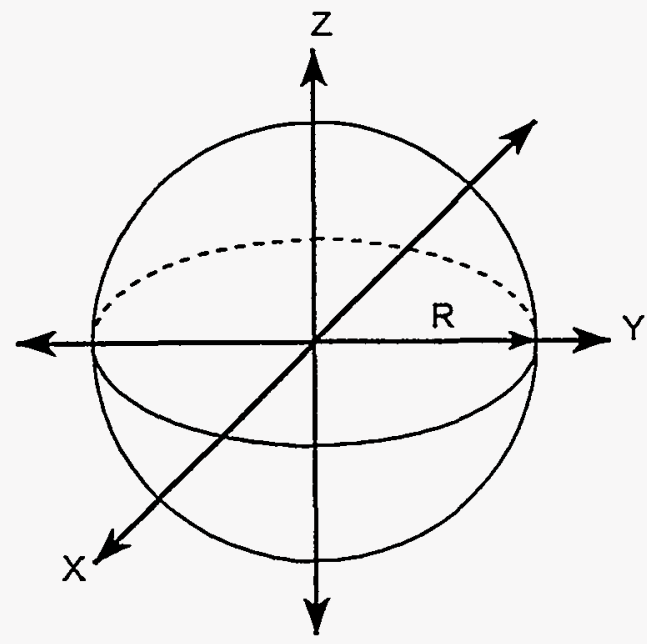

SPHERE LBL $R$

Figure F17.4.17 Example of sphere construction

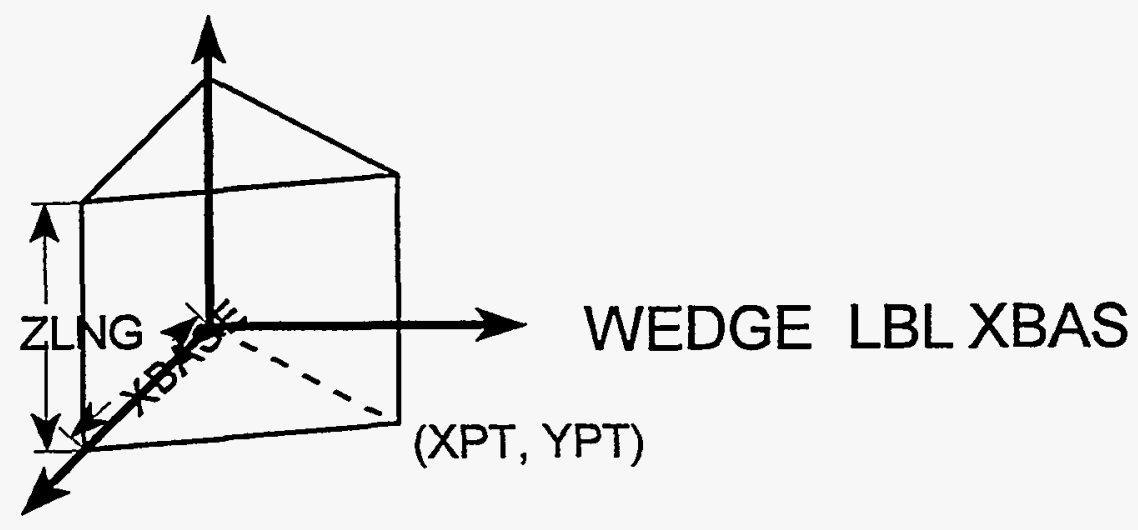

Figure F17.4.18 Example of wedge construction

with a corner at the origin unless otherwise specified by the optional geometry modification data. Figure 17.4.18 shows the correct input sequence for a wedge.

The GEOMETRYMODIFICATION KEYWORD, moddat, is followed by one or more blanks and must be one of the keywords below. The geometry modification data follow the appropriate region dimensions on the 
geometry record. The modification data can be used in any order or combination with respect to a geometry record. The APPROPRIATE MODIFICATION INFORMATION, modinf, follows the keyword as described below.

\section{CHORD, ORIGIN, ROTATE}

CHORD is used to provide a place that truncates a geometry shape. It is used by following the keyword with a subordinate keyword, $+X=,-X=,+Y=,-Y=,+Z=$, or $-Z=$, which defines the direction of the chord and the intercept of the plane on the axis. A plus in the keyword indicates the positive side of the chord is the inside direction. A minus in the keyword indicates the negative side of the chord is the inside direction. Figure F17.4.19 provides two examples of the use of the CHORD option.

ORIGIN is used to translate the origin of the geometric shape to a specified location. It is used by following the keyword with the subordinate keywords, $\mathrm{X}=, \mathrm{Y}=$, and $\mathrm{Z}=$, followed respectively by the translated coordinates. Only the nonzero coordinates and their respective keywords need to specified. Figure F17.4.20 provides an example of the use of the ORIGIN option.

ROTATE is used to rotate the geometric shape with respect to the origin of the coordinate system of the unit. It is used by following the keyword with the subordinate keywords $A 1=, A 2=$, and $A 3=$. The subordinate keywords are the three angles in degrees of the rotation associated with the Euler X-convention. Only the nonzero angles and their respective keywords need to be specified. Figure F17.4.21 provides an explanation of the ROTATION option.

The MEDIA KEYWORD, fmed, is followed by one or more blanks and must be one of the keywords below. MEDIA, HOLE, ARRAY

MEDIA is used to define the location of a mixture relative to the geometric shapes in the unit. The keyword, MEDIA, is followed by one or more blanks and the MIXTURE ID mat, the BLAS ID imp, and the REGION DEFINITION VECTOR (i1, i2, ... in). Figure F17.4.22 shows the input for a set of three intersecting spheres in a cuboid.

HOLE is used to position a unit within a region in another unit relative to the geometric shapes in the other unit. The keyword, HOLE, is followed by one or more blanks and the HOLE ID mat, and the REGION DEFINITION VECTOR, il i2 ... in. The unit being placed in the hole can be rotated and translated using the APPROPRIATE MODIFICATION INFORMATION. The boundary dimensions of the unit being placed using HOLE must precisely match the boundary of the region containing the HOLE. If the unit boundary record crosses the volume of the region containing a hole, the unit boundary must be included as part of the boundary of the unit placed in the hole. The unit being placed in the hole is aligned in the region using ROTATE and ORIGIN.

ARRAY is used to position an array within a region in a surrounding unit relative to the geometric shapes in the surrounding unit The keyword is followed by one or more blanks and the ARRAYID mat and the REGION DEFINITION VECTOR, il i2 ... in. The REGION DEFINITION VECTOR defines the boundary of the array. The subordinate keyword PLACE is then entered, followed

NUREG/CR-0200,

Vol. 2, Rev. 5

F17.4.22 


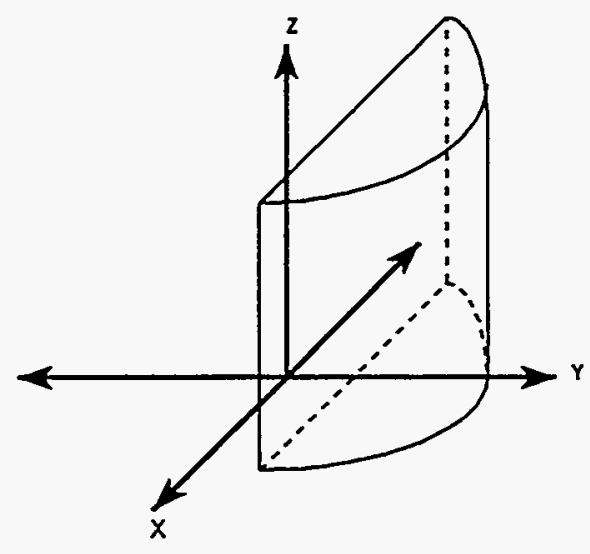

CYLINDER LBL $340 \quad$ CHORD $+Y=1$

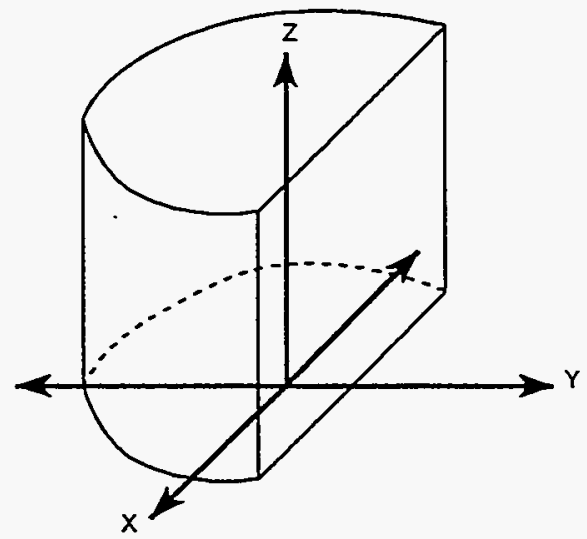

CYLINDER LBL 340 CHORD $-Y=1$

Figure F17.4.19 Examples of the CHORD option

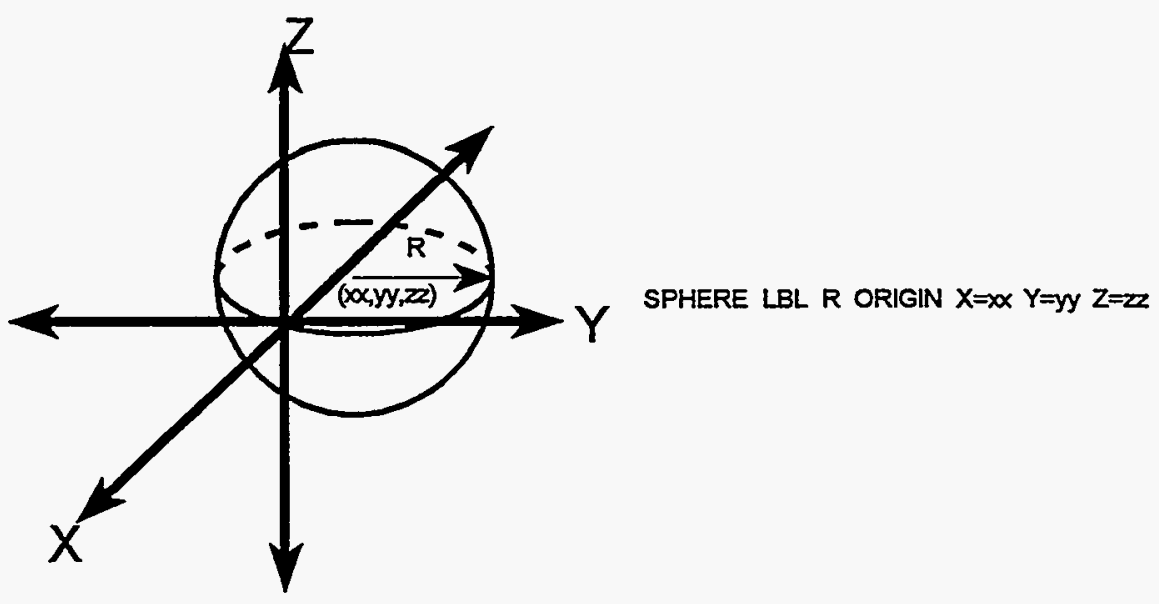

Figure F17.4.20 Example of the ORIGIN option 


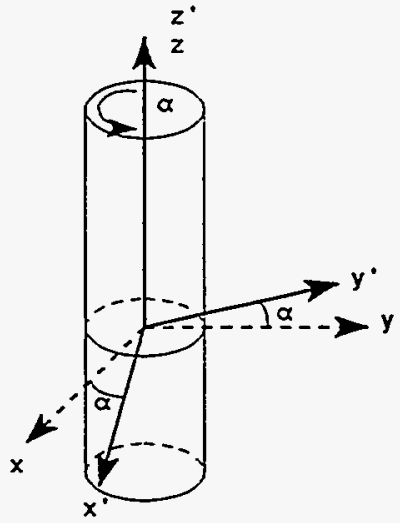

First rolation, $A 1=\alpha$ is counter-clockwise about the $\mathrm{Z}$ axis.
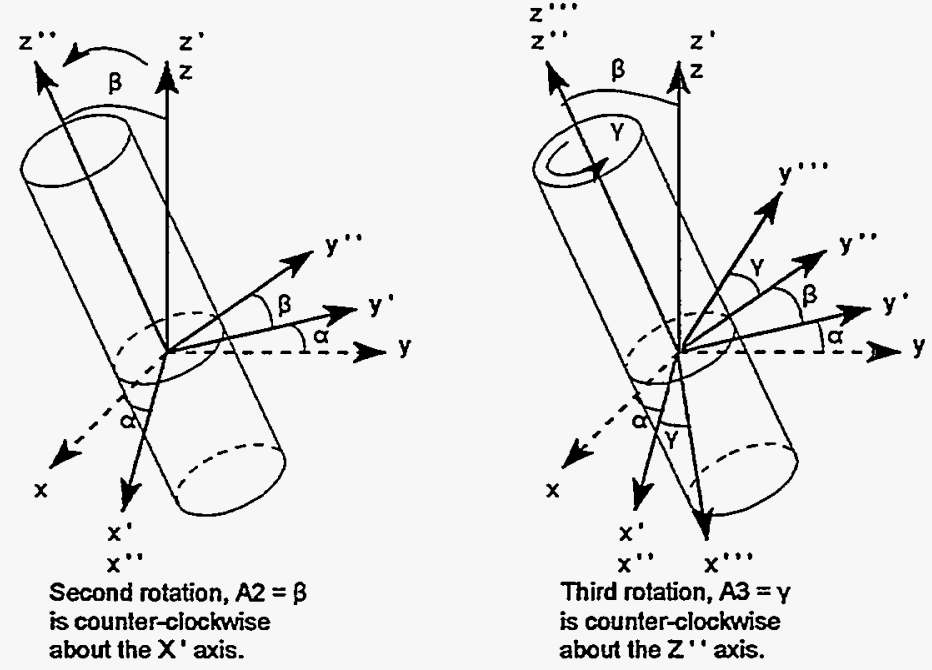

CYLINDER LBL $R$ Zt $Z b$ ROTATE $A 1=\alpha \quad A 2=\beta \quad A 3=\gamma$

Figure F17.4.21 Explanation of the ROTATE option

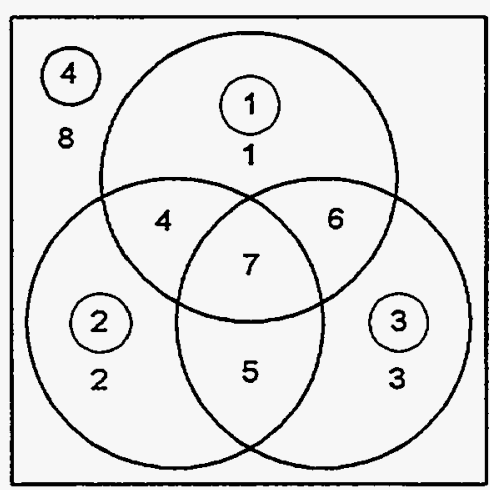

sphere 103 origin $y=2$

sphere 203 origin $x=-2 y=-2$

sphere 303 origin $x=2 \quad y=2$

cuboid $406-6 \quad 6-6 \quad 6-6$

media $1110-20-30$

media $2120-10-30$

$\begin{array}{lllll}\text { media } 3 & \text { I } & 30 & -10 & -20\end{array}$

media $4 \begin{array}{lllll} & 1 & 10 & 20 & -30\end{array}$

media $5120 \quad 30-10$

media $6 \begin{array}{lllll}6 & 30 & 10 & -20\end{array}$

media 71102030

$\begin{array}{llllll}\text { media } 8 & 1 & 40 & -10 & -20 & 30\end{array}$

boundary 40

Figure F17.4.22 Example of the MEDIA record

NUREG/CR-0200,

Vol. 2, Rev. 5

F17.4.24 
by six numbers that precisely locate the array within the surrounding unit. The first three numbers consist of the location in the array of the unit selected to position the array. The next three numbers consist of the position in the surrounding unit that contains the origin of the selected unit.

The MIXTURE, HOLE, specifies the mixture, hole, or array that is to occupy the volume defined by the or ARRAYID mat region if the keyword is MEDIA. This information is followed by one or more blanks. If the region contains a mixture, mat specifies the mixture that is to occupy the volume defined by the region. The mixture ID number is followed by one or more blanks. [A MIXIURE ID of zero indicates a void region (i.e., no material is present in the volume defined by the region).]

The BIAS ID imp specifies the weights that are to be used in the volume defined by each media record. This is used only if the MEDIA keyword is specified. Default weights are used for every imp not specified in the BLASING INFORMATION data. For clarification of how to use imp to specify nondefault weights, see Sect. F17.4.7. The BIASID number is followed by one or more blanks.

REGIONDEFINITION VECTOR iI i2 ... is a series of geometry record numbers used to define the location of a region that contains a material mixture, hole, or array. A positive value indicates the region is located inside the space defined by the geometry record. A negative value indicates the region is located outside the space defined by the geometry record. As many geometry record numbers as are required to define the volume occupied by the region must be entered. Each media card represents a distinct region of the unit. Each region can only be represented by one media card. Care must be taken when regions share boundaries to specify which region contains the boundary.

The BOUNDARY KEYWORD, BOUNDARY is followed by one or more blanks and the region definition vector that defines the boundary of the unit. Each unit must have one and only one boundary record. The boundary record describes the volume contained within the unit. Only that section of the geometry contained within the volume specified by the unit boundary record is part of the unit.

(c) OPTIONAL GEOMETRY COMMENTS ... these data allow the user to enter a comment for any unit. Data are entered in the form:

\section{$\mathrm{COM}=$ delim coment delim}

The keyword COM= signals that a comment is to be read. The first nonblank character following the keyword is the beginning delimiter, delim. The comment can be as long as 132 characters, including imbedded blanks. It must be terminated with the same delimiter that signaled the beginning of the comment. The optional geometry comment must follow the UNIT INITIALIZATION for a unit but can precede or follow any GEOMETRY REGIONDESCRIPTION within the unit. In the event that more than one comment is entered within a unit, the last one is used. Existing comments are printed at the beginning of each unit description in the computer printout.

Additional EXAMPLES of geometry input are given below:

F17.4.25

NUREG/CR-0200, Vol. 2, Rev. 5 
1. Initiate input data for unit No. 6.

UNIT 6

2. Initiate input data for the global unit which is unit No. 4 .

\section{GLOBAL UNIT 4}

3. Create a hemisphere labeled 10 with a radius of $5.0 \mathrm{~cm}$ which contains only material in the sphere with $\mathrm{z}>$ 2.0 with the sphere centered at the origin, and its origin translated to $x=1.0, y=1.5$, and $z=3.0$.

SPHERE $10 \quad 5.0 \quad$ CHORD $+Z=2.0$ ORIGIN $x=1.0 \quad y=1.5 \quad z=3.0$

4. Create a hemicylinder labeled 10 having a radius of $5.0 \mathrm{~cm}$ and a length extending from $z=2.0 \mathrm{~cm}$ to $z=7.0$ $\mathrm{cm}$. The hemicylinder has been truncated parallel to the $\mathrm{z}$ axis at $\mathrm{x}=-3$ such that no material exists between $x=-3$ and $x=5$. Position the origin of the truncated hemicylinder at $x=10 \mathrm{~cm}$ and $y=15 \mathrm{~cm}$ with respect to the origin of the unit and rotate it so it is in the $\mathrm{YZ}$ plane centered at $\mathrm{X}=10$ and at $a 45^{\circ}$ angle with the $y$ plane.

CYLINDER 105.07 .02 .0 CHORD $+x=-3.0$ ORIGIN $x=10.0 y=15.0$ ROTATE A2 $=45$

5. Position array 6 so that the origin of the unit in position $1,2,3$ is located at position $x=2, y=3, z=4$ relative to the origin of the surrounding unit. Specifying the array boundary to be the region that is inside the geometry records labeled 1 and 2 and outside the geometry record labeled 3 used to describe the surrounding unit.

ARRAY 6122 -3 PLACE 1232.03 .04 .0

6. Place unit 2 in the surrounding unit such that the origin of unit 2 is at $x=3, y=3.5, z=4$ relative to the origin of the surrounding unit and the region containing the hole is inside geometry records labeled 1 and 3 and outside geometry record labeled 2 used to describe the surrounding unit.

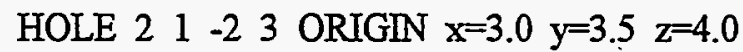

\section{F17.4.5 ARRAY DATA}

ARRAY DEFINITION data ... The array definition data block is used to define the size and type of an array and to position units (defined in the geometry data) in a 3-D lattice that represents the array being described. As many arrays as are necessary can be described in a problem, subject to computer storage limitations. Any number of arrays can be placed in any unit either directly in regions or indirectly using holes. There is no default global array. If a global array is desired it must be explicitly defined.

An array definition data block consists of ARRAY PARAMETERS followed by a UNIT ORIENTATION DESCRIPTION. The sequence ARRAY PARAMETERS, UNTT ORIENTATION DESCRIPTION must be repeated for each array that is to be used in the problem. ARRAY PARAMETERS must be entered for all array problems and consist of parameter input defining (1) an array identification number for the lattice, (2) the array type, (3) the number of units in each direction of the 3-D lattice, (4) the global array number, and (5) a comment to be printed at the beginning of the array in the printout. The array identification number (1), the number of units in 
each direction, (3), and the associated UNIT ORIENTATION DESCRIPTION must be entered for each array that is used in the problem. The array type (2) is entered to specify if the array is cuboidal or hexagonal. If not. entered the array is assumed to be cuboidal. The global array number, (4), should be entered only if desired. A global array number is required to accumulate certain neutron physics information such as certain matrix information. If the global array number is entered more than once, the last value is used. The optional array comment is available for the user's convenience, but is not necessary for the problem. The UNIT ORIENTATION DESCRIPTION consists of a KEYTORD, UNIT ORIENTATION DATA and a DELIMITER which must be entered in order. The KEYWORD is used to indicate the method of entering the unit orientation data. The UNIT ORIENTATTON DATA sequence is used to position units in a 3-D lattice and the DELMMTER is used to terminate the unit orientation data for the array. The adjacent faces of units in contact with each other within an array must be the same size and shape. Multiple arrays are defined by entering the sequence.

Arrays need to be properly placed in a unit for the problem to run correctly. The following is a set of rules used for placing arrays in a region of a unit.

Array Rules

1. Arrays may be nested as low as desired.

2. The array boundary (i.e., the region containing the array) must be completely contained within the volume defined by the units making up the array.

3. If a unit contained within an outer array contains a hole or another array (either directly or nested) the boundary of the outer array cannot cross the volume defined by the array or hole in the unit.

ARRAY PARAMETERS, UNIT ORIENTATION DESCRIPTION for each array that is to be described in the problem.

Enter ARRAY DEFINITION DATA in the form:

\section{READ ARRAY ARRAY PARAMETERS UNIT ORIENTATION DESCRIPTION END ARRAY}

ARRAY PARAMETERS define the array number and the array size. They utilize the following keywords. Enter only those whose value you wish to change.

ARRAY PARAMETERS
ARA $=$ numa
array number for the array being input, no default
TYP $=a t y p$ Default $=$ square
NUX $=n b x \max$
NUY $=n b y \max$
number of units in the $\mathrm{X}$ direction of the array, no default
number of units in the $\mathrm{Y}$ direction of the array, no default

type of array (square or hexagonal). For an array composed of cuboids, atyp may be specified as SQUARE or CUBOIDAL. For an array composed of HEXPRISMS, atyp may be specified as TRIANGULAR or HEXAGONAL.

F17.4.27

NUREG/CR-0200, Vol. 2, Rev. 5 
$\mathrm{NUZ}=n b z \max$

$\mathrm{GBL}=g l o b l$ number of units in the $Z$ direction of the array, no default

array number for the global array (if entered more than once the last value entered becomes the global array). Unit used only for collecting array matrix data. No default.

COM = delim coment delim allows entering a comment that will be printed with the unit orientation data. Maximum comment length is 132 characters.

The UNIT ORIENTATION DESCRIPTION is composed of a KEYWORD, ORIENTATION DATA and a DELIMITER as described below:

\section{KEYWORD}

type enter the word LOOP or FILL, followed by one or more blanks.

LOOP enters unit orientation data in a manner resembling FORTRAN DO loops. The first field contains the unit number, followed by three fields that are treated like FORTRAN DO loops. The arrangement of units may be considered as consisting of a 3-D matrix of unit numbers, with the unit position increasing in the positive $\mathrm{X}, \mathrm{Y}$, and $\mathrm{Z}$ directions, respectively. Each set of mixed unit orientation data for the LOOP option consists of the following parameters, separated by one or more blanks.

\section{ORIENTATION DATA for LOOP}

ltype The unit number, ltype must be greater than zero.

ixI The starting position in the $\mathrm{X}$ direction, $i x I$ must be at least 1 and less than or equal to nbxmax (parameter $N U X=$, see ARRAY PARAMETERS).

ix2 The ending position in the $\mathrm{X}$ direction, $i x 2$ must be at least 1 and less than or equal to $n b x m a x$.

incx The number of units by which increments are made in the positive $\mathrm{X}$ direction. incx must be greater than zero and less than or equal to $n b x m a x$.

iyl The starting position in the $\mathrm{Y}$ direction. iyl must be at least 1 and less than or equal to nbymax (parameter $N U Y=$, see ARRAY PARAMETERS).

iy2 The ending position in the $\mathrm{Y}$ direction, iy2 must be at least 1 and less than or equal to nbymax.

incy The number of units by which increments are made in the positive $\mathrm{Y}$ direction, incy must be greater than zero and less than or equal to nbymax.

izl The starting position in the $Z$ direction, $i z I$ must be at least 1 and less than or equal to $n b z m a x$ (parameter $N U Z=$, see ARRAY PARAMETERS). 
iz2 The ending position in the $\mathrm{Z}$ direction, $i z 2$ must be at least 1 and less than or equal to $n b z m a x$.

incz The number of units by which increments are made in the positive $Z$ direction. incz must be greater than zero and less than or equal to nbzmax.

The sequence ltype through incz is repeated until the entire array is described. If any portion of an array is defined in a conflicting manner, the last entry to define that portion will determine the array's configuration. To utilize this feature, fill the entire array with the most relevant unit number and superimpose the other unit numbers in their proper places. An example showing the use of the LOOP option is given below. This $5 \times 4 \times$ 3 array of units is a matrix of units that has 5 units stacked in the X direction, 4 units in the $Y$ direction, and 3 units in the $Z$ direction. $X$ increases from left to right, and $Y$ increases from bottom to top. Each $Z$ layer is shown separately.

Given:

$\begin{array}{lll}12121 & 21212 & 11111 \\ 11111 & 22222 & 13331 \\ 11111 & 22222 & 13331 \\ 12121 & 21212 & 11111 \\ \text { Z Layer } 1 & \text { ZLayer } & \text { ZLayer }\end{array}$

The data for this array could be entered using the following entries.

(1) $1151141131 \quad$ This fills the entire array with l's.

(2) $2252143111 \quad$ This loads the four 2's in the first $Z$ layer.

(3) $2151231221 \quad$ This loads the second and third rows of 2's in the second $Z$ layer.

(4) $2152143221 \quad$ This loads the desired 2's in the first and fourth rows of the second $Z$ layer.

(5) 3241231331 This loads the 3's in the third $Z$ layer and completes the array data input.

The second layer could have been defined by substituting the following data for entries (3) and (4):

(3) $2151141221 \quad$ This completely fills the second layer with 2's.

(4) $1242143221 \quad$ This loads the four l's in the second layer.

When using the LOOP option, there is no single correct method of entering the data. If a unit is improperly positioned in the array or if some positions in the array are left undefined, it is often easier to add additional data to correctly define it than to try to correct the existing data.

FCL enters data by stringing in unit numbers starting at $X=1, Y=1, Z=1$, and varying $X$, then $Y$, and then $Z$ to fill the array. $n b x \max \times n$ bymax $\times$ nbzmax entries are required. FIDO-like input options are also available for filling the array. 
The FILL option consists of entering a unit number for every position in the array by using the FIDO-like input options specified in Table F17.4.2. The orientation data for the FILL option may be terminated with a T.

\section{DELIMITER}

Enter the word END followed by a blank and the previously entered KEYWORD (i.e., enter END FILL or END LOOP). The delimiter need not be entered if only one set of ARRAY DEFINITION DATA is to be read.

To illustrate the use of the options available in Table F17.4.2, consider the following examples. The positions in an array are numbered sequentially from left to right, bottom to top. A $3 \times 3 \times 1$ array has 9 positions and is numbered as shown below. $X$ increases from left to right and $Y$ increases from bottom to top.

$\begin{array}{lll}7 & 8 & 9 \\ 4 & 5 & 6 \\ 1 & 2 & 3\end{array}$

EXAMPLE 1. Consider a $3 \times 3 \times 1$ array filled with 8 Unit l's and a Unit 2 as shown below.

$\begin{array}{lll}1 & 1 & 1 \\ 1 & 2 & 1 \\ 1 & 1 & 1\end{array}$

The input data to describe this array could be entered as follows:

(1) $111121111 \mathrm{~T}$ This fills the array, one position at a time, starting at the lower left corner. The $\mathrm{T}$ terminates the data.

(2) F1 A5 $2 \mathrm{~T}$

The Fl fills the entire array with l's, the A5 locates the fifth position in the array, and the 2 loads a 2 in that position. The $T$ terminates the data.

(3) F1 Al 4S $2 \mathrm{~T}$

The F1 fills the entire array with l's, the Al locates the first position in the array (lower left corner), the 4S skips over the next four positions in the array, and the 2 loads a 2 in the next (fifth) position. The $T$ terminates the data.

(4) $4 \mathrm{R} 124 \mathrm{R} 1 \mathrm{~T}$

The first 4RI loads l's in the first four positions of the array, a 2 is loaded in the next (fifth) position of the array, and the last 4R1 loads l's in the next four positions of the array. The $T$ terminates the data.

(5) $4^{*} 124 \$ 1 \mathrm{~T}$

The $4 * 1$ loads 1 's in the first four positions of the array. A 2 is loaded in the next position of the array, and the $4 \$ 1$ loads 1 's in the next four positions of the array. The $T$ terminates the data.

NUREG/CR-0200,

Vol. 2, Rev. 5

F17.4.30 
Table F17.4.2 FIDO-like input for mixed box orientation fill option

\begin{tabular}{|c|c|c|c|}
\hline $\begin{array}{l}\text { Count } \\
\text { field }\end{array}$ & $\begin{array}{l}\text { Option } \\
\text { field }\end{array}$ & $\begin{array}{l}\text { Operand } \\
\text { field }\end{array}$ & Function \\
\hline & & $j$ & Stores $j$ at the current position in the array \\
\hline$i$ & $\mathrm{R}$ & $j$ & Stores $j$ in the next $i$ positions in the array \\
\hline$i$ & * & $j$ & Stores $j$ in the next $i$ positions in the array \\
\hline$i$ & $\$$ & $j$ & Stores $j$ in the next $i$ positions in the array \\
\hline \multirow[t]{3}{*}{$i$} & $\mathbf{P}$ & $j$ & Alternately stores $j$ and $-j$ in the next $i$ positions of the array \\
\hline & $\mathrm{F}$ & $j$ & $\begin{array}{l}\text { Fills the remainder of the array with unit number } j \text {, starting with } \\
\text { the current position in the array }\end{array}$ \\
\hline & A & $j$ & Sets the current position in the array to $j$ \\
\hline$i$ & $S$ & & $\begin{array}{l}\text { Increments the current position in the array by } i \text { (This allows } \\
\text { skipping } i \text { positions. } i \text { may be positive or negative.) }\end{array}$ \\
\hline$i$ & Q & $j$ & Repeats the previous $j$ entries $i$ times. The default value of $i$ is 1 \\
\hline$i$ & $\mathrm{~N}$ & $j$ & $\begin{array}{l}\text { Repeats the previous } j \text { entries } i \text { times, inverting the sequence each } \\
\text { time. The default value of } i \text { is } 1\end{array}$ \\
\hline$i$ & B & $j$ & $\begin{array}{l}\text { Back } i \text { entries. From that position, repeat the previous } j \text { entries in } \\
\text { reverse order. See Example } 4 \text {. The default value of } i \text { is } 1\end{array}$ \\
\hline$i$ & I & $j k$ & $\begin{array}{l}\text { Provides the end points, } \mathrm{j} \text { and } \mathrm{k} \text {, with } \mathrm{i} \text { entries linearly interpolated } \\
\text { between them (i.e., a total of } \mathrm{i}+2 \text { points). At least one blank must } \\
\text { separate } \mathrm{j} \text { and } \mathrm{k} \text {. When used for an integer array, the I option } \\
\text { should only be used to generate integer steps [i.e., }(\mathrm{k}-\mathrm{j}) /(\mathrm{i}+\mathrm{l}) \\
\text { should be a whole number] }\end{array}$ \\
\hline$i$ & $\mathrm{~L}$ & $j k$ & $\begin{array}{l}\text { Provides the end points, } j \text { and } k \text {, with } i \text { entries logarithmically } \\
\text { interpolated between them (i.e., a total of } i+2 \text { points). At least } \\
\text { one blank must separate } j \text { and } k\end{array}$ \\
\hline & $\mathrm{T}$ & & Terminates the data reading for the array \\
\hline
\end{tabular}

Note: When entering data utilizing the options in this table, the count field and option field must be adjacent with no imbedded blanks. The operand field may be separated from the option field by one or more blanks. 
EXAMPLE 2. Consider a $4 \times 3 \times 1$ array filled as shown below.

$\begin{array}{llll}1 & 2 & 2 & 1 \\ 1 & 2 & 2 & 1 \\ 1 & 2 & 2 & 1\end{array}$

The input data to describe this array could be entered as follows.

(1) $122112211221 \mathrm{~T}$ This fills the array, one position at a time, starting at the lower left corner. The $T$ terminates the data.

(2) $12 \mathrm{R} 22 \mathrm{R} 1 \mathrm{Q} 42 \mathrm{R} 21 \mathrm{~T} \quad$ A 1 is loaded in the first position of the array. The $2 \mathrm{R} 2$ loads 2 's in the next two positions of the array (positions two and three). The 2Rl loads l's in the next two positions of the array (positions four and five). The Q4 loads the 2 211 from positions two through five in positions six through nine. The last 2R2 loads 2 's in positions ten and eleven of the array. The last 1 loads a 1 in the next position (position twelve). The $T$ terminates the data.

(3) $125 \mathrm{~N} 2 \mathrm{~T}$

The 1 is entered in the first position of the array and the 2 is entered in the second position. The $5 \mathrm{~N} 2$ causes the previous two entries to be repeated five times reversing their order each time. The $T$ terminates the data.

(4) $12 \mathrm{R} 212 \mathrm{Q} 4 \mathrm{~T}$

The first 1 is loaded in the first position of the array. The 2's are loaded in positions two and three of the array. Then a 1 is loaded in the fourth position of the array. This describes the entire bottom row of the array. The $2 Q 4$ then repeats the previous four entries (those loaded in positions one through four of the array) two times. Thus the first row is repeated twice, filling the remainder of the array. The $T$ terminates the data.

EXAMPLE 3. Consider a $6 \times 3 \times 1$ array as shown below.

$\begin{array}{llllll}1 & 2 & 2 & 1 & 1 & 2 \\ 1 & 2 & 2 & 1 & 1 & 2 \\ 1 & 2 & 2 & 1 & 1 & 2\end{array}$

A simple input description for this array is the following:

(1) $122 \mathrm{~N} 22 \mathrm{Q} 6 \mathrm{~T}$ The first position of the array is filled with a 1. The second position of the array is filled with a 2 . The $2 \mathrm{~N} 2$ causes the previous two entries to be repeated two times, reversing their order each time. This completes loading the bottom row of the array. The $2 \mathrm{Q} 6$ repeats the previous six entries twice, completing the second and third rows of the array. The $T$ terminates the data.

NUREG/CR-0200,

Vol. 2, Rev. 5

F17.4.32 
EXAMPLE 4. Consider a $7 \times 3 \times 1$ array as shown below.

$\begin{array}{lllllll}1 & 2 & 3 & 4 & 3 & 2 & 1 \\ 2 & 3 & 4 & 5 & 4 & 3 & 2 \\ 1 & 2 & 3 & 4 & 3 & 2 & 1\end{array}$

The input data to describe this array could be entered as follows:

(1) 1234 1B3 2345 1B3 1234 1B3 T The 123 and 4 are loaded in the first four positions of the array. The 1B3 steps back over the 4 and repeats the 123 sequence in reverse order (i.e., 32 1). This yields the 1234321 in the first row of the array. The same procedure applies to the next two rows.

(2) 1234 IB3 2345 IB10 T The 1234 1B3 yields the first row as explained above. The 2345 enters the 2345 at the left of the second row. The $1 B 10$ enters the 432 at the right of the second row and the entire third row.

\section{F17.4.6 ALBEDO DATA}

ALBEDO DATA ... Albedo boundary conditions are entered using a FACE CODE to define where albedo conditions are to be used, and an $A L B E D O N A M E$ to indicate which albedo condition is to be used on that face. The default value for each face is vacuum. The default values are overridden only on faces for which other albedo names are specified. Albedo boundary conditions are applied only to the outermost region of a problem. Different albedo options are allowed for different global boundaries. If the global unit boundary record definition vector contains a single geometry record label that references a cuboid, any available albedo option is allowed on any surface. However, if a periodic boundary condition is to be used, it must be specified on opposing faces simultaneously. If the global unit boundary record definition vector contains a single geometry record label that references a geometry shape composed of paired planes, i.e. hexprism, dodecahedron, parallelepiped, rhomboid, etc., any albedo type is allowed but the same type must be on all surfaces. If the global unit boundary record definition vector contains a single geometry record label that references any geometry shape, the void, mirror, or white albedo condition is allowed and the same condition must be on all surfaces. If the global unit boundary record definition vector contains more than one geometry record label the void albedo condition is allowed. If no albedo is specified a void albedo is assumed. The white albedo returns an outgoing particle at its point of departure with a random angle.

Enter ALBEDO DATA in the form:

READ BOUNDS

FACE CODE

face

ALBEDONAME

aname

END BOUNDS

F17.4.33

NUREG/CR-0200, Vol. 2, Rev. 5 
The sequence $F A C E C O D E, A L B E D O N A M E$ is entered as many times as necessary to define the appropriate albedo boundary conditions. If multiple entries are made for a face, the ALBEDO NAME associated with the last FACE CODE specifying that face is used.

The FACE CODES are described in Table F17.4.3, and the ALBEDO NAMES are given in Table F17.4.4.

Example: Use a 24-in. concrete albedo boundary condition on the $-Z$ face of a problem with a cuboidal boundary and use mirror image reflection on the $+X$ and $-X$ faces of the cuboid to represent an infinite linear array on a 2-ft-thick concrete pad.

READ BOUNDS $-\mathrm{ZB}=\mathrm{CON} 24$ XFC $=$ MIRROR END BOUNDS

\title{
F17.4.7 BIASING OR WEIGHTING DATA
}

BIASING INFORMATION. . . The average weight of a neutron that survives Russian roulette, wtovg, is defaulted to $d w t a v$ (WTA= in the parameter data, Sect. F17.4.3) for all BLAS IDs and can be overridden by entering biasing information.

The biasing information is used to relate a $B I A S I D$ to the desired energy-dependent values of wtovg. This concept is similar to the way the MIXTURE ID, mat, is related to the macroscopic cross-section data.

The weighting functions used in KENO-VI are energy-dependent values of wtavg that are applicable over a given thickness interval of a material. For example, the weighting function for water ${ }^{2}$ is composed of sets of energy-dependent values of wtavg for 11 intervals, each interval being 3-cm thick. The first set of wtavg's is for the 0 - to 3-cm interval of water, the second set of wtavg's is for the 3- to 6-cm interval of water, etc. The eleventh set of wtavg's is for the 30- to 33-cm interval of water.

To input biasing information, a $B I A S D$ must be assigned to correspond to a set of wtavg. Biasing data can specify a MATERIAL $D$ from the existing KENO V.a weighting library or from the AUXILLARY DATA input. The materials available from the KENO V.a weighting library are listed in Table F17.4.5.

$B I A S I N G$ INFORMATION is entered in the following form:

\section{READ BIAS KEYWORD CORRELATION DATA AUXILIARY DATA END BIAS}

\author{
KEYWORD \\ enter $\mathbf{I D}=$, $\mathbf{W T}=$, or $\mathbf{W T S}=$ \\ ID $=$ specifies that CORRELATION DATA will be entered next. \\ $\mathrm{WT}=$ or $\mathrm{WTS}=$ specifies that $A U X I L I A R Y D A T A$ will be entered next.
}

CORRELATION DATA are used to correlate a set of wtavg to a BIAS ID, imp, as specified in the geometry data. This causes the specified wtavg to be used as the weighting function in the volume defined by that geometry region.

CORRELATTON DATA must be entered in the order shown.

NUREG/CR-0200,

Vol. 2, Rev. 5

F17.4.34 
Table F17.4.3 Face codes for entering boundary (albedo) conditions

\begin{tabular}{|c|c|}
\hline Face code & Faces defined by face codes \\
\hline$+\mathrm{XB}=$ & Positive $\mathrm{X}$ face \\
\hline$\& \mathrm{XB}=$ & Positive X face \\
\hline$-\mathrm{XB}=$ & Negative $\mathrm{X}$ face \\
\hline$+Y B=$ & Positive Y face \\
\hline$\& Y B=$ & Positive Y face \\
\hline$-Y B=$ & Negative $Y$ face \\
\hline$+\mathrm{ZB}=$ & Positive $Z$ face \\
\hline$\& Z B=$ & Positive $Z$ face \\
\hline$-\mathrm{ZB}=$ & Negative $Z$ face \\
\hline $\mathrm{ALL}=$ & All 6 faces \\
\hline $\mathrm{XFC}=$ & Both positive and negative $X$ faces \\
\hline $\mathrm{YFC}=$ & Both positive and negative $Y$ faces \\
\hline $\mathrm{ZFC}=$ & Both positive and negative $Z$ faces \\
\hline$+\mathrm{FC}=$ & Positive $\mathrm{X}, \mathrm{Y}$, and $\mathrm{Z}$ faces \\
\hline$\& F C=$ & Positive $X, Y$, and $Z$ faces \\
\hline$-\mathrm{FC}=$ & Negative $X, Y$, and $Z$ faces \\
\hline $\mathrm{XYF}=$ & Positive and negative $X$ and $Y$ faces \\
\hline $\mathrm{XZF}=$ & Positive and negative $\mathrm{X}$ and $\mathrm{Z}$ faces \\
\hline $\mathrm{YZF}=$ & Positive and negative $Y$ and $Z$ faces \\
\hline$+X Y=$ & Positive $\mathrm{X}$ and $\mathrm{Y}$ faces \\
\hline$+Y X=$ & Positive $\mathrm{X}$ and $\mathrm{Y}$ faces \\
\hline$\& X Y=$ & Positive $X$ and $Y$ faces \\
\hline$\& Y X=$ & Positive $\mathrm{X}$ and $\mathrm{Y}$ faces \\
\hline$+X Z=$ & Positive $\mathrm{X}$ and $\mathrm{Z}$ faces \\
\hline$+Z X=$ & Positive $X$ and $Z$ faces \\
\hline$\& X Z=$ & Positive $X$ and $Z$ faces \\
\hline$\& Z X=$ & Positive $\mathrm{X}$ and $\mathrm{Z}$ faces \\
\hline$+Y Z=$ & Positive $Y$ and $Z$ faces \\
\hline$+Z Y=$ & Positive $Y$ and $Z$ faces \\
\hline$\& Y Z=$ & Positive $Y$ and $Z$ faces \\
\hline$\& Z Y=$ & Positive $Y$ and $Z$ faces \\
\hline$-\mathrm{XY}=$ & Negative $X$ and $Y$ faces \\
\hline$-\mathrm{XZ}=$ & Negative $\mathrm{X}$ and $\mathrm{Z}$ faces \\
\hline$-Y Z=$ & Negative $\mathrm{Y}$ and $\mathrm{Z}$ faces \\
\hline$Y X F=$ & Positive and negative $\mathrm{X}$ and $\mathrm{Y}$ faces \\
\hline $\mathrm{ZXF}=$ & Positive and negative $\mathrm{X}$ and $\mathrm{Z}$ faces \\
\hline $\mathrm{ZYF}=$ & Positive and negative $Y$ and $Z$ faces \\
\hline$-\mathrm{YX}=$ & Negative $X$ and $Y$ faces \\
\hline$-Z X=$ & Negative $X$ and $Z$ faces \\
\hline$-Z Y=$ & Negative $Y$ and $Z$ faces \\
\hline
\end{tabular}

F17.4.35

NUREG/CR-0200, Vol. 2, Rev. 5 
Table F17.4.4 Albedo names available on the KENO-VI albedo library for use with the face codes

\begin{tabular}{|c|c|}
\hline $\begin{array}{l}\text { DPOH2O } \\
\text { DPOH2O } \\
\text { DPO } \\
\text { DPO }\end{array}$ & $\begin{array}{l}30.48 \text {-cm }\left(12 \text { in) double } P_{0} \text { water differential albedo }\right. \\
\text { with } 4 \text { incident angles }\end{array}$ \\
\hline $\begin{array}{l}\text { H2O } \\
\text { WATER }\end{array}$ & $\begin{array}{l}30.48-\mathrm{cm}(12 \mathrm{in} \text {.) water differential albedo with } \\
4 \text { incident angles }\end{array}$ \\
\hline $\begin{array}{l}\text { PARAFFIN } \\
\text { PARA } \\
\text { WAX }\end{array}$ & $\begin{array}{l}30.48-\mathrm{cm}(12 \text { in.) paraffin differential albedo with } \\
4 \text { incident angles }\end{array}$ \\
\hline $\begin{array}{l}\text { CARBON } \\
\text { GRAPHITE } \\
\text { C }\end{array}$ & $\begin{array}{l}200.00 \text {-cm (78.74-in.) carbon differential albedo } \\
\text { with } 4 \text { incident angles }\end{array}$ \\
\hline $\begin{array}{l}\text { ETHYLENE } \\
\text { POLY } \\
\text { CH2 }\end{array}$ & $\begin{array}{l}30.48-\mathrm{cm}(12-\mathrm{in}) \text { polyethylene differential albedo } \\
\text { with } 4 \text { incident angles }\end{array}$ \\
\hline $\begin{array}{l}\text { CONC-4 } \\
\text { CON4 } \\
\text { CONC4 }\end{array}$ & $\begin{array}{l}\text { 10.16-cm (4-in.) concrete differential albedo with } \\
4 \text { incident angles }\end{array}$ \\
\hline $\begin{array}{l}\text { CONC-8 } \\
\text { CON8 } \\
\text { CONC8 }\end{array}$ & $\begin{array}{l}20.32 \text {-cm (8-in.) concrete differential albedo with } \\
4 \text { incident angles }\end{array}$ \\
\hline $\begin{array}{l}\text { CONC-12 } \\
\text { CON12 } \\
\text { CONC12 }\end{array}$ & $\begin{array}{l}\text { 30.48-cm (12-in.) concrete differential albedo } \\
\text { with } 4 \text { incident angles }\end{array}$ \\
\hline $\begin{array}{l}\text { CONC-16 } \\
\text { CON16 } \\
\text { CONC16 }\end{array}$ & $\begin{array}{l}\text { 40.64-cm (16-in.) concrete differential albedo } \\
\text { with } 4 \text { incident angles }\end{array}$ \\
\hline $\begin{array}{l}\text { CONC-24 } \\
\text { CON24 } \\
\text { CONC24 }\end{array}$ & $\begin{array}{l}\text { 60.96-cm (24-in.) concrete differential albedo } \\
\text { with } 4 \text { incident angles }\end{array}$ \\
\hline $\begin{array}{l}\text { VACUUM } \\
\text { VOID } \\
\text { VACU } \\
\text { VAC }\end{array}$ & Vacuum condition \\
\hline $\begin{array}{l}\text { SPECULAR } \\
\text { MIRROR } \\
\text { MIRR } \\
\text { SPEC } \\
\text { SPE } \\
\text { MIR } \\
\text { REFL } \\
\text { REFLECT }\end{array}$ & Mirror image reflection \\
\hline $\begin{array}{l}\text { PERIODIC } \\
\text { PERI } \\
\text { PER }\end{array}$ & Periodic boundary condition \\
\hline WHITE & White boundary condition \\
\hline
\end{tabular}

NUREG/CR-0200,

Vol. 2, Rev. 5

F17.4.36 
id enter the identification (MATERIAL ID) for the material whose weighting function is to be used. A material ID can be chosen from the existing KENO V.a weighting library (Table F17.4.5) or from the $A U X I L I A R Y D A T A$ as described later. If a material ID appears in both the KENO V.a weighting library and the $A U X U L I R Y D A T A$, the wtavg from the auxiliary data will be used.

$i b g n$ is the BIAS ID of the weighting function for the first interval of material $i d$. The geometry card having $i m p=i b g n$ will use the group-dependent wtovg's from the first interval of material id.

iend is the BIAS ID of the group-dependent wtavg's from the (iend-ibgn +1$)$ th interval of material id.

GENERIC EXAMPLE: READ BIAS ID=mm ibgn iend END BIAS where $\mathrm{mm}$ is a material ID from Table F17.4.5, ibgn is the bias ID associated with the 1st interval of material $\mathrm{mm}$, and iend is the bias ID associated with the $($ iend $-i b g n+1)$ interval of material $\mathrm{mm}$.

SPECIFIC EXAMPLE: Use CORRELATION DATA to utilize the water biasing factors in BIAS IDs 2 through 11.

\section{READ BIAS ID=500 211 END BIAS}

AUXILIARY DATA are used to enter user-supplied biasing or weighting information. It can be used to supply biasing information for materials not found in the KENO V.a weighting library or to override the wtovgs from that library. When AUXILIARY DATA are entered, CORRELATION DATA must also be entered in order to use the data. $A U X I L I A R Y$ DATA must be entered in the order shown.

wttitl

enter an arbitrary title name (12 characters maximum), such as CONCRETE, WATER, SPECIALH2O, etc., to identify the material for which you are entering data. Embedded blanks are not allowed.

id

enter an identification number (MATERIAL ID). The value is arbitrary. However, if the data are to be utilized in the problem, this ID must also be used at least once in the CORRELATION DATA.

nsets enter the number of sets of group structures for which wtavg will be read for this ID.

The sequence thkinc, numinc, ngpwt, wtavg, described below, is repeated nsets times.

thkinc

enter the thickness of each increment for which wtavg will be read for this ID.

numinc

enter the number of increments for which wtavg will be read for this ID.

$n g p w t$ enter the number of energy groups for this set of wtavg. 
Table F17.4.5 IDs, group structure and incremental thicknesses for weighting data available on the KENO V.a weighting library

\begin{tabular}{lcccc}
\hline Material & $\begin{array}{c}\text { Material } \\
\text { ID }\end{array}$ & $\begin{array}{c}\text { Group structure } \\
\text { for which weights } \\
\text { are available }\end{array}$ & $\begin{array}{c}\text { Increment } \\
\text { thickness } \\
(\mathrm{cm})\end{array}$ & $\begin{array}{c}\text { Total number of } \\
\text { increments } \\
\text { available }\end{array}$ \\
\hline Concrete & 301 & 16 & 5 & 20 \\
& & 27 & 5 & 20 \\
& & 123 & 5 & 20 \\
Paraffin & 400 & 16 & 3 & 10 \\
& & 27 & 3 & 11 \\
& & 123 & 3 & 10 \\
Water & 500 & 16 & 3 & 10 \\
& & 27 & 3 & 11 \\
& & 123 & 3 & 10 \\
& & 218 & 3 & 11 \\
Graphite & 6100 & 16 & 20 & 6 \\
& & 27 & 20 & 6 \\
& & 123 & 20 & 6 \\
\hline
\end{tabular}

${ }^{a}$ Group-dependent weight averages are supplied for each increment of the specified incremental thickness [i.e., for any given material, the first $n g p$ (number of energy groups) weights apply to the first increment of the thickness specified in Table F17.4.4, the next $n g p$ weights apply to the next increment of that thickness, etc.]. CAUTION--If bias IDs defined in the weighting information data are used in the geometry, the region thickness should be consistent with the incremental thickness of the weighting data in order to avoid overbiasing or underbiasing.

wtavg

enter numinc $x$ ngpwt values of wtovg. For each value of numinc, ngpwt values of wtavg must be supplied.

GENERIC EXAMPLE of AUXILIARY DATA: READ BIAS WT=wttitl id nsets thkinc numinc ngpwt wtavg END BIAS

SPECIFIC EXAMPLE: Enter AUXIIIARY DATA to specify biasing factors for SPECIALWATER to be used in BIAS IDs 6 and 7. The SPECIALWATER biasing factors have a value of 0.69 for BIAS ID 6 and 0.86 for BIAS ID 7 in each energy group. Sixteen-group cross sections are being used. Each weighting region is $3.048 \mathrm{~cm}$ thick. The MATERIAL $\mathrm{D}$ is arbitrarily chosen to be 510. Note that CORRELATION DATA must be entered to allow the AUXILIARY DATA to be used for BIAS IDs 6 and 7.

NUREG/CR-0200,

Vol. 2, Rev. 5

F17.4.38 
WARNING: The user should thoroughly understand weighted tracking before attempting to generate and use auxiliary data for biasing. Incorrect weighting can cause the code to produce incorrect results without obvious symptoms.

\section{CAUTIONS:}

1. Each set of auxiliary or correlation data must be completely described in conjunction with its keyword. Complete sets of these data can be interspersed in an arbitrary order but data within each set must be entered in the specified order.

2. Auxiliary data: If the same id is specified in more than one set of data, the last set having the group structure used in the problem is the set that will be utilized. When auxiliary data are entered, correlation data must also be entered in order to use the auxiliary data.

3. Correlation data: If biasing data define the same bias ID ( $\mathrm{imp}$, from the geometry data) more than once, the value that is entered last supersedes previous entries. Be well aware that multiple definitions for the same bias ID can cause erroneous answers due to overbiasing. Error messages K5-125 and K5-128 may be printed.

An example of multiple definitions for the same bias ID follows:

READ BIAS ID=4002 $7 \mathrm{ID}=50057$ END BIAS .

The data for paraffin $(\mathrm{ID}=400)$ will be used for bias $\mathrm{ID} 2,3$, and 4 , and the data for water $(\mathrm{ID}=500)$ will be used for bias IDs 5,6, and 7. The paraffin data for bias IDs 5,6 , and 7 have been overwritten by water data.

Multiple definitions for the same bias ID are not necessarily incorrect. However, the user should be cautious about doing it and ensure that the desired biasing or weighting functions are utilized in the desired geometry regions.

An example of how the BIASID relates to the energy-dependent values of wtavg is given below.

Assume that a paraffin reflector is to be used, and it is desirable to use the weighting function from the KENO V.a weighting library to minimize the running time for the problem. Also assume that these weighting functions are to be used in the volumes defined in the geometry cards having $i m p=6,7,8$, and 9 . CORRELATION DATA are then entered, and AUXILJARY DATA will not be entered.

KEYWORD is $\mathbf{I D}=$

id is 400 , the ID for paraffin

ibgn is 6 , the first imp that uses the weighting function

iend is 9 , the last imp that uses the weighting function

The biasing data would be: READ BIAS ID=400 69 END BIAS.

The results of these data are the following:

(1) The group-dependent wtavg for the 0 - to 3 -cm interval of paraffin will be used in the volume defined by the geometry region having $i m p=6$. 
(2) The group-dependent wtavg for the 3- to 6-cm interval of paraffin will be used in the volume defined by the geometry region having $i m p=7$.

(3) The group-dependent wtavg for the 6-to 9-cm interval of paraffin will be used in the volume defined by the geometry region having $i m p=8$.

(4) The group-dependent wtavg for the 9- to 12-cm interval of paraffin will be used in the volume defined by the geometry region having imp $=9$.

\section{F17.4.8 START DATA}

START DATA ... Special start options are available for controlling the initial neutron distribution. The default starting distribution is flat over the volume specified by the unrotated, untranslated geometry record specified in the first position of the global unit boundary record in fissile material only. See Table F17.4.6 for the starting distributions available in KENO-VI.

\section{READ START}

The starting information that can be entered is given below. Enter only the data necessary to describe the desired starting distribution.

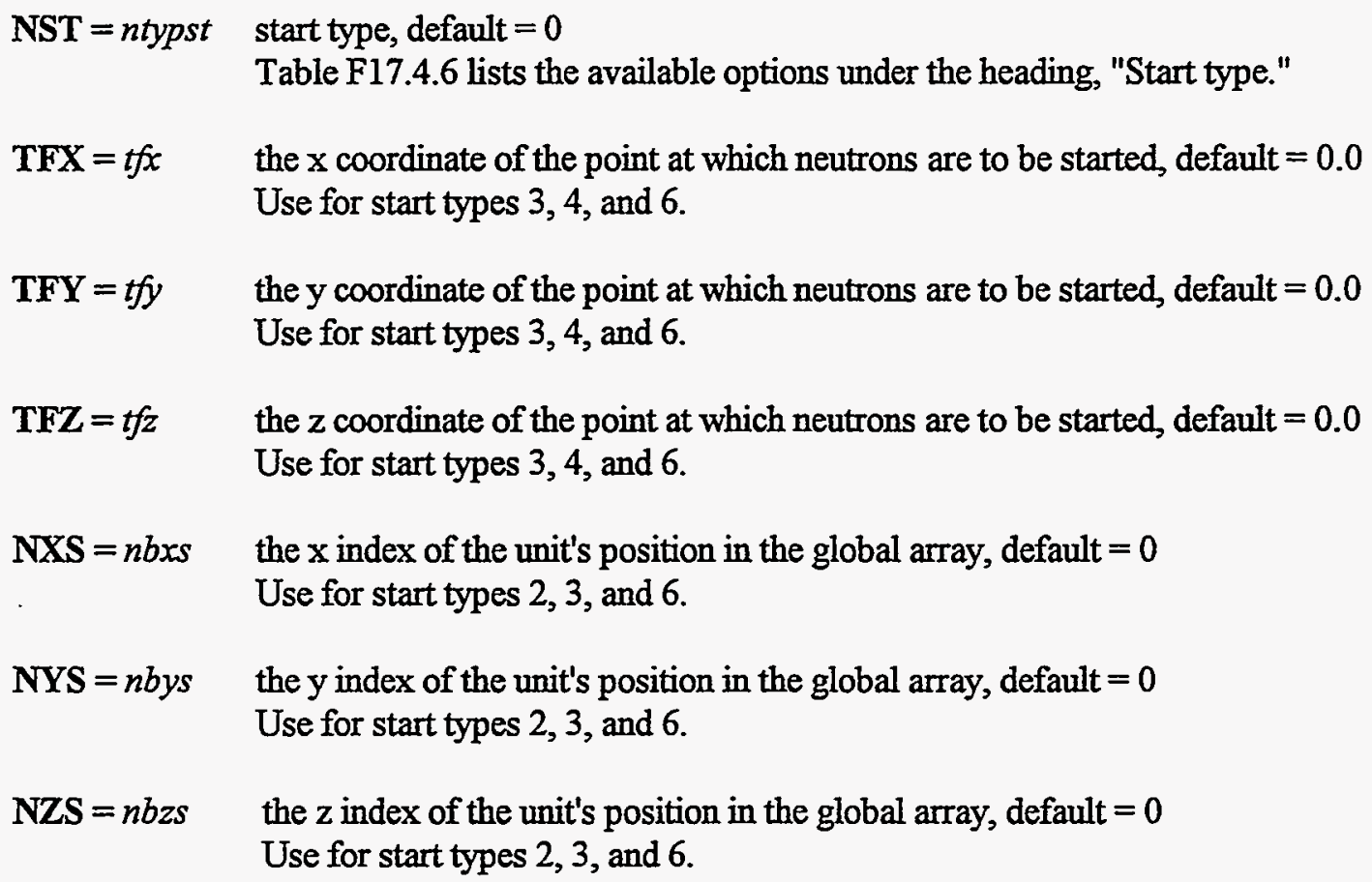

TFY $=t f y \quad$ the $y$ coordinate of the point at which neutrons are to be started, default $=0.0$ Use for start types 3,4 , and 6.

TFZ $=t f z \quad$ the $\mathrm{z}$ coordinate of the point at which neutrons are to be started, default $=0.0$ Use for start types 3,4 , and 6.

NXS $=n b x s \quad$ the $\mathrm{x}$ index of the unit's position in the global array, default $=0$ Use for start types 2,3 , and 6.

NYS $=n b y s \quad$ the $y$ index of the unit's position in the global array, default $=0$ Use for start types 2,3 , and 6.

NZS $=n b z s \quad$ the $z$ index of the unit's position in the global array, default $=0$ Use for start types 2,3 , and 6 .

KFS $=k f i s \quad$ the mixture whose fission spectrum is to be used for starting neutrons that are not in a fissionable medium. Defaulted to the fissionable mixture having the smallest mixture number. Available for start types 3,4, and 6 .

NUREG/CR-0200,

Vol. 2, Rev. 5

F17.4.40 
Table F17.4.6 Starting distributions available in KENO-VI

\begin{tabular}{|c|c|c|c|}
\hline $\begin{array}{l}\text { Start } \\
\text { type }\end{array}$ & $\begin{array}{l}\text { Required } \\
\text { data }\end{array}$ & $\begin{array}{l}\text { Optional } \\
\text { data }\end{array}$ & Starting distribution \\
\hline 0 & None & $\begin{array}{l}\text { NST } \\
\text { XSM } \\
\text { XSP } \\
\text { YSM } \\
\text { YSP } \\
\text { ZSM } \\
\text { ZSP } \\
\text { RFL } \\
\text { PSP }\end{array}$ & $\begin{array}{l}\text { Uniform throughout fissile material within the volume defined by (1) the unrotated, } \\
\text { untranslated geometry record in the first position of the global unit boundary record, } \\
\text { (2) the boundary of the global array having the reflector key set false, or (3) a cuboid } \\
\text { specified by XSM, XSP, YSM, YSP, ZSM, and ZSP }\end{array}$ \\
\hline 1 & NST & $\begin{array}{l}\text { XSM } \\
\text { XSP } \\
\text { YSM } \\
\text { YSP } \\
\text { ZSM } \\
\text { ZSP } \\
\text { RFL } \\
\text { PSP }\end{array}$ & $\begin{array}{l}\text { The starting points are chosen according to a cosine distribution throughout the } \\
\text { volume of a cuboid defined XSM, XSP, YSM, YSP, ZSM, and ZSP. Points that are } \\
\text { not in fissile material are discarded }\end{array}$ \\
\hline 2 & $\begin{array}{l}\text { NST } \\
\text { NXS } \\
\text { NYS } \\
\text { NZS } \\
\text { FCT }\end{array}$ & $\begin{array}{l}\text { XSM } \\
\text { XSP } \\
\text { YSM } \\
\text { YSP } \\
\text { ZSM } \\
\text { ZSP } \\
\text { RFL } \\
\text { PSP }\end{array}$ & $\begin{array}{l}\text { An arbitrary fraction (FCT) of neutrons are started uniformly in the unit located at } \\
\text { position NXS, NYS, NZS in the global array. The remainder of the neutrons are } \\
\text { started in fissile material, from points chosen from a cosine distribution throughout } \\
\text { the volume of a cuboid defined by XSM, XSP, YSM, YSP, ZSM, ZSP }\end{array}$ \\
\hline 3 & $\begin{array}{l}\text { NST } \\
\text { TFX } \\
\text { TFY } \\
\text { TFZ } \\
\text { NXS } \\
\text { NYS } \\
\text { NZS }\end{array}$ & $\begin{array}{l}\text { KFS } \\
\text { PSP }\end{array}$ & $\begin{array}{l}\text { All neutrons are started at position TFX, TFY, TFZ within the unit located at } \\
\text { position NXS, NYS, NZS in the global array }\end{array}$ \\
\hline 4 & $\begin{array}{c}\text { NST } \\
\text { TFX } \\
\text { TFY } \\
\text { TFZ } \\
\text { NBX }\end{array}$ & $\begin{array}{l}\text { KFS } \\
\text { PSP }\end{array}$ & $\begin{array}{l}\text { All neutrons are started at position TFX, TFY, TFZ within units NBX in the global } \\
\text { array }\end{array}$ \\
\hline 5 & $\begin{array}{l}\text { NST } \\
\text { NBX }\end{array}$ & PSP & Neutrons are started uniformly in fissile material in units NBX in the global array \\
\hline 6 & $\begin{array}{c}\text { NST } \\
\text { TFX } \\
\text { TFY } \\
\text { TFZ } \\
\text { LNU }^{a}\end{array}$ & $\begin{array}{l}\text { NXS } \\
\text { NYS } \\
\text { NZS } \\
\text { KFS } \\
\text { PS6 } \\
\text { PSP }\end{array}$ & $\begin{array}{l}\text { The starting distribution is arbitrarily input. INU is the final neutron to be started at } \\
\text { a point TFX, TFY, TFZ relative to the global coordinate system or at a point TFX, } \\
\text { TFY, TFZ, relative to the unit located at the global array position NXS, NYS, NZS }\end{array}$ \\
\hline
\end{tabular}

When entering data for start 6, LNU must be the last entry for each set of data and the INU in each successive set of data must be larger than the previous value of LNU. A set of data consists of required and optional data. The last LNU entered should be equal to the number per generation (parameter NPG $=$ in the parameter input, Sect. F17.4.3). 
$\mathbf{L N U}=$ lfin the final neutron to be started at a point. Default $=0$. Each $l$ fin should be greater than zero and less than or equal to NPG. Each successive lfin should be greater than the previous one.

Use for start type 6.

NBX $=$ nboxst the unit in which neutrons will be started. Default $=0$

Use for start types 4 and 5.

FCT $=$ fract the fraction of neutrons that will be started as a spike. Default $=0$

Use for start type 2.

$\mathrm{XSM}=x s m$ the $-\mathrm{X}$ dimension of the cuboid in which the neutron will be started. For an array problem, XSM is defaulted to the minimum X coordinate of the global array. If the reflector key RFL is YES, and the outer reflector region is a cuboid, XSM is defaulted to the minimum X coordinate of the outer reflector region. If RFL is YES and the outer region of the reflector is not a cuboid, XSM must be entered in the start data and must fit inside the outer reflector region.

Available for start types 0,1 , and 2 .

$\mathrm{XSP}=x s p \quad$ the $+\mathrm{X}$ dimension of the cuboid in which the neutrons will be started. For an array problem, XSP is defaulted to the maximum X coordinate of the global array. If the reflector key RFL is YES, and the outer reflector region is a cuboid, XSP is defaulted to the maximum X coordinate of the outer reflector region. If RFL is YES and the outer region of the reflector is not a cuboid, XSP must be entered in the start data and must fit inside the outer reflector region. Available for start types 0,1 , and 2 .

YSM $=y s m$ the $-Y$ dimension of the cuboid in which the neutron will be started. For an array problem, YSM is defaulted to the minimum $Y$ coordinate of the global array. If the reflector key RFL is YES, and the outer reflector region is a cuboid, YSM is defaulted to the minimum Y coordinate of the outer reflector region, provided that region is a cuboid. If RFL is YES and the outer region of the reflector is not a cuboid, YSM must be entered in the start data and must fit inside the outer reflector region. Available for start types 0,1 , and 2.

YSP $=y s p \quad$ the $+Y$ dimension of the cuboid in which the neutrons will be started. For an array problem, YSP is defaulted to the maximum $Y$ coordinate of the global array. If the reflector key RFL is YES, and the outer reflector region is a cuboid, YSP is defaulted to the maximum $Y$ coordinate of the outer reflector region, provided that region is a cuboid. If RFL is YES and the outer region of the reflector is not a cuboid, YSP must be entered in the start data and must fit inside the outer reflector region.

Available for start types 0,1 , and 2 .

ZSM $=z s m$ the $-Z$ dimension of the cuboid in which the neutrons will be started. For an array problem, XSM is defaulted to the minimum $Z$ coordinate of the global array. If the reflector key RFL is YES, and the outer reflector region is a cuboid, ZSM is defaulted to the minimum $Z$ coordinate of the outer reflector region, provided that region is a cuboid. If RFL is YES and the outer region of the reflector is not a cuboid, ZSM must be entered in the start data and must fit inside the outer reflector region.

Available for start types 0,1 , and 2 .

NUREG/CR-0200,

Vol. 2, Rev. 5

F17.4.42 
ZSP $=z s p \quad$ the $+Z$ dimension of the cuboid in which the neutrons will be started. For an array problem, ZSP is defaulted to the maximum $Z$ coordinate of the global array. If the reflector key RFL is YES, and the outer reflector region is a cuboid, ZSP is defaulted to the maximum Z coordinate of the outer reflector region, provided that region is a cuboid. If RFL is YES and the outer region of the reflector is not a cuboid, ZSP must be entered in the start data and must fit inside the outer reflector region.

Available for start types 0,1 , and 2 .

RFL $=$ rflkey the reflector key. If the reflector key is YES, neutrons can be started in the reflector. If it is NO, all the neutrons will be started in the array. Enter YES or NO. Default= YES.

Available for start types 0,1 , and 2 .

PS6 = lprt6 the key for printing start type 6 input data. If the key is YES, start type 6 data are printed. If it is NO, start type 6 data are not printed. Enter YES or NO. Default $=$ NO.

Available for start type 6.

PSP = lpstp the key for printing the neutron starting points using the tracking format. If the key is YES, print the neutron starting points. If it is NO, do not print the starting points. Enter YES or NO. Default $=$ NO.

Available for all start types.

\section{END START}

\section{F17.4.9 EXTRA 1-D XSECS IDS DATA}

EXTRA 1-D CROSS-SECTION IDS ... Extra 1-D cross-section IDs need not be entered. They are allowed as input in order to simplify future modifications to calculate reaction rates, etc.

\section{READ X1DS EXTRA 1-D CROSS SECTION IDS END X1DS}

\section{EXTRA 1-D CROSS SECTION IDS}

Enter a 1-D identification number for each extra 1-D cross section to be used. These cross sections must be available on the mixture cross-section library. X1D entries are expected to be read (see integer PARAMETER data).

\section{F17.4.10 MIXING TABLE DATA}

CROSS-SECTION MIXING TABLE . . . A cross-section mixing table must be entered if KENO-VI is being run "stand alone" and an ICE mixed cross-section MORSE/KENO V.a format library is not being used. If the parameter $\mathrm{LIB}=$, Sect. $\mathrm{F} 17.4 .3$, is entered, mixing table data must be entered. A cross-section mixing table is entered in the form:

\section{READ MIXT XSEC PARAMETERS MIXING TABLE END MIXT}

The XSEC PARAMETERS include the number of scattering angles and the cross-section message cutoff value. 
$\mathrm{SCT}=n s c t \quad$ where $n s c t$ is the number of discrete scattering angles, default $=1$

The number of scattering angles specifies the number of discrete scattering angles to be used for the cross sections. It needs to be entered only once for a problem. If more than one value is entered, the last one is used for the problem. For assistance in determining the number of discrete scattering angles for the cross sections, see Sect. F17.5.4.3.

EPS $=p b x s \quad$ where $p b x s$ is the value of the $\mathrm{P}_{0}$ cross section for each transfer, above which generated warning messages will be printed, default $=3 \times 10^{-5}$

The cross-section message cutoff value is the value of the $P_{0}$ cross section for each energy transfer above which cross-section processing warning messages will be printed. The primary purpose of entering this cutoff value is to suppress printing these messages when they are generated during cross-section processing. For assistance in determining a value for EPS, see Sect. F17.5.4.4.

The MIXING TABLE is used to specify each mixture and the nuclide IDs and number densities used in the mixtures. It consists of (a) a MIXTURE ID and a set of (b) NUCLIDE IDs, and (c) NUMBER DENSITIES (atoms/b-cm).

(a) MIXTURE ID MIX = mix, where mix defines the mixture being described

(b) NUCLIDE ID nucl enter the nuclide ID number from the AMPX working-format cross-section library

(c) NUMBER DENSTTY dens enter the number density (atoms/b-cm) associated with nuclide ID number nucl

REPEAT the sequence (b) (c) until the mixture has been completely described.

REPEAT the sequence (a) (b) (c) until all the mixtures have been described.

NOTE: If a given nuclide ID is entered more than once in the same mixture, the number densities for that nuclide are summed.

If a mixture number is used as a nuclide $\mathrm{D}$, it is treated as a nuclide and the number density associated with it is used as a density modifier. (If the density is entered as 1 , the mixture is mixed in at full density. If it is entered as 0.5 , the mixture is mixed in at $1 / 2$ its full density.) A Monte Carlo formatted cross-section library is generated on the unit defined by the parameter $\mathrm{XSC}=$. If this data set is saved, subsequent cases can utilize these mixtures without remixing.

\section{F17.4.11 PLOT DATA}

PLOT or PICTURE DATA... Printer plots or pictures of slices through the geometry can be printed showing mixture numbers, unit numbers, or bias ID numbers. The PLOT DATA can include the data for any or all types of pictures. A picture by mixture number is the default. The kind of picture is defined by the parameter $\mathrm{PIC}=$. Printer plots are printed after the volumes are printed and before the final preparations for tracking are completed. PLOT DATA is not required for a problem but can be used to verify the problem description. Two types of plots are available: printer plots, which use either default symbols or symbols entered using the NCH option to represent the system geometry cross section, and screen plots, which are pixel plots of the system cross- 
section using colors entered in the color table. The default option is the printer plot, which is included in the problem output. If SCR=YES is specified, a .gif plot of the 2-D system geometry cross section is generated in the directory where the problem is being run. The actual printing of the plot or picture can be suppressed by entering PLT $=$ NO in the parameter data or picture data. This allows picture data to be kept in the problem data for reference purposes without actually printing the picture(s). Entering a value for PLT in the picture data will override any value entered in the parameter data. However, if a problem is restarted, the value of PLT from the parameter data is used. The upper-left and lower-right coordinates of the plot must be specified relative to the origin of the problem. See Sect. F17.5.9 for a discussion of plot origins and printer plot data.

Enter PLOT DATA in the form:

\section{READ PLOT PICTURE PARAMETERS END PLOT}

PICTURE PARAMETERS are entered using keywords followed by the appropriate data. The plot title and the plot character string must be contained within delimiters. As many picture parameters as are necessary to describe the plot should be entered. Multiple sets of plot data can be entered. The parameter input for each plot is terminated by a labeled or unlabeled END. The labeled END cannot use the word PLOT as the first four characters of the label. For example, END PLT1 is a valid label, but END PLOT1 is not. If an unlabeled END is used, it cannot start in column 1.

TTL $=$ delim ptitl delim Enter a one-character delimiter delim to signal the beginning of the title (132 characters maximum). The title is terminated when delim is encountered the second time.

Default $=$ title of the KENO-VI case

$\mathrm{SCR}=$ plot type

$\mathbf{C L R}=$ color

$\mathbf{P I C}=w r d$

MAT

MIX

MIXT

MIXTURE

MEDI

MEDIA

BOX

BOXT

BOXTYPE

UNT

UNIT

UNITTYPE

\section{Enter YES for a screen plot and NO for a printer plot. Default is NO}

This option is only used in conjunction with screen plots. It changes a color in the color tables. Input consists of 4 integers, the first one being the position in the color table and the next three being the red green and blue color values respectively.

The picture type, wrd, is followed by one or more blanks and must be one of the keywords listed below. The picture type is initialized to MAT; the default is the value from the previous plot.

These keywords will cause the printer plot to represent the mixture numbers used in the specified geometry slice.

These keywords will cause the printer plot to represent the units used in the specified geometry slice. 
IMP

BIAS

BIASID

ID

WTS

WEIG

WEIGHTS

WGT

WGTS

Picture coordinates

Upper left coordinates

$\mathbf{X U L}=f \operatorname{nam}(1)$

YUL= fnam(2)

$\mathbf{Z U L}=$ fnam(3)

Lower right coordinates

$\mathbf{X L R}=$ fnam(4)

$\mathbf{Y L R}=$ fnam $(5)$

$\mathbf{Z L R}=$ fnam( $(\sigma)$

Direction cosines across the page
These keywords will cause the printer plot to represent the bias numbers used in the specified geometry slice.

Enter values for the upper-left and lower-right coordinates of the plot as described below. Data must be entered for all nonzero coordinates unless all six values from the previous plot are to be used.

Enter the $X, Y$, and $Z$ coordinates of the upper-left-hand corner of the plot.

Enter the X coordinate of the upper-left-hand corner of the plot. Default $=$ value from previous plot; initialized to zero if any other coordinates are entered.

Enter the $Y$ coordinate of the upper-left-hand corner of the plot. Default $=$ value from previous plot; initialized to zero if any other coordinates are entered.

Enter the Z coordinate of the upper-left-hand corner of the plot. Default $=$ value from previous plot; initialized to zero if any other coordinates are entered.

Enter the $X, Y$, and $Z$ coordinates of the lower-right-hand corner of the plot.

Enter the X coordinate of the lower-right-hand corner of the plot. Default $=$ value from previous plot; initialized to zero if any other coordinates are entered.

Enter the $Y$ coordinate of the lower-right-hand corner of the plot. Default $=$ value from previous plot; initialized to zero if any other coordinates are entered.

Enter the $\mathrm{Z}$ coordinate of the lower-right-hand corner of the plot. Default $=$ value from previous plot; initialized to zero if any other coordinates are entered.

Enter direction numbers proportional to the direction cosines for the AX axis of the plot. The AX axis is from left to right across the page. If any one of the AX direction cosines are entered, the other two are set to zero. The direction cosines are normalized by the code. 
$\mathrm{UAX}=\operatorname{fnam}(7)$

$\mathrm{VAX}=$ fnam $(8)$

WAX $=$ fnam(9)

Direction cosines down the page

$\mathrm{UDN}=$ fnam $(10)$

$\mathrm{VDN}=$ fnam $(11)$

WDN= fnam $(12)$

Scaling parameters

$\mathrm{DLX}=$ fnam $(13)$

$\mathrm{DLD}=$ fnam(14)

$\mathrm{NAX}=\operatorname{inam}(15)$

$\mathrm{NDN}=\operatorname{inam}(16)$
Enter the X component of the direction cosines for the AX axis of the plot. default $=$ value from previous plot; initialized to zero if any other direction cosines are entered.

Enter the $\mathrm{Y}$ component of the direction cosines for the $\mathrm{AX}$ axis of the plot. Default $=$ value from previous plot; initialized to zero if any other direction cosines are entered.

Enter the $\mathrm{Z}$ component of the direction cosines for the $\mathrm{AX}$ axis of the plot. Default $=$ value from previous plot; initialized to zero if any other direction cosines are entered.

Enter direction numbers proportional to the direction cosines for the DN axis of the plot. The DN axis is from top to bottom down the page. If any one of the DN direction cosines are entered, the other two are set to zero. The direction cosines are normalized by the code.

Enter the X component of the direction cosines for the DN axis of the plot. Default $=$ value from previous plot; initialized to zero if any other direction cosines are entered.

Enter the Y component of the direction cosines for the DN axis of the plot. Default = value from previous plot; initialized to zero if any other direction cosines are entered.

Enter the $Z$ component of the direction cosines for the $D N$ axis of the plot. Default $=$ value from previous plot; initialized to zero if any other direction cosines are entered.

Enter one or more scaling parameters to define the size of the printer plot. NOTE: If any of the scaling parameters are entered for a plot, the value of those that were not entered are recalculated. If none of the scaling parameters are specified for a plot, the values from the previous plot are used.

Horizontal spacing between points on the plot. Default $=$ value from previous plot; initialized to zero if NAX or NDN is entered.

Vertical spacing between points on the plot.

Default = value from previous plot; initialized to zero if NAX or NDN is entered.

NOTE: If either DLX or DLD is entered, the code will calculate the value of the other. If both are entered, the plot may be distorted.

Number of intervals to be printed across the page.

Default $=$ value from previous plot; initialized to zero if DLX or DLD is entered.

Number of intervals to be printed down the page.

Default $=$ value from previous plot; initialized to zero if DLX or DLD is entered. 
NOTE: If either NAX or NDN is entered, the code will calculate the value of the other. If both are entered, the plot may be distorted. If the coordinates of the lower-right-hand corner have been entered, only one item of (DLX, DLD, NAX, NDN) need be entered. If the coordinates have not been entered, it is necessary to enter both NAX and NDN in addition to either DLX or DLD. If the coordinates and NAX or NDN are entered, then DLX and/or DLD will be recomputed. The plot distortion for printers other than 8 lines per inch (lpi) and 6 lpi impact printers can be minimized by entering appropriate values for both NAX and NDN. For a printer that prints 15 characters per inch across the page and 10 characters per inch down the page, $N D N=N A X \times 10 / 15 \times$ DELTAD/DELTAA, where:

DELTAD is the "length of the picture down the page" defined as the difference between the value of the ordinate of the upper-left corner of the plot and the lower-right comer of the plot. For example, if $Z$ is to be printed down the page, DELTAD is the absolute value of difference between the upperleft (ZUL) and lower-right (ZLR) values of $Z$.

DELTAA is the "width of the picture across the page" defined as the difference between the value of the ordinate of the upper-left corner of the plot and the lower-right corner of the plot. For example, if $\mathrm{X}$ is to be printed across the page, DELTAA is the absolute value of difference between the lower-right (XIR) and upper-left (XUL) values of $\mathrm{X}$.

If an $\mathrm{X}-\mathrm{Y}$ slice is to be printed with $\mathrm{X}$ across the page and $\mathrm{Y}$ down the page and the upper-left coordinates of the plot are $X=10, Y=50, Z=12$, and the lower-right coordinates are $X=10, Y=-50, Z=12$, then DELTAA is 20 and DELTAD is 100 . If NAX is specified as 90 , then NDN should be 300 to produce a printer plot having minimum distortion.

Miscellaneous parameters Enter miscellaneous parameters.

$\mathrm{LPI}=\operatorname{inam}(17)$

Number of lines per inch that will be printed down a page for a screen plot. It is used to calculate either lines down the page or characters across the page in both NAX and NDN are not entered. Default $=8$.

$\mathrm{NCH}=\operatorname{delim}$ CHAR delim

Enter a one-character delimiter to signal the beginning of a character string, CHAR. The character string is terminated when delim is encountered the second time. CHAR is a character string with each entry representing a media (mixture) number, unit number, or bias ID. These characters will be used in the plot. The first entry represents media, unit, or bias ID zero; the second entry represents the smallest media, unit, or bias ID used in the problem; the third, the next larger media, unit, or bias $\mathrm{D}$ used in the problem; etc. For example, assume $\mathrm{PIC}=\mathrm{MAT}$ is specified and 15 mixtures are defined in the mixing table and the geometry data use only mixtures 3 and 7 . By default, a blank will be printed for mixture zero, a 1 will be printed for mixture 3 , and a 2 will be printed for mixture 7 . If you wish to print a zero for a void (mixture 0 ), a 3 for mixture 3 , and a 7 for mixture 7, enter $\mathrm{NCH}=$ 037.' See Sect. F17.5.9 for examples.

NUREG/CR-0200, 
The default values of $C H A R$ follow:

\begin{tabular}{|c|c|c|c|c|c|c|c|c|c|c|c|c|c|c|c|}
\hline $\begin{array}{l}\text { MEDIA } \\
\text { SYMBOL }\end{array}$ & 0 & $\begin{array}{l}1 \\
1\end{array}$ & $\begin{array}{l}2 \\
2\end{array}$ & $\begin{array}{l}3 \\
3\end{array}$ & $\begin{array}{l}4 \\
4\end{array}$ & $\begin{array}{l}5 \\
5\end{array}$ & $\begin{array}{l}6 \\
6\end{array}$ & $\begin{array}{l}7 \\
7\end{array}$ & $\begin{array}{l}8 \\
8\end{array}$ & $\begin{array}{l}9 \\
9\end{array}$ & $\begin{array}{l}10 \\
\mathrm{~A}\end{array}$ & $\begin{array}{l}11 \\
B\end{array}$ & $\begin{array}{l}12 \\
\mathrm{C}\end{array}$ & $\begin{array}{l}13 \\
D\end{array}$ & $\begin{array}{l}14 \\
\mathrm{E}\end{array}$ \\
\hline MEDIA & 16 & 17 & 18 & 19 & 20 & 21 & 22 & 23 & 24 & 25 & 26 & 27 & 28 & 29 & 30 \\
\hline SYMBOL & $G$ & $\mathrm{H}$ & I & $\mathrm{J}$ & $\mathrm{K}$ & $\mathrm{L}$ & M & $\mathrm{N}$ & 0 & $\mathrm{P}$ & $Q$ & $\mathbf{R}$ & $\mathbf{S}$ & $\mathrm{T}$ & $\mathrm{U}$ \\
\hline MEDIA & 32 & 33 & 34 & 35 & 36 & 37 & 38 & 39 & 40 & 41 & 42 & 43 & 44 & 45 & 46 \\
\hline SYMBOL & W & $\mathrm{X}$ & $Y$ & $\mathrm{Z}$ & $\#$ & , & $\$$ & - & + & ) & I & $\&$ & $>$ & : & ; \\
\hline MEDIA & 47 & 48 & 49 & 50 & 51 & 52 & 53 & 54 & 55 & 56 & 57 & 58 & & & \\
\hline SYMBOL & . & - & $\%$ & $*$ & $n$ & $=$ & $!$ & ( & @) & $<$ & 1 & 0 & & & \\
\hline
\end{tabular}

$\mathbf{R U N}=\operatorname{fnam}(19)$

Enter YES or NO. A value of YES means the problem will be executed if all the data were acceptable. A value of NO specifies the problem will be terminated after data checking is completed. The default value of RUN is YES. The value entered in the plot data will override the value entered in the parameter data, Sect. F17.4.3, unless the problem is being restarted.

PLT $=$ fnam $(20)$

Enter YES or NO. A value of YES specifies that a plot is to be made. If plot data are entered, PLT is defaulted to YES. If it is desirable to retain the plot data in the problem input without generating a plot, $P L T=N O$ should be entered. $P L T=$ can also be entered in the parameter data, Sect. F17.4.3, but will be overridden by the value entered here unless the problem is being restarted.

\section{F17.4.12 REFERENCES}

1. N. M. Greene et al., AMPX: A Modular Code System for Generating Coupled Multigroup Neutron-Gamma Libraries from ENDF/B, ORNL/TM-3706, March 1976. Also see Sect. F2.3.8 of the SCALE manual.

2. J. R Knight and L. M. Petrie, 16 and 123 Group Weighting Functions for KENO-V.a, ORNL/TM-4660, 1975. 
Tables summarizing KENO-VI input data follow.

NUREG/CR-0200,

Vol. 2, Rev. 5

F17.4.50 
Table F17.4.7 Summary of parameter data

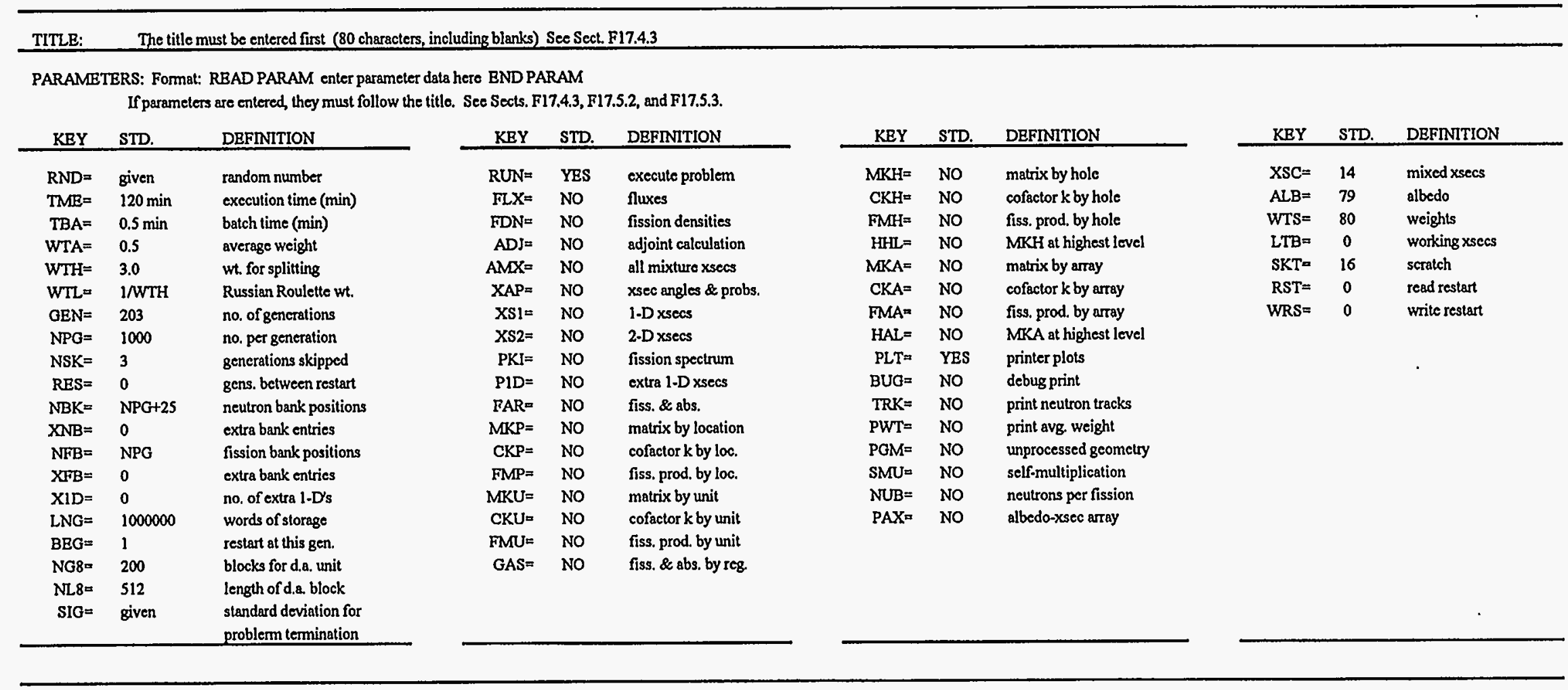

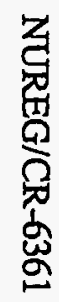


Table F17.4.8 Summary of array data

ARRAY Format: READ ARRAY array parameters data type orientation data END ARRAY See Sects. F17.5.5, F17.5.6, and F17.5.7.

Repeat the sequence ARRAY PARAMETERS DATA TYPE ORIENTATION DATA for each array used in the problem.

\begin{tabular}{|c|c|c|c|}
\hline \multicolumn{3}{|c|}{ ARRAY PARAMETERS } & \multirow{2}{*}{$\begin{array}{l}\text { DATA TYPE } \\
\qquad \begin{array}{l}\text { FILL } \\
\text { LOOP }\end{array}\end{array}$} \\
\hline KEYWORD & DEFAULT & DEFINITION & \\
\hline $\begin{array}{l}\text { ARA }= \\
\text { TYP }=\end{array}$ & $\begin{array}{l}\text { none } \\
\text { cuboidal }\end{array}$ & $\begin{array}{l}\text { no. defining the array } \\
\text { array type (cuboidal or }\end{array}$ & \\
\hline $\begin{array}{l}\text { NUX= } \\
\text { NUY= } \\
\text { NUZ= } \\
\text { GBL= } \\
\text { COM= }\end{array}$ & $\begin{array}{l}\text { none } \\
\text { none } \\
\text { none } \\
\text { none } \\
\text { none }\end{array}$ & $\begin{array}{l}\text { (riangular) } \\
\text { no. of units in X direction } \\
\text { no. of units in Y direction } \\
\text { no. of units in Z direction } \\
\text { global, array number } \\
\text { delim comment delim } \\
\text { optional comment is a } \\
\text { maximum of } 132 \text { characters }\end{array}$ & \\
\hline
\end{tabular}

**If specified, it need be entered only once per problem.

ORIENTATION DATA FOR FLL

ORIENTATION DATA FOR LOOP

Enter unit numbers to define every position in the array. When entering data utilizing the options in this table, the count field and option field must be adjacent with no imbedded blanks. The operand field may be separaled from the
option field by one or more blanks. Ojientation data for FILL is terminated by entering END FILL.

Enter the unit number and nine numbers that define the position(s) of that unit. Data for each of these ten entries are repeated until levery position in the array has been defined. Orientation data fo ENTER DATA IN THE FORM:

\begin{tabular}{|c|c|c|c|c|c|}
\hline $\begin{array}{l}\text { COUNT } \\
\text { FIELD } \\
\end{array}$ & $\begin{array}{l}\text { OPTION } \\
\text { FIELD }\end{array}$ & $\begin{array}{l}\text { OPERAND } \\
\text { FELLD }\end{array}$ & COMMENTS & $\begin{array}{l}\text { DATA } \\
\text { ENTRY } \\
\end{array}$ & COMMENTS \\
\hline$\stackrel{\mathfrak{i}}{\mathfrak{i}}$ & $\begin{array}{l}\mathbf{R} \\
\mathbf{R} \\
\mathbf{S}\end{array}$ & j & \multirow{7}{*}{ 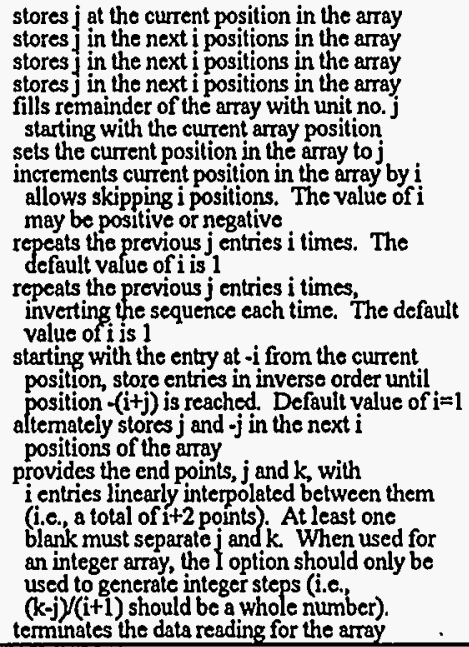 } & $\begin{array}{l}\text { LTYPE } \\
\text { IX1 } \\
\text { IX2 } \\
\text { INCX }\end{array}$ & \multirow{7}{*}{$\begin{array}{l}\text { The unit or box type. LTYPE must be greater than } 0 \text {. } \\
\text { Starting position in the X direction. IXI must be at least } 1 \text { and no larger } \\
\text { than the value entered for NUXX. } \\
\text { Ending position in the X direction. IX2 must be at least } 1 \text { and no larger } \\
\text { than the value of NUX. } \\
\text { The number of units by which increments are made in the } X \text { direction. } \\
\text { The starting position in the Y direction. IY1 must be at least } 1 \text { and less } \\
\text { than the value entered for NUYY } \\
\text { Ending position int he } Y \text { direction. IY } 2 \text { must be at least } 1 \text { and no langer } \\
\text { hhan the value of NUYY. } \\
\text { The number of units by which increments are made in the positive } Y \\
\text { direction. } \\
\text { Starting position in the } Z \text { direction. IZ1 must be at least } 1 \text { and no langer } \\
\text { than NUZ. } \\
\text { Ending position in the } Z \text { direction. IZ2 must be at least } 1 \text { and no larger } \\
\text { than NUZ. } \\
\text { The number of units by which increments are made in the positive } Z \\
\text { direction. }\end{array}$} \\
\hline $\mathbf{i}$ & A & $\mathbf{j}$ & & IYI & \\
\hline $\mathrm{i}$ & $Q$ & $\mathrm{j}$ & & $\begin{array}{l}\text { IY2 } \\
\text { NNCY }\end{array}$ & \\
\hline i & $\mathbf{N}$ & j & & $\mathbf{Z l}$ & \\
\hline $\mathbf{i}$ & B & j & & $\begin{array}{l}\mathrm{IZ2} \\
\text { INCZ }\end{array}$ & \\
\hline i & $\mathrm{P}$ & $j$ & & & \\
\hline i & I & $\mathrm{jk}$ & & & \\
\hline
\end{tabular}


Table F17.4.9 Summary of biasing data

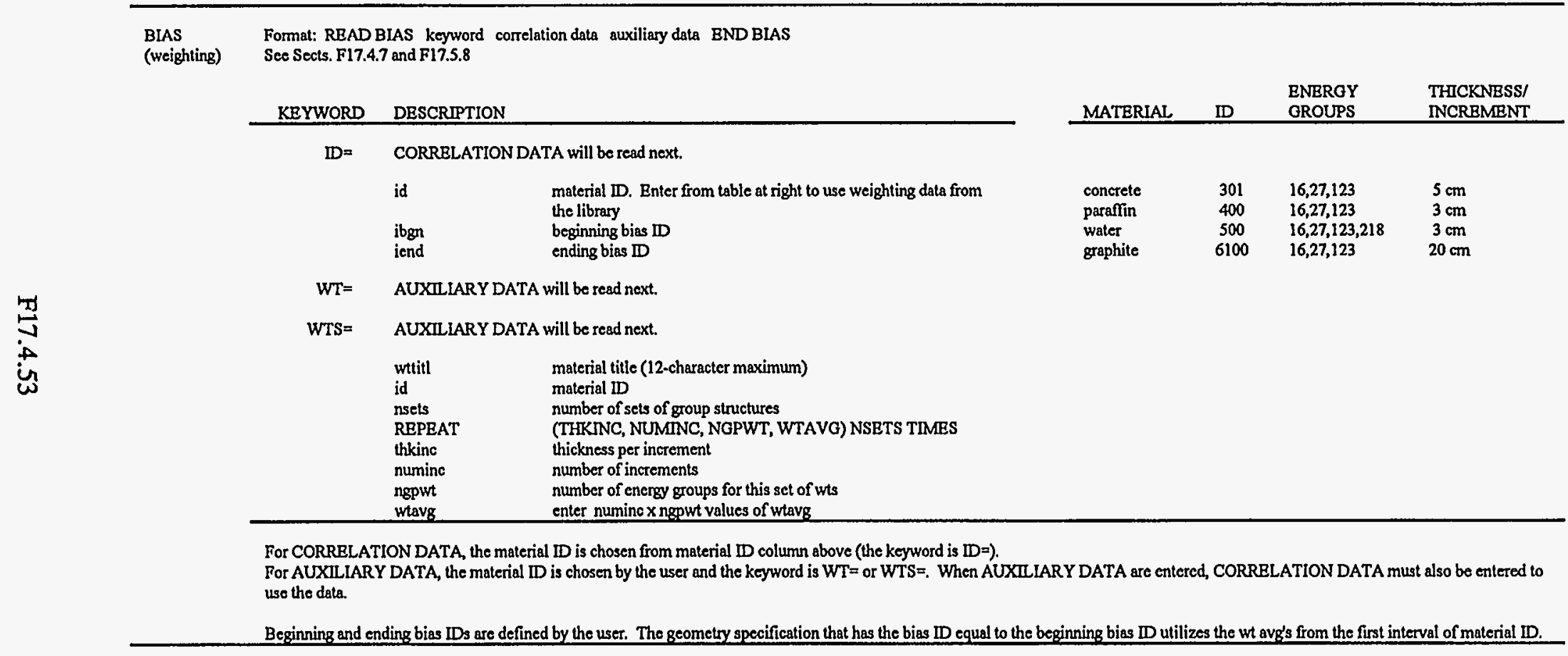


Table F17.4.10 Summary of boundary condition data

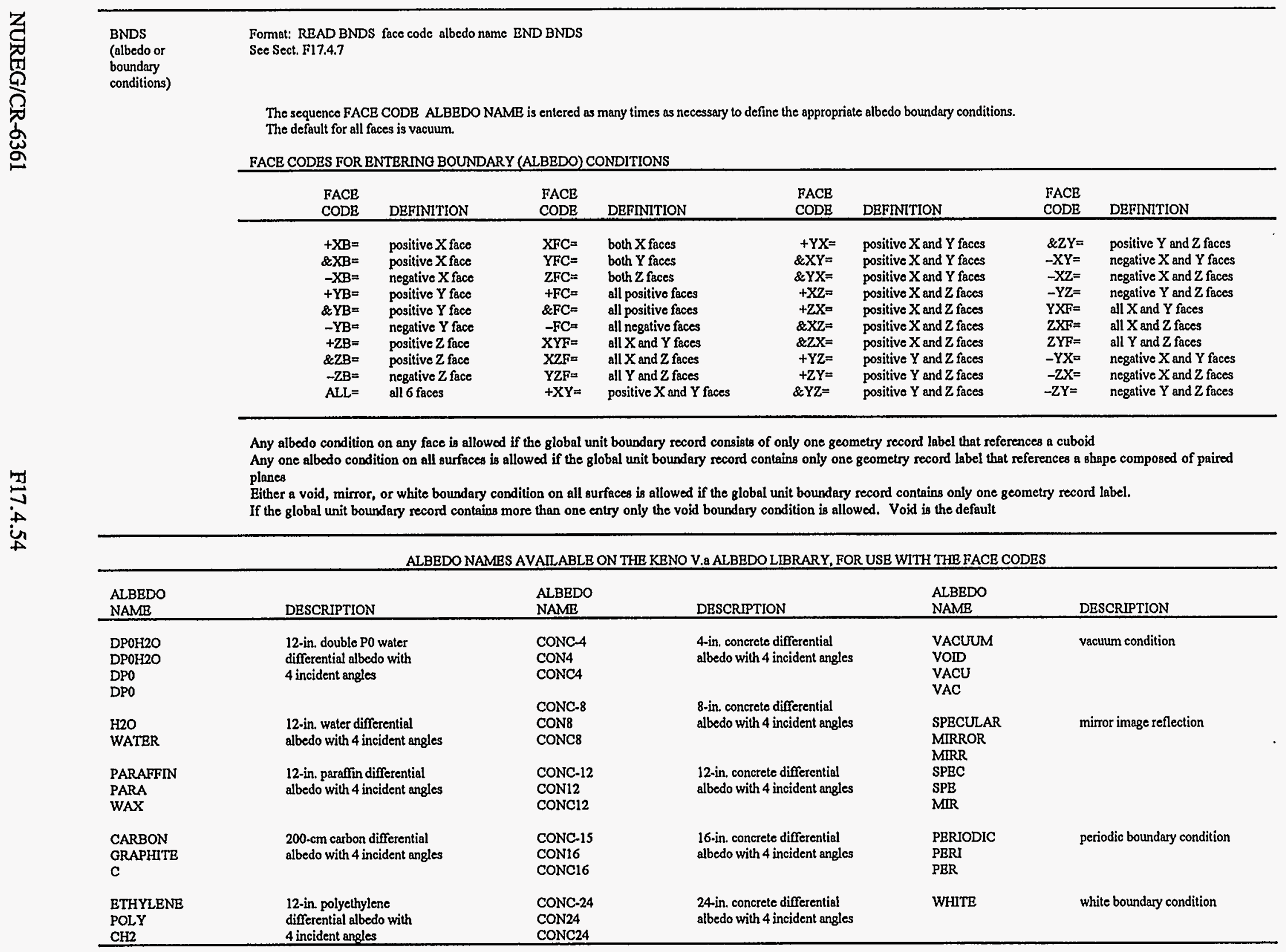


Table F17.4.11 Summary of geometry data

$\begin{array}{ll}\text { GEOMBTRY } & \text { Format: READ GROM geometry region data END GROM } \\ \text { (region) } & \text { See Sects. F17.4.4, F17.5.1.2, F17.5.6, and F17.5.7. }\end{array}$

GEOMETRY REGION DATA consist of SIMPLE OEOMETRY REGION DATA and EXTENDED GEOMETRY REGION DATA.

ENTER GEOMETRY REGION DATA IN THE FOLLOWING FORM

GLOBAL SPECIFICATION

UNIT n

OPTIONAL OEOMETRY COMMENT

GBOMETRY, MODIFICATION, MEDIA, and BOUNDARY DATA

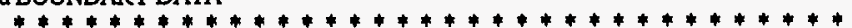

ENTER DATA IN THB FOLLOWING FORM:

GLOBAL Enter once to specify this unit as the global unit

UNIT $n$ =delim comment delim This optional comment can be up to 132 characters. It must begin and end with a delimiter.

Geometry Keyword Label Input Parameters Optional origin data (ORIOIN) Optional chord data (CHORD) Optional rotation data (ROTATE degrees)

Media Keyword Input Parameters

Boundary Keyword Input Parameters Bach unit must have one boundary record.

enter as many geometry and media descriptions as necessary to describe the unit and as many units as necessary to describe the system.

GBOMETRY REOION INPUT DATA REQUIREMENTS

\begin{tabular}{|c|c|c|c|}
\hline $\begin{array}{l}\text { TYPE OF } \\
\text { DATA } \\
\end{array}$ & KBYWORD & $\begin{array}{c}\text { INPUT } \\
\text { PARAMETERS } \\
\end{array}$ & NOTES \\
\hline GEOMETRY & $\begin{array}{l}\text { CONB } \\
\text { CUBOID } \\
\text { CYLINDER } \\
\text { DODECAHEDRON } \\
\text { ECYLINDER } \\
\text { ELLIPSOID } \\
\text { HEXPRISM } \\
\text { HOPPER } \\
\text { PARALLELEPIPED } \\
\text { PLANE* } \\
\text { QUADRATIC* } \\
\text { RHOMBOID } \\
\text { SPHRRB } \\
\text { WEDOE }\end{array}$ & 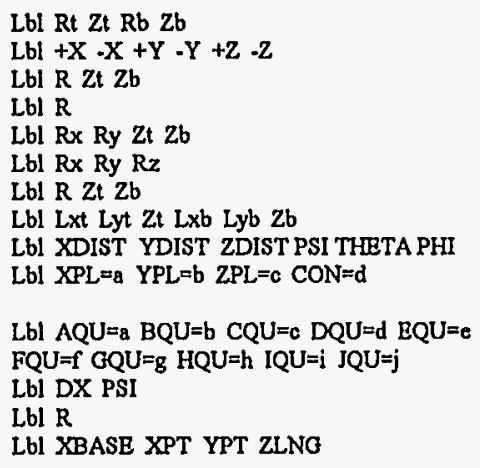 & $\begin{array}{l}\text { Data are entered aner the }=\text { following the respective subordinate } \\
\text { keyword. Only nonzero data are required. } \\
\text { Data are entered after the }=\text { following the respective subordinate } \\
\text { keyword. Only nonzero data are required. }\end{array}$ \\
\hline MODIFICATION* & $\begin{array}{l}\text { CHORD } \\
\text { ORIGIN } \\
\text { ROTATE }\end{array}$ & $\begin{array}{l}+X=-X=+Y=-Y=+Z=-Z= \\
X=Y=Z= \\
A 1=A 2=A 3=\end{array}$ & $\begin{array}{l}\text { Only nonzero data are required. } \\
\text { Only nonzero data are required. } \\
\text { The body is rotated about the Origin using the Euler angle x- } \\
\text { convention. Only nonzero data are required. }\end{array}$ \\
\hline MEDIA** & $\begin{array}{l}\text { MEDIA } \\
\text { HOLE } \\
\text { ARRAY }\end{array}$ & $\begin{array}{l}\text { Mid Bid il i2... } \\
\text { Hid il i2... } \\
\text { Aid il i2... PLACE } n x \text { ny } n z \text { xxyy } z z\end{array}$ & $\begin{array}{l}\text { The region boundary containing the hale must exactly match the } \\
\text { boundary of the unit being placed in the hole. } \\
\text { Place positions the array by placing the origin of the unit in array } \\
\text { position nx ny nz at xx yy } z z \text {. The region boundary containing the } \\
\text { array must be enclosed in or on the aray boundary. }\end{array}$ \\
\hline BOUNDARY & BOUNDARY & i1 i2 ... & Defines the overall volume of the unit. \\
\hline
\end{tabular}

* Modification Data can be entered in any order. Any combination of modification data can follow any geometry record.

* The Region Definition Vector, i1 i2 ..., should contain references to all geometry records which share a boundary with the region being defined. 
Table F17.4.12 Summary of mixing table data

\begin{tabular}{|c|c|c|c|c|}
\hline \multirow[t]{6}{*}{ MIXTURES } & \multicolumn{4}{|c|}{$\begin{array}{l}\text { Format: READ MIXT xsec parameters END MIXT } \\
\text { These data are entered only if an AMPX working-format library is being used, }(\mathrm{LBB} \Rightarrow) \text { in the parameter data, } \\
\text { Sect. F17.4.3. Do not enter if an ICE mixed library is used }(X S C) \text { in the parameter data, Sects. F17.4.10 and } \\
\text { F17.5.5. }\end{array}$} \\
\hline & \multirow[t]{3}{*}{ XSEC PARAMETERS } & \multicolumn{3}{|c|}{$\begin{array}{l}\text { consists of keywords and associated values. } \\
\text { These parameters, if entered, need be entered only once. }\end{array}$} \\
\hline & & KEYWORD & DEFAULT & DEFINITION \\
\hline & & $\mathrm{SCT}=$ & 0.00003 & $\begin{array}{l}\text { No. of discrete scattering angles } \\
0 \text { is isotropic } \\
1 \text { is P1 } \\
2 \text { is P3 } \\
3 \text { is P5 } \\
\text { cross-section message cutoff value } \\
\text { use to suppress message No. K5-60 }\end{array}$ \\
\hline & \multirow{2}{*}{\multicolumn{2}{|c|}{ MIXING TABLE DATA consists of }} & \multicolumn{2}{|c|}{$\begin{array}{l}\text { (1) a keyword and mixture } \mathrm{D} \text { for the mixture } \\
\text { The keyword is } \mathrm{MIX}= \\
\text { The desired mixture number follows the keyword } \\
\text { (2) nuclide } \mathrm{D}^{* *} \\
\text { (3) number density** } \\
\text { **The sequence (2) (3) is repeated for each nuclide in the } \\
\text { mixture. }\end{array}$} \\
\hline & & & \multicolumn{2}{|c|}{$\begin{array}{l}\text { REPEAT the sequence (1) (2)'s (3)'s until all the } \\
\text { mixtures have been described. }\end{array}$} \\
\hline
\end{tabular}


Table F17.4.13 Summary of plot data

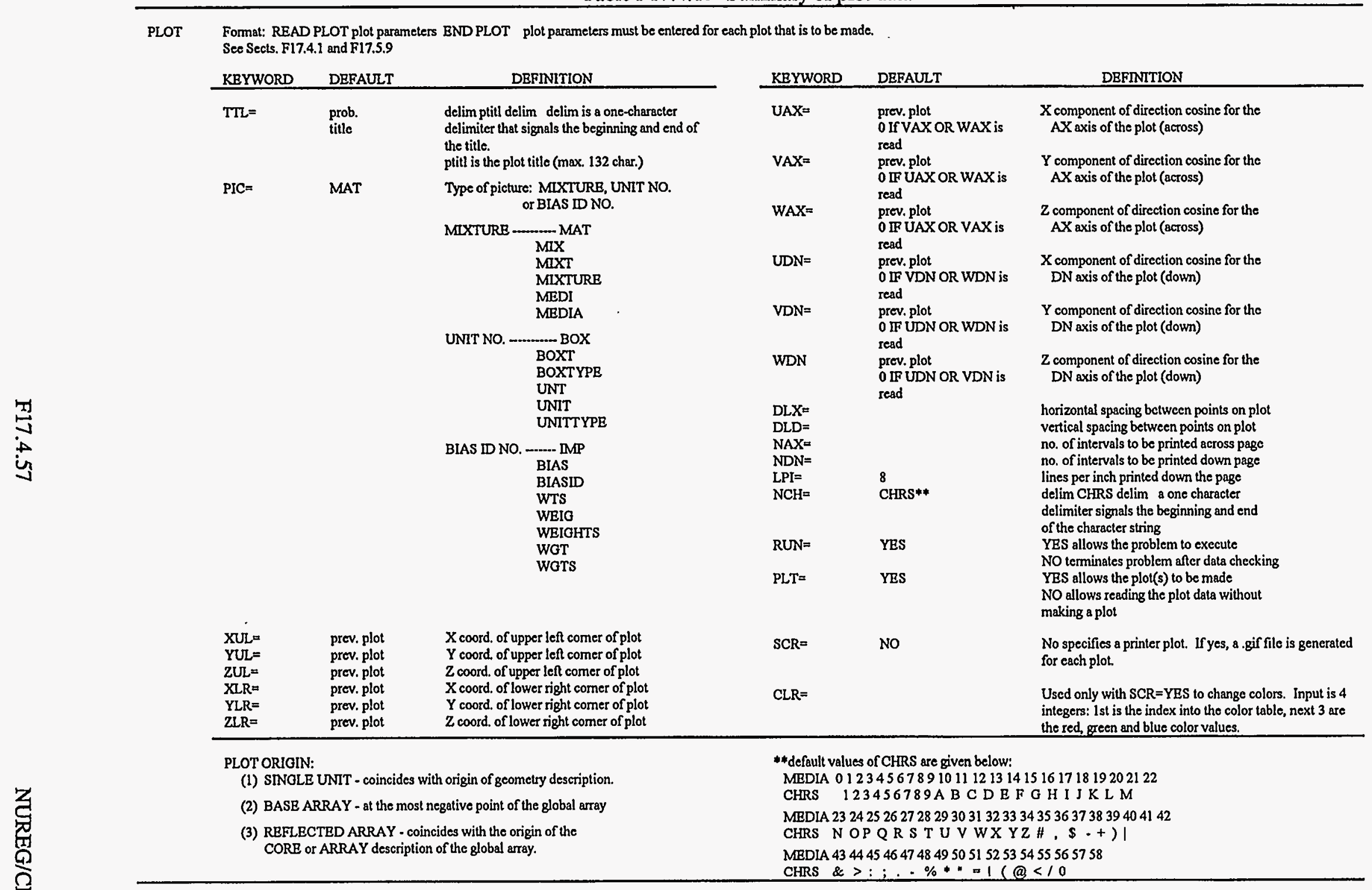


Table F17.4.14 Summary of starting data

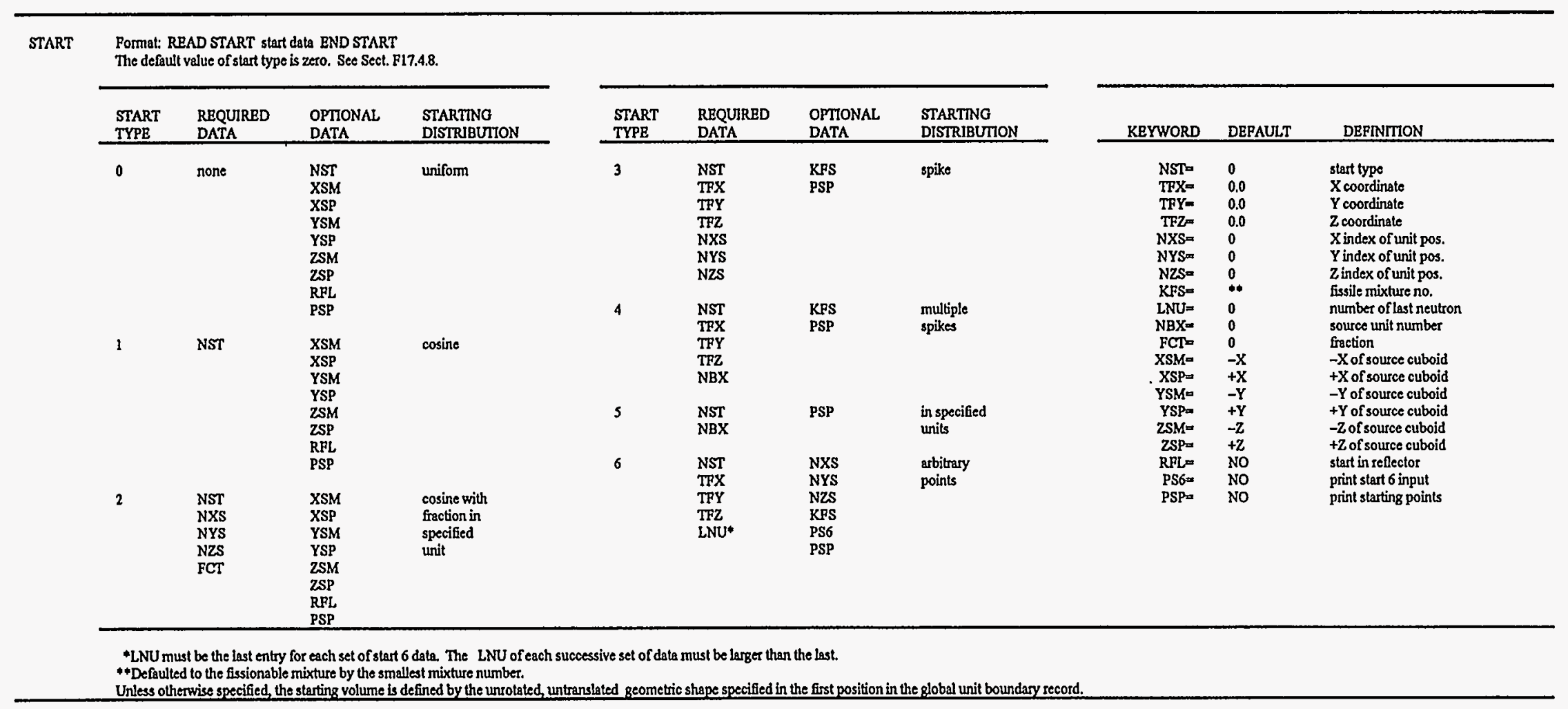




\section{F17.5 NOTES FOR KENO-VI USERS}

This section provides assorted tips primarily designed to assist the KENO-VI user with problem mock-ups. Some information concerning methods utilized by KENO-VI is also included.

\section{F17.5.1 DATA ENTRY}

The KENO-VI data input is entered in blocks that begin and end with keywords as described in Sect. F17.4.1. Only one set of parameter data can be entered for a problem. However, for other data blocks, it is possible to enter more than one block of the same kind of data. When this is done, only the last block of that kind of data is retained for use by the problem.

Within data blocks, a number, $\mathrm{x}$, can be repeated $\mathrm{n}$ times by specifying $\mathrm{nRx}, \mathrm{n}^{*} \mathrm{x}$, or $\mathrm{n} \$ \mathrm{x}$.

\section{F17.5.1.1 Multiple and Scattered Entries in the Mixing Table}

In the following examples, assume 1001 is the nuclide $\mathrm{ID}$ for hydrogen, 8016 is the nuclide $\mathrm{ID}$ for oxygen, 92235 is the nuclide ID for ${ }^{235} \mathrm{U}$, and 92238 is the nuclide $\mathrm{ID}$ for ${ }^{238} \mathrm{U}$. If a given nuclide $\mathrm{ID}$ is used more than once in the same mixture, the result is the summing of all the number densities associated with that nuclide. For example:

$\mathrm{MIX}=192235$ 4.3-2 92238 2.6-3 1001 3.7-2 92235 1.1-3 8016 1.8-2

would be the same as entering

MIX=1 92235 4.41-2 92238 2.6-3 $1001 \quad 3.7-2 \quad 8016 \quad 1.8-2$

A belated entry for a mixture can be made as follows:

$\mathrm{MIX}=11001$ 6.6-2 MIX=2 92235 4.3-2 92238 2.6-3 MLX=1 8016 3.3-2

This is the same as entering

$\mathrm{MTX}=1 \quad 1001$ 6.6-2 8016 3.3-2 MIX=2 92235 4.3-2 92238 2.6-3

\section{F17.5.1.2 Multiple Entries in Geometry Data}

Individual geometry regions cannot be replaced by adding an additional description. However, entire unit descriptions can be replaced by adding a new description having the same unit number. The last description entered for a unit is used in the calculation. For example:

READ GEOM UNIT 1 SPHERE 10 5.0 CUBOID 20 10.0-10.0 10.0-10.0 10.0-10.0

MEDIA 1110 MEDLA $0120-10$ BOUNDARY 20

UNIT 2 CYLINDER $102.05 .0-5.0$ CUBOID 20 10.0-10.0 10.0-10.0 10.0-10.0 
MEDLA 1110 MEDIA $0120-10$ BOUNDARY 20

UNIT 1 CUBOID 10 1.0-1.5 2.5-2.0 5.0-6.0 CUBOID 20 10.0-10.0 10.0-10.0 10.0-10.0

MEDIA 1110 MEDIA 01 -10 20 BOUNDARY 20

END GEOM

is the same as entering

READ GEOM UNIT 1 CUBOID 10 1.0 -1.5 2.5 -2.0 5.0-6.0

CUBOID $2010.0-10.010 .0-10.010 .0-10.0$

MEDIA 1110 BOUNDARYMEDLA $01-1020$

UNIT 2 CYLINDER 102.0 5.0-5.0 CUBOID 20 10.0-10.0 10.0-10 10.0-10.0

MEDIA 1110 MEDLA $01-1020$ BOUNDARY 20 END GEOM

or

READ GEOM UNIT 2 CYLINDER 30 2.0 5.0 -5.0 CUBOID $406 P 10.0$

MEDLA 1130 MEDLA $01-3040$ BOUNDARY 40

UNIT I CUBOID 20 1.0 -1.5 2.5-2.0 5.0-6.0 CUBOID $106 P 10.0$

MEDIA 1120 MEDIA $0110-20$ BOUNDARY 10

END GEOM

The order of entry for unit descriptions is not important because the unit number is assigned as the value following the word UNIT. They need not be entered sequentially nor be numbered sequentially. It is perfectly acceptable to input Units 2,3, and 5, omitting Units 1 and 4 as long as Units 1 and 4 are not referenced in the problem. It is also acceptable to scramble the order of entry as in entering Units 3,2 , and 5.

\section{F17.5.2 DEFAULT LOGICAL UNIT NUMBERS FOR KENO-VI}

The logical unit numbers for data utilized by KENO-VI are listed in Table F17.5.1.

\section{F17.5.3 PARAMETER INPUT}

When the parameter data block is input for a problem, the same keyword may be entered several times. The last value that is entered is used in the problem. Data may be entered as follows:

READ PARAM FLX=YES NGP=1000 TME=0.5 TME=1.0

$N P G=50 T M E=10.0 \mathrm{FLX}=N O$

$N P G=500$

END PARA

This input will result in the problem having $F L X=N O, T M E=10.0$, and $N P G=500$. It may be more convenient for the user to insert a new value than to change the existing data.

NUREG/CR-0200,

Vol. 2, Rev. 5

F17.5.2 
Table F17.5.1. KENO-VI logical unit numbers

\begin{tabular}{|c|c|c|c|}
\hline Function & $\begin{array}{c}\text { Parameter } \\
\text { name }\end{array}$ & $\begin{array}{l}\text { Unit } \\
\text { No. }\end{array}$ & $\begin{array}{c}\text { Variable } \\
\text { name }\end{array}$ \\
\hline Problem input data (EBCDIC or ASCII) & & 5 & INPT \\
\hline Problem input data (binary) & & 95 & $\mathrm{BIN}$ \\
\hline Program output & & 6 & OUTPT \\
\hline Albedo data & $\mathrm{ALB}=$ & 79 & ALBDO \\
\hline Scratch unit & $\mathrm{SKT}=$ & 16 & SKRT \\
\hline Read restart data & $\mathrm{RST}=$ & $\begin{array}{r}0^{a} \\
34^{b}\end{array}$ & $\begin{array}{l}\text { RSTRT } \\
\text { RSTRT }\end{array}$ \\
\hline Write restart data & WRS $=$ & $\begin{array}{r}0^{\circ} \\
35^{\circ}\end{array}$ & $\begin{array}{l}\text { WSTRT } \\
\text { WSTRT }\end{array}$ \\
\hline Direct access storage for input data & & 8 & DIRECT(1) \\
\hline Direct access storage for supergrouped data & & 9 & DIRECT(2) \\
\hline Direct access storage for cross-section mixing & & 10 & DIRECT(3) \\
\hline Mixed cross-section data set & $\mathrm{XSC}=$ & $14^{d}$ & ICEXS \\
\hline Group-dependent weights & WTS $=$ & 80 & WTS \\
\hline AMPX working format cross sections & $\mathrm{LIB}=$ & $0^{a}$ & AMPXS \\
\hline
\end{tabular}

Certain parameter default values should not be overridden unless the user has a very good reason to do so. These parameters are as follows:

1. $\mathrm{X} 1 \mathrm{D}=$ defines the number of extra $1-\mathrm{D}$ cross sections. The use of extra $1-\mathrm{D}$ cross sections - other than the use of the fission cross section for calculating the average number of neutrons per fission-requires programming changes to the code;

2. $\mathbf{N F B}=$ defines the number of neutrons that can be entered in the fission bank;

3. $\mathrm{XFB}=$ defines the number of extra positions in the fission bank (the fission bank is where the information related to a fission is stored);

4. NBK= defines the number of neutrons that can be entered in the neutron bank;

5. $\mathrm{XNB}=$ defines the number of extra positions in the neutron bank (the neutron bank contains information about each history);

6. WTH= defines the factor that determines when splitting occurs;

7. WTA= defines the default average weight given to a neutron that survives Russian roulette; 
8. WTL $=$ defines the factor that determines when Russian roulette is played; and

9. $\mathbf{L N G}=$ sets the maximum words of storage available to the program.

It is recommended that BUG=, the flag for printing debug information, never be set to YES. The user would have to look at the FORTRAN coding to determine what information is printed. BUG=YES prints massive amounts of sparsely labeled information. The user should only rarely consider using TRK=YES. This keyword generates thousands of lines of well-labeled print that provides information about each history at key locations during the tracking procedure. All other parameters can be changed at will to provide features the user wishes to activate.

\section{F17.5.4 CROSS SECTIONS}

KENO-VI always uses cross sections from a mixed cross-section data file. The format of this file is the Monte Carlo processed cross-section file from ICE ${ }^{1}$ (Sect. F8). A mixed cross-section file can be created by (1) executing ICE or (2) using an AMPX working-format library and entering mixing table data in KENO-VI.

\section{F17.5.4.1 Use An ICE Mixed Cross-Section MORSE/KENO-V.a Format Library}

An ICE mixed cross-section MORSE/KENO-Va format library (premixed cross-section data file) from ICE or a previous KENO-VI case may be used. This file should be specified in the job control language on the unit number associated with the parameter $\mathrm{XSC}=$. If a mixing table data block is entered, the premixed cross-section data file will be rewritten. Therefore, a mixing table should not be entered if a premixed cross-section data file is used. The user should verify that the mixtures created by ICE or the previous KENO-VI case are consistent with those used in the geometry data of the problem.

\section{F17.5.4.2 Use an AMPX Working-Format Library}

When an AMPX working-format library is used, a file definition must be specified in the job control language to specify the AMPX working-format library on the unit associated with the parameter $L I B=$. If the mixed cross-section data file is to be saved, a file definition must be specified in the job control language to specify the mixed cross-section file on the unit associated with the parameter $\mathrm{XSC}=$.

Mixing table data must always be entered when an AMPX working format library is used. IDs used in the mixing table must match the IDs on the AMPX working-format library.

\section{F17.5.4.3 Number of Scattering Angles}

The number of scattering angles is defaulted to 1 . This default is not adequate for many applications. The user should specify the scattering angle to be consistent with the cross sections being used. The number of scattering angles is entered in the cross-section mixing table by using the keyword SCT=. See Sect. F17.4.10.

The order of the last Legendre coefficient to be preserved in the scattering distribution is equal to $(2 \times \mathrm{SCT}$ $-1)$. SCT $=1$ could be used with a $P_{1}$ cross-section set such as the 16-group Hansen Roach cross-section library, and $\mathrm{SCT}=2$ for $\mathrm{P}_{3}$ cross-section set such as the SCALE 27-group cross-section library. Isotropic scattering is achieved by entering $\mathrm{SCT}=0$.

NUREG/CR-0200,

Vol. 2, Rev. 5

F17.5.4 


\section{F17.5.4.4 Cross-Section Message Cutoff}

The.cross-section message cutoff value, pbxs, is defaulted to $3 \times 10^{-5}$. Warning messages that are generated when errors are encountered in the $P_{L}$ expansion of the group-to-group transfers will be suppressed if the $P_{0}$ cross section for that particular energy transfer is less than $p b x s$. The value of $p b x s$ is specified in the cross-section mixing table by using the keyword EPS=. See Sect. F17.4.10.

The default value of $p b x s$ is sufficient to ensure that warning messages will not be printed for most of the SCALE $\mathrm{P}_{1}$ and $\mathrm{P}_{3}$ cross-section libraries. However, the 238GROUPNDF5 library requires a value of $p b x s$ as large as $1 \times 10^{-1}$ if $\mathrm{P}_{3}$ cross sections are specified.

If the default value of pbxs allows too many warning messages to be printed, a value can be determined from the printed messages by choosing a number larger than the $\mathrm{P}_{0}$ component on the first line, as shown below.

\section{THE LEGENDRE EXPANSION OF THE CROSS SECTION (P0-PN) IS}

$\left(\begin{array}{lllll}\left(\mathrm{P}_{0}\right) & \left(\mathrm{P}_{1}\right) & \left(\mathrm{P}_{2}\right) & \ldots & \left(\mathrm{P}_{\mathrm{n}}\right)\end{array}\right.$

THE MOMENTS COR $\overline{R E S P O N D I N G ~ T O ~ T H I S ~ D I S T R I B U T I O N ~ A R E ~}$

$\left(\begin{array}{lllll}\left(M_{1}\right) & \left(M_{2}\right) & \ldots & \left(M_{1}\right)\end{array}\right.$

THE MOMENTS CORRESPONDING TO THE GENERATED DISTRIBUTION ARE

$\left(\begin{array}{llll}\left(M_{1}\right) & \left(M_{2}\right) & \ldots & \left(M_{1}\right)\end{array}\right.$

THE LEGENDRE EXPANSION CORRESPONDING TO THESE MOMENTS IS

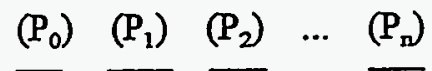

\section{MOMENTS WERE ACCEPTED}

For the following messages, EPS=6.9-5 would cause all three messages to be suppressed. A value less than 5.615159-5 and greater than 4.767635-5 would suppress the second message, and a value less than 6.855362-5 and greater than 5.615159-5 would suppress the first two messages.

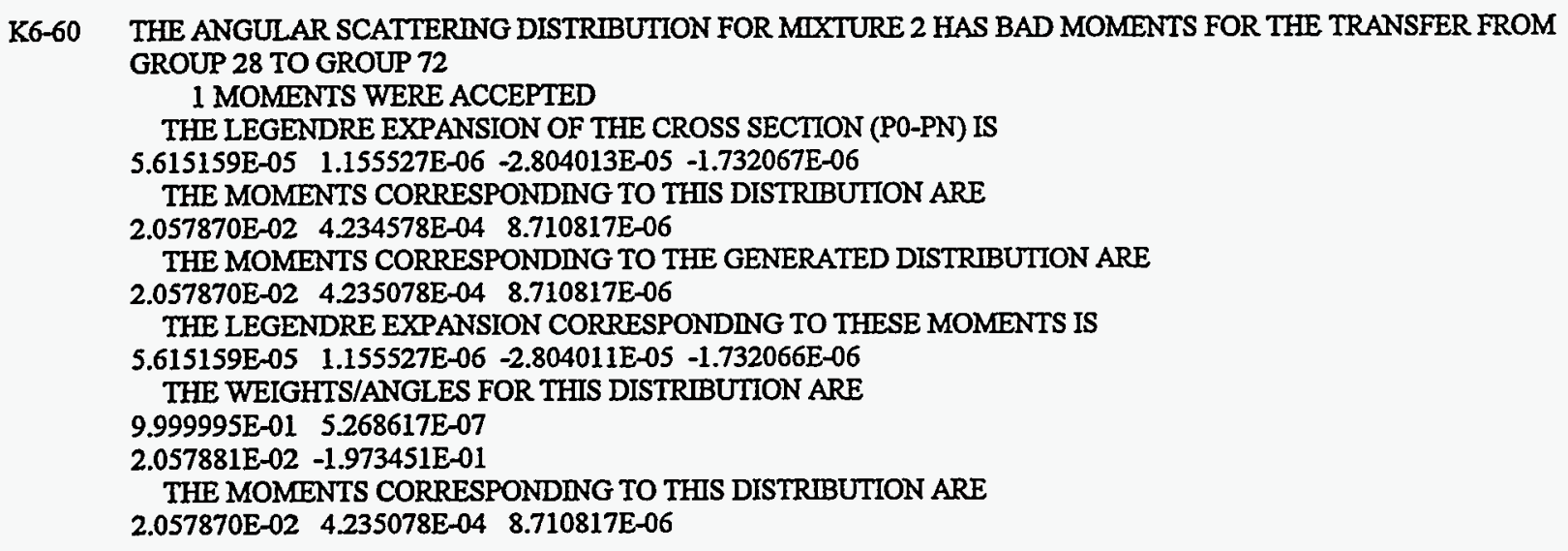

K6-60 THE ANGULAR SCATTERING DISTRIBUTION FOR MIXTURE 2 HAS BAD MOMENTS FOR THE TRANSFER FROM GROUP 31 TO GROUP 75

1 MOMENTS WERE ACCEPTED

THE LEGENDRE EXPANSION OF THE CROSS SECTION (P0-PN) IS

4.767635E-0S 7.834378E-07 -2.381887E-05 -1.174626E-06

THE MOMENTS CORRESPONDING TO THIS DISTRIBUTION ARE 


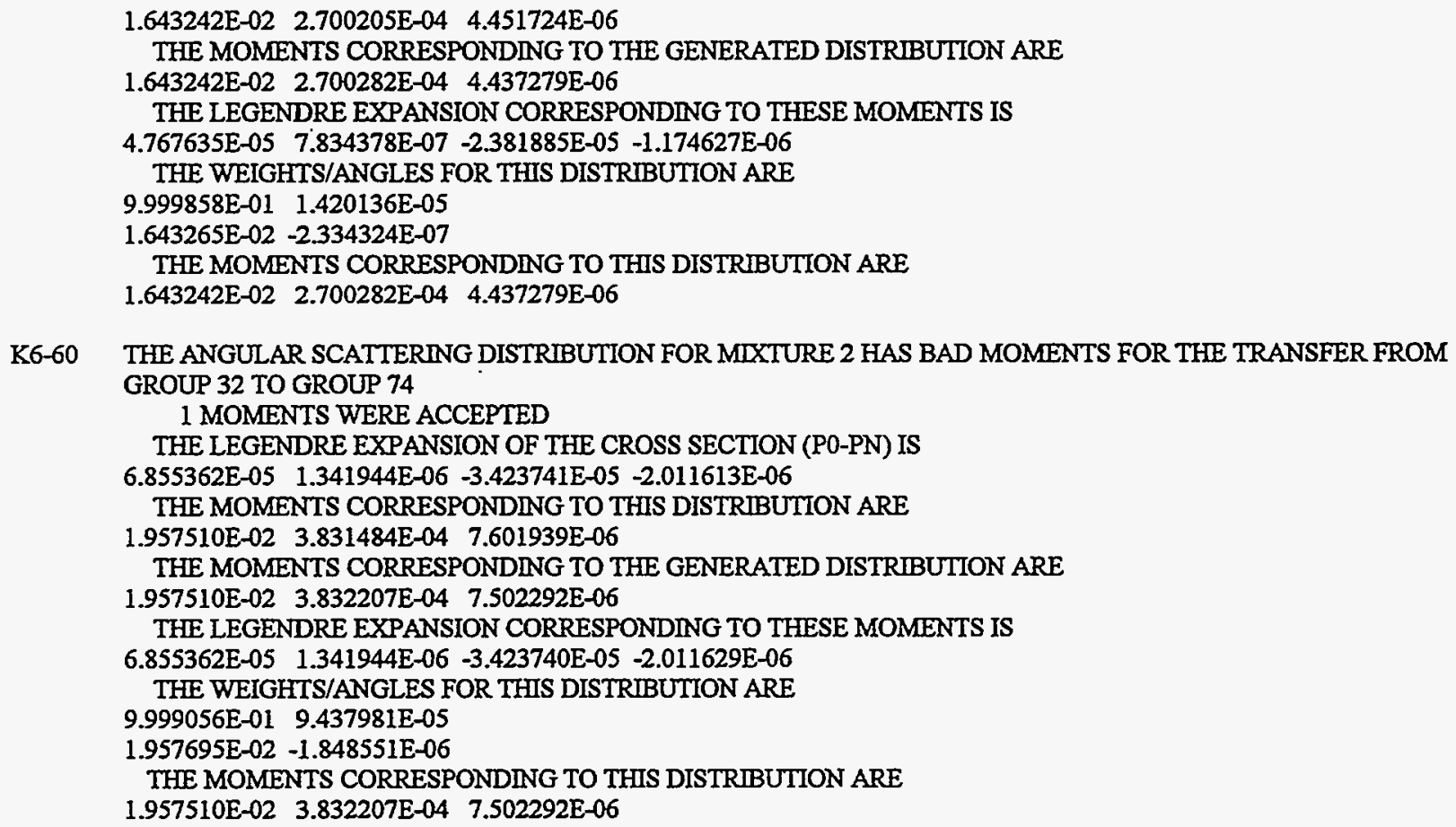

The user need not attempt to suppress all the K6-60 messages. They are printed to inform the user of the fact that the moments of the angular distribution are not moments of a valid probability distribution. The third through sixth lines of the message list the original $P_{n}$ coefficients and their moments. The seventh through tenth lines list the new corrected moments and their corresponding $\mathrm{P}_{\mathrm{n}}$ coefficients.

The weights and angles that are printed in lines 11 through 13 were generated from the corrected moments. The last two lines of the message list the moments generated from those weights and angles. They should match line 8, the moments corresponding to the generated distribution.

For most criticality problems, the first moment contributions are much more significant than the contributions of the higher-order moments; thus the higher-order moments may not affect the results significantly. The user can look at the original moments and corrected moments and make a judgment as to the significance of the change in the moments.

\section{F17.5.5 MIXING TABLE}

Mixtures can be utilized in defining other mixtures. When defining mixture numbers, care should be taken to avoid using a mixture number that is identical to a nuclide ID number if the mixture is to be used in defining another mixture. If a mixture number is defined more than once, it results in a summing effect.

The nuclide mixing loop is done before the mixture mixing loop, which performs mixing in the order of data entry. Thus the order of mixing mixtures into other mixtures is important because a mixture must be defined before it can be used in another mixture. Some examples of correct and incorrect mixing are shown below, using 1001 as the nuclide ID for hydrogen, 8016 as the nuclide ID for oxygen, 92235 as the nuclide ID for ${ }^{235} \mathrm{U}$, and 92238 as the nuclide $\mathrm{ID}$ for ${ }^{238} \mathrm{U}$. 


\section{EXAMPLES OF CORRECT USAGE}

\section{READ MIXT MIX=1 $10016.6-2$ 8016 3.3-2 MIX=2 10.5 END MIXT}

This option results in mixture 1 being full-density water and mixture 2 being half-density water.

\section{READ MIXT MIX=1 20.5 MIX=3 1 0.5 MIX=2 1001 6.6-2 8016 3.3-2 END MIXT}

This option results in mixture 1 being half-density water, mixture 2 being full-density water, and mixture 3 being quarter-density water. Because the nuclide mixing loop is done first, mixture 2 is created first and is available to create mixture 1 , which is then available to create mixture 3 .

3. READ MIXT MIX=1 1001 6.6-2 8016 3.3-2 MIX=2 92235 7.5-4 92238 2.3-2 8016 4.6-2 1.01 END MIXT

This option results in mixture 1 being full-density water and mixture 2 being uranium oxide containing 0.01 density water.

\section{READ MIXT MIX=1 1001 6.6-2 8016 3.3-2 MIX=2 92235 4.4-2 92238 2.6-3 MIX=1 10.5 END MIXI}

This option results in mixture 1 being water at 1.5 density (1001 9.9-2 and 8016 4.95-2) and mixture 2 is highly enriched uranium metal.

\section{EXAMPLES OF INCORRECT USAGE}

\section{READ MIXT MIX=3 1 0.75 MIX=1 2 0.5 MIX=2 1001 6.6-2 8016 3.3-2 END MIXT}

Here the intent is for mixture 2 to be full-density water, mixture 1 to be half-density water, and mixture 3 to be $3 / 8(0.75 \times 0.5)$ density water. Instead, the result for mixture 3 is a void, mixture 1 is half-density water, and mixture 2 is full-density water. This situation occurs because the nuclide mixing loop is done first, thus defining mixture 2, and the mixture mixing loop is done next. Mixture 3 is defined to be mixture 1 multiplied by 0.75 , but since mixture 1 has not.been defined, 0.75 of zero is zero. Mixture 1 is then defined to be mixture 2 multiplied by 0.5 . If the definition of mixture 1 preceded the definition of mixture 3 , as in (2) under examples of correct usage, it would work correctly.

\section{READ MIXT MIX=1 1001 6.6-2 8016 3.3-2 MIX=1001 92235 4.4-2 92238 2.6-3 MIX=2 10010.5 END MIXT}

This option results in mixture 1 being full-density water, mixture 1001 being uranium metal, and mixture 2 being hydrogen with a number density of 0.5 because 1001 is the nuclide $\mathrm{ID}$ number for hydrogen. When a mixture number is identical to a nuclide ID and is used in mixing, that number is assumed to be a nuclide ID rather than a mixture number. The intent was for mixture 1 to be full-density water, mixture 1001 to be uranium metal, and mixture 2 to be half-density uranium metal. 


\section{F17.5.6 GEOMETRY}

In general, KENO-VI geometry descriptions consist of (1) geometry data (Sect. F17.4.4) that define the geometrical shapes present in the problem, and (2) array data (Sect. F17.4.5) that define the placement of the units that were defined in the geometry data. The geometry data block is prefaced by READ GEOM, and the array data block is prefaced by READ ARRAY.

When a 3-D geometrical configuration is described as KENO-VI geometry data, it may be necessary to describe portions of the configuration individually. These individual partial descriptions of the configuration are called units. KENO-VI geometry modeling is subject to the following restrictions:

1. Units are composed of regions. These regions are created using geometric bodies and surfaces that are previously defined or created using quadratic equations. The geometric bodies and surfaces may intersect. Regions are defined relative to the geometric bodies and surfaces in a unit. Holes provide a means of creating complex geometries in a unit and then inserting the unit into existing units. For complex geometries the use of holes may decrease the CPU time required for the problem.

2. All geometrical surfaces must be describable as a set of quadratic equations.

3. When one or more units are utilized to describe an array, each unit used in the array must have a cuboid or hexagonal prism as its outer region.

4. When several units are utilized to describe an array, the adjacent faces of units in contact with each other must be the same size and shape.

5. Units are placed directly into regions using HOLES. Only one hole is allowed in a region. As many holes as will snugly fit without intersecting can be placed in a unit. The outer boundary of the unit in the hole must match exactly the region boundary. Holes are described in more detail in Sect. F17.5.6.1, and nested holes are described in Sect. F17.5.6.2.

6. Complicated systems may require multiple arrays to describe the system. Arrays may be placed in units. These units may be used to create other arrays that may be placed in other units either directly or by using holes. Multiple arrays are described in more detail in Sect. F17.5.6.3.

The geometry package allows any shape describable using quadratic equations to be enclosed or intersected by any other allowable shape. Geometry records are used to describe the geometric shapes contained in a unit. Regions are defined by specifying how they relate to the geometric shapes in the unit. An implication of this type of description is that an entire region volume, specified relative to the geometric shapes, contains only one mixture, hole, or array. Media records are used to specify the contents of each region. Material, hole, and array contents are specified using the keywords: Media, Hole, and Array, respectively, in the media records. A void is specified using the keyword Media with a mixture ID of zero.

If the problem contains arrays, each unit that is used in an array must have as its outer surface a rectangular parallelepiped or a hexagonal prism; therefore it may be necessary to define a void region that is used to achieve the required outer boundary. In order to describe the composite overall geometrical characteristics of the problem, these units may be arranged in either a rectangular or hexagonal array by specifying the number of units in the $x, y$, and $z$ directions. Data must be entered to define the number assigned to the array and the placement of the individual units in the array. The array type is specified using the keyword TYP=, followed by 
either square or triangular. If TYP is not entered, a cuboidal array is assumed. The array number, the number of units in the $\mathrm{x}, \mathrm{y}$, and $\mathrm{z}$ directions, the array type, and the placement data are called array data (Sect. 17.4.5).

An array may be placed in a region of any shape provided the region boundary is contained within the array or shares the array boundary. Only the section of the array contained within the region is recognized by the problem. A particle crosses into and out of the array when it crosses the region boundary. Arrays are positioned relative to the unit origin by placing the origin of a specified unit in the array at a specified location in the unit. The region boundary containing the array is defined using a vector definition array. A global array is not assumed. If a global array is required, such as for collecting matrix information, one must be specified.

To create a geometry mock-up from a physical configuration, the user should exercise a degree of ingenuity and keep in mind the restrictions mentioned earlier. It is important to realize there may be several ways of correctly describing the same physical configuration. Careful analysis of the system can pay off in terms of a simpler mock-up and shorter computer running time. A mock-up with fewer geometry regions may run faster than the same mock-up with extraneous regions. The number of units used can affect the running time, because a transformation of coordinates must be made every time a history moves from one unit into another. Thus if the size of a unit is small, relative to the neutron mean free path, a larger percentage of time is spent processing the transformation of coordinates. Because all boundaries in a unit must be checked for crossings, it may be more efficient to break up complex units into several smaller, simpler units. The trade-off involves the time required to process more boundary crossings vs the time required to transform coordinate systems when unit boundaries are crossed.

Geometry dimensions: The geometry dimensions utilized in KENO-VI require an entry for each required dimension. For example, a $20 \times 20 \times 2.5-\mathrm{cm}$ rectangular parallelepiped would have been described as: CUBOID $1 \quad 10.0-10.0 \quad 10.0-10.01 .25-1.25$. By using the P option (see Table F17.4.2), the same rectangular parallelepiped could be described as: CUBOID 14P10.0 2P1.25 where the first entry is the geometry word label and the remaining entries describe the geometry. The $P$ option simply repeats the dimension following the $P$, the number of times stated before the $P$ and reverses the sign every other time.

$6 \mathrm{P} 8.0$ is equivalent to $8.0-8.08 .0-8.08 .0-8.0$.

Geometry comments: A comment can be entered for each unit in the geometry region data. Similarly, a comment can be entered for each array in the array definition data. A comment can be entered using the keyword COM=. This keyword is followed by a comment whose maximum length is 132 characters. The comment must be preceded and terminated by a delimiter character, which is the first nonblank character encountered after the $\mathrm{COM}=$. One comment is allowed for each unit in the geometry region data. If multiple comments are entered for a unit the last one is used. The comment can be entered anywhere after the UNIT NUMBER DESCRIPTION where a keyword is expected (Sect. F17.4.4). See the following example.

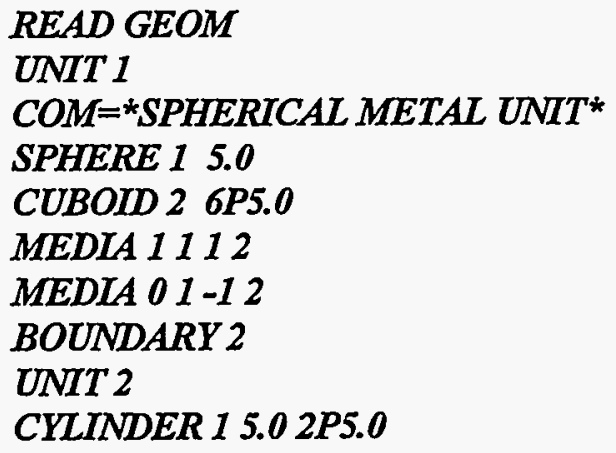




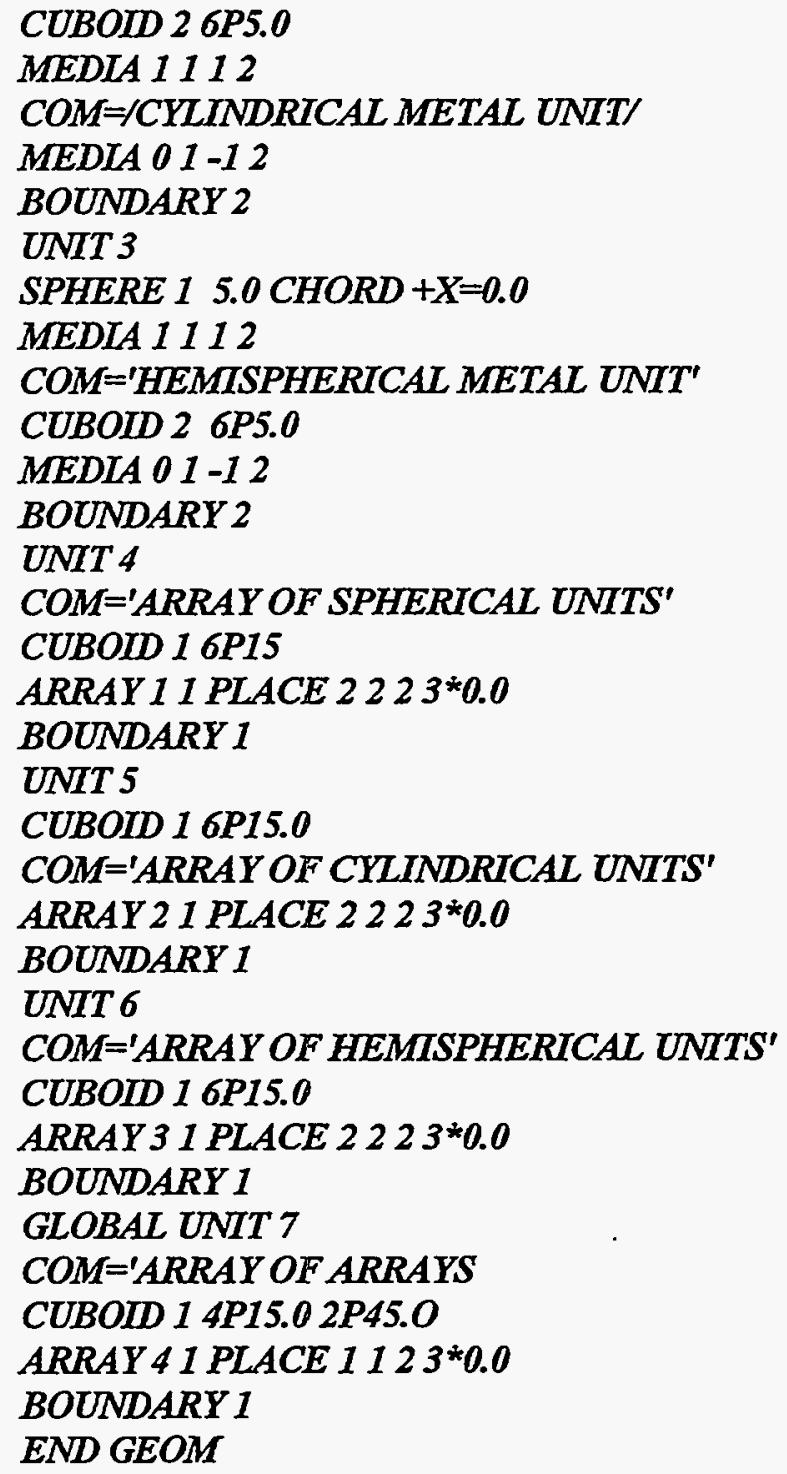

One comment is allowed for each array in the ARRAY DEFINITION DATA. The rules governing these comments are the same as those listed above. However, the comment for an array must precede the UNIT ORIENTATION DESCRIPTION. It can precede the array number (Sect. F17.4.5). Examples of correct array comments are given below.

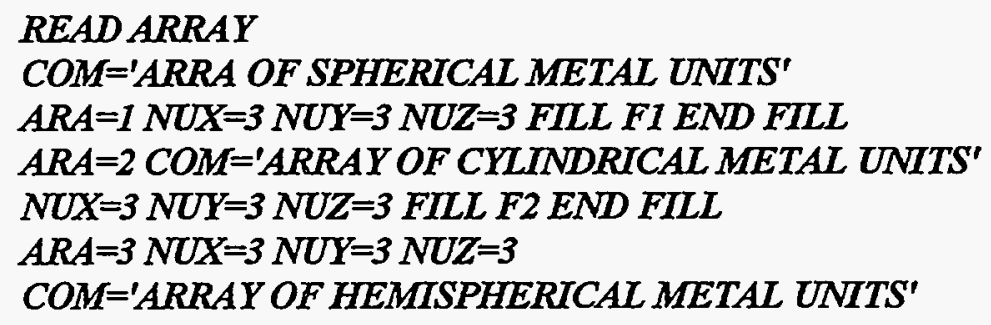

NUREG/CR-0200, 
FILL F3 END FILL

$A R A=4$ COM='COMPOSITE ARRA OF ARRAYS. $Z=1$ IS SPHERES, $Z=2$ IS CYLINDERS, $Z=3$ IS HEMISPHERES'

$N U X=1$ NUY=1 NUZ=3 FILL 456 END FILL

Some of the basics of KENO-VI geometry are illustrated in the following examples:

EXAMPLE 1. Assume a stack of six cylindrical disks, each $5 \mathrm{~cm}$ in radius and $2 \mathrm{~cm}$ thick. The bottom disk is composed of material 1 , and the next disk is composed of material 2, etc., alternately throughout the stack. A square plate of material $3,20 \mathrm{~cm}$ on a side and $2.5 \mathrm{~cm}$ thick, is centered on top of the stack. This configuration is shown in Fig. F17.5.1.

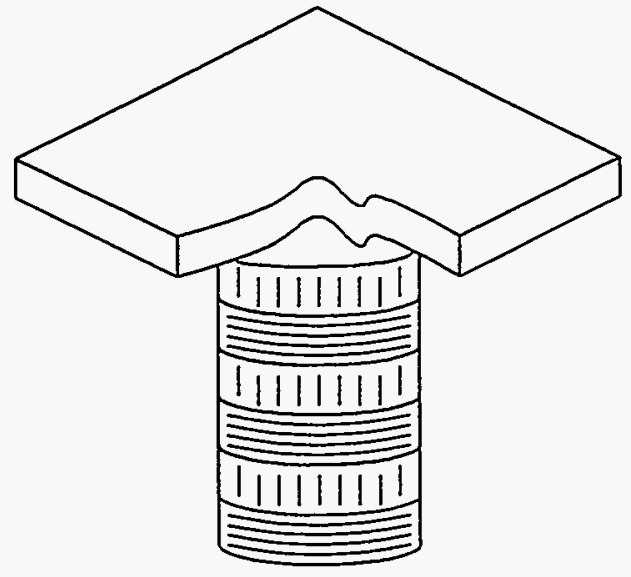

Figure F17.5.1 Stack of disks with a square cap

This problem can be described in a number of ways: as a set of stacked cylinders with a top plate, a set of nested cylinders with a top plate, and an array of cylinders with a top plate, to name just a few. Several alternative acceptable methods that could be used to describe this problem are given below.

This problem can be described using one unit. In this instance, the origin has been chosen at the center bottom of the bottom disk. The bottom disk is defined by the first cylinder description; the next disk is defined by the difference between the first and second cylinder descriptions. Since they both have a radius of 5.0 and a $-z$ length of 0.0 , the first cylinder containing material 1 exists from $z=0.0$ to $z=2.0$, and the second cylinder, containing material 2, exists from $z=2.0$ to $z=4.0$. When all the disks have been described, a void cuboid having the same $\mathrm{x}$ and $\mathrm{y}$ dimensions as the square plate and the same $\mathrm{z}$ dimensions as the stack of disks is defined. The square plate of material 3 is then defined on top of the stack. This method could be used in KENO-V.a to describe this problem. The geometry input is shown below. 
Data description 1, Example 1.

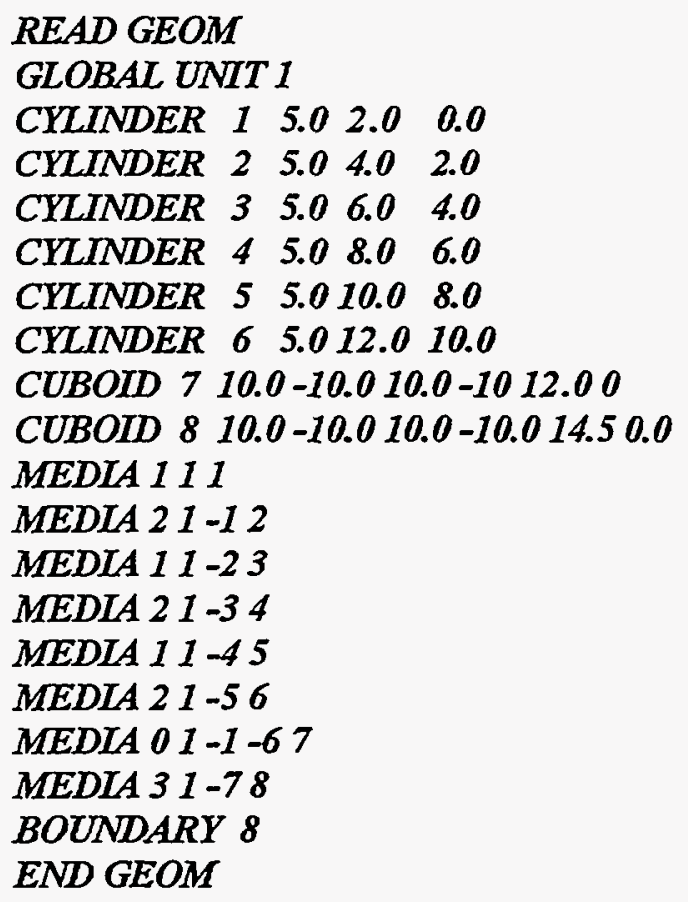

An alternative description of the same example is given below. The origin has been chosen at the center of the disk of material 1, nearest the center of the stack. This disk of material 1 is defined by the first cylinder description, and the disks of material 2 on either side of it are defined by the second cylinder description. The top and bottom disks of material 1 are defined by the third cylinder, and the top disk of material 2 is defined by the last cylinder. The square plate is defined by the two cuboids. This method could also be used in KENO-V.a to describe the problem.

Data description 2, Example 1.

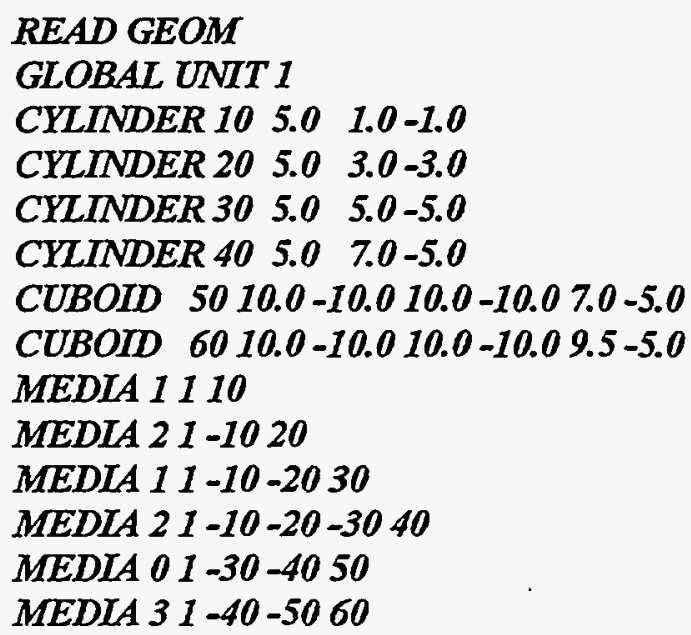

NUREG/CR-0200,

Vol. 2, Rev. 5 
BOUNDARY 60

END GEOM

Example 1 can also be described as an array. Define three different unit types. Unit 1 will define a disk of material 1, Unit 2 will define a disk of material 2, and Unit 3 will define the square plate of material 3. The origin of each unit is defined at the center bottom of the disk or plate being described. The geometry input for this arrangement is shown below.

Data description 3, Example 1.

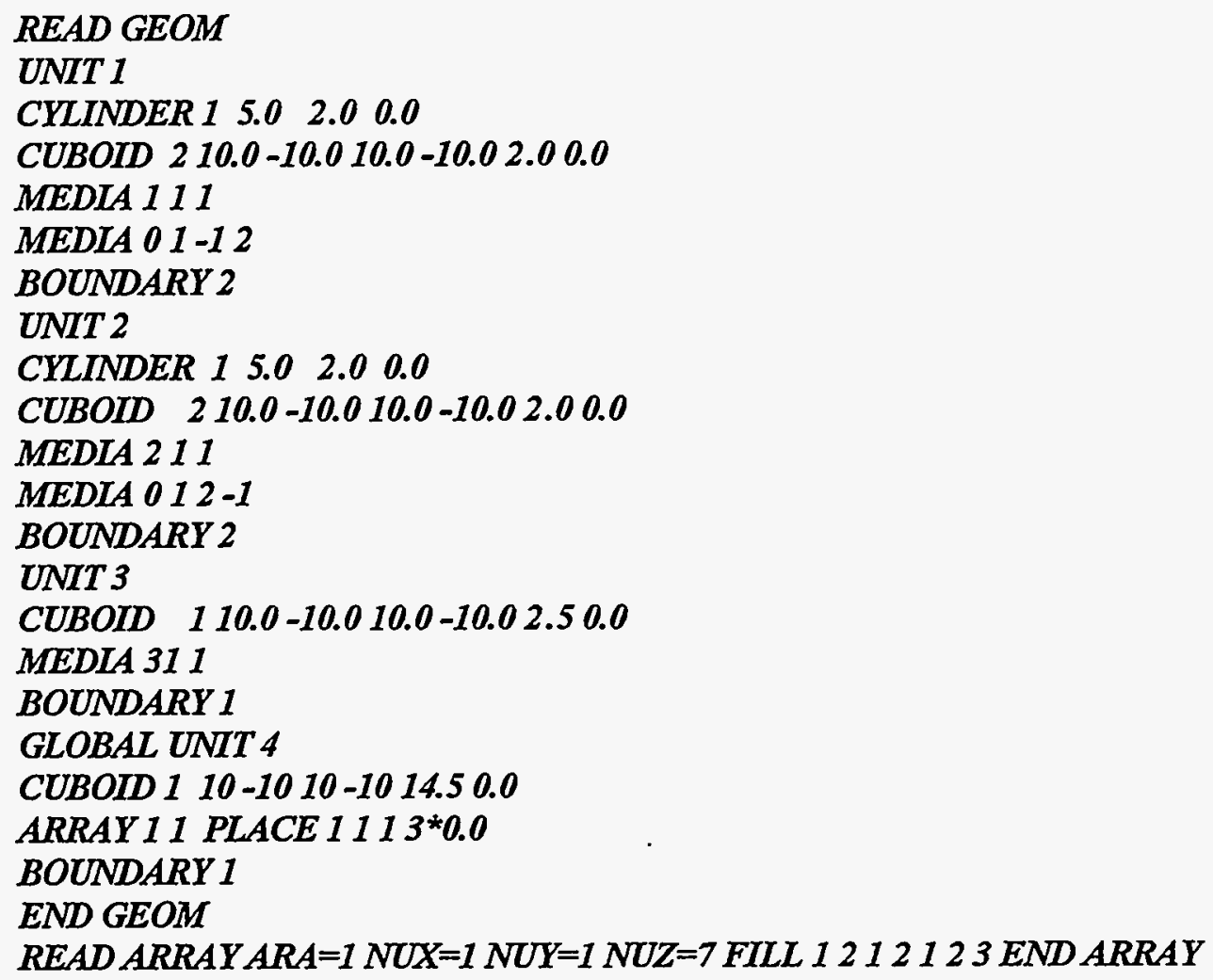

If the user wishes the origin of each unit to be at its center, the geometry region data can be input as shown below. The array data would be identical to that of data description 3, Example 1.

Data description 4, Example 1.

\section{READ GEOM}

UNIT 1

CILINDER $15.01 .0-1.0$

CUBOID $2 \quad 10.0-10.010 .0-10.01 .0-1.0$

MEDIA 111

MEDIA $01-12$

BOUNDARY 2

UNIT 2 
CYLINDER $1 \quad 5.0 \quad 1.0-1.0$

CUBOTD 2 10.0-10.0 10.0-10.0 1.0-1.0

MEDIA 211

MEDIA $01-12$

BOUNDARY 2

UNIT 3

CUBOID 1 10.0 -10.0 10.0 -10.0 1.25 -1.25

MEDLA 311

BOUNDARY 1

GLOBAL UNIT 4

CUBOID $110-1010-1014.50 .0$

ARRAY 11 PLACE 1110.00 .01 .0

BOUNDARY 1

END GEOM

$R E A D$ ARRAY $A R A=1 N U X=1 N U Y=1 N U Z=7$ FILL 1212123 END ARRAY

Be aware that each unit in a geometry description can have its origin defined independent of the other units. It would be correct to use Units 1 and 3 from data descriptions 3, and Unit 2 from data description 4. The array data would remain the same as data description 3, Example 1. The user should define the origin of each unit to be as convenient as possible for the chosen description. Care should be taken when assigning coordinates to the unit used to place the array in its surrounding region.

Another method of describing Example 1 as a bare array is to define Unit 1 to be a disk of material 1 , topped by a disk of material 2. The origin has been chosen at the center bottom of the disk of material 1 . Unit 2 is the square plate of material 3 with the origin at the center of the unit. The array consists of three Unit l's, topped by a Unit 2, as shown below.

Data description 5, Example 1.

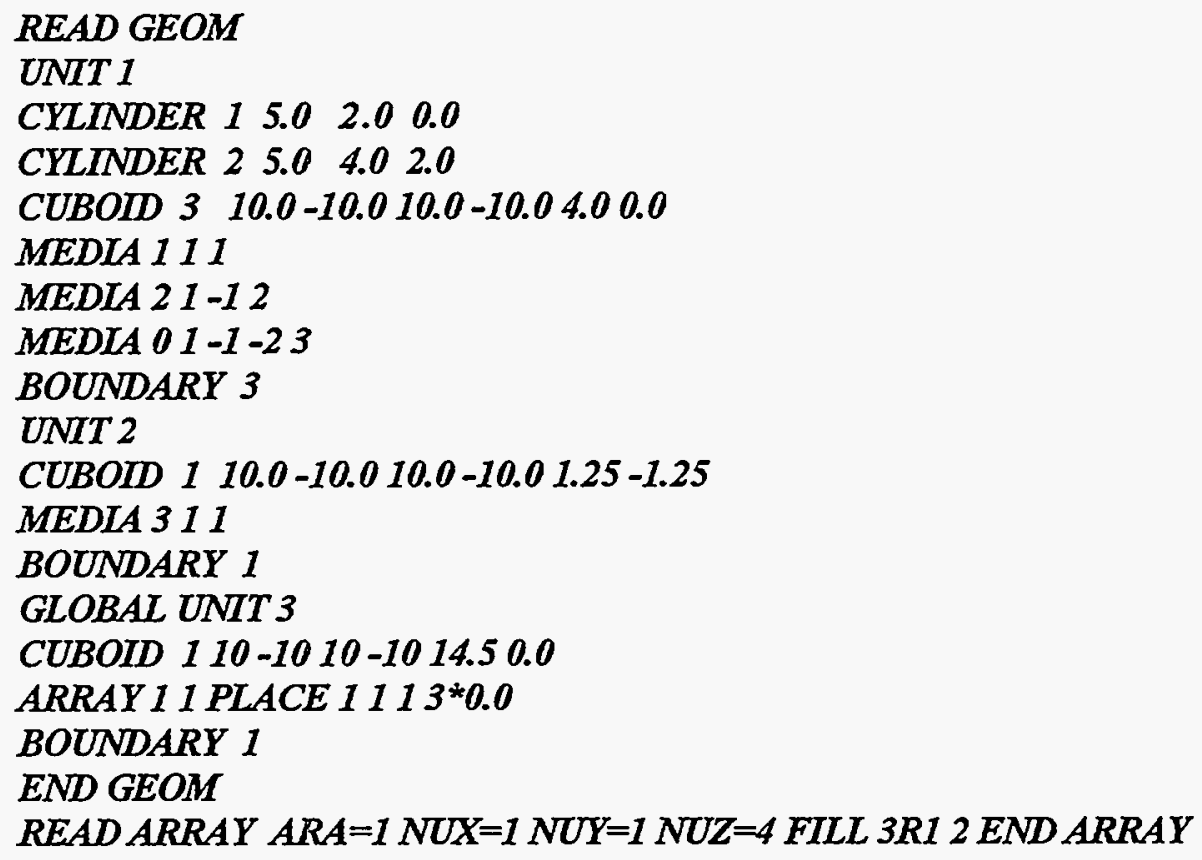

NUREG/CR-0200, Vol. 2, Rev. 5 
Example 1 can be described as a reflected array by treating the square plate as a reflector in the positive $z$ direction. One means of describing this situation is to define Units 1 and 2 as in data description 3, Example 1. The origin of the global unit is defined to be at the center of the array. The corresponding input geometry is shown below.

Data description 6, Example 1.

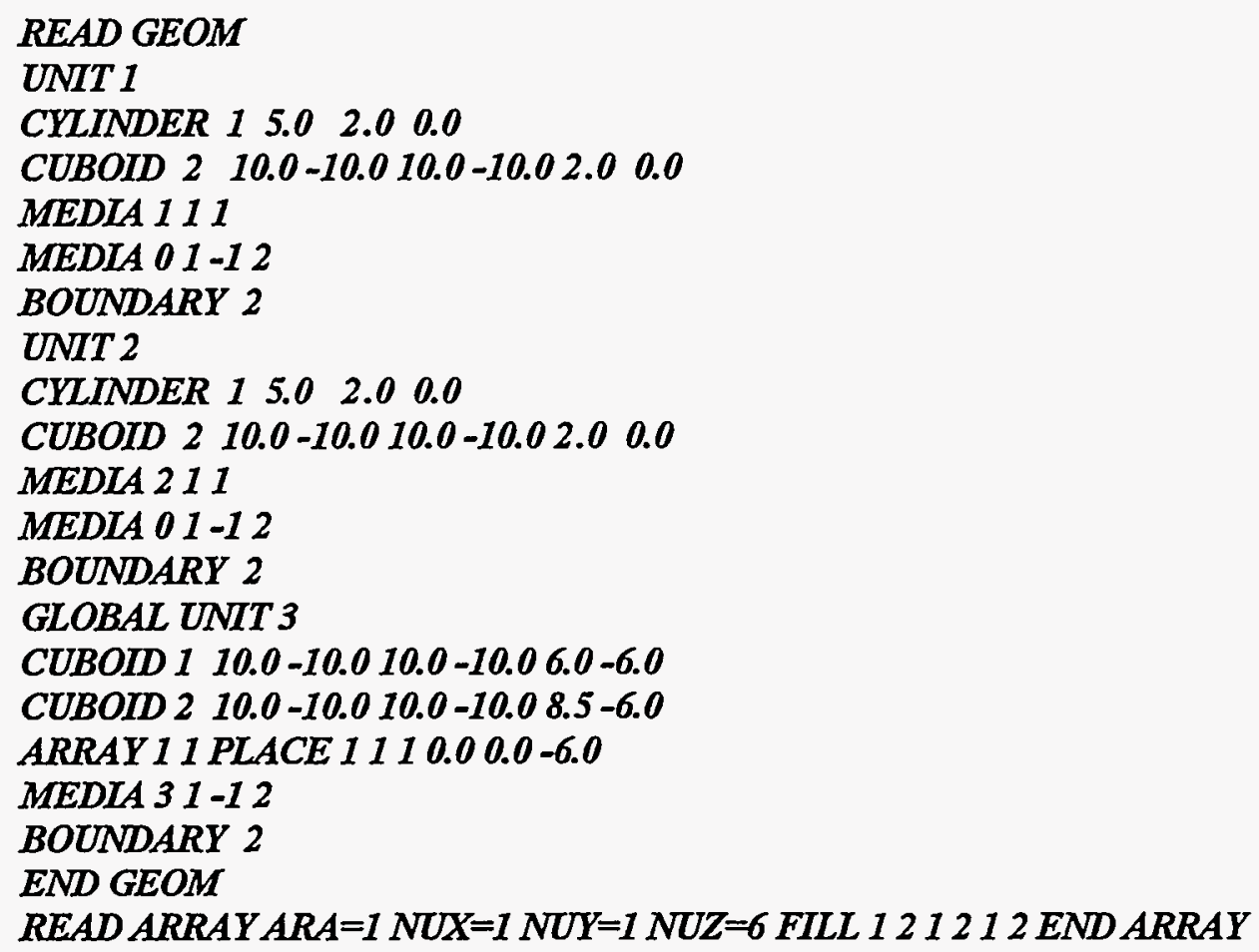

The user could have chosen the origin of the global unit to be at the center bottom of the array in which case the geometry description for the global unit would be:

CUBOID $110.0-10.010 .0-10.012 .00 .0$

CUBOID 2 10.0-10.0 10.0-10.0 14.5 0.0

ARRAY 11 PLACE $1113 * 0.0$

MEDIA $31-12$

BOUNDARY 2

Any position in the array could be used to place the array within the region, keeping in mind the restriction that the region boundary must either coincide with the surface of the array or be contained within the array. If array position $(1,1,3)$ was used to position the array in description 6 of example 1 , the global unit would be:

CUBOID 1 10.0 $-10.010 .0-10.012 .00 .0$

CUBOID 2 10.0-10.0 10.0-10.0 14.5 0.0

ARRAY 11 PLACE 1130.00 .04 .0

MEDIA $31-12$

BOUNDARY 2 
A simpler method of describing Example 1 as a reflected array is to define only one unit as in data description 5, Example 1. The square plate is treated as a reflector as in data description 6, Example 1. The input for this arrangement is given below.

Data description 7, Example 1.

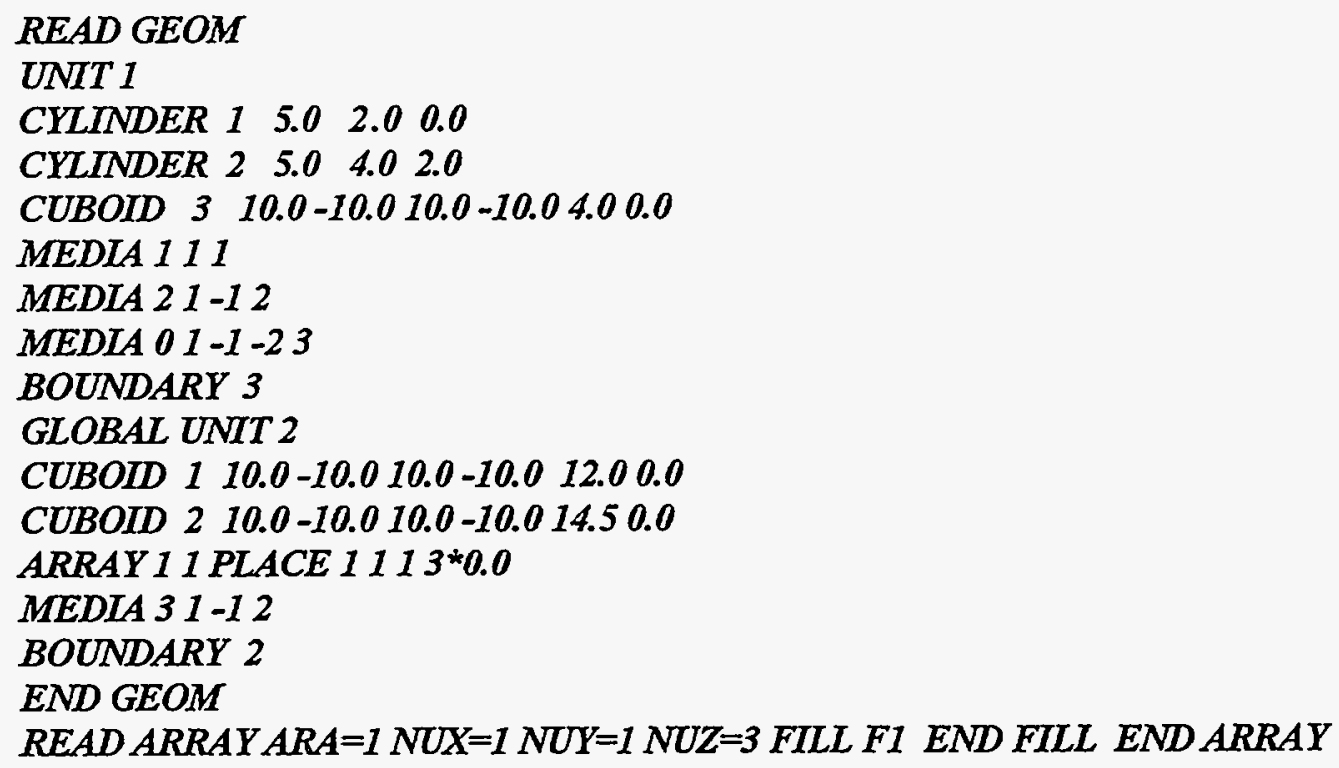

Note that a global unit must be specified for each problem, including a single unit problem. Also each unit must have a boundary record specifying the outermost boundary of the unit.

EXAMPLE 2. Assume the stack of six disks in Example 1 is placed at the center bottom of a cylindrical container composed of material 6 whose inside diameter is $16.0 \mathrm{~cm}$. The bottom and sides of the container are $0.25 \mathrm{~cm}$ thick, the top is open, and the total height of the container is $18.25 \mathrm{~cm}$. Assume the square plate of Example 1 is centered on top of the container.

The geometry input can be described utilizing most of the data description methods associated with Example 1. One method of describing Example 2 as a single unit is given below.

Data description 1, Example 2.

READ GEOM

GLOBAL UNIT 1

CYLINDER $15.0 \quad 1.0-1.0$

CYLINDER $25.0 \quad 3.0-3.0$

CYLINDER $3 \quad 5.0 \quad 5.0 \quad-5.0$

CYLINDER $4 \quad 5.0 \quad 7.0 \quad-5.0$

CYLINDER $5 \quad 8.0 \quad 13.0 \quad-5.0$

CYLINDER $6 \quad 8.25 \quad 13.0 \quad-5.25$

CUBOID $7 \quad 10.0-10.0 \quad 10.0-10.013 .0-5.25$

CUBOID $8 \quad 10.0 \quad-10.0 \quad 10.0-10.0 \quad 15.5-5.25$

MEDIA 111

NUREG/CR-0200,

Vol. 2, Rev. 5

F17.5.16 
MEDLA 2 1-12

MEDIA 1 1-1 -2 3

MEDIA $21-1-2-34$

MEDIA $01-3-45$

MEDLA 61-56

$M E D I A 01-5-67$

MEDLA $31-6-78$

BOUNDARY 8

END GEOM

In the above description, the origin is defined to be at the center of the disk of material 1 nearest the center of the stack of cylinders. This disk is defined by the first cylinder description. The disks of material 2 above and below it are defined by the second cylinder description. The disks of material 1 above and below them are defined by the third cylinder description. The top disk of material 2 is defined by the fourth cylinder description. The void interior of the container is defined by the fifth cylinder description. The container is defined by the last cylinder description. The first cuboid description is used to define a void whose $\mathrm{x}$ and $\mathrm{y}$ dimensions are the same as the square plate, and whose $z$ dimensions are the same as the container. The last cuboid description defines the square plate and the unit boundary. Omission of the first cuboid description would result in the container being encased in a solid cuboid of material 3. Thus both cuboids are necessary to properly define the square plate in this description.

Example 2 can be described as a reflected array. One of the descriptions uses only one unit and is similar to data description 7, example 1. This description is shown below.

Data description 2, Example 2.

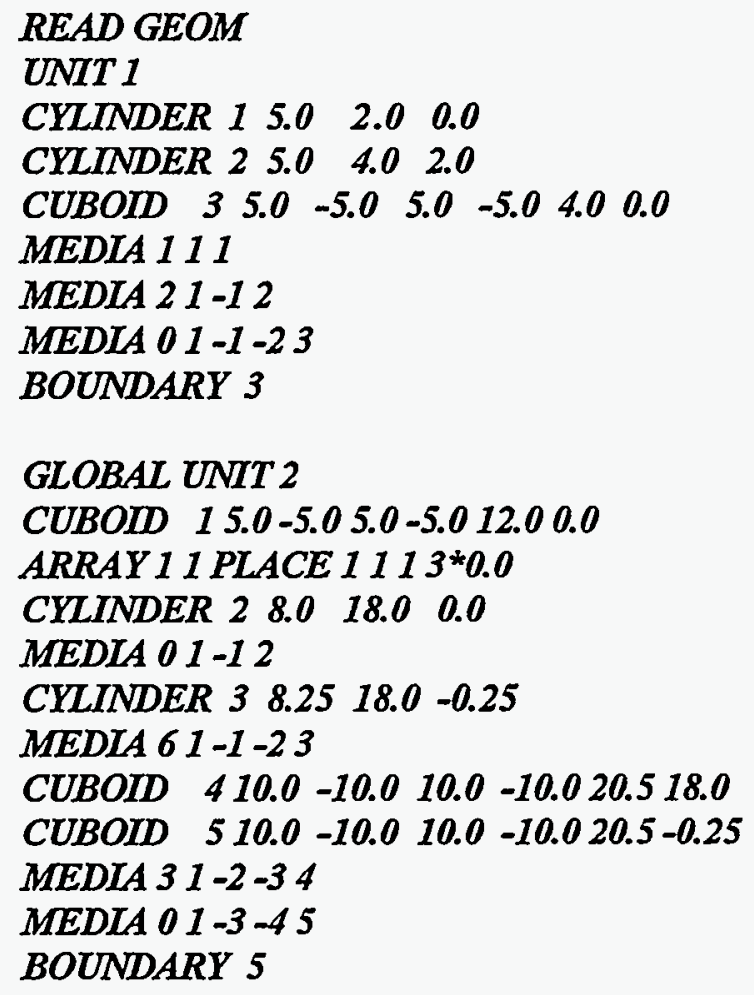


In this data description, the first two cylinder descriptions define a disk of material 1 with a disk of material 2 directly on top of it. A tight-fitting void cuboid is placed around them so they can be stacked three high to achieve the stack of disks shown in Example 1, Fig. F17.5.1. This unit is used to build the array portion of the geometry description. The first cuboid in unit 2 contains the array of disks. Everything after the first cuboid is considered part of the reflector. The first cylinder in Unit 2 defines the void interior of the cylindrical container. The next cylinder defines the walls of the container. The next-to-last cuboid defines the square plate of material 3 that is sitting on top of the container. The last cuboid defines a void volume outside the container from its bottom to its top and having the same $\mathrm{x}$ and $\mathrm{y}$ dimensions as the square plate. Example 2 can be described as a reflected array regardless of the inner radius of the container because, unlike KENO-V.a, intersections are allowed and only the section of the array in the region boundary is considered part of the problem.

Another method to describe Example 2 is as an array composed of units that contain both the stack and container. This description requires a minimum of four units to describe the problem. This configuration is given below in data description 3, Example 2.

Data description 3, Example 2.

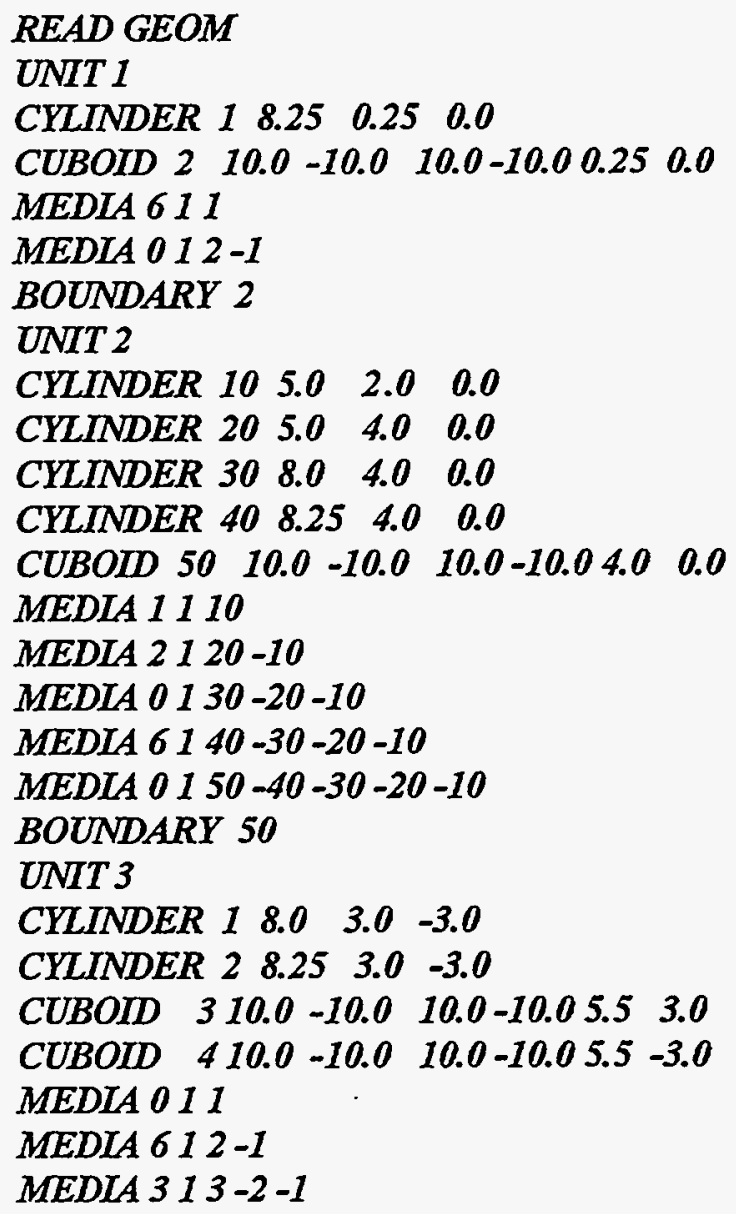


MEDLA $014-3-2-1$

BOUNDARY 4

GLOBAL UNIT 4

CUBOID 1 10.0-10.0 10.0 -10.0 20.75 0.0

ARRAY 11 PLACE $1113 * 0.0$

BOUNDARY 1

END GEOM

READ ARRAY NUX=1 NUY=1 NUZ=5 FILL $13 R 23$ END ARRAY

In the above description, Unit 1 is the bottom of the cylindrical container. The void cuboid is only as tall as the bottom of the container, and its $\mathrm{x}$ and $\mathrm{y}$ dimensions are the same as the square plate on top of the container. If all the units in the array utilize these same dimensions in the $x$ and $y$ directions, the restriction that adjacent faces of units in contact with each other be the same size and shape is satisfied. This array is stacked in the $\mathrm{z}$ direction, so all units must have the same overall dimensions in the $\mathrm{x}$ direction and in the $\mathrm{y}$ direction. Unit 2 will be used in the array three times to create the stack of disks. It contains a disk of material 1 , topped by a disk of material 2. The portion of the container that contains the disks and the cuboid that defines the outer boundaries of the unit are included in Unit 2. Unit 3 describes the empty top portion of the container and the square plate on top of it. The $z$ dimensions of Unit 3 were determined by subtracting three times the total $z$ dimension of Unit 2 from the inside height of the container $[18.0-(3 \times 4.0)=6.0]$. This can also be determined from the overall height of the container by subtracting off the bottom thickness of the container and three times the height of Unit $2[18.25-0.25-(3 \times 4.0)=6.0]$. Unit 4 is the global unit that contains the array. The array is placed in the unit by aligning the bottom center of Unit 1 with the origin of Unit 4 .

EXAMPLE 3. Refer to Example 1, Fig. F17.5.1, and imagine a hole $1.5 \mathrm{~cm}$ in diameter drilled along the centerline of the stack through the disks and the square plate. In KENO-V.a this hole would eliminate the possibility of describing the system as a single unit because the hole in the center of the alternating materials of the stack cannot be described in a manner that allows each successive geometry region to encompass the regions interior to it. However, KENO-VI can easily describe this configuration as a single unit.

Data description 1, Example 3.

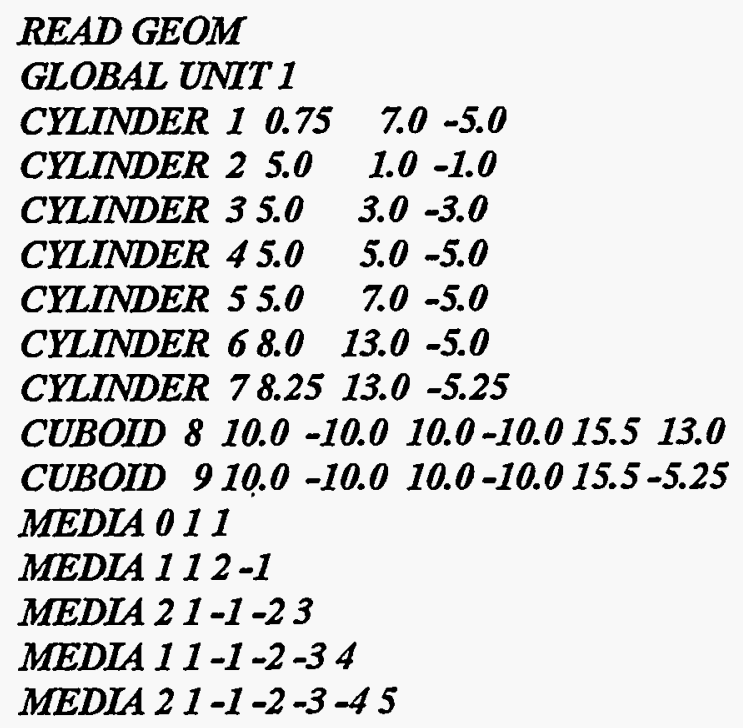


MEDIA $01-1-2-3-4-56$

MEDLA $61-1-4-5-67$

MEDLA $31-6-78$

MEDLA $01-7-89$

BOUNDARY 9

END GEOM

In data description 1, Example 3 above, Unit 1 contains the entire problem description. The first cylinder describes the 1.5-cm-diam hole through the stack. The next four cylinders define the stack. The sixth and seventh cylinders describe the void and container. The two cuboids describe the top plate and surrounding global region of void. The media cards are used to place the materials in the appropriate regions.

EXAMPLE 4. Assume two large cylinders, $2.5 \mathrm{~cm}$ in radius and $5 \mathrm{~cm}$ long, are connected by a smaller cylinder, $0.5 \mathrm{~cm}$ in radius and $10 \mathrm{~cm}$ long, as shown in Fig. F17.5.2. All of the cylinders are composed of material 1. By starting the geometry description in the small cylinder, this system can be described as a single unit.

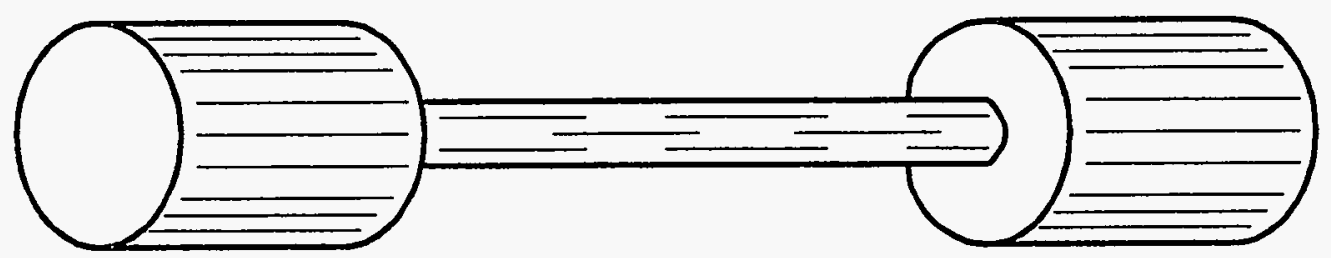

Figure F17.5.2 Two large cylinders joined axially by a small cylinder

Data description 1, Example 4.
READ GEOM
GLOBAL UNIT 1
MEDIA 111
MEDLA 0112 -1
MEDIA 11 1 3 -2
BOUNDARY 3
END GEOM

CYLINDER $10.5 \quad 5.0 \quad-5.0$

CYLINDER $22.5 \quad 5.0 \quad-5.0$

CYLINDER $32.510 .0-10.0$

The origin is at the center of the small cylinder, which is described by the first cylinder description. The second cylinder description defines a void cylinder surrounding the small cylinder. Its radius is the same as the large cylinders, and its height (length) coincides with that of the small cylinder. The last cylinder description defines the large cylinders on either end of the small cylinder. Because the problem was not rotated, the long axes of the cylinders are assumed to coincide with the $z$ axis.

NUREG/CR-0200,

Vol. 2, Rev. 5

F17.5.20 
EXAMPLE 5. Assume two large cylinders with a center-to-center spacing of $15 \mathrm{~cm}$, each having a radius of $2.5 \mathrm{~cm}$ and length of $5 \mathrm{~cm}$, are connected radially by a small cylinder having a radius of $1.5 \mathrm{~cm}$, as shown in Fig. F17.5.3.

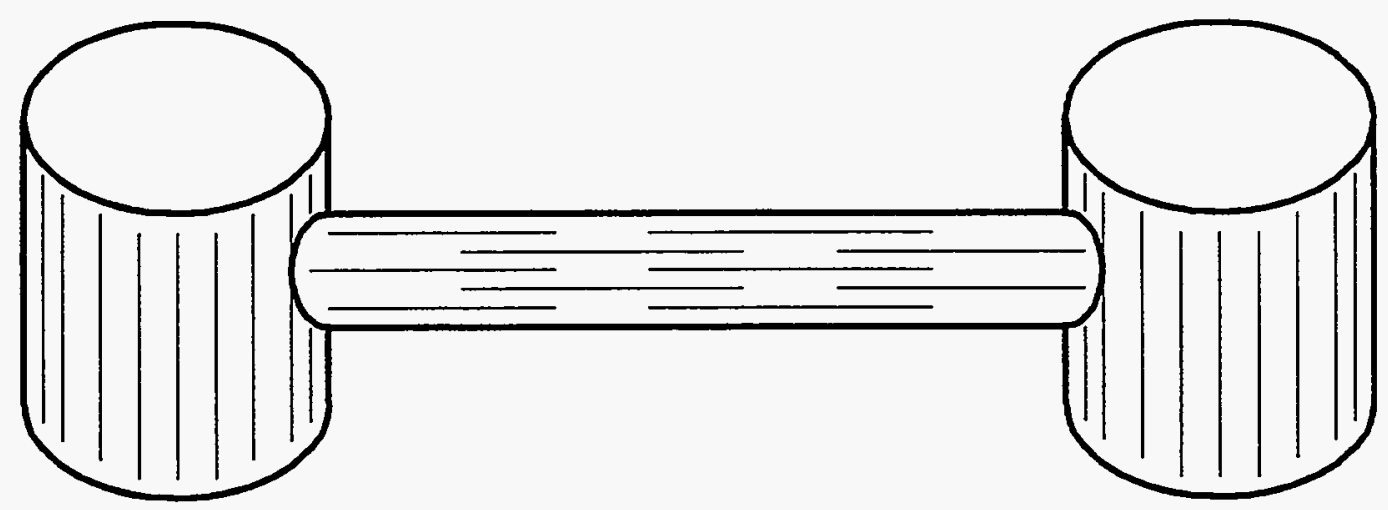

Figure F17.5.3 Two large cylinders radially connected by a small cylinder

This system can be rigorously described in KENO-VI geometry because intersections are allowed. However, either the two large cylinders or the small connecting cylinder must be rotated The small cylinder is rotated in description 1, example 5. The two large cylinders are rotated in description 2 , example 5.

Data description 1, Example 5.

READ GEOM

GLOBAL UNIT 1

CYLINDER $1 \quad 2.52 .5-2.5$

CYLINDER $22.52 .5-2.5$ ORIGIN $Y=15.0$

CYLINDER 31.515 .00 .0 ROTATE $A 2=90$

CUBOID 4 5.0 -5.0 17.5 -2.5 2.5-2.5

MEDIA 111

MEDIA 112

MEDIA $113-1$-2

MEDIA 0 I 4 -3 - -2 -1

BOUNDARY 4

END GEOM

The first and second cylinders define the two large cylinders, and the third cylinder describes the small connecting cylinder. The two large cylinders are oriented along the $\mathrm{z}$ axis. The second large cylinder is translated so its origin is at position $(0.0,15.0,0.0)$. The small cylinder is rotated so that its centerline is parallel to the $y$ axis. Region 1 consists of the material in the first large cylinder. Region 2 consists of the material in the second large cylinder. Region 3 consists of the material in the small cylinder but not in either of the large cylinders. Region 4 is the boundary region. 
Data description 2, Example 5.

READ GEOMETRY

GLOBAL UNIT 1

CYLINDER 12.5 2.5-2.5 ROTATE A2=90

CYLINDER 22.52 .5 -2.5 ROTATE $A 2=90$ ORIGINZ $Z=15.0$

CYLINDER 31.515 .00 .0

CUBOID $4 \quad 2.5-2.52 .5-2.5 \quad 17.5-2.5$

MEDIA 111

MEDIA 112

MEDIA 1 I 3 -1 -2

MEDIA 0 I $4-3-2-1$

BOUNDARY 4

END GEOM

Again, the first and second cylinders describe the two large cylinders. They are both rotated so their long axis is parallel to the $y$ axis. The first large cylinder still maintains its origin at the unit origin. The origin of the second large cylinder is translated to position $(0.0,0.0,15.0)$. The small connecting cylinder has its centerline along the $z$ axis. The media data are identical to that of the previous problem description. It does not matter what order the rotation and translation data are listed after a geometry card. Rotations are always done about the origin prior to the translation. Only nonzero data need be entered for the ROTATE and ORIGIN options.

EXAMPLE 6. Assume two small cylinders, $1.0 \mathrm{~cm}$ in radius and $10 \mathrm{~cm}$ long, are connected by a large cylinder, $2.5 \mathrm{~cm}$ in radius and $5 \mathrm{~cm}$ long, as shown in Fig. F17.5.4.

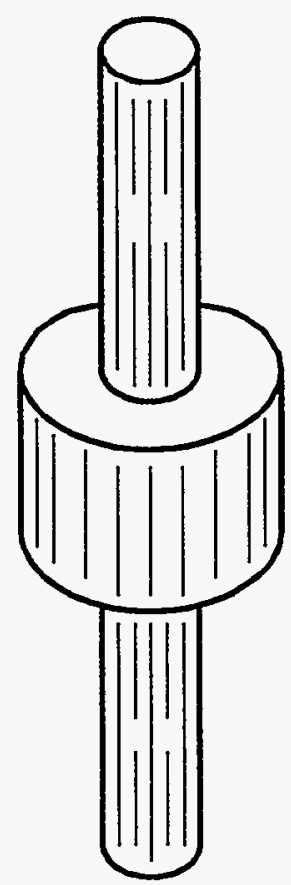

Figure F17.5.4 Two small cylinders joined axially by a large cylinder

NUREG/CR-0200,

Vol. 2, Rev. 5

F17.5.22 
This problem is very similar to example 4 . It can be described as a single unit. Unit 1 defines the large cylinder, and Unit 2 defines the small cylinder. The origin of each unit is at its center. The composite system consists of two Unit 2's and one Unit 1 as shown below. Assume the centerline of the cylinders lies along the $\mathrm{z}$ axis.

Data description 1, Example 6.

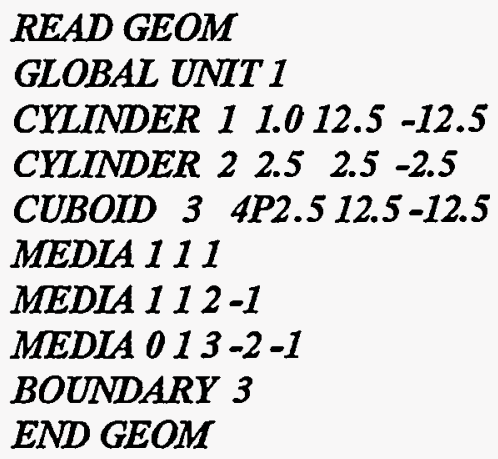

READ GEOM

GLOBAL UNIT 1

CILINDER $11.012 .5-12.5$

CILINDER $22.5 \quad 2.5 \quad-2.5$

CUBOID $3 \quad 4 P 2.512 .5-12.5$

MEDLA 111

MEDLA $112-1$

MEDIA 013 -2 -1

BOUNDARY 3

END GEOM

The first cylinder defines a long, narrow cylinder that includes the top and bottom small cylinders and the inner 1.0-radius cylinder of the large cylinder. The second cylinder defines the remainder of the large cylinder. The cuboid defines the boundary region. It is possible to represent this problem as a single unit because regions do not need to fully enclose all previous regions in the unit as KENO-V.a requires.

EXAMPLE 7. Assume an $11 \times 5 \times 3$ square-pitched array of spheres of material 1, radius $3.75 \mathrm{~cm}$, with a center-to-center spacing of $10 \mathrm{~cm}$ in the $\mathrm{x}, \mathrm{y}$, and $\mathrm{z}$ directions. The data for this system are given below.

Data description 1, Example 7.

\section{READ GEOM}

UNIT 1

SPHERE 13.75

CUBOID 2 6P5.0

$M E D I A 111$

MEDLA $012-1$

BOUNDARY 2

GLOBAL UNIT 2

CUBOID $1055.0-55.025 .0-25.015 .0-15.0$

ARRAY 110 PLACE $6323 * 0.0$

BOUNDARY 10

END GEOM

READ ARRAY NUX=11 $\dot{N U Y=5 ~ N U Z=3 ~ F I L L ~ F 1 ~ E N D ~ F I L L ~ E N D ~ A R R A Y ~}$

EXAMPLE 8. Assume an $11 \times 5 \times 3$ square-pitched array of spheres of material 1 whose radius is 3.75 $\mathrm{cm}$, and whose center-to-center spacing is $10 \mathrm{~cm}$ in the $\mathrm{x}$ direction, $15 \mathrm{~cm}$ in the $\mathrm{y}$ direction, and $20 \mathrm{~cm}$ in the $\mathrm{z}$ direction. The input for this geometry is given below. 
Data description 1, Example 8.

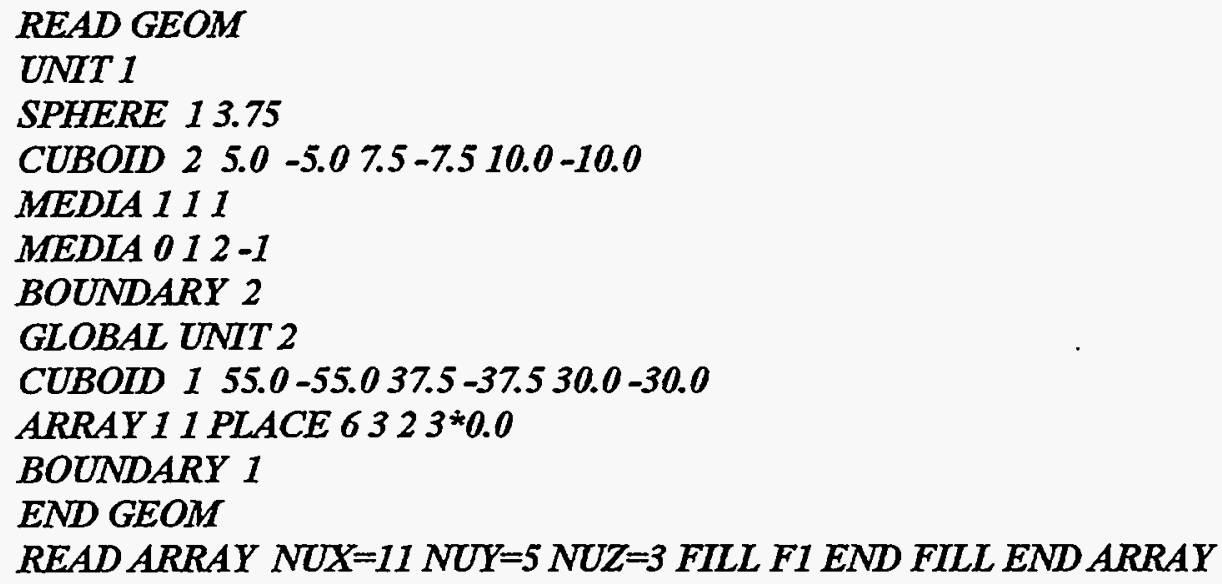

EXAMPLE 9. Assume an $11 \times 5 \times 3$ square-pitched array of spheres of material 1 whose radius is 3.75 $\mathrm{cm}$, and whose center-to-center spacing is $10 \mathrm{~cm}$ in the $\mathrm{x}, \mathrm{y}$, and $\mathrm{z}$ directions. This array is reflected by $30 \mathrm{~cm}$ of material 2 (water) on all faces, and weighted tracking (biasing) is to be used in the water reflector. The array spacing defines the perpendicular distance from the outer layer of spheres to the reflector to be $5 \mathrm{~cm}$ in the x,y, and $z$ directions. The geometry input for this system is given below.

Data description 1, Example 9.

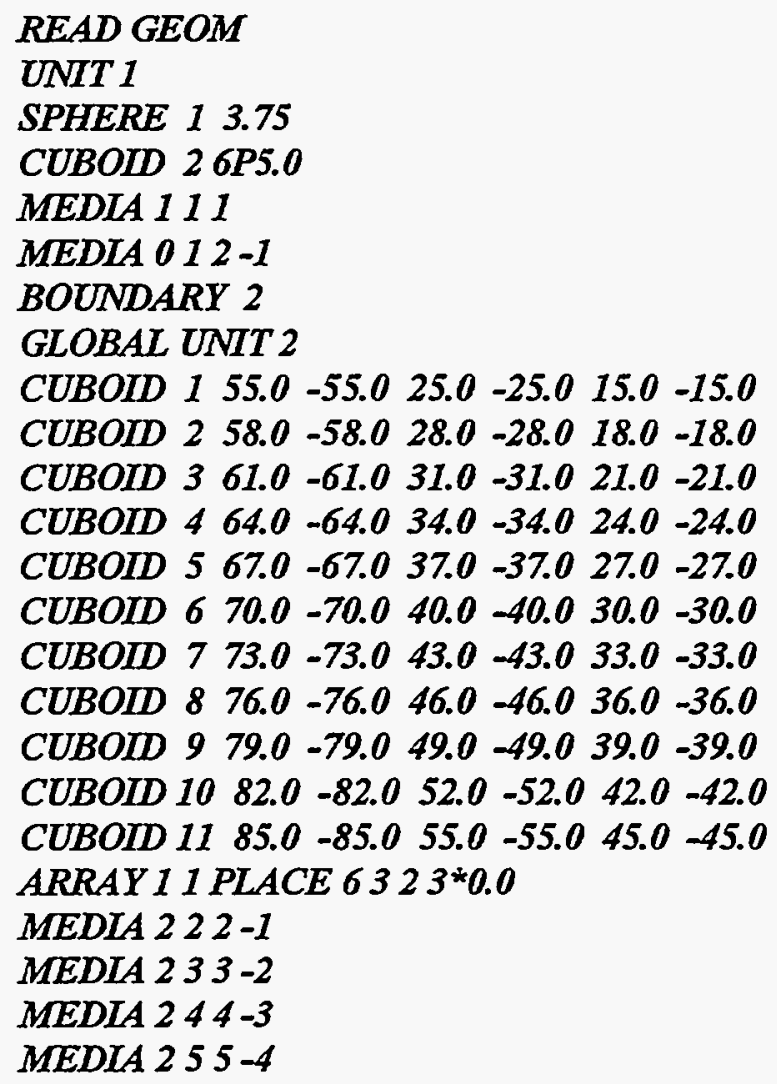


MEDIA $266-5$

MEDIA $277-6$

MEDIA $288-7$

MEDIA $299-8$

MEDIA $21010-9$

MEDLA $21111-10$

BOUNDARY 11

END GEOM

READ ARRAY NUX=11 NUY=5 NUZ=3 FILL F1 END FILL END ARRAY

READ BLAS ID=500 211 END BLAS

The basic unit used to construct the array is defined in Unit 1. The array is positioned in Unit 2 (the global unit) using the ARRAY card and the PLACE option. The array is then surrounded by ten reflector regions, each $3.0 \mathrm{~cm}$ thick, on all sides. The first bias $\mathrm{ID}$ of the reflector is 2 , so the last bias $\mathrm{ID}$ will be 11 because 10 regions are created. The biasing data block is necessary to apply the desired weighting or biasing function to the reflector. The biasing material $\mathrm{ID}$ is obtained from Table F17.4.5. If the biasing data block is omitted from the problem description, the ten reflector regions will not have a biasing function applied to them, and the default value of the average weight will be used. This omission may cause the problem to execute more slowly, and therefore require the use of more computer time.

EXAMPLE 10. Assume the reflector in Example 9 is present only on both $\mathrm{x}$ faces, both $\mathrm{y}$ faces, and the negative $\mathrm{z}$ face. The reflector is only $15.24 \mathrm{~cm}$ thick on these faces. The top of the array (positive $\mathrm{z}$ face) is unreflected.

Data description 1, Example 10.

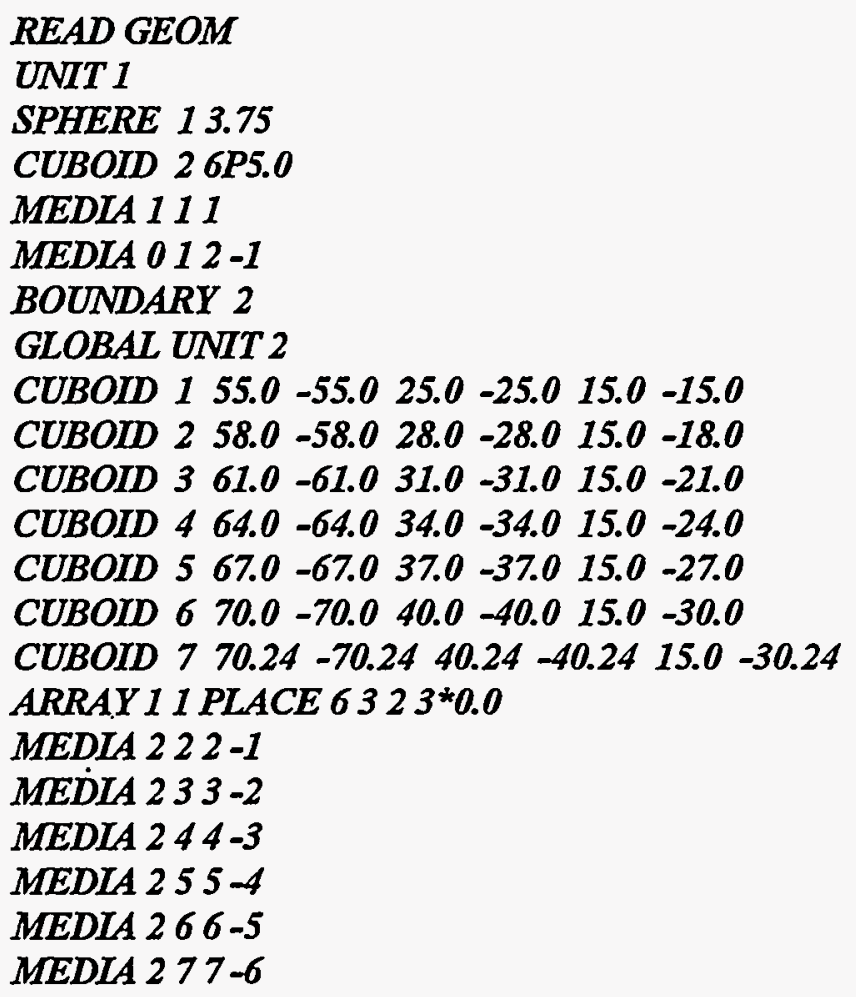


The first cuboid in Unit 2 represents the boundary for the array. The next five cuboids represent the first five regions around the array, each region being $3.0 \mathrm{~cm}$ thick in the $+x,-x,+y,-y$, and $-z$ directions, and of zero thickness in the $+z$ direction. A total thickness of $15 \mathrm{~cm}$ of reflector material is on the appropriate faces. The last cuboid represents the last $0.24 \mathrm{~cm}$ of material 2 on those faces. Thus, the total reflector thickness is 15.24 $\mathrm{cm}$ on each face of the array, except the top which has no reflector. The beginning bias ID is 2 , and the ending bias $\mathrm{DD}$ is 7. The biasing material $\mathrm{ID}$ and thickness per region are obtained from Table F17.4.5. The thickness per region should be very nearly the thickness per region from the table to avoid overbiasing in the reflector. Partial increments at the outer region of a reflector are exempt from this recommendation.

EXAMPLE 11. Assume the array of example 7 has the central unit of the array replaced by a cylinder of material $4,5 \mathrm{~cm}$ in radius and $10 \mathrm{~cm}$ tall. Assume a 20-cm-thick spherical reflector of material 3 (concrete) is positioned so its inner radius is $65 \mathrm{~cm}$ from the center of the array. The minimum inner radius of a spherical reflector for this array is $62.25 \mathrm{~cm}\left(\sqrt{55^{2}+25^{2}+15^{2}}\right)$. If the inner radius is smaller than this, the entire array cannot be contained within the spherical reflector.

Data description 1, Example 11.

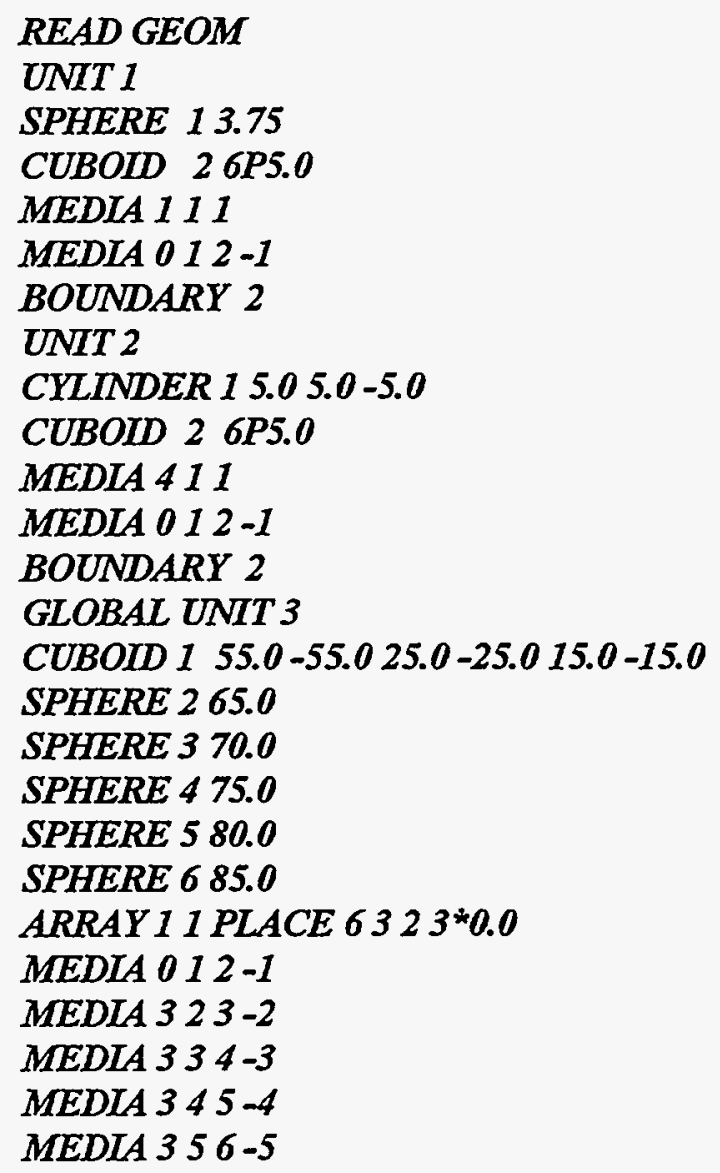

NUREG/CR-0200, 
BOUNDARY 6

END GEOM

READ ARRAY NUX=11 NUY=5 NUZ=3 LOOP 111111151131

$2661331221 E N D A R R A Y$

READ BLAS ID=30125 END BLAS

Unit 1 describes the sphere and spacing utilized in the array. Unit 2 defines the cylinder that is located at the center of the array. Unit 3 defines the global unit. The ARRAY card defines the origin of the array to be at the center of the global unit. The sphere following the ARRAY card defines the inner radius of the reflector. The next four SPHERE cards will generate four spherical regions of material 3, each $5.0 \mathrm{~cm}$ thick. The first ten entries following the word LOOP fill the $11 \times 5 \times 3$ array with Unit 1 . The next ten entries position Unit 2 at the center of the array $(x=6, y=3$, and $z=2)$, replacing the Unit 1 that had been placed there by the first 10 entries. The biasing data block is used to apply the biasing function for concrete to the generated reflector regions.

EXAMPLE 12. Assume a data profile such as fission densities is desired in a cylinder at 1-cm intervals in the radial direction and $1.5-\mathrm{cm}$ intervals axially. The cylinder, composed of material 1 , has a radius of $5 \mathrm{~cm}$ and a height of $15 \mathrm{~cm}$. The cylinders are then nested to create these regions. A biasing data block is not entered because default biasing is desired throughout the cylinder.

Data description 1, Example 12.
READ GEOM
GLOBAL UNIT 1
MEDIA 111
MEDLA $112-1$
MEDLA 113 -2
MEDIA 114 -3
MEDLA 115 -4
BOUNDARY 5
END GEOM

CYLINDER $11.0 \quad 1.5 \quad-1.5$

CYLINDER $22.0 \quad 3.0$-3.0

CYILINDER $33.0 \quad 4.5$-4.5

CYLINDER 44.06 .0 -6.0

CYLINDER $55.07 .5 \quad-7.5$

EXAMPLE 13. Assume a cross composed of two Plexiglas cylinders (material 3) having an inner diameter of $13.335 \mathrm{~cm}$ and an outer diameter of $16.19 \mathrm{~cm}$. The bottom and side legs of the cross are closed by a 3.17-cm-thick piece of Plexiglas. From the center of the intersection the bottom and side legs are $91.44 \mathrm{~cm}$ long, and the top leg is $121.92 \mathrm{~cm}$ long. The cross is filled with $\mathrm{aUO}_{2} \mathrm{~F}_{2}$ solution (material 1) to a height of 28.93 $\mathrm{cm}$ above the center of the cylinder intersection. The cross is then surrounded by a water reflector (material 2 ) that extends from the center of the intersection: $111.74 \mathrm{~cm}$ in the $\pm x$ directions, $20.64 \mathrm{~cm}$ in the $\pm y$ directions, $29.03 \mathrm{~cm}$ in the $+z$ direction, and $-118.428 \mathrm{~cm}$ in the $-z$ direction. A schematic of the assembly is shown in Fig. F17.5.5. 


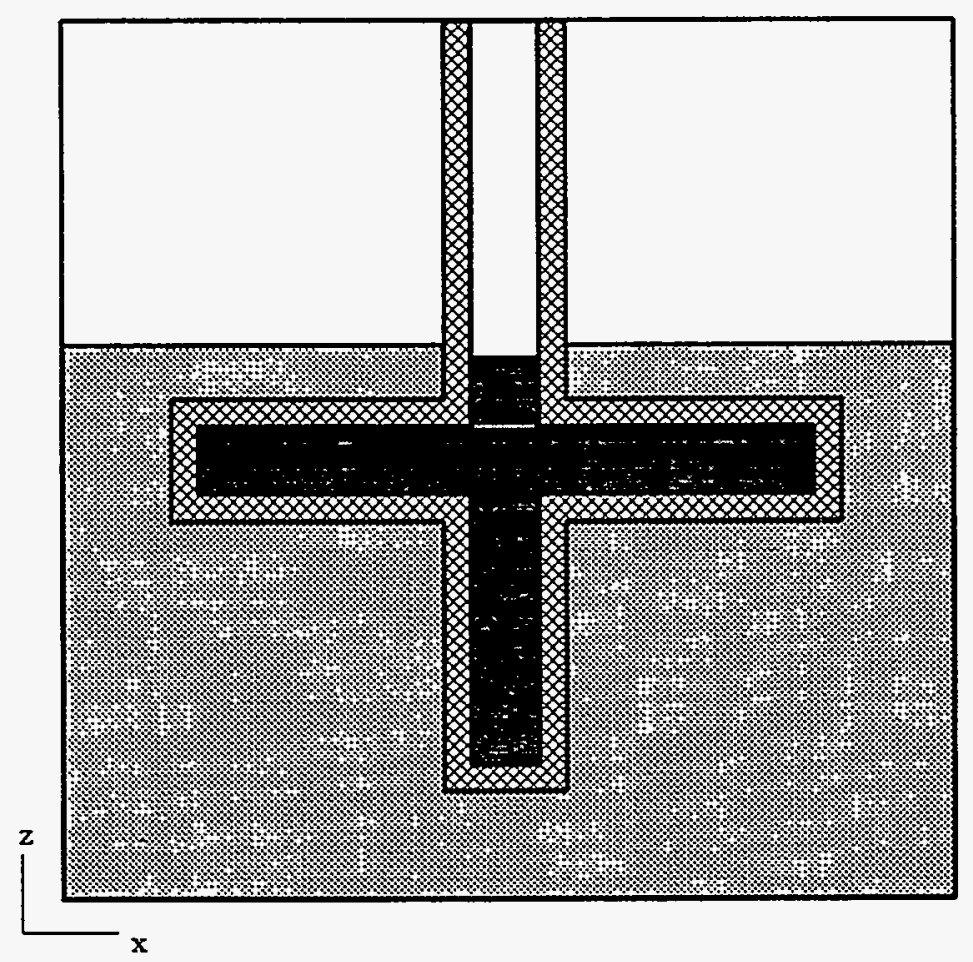

Figure F17.5.5 Plexiglas $\mathrm{UO}_{2} \mathrm{~F}_{2}$-filled cross

Data description of Example 13.

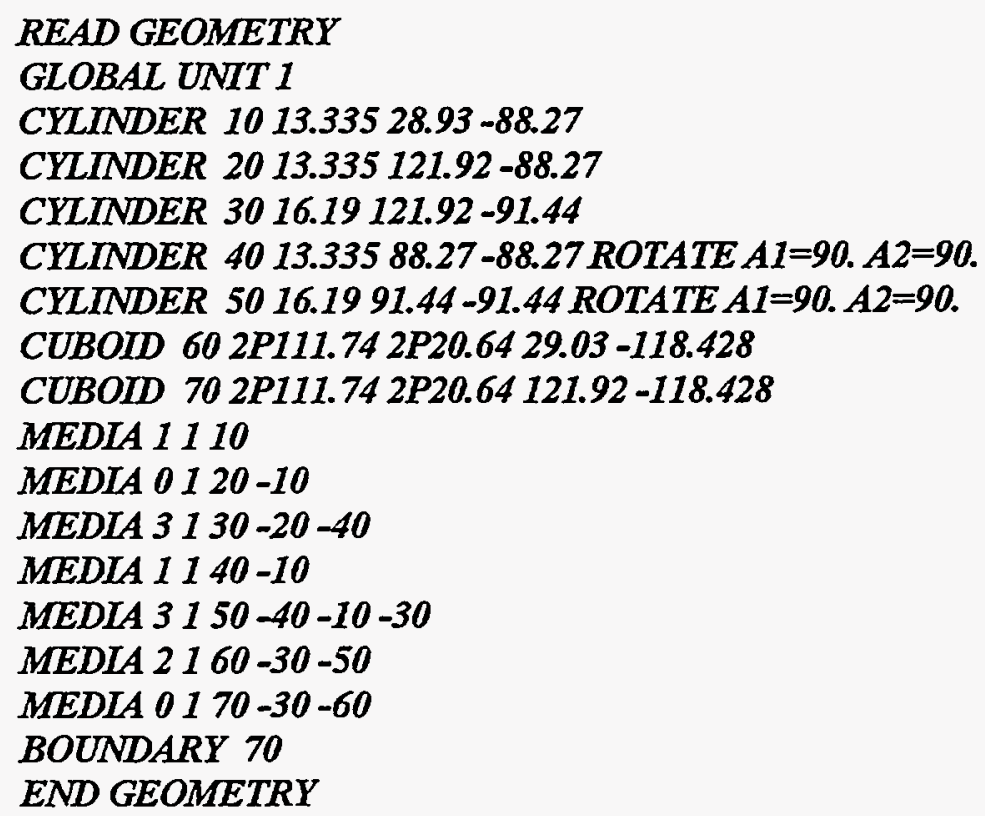


EXAMPLE 14. Assume a Y-shaped aluminum cylinder (material 2) with a 13.95-cm inner radius and a $0.16-\mathrm{cm}$ wall thickness is filled with a $\mathrm{UO}_{2} \mathrm{~F}_{2}$ solution (material 1 ). From the center where the $\mathrm{Y}$ intersects the cylinder, the bottom leg is $76.7 \mathrm{~cm}$ long, the top leg is $135.4 \mathrm{~cm}$ long, and the $Y$ leg is $126.04 \mathrm{~cm}$ long canted at a 29.26-degree angle. The bottom of the bottom leg and the top of the $Y$ leg are sealed with 1.3-cm caps. The $Y$ cylinder is filled to a height of $52.8 \mathrm{~cm}$ above the center where the $Y$ leg intersects the vertical cylinder. The cylinder is surrounded by a water reflector (material 3) that extends out $37.0 \mathrm{~cm}$ in the $\pm x$ direction, 100.0 and $-37.0 \mathrm{~cm}$ in the $\pm y$ direction, and 135.4 and -99.6 in the $\pm z$ direction. A schematic of the assembly is shown in Fig. F17.5.6.

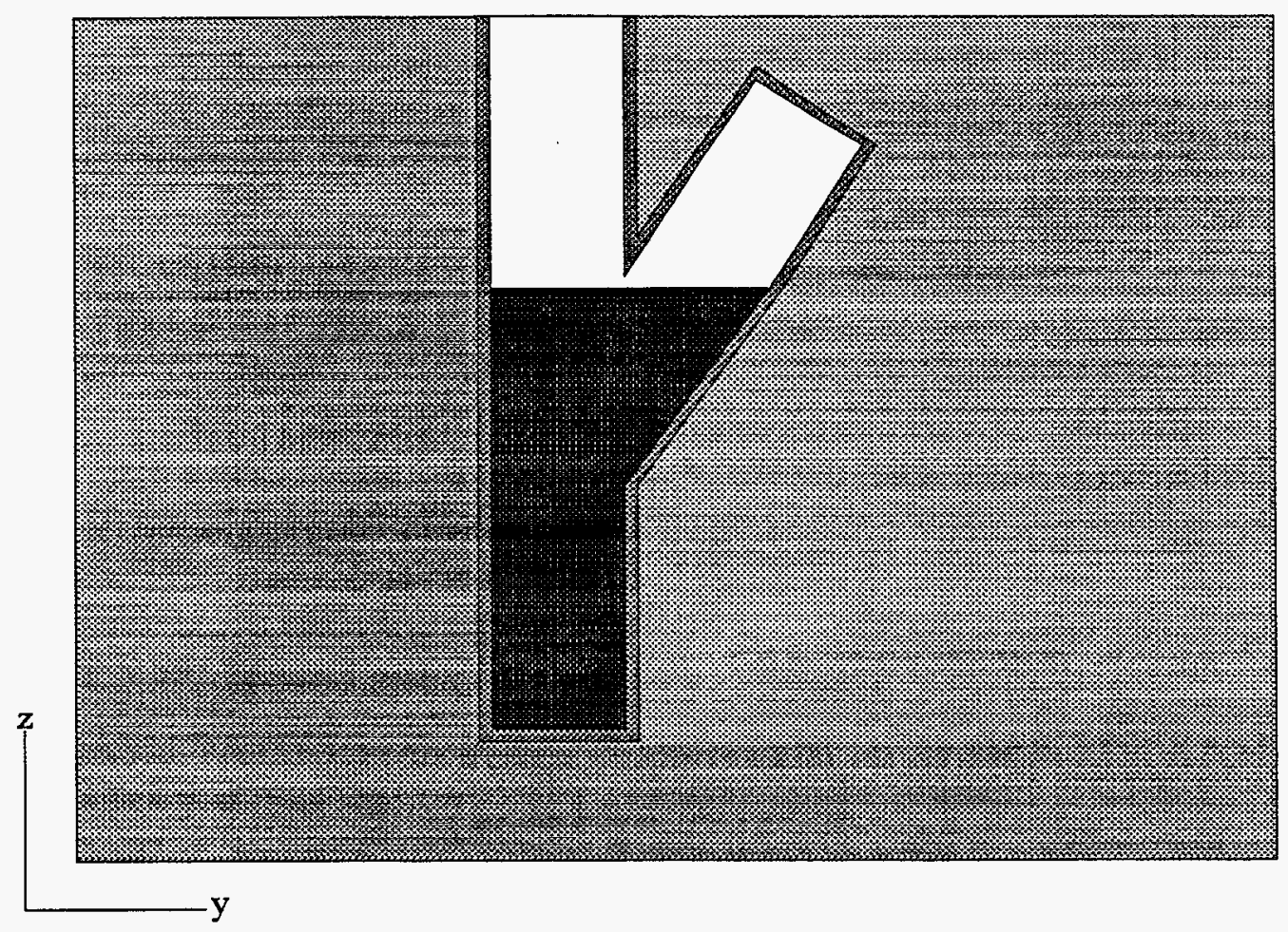

Figure F17.5.6 Y-shaped $\mathrm{UO}_{2} \mathrm{~F}_{2}$-filled aluminum cylinder

Data description of Example 14.

\author{
READ GEOMETRY \\ GLOBAL UNIT 1 \\ $C O M=' 30$ DEG Y CYLINDER' \\ CYLINDER 1013.95 135.4-75.4 \\ CYLINDER 20 14.11 135.4-76.7 \\ CYLINDER 3013.95124 .740 .0 ROTATE A2=29.26 \\ CYLINDER 4014.11126 .040 .0 ROTATE $A 2=-29.26$ \\ CUBOID 50 2P37.0 100.0 -37.0 52.8 -75.4 \\ CUBOID $602 P 37.0100 .0-37.0135 .4-99.6$
}


MEDLA 111050

MEDLA $2120-10-30$

MEDLA 113050 -10

MEDIA 2140 -30-20-10

MEDIA $0110-50$

MEDIA $0130-50-10$

MEDIA $3160-20-40$

BOUNDARY 60

END GEOMETRY

\section{F17.5.6.1 Use of Holes in the Geometry}

Section F17.5.6 tells how KENO-VI geometry allows regions in a unit to intersect, thus eliminating the need for holes. Holes in KENO-VI, however, can be useful in simplifying the input of a problem and decreasing the total CPU time needed for a problem. A HOLE is a means of placing an entire unit within a geometry region. A separate HOLE description is required for every location in a geometry unit where another unit is to be placed. The information contained in a hole geometry card is: (1) the geometry word, HOLE, (2) the unit number of the unit to be placed, and (3) the region definition vector. A hole is placed inside the geometry region defined by the region definition vector. The boundary dimensions of the unit being placed in the hole must precisely match the boundary of the region containing the hole. Only one hole is allowed in a region and holes cannot intersect. Holes can be nested to any depth (see Sect. F17.5.6.2). It is not advisable to use holes that are tangent to other holes or geometry regions, although it is theoretically possible to do so. Frequently holes that are exactly tangent to each other or to other geometry regions may fail to run because the computer code finds that the regions are intersecting due to precision and roundoff. It is not uncommon for a problem that runs on an RISC-6000 to fail on an IBM mainframe using the same data. Therefore, it is recommended that tangency and boundaries shared with holes be avoided.

Tracking in regions that contain holes can be more efficient than tracking in regions that do not contain holes because every boundary region in a unit must be checked for a crossing whenever a crossing is possible. Putting small but complex geometries in a hole will lessen the number of boundaries that need to be checked for possible crossings. However, the indiscriminant use of holes is not advised since the particle must change coordinate systems every time a hole is entered or exited. Therefore, holes should be used carefully only when the system can be simplified significantly by their use.

EXAMPLE 15. One example of a unit that requires holes in KENO-V.a but is better described not using holes in KENO-VI as shown in Fig. F17.5.7, representing nine close-packed rods in an annulus. The large rods are $1.4 \mathrm{~cm}$ in radius and composed of mixture 3 . The small rods are $0.6 \mathrm{~cm}$ in radius and composed of mixture 1. The inside radius of the annulus is $3.6 \mathrm{~cm}$, and the outside radius is $3.8 \mathrm{~cm}$. The annulus is made of mixture 2. The rods and annulus are both $30 \mathrm{~cm}$ long. The annulus is centered in a cuboid having an $8-\mathrm{cm}-$ square cross section and a length of $32 \mathrm{~cm}$. All nonshaded areas are void. 
s.

"00Z0-\&ว/DG8חN
IE'S:LIA

9-6- Z I I FICHU

6-8-८-9- I I I HICIW

0.9IdZ 0'tdo TI aIOGaD

$0{ }^{\circ}$ SIdZ $8^{\circ} \varepsilon$ II YZTNITAD

$00^{\circ}$ SIdZ $9^{\circ} \mathcal{E}$ OI \&ATNIXO

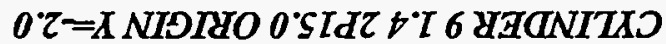

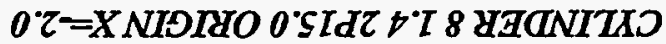

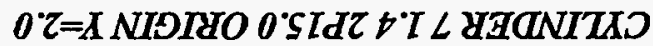

$0^{\circ} Z=X N I D I Y O 0^{\circ} s I d Z t^{\circ} I 9$ \&ZTNITXO

$0^{\circ} Z=R \quad 0^{\circ} Z=X N I D I Y O 0^{\circ} \mathrm{s} I d Z 9^{\circ} 0 \mathrm{~s}$ \&IINITXO

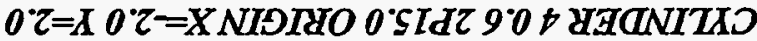

$0^{\circ} \tau=\Lambda \quad 0^{\circ} Z=X N I D I Z O 0^{\circ} S I d Z 9^{\circ} 0$ \& \&BGNITID

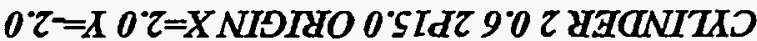

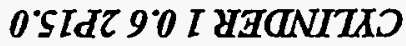

I LINR THEOTD

WOBD बVBय

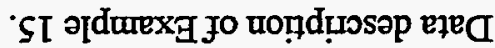

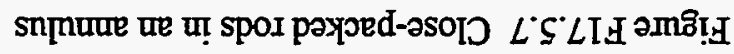

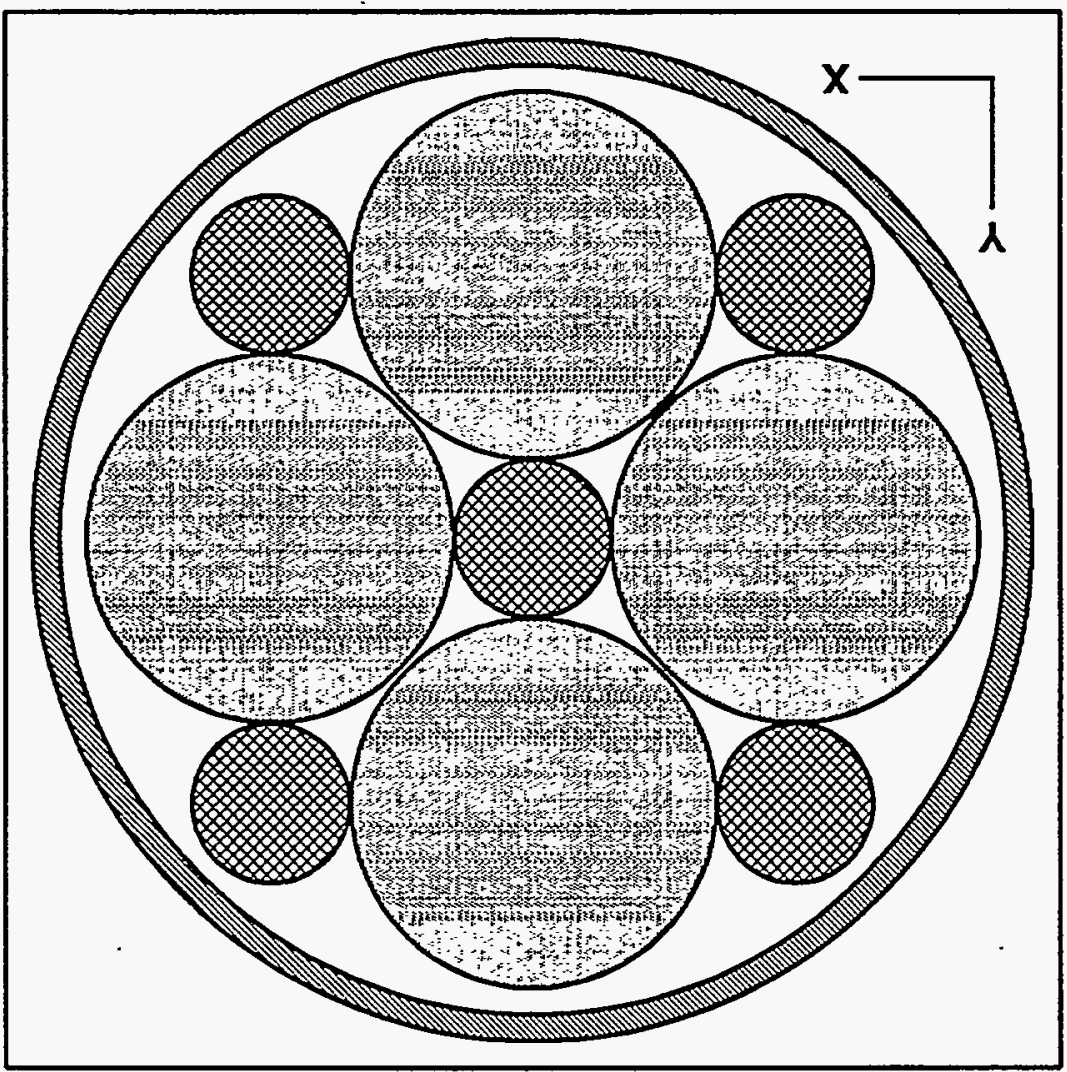


MEDLA $113-6-7$

MEDLA 11 4-7-8

MEDLA 115 -8 -9

MEDLA 31 6-2 -3 -1

MEDLA 31 7-3 -4 -1

MEDIA 31 \& $-4-5-1$

MEDIA $319-5-2-1$

MEDIA 01 10 -1 - - - -3 -4 -5 -6 -7 -8 -9

MEDIA $2111-10$

MEDIA $0112-11$

BOUNDARY 12

END GEOM

The first CYLINDER description represents the middle small rod. The next four cylinder cards describe the four remaining small rods surrounding the middle rod. The ORIGIN modification card is used to shift the origin of each cylinder to the appropriate location. The following four cylinder cards represent the four large rods. Again the ORIGIN modification card is used to shift the origin of each cylinder to the appropriate location. Only the nonzero dimensions need to be entered in the ORIGIN data. The tenth cylinder card is the void in the annulus that contains the rods. The last cylinder card defines the outer surface of the annulus. Finally, the cuboid card describes the surrounding unit boundary.

An array of the unit shown in Fig. F17.5.7 can be easily represented using array description data. For example, a $5 \times 3 \times 2$ array of these shapes with a center-to-center spacing of $8 \mathrm{~cm}$ in $x$ and $y$ and $32 \mathrm{~cm}$ in $z$ can be achieved by defining the global unit as the one containing the array and utilizing the following array data:

READ ARRAY NUX=5 NUY=3 NUZ=2 FILL FI END FILL END ARRAY

or

READ ARRAY NUX=5 NUY=3 NUZ=2 FILL 30*1 END FILL END ARRAY

or

READ ARRAY NUX=5 NUY=3 NUZ=2 LOOP 1151131121 END LOOP END ARRAY

\section{F17.5.6.2 Nesting Holes}

This section illustrates how holes are nested. Holes can be nested to any level. Consider the configuration that was illustrated in Fig. F17.5.7 and replace the large rods with a complicated geometric arrangement. The resultant figure is shown in Fig. F17.5.8. Figure F17.5.9 shows the complicated geometric arrangement that replaced the large rods of Fig. F17.5.7. Figure F17.5.10 shows a component of the arrangement shown in Fig. F17.5.9.

EXAMPLE 16. There is no predetermined "best way" to create a geometry mock-up for a given physical system. The user should decide the order that is most convenient. In order to describe the configuration using nested holes, Fig. F17.5.8, it may be most convenient to start the geometry mock-up at the deepest nesting level,

NUREG/CR-0200,

Vol. 2, Rev. 5

F17.5.32 




Figure F17.5.8 Configuration using nested holes

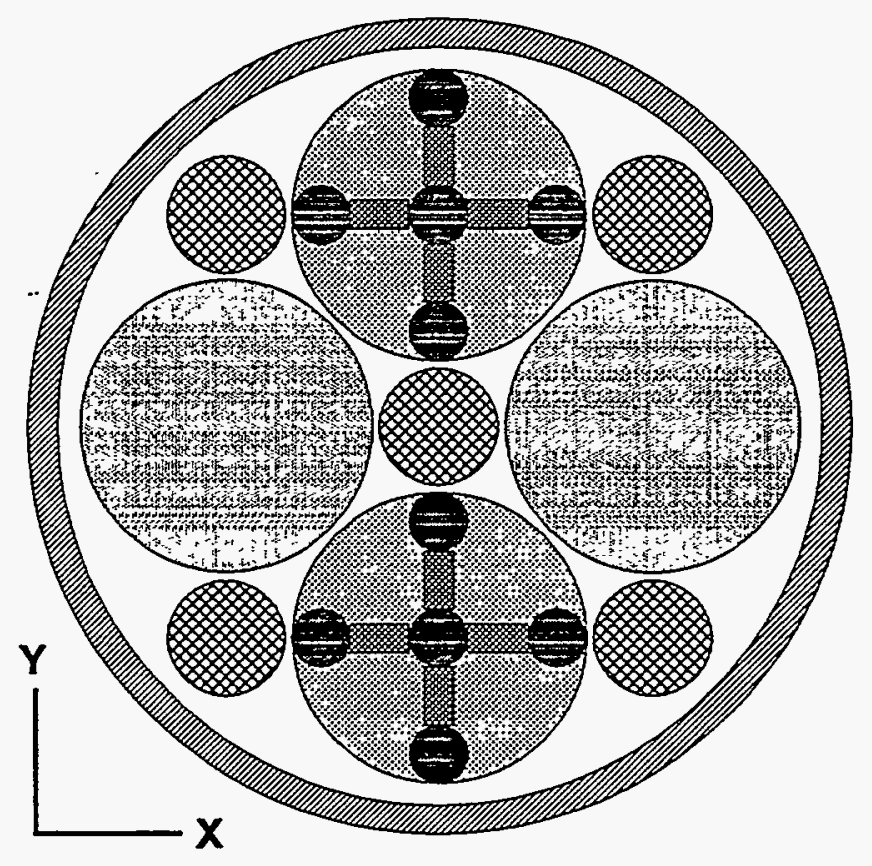

Figure F17.5.9 Complicated geometric arrangement represented by Unit 2 


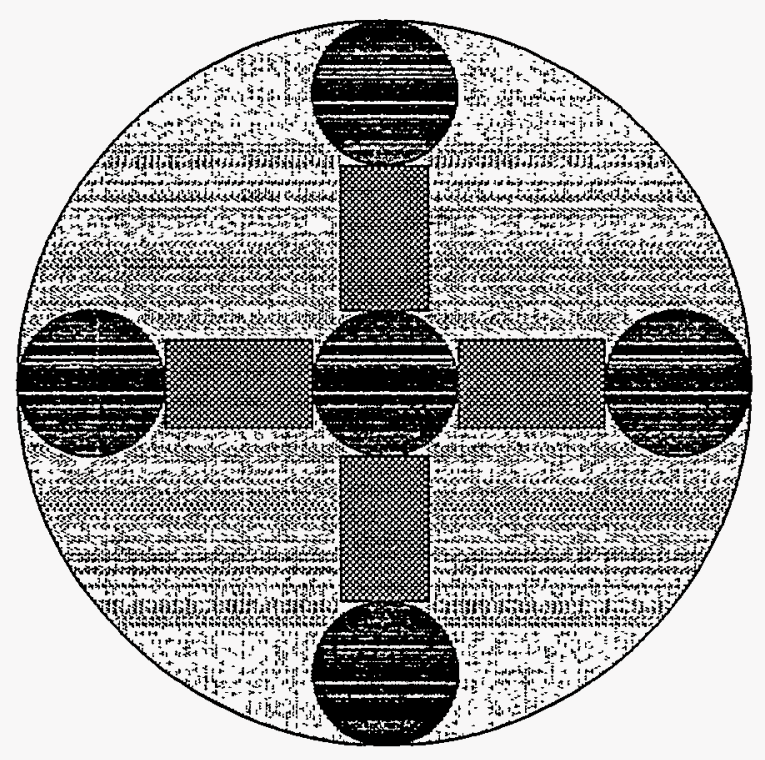

Figure F17.5.10 Geometric component represented by Unit 1

as shown in Fig. F17.5.10. The small cylinders are composed of mixture 1 , and are each $0.1 \mathrm{~cm}$ in radius and $30 \mathrm{~cm}$ long. Five small cylinders are used in the schematic shown in Fig. F17.5.10. Their centers are located at $(0,0,0)$ for the central one, at $(0,-0.4,0)$ for the bottom one, at $(0.4,0,0)$ for the right one, at $(0,0.4,0)$ for the top one, and at $(-0.4,0,0)$ for the left one. The rectangular parallelepipeds (cuboids) are composed of mixture 2. Each one is $30 \mathrm{~cm}$ long and $0.1 \mathrm{~cm}$ by $0.2 \mathrm{~cm}$ in cross section. The large cylinder containing the configuration is composed of mixture 3 , is $30 \mathrm{~cm}$ long, and has a radius of $0.5 \mathrm{~cm}$. A possible geometry mock-up for this system is described as follows:

1. define Unit 1 to contain the five small cylinders and four blocks,

2. define Unit 2 to contain the next two larger-sized cylinders and Unit 1 as holes, and

3. define Global Unit 3 to contain the large cylinders and Unit 2 as holes.

\section{UNIT 1}

CYLINDER $10.12 P 15.0$

CYLINDER $20.12 P 15.0$ ORIGIN Y=0.4

CYLINDER 30.1 2P15.0 ORIGINX $=0.4$

CYLINDER $40.12 P 15.0$ ORIGIN $Y=0.4$

CYLINDER $50.12 P 15.0$ ORIGINX $=0.4$

CUBOID $62 P 0.12 P 0.05$ 2P15.0 ORIGIN $X=0.2$

CUBOID $72 P 0.12 P 0.05$ 2P15.0 ORIGINX $=0.2$

CUBOID $82 P 0.05$ 2P0.1 2P15.0 ORIGIN $Y=0.2$

NUREG/CR-0200,

Vol. 2, Rev. 5 
CUBOID 9 2P0.05 2P0.1 2P15.0 ORIGIN $Y=0.2$

CYLINDER $100.52 P 15.0$

MEDIA 11 1 -6-7-8-9

MEDIA $112-8$

MEDIA 113 13

MEDIA 114 -9

MEDIA $115-6$

MEDIA 21 6-1 -5

MEDIA 2 I 1 -1 -3

MEDIA 21 8-1-2

MEDIA 2 1 $19-1-4$

MEDIA 31 - - - -2 -3 -4 -5 -6 -7 -8 -9 10

BOUNDARY 10

geometry card 1 places the central rod;

geometry card 2 places the bottom cylinder;

geometry card 3 places the cylinder at the right;

geometry card 4 places the top cylinder;

geometry card 5 places the cylinder at the left;

geometry card 6 places the left cuboid whose length is in $\mathrm{x}$;

geometry card 7 places the right cuboid whose length is in $\mathrm{x}$;

geometry card 8 places the bottom cuboid whose length is in $y$;

geometry card 9 places the top cuboid whose length is in $y$, and

geometry card 10 is the surrounding cylinder that defines the system boundary.

Now that Fig. F17.5.10 has been described, consider Fig. F17.5.9. The large plain cylinders are composed of mixture 1 and are $0.5 \mathrm{~cm}$ in radius and $30 \mathrm{~cm}$ long. The cylindrical component of Unit $l$ is the same size, an outer radius of $0.5 \mathrm{~cm}$ and a length of $30 \mathrm{~cm}$. The small cylinders that are located in the interstices between the large cylinders are composed of mixture 2 , are $0.2 \mathrm{~cm}$ in radius, and are $30 \mathrm{~cm}$ long. Unit 2, Fig. F17.5.9, is the annulus that contains the cylinders. Its origin is at its center. The annulus is composed of mixture 4 , has a $1.3-\mathrm{cm}$ inside radius and a $1.4-\mathrm{cm}$ outer radius. The volume between the inner cylinders is void. The large cylinders each have a radius of $0.5 \mathrm{~cm}$ and are tangent; therefore, their origins are offset from the origin of the unit by 0.707107 . This value is from $x^{2}+y^{2}=1.0$ (radius unit $4+$ radius unit 5), where $x$ and $y$ are equal. The geometry mock-up for this portion of the problem follows:

\section{UNIT 2}

CYLINDER $10.22 P 15.0$

CYLINDER 2 0.2 2P15.0 ORIGIN $X=0.707107 \mathrm{Y}=0.707107$

CYLINDER 30.2 2P15.0 ORIGIN $X=0.707107 Y=0.707107$

CYLINDER 4 0.2 2P15.0 ORIGIN $X=0.707107 Y=0.707107$

CYLINDER 5 0.2 2P15.0 ORIGIN $X=0.707107 \quad Y=0.707107$

CILINDER 6 0.5 2P15.0 ORIGIN $X=0.707107$

CYLINDER 7 0.5 2P15.0 ORIGIN $X=0.707107$

CILINDER 80.5 2P15.0 ORIGIN $Y=0.707107$

CYLINDER 9 0.5 2P15.0 ORIGIN $Y=0.707107$

CILINDER $101.32 P 15.0$ 
CYLINDER $111.42 P 15.0$

MEDIA 211

MEDLA 212

MEDLA 213

MEDIA 214

MEDLA 215

MEDLA $116-8-9$

MEDIA $117-8$-9

HOLE $18-3-6$ ORIGIN $Y=0.707107$

HOLE $19-6-7$ ORIGIN $Y=0.707107$

MEDIA $0110-1-2-3-4-5-6-7-8-9$

MEDLA $4111-10$

BOUNDARY 11

In unit 2, cylinder 1 places a small cylinder of mixture 2 at the origin, cylinder 2 places the small cylinder of mixture 2 in the upper-right quadrant, cylinder 3 places the small cylinder of mixture 2 in the upper-left quadrant, cylinder 4 places the small cylinder of mixture 2 in the lower-left quadrant, cylinder 5 places the small cylinder of mixture 2 in the lower-right quadrant, cylinder 6 places the larger cylinder of mixture 1 at the right with its origin at $(0.707107,0.0,0.0)$, cylinder 7 places the larger cylinder of mixture 1 at the left with its origin at $(0.0,0.707107 .0 .0)$, cylinder 8 places the top cylinder that contains the geometric component defined in Unit 1 , cylinder 9 places the bottom cylinder that contains the geometric component defined in Unit 1 , cylinder 10 defines the inner surface of the annulus, and cylinder 11 defines the outer surface of the annulus and the unit boundary.

To complete the geometry mock-up, consider Fig. F17.5.8. Define Unit 3 to be the central rod and four outer rods of $0.6 \mathrm{~cm}$ radius and $30.0 \mathrm{~cm}$ length, and the large annulus of $3.6 \mathrm{~cm}$ inner radius, $3.8 \mathrm{~cm}$ outer radius, and $30 \mathrm{~cm}$ length centered in a cuboid having an 8-cm-square cross section and a length of $32 \mathrm{~cm}$.

\section{GLOBAL UNIT 3}

CYLINDER $10.62 P 15.0$

CYLINDER 20.6 2P15.0 ORIGIN $X=2.0 \mathrm{Y}=2.0$

CYLINDER 30.6 2P15.0 ORIGIN $X=2.0 \mathrm{Y}=2.0$

CYLINDER 4 0.6 2P15.0 ORIGIN $X=2.0 \mathrm{Y}=2.0$

CYLINDER 50.6 2P15.0 ORIGIN $X=2.0 Y=2.0$

CILINDER 6 1.4 2P15.0 ORIGIN $X=2.0$

CYLINDER 7 1.4 2P15.0 ORIGIN $Y=2.0$

CYLINDER 8 1.4 2P15.0 ORIGINX $=2.0$

CYLINDER 91.4 2P15.0 ORIGIN Y $=-2.0$

CYLINDER $103.62 P 15.0$

CYLINDER $113.82 P 15.0$

CUBOID 124 4P4.0 2P16.0

MEDIA 211 - 1 - -7 -8 -9

MEDLA 212 2 $-6-7$

MEDIA 2 1 3 -7 - -8

NUREG/CR-0200,

Vol. 2, Rev. 5

F17.5.36 
MEDLA 21 4-8 -9

MEDLA $215-9-6$

HOLE 2 6-1 -5 -2 ORIGENX=2

HOLE 2 7-1 -2 -3 ORIGEN $Y=2$

HOLE 2 8 -1 -3 -4 ORIGENX=-2

HOLE 2 9 $-1-4-5$ ORIGEN $Y=2$

MEDLA $0110-1$-2 -3 -4 -5 -6 -7 -8 -9

MEDLA $4111-10$

MEDLA $0112-11$

BOUNDARY 12

In unit 3 , cylinder 1 defines the rod of mixture 2 , centered in the annulus, cylinder 2 places a rod of mixture 2 in the upper-right quadrant of the annulus, cylinder 3 places a rod of mixture 2 in the upper-left quadrant of the annulus, cylinder 4 places a rod of mixture 2 in the lower-left quadrant, cylinder 5 places a rod of mixture 2 in the lower-right quadrant, cylinder 6 places the composite annulus of Unit 2 to the right of the central rod, cylinder 7 places the composite annulus of Unit 2 above the central rod, cylinder 8 places the composite annulus of Unit 2 to the left of the central rod, cylinder 9 places the composite annulus of Unit 2 below the central rod, cylinder 10 defines the void volume between the central rod and the annulus, cylinder 11 defines the outer surface of the annulus, and cuboid 12 defines the unit boundary

This problem illustrates two levels of hole nesting. The total input data for the problem is given below. The nuclide IDs are for the 16-group Hansen-Roach working format library. The mixtures used in this problem are not realistic or meaningful. However, the geometry description accurately recreates the geometry arrangement of Fig. F17.5.8. This problem includes the data for a printer plot to be used to verify the validity of the geometry description. The plot data specify a picture that is 260 characters wide, so the picture is generated in two pieces. The left half of the printer plot is shown in Fig. F17.5.11, and the right half is given in Fig. F17.5.11b. The user can tape the two halves together. If the plot were specified to be 130 characters wide, it would all print in one piece. However, some of the detail might have been lost.

Data description of Example 16.

$=$ KENOVI

NESTED HOLES SAMPLE

READ PARAM RUN=NO LIB=41 TME=0.5 END PARAM

READ MLXT SCT=1 MLX=192500 4.7048-2 MLX=2 200 1.0 MLX=35020.1

$M I X=42001.0$

END MLXT

READ GEOM

UNIT 1

CYLINDER $10.12 P 15.0$

CILINDER 20.1 2P15.0 ORIGIN $Y=0.4$

CYLINDER 30.1 2P15.0 ORIGIN $X=0.4$

F17.5.37

NUREG/CR-0200, Vol. 2, Rev. 5 
CYLINDER 4 0.1 2P15.0 ORIGIN $Y=0.4$ CYLINDER 50.1 2P15.0 ORIGIN $X=0.4$ CUBOID $62 P 0.1$ 2P0.05 2P15.0 ORIGINX $=0.2$ CUBOID $72 P 0.12 P 0.05$ 2P15.0 ORIGIN $X=0.2$ CUBOID $82 P 0.052 P 0.12 P 15.0$ ORIGIN $Y=0.2$ CUBOID $92 P 0.052 P 0.12 P 15.0$ ORIGIN $Y=0.2$ CYLINDER $100.52 P 15.0$

MEDIA $1111-6-7-8-9$

MEDLA 112 -8

MEDLA 113 -7

MEDIA 11 4 -9

MEDIA $115-6$

MEDIA $216-1-5$

MEDLA 21 7-1 -3

MEDLA $218-1-2$

MEDIA $219-1-4$

MEDIA 3 1 - 1 -2 -3 - 4 -5 -6 -7 -8 -9 10

BOUNDARY 10

UNIT 2

CYLINDER $10.22 P 15.0$

CYLINDER $20.22 P 15.0$ ORIGIN $X=0.707107 Y=0.707107$

CYLINDER $30.22 P 15.0$ ORIGIN $X=0.707107 \mathrm{Y}=0.707107$

CYLINDER 4 0.2 2P15.0 ORIGIN $X=0.707107 \mathrm{Y}=0.707107$

CYLINDER 5 0.2 2P15.0 ORIGINX $=0.707107 Y=0.707107$

CYLINDER 60.5 2P15.0 ORIGINX $=0.707107$

CYLINDER 7 0.5 2P15.0 ORIGINX $=0.707107$

CYLINDER 80.5 2P15.0 ORIGIN Y $=0.707107$

CYLINDER 90.5 2P15.0 ORIGIN $Y=0.707107$

CYLINDER $101.32 P 15.0$

CYLINDER $111.42 P 15.0$

MEDIA 211

MEDIA 212

MEDIA 213

MEDLA 214

MEDIA 215

MEDIA 11 6-8 -9

MEDIA 11 7-8 -9

HOLE $18-3-6$ ORIGIN $Y=0.707107$

HOLE 19-6-7 ORIGIN $Y=0.707107$

MEDIA 0110 -1 -2 -3 -4 -5 -6 -7 -8 -9

MEDIA $4111-10$

BOUNDARY 11

GLOBAL UNIT 3

CYLINDER $10.62 P 15.0$

CYLINDER 20.6 2P15.0 ORIGINX $=2.0 \mathrm{Y}=2.0$

CYLINDER 30.6 2P15.0 ORIGIN $X=2.0 \mathrm{Y}=2.0$

CYIINDER $40.62 P 15.0$ ORIGIN $X=2.0 Y=2.0$

NUREG/CR-0200,

Vol. 2, Rev. 5

F17.5.38 


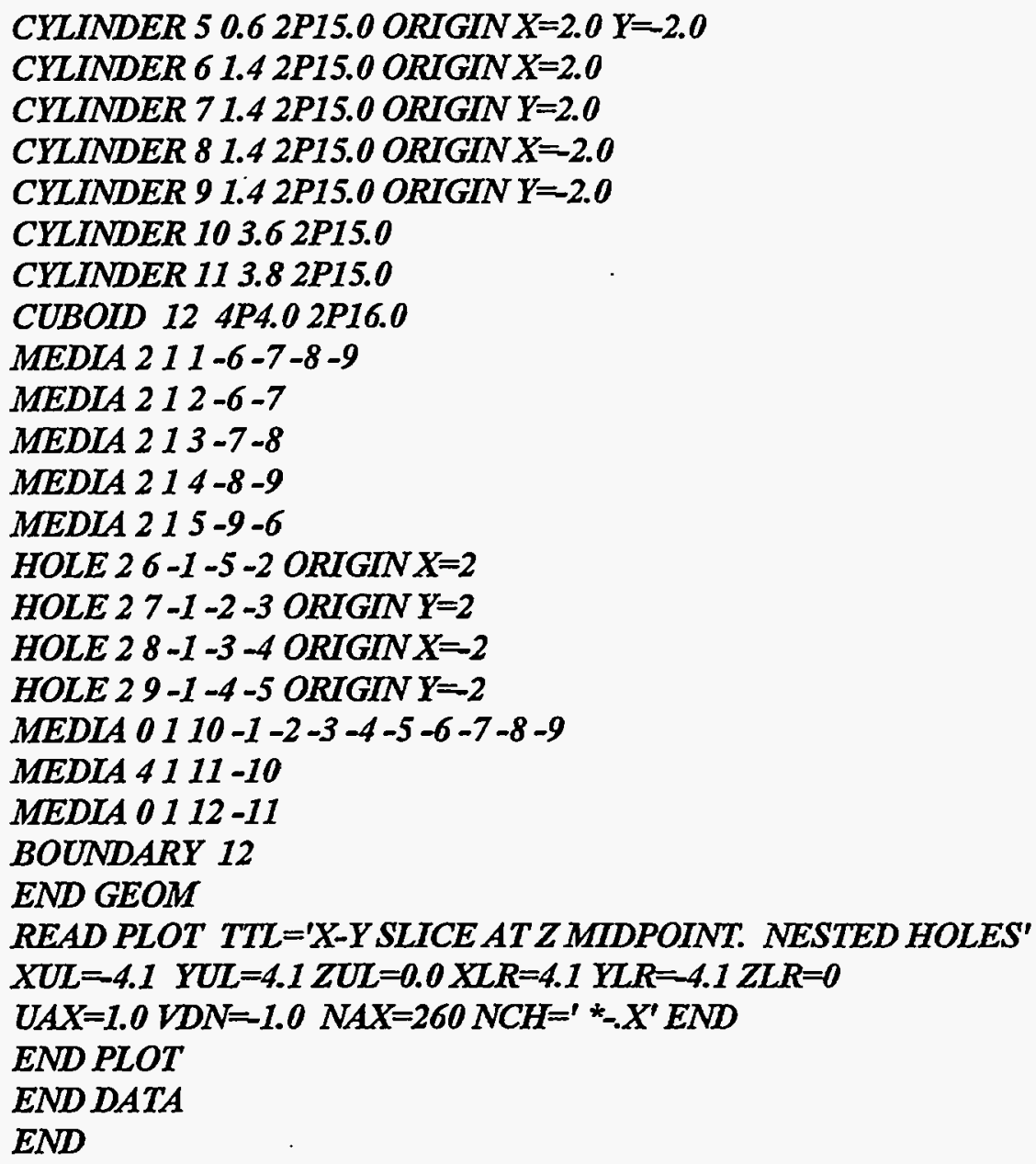

EXAMPLE 17. Section F17.5.6 demonstrates how units are composed of geometry regions and how these units can be stacked in an array. This same procedure can be extended to create multiple arrays. Furthermore, arrays can be used as building blocks within other arrays.

Consider Sample Problem 12 from Sect. F17.D. The description of this sample problem is restated below as Sample Problem 19.

This problem is a critical experiment consisting of a composite array ${ }^{1,2}$ of four highly enriched uranium metal cylinders and four cylindrical Plexiglas containers filled with uranyl nitrate solution. The metal units in this experiment are designated in Table $I$ of ref. 1 as cylinder index 11 and reflector index 1 . A photograph of the experiment is given in Fig. F17.D.3. The coordinate system is defined to be $\mathrm{z}$ up the page, $\mathrm{y}$ across the page, and $x$ out of the page.

The Plexiglas containers have an inside radius of $9.525 \mathrm{~cm}$ and an outside radius of $10.16 \mathrm{~cm}$. The inside height is $17.78 \mathrm{~cm}$ and the outside height is $19.05 \mathrm{~cm}$. Four of these containers are stacked with a center-to-center spacing of $21.75 \mathrm{~cm}$ in the " $y$ " direction and $20.48 \mathrm{~cm}$ in the " $z$ " direction (vertical). This arrangement of four Plexiglas containers can be described as follows: mixture 2 is the uranyl nitrate and mixture 3 is Plexiglas, so the Plexiglas container with its appropriate spacing cuboid can be described as Unit 1 . The array is considered to be bare and suspended with no supports. 


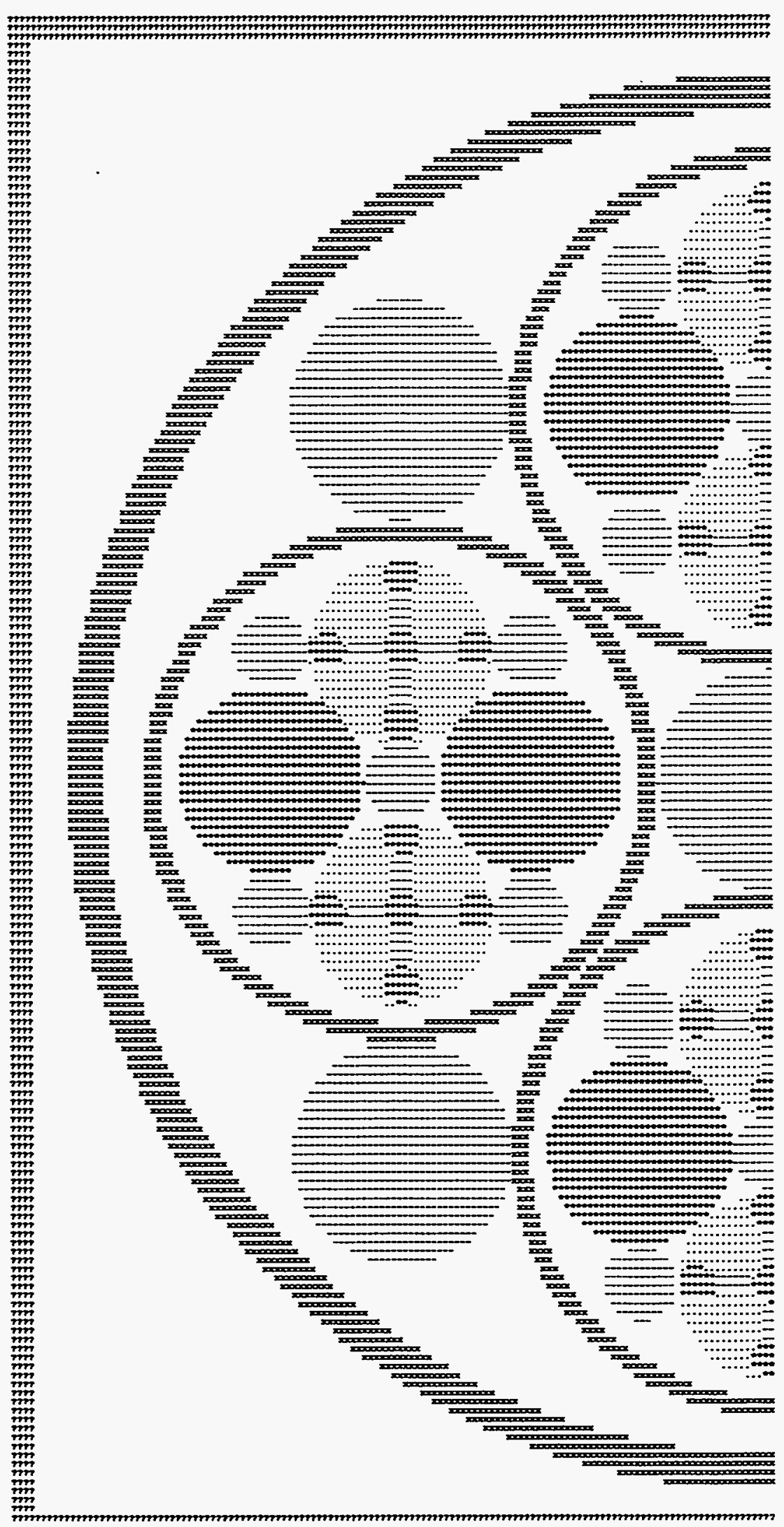

Figure F17.5.11a Left half of printer plot

NUREG/CR-0200,

Vol. 2, Rev. 5

F17.5.40 


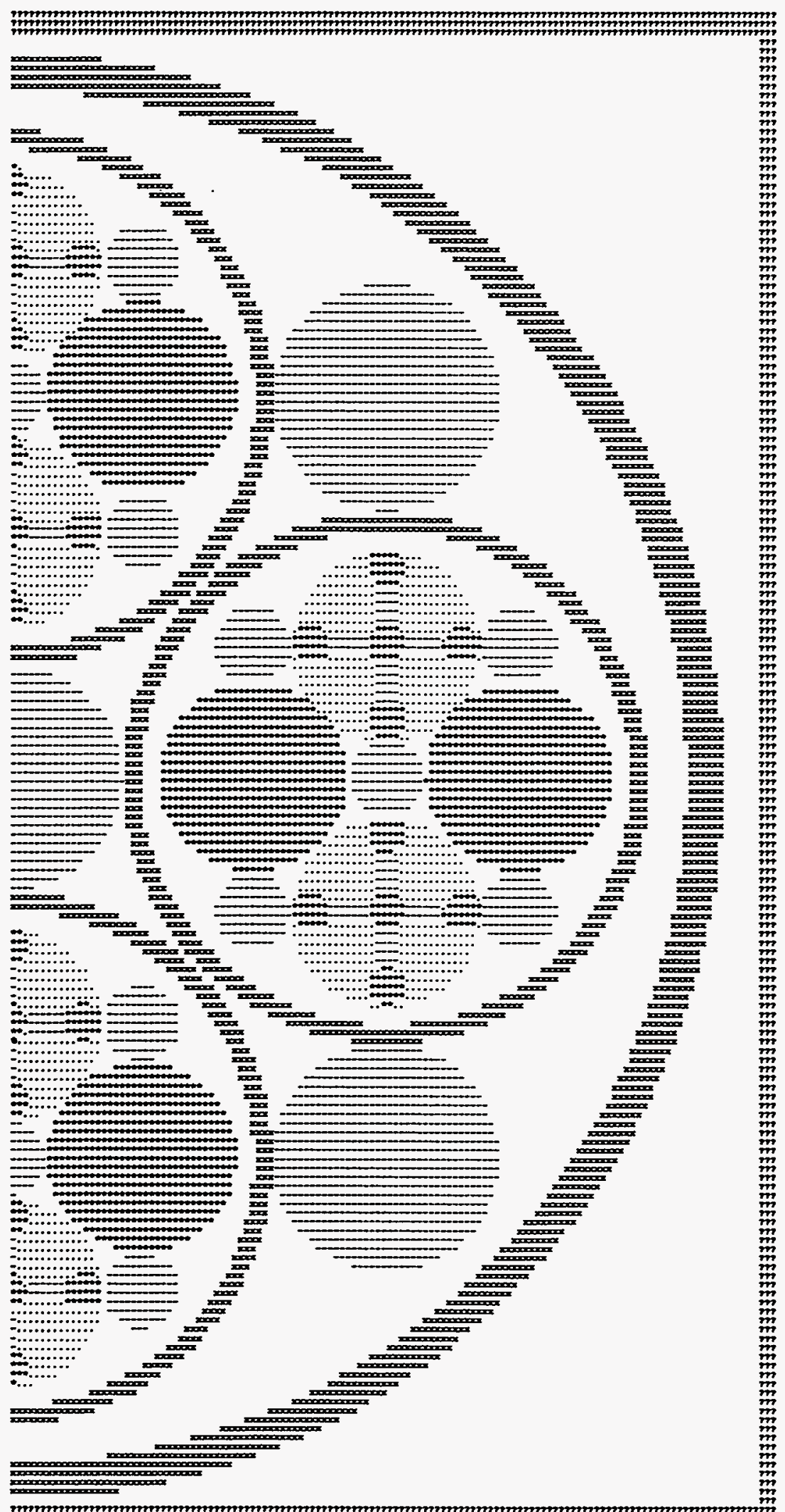

Figure F17.5.11b Right half of printer plot 
UNIT 1

CYLINDER 19.525 2P8.89

CYLINDER 2 10.16 $2 P 9.525$

CUBOID 3 4P10.875 2 P10.24

MEDIA 211

MEDIA 312 - 1

MEDIA $013-2$

BOUNDARY 3

The array of four Plexiglas containers can be described as array 1 in the array data as follows:

$A R A=1 \quad N U X=1 \quad N U Y=2 \quad N U Z=2$ FILL F1 END FILL

The four metal cylinders each have a radius of $5.748 \mathrm{~cm}$ and are $10.765 \mathrm{~cm}$ tall. They have a center-to-center spacing of $13.18 \mathrm{~cm}$ in the "y" direction and $12.45 \mathrm{~cm}$ in the " $z$ " direction (vertical). Thus one of the metal cylinders with its appropriate spacing cuboid can be described as Unit 2. This array is also considered to be bare and unsupported.

UNIT 2

CYLINDER $15.7482 P 5.3825$

CUBOID 2 4P6.59 $2 P 6.225$

MEDLA 111

MEDLA $012-1$

BOUNDARY 2

The array of four metal cylinders can be described as array 2 in the array data.

$A R A=2 \quad N U X=1 \quad N U Y=2 \quad N U Z=2$ FILL F2 END FILL

Now two arrays have been described. The overall dimensions of the array of Plexiglas containers is 21.75 $\mathrm{cm}$ in $\mathrm{x}, 43.5 \mathrm{~cm}$ in $\mathrm{y}$, and $40.96 \mathrm{~cm}$ in $\mathrm{z}$. The overall dimensions of the array of metal cylinders is $13.18 \mathrm{~cm}$ in $\mathrm{x}, 26.36 \mathrm{~cm}$ in $\mathrm{y}$, and $24.9 \mathrm{~cm}$ in $\mathrm{z}$.

In order to describe the composite array, these two arrays must be stacked together into an array. In order for them to be stacked into an array, the adjacent faces must match. This arrangement is accomplished by defining a Unit 3 which contains array 1, the array of Plexiglas solution containers. The overall dimensions of this unit are $21.75 \mathrm{~cm}$ in $x, 43.5 \mathrm{~cm}$ in $y$, and $40.96 \mathrm{~cm}$ in $\mathrm{z}$. The overall dimensions of the array need to be calculated. An array position needs to be chosen which is used to place the array in the unit. The array is placed in the unit by aligning the origin of the unit in the chosen array position with a calculated position in the surrounding unit. The chosen array position and the $\mathrm{X}, \mathrm{Y}$, and $\mathrm{Z}$ positions are entered after the keyword PLACE on the ARRAY card. Unit 3 is defined as follows:

\section{UNIT 3}

CUBOWD $12 P 10.8752 P 21.752 P 20.48$

ARRAY 11 PLACE $1110.0-10.875$-10.24

BOUNDARY 1

NUREG/CR-0200,

Vol. 2, Rev. 5

F17.5.42 
The array of metal cylinders will be defined to be Unit 4. However, this array is smaller in the $y$ and $z$ dimensions than the array of Plexiglas units; therefore, a void region must be placed around the array in those directions, so Unit 4 and Unit 3 will be the same size in $y$ and $z$.

\section{UNIT 4}

CUBOID $12 P 6.592 P 13.182 P 12.45$

CUBOID $22 P 6.592 P 21.752 P 20.48$

ARRAY 2 I PLACE $1110.0-6.59-6.225$

$M E D I A$ O $12-1$

BOUNDARY 2

Now that Unit 3 and Unit 4 have been defined, they must be placed in the global or universe array contained in the global unit. The global unit is specified by putting the keyword GLOBAL prior to the word unit.

\section{GLOBAL UNIT 5}

CUBOID 134.930 .043 .50 .040 .960 .0

ARRAY 31 PLACE 1116.5921 .7520 .48

BOUNDARY 1

The array of arrays is defined as the global array in the array data as follows:

$G B L=3 \quad A R A=3 \quad N U X=2 \quad N U Y=1 \quad N U Z=1 \quad F I L L \quad 43$ END FILL

This discussion completes the geometry description for the problem. The complete input description for the problem is given below. The nuclide IDs are for the 16-group Hansen-Roach working-format library.

Data description of Example 17.

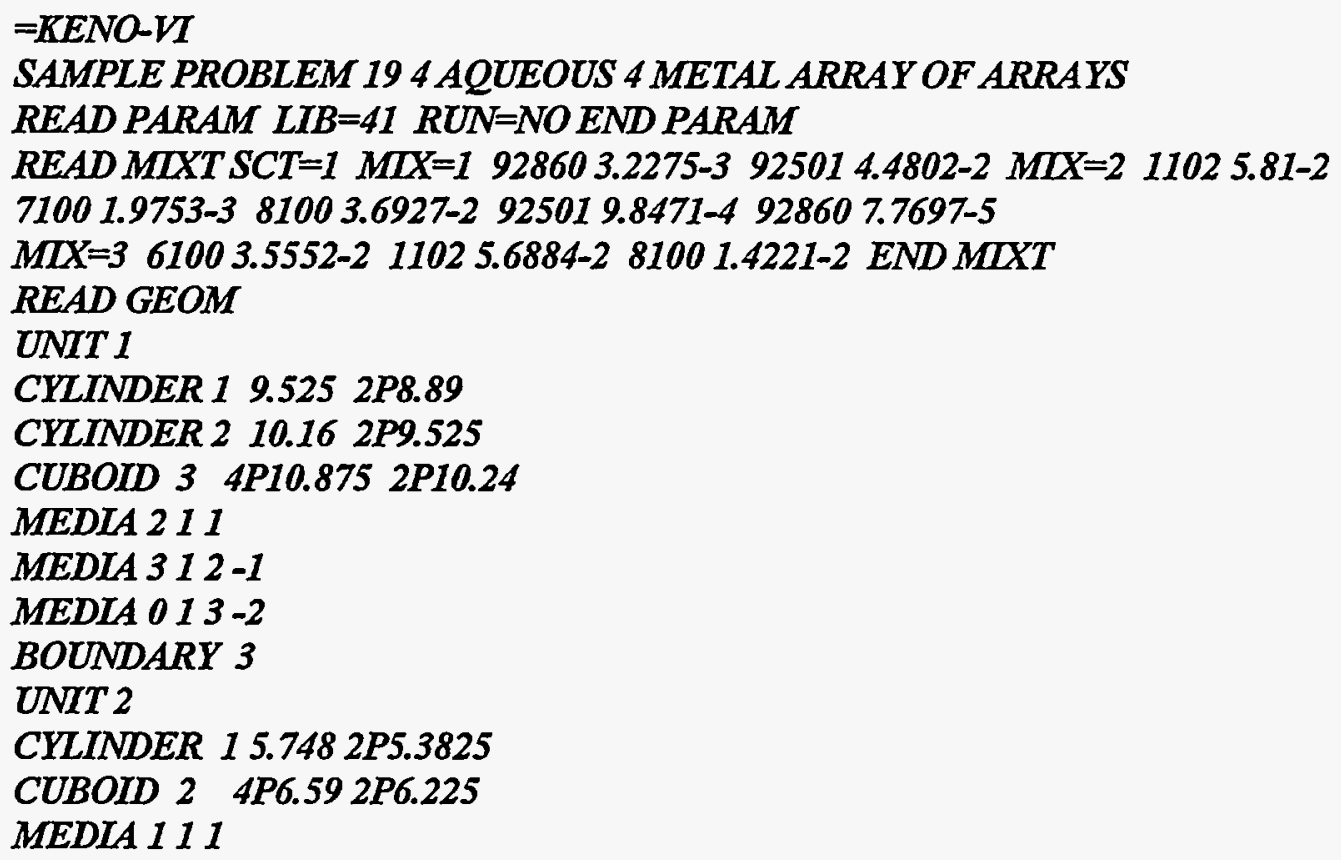


MEDIA $012-1$

BOUNDARY 2

UNIT 3

CUBOID $12 P 10.8752 P 21.752 P 20.48$

ARRAY 11 PLACE $1110.0-10.875-10.24$

BOUNDARY 1

UNIT 4

CUBOID $12 P 6.592 P 13.182 P 12.45$

CUBOID $22 P 6.592 P 21.752 P 20.48$

ARRAY 21 PLACE $1110.0-6.59-6.225$

MEDIA $012-1$

BOUNDARY

GLOBAL UNIT 5

CUBOID 134.930 .043 .50 .040 .960 .0

ARRAY 31 PLACE 1116.5921 .7520 .48

BOUNDARY 1

END GEOM

READ ARRAY ARA=1 NUX=1 NUY=2 NUZ=2 FILL F1 END FILL

$A R A=2 \quad N U X=1 \quad N U Y=2 N U Z=2$ FILL F2 END FILL GBL=3 ARA=3 NUX=2 NUY=1 NUZ=1

FILL 4 3 END FILL

END ARRAY

READ PLOT TTL $=' X-Y$ SLICE $A T Z=10.24^{\prime}$

$X U L=1.0 \quad Y U L=44.5 \quad Z U L=10.24 X L R=35.93 \quad Y L R=1.0 \quad Z L R=10.24$

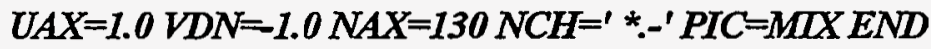

$T T L=' X-Z$ SLICE $A T Y=10.875^{\prime}$

$X U L=1.0 \mathrm{YUL}=10.875 \mathrm{ZUL}=41.96 \mathrm{XLR}=35.93 \mathrm{YLR}=10.875 \mathrm{ZLR}=1.0$

$U A X=1.0$ WDN=1.0 PIC=MLX END END PLOT

END DATA

$E N D$

A printer plot of an $x-y$ slice taken through the bottom layer of the array is shown in Fig. F17.5.12. A printer plot of an $x-z$ slice taken through the left half of the array is shown in Fig. F17.5.13. These printer plots were used to verify the geometry mock-up.

\section{STORAGE ARRAY}

EXAMPLE 18. Consider a storage array of highly enriched uranium buttons, each $2.54 \mathrm{~cm}$ ( $1 \mathrm{in}$.) tall and $10.16 \mathrm{~cm}(4 \mathrm{in}$.) in diameter. These buttons are stored on stainless steel shelves with a center-to-center spacing of $60.96 \mathrm{~cm}(2 \mathrm{ft})$ between them. The shelves are $0.64 \mathrm{~cm}$ (1/4 in.) thick, $45.72 \mathrm{~cm}(18 \mathrm{in}$.) wide, 609.6 $\mathrm{cm}(20 \mathrm{ft})$ long, and are $45.72 \mathrm{~cm}$ (18 in.) from the top of a shelf to the bottom of the shelf above it. Each rack of storage shelves is four shelves high, with the first shelf being $15.24 \mathrm{~cm}(6 \mathrm{in})$ above the floor. The storage room is $586.56 \mathrm{~cm}$ ( $19.5 \mathrm{ft}$ ) in the $\mathrm{x}$ direction by $1293.44 \mathrm{~cm}$ ( $43 \mathrm{ft}$ ) in the $y$ direction, with $365.76 \mathrm{~cm}$ (12-ft) ceilings in the $\mathrm{z}$ direction. The walls, ceiling, and floor are composed of 30.48-cm- (1-ft-)thick concrete. All the aisles between the storage racks are $91.44 \mathrm{~cm}(3 \mathrm{ft})$ wide. The racks are arranged with their length in the $y$ direction and an aisle between them. The array of racks are arranged with two in the $y$ direction and five in the $x$ direction. Mixture 1 is the uranium metal, mixture 2 is the stainless steel, and mixture 3 is the concrete.

NUREG/CR-0200,

Vol. 2, Rev. 5

F17.5.44 


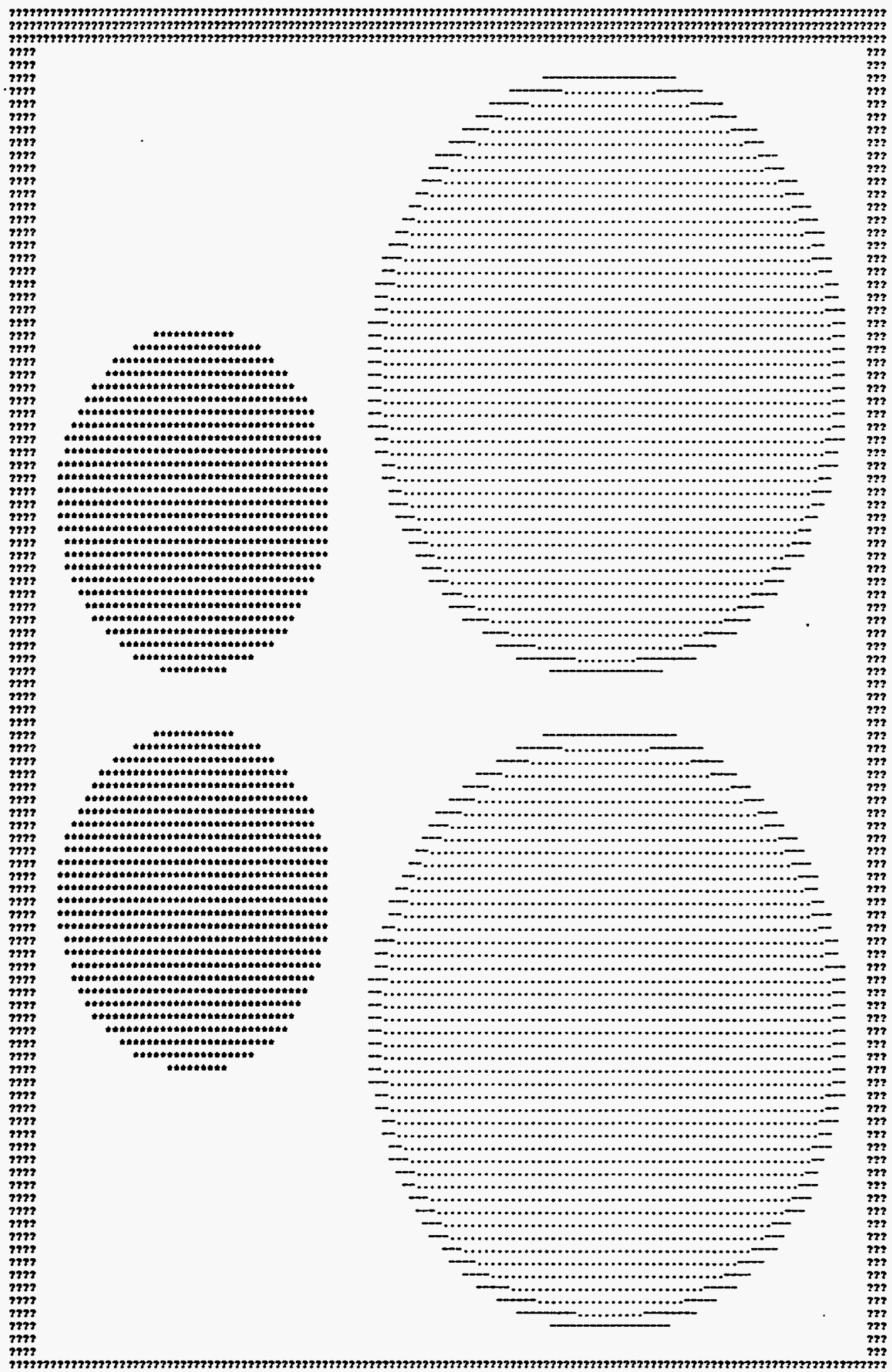

Figure F17.5.12 $\mathrm{x}-\mathrm{y}$ plot of mixed array

F17.5.45

NUREG/CR-0200,

Vol. 2, Rev. 5 


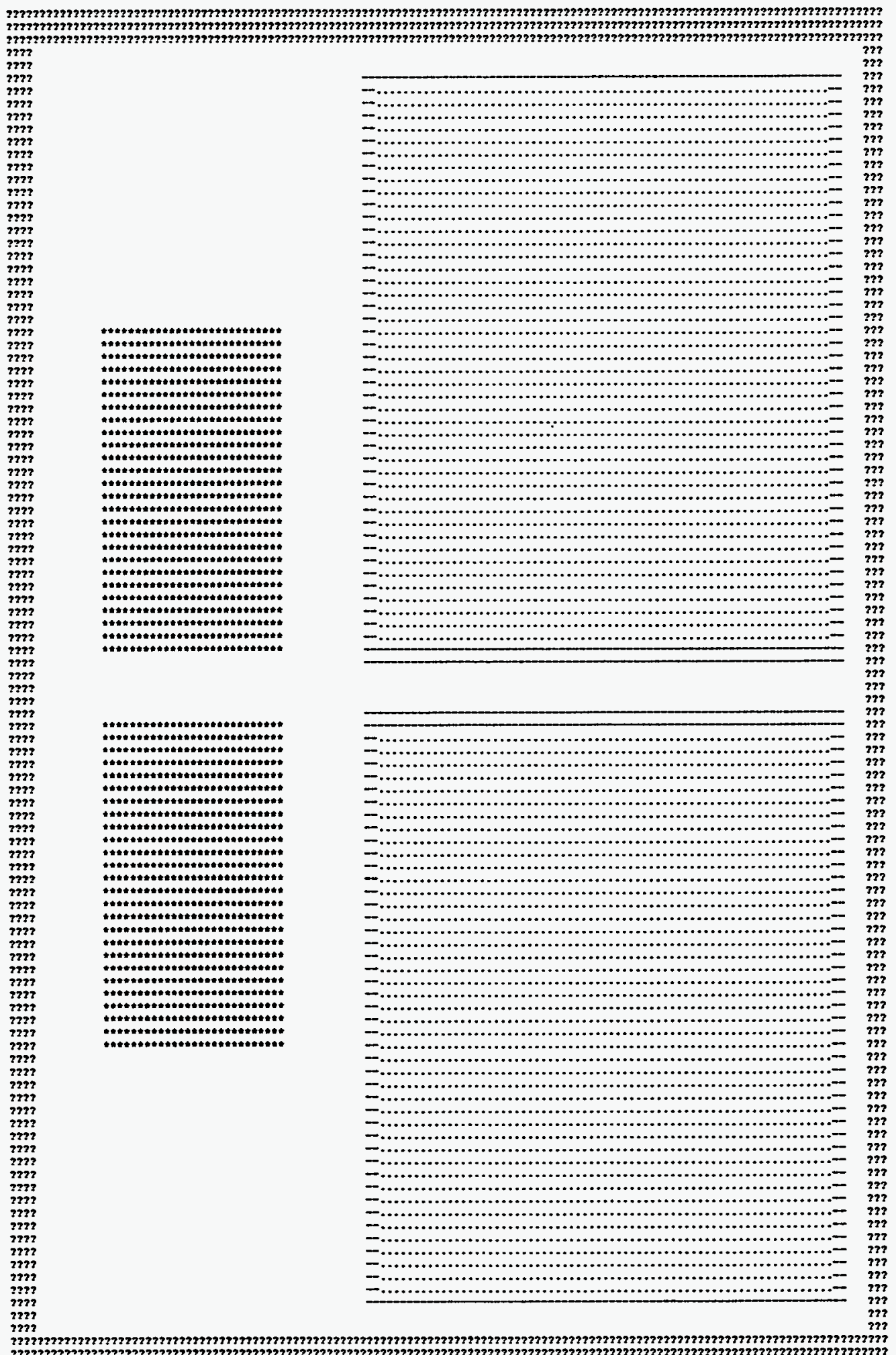

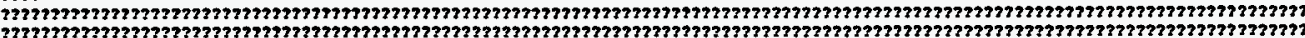

Figure F17.5.13 An x-z plot of mixed array

NUREG/CR-0200,

Vol. 2, Rev. 5

F17.5.46 
First, describe the metal button and its center-to-center spacing. The void vertical spacing has been chosen arbitrarily to extend from the bottom of the button to the next shelf above the button. The shelf of stainless steel is described under the button.

UNIT I

CYLINDER $15.08 \quad 2.540 .0$

CUBOID $2 \quad 2 P 22.86 \quad 2 P 30.48 \quad 45.72 \quad 0.0$

$\begin{array}{llllllll}C U B O I D & 3 & 2 P 22.86 & 2 P 30.48 & 45.72 & -.635\end{array}$

$M E D I A 111$

MEDLA $012-1$

$M E D I A 213-2-1$

BOUNDARY 3

Array 1 creates an array of these buttons that fills one shelf. Unit 2 then contains one of the shelves shown in Fig. F17.5.14.

$A R A=1 \quad N U X=1 \quad N U Y=10 \quad N U Z=1$ FILL F1 END FILL

UNIT 2

CUBOID 145.720 .0609 .600 .046 .3550 .0

ARRAY 11 PLACE 111122.8630 .480 .635

BOUNDARY 1

Stack four Unit 2's vertically to obtain one of the racks shown in Fig. F17.5.14. One rack is defined by array 2.

$A R A=2 \quad N U X=1 \quad N U Y=1 \quad N U Z=4 \quad F I L L \quad F 2$ END FILL

Generate a Unit 3 that contains a rack of shelves and a Unit 4 that is the aisle between the ends of the two racks in the $y$ direction.

UNIT 3

CUBOID 145.720 .0609 .600 .0185 .420 .0

ARRAY 21 PLACE $1113 * 0.0$

BOUNDARY 1

UNIT 4

CUBOID $12 P 22.862 P 45.72185 .42 \quad 0.0$

MEDLA 011

BOUNDARY 1

Stack Units 3 and 4 together in the y direction to create Unit 5 which contains both racks in the $y$ direction and the aisle between them. This configuration is shown in Fig. F17.5.14.

$A R A=3 \quad N U X=1 \quad N U Y=3 N U Z=1$ FILL 343 END FILL

F17.5.47

NUREG/CR-0200, Vol. 2, Rev. 5 

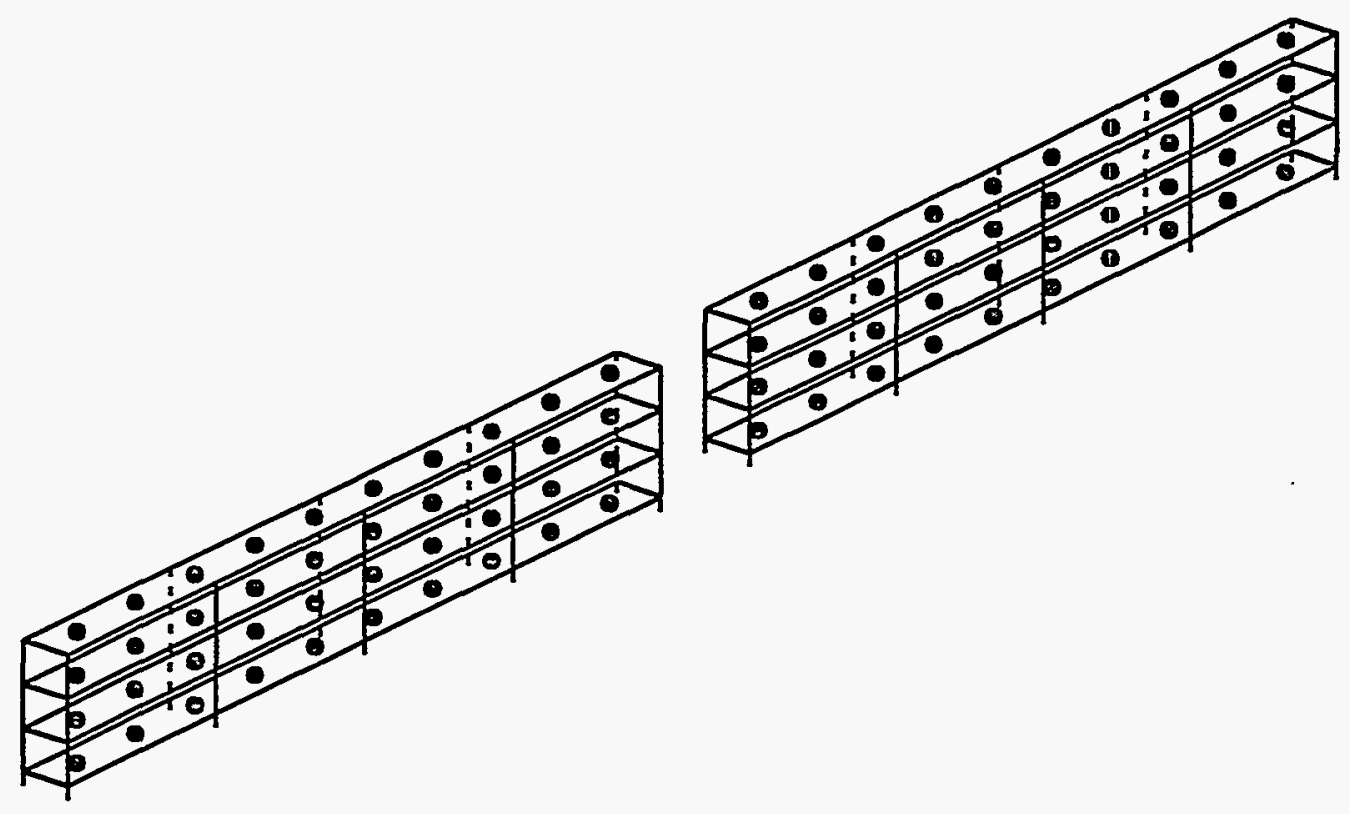

Figure F17.5.14 Two racks of uranium buttons

\section{UNIT 5}

CUBOW 145.720 .01310 .640 .0185 .420 .0

ARRAY 31 PLACE $1113 * 0.0$

BOUNDARY 1

Create a Unit 6, which is an aisle $91.44 \mathrm{~cm}$ (3 ft) wide in the $\mathrm{x}$ direction and $1310.64 \mathrm{~cm}(43 \mathrm{ft})$ in the $y$ direction (full length of the room).

\section{UNIT 6}

CUBODD 191.440 .01310 .640 .0185 .420 .0

MEDIA 011

BOUNDARY 1

Stack Units 5 and 6 in the $x$ direction to achieve the array of racks in the room. Then put the 15.24-cm (6-in.) spacing below the bottom of the racks, the spacing between the top of the top rack and the ceiling, and add the concrete floor, walls, and ceiling around the array. Array 4 describes the array of racks in the room. The core description encompasses this array, and the first reflector descriptions are used to add the spacing between the top rack and the ceiling. The last two reflector descriptions add the ceiling, walls and floor. A perspective of the room is shown in Fig. F17.5.15.

NUREG/CR-0200,

Vol. 2, Rev. 5

F17.5.48 
$G B L=4 \quad A R A=4 \quad N U X=9 \quad N U Y=1 \quad N U Z=1 \quad F I L L 563 Q 25$ END FILL

GLOBAL UNIT 7

$\begin{array}{llll}\text { CUBODD } 1594.36 & 0.01310 .64 & 0.0185 .42 & 0.0\end{array}$

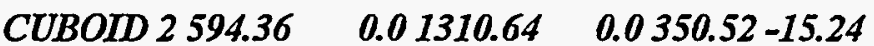

CUBODD $3599.36 \quad-5.001315 .64 \quad-5.00355 .52-20.24$

CUBOID $4604.36-10.001320 .64-10.00360 .52-25.24$

CUBOID 5 609.36 -15.00 1325.64-15.00 365.52 -30.24

CUBOID 6 614.36 -20.00 1330.64-20.00 370.52 -35.24

CUBOID $7619.36-25.001335 .64-25.00375 .52-40.24$

CUBOID 8624.36 -30.00 1340.64-30.00 380.52 -45.24

CUBOID $9624.84-30.481341 .12$-30.48 381.00 -45.72

ARRAY 41 PLACE 1113 *0.0

MEDIA $012-1$

MEDIA 3 2 3-2 -1

MEDIA 3 3 -3

MEDLA $345-4$

MEDIA 35 6-5

MEDLA 36 7-6

MEDIA $378-7$

MEDLA $389-8$

BOUNDARY 9

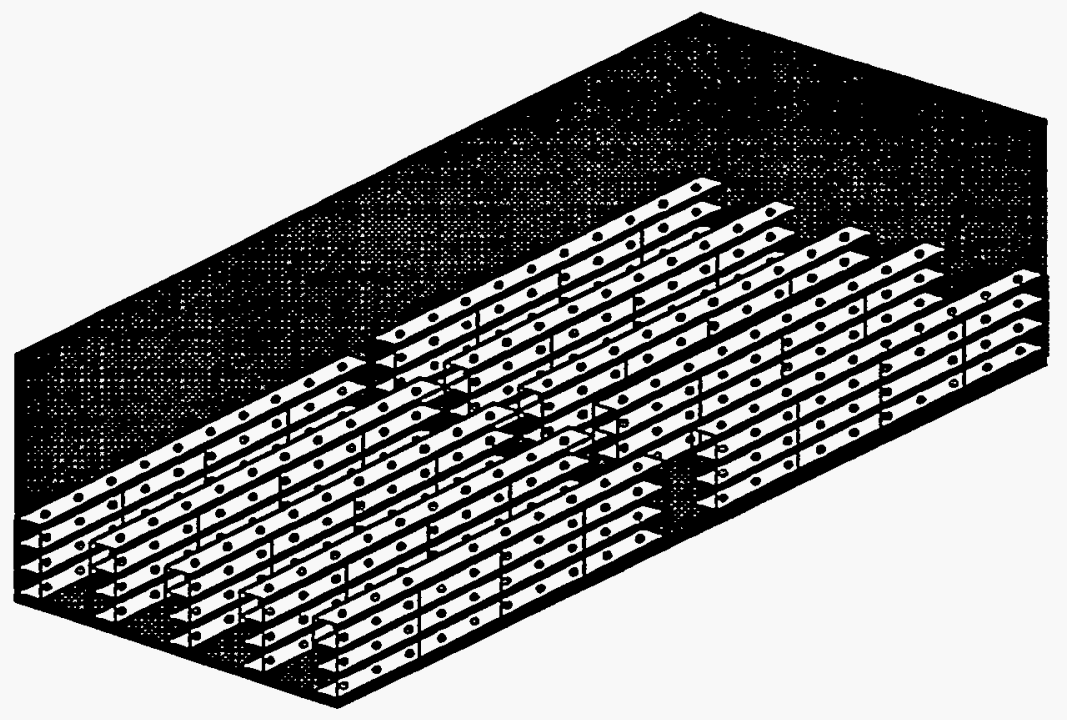

Figure F17.5.15 Entire storage array in the room

F17.5.49

NUREG/CR-0200,

Vol. 2, Rev. 5 
The final mock-up for this room is given below: The printer plots for this problem must be quite large in order to see all the detail because the array is sparse and the shelves are thin. Therefore, the printer plots for this system are not included as figures. The user can generate the printer plots if it is desirable to see them. The first two plots are two pages wide, and the last one is only one page wide. The nuclide IDs used in this problem are for the 16-group Hansen-Roach working-format library.

Data description of Example 18.

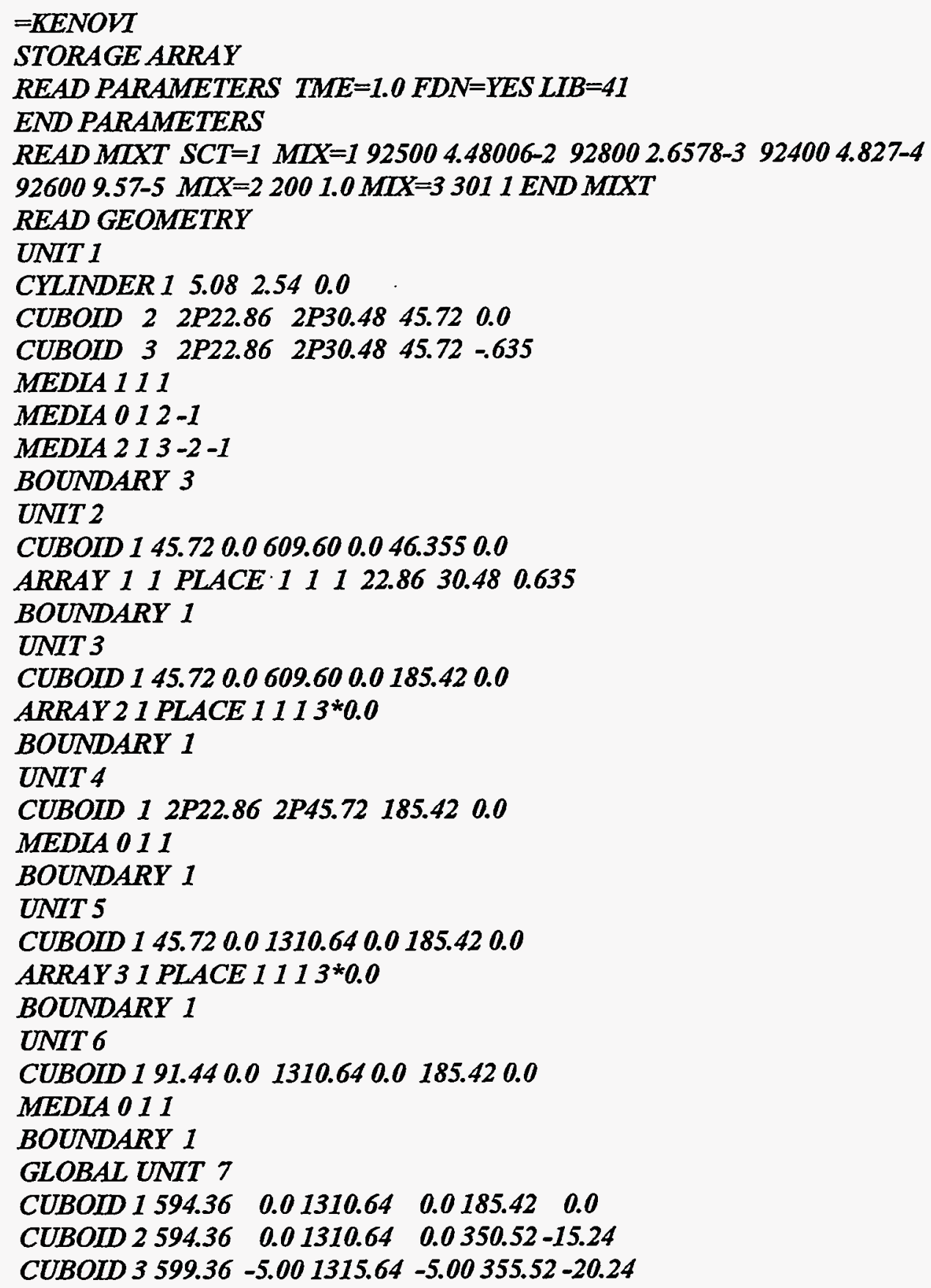




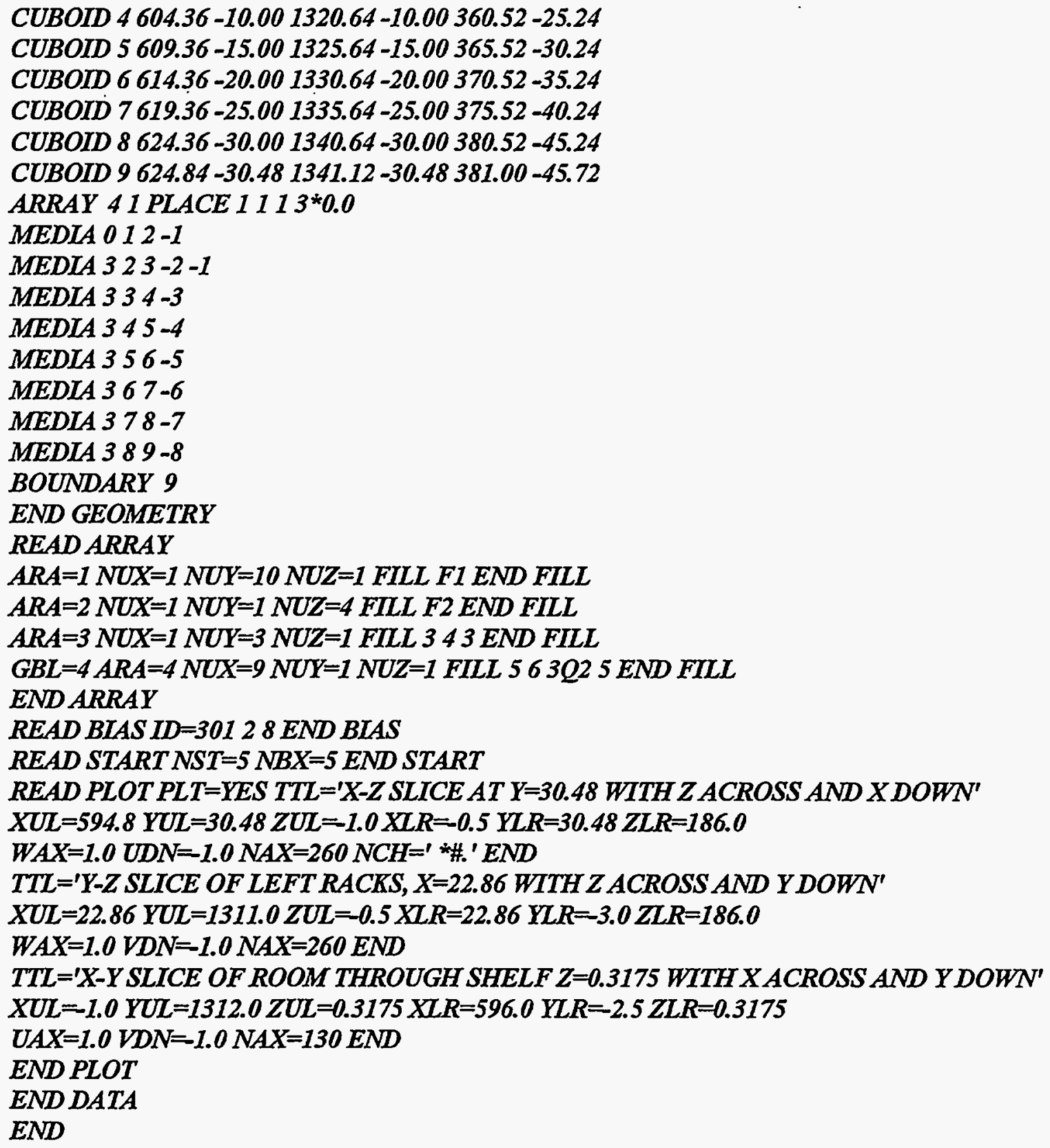

F17.5.6.4 Arrays and Holes

Sections F17.5.6.1 and F17.5.6.2 describe the use of holes, and Sect. F17.5.6.3 describes multiple arrays and arrays of arrays. Holes can also be used to place arrays at locations in other units. This section contains examples to illustrate the combined use of arrays and holes. 


\section{EXAMPLE 19. A SIMPLE CASK}

Consider a cylindrical, mild steel container having an inside radius of $4.15 \mathrm{~cm}$ and a radial wall thickness of $0.45 \mathrm{~cm}$. The thickness of the ends of the container is $1.27 \mathrm{~cm}$, and the inside height is $10.1 \mathrm{~cm}$. Highly enriched uranium rods, $1 \mathrm{~cm}$ in diameter and $10 \mathrm{~cm}$ long, are banded together into square bundles of four. These bundles are then positioned in the mild steel container as shown in Fig. F17.5.16. The rods are positioned on the floor of the container and have a $0.1-\mathrm{cm}$ gap between their tops and the top of the container. Material 1 is uranium and material 2 is steel.

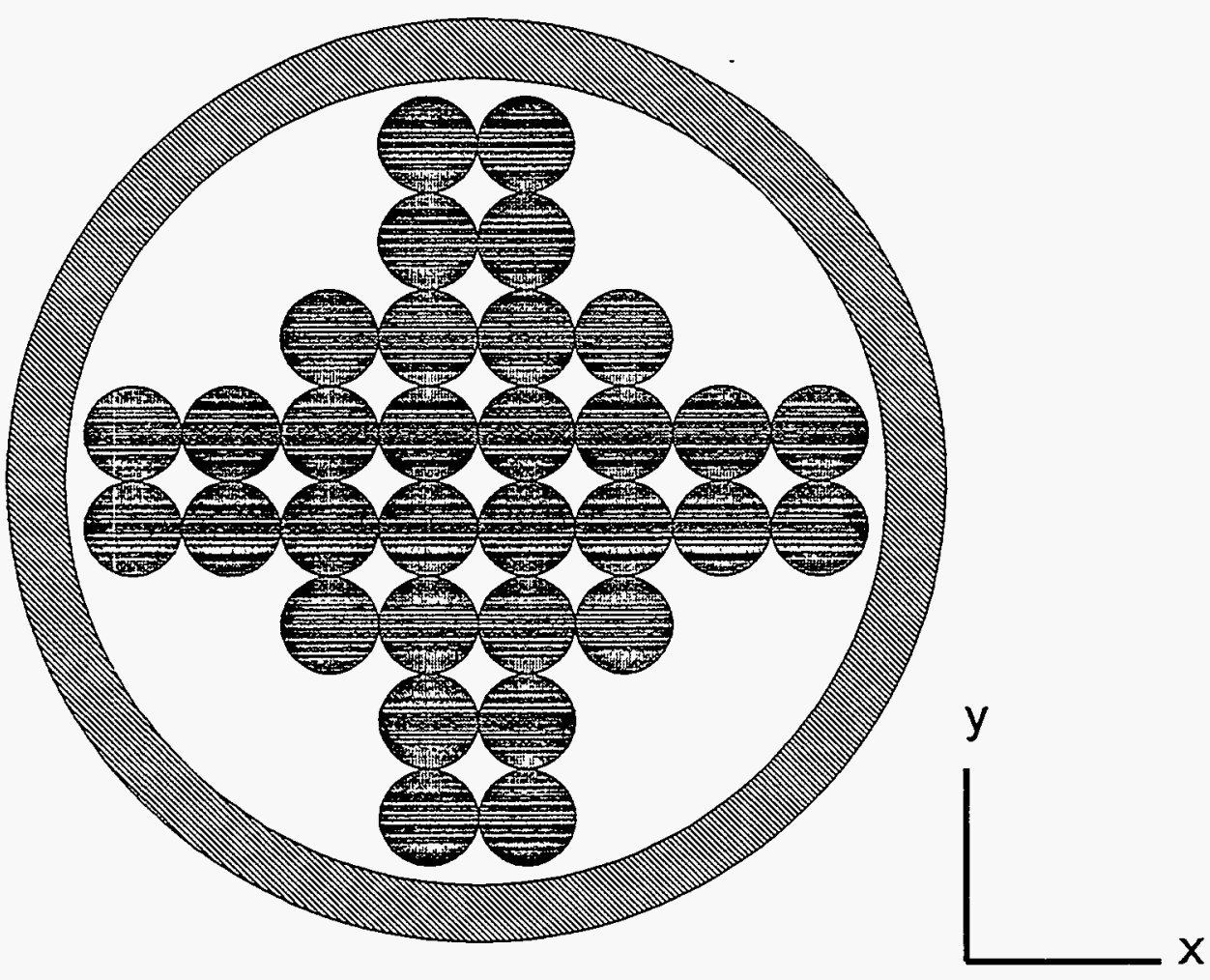

Figure F17.5.16 Uranium rods in a cylindrical container

To generate the geometry description for this system, define Unit 1 to be one uranium rod and its associated square-pitch, close-packed spacing region and Unit 2 to be a void cuboid with the same square pitch.

\section{UNIT 1}

CYLINDER $10.52 P 5.0$

CUBODD $24 P 0.52 P 5.0$

MEDIA 111

MEDIA 012 -1

BOUNDARY 2

NUREG/CR-0200,

Vol. 2, Rev. 5

F17.5.52 


\section{UNIT 2}

CUBOID $14 P 0.52 P 5.0$

MEDIA 011

BOUNDARY 1

Define array 1 to be the central square $10 \times 10$ array, consisting of 32 rods and 68 void positions that can be used to represent the array shown in Fig. F17.5.16.

$A R A=1 \quad N U X=10 N U Y=10 \quad N U Z=1$ FILL $14^{*} 2118 * 2117^{*} 24^{*} 14^{*} 28^{*} 1228 * 14^{*} 24^{*} 17^{*} 2118 * 2$ $1114 * 2$ END FILL

Now place array 1 in Unit 3. The first cylinder card defines the array boundary. Everything external to this boundary is not considered part of the problem. The positions in the array that do not contain rods are filled with cuboids consisting of void. The array boundary must either coincide with the outer boundary of the array or be contained within the array. An exterior void region is placed around the array boundary to coincide with the size of the interior radius of the container. The $10 \times 10$ array with the array boundary is shown in Fig. 17.5.16a.
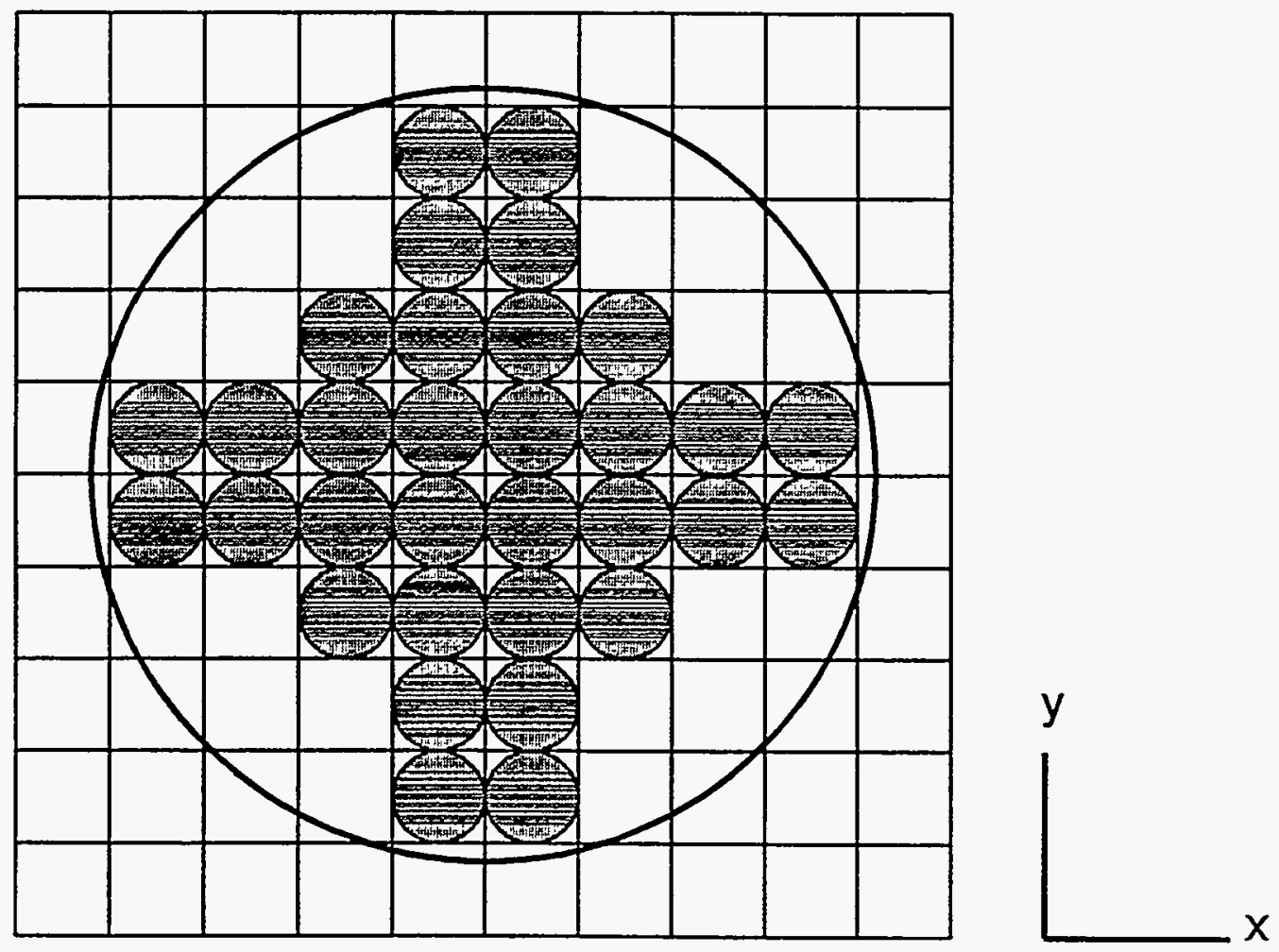

Figure F17.5.16a The $10 \times 10$ array of uranium 32 rods and 68 void cuboids with the array boundary 
UNIT 3

CYLINDER $14.155 .0-5.0$

CYLINDER $24.155 .1-5.0$

ARRAY 11 PLACE 551 - $0.5-0.5-0.0$

MEDIA 012 -1

BOUNDARY 2

The unit containing the array is now placed within the global unit using a hole media card. The location of the hole is determined using ORIGIN data to match the origin of the unit in the hole with a $X, Y, Z$ position in the surrounding unit. In this problem the origin of the unit needs to be at position $(0,0,0)$. Since only nonzero data must be entered, ORIGIN data are not needed for this problem. The boundary region consists of the steel container.

\section{GLOBAL UNIT 4}

CYLINDER $14.155 .1-5.0$

CYLINDER $24.66 .37-6.27$

HOLE 31 ORIGIN $X=0.0 Y=0.0 Z=0.0$

MEDIA $212-1$

BOUNDARY 2

The overall problem description is shown below. Two of the printer plots used for verification of this mock-up are shown in Figs. F17.5.17 and F17.5.18.

Data description of Example 19.

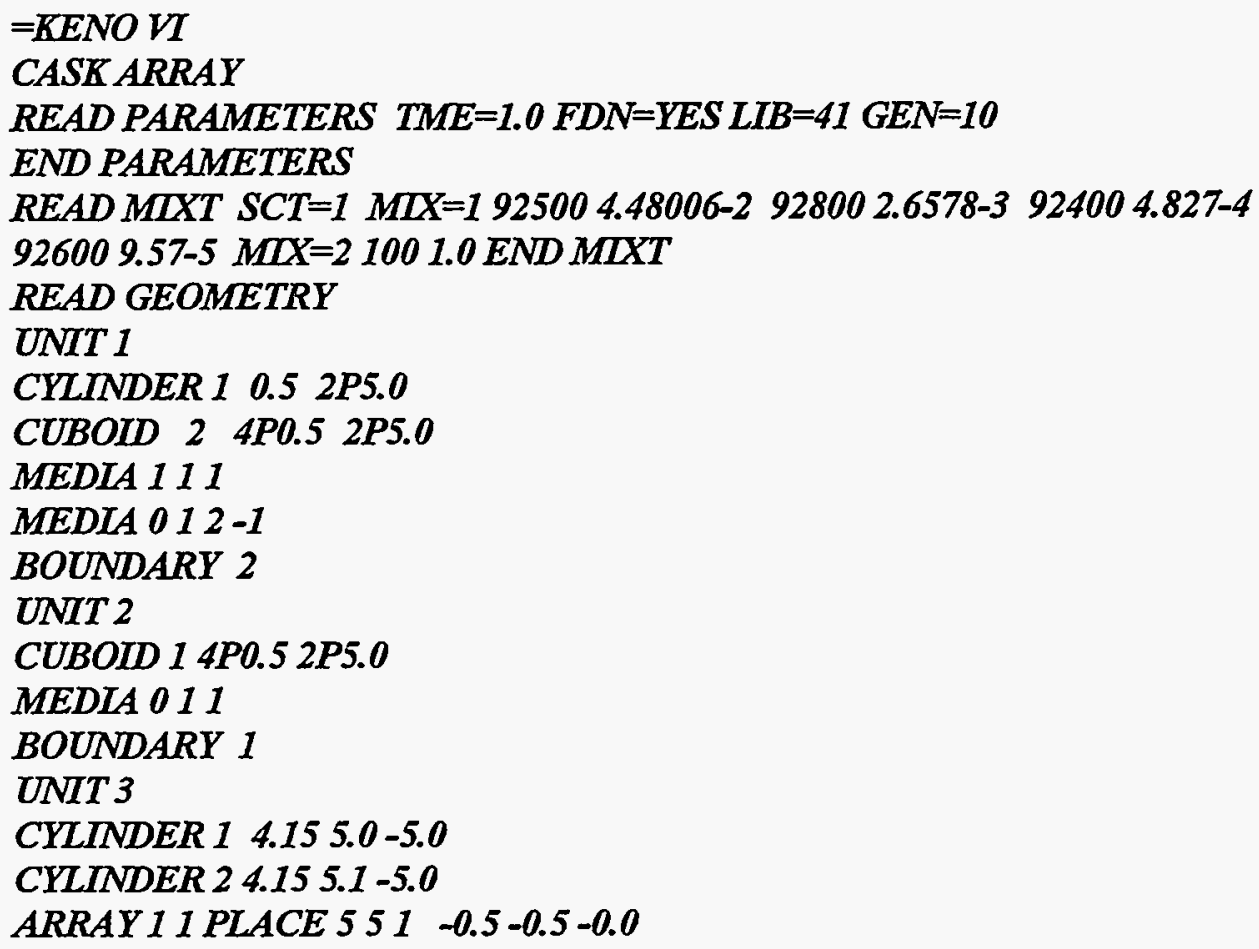

NUREG/CR-0200,

Vol. 2, Rev. 5 


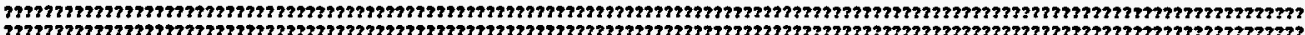

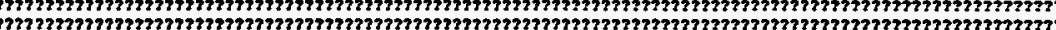

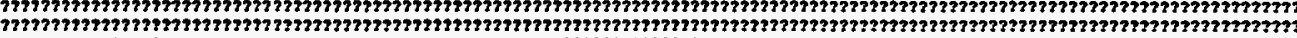

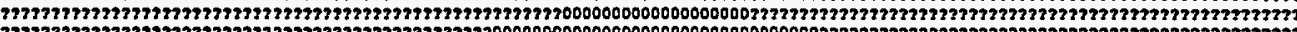

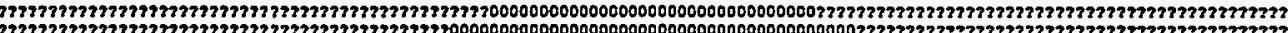
277ร7เ

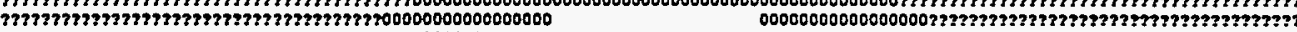

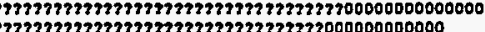

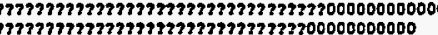

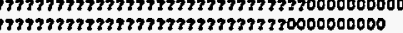

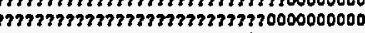

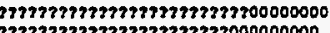

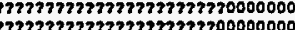

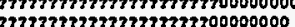

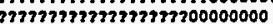

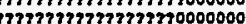

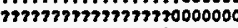
232373? 33?3?37320000000 23m33m?3m?30000000

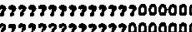
?121273737373730000000 2772777า17370000000 3223ว?3?m?000000

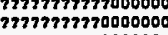
22127?าวก7000000 27727ว777000000 232773737000000 22713737000000 2า127?7200000 22127272000000 2727273000000 .....

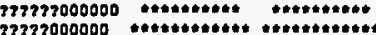

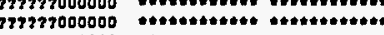
227237000000

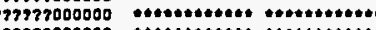
217237000000 ?7m?7m20000000 mm? วา7าว?000000 วงทาว 000000 ?77m?2000000 ?m?7?2000000 ?m?m?200000 mทา?ท22000000 ทา1าวา000000

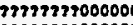
วาว?าวาวด00000

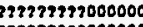
m7?m?m?7\%0000000

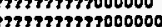

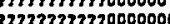

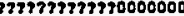

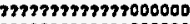

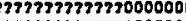

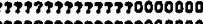

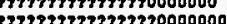

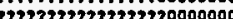

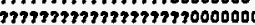

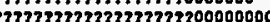

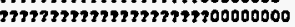

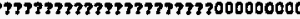

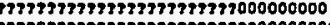

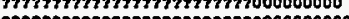

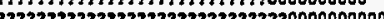

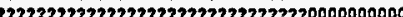

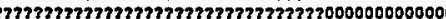

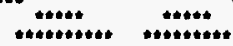

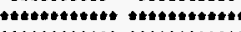

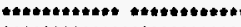

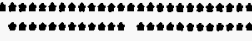

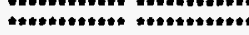
+......

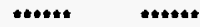
-

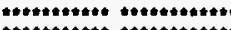
trtwent:" 0000000000000333373333373333737737372333733333

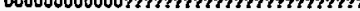

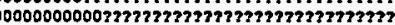

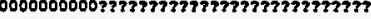

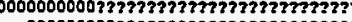

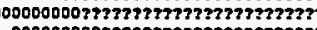

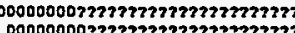
000073 00000373 $000000003277727 ? 28$

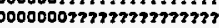
00000007???72?7373?3? 0000000737???7???23? 0000000772737777272 0000000272m?า?23? 000000ว777727772? 000000273?72727? 000000?วm7??? 0000007777m?

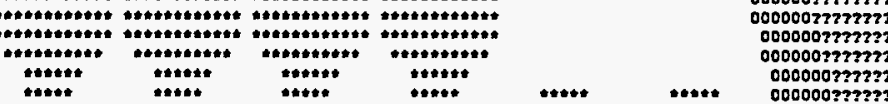

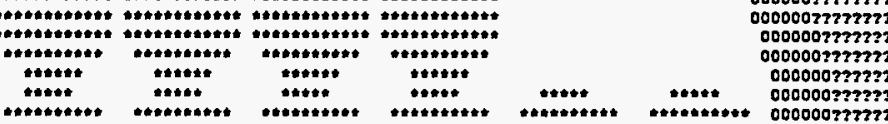
.

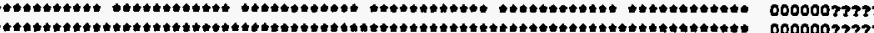
................................

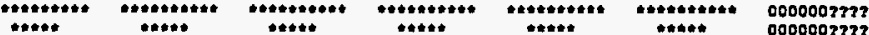
...te.

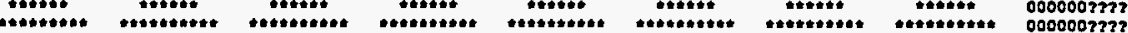

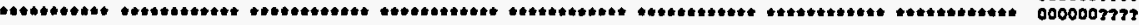
Q 00000077772 00000023717 00000073737 0000072727? (000007m? 000000733739 $000000737 m 79$ (1) 000000037mว?ว??? 00000007777???7? D0000077777777772 000000033272732332? $0000000373773732337 ?$

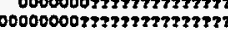
00000000733733535737333

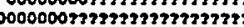

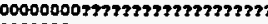

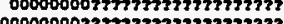

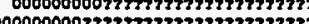

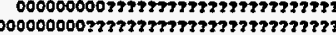

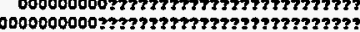

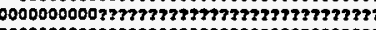

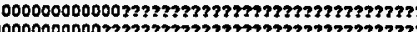

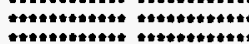

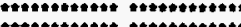

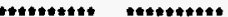

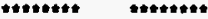

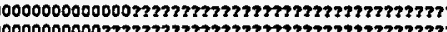

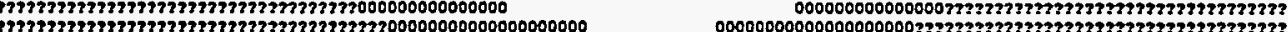

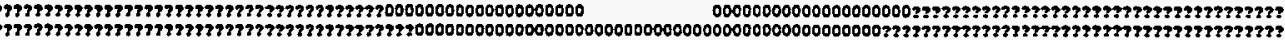

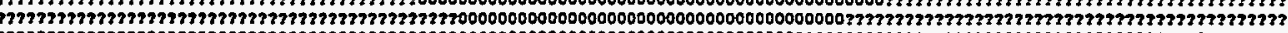

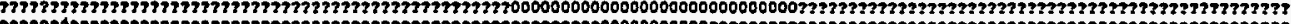
317ราน 

Figure F17.5.17 An $x-y$ slice of uranium rods in a cylindrical container

F17.5.55

NUREG/CR-0200, Vol. 2, Rev. 5 


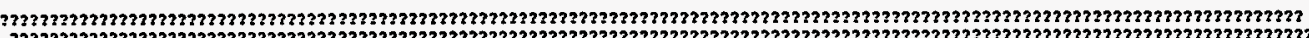

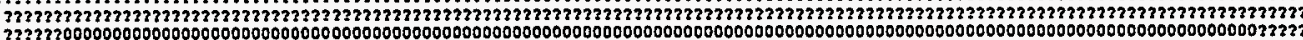
2222230000000000000000000000000000000000000000000000000000000000000000000000000000000000000000000000000000000000000000000000022727 21232000000000000000000000000000000000000000000000000000000000000000000000000000000000000000000000000000000000000000000000000000023232 22?23200000000000000000000000000000000000000000000000000000000000000000000000000000000000000000000000000000000000000000000000000073?3? 223232000000000000000000000000000000000000000000000000000000000000000000000000000000000000000000000000000000000000000000000000000?323? ?213220000000000000000000000000000000000000000000000000000000000000000000000000000000000000000000000000000000000000000000000033?3? ?323?2300000000000000000000000000000000000000000000000000000000000000000000000000000000000000000000000000000000000000000000000000?32?? 3? $332 ? 0000000000000000000000000000000000000000000000000000000000000000000000000000000000000000000000000000000000000000000000722 ? 2$ ?2?23200000000000000000000000000000000000000000000000000000000000000000000000000000000000000000000000000000000000000000000000000??23?

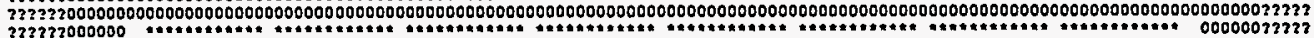
$2 ? 2222000000$ 32???2000000 $323 ? 3000000$ 33232000000 ?33373000000 337373000000 ?3?3?2000000 2????2000000 233232000000 232223000000 ???2?2000000 223223000000 22????000000 ??????000000 ?????2000000 ?????2000000 ????23000000 3 3m? 2722272000000

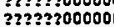
?23?2?0000000 227?22000000 32737300000 277?2?000000 ?3?????000000

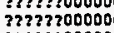
?37?7?000000 im???200000 27227200000 ?2???2000000 ?232?32000000 Z2?2??2000000 22????000000 22?2? 200000 ?2???7000000 ?2??22000000 2?2?232000000 ???322000000 23232200000 2??2? 2000000

?2?222000000

\$2372?000000

?3??32000000

2?2?22000000

213232000000

233373000000

?????2000000

\section{???2?23000000}

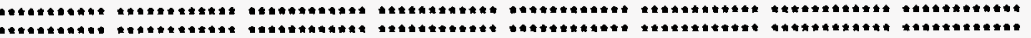
0000022232

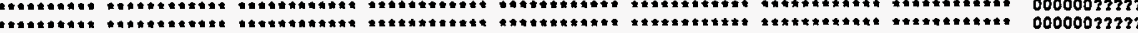

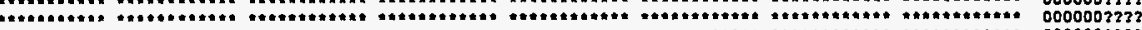

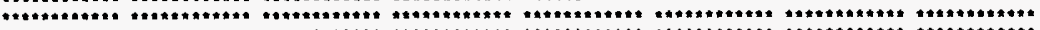

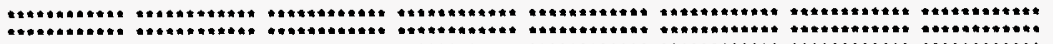
0000023232

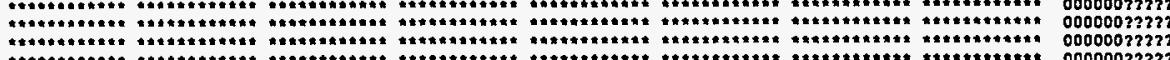

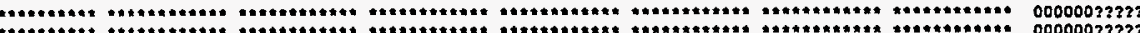

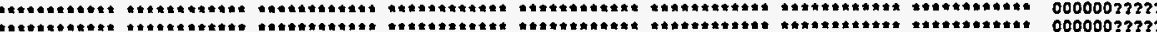

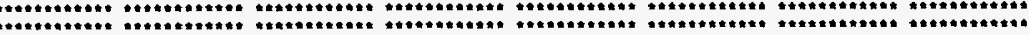

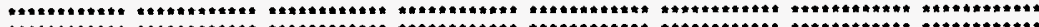

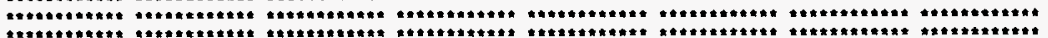
0000023223 000023223 000003333 00000033232 0000032323 (1)

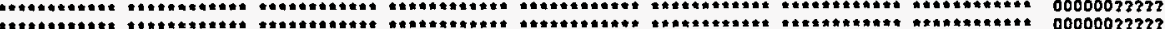

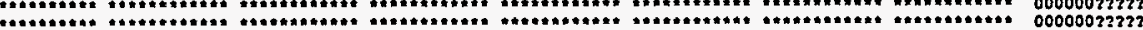

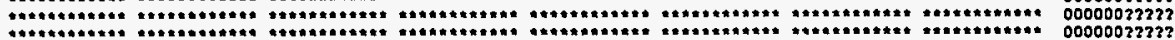
............

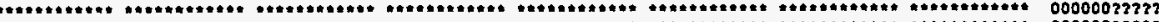

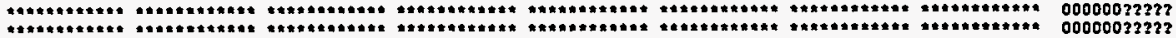

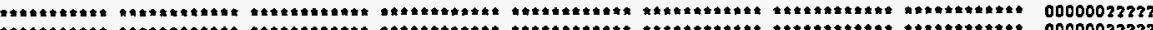

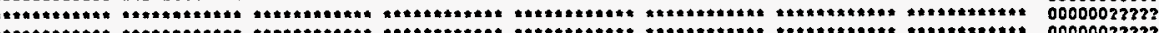

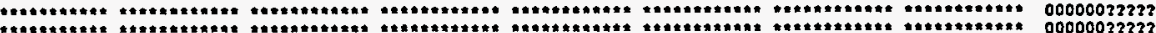
WEkt

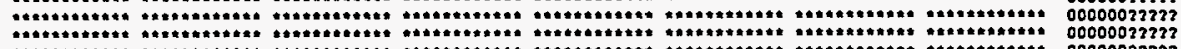
(1)

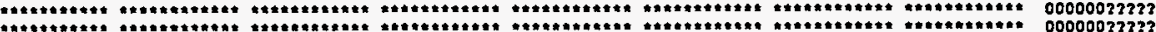

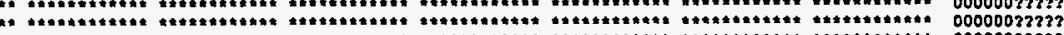

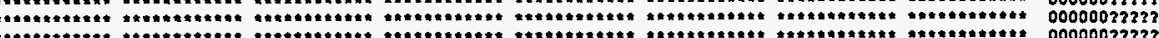

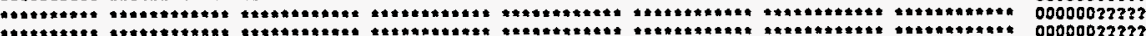

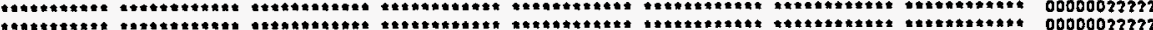

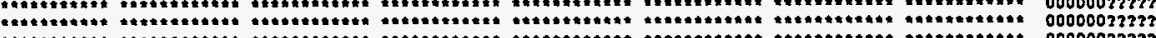

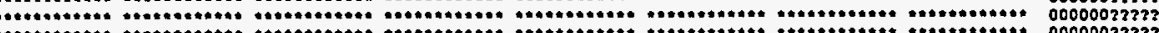

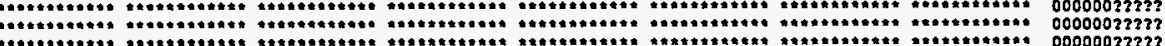

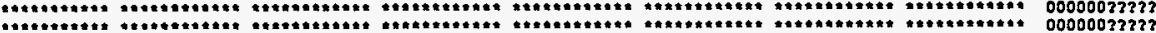

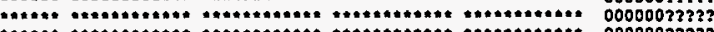

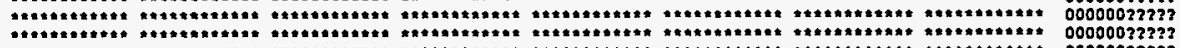

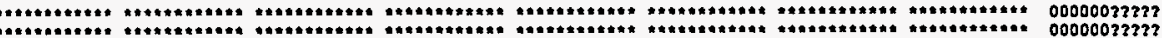

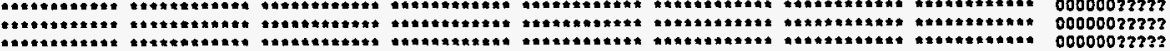

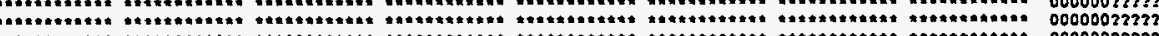

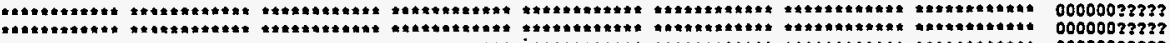

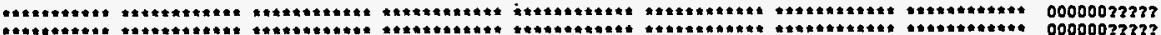

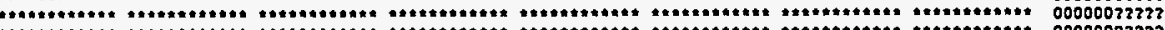

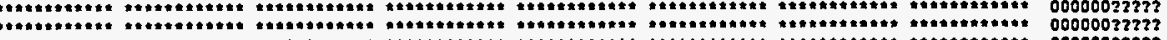

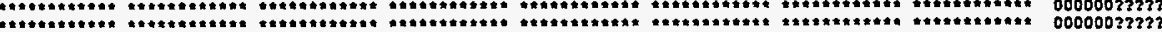

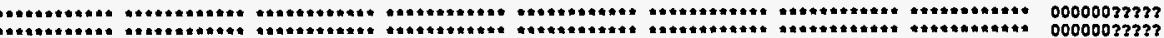
.........

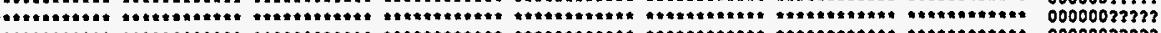

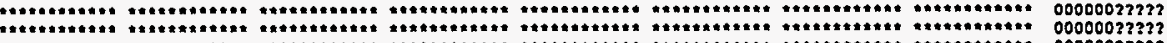

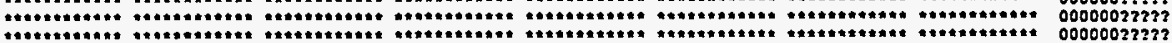

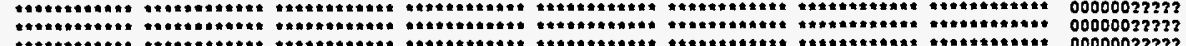

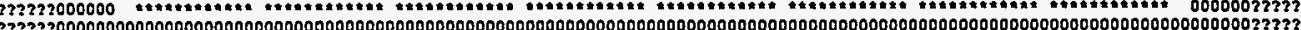
2323320000000000

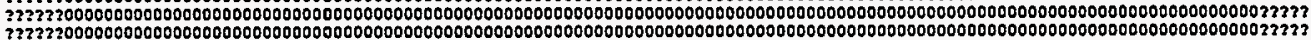
3?3?32000000000000000000000000000000000000000000000000000000000000000000000000000000000000000000000000000000000000000000000002323? ?273?300000000000000000000000000000000000000000000000000000000000000000000000000000000000000000000000000000000000000000000000003232?

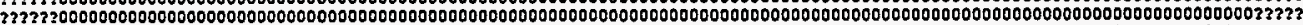

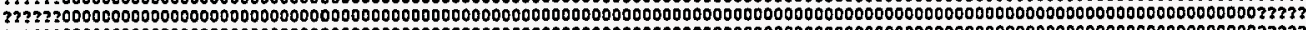

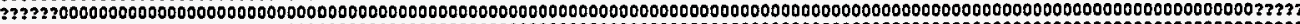
?3?3230000000000000000000000000000000000000000000000000000000000000000000000000000000000000000000000000000000000000000000000002333?

Figure F17.5.18 An $\mathrm{x}-\mathrm{z}$ slice of uranium rods in a cylindrical container

NUREG/CR-0200,

Vol. 2, Rev. 5 


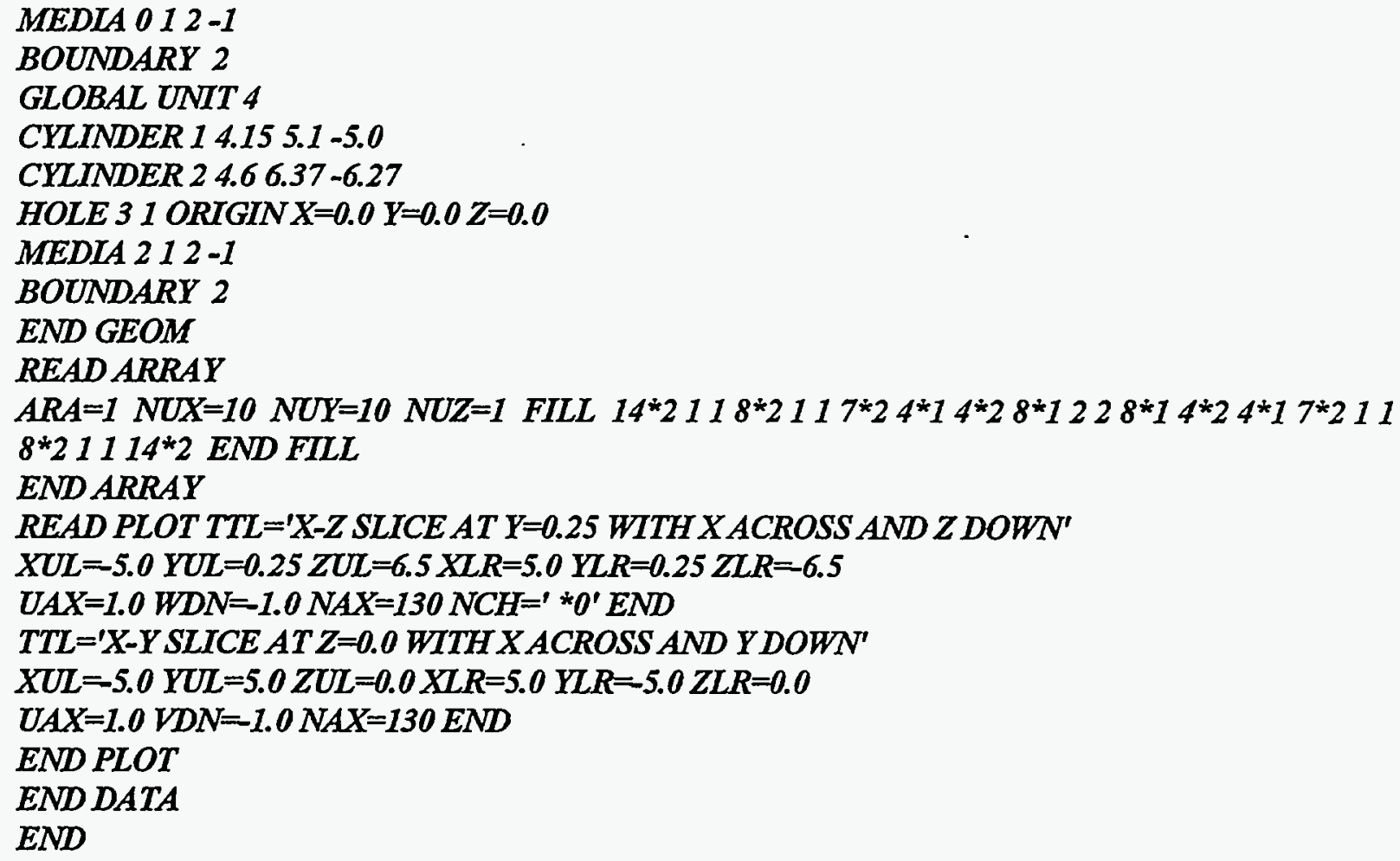

Consider a typical PWR shipping cask, illustrated in Fig. F17.5.19. The interior and exterior of the cask is carbon steel (mixture 7) and a depleted uranium gamma shield (mixture 6) is present in the annulus. The shipping cask contains seven PWR fuel assemblies. Each assembly is a $17 \times 17$ array of fuel rods with water holes as shown. Each assembly is contained in stainless steel (mixture 5). Each fuel rod is clad with Zircaloy (mixture 2) and is composed of $4 \%$ enriched $\mathrm{UO}_{2}$ (mixture 1 ). Rods of $\mathrm{B}_{4} \mathrm{C}$ (mixture 4) clad with stainless steel are positioned between the fuel assemblies. The entire cask is filled with water (mixture 3 ).

To describe the geometry of the cask, start by defining some simple units, as shown in Fig. F17.5.20. Unit 1 represents a fuel rod and its associated square-pitch spacing region. Unit 2 represents a water hole in a fuel assembly.

\section{UNIT I}

CYLINDER 1.41148365 .760 .0

CYLINDER 2.48133365 .760 .0

CUBOID $3.63754-.63754 .63754-.63754365 .760 .0$

MEDLA 111

MEDLA $212-1$

$M E D L A 313-2-1$

BOUNDARY 3

UNIT 2

CUBOID 1 .63754 -.63754.63754 -.63754365.76 0.0

MEDIA 311

BOUNDARY 1 


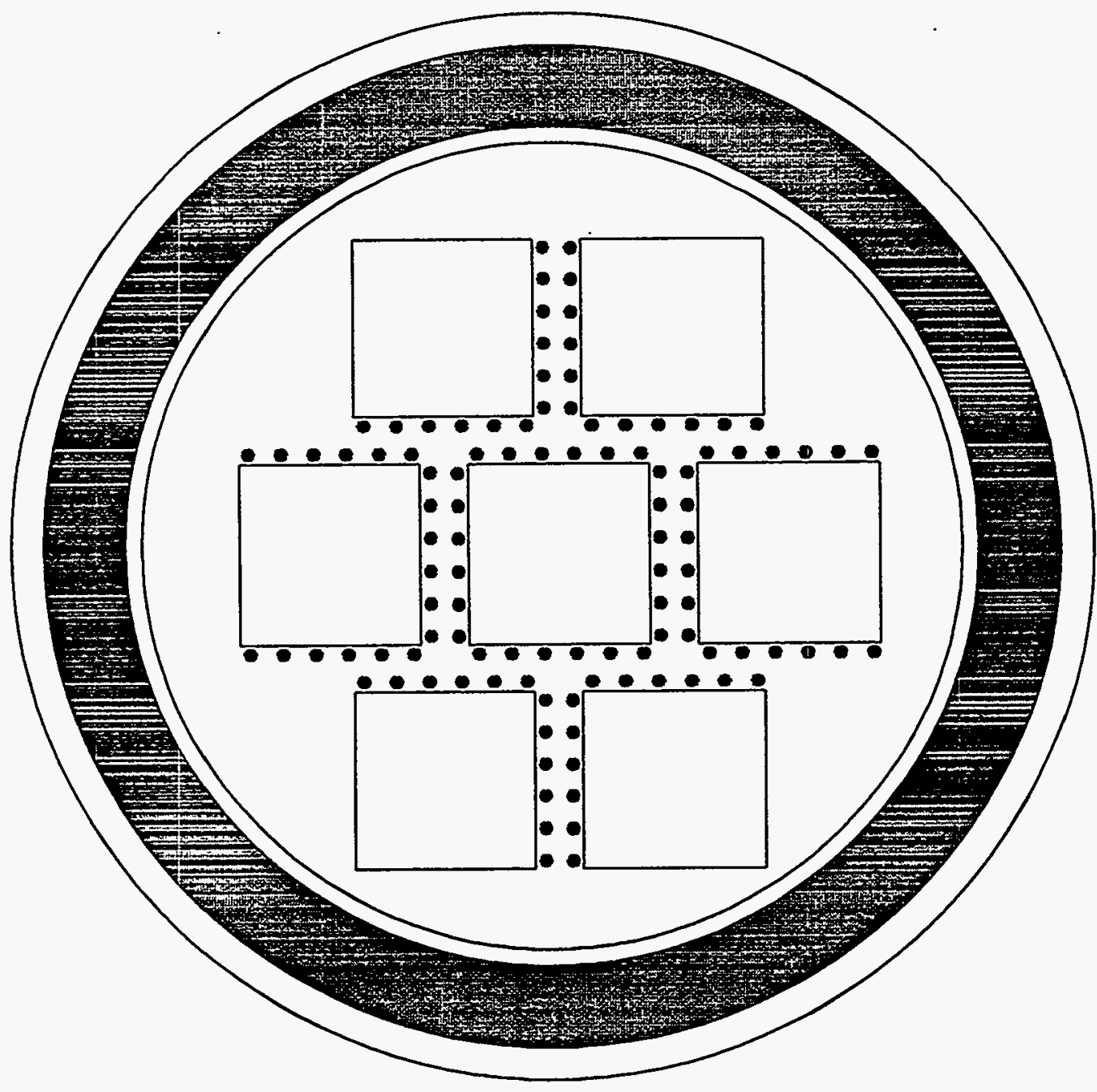

Figure F17.5.19 Typical PWR shipping cask

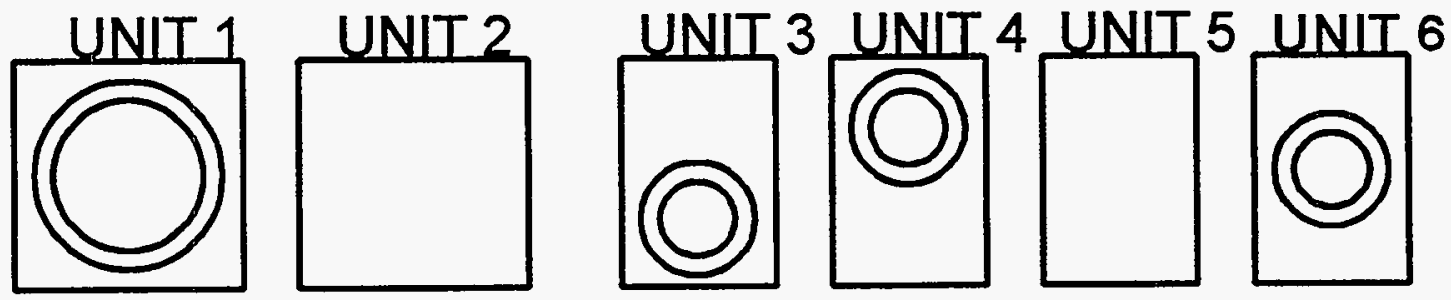

Figure F17.5.20 Simple units

NUREG/CR-0200,

Vol. 2, Rev. 5

F17.5.58 
Units 3,4 , and 6 represent the $B_{4} C$ rods with their various spacings, and Unit 5 is a water hole that is used in association with some of the $\mathrm{B}_{4} \mathrm{C}$ rods.

\section{UNIT 3}

CILINDER 1.584365 .760 .0

CILINDER $2 \quad .635365 .760 .0$

CUBOID $\quad 3 \quad .9912-.99122 .2352-1.27365 .760 .0$

MEDIA 411

MEDLA $512-1$

MEDIA 3 13 -2 -1

BOUNDARY 3

UNIT 4

CYLINDER $1 \quad .584365 .760 .0$

CYLINDER 2.635365 .760 .0

CUBOID $3 \quad .9912-.99121 .2702-2.235365 .760 .0$

MEDIA 411

MEDIA $512-1$

MEDIA 3 1 3-2 -1

BOUNDARY 3

UNIT 5

CUBOID 1 .9912 -.9912 1.7526-1.7526 365.76 0.0

MEDLA 311

BOUNDARY 1

\section{UNIT 6}

CYLINDER 1.584365 .760 .0

CYLINDER 2.635365 .760 .0

CUBOID $3 \quad 1.1875215-1.18752151 .883706-1.883706365 .760 .0$

MEDIA 411

MEDLA 512 -1

MEDLA 3 1 3-2 -1

BOUNDARY 3

Units 1 and 2 are stacked together into array 1 to form the array of fuel pins and water holes in a fuel assembly, as shown in Fig. F17.5.21. This array is then encompassed with a layer of water and a layer of stainless steel to complete a fuel assembly (Unit 7), as shown in Fig. F17.5.22.

$A R A=1 \mathrm{NUX}=17 \mathrm{NUY}=17 \mathrm{NUZ}=1 \mathrm{FILL}$

39R1 2 2Q3 8R1 2 9R1 2 22R1 2 4Q3 38R1 2 4Q3

Q51 22R1 2 Q10 Q9 2Q3 39R1 END FILL

\section{UNIT 7}

CUBOID $110.83818-10.8381810 .83818-10.83818365 .760 .0$

CUBOID $211.112495-11.11249511 .112495-11.112495365 .760 .0$

CUBOID $311.302238-11.30223811 .302238-11.302238365 .760 .0$ 


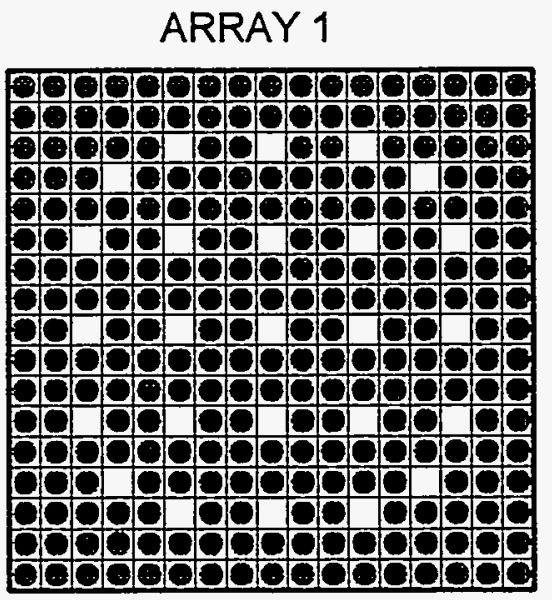

Figure F17.5.21 Fuel pin array

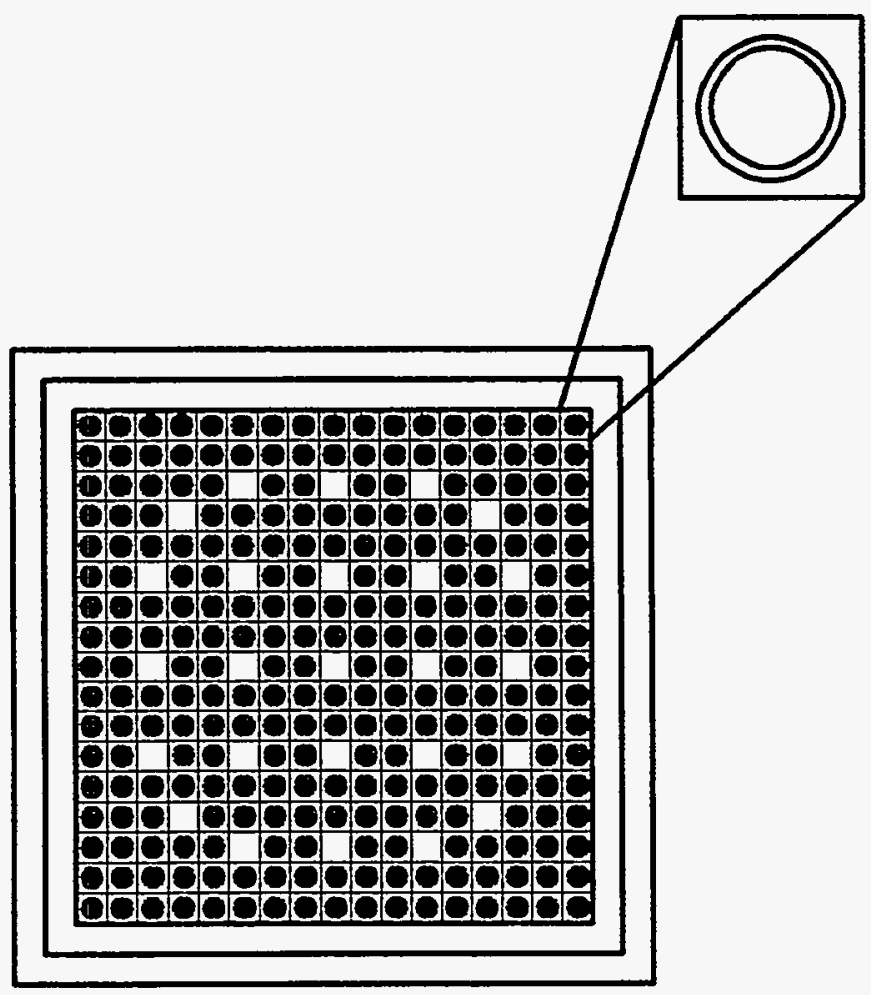

Figure F17.5.22 Fuel assembly

NUREG/CR-0200,

Vol. 2, Rev. 5

F17.5.60 
ARRAY 11 PLACE $9913 * 0.0$

$M E D L A 312-1$

MEDIA 5 1 3 -2 -1

BOUNDARY 3

An array of Unit 6's is created to represent the array of $\mathrm{B}_{4} \mathrm{C}$ rods that is positioned between the fuel assemblies. This array of $\mathrm{B}_{4} \mathrm{C}$ rods is placed directly in the problem, as shown in Fig. F17.5.23.

$A R A=2 N U X=2 N U Y=6 N U Z=1 \quad F I L L F 6 \quad E N D$ FILL

The next step is to create the central array of three fuel assemblies with $\mathrm{B}_{4} \mathrm{C}$ rods between then. This configuration is accomplished by placing fuel assemblies (Unit 7) and $\mathrm{B}_{4} \mathrm{C}$ rod arrays (Array 2) into a unit (unit 8). The resultant geometry is shown in Fig. F17.5.24.

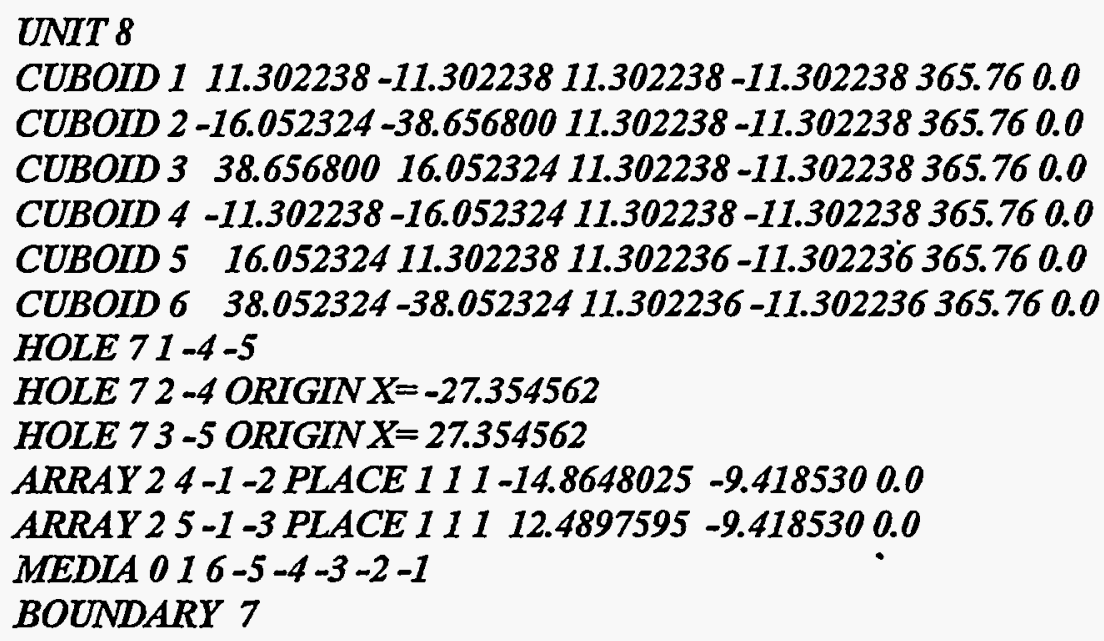

UNIT 8

CUBOID $111.302238-11.30223811 .302238-11.302238365 .760 .0$

CUBOID 2 -16.052324 -38.656800 11.302238-11.302238 365.76 0.0

CUBOID $3 \quad 38.65680016 .05232411 .302238-11.302238365 .760 .0$

CUBOID 4 -11.302238 -16.052324 11.302238 -11.302238 365.76 0.0

CUBOID $516.05232411 .30223811 .302236-11.302236365 .760 .0$

CUBOID $6 \quad 38.052324-38.05232411 .302236-11.302236365 .760 .0$

HOLE $71-4-5$

HOLE $72-4$ ORIGIN $X=-27.354562$

HOLE 73-5 ORIGINX=27.354562

ARRAY 2 4 -1 -2 PLACE 111 -14.8648025 -9.4185300.0

ARRAY 2 5 -1 -3 PLACE 11112.4897595 -9.418530 0.0

MEDIA $016-5-4-3-2-1$

BOUNDARY 7

Units 3,4 , and 5 are used to define the arrays of $\mathrm{B}_{4} \mathrm{C}$ rods that fit above and below the central array, as shown in Fig. F17.5.25.

$A R A=3 \quad N U X=39 N U Y=1 \quad N U Z=1 \quad F I L L 352 Q 2342 Q 25432 Q 25342 Q 25432 Q 252 Q 23$

END FILL

$A R A=4 N U X=39 N U Y=1 \quad N U Z=1 \quad F I L L 452 Q 2432 Q 25342 Q 25432 Q 25342 Q 252 Q 24$

END FILL 


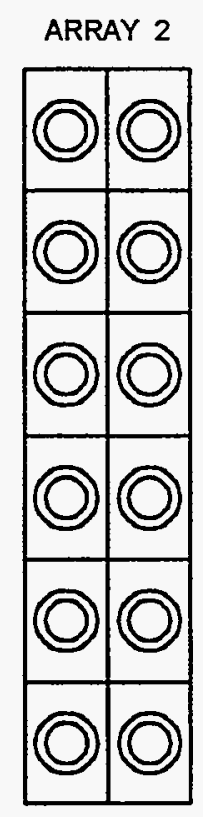

Figure $\mathrm{F} 17.5 .232 \times 6$ array of $\mathrm{B}_{4} \mathrm{C}$ rods

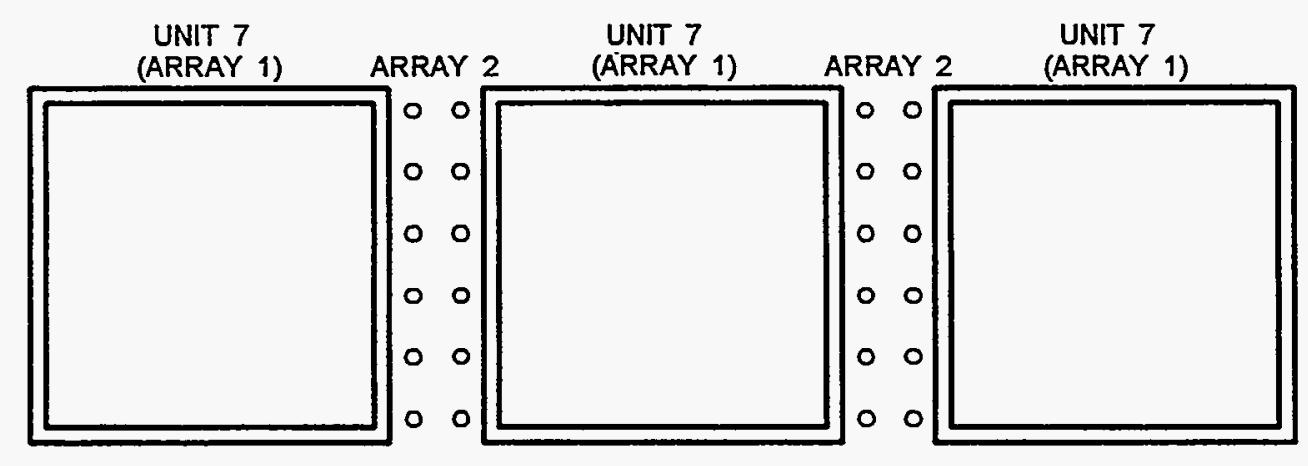

Figure F17.5.24 Central array 

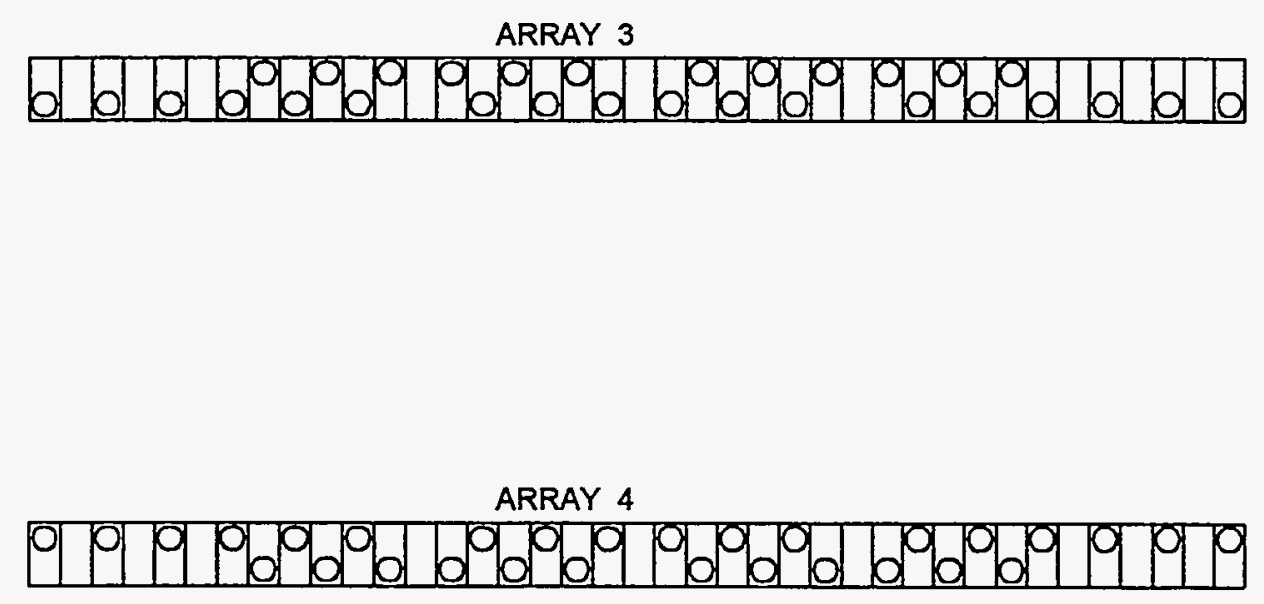

Figure $\mathrm{F}$ 17.5.25 Long $\mathrm{B}_{4} \mathrm{C}$ rod arrays

Unit 8 is positioned between arrays 3 and 4, forming the central section of the global unit, as shown in Fig. F17.5.26. The description below shows how the three central fuel assemblies and $\mathrm{B}_{4} \mathrm{C}$ rods are combined. This is the case of the global unit.

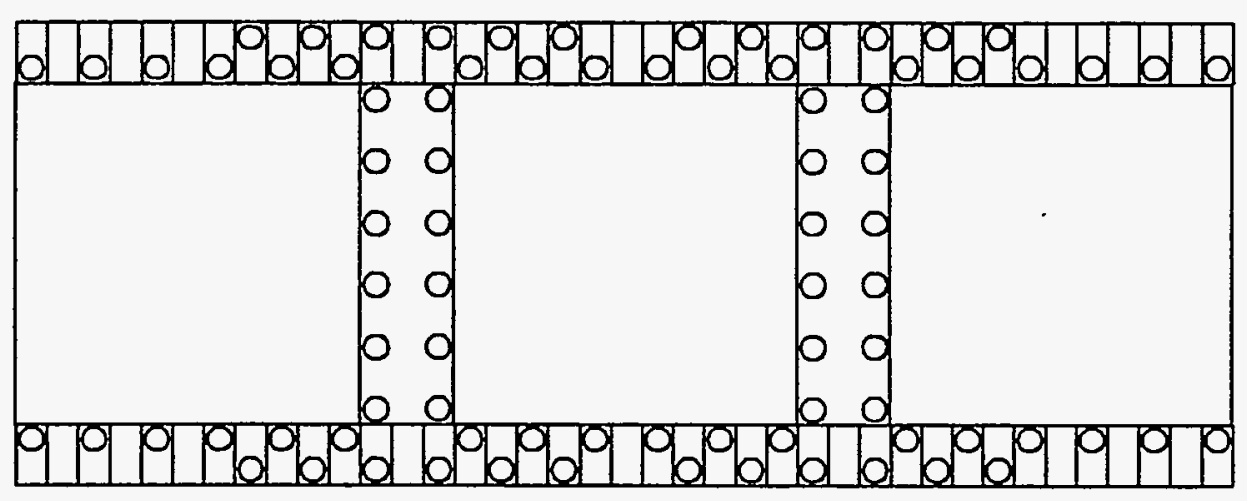

Figure F17.5.26 Central section of global unit with long $\mathrm{B}_{4} \mathrm{C}$ arrays

CUBOID $138.052324-38.05232411 .302236-11.302236365 .760 .0$

CUBOID $238.052324-38.05232414 .80743611 .302236365 .760 .0$

CUBOID $338.052324-38.05232411 .302236-14.807436365 .760 .0$

HOLE 81

ARRAY 32 -1 PLACE 20110.013 .0548360 .0

ARRAY 43 -1 PLACE 20110.013 .0548360 .0

F17.5.63

NUREG/CR-0200,

Vol. 2, Rev. 5 
Next, Unit 7 and array 2 are stacked together to form the array of two fuel assemblies separated by $\mathrm{B}_{4} \mathrm{C}$ rods, as shown in Fig. F17.5.27. This arrangement is designated as unit 9. The origin of unit 9 is specified at the center of the $\mathrm{B}_{4} \mathrm{C}$ array in the $\mathrm{x}$ and $\mathrm{y}$ directions and the bottom of the array in the $\mathrm{z}$ direction.

\section{UNIT 9}

CUBOID $12.375043-2.37504311 .302236-11.302236365 .760 .0$

CUBOID $2-2.375043-24.97951911 .302238-11.302238365 .760 .0$

CUBOID $324.9795192 .37504311 .302238-11.302238365 .760 .0$

CUBODD $424.979519-23.791997511 .302238-11.302238365 .760 .0$

ARRAY 21 PLACE 111 -1.1875215 -9.418530 0.0

HOLE 72 -1 ORIGINX=13.67728

HOLE 73-1 ORIGINX $=13.67728$

MEDIA $014-3-2-1$

BOUNDARY 4

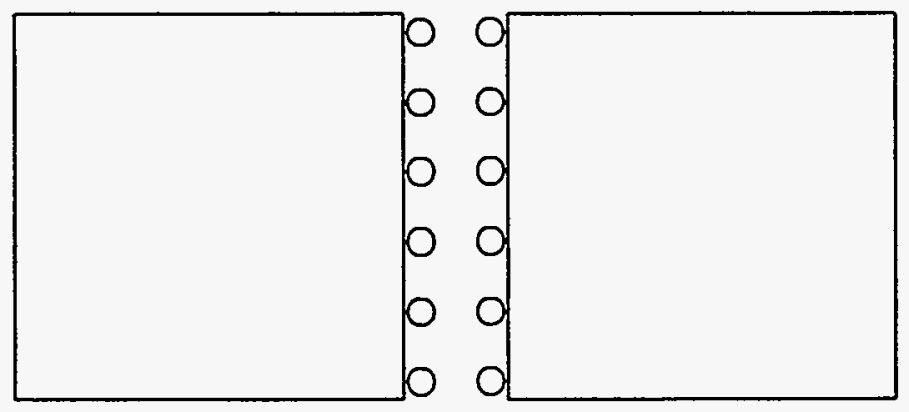

Figure F17.5.27 Two fuel assemblies and $\mathrm{B}_{4} \mathrm{C}$ rods

All necessary subassemblies that make up the shipping cask have been built. The shipping cask is now assembled by first specifying the origin of the central section (see Fig. F17.5.26) to be at the center of the array in $x$ and $y$ and the bottom of the array in the $z$ direction. A cylinder of water defining the interior of the shipping cask is described around the array. A HOLE is used to place a Unit 9 (Fig. F17.5.27) below the array, and a second HOLE is used to place another Unit 9 above the array. At this point a cylinder of steel is placed around the water, which is in turn encased by depleted uranium. The depleted uranium is then contained in the outer steel cylinder of the shipping cask. The lid is then placed on the shipping cask and a boundary region is defined that encloses the entire cask assembly. This information completes the shipping cask description of Fig. F17.5.19. The geometry data for this shipping cask are shown below. The plot data have been included for verification of the geometry description. However, the plot generated by this data is quite large and is therefore not included in this document.

NUREG/CR-0200, 


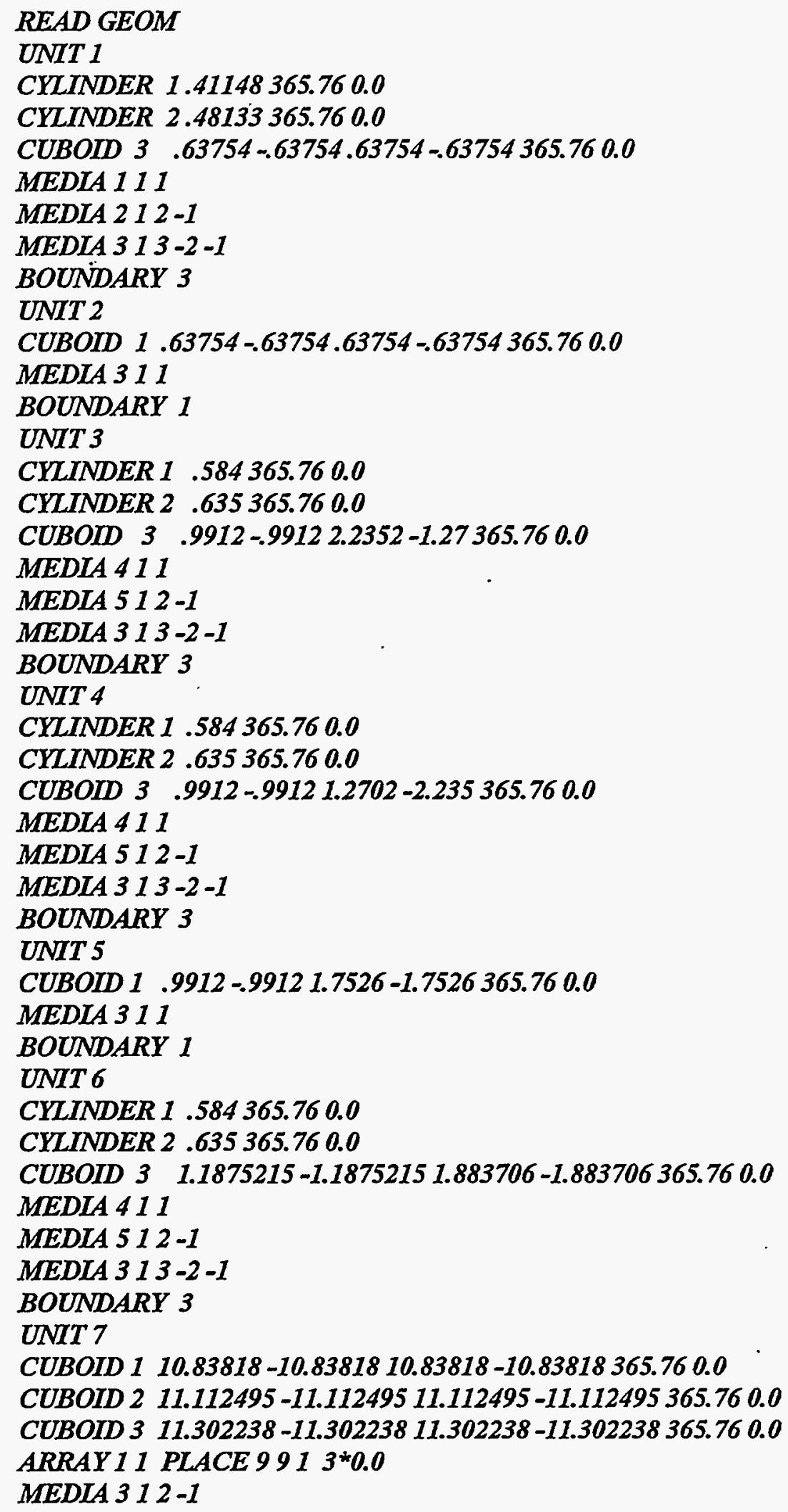




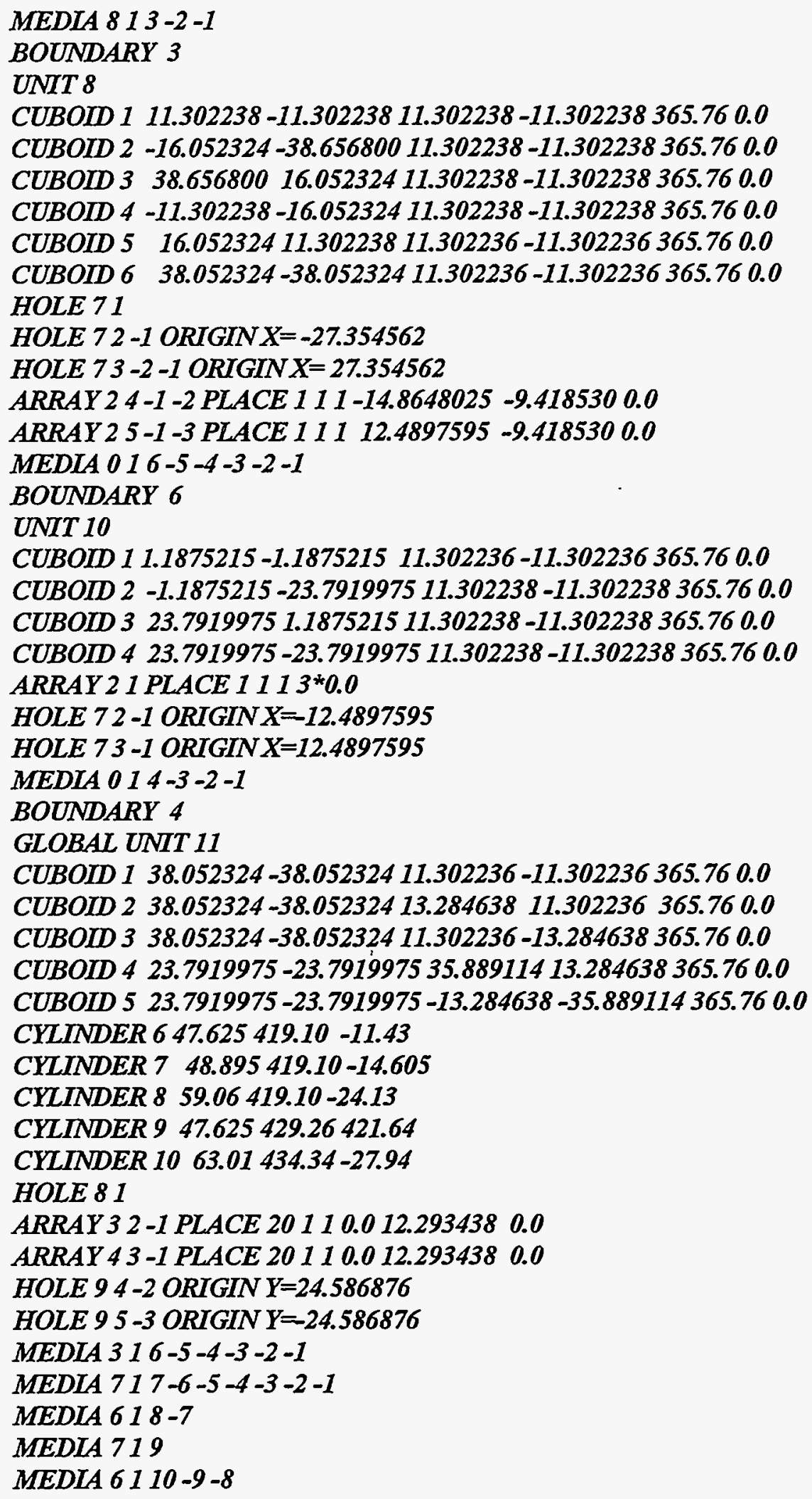




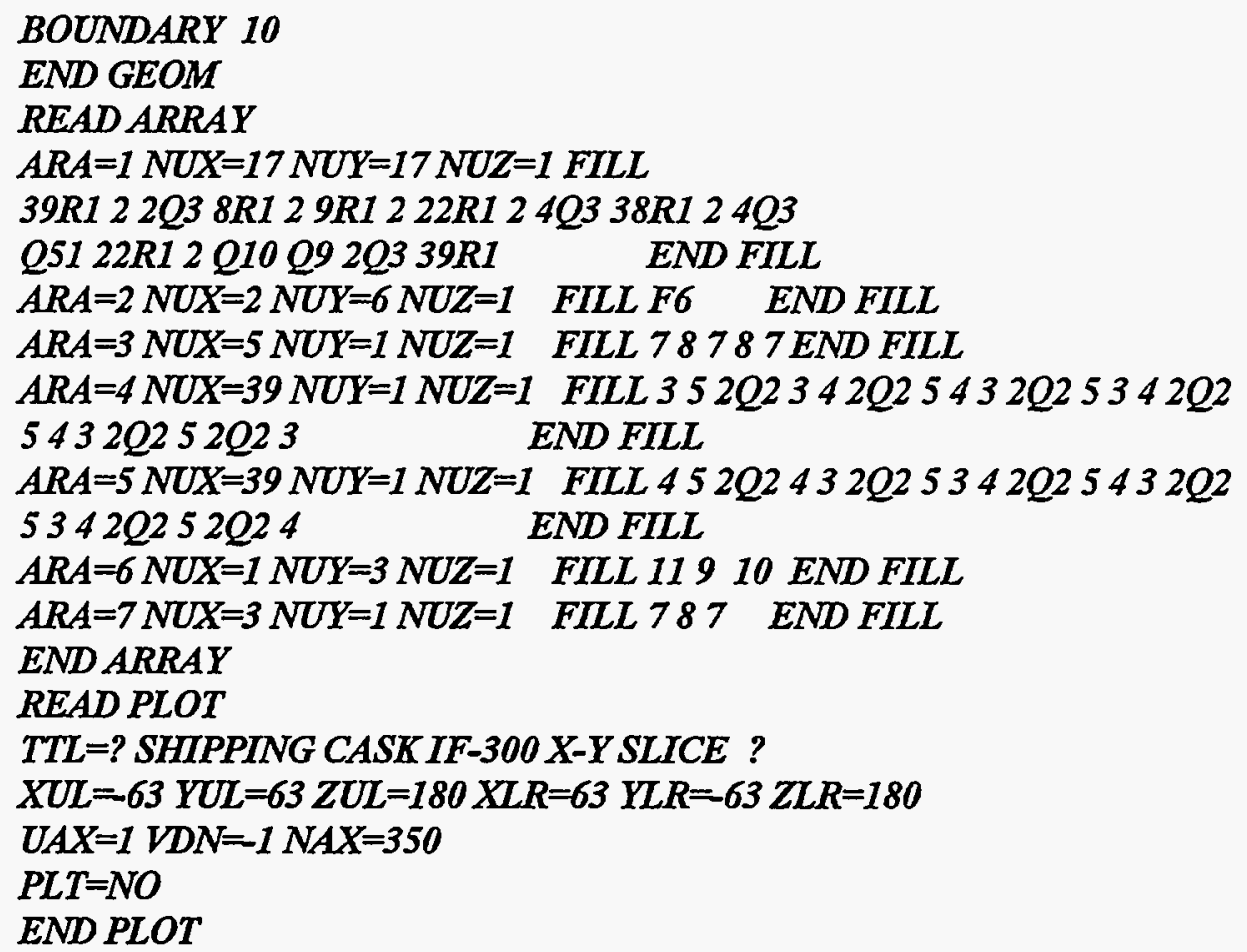

F17.5.6.5 Triangular Pitched Arrays (Sample problem 20)

EXAMPLE 21. Triangular pitched arrays can be described in KENO-VI by defining the units that make up the array as hexprism and in the array data block setting TYP=TRIANGULAR. This includes close-packed triangular pitched arrays. Since the arrays are constructed by stacking hexprisms care must be taken to ensure the array boundary is completely enclosed within the stacked unit. Below is an example of a triangular pitched array.

The first and second unit are the hexprisms that make up the array. Unit 1 is the fuel cell that is stacked in a triangular pitched or hexagonal lattice. Unit 2 is a dummy unit that is used to fill in the array so the array boundary is contained withing the stacked units. Since the array is not moderated unit 2 contains void. Figure F17.5.28 shows an X-Y cross-section schematic of units 1 and 2.

\section{UNIT 1}

COM='SINGLE CELL FUEL CANIN HEXPRISM'

CYLINDER $10 \quad 10.1618 .288 \quad 0.0$

CYLINDER $2010.31218 .288-0.152$

HEXPRISM 30 10.503 18.288-0.152

MEDLA 1110

MEDIA 2 I 120 -10

MEDLA $001130 \quad-20 \quad-10$

BOUNDARY 30 
UNIT 2

COM='EMPTY $C E L L '$

HEXPRISM $10 \quad 10.503 \quad 18.288 \quad-0.152$

MEDIA 01110

BOUNDARY 10
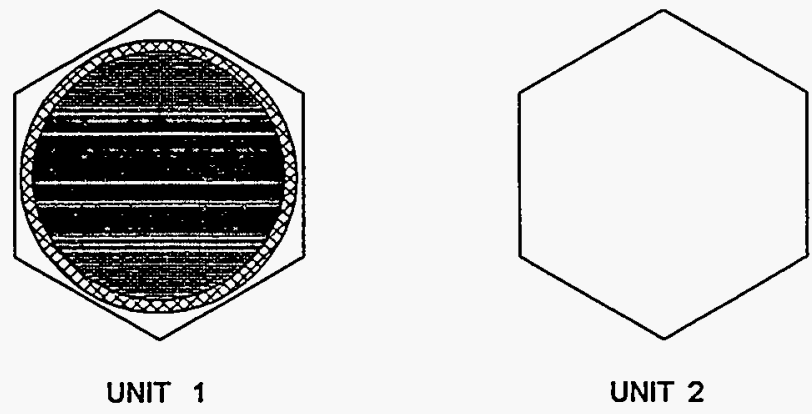

UNIT 2

Figure F17.5.28 Fuel cell and empty cell set up as hexprisms

Unit 3 is the global unit that contains the array and array boundary. The array is an unmoderated triangular pitched assembly of 7 cells. Figure F17.5.29 shows an X-Y cross-section schematic of the assembly.

GLOBAL UNIT 3

COM='7 CYLINDERS INA CIRCLE WITH CYLINDRICAL BOUNDARY'

CYLINDER $10 \quad 32.00018 .288-0.152$

ARRAY 110 PLACE $3313 * 0.0$

BOUNDARY 10

READ ARRAY GBL =1 ARA=1 TYP=TRIANGULAR NUX=5 NUY=5 NUZ=1

FILL 7*2 2*1 2*23*12*22*17*2 END FILL END ARRAY

NUREG/CR-0200,

Vol. 2, Rev. 5

F17.5.68 


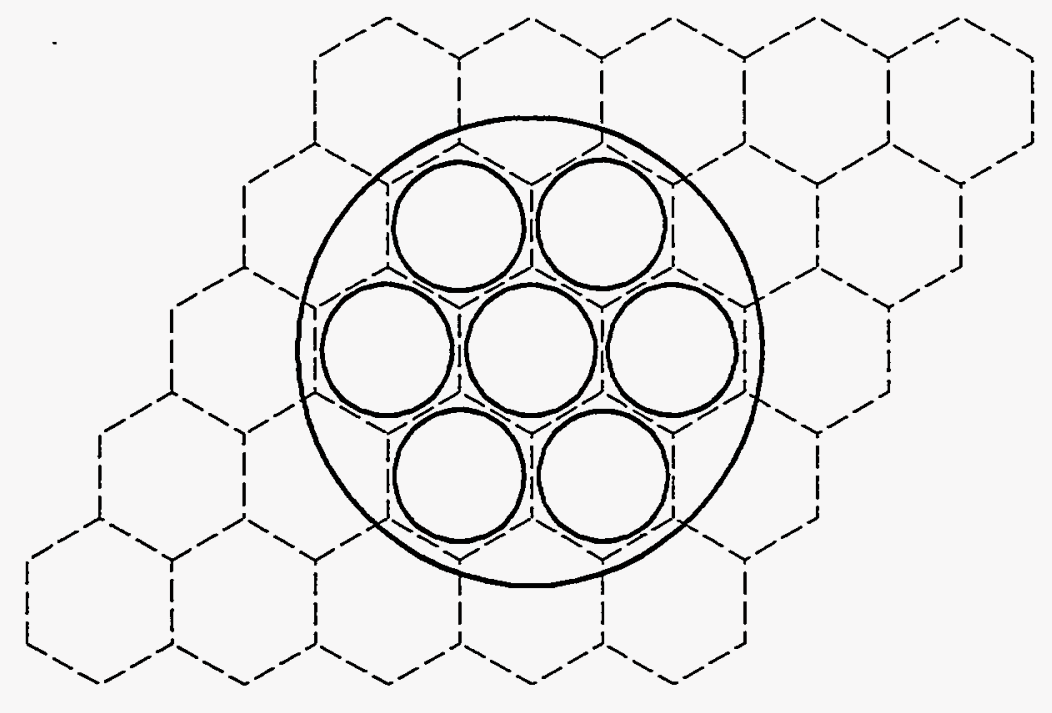

Figure F17.5.29 Seven cylinders stacked in a triangular pitched array with a cylindrical array boundary

The overall problem description is shown below. The working format library used in the mixing table was generated from the 27 groupndf4 master library using BONAMI and NITAWL and stored in unit 4. An X-Y cross-section printer plot used for verification of this mock-up is shown in Fig. F17.5.30.

Data description of Example 21.

$=$ KENOVI

SAMPLE PROBLEM 20 TRIANGULAR PITCHED ARRAY 7 PINS IN A CIRCLE

READ PARAMETERS LNG $=20000 \mathrm{LIB}=4$ END PARAMETERS

READ MIXT SCT $=2$

$\mathrm{MIX}=1 \quad 892235$ 1.37751E-03 892238 9.92354E-05 808016 3.32049E-02

$8090192.95349 \mathrm{E}-03$ 801001 6.05028E-02

$\mathrm{MLX}=2$ 1413027 6.02374E-02

END MIXT

READ GEOMETRY

UNIT 1

COM='SINGLE CELL FUEL CAN IN HEXPRISM'

CYLINDER $10 \quad 10.16 \quad 18.288 \quad 0.0$

CYLINDER $2010.312 \quad 18.288-0.152$

HEXPRISM $3010.503 \quad 18.288-0.152$

MEDIA 1110

MEDIA $2120-10$

MEDIA $0130-20-10$

BOUNDARY 30 


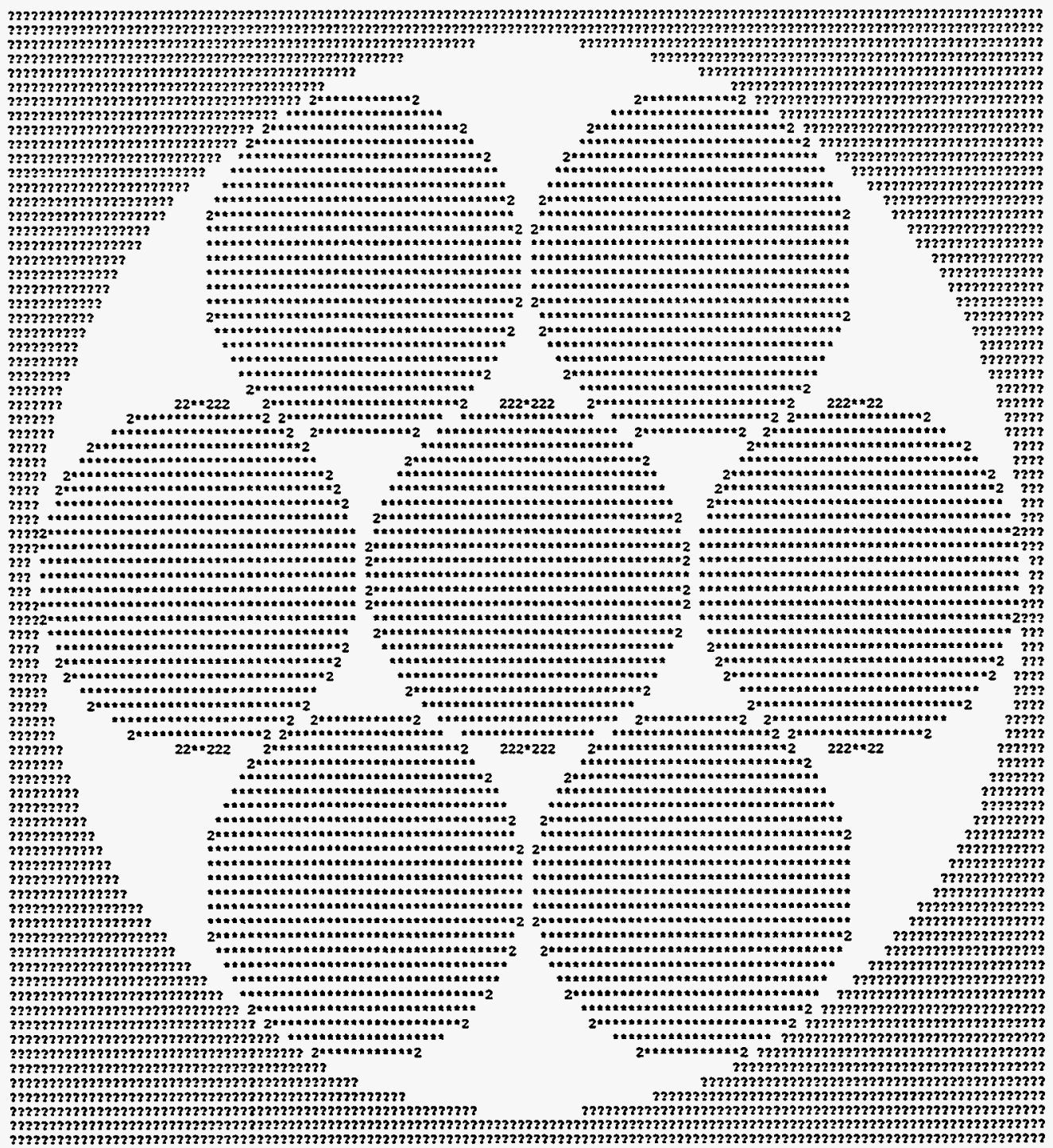

Figure F17.5.30 X-Y slice of 7 cylinders in a triangular pitched array

NUREG/CR-0200,

Vol. 2, Rev. 5

F17.5.70 
UNIT 2

COM='EMPTY CELL'

HEXPRISM $10 \quad 10.50318 .288-0.152$

MEDIA 0110

BOUNDARY 10

GLOBAL UNIT 3

CYLINDER $1032.00018 .288-0.152$

COM='7 CYLINDERS INA CIRCLE WITH CILINDRICAL BOUNDARY'

ARRAY 110 PLACE $3313 * 0.0$

BOUNDARY 10

END GEOMETRY

READ ARRAY GBL=1 TYP=TRLANGULAR NUX=5 NUY=5 NUZ=1

FILL 7*2 2*1 2*23*12*22*17*2 END FILL END ARRAY

END DATA

END

\section{F17.5.7 ALTERNATIVE SAMPLE PROBLEM MOCK-UPS}

The geometry data for KENO-VI can often be described correctly in several ways. Some alternative geometry descriptions are given here for sample problems 12 and 13. (See Appendix F17.D.)

\section{F17.5.7.1 Sample Problem 12, Fïrst Alternative}

This mock-up maintains the same overall unit dimensions that were used in sample problem 12 . In sample problem 12, the origin of Unit 1 , the solution cylinder, is at the center of the unit; the origin of Units 2, 3,4 , and 5 , the metal cylinders, are at the center of the cylinders. In this mock-up, the unit numbers remain the same and the origin of each unit is at the center of the unit. In each unit the cylinder is offset by specifying the position of its centerline relative to the origin of the unit.

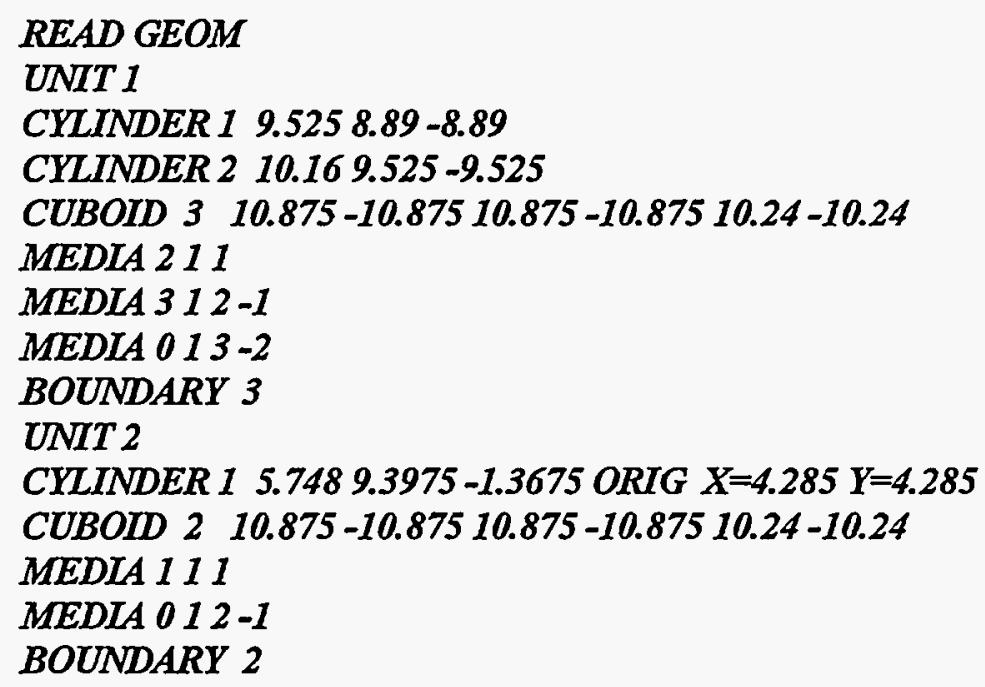


UNIT 3

CILINDER 1 5.748 9.3975 -1.3675 ORIG $X=4.285 \quad Y=4.285$

CUBODD $210.875-10.87510 .875-10.87510 .24-10.24$

MEDLA 111

MEDIA $012-1$

BOUNDARY 2

UNIT 4

CYLINDER I 5.7481 .3675 -9.3975 ORIG $X=4.285 \quad Y=4.285$

CUBOW $2 \quad 10.875-10.87510 .875-10.87510 .24-10.24$

$M E D I A 111$

MEDIA $012-1$

BOUNDARY 2

UNIT 5

CYLINDER I 5.748 1.3675 -9.3975 ORIG $X=4.285 \mathrm{Y}=4.285$

CUBOID $2 \quad 10.875-10.87510 .875-10.87510 .24-10.24$

MEDIA 111

MEDLA $012-1$

BOUNDARY 2

GLOBAL UNIT 6

CUBOID $121.75-21.7521 .75-21.7520 .48-20.48$

ARRAY 1 PLACE 111 -10.875 -10.875-10.24

BOUNDARY 1

END GEOM

READ ARRAY ARA=1 NUX=2 NUY=2 NUZ=2 FILL 21314151 END ARRAY

F17.5.7.2 Sample Problem 12, Second Alternative

In this mock-up, the outer boundaries of the system are made as close fitting as possible on all six faces. The origin of each unit is located at the center of the cylinder. The origin of the global unit is the point in the array where units 1 through 8 meet. Units $1,3,5$, and 7 contain the metal cylinders. Units $2,4,6$, and 8 contain the solution cylinders.

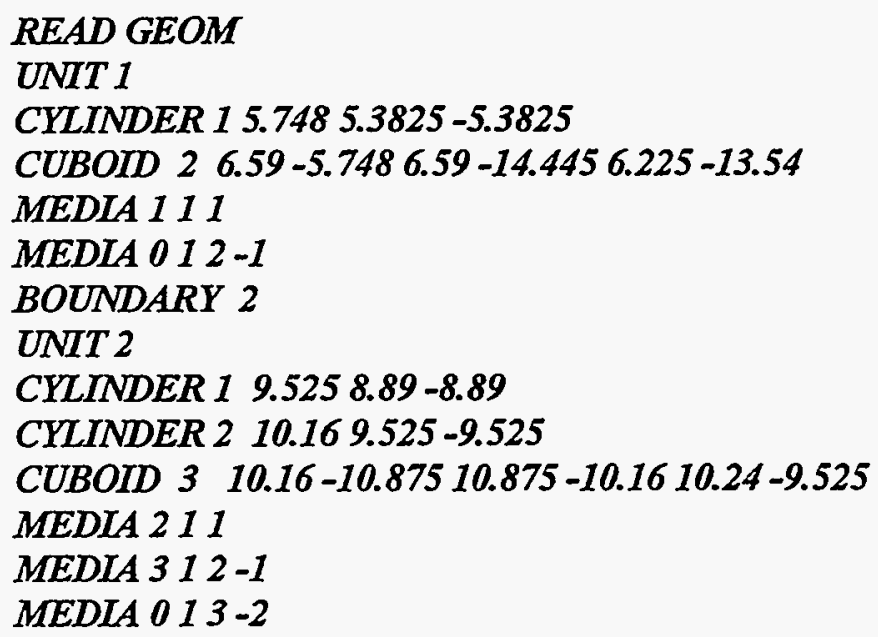

NUREG/CR-0200,

Vol. 2, Rev. 5 


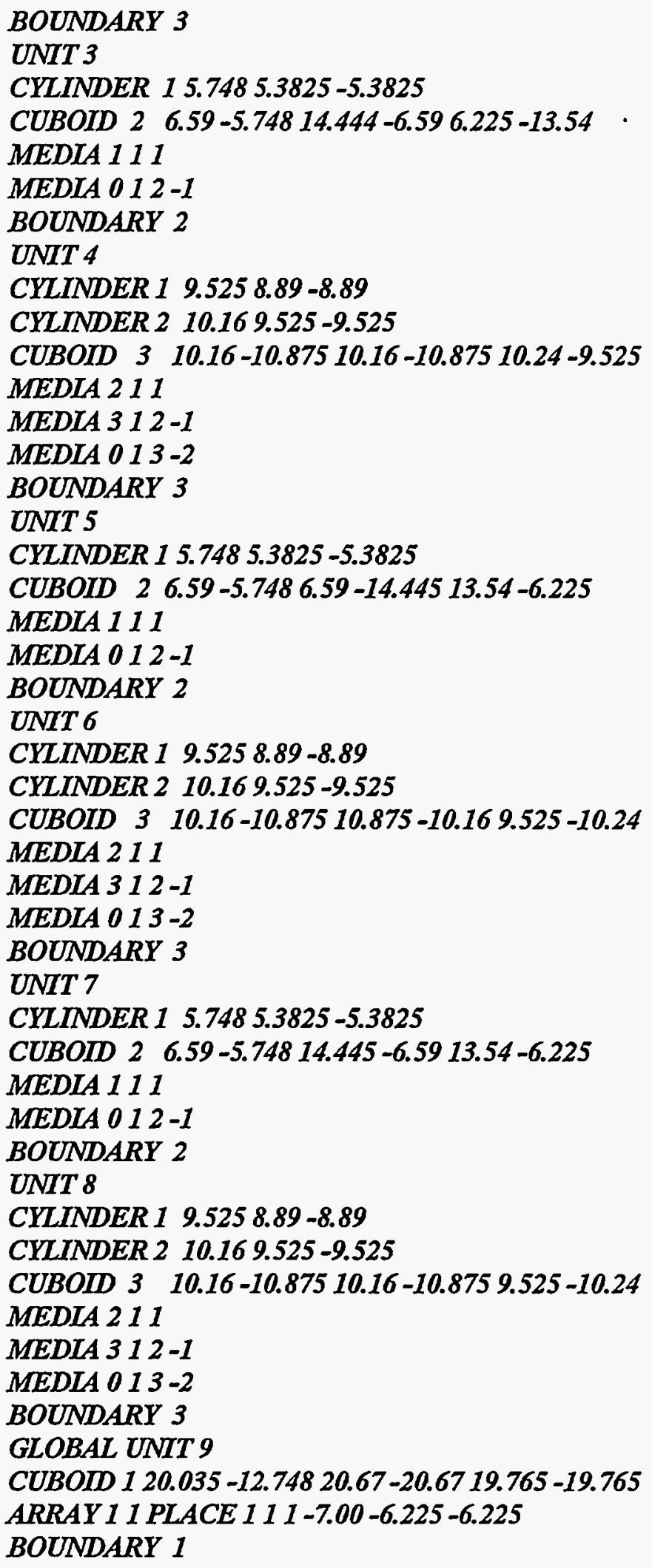




\section{F17.5.7.3 Sample Problem 13, Alternative}

This mock-up maintains the same overall unit dimensions that were used in sample problem 13 , Appendix F17.D. In sample problem 13, the origin of the unit is located at the center of the ring in the $x$ and $y$ directions and the base of the ring in the $z$ direction. The uranium metal cuboids are directly placed in the problem. In this mock-up, the problem is set up as an array of three units. The origin of Units 1 and 2 are located at the center of the cylinder. In Unit 3 , the origin is at the center of the unit.

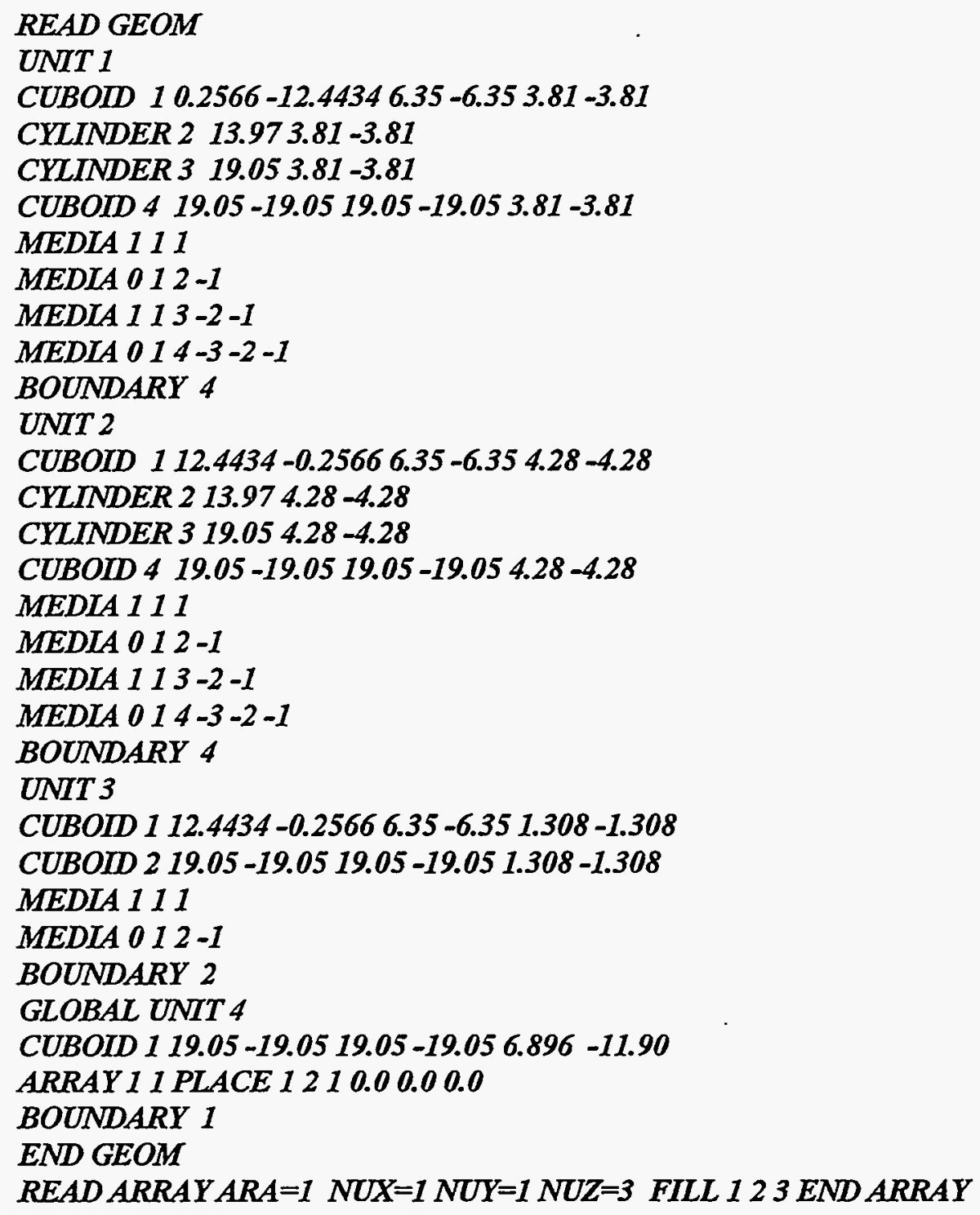




\section{F17.5.8 BIASING OR WEIGHTING DATA}

Section F17.2.3 discusses the basis of weighting or biasing. The use of biasing data in reflected problems has been illustrated in Examples 9, 10, and 11 of Sect. F17.5.6. Section F17.4.7 discusses the input directions for entering biasing data.

Every MEDIA-type card requires a bias ID to associate that geometry region with a biasing or weighting function. A biasing or weighting function is a set of energy-dependent values of the average weight that are applicable in a given region. The default function for all bias IDs is constant through all energy groups and is defined to be the default value of weight average which can be specified in the parameter data. A bias ID can be associated with a biasing function, other than default, by specifying it in the biasing input data. This function can be chosen from the weighting library or can be input from biasing data. Table F17.4.5 lists the materials and energy-group structures for biasing functions available from the weighting library.

In general, the use of biasing should be restricted to external reflectors unless the user has generated correct biasing functions for other applications. Improper use of biasing functions can result in erroneous answers without giving any indication that they are invalid. Caution should be exercised in the generation and use of biasing functions.

Biasing functions are most applicable to thick external reflectors. Their use can significantly reduce the amount of computer time required to obtain answers in KENO-VI. If the user wishes to use a biasing function for a concrete reflector, for example, the following steps must be included in preparing the input data:

1. The geometry region data must define the shape and dimensions of the reflector, using the mixture ID for concrete and a sequence of bias Ds that associate the geometry region with the appropriate interval of the concrete weighting function. CAUTION: THE THICKNESS OF EACH REGION UTILIZING BIASING FUNCTIONS MUST MATCH OR VERY NEARLY MATCH THE INCREMENT THICKNESS OF THE WEIGHTING DATA. NO CHECK IS MADE ON THE REQUIREMENT. IT IS THE USER'S RESPONSIBILITY TO ENSURE CONSISTENCY.

2. Biasing data must be entered. These data must include the material ID for the reflector material (from Table F17.4.5 or as specified on cards) and a beginning and ending bias ID. The beginning bias ID is used to select the first set of energy-dependent average weights, and the subsequent sets of energy-dependent average weights are assigned consecutive IDs until the ending bias $\mathrm{D}$ is reached.

Small deviations in reflector region thickness are allowed, such as using three generated regions with a thickness per region of $5.08 \mathrm{~cm}$ to generate a $15.24-\mathrm{cm}$-thick reflector of concrete, or using five generated regions with a thickness per region of $3.048 \mathrm{~cm}$ to generate a 15.24-cm-thick reflector of water. See Table F17.4.5 for a list of the increment thickness for each material in the weighting library. It is acceptable for the thickness of the last reflector, and thus the region, to be significantly different than the increment thickness. For example, a reflector card specifying five generated regions with a thickness per region of $3.0 \mathrm{~cm}$ could be followed by a reflector card specifying one region with a thickness per region of $0.24 \mathrm{~cm}$. Assume material 2 is water and a 15.24-cm-thick cuboidal reflector of water surrounding a cube of material $1,20 \mathrm{~cm}$ on a side, is desired. The required reflector description and biasing data could be entered as follows: 
GLOBAL UNIT 1
CUBOID $16 P 10.0$
CUBOID $26 P 13.0$
CUBOID $36 P 16.0$
CUBOID $46 P 19.0$
CUBOID 5 6P22.0
CUBOID 6 6P25.0
CUBOW $76 P 25.24$
MEDIA 111
MEDIA $222-1$
MEDIA $233-2$
MEDIA $244-3$
MEDIA $255-4$
MEDIA $266-5$
MEDIA $277-6$
BOUNDARY 7
READ BLAS WD=500 27 END BLAS

The same 15.24-cm-thick reflector can be described by including the extra $0.24 \mathrm{~cm}$ in the last region as shown below:

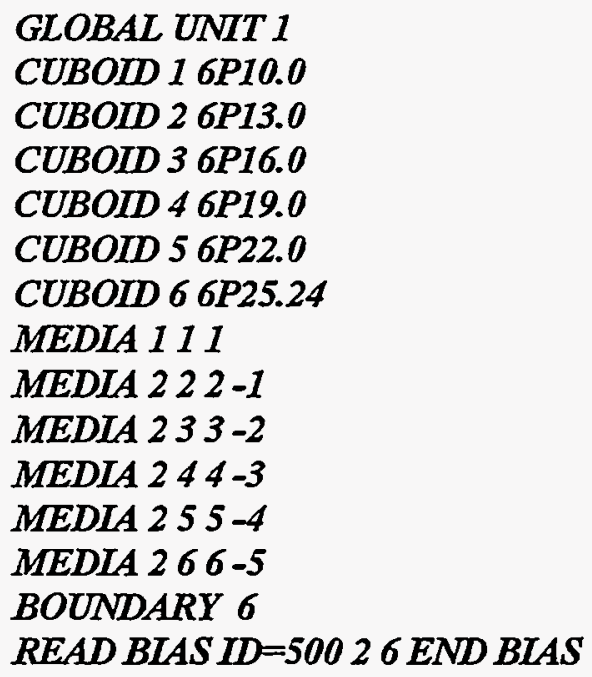

Here the weighting functions associated with bias IDs 2,3,4, and 5 each have a thickness of $3.0 \mathrm{~cm}$, corresponding exactly to the increment thickness for water in Table F17.4.5. Bias ID 6 is used for the last generated region, which is $3.24 \mathrm{~cm}$ thick.

The following examples illustrate the use of biasing data. Suppose the user wishes to use the weighting function for water from Table F17.4.5 for bias IDs 2 through 6 . The biasing input data would then be:

\section{READ BIAS ID=5002 6 END BLAS}

The energy-dependent values of weight average for the first 3-cm interval of water will be used for weighting the geometry regions that specify a bias of $\mathrm{ID}$ of 2 . The energy-dependent values of weight average NUREG/CR-0200, 
for the second 3-cm interval of water will be used for geometry regions that specify a bias $\mathrm{ID}$ of 3 , etc. Thus the energy-dependent values of weight average for the fifth $3-\mathrm{cm}$ interval of water will be used for geometry regions that specify a bias $\mathrm{ID}$ of 6 . Geometry regions that use bias $\mathrm{Ds}$ other than $2,3,4,5$, and 6 will use the default value of weight average that is constant for all energies as a biasing function.

Several sets of biasing data can be entered at once. Assume the user wishes to use the weighting function for concrete from Table F17.4.5 for bias IDs 2 through 4 and the weighting function for water for bias IDs 5 through 7. The appropriate input data block is:

\section{READ BLAS ID=30124ID=500 57 END BLAS}

The energy-dependent values of weight average for the first $5-\mathrm{cm}$ interval of concrete will be used for the geometry regions that specify a bias $\mathrm{ID}$ of 2 , the energy-dependent values of weight average for the second $5-\mathrm{cm}$ interval of concrete will be used for the geometry regions that specify a bias $\mathrm{ID}$ of 3 , and the energy-dependent values of weight average for the third 5-cm interval of concrete will be used for the geometry regions that specify a bias $\mathrm{ID}$ of 4 . The energy-dependent values of weight average for the first 3-cm interval of water will be used for geometry regions that specify a bias ID of 5, the values for the second 3-cm interval of water will be used for geometry regions that specify a bias $\mathrm{ID}$ of 6 , and the values for the third 3-cm interval of water will be used for geometry regions that specify a bias $\mathrm{D}$ of 7 . The default value of weight average will be used for all bias Ds outside the range 2 through 7.

If the biasing data block' defines the same bias ID more than once, the value that is entered last supersedes previous entries. Assume the following data block is entered.

\section{READ BLAS ID=400 $27 I D=50057$ END BLAS}

Then the data for paraffin (ID=400) will be used for bias $\mathrm{IDs} 2,3$, and 4 , and the data for water $(\mathrm{ID}=500)$ will be used for bias IDs 5,6 , and 7 .

\section{EXAMPLE 1. USE OF BIASING DATA}

Assume a 5-cm-radius sphere of material 2 is reflected by a 20 -cm-thickness of material 1 (concrete). The concrete reflector is spherical and close fitting upon the sphere of material 2 . The mixing table must specify material 1 and material 2. Material 1 must be defined as concrete. The geometry and biasing data should be entered as follows:
READ GEOM
GLOBAL UNIT 1
SPHERE 15.0
SPHERE 210.0
SPHERE 315.0
SPHERE 420.0
SPHERE 525.0
MEDIA 211
MEDIA 12 2-1
MEDIA 13 3-2
MEDIA 144 -3
MEDLA 155 -4
BOUNDARY 5 


\section{END GEOM}

READ BLAS ID=301 25 END BLAS

In the above example, the bias ID for the first reflector region is 2 ; the second, 3 ; the third, 4; and the fourth 5 . The biasing data block specifies that the biasing function for material ID 301 (concrete) will be used from the weighting library. The energy-dependent weighting function of the first $5 \mathrm{~cm}$ of concrete is represented by bias ID 2 , the second $5-\mathrm{cm}$ interval by bias ID 3 , the third $5-\mathrm{cm}$ interval by bias ID 4 , and the fourth 5-cm interval by bias ID 5 .

\section{F17.5.9 PRINTER PLOTS}

Printer plots are generated only if a plot data block has been entered for the problem and PLT=NO has not been entered in the parameter data or the plot data. See Sect. F17.4.11 for a description of plot data. When a printer plot is to be made, the user MUST correctly specify the upper left-hand comer of the plot with respect to the origin of the plot. The origin of a plot is defined as the origin of the global unit.

Printer plots can represent mixture numbers, unit numbers or bias ID numbers. A title can be entered for each plot. If plot titles are omitted, the title of the KENO-VI case will be printed for each plot title until a plot title is entered. If a plot title is entered and a subsequent plot title is omitted, the last plot title prior to the omitted one will be used for the omitted one.

The upper-left and lower-right coordinates define the area (i.e., the slice and its location) for which the plot is to be made. The direction cosines across the page and the direction cosines down the page define the direction of the vector across the page and the vector down the page with respect to the geometry coordinate system. One of the simplest ways of generating a plot is to specify the desired coordinates of the upper-left and lower-right comers of the plot. Determine which plot axis is to be across the page and which is to be down. The sign of the direction cosine should be consistent with the direction of that component when moving from the upper-left to lower-right corner. For example, to draw a plot of an $x-z$ slice at $y=5.0$ with $x$ across the page and $z$ down the page for a system whose $x$ coordinates ranges from 0.0 to 10.0 and whose $z$ coordinates range from 0.0 to 20.0 , the upper-left coordinate could be $\mathrm{XUL}=0.0 \mathrm{YUL}=5.0 \mathrm{ZUL}=20.0$ and the lower-right coordinates could be $X L R=10.0$ YLR=5.0 ZLR=0.0. Since $x$ is to be plotted across the page with $x=0.0$ at the left and $x=10.0$ at the right, only the $x$ component of the direction cosines across the page need be entered. It should be positive because going from 0.0 to 10.0 is moving in the positive direction. Thus UAX $=1.0$ would be entered for the direction cosines across the page. VAX and WAX could be omitted. $Z$ is to be plotted down the page with $z=20.0$ at the top and $z=0.0$ at the bottom. Therefore, only the $z$ component of the direction cosines down the page need to be defined. It should be negative because moving from 20.0 to 0.0 is moving in the negative direction. Thus WDN=-1.0 would be entered for the direction cosines down the page. UDN and VDN could be omitted. The sign of the direction cosines should be consistent with the coordinates of the upper-left and lowerright corners in order to get a plot.

It is not necessary that the plot be made for a slice orthogonal to one of the axes. Plots can be made of slices cut at any desired angle, but the user should exercise caution and be well aware of the distortion of shapes that can be introduced. (Nonorthogonal slices through cylinders plot as ellipses.)

The user can specify the horizontal and vertical spacing between points on the plot. It is usually advisable to enter one or the other. Entering both of them can cause distortion of the plot. DLX= is used to specify the horizontal spacing between points, and $D L D=$ is used to specify the vertical spacing between points. When only one of them is specified, the code calculates the correct value of the other such that the plot will not be distorted. The spacing for an undistorted plot is defined as DLD*LPI=DLX*CPI, where LPI is the number

NUREG/CR-0200,

Vol. 2, Rev. 5

F17.5.78 
of lines per inch printed vertically and CPI is the number of characters per inch horizontally. These parameters are a function of the printer or print chain. The vertical distortion factor, VDIS, is then defined by VDIS= (DLD*LPI)/(DLX*CPI). The code then calculates the number of intervals that will be printed across the page and down the page if both the upper-left and lower-right coordinates of the plot were entered. In some instances, it can be desirable to distort a plot by entering both DLX and DLD. It might be desirable to compress one dimension relative to another. If $D L X=0.5$ and $D L D=5.0$ are entered as data for a printer that prints 10 characters per inch across and 8 lines per inch down, the portion of the plot that is printed in the vertical direction will be reduced by a factor of 8 relative to the portion printed in the horizontal direction $((5.0 * 8) /(0.5 * 10))$. That is, if the coordinates specify a perfect square, the plot will be a rectangle that is about 8 times as wide as it is tall.

DLX or DLD can be specified by the user to be small enough to show the desirable detail in the plot. The plot is generated by starting at the upper-left corner of the plot and generating a point every DLX across the page; then moving down DLD and repeating the generation of the points across the page.

NAX specifies the number of intervals that will be printed across the page. It may be convenient for the user to specify the number of characters that can be printed across the page on the printer that will be used. Larger plots can be created by specifying multiples of this number. In that case, the plot must be taped together to see the overall plot. The plot will print one page wide and full length. Then the next page width and full length will be printed, etc., until the entire plot is completed.

NDN specifies the number of intervals that will be printed down the page. If both NAX and NDN are entered, the plot may be distorted. If one of them is entered, the value of the other will be calculated so the plot will not be distorted.

LPI, the number of lines per inch that are printed on a page, can be entered to be consistent with the printer that will be used. The default value is 8 lines per inch. This parameter must be entered only once for a problem. It should be entered in the data for the first plot, so all the plots will be printed in the same manner.

When a plot is being made, the first character represents the coordinates of the upper-left comer. The value of DELV is added to the coordinate that is to be printed across the page, and the next character is printed. DELV is added to that value to determine the location of the next character. That is, a point is determined every DELV across the page and a character is printed for each point. When a line has been completed, a new line is begun DELU from the first line. This procedure is repeated until the plot is complete. Some examples of printer plots are shown in Sects. F17.5.6.1, F17.5.6.2, F17.5.6.3, and F17.5.6.4. Further examples are shown below.

\section{EXAMPLE 1. SLNGLE UNIT WITH CENTERED ORIGIN}

Consider two concentric cylinders in a cuboid. The inner cylinder is $5.2 \mathrm{~cm}$ in diameter. The outer cylinder has an inside diameter of $7.2 \mathrm{~cm}$ and an outside diameter of $7.6 \mathrm{~cm}$. Both cylinders are $30 \mathrm{~cm}$ high. They are contained in a tight-fitting box whose wall thickness is $0.5 \mathrm{~cm}$ and whose top and bottom are each 1.0 $\mathrm{cm}$ thick. The inner cylinder is composed of mixture 1 , the outer cylinder is made of mixture 4 , and the box is made of mixture 2 . The problem can be described with its origin at the center of the inner cylinder. The problem description for this arrangement is shown below:

\section{$=K E N O V I$}

SINGLE UNIT CONCENTRIC CYLINDERS IN CUBOID WITH ORIGIN AT CENTER

READ PARAM RUN=NO LIB=4I TME=0.5 END PARAM

READ MIXT SCT=1 MLX=192500 4.7048-2 MLX=2 200 1.0 MIX=3 5020.1

$M T X=42001.0$

END MTXT

F17.5.79

NUREG/CR-0200, Vol. 2, Rev. 5 


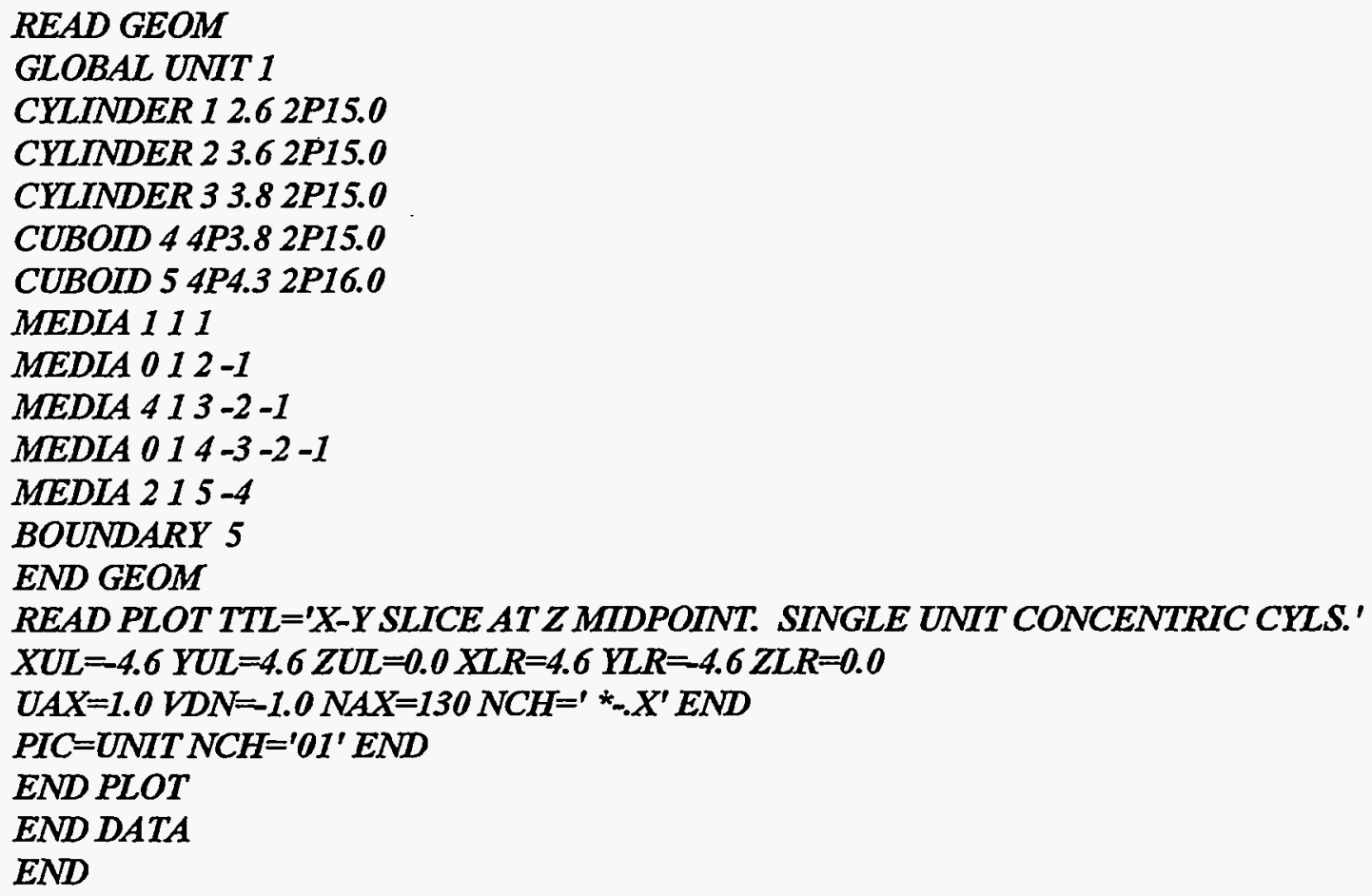

The plot data block included above is set up to draw a mixture map of an $x-y$ slice taken at the halfheight $(z=0.0)$ and a unit map for the same slice. The code will print question marks for points outside the range of the problem geometry description. By setting the plot dimensions slightly larger than the geometry dimensions, a border of question marks will be printed around the specified plot. This border verifies that the outer boundaries of the geometry are contained within the plot dimensions. In the above example, the geometry dimensions extend from $x=-4.3$ to $x=4.3$, from $y=-4.3$ to $y=4.3$, and from $z=-16.0$ to $z=16.0$. An $x-y$ slice is to be printed at the half-height $(z=0.0)$. The desired plot data set the upper left-hand corner of the plot to be $x=-4.6$ and $y=4.6$. The lower right-hand corner of the plot is specified as $x=4.6$ and $y=-4.6$. These data are entered by specifying the upper left-hand comer as $\mathrm{XUL}=-4.6 \mathrm{YUL}=4.6 \mathrm{ZUL}=0.0$ and the lower right-hand comer as $\mathrm{XLR}=4.6 \mathrm{YLR}=-4.6 \mathrm{ZLR}=0.0$. It is desired to print $\mathrm{x}$ across the page and $y$ down the page. Therefore, the $\mathrm{x}$ direction cosine is specified across the page, in the direction from $x=-4.6$ to $x=4.6$ as UAX $=1.0$. The $y$ direction cosine is specified down the page, from $y=4.6$ to $y=-4.6$ as VDN $=-1.0$. It was desirable for the plot to be one page wide (130 characters), so the number of characters across the page was specified as NAX $=130$. An arbitrary choice was made to print a blank for a void, a * for mixture $1, a$ - for mixture 2 , and a . for mixture 4 . Mixture 3 was not used in the problem, so a character did not have to be entered for it in the character string. Thus a character string of $\mathrm{NCH}==^{*}$ *.' $^{\prime}$ would have been sufficient, but a string of $\mathrm{NCH}={ }^{\prime} *-\mathrm{x}^{\prime}$ was entered. Since only three mixtures were used, only the first four characters were utilized. The blank represents a void, the * represents the smallest mixture number used in the problem (mixture 1), the - represents the next smallest mixture number used in the geometry description (mixture 2), and the . represents the largest mixture number used in the geometry (mixture 4). The resultant printer plot and associated data are shown in Figs. F17.3.31 and F17.3.32. A second printer plot covering the same area shows a unit map rather than a mixture map. This unit map and associated data are shown in Figs. F17.3.33 and F17.3.34. 
$x-y$ slice at $z$ midpoint. single unit concentric cyls.

mixture map

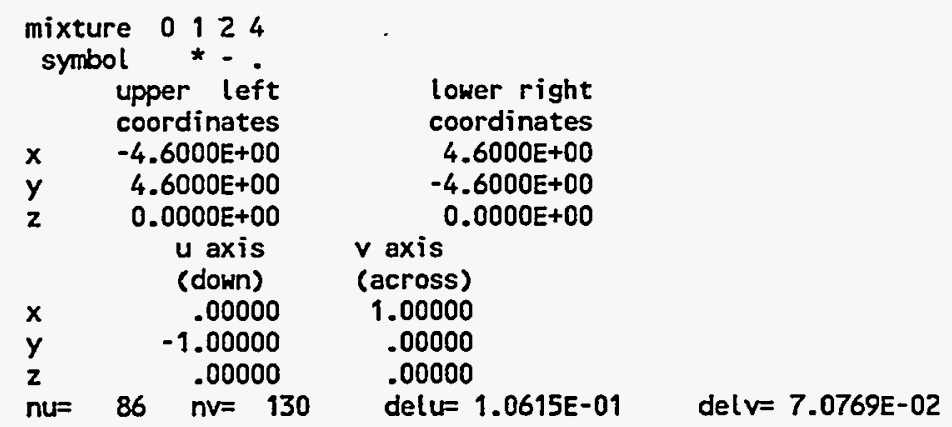

Figure F17.5.31 Associated data for single unit mixture map 


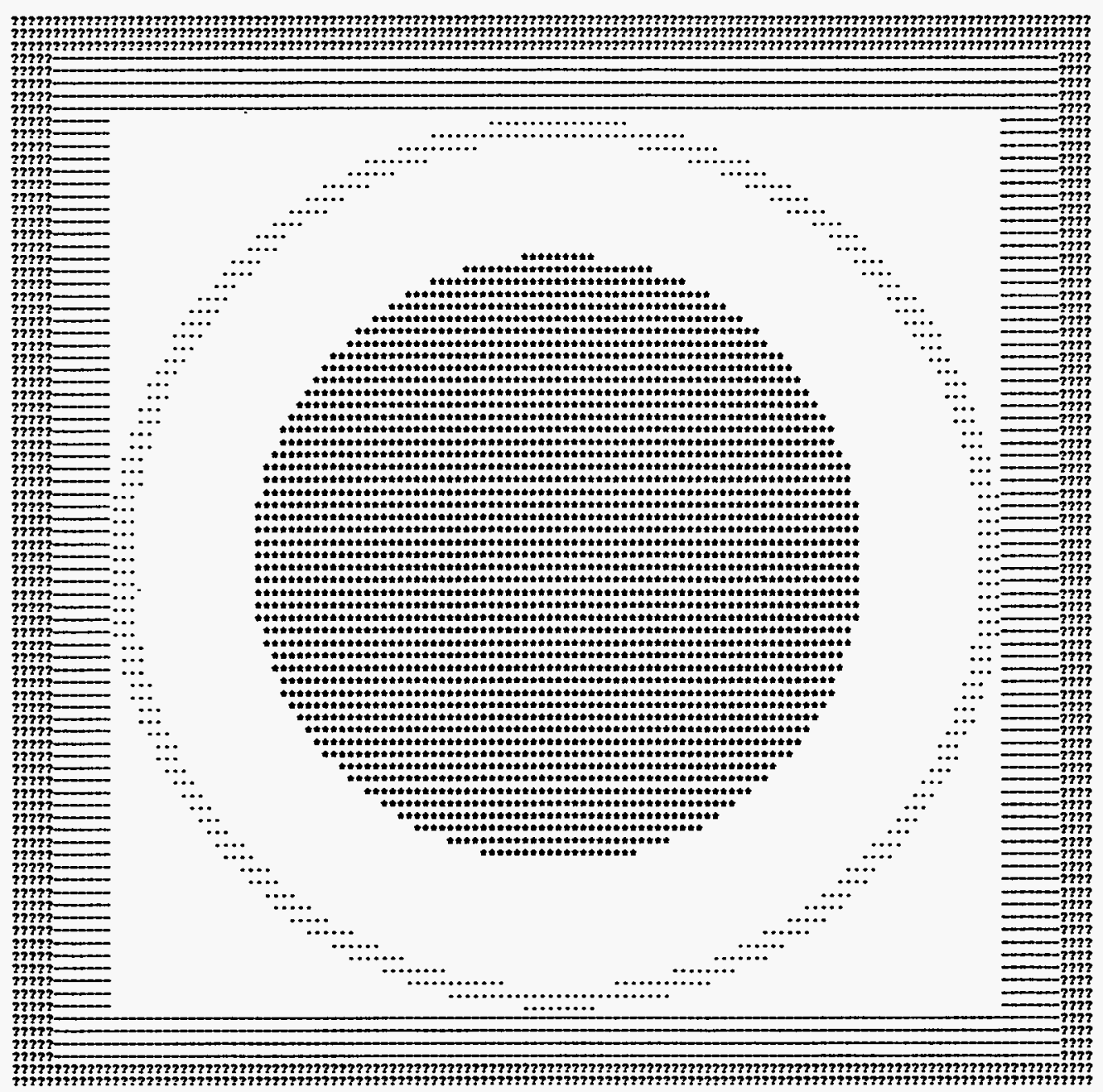

Figure F17.5.32 Mixture map of single unit with centered origin

$x-y$ slice at $z$ midpoint. single unit concentric cyls.
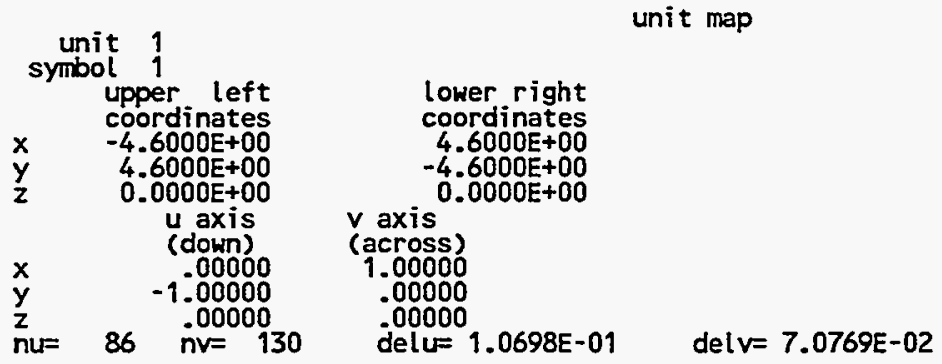

Figure F17.5.33 Associated data for single unit map

NUREG/CR-0200,

Vol. 2, Rev. 5

F17.5.82 


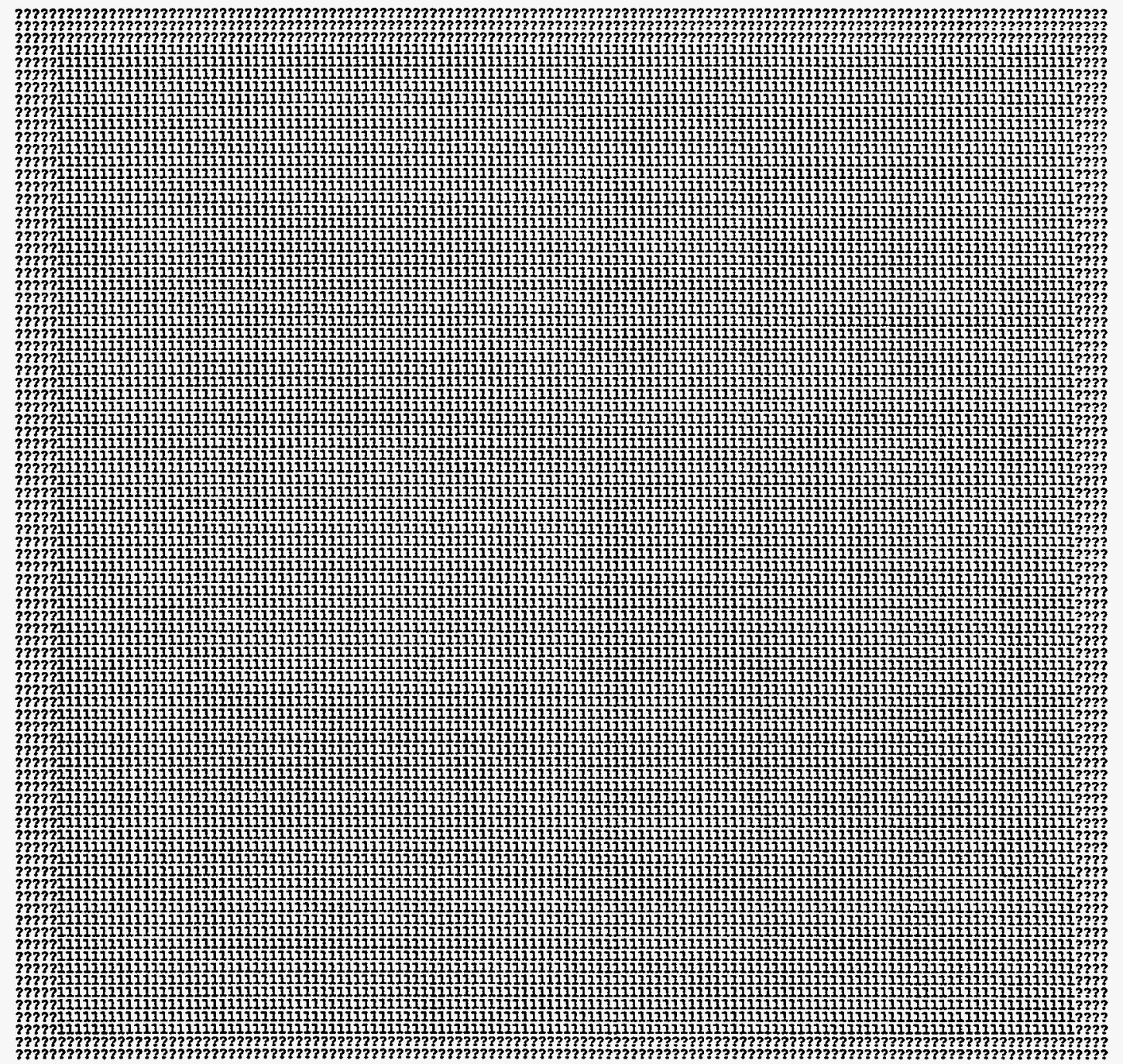

Figure F17.5.34 Unit map printer plot for single unit with centered origin

F17.5.83

NUREG/CR-0200, Vol. 2, Rev. 5 
Figure F17.5.34 shows a block of l's surrounded by a border of ?'s. This arrangement indicates that the entire slice specified in the plot data was part of Unit 1. For this problem the entire volume is Unit 1.

\section{EXAMPLE 2. SINGLE UNIT WITH OFFSET ORIGIN}

The physical problem is the same as that described in Example 1, two concentric cylinders in a cuboid. The dimensions are exactly the same. The difference is in the choice of the origin. In this geometry description, the origin was specified as the most negative point of the unit. Thus the cylinders must have an origin specified to center them in the cuboid, and the cuboid extends from 0.0 to 8.6 in $x$ and $y$ and from 0.0 to 32 in $z$, as shown in the problem description below:

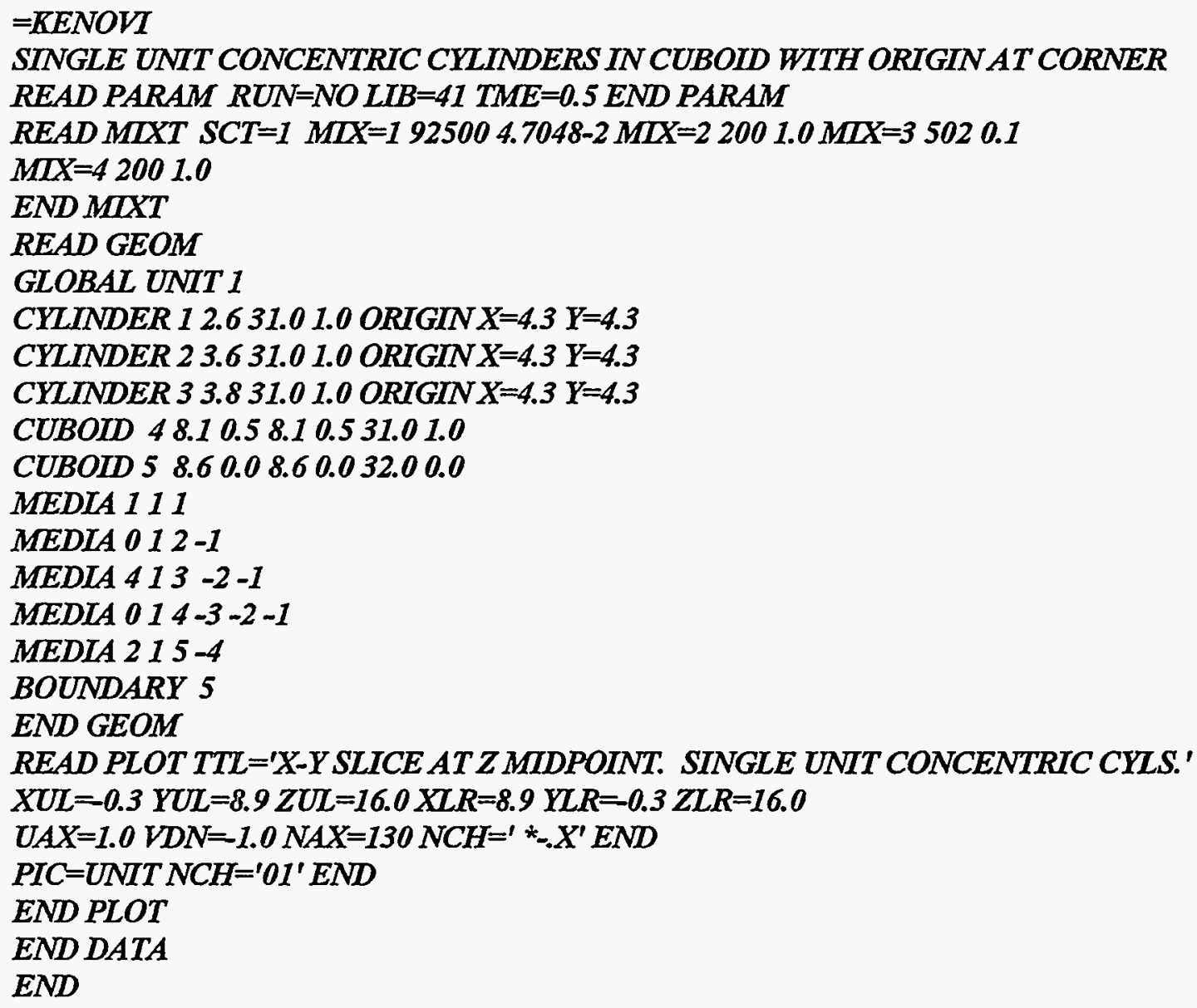

The plot data included above will draw a mixture map of an $x-y$ slice taken at the half-height $(z=16.0)$. It will also draw a unit map of the same slice. The plot dimensions extend $0.3 \mathrm{~cm}$ beyond the problem dimensions to provide a border of question marks around the plot. The associated plot data specification for the mixture map is shown in Fig. F17.5.35, the mixture map is shown in Fig. F17.5.36, and the associated plot data for the unit map is shown in Fig. F17.5.37. The unit map is identical to Fig. F17.5.34 and is not included. Note that Fig. F17.5.36 is identical to Fig. F17.5.29.

NUREG/CR-0200, 
$x-y$ slice at $z$ midpoint. single unit concentric cyls.

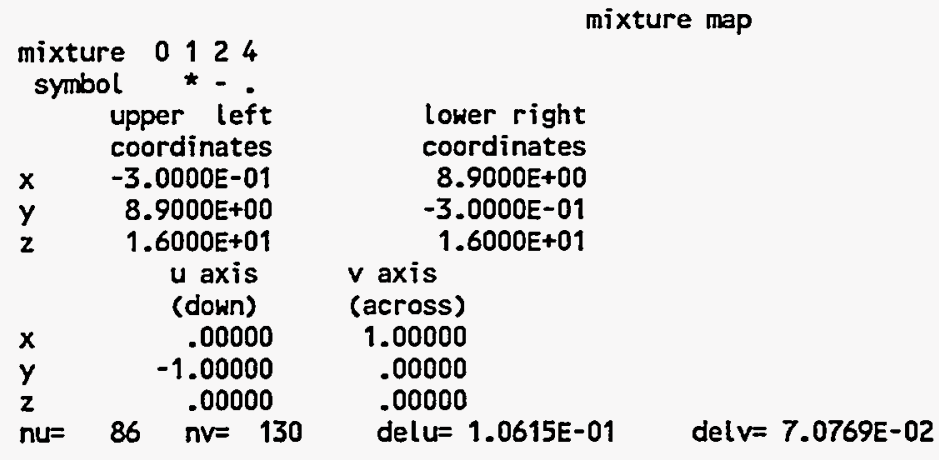

Figure F17.5.35 Associated data for mixture map of single unit with offset origin

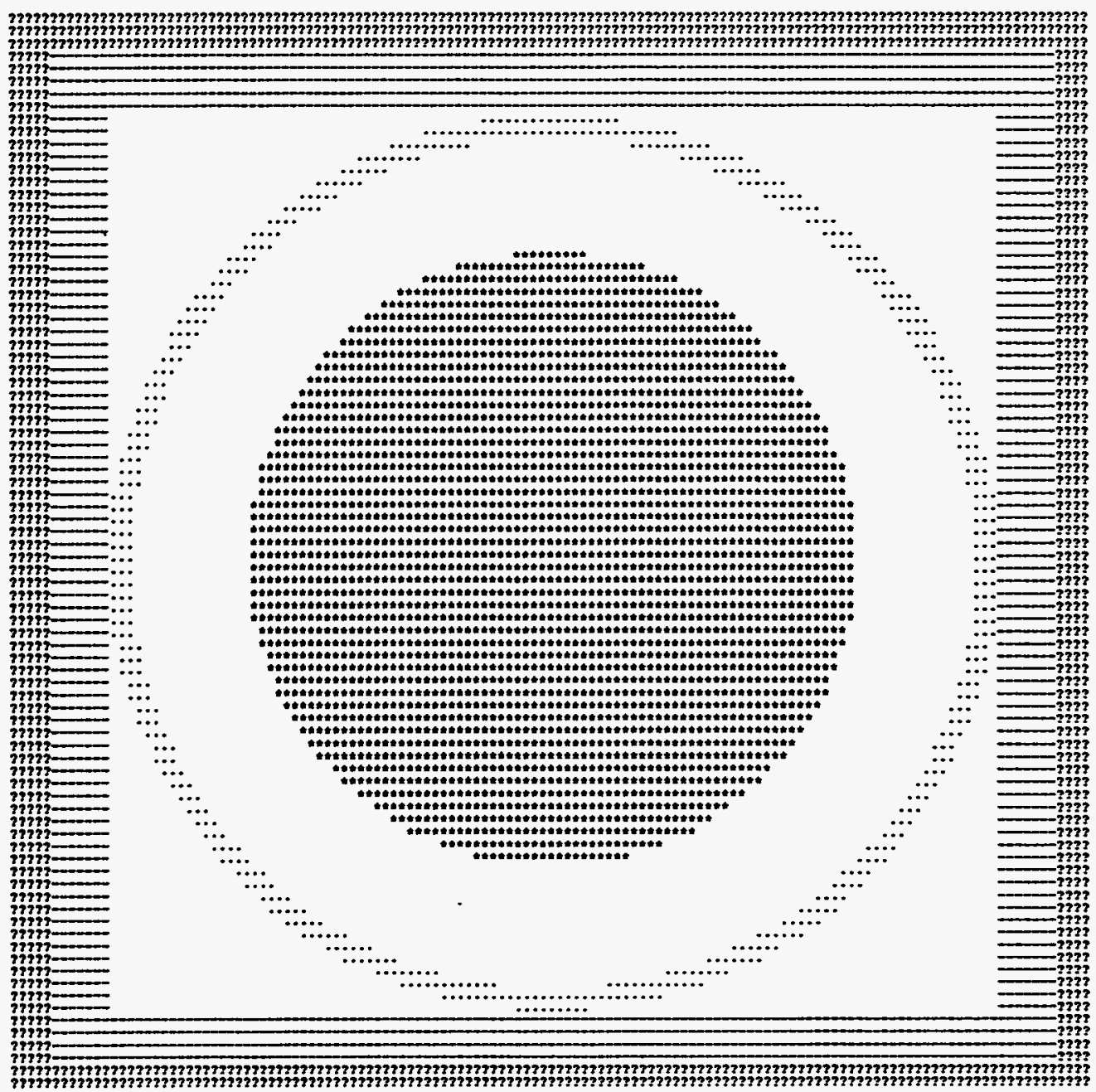

Figure F17.5.36 Mixture map of single unit with offset origin 


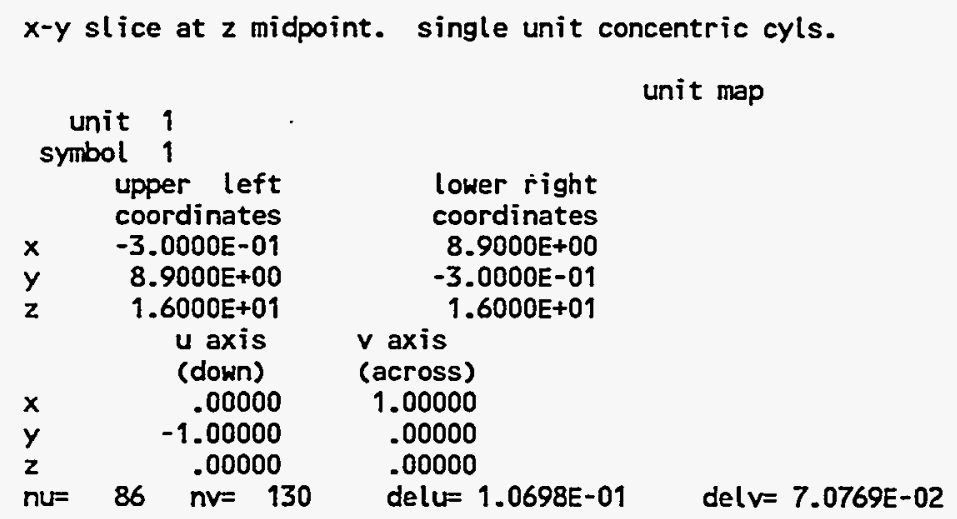

Figure F17.5.37 Associated data for unit map of a single unit with offset origin

EXAMPLE 3. A $2 \times 2 \times 2$ UNREFLECTED ARRAY OF CONCENTRIC CYLINDERS IN CUBOIDS

The physical representation of this example is a $2 \times 2 \times 2$ array of the configuration described in Example 1 of this section. The input data description for this array is given below:

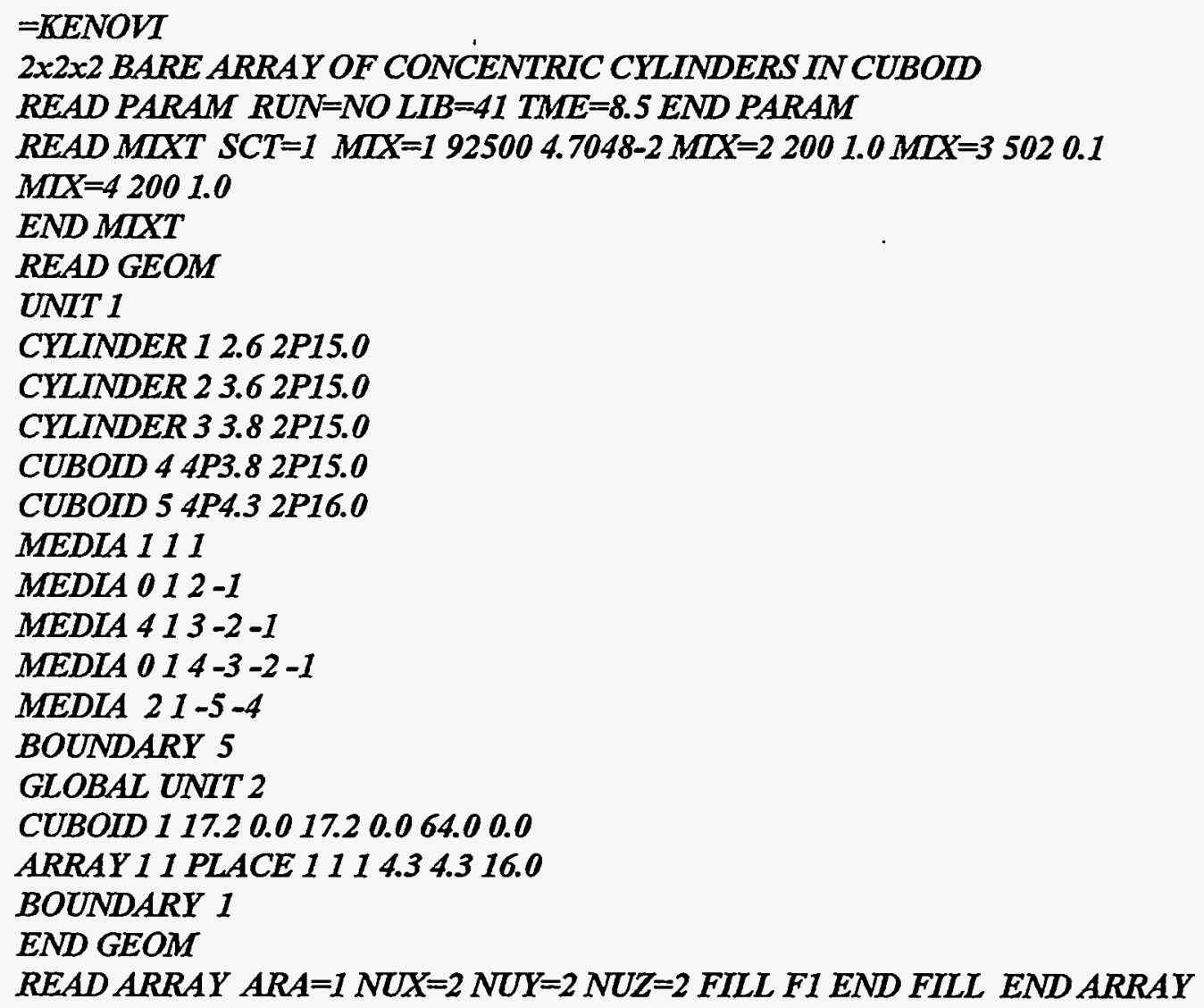


READ PLOT TTL ='X-Y SLICE AT HALF HEIGHT OF BOTTOM LAYER'

$X U L=0.3 Y U L=17.5 Z U L=16.0 X L R=17.5 Y L R=0.3 Z L R=16.0$

$U A X=1.0 \mathrm{VDN}=1.0 \mathrm{NAX}=130 \mathrm{NCH}{ }^{\prime}{ }^{*} . X^{\prime} E N D$

$T T L=' X-Z$ SLICE THROUGH FRONT ROW, $Y=12.9 . '$

$X U L=1.0 Y U L=12.9 \mathrm{ZUL}=65.0 X L R=18.2 \mathrm{YLR}=12.9 \mathrm{ZLR}=1.0$

$U A X=1.0 \quad W D N=1.0 \mathrm{NAX}=60 \mathrm{END}$

END PLOT

END DATA

$E N D$

As stated at the beginning of Sect F17.5.9, the origin of the plot is located at the most negative point of the array. Each individual unit in the array is $8.6 \mathrm{~cm}$ wide in $\mathrm{x}$ and $\mathrm{y}$ and is $32 \mathrm{~cm}$ high in $z$. Since the array has two units stacked in each direction, the array is $17.2 \mathrm{~cm}$ wide in $\mathrm{x}$ and $\mathrm{y}$ and is $64 \mathrm{~cm}$ high. Therefore, the array exists from $x=0.0$ to $x=17.2$, from $y=0.0$ to $y=17.2$ and from $z=0.0$ to $z=64.0$.

The first printer plot is to generate an $x$-y slice through the array at the half-height of the first layer, as shown in Fig. F17.5.38. This plot occurs at $z=16.0 \mathrm{~cm}$. It is desirable to define the outer boundaries of the array by setting the boundaries of the plot larger than the array. In this case, the boundaries were arbitrarily set $0.3 \mathrm{~cm}$ larger than the array, resulting in a border of question marks around the array. If the plot were to exclude everything external to the array, the following coordinates could have been entered: $\mathrm{XUL}=0.0 \mathrm{YUL}=17.2$ $\mathrm{ZUL}=16.0 \mathrm{XLR}=17.2 \mathrm{YLR}=0.0 \mathrm{ZLR}=16.0$. These coordinate choices would have eliminated all the question marks. The existing picture was made using $X U L=0.3 \mathrm{YUL}=17.5 \mathrm{ZUL}=16.0 \mathrm{XLR}=17.5 \mathrm{YLR}=0.3 \mathrm{ZLR}=16.0$.

The second printer plot is to generate an $x-z$ slice through the center of the front row of the array. In order to obtain a boundary of question marks, the coordinates of $x$ and $z$ were arbitrarily set $1.0 \mathrm{~cm}$ larger than the boundaries of the array. The center of the front row occurs at $y=12.9$. The coordinates of the plot were: $\mathrm{XUL}=1.0 \mathrm{ZUL}=65.0 \mathrm{YUL}=12.9 \mathrm{XLR}=18.2 \mathrm{ZLR}=1.0 \mathrm{YLR}=12.9$. The plot was defined to be half a page wide by entering $N A X=60$. The resultant mixture map is shown in Fig. F17.5.39.

EXAMPLE 4. A $2 \times 2 \times 2$ REFLECTED ARRAY WITH THE ORIGIN AT THE MOST NEGATIVE POINT OF THE ARRAY

The array is the array described in Example 3 of this section and has a 15.24-cm (6-in.) concrete reflector on all faces. The input data description for this array is given below.

$=$ KENOVI

$2 \times 2 \times 2$ REFLECTED ARRAY OF CONCENTRIC CILINDERS IN CUBOWD

READ PARAM RUN=NO LIB=41 TME=0.5 END PARAM

READ MTXT SCT=1 MLX=192500 4.7048-2 MTX=2 $2001.0 M L X=33011.0$

$M I X=42001.0$

END MLXT

READ GEOM

UNIT 1

CYLINDER $12.62 P 15.0$

CYLINDER $23.62 P 15.0$

CILINDER $33.82 P 15.0$

CUBOID 4 4P3.8 2P15.0

CUBOID 5 4P4.3 2P16.0

MEDIA 111

F17.5.87

NUREG/CR-0200, Vol. 2, Rev. 5 


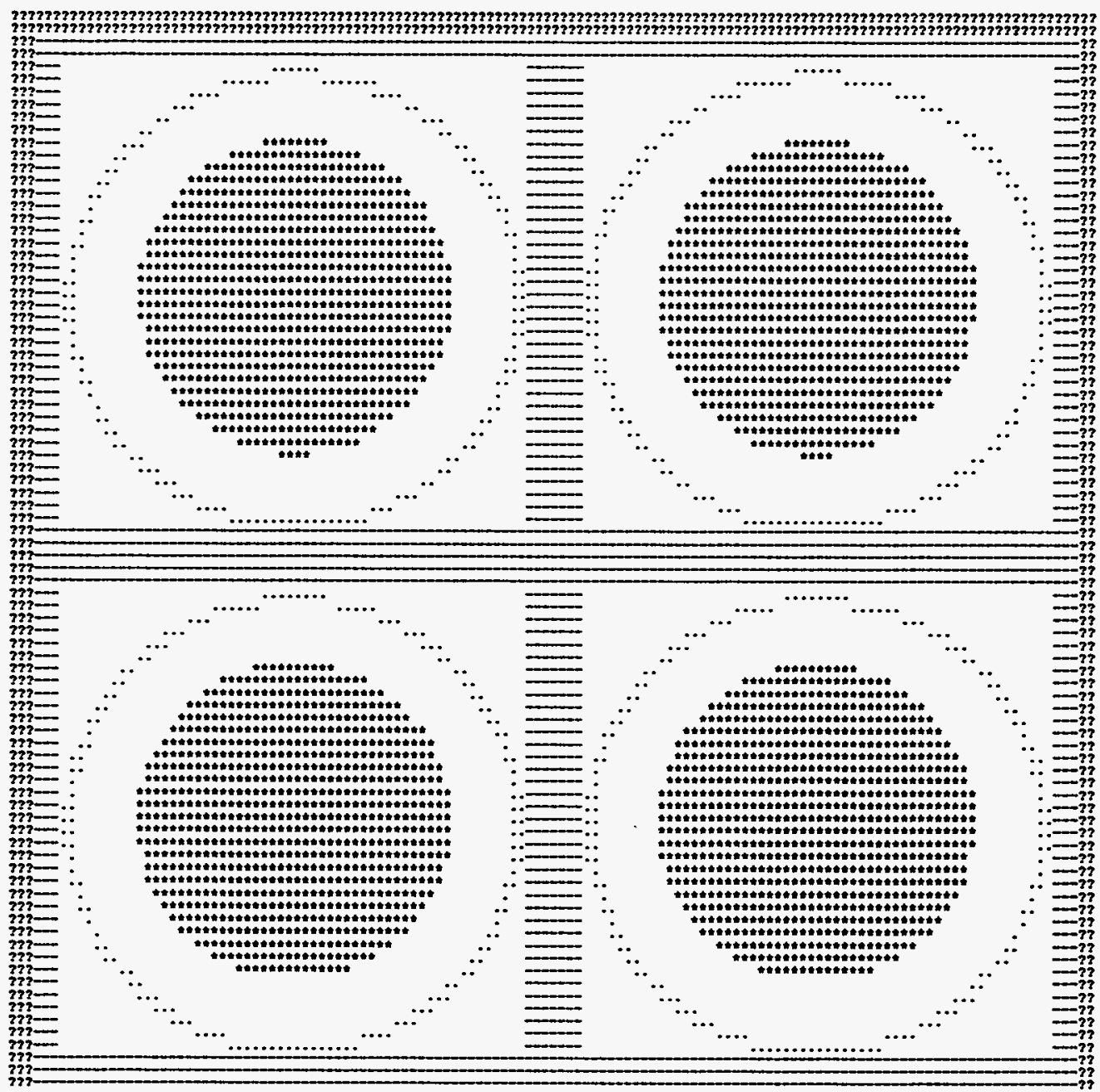

Figure F17.5.38 x-y plot of $2 \times 2 \times 2$ bare array

NUREG/CR-0200,

Vol. 2, Rev. 5

F17.5.88 


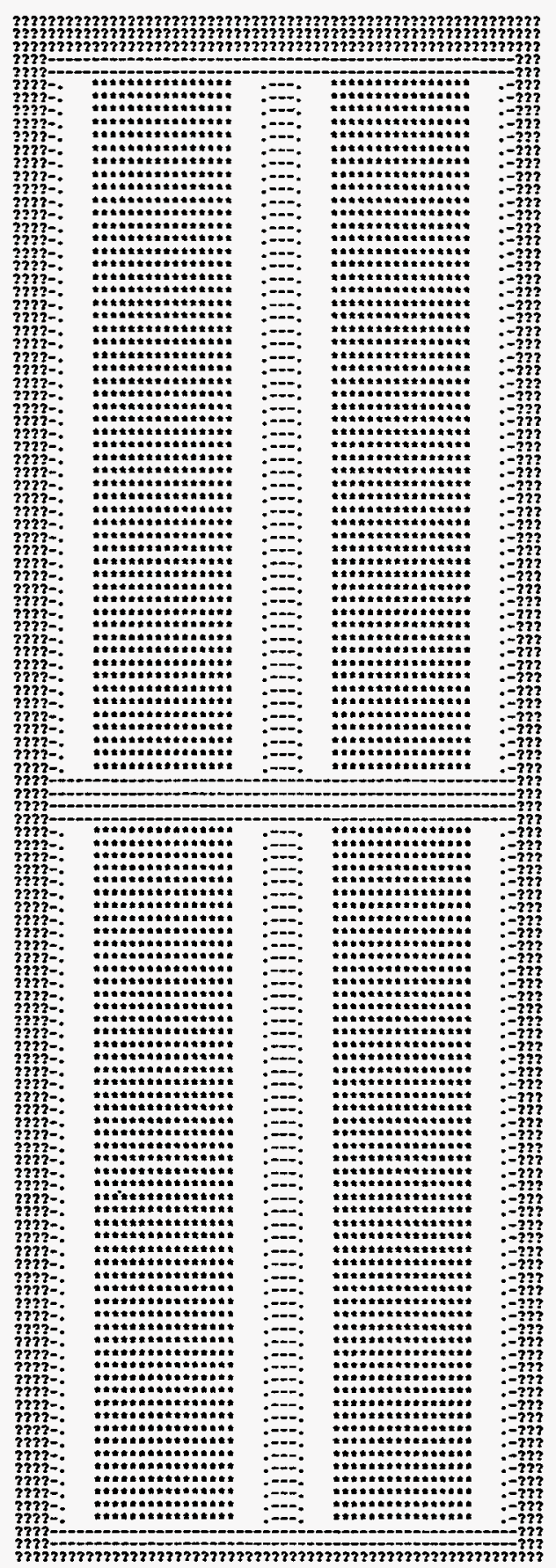

Figure F17.5.39 x-z plot of $2 \times 2 \times 2$ bare array 


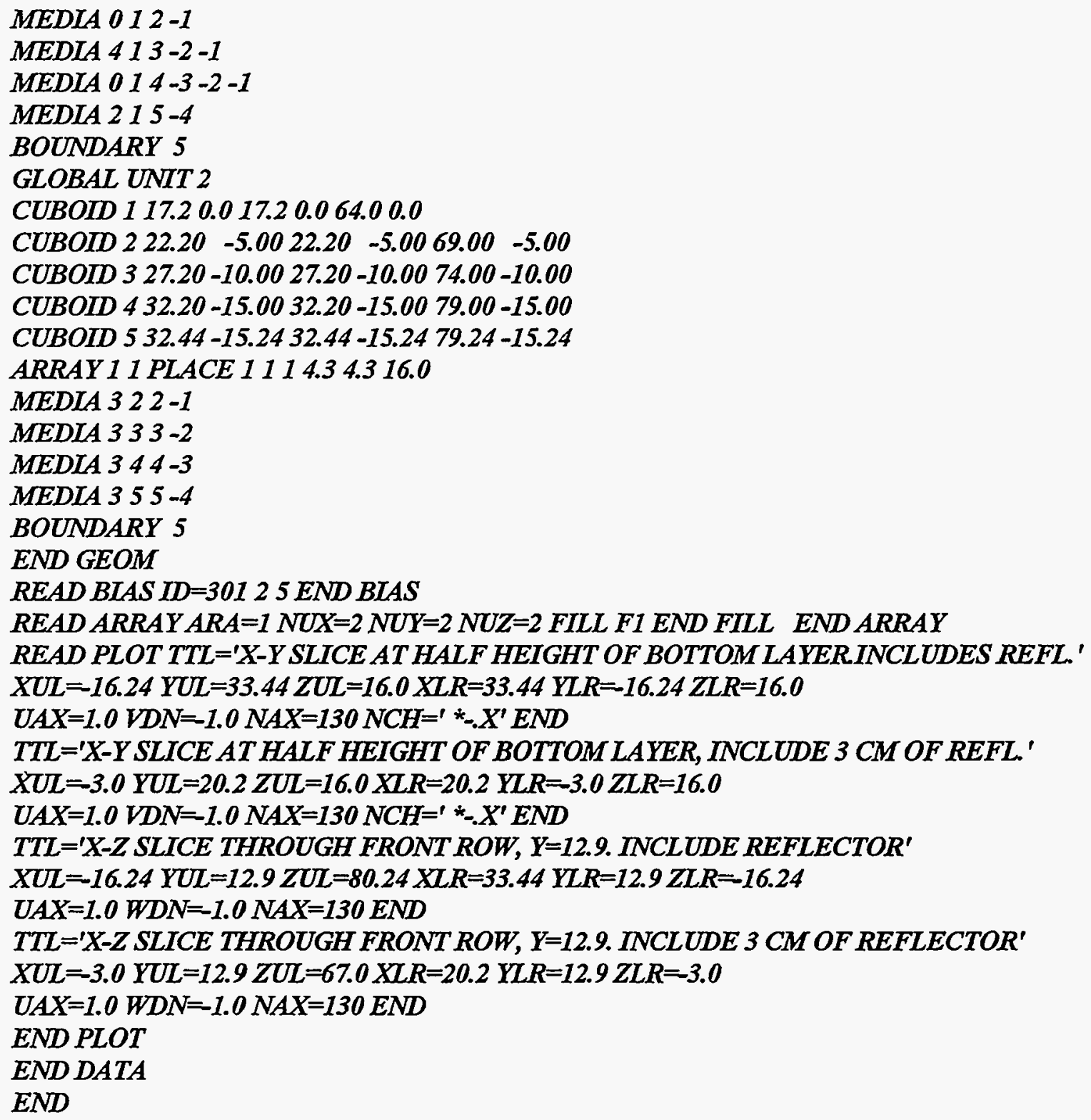

The ARRAY record, associated with the first geometry record in global unit 2 , specifies the coordinates of the most negative point of the array to be $(0.0,0.0,0.0)$ and the most positive point to be $(17.2,17.2,64.0)$. Thus the reflected array extends from $-15.24 \mathrm{~cm}$ to $+32.44 \mathrm{~cm}$ in $\mathrm{x}$ and $\mathrm{y}$ and from -15.24 to $+79.24 \mathrm{in} z$.

The first printer plot for this example shows an $x-y$ slice through the array and reflector at the half-height of the bottom layer. A border of question marks is used to verify that the entire reflector has been shown. This border is accomplished by arbitrarily setting the picture boundaries $1 \mathrm{~cm}$ beyond the reflector boundaries. The coordinates used for this plot are: $\mathrm{XUL}=-16.24 \mathrm{YUL}=33.44 \mathrm{ZUL}=16.0 \mathrm{XLR}=33.44 \mathrm{YLR}=-16.24$ $Z L R=16.0$. The plot data description is shown in Fig. F17.5.40, and the plot is shown in Fig. F17.5.41. 
$x-y$ slice at half height of bottom layer includes refl.

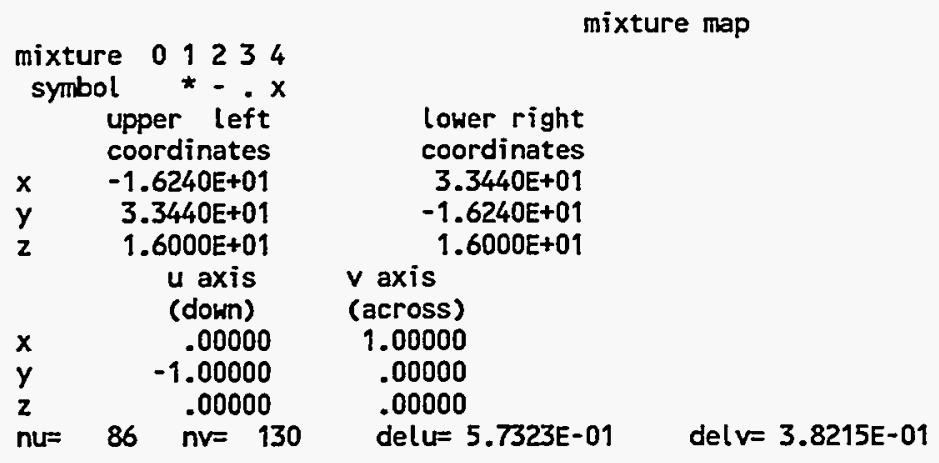

Figure F17.5.40 Plot data for $x-y$ slice of example 4 


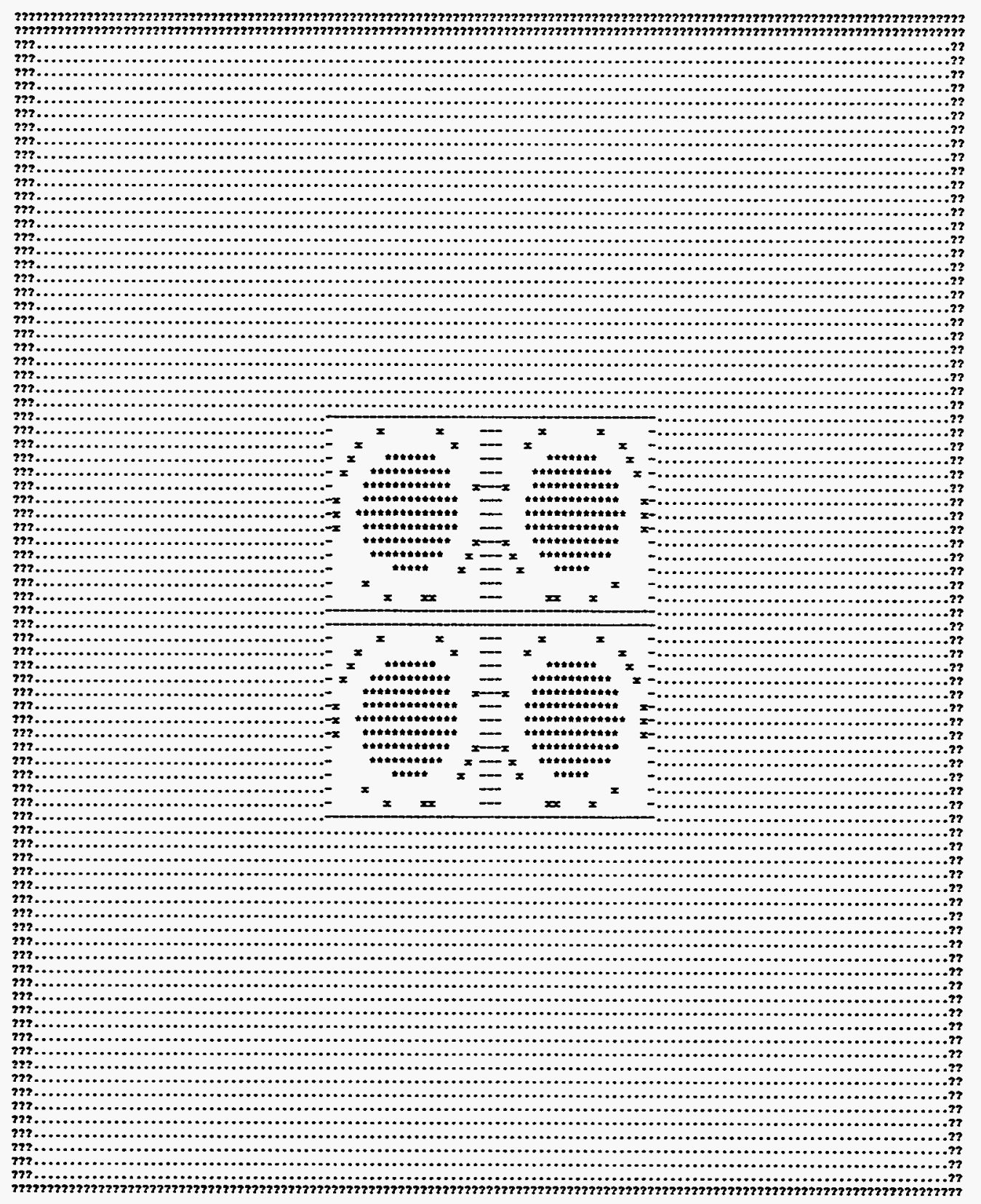

Figure F17.5.41 x-y plot of $2 \times 2 \times 2$ reflected array

The next printer plot is the same as the previous plot, except the plot includes only the first $3 \mathrm{~cm}$ of the reflector. This results in the picture being large enough to show more detail. The coordinates used for this plot are: $\mathrm{XUL}=-3.0 \mathrm{YUL}=20.2 \mathrm{ZUL}=16.0 \mathrm{XLR}=20.2 \mathrm{YLR}=-3.0 \mathrm{ZLR}=16.0$. This plot data description is given in Fig. F17.5.42, and the plot is shown in Fig. F17.5.43.

NUREG/CR-0200,

Vol. 2, Rev. 5 
$x-y$ slice at half height of botton layer, include $3 \mathrm{~cm}$ of refl.

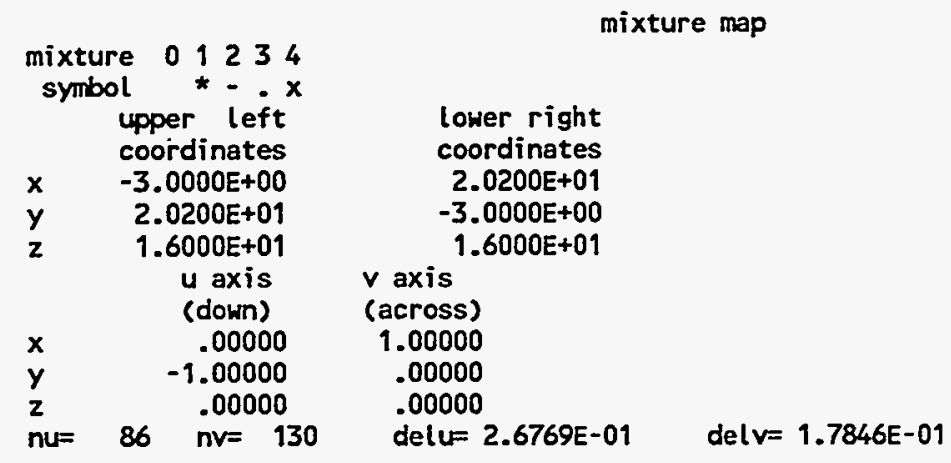

Figure F17.5.42 Plot data for enlarged $x-y$ slice of example 4

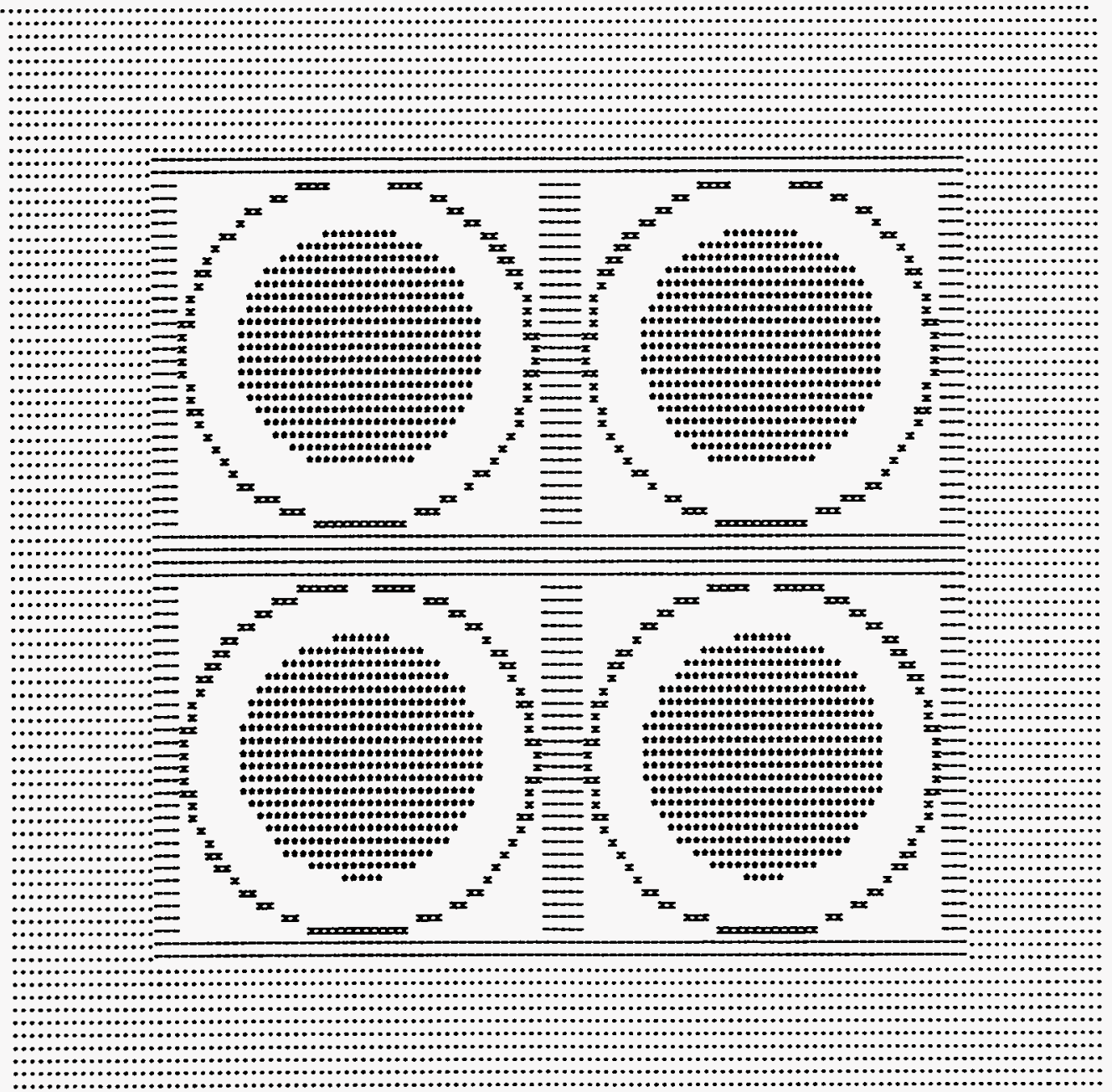

Figure F17.5.43 Enlarged x-y plot of $2 \times 2 \times 2$ reflected array

F17.5.93

NUREG/CR-0200,

Vol. 2, Rev. 5 
The third printer plot for this example is an $\mathrm{x}-\mathrm{z}$ slice through the center of the front row. An extra $1 \mathrm{~cm}$ is included in the coordinates to provide a border of question marks around the plot. The coordinates are: $\mathrm{XUL}=16.24 \mathrm{YUL}=12.9 \mathrm{ZUL}=80.24 \mathrm{XIR}=33.44 \mathrm{YLR}=12.9 \mathrm{ZLR}=-16.24$. The resultant plot data and plot are shown in Figs. F17.5.44 and F17.5.45.

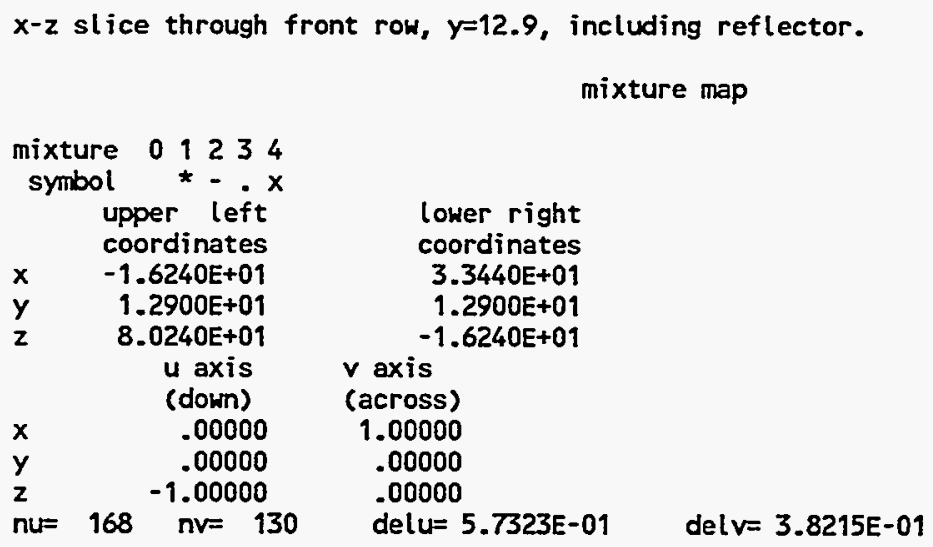

Figure F17.5.44 Plot data for $x-z$ slice of example 4

NUREG/CR-0200, 


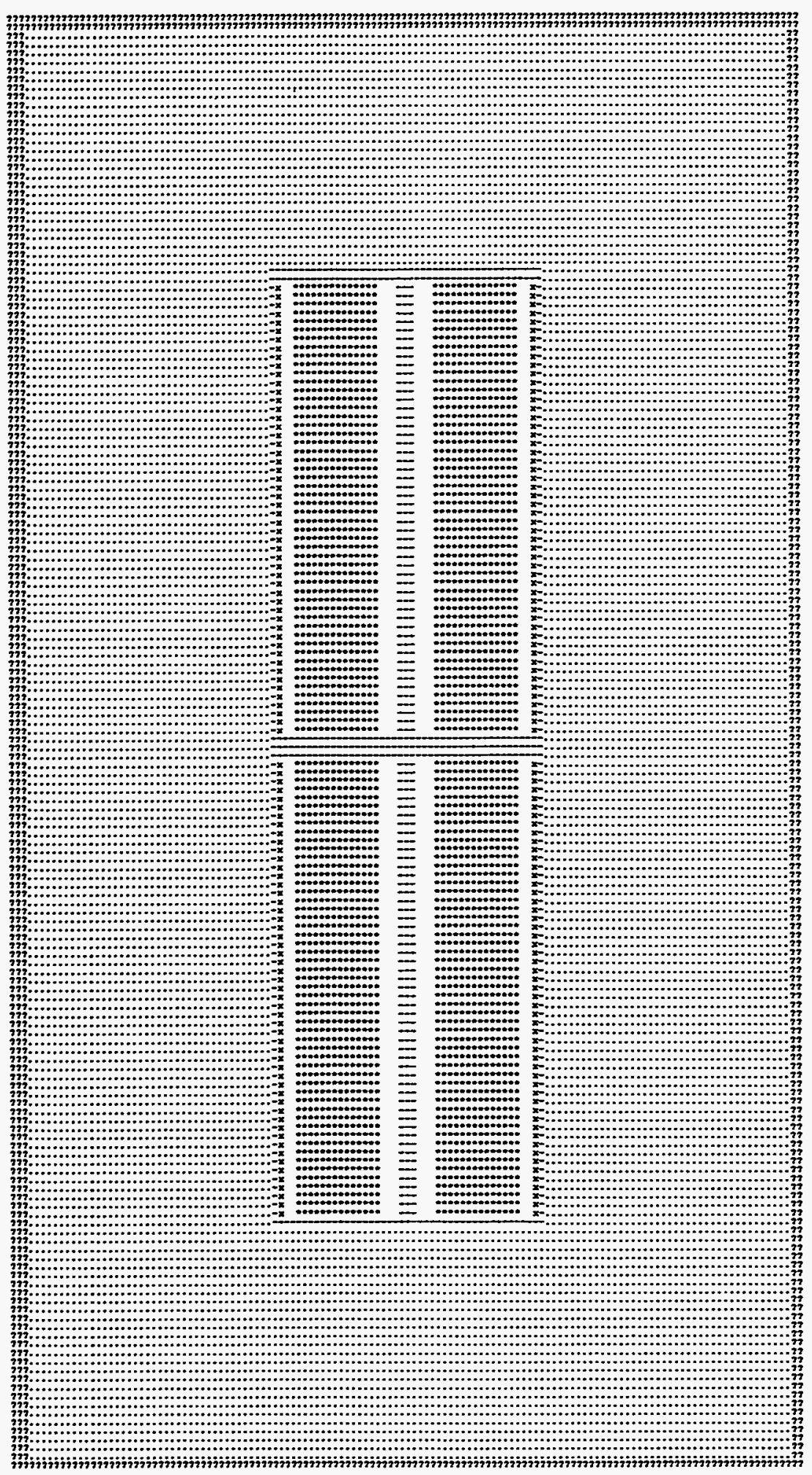

Figure F17.5.45 x-z plot for $2 \times 2 \times 2$ reflected array 
The last printer plot for this example is the same as the previous one, except only $3 \mathrm{~cm}$ of the reflector is included in the plot. The plot data and associated plot are shown in Figs. F17.5.46 and F17.5.47.

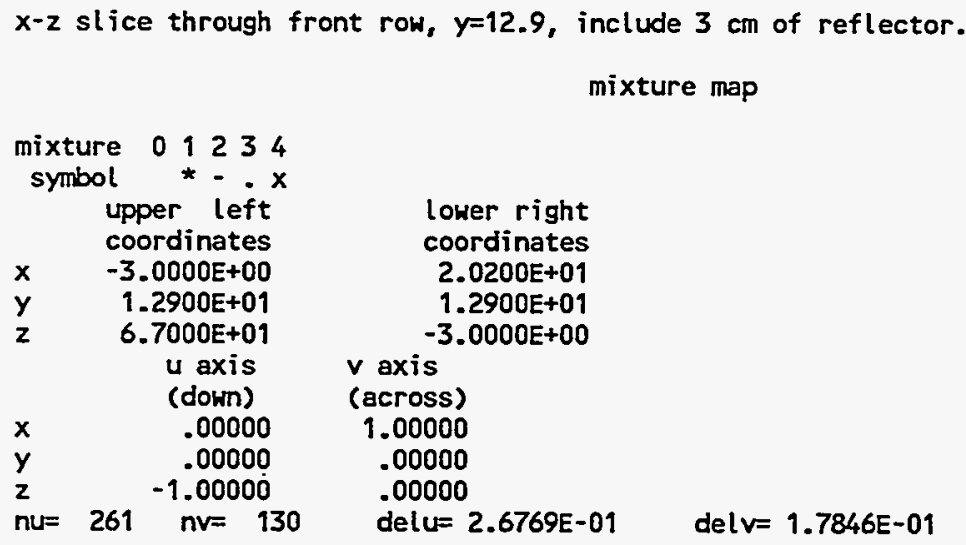

Figure F17.5.46 Plot data for enlarged $x-z$ slice of example 4 


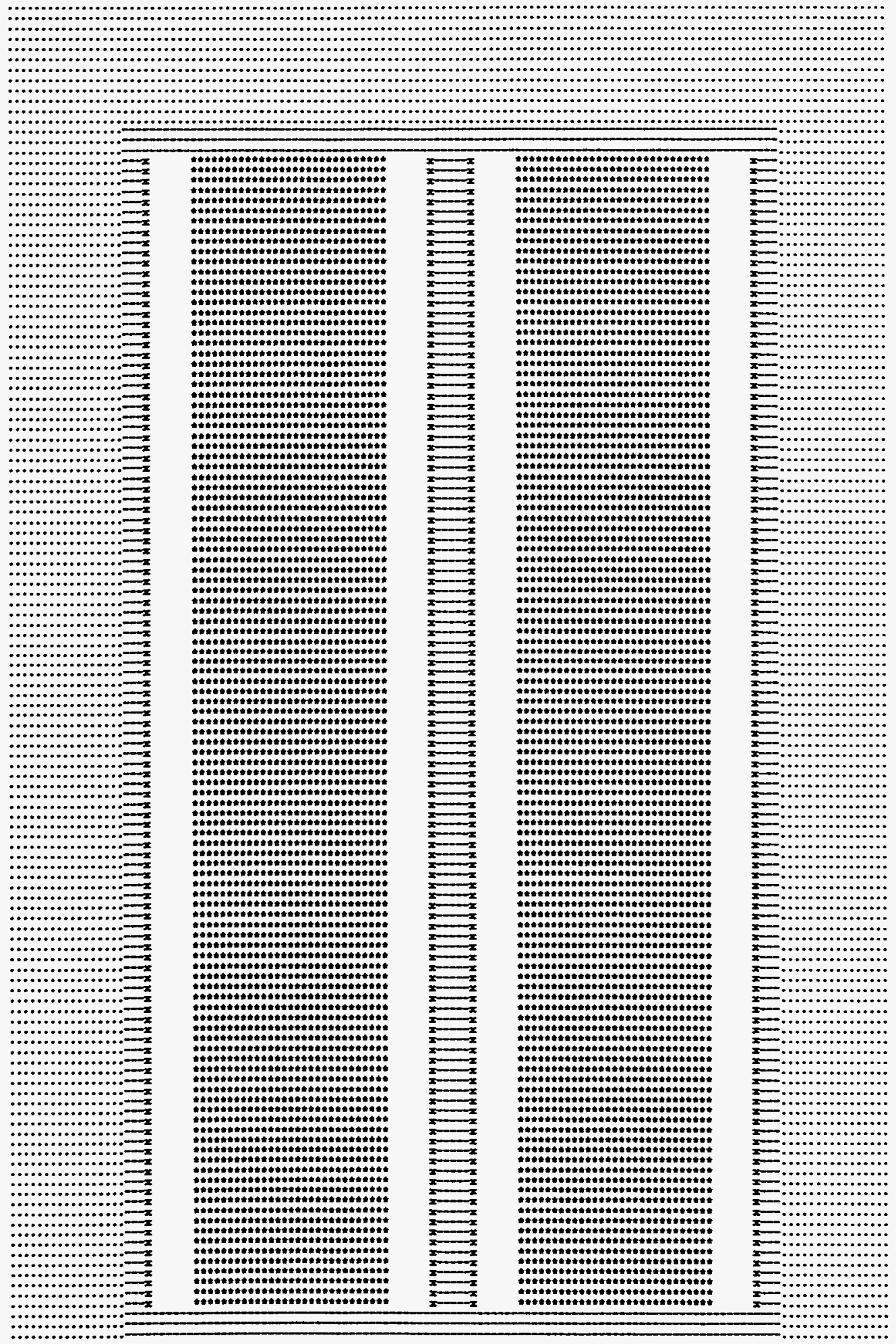

Figure F17.5.47 Enlarged x-z plot of $2 \times 2 \times 2$ reflected array 


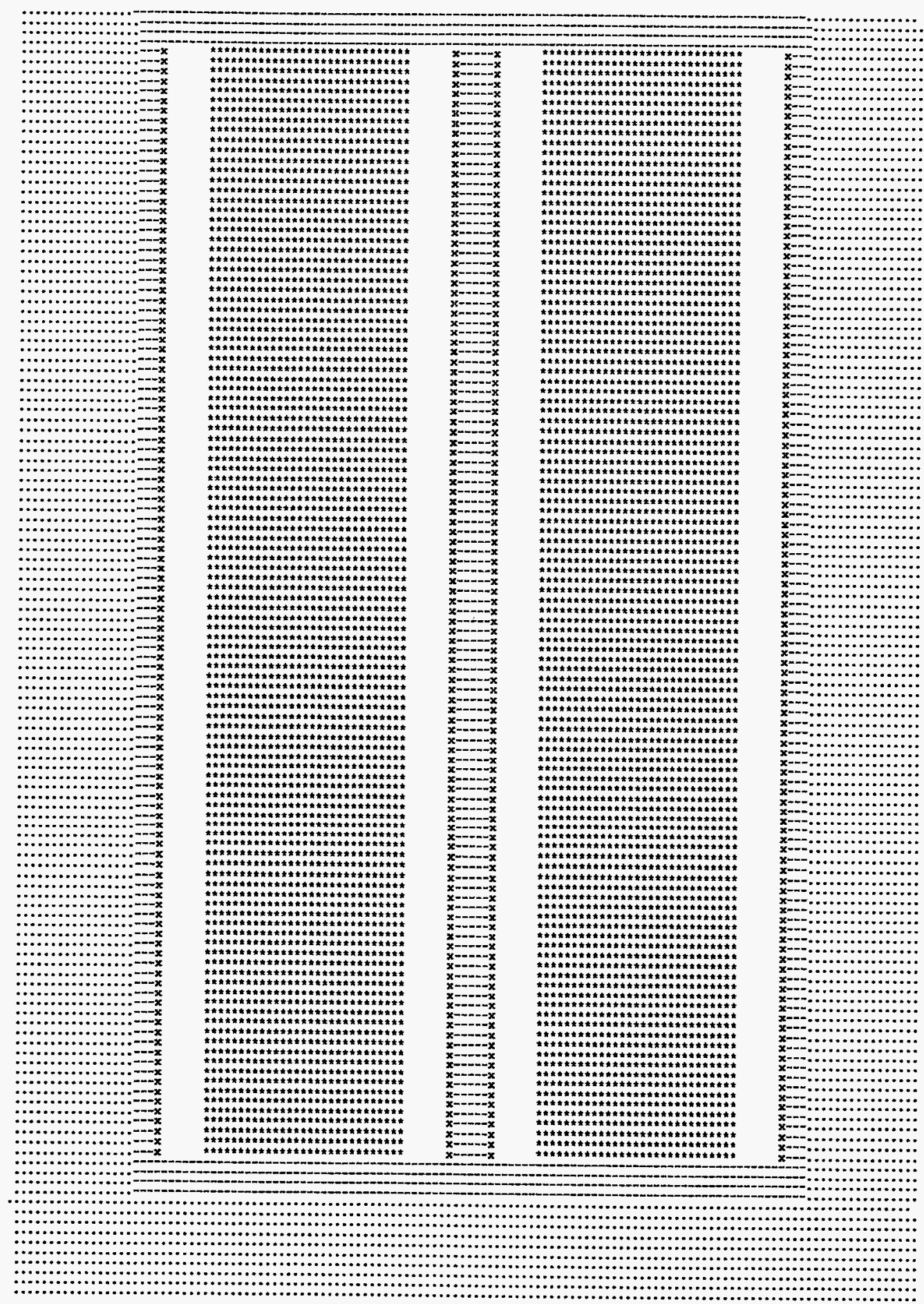

0.04267 minutes were required for this picture. total elapsed time is .12800 minutes.

Figure F17.5.47 (continued)

NUREG/CR-0200,

Vol. 2, Rev. 5 
This example is physically identical to Example 4. The difference is in the specification of the origin. The bare array is $17.2 \mathrm{~cm}$ wide in $x$ and $y$ and $64 \mathrm{~cm}$ high. The origin $(0,0,0)$ can be placed at the exact center of the array by specifying the most negative point of the array as $x=-8.6, y=-8.6$ and $z=-32.0$. This positioning is done using the CUBOID card in association with the PLACE section of the ARRAY card. Because the origin is located at a different position, the coordinates of the plots will also be different. The input data description for this example is given below.

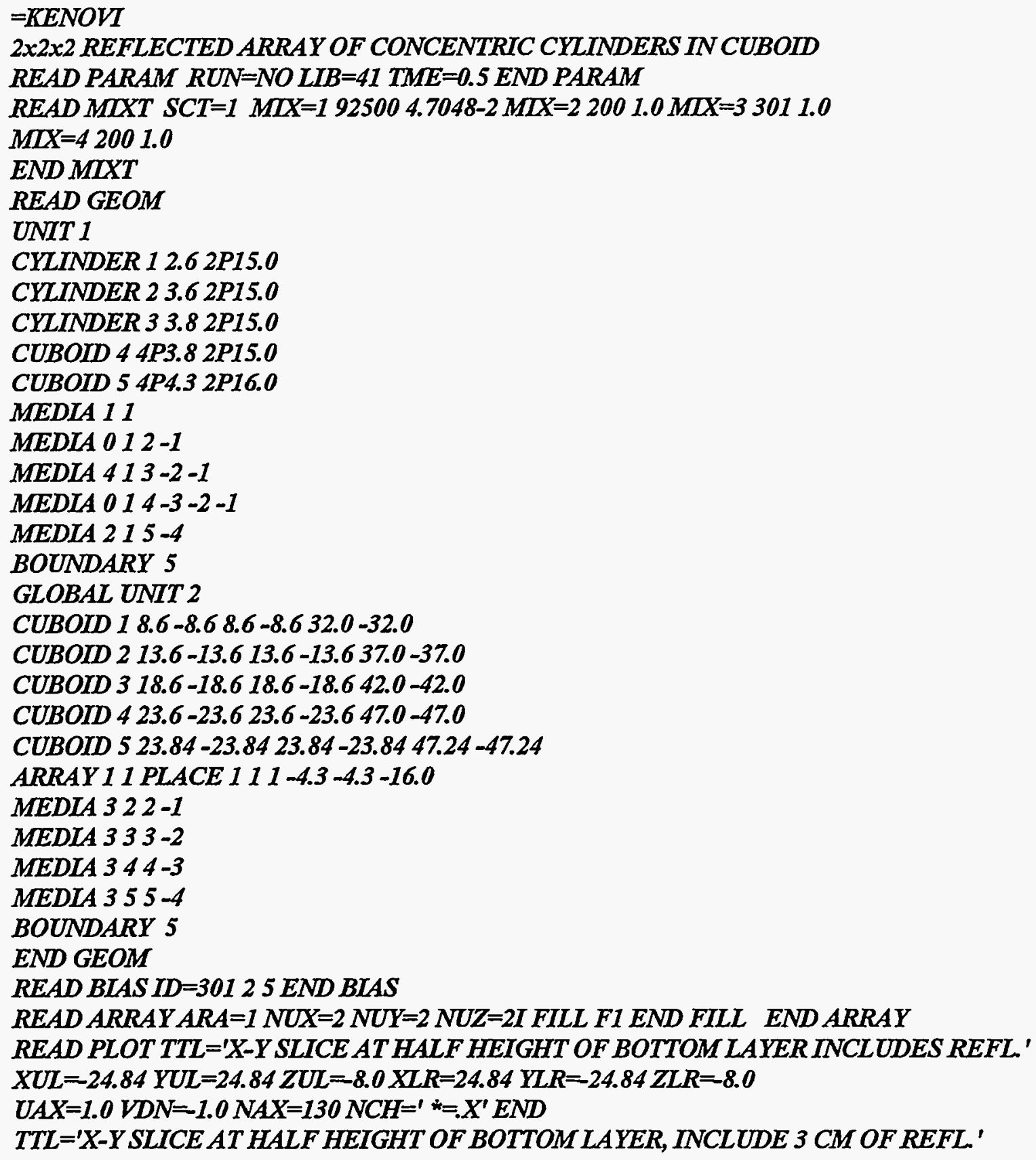




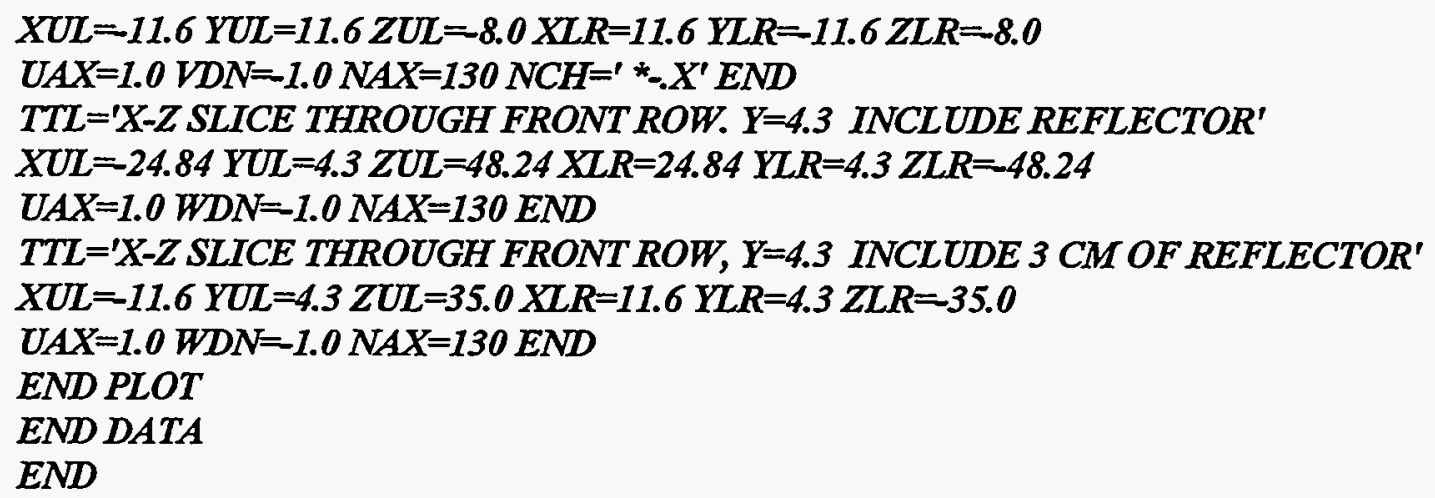

The first printer plot for this example covers identically the same area as the first printer plot for Example 4. The plot data for this plot and the actual plot are given in Figs. F17.5.48 and F17.5.49.

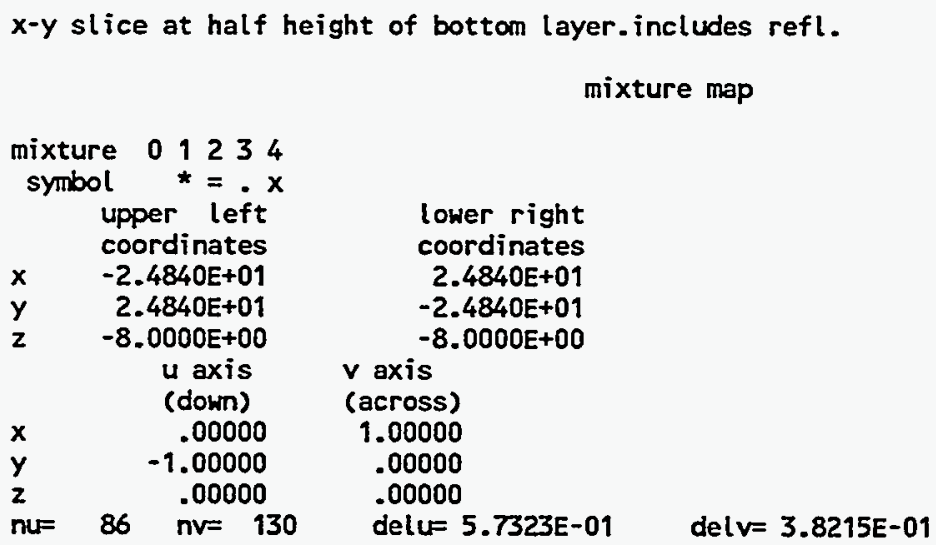

Figure F17.5.48 Plot data for $x-y$ slice of example 5

NUREG/CR-0200,

Vol. 2, Rev. 5 


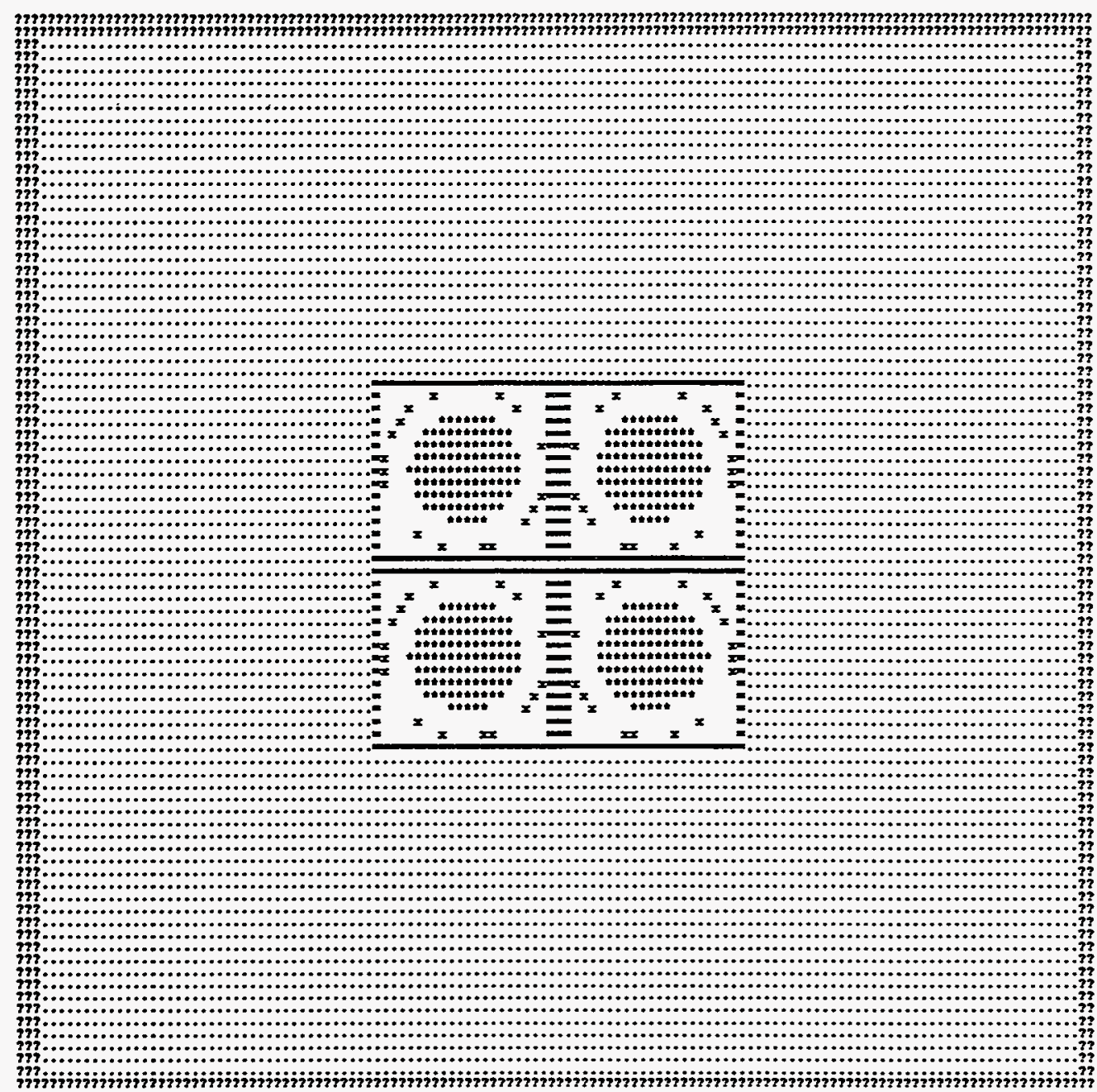

Figure F17.5.49 The $x-y$ plot of $2 \times 2 \times 2$ reflected array with centered origin 
The Example 5 plot data and associated plots for an enlarged $x-y$ plot, an $x-z$ plot and an enlarged $x-z$ plot are given in Figs. F17.5.50 through F17.5.55.

$x-y$ slice at half height of bottom layer, include $3 \mathrm{~cm}$ of refl.

mixture map

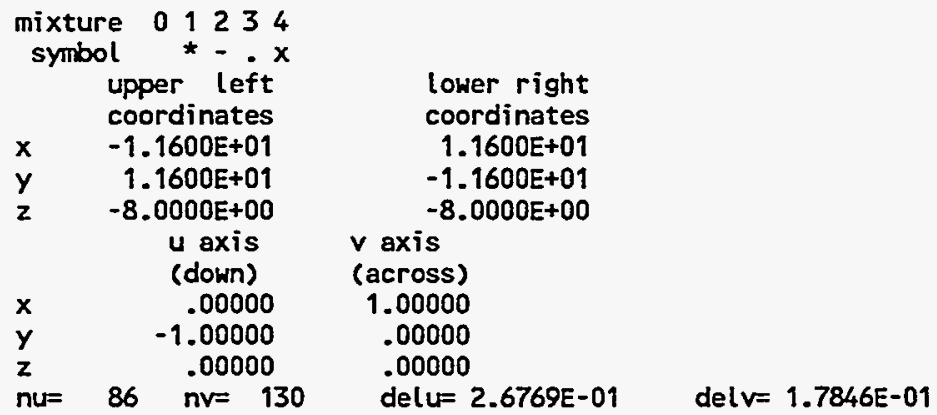

Figure F17.5.50 Plot data for an enlarged $x-y$ slice of example 5 


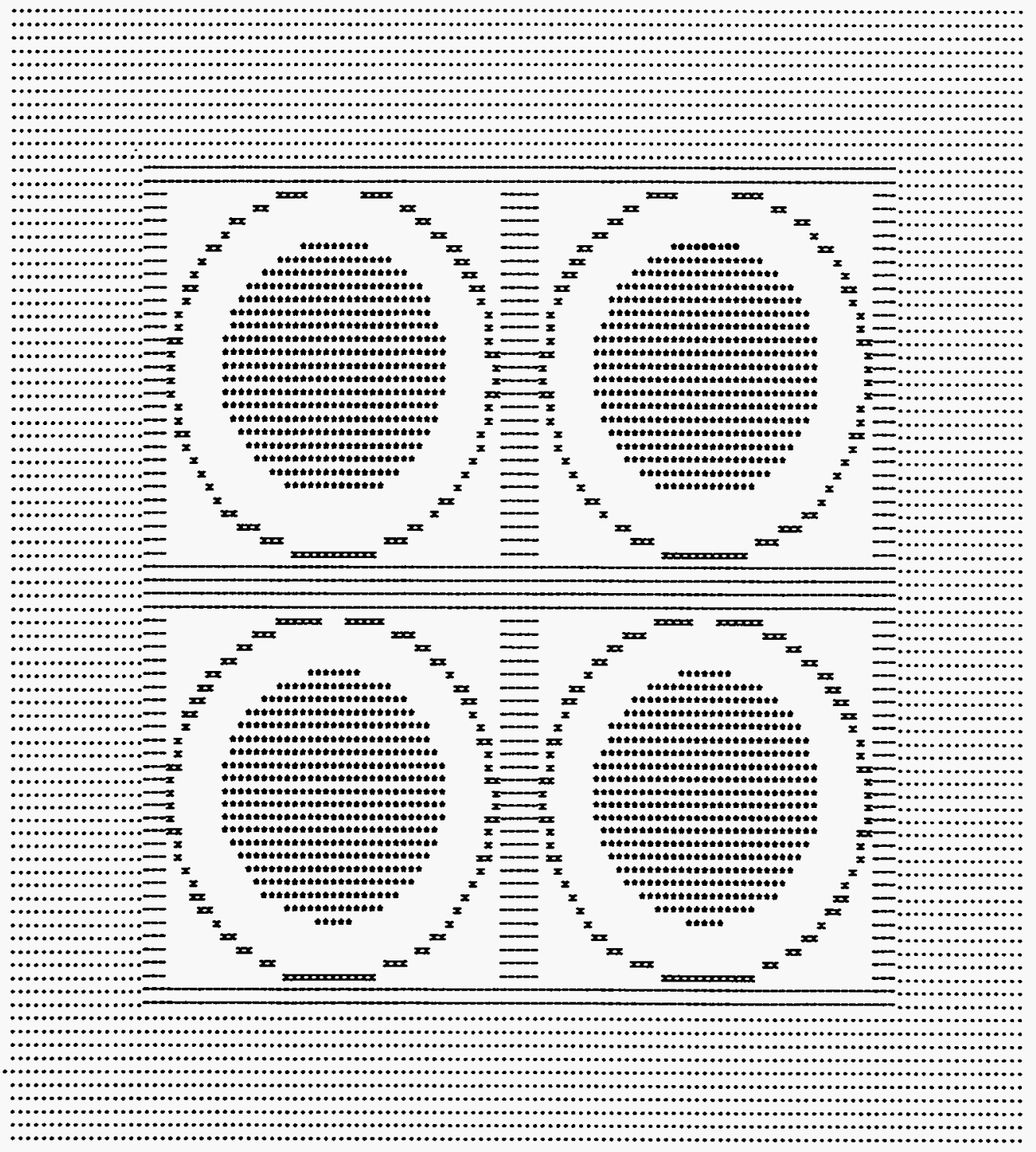

Figure F17.5.51 Enlarged z-y plot of $2 \times 2 \times 2$ reflected array with centered origin

$x-z$ slice through front row. $y=4.3$ include reflector

mixture map

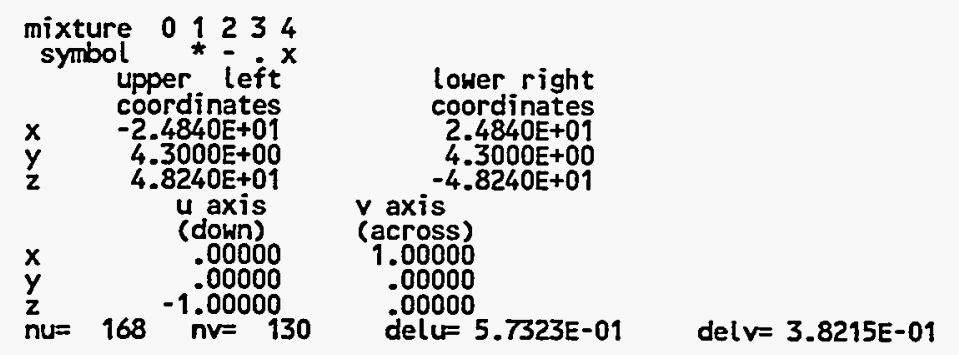

Figure F17.5.52 Plot data for $\mathrm{x}-\mathrm{z}$ slice of example 5

F17.5.103 


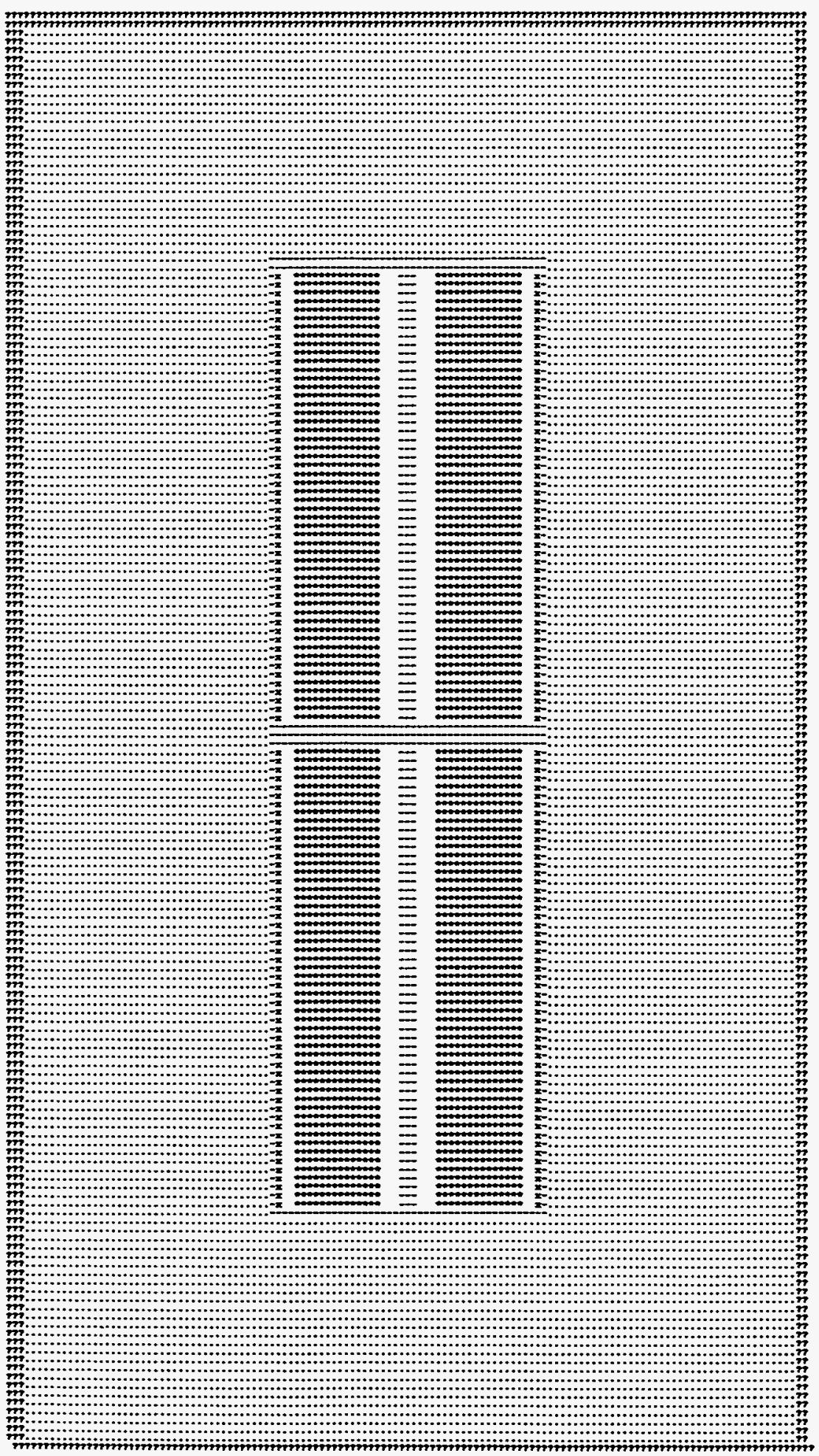

Figure F17.5.53 $\mathrm{x}-\mathrm{z}$ plot of reflected $2 \times 2 \times 2$ array with centered origin

NUREG/CR-0200,

Vol. 2, Rev. 5

F17.5.104 


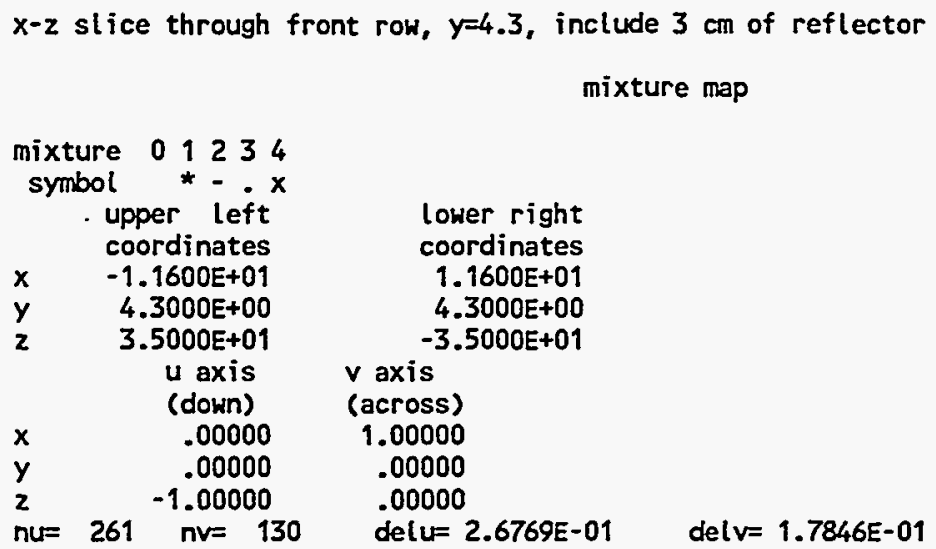

Figure F17.5.54 Plot data for enlarged $x-z$ slice of example 5 


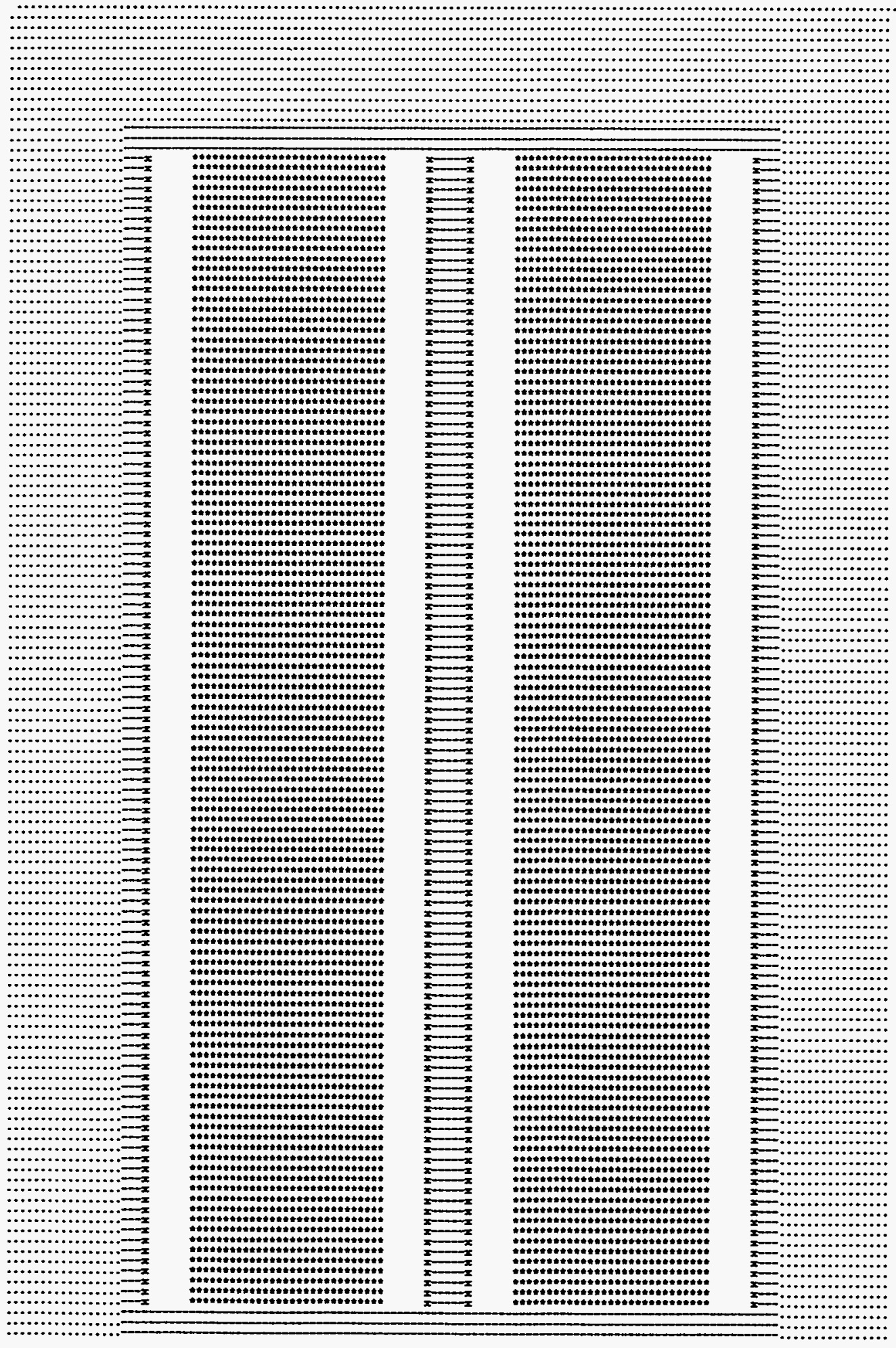

Figure F17.5.55 Enlarged $x-z$ plot of reflected $2 \times 2 \times 2$ array with centered origin

NUREG/CR-0200,

Vol. 2, Rev. 5

F17.5.106 


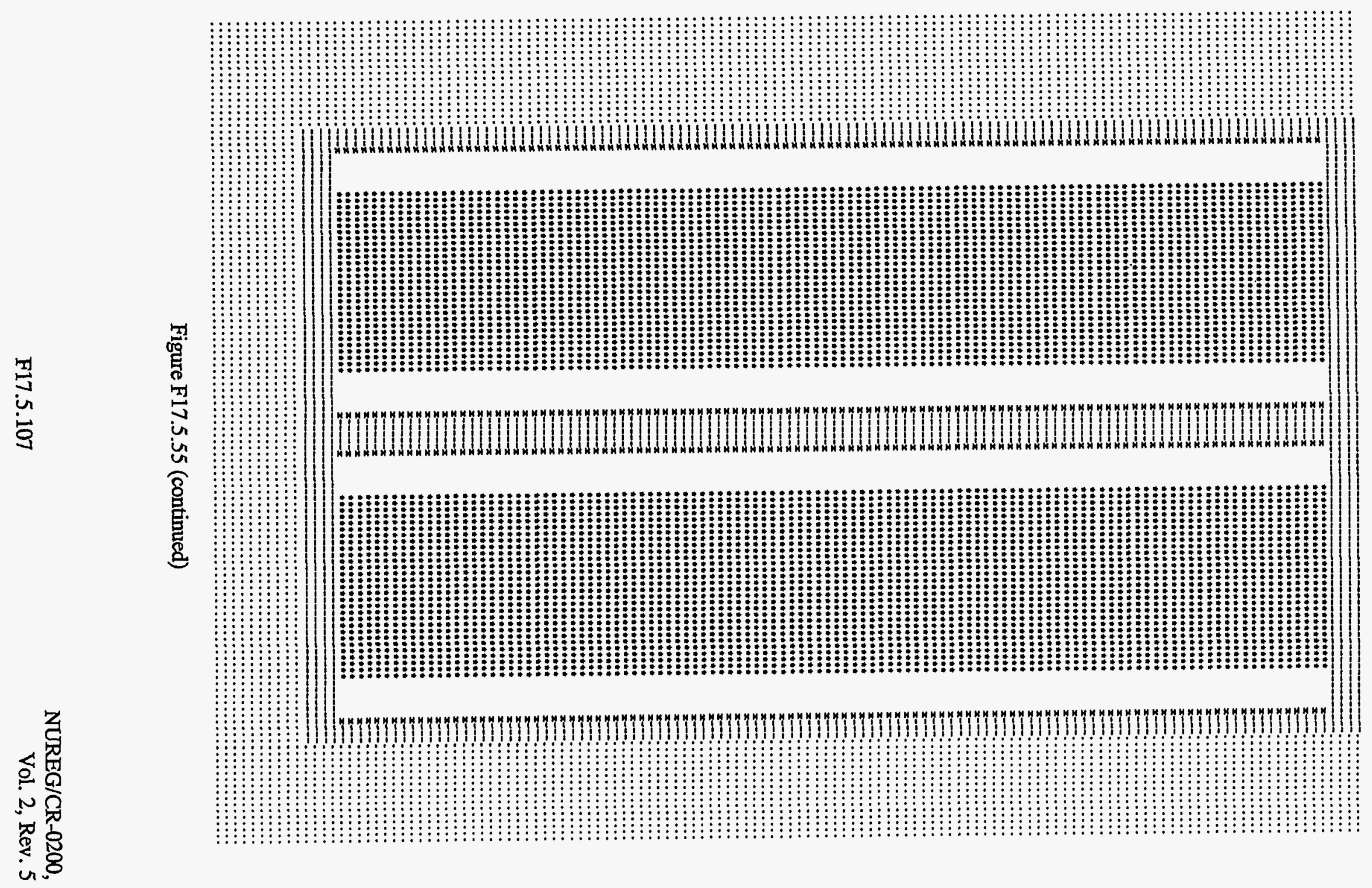




\section{EXAMPLE 6. NESTED HOLES}

Refer to the nested hole description of Sect. F17.5.6.2. The mixture map for this problem is shown in two parts in Figs. F17.5.11 and F17.5.12. This example is one that involves a reasonably complicated placement of units; therefore, it might be useful to the user to generate both a mixture map and a unit map for the problem. Because an enlarged printer plot of the mixture map was already presented in Figs. F17.5.11 and F17.5.12, the mixture map in this section was reduced to fit on one page width by changing NAX from 260 to 130 . The resultant mixture map is shown in Fig. F17.5.56. The plot data and actual plot for the unit map are shown in Figs. F17.5.57 and F17.5.58. The data description for Example 6 follows.

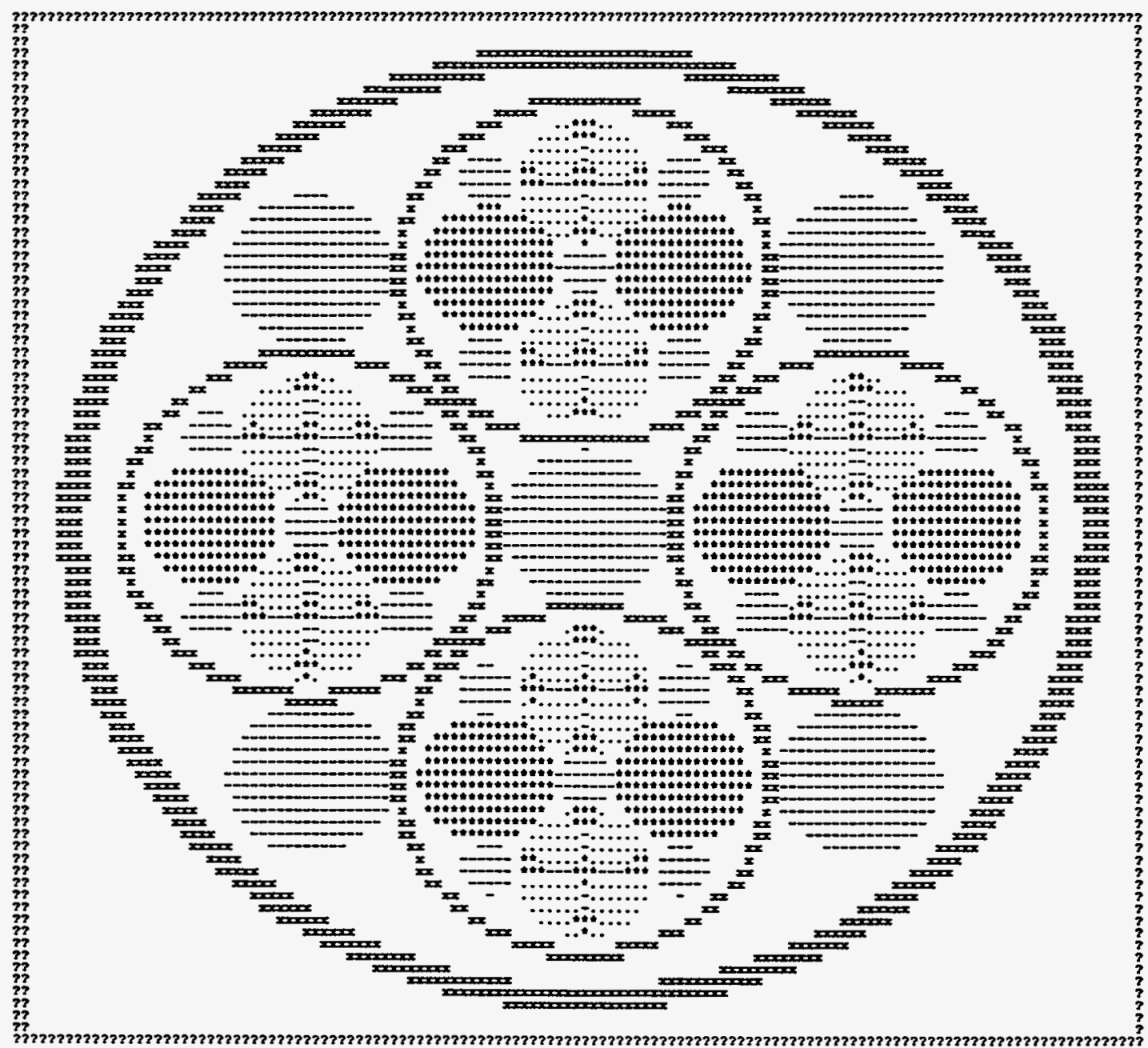

Figure F17.5.56 Mixture map of nested holes problem

NUREG/CR-0200,

Vol. 2, Rev. 5

F17.5.108 
$x-y$ slice at $z$ midpoint. nested holes, unit map.

\section{unit map}

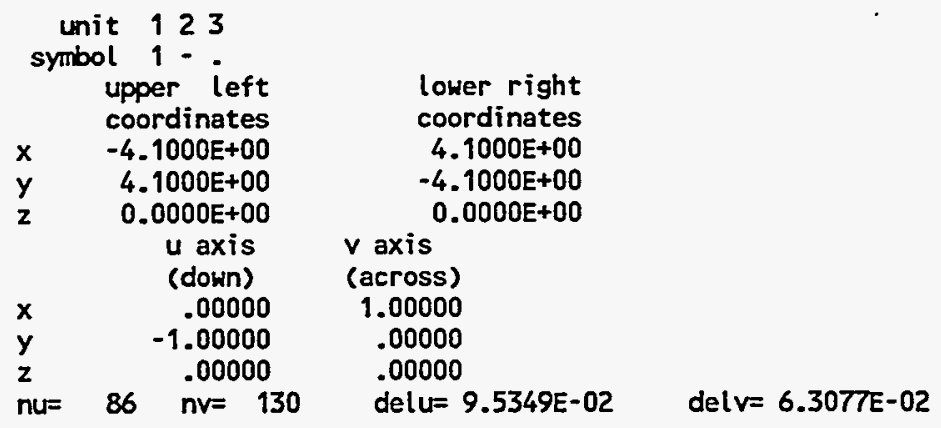

Figure F17.5.57 Plot data for unit map of nested holes 


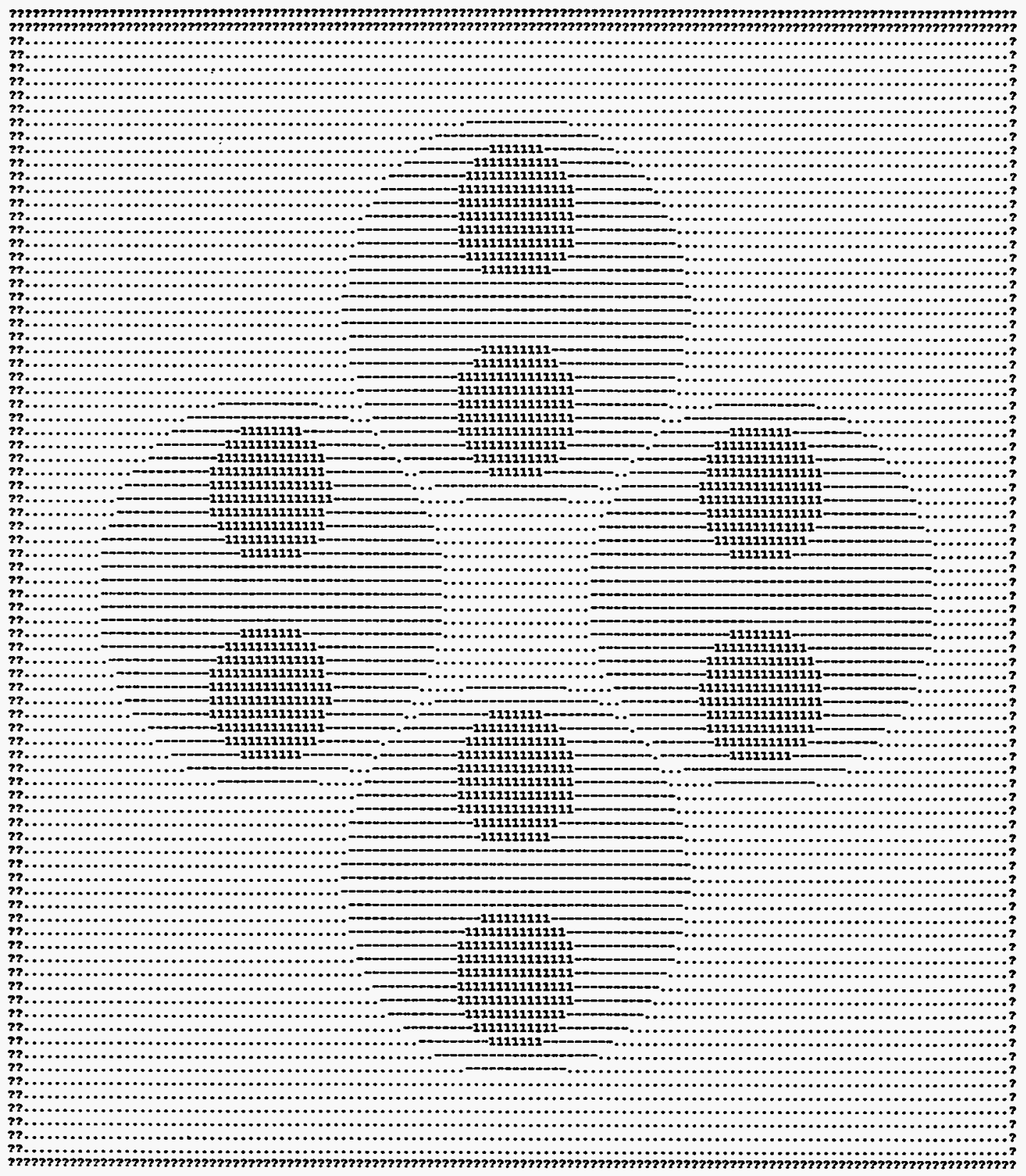

Figure F17.5.58 Unit map of nested holes problem 
$=$ KENOVI

NESTED HOLES SAMPLE

READ PARAM RUN=NO LIB=41 TME=0.5 END PARAM

READ MLXT SCT=1 MIX=192500 4.7048-2 MIX=2 $2001.0 M T X=35020.1$

$M T X=42001.0$

END MIXT

READ GEOM

UNIT 1

CYLINDER $10.12 P 15.0$

CYLINDER 2 0.1 2P15.0 ORIGIN $Y=0.4$

CYLINDER 30.1 2P15.0 ORIGINX $=0.4$

CILINDER 40.1 2P15.0 ORIGIN $Y=0.4$

CIIINDER 50.1 2P15.0 ORIGINX $=0.4$

CUBOID $62 P 0.12 P 0.05$ 2P15.0 ORIGIN $X=0.2$

CUBOW $72 P 0.12 P 0.05$ 2P15.0 ORIGINX $=0.2$

CUBOID $82 P 0.05$ 2P0.1 2P15.0 ORIGIN $Y=0.2$

CUBOID $92 P 0.05$ 2P0.1 2P15.0 ORIGIN $Y=0.2$

CYLINDER $100.52 P 15.0$

MEDLA 111 -6 -7-8 -9

MEDLA $112-8$

MEDLA 113 -7

MEDLA 11 4-9

MEDLA $115-6$

MEDIA $216-1-5$

MEDIA 2 1 7-1 -3

MEDLA 2 1 8 -1 -2

MEDLA 21 9-1 -4

MEDIA 3 1 -1 -2 -3 -4 -5 -6 -7-8 -9 10

BOUNDARY 10

UNIT 2

CYLINDER $10.22 P 15.0$

CYLINDER $20.22 P 15.0$ ORIGIN $X=0.707107 Y=0.707107$

CILINDER $30.22 P 15.0$ ORIGIN $X=0.707107 Y=0.707107$

CYLINDER 4 0.2 2P15.0 ORIGIN $X=0.707107 Y=0.707107$

CILINDER 50.2 2P15.0 ORIGIN $X=0.707107 Y=0.707107$

CYLINDER $60.52 P 15.0$ ORIGINX $=0.707107$

CYLINDER 70.5 2P15.0 ORIGIN $X=0.707107$

CYLINDER $80.52 P 15.0$ ORIGIN $Y=0.707107$

CYLINDER 90.5 2P15.0 ORIGIN $Y=0.707107$

CIIINDER $101.32 P 15.0$

CILINDER $111.42 P 15.0$

MEDIA 211

MEDIA 212

MEDIA 213

MEDIA 214

MEDIA 215

MEDIA $116-8$-9
NUREG/CR-0200, Vol. 2, Rev. 5 


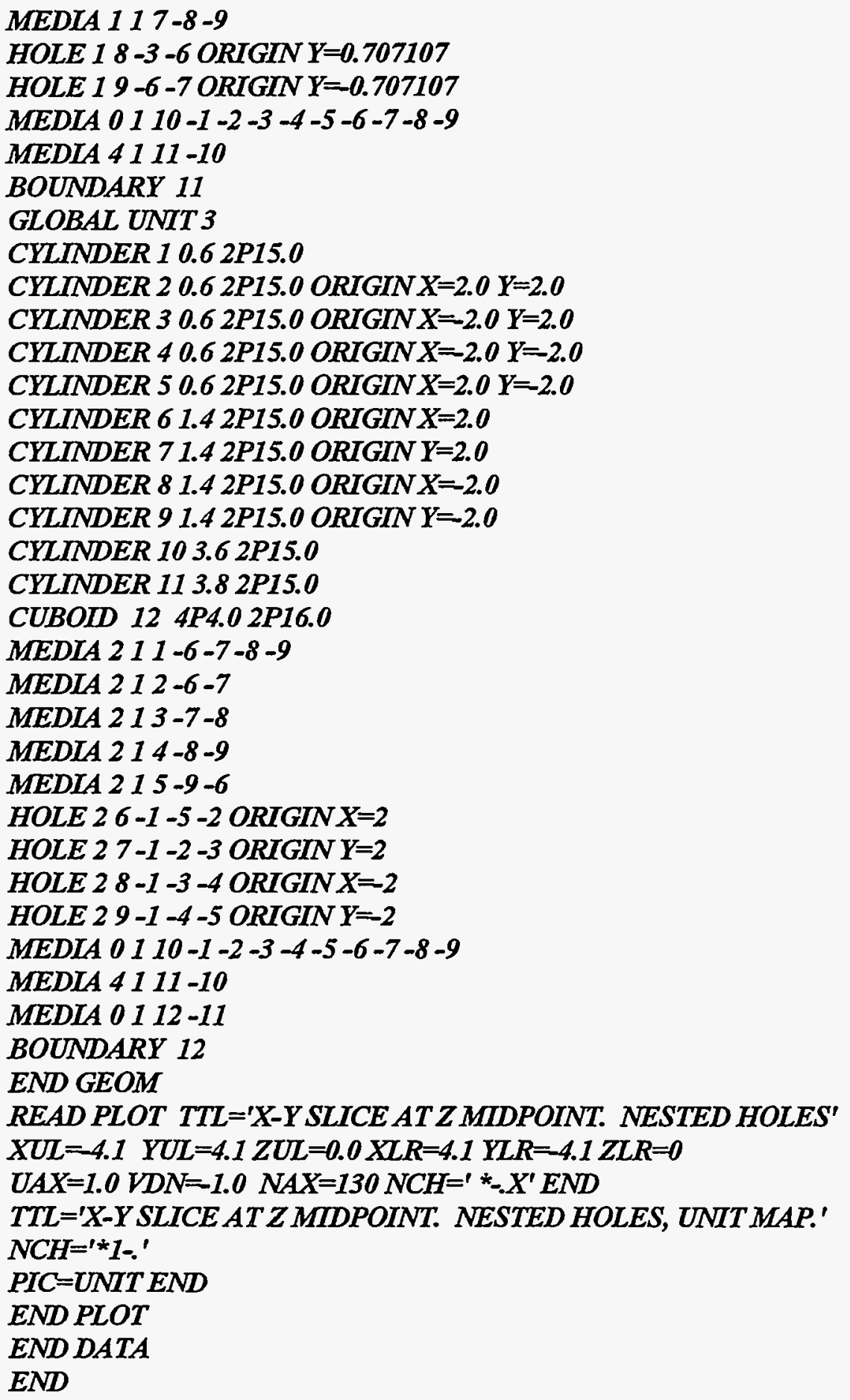

NUREG/CR-0200, 
The plot data description shown in Fig. F17.5.57 shows the symbols that represent each unit in the geometry mock-up. The unit map is shown in Fig. F17.5.58. The user can utilize this map to verify the correct placement of the units. Note that the unit map prints the units that are present at the deepest nesting level for the 2-D slice. It does not show any detail within a unit.

\section{EXAMPLE 7. LARGE STORAGE ARRAY}

The storage array described in Sect. F17.5.6.3 and Fig. F17.5.15 is such a sparse array that the mixture map had to be very large in order to show the detail of the shelves and uranium buttons. The mixture maps for this configuration were not presented in Sect. F17.5.6.3, but the data description was listed so the user could generate them. It may be useful to generate a unit map for this kind of problem. The data description for generating unit maps for this storage array is given below.

READ PLOT PLT $=Y E S P I C=U N T$

$T T L=' X-Z$ SLICE $A T$ Y $=30.48$ WITH $Z$ ACROSS $A N D X D O W N^{\prime}$

$X U L=624.84 Y U L=30.48 Z U L=15.0 X L R=30.48 Y L R=30.48 Z L R=201.0$

$W A X=1.0 U D N=1.0 \mathrm{NAX}=60 \mathrm{NDN}=60 \mathrm{NCH}={ }^{\prime} 1234567^{\prime} \mathrm{END}$

$T T L=' X-Y$ SLICE OF ROOM THROUGH SHELF $Z=0.3175$ WITH $X$ ACROSS AND Y DOWN'

$X U L=30.48 Y U L=1341.0 \quad Z U L=0.3175 X L R=624.84$ YLR=-30.4 ZLR=0.3175

$U A X=1.0 \mathrm{VDN}=1.0 \mathrm{NAX}=60 \mathrm{NDN}=60 \mathrm{END}$

END PLOT

The plot data and unit map for an $x-z$ slice through the array at $y=30.48 \mathrm{~cm}$ are given in Figs. F17.5.59 and F17.5.60. The unit maps have been intentionally distorted by restricting the $x$ direction, which extends from $624.84 \mathrm{~cm}$ to $-30.48 \mathrm{~cm}$ to 60 lines. The $\mathrm{z}$ direction, which extends from the bottom of the reflector at $-30.84 \mathrm{~cm}$ to just about the array at $201.0 \mathrm{~cm}$, is printed in 60 characters. Since the $\mathrm{x}$ direction is larger then the $\mathrm{z}$ direction, the plot is considerably compressed in the $\mathrm{x}$ direction. This unit map was created with $\mathrm{z}$ across the page and $x$ down the page. Thus the unit map shows five rows of shelves in the $x$ direction represented by I's for Unit 1, with the aisles represented by 6's for Unit 6 . The borders of Unit 7's are part of the concrete floor, walls, and ceilings.

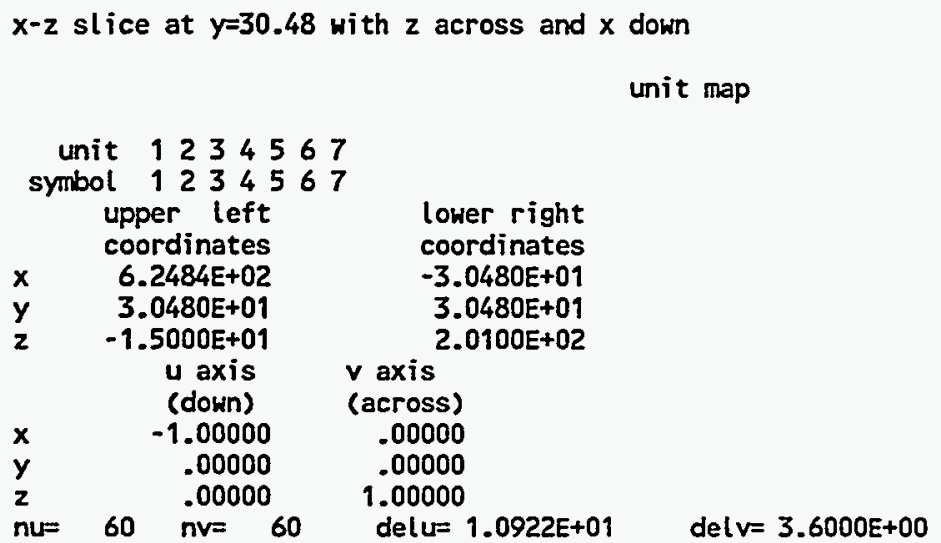

Figure F17.5.59 Plot data for $\mathrm{x}-\mathrm{z}$ slice of storage array

F17.5.113

NUREG/CR-0200, Vol. 2, Rev. 5 


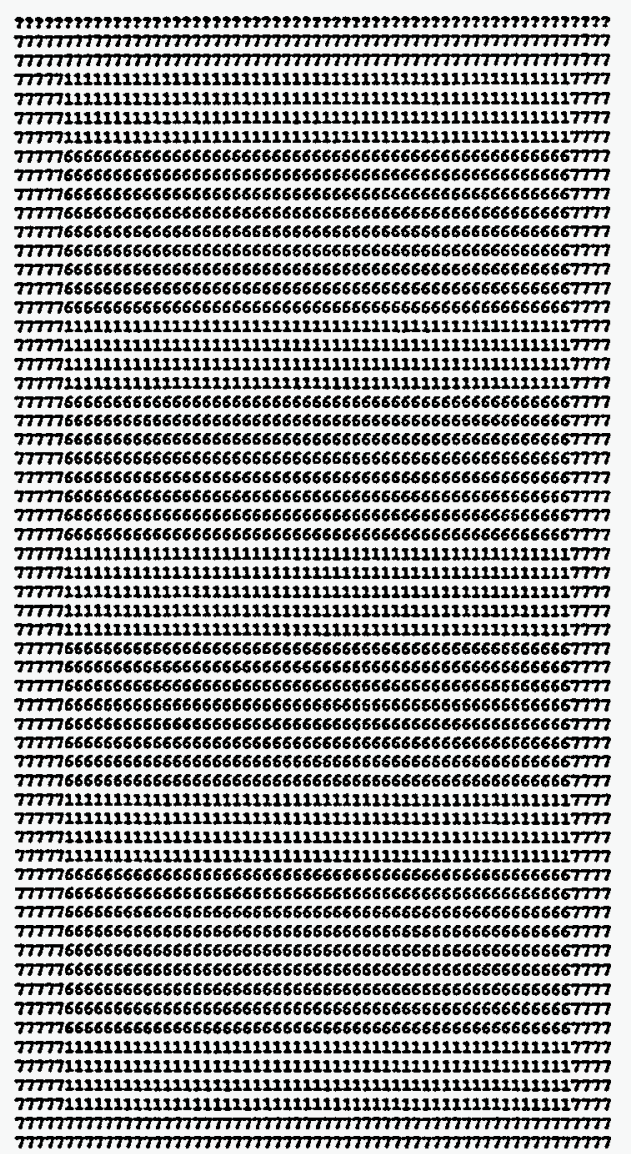

Figure F17.5.60 x-z plot of storage array

The plot data and unit map for an $x-y$ slice through the shelf are given in Figs. F17.5.61 and F17.5.62. The unit maps have been intentionally distorted by restricting the y direction, which extends from $1341.0 \mathrm{~cm}$ to $-30.48 \mathrm{~cm}$ to 60 lines. The $x$ direction, which extends from $-30.84 \mathrm{~cm}$ to $624.84 \mathrm{~cm}$, is also printed in 60 characters. Since the $\mathrm{y}$ direction is larger then the $\mathrm{x}$ direction the plot is considerably compressed in the $\mathrm{y}$ direction. This unit map was created with $x$ across the page and $y$ down the page. This shows 5 rows of shelves in the $x$ direction represented by l's for Unit 1 and separated by aisles of 6's for Unit 6. Two rows of shelves are in the y direction, represented by l's for Unit 1 and separated by aisles of 4's for Unit 4. The border of 7's are the concrete walls. 
$x-y$ slice of room through shelf $z=0.3175$ with $x$ across and $y$ down

unit map

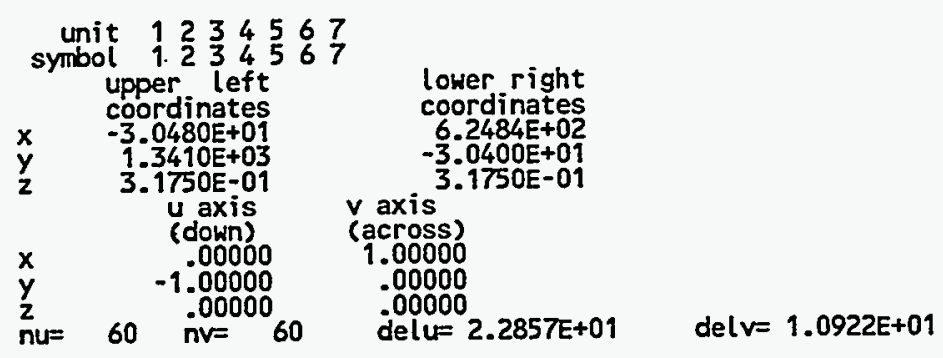

Figure F17.5.61 Plot data for $x-y$ slice of storage array

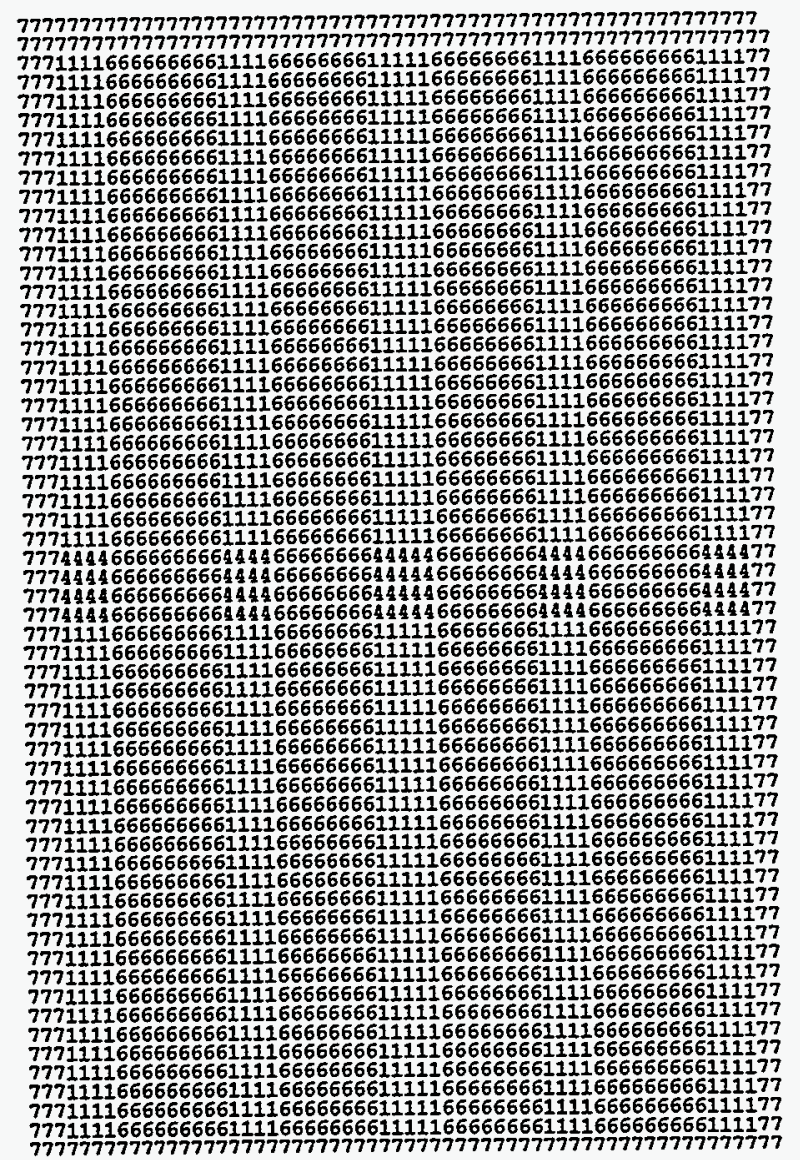

Figure F17.5.62 x-y plot of storage array

F17.5.115

NUREG/CR-0200, Vol. 2, Rev. 5 


\section{F17.5.10 RESTART CAPABILITIES}

Restart data can be written and used for restarting a problem. This type of data is saved by specifying file definition data in the job control language on the unit associated with parameter WRS $=$ when it is written, and RST= when it is read. Most input data can be changed only if the problem is restarted with the first generation. However, certain parameter data can be changed if the problem is restarted at a generation greater than 1 .

Parameters that can be changed when a problem is restarted at a generation greater than 1 include: $\mathrm{RND}=\mathrm{TME}=\mathrm{TBA}=, \mathrm{GEN}=\mathrm{RES}=, \mathrm{LNG}=\mathrm{BEG}=\mathrm{AMX}=\mathrm{XAP}=, \mathrm{XS1}=, \mathrm{XS} 2=\mathrm{PKI}=, \mathrm{P} 1 \mathrm{D}=, \mathrm{CKU}=, \mathrm{CKP}=$, $\mathrm{CKH}=, \mathrm{CKA}=, \mathrm{FMU}=, \mathrm{FMP}=, \mathrm{FMH}=, \mathrm{FMA}=\mathrm{BUG}=\mathrm{TRK}=\mathrm{PWT}=, \mathrm{PGM}=, \mathrm{RUN}=, \mathrm{PLT}=\mathrm{NB} 8=, \mathrm{NL} 8=$, and $\mathrm{PAX}=$. All logical unit numbers can be changed.

If $\mathrm{NSK}=$ is changed, it will cause the fluxes, fission densities, leakage, absorptions, and fissions to be incorrect.

$\mathrm{FLX}=, \mathrm{FDN}=, \mathrm{FAR}=\mathrm{MKU}=, \mathrm{MKP}=\mathrm{MKH}=$ and $\mathrm{MKA}=$ can be changed subject to the following restrictions:

1. If the original problem written to a particular restart file specified YES and the restarted problem specifies NO, the data will be calculated but not printed. A warning message will be printed.

2. If the original problem written to a particular restart file specified NO and the restarted problem specifies YES, an error message is printed and the problem is terminated.

The parameters RUN= and PLT= differ from other parameters because they can be set in the parameter data and overridden in the plot data. Their values are stored in a common block that is written out if a problem is to be restarted. Therefore, when a problem is rum, the value entered in the plot data will override the value that was entered in the parameter data. However, if the problem is restarted, the value from the restart file will be used unless it is overridden by entering additional data.

If WRS = is defined in the parameter data and RES= is not entered, a full restart data file is not written. The input data are written on the restart data file, but the calculated data are not. When the restart data file is written in this manner, it can only be used to restart a problem at the first generation. Any desired data can be overridden when a problem is restarted at the first generation by reading in the desired data.

To write a complete restart data file, both WRS = and RES= must be specified in the parameter data. However, WRS = is defaulted to 35 if a value greater then zero is entered for RES=. In this case, a file definition data for Unit 35 must be supplied by the user in order to save the restart data.

A problem that is restarted can also write a restart data file. These data are written on the same data file if no entry for WRS= is made in the parameter data. It can be written on a different unit if WRS=is so specified in the parameter data and the proper file definition data are included in the job control language. If a restarted problem does not have RES $=0$ specified in the parameter data, it will continue writing calculated restart data. Therefore, the user can run a long problem a little bit at a time by allowing the restarted problem to write restart data and then restarting the problem with those data. This procedure can be done in sequence until the desired number of generations have been completed.

For example, consider a problem that is to run 500,000 histories ( 500 generations of 1000 histories per generation) and the amount of computer time available at any given time is quite limited. On the first pass, $\mathrm{GEN}=500 \mathrm{NPG}=1000 \mathrm{RES}=500 \mathrm{WRS}=35$ should be included in the parameter data and a unit specification for Unit 35 should be included in the job control language when the problem is run. Note that 35 is an arbitrary number chosen by the user. KENO-VI will automatically pull the job before it runs out of time or I/Os. A restart data file will be written on Unit 35 for the last generation that was completed. If the user wishes to restart the 
problem by reading the data from Unit 35 and writing a new restart file on the same unit, the parameter data for the second and all subsequent passes would be: READ PARAM BEG=500 RST=35 END PARAM.

If the user wishes to nun additional histories to improve convergence, $B E G$ should be set to 1 greater than the last generation saved on the restart file. For example, if a problem was originally run with $\mathrm{GEN}=100$, $\mathrm{RES}=100 \mathrm{WRS}=35$, then the restart problem should specify $\mathrm{BEG}=101 \mathrm{GEN}=200 \mathrm{RST}=35$, in order to run an additional 100 generations.

The random sequence can be changed when a problem is restarted by entering a different random number in the parameter data. The starting random number is acceptable for changing the random sequence of a problem that is to be restarted at a generation greater than 1.

Note that if a problem is restarted from one unit and restart data are written to another unit, the new problem description becomes the "original problem" for the new restart dataset.

Parameter data can be changed by entering new values for the desired options, which has the effect of inputting additional data within the parameter data block as explained in Sect. F17.5.3. However, all other data blocks that are to be changed must be entered as an entire data block and will completely replace that data block from the restart problem. When a problem is restarted and some of the data are overridden, the original restart data blocks are retained on the unit defined by WRS $=$, if it is the same as the unit defined by RST $=$. If the unit number associated with WRS $=$ is different from the unit number associated with $\mathrm{RST}=$, the resultant data blocks are written on the unit number associated with WRS=. For example, if the original problem is a single unit problem with RST $=95$ and WRS $=95$, and an array data block is entered to change it to an array problem, the original single unit problem data blocks remain on Unit 95. However, if the single unit problem is restarted with $\mathrm{RST}=95$ and WRS $=96$ and an array data block is entered to change the problem to an array problem, the original single unit data blocks remain on Unit 95 and the resultant array problem data blocks are retained on Unit 96.

When a problem is restarted, the only way to change data in a data block is to reenter a new data block. For example, if in the original problem an array data block was entered as: READ ARRAY ARA $=1$ NUX=11 $N U Y=5 N U Z=3$ END ARRAY and the problem is to be restarted at the first generation as an $11 \times 5 \times 6$ array, the following data block must be entered: READ ARRAY ARA=1 NUX=11 NUY $=5$ NUZ=6 END ARRAY.

Section F17.2.6 contains some information pertaining to the restart capability. Other information may be found in Sect. F17.4.3. The structure of the restart file is listed in Table F17.5.2, and the variables referenced in that table are listed in Table F17.5.3.

\section{F17.5.11 RANDOM SEQUENCE}

The random number package utilized by KENO-VI always starts with the same seed and thus always reproduces the same sequence of random numbers. The current random number is printed at various places in the KENO-VI printout, and any of them except the one printed in the parameter table can be used to activate a different random sequence. The user can rerun a problem with a different random sequence by simply entering a hexidecimal random number, other than the starting random number, in the parameter data. The last digit of the random number should always be an odd number. For example, by entering RND=A10C1893E6D5 in the parameter data, the problem will be run with a different random sequence. 
Table F17.5.2 Structure of RESTART file

Record No.

Contents

(1)

TITLE(20), NBA, NPB, NSKIP, NRSTRT, NBANK, NFBNK, NXBNK, NXFBK, NUMXID, RFLT(6),RNDNUM, LOG(33)

(This record contains the title and parameter data.)

(2)

MT(LMT) $\quad \mathrm{LMT}=5+\mathrm{NUMXID}$

(This record contains the identifiers of the 1-D cross-section arrays.)

(3 to NUMPT+2)

NDX $=1$, NUMPT $\quad$ NUMPT $=11$

(a) NDX,NREC

(This record contains the index for each type of data and the number of records of data associated with each type of data.)

(b) NREC - 1 record of data

(These records contain the data associated with the specified type of data.)

NDX $=1$ (geometry data)

(b1) LLNGTH, KMAX, NQUAD, MAXSFU, REGTOT, SECTOT, MAXREG, NIAR, NGWRDS, MAXGWD, MAXSEC, NGBLU, NBOXT, MAXMIX, MAXIMP, NUMHOL, NUCOM, EXRFL

(b2) MAT(REGTOT), IMP(REGTOT), IGEOM(REGTOT), IGWDPT(0:NGWRDS), ARANDX(REGTOT), NSURFT(NBOXT), NSU(NBOXT), KBNDSQ((NBOXT), KBNDSM(NBOXT), KBNDSX(NBOXT), KBNDSG(NBOXT), NGWPU(NBOXT), IBNDS(NBOXT), BOXBND(3,NBOXT), ARABND(3,NIAR), IRFPOS(3,NIAR), QC(NQUAD,11), REGION(NAXGWD, REGTOT), SECTOR(SECTOT), HOLROT(3,3,NUMHOL), KHOLE(NUMHOL), LHOLU(NUMHOL), HOLX(NUMHOL), HOLY(NUMHOL), HOLZ(NUMHOL), ICOMC(NBOXT), UCOMNT(33,NUCOM)

NDX $=2$ (array data)

(b1) LLNGTH, NGLOBL, MAXARA, NACOM, LSGUN, MBOX, LFIL

(b2) NBXMAX(MAXARA), NBYMAX(MAXARA), NBZMAX(MAXARA), ITYPE(MAXARA), LPT(MAXARA), LNG(MAXARA), ICOMA(MAXARA), ACOMNT(33,NACOM)

$I=1$, MAXARA (The following records are written for each array.)

NUREG/CR-0200, Vol. 2, Rev. 5 
Table F17.5.2 (continued)

Record No.

Contents

(b3) LBA(NBXMAX(I),NBYMAX(I),NBZMAX(I))

$\mathrm{NDX}=3$ (mixing table data)

(b1) LLNGTH, NMIX, NSCT, MIX, MIXT, NPL, PBXS

(b2) MIXTUR(NMIX), NUC(NMIX), DEN(NMIX)

NDX $=4$ (extra data)

(b1) LLNGTH, LNEXTR

(b2) D(LLNGTH)

NDX $=5$ (weighting function by energy group and importance reg.)

(b1) LLNGTH, NIMP

(b2) WTAVG(NGP,NIMP)

$\mathrm{NDX}=6($ start data $)$

(b1) LLNGTH, NTYPST, TFX, TFY,TFZ, NBXS, NBYS, NBZS, KFIS, LFIN, NBOXST, FRACT, FISVOL, XSM, XSP, YSM, YSP, ZSM, ZSP, RFLKEY, LPRT6, LPSTP

(b2) IF (NTYPST .EQ. 6) NUBANK(LFIN,LBANK0)

$\mathrm{NDX}=7$ (albedo data)

(b1) LLNGTH, NALB, NANG, NG, INTR(6), RNAMES(2,6), IDALB(6), NBXL(6), LNXX

IF (NALB .GT. 0)

(b2) NABS(3,NALB), LABS(3,NALB)

(b3) MAL(3,NANG,NG)

(b4) EALB(NG+1) (group boundaries)

$\mathrm{I}=1, \mathrm{NALB}$

F17.5.119

NUREG/CR-0200, Vol. 2, Rev. 5 
Table F17.5.2 (continued)

Record No.

Contents

(b5(i)) PLIM(NANG), CPOL(NANG), SPOL(NANG)

(b6(i))ALB(LENG) (LENG is the length of the albedos for a given angle.)

(b7(i)) A(LENG,NANG)

$\mathrm{NDX}=8$ (mixed cross sections)

(b1) LLNGTH, NMAT, NGP, MAXANG

(b2) LXS(MANG,MATT) $\mathrm{MANG}=2 * \mathrm{NSCT}+4$

$I=1$, MATT for each existing mixture

(b3(i)) $\mathrm{ID}(50)$ the mixture information record

(b4(i)) X1D(NN1D,NGP+1) NN1D = ID(28) No. of 1-Ds

(b5(i)) MWA(3,NGP)

(b6(i)) P0(LNG) $\quad$ LNG $=$ MWA(2,NGP)

$\mathrm{J}=1, \mathrm{NSCT}$

(b7(i,j)) ANG(LNG)

(b8(i,j)) PRB(LNG)

NDX $=9$ (energies and inverse velocities)

(b1) LLNGTH

(b2) E(NGP+1), VINV(NGP)

NDX $=10$ (plot data)

(b1) LLNGTH, NUMPLT

$\mathrm{I}=1, \mathrm{NUMPLT}$

(b2(i)) XL, YL, ZL, XR, YR, ZR, VX, VY, VZ, UX, UY, UZ, DELV, DELU, NV, NU, LPIC, NSTOR(49)

NUREG/CR-0200,

Vol. 2, Rev. 5

F17.5.120 
Table F17.5.2 (continued)

Record No.

Contents

NDX $=11$ (biasing data)

(b1) LLNGTH, NUMIDS, NCS, NTSETS

IF ((NUMIDS + NCS).GT.0),

(b2) ID(NUMIDS), IBGN(NUMIDS), IEND(NUMIDS), WTTITL (3,NUMIDS), NCID(NCS), NCSETS(NCS), CRDTTL(3,NCS), NCTHK(NTSETS), NUMINC(NTSETS), NGPWTS(NTSETS), IPTWT(NTSETS)

$\mathrm{I}=1, \mathrm{NCS}$

$\mathrm{J}=1, \operatorname{NSETS}(\mathrm{l})$

(b3(i,j)) WTAVG(NGPWTS(j,i),NUMINC(j,i))

(14 to END)

Calculated data as listed below

(a) IGEN, RND, NPB, NGP, KMAX, LBANK, NBANK, DLIF(15),

LIF(20), LOJC(36), EFFK(I), I=1,IGEN)

(This record contains parameter data, COMMON /LIFETM/ part of COMMON/LOGIC/ and k-effectives by generation.)

(b) NUBANK(LBANK,NBANK)

(c) IF(LOJC(4)) FISDEN(KMAX,3)

(If fission densities are calculated, the fission densities are written on the restart file.)

(d) IF(LOJIC(10)) TP(MATDIM,MATDIM,3), SNP(MATDIM), SP(MATDIM)

(If matrix data by position are calculated, the matrix by position data are written on the restart file.)

(e) IF(LOJC(7))

TU(NBOXT, NBOXT,3), SNU(NBOXT), SU(NBOXT)

(If matrix data by unit are calculated, the matrix by unit data are written on the restart file.)

(f) IF(LOJC(13))

TH(NUMHOL,NUMHOL,3), SNH(NUMHOL), SH(NUMHOL)

(If matrix data by hole are calculated, the matrix by hole data are written on the restart file.) 
Table F17.5.2 (continued)

Record No.

Contents

(g) $\operatorname{IF(LOJC(17))~}$

TA(NUMARA,NUMARA,3), SNA(NUMARA), SA(NUMARA)

(If matrix data by array are calculated, the matrix by array data are written on the restart file.)

(h) 1 to NGP (the following records are written for each energy group)

(hl) IGROUP, FLEAK(3)

(h2) FMABS(LREG,3), FMFIS(LREG,3)

(h3) IF(LOJC(3)) FLUX(KMAX,3)

Repeat (a through $h$ ) until LOJC(34) is TRUE (i.e., until the last generation is completed). 
Table F17.5.3 Key of RESTART file variables

\begin{tabular}{|c|c|}
\hline TITLE & 80-character KENO-VI problem title \\
\hline NBA & Number of generations in the KENO-VI problem \\
\hline NPB & Number of histories per generation \\
\hline NSKIP & Number of generations to be skipped in averaging k-effective \\
\hline NRSTRT & Number of generations between writing restart data \\
\hline NBANK & Number of positions in the neutron bank \\
\hline NFBNK & Number of positions in the fission bank \\
\hline NXBNK & Number of extra entries in the neutron bank \\
\hline NXFBK & Number of extra entries in the fission bank \\
\hline NUMXID & Number of extra $1-D$ cross sections \\
\hline RFLT & Contains tmax, tbtch, dwtav, wthigh, wtlow, tsigma \\
\hline TBTCH & Time allowed for each generation \\
\hline RNDNUM & Random number with which the problem will be started \\
\hline LOG & First 33 positions of COMMON /LOGIC/ \\
\hline LMT & Number of $1-D$ cross-section identifiers. LMT $=5+N U M X 1 D$ \\
\hline MT & Array containing the $1-\mathrm{D}$ cross-section identifiers \\
\hline NUMPT & Number of kinds of data that are written on the restart file \\
\hline NDX & Index for the type of data \\
\hline NREC & Number of records for the specified type of data \\
\hline $\mathrm{NDX}=1$ & Geometry data \\
\hline LLNGTH & The length of record b2 \\
\hline KMAX & Number of geometry regions used \\
\hline NQUAD & Number of quadratic equations in the problem \\
\hline MAXSFU & Maximum number of surfaces in a unit \\
\hline REGTOT & Number of MEDIA type cards read in the geometry data \\
\hline SECTOT & Number of sectors $\mathrm{x}$ number of geometry cards in a unit summed over all units \\
\hline MAXREG & Maximum number of regions in a unit \\
\hline NIAR & Number of arrays read in the problem \\
\hline NGWRDS & Number of geometry words in the problem \\
\hline MAXGWD & Largest number of geometry words in a unit \\
\hline MAXSEC & Largest number of sectors in a unit \\
\hline NGBLU & The global unit number \\
\hline NBOX & Largest unit number in the geometry data \\
\hline NBOXT & NBOX + the number extra units generated by KENO-VI \\
\hline MAXIMIX & Largest mixture number encountered in the geometry data \\
\hline MAXIMP & Largest biasing number encountered in the geometry data \\
\hline NUMHOL & Number of holes in the geometry data \\
\hline NUCOM & The number of units having comments in the geometry region data \\
\hline EXRFL & Logical flag. Value is TRUE if a reflector is present \\
\hline MAT & Array containing the mixtures used in the geometry \\
\hline IMP & Array containing the bias IDs used in the geometry \\
\hline IGWDPT & Array containing the offset to the last quadratic for each geometry word in QC \\
\hline ARANDX & Array containing the offset for each array into ARABNDS \\
\hline
\end{tabular}


Table F17.5.3 (continued)

\begin{tabular}{|c|c|}
\hline NSURFT & Array containing the number of quadratic equations in each unit \\
\hline NSU & Array containing the number of sectors in each unit \\
\hline KBNDSQ & Array of offsets to the first quadratic of each unit in the QC array \\
\hline KBNDSM & Array of pointers into the SECTOR array \\
\hline NKBNDSX & Array of offsets of the first entry for each unit into the SECTOR array \\
\hline KBNDSG & Array of offsets of the first entry of each unit into the IGWDPT array \\
\hline NGWPU & Array containing the number of geometry words in each unit \\
\hline IBNDS & Array of offsets into IGWDPT to first boundary quadratic in a unit \\
\hline BOXBND & Array containing the most negative boundary for each unit \\
\hline ARABND & Array containing the most negative boundary for each array \\
\hline IRFPOS & Array containing the array position of the reference unit used to postion the array \\
\hline QC & Array containing the coefficients of the quadratic equations for each surface \\
\hline REGION & Array of sector data based on geometry input cards \\
\hline SECTOR & Array containing information relating each sector to each geometry card for each unit \\
\hline HOLROT & Array containing rotation data for each hole \\
\hline KHOLE & Region number that contains the hole \\
\hline LHOLU & Unit that is placed in the hole \\
\hline HOLX & $\begin{array}{l}\text { X coordinate of the origin of the unit in the hole with respect to the unit that contains the } \\
\text { hole }\end{array}$ \\
\hline HOLY & $\begin{array}{l}\text { Y coordinate of the origin of the unit in the hole with respect to the unit that contains the } \\
\text { hole }\end{array}$ \\
\hline HOLZ & $\begin{array}{l}Z \text { coordinate of the origin of the unit in the hole with respect to the unit that contains the } \\
\text { hole }\end{array}$ \\
\hline ICOMC & The index into the comment array for a unit \\
\hline UCOMNT & Comments associated with units specified in the geometry region data \\
\hline $\mathrm{NDX}=2$ & Array or unit orientation data \\
\hline LLNGTH & Length of the b2 record \\
\hline NGLOBL & Global array number \\
\hline MAXARA & Largest array number encountered in the array data \\
\hline NACOM & The number of arrays having comments in the array data \\
\hline LSGUN & Logical flag. Value is TRUE if there is no array present \\
\hline MBOX & A logical variable that is set.TRUE. if arrays are used. \\
\hline NBXMAX & Number of units in the $\mathrm{X}$ direction of each array \\
\hline NBYMAX & Number of units in the $Y$ direction of each array \\
\hline NBZMAX & Number of units in the $Z$ direction of each array \\
\hline ITYPE & Pitch indicator, 1 for square-pitched arrays, 2 for triangular-pitched arrays \\
\hline LPT & Pointer to locate the beginning of each unit orientation array \\
\hline LNG & Length of each unit orientation array \\
\hline ICOMA & The index into the comment array for arrays \\
\hline LBA & Contains the unit orientation arrays for all arrays \\
\hline MAXARA & The largest array number \\
\hline
\end{tabular}

NUREG/CR-0200, Vol. 2, Rev. 5

F17.5.124 
Table F17.5.3 (continued)

\begin{tabular}{|c|c|}
\hline NACOM & Number of array comments \\
\hline ACOMNT & Comments \\
\hline $\mathrm{NDX}=3$ & Mixing table data \\
\hline LLNGTH & Length of $b 2$ record \\
\hline NMIX & Number of entries in the mixing table \\
\hline NSCT & Number of scattering angles \\
\hline MIX & Number of different mixtures to be mixed \\
\hline MIXT & Largest mixture number to be mixed \\
\hline NPL & Order of Legendre coefficients +1 \\
\hline MTXTUR & Array of mixture numbers used in the mixing table \\
\hline NUC & Array of the nuclide ID numbers used in the mixing table \\
\hline DEN & Array of the number densities used in the mixing table \\
\hline $\mathrm{NDX}=4$ & Extra data \\
\hline LLNGTH & Length of $b 2$ record \\
\hline LENGTH & $\mathrm{D}(\mathrm{LENGTH})$ is the data contained in the $\mathrm{b} 2$ record \\
\hline LNXTR & Length of the extra data \\
\hline $\mathrm{NDX}=5$ & Weighting function \\
\hline LLNGTH & Length of $b 2$ record \\
\hline NIMP & Number of biasing regions \\
\hline WTAVG & Average weight by energy group and biasing region \\
\hline $\mathrm{NDX}=6$ & Start data (initial source distribution) \\
\hline LLNGTH & Length of $b 2$ record \\
\hline ṄTYPST & Start type to define the initial source distribution \\
\hline TFX & $\mathrm{X}$ coordinate of neutron starting point \\
\hline TFY & $Y$ coordinate of neutron starting point \\
\hline TFZ & $\mathrm{Z}$ coordinate of neutron starting point \\
\hline NBXS & $\mathrm{X}$ index of unit's position in the global array \\
\hline NBYS & $Y$ index of unit's position in the global array \\
\hline NBZS & $Z$ index of unit's position in the global array \\
\hline KFIS & Mixture whose fission spectrum is used for initial source \\
\hline LFIN & Last neutron to be started at the specified point \\
\hline NBOXST & Unit in which neutrons will be started \\
\hline FRACT & Fraction of initial source to be started as a spike \\
\hline FISVOL & Fraction of global system that contains fissile material \\
\hline XSM & -X dimension of cuboid in which neutrons will be started \\
\hline XSP & $+\mathrm{X}$ dimension of cuboid in which neutrons will be started \\
\hline YSM & -Y dimension of cuboid in which neutrons will be started \\
\hline
\end{tabular}

F17.5.125

NUREG/CR-0200, Vol. 2, Rev. 5 
Table F17.5.3 (continued)

\begin{tabular}{|c|c|}
\hline$\overline{\text { YSP }}$ & $+Y$ dimension of cuboid in which neutrons will be started \\
\hline ZSM & $-Z$ dimension of cuboid in which neutrons will be started \\
\hline ZSP & $+Z$ dimension of cuboid in which neutrons will be started \\
\hline RFLKEY & Logical variable. Set TRUE if neutrons can be started in reflector \\
\hline LPRT6 & Logical variable. Set TRUE to print start type 6 data \\
\hline LPSTP & Logical variable. Set TRUE to print initial source points \\
\hline NUBANK & $\begin{array}{l}\text { The neutron bank. The variables that are used from the neutron bank are: } \\
\mathrm{X}(\mathrm{NPB}), \mathrm{Y}(\mathrm{NPB}), \mathrm{Z}(\mathrm{NPB}), \mathrm{NBX}(\mathrm{NPB}), \mathrm{NBY}(\mathrm{NPB}), \mathrm{NBZ}(\mathrm{NPB})\end{array}$ \\
\hline LFIN & The last neutron for which start type 6 data was entered \\
\hline LBANK & The number of positions per neutron in the neutron bank \\
\hline NPB & Number of histories per generation \\
\hline $\mathrm{X}$ & $\mathrm{X}$ coordinate of neutron starting point for start type 6 \\
\hline $\mathrm{Y}$ & Y coordinate of neutron starting point for start type 6 \\
\hline $\mathrm{Z}$ & $\mathrm{Z}$ coordinate of neutron starting point for start type 6 \\
\hline NBX & $X$ index of unit's position in the global array for start type 6 \\
\hline NBY & $Y$ index of unit's position in the global array for start type 6 \\
\hline NBZ & $\mathrm{Z}$ index of unit's position in the global array for start type 6 \\
\hline $\mathrm{NDX}=7$ & Albedo data \\
\hline LLNGTH & Length of $b 2$ record \\
\hline NALB & Number of different differential albedos to be used \\
\hline NANG & Number of angles available in the albedo function \\
\hline NG & Number of energy groups available in the albedo function \\
\hline INTR & Type of boundary condition for each face \\
\hline RNAMES & Name of boundary condition \\
\hline IDALB & Index to the correct set of albedo data \\
\hline NBXI & Specifies the face where the history will reenter \\
\hline LNXX & Logical flag. Set TRUE for either specular or differential reflection \\
\hline NABS & Pointers into the albedo data for each albedo used \\
\hline LABS & Length of the albedo data for each albedo used \\
\hline MAL & Pointer array for albedos \\
\hline EALB & Energy boundaries for albedos \\
\hline PLIM & Incident polar angle bins \\
\hline CPOL & Cosine of returning polar angle \\
\hline SPOL & Sine of returning polar angle \\
\hline ALB & Probabilities for the returning energy group \\
\hline A & Probabilities for the returning angle \\
\hline LENG & Length of albedo data for a given angle \\
\hline $\mathrm{NDX}=8$ & Mixed cross sections \\
\hline LLNGTH & Length of $b 2$ record \\
\hline NMAT & Number of mixtures used in the problem \\
\hline NGP & Number of energy groups from the cross-section file \\
\hline
\end{tabular}

NUREG/CR-0200, Vol. 2, Rev. 5 
Table F17.5.3 (continued)

\begin{tabular}{|c|c|}
\hline MAXANG & Number of scattering angles \\
\hline LXS & Length of each cross-section set \\
\hline MANG & $2 * \mathrm{NSCT}+4$ \\
\hline $\mathrm{D}$ & Head record from mixed cross-section file \\
\hline X1D & 1-D cross sections \\
\hline NN1D & Number of $1-\mathrm{D}$ cross sections $(\mathrm{ID}(28))$ \\
\hline MWA & Pointer array for cross sections \\
\hline P0 & Group-to-group transfer probabilities \\
\hline ANG & Scattering angles \\
\hline PRB & Probabilities for scattering at angle ANG \\
\hline LNG & Length of the $\mathrm{P} 0$ arrays \\
\hline $\mathrm{NDX}=9$ & Energies and inverse velocities \\
\hline LLNGTH & Length of $b 2$ record \\
\hline NGP & Number of energy groups \\
\hline $\mathrm{E}$ & Energy group bounds \\
\hline VINV & Inverse velocities \\
\hline $\mathrm{NDX}=10$ & Plot data \\
\hline LLNGTH & Length of $b 2$ record \\
\hline NUMPLT & Number of plots to be generated \\
\hline $\mathrm{XI}$ & $\mathrm{X}$ coordinate of the upper-left corner of the plot \\
\hline $\mathrm{YL}$ & $Y$ coordinate of the upper-left corner of the plot \\
\hline $\mathrm{ZL}$ & $\mathrm{Z}$ coordinate of the upper-left corner of the plot \\
\hline XR & $\mathrm{X}$ coordinate of the lower-right corner of the plot \\
\hline YR & Y coordinate of the lower-right corner of the plot \\
\hline ZR & $\mathrm{Z}$ coordinate of the lower-right corner of the plot \\
\hline $\mathrm{VX}$ & $\mathrm{X}$ component of the direction cosine for the across axis of the plot \\
\hline VY & $\mathrm{Y}$ component of the direction cosine for the across axis of the plot \\
\hline $\mathrm{VZ}$ & $\mathrm{Z}$ component of the direction cosine for the across axis of the plot \\
\hline UX & $\mathrm{X}$ component of the direction cosine for the down axis of the plot \\
\hline UY & Y component of the direction cosine for the down axis of the plot \\
\hline UZ & $\mathrm{Z}$ component of the direction cosine for the down axis of the plot \\
\hline DELV & Horizontal spacing between points on the plot \\
\hline DELU & Vertical spacing between points on the plot \\
\hline NV & Number of characters across the plot \\
\hline $\mathrm{NU}$ & Number of characters down the plot \\
\hline LPIC & Plot type indicator. $\mathrm{LPIC}=1$ mixture, $\mathrm{LPIC}=2$ unit $\mathrm{LPIC}=3$ bias $\mathrm{ID}$ \\
\hline NSTOR & $\begin{array}{l}\text { An array that contains PTITL and TABLE. The first } 33 \text { words are PTITL and the } \\
\text { last } 16 \text { are TABLE. }\end{array}$ \\
\hline $\mathrm{NDX}=11$ & Biasing data \\
\hline
\end{tabular}


Table F17.5.3 (continued)

\begin{tabular}{ll}
\hline LLNGTH & Length of b2 record \\
NUMIDS & Number of bias IDs requested \\
NCS & Number of bias IDs entered from cards \\
NTSETS & Total number of group structures for all IDs \\
ID & ID number or set of weights to be read from WTS file \\
IBGN & Beginning importance region number assigned to ID \\
IEND & Ending importance region number assigned to ID \\
WTTITL & Title associated with the ID \\
NCID & ID to be read from cards \\
NCSETS & Number of group structures to be read from cards \\
CRDTTL & Title associated with the ID read from cards \\
NCTHK & Thickness per increment from cards \\
NUMINC & Number of increments from cards \\
NGPWTS & Number of energy groups for this set of weights \\
IPTWT & Pointer into the weights from cards \\
WTAVG & Weighting function by energy group and importance region
\end{tabular}

Calculated data

IGEN

RND

NPB

NGP

KMAX

LBANK

NBANK

DLIF

LIF

LOJC

EFFK

NUBANK

FISDEN

TP

SNP

SP

TU

SNU

SU

TH

SNH

SH

TA

SNA

SA
Generation for which this set of restart data was written

Last random number that was used

Number of generations

Number of histories per generation

Number of geometry regions used

Number of positions per neutron in the neutron bank

Number of positions in the neutron bank

The double precision portion of COMMON/LIFETM/

The single precision portion of COMMON /LIFETM/

An array equivalenced to COMMON $/ \mathrm{LOGIC/}$

Array containing k-effectives by generation

The neutron bank, NBANK by IBANK

Array containing the fission densities

Fission production matrix by array position

Eigenvector of the fission production matrix by array position

Source vector by array position

Fission production matrix by unit

Eigenvector of the fission production matrix by unit

Source vector by unit

Fission production matrix by hole

Eigenvector of the fission production matrix by hole

Source vector by hole

Fission production matrix by array

Eigenvector of the fission production matrix by array

Source vector by array

NUREG/CR-0200,

Vol. 2, Rev. 5 
Table F17.5.3 (continued)

IGROUP

FLEAK

FMABS

FMFIS

FLUX

LOIIC(4)

LOJC(10)

LOJIC(7)

LOJC(13)

LOJC(17)

LOJC(3)
Current energy group

Leakage fraction

Absorption fraction

Total fission production

Flux

Key indicating whether to calculate fission densities Specified by entering FDN= in the parameter data

Key indicating whether to calculate matrix data by position Specified by entering MKP $=$ in the parameter data

Key indicating whether to calculate matrix data by unit Specified by entering MKU= in the parameter data

Key indicating whether to calculate matrix data by hole

Specified by entering $\mathrm{MKH}=$ in the parameter data

Key indicating whether to calculate matrix data by array

Specified by entering MKA = in the parameter data

Key indicating whether to calculate fluxes

Specified by entering FLX= in the parameter data 


\section{F17.5.12 MATRIX K-EFFECTIVE}

Matrix k-effective calculations provide an alternative method of calculating the k-effective of the system. Cofactor $\mathrm{k}$-effectives and source vectors are additional information that can be provided when the matrix $k$-effective is calculated. The necessary source and fission weight data are collected during the neutron tracking procedure in subroutine TRACK. This information is converted to a FISSION PRODUCTION MATRIX, which is the number of next generation neutrons produced at $J$ by a neutron born at $I$. The principal eigenvalue of the fission probability matrix is the matrix k-effective. KENO-VI offers four alternatives when calculating matrix k-effective as discussed below:

1. If $\mathrm{MKP}=\mathrm{YES}$ is specified in the parameter data, the fission production matrix is collected by array position or position index. The position index is used to reference a given location in a 3-D lattice. For a $2 \times 2 \times 2$ array there are eight unique position indices as follows:

\begin{tabular}{cccc} 
POSITION & \multicolumn{3}{c}{ POSITION } \\
NDDEX & $\mathrm{X}$ & $\mathrm{Y}$ & $\mathrm{Z}$ \\
& & & \\
\hline 1 & 1 & 1 & 1 \\
2 & 2 & 1 & 1 \\
3 & 1 & 2 & 1 \\
4 & 2 & 2 & 1 \\
5 & 1 & 1 & 2 \\
6 & 2 & 1 & 2 \\
7 & 1 & 2 & 2 \\
8 & 2 & 2 & 2
\end{tabular}

The fission production matrix is the number of next-generation neutrons produced at index $\mathrm{J}$ by a neutron born at index I. This matrix is used to calculate the matrix k-effective, cofactor k-effectives and the source vector by position index. Because the size of the fission probability matrix is the square of the array size (for a $4 \times 4 \times 4$ array there are 4096 entries), it can use vast amounts of computer memory.

2. If $M K U=Y E S$ is specified in the parameter data, the fission production matrix is collected by unit. It is the number of next-generation neutrons produced in unit $\mathrm{J}$ by a neutron born in unit $\mathrm{I}$. This matrix is used to calculate the matrix k-effective, cofactor k-effectives and source vector by unit.

3. If $\mathrm{MKH}=\mathrm{YES}$ is specified in the parameter data, the fission production matrix is collected by hole number. Matrix information can be collected at either the highest hole nesting level (first level of nesting) or the deepest hole nesting level. HHL=YES specifies that the matrix information will be collected at the first nesting level. By default, the matrix information is collected at the deepest nesting level. The fission production matrix is the number of next-generation neutrons produced in hole $J$ by a neutron born in hole I. This matrix is used to calculate the matrix k-effective, cofactor k-effectives and the source vector by hole.

4. If $\mathrm{MKA}=\mathrm{YES}$ is specified in the parameter data, the fission production matrix is collected by array number. It can be collected at the highest array level (first level of nesting) or at the deepest array level. $\mathrm{HAL}=\mathrm{YES}$ specifies that the matrix information will be collected at the first nesting level. By default, 
the matrix information is collected at the deepest nesting level. The fission production matrix is the number of next-generation neutrons produced in array $\mathrm{J}$ by a neutron born in array $\mathrm{I}$. This matrix is used to calculate the matrix k-effective, cofactor k-effectives and the source vector by array.

The user can simultaneously utilize all methods of calculating the matrix k-effective. The results are labeled in the printout. Matrix k-effectives cannot be calculated for a single unit problem. If the user wishes to calculate matrix information for a single unit the geometry data must include a second global unit that contains a $1 \times 1 \times 1$ array composed of the first unit. An array data block consisting of READ ARRAY ARA=1 NBX=1 NBY $=1$ NBZ=1 FLLL 1 END FILL END ARRAY must also be included. These actions convert the single unit problem into a $1 \times 1 \times 1$ array.

A cofactor $k$-effective is the eigenvalue of the fission production matrix, reduced by the row and column that references the specified unit or position index. The difference between the k-effective for the system and the cofactor k-effective for a unit or position index is an indication of the in situ k-effective of that unit or the contribution that unit makes to the k-effective of the system. The cofactor k-effective of a unit devoid of fissile material should approximate the k-effective of the system.

\section{F17.5.13 DEVIATIONS}

When a deviation is calculated by KENO-VI, it is the standard deviation of the mean. A large sample and a normal distribution are assumed for this calculation. If these assumptions are not true, the deviations cannot be assumed to be correct. If results are correlated, the calculated deviations will be in error.

\section{F17.5.14 GENERATION TIME AND LIFETIME}

The generation time and lifetime calculations utilize the average velocity. The validity of these calculations is determined by how accurately the average velocity represents the spectrum over the range of the energy group. The lifetime and generation time calculated by KENO-VI are not kinetics parameters. The lifetime is the average lifespan of a neutron (in seconds) from the time it is born until it is absorbed or leaks from the system. The generation time is the average time (in seconds) between successive neutron generations.

\section{F17.5.15 REFERENCES}

1. S. K. Fraley, Users Guide for ICE-II, ORNL/CSD/TM-9/R1, Union Carbide Corp., Nucl. Div., Oak Ridge Natl. Lab., July 1977.

2. J. T. Thomas, "Critical Three-Dimensional Arrays of U(93.2)-Metal Cylinders," Nucl. Sci. Eng. 52, 350 (November 1973).

3. J. T. Thomas, Critical Three-Dimensional Arrays of Neutron-Interacting Units, Part II, ORNL/TM868, Union Carbide Corp., Nucl. Div., Oak Ridge Natl. Lab., July 1964. 


\section{F17.6 DESCRIPTION OF OUTPUT}

This section contains a brief description and explanation of the KENO-VI output. Portions of the printout will not be printed for every problem. Some printout is optional and is so noted in this section.

\section{F17.6.1 HEADER PAGE}

The first page of print from KENO-VI is the header page. A sample header page is shown in Fig. F17.6.1.

The first line of block letters prints KENO-VI. The second line of block letters gives the job name from the job control language. The third line gives the date the job was run as month/day/year. The last line prints the time when the execution of the problem began (hour/minute/second) in terms of a 24-h clock, with midnight being $2400 \mathrm{~h}$. The header page is printed from subroutine MESAGE. 


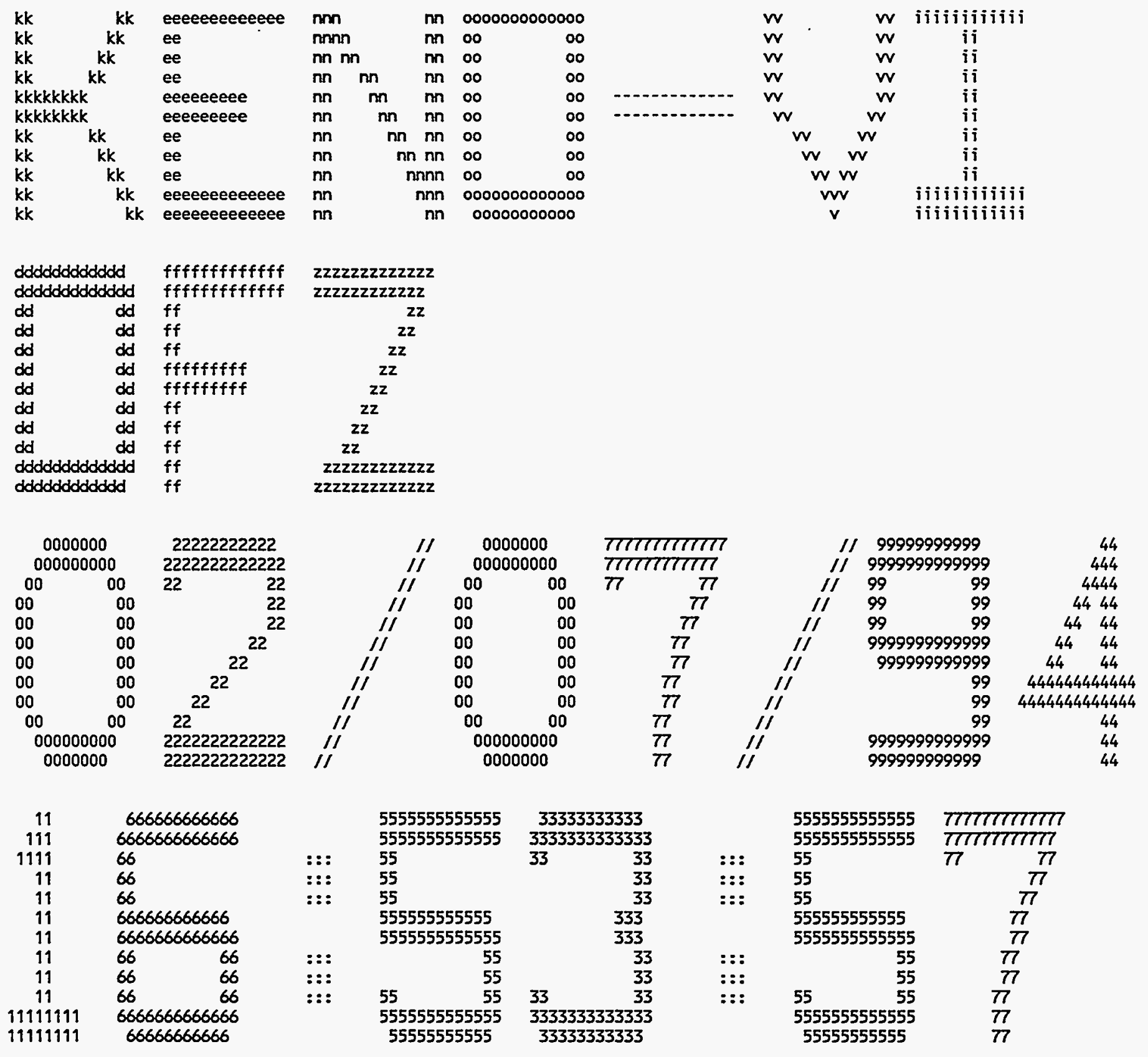

Figure F17.6.1 Sample KENO-VI header page

NUREG/CR-0200,

Vol. 2, Rev. 5

F17.6.2 


\section{F17.6.2 PROGRAM VERIFICATION INFORMATION}

Program verification information (Fig. F17.6.2) is printed after the header page. It lists the name of the program, the date the load module was created, the library that contains the load module, the computer code name from the configuration control table, and the revision number. The job name, date, and time of execution are also printed. This information may be used for quality assurance purposes.

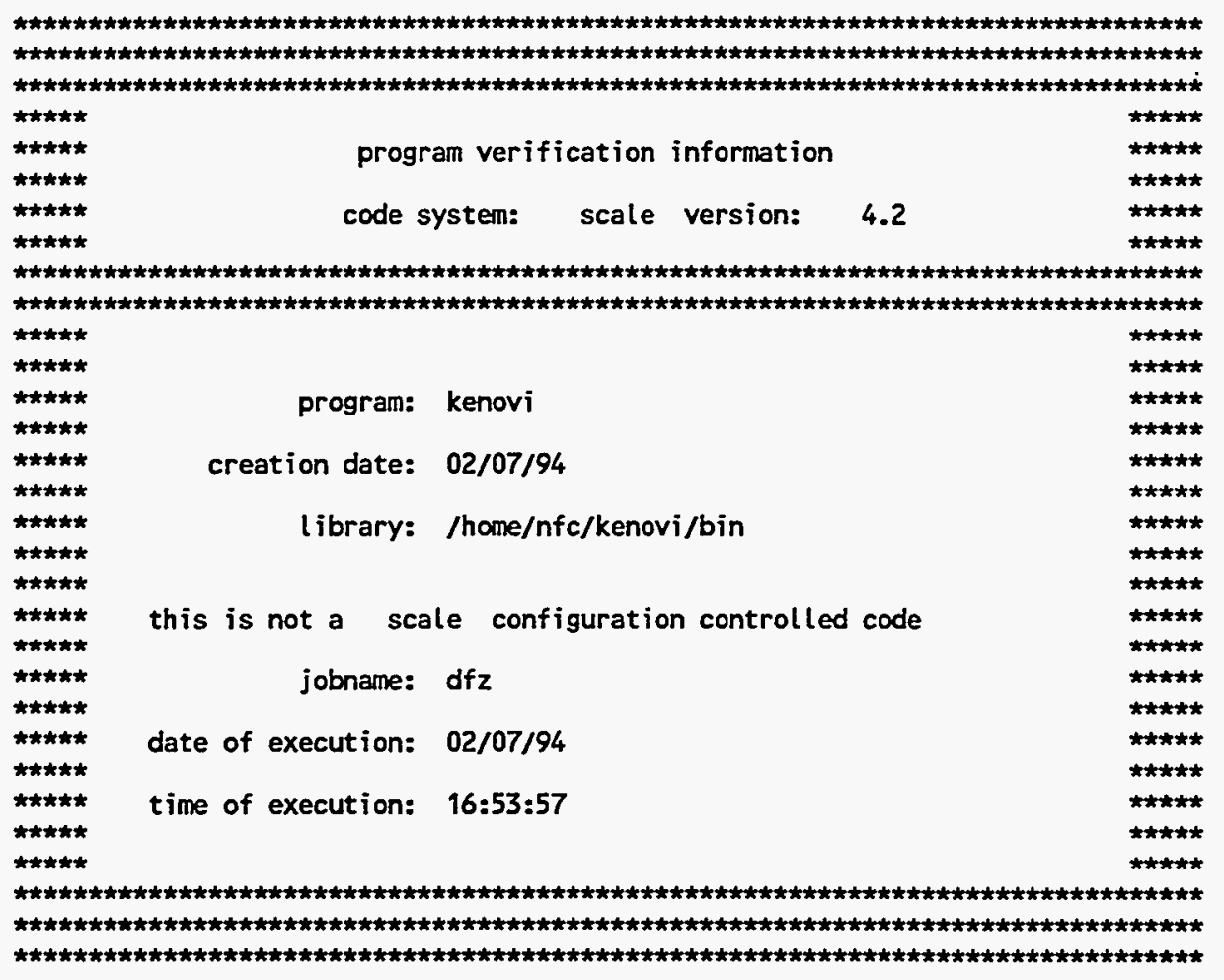

Figure F17.6.2 Sample program verification table 


\section{F17.6.3 TABLES OF PARAMETER DATA}

The first two tables printed by KENO-VI list the numeric parameters and logical parameters that are used in the problem. They should always be examined by the user to verify that the parameter data block was input as desired. Examples of these tables are shown in Figs. F17.6.3 and F17.6.4.

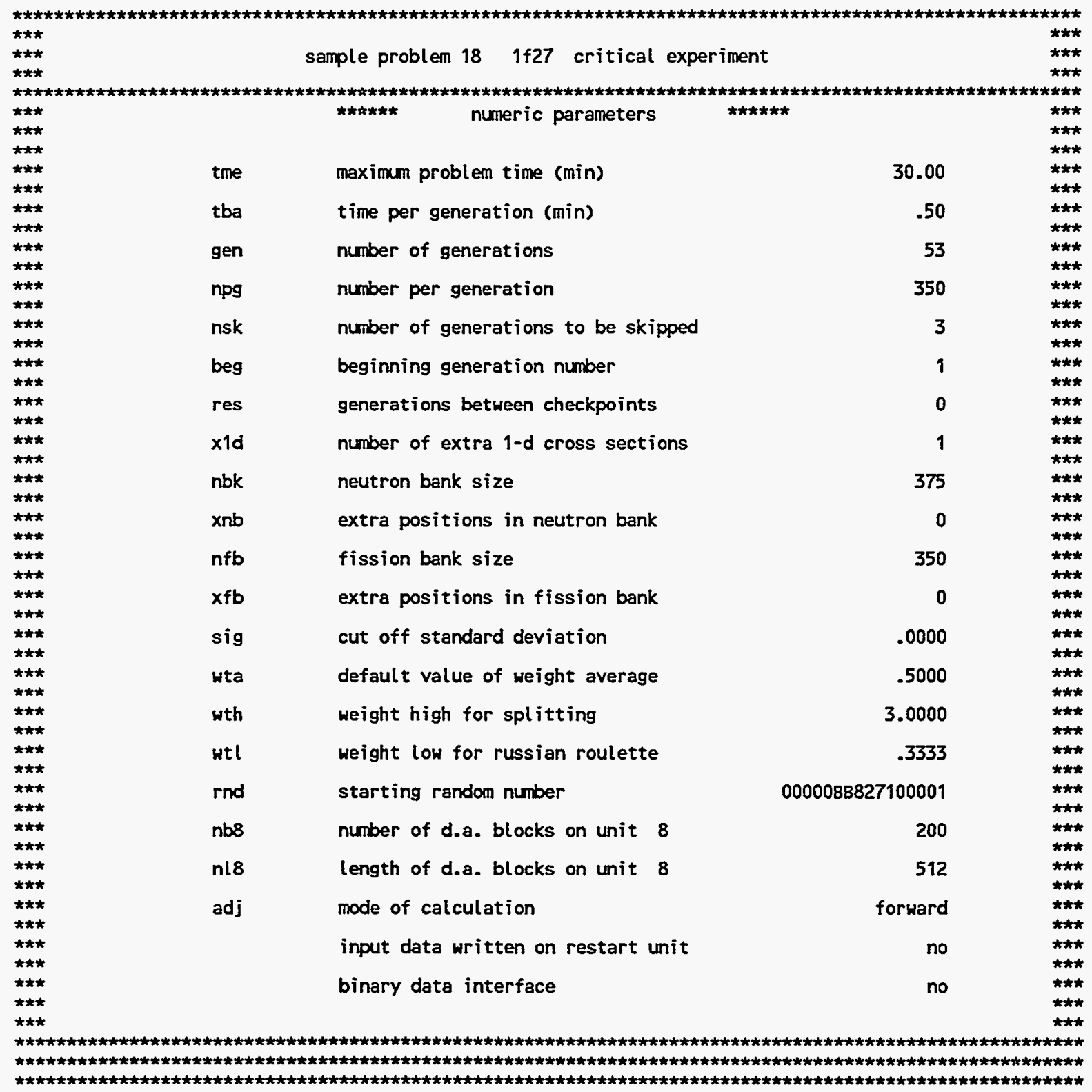

Figure F17.6.3 Sample table of numeric parameter data

NUREG/CR-0200,

Vol. 2, Rev. 5

F17.6.4 


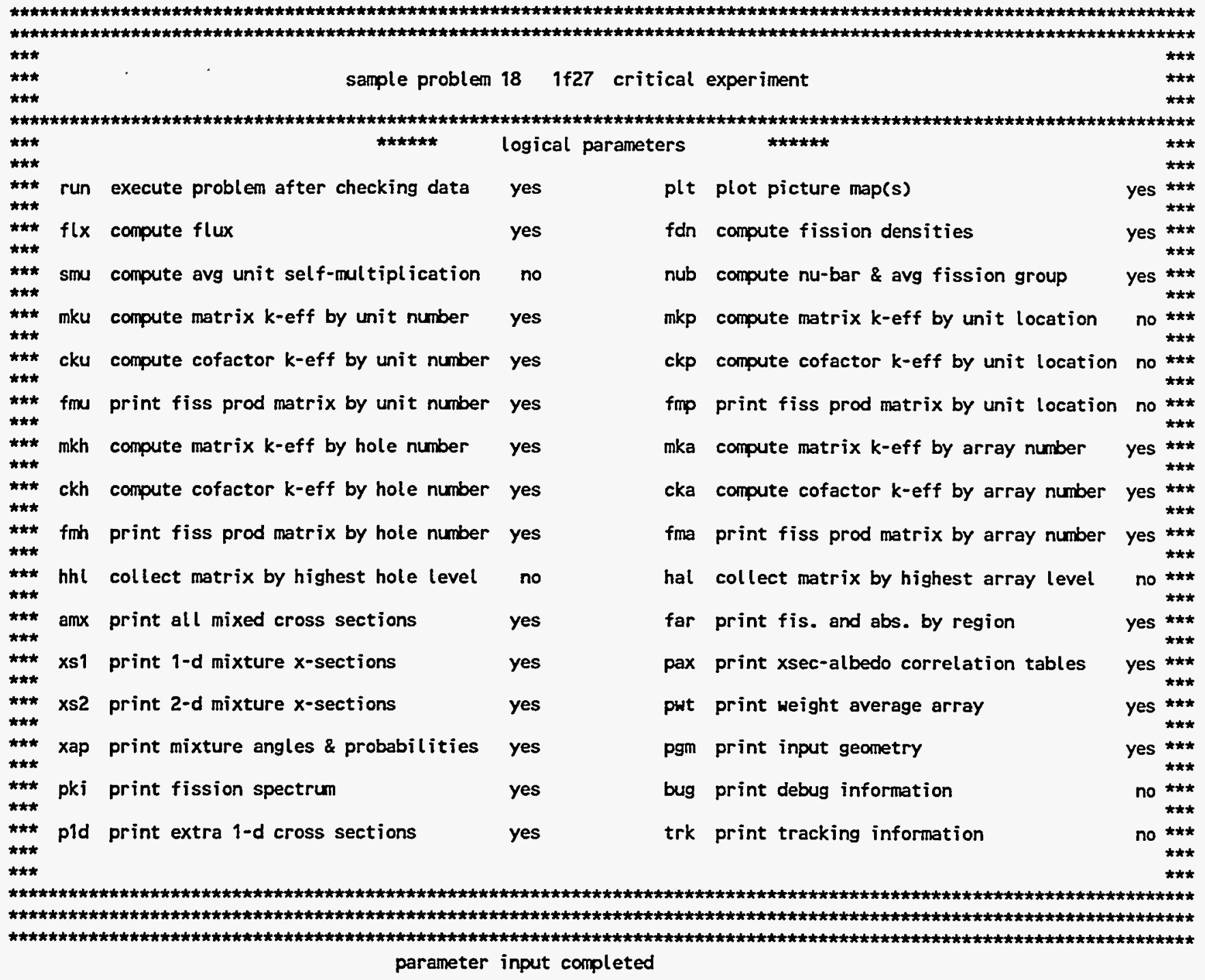

0 io's were used reading the parameter data

Figure F17.6.4 Sample table of logical parameter data 
The title of the problem is printed at the top of each table. The first table, shown in Fig. F17.6.3, lists the numeric parameter data. It contains a triple column that lists the applicable parameter keyword used to input the data, a brief explanation of its meaning, and the associated data value. The last two entries in this table are slightly different than the others because a keyword is not listed with them. The INPUT DATA WRITTEN ON RESTART UNIT is set YES if a unit number is provided for writing restart data (WRS=). The BINARY DATA INTERFACE is set YES if a unit number is provided for reading restart data (RST=).

The second table, shown in Fig. F17.6.4, lists the logical parameter data. It contains two triple columns, each listing the applicable parameter keyword, a brief explanation of the parameter's function, and the value associated with the parameter. Messages concerning the parameter data may be printed at the bottom of the table. If the problem is one that is being restarted, the title of the parent case is printed at the bottom of the table. If the restart title or messages are not printed, the bottom section of the table is omitted. If the user desires to change some of the data in these tables, the appropriate parameter keyword must be entered in the parameter data, followed by an equal sign and the desired value. Following this table is a statement affirming the completion of the parameter input and a statement of the number of $\mathrm{L} / \mathrm{O}$ s used in reading the parameter data.

At this point, the unprocessed input geometry, shown in Fig. F17.6.5, may be printed as described in Sect. F17.6.4. These data are followed by a statement affirming the completion of the data reading and a table listing the geometry parameter summary data, as shown in Fig. F17.6.5a.

\section{F17.6.4 UNPROCESSED GEOMETRY INPUT DATA}

This printout is optional and is usually used to locate code difficulties, to show all the geometry input data when only part of it is used in the problem, or to show the order in which units were entered. It is considered debug information and is printed only if $P G M=Y E S$ is specified in the parameter input data as described in Sect. F17.4.3. Standard KENO-VI use does not require printing these data because the processed geometry that is used in the problem is always printed. See Sects. F17.6.15 and F17.6.16 for examples of the standard printed KENOVI geometry data. An example of the data printed in the unprocessed geometry input data is shown in Fig. F17.6.5. The unprocessed geometry is printed by subroutine KENOG.

When the unprocessed geometry input is printed, the problem title is located at the top of the page, followed by the heading "GEOMETRY DESCRIPTION INPUT." The region-dependent geometry information is then printed. If the problem contains a unit orientation array, the problem title is printed again, followed by the unit orientation and a statement affirming the completion of the data input. A summary table of the geometry input data is then printed, as shown in Fig. F17.6.5a. This table contains summations of the different geometry parameters used in the problem such as number of units, quadratic equation, geometry words, and holes. 


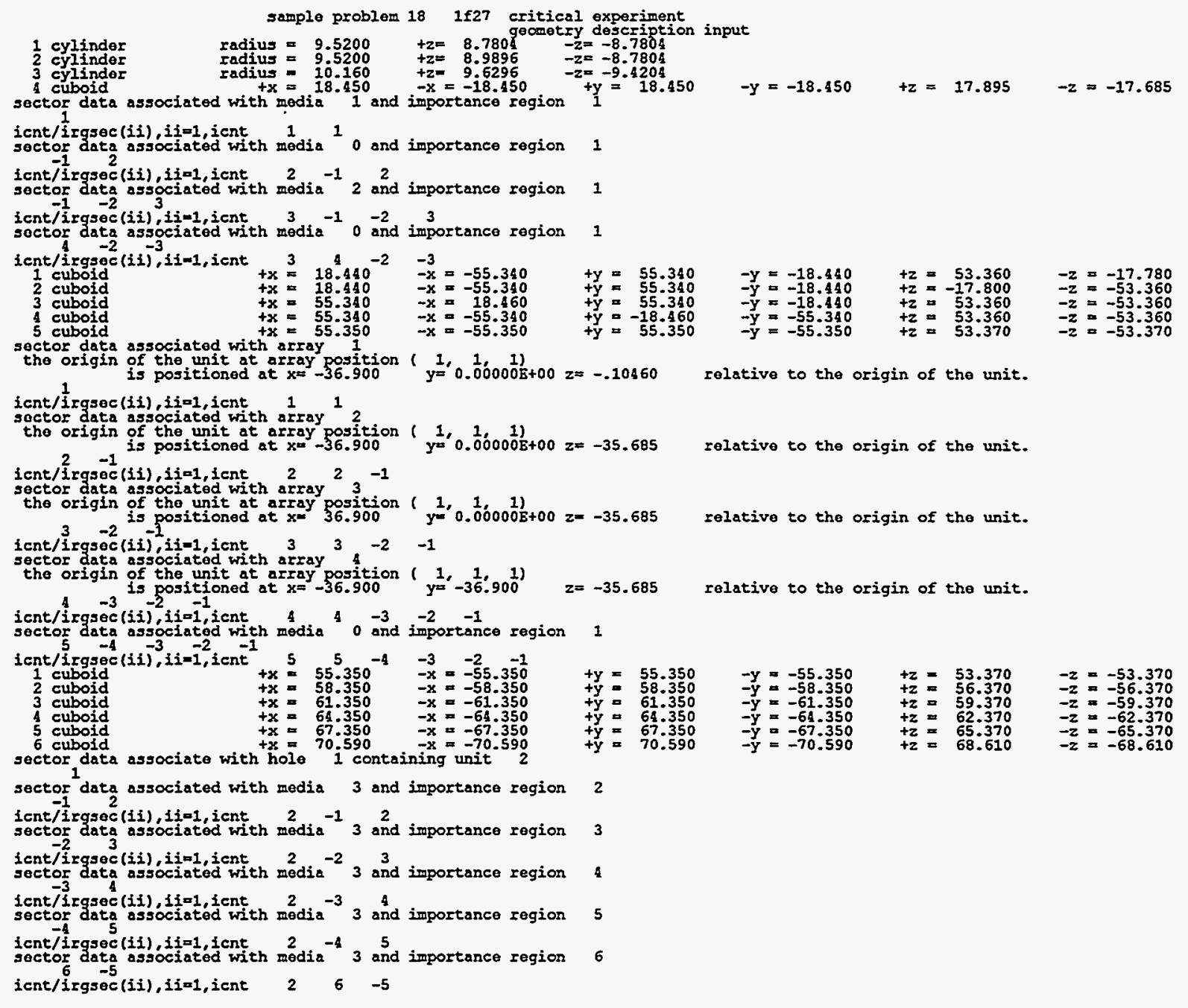

Figure F17.6.5 Example of unprocessed geometry input data 


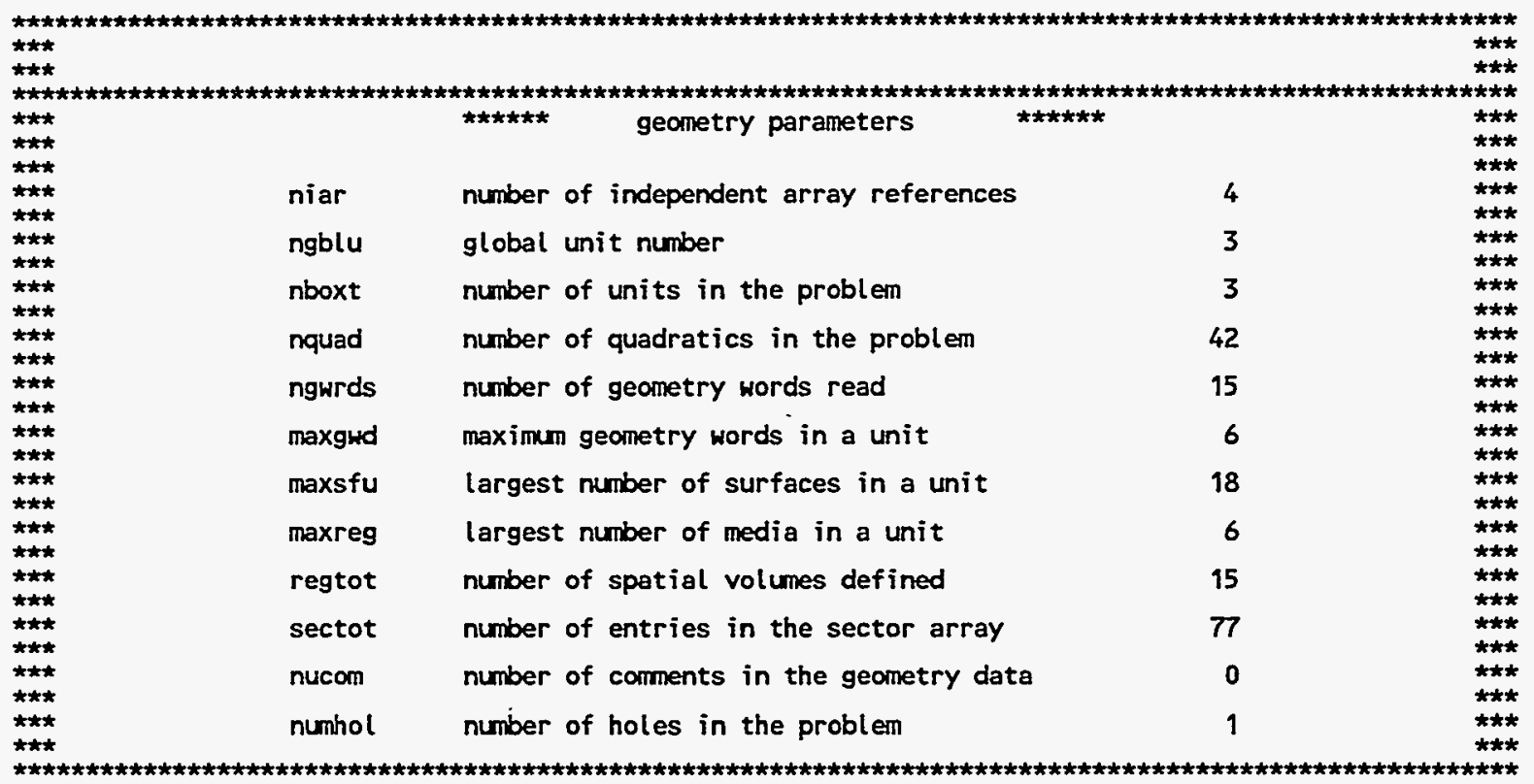

$\star * * * * * * * * * * * * * * *$ data reading completed $* * * * * * * * * * * * * * *$

Figure F17.6.5a Sample table of geometry input data

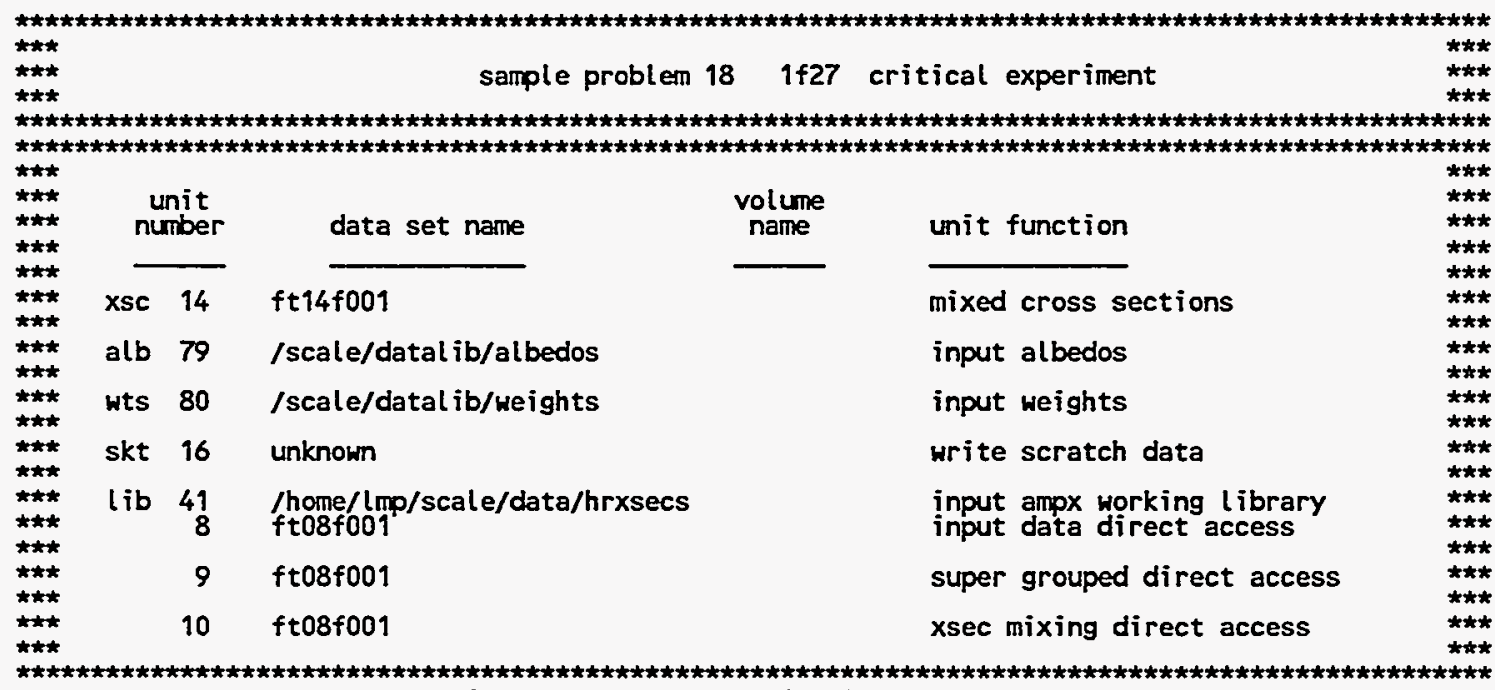
....... 0 io's were used preparing input data $\quad . . . .$.

Figure F17.6.6 Sample table of data sets used in the problem

NUREG/CR-0200,

Vol. 2, Rev. 5

F17.6.8 


\section{F17.6.5 TABLE OF DATA SETS USED IN THE PROBLEM}

This table, printed from subroutine DATAIN, lists unit numbers that are specified in the parameter data or are defaulted in the code, and information pertinent to them. This information is given in the following order, left to right: (1) the keyword used in the parameter data to define the unit number, (2) the unit number, (3) the data set name, (4) the name of the volume on which the data set resides, and (5) the type of data contained on the data set. For UNIX systems the volume name is left blank. This table can be useful for quality assurance purposes. Information for units whose default values have not been overridden are printed even though they may not be used in the problem. Information for every unit specified in the parameter data is also printed. Units 8 , 9 , and 10 are the direct-access devices, and their unit numbers are fixed within the code. This table is followed by a statement of the number of $I / O$ s used preparing the input data and writing it on the direct access data sets. It should be carefully scrutinized to verify that the desired data set name is associated with the proper unit number and volume. An example of this table is shown in Fig. F17.6.6.

\section{F17.6.6 MIXING TABLE DATA}

These data are printed by subroutine PRTMIX only if a mixing table data block is entered in the problem. It is not considered optional because it cannot be suppressed. A sample of the mixing table data is shown in Fig. F17.6.7.

The data printed in this table include the problem title and the number of scattering angles. This is followed by the entry number, the mixture number, the nuclide $\mathrm{ID}$ number, and the number density of each entry, printed in columnar form. After all the entries have been printed, the number of $\mathrm{V} / \mathrm{O}$ used in mixing the cross sections is printed. If extra $1-D$ cross sections were specified in the problem (see $X 1 D=$, Sect. F17.4.3), the extra 1-D cross-section IDs will be printed under the heading "1-D Cross-Section Array ID Numbers." If $\bar{v}$ is to be calculated (see NUB=, Sect. F17.4.3), six ID numbers will be printed. The ID number for the total cross section, $\Sigma_{\mathrm{T}}$, is 1 ; the ID number for the sum of the transfer array normalized by $\Sigma_{\mathrm{T}}$ is 2002 ; the ID number for $v \Sigma_{\mathrm{f}}$ is 1452 ; the normalized absorption cross section, $\Sigma_{\mathrm{abs}} / \Sigma_{\mathrm{T}}, \mathrm{ID}$ number is 27 ; the normalized fission cross section, $\Sigma_{f} / \Sigma_{\mathrm{T}}, \mathrm{ID}$ number is 18 ; the fission spectrum, $\chi_{0} \mathrm{ID}$ number is 1018 . $\chi$ is summed and normalized to 1.0. Other ID numbers that appear in this list have been specified by the user. If the number of blocks on the direct-access data set are insufficient to hold the cross-section data, a message is printed stating: THE NUMBER OF DIRECT ACCESS BLOCKS ON UNIT HAS BEEN INCREASED TO If the problem is to write a restart data set (RES=, Sect. F17.4.3), a message is printed stating that restart information was written and the restart $\mathrm{I} / \mathrm{O}$ unit number is specified. This sequence is followed by a statement of the number of I/Os used in preparing the cross sections. The user should examine the mixing table carefully to verify that the proper nuclides are specified for the proper mixtures and that all the number densities are correct. The mixing table is printed in subroutine PRTMIX. Following this table is a statement of the unit number from which the cross-section data were read and a list of the cross-section $\mathrm{Ds}$ and their titles. This information is printed by subroutine MIXMIX. The 1-D cross-section array D numbers are then printed. 


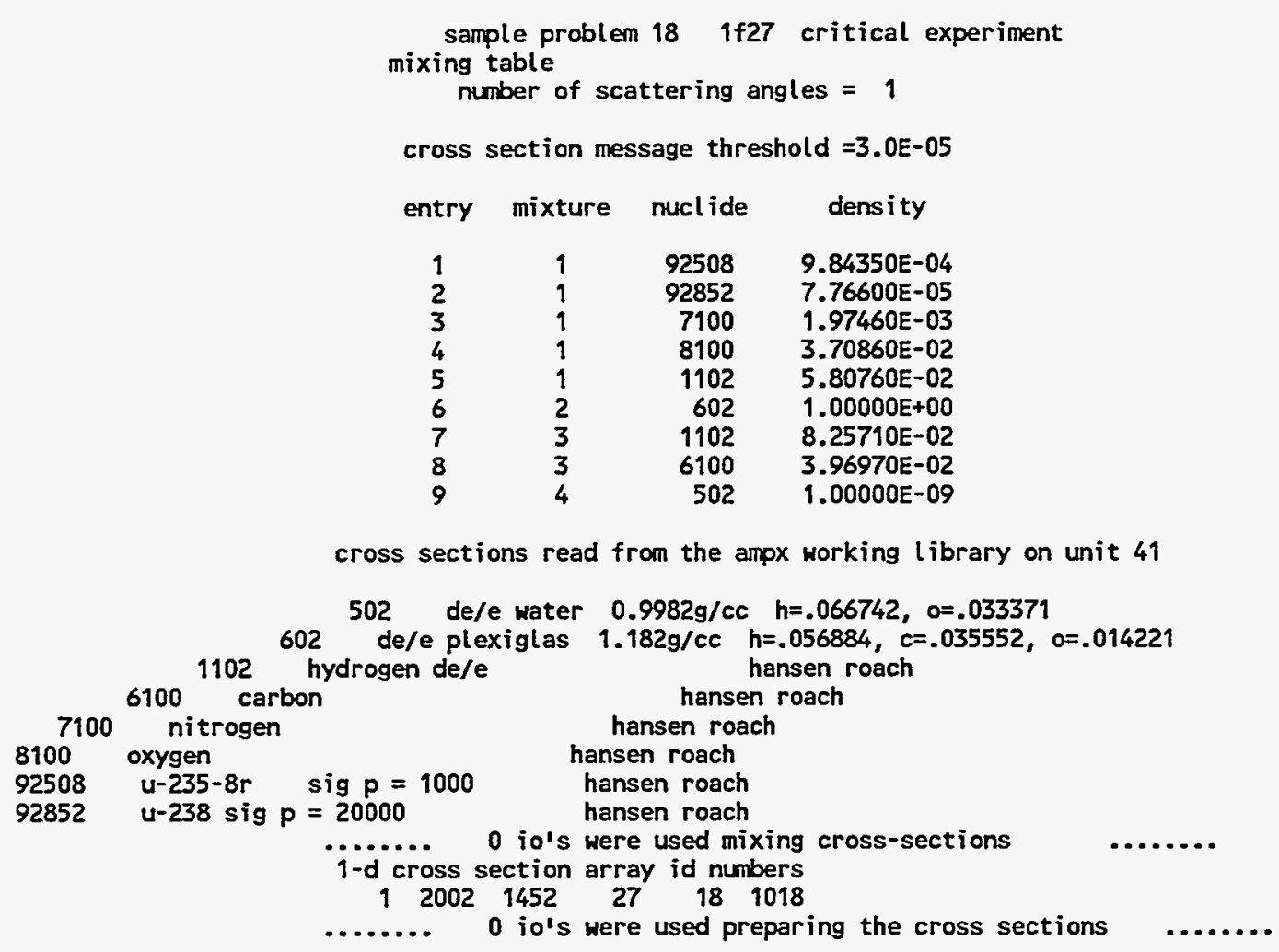

Figure F17.6.7 Example of mixing table data

\section{F17.6.7 ALBEDO CROSS-SECTION CORRESPONDENCE}

Printing the albedo cross-section correspondence tables is optional. The headings for the tables are printed in subroutine CORRE, then subroutine RATIO prints the data. These tables are printed only if PAX $=$ YES is specified in the parameter data as described in Sect. F17.4.3. Examples of these tables are shown in Figs. F17.6.8 and F17.6.9.

The table shown in Fig. F17.6.8 contains, left to right, the cross-section energy group, the lower and upper lethargy bounds, the corresponding albedo energy groups, and the cumulative probability associated with each albedo energy group for choosing the albedo energy group corresponding to the cross-section energy group. The table shown in Fig. F17.6.9 is the inverse of the table shown in Fig. F17.6.8. It provides the cumulative probabilities for choosing the cross-section energy group corresponding to the albedo energy group. The information in these tables is automatically generated by KENO-VI.

NUREG/CR-0200,

Vol. 2, Rev. 5

F17.6.10 


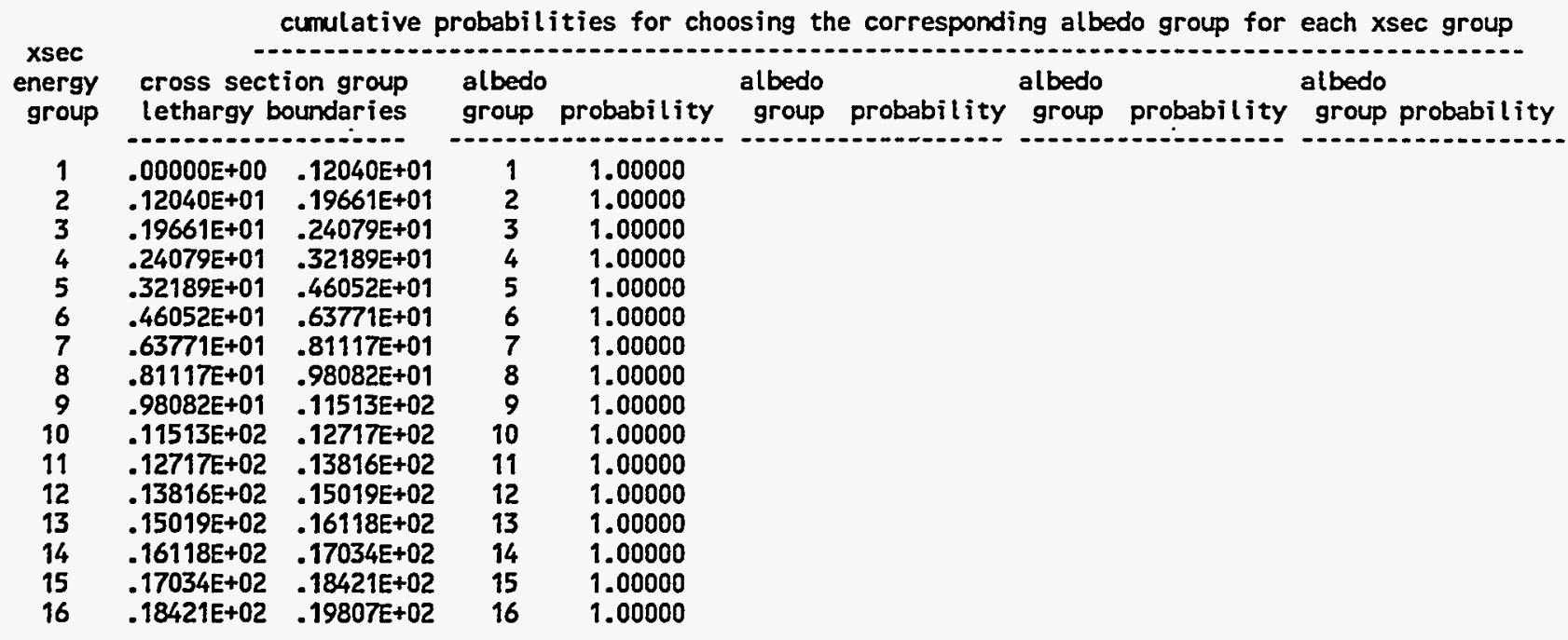

Figure F17.6.8 Cumulative probabilities for correlating the albedo energy group to the cross-section energy group

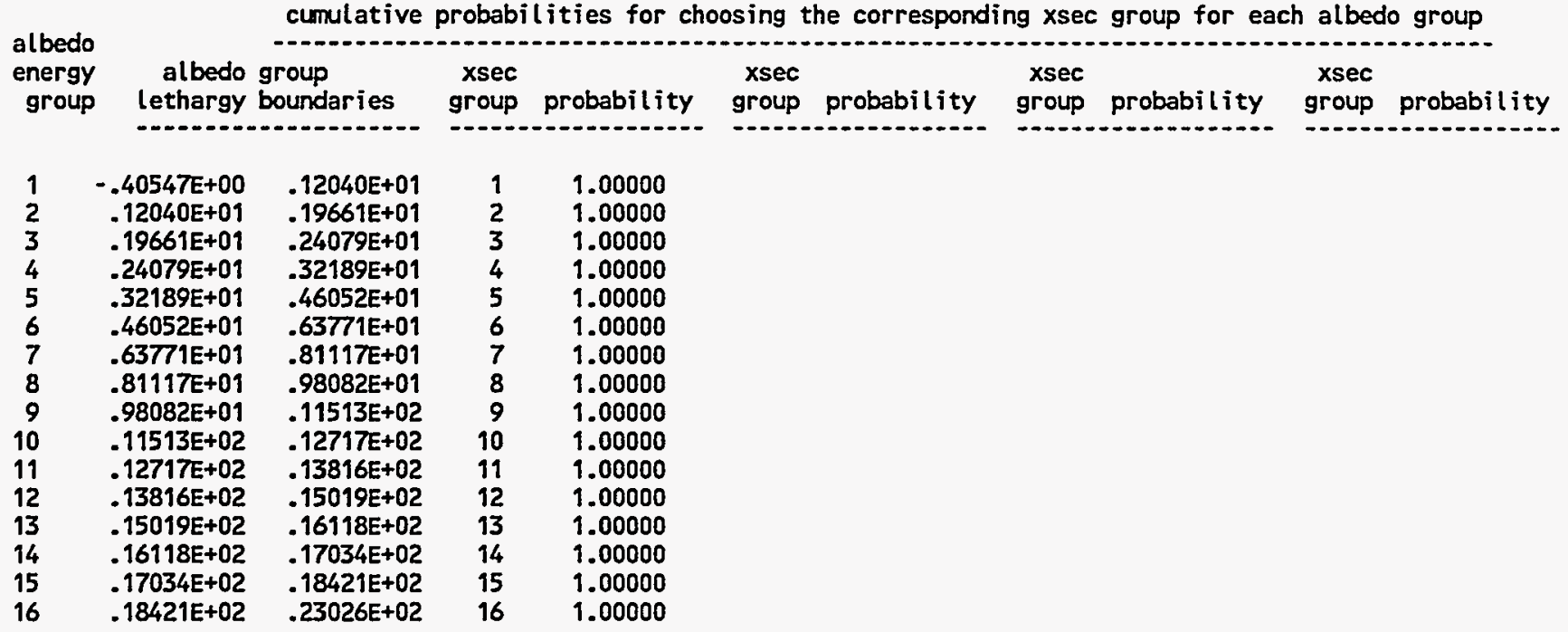

Figure F17.6.9 Cumulative probabilities for correlating the cross-section energy group to the albedo energy group 


\section{F17.6.8 1-D MACROSCOPIC CROSS SECTIONS}

The decision to print the 1-D mixture cross sections is optional. They are printed in subroutine PRT1DS only if XS1=YES is specified in the parameter data as described in Sect. F17.4.3. When the 1-D cross sections are to be printed, they are printed a group at a time for each mixture. The 1-D mixture cross sections for a mixture are shown in Fig. F17.6.10.

When the 1-D mixture cross sections are printed, the problem title is printed at the top of the page. The mixture $\mathrm{ID}$ and MLXTURE INDEX numbers are then printed. ID is the mixture number from the mixing table, and MIXTURE INDEX is the index used to reference it followed by a heading to identify the different 1-D cross sections. GROUP is the energy group, SGT is the total cross section for the mixture, NAP is the nonabsorption probability, ABP is the absorption probability, NFP is the production probability, $\mathrm{CHI}$ is the fission spectrum, MWA1 is the pointer for the first position of the cross sections for the energy group, MWA2 is the pointer for the last position of the cross sections for the energy group, and MWA3 contains the group for the transfer corresponding to the first position. SUM is the sum of the absorption probability and the nonabsorption probability. The absorption probability is defined as the absorption cross section divided by the total cross section. The nonabsorption probability is the sum of the group-to-group transfers for this group, divided by the total cross section. The production probability is defined as the fission production cross section divided by the total cross section, $v \Sigma_{\mathrm{f}} / \Sigma_{\mathrm{T}}$. The nonabsorption probability and the production probability are not true probabilities in that they may be greater than 1 . This is because the nonabsorption probability has the $(n, 2 n)$ transfer array summed into the total transfer array twice, and the $(n, 3 n)$ is summed three times, etc.

\section{F17.6.9 EXTRA 1-D CROSS SECTIONS}

Printing the extra 1-D cross sections is optional. They are printed in subroutine PRTIDS if P1D=YES is specified in the parameter data (Sect. F17.4.3). Extra 1-D cross sections are not used in KENO-VI unless $N U B=Y E S$ is specified in the parameter data or the user has altered the code to access and utilize other 1-D cross sections. If $N U B=Y E S$ is specified, the extra 1-D cross section is the fission cross section, and is used to calculate the average number of neutrons per fission. This is printed only for fissile mixtures as shown in Fig. F17.6.10. The fission cross-section heading is XSEC ID 18, and it follows the table of 1-D cross sections.

\section{F17.6.10 2-D MACROSCOPIC CROSS SECTIONS}

The decision to print the 2-D mixture cross sections is optional. They are printed in subroutine PRT2DS only if XS2=YES is specified in the parameter data. They are printed after the 1-D cross sections for the mixture. A heading is printed, followed by the transfer data. An example of the 2-D mixture cross sections is given in Fig. F17.6.11.

\section{F17.6.11 PROBABILITIES AND ANGLES}

Printing the probabilities and angles is optional. They are printed if the number of scattering angles is greater than zero and XAP=YES is specified in the parameter data as described in Sect. F17.4.3. The probabilities and angles are printed for each mixture by subroutine PRT2DS. An example of the probabilities is shown in Fig. F17.6.12, and an example of the angles is shown in Fig. F17.6.13. If the group-to-group transfer for a mixture is isotropic, the first angle for that transfer will be set to -2.0 as a flag to the code.

NUREG/CR-0200, 


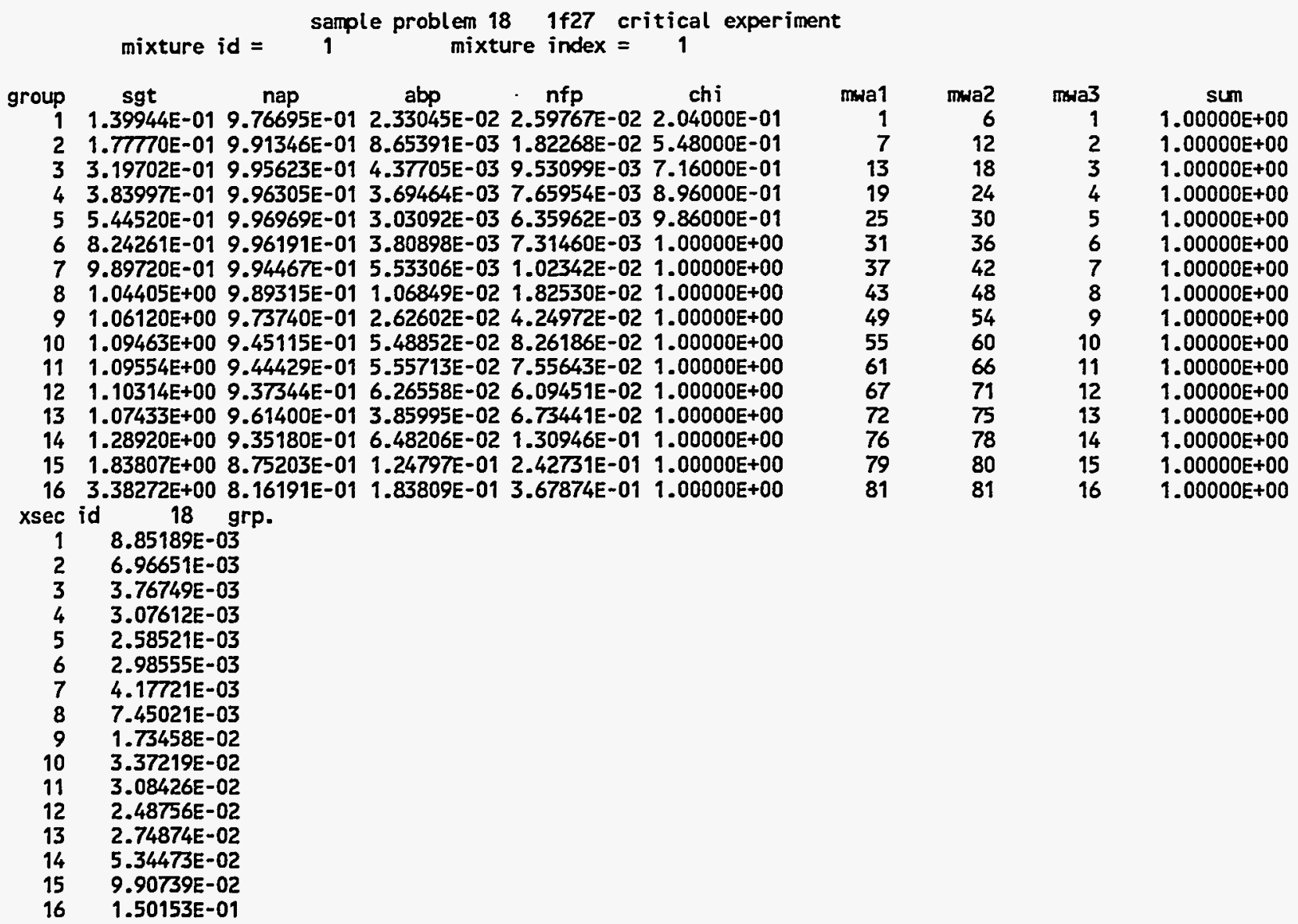

Figure F17.6.10 Example of macroscopic 1-D cross sections

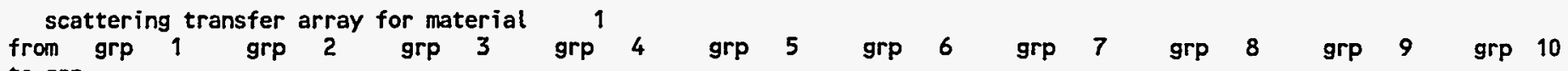

$\begin{array}{llllllllllll}\text { to grP } & \text { 2.54209E-01 3.10539E-01 2.98182E-01 3.71084E-01 } 4.55319 E-01 & 4.72411 E-01 & 4.56823 E-01 & 4.47266 E-01 & 4.48962 E-01 & 3.30557 E-0\end{array}$

+1 4.48688E-01 2.73107E-01 4.37470E-01 4.85849E-01 4.56102E-01 4.37482E-01 4.45877E-01 4.54113E-01 3.88724E-01 4.51241E-0

+2 1.04476E-01 2.31550E-01 1.97693E-01 1.18779E-01 7.31741E-02 7.39104E-02 7.95987E-02 6.85965E-02 1.07909E-01 1.52634E-0

+ 3 1.06680E-01 1.39556E-01 5.49774E-02 2.00378E-02 1.25166E-02 1.32261E-02 1.23322E-02 2.02416E-02 3.82178E-02 4.37863E-0;

$+4 \quad 6.46550 \mathrm{E}-02$ 3.86576E-02 9.48767E-03 3.33964E-03 2.35355E-03 2.12183E-03 3.59935E-03 6.85965E-03 1.07909E-02 1.30236E-0;

$+5 \quad 2.12918 E-02 \quad 6.59086 E-03 \quad 2.18946 E-03$ 9.10810E-04 5.34899E-04 8.48732E-04 $1.77017 \mathrm{E}-03$ 2.92379E-03 5.39546E-03 8.75725E-0: from grp 11 grp 12 grp 13 grp 14 grp 15 grp 16 to grp

+ 0 3.02946E-01 3.19203E-01 2.89136E-01 3.46347E-01 8.10619E-01 1.00000E+00

+1 4.94030E-01 4.59900E-01 4.33884E-01 4.94691E-01 1.89381E-01

+2 1.35724E-01 1.32774E-01 2.07145E-01 1.58962E-01

+3 4.03578E-02 6.63872E-02 6.98356E-02

$+42.02070 \mathrm{E}-02$ 2.17359E-02

+5 6.73566E-03

Figure F17.6.11 Example of 2-D macroscopic cross sections 


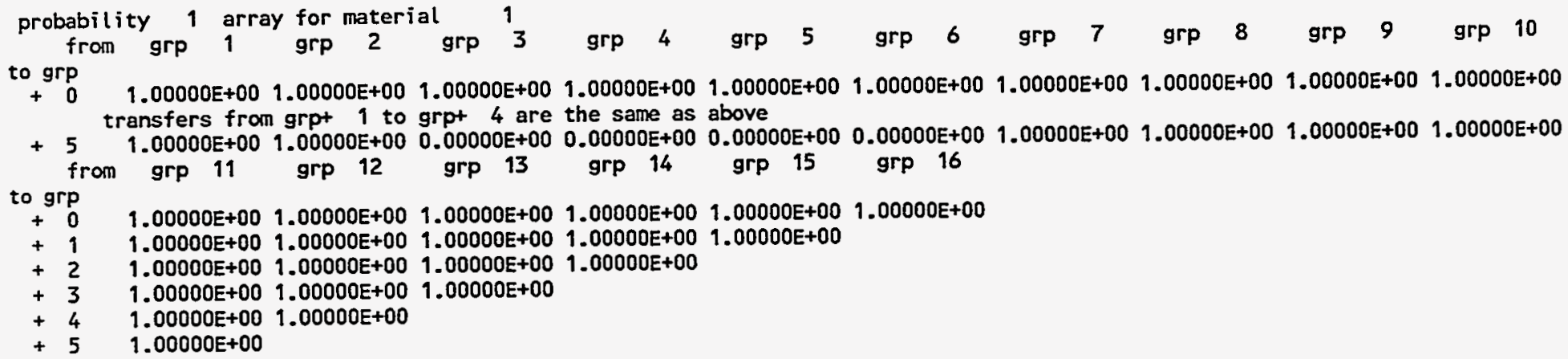

Figure F17.6.12 Example of macroscopic probabilities

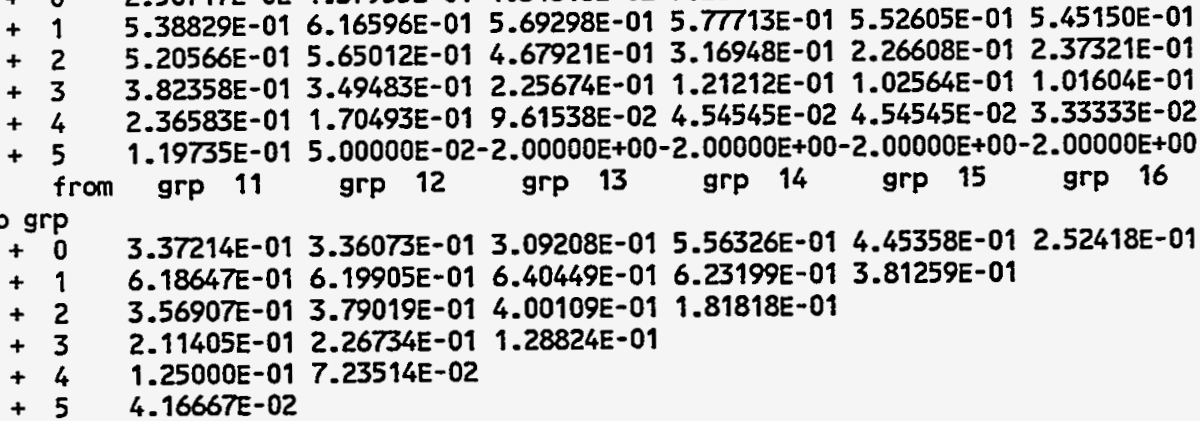

Figure F17.6.13 Example of macroscopic angles 


\section{F17.6.12 TABLE OF ADDITIONAL INFORMATION}

This table contains information determined by the input data and is printed by subroutine NSUPG. An example of this table is shown in Fig. F17.6.14.

This table should be examined by the user to verify the problem data. The NUMBER OF ENERGY GROUPS is read either from the Monte-Carlo-formatted library, identified by the keyword XSC and the unit function name MIXED CROSS SECTIONS from the Table of Data Sets in Sect. F17.6.5, or from the restart unit, identified by the keyword RST and the unit function name, READ RESTART DATA. The NO. OF FISSION SPECTRUM SOURCE GROUP is the number of different energy groups for which a fission spectrum is defined. In the present version, this number should always be 1 . The NO. OF SCATTERING ANGLES IN XSECS is the number of scattering angles to be used in processing the cross sections. The default value is 1 and may be overridden by specifying the parameter $\mathrm{SCT}=$ in the mixing table input as described in Sect. F17.4.10. One scattering angle yields $P_{1}$ cross sections, two scattering angles yield $P_{3}$ cross sections, three scattering angles yield $\mathrm{P}_{5}$ cross sections, etc. ENTRIES/NEUTRON IN THE NEUTRON BANK specifies the number of pieces of data that are banked for each history during tracking. ENTRIES/NEUTRON IN THE FISSION BANK is the amount of data stored for each source neutron for each generation.

The NUMBER OF MIXTURES USED is the number of different mixtures (media) used in the geometry data utilized by the problem. This value may be less than the total number of different mixtures specified in the geometry data if portions of the geometry data are not used in the problem.

The NUMBER OF BIAS IDS USED is the number of different biasing regions used in the problem. This will always be 1 unless a biasing data block is entered in the problem as described in Sect. F17.4.7.

The NUMBER OF DIFFERENTIAL ALBEDOS USED is the number of different differential albedo reflectors used in the problem. This value will always be zero unless the boundary condition data specify the use of differential albedo reflection on one or more faces of the system as described in Sect. F17.4.6. Also check the BOUNDARY CONDITION data printed in this table. The number of different differential albedos specified on the faces should be consistent with the NUMBER OF DIFFERENTIAL ALBEDOS USED. Specular, mirror, vacuum, and periodic are not differential albedos. Be aware that several different keywords may be used to specify the same differential albedo. See Table F17.4.4 for a list of differential albedo keywords.

The TOTAL INPUT GEOMETRY REGIONS is the number of geometry regions specified in the problem input. This is defined by the MEDIA-type record used in describing the data. The MEDIA records start with the words MEDIA, ARRAY, and HOLE. The NUMBER OF GEOMETRY REGIONS USED is the number of geometry regions used in the problem. It may be less than or equal to the TOTAL INPUT GEOMETRY REGIONS. (The LARGEST GEOMETRY UNIT NUMBER is the largest unit number used in the problem) The LARGEST ARRAY NUMBER is the largest array number specified in the array data. (See Sect. F17.4.5.)

USE LATTICE GEOMETRY is determined by the logical flag that indicates whether or not the problem is a single-unit problem. This should be YES for any problem that is not a single-unit problem and NO for a single-unit problem. By definition, a single-unit problem is a problem that does not utilize array data in any form. Section F17.4.5 describes array data. The GLOBAL ARRAY NUMBER is the number of the array designated as the global array. Any array in a problem can be designated the global array. The global array is used only when matrix data are being collected.

The NUMBER OF UNITS IN THE GLOBAL X/Y/Z DIR defines the size of the global array in terms of the number of units that are located along the edge of the array boundaries in the $x / y / z$ directions. For a single unit, all three of these values should be zero. For a simple $1 \times 1 \times 1$ array consisting of one unit type, all three of these numbers should be 1 . 


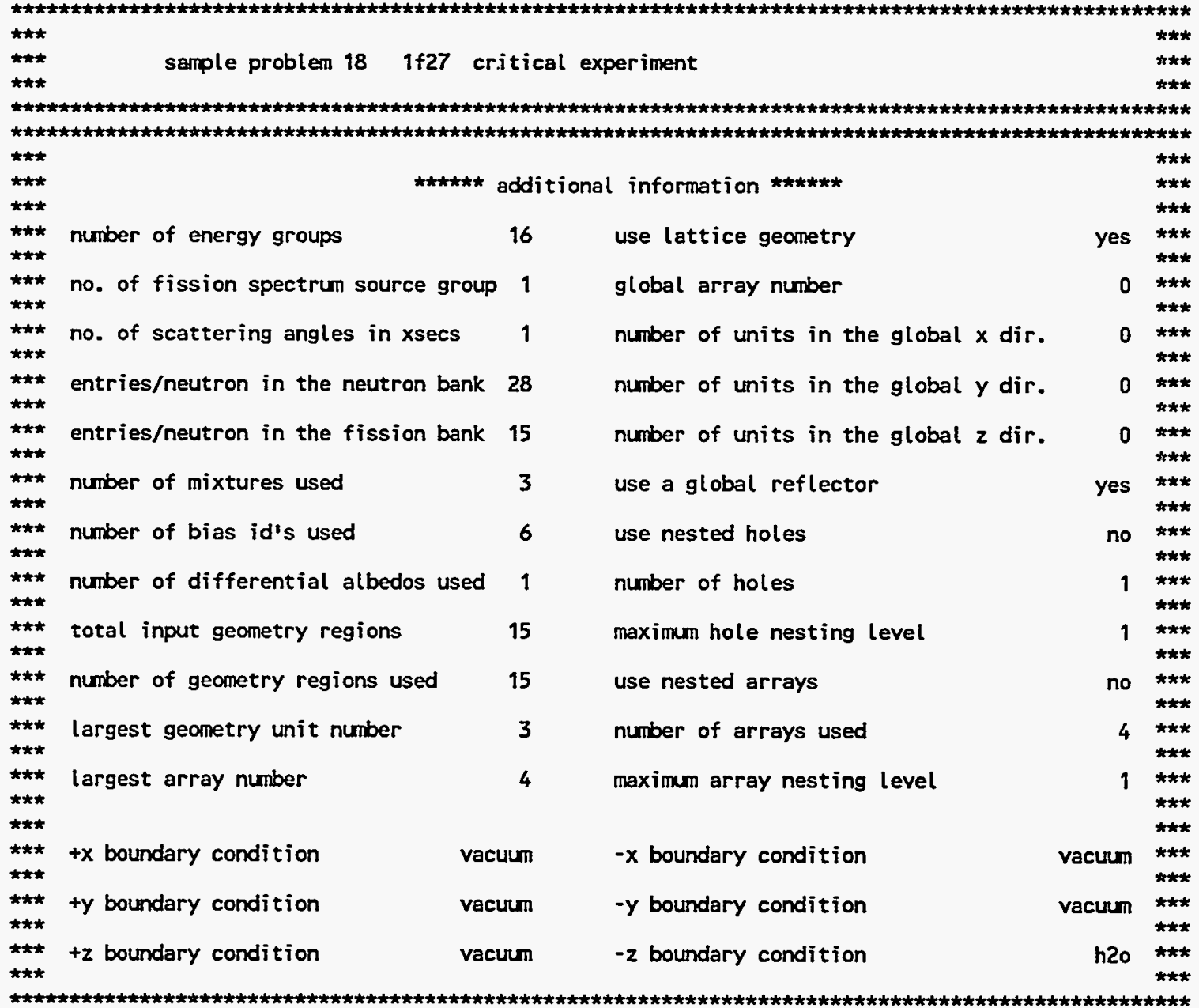

Figure F17.6.14 Sample table of additional information

USE GLOBAL REFLECTOR indicates if the global array is reflected.

USE NESTED HOLES is set YES if holes are nested deeper than one level.

NUMBER OF HOLES is the number of HOLES that are entered in the geometry region data (Sect. F17.4.4).

The MAXIMUM HOLE NESTING LEVEL is the deepest level of hole nesting.

USE NESTED ARRAYS is set YES if arrays are nested deeper than one level.

NUREG/CR-0200,

Vol. 2, Rev. 5

F17.6.16 
The NUMBER OF ARRAYS USED is the number of array descriptions (Sect. F17.4.5) actually used in the problem description.

MAXIMUM ARRAY NESTING LEVEL is the deepest level of array nesting.

Six BOUNDARY CONDITIONs are printed near the bottom of the table. They show the type of boundary condition that is applied to each face of the system. These should all be VACUUM unless albedo boundary conditions are applied to one or more faces of the system as described in Sect. F17.4.6. Also refer to the NUMBER OF DIFFERENTIAL ALBEDOS USED, discussed previously in the description of this table of information.

\section{F17.6.13 TABLE OF SPACE AND SUPERGROUP INFORMATION}

Another table printed by KENN-VI, as shown in Fig. F17.5.15, summarizes the space requirements for the problem and prints information related to the supergroups. This table is printed by subroutines NSUPG and LIMLN.

This table contains information about the space requirements of the problem and the number of supergroups used in the problem. The table is basically self-explanatory.

The TOTAL SPACE AVAILABLE is the amount of memory (in words) available to contain the data for the problem. The NONSUPERGROUP STORAGE is the number of words of memory containing nonsupergrouped data. Following this information are statements concerning the amount of storage available for supergrouped data, the amount of storage available for constructing the supergroups, the amount of storage available for each supergroup, the number of words of storage needed for the largest supergroup, the amount of storage needed to run the problem, and the amount of storage that would be necessary to run the problem with one supergroup, and the number of words of storage that will be used to run this problem.

The bottom portion of this table contains information about the supergroups. Warning and error messages may appear in this portion of the table. The printed supergroup data include the supergroup number, the first energy group in the supergroup, the last energy group in the supergroup, the length (in words) of the cross-section data for the supergroup, the length (in words) of the albedo data for the supergroup, and the total length (in words) of all the data for the supergroup. This information is printed for each supergroup.

\section{F17.6.14 ARRAY SUMMARY}

The arrays that are used in the problem are summarized in the table shown in Fig. F17.6.16. This table is printed by subroutine PRTARA whenever more than one array is used in the problem.

The ARRAYNUMBER is the number by which the array is designated in the input data. The number of units in the $x, y$, and $z$ directions is listed for each array. The global array is flagged by the word GLOBAL. The NESTINGLEVEL indicates the level of nesting for each array. Arrays can be nested to any level, limited only by the capability of the computer. A nesting level of 1 is the highest or first nesting level. The larger the number in the nesting level column, the deeper the nesting level. 


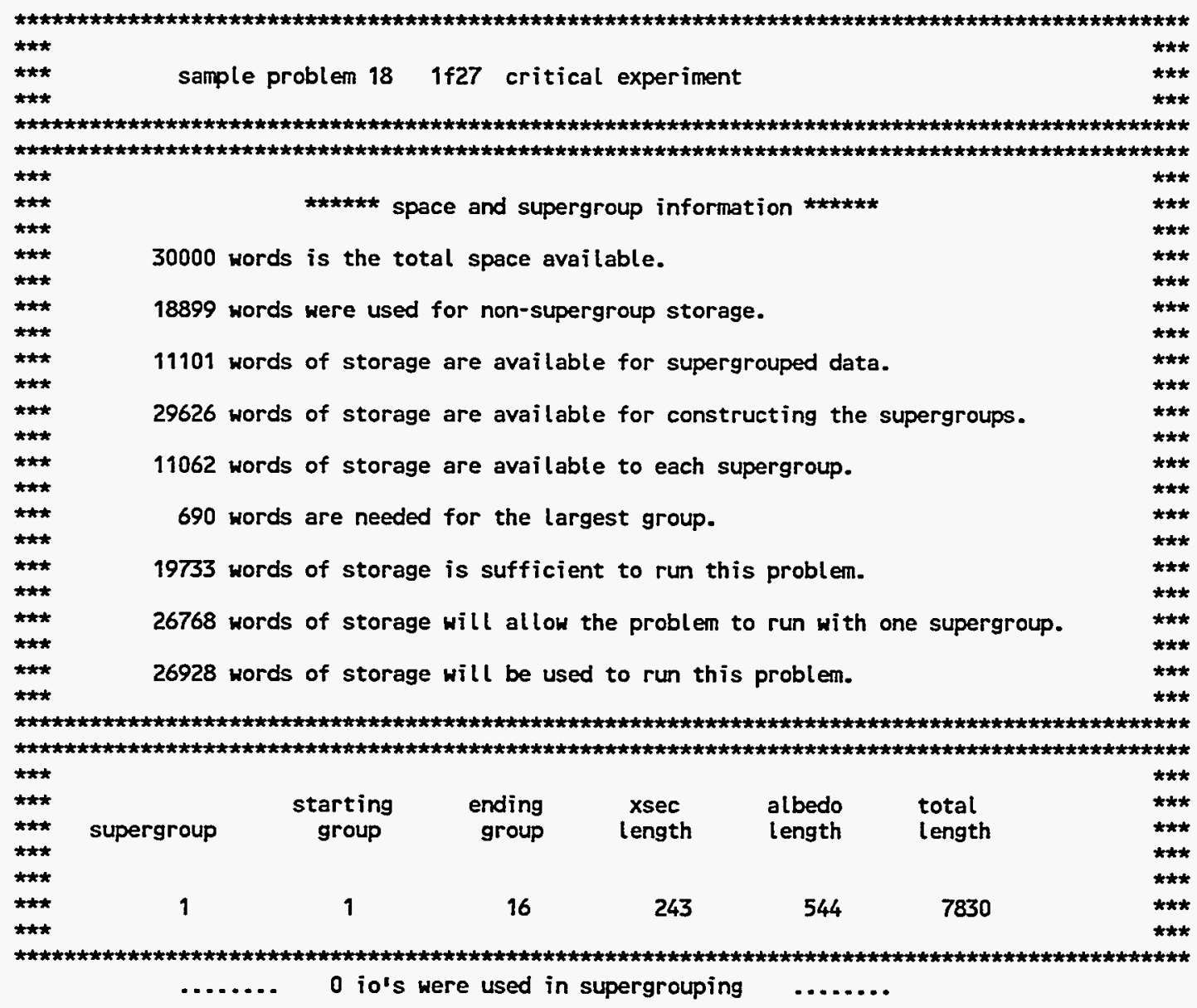

Figure F17.6.15 Sample table of space and supergroup information

\begin{tabular}{|c|c|c|c|c|c|c|}
\hline $\begin{array}{l}* \star \\
k \star \\
k \star \\
* \star \\
k \star\end{array}$ & $\begin{array}{l}\text { array } \\
\text { number }\end{array}$ & $\begin{array}{c}\text { units in } \\
x \text { dir. }\end{array}$ & $\begin{array}{l}\text { units in } \\
y \text { dir. }\end{array}$ & $\begin{array}{l}\text { units in } \\
z \text { dir. }\end{array}$ & $\begin{array}{c}\text { nesting } \\
\text { level }\end{array}$ & $\begin{array}{l}\star * \\
\star * \\
\star * \\
\star\end{array}$ \\
\hline$* *$ & 1 & 2 & 2 & 2 & 1 & $\star \star *$ \\
\hline $\begin{array}{l}k \star \star \\
y \neq \star\end{array}$ & 2 & 2 & 2 & 1 & 1 & $\begin{array}{l}* * \\
\star *\end{array}$ \\
\hline $\begin{array}{l}* \star \\
* \star\end{array}$ & 3 & 1 & 2 & 3 & 1 & $\begin{array}{l}\star \star \\
\star \star\end{array}$ \\
\hline $\begin{array}{l}k * \\
* *\end{array}$ & 4 & 3 & 1 & 3 & 1 & $\begin{array}{l}\star \star \\
\star *\end{array}$ \\
\hline
\end{tabular}

....... 0 io's were used loading the data $\ldots . . .$.

Figure F17.6.16 Examples of array summary

NUREG/CR-0200,

Vol. 2, Rev. 5

F17.6.18 


\section{F17.6.15 GEOMETRY DATA}

The geometry region data utilized by the problem are printed by subroutine PRTJOM and cannot be suppressed. They should be carefully examined by the user to verify the mixture number, bias $\mathrm{ID}$, and geometry specifications used in the problem. If geometry region data are input but are not referenced in the unit orientation array data, they will not be printed here. An example would be to input geometry region data describing Units $1,2,3$, and 4 and to utilize only Units 1,3 , and 4 in the unit orientation array. Then the geometry region data for Unit 2 will not be printed. An example of the geometry region printout for a problem is given in Fig. F17.6.17.

The problem title and a heading are printed at the top of each page. The unit number followed by the GEOMETRY data for that unit is then printed. Each geometry record type used in the unit, numbered in the order they appear in the unit, is printed out. Following each geometry record type is the set of quadratic equations that describe the input geometry for that geometry record. The MEDIA data, consisting of four columns, is then listed in the order it appears in the problem. The first column contains the media-type record. The second column contains the media/hole/array number. The third column contains the bias ID number if the media-type record is MEDIA and is otherwise blank. The fourth column contains the sector definition array, which describes the region location relative to the GEOMETRY records listed above for that unit.

The data consisting of the unit number, GEOMETRY data, and MEDIA data are repeated for each unit used in the problem. The global unit has a heading printed before the unit number to identify it as the global unit.

\section{F17.6.16 UNIT ORIENTATION DESCRIPTION}

Each unit orientation description defines the location of units in the 3-D lattice that represents the specified array. The array that is described is identified in the heading: UNIT ORIENTATION DESCRIPTION FOR ARRAY _. The arrays used in the problem are stacked together to represent the physical problem being analyzed. The unit orientation description is not printed if only Unit 1 is described in the problem. The user should carefully examine the unit orientation descriptions to ensure the proper placement of the units in each lattice. A sample unit orientation description is shown in Fig. F17.6.18.

If a very large array is utilized by the problem, its unit orientation description may be spread over several pages. When checking the printout, the user should pay careful attention to the headings that indicate the portion of each lattice being printed. The unit orientation descriptions are printed in subroutine PRTLBA.

\section{F17.6.17 VOLUME INFORMATION}

Three tables of volumes are printed by subroutine VOLUME and cannot be suppressed. Currently, the volume data contained in these tables are meaningless. Future work on KENO-VI includes calculating the volumes of each region as is done in KENO-V.a. The first table printed will include the volume of each individual region and the cumulative volumes for each region in the unit. The second table will list the number of times each unit is used in the problem and the total volume of each region throughout the entire problem description. The third table will list the total volume of each mixture used in the problem. An example of the volume printout is given in Fig. F17.6.19. 


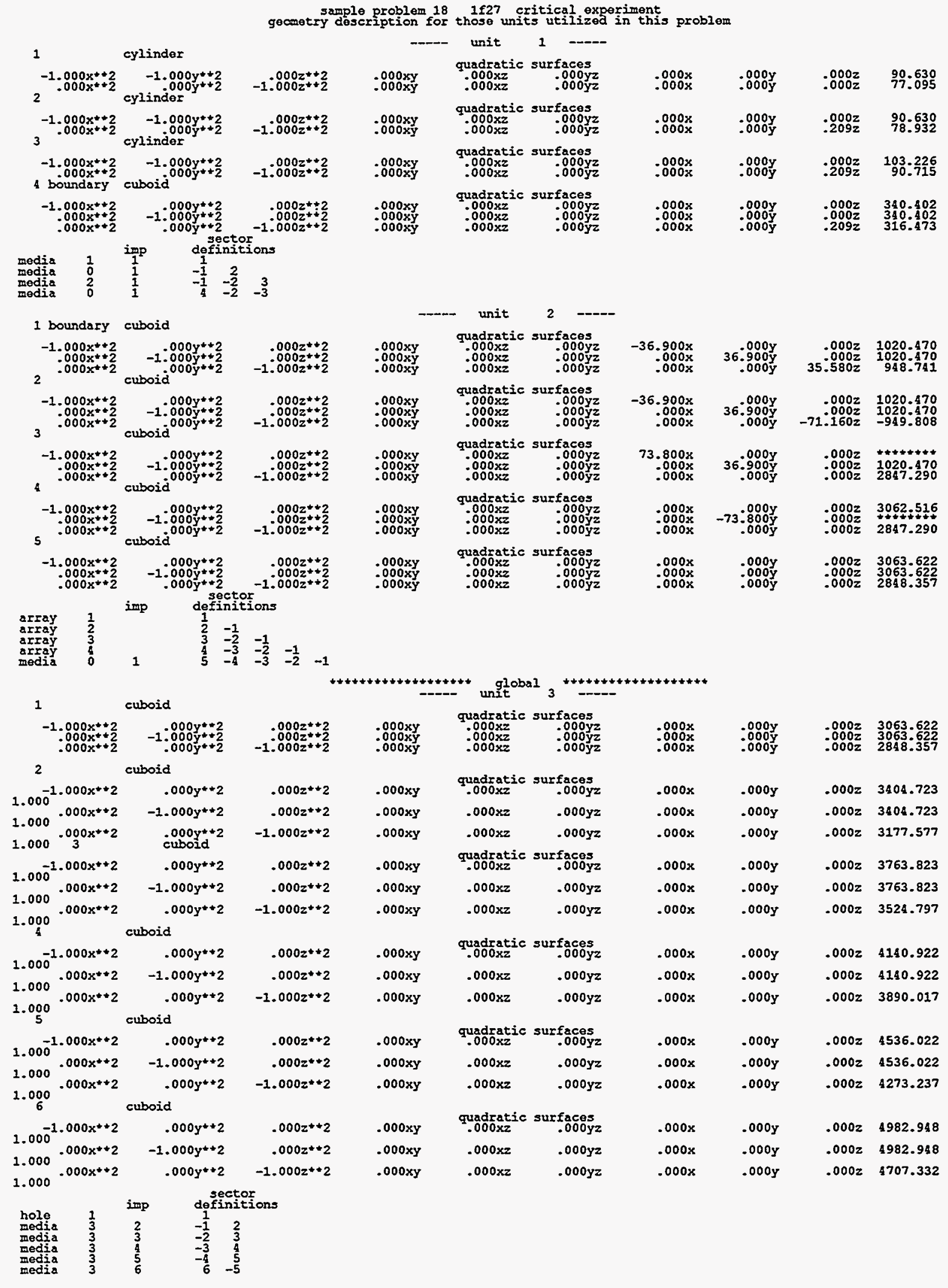

Figure F17.6.17 Example of geometry region data 
sample problem $18 \quad 1 \mathrm{f27}$ critical experiment

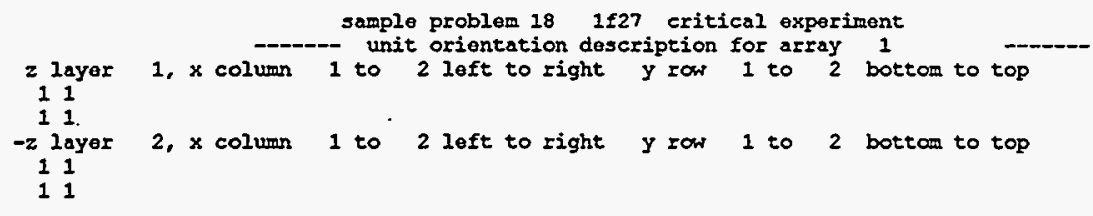

Figure F17.6.18 Example of unit orientation description

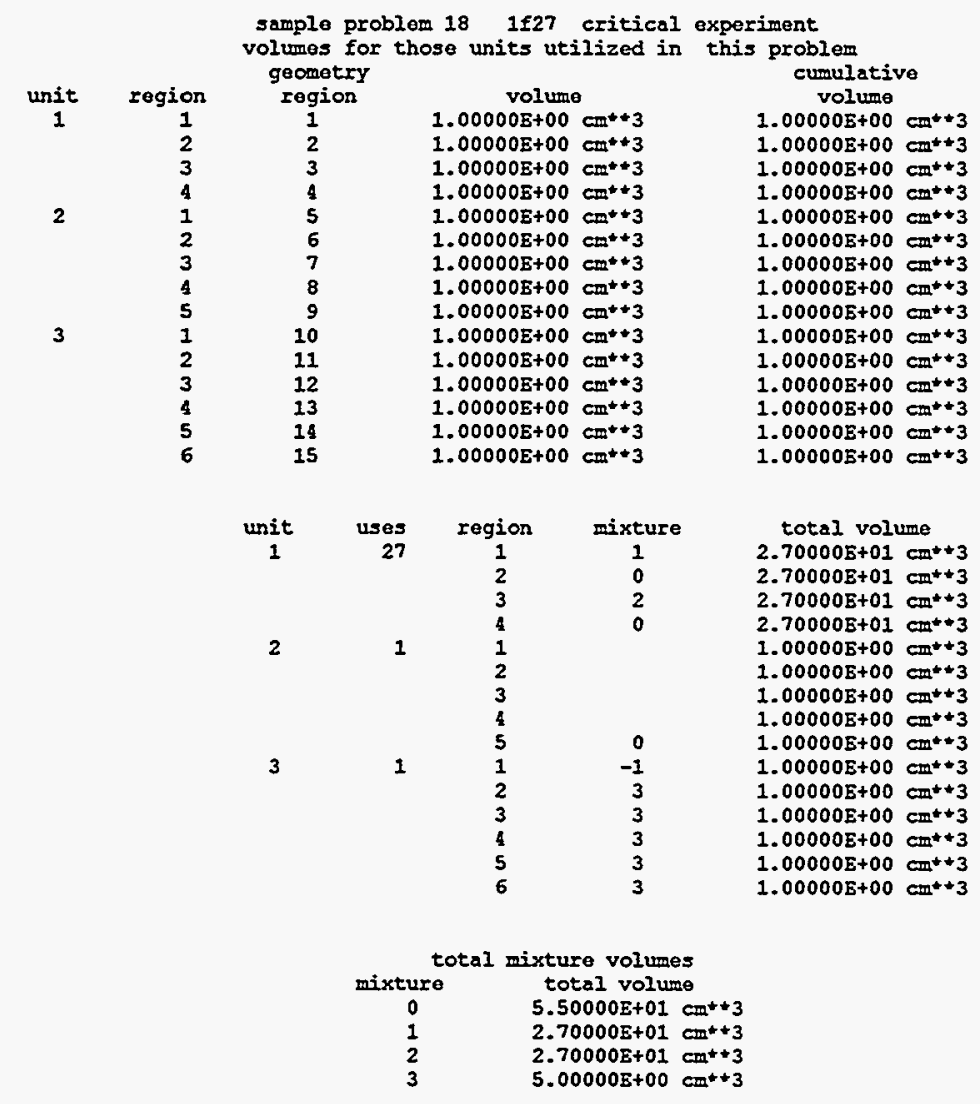

Figure F17.6.19 Sample volume information

F17.6.21

NUREG/CR-0200,

Vol. 2, Rev. 5 
The unit number is printed under the heading UNIT. The REGION refers to the number of the geometry region within the unit determined by the order of the MEDIA records in the unit. The geometry regions within a unit are numbered sequentially, starting with 1. GEOMETRY REGION refers to the entry number for the individual geometry region. These regions are numbered sequentially, starting with 1 , through the TOTAL INPUT GEOMETRY REGIONS defined in Sect. F17.6.12. The VOLUME is the net volume of the individual region. The CUMULATIVE VOLUME is calculated from the dimensions of the region. In the second table, USES indicates the number of times the unit is used in the problem. MIXTURE is the mixture number used in the region. A minus sign indicates an array or unit, placed in a hole, in that region. TOTAL VOLUME is the total volume of that region, determined by multiplying the VOLUME of the region by the number of times the unit containing that region is used in the problem. In the third table, the mixtures used in the problem are listed along with their total volumes. For example, assume region 1 is a cube $3 \mathrm{~cm}$ on a side, region 2 is a cube $4 \mathrm{~cm}$ on a side, and region 3 is a cube $5 \mathrm{~cm}$ on a side. The CUMULATIVE VOLUME of region 1 is $9 \mathrm{cc}$, of region 2 is $16 \mathrm{cc}$, and region 3 is $25 \mathrm{cc}$. The VOLUME of region 1 is $9 \mathrm{cc}$, region 2 is $5 \mathrm{cc}(16-9)$, and region 3 is $9 \mathrm{cc}$ (25-16). The TOTAL VOLUME of each region is determined by multiplying the VOLUME for a region by the number of times the unit containing that region is used in the problem. The number of times a unit is used in the problem is listed under the heading USES.

\section{F17.6.18 BIASING INFORMATION}

This table specifies the weighting or biasing data to be used in the problem. An example of biasing information is given in Fig. F17.6.20.

The user is responsible for determining from the input data whether the group-dependent weights (wtavg) for the specified material(s) were obtained from the weighting library or were entered by the user. The group-dependent weights can be printed for verification purposes as shown in Sect. F17.6.19.

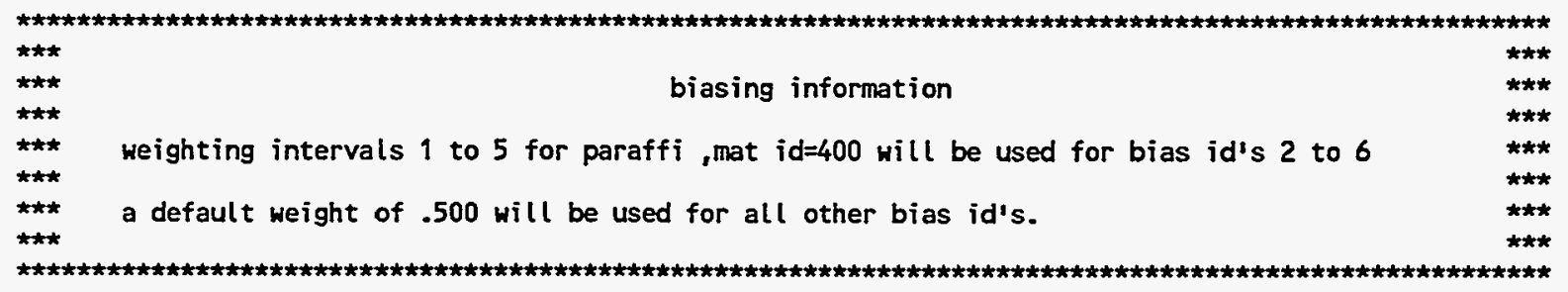

Figure F17.6.20 Biasing information

\section{F17.6.19 GROUP-DEPENDENT WEIGHTS}

Printing the group-dependent weights is optional. They are printed by subroutine PRTWTS if PWT=YES (Sect. F17.4.3) is entered in the parameter data. An example of the printed group-dependent weights is shown in Fig. F17.6.21.

The title is printed at the top of the table. The average weight (wtavg) is printed for each energy group and each BIAS ID. The BIAS ID number printed at the top of the column corresponds to the BIAS ID used in the geometry region description and printed in the biasing information.

NUREG/CR-0200,

Vol. 2, Rev. 5

F17.6.22 
sample problem $18 \quad 1$ f27 critical experiment

group dependent weights

\begin{tabular}{|c|c|c|c|c|c|c|}
\hline $\begin{array}{l}\text { energy } \\
\text { group }\end{array}$ & $\begin{array}{l}\text { bias } \\
\text { id }\end{array}$ & $\underset{\text { id }}{\text { bias }} 2$ & $\underset{\text { id }}{\operatorname{bias}} 3$ & $\underset{\text { id }}{\text { bias }} 4$ & bias 5 & bias 6 \\
\hline $\begin{array}{l}1 \\
2 \\
3 \\
4 \\
5 \\
6 \\
7 \\
8 \\
9 \\
10 \\
11 \\
12 \\
13 \\
14 \\
15 \\
16 \\
1 \text { f27 X }\end{array}$ & $\begin{array}{l}5.00000 E-01 \\
5.00000 E-01 \\
5.00000 E-01 \\
5.00000 E-01 \\
5.00000 E-01 \\
5.00000 E-01 \\
5.00000 E-01 \\
5.00000 E-01 \\
5.00000 E-01 \\
5.00000 E-01 \\
5.00000 E-01 \\
5.00000 E-01 \\
5.00000 E-01 \\
5.00000 E-01 \\
5.00000 E-01 \\
5.00000 E-01\end{array}$ & 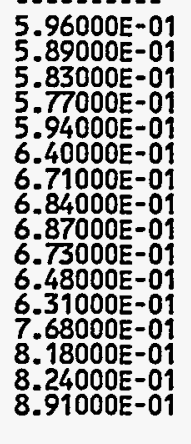 & $\begin{array}{l}8.46000 \mathrm{E}-01 \\
8.73000 \mathrm{E}-01 \\
9.15000 \mathrm{E}-01 \\
9.72000 \mathrm{E}-01 \\
1.14000 \mathrm{0}+00 \\
1.44000 \mathrm{E}+00 \\
1.63000 \mathrm{E}+00 \\
1.750000 \mathrm{0}+00 \\
1.84000 \mathrm{E}+00 \\
1.88000 \mathrm{E}+00 \\
1.89000 \mathrm{E}+00 \\
1.95000 \mathrm{E}+00 \\
2.65000 \mathrm{E}+00 \\
2.97000 \mathrm{E}+00 \\
3.05000 \mathrm{E}+00 \\
3.52000 \mathrm{E}+00\end{array}$ & $\begin{array}{l}1.28000 \mathrm{E}+00 \\
1.50000 \mathrm{E}+00 \\
1.80000 \mathrm{E}+00 \\
2.17000 \mathrm{E}+00 \\
2.99000 \mathrm{E}+00 \\
4.46000 \mathrm{E}+00 \\
5.38000 \mathrm{E}+00 \\
6.02000 \mathrm{E}+00 \\
6.57000 \mathrm{E}+00 \\
6.95000 \mathrm{E}+00 \\
7.12000 \mathrm{E}+00 \\
7.48000 \mathrm{E}+00 \\
1.03000 \mathrm{E}+01 \\
1.16000 \mathrm{E}+01 \\
1.19000 \mathrm{E}+01\end{array}$ & $\begin{array}{l}30 E+00 \\
0 E+00 \\
0 E+00 \\
0 E+00 \\
0 E+00 \\
0 E+01 \\
0 E+01 \\
0 E+01 \\
0 E+01 \\
0 E+01 \\
0 E+01 \\
0 E+01 \\
0 E+01 \\
0 E+01 \\
0 E+01 \\
0 E+01\end{array}$ & $\begin{array}{l}O E+00 \\
O E+0 D \\
O E+01 \\
O E+01 \\
O E+01 \\
O E+01 \\
O E+01 \\
O E+01 \\
O E+01 \\
O E+02 \\
O E+02 \\
O E+02 \\
O E+02 \\
O E+02 \\
O E+02 \\
O E+02\end{array}$ \\
\hline
\end{tabular}

Figure F17.6.21 Example of biasing data

\section{F17.6.20 PICTURE OR PLOT REPRESENTATION}

Printer plots representing 2-D slices through the geometrical description of the problem are optional. They are created if picture or plot data are entered as specified in Sect. F17.4.11 unless PLT=NO is specified either in the plot data or the parameter data (Sect. F17.4.3). A sample picture and its associated data are shown in Figs. F17.6.22 and F17.6.23.

Figure F17.6.22 summarizes the data used to generate the picture or plot. Figure F17.6.23 is an example of a printer plot of the 2-D slice specified through the geometrical description of the problem.

In Fig. F17.6.22, the plot title is printed at the top of the page. If a plot title was not entered in the plot data, the plot title is defaulted to the problem title. The title is followed by a heading that specifies the type of picture (MIXTURE MAP, BIAS ID MAP or UNIT MAP). This heading is followed by a table that correlates the symbols to be used in the printer plot with the mixture numbers, bias ID numbers or unit numbers that were used in the problem. The coordinates of the upper-left comer and lower-right corner of the picture are then printed. This is followed by the direction cosines down and across the page. NU is the number of characters printed in the " $U$ " direction, NV is the number of characters printed in the "V" direction, DELU is the incremental distance, in cm, represented by each character in the " $U$ " direction, and DELV is the incremental distance, in $\mathrm{cm}$, represented by each character in the "V" direction.

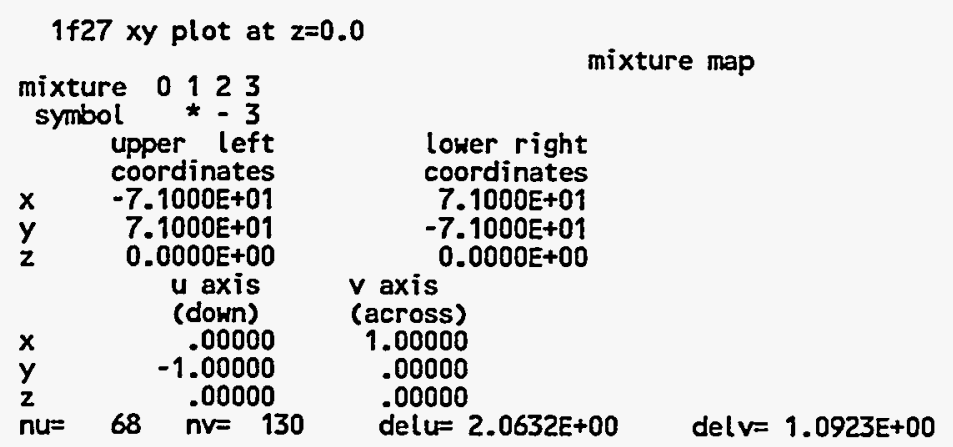

Figure F17.6.22 Summary of picture symbols and coordinates

F17.6.23

NUREG/CR-0200, Vol. 2, Rev. 5 
Figure F17.6.23 shows a printer plot of a 2-D slice specified through the geometrical description of the problem. These plots aid the user in verifying that the problem is described correctly. Any number of plots can be made.

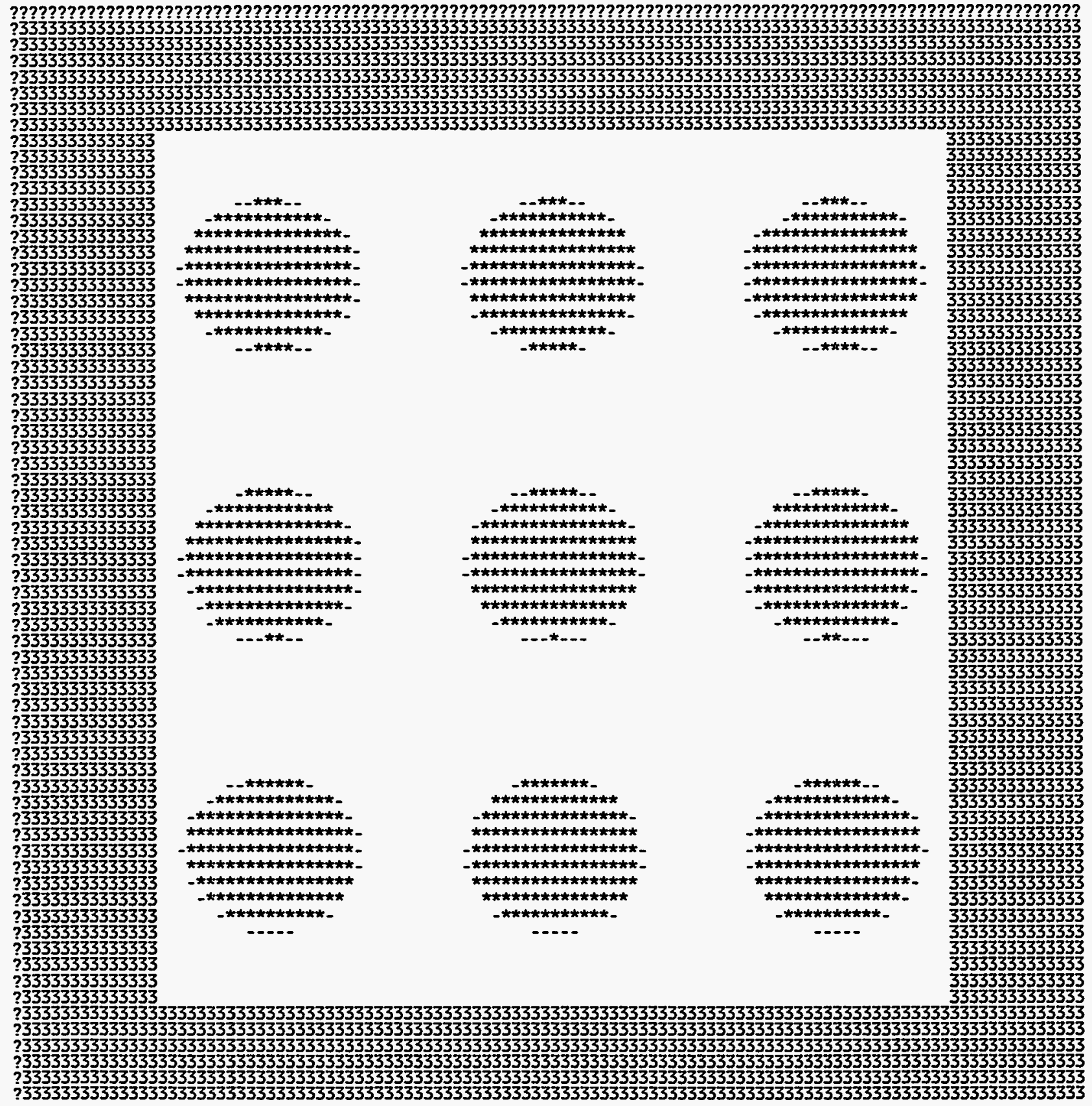

Figure F17.6.23 Sample plot representation

NUREG/CR-0200, Vol. 2, Rev. 5

F17.6.24 


\section{F17.6.21 CONCLUDE PRETRACKING EDITS}

Prior to calculating the k-effectives for each generation, KENO-VI prints a final edit as shown in Fig. F17.6.24.

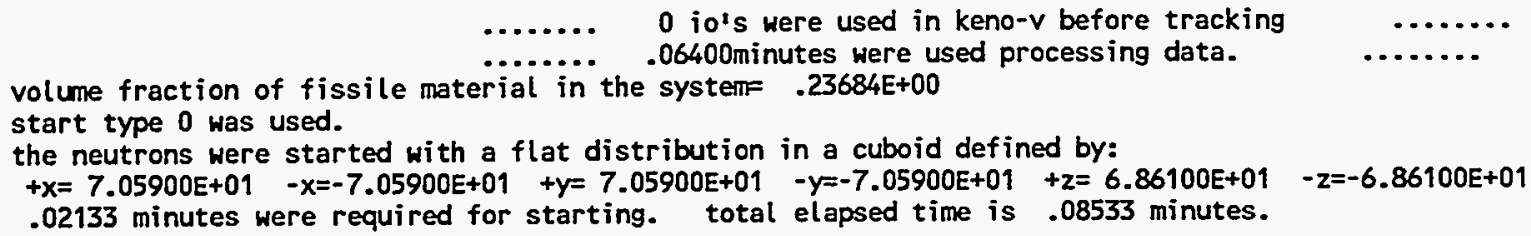

Figure F17.6.24 Pretracking edits

The information printed in this edit includes the number of I/Os used prior to tracking, the time in minutes used for preparing and processing the data prior to preparing the initial source distribution, and the volume fraction of fissile material in the system. The volume fraction of fissile material in the core is currently. meaningless. Future plans for KENO-VI include the ability to calculate volumes and volume fractions. If $\mathrm{RFL}=\mathrm{NO}$ (Sect. F17.4.8) was specified in the start data, the volume fraction message is changed to: VOLUME FRACTION OF FISSILE MATERIAL IN THE CORE $=$.

Most of the remaining data printed in this edit are related to the choice of the initial neutron source distribution. Once the initial source distribution has been prepared, the time required for preparing them (starting) is printed, as well as the total cumulative time used by the code. Start type 0 , which generates a flat, random distribution over all fissile material in the problem, is the default source distribution.

\section{F17.6.22 PRINT STARTING POINTS}

This printout is optional and is used to verify the initial source starting points. An example of this information is given in Fig. F17.6.25.

The information pertinent to the initial source distribution is printed two lines at a time and appears under the designated headings. For example, the coordinates $\mathrm{X}, \mathrm{Y}$, and $\mathrm{Z}$ are printed on one line and the direction cosines $U, V$, and $W$ are printed directly under them. The data printed for each source neutron include the following:

NEUTRON is the ID number of the neutron.

$X, Y$, and $Z$ are the coordinates of the starting point relative to the coordinate system of the unit.

WT is the current weight (WT is always 1.0 for a neutron when it is started).

$\mathrm{K}$ is the region number that contains the point $\mathrm{X}, \mathrm{Y}, \mathrm{Z}$.

NBX, NBY, NBZ are the coordinates of the unit within the array. 


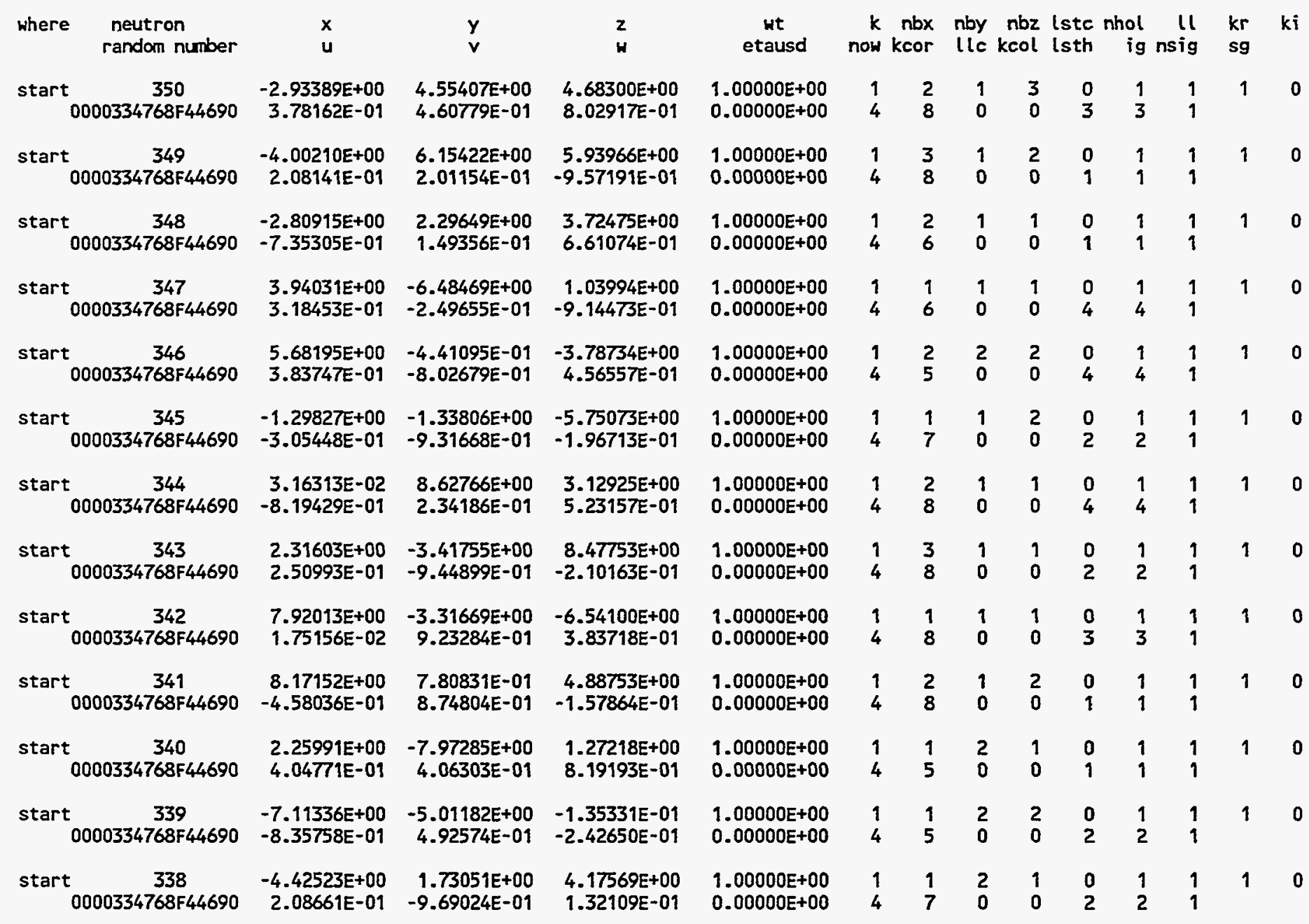

Figure F17.6.25 Example of initial source points

LSTC is the last unit where the neutron resided

NHOL is the hole where the neutron currently resides.

LL is the unit or box type number.

$\mathrm{KR}$ is the mixture number present at the starting point.

$\mathrm{KI}$ is the bias $\mathrm{ID}$ number at the point.

\section{NUREG/CR-0200,}

Vol. 2, Rev. 5

F17.6.26 
RANDOMNUMBER is the current random number.

$\mathrm{U}, \mathrm{V}$, and $\mathrm{W}$ are the direction cosines defining the direction the history is traveling.

ETAUSD is the amount of the distance to collision already traversed.

NOW is the array where the neutron currently resides.

KCOR is the core boundary region of the array where the neutron currently resides.

LLC is the unit surrounding the array the unit is in.

$\mathrm{KCOL}$ is the region number in which the last collision occurred.

IG is the energy group.

NSIG is the position of the group IG in the supergroup.

$\mathrm{SG}$ is the supergroup number.

When starting points are printed, many of the above named variables have not been initialized. For starting, the variables of interest are $X, Y, Z, U, V, W, N B X, N B Y, N B Z$, and LL.

\section{F17.6.23 K-EFFECTIVES BY GENERATION}

At the completion of each generation, KENO-VI prints the k-effective for that generation and associated information. An example of this printout is given in Fig. F17.6.26.

The k-effectives for each generation are printed in subroutine FISFLX. The headings are printed by subroutine GUIDE. The problem title is printed at the top of the page. A descriptive heading is printed at the top of each column of data. The data that are printed include (1) the generation number, (2) the k-effective calculated for the generation, (3) the elapsed CPU time in minutes, (4) the average value of $k$-effective through the current generation (excluding the nskip- $I$ generations), (5) the deviation associated with the average k-effective, (6) the matrix k-effective for the generation, and (7) the deviation associated with the matrix k-effective. The last two columns are filled with zeros if the user did not specify matrix $k$-effective calculations. The matrix $k$-effective is the largest eigenvalue of the fission production matrix. Matrix information can be calculated based on (1) position index, (2) unit number, (3) hole number, and (4) array number. The matrix k-effective printed in the sixth column is based on this order. If the matrix $\mathrm{k}$-effective is calculated by position index, it is the one printed in the sixth column. The matrix k-effective by unit number is given second preference, followed by hole number and then array number.

After the last generation, a message is printed to indicate why execution was terminated. If matrix k-effectives were calculated, this information is followed by a message stating the method used to determine the matrix k-effectives printed under the heading "MATRIX K-EFFECTIVE," as shown in Fig. F17.6.26. 


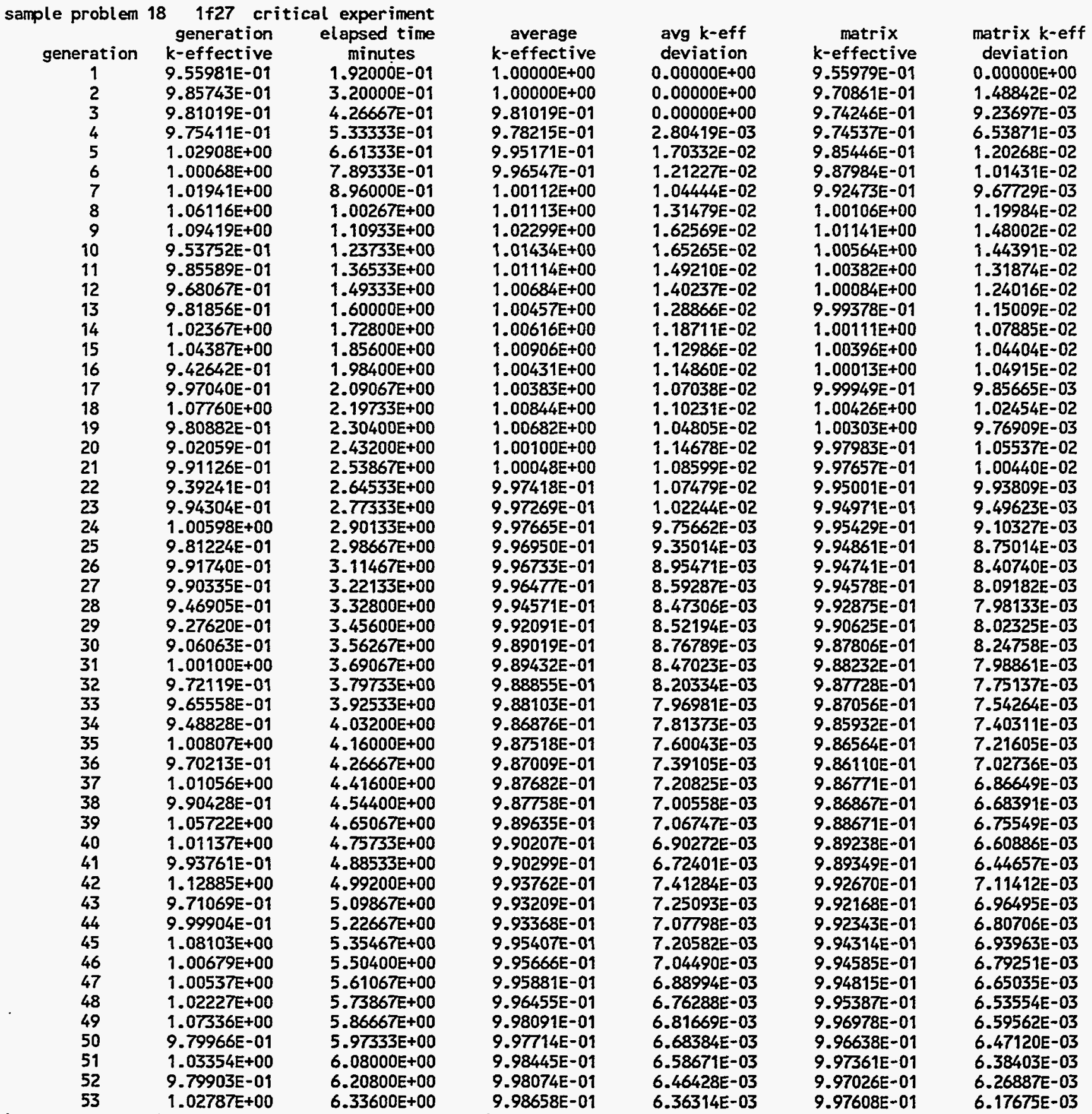

keno message number k6-123

execution terminated due to completion of the specified number of generations.

the matrix $k$-effective is the largest eigenvalue of the fission production by unit number matrix.

Figure F17.6.26 Example of k-effectives by generation

NUREG/CR-0200,

Vol. 2, Rev. 5

F17.6.28 
The user should examine this portion of the printed results to ensure that the two methods of calculating k-effective are in acceptable agreement and to verify that the average value of $k$-effective has become relatively stable. If the k-effectives appear to be oscillating or drifting significantly, the user should consider rerunning the problem with a larger number of histories per generation.

If a problem is restarted, the generation numbers and $k$-effectives are printed and the words FROM RESTART UNIT are printed in the elapsed time column. All other columns are blank. When the generation at which the problem is to be restarted is reached, the print reverts to the normal format as shown in Fig. F17.6.26.

\section{F17.6.24 FINAL K-EFFECTIVE EDIT}

The final edit of the k-effectives is printed by subroutine KEDIT following the k-effectives by generation. The title is printed at the top of the page, followed by the lifetime and the generation time and their associated deviations. The lifetime and generation time calculated by KENO-VI are not kinetics parameters. The lifetime is the average lifespan of a neutron (in seconds) from the time it is born until it is absorbed or leaks from the system. The generation time is the average time (in seconds) between successive neutron generations. If NUB=YES is specified in the parameter data, (Sect. F17.4.3) the average number of neutrons per fission, NU BAR and its associated deviation are printed and the AVERAGE FISSION GROUP (the average energy group at which fission occurs) and its associated deviation are printed. If SMU=YES is specified in the parameter data, the average self-multiplication of a unit and its associated deviation is printed. This self-multiplication results from fissions caused by neutrons born in the unit. Fissions caused by neutrons that exit the unit and return are not included. Then the final k-effective edit is printed as shown in Fig. F17.6.27.

The final k-effective edit prints the average k-effective and its associated deviation and the limits of $k$-effective for the 67,95 , and $99 \%$ confidence intervals. The number of histories used in calculating the average $\mathrm{k}$-effective is also printed. This is done skipping various numbers of generations. The user should carefully examine the final $\mathrm{k}$-effective edit to determine if the average $\mathrm{k}$-effective is relatively stable. If a noticeable drift is apparent as the number of initial generations skipped increases, it may indicate a problem in converging the source. If this appears to be the case, the problem should be rerun with a better initial source distribution and should be run for a sufficient number of generations that the average k-effective becomes stable.

\section{F17.6.25 PLOT OF AVERAGE K-EFFECTIVE BY GENERATION RUN}

This plot consists of average k-effectives plotted vs the number of generations run. The limits of 1 standard deviation are plotted on each side of each average k-effective. These average k-effectives are not necessarily the same as the average k-effectives described in Sect. F17.6.23. The code omits the k-effectives of the first nskip generations when the average k-effectives for this plot are calculated. Although the k-effective of the nskip +1 generation is summed into the average $\mathrm{k}$-effective, it is not plotted because standard deviations cannot be calculated for a single point. Thus if nskip is 3 (i.e., the first three generations are skipped), the first value plotted is the average $k$-effective corresponding to the fifth generation run. The dotted line represents the value of the average $k$-effective corresponding to the smallest deviation when the average $k$-effective and its deviation are computed for each generation over the range of nskip +2 through the total number of generations. Figure F17.6.28 is an example of this type of plot. The primary use for this plot is to determine if the problem has source convergence difficulties. 
lifetime $=1.38892 E-04+$ or $-2.38902 E-05$ nu bar $=2.45311 \mathrm{E}+00+$ or $-4.42297 \mathrm{E}-05$ no. of initial

generations

skipped

average
-effective

$\begin{array}{lll}3 & .99901+\text { or }-.00648 \\ 4 & .99949+\text { or }-.00660 \\ 5 & .99888+\text { or }-.00671 \\ 6 & .99884+\text { or }-.00685 \\ 7 & .99839+\text { or }-.00699 \\ 8 & .99700+\text { or }-.00700 \\ 9 & .99479+\text { or }-.00679 \\ 10 & .99574+\text { or }-.00689 \\ 11 & .99598+\text { or }-.00705 \\ 12 & .99666+\text { or }-.00719 \\ 17 & .99650+\text { or }-.00790 \\ 22 & .99946+\text { or }-.00799 \\ 27 & 1.00076+\text { or }-.00950 \\ 32 & 1.01266+\text { or }-.00947 \\ 37 & 1.02267+\text { or }-.01080 \\ 42 & 1.01646+\text { or }-.01091 \\ 47 & 1.01948+\text { or }-.01450\end{array}$

sample problem $18 \quad 1$ f27 critical experiment generation time $=3.91864 E-05+$ or $-8.51522 E-07$ average fission group $=1.45973 \mathrm{E}+01+$ or $-6.94393 \mathrm{E}-03$

67 per cent

confidence interval .99253 to 1.00549 .99290 to 1.00609 .99217 to 1.00558 .99199 to 1.00569 .99140 to 1.00538 .99000 to 1.00400 98799 to 1.00158 .98886 to 1.00263 98894 to 1.00303 98948 to 1.00385 .98860 to 1.00440 99147 to 1.00744 99125 to 1.01026 1.00319 to 1.02214 1.01187 to 1.03347 1.00556 to 1.02737 1.00499 to 1.03398
95 per cent confidence interval .98605 to 1.01197 .98630 to 1.01269 .98546 to 1.01229 .98514 to 1.01254 .98442 to 1.01236 .98300 to 1.01099 .98120 to 1.00838 98197 to 1.00951 .98189 to 1.01008 .98229 to 1.01104 .98071 to 1.01230 .98349 to 1.01543 .98175 to 1.01976 .99371 to 1.03161 1.00108 to 1.04426 .99465 to 1.03827 .99049 to 1.04848
99 per cent (per cent) .97970 to 1.01928 97876 to 1.01900 .97829 to 1.01939 .97743 to 1.01935 97600 to 1.01799 97440 to 1.01517 .97508 to 1.01640 .97484 to 1.01712 .97510 to 1.01823 .97281 to 1.02020 .97550 to 1.02341 .97224 to 1.02927 .98424 to 1.04109 .99028 to 1.05506 .98375 to 1.04918 .97599 to 1.06298 number of variance

$\begin{array}{lr}17500 & \text { (per cent) } \\ 17150.2217\end{array}$

$\begin{array}{ll}17150 & 23.2287 \\ 16800 & 23.5308\end{array}$

$16800 \quad 23.5308$

16450

16100

15750

15400

15050

14700

14350

12600

10850

9100

7350

5600

3850

2100

23.4550

23.5944 24.8216 26.6241 26.9694 26.8762 26.9732 28.9327 34.3414 33.7045 38.8785 42.2001 40.1501
56.3393

Figure F17.6.27 Example of the final k-effective edit 


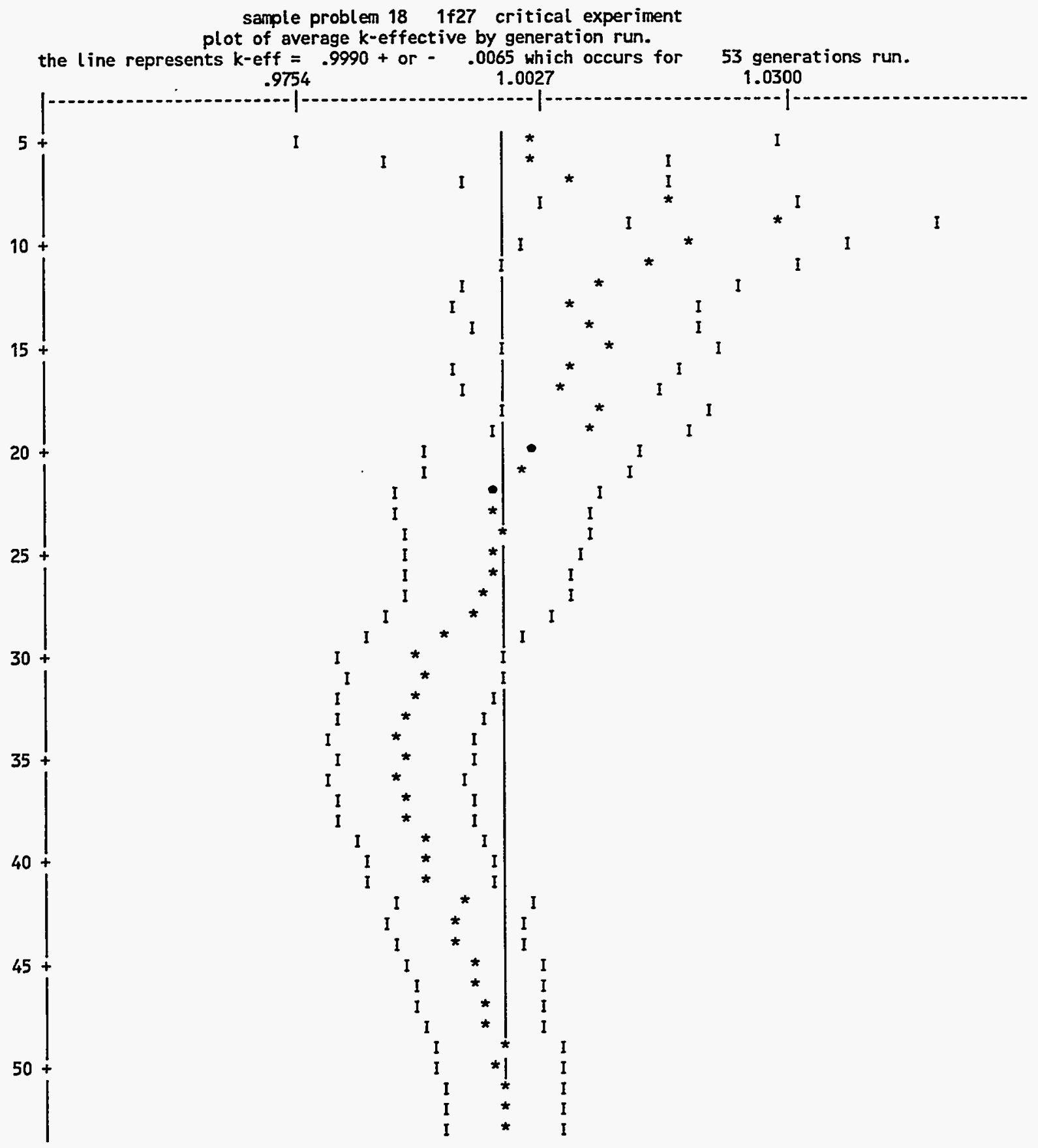

Figure F17.6.28 Sample plot of average k-effective by generation run 


\section{F17.6.26 PLOT OF AVERAGE K-EFFECTIVE BY GENERATION SKIPPED}

This plot illustrates the average k-effective vs the number of generations skipped, as shown in Fig. F17.6.29. The limits of 1 standard deviation are plotted on either side of the average k-effective. The dotted line represents the value of the average $k$-effective corresponding to the smallest deviation. The average $\mathrm{k}_{\mathrm{eff}}$ and the minimum standard deviation $(\sigma)$ of the system are listed at the top of the plot. These are determined by computing an average $k_{\text {eff }}$ and $\sigma$ for each number of generations skipped over the range of nskip +1 to $n g e n-2$. The average $k_{e f f}$ and $\sigma$ for a given number of generations skipped is calculated by batching the generation $k_{e f f} s$ differently and keeping the largest $\sigma$ calculated. The plot is essentially a plot of the data described in Sect. F17.6.24 plotted over the range of nskip +1 to ngen -2 , where ngen is the number of generations run. It is useful for determining if source convergence has been achieved.

\section{F17.6.27 FINAL EDIT OF FISSIONS, ABSORPTIONS, AND LEAKAGE}

This table is printed by subroutine KEDIT after the final k-effective edit. It prints the fission fraction for each group and the fission production, absorptions, and leakage with their associated percent deviation. If FAR =YES is specified in the parameter data, the fission production and absorptions and their percent deviation are also printed for each geometry region utilized in the problem. The FISSIONS, ABSORPTIONS, and LEAKAGE are given in units of neutrons per source neutron. Examples of the final edits of fissions, absorptions, and leakage are shown in Figs. F17.6.30 and F17.6.31.

If $F A R=N O$ is specified, region-dependent fissions and absorptions are not printed. Figure F17.6.30 demonstrates the printout if $F A R=N O$.

IfFAR $=$ YES is specified in the parameter data, the fissions, and absorptions for each geometry region are printed for each energy group as shown in Fig. F17.6.31. Leakage is not collected by geometry region but rather represents the leakage from the system. In both figures, GROUP is the energy group number, FISSION FRACTION is the fraction of the fissions that occur in that energy group. The percentage deviation for the fission fraction is the same as that of the fissions in the same group. The heading UNIT refers to the unit and REGION to the region number within the specified unit. The geometry regions are numbered sequentially within each unit, starting with 1 . The sum of the fissions for every region for a given energy group is the total printed for that energy group. The same is true of absorptions. The fissions, absorptions, and leakages are given in units of "per source neutron." The SYSTEM TOTAL is the sum, over all the energy groups, of the fissions, absorptions and leakage. The associated percentage deviation is printed for each.

The sum of the leakage and absorptions printed for the system total should be close to 1 . The fissions printed for the system total should be the same as the first k-effective printed in the final k-effective edit described in Sect. F17.6.24. If differential albedos are used, the leakage does not include the weight lost in the albedo reflection. A message stating the weight lost in the albedo is printed. This weight loss is due to absorptions in the albedo reflector and leakage from the albedo reflector. No leakage is associated with faces having specular, mirror image, or periodic reflection. Thus there is no leakage associated with an infinite problem. The total elapsed time and final random number are printed at the end of this edit.

\section{F17.6.28 MATRIX K-EFFECTIVE BY UNIT LOCATION}

The matrix k-effective by unit location (also referred to as array position or position index) is calculated if MKP=YES is specified in the parameter data (Sect. F17.4.3). It is the largest eigenvalue of the fission production matrix, collected by position index. The position index is a number referencing a position in a 3-D lattice. An example of the matrix k-effective by unit locations is given in Fig. F17.6.32. It is contained within two rows of asterisks to draw attention to it.

NUREG/CR-0200,

Vol. 2, Rev. 5

F17.6.32 


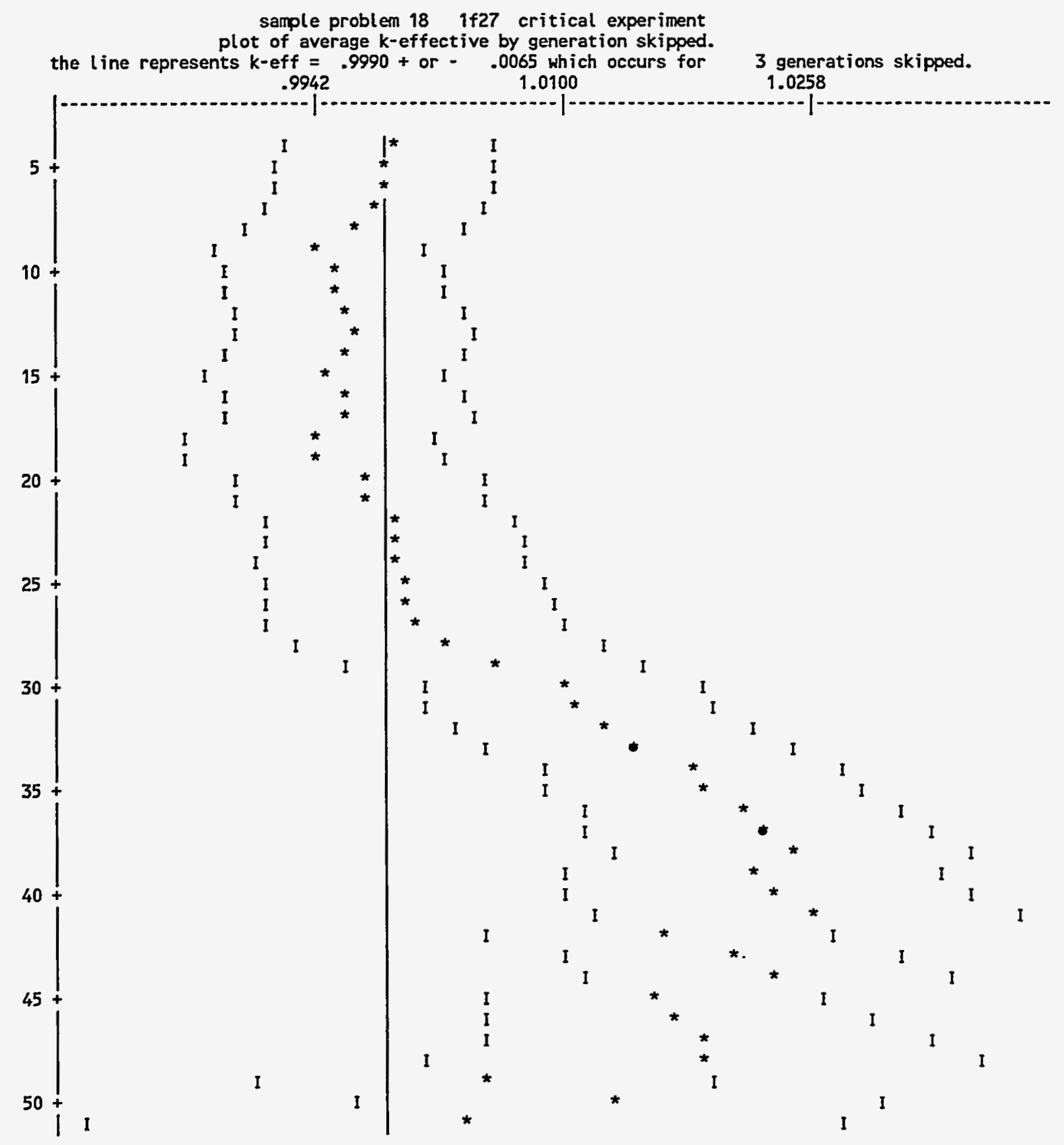

Figure F17.6.29 Sample plot of average k-effective by generation skipped

F17.6.33

NUREG/CR-0200,

Vol. 2, Rev. 5 
kenovi sample problem 2 case $2 c 8$ bare with 8 unit types matrix cal

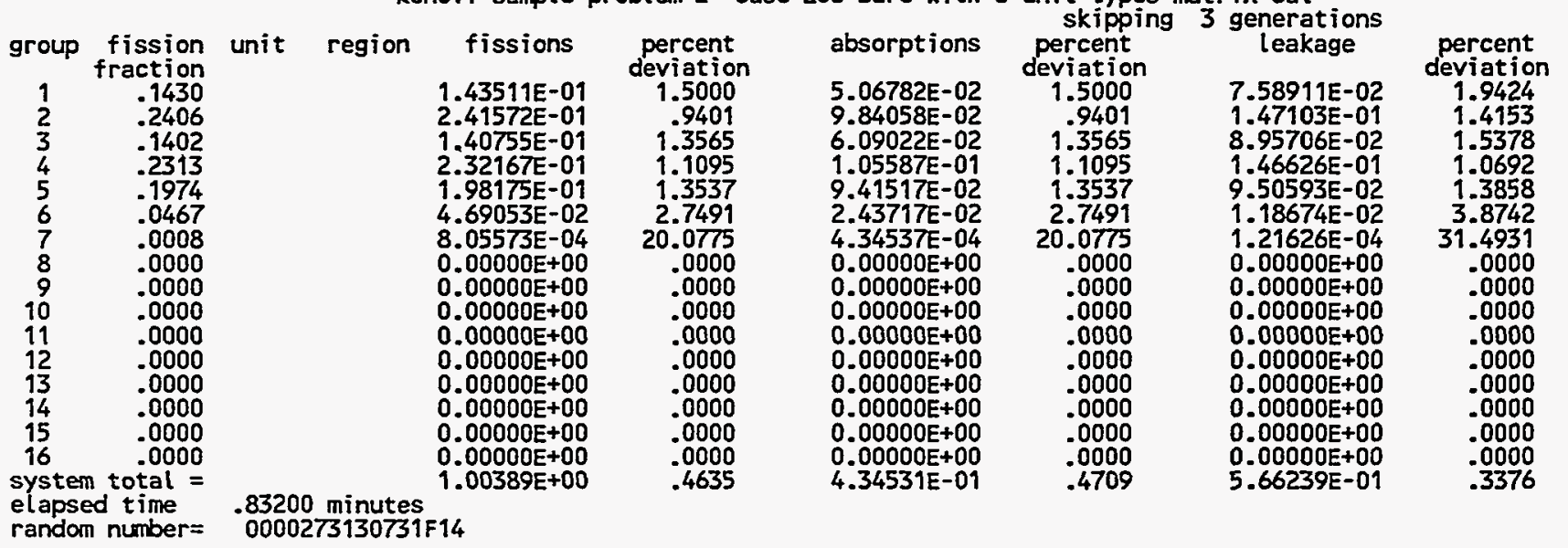

Figure F17.6.30 Sample of the final edit of fissions, absorptions, and leakage with region-dependent information suppressed

sample problem $18 \quad 1$ f27 critical experiment

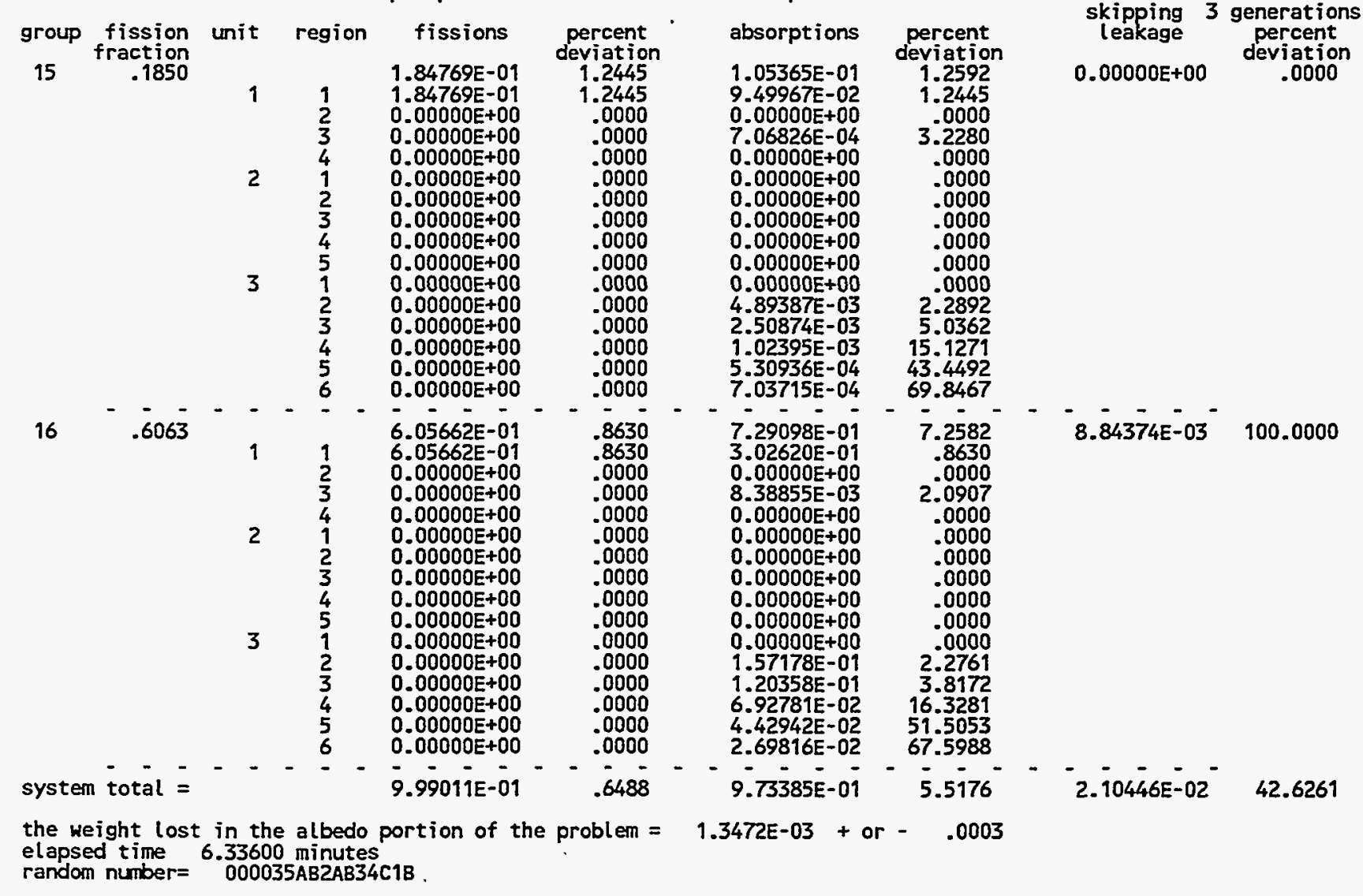

Figure F17.6.31 Sample of the final edit of fissions, absorptions, and leakage by region

NUREG/CR-0200,

Vol. 2, Rev. 5

F17.6.34 
kenovi sample problem 2 case $2 c 8$ bare with 8 unit types matrix cal

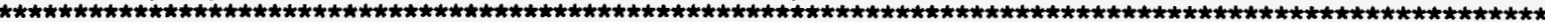

position k-effective $=1.00224 \mathrm{E}+00+$ or $-7.92895 \mathrm{E}-03$

the position $k$-effective is the-largest eigenvalue of the fission production by position index matrix.

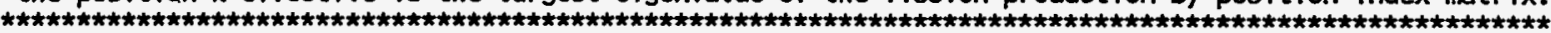

Figure F17.6.32 Example of matrix k-effective by unit location

\section{F17.6.29 FISSION PRODUCTION BY POSITION INDEX MATRIX}

To obtain this information, the user must specify MKP=YES and FMP=YES in the parameter data. It is then printed by subroutine MATRIX. The number of entries in the fission production matrix by position index is the array size +1 squared. Thus for a $2 \times 2 \times 2$ array there are 81 entries, and for a $4 \times 4 \times 4$ array there are 4225 entries in the fission production matrix by position index. The last position in the matrix contains information for all neutrons outside the array. An example of the fission production matrix by position index for a $2 \times 2 \times 2$ array is shown in Fig. F17.6.33.

The position index definition is given in Sect F17.6.31. For each position index in the array, the number of next-generation neutrons produced at position index $J$ per neutron born at position index $I$ is determined. The fission production matrix by position index is used to determine the matrix $k$-effective, cofactor $k$-effective, and source vector by position index.

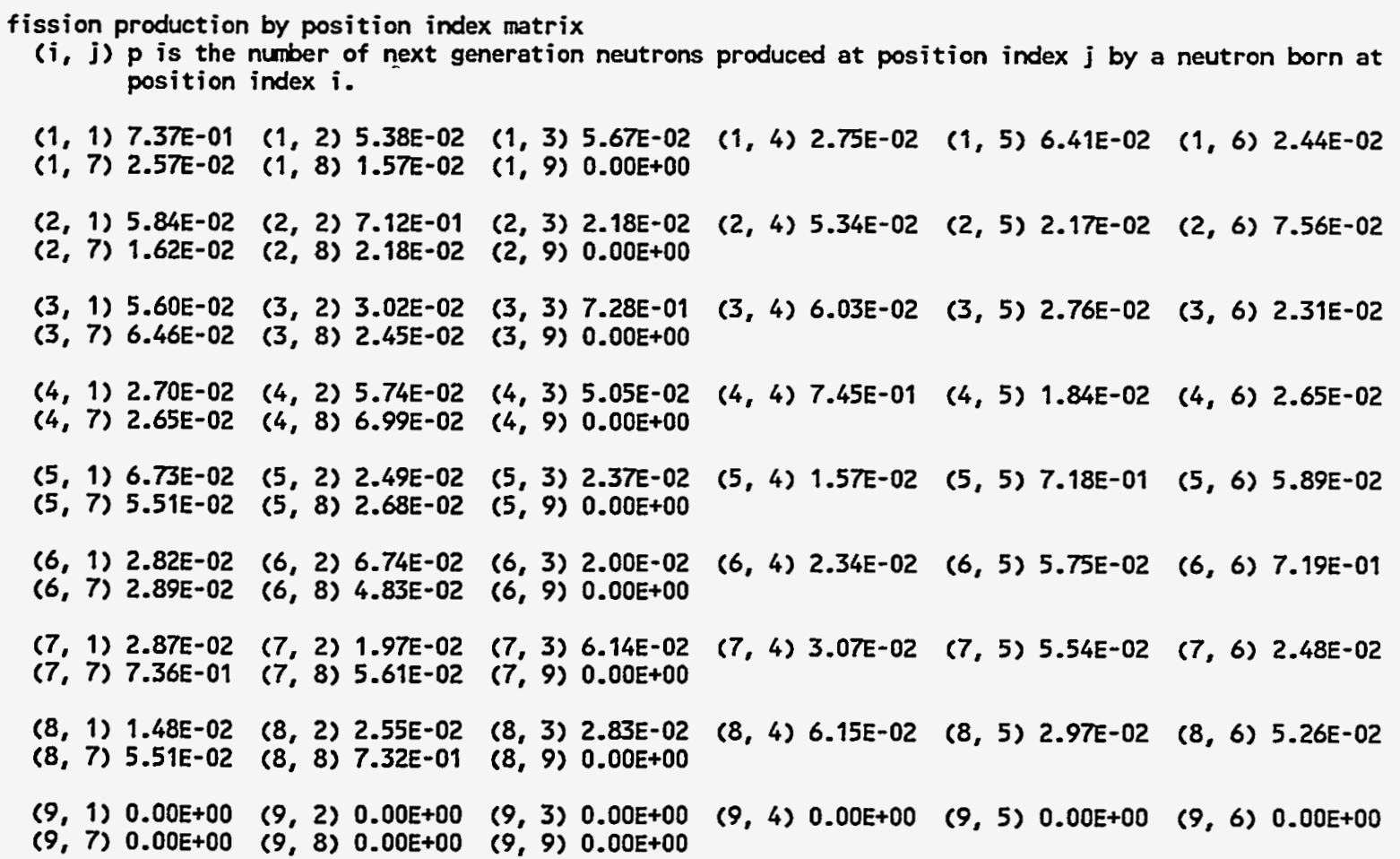

Figure F17.6.33 Sample fission production matrix by position index 


\section{F17.6.30 SOURCE VECTOR BY POSITION INDEX}

This information is printed by subroutine MATRIX only if MKP=YES is specified in the parameter data. The source vector by position index is the eigenvector of the fission production matrix by position index and should sum to 1.0. It represents the fission source for the specified locations in the three-dimensional (3-D) lattice representing the physical problem being analyzed. The position index is defined in Sect. F17.6.31. An example of the source vector by position index is shown in Fig. F17.6.34. The average self-multiplication by array position is the overall average of the self-multiplication of all units used in the problem.

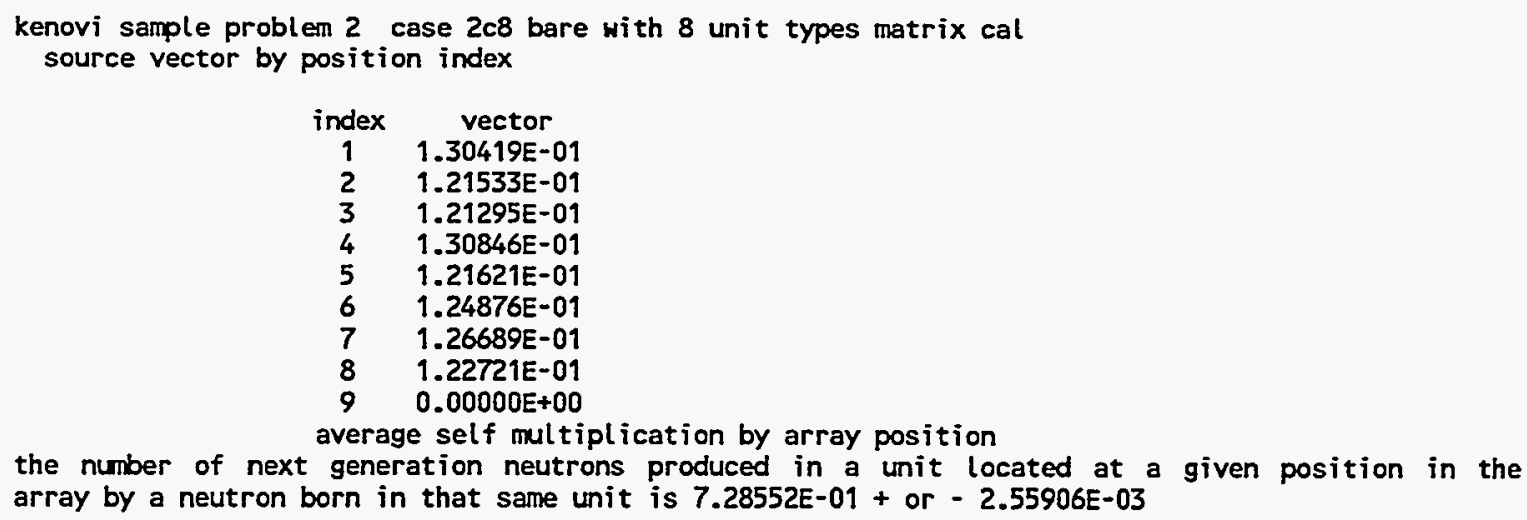

Figure F17.6.34 Example of source vector by position index

\section{F17.6.31 COFACTOR K-EFFECTIVE BY POSITION INDEX}

These data are printed by subroutine MATRIX only if MKP=YES is specified in the parameter data. This input means that the fission production matrix is collected by position index. Calculating and printing cofactor k-effectives by position index can be avoided by specifying $\mathrm{CKP}=\mathrm{NO}$ in the parameter data. An example of the cofactor k-effective by position index is shown in Fig. F17.6.35. See Appendix F17. D for a description of the problem used for the example.

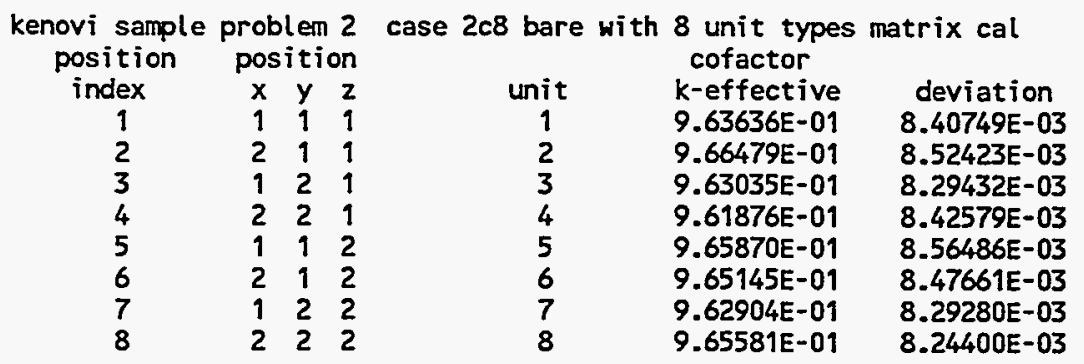

Figure F17.6.35 Example of cofactor k-effective by position index

NUREG/CR-0200,

Vol. 2, Rev. 5

F17.6.36 
The cofactor k-effective for a given position index is the largest eigenvalue of the fission production matrix collected by position index, reduced by the row and column associated with that position index. Thus the cofactor $k$-effective is the value of $k$-effective for the system calculated without the fission source of the unit located at the specified position index.

The POSITION INDEX is a number referencing a position in a three-dimensional (3-D) lattice. POSITION is the $x, y$, and $z$ location within the lattice. UNIT is the unit located at the specified location in the lattice. Thus in Fig. F17.6.35, Unit 1 is located at the lower left-hand front corner of the array or 3-D lattice representing the problem $(x=1, y=1, z=1)$ and the corresponding POSITION INDEX is 1 . POSITION INDEX 8 is the top right-hand back corner of the lattice, POSITION $x=2, y=2, z=2$ and the unit located at that position is UNIT 8.

\section{F17.6.32 MATRIX K-EFFECTIVE BY UNIT NUMBER}

The matrix k-effective by unit number (unit k-effective) is the largest eigenvalue of the fission production by unit matrix. It is calculated only if MKU=YES is specified in the parameter data (Sect. F17.4.3). An example of the matrix k-effective by unit is given in Fig. F17.6.36.

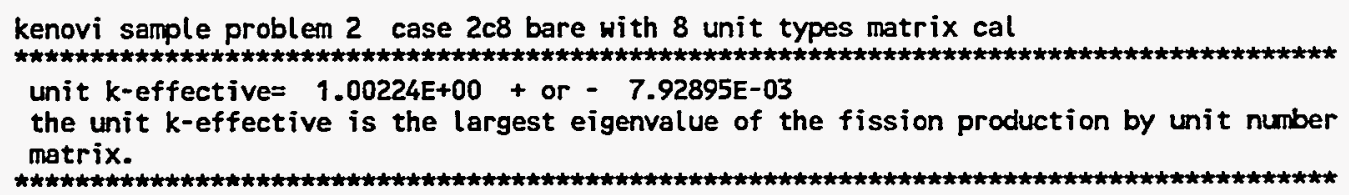

Figure F17.6.36 Example of matrix k-effective by unit number 


\section{F17.6.33 FISSION PRODUCTION BY UNIT NUMBER MATRIX}

These data are printed by subroutine MATRIX only if MKU=YES is specified in the parameter data, which results in the code calculating the fission production matrix by unit. Thus for each unit in the array, the number of next-generation neutrons produced in Unit J per neutron born in Unit $I$ is determined. This is the fission production matrix by unit, and it is used to determine the matrix k-effective by unit, the cofactor $k$-effective by unit, and the source vector by unit. An example of the fission production matrix by unit is shown in Fig. F17.6.37.

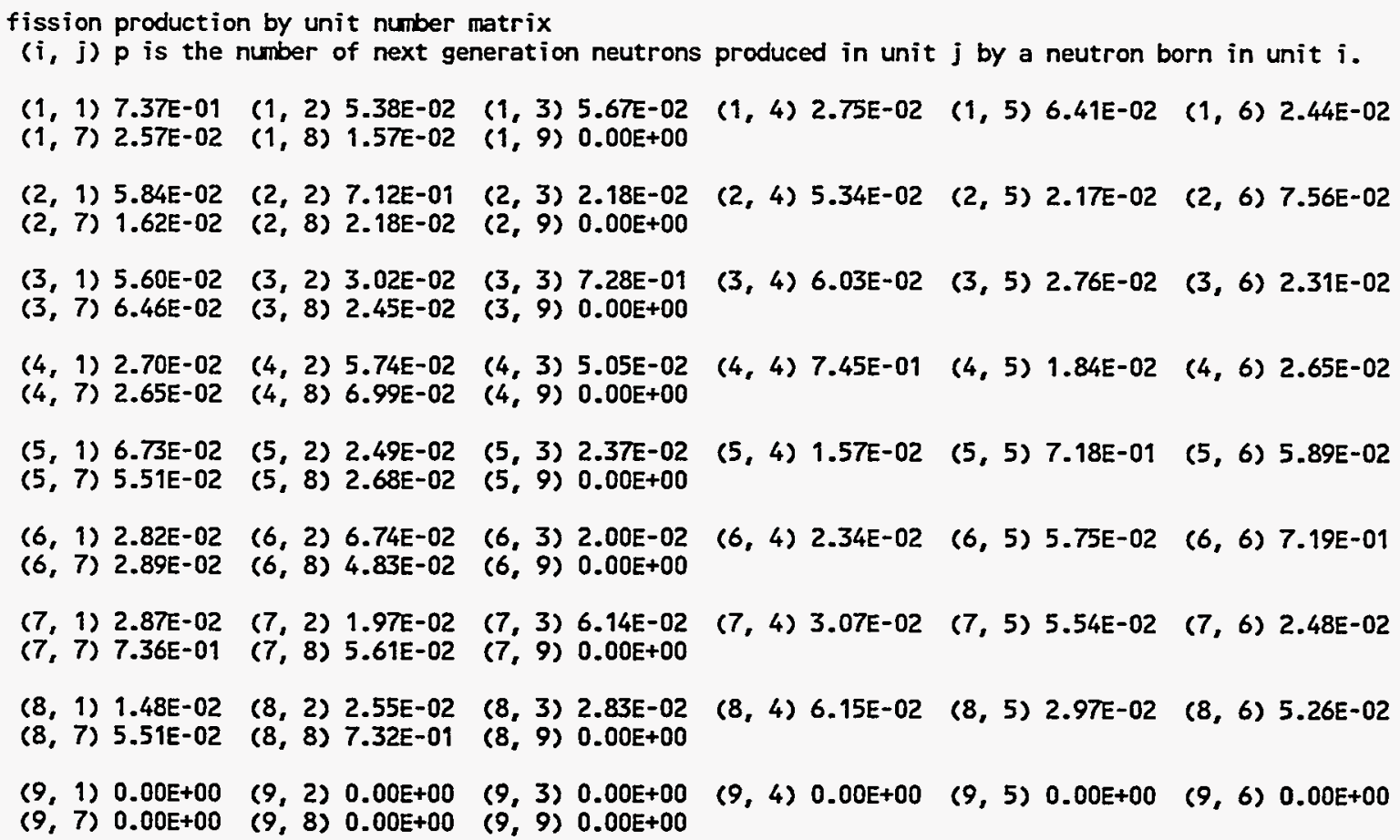

Figure F17.6.37 An example of the fission probability matrix by unit

\section{F17.6.34 SOURCE VECTOR BY UNIT NUMBER}

These data are printed by subroutine MATRIX only if MKU=YES is specified in the parameter data. The source vector by unit is the eigenvector of the fission production matrix by unit. It represents the fission source for the units used in the problem. The components of the source vector should sum to 1.0. An example of the source vector by unit is given in Fig. F17.6.38. The average self-multiplication by unit is printed following the source vector. This value of self-multiplication includes those histories born in the unit which cause fissions in the same unit regardless of whether or not it exited and then returned. Therefore, this value will not agree with the value printed for the self-multiplication of the unit in Sect. F17.6.24 if the problem utilizes multiple units, the system is reflected, or a differential albedo is used in the problem. 


\section{F17.6.35 COFACTOR K-EFFECTIVE BY UNIT NUMBER}

Cofactor k-effectives are printed by subroutine MATRIX only if MKU=YES is specified in the parameter data. Calculating and printing cofactor k-effectives by unit can be avoided by specifying $\mathrm{CKU}=\mathrm{NO}$ in the parameter data. The cofactor k-effective for a given unit is the k-effective of the system calculated without the fission source of that unit. This calculation is accomplished by determining the eigenvalue of the fission production matrix by unit after it has been reduced by the row and column associated with that unit. An example of the cofactor k-effective by unit is given in Fig. F17.6.39.

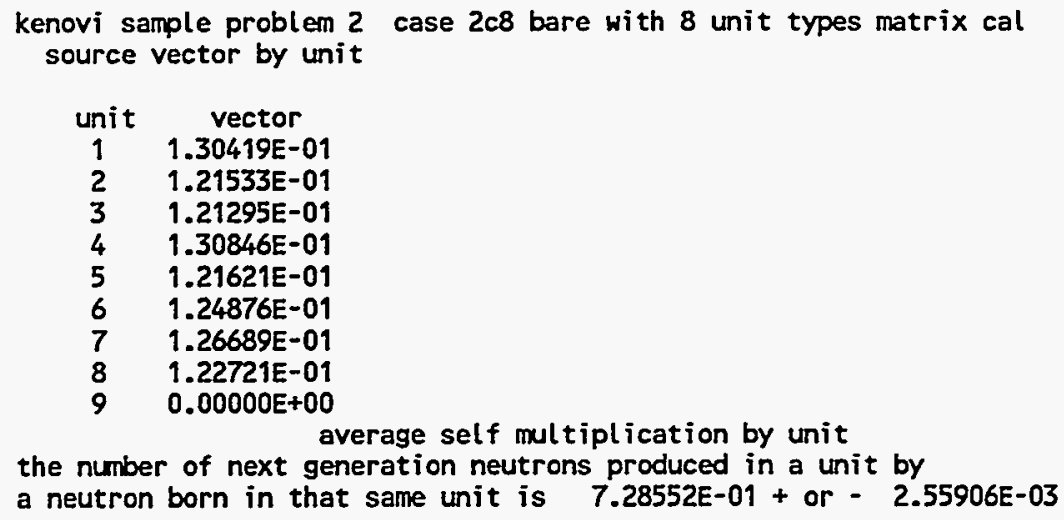

Figure F17.6.38 Example of the source vector by unit

\begin{tabular}{|c|c|c|c|}
\hline & $\begin{array}{c}\text { unit } \\
1 \\
2 \\
3 \\
4 \\
5 \\
6 \\
7 \\
8 \\
9\end{array}$ & $\begin{array}{c}\text { cofactor } \\
\text { k-effective } \\
9.63636 \mathrm{E}-01 \\
9.66479 \mathrm{E}-01 \\
9.63035 \mathrm{E}-01 \\
9.61876 \mathrm{E}-01 \\
9.65870 \mathrm{E}-01 \\
9.65145 \mathrm{E}-01 \\
9.62904 \mathrm{E}-01 \\
9.65581 \mathrm{E}-01 \\
1.00223 \mathrm{E}+00\end{array}$ & $\begin{array}{c}\text { deviation } \\
8.40749 E-03 \\
8.52423 E-03 \\
8.29432 E-03 \\
8.42579 E-03 \\
8.56486 E-03 \\
8.47661 E-03 \\
8.29280 E-03 \\
8.24400 E-03 \\
7.92840 E-03\end{array}$ \\
\hline
\end{tabular}

Figure F17.6.39 Example of cofactor k-effective by unit number

\section{F17.6.36 MATRIX K-EFFECTIVE BY HOLE NUMBER}

The matrix k-effective by hole number is calculated if MKH $=Y E S$ was specified in the parameter data, Sect. F17.4.3. It is the largest eigenvalue of the fission production matrix collected by hole number. An example of the matrix k-effective by hole number is given in Fig. F17.6.40. 


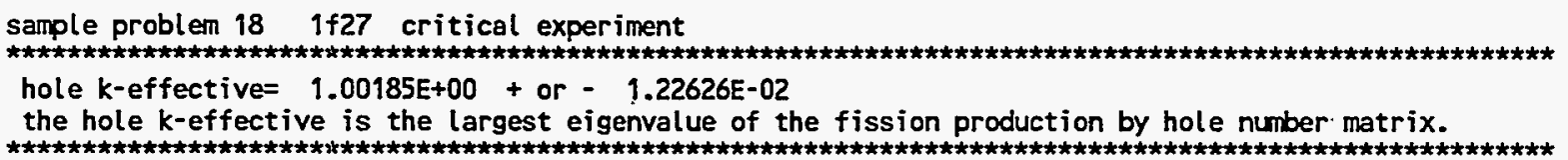

Figure F17.6.40 Example of matrix k-effective by hole number

\section{F17.6.37 FISSION PRODUCTION BY HOLE NUMBER MATRIX}

This fission production matrix is collected by hole number. It is printed only if MKH=YES and FMH=YES were specified in the parameter data, Sect. F17.4.3. An example of this fission production matrix is given in Fig. F17.6.41. This matrix indicates the number of next-generation neutrons produced in hole number $\mathrm{J}$ by a neutron born in hole number $\mathrm{I}$.

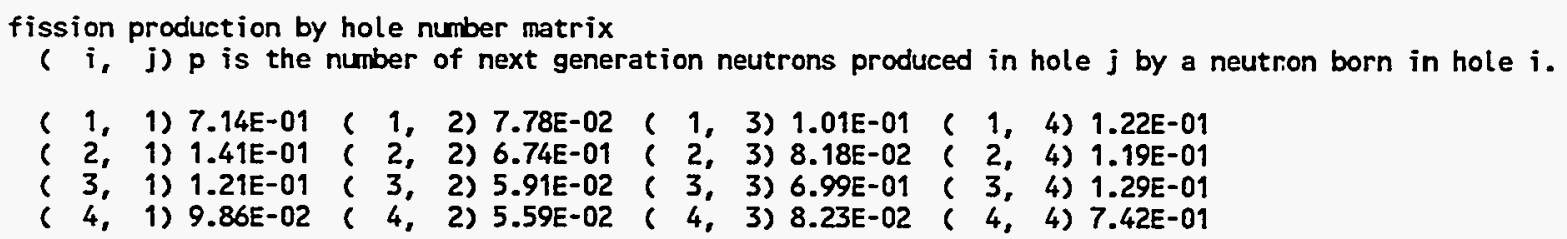

Figure F17.6.41 Example of fission production matrix by hole

\section{F17.6.38 SOURCE VECTOR BY HOLE NUMBER}

This information is printed by subroutine MATRIX only if MKH=YES is specified in the parameter data, Sect F17.4.3. The source vector by hole is the eigenvalue of the fission production matrix by hole number. The source vector should sum to 1.0. An example of the source vector by hole is shown in Fig. F17.6.42. The average self-multiplication by hole is the overall average of the self-multiplication of all the holes in the problem.

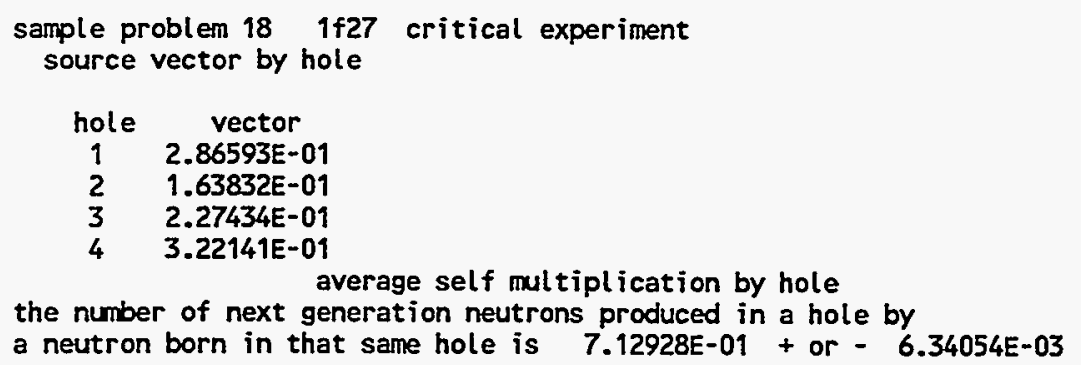

Figure F17.6.42 Example of source vector by hole number

NUREG/CR-0200,

Vol. 2, Rev. 5

F17.6.40 


\section{F17.6.39 COFACTOR K-EFFECTIVE BY HOLE NUMBER}

The cofactor k-effective by hole number is calculated if $\mathrm{CKH}=\mathrm{YES}$ is entered in the parameter data, Sect. F17.4.3. The cofactor $k$-effective for a given hole is the $k$-effective of the system calculated without the fission source of that hole. This calculation is done by determining the eigenvalue of the fission production matrix by hole after it has been reduced by the row and column associated with that hole. An example of the cofactor $k$-effective by hole number is given in Fig. F17.6.43.

\begin{tabular}{cccc}
\multicolumn{2}{c}{ sample problem 18} & $\begin{array}{c}1 \mathrm{f27} \text { critical experiment } \\
\text { cofactor } \\
\text { k-effective }\end{array}$ & $\begin{array}{c}\text { deviation } \\
\text { hole }\end{array}$ \\
$\begin{array}{ccc}\text { unit } \\
1\end{array}$ & 2 & $8.81048 \mathrm{E}-01$ & $1.45277 \mathrm{E}-02$ \\
2 & 3 & $9.34888 \mathrm{E}-01$ & $1.30223 \mathrm{E}-02$ \\
3 & 4 & $9.10727 \mathrm{E}-01$ & $1.26868 \mathrm{E}-02$ \\
4 & 5 & $8.89370 \mathrm{E}-01$ & $1.48242 \mathrm{E}-02$
\end{tabular}

Figure F17.6.43 Example of cofactor k-effective by hole number

\section{F17.6.40 MATRIX K-EFFECTIVE BY ARRAY NUMBER}

The matrix k-effective by array number is calculated if MKA=YES is entered in the parameter data, Sect. F17.4.3. It is the largest eigenvalue of the fission production matrix collected by array number. An example is given in Fig. F17.6.44. The number of next-generation neutrons produced in array number $\mathrm{J}$ by a neutron born in array number $I$ is given in this fission production matrix.

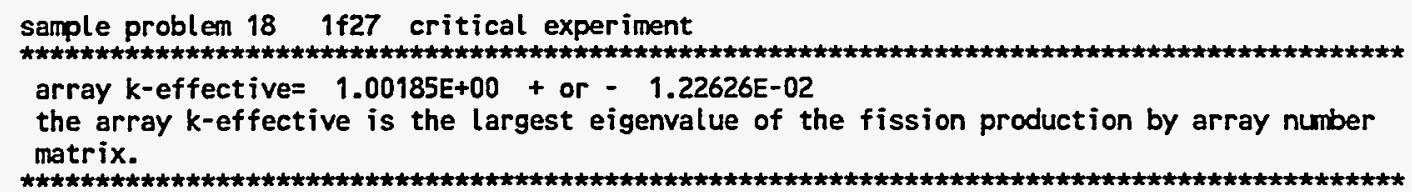

Figure F17.6.44 Example of matrix k-effective by array number

\section{F17.6.41 FISSION PRODUCTION BY ARRAY NUMBER MATRIX}

The fission production matrix collected by array number is shown in Fig. F17.6.45. It is printed only if MKA=YES and FMA=YES are specified in the parameter data (Sect. F17.4.3). 


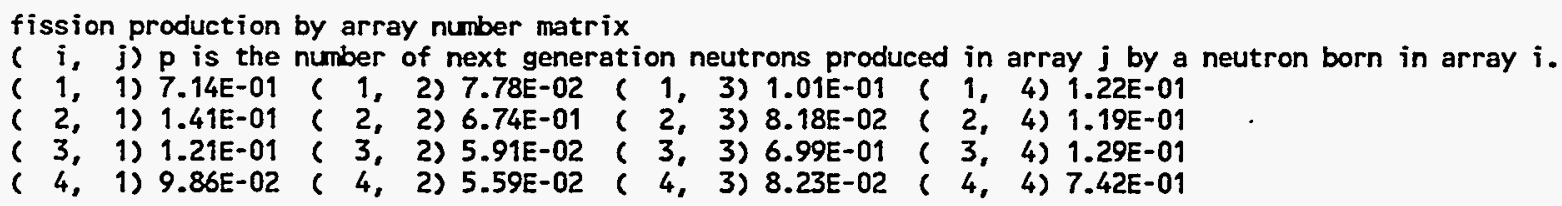

Figure F17.6.45 An example of the fission production matrix by array number

\section{F17.6.42 SOURCE VECTOR BY ARRAY NUMBER}

This information is printed by subroutine MATRIX only ifMKA=YES is specified in the parameter data (Sect. F17.4.3). The source vector by array number is the eigenvector of the fission production matrix by array number. The source vector should sum to 1.0. An example of the source vector by array number is shown in Fig. F17.6.46. The average self-multiplication by array number is the overall self-multiplication of all the arrays in the problem.

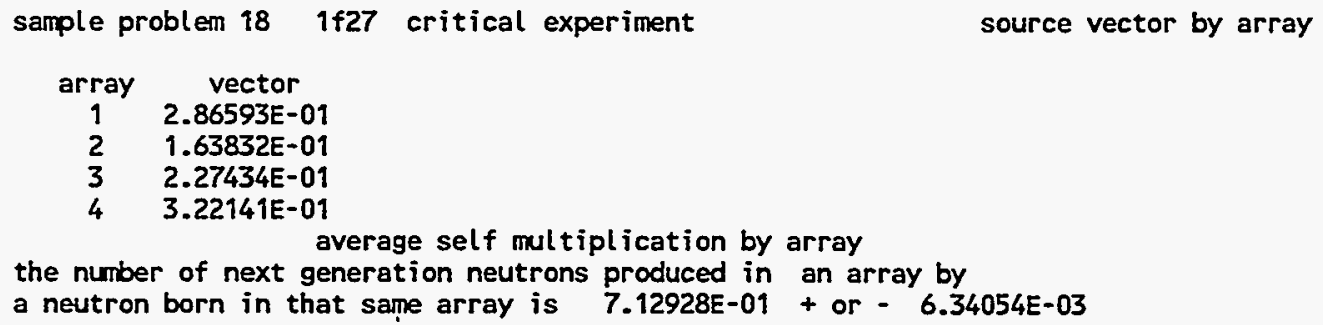

Figure F17.6.46 Example of source vector by array number

\section{F17.6.43 COFACTOR K-EFFECTIVE BY ARRAY NUMBER}

The cofactor $\mathrm{k}$-effective by array number is calculated if CKA=YES is entered in the parameter data (Sect F17.4.3). The cofactor k-effective for a given array is the k-effective of the system calculated without the fission source of that array. This calculation is achieved by determining the eigenvector of the fission production matrix by array after reducing it by the row and column associated with the specified array. Figure F17.6.47 is an example of the cofactor k-effective by array number.

$\begin{array}{cccc}\text { sample problem } 18 \quad 1 f 27 & \text { critical } \\ \text { array } & \begin{array}{c}\text { experiment } \\ \text { array } \\ \text { index }\end{array} & \begin{array}{c}\text { cofactor } \\ \text { number } \\ \text { k-effective }\end{array} & \begin{array}{c}\text { deviation } \\ 1\end{array} \\ 2 & 1 & 8.81048 E-01 & 1.45277 \mathrm{E}-02 \\ 3 & 2 & 9.34888 \mathrm{E}-01 & 1.30223 \mathrm{E}-02 \\ 4 & 3 & 9.10727 \mathrm{E}-01 & 1.26868 \mathrm{E}-02 \\ & 4 & 8.89370 \mathrm{E}-01 & 1.48242 \mathrm{EE}-02\end{array}$

Figure F17.6.47 Example of cofactor k-effective by array number

NUREG/CR-0200,

Vol. 2, Rev. 5

F17.6.42 


\section{F17.6.44 FISSION DENSITY EDIT}

The fission density edit is optional. Subroutine KEDIT prints the fission density for each geometry region if FDN=YES is specified in the parameter data. An example of the fission density edit is shown in Fig. F17.6.48.

The UNIT is the unit number from the geometry data, the REGION is the region number relative to the unit, the FISSION DENSITY is the fissions/(cc source-neutron) for that geometry region, the PERCENT DEVIATION is the uncertainty associated with the fission density, and the TOTAL FISSIONS is the total number of fissions per source neutron in the geometry region.

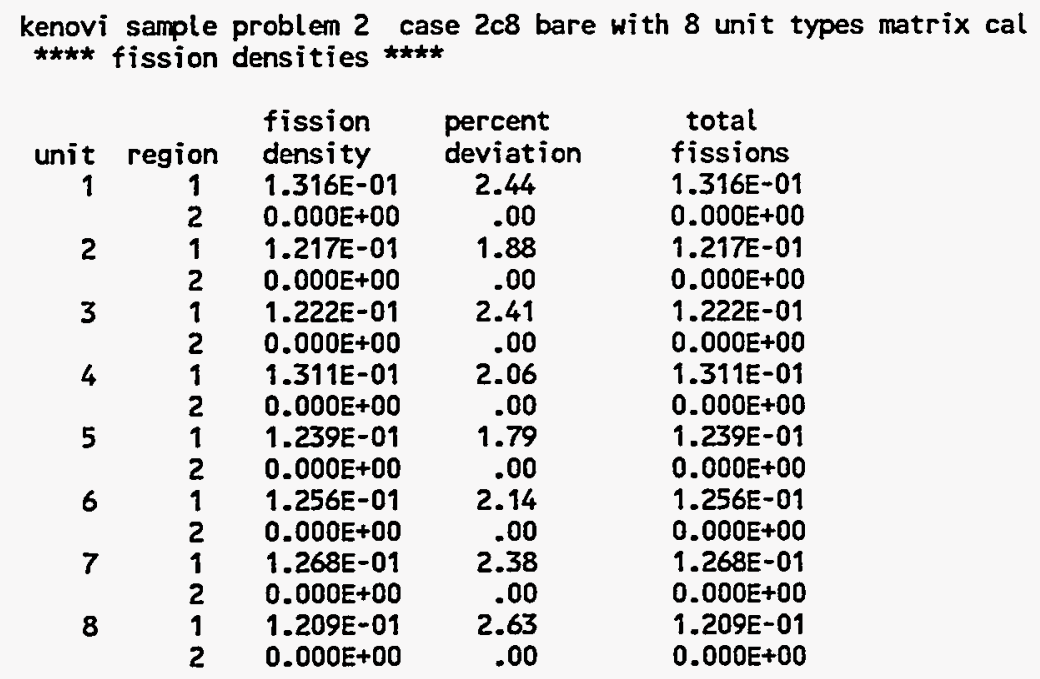

Figure F17.6.48 Example of the fission density edit

\section{F17.6.45 FLUX EDIT}

Printing the fluxes is optional. They are printed by subroutine PRTFLX only if FLX=YES is specified in the parameter data. The fluxes are printed for each unit and each geometry region in the unit for every energy group. A sample of a flux edit is given in Fig. F17.6.49. 


\begin{tabular}{|c|c|c|}
\hline X & $\begin{array}{l}\text { for unit } \\
\text { region } \\
\text { flux }\end{array}$ & $\begin{array}{c}1 \\
1 \\
\text { percent } \\
\text { deviation }\end{array}$ \\
\hline $\begin{array}{r}1 \\
2 \\
3 \\
4 \\
5 \\
6 \\
7 \\
8 \\
9 \\
10 \\
11 \\
12 \\
13 \\
14 \\
15\end{array}$ & $\begin{array}{l}4.591 \mathrm{E}-02 \\
8.954 \mathrm{E}-02 \\
4.254 \mathrm{E}-02 \\
5.984 \mathrm{E}-02 \\
5.898 \mathrm{E}-02 \\
4.006 \mathrm{E}-02 \\
3.146 \mathrm{E}-02 \\
2.766 \mathrm{E}-02 \\
2.543 \mathrm{E}-02 \\
1.659 \mathrm{E}-02 \\
1.421 \mathrm{E}-02 \\
1.416 \mathrm{E}-02 \\
1.272 \mathrm{E}-02 \\
9.517 \mathrm{E}-03 \\
1.821 \mathrm{E}-02 \\
3.013 \mathrm{E}-02\end{array}$ & $\frac{2}{2} \frac{2}{2}$ \\
\hline
\end{tabular}

sample problem 18

$\begin{array}{cc}\text { region } 2 \\ \text { flux } & \begin{array}{c}\text { percent } \\ \text { deviation }\end{array} \\ 3.484 \text { E- } 04 \quad 7.80\end{array}$

$\begin{array}{ll}3.484 E-04 & 7.80 \\ 6.445 E-04 & 7.34\end{array}$

$2.735 E-04 \quad 7.96$

4.034E-04 10.34

$3.564 \mathrm{E}-04 \quad 7.11$

$2.456 E-04 \quad 7.87$

2.252E-04 12.05

$1.745 E-04 \quad 10.03$

1.783E-04 9.70

$1.266 \mathrm{E}-04 \quad 9.97$

$9.449 \mathrm{E}-05 \quad 12.27$

$8.552 E-05 \quad 13.27$

$8.081 E-05 \quad 19.55$

6.425E-05 12.73

1.947E-04

7.287E-04
$1+27$

$\begin{array}{cccc}\begin{array}{c}\text { region } \\ \text { flux }\end{array} & \begin{array}{c}3 \\ \text { percent } \\ \text { deviation }\end{array} & \begin{array}{c}\text { region } \\ \text { flux }\end{array} & \begin{array}{c}4 \\ \text { percent } \\ \text { deviation }\end{array} \\ 1.058 \mathrm{E}-02 & 3.55 & 1.269 \mathrm{E}-01 & 2.78 \\ 2.227 \mathrm{E}-02 & 3.16 & 2.575 \mathrm{E}-01 & 2.07 \\ 1.274 \mathrm{E}-02 & 4.16 & 1.144 \mathrm{E}-01 & 3.34 \\ 1.739 \mathrm{E}-02 & 3.77 & 1.498 \mathrm{E}-01 & 3.23 \\ 2.026 \mathrm{E}-02 & 3.75 & 1.646 \mathrm{E}-01 & 2.74 \\ 1.735 \mathrm{E}-02 & 4.18 & 1.216 \mathrm{E}-01 & 3.32 \\ 1.414 \mathrm{E}-02 & 4.05 & 1.065 \mathrm{E}-01 & 3.94 \\ 1.243 \mathrm{E}-02 & 4.62 & 9.311 \mathrm{E}-02 & 4.29 \\ 1.232 \mathrm{E}-02 & 5.31 & 8.840 \mathrm{E}-02 & 4.62 \\ 9.890 \mathrm{E}-03 & 5.67 & 6.730 \mathrm{E}-02 & 3.91 \\ 7.372 \mathrm{E}-03 & 5.50 & 5.593 \mathrm{E}-02 & 5.57 \\ 7.395 \mathrm{E}-03 & 5.24 & 5.707 \mathrm{E}-02 & 4.43 \\ 6.840 \mathrm{E}-03 & 5.59 & 5.130 \mathrm{E}-02 & 5.54 \\ 5.822 \mathrm{E}-03 & 7.08 & 4.114 \mathrm{E}-02 & 5.88 \\ 1.761 \mathrm{E}-02 & 4.15 & 1.094 \mathrm{E}-01 & 4.50 \\ 1.586 \mathrm{E}-01 & 2.06 & 9.496 \mathrm{E}-01 & 2.42\end{array}$

Figure F17.6.49 An example of a flux edit

The title of the problem is printed at the top of the page. The heading FLUXES FOR UNIT indicates the geometry unit for which fluxes are being printed. The region numbers relative to the unit are identified by the heading REGION The geometry regions within each unit are numbered sequentially, beginning with one. GROUP is the heading for the energy groups. The headings FLUX and PERCENT DEVIATION are printed for each geometry region in the unit. The flux and its associated percentage deviation are printed for every energy group and every geometry region. The flux is in units of neutrons $/ \mathrm{cm}^{2} / \mathrm{source}$ neutron.

\section{F17.6.46 FREQUENCY DISTRIBUTIONS}

Subroutine FREAK is responsible for printing the frequency distributions that are the last data printed for a problem. A frequency distribution consists of a bar graph indicating the number of generations having $\mathrm{k}$ effective in a specified interval. The intervals are determined by the code, based on the upper and lower limits of the k-effectives calculated for the generations. One asterisk is printed for each generation k-effective. Four frequency distributions are printed as shown in Fig. F17.6.50. 
kenovi sample problem 2 case $2 c 8$ bare with 8 unit types matrix cal

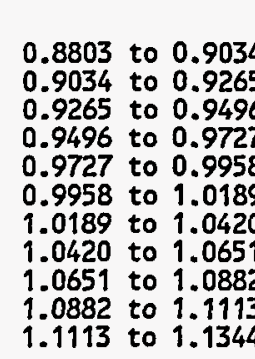

$$
\star
$$$$
\text { frequency for generations }
$$

4 to 103

$\star * * * *$

$\star \star \star \star * * *$

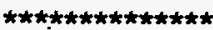

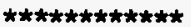

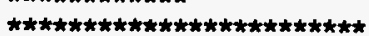

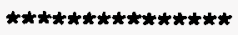

$\star \star * * * * * * * * * *$

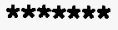

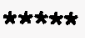

$\star$

0.8803 to 0.9034

0.9034 to 0.9265

0.9265 to 0.9496

0.9496 to 0.9727

0.9727 to 0.9958

0.9958 to 1.0189

1.0189 to 1.0420

1.0420 to 1.0651

1.0651 to 1.0882

1.0882 to 1.1113

1.1113 to 9.1344

0.8803 to 0.9034

0.9034 to 0.9265

0.9265 to 0.9496

0.9496 to 0.9727

0.9727 to 0.9958

0.9958 to 1.0189

1.0189 to 1.0420

1.0420 to 1.0651

1.0651 to 1.0882

1.0882 to 1.1113

1.1113 to 1.1344

0.8803 to 0.9034

0.9034 to 0.9265

0.9265 to 0.9496

0.9496 to 0.9727

0.9727 to 0.9958

0.9958 to 1.0189

1.0189 to 1.0420

1.0420 to 1.0651

1.0651 to 1.0882

1.0882 to 1.1113

1.1113 to 1.1344

frequency for generations 29 to 103

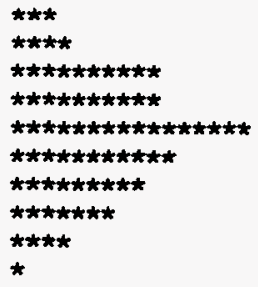

$\star * \star$

$\star \star \star \star \star *$

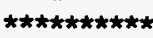

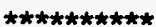

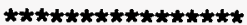

$\star * \star * * * * \star * \star * \star * *$

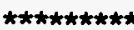

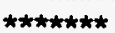

$\star * \star * *$

*

frequency for generations 54 to 103

$\star \star \star$

ttt

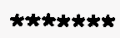

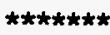

$\star \star \star \star \star * \star * * \star$

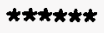

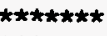

$\star \star \star \star * * *$

$\star \star \star \star *$

*

frequency for generations 79 to 103

*

$\star * \star *$

$\star \star \star *$

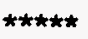

$\star \star * * * *$

trt

$\star \star \star$

$\star \star$

Figure F17.6.50 Example of frequency distributions 


\section{F17.7 WARNING MESSAGES AND ERROR MESSAGES}

KENO-VI prints warning and error messages that are identified by K6-, followed by a unique number, such as K6-2. For additional information concerning the message, simply look up the identifier number in this section.

Warning messages appear when a possible error is encountered. If the code alters data, that fact is stated in the message. It is the responsibility of the user to verify correct usage whenever a warning message is printed.

When an error is encountered, the error flag MFLAG is set true and an error message is printed. The code stops if the error is too severe to continue. The warning and error messages in this section may show an underscore __ or a numbered underscore (1), where data will be printed by the code. The explanation of the message will show an underscore or a numbered underscore to indicate the corresponding data.

\section{F17.7.1 MESSAGES}

\section{K6-2 *** ERROR *** ERROR *** THE NUMBER OF ENERGY GROUPS IS OUT OF RANGE FOR THE CROSS SECTION LIBRARY ON UNIT _ _ . THE JOB CONTROL LANGUAGE MAY NOT SPECIFY A VALID DATA SET ON THIS UNIT OR THE MODULE THAT WAS TO CREATE THE CROSS SECTION LIBRARY ON THIS UNIT MAY HAVE FAIIED.}

This message occurs in subroutine INITAL after subroutine PARAM has been executed. Check unit number to see that it was properly specified in the job control language. Verify that the data set name associated with this unit number is the correct one. This information is given in the printout in the third table. Make sure the module that generated the cross sections executed properly and that the data were saved or passed correctly. When this message is printed for an AMPX working-format library, a STOP 108 is executed. When this message is printed for a mixed cross-section format library, a STOP 109 is executed.

\section{K6-3 *** WARNING *** THE CROSS SECTION LIBRARY ON UNIT GROUPS. \\ HAS ENERGY}

This message is printed in subroutine INITAL after the call to PARAM. It is activated if the cross-section library has more than 300 energy groups. The largest standard cross-section library in the SCALE system contains 238 energy groups.

\section{K6-4 INVALID INPUT PARAMETER NAME}

This message comes from subroutine PARAM. The keyword for entering parameter data was misspelled. A list of allowed keywords is given in Table F17.4.1 in the KENO-VI input outline.

\section{K6-5 ***** AN ERROR WAS ENCOUNTERED IN THE ALPHANUMERIC PARAMETER DATA. THE DATA WERE *****}

This message comes from subroutine PARAM. The keyword for the alphanumeric parameter data was entered correctly, but the data associated with it were not YES or NO as is required. The in the error message could be something like FLX $=$ YEX instead of FLX $=$ YES. 
K6-6 ***** WARNING ***** READ FLAG FOUND WHEN LOOKING FOR END FLAG. PARAMETER INPUT ASSUMED COMPLETE

This message occurs in subroutine PARAM. It indicates that the keywords END PARAMETERS were not found. The keywords READ were found instead. The code assumes the parameter data are complete and proceed normally.

\section{K6-7 ATTEMPT TO FIND END PARAMETER FLAG WAS UNSUCCESSFUL}

This message from subroutine PARAM occurs during the reading of the parameter data if the word END is found and it is not followed by the word PARAMETERS. A STOP 118 may be executed when this message is printed.

K6-8 ***** AN END OF FILE WAS ENCOUNTERED WHILE ATTEMPTING TO READ PARAMETER DATA *****

This self-explanatory message is from subroutine PARAM. A STOP 118 may be executed when this message is printed.

K6-9 *** DUE TO INCONSISTENCIES BETWEEN INPUT AND RESTART DATA, FISSIONS AND ABSORPTIONS BY REGION WILL BE CALCULATED BUT NOT PRINTED. INPUT DATA SET FAR=NO, BUT DATA FROM THE RESTART UNIT SPECIFIED YES.

This message occurs in subroutine PARTBL. It is mostly self-explanatory. The original problem (parent case) that wrote the restart data specified data inconsistent with the parameter data input to the restarted problem. The title of the parent case is given at the end of the parameter tables. The specification of the restart unit RST is given in the third table of the KENO-VI output.

K6-10 *** DUE TO INCONSISTENCIES BETWEEN INPUT AND RESTART DATA, FLUXES WILL BE CALCULATED BUT NOT PRINTED. INPUT DATA SET FLX=NO, BUT DATA FROM THE RESTART UNIT SPECIFIED YES.

This message occurs in subroutine PARTBL. It is basically self-explanatory. The original problem (parent case) that wrote the restart data specified data that did not agree with the parameter data input to the restarted problem. The title of the parent case is given at the end of the parameter tables. The specification of the restart unit RST is given in the third table of the KENO-VI output.

\section{K6-11 *** ERROR ***A BOUNDARY GEOMETRY WORD WAS NOT SPECIFIED FOR UNIT _.}

This self-explanatory message is from subroutine KENOG. A BOUNDARY record must be associated with each unit identifying the outermost region of the unit.

K6-12 *** WARNING *** INPUT PARAMETER NBK WAS ENTERED AS __. IT WAS CHANGED TO _ _ AT LEAST _ _ POSITIONS ARE NECESSARY TO ACCOMMODATE THE NEUTRON BANK DATA.

NUREG/CR-0200, 
This self-explanatory message is from subroutine PARTBL. NBK should not be entered as input data unless it is known that the default value is inadequate.

\section{K6-13 *** ERROR *** MEDIA DATA MUST BE ENTERED FOR UNIT __.}

This message is from subroutine KENOG. Either another UNIT record or an END GEOM record was encountered prior to inputting MEDIA data for the current unit.

K6-14 ***** ERROR - KEYWORD IS NOT A VALID MIXING TABLE KEYWORD.

This message is from subroutine MIXIT. It can only be encountered if a mixing table is expected (i.e., READ MTX or READMIXT has been entered as data). At this point the only valid keywords are MIX $=, E P S=$ or $\mathrm{SCT}=$. The keyword that was entered is printed in the message. See Sect. F17.4.10 for assistance in setting up the mixing table data. A common error made by KENO-IV users is to enter a negative nuclide ID number in the mixing table. The code will interpret this to be a keyword. A whole list of K6-14 error messages will be generated as the code reads through the mixing table in search of a valid keyword. The code considers any character string that does not begin with a number to be a keyword.

\section{K6-15 MIXING TABLE TOO BIG}

This message is from subroutine MIXIT. It indicates that additional core space is necessary to allow entry of the existing mixing table. A STOP 114 is executed in conjunction with this message and a traceback may be printed from subroutine STOP.

\section{K6-16 *** ERROR *** ERROR *** A VALUE MUST BE ENTERED FOR LIB IN THE PARAMETER INPUT SO CROSS SECTIONS CAN BE MIXED.}

This message is from subroutine DATAIN. It occurs when a mixing table has been read but the unit number for the AMPX working library is undefined. This situation is corrected by entering $L I B=$ _ in the parameter input data and making sure the desired AMPX working library is properly defined as being on that unit in the job control language.

\section{K6-17 UNRECOGNIZABLE GEOMETRY WORD}

This message is from subroutine KENOG. In the process of reading the geometry data, the word was encountered when a geometry word was expected. Several of these messages may be generated. A message is generated for each word of data that is read, until a valid geometry word is found. The data are out of phase or the geometry word is misspelled. Check the previous geometry record for a mixture ID, a bias $\mathrm{ID}$, and the proper number of dimensions. See Sect. F17.4.4 for a list of accepted geometry words.

K6-18 ***** ERROR ***** INVALID INDEX INTO KEYWRD ARRAY. INP= SUBROUTINE KENOG FOR A CODE ERROR.

This message is from subroutine KENOG. This message usually means that a code error was introduced when changes were made to the program. Check subroutine KENOG, function LCOMPR, and KEYWRD data block. 
This self-explanatory message from subroutine KENOG indicates that a global unit has not been specified. The outermost unit in the problem must be specified as the GLOBAL UNIT. See Sect. F17.4.4 to determine the correct specification.

K6-20 ***** ERROR *****GEOMETRY WORD INDEX OUT OF RANGE ON SCRATCH UNIT__FOR GEOMETRY WORD NUMBER _ INP $=$ _ GWRD $=$

This message from subroutine READGM means that INP is negative or larger than NP when the geometry data are read from the scratch unit, SKRT. This usually means that a code error was introduced when changes were made to the program. True geometry errors should be detected when the scratch unit, SKRT, is written. A STOP 125 is executed when this message is printed.

K6-21 I IS AN INVALID PARAMETER NAME FOR BIASING DATA. ID=OR WT=OR WTS= SHOULD HAVE BEEN ENTERED.

This self-explanatory message is from subroutine RDBIAS. See Sect. F17.4.7 for assistance in determining the proper procedure for entering biasing data.

K6-22 FIRST TWO NUMBERS ARE WORDS OF STORAGE NEEDED AND ALLOCATED. THIRD IS REQUIRED ADDITIONAL REGION SIZE.

\section{PERTINENT CONSTANTS}

This message from subroutine WATES indicates that the allocated computer storage will not hold the weighting or biasing array. The first number printed is the amount of storage, in words, needed to hold the data. The second number is the allocated computer storage in words. The third number is the minimum additional region size, in units of $\mathrm{K}$ bytes necessary to hold the biasing or weighting data to this point. Increase the region size for the "go step" in the job control language by the additional required region size (the third number) and resubmit the problem. A STOP 150 is executed when this message is printed.

\section{K6-23 *** ERROR *** ERROR *** NO__ENERGY GROUP WEIGHTS WERE FOUND FOR ID *** ERROR *** ERROR ***}

This message from subroutine WATES occurs if the weights requested in the biasing information were not on the standard weights data set and were not entered using biasing data. See Table F17.4.5 for the weights that are available on the standard data set. The procedure for entering weights in the biasing data is explained in Sect. F17.4.7.

\section{K6-24 INCORRECT FLAG RETURNED FROM AREAD. IRET=}

This message from subroutine RDBIAS indicates that an error was encountered while reading the biasing data. The biasing data were not entered properly. See Sect. F17.4.7 for assistance.

NUREG/CR-0200,

Vol. 2, Rev. 5
F17.7.4 
K6-25 THE FIRST NUMBER IS THE STORAGE NEEDED; THE SECOND, THE AMOUNT ALLOCATED. PERTINENT CONSTANTS

This message is from subroutine ARAYIN or subroutine GEOMIN. It indicates that additional core space is required to allow the use of the array definition data or the geometry region data. At least ___ words of storage are needed to run the problem but only ___ words of storage are available. Increase the amount of computer storage requested in the job control language to correspond to the amount needed. A STOP 100 or 155 is executed in conjunction with this message, and a traceback may be printed from subroutine STOP.

K6-26 SET NUMBER OF THE UNIT ORIENTATION DATA CONTAINS ERROR(S)

This message from subroutine RDBOX is triggered when input errors are recognized in the unit orientation data. A set of unit orientation data consists of ten numbers as shown in the companion message K6-27. The number of errors printed in this message is a lower bound. More errors may actually exist. This message often means that a number was omitted or a blank was omitted when entering the unit orientation data.

K6-27 LTYPE= $-\mathrm{IZ} 2=$ $\mathrm{IX1}=$ $\mathrm{IX} 2=$ $\mathrm{INCX}=$ $\Pi 1=$ $\Gamma \mathrm{Y} 2=$ $\mathrm{INCY}=$ $\mathrm{IZl}=$

This message is a companion message for $\mathrm{K} 6-26$. It indicates how the unit orientation data description for the set named in K6-26 was entered. See Sect. F17.4.5 for information pertaining to unit orientation data.

K6-28 THE ABOVE UNIT ORIENTATION RECORD(S) CONTAIN(S) AT LEAST ONE OF THE FOLLOWING ERRORS

1. IX1,IY1,IZ1,INCX,INCY, OR INCZ IS LESS THAN OR EQUAL TO ZERO

2. IX2 IS LESS THAN IX1, IY2 IS LESS THAN IY1, OR IZ2 IS LESS THAN IZ1

3. IX2 IS GREATER THAN NBXMAX, IY2 IS LARGER THAN NBYMAX OR IZ2 IS LARGER THANNBZMAX

\section{LTYPE IS LESS THAN I OR GREATER THAN NBOX}

This self-explanatory message is from subroutine RDBOX. It pertains to the input orientation data for LOOP. See Sect. F17.4.5 for input instructions.

\section{K6-29 *** ERROR *** THE ARRAY SLZE HAS BEEN SPECIFIED INCORRECTLY.}

NBXMAX= NBYMAX $=$ NBZMAX $=$

UNIT ORIENTATION DATA CANNOT BE READ UNLESS NBXMAX, NBYMAX, AND NBZMAX ARE GREATER THAN ZERO.

This message from subroutine ARAYIN indicates that the array definition data were incorrectly specified. It occurs only if one or more of NBXMAX, NBYMAX, or NBZMAX is less than 1. In the array information data these are entered in the form $\mathrm{NUX}=\quad \mathrm{NUY}=$ $\mathrm{NUZ}=$ See Sect. F17.4.5. If a unit orientation data description is to be entered, NBXMAX, NBYMAX, and NBZMAX must all be greater than zero. 
WAS READ INSTEAD.

This message from subroutine ARAYIN occurs if the unit orientation data description is terminated with the incorrect END flag. IS AN INVALID PARAMETER NAME IN THE ARRAY DATA.

This message is written from subroutine ARAYIN if the array data block contains an incorrect keyword. The allowed keywords include NUX $=N U Y=N U Z=$ FIL and LOOP. See Sect. F17.4.5 for additional assistance. A STOP 101 is executed when this message is printed.

K6-32 *** AN ERROR EXISTS IN UNIT ORIENTATION ARRAY NUMBER ****

This message from subroutine SORTA is printed when an error is recognized in the array description. The type of error that will trigger the message is for a position in the unit orientation array to be undefined, zero, negative or greater than NBOX, the number of input units. K6-33 is a companion message.

K6-33 UNIT IS INVALID AT XINDEX= Y INDEX= $\mathrm{ZINDEX}=$

This message comes from subroutine SORTA. It is printed for each position in the unit orientation array that is in error. The message is printed a maximum of 10 times. Refer to Sect. F17.4.5 for assistance in correcting the error(s).

\section{K6-34 ***** ERROR ***** THE NUMBER OF MIXTURES REQUESTED IN THE GEOMETRY IS THE NUMBER OF MIXTURE CROSS SECTIONS IS}

This message from subroutine FLDATA occurs if the number of mixture cross sections from the restart unit, RSTRT, does not equal the number of mixtures requested in the geometry for a restarted problem.

K6-35 ***** ERROR ***** IN THE ALBEDO INPUT DATA IS AN INVALID FACE CODE NAME.

This message is from subroutine RDREF. It occurs if an invalid face code name was entered in the albedo data. See Table F17.4.3 in Sect. F17.4.6 for a list of acceptable face code names.

\section{K6-36 A PERIODIC BOUNDARY CONDITION WAS SPECIFIED WITH A NON-COMPATIBLE BOUNDARY CONDITION ON THE OPPOSING FACE. THE PROBLEM WILL NOT BE RUN.}

This self-explanatory message is from subroutine RDREF. If a periodic boundary condition is specified on one $x$ face, it must also be specified on the other $x$ face, etc.

K6-37 ***** ERROR AVERAGE NU-BAR AND AVG. FISSION GROUP WAS SPECIFIED, BUT THE FISSION XSEC ID (18) WAS NOT FOUND IN THE EXTRA 1-D ARRAY (MT).

This message is from subroutine IDX1D. It indicates that the parameter data contained NUB=YES but the corresponding necessary type of data was absent from the extra 1-D array. This can be due to a code error or an error concerning the extra $1-\mathrm{D}$ data $(\mathrm{XID}=$ in the parameter data). 
K6-38 INPUT DATA INDICATED NO EXTRA 1-D XSEC IDS TO BE READ, BUT A READ FLAG WAS ENCOUNTERED.

This message from subroutine DATAIN is printed when the parameter data did not specify X1D= and the words READ XIDS were encountered later in the data. If extra 1-D data are to be used, XID= must be entered in the parameter data and appropriate code modifications must be made to properly utilize the extra l-D data.

\section{K6-39 INVALID START PARAMETER NAME}

This message is from subroutine RDSTRT. It indicates that an invalid start parameter name was encountered when the start data block was being read. A list of allowed start parameter names is contained in Sect. F17.4.8.

K6-40 LNUFOR START TYPE 6 WAS ENTERED AS . IT WAS CHANGED TO WHECH IS THE VALUE ENTERED FOR NFB. THE LARGEST VALUE NEEDED FOR LNU IS NPG. THE LARGEST VALUE ALLOWED FOR LNU IS NFB. BOTH NPG AND NFB ARE PARAMETER DATA.

This self-explanatory message is from subroutine RDSTRT. See Sect. F17.4.8 for assistance in determining a valid value for LNU. NFB, the fission bank size, is the largest value allowed for LNU. NPG, the number of histories per generation, is the smallest value allowed for LNU.

K6-41 *** ERROR *** ALPHANUMERIC START DATA MUST BE ENTERED AS YES OR NO. THE DATA READ WERE

This self-explanatory message is from subroutine RDSTRT. See Sect. F17.4.8 for assistance concerning start data.

K6-42 END _ FLAG WAS NOT FOUND. WAS READ INSTEAD.

This message is from subroutine DATAIN. It occurs when the READ _ and END When entering data blocks, each block must start with READ and end with END do not match.

K6-43 ***** AN END OF FILE WAS ENCOUNTERED BEFORE AN END DATA WAS FOUND. THE PROBLEM WILL NOT RUN.

This message is from subroutine DATAIN. It occurs when an end of file is encountered while reading data.

\section{K6-44 ${ }^{* * * * *}$ ERROR ${ }^{* * * * *}$ SECTOR DATA WAS NOT FOUND FOR ARRAY}

This self-explanatory message is from subroutine ARRAY. This message usually means that sector data was left off the ARRAY media record. See Sect. F17.4.4 for assistance is specifying an array. 
This message from subroutine DATAIN is printed whenever an invalid data block identifier is encountered. This situation can be caused by having the data out of order, by omitting data or by misspelling data. A block identifier consists of the words READ XXXX, where XXXX is a keyword identifying the type of data to be read. Acceptable keywords are listed in Table F17.4.1 (Sect. F17.4.1).

Consider the following examples:

ERROR MESSAGE EXAMPLE 1

READ PARAM TME=2.9 FLX=YES XSC=38 END PARAM

READ GOEM GLOBAL UNIT 1

CYLINDER 1 5.0 5.0 -5.0 MEDIA 111 BOUNDARY 1 END GEOM

END DATA

END

The following message would occur:

***** ILLEGAL DATA BLOCK IDENTIFIER READ GOEM *****

The keyword GEOM was misspelled as GOEM. The correct data block identifier is READ GEOM.

ERRORMESSAGE EXAMPLE 2

READ PARAM TME=2.9 FLX=YES XSC=38 END PARAM

END GEOM

CYLINDER 1 5.0 5.0 -5.0 MEDIA 111 BOUNDARY 1 END GEOM

END DATA

END

The following message would occur:

\section{***** ILLEGAL DATA BLOCK CYLINDER *****}

The words END GEOM are read and recognized as the end of a data block. The words CYLI and NDER are then read as the data block identifier. Since CYLI is not END, the code assumes it is at the beginning of a data block that is identified by the keyword NDER, which is not one of the acceptable keywords.

ERRORMESSAGE EXAMPLE 3

READ PARAM TME=2.9 FLX=YES XSC $=38$ END PARAM

END GEOM

READ GEOM

GLOBAL UNIT 1

CYLINDER 15.0 5.0 -5.0 MEDIA 111 BOUNDARY 1

END GEOM

NUREG/CR-0200,

Vol. 2, Rev. 5 
In this example, no errors will be found and the problem will run correctly. The END PARAM signals the end of the parameter data block. The first END GEOM signals the end of a geometry block, the READ GEOM signals the beginning of a geometry block, the second END GEOM signals the end of a geometry block, and the END DATA signals the end of the problem.

K6-46 ***** IPT= IS OUTSIDE THE ALLOWABLE LIMIT OF

This self-explanatory message is from subroutine DATAIN. It is indicative of a code error. IPT is the index into the LPOINT array, which contains the direct-access pointers for the various types of data.

LPOINT(1) is the pointer for the geometry region data.

LPOINT(2) is the pointer for the array description (unit orientation) data.

LPOINT(3) is the pointer for the mixing table data.

LPOINT(4) is the pointer for extra data.

LPOINT(5) is the pointer for the biasing or weighting data.

LPOINT(6) is the pointer for the start data.

LPOINT(7) is the pointer for the albedo data.

LPOINT(8) is the pointer for the mixed cross-section data.

LPOINT(9) is the pointer for the energy and inverse velocity data.

LPOINT(10) is the pointer for the plot data.

LPOINT(11) is the pointer for the biasing input data.

LPOINT(12) is the pointer for albedo-xsec energy correspondence.

A STOP 152 is executed when this message is printed.

K6-48 *** ERROR *** AN ERROR WAS ENCOUNTERED WHILE ATTEMPTING TO READ RESTART DATA FROM UNIT $\mathrm{NDX}=$ NREC $=$

This message is from subroutine RDRST. It indicates that the restart data associated with the index NDX had the wrong number of records. This message can also be caused by a code error introduced as the result of making changes in the code.

NDX $=1$ is the geometry data. NREC should be 3 .

$\mathrm{NDX}=2$ is the array description data. NREC should be 3 or more.

NDX $=3$ is the mixing table data. NREC should be 3 .

$\mathrm{NDX}=4$ is the extra data. NREC must be set by the user.

NDX $=5$ is the biasing or weight data. NREC should be 3 .

NDX $=6$ is the start data. NREC should be 3 .

$\mathrm{NDX}=7$ is the albedo data. NREC should be at least 2 .

NDX $=8$ is the mixed cross-section data.

$\mathrm{NDX}=9$ is the energy and inverse velocity data.

$\mathrm{NDX}=10$ is the plot data.

NDX $=11$ is the biasing input data.

$\mathrm{NDX}=12$ is the albedo-xsec energy correspondence. 
A STOP 123 is executed when this message is printed.

K6-49 WORDS ARE NEEDED TO HOLD THE ALBEDO DATA. BUT ONLY WORDS ARE AVAIILABLE.

This message from subroutine RDALB is self-explanatory. More space is needed to contain the albedo data. A STOP 120 is executed when this message is printed.

K6-50 THE SPACE AVAILABLE IN SUBROUTINE RDICE IS MORE IS NEEDED.

This self-explanatory message from subroutine RDICE indicates that more space is needed to store the macroscopic cross sections in ICE format. A STOP 122 is executed when this message is printed.

K6-51 ***** ERROR ***** THE _ FACE REQUESTED A DIFFERENTIAL ALBEDO THAT IS NOT ON THE ALBEDO DATA SET. THE REQUESTED ALBEDO NAME IS

This self-explanatory message is from subroutine ALBRD. A list of the albedos that are on the standard albedo data set is given in Table F17.4.4 (Sect. F17.4.6).

\section{K6-52 MIXTURE NUMBER TOO LARGE}

This self-explanatory message is from subroutine MIXCRS. A STOP 111 is executed in conjunction with this message, and a traceback may be printed from subroutine STOP.

\section{K6-53 NOT ENOUGH STORAGE TO MIX}

This message from subroutine MIXER indicates that more storage is necessary in order to do the cross-section mixing operations. A STOP 112 is executed in conjunction with this message, and a traceback may be printed from subroutine STOP.

\section{K6-54 NOT ENOUGH STORAGE TO MAKE ANGLES}

This message from subroutine MIXER indicates that more storage is necessary to perform the calculations required to make the angles during the cross-section mixing operations. A STOP 113 is executed in conjunction with this message, and a traceback may be printed from subroutine STOP.

\section{K6-55 **** ERROR FOUND IN MIXING CROSS SECTIONS ****}

THE FOLLOWING NUCLIDE(S) SPECIFIED IN THE MIXING TABLE WERE NOT FOUND ON THE CROSS SECTION LIBRARY.

\section{ENTRY NUCLIDE ID}

NUREG/CR-0200, 
This self-explanatory message is from subroutine MIXMIX. Either a nuclide ID was misspelled, or it was not in the cross-section library.

\section{K6-56 ERROR - MIXTURE ___ LACKS EITHER NU*FISSION OR CHI DATA.}

This message from subroutine NORMID indicates that a mixture that contains fissile material is missing the nu-fission cross section or the fission spectrum. A STOP 115 is executed when this message is printed.

\section{K6-57 NOT ENOUGH STORAGE TO MAKE ANGLES AND PROBS}

This self-explanatory message from subroutine MAKANG indicates that more storage is needed to complete the cross-section mixing operations. Resubmit the problem and request more storage space in the job control language. A STOP 110 is executed in conjunction with this message, and a traceback may be printed from subroutine STOP.

K6-58 This message appears in two forms, listed below:

K6-58 ** ERROR **** ERROR ** INVALID BIAS ID IN REGION OF UNIT

This form of message K6-58 is from subroutine READGM. It is printed if a negative or zero bias ID is encountered anywhere in the geometry data. The error flag (MFLAG) is not activated so the problem will execute if the unit containing the error is not utilized in the unit orientation array. If that unit is used in the unit orientation array, the following form of message K6-58 will also be printed.

\section{K6-58 *** ERROR *** INVALID BIAS ID IN REGION ABOVE.}

This form of message K6-58 is from subroutine PRTJOM. It is printed if a negative or zero bias $\mathrm{DD}$ is entered for the specified geometry region. The problem will not execute if this form of message K6-58 is printed. Review Sect. F17.4.4 for correct geometry data specification information.

\section{K6-59 THE CALCULATION WAS TERMINATED BECAUSE OF EXCESSIVE SPLITTING}

This message from subroutine GUIDE is printed only if message K6-128 is printed 50 or more times for a given generation. This message indicates that the problem and/or the code is incapable of achieving a reasonable solution. If changes have been made in the code, they should be carefully scrutinized. If a biasing data block has been entered (Sect. F17.4.7), it should be checked carefully.

K6-60 THE ANGULAR SCATTERING DISTRIBUTION FOR MIXTURE FOR THE TRANSFER FROM GROUP TO GROUP HAS BAD MOMENTS MOMENTS WERE ACCEPTED.

THE LEGENDRE EXPANSION OF THE CROSS SECTION (P0-PN) IS

$\begin{array}{lllll}\left(P_{0}\right) & \left(P_{1}\right) & \left(P_{2}\right) & \ldots & \left(P_{n}\right)\end{array}$

THE MOMENTS CORRESPONDING TO THIS DISTRIBUTION ARE 
$\left(\begin{array}{llll}\left(M_{1}\right) & \left(M_{2}\right) & \ldots & \left(M_{n}\right)\end{array}\right.$

THE MOMENTS CORRESPONDING TO THE GENERATED DISTRIBUTION ARE

$\underline{\left(M_{1}\right)} \quad \stackrel{\left(M_{2}\right)}{-} \quad \cdots \quad \underline{\left(M_{n}\right)}$

THE LEGENDRE EXPANSION CORRESPONDING TO THESE MOMENTS IS

$\begin{array}{lllll}\left(P_{0}\right) & \left(P_{1}\right) & \left(P_{2}\right) & \ldots & \left(P_{n}\right)\end{array}$

THE WEIGHTS/ANGLES FOR THIS DISTRIBUTION ARE

$\begin{array}{llll}\left(W_{1}\right) & \left(W_{2}\right) & \cdots & (W m)\end{array}$

$\overline{\left(A_{1}\right)} \quad \overline{\left(A_{2}\right)} \quad \ldots \quad(\overline{A m})$

THE MOMENTS CORRESPONDING TO THIS DISTRIBUTION ARE

$\underline{\left(M_{1}\right)} \quad \underline{\left(M_{2}\right)} \quad \cdots \quad \underline{\left(M_{n}\right)}$

This message from subroutine BADMOM indicates that the moments from the cross-section data are incorrect for the group transfer shown. The code replaces the incorrect moments with acceptable moments and proceeds normally. The moments printed in the last line of the message should match those printed in the eighth line. The user can suppress these messages by entering an appropriate value for the "cross-section message cutoff parameter," EPS= in the mixing table data, Sect. F17.4.10. See Sect. F17.5.4.4 for assistance in determining an appropriate value.

K6-61 ***ERROR*** POSITIVE INTEGER.

IS NOT A VALID UNIT NUMBER A UNIT NUMBER MUST BE A

This error message from subroutine KENOG indicates a unit number less than or equal to zero was specified. Unit numbers must be positive, nonzero integers.

K6-62 ***** ERROR ***** INSUFFICIENT DATA FOLLOWING THE KEYWORD ARRAY

This self-explanatory message is from subroutine ARRAY. The data following the keyword ARRAY are misspelled or incomplete. See Sect. F17.4.5 for assistance in determining the correct method for inputting array data.

\section{K6-63 NOT ENOUGH IOs ARE LEFT TO PRINT THE FLUXES.}

This message from subroutine FITFLX is self-explanatory. The number of IOs specified in the job control language must be increased, and the problem must be renun if printed fluxes are required. All other results are unaffected by the failure to print the fluxes.

K6-64 THE ANGULAR SCATTERING DISTRIBUTION FOR MIXTURE HAS BAD MOMENTS FOR THE TRANSFER FROM GROUP TO GROUP . MOMENTS WERE ACCEPTED. THE PO COEFFICIENT IS

NUREG/CR-0200,

Vol. 2, Rev. 5

F17.7.12 
This message from subroutine BADMOM is printed to inform the user that the cross sections were altered by the code because the moments from the cross-section data were incorrect for the group transfer shown. The $\mathrm{P}_{0}$ coefficient was larger than the "cross-section message cutoff parameter," EPS, but the relative change in the moments was smaller than EPS.

K6-65 ** WARNING ** AN AMPX WORKING LIBRARY WAS SPECIFIED ON UNIT MIXING DATA WAS READ. MIXED CROSS SECTIONS FORM UNIT WIL BE USED. ** WARNING**

This message from subroutine ICEMIX occurs if the parameter data specified LIB= but no crosssection mixing data block was entered. The cross-section mixing data block begins with READ MIXT. See Sect. F17.4.3 for parameter data and Sect. F17.4.10 for mixing table information.

K6-66 ** WARNING ** MIXTURES WERE REQUESTED IN THE GEOMETRY, BUT ONLY MIXTURES ARE ON THE MIXED CROSS SECTION LIBRARY. ** WARNING **

This message from subroutine ICEMIX indicates that more mixtures were requested in the geometry region data than were available on the mixed cross-section library. See Sect. F17.4.3 for the specification of the unit number of the mixed cross-section library (XSC=), Sect. F17.4.10 for the specification of the mixing table, and Sect. F17.4.4 to determine the mixtures used in the geometry region data.

K6-67 ***** ERROR ***** THE ADJOINT INPUT PARAMETER WAS INDICATOR FROM THE MIXTURE CROSS SECTION LIBRARY WAS BUT THE ADJOINT EXECUTE. . KENO WILL NOT

This message from subroutine ICEMIX occurs if the adjoint input parameter ADJ= specified a forward calculation and the cross sections were adjointed or the adjoint input parameter specified an adjoint calculation and the cross sections were not adjointed. $T$ indicates true, $F$ indicates false.

K6-68 THE MIXED CROSS SECTION LIBRARY ONUNIT IS COMPLETELY COUPLED. KENO WILL NOT BE EXECUTED.

This message is from subroutine ICEMIX. It indicates that the mixed cross-section library is a completely coupled neutron-gamma library and therefore cannot be used for a KENO-VI calculation. A STOP 106 is executed when this message is printed.

K6-69 THE AMOUNT OF REMAINING SPACE IS INSUFFICIENT TO CONTAIN THE NECESSARY DATA. LIMIT $=$

This message from subroutine RDTAPE indicates that more storage is needed to allow processing of the premixed ice format cross-section data. A STOP 124 is executed when this message is printed.

\section{K6-70 ERROR IN SUBROUTINE WRTRST. NDX=}

This message from subroutine WRTRST occurs only if the type of data to be written on the restart (WSTRT) unit is undefined (i.e., NDX is less than 1 or greater than 12). NDX is the index in the LPOINT array 
as described in messages $\mathrm{K} 6-46$ and $\mathrm{K} 6-48$. This error is usually caused by code errors that were introduced when changes were made to the code. A STOP 133 is executed when this message is printed.
K6-71 INSUFFICIENT SPACE ALLOWED IN SUBROUTINE ALBWRT. ALLOWED, BUT WORDS WERE REQUESTED.
WORDS ARE

This message from subroutine WRTALB indicates that more core storage is needed to allow loading the albedo data from the direct-access device into core. A STOP 105 is executed when this message is printed. Resubmit the problem, requesting more storage space in the job control language.

\section{K6-72 ARRAY IS TOO LARGE TO FIT IN SPACE ALLOTTED IN SUBROUTINE WRTICE.}

This message is from subroutine WRTICE. It indicates that more storage is needed to allow loading the mixed cross-section data from the direct-access device into core. A STOP 132 is executed when this message is printed. Resubmit the problem, requesting more storage space in the job control language.

K6-73 ***** ERROR *****__ MIXTURES WERE REQUESTED IN THE GEOMETRY DATA, BUT ONLY _ OF THESE WERE FOUND IN THE MIXED CROSS SECTIONS. ***** ERROR *****

This self-explanatory message is from subroutine BOOK3. Either the wrong mixed cross-section data set $(\mathrm{XSC}=$ from the parameter data, Sect. F17.4.3) is being used, or one or more mixture numbers are in error in the geometry region data (see Sect. F17.4.4).

K6-74 *****__ WORDS OF STORAGE WERE ALLOCATED TO RUN THIS PROBLEM, BUT WORDS ARE REQUIRED FOR THE INPUT DATA. *****

This self-explanatory message is from subroutine BOOK3. Additional storage is required to run this problem. Alter the job control language to request sufficient storage.

K6-75 *** NOT ENOUGH STORAGE TO PRINT ONE DIMENSIONAI CROSS SECTIONS. LOCATIONS ARE NEEDED, BUT ONLY ARE AVAILABLE

This self-explanatory message is from subroutine PRTXS. Additional storage must be requested in the job control language in order to print the 1-D mixture cross sections.

K6-76 *** NOT ENOUGH STORAGE TO PRINT TWO DIMENSIONAL CROSS SECTIONS. LOCATIONS ARE NEEDED, BUT ONLY ARE AVAILABLE.

This self-explanatory message is from subroutine PRTXS. Additional storage is needed to print the 2-D mixture cross sections. More storage must be requested in the job control language.

K6-77 *** NOT ENOUGH STORAGE TO PRINT ANGLES AND PROBABILITIES. ARE NEEDED, BUT ONLY ARE AVAILABLE. LOCATIONS

This self-explanatory message is from subroutine PRTXS. Additional storage must be requested in the job control language to print the angles and probabilities for the mixture cross sections.

NUREG/CR-0200, Vol. 2, Rev. 5

F17.7.14 
This message is from subroutine NSUPG. In the process of supergrouping the energy-dependent information, the code ran out of available storage space. An attempt has been made to estimate the amount of storage needed, but the estimate may be low. Resubmit the job and request sufficient storage in the job control language.

\section{K6-79 THIS PROBLEM IS TOO LARGE FOR THE AMOUNT OF CORE THAT WAS ALLOCATED.}

This message is from subroutine NSUPG. It occurs during the process of determining the number of supergroups if the amount of storage is found to be insufficient to contain the energy-dependent information associated with one of the energy groups. Change the job control language to allow more storage. A STOP 116 is executed in conjunction with this message, and a traceback may be printed from subroutine STOP.

K6-80 WORDS OF STORAGE WERE ALLOCATED, BUT AT LEAST ADDITIONAL WORDS ARE NEEDED TO HOLD THE INPUT DATA. EVEN MORE SPACE WILL BE NECESSARY TO RUN THE PROBLEM.

This message from subroutine NSUPG is printed if the available storage is too small to hold the input data. Change the job control language to allow more storage.
K6-81 THE AVAILABLE SPACE IS TOO SMALL TO CONTAIN THE DATA OF THE LARGEST ENERGY GROUP. MAXI = This message is from subroutine NSUPG. LFTLNG= LTOT $=$ LTOTAL $=$ $\mathrm{NSG}=$

MAXL is the size of the energy-dependent data associated with the largest energy group.

LFTLNG is the amount of space available to the super group.

LTOT is the total length of the cross-section data.

LTOTAL is the total length of the albedo data.

NSG is the supergroup being processed.

A STOP 117 is executed when this message is printed. Increase LNG, make sure the system memory limit is sufficient, and resubmit the problem.

K6-82 TOO MANY STORAGE LOCATIONS REQUIRED. BUT ONLY ARE AVAILABLE.

WORDS OF STORAGE ARE NEEDED,

This self-explanatory message is from subroutine POINT. To run the problem, the job control language must be changed to increase the amount of storage to be consistent with that specified in the message.

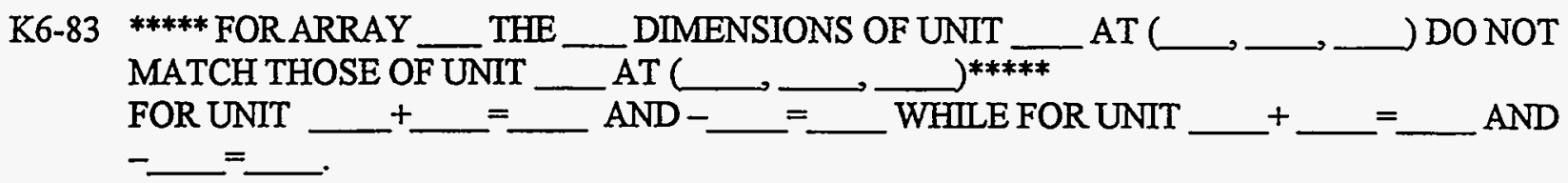

This message is from subroutine ARASIZ. The common faces of adjacent units must be the same size and shape. This message occurs whenever this requirement is not met. One or more of the dimensions of the 
units specified in the message may be incorrect, or the array definition data may be incorrect. Carefully check the input data relating to the geometry region data and the array definition data as described in Sects. F17.4.4 and F17.4.5.

K6-84 ********** UNIT THE INPUT DATA IN UNIT ORIENTATION ARRAY NUMBER IS UNDEFINED IN

This message from subroutine ARASIZ occurs when the array description data block specifies a unit that was not defined in the geometry region data. Verify the geometry region data and the array definition data as described in Sects. F17.4.4 and F17.4.5.

K6-85 UNIT _ AT POSITION $\mathrm{X}=\ldots \mathrm{Y}=\ldots \mathrm{Z}=$ IN UNIT ORIENTATION ARRAY NUMBER IS INVALID BECAUSE IT IS LESS THAN ZERO OR LARGER THAN THE LARGEST UNIT NUMBER IN THE INPUT DATA.

This message from subroutine ARASIZ occurs if the unit number named in the message is less than or equal to zero or greater than NBOX (the number of different box types). The position of the offending unit is also given. This error usually results from leaving some positions undefined in the unit orientation array or from erroneous data in the unit orientation data. (This includes extra data, misspelled data and omitted data.) See Sect. F17.4.5 for additional information.

K6-86 GEOMETRY WORD INDEX OUT OF RANGE. IGEOM= IN SUBROUTINE PRTJOM.

This message from subroutine PRTJOM is self-explanatory. The printed value of IGEOM must be greater than zero and less than 27 to be valid. If the geometry words (see fgeom in Sect. F17.4.4) are correct, this message is due to a code error that has been introduced when changes were made to the code.

K6-87 ***** ERROR **** INSUFFICIENT DATA FOLLOWED THE KEYWORD "MEDIA".

This message from subroutine MEDIA is self-explanatory. Either the material, bias ID or sector data were not included on the media record, or noninteger data were inadvertently entered. See Sect. F17.4.4 for additional information on the type of data required on a MEDIA record.

K6-88

***** ERROR ***** SECTOR DATA WAS NOT FOUND FOR MEDIA

This message from subroutine MEDIA is self-explanatory. Either the material, bias ID or sector data were not included on media record or noninteger data were inadvertently entered. See Sect. F17.4.4 for additional information on the type of data required on a MEDIA record.

K6-89 *** ERROR *** VOLUME HAS BEEN MULTIPLY DEFINED. NEUTRON _ UNIT _ AT POINT X1 $=\ldots \mathrm{Y} 1=\ldots \mathrm{Zl}=\ldots$ MOVING IN DIRECTION $\mathrm{U}=\ldots \mathrm{V}=\ldots \mathrm{W}=\ldots$ THIS POINT WAS LOCATED INSIDE THE FOLLOWING REGIONS. REGION NUMBER =

REGIONं NUMBER $=$

NUREG/CR-0200,

Vol. 2, Rev. 5

F17.7.16 
This message is from subroutine TRACK. It is caused by incorrectly specifying the vector definition arrays in the media records of a unit. It can be caused by incorrectly specifying regions that share a common boundary so the boundary between regions is contained in only one region. See Sect. F17.4.4 for more information concerning vector definition arrays on MEDIA records.

K6-90 THE UNIT ORIENTATION DESCRIPTION MAY APPEAR TO BE INCORRECT BECAUSE THE ARRAY SIZE WAS INCORRECTLY SPECIFIED.

This warning message from subroutine PRTLBA occurs if NBXMAX, NBYMAX or NBZMAX $(\mathrm{NUX}=, \mathrm{NUY}=, \mathrm{NUZ}=$ ) from the array data, Sect. F17.4.5, was incorrectly specified.

K6-95 REGION NUMBER IN UNIT NUMBER CONTAINS AN ERROR IN THE DIMENSIONS.

This message from subroutine VOLUME indicates an error in the geometry input data such that the negative dimension specification for a cube or cuboid is larger than the positive dimension specification (i.e., the $-\mathrm{x}$ dimension is greater than the $+\mathrm{x}$ dimension, or the $-\mathrm{y}$ dimension is greater than the ty dimension or the $-\mathrm{z}$ dimension is greater than the $+z$ dimension). This message is also printed if the magnitude of the chord for a cylinder or sphere is larger than the radius. See Sect. F17.4.4 for assistance in specifying the geometry correctly.

K6-96 THE VOLUME DEFINED BY GEOMETRY RECORD IS NEGATIVE.

This message from subroutine VOLUME is printed whenever a negative volume is calculated. This can result from the positive dimension being smaller than the negative dimension on a face of a geometry region. It can also be the result of roundoff when the volumes are calculated. Either the geometry regions are incorrectly specified, or the data are out of order, or the dimensions are so tight fitting that roundoff causes the net volume of the region to be negative. If the error is caused by roundoff, adjust the appropriate dimensions slightly. See Sect. F17.4.4.

K6-97 ERROR ERROR. THE VOLUME FOR UNIT IS NEGATIVE.

This message is from subroutine VOLUME. A negative volume for a unit can be caused by having a unit consisting of one region and having a positive dimension smaller than the negative dimension on one or more faces. Message K6-95 or K6-96 may accompany this message. See Sect. F17.4.4 for assistance in specifying the geometry data correctly.

K6-99 This message appears in three forms, listed below:

K6-99 *** ERROR IN UNIT _ *** THE LAST GEOMETRY REGION OF A UNIT UTILIZED IN THE UNIT ORIENTATION DESCRIPTION OF THE ARRAY DATA MUST BE A CUBOID.

This message is from subroutine ARASIZ. It can occur when a single unit problem whose outer region is not a cuboid is specified as a $1 \times 1 \times 1$ array. To eliminate this message, add a cuboidal outer region containing void, or remove the array data. If the problem is an array problem with the array type either defaulted or specified as cuboidal, be sure each unit used in the unit orientation description ends with a cuboid. See Sects. F17.4.4 and F17.4.5. 

UNIT ORIENTATION DESCRIPTION OF THE ARRAY DATA MUST BE A HEXPRISM.

This message is from subroutine ARASIZ. It can occur when a single unit problem whose outer region is not a hexprism is specified as a $1 \times 1 \times 1$ array. To eliminate this message, add a hexagonal outer region containing void, or remove the array data. If the problem is an array problem with the array type specified as triangular, be sure each unit used in the unit orientation description ends with a hexprism. See Sects. F17.4.4 and F17.4.5.

\section{K6-99 *** ERROR INUNIT __*** THE ARRAY TYPE SPECIFIED IN THIS UNIT IS UNDEFINED. SPECIFY IF THE ARRAY TYPE IS CUBOID OR HEXPRISM.}

This message is from subroutine ARASIZ. It can occur if the array type, TYP=, is incorrectly specified in the array data. Check the spelling of the array type. See Sect. F17.4.5.

\section{K6-100 THIS PROBLEM WILL NOT BE RUN BECAUSE ERRORS WERE ENCOUNTERED IN THE INPUT DATA.}

This message is from subroutine BOOK5 and indicates that other error messages were printed in the problem output. Find these messages and correct the data accordingly. A STOP 129 is executed when this message is printed.

\section{K6-101 *** ERROR *** NO FISSILE MATERIAL WAS FOUND IN SUBROUTINE START.}

This message is from subroutine START. It indicates that none of the mixtures utilized in this problem have a fission spectrum associated with them. Either the geometry data did not specify a fissionable mixture number, the mixing table is incorrect, the wrong mixed cross-section data set was accessed, or the mixed crosssection data set was incorrectly or incompletely made. A STOP 128 is executed in conjunction with this message, and a traceback may be printed from subroutine STOP.

K6-102 *** ERROR *** THE START DATA SPECIFIES THAT NEUTRONS CAN BE STARTED IN THE REFLECTOR HOWEVER NEUTRONS WILL NOT BE STARTED BECAUSE THE OUTER REGION OF THE REFLECTOR IS NOT A CUBE OR CUBOID. NEUTRONS CAN BE STARTED FOR THE EXISTING GEOMETRY IF XSM, XSP, YSM, YSP, ZSM AND ZSP ARE ENTERED AS START DATA. XSM, XSP, YSM, YSP, ZSM AND ZSP MUST FIT WITHIN THE OUTER REGION OF THE REFLECTOR *** ERROR ***

This message is from subroutine START. Start type 0 allows starting points throughout noncuboidal regions. If a start type other than 0 or 6 is desired and the outermost region of the reflector is not a cuboid, data must be input to specify an imaginary cube or cuboid within this outer region. See Sect. F17.4.8 for assistance in specifying these data.

K6-103 START TYPE IS OUT OF RANGE.

This message from subroutine START indicates that the start type was less than zero or greater than 6. The start type is defined by entering the keyword NST = followed by the desired start type in the start data. The available starting options are given in Table F17.4.6 (Sect. F17.4.8).

NUREG/CR-0200,

Vol. 2, Rev. 5

F17.7.18 
K6-104 A POSIT ERROR INDICATES THAT THE POINT $X=\ldots Y=\ldots Z=\quad$ DOES NOT OCCUR WITHIN UNIT _. IF XSM, XSP, YSM, YSP, ZSM AND ZSP ARE ENTERED IN THE START DATA, VERIFY THAT THEY FIT WITHIN THE OVERALL COORDINATES OF THE SYSTEM. THE OVERALL COORDINATES MAY NOT BE PRINTED FOR A BARE ARRAY.

If XSM, XSP, YSM, YSP, ZSM, ZSP were entered in the start data. Verify that they fit within the overall coordinates of the system. The overall coordinates may not be printed for a bare array. This message from subroutine START may result from precision difficulties. It is allowed to occur a maximum of five times before being considered fatal. A code error may be the cause of this message if it becomes fatal.

K6-105 ***** WARNING, ONLY INDEPENDENT STARTING POSITIONS WERE GENERATED. ******

This message is from subroutine START. KENO-VI must have $n p b$ (NPG=, see parameter data, Sect. F17.4.3) starting positions. This message is to inform the user that fewer than $n p b$ starting positions were generated. The remaining starting positions are randomly selected from those that were generated, thus giving duplicate starting positions. If the number of independent starting positions is nearly $n p b$, the starting distribution is probably acceptable. If it is much smaller than $n p b$, a different start type should be used to give a better starting distribution. See the start data in Sect. F17.4.8 for assistance.

K6-106 POSIT ERROR --- UNIT _ HAS MULTIPLY DEFINED SPACE $\mathrm{X}=\ldots \mathrm{Y}=\ldots \mathrm{Z}=\ldots$ SECTOR INSIDE

This message from subroutine POSIT is usually the result of an incorrectly specified starting point for the initial source distribution when NST $=3,4$ or 6 is specified in the start data. The starting point may not be consistent with the unit's position in the global array. The message can also be caused by a code error that was introduced when changes were made to the code. $\mathrm{X}, \mathrm{Y}, \mathrm{Z}$ is the location of the neutron and SECTOR INSIDE is the sectors which contain that point. See Sect. F17.4.4 for correct geometry words.

K6-107 POSIT ERROR $X=\_Y=\quad Z=$

This message from subroutine POSIT may result from precision difficulties or a code error. $\mathrm{X}, \mathrm{Y}, \mathrm{Z}$ is the location of the neutron in unit UNIT. K6-104 is a companion message.

K6-108 POSITION (_ — $\longrightarrow$ IS NOT VALID FOR THE POSITION OF THE SPIKE FOR START TYPE 2.

This message from subroutine START2 indicates that NXS, NYS or NZS was entered as zero. See Sect. F17.4.8 for the correct start data specification.

K6-109 ***** INVALID GEOMETRY TYPE IN START. IGEO= _

This message from subroutine STRTSU is probably the result of a code error.

K6-110 ***** ERROR ERROR THE PROBLEM WILL NOT BE EXECUTED BECAUSE NO FISSILE MATERIAL WAS FOUND. ***** 
This message from subroutine VOLFIS occurs when the volume of fissile material is found to be zero. Check to be sure the fissile material was correctly specified in the geometry data, check the volume of the fissile material in the printout to be sure it is nonzero, verify that the mixing table is correct or the correct ice mixed cross-section data set is used if a mixing table is not used. A STOP 131 is executed when this message is printed.

\section{K6-11 ** RESTART DATA IS NOT AVAILABLE FOR RESTARTING WITH GENERATION AS SPECIFIED IN THE INPUT DATA ** \\ ** HOWEVER, AVAILABLE RESTART DATA WAS ALLOWED RESTARTING WITH GENERATION **}

This message from subroutine RDCALC indicates that $n b a s$ (BEG=, Sect. F17.4.3) was not consistent with the set of restart data that was to be used. A set of restart data is written every nrstrt (RES=, Sect. F17.4.3). The value of $n b a s$ should be 1 greater than one of these generations.

K6-112 ERROR IN RESTART. PARAMETER DATA AND RESTART DATA DO NOT AGREE. NUMBER PER GENERATION FROM RESTART, NPBT= NUMBER PER GENERATION FROM INPUT DATA, NPB= NUMBER OF ENERGY GROUPS FROM RESTART, NGPT $=$ NUMBER OF ENERGY GROUPS FROM INPUT DATA, NGP=

This message is from subroutine RDCALC. A restarted problem MUST use the same number per generation and the same number of energy groups as the parent problem that wrote the restart data. Verify that the correct data set is mounted on unit rstrt. (RST=, Sect. F17.4.3). This message can also be caused by a code error.

K6-113 ERROR IN RESTART. PARAMETER DATA AND RESTART DATA DO NOT AGREE. FISSION DENSITIES, FLUXES, OR REGION DEPENDENT FISSIONS AND ABSORPTIONS WERE REQUESTED, BUT THE GEOMETRY DATA IS INCONSISTENT.

NUMBER OF GEOMETRY REGIONS FROM RESTART, KREFT= NUMBER OF GEOMETRY REGIONS FROM INPUT DATA, KREFM=

This message is from subroutine RDCALC. Verify that the correct data set is accessed on unit rstrt (RST=, Sect. F17.4.3). A code error can also cause this message.

K6-114 *** ERROR ***** ERROR *** PARAMETER DATA SPECIFIED FLUXES BUT THE RESTART DATA DID NOT INCLUDE FLUXES.

This message is from subroutine RDCALC. The restarted problem can turn off fluxes if the parent case that wrote the restart data set calculated fluxes. However, if the parent case did not calculate fluxes, the restarted problem cannot calculate fluxes either if the correct restart data set was accessed on rstrt (RST=, Sect. F17.4.3). The parameter data FLX $=$ YES must be removed from the input data, or FLX=NO must be entered later in the parameter data of the restarted problem.

K6-115 *** ERROR ***** ERROR *** PARAMETER DATA SPECIFIED REGION DEPENDENT FISSIONS AND ABSORPTIONS, BUT THEY WERE NOT INCLUDED ON RESTART. 
This message is from subroutine RDCALC. The restarted problem specified FAR=YES in the parameter data block, but the parent case that wrote the restart data set did not calculate region-dependent fissions and absorptions. The restarted problem can turn off region-dependent data if the parent case calculated them, but cannot turn them on if they were not calculated by the parent case. Verify that the correct restart data set is accessed on rstrt (RST=, Sect. F17.4.3). Remove FAR $=$ YES from the parameter data of the restarted problem or add FAR=NO later in the parameter data. Section F17.5.3 illustrates methods of changing the parameter input data.

\section{K6-116 *** ERROR ***** ERROR *** EXECUTION IS TERMINATED *** ERROR *** *** ERROR ***}

This message from subroutine RDCALC is a companion to messages K6-112 through K6-115. A STOP 121 is executed when this message is printed.

\section{K6-117 THE CALCULATION WAS TERMINATED BECAUSE ERRORS WERE ENCOUNTERED IN THE START DATA.}

This message is from subroutine GUIDE. It will be accompanied by one or more of messages K6-101 through K6-104 or K6-106 through K6-110. A STOP 130 is executed when this message is printed.

\section{K6-118 EXECUTION TERMINATED. RAKBAR HAS BECOME ZERO OR NEGATIVE.}

This message is from subroutine GUIDE. If this message appears without other error messages, a code error is the probable cause.

K6-119 JOB PULLED GENERATION= NEUTRON=

This message from subroutine GUIDE indicates that the problem is looping, or the time allotted for each generation, $t b t c h$ (TBA=, Sect. F17.4.3) is too small. If $t b t c h$ (TBA $\Rightarrow$ ) is increased significantly and the message occurs again for the same generation and the same neutron, it is due to a code error.

K6-120 EXECUTION TERMINATED DUE TO INSUFFICIENT IO'S. APPROXIMATELY__ IOs ARE NEEDED PER GENERATION, BUT ONLY REMAIN.

This message is from subroutine GUIDE. The problem can be resubmitted if more histories are desired. Be sure to change the job control language to request sufficient IOs to allow the problem to run.

K6-121 EXECUTION TERMINATED DUE TO INSUFFICIENT TIME IN THE JOB STEP. SECONDS ARENEEDED PER GENERATION, BUT ONLY REMAIN IN THE JOB STEP.

This message is from subroutine GUIDE. If more histories are desired, change the job control language to allow adequate time and resubmit the problem.

K6-122 EXECUTION TERMINATED DUE TO EXCEEDING THE TIME SPECIFIED FOR THE PROBLEM. 
This message is from subroutine GUIDE. If more histories are desired, increase tmax (TME=, Sect. F17.4.3) to allow computation of the desired number of histories.

K6-123 EXECUTION TERMINATED DUE TO COMPLETION OF THE SPECIFIED NUMBER OF GENERATIONS.

This message from subroutine GUIDE states that the requested number of histories have been completed. If more histories are desired, increase the number of generations (GEN=, Sect. F17.4.3).

K6-124 ***** ERROR ***** THE OPTION TO USE EXTRA 1-D'S WAS SPECIFIED BUT ID NO. WAS NOT FOUND IN THE EXTRA I-D ARRAY.

This self-explanatory message is from function INDX. If extra 1-Ds are specified in the parameter data $(\mathrm{X} 1 \mathrm{D}=$, Sect F17.4.3), extra 1-D IDs must be entered as data. See Sect. F17.4.9. A STOP 107 is executed when this message is printed.

\section{K6-125 EXCEEDED NEUTRON BANK SIZE}

This message from subroutine BANKER indicates that the number of banked particles exceeds the bank size. This situation can be corrected by increasing nbank (NBK=, Sect. F17.4.3).

K6-129 *** ERROR IN SUBROUTINE ALBEDO *** FACE NUMBER USES ALBEDO NUMBER $=$ INCIDENT XSEC ENERGY GROUP= INCIDENT ALBEDO ENERGY GROUP= INCIDENT ANGLE INDEX= RANDOMNUMBER =

This message from subroutine ALBEDO indicates that a code error was encountered when trying to determine the output energy group during the albedo treatment.

K6-130 *** ERROR IN SUBROUTINE ALBEDO *** FACE NUMBER USES ALBEDO NUMBER $=$ RETURNING XSEC ENERGY GROUP=

INCIDENT ALBEDO ENERGY GROUP=

INCIDENT ANGLE INDEX=

RETURNING ALBEDO ENERGY GROUP= RANDOM NUMBER $=$

This message from subroutine ALBEDO indicates that a code error was encountered while trying to compute the returning angle in the albedo treatment.

\section{K6-131 NO FISSIONS}

This message from subroutine NSTART indicates that none of the generations encountered a fissile material so no fission points were generated.

K6-132 WARNING....ONLY INDEPENDENT FISSION POINTS WERE GENERATED 
This message from subroutine NSTART indicates that less than $n p b$ (NPG=, Sect. F17.4.3) fission points were generated during the previous generation. Because $n p b$ fission points are required by the code, the remaining fission points are randomly selected from those that were generated, thus utilizing duplicate fission points. If the number of fission points is considerably less than $n p b$ for most of the generations, the answer can be affected.

\section{K6-133 NUMBER OF GENERATIONS RUN WAS INSUFFICIENT TO EDIT}

This message from subroutine KEDIT occurs if the number of generations completed is less than nskip+1 (NSK=, Sect. F17.4.3). In this instance, the summaries for the problem cannot be printed.

K6-134 FLUXES FOR UNIT WILL NOT FIT IN CORE.

This message from subroutine FITFLX indicates that the flux array is too large for the available core space. More space can be allocated in the job control language if desired.

K6-137 INPUT DATA SAD TO PRINT WEIGHTS, BUT THEY WERE NOT PRINTED BECAUSE THE NUMBER OF ENERGY GROUPS EXCEEDS THE AVAILABLE SPACE.

This message is from subroutine MASTER. In order to accommodate the specified number of energy groups, more computer storage must be requested in the job control language.

K6-138 ********** A WEIGHT OF 0.0 INDICATES THAT WEIGHTS WERE NOT READ OR GENERATED FOR THE BIAS ID.

********* WEIGHTS OF 0.0 WILL BE DEFAULTED TO 0.5 PRIOR TO EXECUTION

**********

This message is from subroutine PRTWTS. It is printed to alert the user that weights were not entered, defaulted, or generated. This message may appear as the result of a code error.

K6-139 ***** ERROR ***** NO VALID MIXTURES WERE FOUND IN THE GEOMETRY DESCRIPTION.

This message from subroutine ICEMIX indicates that the geometry data did not specify any valid mixtures. Check the geometry data (Sect. F17.4.4) and correct any errors that are found. This message can also be triggered if the unit orientation data description is not properly entered for geometry having more than one unit.

K6-140 ***ERROR*** NOT ENOUGH STORAGE FOR START TYPE 6 DATA. 1ST IS AMT NEEDED, 2ND IS AMT AVAILABLE. PERTINENT CONSTANTS (1) (2)

This message from subroutine SAVST6 indicates that more computer storage is necessary to run this problem. At least (1) words of storage are needed to run the problem, but only (2) words of storage were available. Increase the amount of computer storage requested in the job control language to correspond to the amount of storage needed. A STOP 126 is executed in conjunction with this message and a traceback may be printed from subroutine STOP. 


\section{K6-141 DATA CANNOT BE CHANGED WHEN A PROBLEM IS RESTARTED AT A GENERATION GREATER THAN ONE.}

This message from subroutine DATAIN is printed if data other than parameter data are entered for a problem being restarted at a generation greater than one. If data other than certain parameter data are to be changed, the problem must be restarted with the first generation. The error flag is set so the problem will not execute.

\section{K6-142 NO GEOMETRY DATA HAS BEEN SPECIFIED IN THE INPUT DATA.}

This message from subroutine DATAIN indicates that a geometry data block was not entered for the problem either as input data or from the restart unit. Correct the data and resubmit the problem. A STOP 135 is executed in conjunction with this message, and a traceback may be printed from subroutine STOP.

\section{K6-143 UNIT ORIENTATION DATA IS REQUIRED IF MÓRE THAN ONE UNIT TYPE IS SPECIFIED IN THE GEOMETRY DATA.}

This self-explanatory message is from subroutine DATAIN. Enter an array $i$ or unit orientation data block as described in Sects. F17.4.5 and F17.5.6. A STOP 136 is executed in conjunction with this message, and a traceback may be printed from subroutine STOP.

K6-144 DUE TO INCONSISTENCIES BETWEEN INPUT AND RESTART DATA, MATRIX INFORMATION BY UNIT TYPE WILL BE CALCULATED BUT NOT PRINTED. INPUT DATA SET MKU=NO, BUT DATA FROM THE RESTART UNIT SPECIFIED YES.

This self-explanatory warning message is from subroutine PARTBL. The matrix information by unit type cannot be eliminated if it was calculated by the original problem (parent case) that wrote the restart data. However, printing it can be avoided. Verify that the correct problem is being used for restarting the problem (the title is printed at the bottom of the parameter tables). Also verify the specification of the restart unit, RST, in the third table of the output.

\section{K6-145 DUE TO INCONSISTENCIES BETWEEN INPUT AND RESTART DATA, MATRIX INFORMATION BY UNIT LOCATION WILL BE CALCULATED BUT NOT PRINTED. INPUT DATA SET MKP=NO, BUT DATA FROM THE RESTART UNIT SPECIFIED YES.}

This self-explanatory warning message is from subroutine PARTBL. The matrix information by unit location (also called array position or position index) cannot be eliminated if it was calculated by the original problem (parent case) that wrote the restart data. However, printing it can be avoided. Verify that the correct problem is being used for restarting the problem (the title is printed at the bottom of the parameter tables). Also verify the specification of the restart unit, RST, in the third table of the output.

\section{K6-146 *** ERROR ***** ERROR *** PARAMETER DATA SPECIFIED MATRIX INFORMATION BY} UNIT TYPE BUT IT WAS NOT FOUND ON THE RESTART UNIT.

This message from subroutine RDCALC is printed if a restarted problem requests matrix information by unit type when it was not requested and calculated by the original problem (parent case) that wrote the restart data. Verify that the correct restart data are being used and that the restart unit (RST) is correctly specified. 
Eliminate the request for matrix information by unit type (MKU $=$, in the parameter data) if it is not necessary. The problem must be restarted with the first generation ( $\mathrm{BEG}=1$, in the parameter data) if matrix information by unit type is required and was not calculated by the parent case. A STOP 121 is executed in conjunction with this message.

\section{K6-147 *** ERROR ***** ERROR *** PARAMETER DATA SPECIFIED MATRIX INFORMATION BY UNIT LOCATION BUT IT WAS NOT FOUND ON THE RESTART UNIT.}

This message from subroutine RDCALC is printed if a restarted problem requests matrix information by unit location (also called array position or position index) when it was not requested and calculated by the original problem (parent case) that wrote the restart data. Verify that the correct restart data are being used and that the restart unit (RST) is correctly specified in the first table following the parameter table. Eliminate the request for matrix information by unit location ( $\mathrm{MKP}=$, in the parameter data) if it is not necessary. If matrix information by unit location is required and if it was not calculated by the parent case, the problem must be restarted with the first generation ( $\mathrm{BEG}=1$, in the parameter data). A STOP 121 is executed in conjunction with this message.

\section{K6-149 A CROSS SECTION LIBRARY WAS SPECIFIED FOR A RESTARTED PROBLEM, BUT MIXING TABLE DATA WERE NOT AVAILABLE. THE PROBLEM WILL NOT EXECUTE.}

This message from subroutine $R D R S T$ means that $L I B=$ was entered in the parameter data block and a mixing table data block was not available. A flag is set to terminate execution when the data reading has been completed. If cross sections are to be used from the restart unit $(\mathrm{RST}=)$, eliminate the $\mathrm{LIB}=$ or $\mathrm{XSC}=$ from the parameter data. If new cross sections are to be mixed, $\mathrm{LIB}=$ must be specified in the parameter data. The IDs in the mixing table must be available on the cross-section library specified by LIB=. A problem can be restarted using a new mixed cross-section library by specifying $\mathrm{XSC}=$ in the parameter data.

K6-151 *** ERROR *** IS AN INVALID ARRAY TYPE IN THE ARRAY DEFINITION DATA

This message from subroutine ARAYIN indicates that a parameter name was misspelled or the data were out of order. See Sect. F17.4.5 for a list of the array parameter names. A stop 137 is executed in conjunction with this message.

\section{K6-152 *** ERROR *** IRET $=$ A PREMATURE TERMINATION WAS ENCOUNTERED WHILE READING ARRAY DATA. IRET $=1$ INDICATES AN END WAS FOUND. IRET=2 INDICATES AN END OF FILE.}

This message from subroutine ARAYIN indicates that an array number was specified without entering the corresponding UNIT ORIENTATION DESCRIPTION. See Sects. F17.4.5 and F17.5.6 for assistance.

\section{K6-153 FIRST TWO NUMBERS ARE WORDS OF STORAGE NEEDED AND ALLOCATED. THIRD IS ADDITIONAL REGION SIZE NEEDED.}

This message from subroutine SORTA indicates that the allocated computer storage is too small to allow loading the unit orientation data prior to determining the nesting level of the arrays defined by the unit orientation data. The first number printed is the amount of storage, in words, needed to hold these data. The second number is the amount of computer storage that was allocated, and the third number is the minimum 
additional region size, in units of Kbytes, necessary to hold these data. Increase the region size for the "go step" in the job control language by the additional required region size (the third number) and resubmit the problem. A STOP 138 is executed in conjunction with this message.

K6-154 *** ERROR *** LEVELA= IS LARGER THAN THE NUMBER OF ARRAYS.

This message from subroutine SORTA indicates that the array data specified in the problem are recursively nested. An example of this is the following:

array 1 contains array 3 , array 2 contains array 1 , array 3 contains array 2

Thus the definition of array 1 and array 3 are intertwined in a never-ending loop. Correct the array data (Sect. F17.4.5) and resubmit the problem. If the input data did not specify recursive nesting, a code error has occurred. A STOP 139 is executed in conjunction with this message.

K6-155 *** ERROR *** THE NESTING FLAG OR NUMBER OF ARRAY LEVELS HAS BEEN DESTROYED BY A CODE ERROR. THE ORIGINAL NESTING FLAG WAS SET THE ORIGINAL NESTING LEVEL WAS IT IS NOW SET IT IS NOW

This self-explanatory message is from subroutine LODARA. A STOP 140 is executed in conjunction with this message.

K6-156 *** ERROR *** MIXTURE CONTAINS AT LEAST ONE ZERO VALUE FOR THE TOTAL CROSS SECTION.

This message is from subroutine XSECID. All the total cross sections must be positive. Zero total cross sections can occur if all the components of a mixture are mixed with a zero number density. Correct the mixing table for the specified mixture and resubmit the problem.

K6-157 *** ERROR *** THE FIRST HOLE IN A UNIT MUST FOLLOW A VALID GEOMETRY REGION.

This message is from subroutine READGM. If holes are to be utilized in the geometry region data (Sect. F17.4.4), they must follow the region in which they are to be placed. This message indicates that HOLE was the first geometry description in a unit or was placed inside an ARRAY description. Correct the geometry region data and resubmit the problem.

K6-158 *** ERROR *** ERROR IN THE NUMBER OF HOLES. IHOL= NUMHOL $=$

This message is from subroutine READGM. A code error is the probable cause of this error.
K6-159 *** ERROR *** ARRAYNUMBER NOT ENTERED IN THE ARRAY DATA.
SPECIFIED IN THE GEOMETRY REGION DATA WAS

This message from subroutine SORTA occurs if the array number specified for an ARRAY region description of the GEOMETRY data (Sect. F17.4.4) did not have the corresponding UNIT ORIENTATION NUREG/CR-0200, Vol. 2, Rev. 5 
DATA entered in the ARRAY DATA (Sect. F17.4.5). A STOP 142 is executed in conjunction with this message when it is printed from subroutine SORTA. Correct the data and resubmit the problem.

\section{K6-160 THE HOLES ARE RECURSIVELY NESTED.}

This message from subroutine HOLE indicates that the geometry region data description (Sect. F17.4.4) specifies holes that are recursively nested. This situation can happen if a unit contains a hole whose definition traces back to the same unit or are defined in terms of each other. A simple example of recursive nesting follows:

\section{UNIT 1 CUBOID 16 PI0.0 HOLE $213 * 0.0$ BOUNDARY 1 \\ UNIT 2 CUBOID 16 PI0.0 HOLE $113^{*} 0.0$ BOUNDARY 1}

Thus unit 1 contains unit 2 , and unit 2 contains unit 1 . Check the geometry region data for recursive nesting. In the absence of recursive nesting, a code error is the probable cause of this message. A STOP 143 is executed when this message occurs and a traceback is printed.

K6-163 *** ERROR *** ARRAY NUMBER IS _ WORDS LONG, BUT ONLY _ WORDS ARE AVAILABLE WHEN WRTING RESTART. THE RESTART FILE WILL BE INCOMPLETE. THE PROBLEM WILL NOT EXECUTE.

This message is from subroutine WRTARA. It indicates that the available computer storage is too small to hold the array data from the direct-access device. This situation in turn will cause the restart data file to be incomplete. Increase the requested storage space in the job control language and resubmit the problem.

K6-164 *** WARNING *** ARRAY NUMBER __ IS __ WORDS LONG, BUT ONLY WORDS ARE AVAILABLE WHEN READING RESTART. THIS ARRAY WILL NOT BE AVAILABLE. THE PROBLEM WILL NOT EXECUTE IF THIS ARRAY IS USED.

This message is from subroutine RDARA. It occurs when the restart data file is being loaded from the restart unit and the allocated space is insufficient to hold the data for the specified array. Resubmit the problem, requesting more storage space in the job control language.

\section{K6-168 INSUFFICIENT DATA FOLLOWING THE KEYWORD "HOLE".}

This self-explanatory message is from subroutine RDARA. Check the data following the keyword "HOLE." Either the data are missing or noninteger data were inadvertently entered. See Sect. F17.4.4.

K6-170 ***** ERROR ***** SECTOR DATA WAS NOT FOUND FOR HOLE

This self-explanatory message is from subroutine HOLEIN. Check the sector data following the HOLE media record corresponding to hole number . Either the data are missing or noninteger data were inadvertently entered. See Sect. F17.4.4.

K6-171 ERROR - DIRECTION COSINES DOWN THE PAGE WERE ALL INPUT AS ZERO. 
This message from subroutine RDPLOT indicates that the values for UDN $=, V D N=$ and WDN= were all zero. A zero value vector does not define a direction, so an error has occurred. See Sect. F17.4.11 for information concerning direction cosines down the page.

\section{K6-172 ERROR - DIRECTION COSINES ACROSS THE PAGE WERE ALL INPUT AS ZERO.}

This message from subroutine $\mathrm{RDPLOT}$ indicates that the values for $\mathrm{UAX}=, \mathrm{VAX}=$ and WAX $=$ were all zero. This message is an error because a zero value vector does not define a direction. See Sect. F17.4.11 for assistance in defining direction cosines across the page.

K6-173 ERRORS WERE DETECTED IN THE INPUT DATA FOR THIS PICTURE. IT WILL NOT BE DRAWN.

This message from subroutine RDPLOT is a companion to messages K6-174, K6-180, K6-171 and K6-172. Correct the error that triggered the companion message, and resubmit the problem.

K6-174 ERROR IN KENO PICTURE DATA SHOULD BE ENTERED AS YES OR NO.

This self-explanatory message is from subroutine RDPLOT. Correct the error and resubmit the problem. See Sect. F17.4.11 for assistance.

K6-175 DUE TO INCONSISTENCIES BETWEEN INPUT AND RESTART DATA, MATRLX INFORMATION BY HOLE WILL BE CALCULATED BUT NOT PRINTED. INPUT DATA SET MKH= NO, BUT DATA FROM THE RESTART UNIT SPECIFIED YES.

This self-explanatory warning message is from subroutine PARTBL. The matrix information by hole cannot be eliminated if it was calculated by the original problem (parent case) that wrote the restart data. However, printing it can be avoided. Verify that the correct problem is being used for restarting the problem (the title is printed at the bottom of the parameter tables). Also, verify the specification of the restart unit, RST, in the third table of the computer output.

K6-176 DUE TO INCONSISTENCIES BETWEEN INPUT AND RESTART DATA, MATRIX INFORMATION BY ARRAY WILL BE CALCULATED BUT NOT PRINTED. INPUT DATA SET $M K A=N O$, BUT DATA FROM THE RESTART UNIT SPECIFIED YES.

This self-explanatory warning message is from subroutine PARTBL. The matrix information by array cannot be eliminated if it was calculated by the original problem (parent case) that wrote the restart data. However, printing it can be avoided. Verify that the correct problem is being used for restarting the problem (the title is printed at the bottom of the parameter tables). Also, verify the specification of the restart unit, RST, in the third table in the computer output.

\section{K6-177 ***ERROR *** *** ERROR *** PARAMETER DATA SPECIFIED MATRIX INFORMATION BY HOLE BUT IT WAS NOT FOUND ON THE RESTART UNIT.}

This message from subroutine RDCALC is printed if a restarted problem requests matrix information by hole when it was not requested and calculated by the original problem (parent case) that wrote the restart data.

NUREG/CR-0200,

Vol. 2, Rev. 5

F17.7.28 
Verify that the correct restart data file is being used and that the restart unit (RST) is correctly specified. Eliminate the request for matrix information by hole $(\mathrm{MKH}=$, in the parameter data) if it is not necessary. The problem must be restarted with the first generation (BEG $=1$, in the parameter data) if matrix information by hole is required and was not calculated by the parent case. A STOP 121 is executed in conjunction with this message.

\section{K6-178 *** ERROR ****** ERROR *** PARAMETER DATA SPECIFIED MATRIX INFORMATION BY ARRAY BUT IT WAS NOT FOUND ON THE RESTART UNIT.}

This message from subroutine RDCALC is printed if a restarted problem requests matrix information by array (also called array position or position index) when it was not requested and calculated by the original problem (parent case) that wrote the restart data. Verify that the correct restart data are being used and that the restart unit (RST) is correctly specified in the first table following the parameter tables. Eliminate the request for matrix information by array ( $M K A=$, in the parameter data) if it is not necessary. If matrix information by array is required and if it was not calculated by the parent case, the problem must be restarted with the first generation ( $B E G=1$, in the parameter data). A STOP 121 is executed in conjunction with this message.

K6-180 ERROR IN KENO PICTURE DATA - KEYWORD IS NOT VALID.

This message from subroutine RDPLOT indicates that the plot or picture data are out of order or a keyword is incorrectly spelled. See Sect. F17.4.11 for a list of correct keywords.

K6-181 ***ERROR*** LPIC IS OUT OF RANGE. LPIC=

This message from subroutine PRTPLT indicates that a code error has occurred or the type of plot $(\mathrm{PIC}=$ ) was not properly specified. lpic $=1$ for a mixture map, lpic $=2$ for a unit map and $l p i c=3$ for a bias ID map. Any other values of lpic are invalid.

\section{K6-182 INSUFFICIENT SPACE FOR PLOTTING ARRAYS. FIRST NOS ARE STORAGE NEEDED AND ALLOCATED. LAST IS REQUIRED ADDITIONAL REG. SIZE.}

This message from subroutine BOOK5 is accompanied by a STOP 147 . It indicates that the allocated computer storage will not hold the plot data. The first number printed is the amount of storage, in words, needed to hold these data. The second number is the amount of computer storage that was allocated, and the third number is the minimum additional region size, in units of Kbytes, necessary to hold the data. Increase the region size for the "go step" in the job control language by this third number and resubmit the problem. If additional computer storage is not available, eliminate the fluxes, fissions and absorptions by region, matrix information or other space consuming options (see Sect. F17.4.3).

K6-184 ******__ WORDS OF STORAGE ARE NEEDED FOR THE WEIGHTS, BUT ONLY WORD $\overline{S \text { ARE AVAILABLE. }}$

This message from subroutine RDBIAS indicates that the allocated computer storage is not sufficient to process the biasing or weighting data for the problem. Increase the region size in the "go step" of the job control language. The additional required region size is four times (the difference of the two numbers plus 1023) divided by 1024. A STOP 151 is executed when this message is printed. 
K6-185 *** ERROR *** THE NUMBER OF SETS OF BIASING CORRELATION DATA EXCEEDS THE NUMBER THAT WAS WRITTEN WHEN THE BIASING DATA WAS READ. WERE WRITTEN, BUT AN ATTEMPT WAS MADE TO READ

This message from subroutine WAITIN is accompanied by a STOP 148. It is indicative of a code error, unless accompanied by error messages related to the biasing input data.

K6-186 *** ERROR *** THE NUMBER OF SETS OF BIASING AUXILIARY DATA EXCEEDS THE NUMBER THAT WAS WRITTEN WHEN THE BIASING DATA WAS READ. WRITTEN, BUT AN ATTEMPT WAS MADE TO READ WERE

This message from subroutine WAITIN is accompanied by a STOP 149. It is indicative of a code error, unless accompanied by error messages related to the biasing input data.

K6-187 ***** WARNING - INTERVALS IN THE ABOVE RANGE WERE NOT USED. THIS COULD LEAD TO IMPROPER BIASING.

This message from subroutine LODWTS is printed to remind the user that at least one of the specified intervals was not utilized in the problem, which can result in improper biasing. Biasing should not be used between fissile units. When biasing is used, it should be flat, or increasing, as distance from the fissile material increases, and flat, or decreasing, as a history moves toward fissile material. See Sect. F17.5.8 for additional assistance.

K6-188 *** ERROR *** HOLE NUMBER REFERENCES UNDEFINED UNIT NUMBER

This message is printed by subroutine HOLE and READGM if the unit number referenced by the hole is less than 1 or greater than the largest unit number in the geometry data. The message is printed by subroutine HOLE if the unit number referenced by the hole is larger than zero and not greater than the largest unit number in the geometry data, but is a unit number for which all data are missing otherwise it is printed by subroutine READGM. Specify a valid unit number (lhole - see GEOMETRY DESCRIPTION, Sect. F17.4.4) and resubmit the problem.

K6-190 ERROR IN PICTURE DATA - OPTION IS NOT VALID FOR KEYWORD PIC $=$.

This message from subroutine RDPLOT indicates an incorrect option associated with the keyword PIC=. See Sect. F17.4.11. Acceptable options include MAT, MIX, MIXT, MEDI, BOX, BOXT, UNT, UNIT, IMP, BIAS, WTS, WGT, WGTS or WEIGH.

K6-191 ***** ERROR ***** START TYPE HAVE A GLOBAL ARRAY. ***** ERROR ***** IS INVALID FOR A PROBLEM THAT DOES NOT

This message from subroutine DATAIN occurs if the start type (NST= in the start data, Sect. F17.4.8) is 2,3,4, or 5. A global array is required in order to use the specified start type.

K6-192 MATRIXINFORMATION BY ARRAY WAS SPECIFIED AS YES IN THE PARAMETER DATA $(M K A=)$, BUT IS NOT ALLOWED BECAUSE ARRAY DATA WERE NOT SPECIFIED. 
This warning message from subroutine DATAIN is self-explanatory. The code redefines the problem, so matrix information will not be collected by array number.

K6-193 MATRIX INFORMATION BY HOLE WAS SPECIFIED AS YES IN THE PARAMETER DATA $(\mathrm{MKH}=)$, BUT IS NOT ALLOWED BECAUSE HOLE DATA WERE NOT SPECIFIED.

This warning message from subroutine DATAIN is self-explanatory. The code redefines the problem, so matrix information will not be collected by hole number.

K6-194 MATRIX INFORMATION BY UNIT LOCATION WAS SPECIFIED AS YES IN THE PARAMETER DATA (MKP=), BUT IS NOT ALLOWED BECAUSE A GLOBAL ARRAY WAS NOT SPECIFIED.

This warning message from subroutine DATAIN is self-explanatory. The code redefines the problem, so matrix information will not be collected by unit location.

K6-195 ***** ERROR ***** CHARACTER STRING EXCEEDS THE SPECIFIED LENGTH. CHECK FOR ENDING DELIMITER.

This error message is from subroutine RCHRS. It indicates that either the character string exceeds 132 characters or the ending delimiter was omitted for $\mathrm{TTL}=$ (plot title, Sect. F17.4.11) or for COM= (unit comment, Sect. F17.4.4, or array comment, Sect. F17.4.5). A STOP 153 is executed when this message is printed.

K6-196 A PROBLEM CANNOT BE RESTARTED WHEN RESTART DATA DO NOT EXIST FOR THE SPECIFIED GENERATION AND THE NEXT GENERATION FOR WHICH RESTART DATA ARE AVAILABLE IS LARGER THAN THE REQUESTED NUMBER OF GENERATIONS. EXECUTION IS TERMINATED.

This message from subroutine RDCALC indicates that a problem was to be restarted but the requested number of generations (GEN=, Sect. F17.4.3) was smaller than the beginning generation number ( $\mathrm{BEG}=$, Sect. F17.4.3). The beginning generation number for a restarted problem is the generation at which the calculation of k-effectives and associated information is resumed. Therefore, the number of generations to be run must be larger than the beginning generation number. Correct the data and resubmit the problem. A STOP 154 is executed when this message is printed.

K6-198 *** ERROR *** ARRAY _ CONTAINS AN ERROR IN THE INPUT DATA.

This message from subroutine ARAYIN is printed as the result of an error in the FILL input data for the specified array. One or more messages from the library routine YREAD should immediately precede this message and indicate the nature of the error. Correct the data and resubmit the problem. Messages K6-32, $\mathrm{K} 6-33$, and/or K6-85 may also print as a result of this error.

K6-199 *** ERROR *** AN ARRAY WAS SPECIFIED IN THE GLOBAL UNIT, BUT ARRAY DATA WERE NOT ENTERED 
This message from subroutine SORTA occurs if array data are not entered when the global unit geometry specifies an array. A STOP 156 is executed in conjunction with this message. Enter the appropriate array data and resubmit the problem.

K6-200 *** ERROR *** START TYPE 6 WAS SPECIFIED IN THE START DATA, BUT THE STARTING POINTS WERE NOT SPECIFIED.

This message from subroutine RDSTRT indicates that start type 6 was specified but the corresponding starting points were not included in the START data block. Enter the corresponding starting points or change the start type. See Sect. F17.4.8.

K6-201 *** WARNING *** NEUTRON _ SPECIFIED A POSITION IN THE GLOBAL ARRAY. THE GLOBAL UNIT DID NOT CONTAIN AN ARRAY SO THE POSITION WAS IGNORED.

This warning message from subroutine START6 indicates that extraneous data were specified in the start type 6 data. Verify that the correct global unit is specified.

K6-202 *** ERROR *** ONLY START TYPES 0, 1, OR 6 ARE VALID FOR A PROBLEM WITHOUT AN ARRAY IN THE GLOBAL UNIT.

This message from subroutine START indicates that the specified start type is not valid for the problem. Choose an appropriate start type. A STOP 157 is executed when this message is printed.

K6-204 EXECUTION TERMINATED DUE TO ACHIEVING THE STANDARD DEVIATION SPECIFIED FOR THE PROBLEM.

This message from subroutine GUIDE states that the requested standard deviation has been achieved. If a lower standard deviation is desired decrease the requested standard deviation (SIG=, Sect. F17.4.3).

K6-206 *** ERROR *** THE UNIT SPECIFIED FOR STARTING IS NOT USED IN THE PROBLEM OR IS UNDEFINED.

This message from subroutine START indicates that the unit in which neutrons are to be started is undefined. Verify that the global unit or array is correctly specified. Check the start data for start types 4 and 5 (Sect. F17.4.8) to be sure NBX=is correctly specified. A STOP 158 is executed when this message is printed.

K6-207 *** ERROR *** THE STARTING ARRAY POSITION IS INVALID.

This message from subroutine START indicates that the array position NXS, NYS, or NZS is not valid for start types 3 or 6 . NXS, NYS, and NZS must be larger than zero and no larger than NBXMAX, NBYMAX, and NBZMAX of the global array, respectively. Verify that the global unit or array is correctly specified. Correct the start data (Sect. F17.4.8) and resubmit the problem. A STOP 159 is executed when this message is printed.

K6-208 *** WARNING *** THE FRACTION OF NEUTRONS STARTED AS A SPIKE WAS LESS THAN ZERO. IT HAS BEEN RESET TO ZERO.

NUREG/CR-0200,

Vol. 2, Rev. 5

F17.7.32 
This message from subroutine START indicates that FCT= was incorrectly specified in the start data for start type 2. The resultant starting distribution is a cosine distribution throughout the volume of a cuboid defined by XSM, XSP, YSM, YSP, ZSM, and ZSP (see Sect. F17.4.8). If a "spike" was desired, set FCT= to a positive number between 0.0 and 1.0. If FCT $=0.0$ is specified, a cosine distribution without a "spike" is used as the starting distribution. If FCT $=1.0$ is specified, all the neutrons are started as a "spike" (i.e., they are started uniformly in the unit located at position NXS, NYS, NZS in the global array, as indicated in Sect. F17.4.8).

K6-209 *** WARNING *** THE FRACTION OF NEUTRONS STARTED AS A SPIKE WAS GREATER THAN ONE. IT HAS BEEN RESET TO ONE.

This message from subroutine START indicates that FCT= was incorrectly specified in the start type 2 data. The code reset FCT $=1$ so all of the neutrons are started as a "spike" (i.e., they are started uniformly in the unit located at NXS, NYS, NZS in the global array, as indicated in Sect. F17.4.8).

K6-210 *** ERROR *** THE UNIT SPECIFIED FOR STARTING IS NOT IN THE GLOBAL ARRAY.

This message from subroutine START indicates that the unit specified by NBX= does not occur in the global array. Verify that the global array is correctly specified and that the unit specified by NBX=is correct (see Sect. F17.4.8).

\section{K6-211 *** ERROR *** THE NUMBER OF SETS OF BIAS FACTORS FROM RECORDS EXCEEDS THE NUMBER THAT WAS WRITTEN WHEN THE BIASING DATA WAS READ. WERE WRITTEN BUT AN ATTEMPT WAS MADE TO READ}

This message from subroutine WAITIN is indicative of a code error. A STOP 161 is executed when this message is printed.

\section{K6-212 *** ERROR *** THE BIASING DATA SPECIFIED IBGN= _ AND IEND= _. IBGN MUST BE LARGER THAN ZERO AND IEND MUST BE AT LEAST AS LARGE AS IBGN. THE PROBLEM WILL NOT BE RUN.}

This message from subroutine RDBIAS indicates an error in the biasing data. The biasing correlation data are order dependent. The order of data entry is: $\mathrm{D}=\mathrm{nn}$ ibgn iend, where $\mathrm{nn}$ is an $\mathrm{ID}$ number from Table F17.4.5 and ibgn is the beginning BIAS ID and iend is the ending BIAS ID (see Sects. F17.4.7 and F17.5.8). In order to continue checking the input data, if ibgn is less than or equal to zero, it is set to 1. Similarly, if iend is less than ibgn, it is set to ibgn.

\section{K6-213 *** ERROR *** INSUFFICIENT SPACE ALLOCATION. MASTER WAS NOT CALLED.}

This error message is printed from subroutine KENOVI when KENO-VI is executed in the "stand-alone mode" and from subroutine O0O019 when executed as part of a CSAS analytical sequence. The message indicates that the job control language must be altered to provide more computer memory to be utilized by the problem. A STOP 162 is executed when this message is printed.

K6-214 *** ERROR *** THE BASE OF A TRIANGULAR FACE OF A WEDGE CANNOT BE ZERO. 
This self-explanatory message is from subroutine WEDGE. The input data for the wedge following the keyword WEDGE are incorrect. See Sect. F17.4.4.

K6-215 *** ERROR *** THE Y COORDINATE OF A TRIANGULAR FACE OF A WEDGE CANNOT BE ZERO.

This self-explanatory message is from subroutine WEDGE. The input data for the wedge following the keyword WEDGE are incorrect. See Sect. F17.4.4.

K6-216 ***** ERROR ***** XNB= _ IS THE MAXIMUM VALUE THAT CAN BE SPECIFIED IN THE PARAMETER DATA. XNB MUST BE SMALL ENOUGH TO FIT IN THE EXTRA ARRAY OF COMMON NUTRON.

This message from subroutine FLDATA indicates that the value of XNB was set too large. Decrease the size of XNB and retry the problem.

K6-217 *** ERROR *** DIFFERENTIAL ALBEDOS CANNOT BE USED IN AN ADJOINT PROBLEM.

This self-explanatory message is from subroutine FLDATA. Describe reflector material in the mixing table and the geometry instead of using differential albedos or run the problem in the forward mode.

K6-218 ***** ERROR ***** TO START IN A GLOBAL QUADRATIC GEOMETRY, IGEO = VALUES FOR XSM, XSP, YSM, YSP, ZSM, AND ZSP MUST BE ENTERED AS START DATA.

This self-explanatory error message is from subroutine STRTSU. A GLOBAL QUADRATIC GEOMETRY implies an infinite media. The boundary of the starting points must be entered. See Sect. F17.4.8.

K6-219 ***ERROR***THE START DATA SPECIFIED STARTING POINTS CHOSEN FROM A COSINE DISTRIBUTION BUT NONE WERE FOUND.

This message from subroutine START is printed if start type 2 was specified and the code was unable to start any neutrons in the cuboid defined by XSM, XSP, YSM, YSP, ZSM, ZSP. Verify that fissile material exists within that cuboid. If it doesn't, respecify the starting cuboid to contain fissile material or choose a different start type. If message K6-105 states that only 0 independent starting points were generated, it indicates that the code was unable to start any neutrons in the spike specified by start type 2. Verify that the unit specified for the spike contains fissile material. If only a very small fraction of the volume of this unit is fissile, it may be necessary to input a larger value for the KENO-VI parameter "TMAX $=$ " or choose a different start type. The problem will not be run if message $\mathrm{K} 6-219$ is printed.

K6-220 ERROR IN PICTURE DATA.

IF THE COORDINATE OF THE LOWER RIGHT-HAND CORNER IS ENTERED, ONE OF THE PLOT PARAMETERS DLX, DLD, NAX, OR NDN MUST BE ENTERED. CURRENT VALUES ARE LISTED BELOW. TITLE:

(Problem title is listed here)

NUREG/CR-0200,

Vol. 2, Rev. 5

F17.7.34 


\section{UPPER-LEFT UPPER-RIGHT \\ COORDINATES COORDINATES}

$\begin{array}{lll}X & \text { xu } & \text { xl } \\ Y & \text { yu } & \text { yl } \\ Z & \text { zu } & \text { zl }\end{array}$

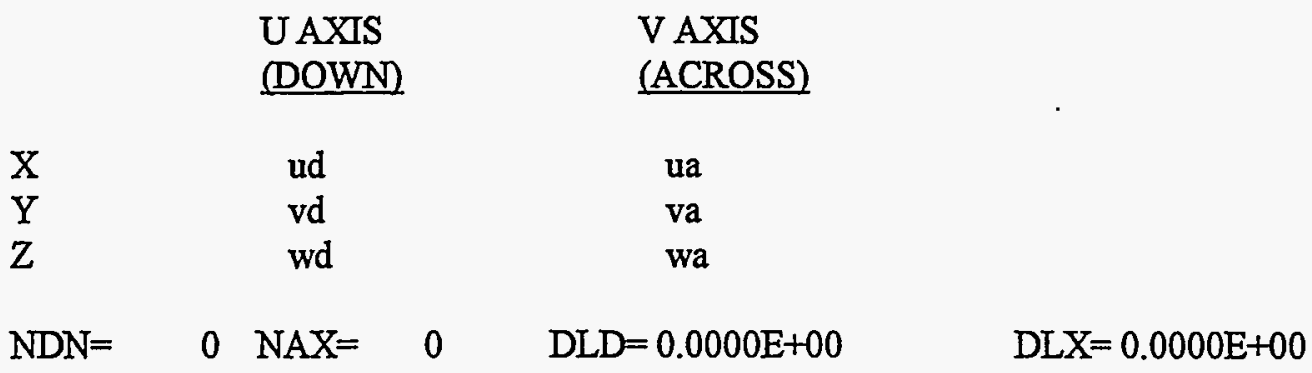

This message from subroutine RDPLOT indicates that the coordinates of the lower-right-hand corner of the plot were specified in the input data without specifying one of the following plot parameters: (1) NDN, the number of characters down the page, (2) NAX, the number of characters across the page, (3) DLD, the vertical spacing between points, or DLX, the horizontal spacing between points. The problem will not be run. To correct the error, specify NDN, NAX, DLD, or DLX in the plot data and resubmit the problem. See Sect. F17.4.11 and F17.5.9 for assistance.

K6-221 ***** ERROR ***** THE LENGTH OF THE EDGE ALONG THE BASE OF THE X-AXIS FOR A RHOMBOID MUST BE GREATER THAN 0.0. CHECK GEOMETRY WORD

This self-explanatory message is from subroutine RHOMB. Check the data following the keyword RHOMB. See Sect. F17.4.4.

K6-222 ***** ERROR ***** THE ANGLE BETWEEN THE Y-AXIS AND THE Y-EDGE OF THE BASE MUST BE BETWEEN 0 AND 90 DEGREES. CHECK GEOMETRY WORD

This self-explanatory message is from subroutine RHOMB. Check the data following the keyword RHOMB. See Sect. F17.4.4.

K6-223 ***** ERROR ***** THE NUMBER OF SCATTERING ANGLES, SCT, ENTERED IN THE MIXING TABLE MUST NOT EXCEED 13. SCT $=$ WAS ENTERED.

This self-explanatory message is from subroutine MIXIT. Adjust the data following the keyword SCT= in the parameter data. See Sect. F17.4.3.

K6-224 *** ERROR *** THE HEIGHT OF A WEDGE CANNOT BE ZERO.

This self-explanatory message is from subroutine WEDGE. The input data for the wedge following the keyword WEDGE are incorrect. See Sect. F17.4.4. 
This self-explanatory error message is from subroutine STRTSU. A GLOBAL PLANE GEOMETRY implies an infinite media. The boundary of the starting points must be entered. See Sect. F17.4.8.

K6-226 ***** ERROR ***** XDIST, YDIST, AND ZDIST SPECIFIED FOR A PPIPED MUST BE GREATER THAN 0.0 .

This self-explanatory message is from subroutine PPIPED. Check the data following the keyword PPIPED. See Sect. F17.4.4.

K6-227 ***** ERROR ***** PSI, THETA, AND PHI SPECIFIED FOR A PARALLELEPIPED MUST BE GREATER THAN OR EQUAL TO 0.0 AND LESS THAN 90.0.

This self-explanatory message is from subroutine PPIPED. Check the data following the keyword PPIPED. See Sect. F17.4.4.

K6-228 ***** ERROR ***** THE CALCULATION WAS TERMINATED BECAUSE THE SAME SPACE IS DEFINED IN MULTIPLE REGIONS

This message from subroutine GUIDE is printed only if message $\mathrm{K} 6-89$ is printed 10 or more times for a given generation. This indicates that the problem defines the same space in multiple regions. If changes have been made in the code, they should be carefully scrutinized. It is probably caused by not correctly specifying the vector definition arrays in the media records of a unit. It can be caused by not correctly specifying regions that share a common boundary so the boundary between regions is contained in only one region. See Sect. F17.4.4 for more information concerning vector definition arrays on MEDIA records.

\section{K6-229 ***** ERROR ***** IN UNIT ____ GEOMETRY RECORDS WERE SPECIFIED BUT WAS SPECIFIED IN A SECTOR DEFINITION ARRAY.}

This message from subroutine KENOG is printed if a geometry record, larger than the total number of geometry specified in a unit, is referenced in the sector definition array of a media record for that unit.

K6-230 ***** ERROR ***** THE CALCULATION WAS TERMINATED BECAUSE A GEOMETRY WORD IN UNIT PRODUCES AN IMAGINARY BOUNDARY.

This message from subroutine PNTCHK should only be produced by the geometry word QUADRATIC when used as part of an array boundary. The boundary produces imaginary results. Check the coefficients of the geometry word.
K6-231 ***** ERROR ***** THE CALCULATION WAS TERMINATED BECAUSE ARRAY _ IS NOT PROPERLY POSITIONED IN REGION THE ARRAY BOUNDARY IS OUTSIDE THE OF UNIT SIDE BY

This message from subroutine PNTCHK is printed only if an array is placed in a region such that there is space in the region not occupied by the array. Reposition your array.

NUREG/CR-0200, 
This error message from subroutine READGM means more than one geometry record in the specified unit was given the same label.

K6-233 ***** ERROR ***** A VECTOR DEFINITION ARRAY IN UNIT GEOMETRY RECORD WHICH HAS NOT BEEN SPECIFIED.

REFERENCES

This error message from subroutine KLANGA means a geometry record was specified in a vector definition array that has not been defined in the specified unit.

LABEL

This error message from subroutine KLANGA means a geometry label used in the unit boundary definition vector has the opposite sign of the same geometry label used in a media, array, or hole definition vector in the same unit. The geometry labels used in the unit boundary definition vector do not need to be repeated in the other definition vectors in the unit. If they are repeated they need to have the same sign as those used in the boundary definition vector.

\section{K6-235 ***** ERROR ***** BOUNDARY SECTOR DATA WAS NOT BOUND FOR UNIT}

This error message from subroutine BNDRY means a boundary record is present in the specified unit but does not contain sector data.

K6-236 ***** ERROR ***** THE UNIT BOUNDARY RECORD CONTAINS MORE THAN ONE POSITIVE GEOMETRY RECORD LABEL.

This error message from subroutine JOMCHK is printed when the boundary record of a unit used in an array contains more than one positive geometry record label. When a unit is used in an array, the boundary record must contain only one positive geometry record label that is consistent with the type of array it is used in.

\section{K6-237 ***** ERROR ***** THE GLOBAL UNIT BOUNDARY IS NOT DEFINED BY A SINGLE CUBOID BUT CONTAINS MULTIPLE ALBEDOS.}

This error message from subroutine JOMCHK indicates more than one albedo type was specified for the problem but a single cuboid was not used to define the global unit boundary. Multiple albedo types are only allowed if a single cuboid is used to define the global unit boundary.

K6-238 ***** ERROR ***** THE GLOBAL UNIT BOUNDARY USES MULTIPLE GEOMETRY WORDS BUT NOT THE VOID ALBEDO.

This error message from subroutine JOMCHK indicates an albedo other than void was specified with a global unit boundary definition vector containing more than one geometry record label. Multiple geometry 
record labels are allowed in the global unit boundary definition vector only for the void albedo on all surfaces. Void is the default boundary condition.

\section{K6-239 ***** ERROR ***** ALBEDO OTHER THAN VOID WHITE OR REFLECTED USED WITH NONPAIRED PLANE BOUNDARY.}

This error message from subroutine JOMCHK indicates an albedo other than void, white, or mirror is specified but the global unit boundary definition vector is specified by a nonpaired plane geometry record. Only void, mirror, or white albedo conditions may be used when the global boundary uses nonpaired planes.

\section{F17.7.2 STOP CODES}

The STOP codes that are encountered in KENO VI are listed in tabular form, indicating the subroutine where they occur and the associated error message. A STOP is executed whenever a fatal error is recognized. Look up the associated message number to determine the appropriate corrective measures. A traceback may be generated whenever subroutine STOP is called to print a message. If no traceback is indicated in the STOP CODE table, a stop is executed as soon as the associated message is printed, as shown in the following: 


\begin{tabular}{|c|c|c|c|}
\hline STOP & & & $\begin{array}{l}\text { ASSOCIATED } \\
\text { MESSAGE }\end{array}$ \\
\hline$\frac{\text { NO. }}{20}$ & SUBROUTINE & TRACEBACK & $\frac{\text { MESSAGE }}{\text { See Sect. F17.7.3 }}$ \\
\hline 100 & ARAYIN & Yes & $\mathrm{K} 6-25$ \\
\hline 101 & ARAYIN & No & K6-31 \\
\hline 105 & WRTALB & No & K6-71 \\
\hline 106 & ICEMTX & No & K6-68 \\
\hline 107 & $\mathbb{N D X}$ & No & K6-124 \\
\hline 108 & INITAL & No & $\mathrm{K} 6-2$ \\
\hline 109 & INITAL & No & $\mathrm{K} 6-2$ \\
\hline 110 & MAKANG & Yes & K6-57 \\
\hline 111 & MIXCRS & Yes & $\mathrm{K} 6-52$ \\
\hline 112 & MIXER & Yes & K6-53 \\
\hline 113 & MIXER & Yes & $\mathrm{K} 6-54$ \\
\hline 114 & MIXIT & Yes & K6-15 \\
\hline 115 & NORM1D & No & $\mathrm{K} 6-56$ \\
\hline 116 & NSUPG & Yes & $\mathrm{K} 6-79$ \\
\hline 117 & NSUPG & No & K6-81 \\
\hline 118 & PARAM & No & $\mathrm{K} 6-7$ or $\mathrm{K} 6-8$ \\
\hline 120 & RDALB & No & $\mathrm{K} 6-49$ \\
\hline 121 & RDCALC & No & $\begin{array}{l}\mathrm{K} 6-116 \text { or } \mathrm{K} 6-146 \\
\text { or } \mathrm{K} 6-147 \text { or } \mathrm{K} 6-177 \\
\text { or } \mathrm{K} 6-178\end{array}$ \\
\hline 122 & RDICE & No & $\mathrm{K} 6-50$ \\
\hline 123 & RDRST & No & $\mathrm{K} 6-48$ \\
\hline 124 & RDTAPE & No & $\mathrm{K} 6-69$ \\
\hline 125 & READGM & No & $\mathrm{K} 6-20$ \\
\hline 126 & SAVST6 & Yes & $\mathrm{K} 6-140$ \\
\hline 128 & START & Yes & K6-101 \\
\hline 129 & BOOK5 & No & $\mathrm{K} 6-100$ \\
\hline 130 & BOOK1 & No & $\begin{array}{l}\mathrm{K} 6-117 \text { or } \mathrm{K} 6-128 \text { or } \\
\mathrm{K} 6-228\end{array}$ \\
\hline 131 & VOLFIS & No & K6-110 \\
\hline 132 & WRTICE & No & $\mathrm{K} 6-72$ \\
\hline 133 & WRTRST & No & $\mathrm{K} 6-70$ \\
\hline 135 & DATAIN & Yes & K6-142 \\
\hline 136 & DATAIN & Yes & K6-143 \\
\hline 137 & ARAYIN & No & K6-151 \\
\hline 138 & SORTA & Yes & K6-153 \\
\hline 139 & SORTA & No & K6-154 \\
\hline 140 & LODARA & No & K6-155 \\
\hline 142 & SORTA & No & K6-159 \\
\hline 143 & HOLE & No & K6-160 \\
\hline 147 & BOOK5 & Yes & K6-182 \\
\hline 148 & WAITIN & No & K6-185 \\
\hline 149 & WAITIN & No & K6-186 \\
\hline
\end{tabular}

F17.7.39

NUREG/CR-0200, Vol. 2, Rev. 5 


\begin{tabular}{|c|c|c|c|}
\hline $\begin{array}{l}\text { STOP } \\
\text { NO. }\end{array}$ & SUBROUTINE & TRACEBACK & $\begin{array}{c}\text { ASSOCIATED } \\
\text { MESSAGE }\end{array}$ \\
\hline 150 & WATES & Yes & $\mathrm{K} 6-22$ \\
\hline 151 & RDBIAS & No & K6-184 \\
\hline 152 & DATAIN & No & $\mathrm{K} 6-46$ \\
\hline 153 & RCHRS & Yes & K6-195 \\
\hline 154 & RDCALC & No & K6-196 \\
\hline 155 & GEOMIN & Yes & $\mathrm{K} 6-25$ \\
\hline 156 & SORTA & Yes & K6-199 \\
\hline 157 & START & No & K6-202 \\
\hline 158 & START & No & K6-206 \\
\hline 159 & START & No & $\mathrm{K} 6-207$ \\
\hline 160 & START & No & K6-210 \\
\hline 161 & WAITIN & No & $\mathrm{K} 6-211$ \\
\hline 162 & $\begin{array}{l}\text { KENO-VI, } \\
\text { O0O019 }\end{array}$ & Yes & $\mathrm{K} 6-213$ \\
\hline
\end{tabular}

\section{F17.7.3 MESSAGES ASSOCIATED WITH STOP 20 IN KENO-VI}

The error messages that are associated with a STOP 20 in KENO-VI are listed below in numerical order. Look up the appropriate message number to determine corrective measures.

\section{LMP001 DA ERROR - INVALID UNIT NUMBER. THE LOGICAL UNIT NUMBER IS}

This message from the subroutine library direct-access routines indicates that an invalid unit number was specified as a direct-access device. In KENO-VI, this message is indicative of a code error.

\section{LMP002 DA ERROR - FORTRAN USING THIS UNIT. THE LOGICAL UNIT NUMBER IS}

This message from the subroutine library direct-access routines indicates that the specified unit number is open as a sequential dataset rather than a direct-access dataset. In KENO-VI, this error may be caused by entering a direct-access unit number for $\mathrm{LIB}=$ or $\mathrm{XSC}=$.

\section{LMP003 DA ERROR - DCB NOT OPEN.} THE LOGICAL UNIT NUMBER IS

This message from the subroutine library direct-access routines indicates that the program attempted to read or write on a direct-access device, but the data control block was not open. In KENO-VI this message is indicative of a code error.

LMP004 DA ERROR - UNABLE TO OPEN DCB. THE LOGICAL UNIT NUMBER IS 
This message from the subroutine library direct-access routines indicates that the program is unable to open the data control block for the direct-access device. This message indicates that the job control language did not include proper specification of the above named unit.

LMP005 DA ERROR - RELATIVE BLOCK NOT IN DATA SET. RELATIVE BLOCK NUMBER IS

This message from the subroutine library direct-access routines indicates that the number of direct-access blocks is too small for the problem. Increase the number of direct access blocks in the KENO-VI parameter data by entering the parameter NB8=nnn, where nnn is larger. For example, if the relative block number is 201, try increasing the number of direct-access blocks to 300 or more.

\section{LMP006 DA ERROR - INVALID BLOCK LENGTH. THE BLOCK LENGTH IS}

This message from the subroutine library direct-access routines indicates that the length of the directaccess blocks is invalid. A valid block length must be positive. This message is indicative of a code error.

\section{LMP007 DA ERROR-DCB ALREADY OPEN. THE LOGICAL UNIT NUMBER IS}

This message from the subroutine library direct-access routines indicates that the data control block for the above named unit was previously opened and not closed.

\section{LMP008 DA ERROR - PERMANENT I/O ERROR}

This message from the subroutine library direct-access routines indicates that a permanent IO error has occurred. 


\section{F17.A ALPHABETICAL INDEX OF SUBROUTINES}

This section provides a convenient alphabetical index of the subroutines used in KENO-VI, the subroutines that call it, and the subroutines it calls. 


\begin{tabular}{|c|c|c|}
\hline $\begin{array}{l}\text { SUBROUTINE } \\
\text { NAHE }\end{array}$ & $\begin{array}{l}\text { CALLING } \\
\text { SUBROUTINE }\end{array}$ & $\begin{array}{l}\text { CALLED } \\
\text { SUBROUTINE }\end{array}$ \\
\hline$\overline{A L B E D O}$ & TRACK & $\begin{array}{l}\text { DAZIRN } \\
\text { FLTRN }\end{array}$ \\
\hline ALBRD & DIFALB & ALBUSE \\
\hline ALBUSE & ALBRD & $\begin{array}{l}\text { INQUIR } \\
\text { IO } \\
\text { RITE }\end{array}$ \\
\hline ALOCAT & $\begin{array}{l}\text { KENOVI } \\
000019\end{array}$ & \\
\hline ANGLES & PRANG & FIND \\
\hline ARALBA & JOMITY & PRTLBA \\
\hline ARASIZ & CORSIZ & LSCAN \\
\hline ARAYIN & DATAIN & $\begin{array}{l}\text { AREAD } \\
\text { BOX } \\
\text { CLEAR } \\
\text { IREAD } \\
\text { RCHRS } \\
\text { RDBOX } \\
\text { STOP } \\
\text { YREAD }\end{array}$ \\
\hline AREAD & $\begin{array}{l}\text { ARAYIN } \\
\text { ARRAY } \\
\text { CHORD } \\
\text { DATAIN } \\
\text { KENOG } \\
\text { MIXIT } \\
\text { ORIGIN } \\
\text { PARAM } \\
\text { PLANE } \\
\text { QUAD } \\
\text { RCHRS } \\
\text { RDBIAS } \\
\text { RDPLOT } \\
\text { RDREF } \\
\text { RDSTRT } \\
\text { ROTATE } \\
----\end{array}$ & \\
\hline ARRAY & KENOG & $\begin{array}{l}\text { AREAD } \\
\text { DREAD } \\
\text { IREAD } \\
\text { LCOMPR } \\
\text { LREAD }\end{array}$ \\
\hline ARSCAN & SORTA & - \\
\hline BADHOH & PRANG & $\ldots$ \\
\hline BANKER & GUIDE & MOVE \\
\hline BIRITE & PARAM & \\
\hline BNDRY & KENOG & $\begin{array}{l}\text { IREAD } \\
\text { LREAD }\end{array}$ \\
\hline
\end{tabular}

NUREG/CR-0200,

Vol. 2, Rev. 5

F17.A.2 


\begin{tabular}{|c|c|c|}
\hline $\begin{array}{l}\text { SUBROUTINE } \\
\text { NAME }\end{array}$ & $\begin{array}{l}\text { CALLING } \\
\text { SUBROUT INE }\end{array}$ & $\begin{array}{l}\text { CALLED } \\
\text { SUBROUT INE }\end{array}$ \\
\hline$\overline{\mathrm{B} 00 \mathrm{~K} 1}$ & MASTER & $\begin{array}{l}\text { FITFLX } \\
\text { FREAK } \\
\text { JSTIME } \\
\text { KEDIT }\end{array}$ \\
\hline BOOK2 & MASTER & $\begin{array}{l}\text { DATAIN } \\
\text { IOSDUN } \\
\text { OPENDA }\end{array}$ \\
\hline - & $--2-2-2$ & $\begin{array}{l}\text { CORRE } \\
\text { ICEMIX } \\
\text { IOSDUK } \\
\text { MIXER } \\
\text { NSUPG } \\
\text { POINT } \\
\text { HRTRST }\end{array}$ \\
\hline BOOK4 & MASTER & $\begin{array}{l}\text { JOHITY } \\
\text { LODHTS }\end{array}$ \\
\hline BOOK5 & MASTER & $\begin{array}{l}\text { CLEAR } \\
\text { GUIDE } \\
\text { IOSDUN } \\
\text { JSTIME } \\
\text { PRTPLT } \\
\text { STOP }\end{array}$ \\
\hline BOX & ARAYIK & \\
\hline BOXC & LOADIT & \\
\hline CHKSTR & GUIDE & $\begin{array}{l}\text { MOVE } \\
\text { TRKWRT }\end{array}$ \\
\hline CHOOSE & $\begin{array}{l}\text { START4 } \\
\text { START5 }\end{array}$ & FLTRN \\
\hline CHORD & 10- & $\begin{array}{l}\text { AREAD } \\
\text { CLEAR } \\
\text { DREAD } \\
\text { LCOMPR }\end{array}$ \\
\hline CLEAR & $\begin{array}{l}\text { ARAYIN } \\
\text { BOOK5 } \\
\text { CHORD } \\
\text { CONE } \\
\text { CORRE } \\
\text { CROSS } \\
\text { CUBOID } \\
\text { CYLNDR } \\
\text { DATAIN } \\
\text { DODECA } \\
\text { ECYL } \\
\text { ELLIPS } \\
\text { FILLSG } \\
\text { GEOHIN } \\
\text { GUIDE } \\
\text { HOLE } \\
\text { HOPPER } \\
\text { HUNTER } \\
\text { HXPRSH } \\
\text { KENOG } \\
\text { KLANGA } \\
\text { LODARA }\end{array}$ & \\
\hline
\end{tabular}




\begin{tabular}{|c|c|c|}
\hline $\begin{array}{l}\text { SUBROUT INE } \\
\text { NAME }\end{array}$ & $\begin{array}{l}\text { CALLING } \\
\text { SUBROUTINE }\end{array}$ & $\begin{array}{l}\text { CALLED } \\
\text { SUBROUTINE }\end{array}$ \\
\hline \multirow[t]{2}{*}{ CLEAR (cont.) } & $\begin{array}{l}\text { LOOWTS } \\
\text { MAKANG } \\
\text { MATK } \\
\text { MESH } \\
\text { MIXCRS } \\
\text { NNITL } \\
\text { NSTART } \\
\text { PARAM } \\
\text { PLANE } \\
\text { PPIPED } \\
\text { PRTPLT } \\
\text { QUAD } \\
\text { RDALB } \\
\text { RDICE } \\
\text { RDPLOT } \\
\text { RDSTRT } \\
\text { RDTAPE } \\
\text { RELATE }\end{array}$ & \\
\hline & $\begin{array}{l}\text { RGUSED } \\
\text { RHOWB } \\
\text { RTARA } \\
\text { SAVST6 } \\
\text { SORTA } \\
\text { SPHERE } \\
\text { START } \\
\text { TRACK } \\
\text { UNTCRS } \\
\text { VOLUME } \\
\text { WEDGE }\end{array}$ & \\
\hline CLOSDA & $\begin{array}{l}\text { KENOVI } \\
\text { MIXER } \\
\text { O0D019 }\end{array}$ & \\
\hline CLRKIT & RDPLOT & \\
\hline CMPRS & MIXMIX & \\
\hline CONE & KENOG & $\begin{array}{l}\text { CLEAR } \\
\text { DREAD }\end{array}$ \\
\hline CORRE & BOOK3 & $\begin{array}{l}\text { CLEAR } \\
\text { INQUIR } \\
\text { RATIO } \\
\text { REED } \\
\text { RITE }\end{array}$ \\
\hline CORSIZ & JOHITY & $\begin{array}{l}\text { ARASIZ } \\
\text { LOCBOX }\end{array}$ \\
\hline CREAD & RDREF & \\
\hline CROSS & TRACK & CLEAR \\
\hline CRSPRD & $\begin{array}{l}\text { PPIPED } \\
\text { RHOMB }\end{array}$ & \\
\hline CUBOID & KENOG & $\begin{array}{l}\text { CLEAR } \\
\text { DREAD }\end{array}$ \\
\hline CYLNDR & KENOG & $\begin{array}{l}\text { CLEAR } \\
\text { DREAD }\end{array}$ \\
\hline
\end{tabular}

NUREG/CR-0200, Vol. 2, Rev. 5

F17.A.4 


\begin{tabular}{|c|c|c|}
\hline $\begin{array}{l}\text { SUBROUTINE } \\
\text { NAME }\end{array}$ & $\begin{array}{l}\text { CALLING } \\
\text { SUBROUTINE }\end{array}$ & $\begin{array}{l}\text { CALLED } \\
\text { SUBROUT INE }\end{array}$ \\
\hline$\overline{\text { DATAIN }}$ & BOOK2 & $\begin{array}{l}\text { ARAYIN } \\
\text { AREAD } \\
\text { CLEAR } \\
\text { EXTRA } \\
\text { FLDATA } \\
\text { GEOHIN } \\
\text { IDXID } \\
\text { IOWRT } \\
\text { MIXIT } \\
\text { RDBIAS } \\
\text { RDPLOT } \\
\text { RDREF } \\
\text { RDRST } \\
\text { RDSTRT } \\
\text { RT } \\
\text { RTARA } \\
\text { SAVST6 } \\
\text { STOP } \\
\text { HRTPLT } \\
\text {-.-.-. }\end{array}$ \\
\hline DAZIRN & $\begin{array}{l}\text { ALBIN } \\
\text { STRTSU } \\
\text { TRACK }\end{array}$ & \\
\hline DGTISO & $\begin{array}{l}\text { SORTBK } \\
\text { START } \\
\text { STRTSU } \\
\text { TRACK }\end{array}$ & \\
\hline DIFALB & FLDATA & ALBRD \\
\hline DITTO & KENOG & \\
\hline DODECA & KENOG & $\begin{array}{l}\text { CLEAR } \\
\text { DREAD }\end{array}$ \\
\hline DOTPRD & TRACK & \\
\hline DREAD & $\begin{array}{l}\text { ARRAY } \\
\text { CHORD } \\
\text { CONE } \\
\text { CUBOID } \\
\text { CYLNDR } \\
\text { DOOECA } \\
\text { ECYL } \\
\text { ELLIPS } \\
\text { HOPPER } \\
\text { HXPRSH } \\
\text { ORIGIN } \\
\text { PLANE } \\
\text { PPIPED } \\
\text { OUAD } \\
\text { RHOMB } \\
\text { ROTATE } \\
\text { SPHERE } \\
\text { WEDGE }\end{array}$ & \\
\hline ECYL & KENOG & $\begin{array}{l}\text { CLEAR } \\
\text { DREAD }\end{array}$ \\
\hline EDITOR & KEDIT & \\
\hline
\end{tabular}




\begin{tabular}{|c|c|c|}
\hline $\begin{array}{l}\text { SUBROUTINE } \\
\text { NAME }\end{array}$ & $\begin{array}{l}\text { CALLING } \\
\text { SUBROUTINE }\end{array}$ & $\begin{array}{l}\text { CALLED } \\
\text { SUBROUTINE }\end{array}$ \\
\hline ELLIPS & KENOG & $\begin{array}{l}\text { CLEAR } \\
\text { DREAD }\end{array}$ \\
\hline EXPRN & TRACK & \\
\hline EXTRA & DATAIN & \\
\hline FILLSG & NSUPG & $\begin{array}{l}\text { CLEAR } \\
\text { FIL2D } \\
\text { INQUIR } \\
\text { RD } \\
\text { REED } \\
\text { RITE } \\
\text { RT } \\
\text { SGALB } \\
\text { SGHT }\end{array}$ \\
\hline FIL2D & FILLSG & RD \\
\hline FIND & $\begin{array}{l}\text { ANGLES } \\
\text { GETMUS }\end{array}$ & $Q$ \\
\hline FINDBX & $\begin{array}{l}\text { LOCATE } \\
\text { TRACK }\end{array}$ & \\
\hline FISFLX & GUIDE & $\begin{array}{l}\text { JSTIME } \\
\text { LOOPER } \\
\text { MATK } \\
\text { STATIS }\end{array}$ \\
\hline FITFLX & BOOK1 & $\begin{array}{l}\text { IOLEFT } \\
\text { PRTFLX } \\
\text { RD }\end{array}$ \\
\hline FLDATA & DATAIN & $\begin{array}{l}\text { DIFALB } \\
\text { REED } \\
\text { RGUSED } \\
\text { RITE } \\
\text { SORTA } \\
\text { SORTR } \\
\text { WATES } \\
\end{array}$ \\
\hline FLTRH & $\begin{array}{l}\text { ALBIN } \\
\text { CHOOSE } \\
\text { NSTART } \\
\text { START } \\
\text { STARTO } \\
\text { START1 } \\
\text { START5 } \\
\text { START6 } \\
\text { STRTSU } \\
\text { TRACK } \\
\end{array}$ & \\
\hline FREAD & $\begin{array}{l}\text { MIXIT } \\
\text { PARAM } \\
\text { RDBIAS } \\
\text { RDPLOT } \\
\text { RDSTRT } \\
\end{array}$ & \\
\hline $\begin{array}{l}\text { FREAK } \\
\end{array}$ & BOOK1 & \\
\hline $\begin{array}{l}\text { FREECR } \\
\end{array}$ & NSUPG & \\
\hline FSABED & KEDIT & \\
\hline
\end{tabular}

NUREG/CR-0200,

Vol. 2, Rev. 5

F17.A.6 


\begin{tabular}{|c|c|c|}
\hline $\begin{array}{l}\text { SUBROUT INE } \\
\text { NAME }\end{array}$ & $\begin{array}{l}\text { CALLING } \\
\text { SUBROUT INE }\end{array}$ & $\begin{array}{l}\text { CALLED } \\
\text { SUBROUT INE }\end{array}$ \\
\hline$\overline{\text { GEOMIN }}$ & DATAIH & $\begin{array}{l}\text { CLEAR } \\
\text { KENOG } \\
\text { READGM } \\
\text { STOP }\end{array}$ \\
\hline GETMUS & PRANG & $\begin{array}{l}\text { FIND } \\
Q\end{array}$ \\
\hline GETPTR & RCHRS & \\
\hline GOCURS & VOLUME & HUNTER \\
\hline GTVOLS & VOLUME & \\
\hline GUIDE & $800 \times 5$ & $\begin{array}{l}\text { BANKER } \\
\text { CHKSTR } \\
\text { CLEAR } \\
\text { FISFLX } \\
\text { INDX } \\
\text { INQUIR } \\
\text { IOLEFT } \\
\text { JSTIME } \\
\text { NSTART } \\
\text { PULL } \\
\text { RD } \\
\text { RDCALC } \\
\text { REED } \\
\text { RESET } \\
\text { RITE } \\
\text { START } \\
\text { TRACK } \\
\text { WRTCAL } \\
\text { WRTA }\end{array}$ \\
\hline HOLE & $\begin{array}{l}\text { LODARA } \\
\text { SORTA }\end{array}$ & $\begin{array}{l}\text { CLEAR } \\
\text { STOP }\end{array}$ \\
\hline HOLEIK & KENOG & $\begin{array}{l}\text { IREAD } \\
\text { LREAD }\end{array}$ \\
\hline HOPPER & KENOG & $\begin{array}{l}\text { CLEAR } \\
\text { DREAD }\end{array}$ \\
\hline HROTRH & $\begin{array}{l}\text { LOCATE } \\
\text { TRACK }\end{array}$ & MOVE \\
\hline HUNTER & $\begin{array}{l}\text { GOCURS } \\
\text { VOLUME }\end{array}$ & $\begin{array}{l}\text { CLEAR } \\
\text { MOVE }\end{array}$ \\
\hline HXPRSM & KENOG & $\begin{array}{l}\text { CLEAR } \\
\text { DREAD }\end{array}$ \\
\hline ICEMIX & BOOK3 & RDTAPE \\
\hline I COMPA & START6 & \\
\hline IDX1D & DATAIN & IREAD \\
\hline INDX & GUIDE & \\
\hline INITAL & $\begin{array}{l}\text { KENOVI } \\
\text { O00019 }\end{array}$ & $\begin{array}{l}\text { IOLEFT } \\
\text { JSTIME } \\
\text { MESAGE } \\
\text { OPNFIL } \\
\text { PARAM }\end{array}$ \\
\hline
\end{tabular}

NUREG/CR-0200,

F17.A.7

Vol. 2, Rev. 5 


\begin{tabular}{|c|c|c|}
\hline $\begin{array}{l}\text { SUBROUTINE } \\
\text { NAME }\end{array}$ & $\begin{array}{l}\text { CALLING } \\
\text { SUBROUTINE }\end{array}$ & $\begin{array}{l}\text { CALLED } \\
\text { SUBROUTINE }\end{array}$ \\
\hline INITAL (cont.) & & $\begin{array}{l}\text { PARTBL } \\
\text { SCANON }\end{array}$ \\
\hline INQUIR & $\begin{array}{l}\text { ALBUSE } \\
\text { CORRE } \\
\text { FILLSG } \\
\text { GUIDE } \\
\text { MIXIT } \\
\text { NNITL } \\
\text { NSUPG } \\
\text { PRANG } \\
\text { PRTPLT } \\
\text { RDALB } \\
\text { RDARA } \\
\text { RDICE } \\
\text { RDRST } \\
\text { RDTAPE } \\
\text { RDWTS } \\
\text { RT } \\
\text { RTARA } \\
\text { SAVST6 } \\
\text { SGALB } \\
\text { WAITIN } \\
\text { HATES } \\
\text { WRTALB } \\
\text { WRTICE } \\
\text { WRTPLT } \\
\text { WRTRST }\end{array}$ & \\
\hline 10 & $\begin{array}{l}\text { ALBUSE } \\
\text { MAKTAP } \\
\text { MIXMIX } \\
\text { RDAL8 } \\
\text { RDARA } \\
\text { RDBIAS } \\
\text { RDCALC } \\
\text { RDICE } \\
\text { RDPLOT } \\
\text { RDRST } \\
\text { RDSTRT } \\
\text { RDTAPE } \\
\text { RDWTS } \\
\text { SAVST6 } \\
\text { HAITIN } \\
\text { HATES } \\
\text { WRTALB } \\
\text { HRTARA } \\
\text { HRTCAL } \\
\text { HRTICE } \\
\text { HRTPLT } \\
\text { HRTRST } \\
\text { WRTWTS }\end{array}$ & \\
\hline IOLEFT & $\begin{array}{l}\text { FITFLX } \\
\text { GUIDE } \\
\text { INITAL } \\
\text { IOSDUN }\end{array}$ & \\
\hline IONUMS & 000019 & \\
\hline
\end{tabular}

NUREG/CR-0200,

Vol. 2, Rev. 5 


\begin{tabular}{|c|c|c|}
\hline $\begin{array}{l}\text { SUBROUTINE } \\
\text { NAME }\end{array}$ & $\begin{array}{l}\text { CALLING } \\
\text { SUBROUTINE }\end{array}$ & $\begin{array}{l}\text { CALLED } \\
\text { SUBROUTINE }\end{array}$ \\
\hline$\overline{\text { IOSDUN }}$ & $\begin{array}{l}\text { BOOK2 } \\
\text { BOOK3 } \\
\text { BOOK5 } \\
\text { JOHITY }\end{array}$ & IOLEFT \\
\hline IOWRT & DATAIN & \\
\hline - & $\begin{array}{l}\text { ARAYIN } \\
\text { ARRAY } \\
\text { HOLEIH } \\
\text { IDXID } \\
\text { KENOG } \\
\text { MEDIA } \\
\text { MIXIT } \\
\text { PARAM } \\
\text { RDBIAS } \\
\text { RDBOX } \\
\text { RDPLOT } \\
\text { RDSTRT }\end{array}$ & \\
\hline IXALB & $\begin{array}{l}\text { LIMLH } \\
\text { HSUPG }\end{array}$ & \\
\hline JLL2 & MIXER & \\
\hline JOMITY & BOOK4 & $\begin{array}{l}\text { ARALBA } \\
\text { CORSIZ } \\
\text { IOSDUN } \\
\text { LOADIT } \\
\text { PRT JOH } \\
\text { VOLUME }\end{array}$ \\
\hline JSTIME & $\begin{array}{l}\text { BOOK1 } \\
\text { BOOK5 } \\
\text { FISFLX } \\
\text { GUIDE } \\
\text { INITAL } \\
\text { KEDIT } \\
\text { MATRIX } \\
\text { PRTPLT } \\
\text { START } \\
\end{array}$ & \\
\hline EDIT & B0OK1 & $\begin{array}{l}\text { EDITOR } \\
\text { JSTIME } \\
\text { LOOPER } \\
\text { MATRIX } \\
\text { PLTKEF } \\
\text { RNDOUT }\end{array}$ \\
\hline KENOG & GEOHIN & $\begin{array}{l}\text { AREAD } \\
\text { ARRAY } \\
\text { CHORD } \\
\text { CLEAR } \\
\text { CONE } \\
\text { CUBOID } \\
\text { CYLNDR } \\
\text { DITTO } \\
\text { DODECA } \\
\text { ECYL } \\
\text { ELLIPS } \\
\text { HOLEIN } \\
\text { HOPPER } \\
\text { HXPRSM } \\
\text { IREAD }\end{array}$ \\
\hline
\end{tabular}

NUREG/CR-0200,

F17.A.9

Vol. 2, Rev. 5 


\begin{tabular}{|c|c|c|}
\hline $\begin{array}{l}\text { SUBROUTINE } \\
\text { NAME }\end{array}$ & $\begin{array}{l}\text { CALLING } \\
\text { SUBROUTINE }\end{array}$ & $\begin{array}{l}\text { CALLED } \\
\text { SUBROUT INE }\end{array}$ \\
\hline KENOG (cont.) & & $\begin{array}{l}\text { LCOMPR } \\
\text { MEDIA } \\
\text { ORIGIN } \\
\text { PLANE } \\
\text { PPIPED } \\
\text { QUAD } \\
\text { RCHRS } \\
\text { RHOMB } \\
\text { ROTATE }\end{array}$ \\
\hline & & $\begin{array}{l}\text { ROTRNS } \\
\text { SPHERE } \\
\text { WEDGE }\end{array}$ \\
\hline KENOVI & & $\begin{array}{l}\text { ALOCAT } \\
\text { CLOSDA } \\
\text { INITAL } \\
\text { MASTER } \\
\text { OPNFIL } \\
\text { STOP }\end{array}$ \\
\hline KLANGA & READGM & $\begin{array}{l}\text { CLEAR } \\
\text { PRTSEC }\end{array}$ \\
\hline LABL & MATRIX & \\
\hline LCOMPR & $\begin{array}{l}\text { ARRAY } \\
\text { CHORD } \\
\text { KENOG } \\
\text { ORIGIN } \\
\text { PLANE } \\
\text { QUAD } \\
\text { ROTATE }\end{array}$ & \\
\hline LDWRT & TRACK & \\
\hline LEGEND & PRANG & \\
\hline LIBEQL & PARAM & \\
\hline LIMLN & MSUPG & IXALB \\
\hline LOADIT & JOMITY & $\begin{array}{l}\text { BOXC } \\
\text { LODALB } \\
\text { LODARA } \\
\text { PRTARA } \\
\text { REED }\end{array}$ \\
\hline LOCATE & $\begin{array}{l}\text { MESH } \\
\text { START }\end{array}$ & $\begin{array}{l}\text { FINDBX } \\
\text { HROTRH } \\
\text { MOVE } \\
\text { POSIT }\end{array}$ \\
\hline LOCBOX & $\begin{array}{l}\text { CORSIZ } \\
\text { LODARA } \\
\text { SORTA } \\
\text { START } \\
\text { TKARRY } \\
\text { TRACK }\end{array}$ & \\
\hline LODALB & LOADIT & REED \\
\hline
\end{tabular}

NUREG/CR-0200,

Vol. 2, Rev. 5 


\begin{tabular}{|c|c|c|}
\hline $\begin{array}{l}\text { SUBROUTINE } \\
\text { NANE }\end{array}$ & $\begin{array}{l}\text { CALLING } \\
\text { SUBROUTINE }\end{array}$ & $\begin{array}{l}\text { CALLED } \\
\text { SUBROUTINE }\end{array}$ \\
\hline LODARA & LOADIT & $\begin{array}{l}\text { CLEAR } \\
\text { HOLE } \\
\text { LOCBOX } \\
\text { REED }\end{array}$ \\
\hline LODRGC & RGUSED & $----\infty-\infty$ \\
\hline LODWTS & В00K4 & $\begin{array}{l}\text { CLEAR } \\
\text { PRTWTS } \\
\text { RD } \\
\text { REED }\end{array}$ \\
\hline LOOPER & $\begin{array}{l}\text { FISFLX } \\
\text { KEDIT }\end{array}$ & $\begin{array}{l}\text { REED } \\
\text { RITE }\end{array}$ \\
\hline LREAD & $\begin{array}{l}\text { ARRAY } \\
\text { HOLEIK } \\
\text { MEDIA } \\
\text { MIXIT }\end{array}$ & \\
\hline LSCAN & $\begin{array}{l}\text { ARASIZ } \\
\text { RGUSED } \\
\text { START }\end{array}$ & \\
\hline MAKANG & MIXER & $\begin{array}{l}\text { CLEAR } \\
\text { PRANG } \\
\text { REED } \\
\text { STOP }\end{array}$ \\
\hline MAKTAP & MIXER & $\begin{array}{l}\text { IO } \\
\text { REED } \\
\text { SCOOT }\end{array}$ \\
\hline MASTER & $\begin{array}{l}\text { KENOVI } \\
\text { O00019 }\end{array}$ & $\begin{array}{l}\text { BOOK1 } \\
\text { BOOK2 } \\
\text { 800K3 } \\
\text { 800K4 } \\
\text { B00K5 }\end{array}$ \\
\hline MATK & $\begin{array}{l}\text { FISFLX } \\
\text { MATRIX }\end{array}$ & CLEAR \\
\hline MATRIX & KEDIT & $\begin{array}{l}\text { JSTIME } \\
\text { LABL } \\
\text { HATK }\end{array}$ \\
\hline MEDIA & KENOG & $\begin{array}{l}\text { IREAD } \\
\text { LREAD }\end{array}$ \\
\hline MESAGE & INITAL & --0 \\
\hline MESH & PRINT & $\begin{array}{l}\text { CLEAR } \\
\text { LOCATE }\end{array}$ \\
\hline HGCWRD & MIX2D & \\
\hline MIXCRS & MIXER & $\begin{array}{l}\text { CLEAR } \\
\text { STOP }\end{array}$ \\
\hline MIXER & BoOK 3 & $\begin{array}{l}\text { CLOSDA } \\
\text { JLL2 } \\
\text { MAKANG } \\
\text { MAKTAP } \\
\text { HIXCRS } \\
\text { MIXMIX }\end{array}$ \\
\hline
\end{tabular}

NUREG/CR-0200,

F17.A.11

Vol. 2, Rev. 5 


\begin{tabular}{|c|c|c|}
\hline $\begin{array}{l}\text { SUBROUTINE } \\
\text { NAME }\end{array}$ & $\begin{array}{l}\text { CALLING } \\
\text { SUBROUTINE }\end{array}$ & $\begin{array}{l}\text { CALLED } \\
\text { SUBROUT INE }\end{array}$ \\
\hline MIXER (cont.) & & $\begin{array}{l}\text { OPENDA } \\
\text { REED } \\
\text { STOP } \\
\text { XLNTHS }\end{array}$ \\
\hline MIXIT & DATAIN & $\begin{array}{l}\text { AREAD } \\
\text { FREAD } \\
\text { INQUIR } \\
\text { IREAD } \\
\text { LREAD } \\
\text { RDMIXT } \\
\text { RITE } \\
\text { STOP }\end{array}$ \\
\hline MIXMIX & MIXER & $\begin{array}{l}\text { CMPRS } \\
\text { IO } \\
\text { MIX1D } \\
\text { MIX2D } \\
\text { MIX2M } \\
\text { NNITL } \\
\text { NORMID } \\
\text { HORM2D } \\
\text { PRTMIX } \\
\text { REED } \\
\text { RITE } \\
\text { SUMSCT }\end{array}$ \\
\hline MIX1D & MIXHIX & \\
\hline MIX2D & MIXMIX & MGCWRD \\
\hline MIX2M & MIXMIX & \\
\hline MOVE & $\begin{array}{l}\text { BANKER } \\
\text { CHKSTR } \\
\text { HROTRN } \\
\text { HUNTER } \\
\text { LOCATE } \\
\text { NSTART } \\
\text { RESET } \\
\text { SAVST6 } \\
\text { SORTBK } \\
\text { START } \\
\text { START6 } \\
\text { TKARRY } \\
\text { TRACK } \\
\text { VOLUME } \\
\text { HATES }\end{array}$ & \\
\hline NKITL & MIXMIX & $\begin{array}{l}\text { CLEAR } \\
\text { INQUIR } \\
\text { RITE }\end{array}$ \\
\hline NORM1D & MIXMIX & \\
\hline NORM2D & MIXMIX & \\
\hline NORMAL & TRACK & \\
\hline NSTART & GUIDE & $\begin{array}{l}\text { CLEAR } \\
\text { FLTRN } \\
\text { MOVE } \\
\text { SORTBK }\end{array}$ \\
\hline
\end{tabular}

NUREG/CR-0200, Vol. 2, Rev. 5 


\begin{tabular}{|c|c|c|}
\hline $\begin{array}{l}\text { SUBROUT IME } \\
\text { HAME }\end{array}$ & $\begin{array}{l}\text { CALLING } \\
\text { SUBROUTINE }\end{array}$ & $\begin{array}{l}\text { CALLED } \\
\text { SUBROUT INE }\end{array}$ \\
\hline NSUPG & BoOK3 & $\begin{array}{l}\text { FILLSG } \\
\text { FREECR } \\
\text { INQUIR } \\
\text { IXALB } \\
\text { LIMLN } \\
\text { OPENDA } \\
\text { POINT } \\
\text { PRATBL } \\
\text { PRTXS } \\
\text { REED } \\
\text { RITE } \\
\text { STOP }\end{array}$ \\
\hline OPENDA & $\begin{array}{l}\text { BOOK2 } \\
\text { MIXER } \\
\text { NSUPG }\end{array}$ & $--2-0-2--1$ \\
\hline OPNFIL & $\begin{array}{l}\text { INITAL } \\
\text { KENOVI } \\
\text { OOO019 } \\
\text { PARAM } \\
\text { RDSTRT }\end{array}$ & ------- \\
\hline ORIGIN & KENOG & $\begin{array}{l}\text { AREAD } \\
\text { DREAD } \\
\text { LCOHPR }\end{array}$ \\
\hline 000019 & & $\begin{array}{l}\text { ALOCAT } \\
\text { CLOSDA } \\
\text { INITAL } \\
\text { IONUMS } \\
\text { MASTER } \\
\text { OPNFIL } \\
\text { SETBIN } \\
\text { STOP }\end{array}$ \\
\hline PARAM & INITAL & $\begin{array}{l}\text { AREAD } \\
\text { BIRITE } \\
\text { CLEAR } \\
\text { FREAD } \\
\text { IREAD } \\
\text { LIBEQL } \\
\text { OPNFIL } \\
\text { RHDIH } \\
\text { RNDOUT } \\
\text { TIMFAC } \\
\text { ZREAD }\end{array}$ \\
\hline PARTBL & INITAL & RHDOUT \\
\hline PERIOD & TRACK & $=---$ \\
\hline PLANE & KENOG & $\begin{array}{l}\text { AREAD } \\
\text { CLEAR } \\
\text { DREAD } \\
\text { LCOHPR }\end{array}$ \\
\hline PLTKEF & KEDIT & $=-$ \\
\hline POINT & NSUPG & \\
\hline POSIT & LOCATE & STOP \\
\hline
\end{tabular}

NUREG/CR-0200,

F17.A.13

Vol. 2, Rev. 5 


\begin{tabular}{|c|c|c|}
\hline $\begin{array}{l}\text { SUBROUTINE } \\
\text { NAME }\end{array}$ & $\begin{array}{l}\text { CALLING } \\
\text { SUBROUTINE }\end{array}$ & $\begin{array}{l}\text { CALLED } \\
\text { SUBROUTINE }\end{array}$ \\
\hline PPIPED & KENOG & $\begin{array}{l}\text { CLEAR } \\
\text { CRSPRD } \\
\text { DREAD }\end{array}$ \\
\hline PRANG & MAKANG & $\begin{array}{l}\text { ANGLES } \\
\text { BADMOM } \\
\text { GETMUS } \\
\text { INQUIR } \\
\text { LEGEND } \\
\text { RD } \\
\text { RITE }\end{array}$ \\
\hline PRATBL & NSUPG & RTADJ \\
\hline PRINT & PRTPLT & MESH \\
\hline PRTARA & LOADIT & \\
\hline PRTFLX & FITFLX & \\
\hline PRTJOM & JOMITY & \\
\hline PRTLBA & ARALBA & \\
\hline PRTHIX & MIXMIX & \\
\hline PRTPLT & BOOK5 & $\begin{array}{l}\text { CLEAR } \\
\text { INQUIR } \\
\text { JSTIME } \\
\text { PRINT } \\
\text { REED } \\
\text { RELATE } \\
\text { UNTCRS }\end{array}$ \\
\hline $\begin{array}{l}\text { PRTPOS } \\
-\end{array}$ & TRACK & \\
\hline PRTSEC & KLANGA & \\
\hline PRTWTS & LODWTS & \\
\hline PRTXS & HSUPG & $\begin{array}{l}\text { PRT 1D } \\
\text { PRT1DS } \\
\text { PRT2DS } \\
\text { REED } \\
\end{array}$ \\
\hline PRT1D & PRTXS & \\
\hline PRT1DS & PRTXS & \\
\hline $\begin{array}{l}\text { PRT2DS } \\
-\end{array}$ & PRTXS & \\
\hline PULL & GUIDE & \\
\hline$Q$ & $\begin{array}{l}\text { ANGLES } \\
\text { FIND } \\
\text { GETMUS }\end{array}$ & \\
\hline QUAD & KENOG & $\begin{array}{l}\text { AREAD } \\
\text { CLEAR } \\
\text { DREAD } \\
\text { LCOMPR } \\
\text { VEXCAV } \\
\end{array}$ \\
\hline RATIO & CORRE & \\
\hline
\end{tabular}

NUREG/CR-0200,

Vol. 2, Rev. 5

F17.A.14 


\begin{tabular}{|c|c|c|}
\hline $\begin{array}{l}\text { SUBROUTINE } \\
\text { NAME }\end{array}$ & $\begin{array}{l}\text { CALLING } \\
\text { SUBROUTINE }\end{array}$ & $\begin{array}{l}\text { CALLED } \\
\text { SUBROUTINE }\end{array}$ \\
\hline RCHRS & $\begin{array}{l}\text { ARAYIN } \\
\text { KENOG } \\
\text { RDPLOT }\end{array}$ & $\begin{array}{l}\text { AREAD } \\
\text { GETPTR } \\
\text { RCRDLN } \\
\text { RSTPTR } \\
\text { STOP }\end{array}$ \\
\hline RCOLOR & ROPLOT & $\begin{array}{l}\text { AREAD } \\
\text { IREAD }\end{array}$ \\
\hline RCRDLN & RCHRS & \\
\hline - & $\begin{array}{l}\text { FILLSG } \\
\text { FIL2D } \\
\text { FITFLX } \\
\text { GUIDE } \\
\text { LOOHTS } \\
\text { PRAHG } \\
\text { SGALB } \\
\text { SGHT }\end{array}$ & ------0 \\
\hline RDALB & RDRST . & $\begin{array}{l}\text { CLEAR } \\
\text { IHQUIR } \\
\text { IO } \\
\text { RITE }\end{array}$ \\
\hline RDARA & RDRST & $\begin{array}{l}\text { INQUIR } \\
\text { IO } \\
\text { RITE }\end{array}$ \\
\hline RDBIAS & DATAIK & $\begin{array}{l}\text { AREAD } \\
\text { FREAD } \\
\text { I0 } \\
\text { IREAD } \\
\text { WAITIN }\end{array}$ \\
\hline RDBOX & ARAYIN & IREAD \\
\hline RDCALC & GUIDE & $\begin{array}{l}\text { IO } \\
\text { RDGRP } \\
\text { RITE } \\
\text { RNDIN } \\
\text { SHUFL } \\
\text { STOP }\end{array}$ \\
\hline RDGRP & RDCALC & \\
\hline RDICE & RDRST & $\begin{array}{l}\text { CLEAR } \\
\text { INQUIR } \\
\text { IO } \\
\text { RITE }\end{array}$ \\
\hline RDKIXT & MIXIT & \\
\hline RDPLOT & DATAIN & $\begin{array}{l}\text { AREAD } \\
\text { CLEAR } \\
\text { FREAD } \\
\text { IO } \\
\text { IREAD } \\
\text { RCHRS }\end{array}$ \\
\hline RDREF & DATAIN & $\begin{array}{l}\text { AREAD } \\
\text { CREAD }\end{array}$ \\
\hline
\end{tabular}




\begin{tabular}{|c|c|c|}
\hline $\begin{array}{l}\text { SUBROUTINE } \\
\text { NAME }\end{array}$ & $\begin{array}{l}\text { CALLING } \\
\text { SUBROUTINE }\end{array}$ & $\begin{array}{l}\text { CALLED } \\
\text { SUBROUT INE }\end{array}$ \\
\hline$-2-2-2-2-1$ & 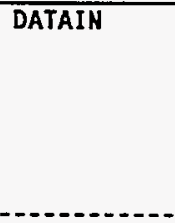 & $\begin{array}{l}\text { INQUIR } \\
\text { IO } \\
\text { RDALB } \\
\text { RDARA } \\
\text { ROICE } \\
\text { RDWTS } \\
\text { RITE }\end{array}$ \\
\hline RDSTRT & DATAIN & $\begin{array}{l}\text { AREAD } \\
\text { CLEAR } \\
\text { FREAD } \\
\text { IO } \\
\text { IREAD } \\
\text { OPNFIL }\end{array}$ \\
\hline RDTAPE & ICEMIX & $\begin{array}{l}\text { CLEAR } \\
\text { INQUIR } \\
\text { IO } \\
\text { RITE } \\
\text { XSEC1D } \\
\text { XTENDA }\end{array}$ \\
\hline RDWTS & RDRST & $\begin{array}{l}\text { INQUIR } \\
\text { IO } \\
\text { RITE }\end{array}$ \\
\hline READGH & GEOMIH & $\begin{array}{l}\text { KLANGA } \\
\text { ROTHOL }\end{array}$ \\
\hline REED & $\begin{array}{l}\text { CORRE } \\
\text { FILLSG } \\
\text { FLDATA } \\
\text { GUIDE } \\
\text { LOADIT } \\
\text { LODALB } \\
\text { LODARA } \\
\text { LODWTS } \\
\text { LOOPER } \\
\text { MAKANG } \\
\text { MAKTAP } \\
\text { HIXER } \\
\text { HIXHIX } \\
\text { HSUPG } \\
\text { PRTPLT } \\
\text { PRTXS } \\
\text { SGALB } \\
\text { SORTA } \\
\text { START6 } \\
\text { HATES } \\
\text { WRTALB } \\
\text { WRTARA } \\
\text { WRTCAL } \\
\text { WRTICE } \\
\text { WRTRST } \\
\text { WRTWTS } \\
\text { WRI }\end{array}$ & \\
\hline RELATE & PRTPLT & CLEAR \\
\hline RESET & GUIDE & MOVE \\
\hline RGUSED & FLDATA & $\begin{array}{l}\text { CLEAR } \\
\text { LODRGC } \\
\text { LSCAN }\end{array}$ \\
\hline
\end{tabular}

NUREG/CR-0200,

Vol. 2, Rev. 5

F17.A.16 


\begin{tabular}{|c|c|c|}
\hline $\begin{array}{l}\text { SUBROUTINE } \\
\text { NAME }\end{array}$ & $\begin{array}{l}\text { CALLING } \\
\text { SUBROUTINE }\end{array}$ & $\begin{array}{l}\text { CALLED } \\
\text { SUBROUT INE }\end{array}$ \\
\hline RHOHB & KENOG & $\begin{array}{l}\text { CLEAR } \\
\text { CRSPRD } \\
\text { DREAD }\end{array}$ \\
\hline RITE & $\begin{array}{l}\text { ALBUSE } \\
\text { CORRE } \\
\text { FILLSG } \\
\text { FLDATA } \\
\text { GUIDE } \\
\text { LOOPER } \\
\text { MIXIT } \\
\text { MIXMIX } \\
\text { HNITL } \\
\text { HSUPG } \\
\text { PRANG } \\
\text { RDALB } \\
\text { RDARA } \\
\text { RDCALC } \\
\text { RDICE } \\
\text { RDRST } \\
\text { RDTAPE } \\
\text { RDWTS } \\
\text { RT } \\
\text { RTARA } \\
\text { SAVST6 } \\
\text { WAITIN } \\
\text { WATES } \\
\text { WRTPLT }\end{array}$ & \\
\hline RNDIN & $\begin{array}{l}\text { PARAM } \\
\text { RDCALC }\end{array}$ & \\
\hline RNDOUT & $\begin{array}{l}\text { KEDIT } \\
\text { PARAM } \\
\text { PARTBL } \\
\text { TRKWRT } \\
\text { URTCAL } \\
\text { WRTRST }\end{array}$ & $-2--0-0-2-0$ \\
\hline ROTATE & KENOG & $\begin{array}{l}\text { AREAD } \\
\text { DREAD } \\
\text { LCOMPR }\end{array}$ \\
\hline ROTHOL & READGM & \\
\hline ROTRNS & KENOG & \\
\hline $\begin{array}{l}\text { RSTPTR } \\
-\end{array}$ & RCHRS & $-2-2-2-2-1$ \\
\hline RT & $\begin{array}{l}\text { DATAIN } \\
\text { FILLSG }\end{array}$ & $\begin{array}{l}\text { INQUIR } \\
\text { RITE }\end{array}$ \\
\hline RTADJ & PRATBL & $--\ldots+-$ \\
\hline RTARA & DATAIN & $\begin{array}{l}\text { CLEAR } \\
\text { INQUIR } \\
\text { RITE }\end{array}$ \\
\hline SAVST6 & DATAIN & $\begin{array}{l}\text { CLEAR } \\
\text { INQUIR } \\
\text { IO } \\
\text { MOVE } \\
\text { RITE } \\
\text { STOP }\end{array}$ \\
\hline
\end{tabular}




\begin{tabular}{|c|c|c|}
\hline $\begin{array}{l}\text { SUBROUTINE } \\
\text { NAME }\end{array}$ & $\begin{array}{l}\text { CALLIHG } \\
\text { SUBROUTINE }\end{array}$ & $\begin{array}{l}\text { CALLED } \\
\text { SUBROUTINE }\end{array}$ \\
\hline SCANON & INITAL & \\
\hline SCOOT & MAKTAP & \\
\hline SETBIN & 000019 & \\
\hline SFLRA & TRACK & \\
\hline SGALB & FILLSG & $\begin{array}{l}\text { INQUIR } \\
\text { RD } \\
\text { REED }\end{array}$ \\
\hline SGUT & FILLSG & RD \\
\hline SHUFL & RDCALC & \\
\hline SORTA & FLDATA & $\begin{array}{l}\text { ARSCAN } \\
\text { CLEAR } \\
\text { HOLE } \\
\text { LOCBOX } \\
\text { REED } \\
\text { STOP }\end{array}$ \\
\hline SORTBK & NSTART & $\begin{array}{l}\text { DGTISO } \\
\text { MOVE }\end{array}$ \\
\hline SORTR & FLDATA & \\
\hline SPHERE & KENOG & $\begin{array}{l}\text { CLEAR } \\
\text { DREAD }\end{array}$ \\
\hline START & GUIDE & $\begin{array}{l}\text { CLEAR } \\
\text { DGTISO } \\
\text { FLTRN } \\
\text { JSTIME } \\
\text { LOCATE } \\
\text { LOCBOX } \\
\text { LSCAN } \\
\text { MOVE } \\
\text { STARTO } \\
\text { START1 } \\
\text { START2 } \\
\text { START3 } \\
\text { START4 } \\
\text { START5 } \\
\text { START6 } \\
\text { STOP } \\
\text { STRTSU } \\
\text { VOLFIS }\end{array}$ \\
\hline STARTO & START & FLTRN \\
\hline START1 & $\begin{array}{l}\text { START } \\
\text { START2 }\end{array}$ & FLTRN \\
\hline START2 & START & $\begin{array}{l}\text { START1 } \\
\text { START5 }\end{array}$ \\
\hline START3 & START & \\
\hline START4 & START & CHOOSE \\
\hline STARTS & $\begin{array}{l}\text { START } \\
\text { START2 }\end{array}$ & $\begin{array}{l}\text { CHOOSE } \\
\text { FLTRN }\end{array}$ \\
\hline
\end{tabular}

NUREG/CR-0200,

Vol. 2, Rev. 5

F17.A.18 


\begin{tabular}{|c|c|c|}
\hline $\begin{array}{l}\text { SUBROUTINE } \\
\text { NAME }\end{array}$ & $\begin{array}{l}\text { CALLING } \\
\text { SUBROUTINE }\end{array}$ & $\begin{array}{l}\text { CALLED } \\
\text { SUBROUTINE }\end{array}$ \\
\hline$\overline{\text { START6 }}$ & START & $\begin{array}{l}\text { FLTRN } \\
\text { ICOMPA } \\
\text { MOVE } \\
\text { REED }\end{array}$ \\
\hline STATIS & FISFLX & \\
\hline STOP & $\begin{array}{l}\text { ARAYIN } \\
\text { BOOK5 } \\
\text { DATAIN } \\
\text { GEOHIN } \\
\text { HOLE } \\
\text { KENOVI } \\
\text { MAKANG } \\
\text { MIXCRS } \\
\text { MIXER } \\
\text { MIXIT } \\
\text { MSUPG } \\
\text { OOOO19 } \\
\text { POSIT } \\
\text { RCHRS } \\
\text { RDCALC } \\
\text { SAVST6 } \\
\text { SORTA } \\
\text { START } \\
\text { HATES } \\
\text { - }\end{array}$ & \\
\hline STRTSU & START & $\begin{array}{l}\text { DAZIRN } \\
\text { DGTISO } \\
\text { FLTRN }\end{array}$ \\
\hline SUMSCT & MIXMIX & 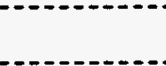 \\
\hline TIMFAC & PARAM & \\
\hline TKARRY & TRACK & $\begin{array}{l}\text { LOCBOX } \\
\text { MOVE }\end{array}$ \\
\hline TRACK & GUIDE & $\begin{array}{l}\text { ALBEDO } \\
\text { ALBIN } \\
\text { CLEAR } \\
\text { CROSS } \\
\text { DAZIRN } \\
\text { DGTISO } \\
\text { EXPRN } \\
\text { FINDBX } \\
\text { FLTRN } \\
\text { HROTRN } \\
\text { LDHRT } \\
\text { LOCBOX } \\
\text { MOVE } \\
\text { PRTPOS } \\
\text { SFLRA } \\
\text { TKARRY } \\
\text { TRKWRT }\end{array}$ \\
\hline TRKWRT & TRACKR & RNDOUT \\
\hline UNTCRS & PRTPLT & CLEAR \\
\hline VEXCAV & QUAD & \\
\hline VOLFIS & START & \\
\hline
\end{tabular}

NUREG/CR-0200, 


\begin{tabular}{|c|c|c|}
\hline $\begin{array}{l}\text { SUBROUTINE } \\
\text { NAME }\end{array}$ & $\begin{array}{l}\text { CALLING } \\
\text { SUBROUTINE }\end{array}$ & $\begin{array}{l}\text { CALLED } \\
\text { SUBROUTINE }\end{array}$ \\
\hline VOLUME & JOMITY & $\begin{array}{l}\text { CLEAR } \\
\text { GOCURS } \\
\text { GTVOLS } \\
\text { HUNTER } \\
\text { MOVE }\end{array}$ \\
\hline WAITIN & RDBIAS & $\begin{array}{l}\text { IHQUIR } \\
\text { IO } \\
\text { RITE }\end{array}$ \\
\hline WATES & FLDATA & $\begin{array}{l}\text { INQUIR } \\
\text { IO } \\
\text { MOVE } \\
\text { REED } \\
\text { RITE } \\
\text { STOP }\end{array}$ \\
\hline HEDGE & KENOG & $\begin{array}{l}\text { CLEAR } \\
\text { DREAD }\end{array}$ \\
\hline WRTALB & WRTRST & $\begin{array}{l}\text { INQUIR } \\
\text { IO } \\
\text { REED }\end{array}$ \\
\hline WRTARA & WRTRST & $\begin{array}{l}\text { IO } \\
\text { REED }\end{array}$ \\
\hline WRTCAL & GUIDE & $\begin{array}{l}\text { I0 } \\
\text { REED } \\
\text { RNDOUT } \\
\text { HRTGRP }\end{array}$ \\
\hline HRTGRP & WRTCAL & \\
\hline HRTICE & WRTRST & $\begin{array}{l}\text { INQUIR } \\
\text { IO } \\
\text { REED }\end{array}$ \\
\hline WRTPLT & DATAIN & $\begin{array}{l}\text { INQUIR } \\
\text { I0 } \\
\text { RITE }\end{array}$ \\
\hline WRTRST & BOOK3 & $\begin{array}{l}\text { INQUIR } \\
\text { IO } \\
\text { REED } \\
\text { RNDOUT } \\
\text { WRTALB } \\
\text { WRTARA } \\
\text { WRTICE } \\
\text { WRTWTS }\end{array}$ \\
\hline WRTHTS & URTRST & $\begin{array}{l}10 \\
\text { REED }\end{array}$ \\
\hline XLNTHS & MIXER & \\
\hline XSEC1D & RDTAPE & \\
\hline $\begin{array}{l}\text { XTENDA } \\
\end{array}$ & RDTAPE & \\
\hline $\begin{array}{l}\text { YREAD } \\
-\cdots---\end{array}$ & ARAYIN & \\
\hline ZREAD & PARAM & \\
\hline
\end{tabular}

NUREG/CR-0200,

Vol. 2, Rev. 5 


\section{F17.B ALPHABETICAL INDEX OF COMMONS}

This section lists the labeled common blocks used in KENO-VI and an alphabetical listing of the subroutines that reference them. 


\begin{tabular}{|c|c|c|c|}
\hline $\begin{array}{l}\text { COMMON } \\
\text { NAME }\end{array}$ & SUBROUTINE & $\begin{array}{l}\text { COMMON } \\
\text { NAME }\end{array}$ & SUBROUTINE \\
\hline ALBNAM & $\begin{array}{l}\text { ALBEDO } \\
\text { ALBRD } \\
\text { ALBUSE } \\
\text { BOOK3 } \\
\text { CORRE } \\
\text { DATAIN } \\
\text { DIFAIB } \\
\text { FILISG } \\
\text { FLDATA } \\
\text { GUIDE } \\
\text { KEDIT } \\
\text { LIMIN } \\
\text { LOADIT } \\
\text { NSUPG } \\
\text { PARAM } \\
\text { POINT } \\
\text { PRATBL } \\
\text { RDALB } \\
\text { RDREF } \\
\text { RDRST } \\
\text { SGALB } \\
\text { TRACK } \\
\text { WRTALB } \\
\text { WRTRST } \\
\\
\text { ALBEDO } \\
\text { ALBRD } \\
\text { ALBUSE } \\
\text { BOOK3 } \\
\text { CORRE } \\
\text { DATAIN } \\
\text { DIFALB } \\
\text { FILLSG } \\
\text { FLDATA } \\
\text { GUIDE } \\
\text { KEDIT } \\
\text { LIMLN } \\
\text { LOADIT } \\
\text { NSUPG } \\
\text { PARAM } \\
\text { POINT } \\
\text { PRATBL } \\
\text { RDALB } \\
\text { RDREF } \\
\text { RDRST } \\
\text { SGALB } \\
\text { TRACK } \\
\text { WRTALB } \\
\text { WRTRST }\end{array}$ & $\begin{array}{l}\text { BLKINC } \\
\text { BOUNDY } \\
\text { DIMEN }\end{array}$ & $\begin{array}{l}\text { ANGLES } \\
\text { BADMOM } \\
\text { FIND } \\
\text { GETMUS } \\
\text { LEGEND } \\
\text { PRANG } \\
\text { Q } \\
\text { BOOK2 } \\
\text { FITFLX } \\
\text { GUIDE } \\
\text { NSUPG } \\
\text { PARAM } \\
\text { PRATBL } \\
\text { RDTAPE } \\
\\
\text { CORSIZ } \\
\text { TRACK } \\
\text { ARASIZ } \\
\text { ARAYIN } \\
\text { BOOK1 } \\
\text { BOOK2 } \\
\text { BOOK3 } \\
\text { BOOK4 } \\
\text { BOOK5 } \\
\text { BOX } \\
\text { BOXC } \\
\text { CORRE } \\
\text { CORSIZ } \\
\text { CROSS } \\
\text { DATAIN } \\
\text { EDITOR } \\
\text { FILISG } \\
\text { FIL2D } \\
\text { FISFLX } \\
\text { FITFLX } \\
\text { FLDATA } \\
\text { GEOMIN } \\
\text { GUIDE } \\
\text { HROTRN } \\
\text { ICEMIX } \\
\text { INITAI } \\
\text { JOMITY } \\
\text { KEDIT } \\
\text { KENOG } \\
\text { LIMLN } \\
\text { LOCATE } \\
\text { LOCBOX }\end{array}$ \\
\hline
\end{tabular}

NUREG/CR-0200,

Vol. 2, Rev. 5

F17.B.2 


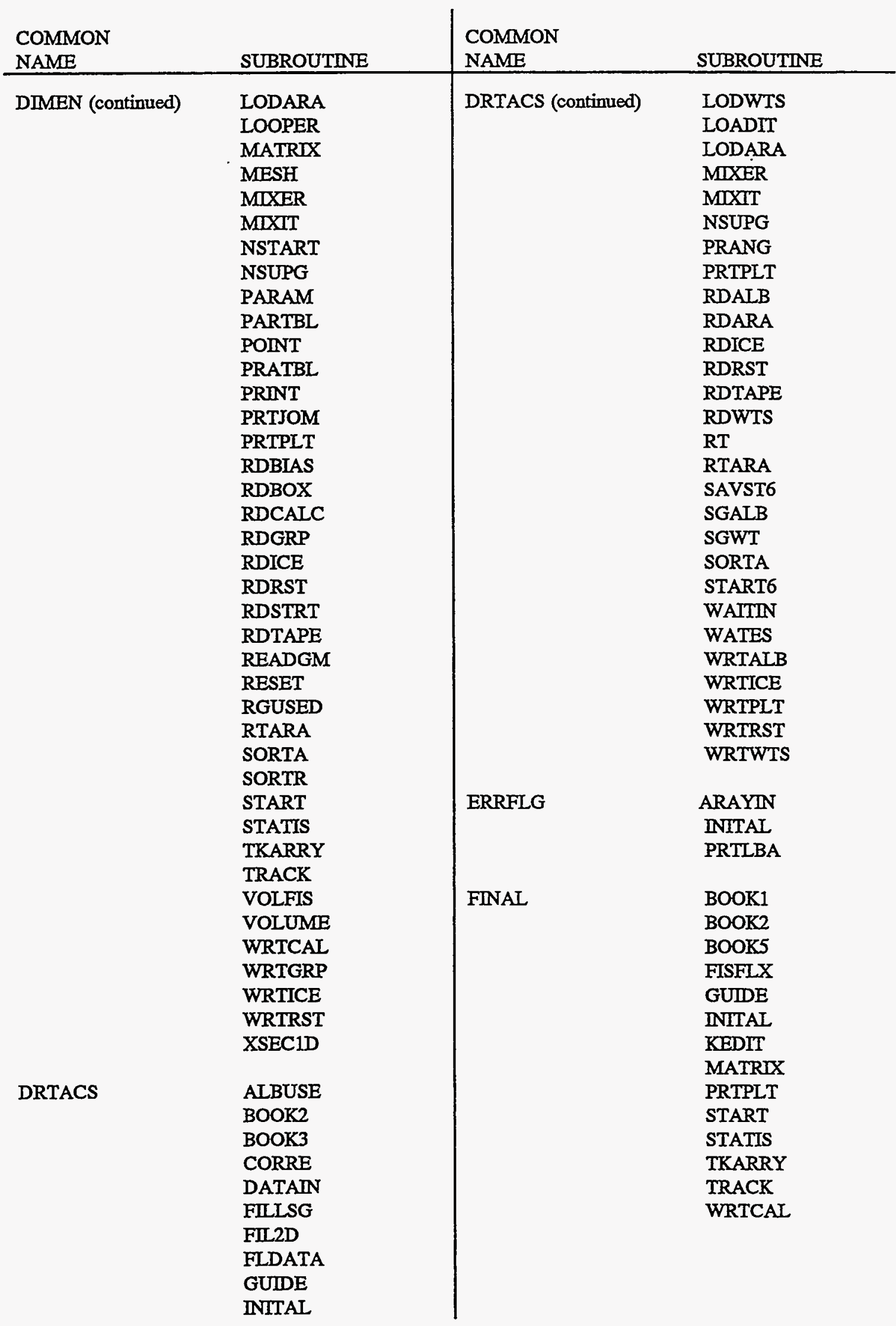

NUREG/CR-0200, 


\begin{tabular}{|c|c|c|c|}
\hline $\begin{array}{l}\text { COMMON } \\
\text { NAME }\end{array}$ & SUBROUTINE & $\begin{array}{l}\text { COMMON } \\
\text { NAME }\end{array}$ & SUBROUTINE \\
\hline $\begin{array}{l}\text { LIFETM } \\
\text { LOGIC }\end{array}$ & $\begin{array}{l}\text { BOOK1 } \\
\text { EDITOR } \\
\text { FISFLX } \\
\text { GUIDE } \\
\text { KEDIT } \\
\text { RDCALC } \\
\text { BOOK1 } \\
\text { BOOK2 } \\
\text { BOOK3 } \\
\text { BOOK4 } \\
\text { BOOK5 } \\
\text { ALBRD } \\
\text { ARASIZ } \\
\text { ARAYIN } \\
\text { CHKSTR } \\
\text { CORRE } \\
\text { CORSIZ } \\
\text { DATAIN } \\
\text { EDITOR } \\
\text { FILISG } \\
\text { FIL2D } \\
\text { FISFLX } \\
\text { FITFLX } \\
\text { FLDATA } \\
\text { GUIDE } \\
\text { ICEMIX } \\
\text { IDXID } \\
\text { INITAL } \\
\text { JOMITY } \\
\text { KEDIT } \\
\text { KENOG } \\
\text { LOCATE } \\
\text { LOOPER } \\
\text { MATRIX } \\
\text { MESH } \\
\text { MIXER } \\
\text { NSUPG } \\
\text { PARAM } \\
\text { PARTBL } \\
\text { POINT } \\
\text { POSIT } \\
\text { PRTJOM } \\
\text { PRTPLT } \\
\text { PRTXS } \\
\text { RATIO } \\
\text { RDBIAS } \\
\text { RDBOX } \\
\text { RDCALC } \\
\text { RDGRP }\end{array}$ & LOGIC (continued) & $\begin{array}{l}\text { RDREF } \\
\text { READGM } \\
\text { RESET } \\
\text { RDRST } \\
\text { RDTAPE } \\
\text { RTARA } \\
\text { SORTA } \\
\text { SORTR } \\
\text { START } \\
\text { STATIS } \\
\text { TKARRY } \\
\text { TRACK } \\
\text { TRKWRT } \\
\text { VOLFIS } \\
\text { VOLUME } \\
\text { WATES } \\
\text { WRTCAL } \\
\text { WRTGRP } \\
\text { WRTRST } \\
\\
\text { ALBEDO } \\
\text { CORSIZ } \\
\text { FILLSG } \\
\text { FISFLX } \\
\text { GOCURS } \\
\text { GUIIE } \\
\text { HROTRN } \\
\text { HUNTER } \\
\text { KEDIT } \\
\text { LOCATE } \\
\text { LODARA } \\
\text { MESH } \\
\text { POINT } \\
\text { PRINT } \\
\text { PRTJOM } \\
\text { PRTPLT } \\
\text { RESET } \\
\text { START } \\
\text { TKARRY } \\
\text { TRACK } \\
\text { VOLUME } \\
\text { BOOK2 } \\
\text { BOOK3 } \\
\text { BOOK4 } \\
\text { BOOK5 } \\
\text { START6 }\end{array}$ \\
\hline
\end{tabular}

NUREG/CR-0200,

Vol. 2, Rev. 5

F17.B.4 


\begin{tabular}{|c|c|c|c|}
\hline $\begin{array}{l}\text { COMMON } \\
\text { NAME }\end{array}$ & SUBROU'TINE & $\begin{array}{l}\text { COMMON } \\
\text { NAME }\end{array}$ & SUBROUTINE \\
\hline \multirow[t]{2}{*}{ MATRX } & $\begin{array}{l}\text { FLDATA } \\
\text { MATRIX } \\
\text { PRATBL } \\
\text { SORTA } \\
\text { RESET }\end{array}$ & PICTTI (continued) & $\begin{array}{l}\text { PRINT } \\
\text { PRTPLT } \\
\text { RDPLOT } \\
\text { RELATE }\end{array}$ \\
\hline & & POINTR & BOOK1 \\
\hline \multirow[t]{4}{*}{ MSTR } & BOOK1 & & BOOK3 \\
\hline & BOOK3 & & $\begin{array}{l}\text { BUUK4 } \\
\text { BOOK5 }\end{array}$ \\
\hline & BOOK4 & & DATAIN \\
\hline & BOOK5 & & $\begin{array}{l}\text { FILLSG } \\
\text { ICEMXX }\end{array}$ \\
\hline \multirow[t]{21}{*}{ NUTRON } & $\begin{array}{l}\text { ALBEDO } \\
\text { CHKSTR } \\
\text { CHOOSE } \\
\text { CROSS } \\
\text { FINDBX } \\
\text { FLDATA }\end{array}$ & & $\begin{array}{l}\text { LOADIT } \\
\text { NSUPG } \\
\text { POINT } \\
\text { RDCALC } \\
\text { WRTCAL }\end{array}$ \\
\hline & GUIDE & RTRN & CONE \\
\hline & HROTRN & & CUBOID \\
\hline & LOCATE & & CYLNDR \\
\hline & MESH & & DITTO \\
\hline & NSTART & & DODECA \\
\hline & RESET & & ECYL \\
\hline & SHUFL & & ELLIPS \\
\hline & START & & HOLENN \\
\hline & STARTO & & HOPPER \\
\hline & START1 & & HXPRSM \\
\hline & START2 & & KENOG \\
\hline & START3 & & ORIGN \\
\hline & START4 & & PLANE \\
\hline & START5 & & PPIPED \\
\hline & START6 & & QUAD \\
\hline & STRTSU & & READGM \\
\hline & TKARRY & & RHOMB \\
\hline & TRACK & & ROTATE \\
\hline & TRKWRT & & ROTHOL \\
\hline & & & ROTRNS \\
\hline \multirow[t]{2}{*}{ PCOLOR } & PCOLOR & & SPHERE \\
\hline & & & WEDGE \\
\hline \multirow[t]{7}{*}{ PICT } & CLRNIT & & \\
\hline & MESH & RUNTYP & BIRITE \\
\hline & PRINT & & DATAIN \\
\hline & PRTPLT & & INITAL \\
\hline & RDPLOT & & KENOVI \\
\hline & RELATE & & 000019 \\
\hline & & & PARAM \\
\hline PICTTL & CLRNIT & & PARTBL \\
\hline & MESH & & \\
\hline
\end{tabular}




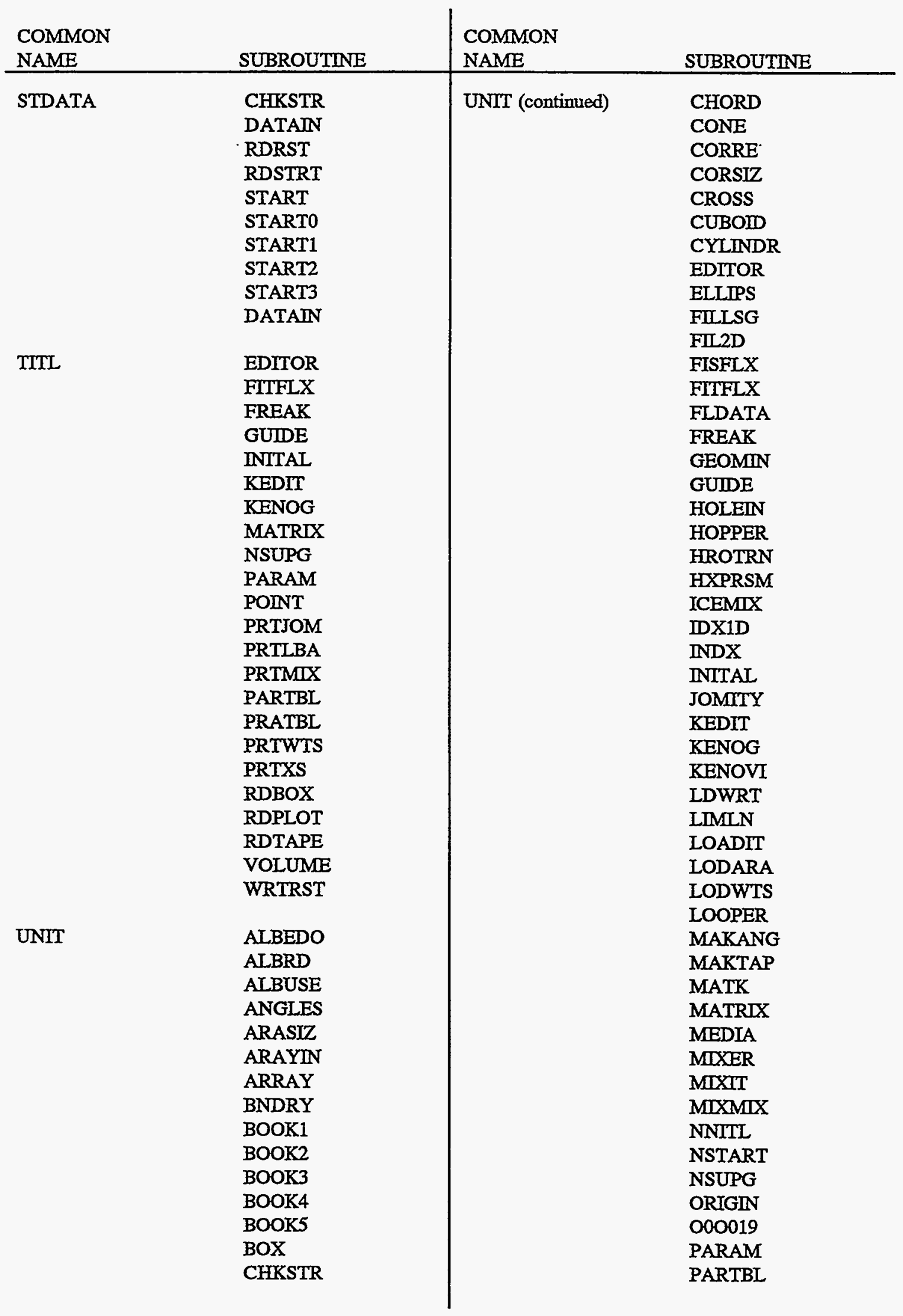

NUREG/CR-0200,

Vol. 2, Rev. 5

F17.B.6 


\begin{tabular}{|c|c|c|c|}
\hline $\begin{array}{l}\text { COMMON } \\
\text { NAME }\end{array}$ & SUBROUTINE & $\begin{array}{l}\text { COMMON } \\
\text { NAME }\end{array}$ & SUBROUTINE \\
\hline UNIT (continued) & $\begin{array}{l}\text { PLANE } \\
\text { POINT } \\
\text { POSIT } \\
\text { PPIPED } \\
\text { PRANG } \\
\text { PRINT } \\
\text { PRTARA } \\
\text { PRTFLX } \\
\text { PRTJOM } \\
\text { PRTLBA } \\
\text { PRTPLT } \\
\text { PRTPOS } \\
\text { PRTXS } \\
\text { QUAD } \\
\text { RATIO } \\
\text { RDALB } \\
\text { RDBIAS } \\
\text { RDBOX } \\
\text { RDCALC } \\
\text { RDGRP } \\
\text { RDICE } \\
\text { RDPLOT } \\
\text { RDREF } \\
\text { RDRST } \\
\text { RDSTRT } \\
\text { RDTAPE } \\
\text { RDWTS } \\
\text { READGM } \\
\text { RHOMB } \\
\text { ROTATE }\end{array}$ & UNIT (continued) & $\begin{array}{l}\text { ROTHOL } \\
\text { SGWT } \\
\text { SHUFL } \\
\text { SORTA } \\
\text { SORTR } \\
\text { SPHERE } \\
\text { START } \\
\text { START2 } \\
\text { START6 } \\
\text { STATIS } \\
\text { STRTSU } \\
\text { TKARRY } \\
\text { TRACK } \\
\text { TRKWRT } \\
\text { VEXCAV } \\
\text { VOLFIS } \\
\text { VOLUME } \\
\text { WAITIN } \\
\text { WATES } \\
\text { WEDGE } \\
\text { WRTALB } \\
\text { WRTCAL } \\
\text { WRTGRP } \\
\text { WRTICE } \\
\text { WRTRST } \\
\text { WRTWTS } \\
\text { RT } \\
\text { RTARA } \\
\text { SAVST6 } \\
\text { SGALB }\end{array}$ \\
\hline
\end{tabular}




\section{F17.C KENO-VI INPUT SUMMARY}

This appendix consists of a summary of the KENO-VI input data requirements. 
Table F17.C.1 Summary of parameter data

TTTLE: The title must be entered first ( 80 characters, including blanks) Sce Scet. F17.4.3

PARAMETERS: Format: READ PARAM enter pammeter data here BND PARAM

If parameters are entered, they must follow the title. See Sects. F17.4.3, F17.5.2, and F17.5.3.

\begin{tabular}{|c|c|c|}
\hline KEY & STD. & DEFINITION \\
\hline RND $=$ & given & random number \\
\hline $\mathrm{TME}=$ & $30 \mathrm{~min}$ & execution time (min) \\
\hline TBA $=$ & $0.5 \mathrm{~min}$ & batch time (min) \\
\hline WTA $=$ & 0.5 & average weight \\
\hline WTH $=$ & 3.0 & wt. for splitting \\
\hline$W T Z=$ & $1 /$ WTH & Russian Roulette wt. \\
\hline $\mathrm{GEN}=$ & 103 & no. of generations \\
\hline$N P G=$ & 300 & no. per generntion \\
\hline NSK $=$ & 3 & generations skipped \\
\hline RES $=$ & $\mathbf{0}$ & gens, between restart \\
\hline $\mathrm{NBK}=$ & $N P G+25$ & neutron bank positions \\
\hline $\mathrm{XNB}=$ & & extra bank entries \\
\hline $\mathrm{NFB}=$ & NPG & fission bank positions \\
\hline $\mathrm{XFB}=$ & $\mathbf{0}$ & extra bank entries \\
\hline $\mathrm{X} 1 \mathrm{D}=$ & $\mathbf{0}$ & no. of extra 1-D's \\
\hline$L N G=$ & 1000000 & words of storage \\
\hline$B E G=$ & 1 & restart at this gen. \\
\hline NG8 $=$ & 200 & blocks for d.a. unit \\
\hline NLB $=$ & 512 & length of d,a. block \\
\hline SIG $=$ & given & standand deviation to \\
\hline
\end{tabular}

\begin{tabular}{rll} 
KRY & STD. & DEFINITION \\
\hline RUN $=$ & YES & execute problem \\
FIX $=$ & NO & fluxes \\
FDN $=$ & NO & fission densitics \\
$\mathrm{ADI}=$ & NO & sdjoint calculation \\
$\mathrm{AMX}=$ & NO & all mixture xBecs \\
$\mathrm{XAP}=$ & NO & xsec angles \& probs. \\
$\mathrm{XS1}=$ & NO & 1-D xsecs \\
$\mathrm{XS2}=$ & NO & 2-D xeccs \\
$\mathrm{PKI}=$ & NO & fission epectrum \\
$\mathrm{PID}=$ & NO & extra 1-D xsecs \\
$\mathrm{FAR}=$ & NO & fise. \& abs. \\
$\mathrm{MRP}=$ & NO & matrix by location \\
$\mathrm{CKP}=$ & NO & cofactor k by loc. \\
$\mathrm{FMP}=$ & NO & fiss, prod. by loc. \\
$\mathrm{MKU}=$ & NO & matrix by unit \\
$\mathrm{CKU}=$ & NO & cofactor k by unit \\
$\mathrm{FMU}=$ & NO & fiss. prod. by unit \\
& & \\
& & \\
& & \\
\hline
\end{tabular}

\begin{tabular}{cll} 
KEY & STD. & DEFINTTION \\
\hline MKH $=$ & NO & matrix by hole \\
CKH $=$ & NO & cofactor $k$ by hole \\
FMH $=$ & NO & fiss. prod. by hole \\
HHL $=$ & NO & MKH at highest level \\
MKA $=$ & NO & matrix by array \\
CKA $=$ & NO & cofactor $k$ by array \\
FMA $=$ & NO & fiss. prod. by array \\
HAL $=$ & NO & MKA at highest level \\
PLT $=$ & YES & printer plots \\
BUG $=$ & NO & debug print \\
TRK $=$ & NO & print neutron tracks \\
PWT $=$ & NO & print avg. weight \\
PGM $=$ & NO & unprocessed geometry \\
SMU $=$ & NO & self-multiplication \\
NUB $=$ & NO & neutrons per fission \\
PAX $=$ & NO & albedo-xsec array \\
& & \\
& & \\
& & \\
\end{tabular}

\begin{tabular}{rcl} 
KEY & STD. & DEFINITION \\
\hline XSC $=$ & 14 & mixed xsecB \\
ALB $=$ & 79 & albedo \\
WTS $=$ & 80 & weights \\
LTB $=$ & 0 & working $x$ xecs \\
SKT $=$ & 16 & scratch \\
RST $=$ & 0 & read restart \\
WRS $=$ & 0 & write restart
\end{tabular}

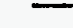


Table F17.C.2 Summary of array data

ARRAY Format: READ ARRAY amay parameters data type orientation data END ARRAY See Sects. F17.5.5, F17.5.6, and F17.5.7.

Repeat the sequence ARRAY PARAMETERS DATA TYPE ORIENTATION DATA for each array used in the problem.

\begin{tabular}{|c|c|c|}
\hline \multicolumn{3}{|c|}{ ARRAY PARAMETERS } \\
\hline KEYWORD & DEFAULT & DEFINITION \\
\hline $\begin{array}{l}\mathrm{ARA}= \\
\mathrm{TXP}=\end{array}$ & 1 & $\begin{array}{l}\text { no. defining the array } \\
\text { armay type (cuboidal or }\end{array}$ \\
\hline $\begin{array}{l}\text { NUX }= \\
\text { NUY }= \\
\text { NUZ }= \\
\text { GBI= } \\
\text { COM= }\end{array}$ & $\begin{array}{l}1 \\
1 \\
1 \\
\text { none } \\
\text { none }\end{array}$ & $\begin{array}{l}\text { no. of units in } X \text { direction } \\
\text { no. of units in } \mathbf{X} \text { direction } \\
\text { no. of units in } Z \text { direction } \\
\text { global, array number" } \\
\text { delim comment delim } \\
\text { optional comment is a } \\
\text { maximum of } 132 \text { characters }\end{array}$ \\
\hline
\end{tabular}

DATA TYPE

If specified, it need be entered only once per problem.

ORIENTATION DATA FOR FILI

ORIENTATION DATA FOR LOOP

Enter unit numbers to define every position in the array. When entering data utilizing the options in this table, the count ficld and option fickd must be adjacent with no imbedded blanks. The opernind fied may be
Beparated from the option fied by one or more blanks. Orientation data for FlLL are terminated by entering
END FIL.

年

Enter the unit number and nine numbers that define the position(o) of that unit. Data for each of these ten entrices are repeated until every position in the array hns been definod. Orientation

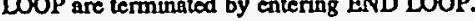
ENTER DATA IN THE FORM

\begin{tabular}{lll}
\hline COUNT & OPTION & OPERAND \\
FERLD & FIELD & FIELD \\
\hline
\end{tabular}

DATA

COMMENTS

LTYPE

stores $j$ at the current position in the array

stores in the next i positions in the array

stores $j$ in the next i positions in the array

fills remainder of the array with unit no.

starting with the current array position

increments current position in the array by $i$

repeats the previous $j$ catries $i$ times. The

default value of is is 1
repeats the previous $j$ entries $i$ times,

value of $i$ is 1

FILL,

hasting with the entry at -i from the current

position, storo entries in inverse onder until

position $-(i+j)$ is reachod. Default valuc

positions of the armay

provides the end points, $j$ and $k$, with

$i$ entries linearly interpolatod between them

(i.e., a total of $i+2$ points). At least one

blank must separate point. Ahen used for

in to

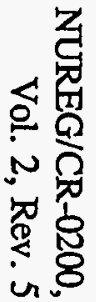

$(k-j) /(i+1)$ should be a whole number).

IX2

INCX

IY1

IY2

INCY

IZ1

IZ2

INCZ
The unit or box type. LTYPE must be greater than 0 . larger than the value entered for NUX. Exding position in the $X$ direction

The number of units by which increments are made in the $\mathrm{X}$ direction.

列 Ending position int he $Y$ direction. IY2 must be at least 1 and no

列 $n$ in the $\mathrm{Z}$ direction. IZ1 must be at least 1 and $\mathrm{n}$ larger than NUZ Ending position in the $Z$ direction. IZ2 must be at least 1 and no

The number of units by which increments are made in the positive $\mathrm{Z}$ direction. 
Table F17.C.3 Summary of biasing data

\begin{tabular}{|c|c|c|c|c|c|c|c|}
\hline \multirow[t]{7}{*}{$\begin{array}{l}\text { BIAS } \\
\text { (weighting) }\end{array}$} & \multicolumn{2}{|c|}{$\begin{array}{l}\text { Pormat: READ BLAS keyword } \\
\text { See Sects. F17.4.7 and F17.5.8 }\end{array}$} & correlation data auxiliary data END BIAS & & & & \\
\hline & KEYWORD & DESCRIPTION & & MATERIAL & ID & $\begin{array}{l}\text { ENERGY } \\
\text { GROUPS }\end{array}$ & $\begin{array}{l}\text { THICKNESSI } \\
\text { INCREMENT }\end{array}$ \\
\hline & \multirow[t]{2}{*}{$\mathrm{ID}=$} & \multicolumn{2}{|c|}{ CORRELATION DATA will be read next. } & & & & \\
\hline & & $\begin{array}{l}\text { id } \\
\text { ibgn } \\
\text { iend }\end{array}$ & $\begin{array}{l}\text { material ID. Enter from table at right to use weighting data } \\
\text { from the library } \\
\text { beginning bias ID } \\
\text { coding bias ID }\end{array}$ & $\begin{array}{l}\text { concrete } \\
\text { parafinin } \\
\text { water } \\
\text { graphite }\end{array}$ & $\begin{array}{r}301 \\
400 \\
500 \\
6100\end{array}$ & $\begin{array}{l}16,27,123 \\
16,27,123 \\
16,27,123,218 \\
16,27,123\end{array}$ & $\begin{array}{r}5 \mathrm{~cm} \\
3 \mathrm{~cm} \\
3 \mathrm{~cm} \\
20 \mathrm{~cm}\end{array}$ \\
\hline & \multirow{3}{*}{$\begin{array}{r}\mathrm{WT}= \\
\mathrm{WTS}=\end{array}$} & \multicolumn{2}{|c|}{ AUXILIARY DATA will be read next. } & & & & \\
\hline & & \multicolumn{2}{|c|}{ AUXILARY DATA will be read next. } & & & & \\
\hline & & $\begin{array}{l}\text { wttitl } \\
\text { id } \\
\text { nsetg } \\
\text { REPEAT } \\
\text { thkinc } \\
\text { numinc } \\
\text { ngpwt } \\
\text { wtavg }\end{array}$ & $\begin{array}{l}\text { material title (12-character maximum) } \\
\text { material ID } \\
\text { number of sets of group structures } \\
\text { (THKINC, NUMINC, NGPWT, WTAVG) NSETS TIMES } \\
\text { thickness per increment } \\
\text { number of increments } \\
\text { number of energy groups for this set of wts } \\
\text { enter numinc } x \text { ngpwt values of wtavg }\end{array}$ & & & & \\
\hline
\end{tabular}

For CORRELATTON DATA, the material ID is chosen from material ID column above (the keyword is ID $=$ ).
For AUXIIIIARY DATA, the material ID is chosen by the user and the keyword is WT $=$ or WTS $=$. When AUXIUARY DATA are entered, CORRELATION DATA must also be entered to use tho data.

Beginning and ending bias IDs are defined by the user. The geometry specificaiton that has the bias ID equal to the beginning bias ID utilizes the wt av from the first interval of 
Table F17.C. 4 Summary of boundary condition data

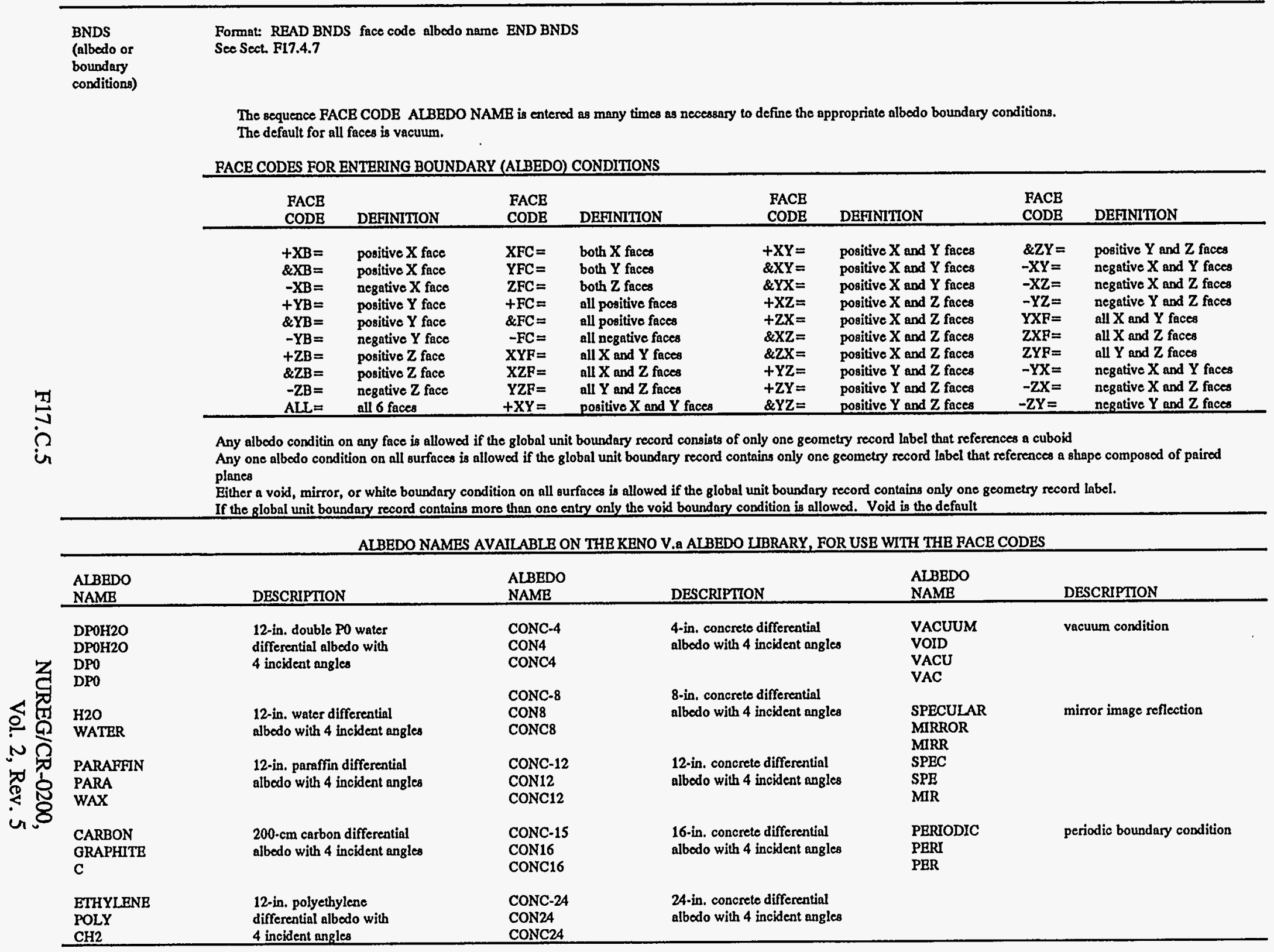


GEOMETRY Pormat: READ GEOM geometry region data END GEOM

GEOMETRY REGION DATA consist of SIMPLE GEOMETRY REGION DATA and EXTENDED GEOMETRY REGION DATA. ENTER GEOMETRY REGION DATA IN THE FOLIOWING FORM:

\section{GLOBAL SPECIFICATION}

UNIT D

OPTIONAL GEOMETRY COMMENT

GEOMETRY, MODIFICATION, MEDIA, and BOUNDARY DATA

\section{ENTER DATA IN THE FOLLOWING FORM \\ GLOBAL Enter once to specify this unit as the global unit.}

COM=delim comment delim This optional comment can be up to 132 characters. It must begin and end with a delimiter

Geometry Keyword Label Input Parameters Optional origin data (ORIGIN) Optional chord data (CHORD) Optional rotation data (ROTATE degrees)

Media Keytrod Inpun Panneters

Each unit must have one boundary record.

Enter as many geometry and media descriptions as neceasary to describe the unit and as many units as necessary to describe the system.

GEOMETRY REGION INPUT DATA REOUIREMENTS

\begin{tabular}{|c|c|c|c|}
\hline $\begin{array}{l}\text { TYPB OF } \\
\text { DATA }\end{array}$ & KEYWORD & $\begin{array}{c}\text { INPUT } \\
\text { PARAMETERS } \\
\end{array}$ & NOTES \\
\hline GEOMETRY & $\begin{array}{l}\text { CONE } \\
\text { CUBOID } \\
\text { CYLINDER } \\
\text { DODECAHEDRON } \\
\text { ECYLINDER } \\
\text { ELUPSOID } \\
\text { HEXPRISM } \\
\text { HOPPER } \\
\text { PARALILELPIPED } \\
\text { PLANE* } \\
\text { QUADRATI* } \\
\text { RHOMBOID } \\
\text { SPHBRB } \\
\text { WEDGE }\end{array}$ & 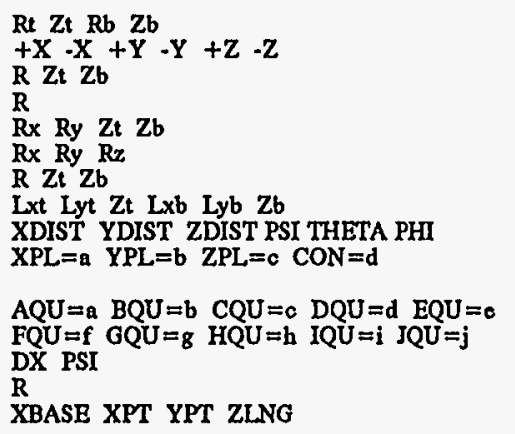 & $\begin{array}{l}\text { Data are entered after the }=\text { following the respective subordinate } \\
\text { keyword. Only nonzero data are required. } \\
\text { Date are entered after the = following the respective subordiante } \\
\text { keyword. Only nonzero data are required. }\end{array}$ \\
\hline MODIFICATION• & $\begin{array}{l}\text { CHORD } \\
\text { ORIGIN } \\
\text { ROTATE }\end{array}$ & $\begin{array}{l}+X=-X=+Y=-Y=+Z=-Z= \\
X=Y=Z= \\
A 1=A 2=A 3=\end{array}$ & $\begin{array}{l}\text { Only nonzero data are required. } \\
\text { Only nonzero data are required. } \\
\text { The body is rolated about the Origin using the Euler angle } x \text { - } \\
\text { convention. Only nonzer data are required. }\end{array}$ \\
\hline MEDIA & $\begin{array}{l}\text { MEDIA } \\
\text { HOLB } \\
\text { ARRAY }\end{array}$ & $\begin{array}{l}\text { Mid Bid i1 i2 ... } \\
\text { Hid il i2 ... } \\
\text { Aid il i2 ... PLACE } n x \text { ny } n z x x \text { yy } z z\end{array}$ & $\begin{array}{l}\text { The region boundary containing the hole must exactly match the } \\
\text { boundary of the unit being placed in the hole. } \\
\text { Place positions the array by placing the origin of the unit in array } \\
\text { position nx ny } \mathrm{nz} \text { at } x \times y y, z z \text {. The region boundary containing } \\
\text { the array must be enclosed in or on the array boundary. }\end{array}$ \\
\hline BOUDARY & BOUNDARY & i1, i2, ... & Defines the overal volume of the unit. \\
\hline
\end{tabular}

Modification Data can be entered in any order. Any combination of modification data can follow any geomelry recond.

The Region Definition Vector, il i2 . should contnin references to all geometry records which share a boundary with the region being defined 
Table F17.C.6 Summary of mixing table data

\begin{tabular}{|c|c|c|c|c|}
\hline \multirow[t]{6}{*}{ MIXTURES } & \multicolumn{4}{|c|}{$\begin{array}{l}\text { Format: READ MIXT xsec parameters END MIXT } \\
\text { These data are entered only if an AMPX working-format library is being used (LIB }=\text { ) in the parameter } \\
\text { data, Sect. F17.4.3. Do not enter if an ICE mixed library is used, }(\mathrm{XSC}=) \text { in the parameter data, } \\
\text { Sects. F17.4.10 and F17.5.5. }\end{array}$} \\
\hline & \multirow[t]{3}{*}{ XSEC PARAMETERS } & \multicolumn{3}{|c|}{$\begin{array}{l}\text { consists of keywords and associated values. } \\
\text { These parameters, if entered, need be entered only once. }\end{array}$} \\
\hline & & KEYWORD & DEFAULT & DEFINITION \\
\hline & & $\mathrm{SCT}=$ & .00003 & $\begin{array}{l}\text { No. of discrete scattering angles } \\
0 \text { is isotropic } \\
1 \text { is P1 } \\
2 \text { is P3 } \\
3 \text { is P5 } \\
\text { cross-section message cutoff value } \\
\text { use to suppress message No. K5-60 }\end{array}$ \\
\hline & \multirow{2}{*}{\multicolumn{2}{|c|}{ MIXING TABLE DATA consist of }} & \multicolumn{2}{|c|}{$\begin{array}{l}\text { (1) a keyword and mixture ID for the mixture } \\
\text { The keyword is MIX = } \\
\text { The desired mixture number follows the keyword } \\
\text { (2) nuclide ID** } \\
\text { (3) number density** } \\
\text { **The sequence (2) (3) is repeated for each nuclide } \\
\text { in the mixture. }\end{array}$} \\
\hline & & & \multicolumn{2}{|c|}{$\begin{array}{l}\text { REPEAT the sequence (1) (2)'s (3)'s until all the } \\
\text { mixtures have been described. }\end{array}$} \\
\hline
\end{tabular}


Table F17.C.8 Summary of starting data

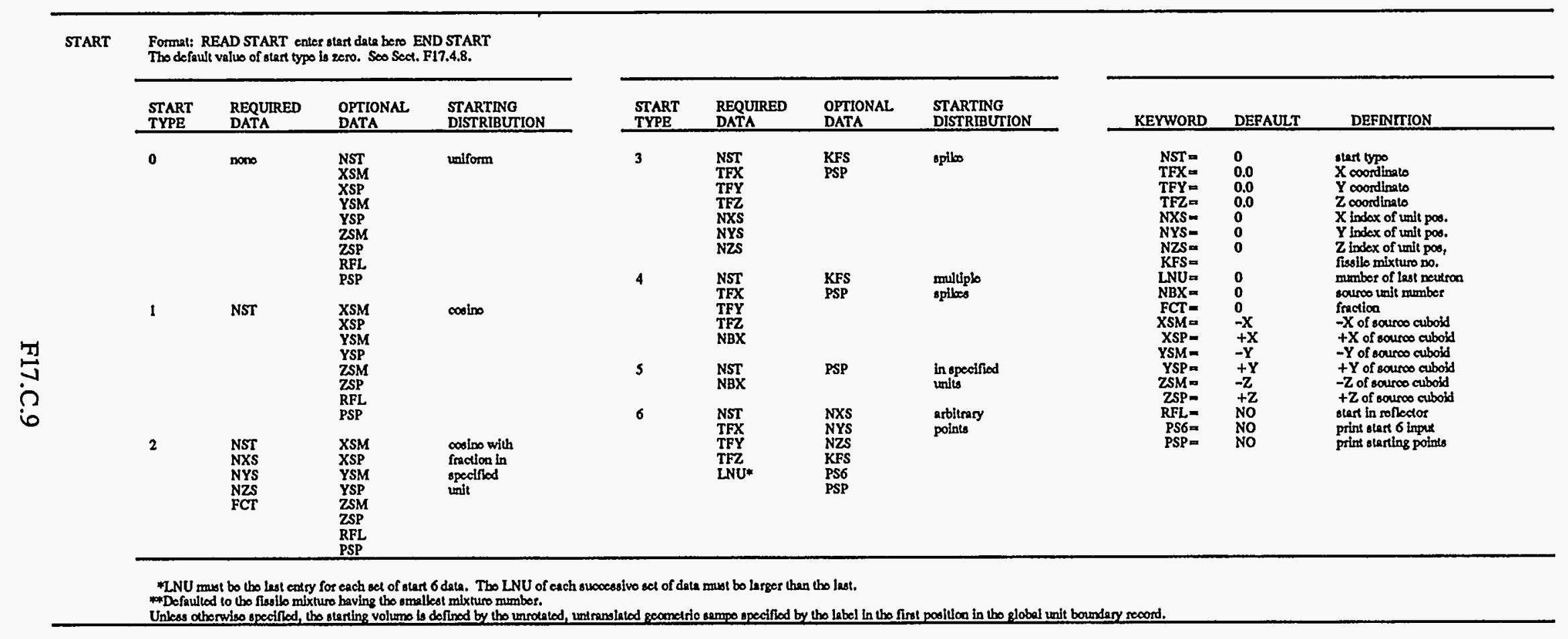

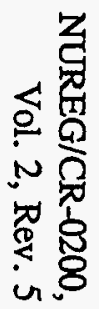




\section{F17.D SAMPLE PROBLEMS}

This section contains sample problems to demonstrate some of the options available in KENO-VI. All the options of KENO V.a are available in KENO VI. When KENO VI is run as a part of SCALE, the driver allows KENO VI to be executed each time it encounters an "=KENOVI" These KENO-VI problems are set up to run as stand-alone KENO-VI. A working format cross-section set was generated on unit 4, using BONAMI and NITAWL, for use with this problem set.

\section{F17.D.1 KENO-VI SAMPLE PROBLEM DATA}

A brief problem description and the associated record input data are included for each KENO-VI sample problem. Different options may be easily activated by making changes in the data. These problems use a 27group AMPX working-format library on Unit 4 which was generated using BONAMI and NITAWL from the 27groupndf4 master library. The nuclide identifiers for this library are consistent with the SCALE 4.3 identifiers created by CSAS. Input data to create this library are given in Sect. F17.D.2. The unit number is defined by the parameter LIB $=$ in the parameter data.

\section{SAMPLE PROBLEM 1 2C8 BARE}

This simple $2 \times 2 \times 2$ array of uranium metal cylinders is described in the article "Critical ThreeDimensional Arrays of U(93.2)-Metal Cylinders"' by J. T. Thomas. This critical experiment is designated in Table II of that article as cylinder index 11 and reflector index 1. Figure F17.D.1 shows the critical experiment.

\section{INPUT DATA}

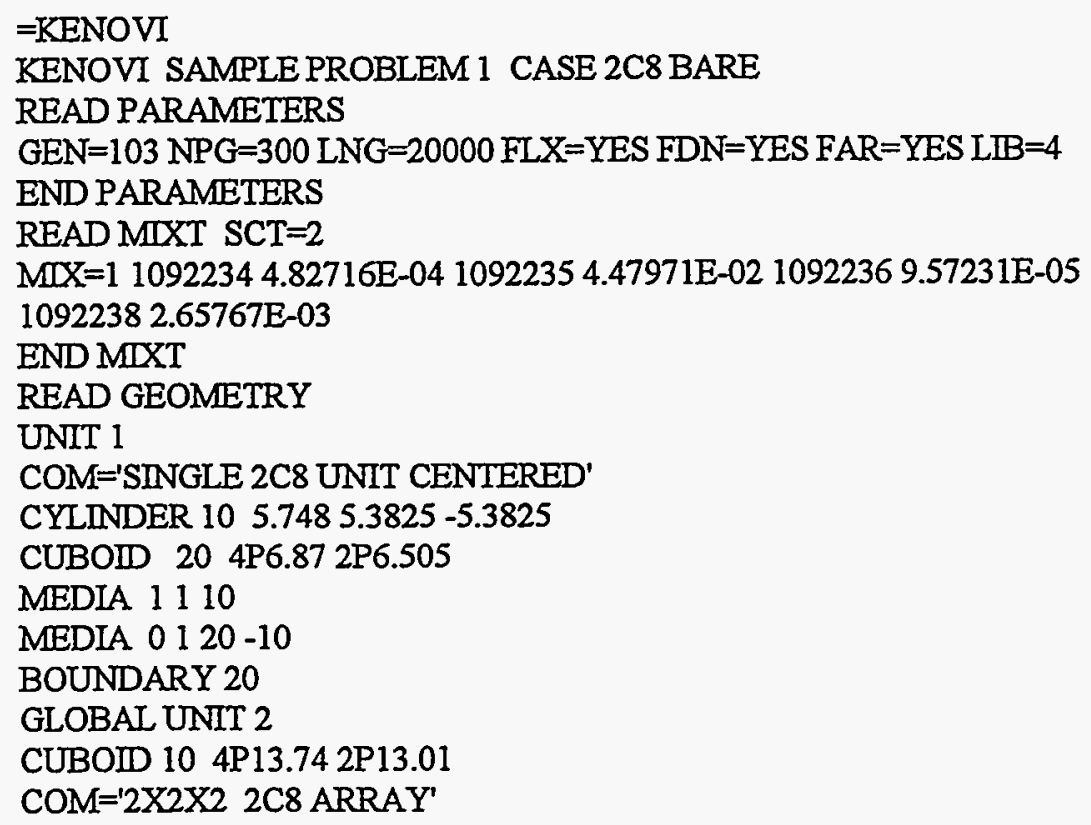




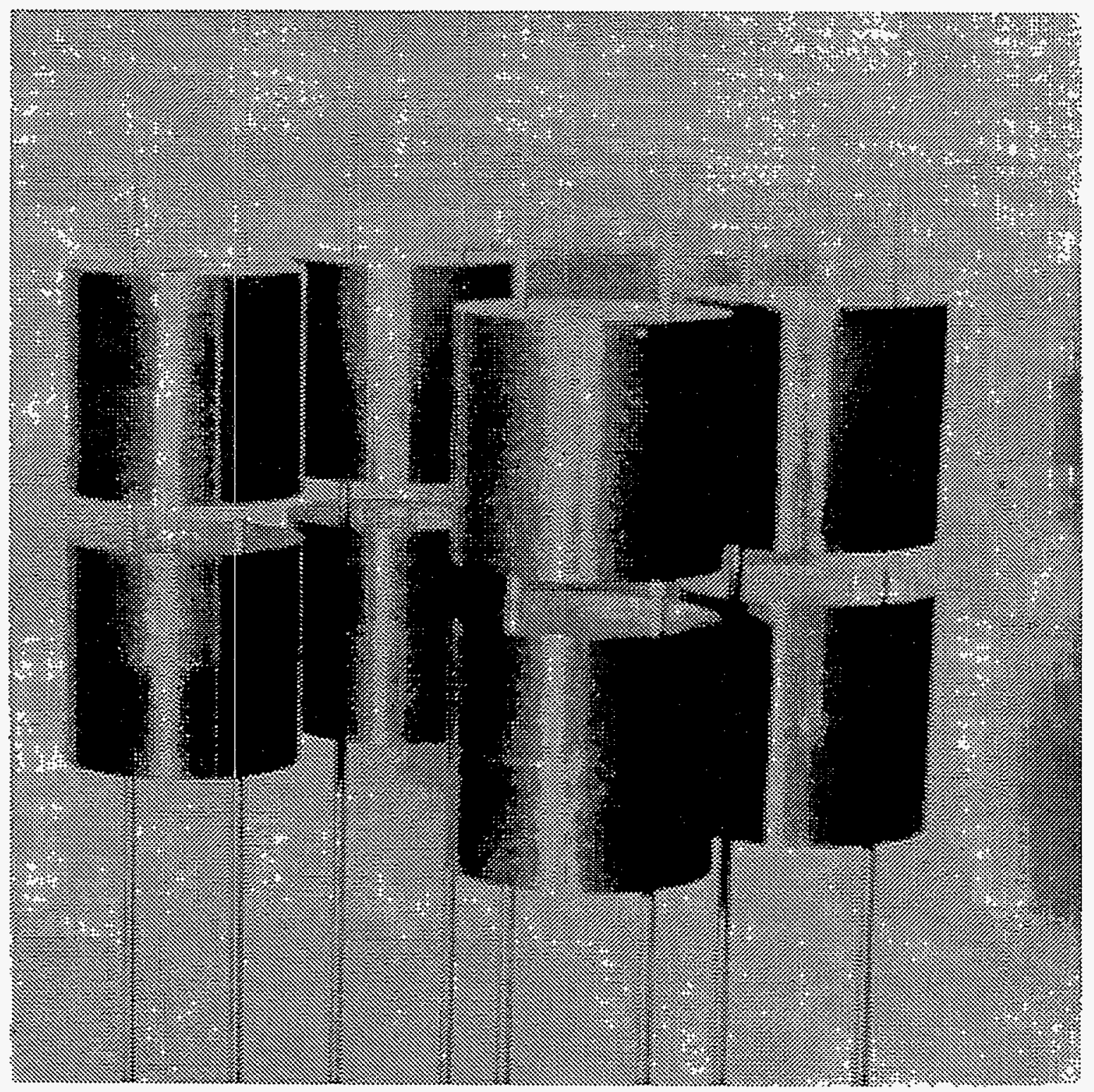

Figure F17.D.1. Critical 2C8 bare assembly

NUREG/CR-0200,

Vol. 2, Rev. 5

F17.D.2 
ARRAY $1+10$ PLACE $1112 R-6.87-6.505$

BOUNDARY 10

END GEOMETRY

READ ARRAY GBL=1 NUX=2 NUY=2 NUZ $=2$ FILL F1 END ARRAY

END DATA

END

\section{SAMPLE PROBLEM 2 CASE 2C8 BARE WITH 8 UNIT TYPES MATRIX CALCULATION}

This problem is the same as sample problem 1 except it is set up as a mixed box problem with each unit of the array defined as a different unit type. Matrix $k$-effectives will be calculated for this problem by both unit type and array position. The print flags are set to print all matrix data.

\section{INPUT DATA}

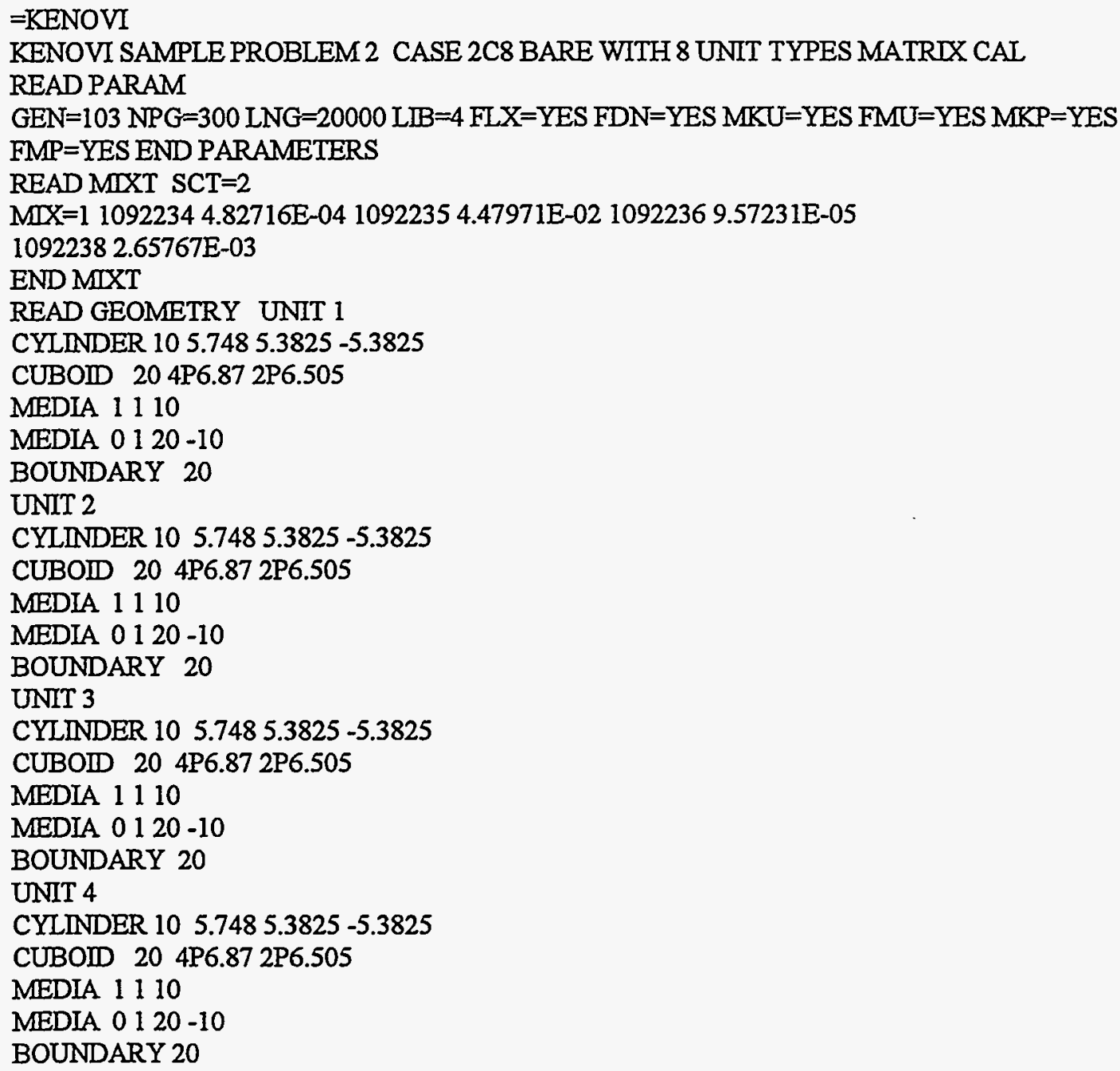




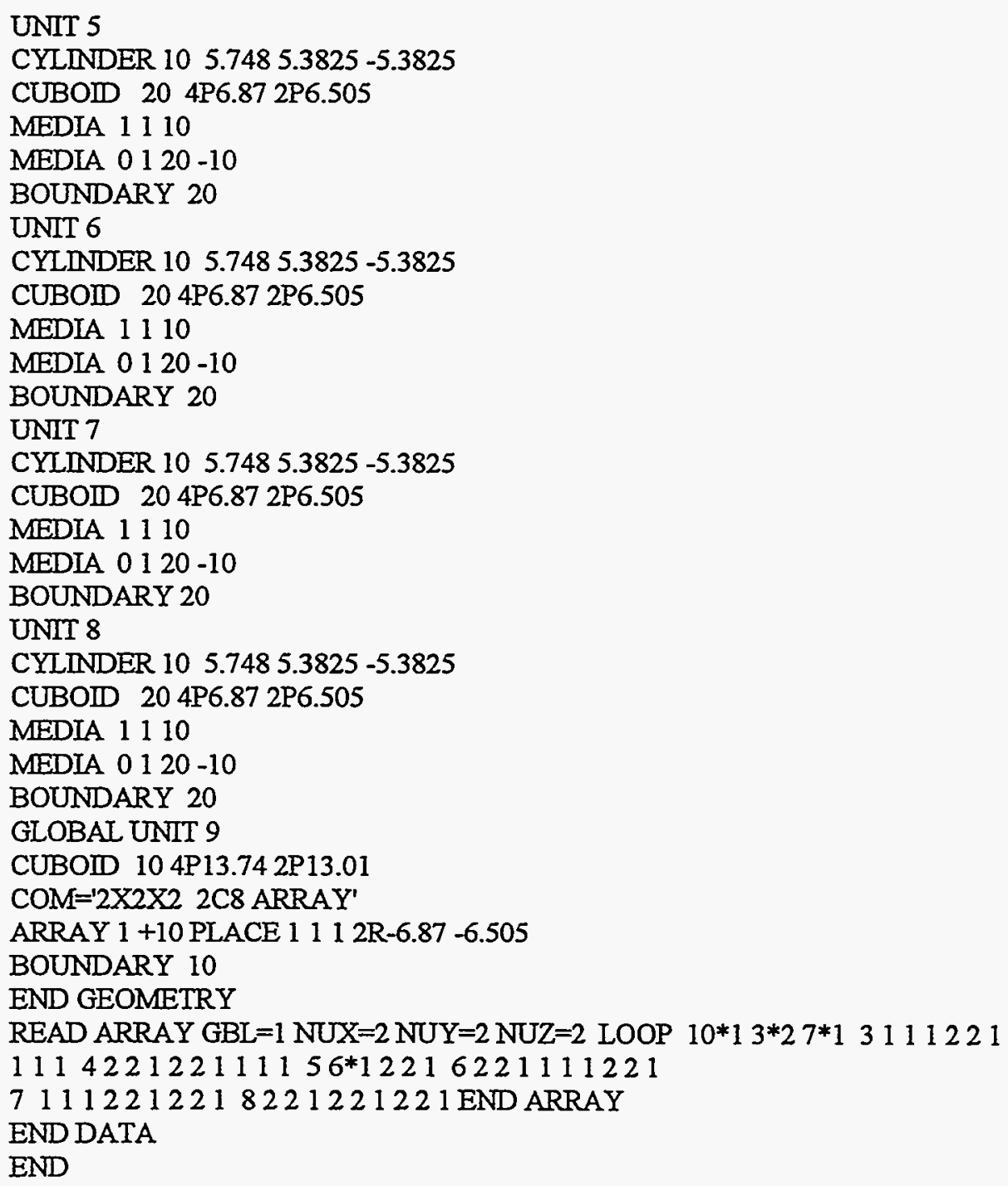

\section{SAMPLE PROBLEM 3 2C8 15.24-CM PARAFFIN REFL}

A $2 \times 2 \times 2$ array of uranium metal cylinders is reflected by $6 \mathrm{in}$. of paraffin on all faces. This critical experiment ${ }^{1}$ is designated as cylinder index 11 and reflector index 5 in Table II of ref. 1. Figure F17.D.2 shows half of the critical experiment, which consisted of the half shown and the mirror image of it. These two assemblies were moved together to achieve criticality. The top reflector is missing in Fig. F17.D.2, but it was present when criticality was achieved.

NUREG/CR-0200,

Vol. 2, Rev. 5 


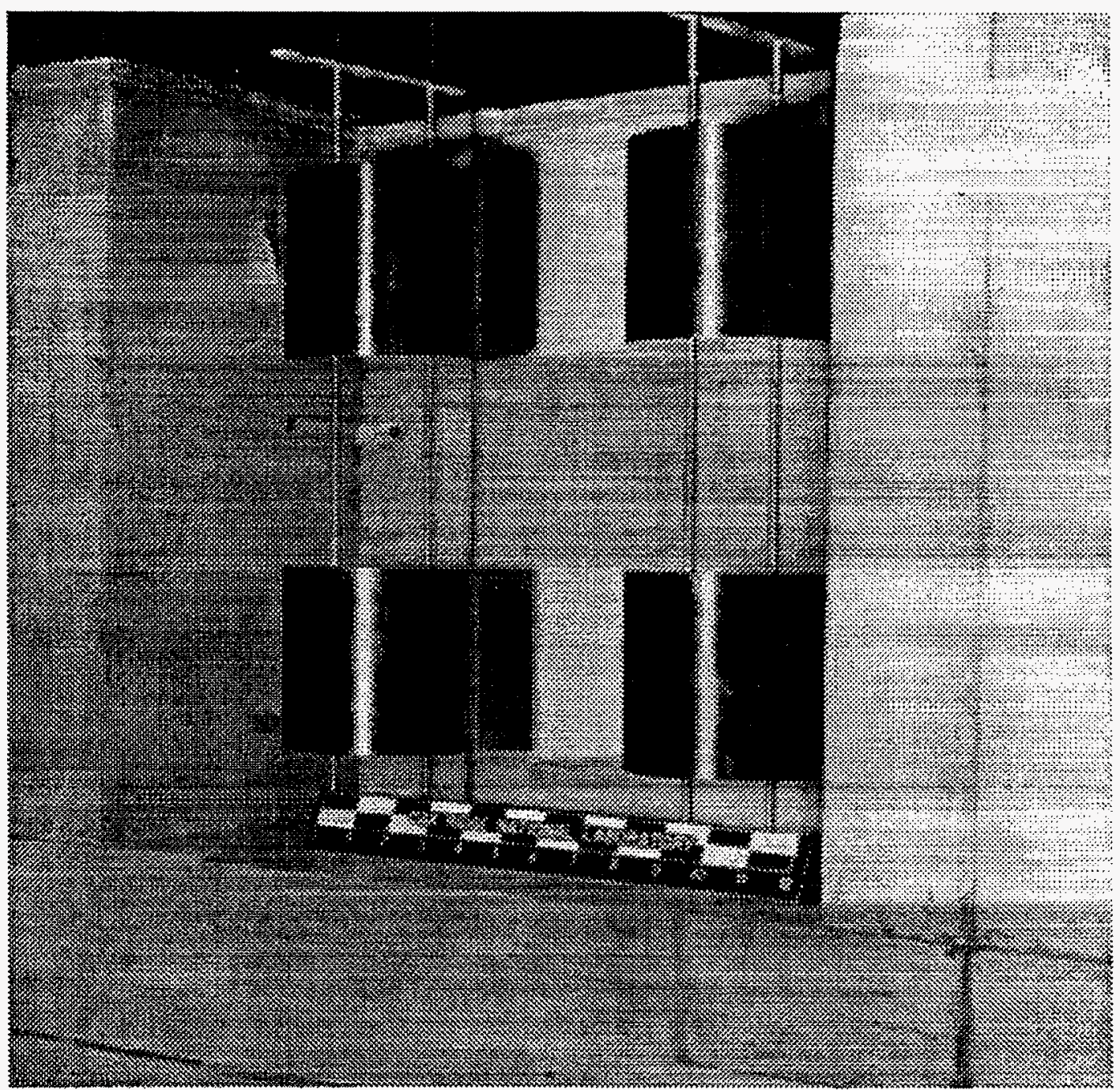

Figure F17.D.2. Half of the paraffin reflected $2 \mathrm{C} 8$ assembly before the top reflector was added 


\section{INPUT DATA}

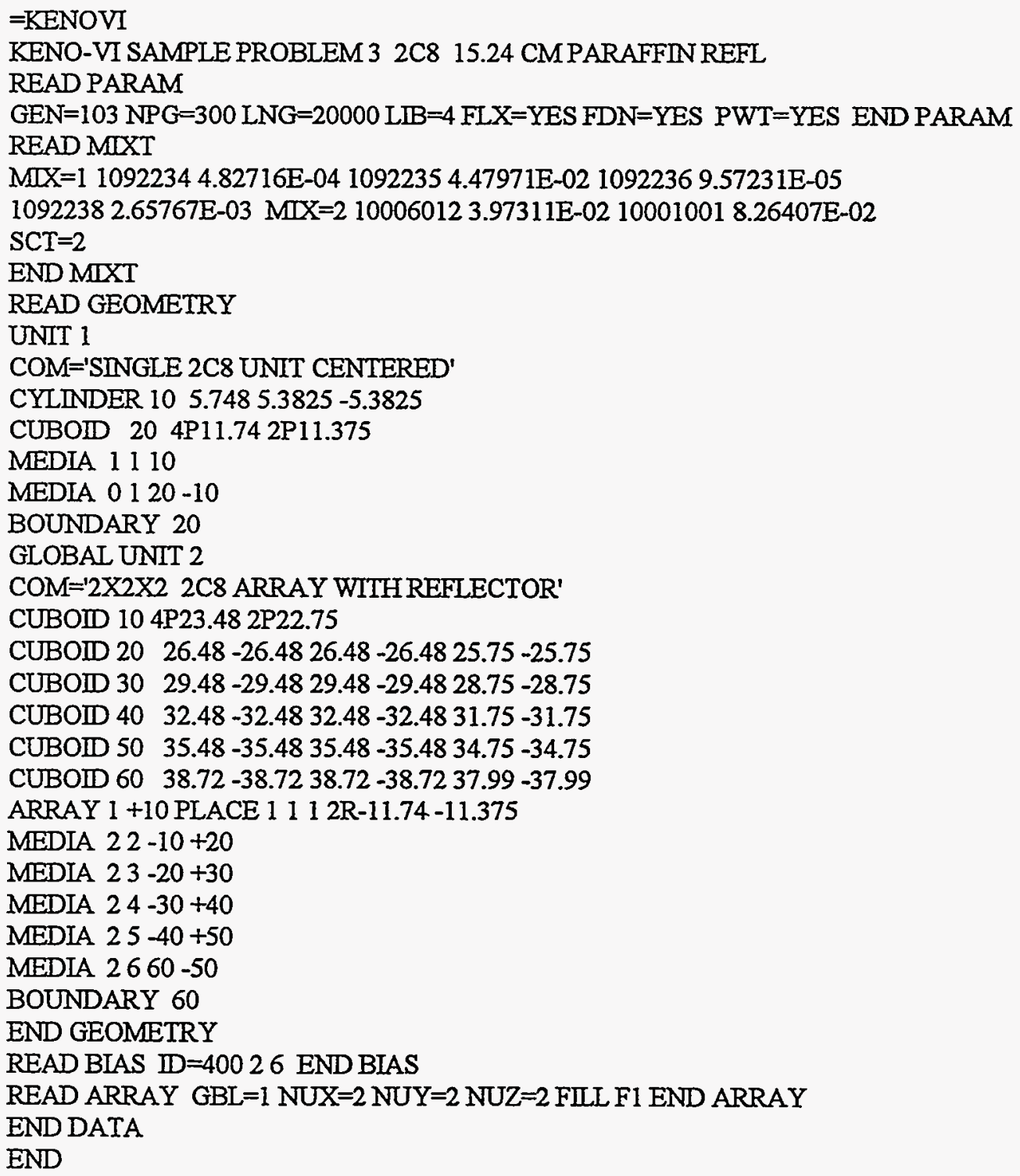

END

SAMPLE PROBLEM 4 2C8 15.24-CM PARAFFIN REFL AUTOMATIC REFL

This problem is the same as sample problem 3 , except it is set up using more reflector regions.

INPUT DATA

$=$ KENOVI $\mathrm{COND}=500$

KENO-VI SAMPLE PROBLEM 4 2C8 15.24 CMPARAFFIN REFL

NUREG/CR-0200, 


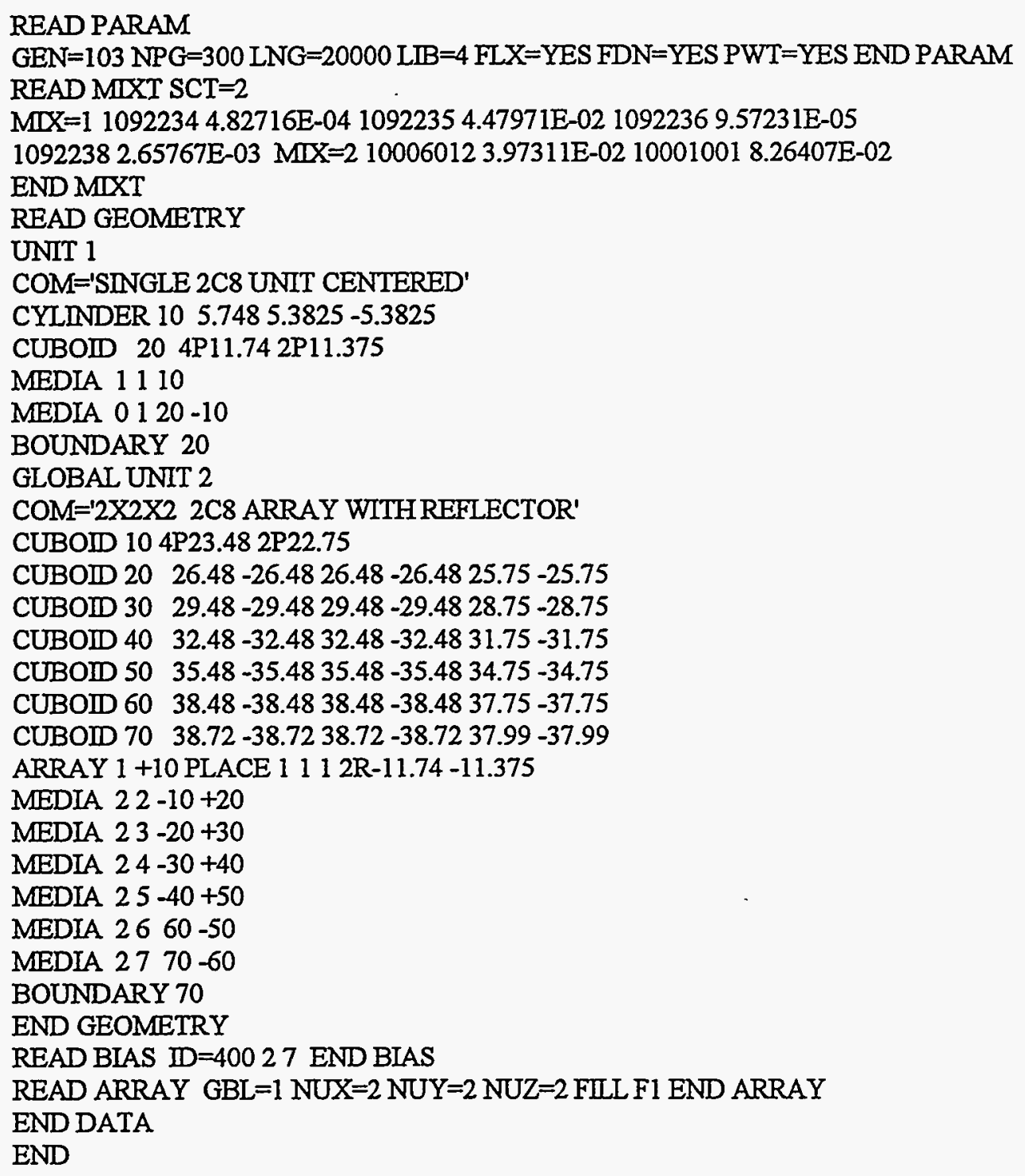

This problem is the same as samples problems 3 and 4 except the reflector is represented by a 12 -in. paraffin albedo. Note the decrease in execution time when using an albedo reflector instead of doing actual tracking. Note also that k-effective is somewhat higher for this system, probably due to the small edge size of the system. ${ }^{2}$

\section{INPUT DATA}

$=$ KENOVI $\quad$ COND $=500$

KENOVI SAMPLE PROBLEM 5 2C8 12 INCH PARAFFIN ALBEDO REFLECTOR READ PARA 
GEN $=103$ NPG $=300$ LNG $=20000 \mathrm{FLX}=$ YES FAR=YES FDN=YES LIB=4 END PARA

READ MIXT MIX=1 1092234 4.82716E-04 1092235 4.47971E-02

1092236 9.57231E-05 1092238 2.65767E-03 SCT=2 END MIXT

READ BOUNDS ALL=PARAFFIN END BOUNDS

READ GEOMETRY

UNIT 1

COM='SINGLE 2C8 UNIT CENTERED'

CYLINDER $105.7485 .3825-5.3825$

CUBOID 20 4P11.74 2P11.375

MEDIA 1110

MEDIA $0120-10$

BOUNDARY 20

GLOBAL UNIT 2

CUBOID $104 \mathrm{P} 23.482 \mathrm{P} 22.75$

COM='2X2X2 2C8 ARRAY'

ARRAY $1+10$ PLACE 1112 2R-11.74 -11.375

BOUNDARY 10

END GEOMETRY

READ ARRAY $G B L=1 N U X=2 N U Y=2 N U Z=2$ FLLL $F 1$ END ARRAY

END DATA

END

SAMPLE PROBLEM 6 ONE 2C8 UNIT (SINGLE UNIT)

One of the $2 \mathrm{C}$ units is described and run as a single-unit problem, and its k-effective is calculated.

INPUT DATA

$=$ KENOVI $\quad$ COND $=500$

KENOVI SAMPLE PROBLEM 6 ONE 2C8 UNIT (SINGLE UNIT)

READ PARA.

GEN=103 NPG=300 LNG=20000 LIB=4 FLX=YES FDN=YES FAR=YES END PARA

READ MIXT

$\mathrm{SCT}=2 \mathrm{MIX}=1 \quad 1092234$ 4.82716E-04 1092235 4.47971E-02 1092236

9.57231E-05 1092238 2.65767E-03 END MIXT

READ GEOMETRY

GLOBAL UNIT 1

COM='SINGLE 2C8 UNNT CENTERED'

CYLINDER $10 \quad 5.748$ 5.3825 -5.3825

MEDIA 1110

BOUNDARY 10

END GEOMETRY

END DATA

END

NUREG/CR-0200,

Vol. 2, Rev. 5

F17.D.8 


\section{SAMPLE PROBLEM 7 BARE 2C8 USING SPECULAR REFLECTION}

One of the $2 \mathrm{C} 8$ units $^{1}$ is described and the $2 \times 2 \times 2$ array is simulated by using specular reflection on the positive $\mathrm{x}, \mathrm{y}$, and $\mathrm{z}$ faces of the unit. This problem is a simulation of sample problem 1 .

\section{INPUT DATA}

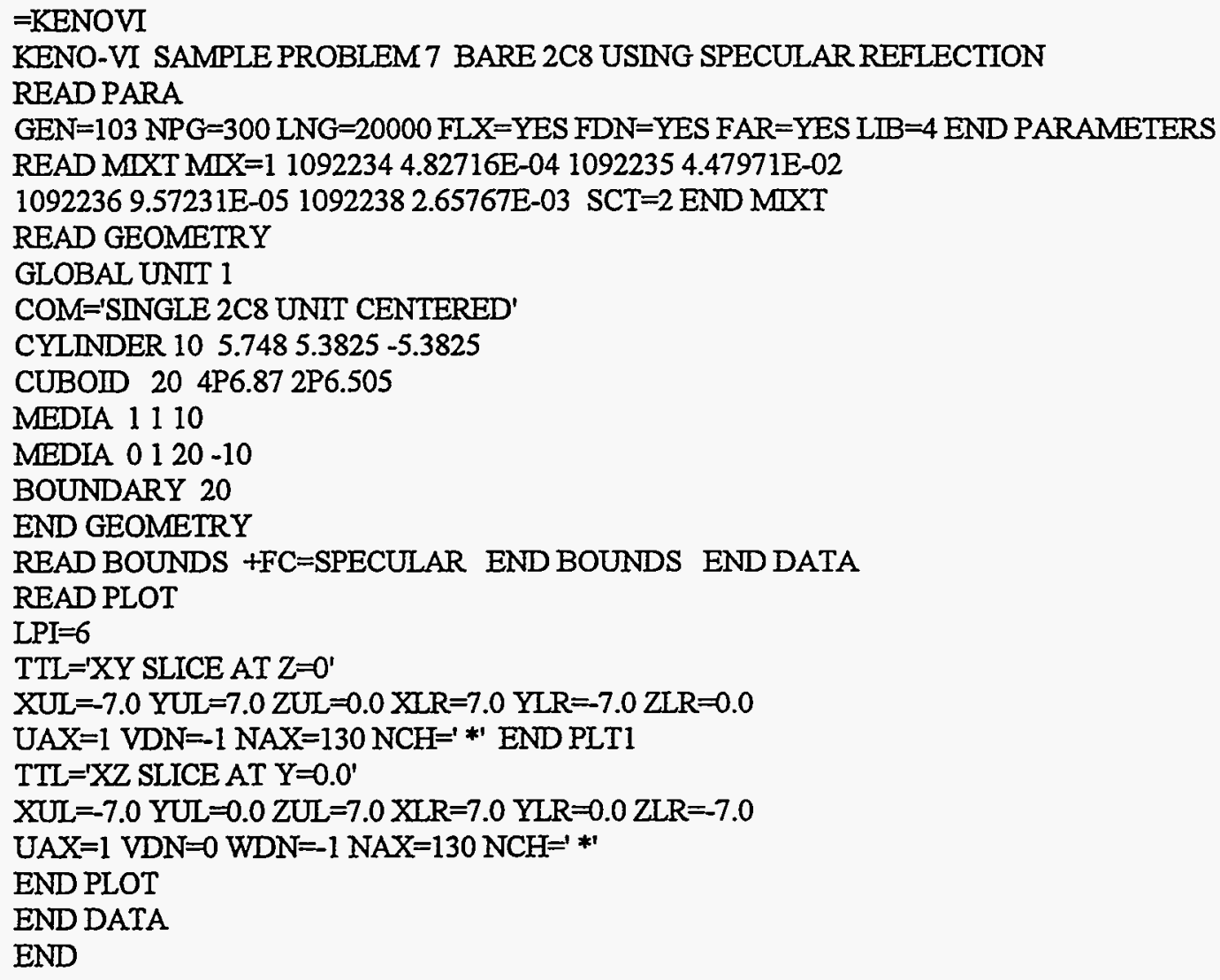

\section{SAMPLE PROBLEM 8 INFINITELY LONG CYLINDER FROM 2 C8 UNIT}

The fuel cylinder radius from sample problem 1 is used. The length of the cylinder is arbitrarily chosen to be $20 \mathrm{~cm}$, and the unit is specularly reflected on the top and bottom to create an infinitely long cylinder.

\section{INPUT DATA}

$=\mathrm{KENOVI} \quad \mathrm{COND}=500$

KENO-VI SAMPLE PROBLEM 8 INFINITEL Y LONG CYLINDER FROM 2 C8 UNIT

READ PARAMETERS GEN $=103 \mathrm{NPG}=300 \mathrm{LNG}=20000 \mathrm{LIB}=4$ END PARAMETERS

READ MIXT MIX=1 1092234 4.82716E-04 1092235 4.47971E-02

1092236 9.57231E-05 1092238 2.65767E-03 SCT=2

END MIXTURES

READ GEOMETRY 
GLOBAL UNIT 1

COM='SINGLE 2C8 UNIT CENTERED'

CYLINDER $10 \quad 5.748$ 2P 10.0

CUBOID 20 4P6.87 2P10.0

MEDIA 1110

MEDIA $0120-10$

BOUNDARY 20

END GEOMETRY

READ BOUNDS ZFC=MIRROR END BOUNDS

READ PLOT

PLT $=$ NO LPI $=6$

TTL $=$ 'XY SLICE AT $Z=0.0^{\prime}$

$\mathrm{XUL}=7 \mathrm{YUL}=7 \mathrm{ZUL}=0.0 \mathrm{XLR}=7 \mathrm{YLR}=7 \mathrm{ZLR}=0.0$

$\mathrm{UAX}=1 \mathrm{VDN}=1 \mathrm{NAX}=130 \mathrm{NCH}={ }^{\prime}$ *' END PLT 1

$\mathrm{TTL}=\mathrm{XZ}$ SLICE AT $\mathrm{Y}=0.0^{\circ}$

$\mathrm{XUL}=7 \mathrm{YUL}=0.0 \mathrm{ZUL}=11 \mathrm{XLR}=7 \mathrm{YLR}=0.0 \mathrm{ZLR}=11$

$U A X=1$ VDN $=0$ WDN $=1$ NAX $=130 \mathrm{NCH}={ }^{\prime}$ *'

END PLOT

END DATA

END

\section{SAMPLE PROBLEM 9 INFINITE ARRAY OF 2 C8 UNITS}

The geometry description from sample problem 1 is used, and the cuboid is specularly reflected on all faces to create an infinite array of $2 \mathrm{C} 8$ units having an edge-to-edge spacing of $2.244 \mathrm{~cm}$ in the $\mathrm{x}$ and $\mathrm{y}$ directions and $2.245 \mathrm{~cm}$ in the $\mathrm{z}$ direction.

\section{INPUT DATA}

$=$ KENOVI

KENO-VI SAMPLE PROBLEM 9 INFINITE ARRAY OF 2 C8 UNITS

READ PARAMETERS

GEN=103 NPG=300 LNG=20000 LIB=4 GEN=33 END PARAMETERS

READ MIXTURES SCT $=2$

$\mathrm{MIX}=1$ 1092234 4.82716E-04 1092235 4.47971E-02 1092236 9.57231E-05

$10922382.65767 \mathrm{E}-03$

END MIXT

READ GEOMETRY

GLOBAL UNTT 1

COM='SINGLE 2C8 UNIT CENTERED'

CYLINDER $10 \quad 5.7485 .3825$-5.3825

CUBOID $20 \quad 4 \mathrm{P} 6.87$ 2P6.505

MEDIA 1110

MEDIA $0120-10$

BOUNDARY 20

END GEOMETRY

READ BOUNDS ALL=MIRROR END BOUNDS

READ PLOT

$\mathrm{LPI}=6$

TTL $=$ 'XY SLICE AT $Z=0^{\prime}$

NUREG/CR-0200,

Vol. 2, Rev. 5

F17.D.10 
$\mathrm{XUL}=-7.0 \mathrm{YUL}=7.0 \mathrm{ZUL}=0.0 \mathrm{XIR}=7.0 \mathrm{YLR}=-7.0 \mathrm{ZLR}=0.0$

$\mathrm{UAX}=1 \mathrm{VDN}=1 \mathrm{NAX}=130 \mathrm{NCH}={ }^{*}$ *' ENDPLT1

TTL $=$ XZ SLICE AT $Y=0.0^{\prime}$

$\mathrm{XUL}=-7.0$ YUL $=0.0 \mathrm{ZUL}=7.0 \mathrm{XLR}=7.0 \mathrm{YLR}=0.0 \mathrm{ZLR}=-7.0$

$\mathrm{UAX}=1 \mathrm{VDN}=0 \mathrm{WDN}=-1 \mathrm{NAX}=130 \mathrm{NCH}={ }^{\prime} * 1$

END PLOT

END DATA

END

SAMPLE PROBLEM 10 2C8 BARE WRTE RESTART

This problem is the same as sample problem 1, a $2 \times 2 \times 2$ array of metal cylinders. Restart information is written on unit 94 after the completion of every fifth generation.

\section{INPUT DATA}

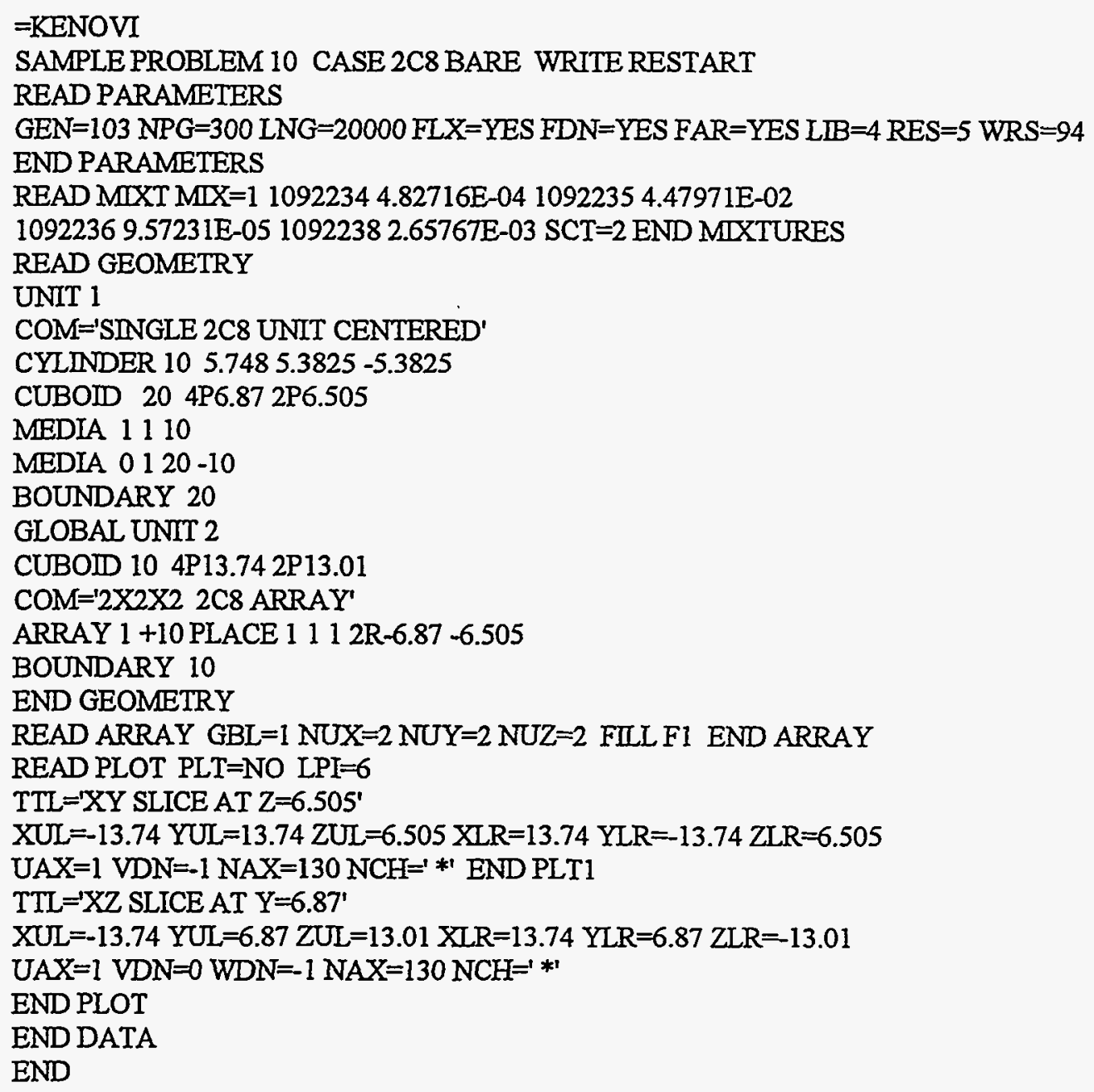




\section{SAMPLE PROBLEM 11 2C8 BARE READ RESTART DATA}

This problem is a restart of sample problem 10. The problem is restarted from the tenth set of restart data that was written by sample problem 10 (i.e., it restarts with the fifty-first generation).

\section{INPUT DATA}

$=$ KENOVI

SAMPLE PROBLEM 11 2C8 BARE READ RESTART DATA

READ PARAM $B E G=51 \quad$ RST=94 RES=0 END PARAM

END DATA

END

\section{SAMPLE PROBLEM 124 AQUEOUS 4 METAL}

This problem is a critical experiment consisting of a composite array $y^{1,3}$ of four highly enriched uranium metal cylinders and four cylindrical plexiglas containers filled with uranyl nitrate solution. The metal units in this experiment are designated in Table $I I$ of ref. 1 as cylinder index 11 and reflector index 1 . A photograph of the experiment is given in Fig. F17.D.3. 


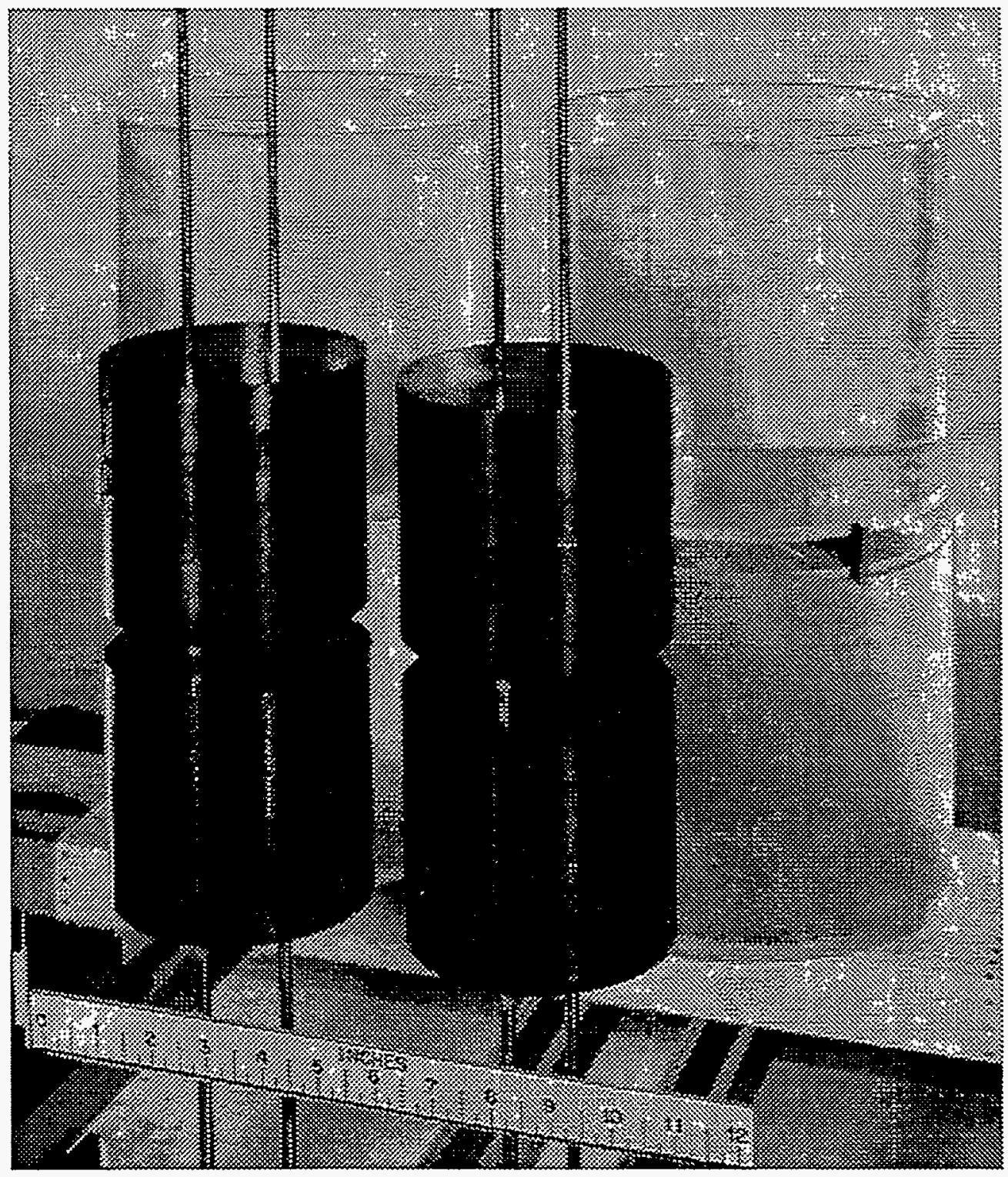

Figure F17.D.3. Critical assembly of 4 solution units and 4 metal units 


\section{INPUT DATA}

$=\mathrm{KENOVI} \quad \mathrm{COND}=500$

SAMPLE PROBLEM 124 AQUEOUS 4 METAL MIXED UNITS

READ PARAM

GEN=103 NPG=300 LNG=20000 LIB=4 FLX=YES FDN=YES NUB=YES SMU=YES

MKU $=$ YES FMP=YES FMU $=$ YES END PARAM

READ MIXT SCT $=2$

$\mathrm{MLX}=1$ 1092234 4.82716E-04 1092235 4.47971E-02 1092236 9.57231E-05

$10922382.65767 \mathrm{E}-03$

$\mathrm{M} T \mathrm{XX}=22001001$ 5.77964E-02 2007014 2.13092E-03 2008016 3.74130E-02

2092234 1.06784E-05 2092235 9.84599E-04 2092236 5.29385E-06

$20922386.19413 \mathrm{E}-05$

MTX=3 11001001 5.68187E-02 11006012 3.55117E-02 11008016 1.42047E-02

END MIXT

READ GEOM

UNIT 1

CYLINDER $10 \quad 9.5258 .89-8.89$

CYLINDER $20 \quad 10.169 .525-9.525$

CUBOID $30 \quad 10.875-10.87510 .875-10.875 \quad 10.24-10.24$

MEDIA 2110

MEDIA $31-1020$

MEDIA $0130-20$

BOUNDARY 30

UNIT 2

CYLINDER $10 \quad 5.7485 .3825-5.3825$

CUBOID $20 \quad 6.59-15.166 .59-15.166 .225-14.255$

MEDIA 1110

MEDIA $0120-10$

BOUNDARY 20

UNIT 3

CYLINDER $10 \quad 5.7485 .3825-5.3825$

CUBOID $20 \quad 6.59-15.16 \quad 15.16-6.596 .225-14.255$

MEDIA 1110

MEDIA $0120-10$

BOUNDARY 20

UNIT 4

CYLINDER $10 \quad 5.7485 .3825-5.3825$

CUBOID $206.59-15.166 .59-15.1614 .255-6.225$

MEDIA 1110

MEDIA $0120-10$

BOUNDARY 20

UNIT 5

CYLINDER $10 \quad 5.7485 .3825-5.3825$

CUBOID $20 \quad 6.59-15.1615 .16-6.5914 .255-6.225$

MEDIA 1110

MEDIA $0120-10$

BOUNDARY 20

GLOBAL

UNIT 6

CUBOID $1043.5 \quad 0.043 .50 .040 .960 .0$

NUREG/CR-0200,

Vol. 2, Rev. 5

F17.D.14 
ARRAY 1 +10 PLACE 11115.1615 .1614 .255

BOUNDARY 10

END GEOM

READ ARRAY NUX=2 NUY $=2$ NUZ $=2$ LOOP

1 3R2 1211212 9R1 3 3Rl 221 3Rl 4 6R1 2215 3Rl 221221

END ARRAY

READ PLOT

TTL='X-Y @Z=15.16 LOWER LEFT QUARTER OF ARRAY TO COMPARISON WITH SMP12A'

$X U L=0.5$ YUL $=44.0 \mathrm{ZUL}=15.16 \mathrm{XIR}=44.5 \mathrm{YLR}=21.0 \mathrm{ZLR}=15.16$

$\mathrm{UAX}=1.0 \mathrm{VDN}=1.0 \mathrm{NCH}={ }^{\prime} * .31 \mathrm{NAX}=130$

END PLT1

TTL='X-Z @Y=15.16 LOWER LEFT QUARTER OF ARRAY TO COMPARISON WITH SMP12A'

$\mathrm{XUL}=-0.5 \mathrm{YUL}=15.16 \mathrm{ZUL}=21.0 \mathrm{XIR}=44.16 \mathrm{YLR}=15.16 \mathrm{ZLR}=-0.5$

$\mathrm{UAX}=1.0 \mathrm{WDN}=1.0 \mathrm{NCH}=\prime^{*} \cdot 3^{\prime} \mathrm{NAX}=130$

END PLT2

TTL='X-Y PLOT OF ENTIRE ARRAY AT Z $=15.16^{\prime}$

$X U L=0.5$ YUL $=44.0 \mathrm{ZUL}=15.16 \mathrm{XIR}=44.5 \mathrm{YLR}=-1.0 \mathrm{ZLR}=15.16$

$\mathrm{UAX}=1.0 \mathrm{VDN}=-1.0 \mathrm{NCH}={ }^{\prime} * .3^{\prime} \mathrm{NAX}=130$

END PLT3

TTL $=$ 'X-Z PLOT OF ENTIRE ARRAY AT Y $=15.16$

$\mathrm{XUL}=0.5 \mathrm{YUL}=15.16 \mathrm{ZUL}=41.0 \mathrm{XLR}=44.16 \mathrm{YLR}=15.16 \mathrm{ZLR}=-1.0$

$\mathrm{UAX}=1.0 \mathrm{WDN}=-1.0 \mathrm{NCH}={ }^{\prime} * .3^{\prime} \mathrm{NAX}=130$

END PLT4

END PLOT

END DATA

END

\section{SAMPLE PROBLEM 13 TWO CUBOIDS IN A CYLINDRICAL ANNULUS}

This critical experiment ${ }^{4}$ consists of two assemblies of $93.2 \%{ }^{235} U$-enriched uranium metal $(\rho=18.69$ $\mathrm{g} / \mathrm{cc}$ ) stacked vertically. The bottom assembly contains a uranium metal cuboid offset to the left within a uranium metal cylindrical annulus. The top assembly contains a uranium metal cuboid offset to the right within a uranium metal cylindrical annulus. The cuboid extends above the annulus. A drawing of the two sections and the total assembly is given in Fig. F17.D.4.

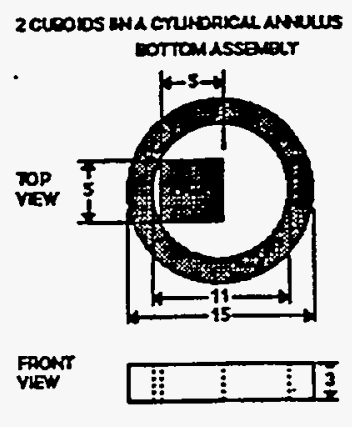

BOTIONASsentr

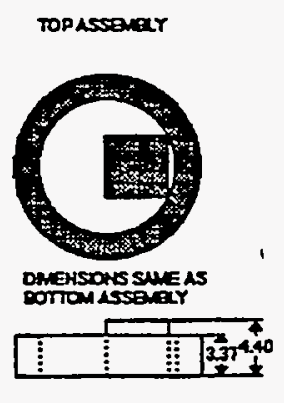

TOPASSanal
Cath-DHo co-19252

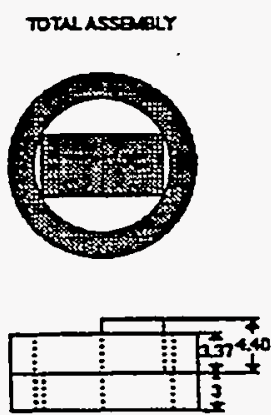

TOTAL ASSEMaY

MLIDESONS ARE MINCHES

Figure F17.D.4 Drawing of two cuboids in an annulus critical assembly 


\section{INPUT DATA}

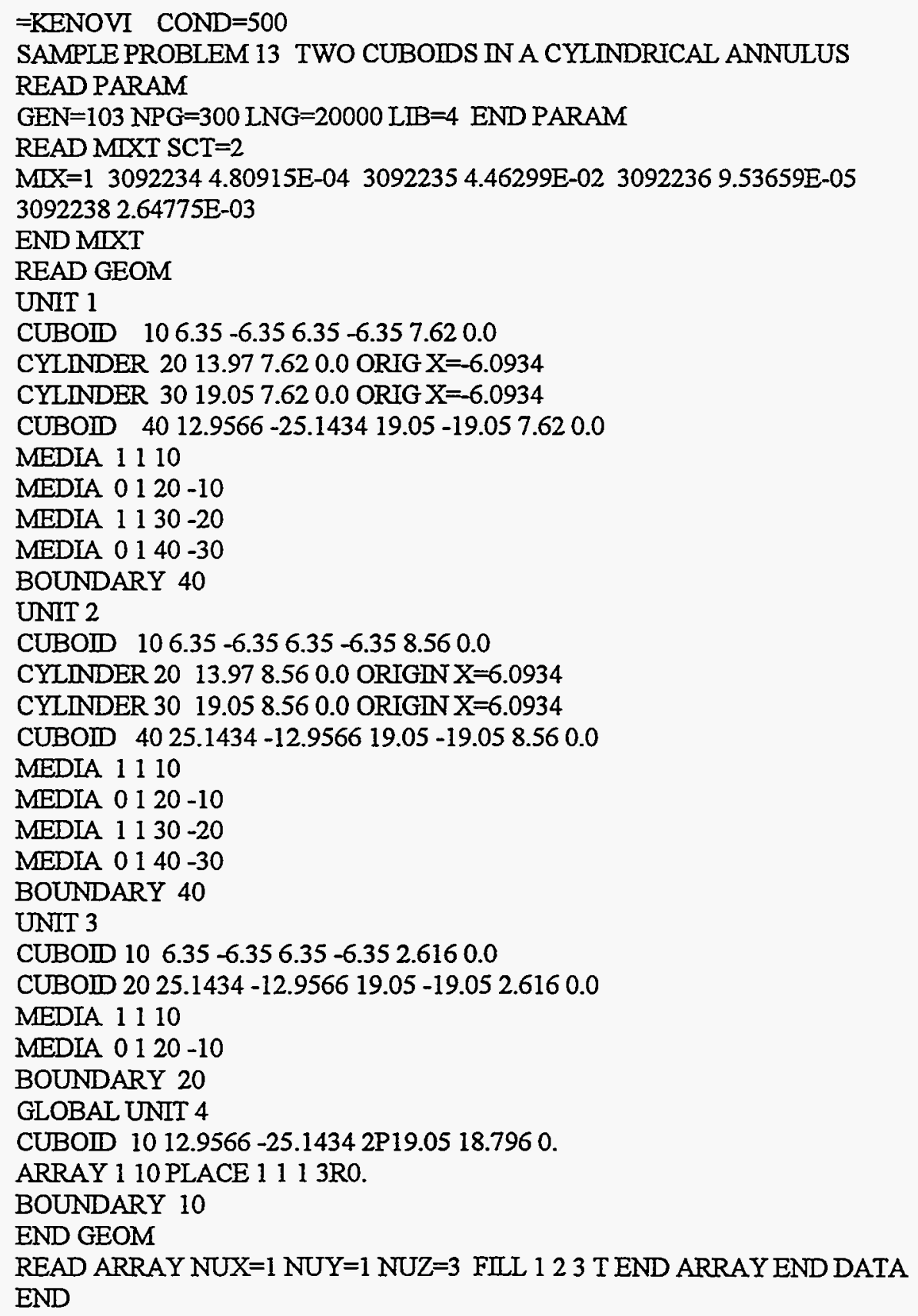

\section{SAMPLE PROBLEM 14 UMETAL CYLINDER IN AN ANNULUS}

This critical experiment ${ }^{4}$ consists of a $93.2{ }^{235} \mathrm{U}$-enriched uranium metal cylinder within a cylindrical annulus of the same material as shown in Fig. F17.D.5. The uranium metal specification is identical to that used in sample problem 13.

NUREG/CR-0200, 


\section{INPUT DATA}

$=$ KENOVI $\mathrm{COND}=500$

SAMPLE PROBLEM 14 UMETAL CYLINDER IN AN ANNULUS

READ PARAM GEN $=103 \mathrm{NPG}=300 \mathrm{LNG}=20000 \mathrm{LIB}=4$

END PARAM

READ MIXT SCT $=2$

MIX=1 3092234 4.80915E-04 3092235 4.46299E-02 3092236 9.53659E-05

3092238 2.64775E-03

END MIXT

READ GEOM

GLOBAL UNTT 1

CYLINDER 108.8910 .1090 .0 ORIG $X=5.08$

CYLINDER 2013.9710 .1090 .0

CYLINDER 3019.0510 .1090 .0

MEDIA 1110

MEDIA $0120-10$

MEDIA $1130-20-10$

BOUNDARY 30

END GEOM

READ PLOT

$\mathrm{TTL}=$ 'X-Y SLICE AT Z $=5.0^{\prime}$

$X U L=19.1$ YUL=19.1 ZUL=5.0 XIR=19.5 YLR=-19.5 ZLR=5.0

$\mathrm{UAX}=1 \mathrm{VDN}=-1 \mathrm{NAX}=130 \mathrm{NCH}={ }^{\prime}$ *' END PLT1

TTL $=$ 'Y $Z$ S SLICE AT X $=0.0^{\prime}$

$X U L=0.0$ YUL $=19.5 \mathrm{ZUL}=10.2 \mathrm{XIR}=0.0 \mathrm{YLR}=19.5 \mathrm{ZLR}=-1.0$

$\mathrm{VAX}=1 \mathrm{WDN}=-1 \mathrm{NAX}=130 \mathrm{NCH}={ }^{* \prime}$ END PLT2

END PLOT

END DATA

END

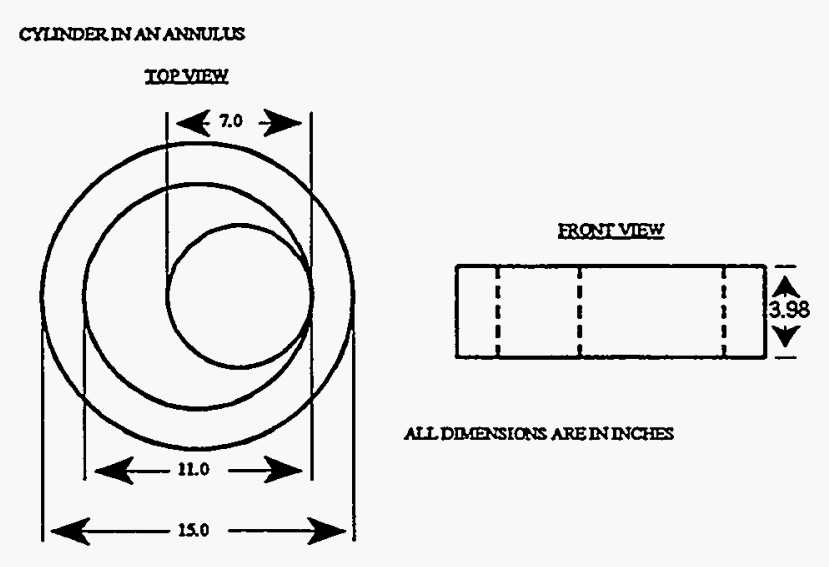

Figure F17.D.5. Drawing of the cylinder in an annulus critical assembly 


\section{SAMPLE PROBLEM 15 SMALL WATER REFLECTED SPHERE ON PLEXIGLAS COLLAR}

This critical experiment ${ }^{5}$ is a small highly enriched uranium sphere supported by a plexiglas doughnut in a tank of water. The sphere extends down through the hole of the doughnut. However, the KENO VI geometry package cannot rigorously describe a doughnut; therefore, the KENO VI mockup of this problem describes the doughnut as an annular cylindrical plate and the sphere is supported by it. Both are contained in a cylindrical tank of water. A drawing of the experiment is given in Fig. F17.D.6. This drawing shows the sphere above the cylindrical collar for the sake of clarity. The sphere is actually supported by the collar and extends into the opening in its center. The actual experiment utilized a torus or doughnut instead of a cylindrical collar.

\section{INPUT DATA}

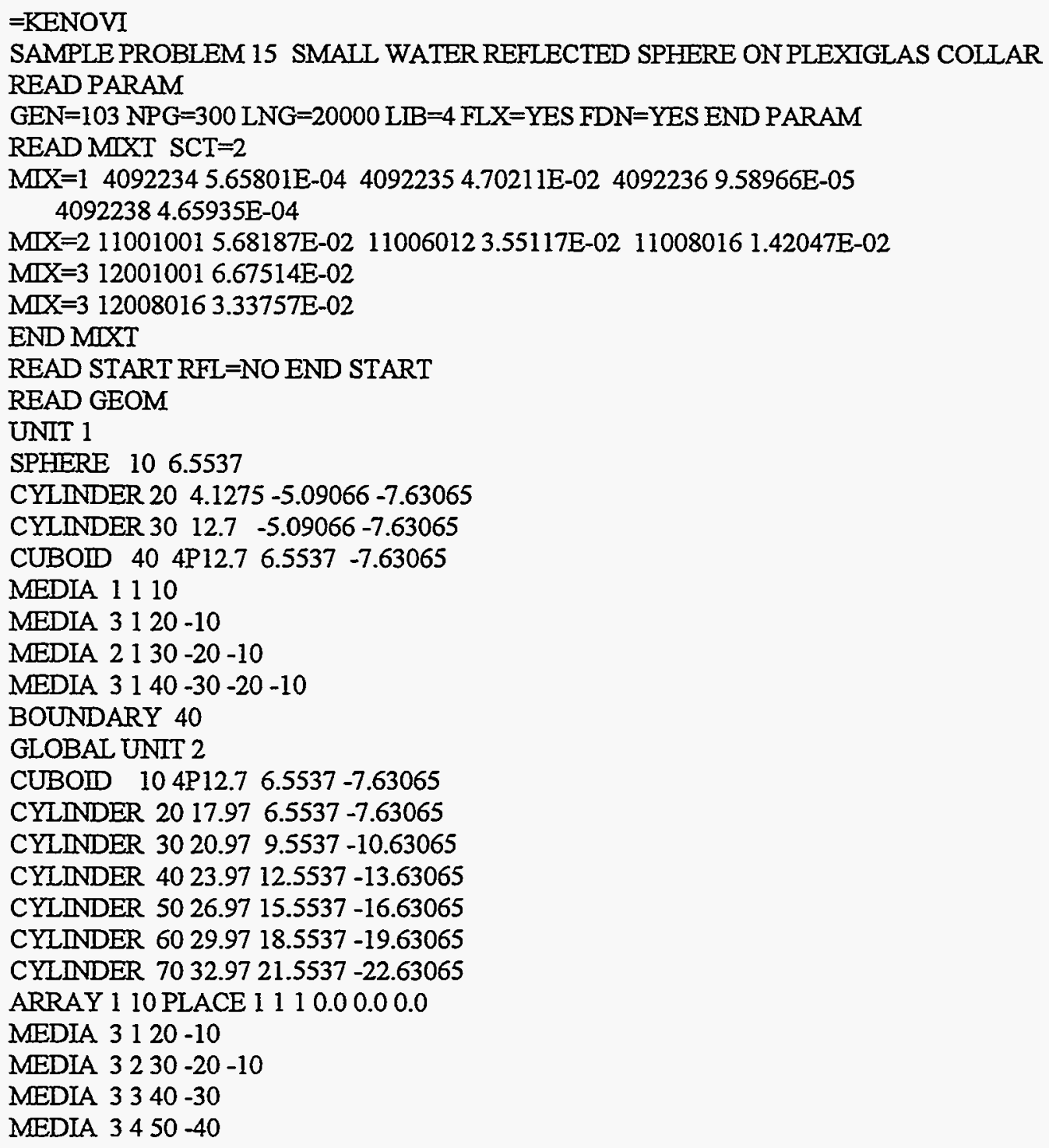

NUREG/CR-0200, 
MEDIA $3560-50$

MEDIA $3670-60$

BOUNDARY 70

END GEOM

READ ARRAY NUX=1 NUY=1 NUZ=1 FILI 1 END FILL END ARRAY

READ BIAS ID $=50026$ END BIAS

READ PLOT TTL='X-Z SLICE THROUGH THE CENTER OF THE SPHERE'

$X U L=-20.0 \mathrm{ZUL}=10.0 \mathrm{YUL}=0.0 \mathrm{XIR}=20.0 \mathrm{YLR}=0.0 \mathrm{ZLR}=10.0$

$\mathrm{UAX}=1.0 \mathrm{WDN}=-1.0 \mathrm{NAX}=130 \mathrm{NCH}={ }^{\prime} * 0-$

END PLOT

END DATA

END

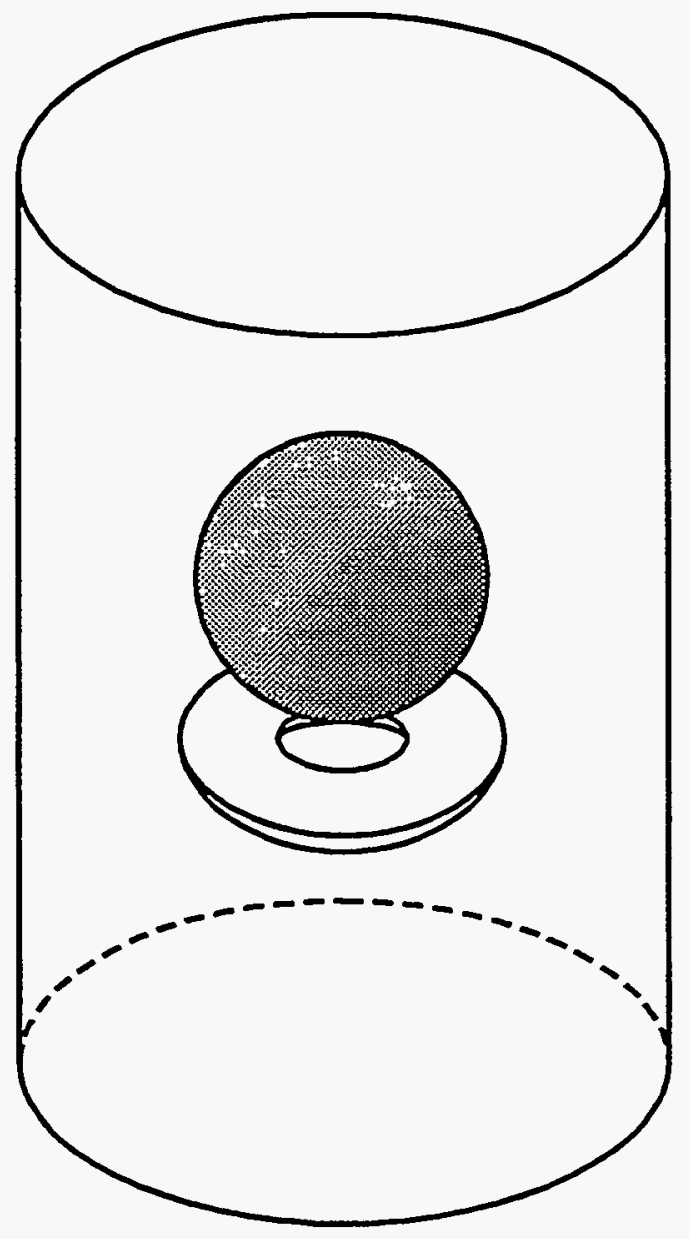

Figure F17.D.6 Drawing of a critical assembly consisting of a uranium sphere on a plexiglas collar with a cylindrical water reflector

F17.D.19

NUREG/CR-0200,

Vol. 2, Rev. 5 


\section{SAMPLE PROBLEM 16 UO2F2 INFINITE SLAB K-INFINITY}

This problem solves for the $k$-infinity of an infinite number of slabs of uranyl fluoride solution contained in pyrex glass and separated by borated uranyl fluoride solution. The uranyl fluoride slab is $4.958 \mathrm{~cm}$ thick, $93.2 \%$ enriched, and has a density of $578.7 \mathrm{~g} \mathrm{U} / \mathrm{L}$. The pyrex glass is $1.27 \mathrm{~cm}$ thick and is present on both faces of the uranyl fluoride solution. A total of $27.46 \mathrm{~cm}$ of borated solution separates the pyrex glass of adjacent slabs of solution. $1.482 \times 10^{-27}$ atoms of boron per milliliter are present in the borated solution.

\section{INPUT DATA}

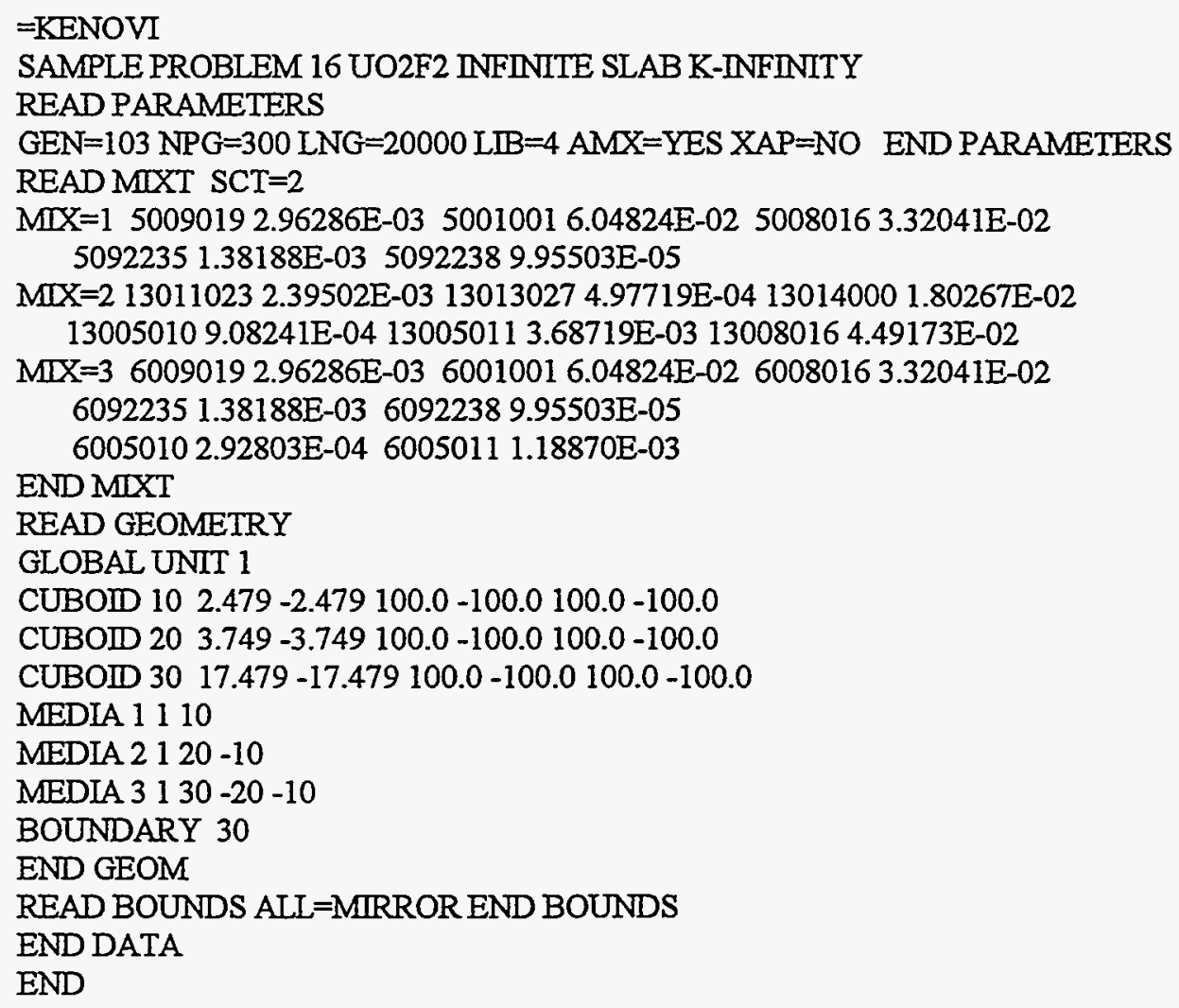

\section{SAMPLE PROBLEM 17 93\% UO2F2 SOLUTION SPHERE ADJOINT CALCULATION}

A single $93 \%$ enriched uranyl fluoride sphere is run as an adjoint calculation. The result for the forward and adjoint k-effectives should be the same within statistical error when the problem is run both ways.

INPUT DATA

$=$ KENOVI $\quad$ COND $=500$

SAMPLE PROBLEM 17 93\% UO2F2 SOLUTION SPHERE ADJOINT CALCULATION

READ PARAMETERS

GEN $=103 \mathrm{NPG}=300 \mathrm{LNG}=20000 \mathrm{LIB}=4 \mathrm{AMX}=\mathrm{YES} \mathrm{PWT}=\mathrm{YES}$

NUREG/CR-0200,

Vol. 2, Rev. 5

F17.D.20 


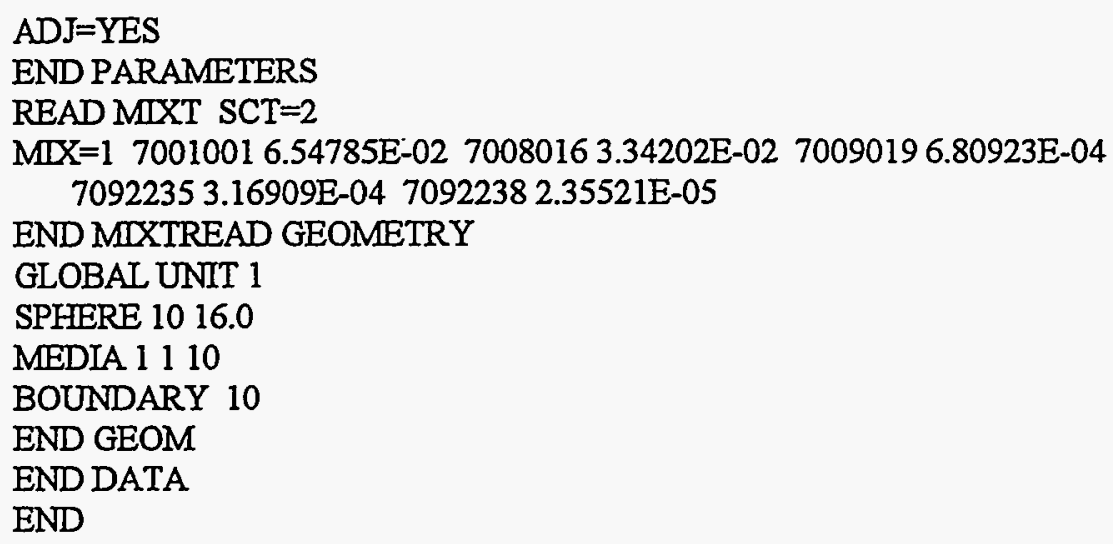

\section{SAMPLE PROBLEM 18 1F27 DEMONSTRATION OF OPTIONS}

A reflected cubic array of 27 cylinders of aqueous uranyl nitrate in plexiglas bottles. ${ }^{6}$ The walls of the bottles were $0.64-\mathrm{cm}$ thick, and each bottle was filled with $5 \mathrm{~L}$ of $92.6 \%$ enriched solution at a concentration of $415 \mathrm{~g} / \mathrm{L}$, a specific gravity of 1.555 and $0.39^{*} \mathrm{mg}$ excess nitrate/g soln. The $3 \times 3 \times 3$ array was surrounded by a 6-in paraffin reflector. Most of the print options available in KENO-VI are exercised in this problem. A perspective of this critical experiment is shown in Fig. F17.D.7. A photograph of one of the experiments utilized 27 of the plexiglas bottles is shown in Fig. F17.D.8. Sample problem 18 has $15.24 \mathrm{~cm}$ of paraffin on all six faces rather than the $2.54-\mathrm{cm}$ plexiglas shown on five faces.

\section{INPUT DATA}

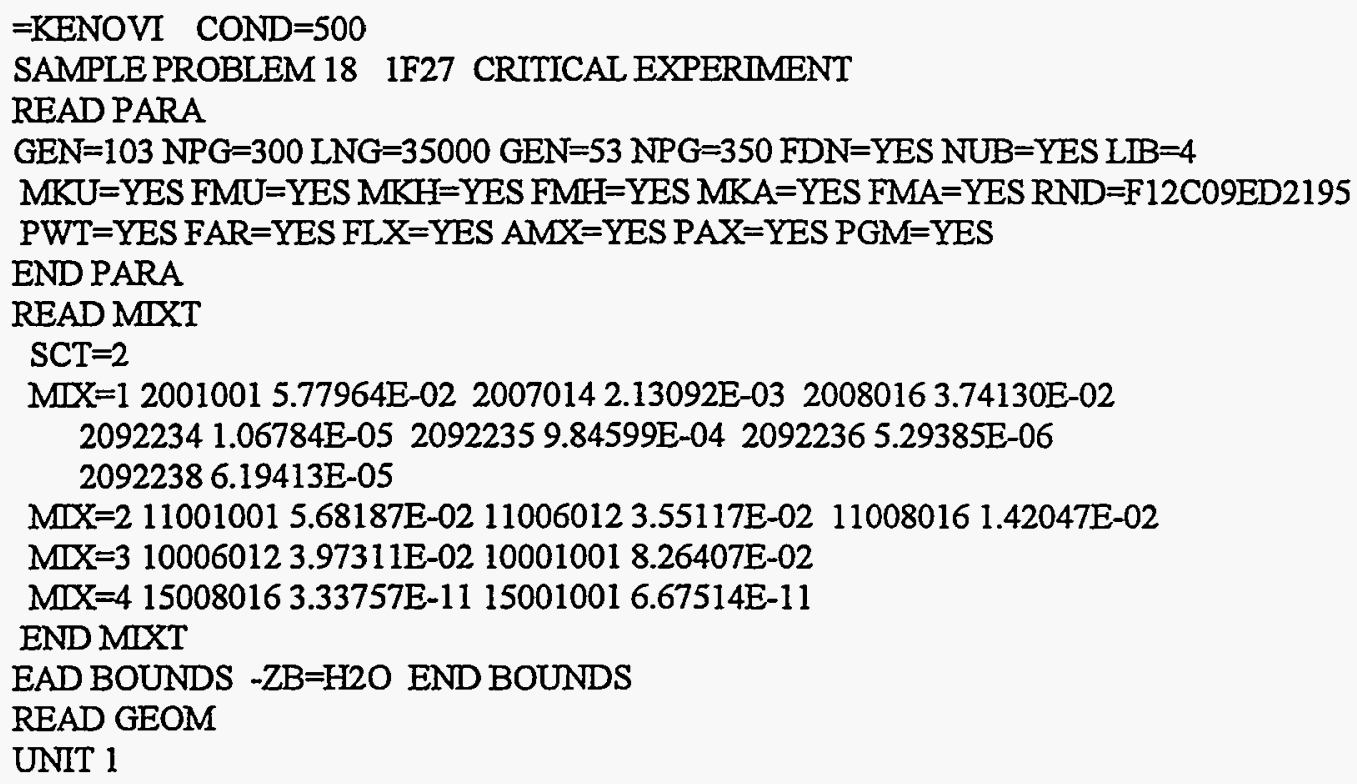

From experimental facility documents (not reported in ORNL/TM-719). 
CYLINDER $109.528 .7804-8.7804$

CYLINDER $209.528 .9896-8.7804$

CYLINDER $30 \quad 10.169 .6296-9.4204$

CUBOID 4018.45 -18.45 18.45 -18.45 17.8946 -17.6854

MEDIA 1110

MEDIA 0 1-10 20

MEDIA 21 -10-20 30

MEDIA $0140-20-30$

BOUNDARY 40

UNIT 2

CUBOID $10 \quad 18.45-55.35 \quad 55.35-18.45 \quad 53.37-17.79$

CUBOID $20 \quad 18.45$-55.35 55.35 - 18.45 - 17.79 -53.37

CUBOID $30 \quad 55.35 \quad 18.45 \quad 55.35$-18.45 $53.37-53.37$

CUBOID $40 \quad 55.35$ - 55.35 -18.45 -55.35 $53.37-53.37$

CUBOID $50 \quad 55.35$-55.35 55.35 -55.35 53.37 -53.37

ARRAY 110 PLACE $111-36.900 .0-0.1046$

ARRAY 2 20-10 PLACE $1111-36.900 .0-35.6846$

ARRAY $330-20$-10 PLACE $11136.900 .0-35.6846$

ARRAY 440 -30 -20 -10 PLACE 111 -36.90 -36.90 -35.6846

MEDIA $0150-40-30-20-10$

BOUNDARY 50

GLOBAL UNIT 3

CUBOID $10 \quad 55.35-55.3555 .35-55.3553 .37-53.37$

CUBOID $20 \quad 58.35$-58.35 58.35 -58.35 56.37 -56.37

CUBOID $3061.35-61.3561 .35-61.3559 .37-59.37$

CUBOID $4064.35-64.3564 .35-64.3562 .37-62.37$

CUBOID $50 \quad 67.35-67.3567 .35-67.3565 .37-65.37$

CUBOID $6070.59-70.5970 .59-70.5968 .61-68.61$

ARRAY 510 PLACE $1113 * 0.0$

MEDIA $32-1020$

MEDIA 3 3 -20 30

MEDIA $34-3040$

MEDIA $35-4050$

MEDIA $3660-50$

BOUNDARY 60

END GEOM

READ BIAS ID=400 26 END BIAS

READ ARRAY

$A R A=1$ NUX $=2$ NUY $=2$ NUZ $=2$ FILL F1 END FILL

$A R A=2$ NUX $=2$ NUY $=2$ NUZ $=1$ FILL F1 END FILL

$A R A=3$ NUX $=1$ NUY $=2$ NUZ $=3$ FILL F1 END FILL

$A R A=4$ NUX $=3$ NUY $=1$ NUZ $=3$ FILL F1 END FLL

$G B L=5$ ARA $=5$ NUX $=1$ NUY $=1$ NUZ $=1$ FILL F2 END FUL

END ARRAY

READ PLOT

TTL $={ }^{\prime} 1 F 27$ XY PLOT AT $Z=0.0^{\prime}$

$\mathrm{XUL}=71.0 \mathrm{YUL}=71.0 \mathrm{ZUL}=0.0$

$\mathrm{XIR}=71.0 \mathrm{YLR}=71.0 \mathrm{ZLR}=0.0$

$\mathrm{UAX}=1 \mathrm{VDN}=-1 \mathrm{NAX}=130 \mathrm{NCH}={ }^{\prime} *-3$ '

END PLT1

TTL='UNIT MAP 1F27 XY PLOT AT $\mathrm{Z}=0.0^{\prime}$

PIC=UNIT NCH $=123456^{\prime}$

END PLOT END DATA

END

NUREG/CR-0200,

Vol. 2, Rev. 5

F17.D.22 


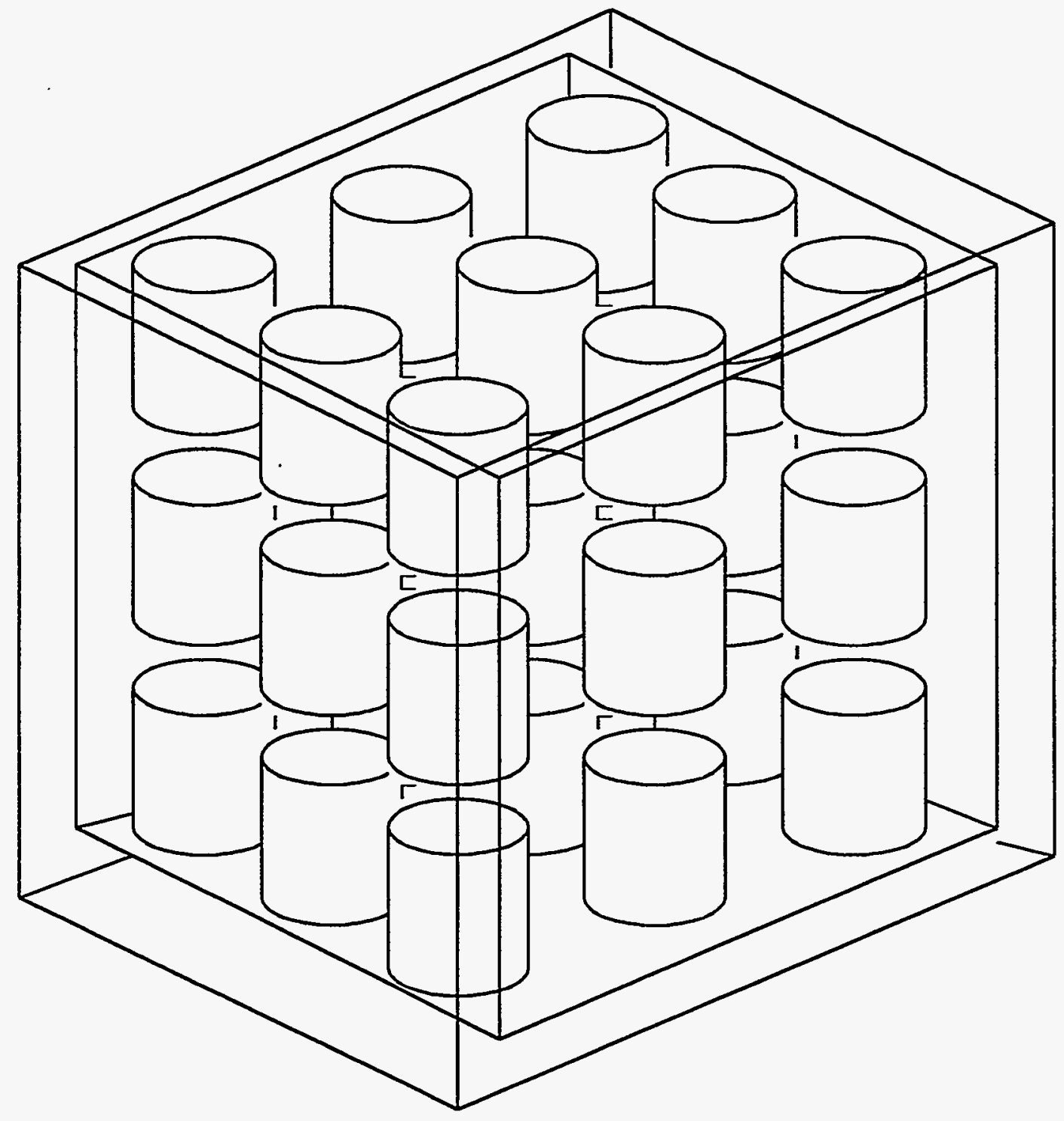

Figure F17.D.7 Perspective of critical IF27 experiment 


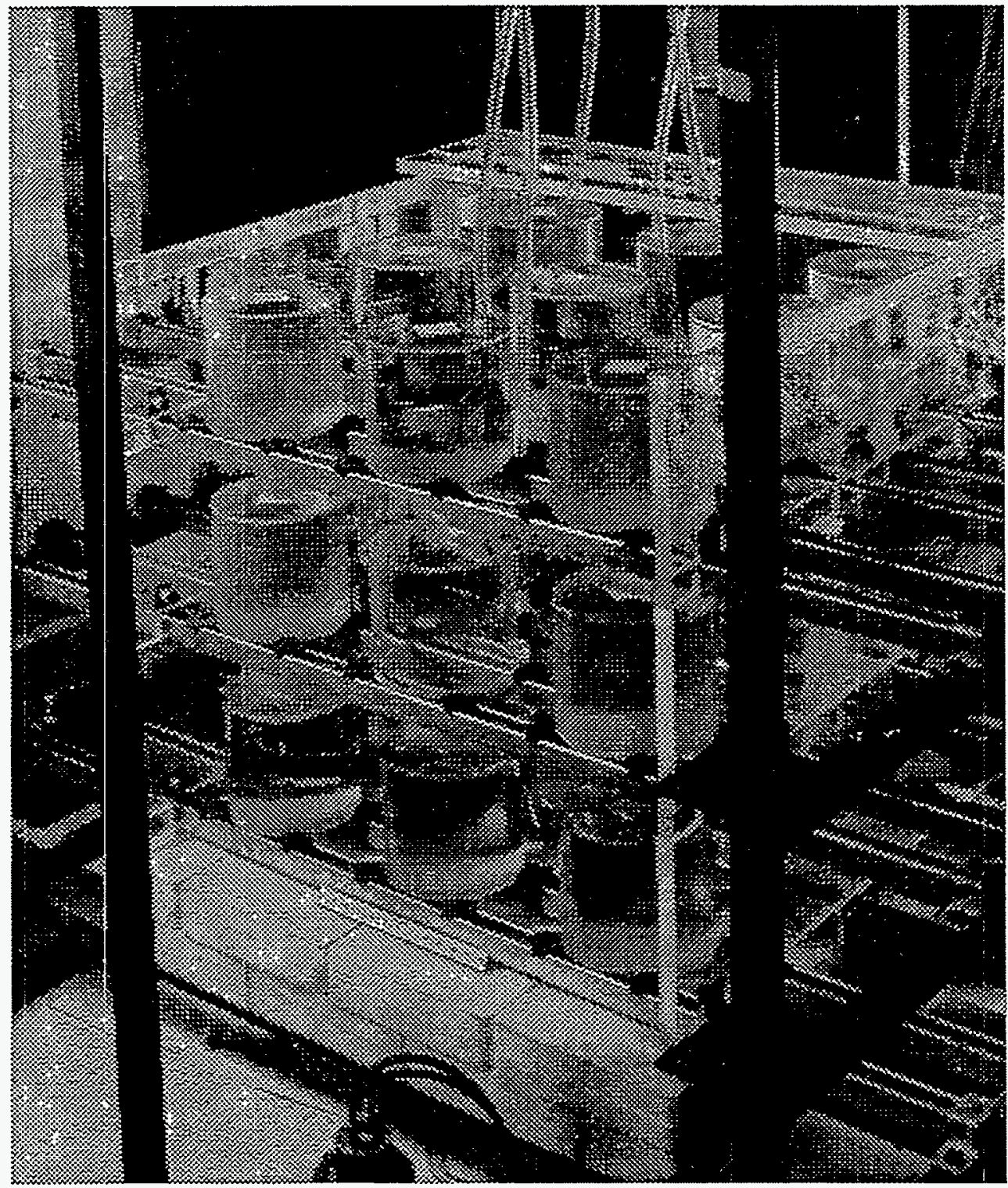

Figure F17.D.8 View of a 27 -unit cubic array with 2.54-cm-thick plexiglas reflector on five sides and a 15.24-cm-thick paraffin base

NUREG/CR-0200,

Vol. 2, Rev. 5 


\section{SAMPLE PROBLEM 194 AQUEOUS 4 METAL ARRAY OF ARRAYS (SAMP PROB 12)}

This critical experiment was described previously as SAMPLE PROBLEM 12. The input data given below utilize the array of arrays option. See Fig. F17.D.3.

\section{INPUT DATA}

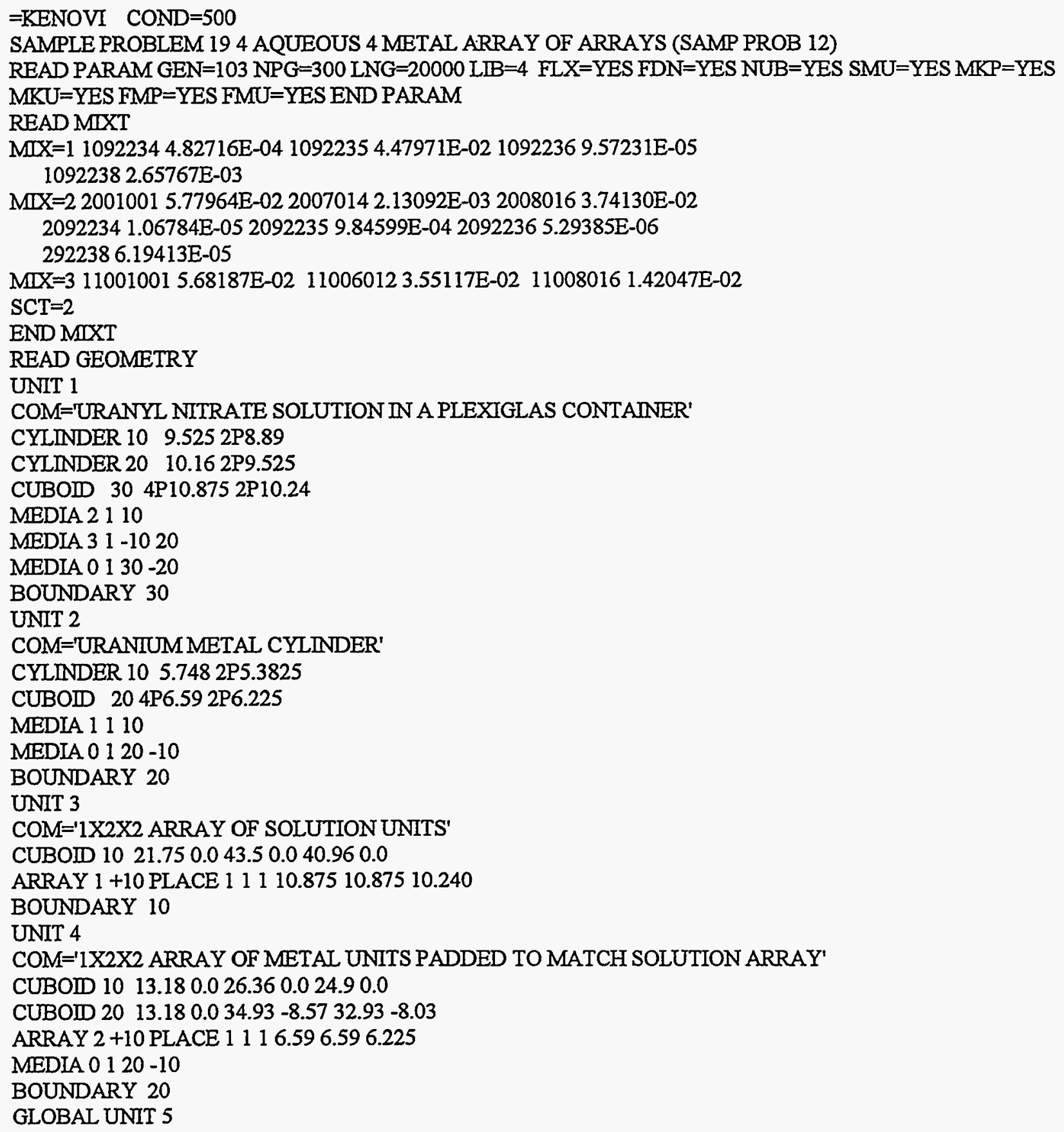


COM='GLOBAL UNIT OF ARRAYS 1 AND 2'

CUBOID 1034.930 .043 .50 .040 .960 .0

ARRAY $3+10$ PLACE 11108.578 .03

BOUNDARY 10

END GEOM

READ ARRAY ARA $=1$ NUX $=1$ NUY $=2$ NUZ $=2$ FILL F 1 END FILL

$A R A=2$ NUX $=1$ NUY $=2$ NUZ $=2$ FILL F 2 END FILL GBL $=3 \quad A R A=3 \quad N U X=2 N U Y=1 \quad N U Z=1$

COM $=$ 'COMPOSITE ARRAY OF SOLUTION AND METAL UNITS'

FILL 43 END FILL

END ARRAY

READ PLOT

TTL=' X-Y SLICE AT $Z=14.255$ THRU LOWER UNITS @ METAL UNIT AXIS MIDPOINT'

$\mathrm{XUL}=0.5 \mathrm{YUL}=44 \mathrm{ZUL}=14.255 \mathrm{XLR}=36 \mathrm{YLR}=1 \mathrm{ZLR}=14.255$

$\mathrm{UAX}=1.0 \mathrm{VDN}=1.0 \mathrm{NAX}=130 \mathrm{NCH}=1.12$ END PLT 1

TTL=' X-Y SLICE AT Z=26.705 THRU UPPER UNITS @ METAL UNIT AXIS MIDPOINT'

$X U L=0.5$ YUL $=44$ ZUL $=26.705$ XLR $=36$ YLR $=1 \quad Z L R=26.705$

$U A X=1.0 \mathrm{VDN}=1.0 \mathrm{NAX}=130 \mathrm{NCH}=.12^{\prime} \mathrm{END}$ PLT2

TTL $=$ ' X-Z SLICE AT Y=15.16 THROUGH A UNIT 1 AND A UNIT 2'

$\mathrm{XUL}=0.5 \mathrm{YUL}=15.16 \mathrm{ZUL}=41 . \mathrm{XLR}=36 \mathrm{YLR}=15.16 \mathrm{ZLR}=1$

$\mathrm{UAX}=1.0 \mathrm{WDN}=1.0 \mathrm{NAX}=130 \mathrm{END}$ PLT3

TTL $=$ ' $X-Z$ SLICE AT $Y=28.34$ THROUGH A UNTT 1 AND A UNIT $2 '$

$X U L=0.5 \mathrm{YUL}=28.34 \mathrm{ZUL}=41 . \mathrm{XLR}=36 \mathrm{YLR}=28.34 \mathrm{ZLR}=-1$

$\mathrm{UAX}=1.0 \mathrm{WDN}=-1.0 \mathrm{NAX}=130 \mathrm{END}$ PLT4

TTL $=$ ' Y-Z SLICE AT $X=6.59$ THROUGH ALL 4 UNITS 2'

$\mathrm{XUL}=6.59 \mathrm{YUL}=1 \mathrm{ZUL}=41 . \mathrm{XLR}=6.59 \mathrm{YLR}=45 \mathrm{ZLR}=1$

$\mathrm{VAX}=1.0 \mathrm{WDN}=1.0 \mathrm{NAX}=130$ END PLT5

$T I L=' Y-Z$ SLICE $A T$ I $=24.055$ THROUGH ALL 4 UNITS $1^{\prime}$

$\mathrm{XUL}=24.055 \mathrm{YUL}=-1 \mathrm{ZUL}=41 . \mathrm{XIR}=24.055 \mathrm{YLR}=45 \mathrm{ZLR}=-1$

$\mathrm{VAX}=1.0 \mathrm{WDN}=1.0 \mathrm{NAX}=130 \mathrm{END}$ PLT6

END PLOT

END DATA

END

\section{SAMPLE PROBLEM 20 TRIANGULAR-PITCHED ARRAY}

This problem is a critical experiment ${ }^{7}$ consisting of seven cylinders in a triangular-pitched unreflected array. The central cylinder has six cylinders arranged around it. The surface-to-surface separation between the units is 0.15 in. Each unit consists of a 60-mil-thick aluminum can with an 8-in. inside diameter, filled with a solution of $93.2 \%$ enriched uranyl fluoride with a H/235 $\mathrm{U}$ atomic ratio of 44.3 and a density of $576.87 \mathrm{~g} \mathrm{U} / \mathrm{L}$. The apparatus for conducting this experiment is shown in Fig. F17.D.9. 


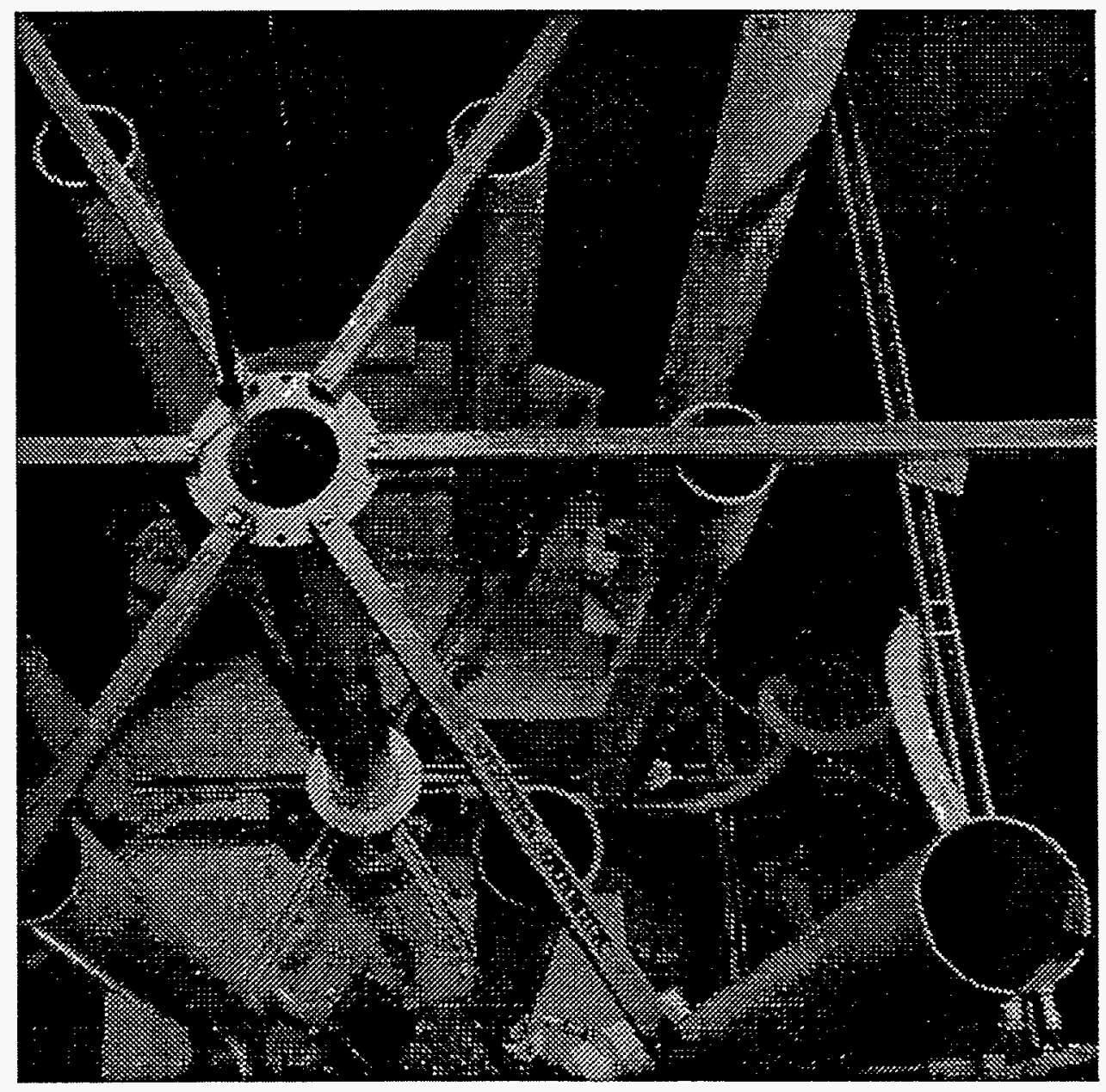

Figure F17.D.9 Typical arrangement for critical experiments with interacting arrays of aluminum cylinders containing enriched ${ }^{235} \mathrm{U}$ solutions 


\section{INPUT DATA}

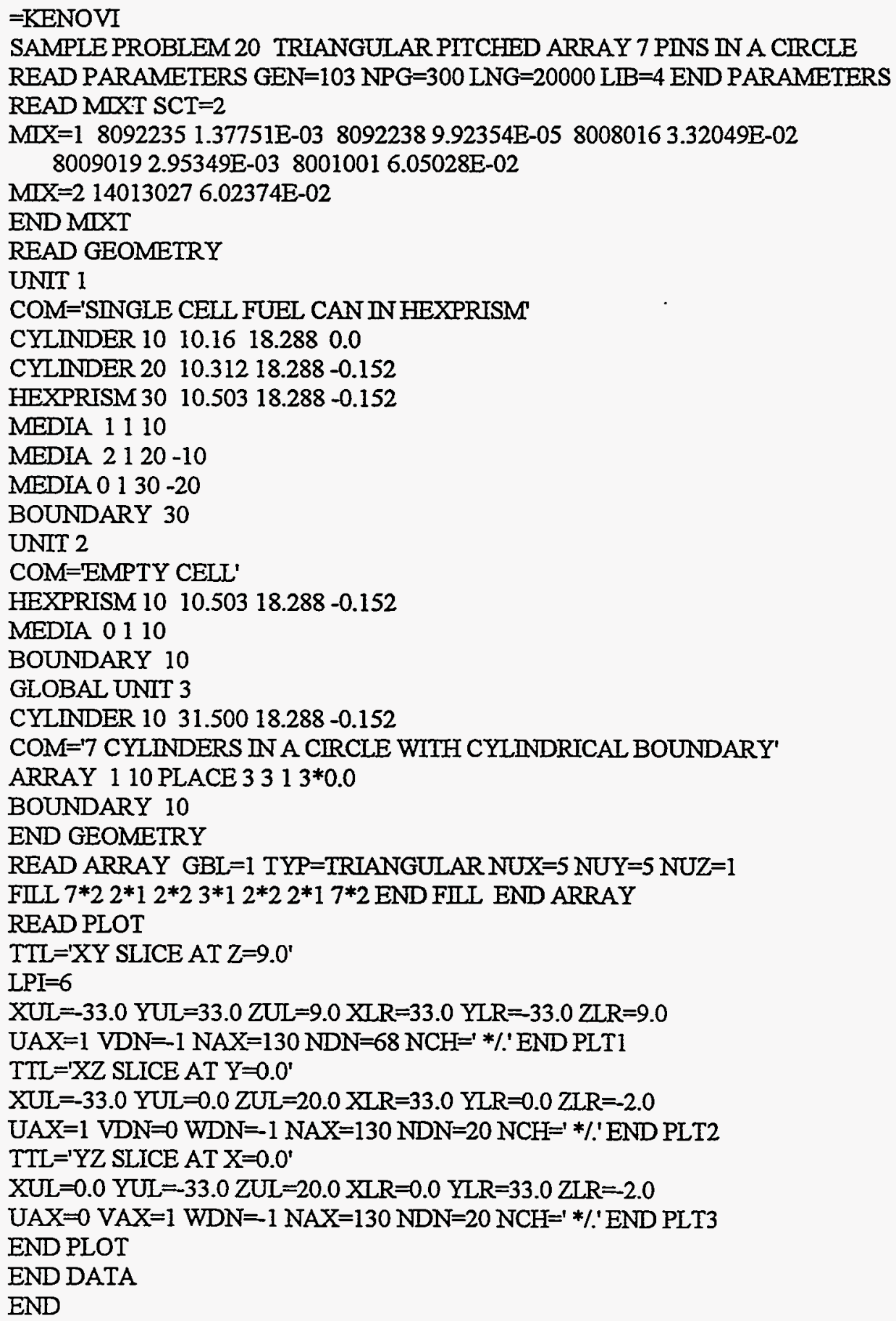

NUREG/CR-0200,

Vol. 2, Rev. 5

F17.D.28 


\section{SAMPLE PROBLEM 21 PARTIALLY FILLED SPHERE}

This critical experiment ${ }^{8}$ consisted of a partially filled, unreflected spherical container. This aluminum container had an inside diameter of 27.244 in. and a wall thickness of 1/16 in. It is referred to in the report as the 27.3-in.-diam vessel. The sphere was $98 \%$ filled with uranyl fluoride at an enrichment of $4.89 \%$ with an $\mathrm{H} /{ }^{235} \mathrm{U}$ atomic ratio of 1099 . The height of the solution in the sphere was $64.6 \mathrm{~cm}$ above the bottom of the sphere. A schematic diagram of the apparatus used in the experiment is given in Fig. F17.D.10. The steel tank was ignored.

\section{INPUT DATA}

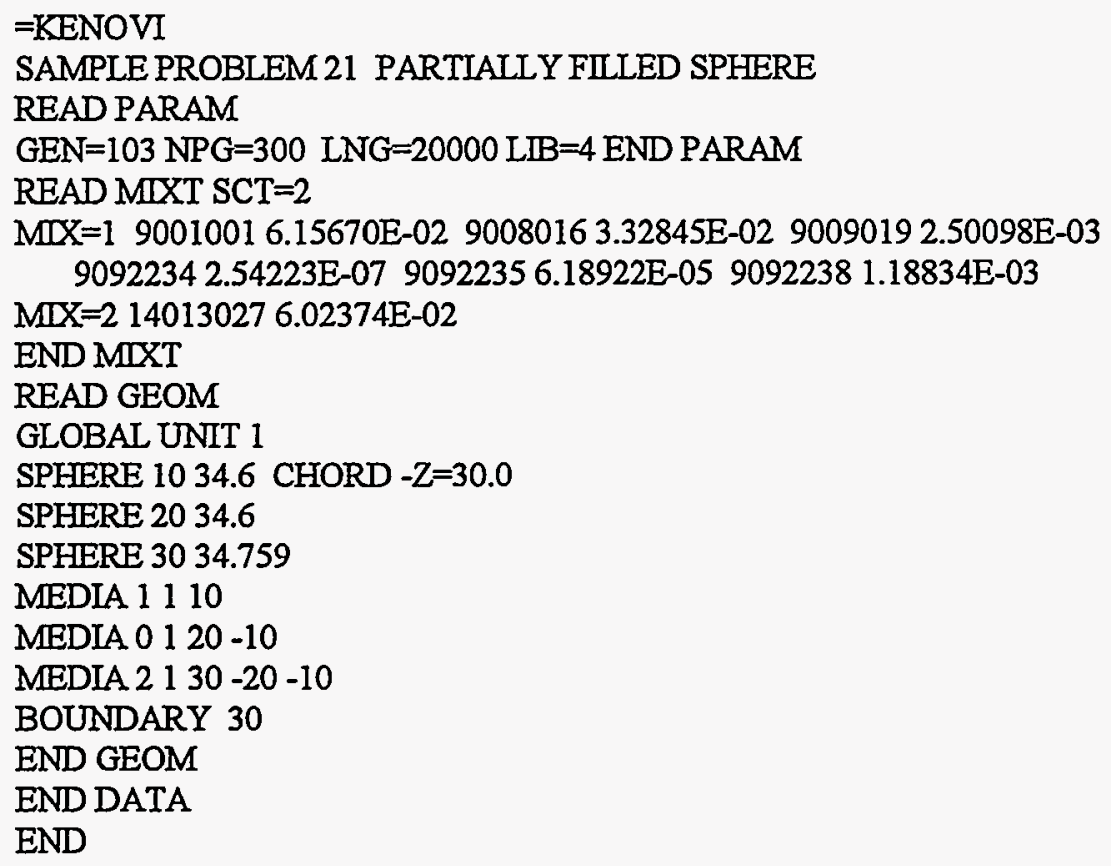




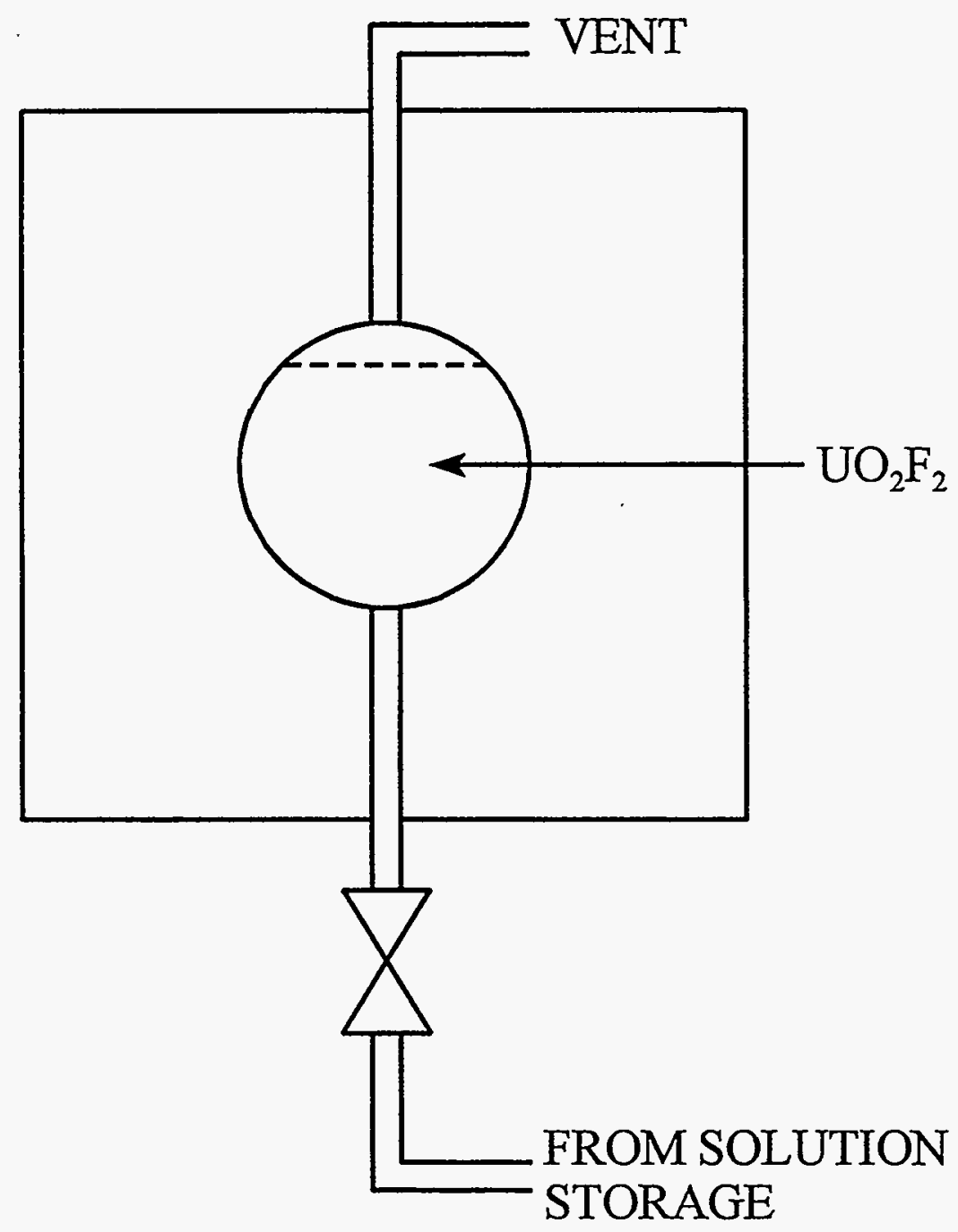

Figure F17.D.10 Schematic of bare partially filled sphere experiment inside a 9.5-ft-diam, 9-ft-high steel tank

NUREG/CR-0200,

Vol. 2, Rev. 5

F17.D.30 


\section{SAMPLE PROBLEM 22 CASE 2C8 BARE WITH 3 NESTED HOLES, EACH IS EQUAL VOLUME}

The physical representation of this sample problem is the critical experiment described in sample problem 1. It is a simple $2 \times 2 \times 2$ array of $93.2 \%$ enriched uranium metal cylinders. This sample problem defines a uranium cylinder in a void spacing cuboid using nested holes. Eight of these units are stacked together in a $2 \times 2 \times 2$ array.

\section{INPUT DATA}

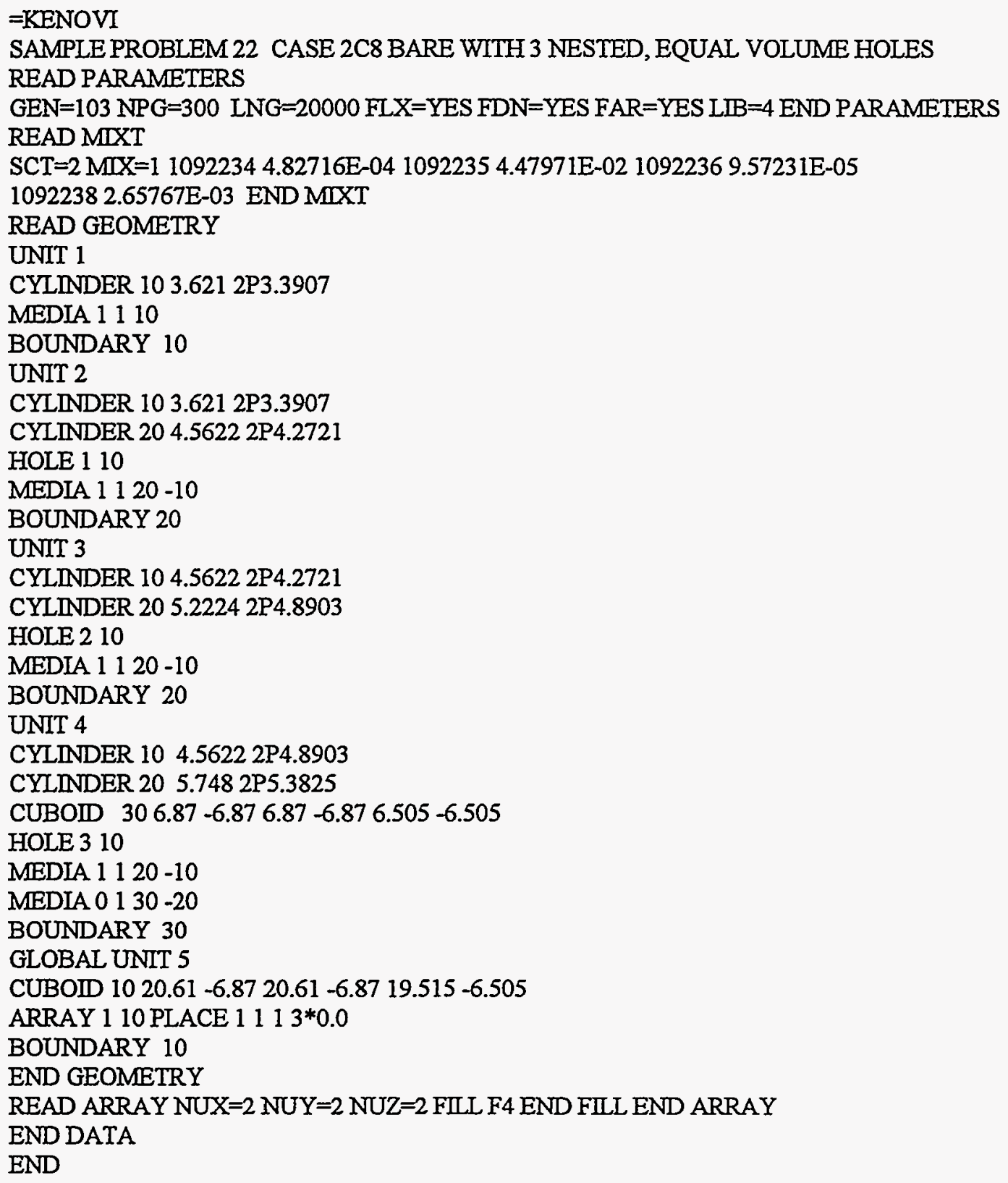




\section{SAMPLE PROBLEM 23 CASE 2C8 BARE AS STACKED CYLINDERS}

The physical representation of this sample problem is the critical experiment described in sample problem 1. This sample problem describes each of the eight units in the critical $2 \times 2 \times 2$ array using hemicylinders with different chord sizes and directions.

\section{INPUT DATA}

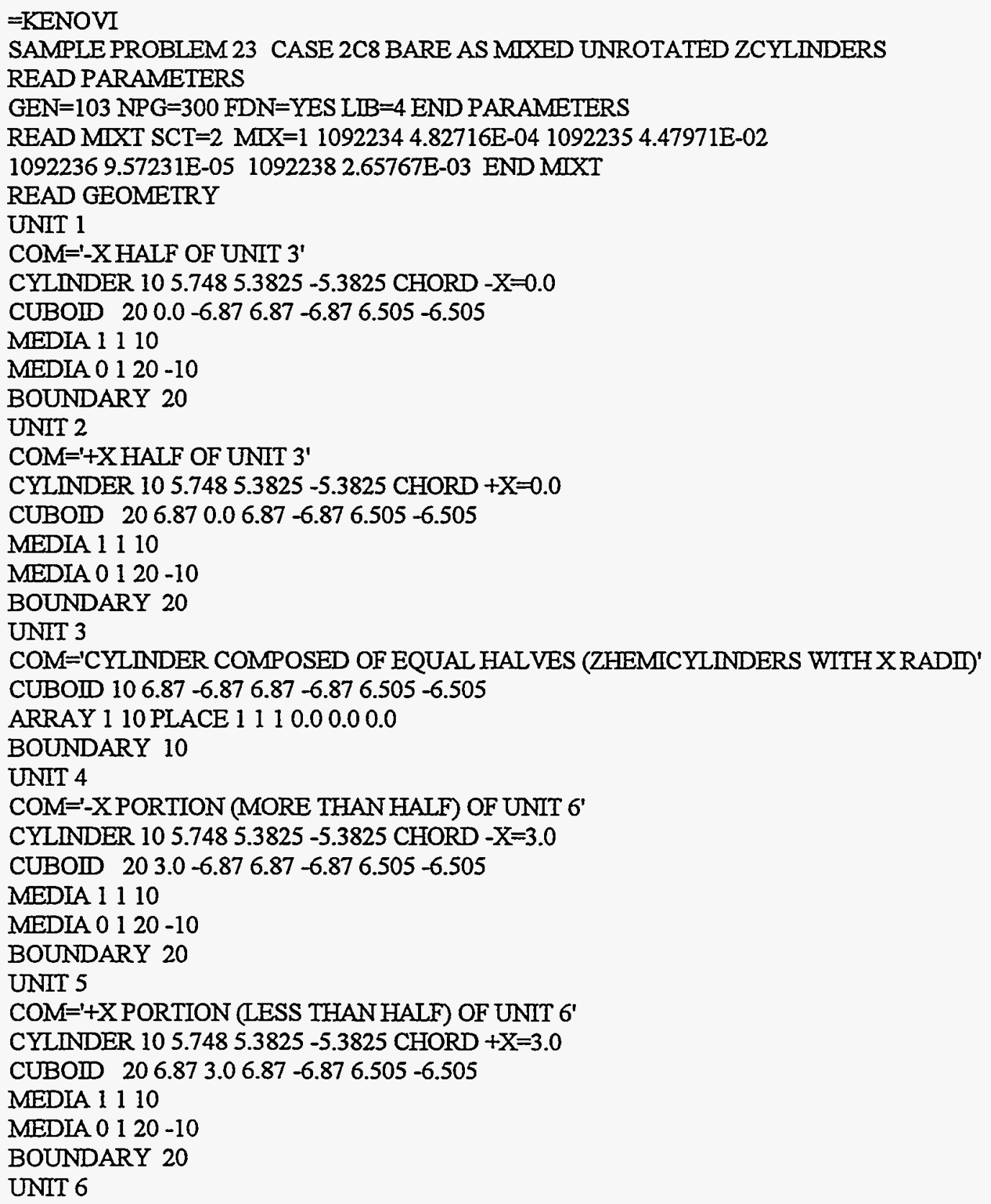


COM='CYLINDER COMPOSED OF UNEQUAL HALVES (ZHEMICYLINDERS WITH X RADI)'

CUBOID $106.87-6.876 .87-6.876 .505-6.505$

ARRAY 210 PLACE $1113 * 0.0$

BOUNDARY 10

UNIT 7

COM='CYLINDER OF A SINGLE ZHEMICYLINDER IN THE -X DIRECTION'

CYLINDER $105.7485 .3825-5.3825$ CHORD $-\mathrm{X}=5.748$

CUBOID $206.87-6.876 .87-6.876 .505-6.505$

MEDIA 1110

MEDIA $0120-10$

BOUNDARY 20

UNIT 8

COM $=$ 'CYLINDER OF A SINGLE ZHEMICYLINDER IN THE +X DIRECTION'

CYLINDER 10 5.748 5.3825 -5.3825 CHORD $+\mathrm{X}=5.748$

CUBOID $206.87-6.876 .87-6.876 .505-6.505$

MEDIA 1110

MEDIA $0120-10$

BOUNDARY 20

UNIT 9

COM='-Y HALF OF UNIT 11 '

CYLINDER $105.7485 .3825-5.3825$ CHORD $-\mathrm{Y}=0.0$

CUBOID $206.87-6.870 .0-6.876 .505-6.505$

MEDIA 1110

MEDIA 0120 -10

BOUNDARY 20

UNIT 10

COM $='+Y$ HALF OF UNIT $11 '$

CYLINDER $105.7485 .3825-5.3825$ CHORD $+Y=0.0$

CUBOID $206.87-6.876 .870 .06 .505-6.505$

MEDIA 1110

MEDIA $0120-10$

BOUNDARY 20

UNIT 11

COM='CYLINDER COMPOSED OF EQUAL HALVES (ZHEMICYLINDERS WITH Y RADII)'

CUBOID $106.87-6.876 .87-6.876 .505-6.505$

ARRAY 310 PLACE 1110.00 .00 .0

BOUNDARY 10

UNIT 12

COM='-Y PORTION (MORE THAN HALF) OF UNIT 14'

CYLINDER $105.7485 .3825-5.3825$ CHORD $-\mathrm{Y}=3.0$

CUBOID $206.87-6.873 .0-6.876 .505-6.505$

MEDIA 1110

MEDIA $0120-10$

BOUNDARY 20

UNIT 13

COM $=$ '+Y PORTION (LESS THAN HALF) OF UNIT 14'

CYLINDER $105.7485 .3825-5.3825$ CHORD $+Y=3.0$

CUBOID $206.87-6.876 .873 .06 .505-6.505$

MEDIA 1110

MEDIA $0120-10$

BOUNDARY 20 
UNIT 14

COM='CYLINDER COMPOSED OF UNEQUAL HALVES (ZHEMICYLINDERS WITH Y RADI)'

CUBOID 10 6.87 -6.87 6.87-6.87 6.505-6.505

ARRAY 4 10 PLACE 1 I $13 * 0.0$

BOUNDARY 10

UNIT 15

COM $=$ 'CYLINDER OF A SINGLE ZHEMICYLINDER IN THE - Y DIRECTION'

CYIINDER $105.7485 .3825-5.3825$ CHORD $-\mathrm{Y}=5.748$

CUBOID $206.87-6.876 .87-6.876 .505-6.505$

MEDIA 1110

MEDIA $0120-10$

BOUNDARY 20

UNIT 16

COM $=$ 'CYLINDER OF A SINGLE ZHEMICYLINDER IN THE +Y DIRECTION'

CYLINDER $105.7485 .3825-5.3825 \mathrm{CHORD}+\mathrm{Y}=-5.748$

CUBOID $206.87-6.876 .87-6.876 .505-6.505$

MEDIA 1110

MEDIA $0120-10$

BOUNDARY 20

GLOBAL UNIT 17

CUBOID 10 13.74 -13.74 13.74-13.74 13.010-13.010

ARRAY 5 10 PLACE $1111-6.87-6.87-6.505$

BOUNDARY 10

END GEOMETRY

READ ARRAY

COM='ARRAY 1 DEFINES UNIT 3 (ZHEMICYLINDERS WITH XRADII)'

$A R A=1$ NUX $=2$ NUY $=1$ NUZ=1 FILL 12 END FILL

COM='ARRAY 2 DEFINES UNIT 6 (ZHEMICYLINDERS WITH X RADII)'

$A R A=2$ NUX $=2$ NUY $=1$ NUZ=1 FILL 45 END FILL

COM='ARRAY 3 DEFINES UNIT 11 (ZHEMICYLINDERS WITH Y RADII'

$A R A=3$ NUX $=1$ NUY=2 NUZ=1 FILL 910 END FILL

COM='ARRAY 4 DEFINES UNIT 14 (ZHEMICYLINDERS WITH Y RADI)'

$A R A=4 N U Z=1$ NUY $=2$ NUZ $=1$ FIL 1213 END FILL

COM='ARRAY 5 DEFINES THE TOTAL 2C8 PROBLEM'

GBL $=5$ ARA $=5$ NUX=2 NUY=2 NUZ=2 FILL 376811151416 END FILL

END ARRAY

END DATA

END

\section{SAMPLE PROBLEM 24 CASE 2C8 BARE AS STACKED X-ROTATED CYLINDERS}

The physical representation of this sample problem is the critical experiment described in sample problem 1 except the long axis of the cylinders are oriented along the $\mathrm{x}$-axis This sample problem describes each of the eight units in the critical $2 \times 2 \times 2$ array using hemicylinders with different chord sizes and directions whose long axes are rotated in the $\mathrm{x}$-direction.

NUREG/CR-0200,

Vol. 2, Rev. 5

F17.D.34 


\section{INPUT DATA}

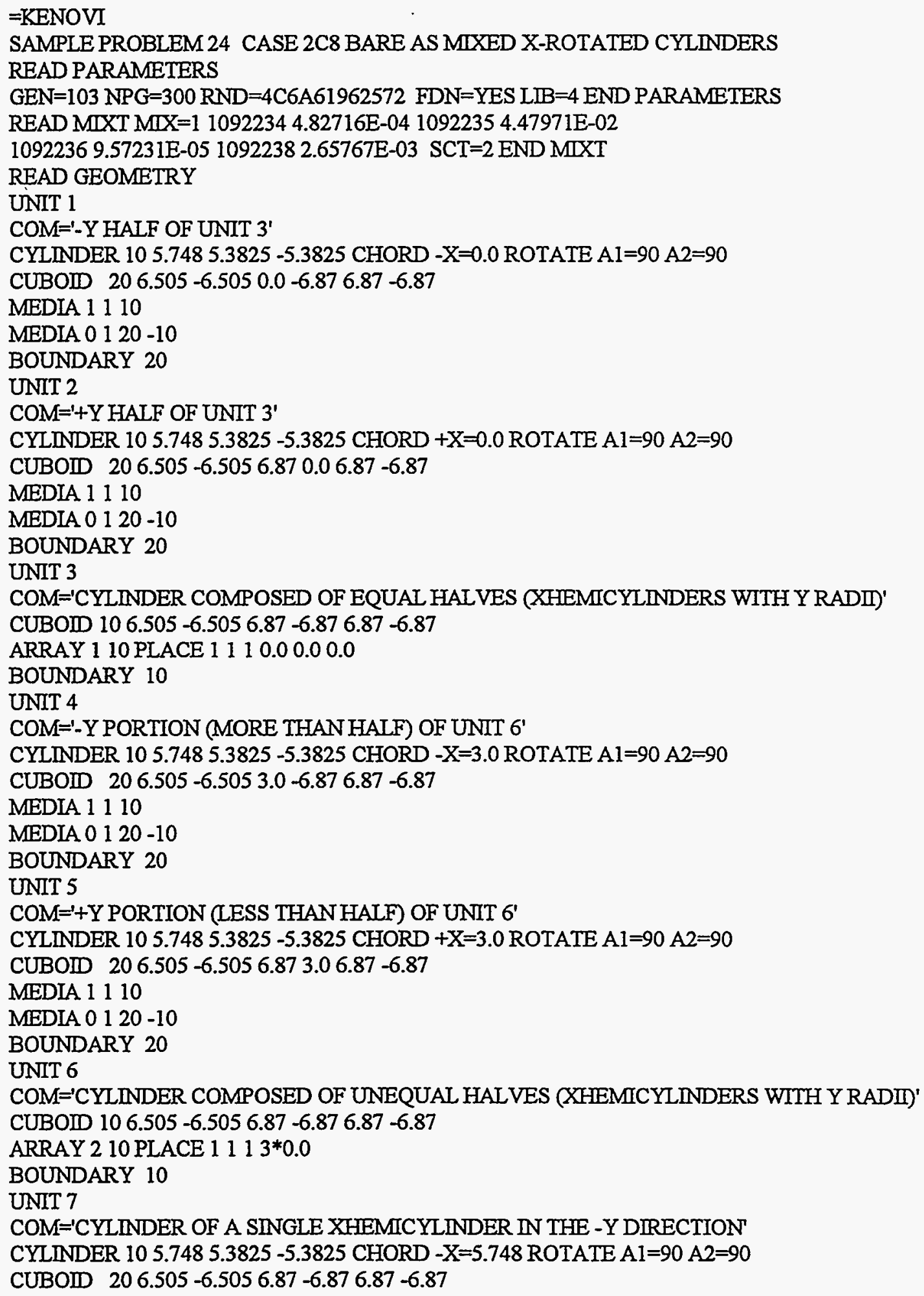




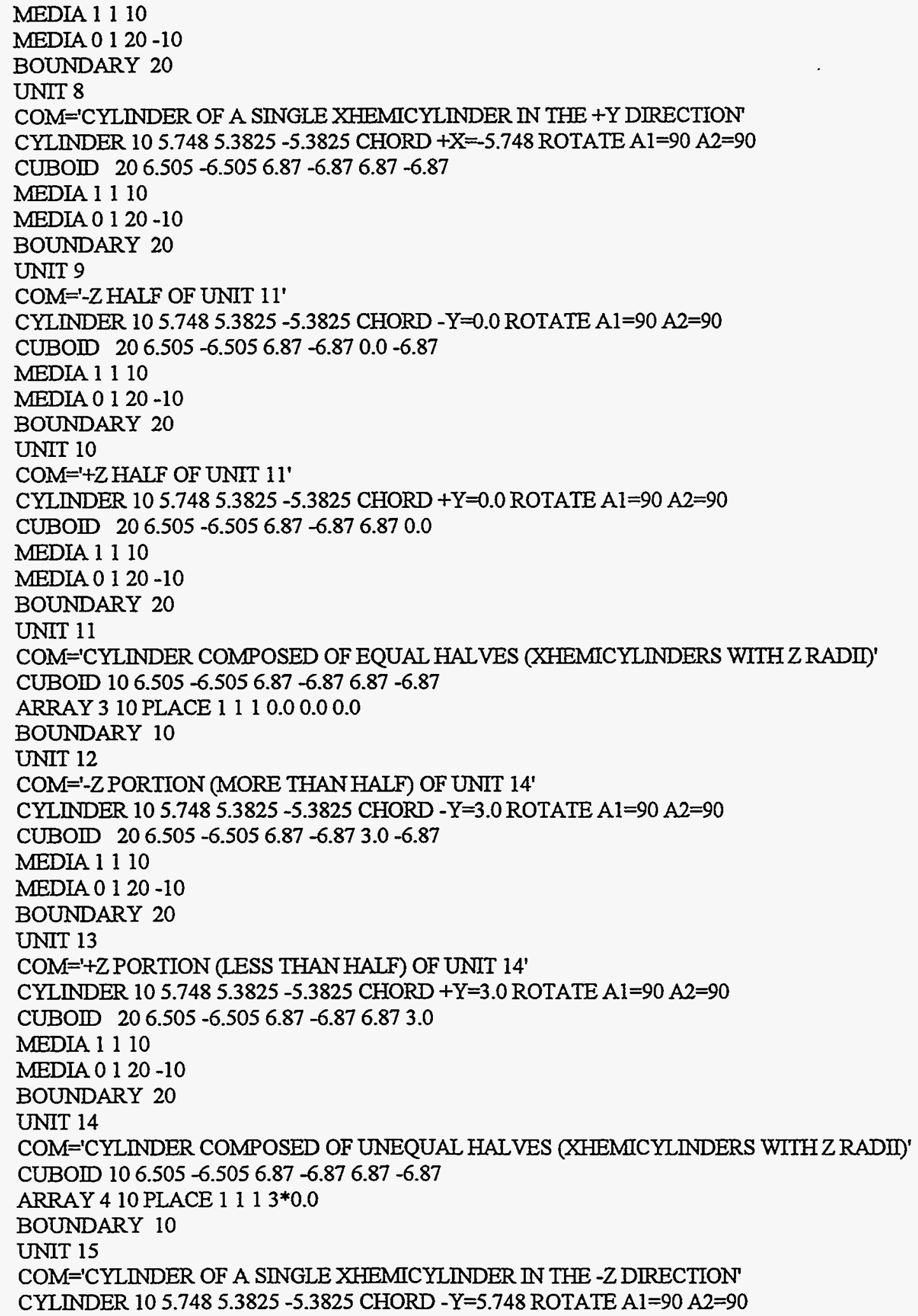

NUREG/CR-0200, 
CUBOID $206.505-6.5056 .87-6.876 .87-6.87$

MEDIA 1110

MEDIA $0120-10$

BOUNDARY 20

UNIT 16

COM $=$ 'CYLINDER OF A SINGLE XHEMICYLINDER IN THE + Z DIRECTION'

CYLINDER $105.7485 .3825-5.3825$ CHORD $+Y=-5.748$ ROTATE Al $=90$ A2 $=90$

CUBOD $206.505-6.5056 .87-6.876 .87-6.87$

MEDIA 1110

MEDIA $0120-10$

BOUNDARY 20

GLOBAL UNIT 17

CUBOID $1013.01-13.0113 .74-13.7413 .74-13.74$

ARRAY 5 10 PLACE $111-6.505-6.87-6.87$

BOUNDARY 10

END GEOMETRY

READ ARRAY

COM='ARRAY 1 DEFINES UNIT 3 (XHEMICYLINDERS WITH Y RADII)'

$A R A=1$ NUX $=1$ NUY $=2$ NUZ $=1$ FILL 12 END FILL

COM='ARRAY 2 DEFINES UNIT 6 (XHEMICYLINDERS WITH Y RADI)'

$A R A=2$ NUX $=1$ NUY $=2$ NUZ $=1$ FILL 45 END FILL

COM='ARRAY 3 DEFINES UNIT 11 (XIEMICYLINDERS WITH $Z$ RADII)'

$A R A=3$ NUX $=1$ NUY $=1$ NUZ $=2$ FLL 910 END FILL

COM='ARRAY 4 DEFINES UNIT 14 (XHEMICYLINDERS WITH $Z$ RADII)'

$A R A=4$ NUX $=1$ NUY=1 NUZ=2 FIIL 1213 END FIIL

COM='ARRAY 5 DEFINES THE TOTAL 2C8 PROBLEM'

$A R A=5 N U X=2$ NUY=2 NUZ=2 FILL 376811151416 END FILL

END ARRAY

END DATA

END

\section{SAMPLE PROBLEM 25 CASE 2C8 BARE AS MIXED YHEMICYLINDERS}

The physical representation of this sample problem is the critical experiment described in sample problem 1 except the long axis of the cylinders are oriented along the $y$-axis. This sample problem describes each of th eight units in the critical $2 \times 2 \times 2$ array using hemicylinders with different chord sizes and directions whose long axes are rotated in the $y$-direction.

INPUT DATA

$=$ KENOVI

SAMPLE PROBLEM 25 CASE 2C8 BARE AS MIXED Y-ROTATED CYLINDERS

READ PARAMETERS

GEN=103 NPG=300 FDN=YES LIB=4 END PARAMETERS

READ MIXT MIX=1 1092234 4.82716E-04 1092235 4.47971E-02

1092236 9.57231E-05 1092238 2.65767E-03 SCT=2 END MIXT

READ GEOMETRY

UNIT 1 
COM='-X HALF OF UNIT 3'

CYLINDER $105.7485 .3825-5.3825 \mathrm{CHORD}-\mathrm{Y}=0.0$ ROTATE $\mathrm{Al}=180 \mathrm{~A} 2=90 \mathrm{~A} 3=90$

CUBOID $200.0-6.876 .505-6.5056 .87-6.87$

MEDIA 1110

MEDIA $0120-10$

BOUNDARY 20

UNIT 2

COM='+X HALF OF UNIT 3'

CYLINDER $105.7485 .3825-5.3825 \mathrm{CHORD}+\mathrm{Y}=0.0$ ROTATE $\mathrm{A} 1=180 \mathrm{~A} 2=90 \mathrm{~A} 3=90$

CUBOID $206.870 .06 .505-6.5056 .87-6.87$

MEDIA 1110

MEDIA $0120-10$

BOUNDARY 20

UNIT 3

COM='CYLINDER COMPOSED OF EQUAL HALVES (YHEMICYLINDERS WITH X RADI)'

CUBOID $106.87-6.876 .505-6.5056 .87-6.87$

ARRAY 110 PLACE 1110.00 .00 .0

BOUNDARY 10

UNIT 4

COM='-XPORTION (MORE THAN HAIF) OF UNIT $6^{\prime}$

CYLINDER $105.7485 .3825-5.3825$ CHORD $-Y=3.0$ ROTATE $A 1=180$ A2 $=90$ A3 $=90$

CUBOID $203.0-6.876 .505-6.5056 .87-6.87$

MEDIA 1110

MEDIA $0120-10$

BOUNDARY 20

UNTT 5

COM $='+X$ PORTION (LESS THAN HALF) OF UNIT 6 '

CYLINDER $105.7485 .3825-5.3825 \mathrm{CHORD}+\mathrm{Y}=3.0$ ROTATE $\mathrm{A} 1=180 \mathrm{~A} 2=90 \mathrm{~A} 3=90$

CUBOID $206.873 .06 .505-6.5056 .87-6.87$

MEDIA 1110

MEDIA $0120-10$

BOUNDARY 20

UNIT 6

COM='CYLINDER COMPOSED OF UNEQUAL HALVES (YHEMICYLINDERS WITH X RADII)'

CUBOID $106.87-6.876 .505-6.5056 .87-6.87$

ARRAY 210 PLACE $1113 * 0.0$

BOUNDARY 10

UNIT 7

COM='CYLINDER OF A SINGLE YHEMICYLINDER IN THE -X DIRECTION'

CYLINDER $105.7485 .3825-5.3825$ CHORD $-Y=5.748$ ROTATE $A 1=180$ A2 $=90$ A3 $=90$

CUBOID $206.87-6.876 .505-6.5056 .87-6.87$

MEDIA 1110

MEDIA $0120-10$

BOUNDARY 20

UNIT 8

COM $=$ 'CYLINDER OF A SINGLE YHEMICYLINDER IN THE +X DIRECTION'

CYLINDER $105.7485 .3825-5.3825$ CHORD $+Y=5.748$ ROTATE A1 $=180 \mathrm{~A} 2=90 \mathrm{~A} 3=90$

CUBOID $206.87-6.876 .505-6.5056 .87-6.87$

MEDIA 1110

MEDIA 0120 -10

BOUNDARY 20

NUREG/CR-0200,

Vol. 2, Rev. 5

F17.D.38 


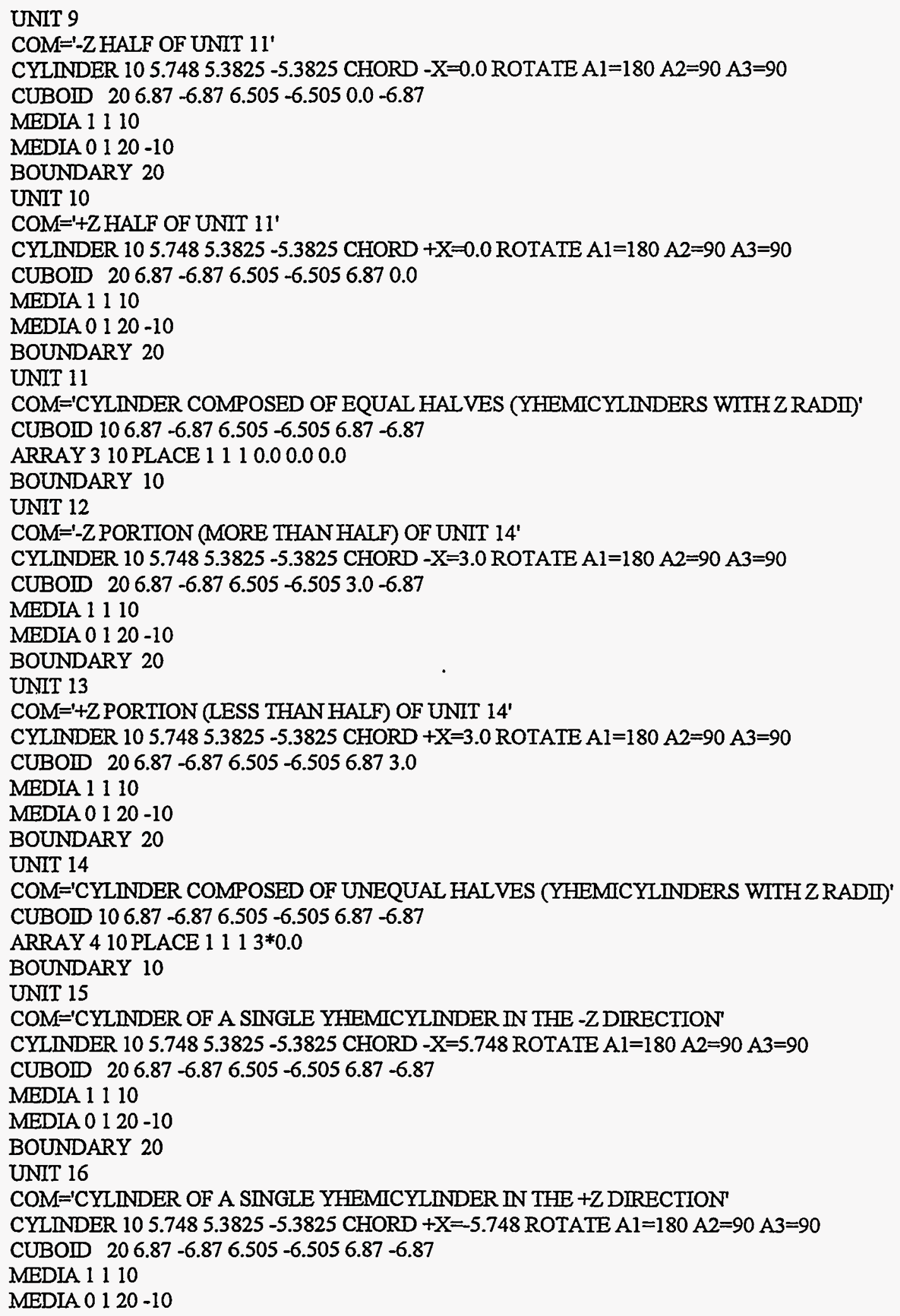


BOUNDARY 20

GLOBAL UNIT 17

CUBOID $1013.74-13.7413 .01-13.0113 .74-13.74$

ARRAY 5 10 PLACE $111-6.87-6.505-6.87$

BOUNDARY 10

END GEOMETRY

READ ARRAY

COM='ARRAY 1 DEFINES UNIT 3 (YHEMICYLINDERS WITH $Z$ RADII)'

$A R A=1$ NUX=2 NUY=1 NUZ=1 FILL 12 END FILL

COM='ARRAY 2 DEFINES UNIT 6 (YHEMICYLINDERS WITH $Z$ RADII)'

$A R A=2$ NUX $=2$ NUY $=1$ NUZ $=1$ FILL 45 END FILL

COM='ARRAY 3 DEFINES UNIT 11 (YHEMICYLINDERS WITH X RADII)'

$A R A=3$ NUX $=1$ NUY $=1$ NUZ $=2$ FILL 910 END FILL

COM='ARRAY 4 DEFINES UNIT 14 (YHEMICYLINDERS WITH X RADII'

$A R A=4$ NUX=1 NUY=1 NUZ=2 FILL 1213 END FILL

COM $=$ 'ARRAY 5 DEFINES THE TOTAL 2C8 PROBLEM'

GBL $=5$ ARA $=5$ NUX=2 NUY=2 NUZ=2 FILL 376811151416 END FILL

END ARRAY

END DATA

END

\section{F17.D.2 SAMPLE PROBLEM WORKING FORMAT LIBRARY}

The KENO VI sample problems use nuclide IDs that are consistent with the SCALE 4.3 CSAS nuclide ID naming convention. The first time a nuclide is encountered, its ZA number is used. Nuclides are identified by the ZA number plus 1000000 times the mixture number. Either CSASN or the BONAMINITAWL explicit sequence can be used to create a problem-dependent working-format cross-section library suitable for use with the sample problems. CSASN or the BONAMI/NITAWL sequence can (1) be run alone with logical unit 4 of the job control language saved for later use with the KENO-VI sample problems, or (2) be placed in the job stream in front of the KENO VI sample problems

The CSASN SCALE control module is easy to use because it calculates the necessary resonance data required to create the problem-dependent AMPX working-format library. It is recommended that the SCALE 4.3 version of CSASN be used if it is operational at the installation where the problems are to be run. CSASN is one of the control modules associated with CSAS4 or CSAS6 and is automatically operational if CSAS4 or CSAS6 is operational. See Sect. C4 or C6 of the SCALE manual for assistance in using CSASN. If the SCALE DRIVER and the control modules are not operational at your installation, the SCALE 4.3 version of BONAMI and NITAWL should be used to create the problem-dependent AMPX working format cross-section library. Obtaining accurate resonance data for BONAMI and NITAWL may be difficult. See Sect. F1 and F2 of the SCALE manual for assistance in using BONAMI and NITAWL.

The KENO-VI sample problem input data are independent of energy group structure. However, if a cross-section library containing BONARENKO shielding factors is used, BONAMI must be run before NITAWL to provide the Bondarenko corrections necessary for the this library. If CSASN is used to create the AMPX working-format cross-section library, the Bondarenko corrections are automatically performed when necessary. To use a different master library, simply supply the desired master cross-section library name in the CSASN data. See Sects. M7.5.3, M7.5.4, and C4.5.2 for additional information and examples. See Sect. M4 for information about the master format cross-section libraries that are available in SCALE.

Data for both CSASN and the BONAMINITAWL sequence are provided to create a problem-dependent AMPX working-format cross-section library suitable for use with the KENO-VI sample problems. These data,

NUREG/CR-0200,

Vol. 2, Rev. 5

F17.D.40 
which include all of the mixtures used in the 25 KENO-VI sample problems, will create an AMPX workingformat cross-section library. The nuclide IDs from the BONAMINITAWL sequence match those in the KENOVI sample problem mixing tables.. This cross-section library is problem-specific and is not appropriate for use with other problems. None of the KENO-VI sample problems involve arrays of pins. Therefore, Dancoff corrections have not been incorporated into any of the nuclides in this library.

\section{F17.D.2.1 CSASN Data}

The CSASN input data to produce an AMPX working-format cross-section library for the KENO-VI sample problems are given on the following page.

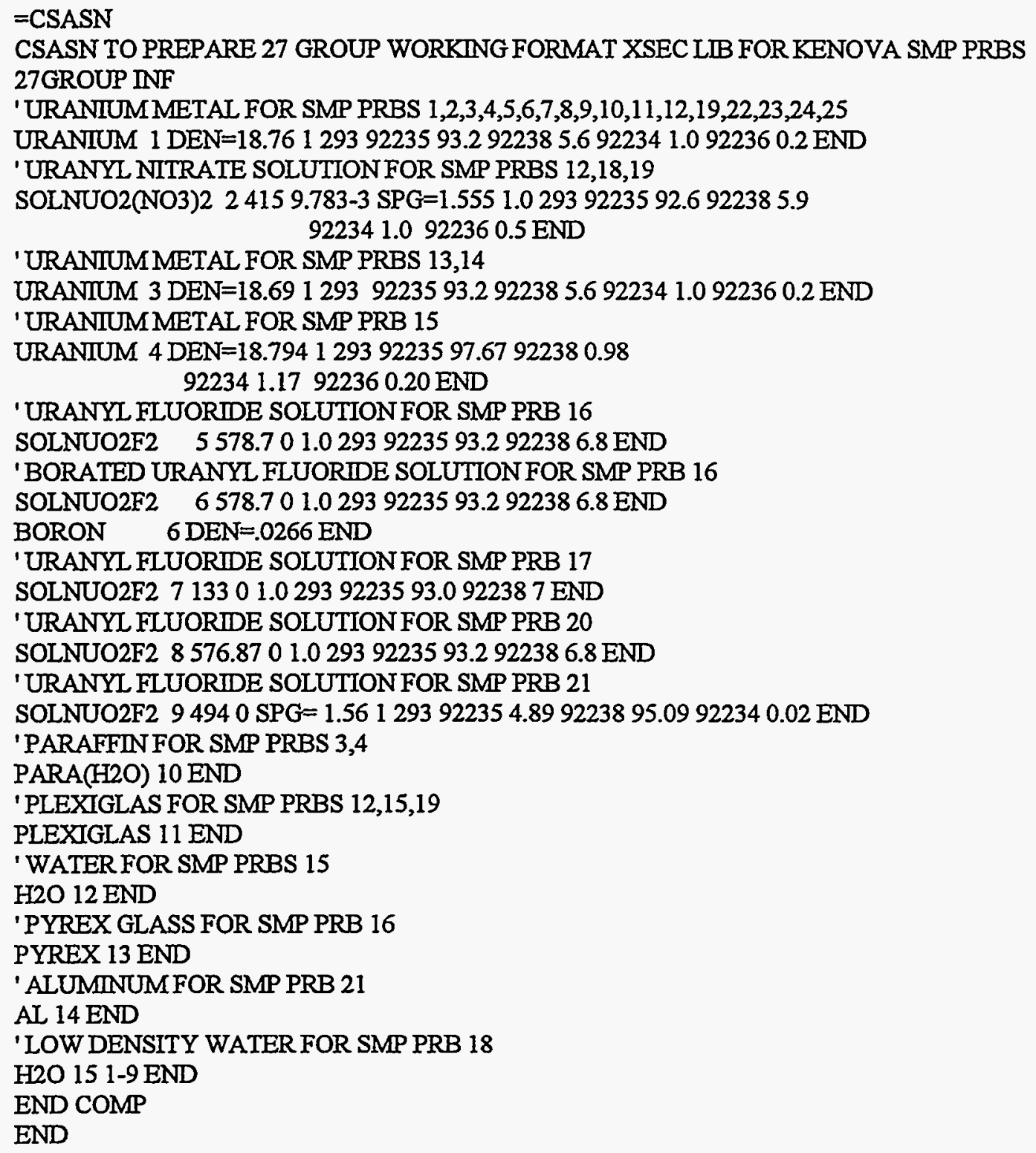




\section{F17.D.2.2 BONAMI Data}

The BONAMI input data to produce an AMPX working-format cross-section library for the KENO-VI sample problems are given below. This input is only required if BONDARENKO shielding factors are used for the referenced nuclides in the specified master cross-section library. If the SCALE DRIVER is not used, the first $(\Leftrightarrow \mathrm{BONAMI})$ and last (END) records should be omitted from the BONAMI data.

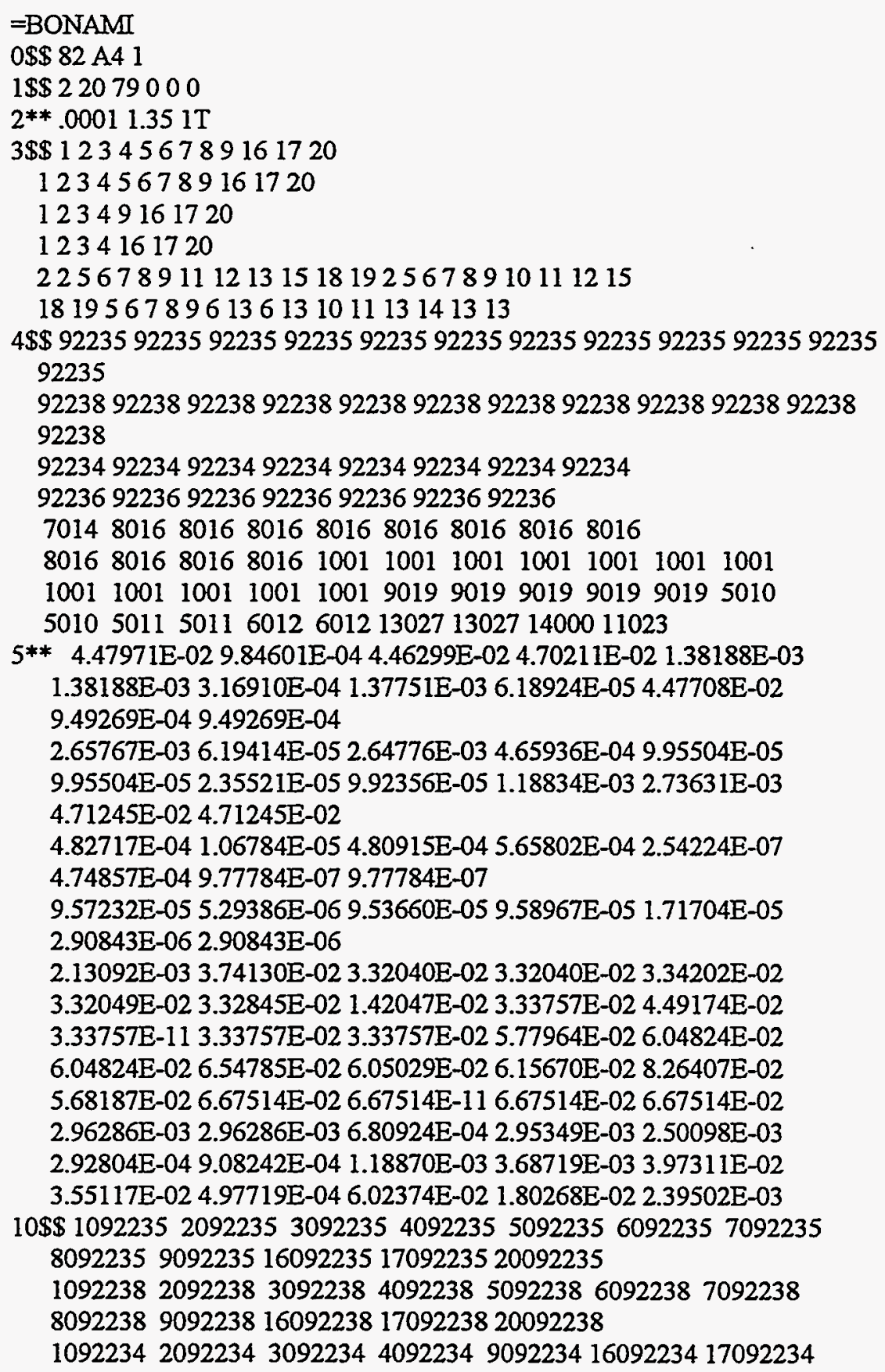

NUREG/CR-0200,

Vol. 2, Rev. 5

F17.D.42 


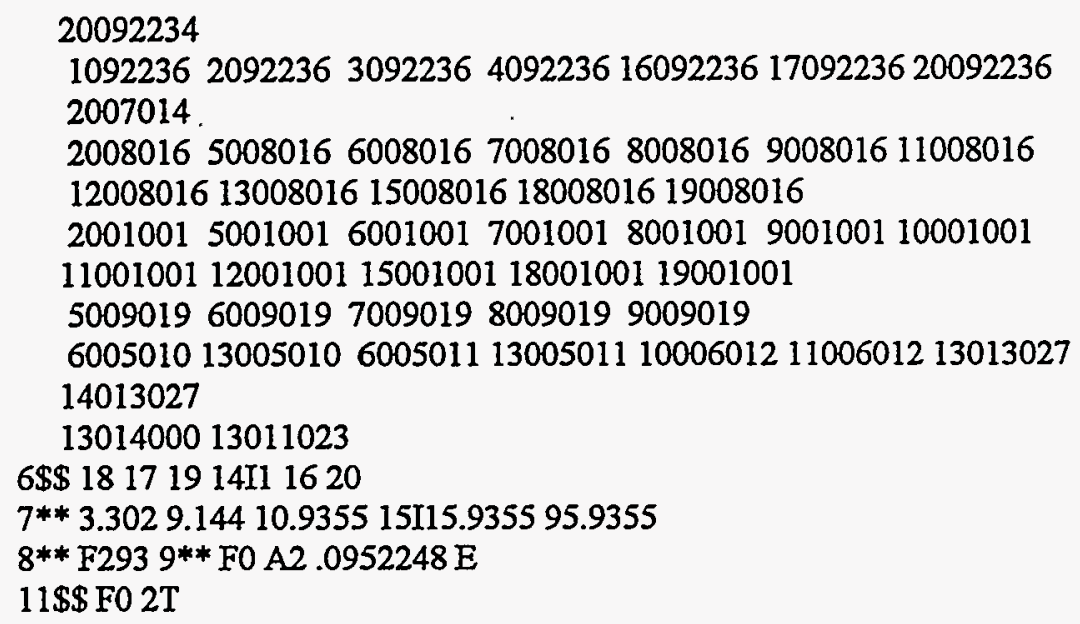

\section{F17.D.2.3 NITAWL Data}

The NITAWL input data to produce an AMPX working-format cross-section library for the KENO-VI sample problems are given below. If the SCALE DRIVER is not used, the first (=NITAWL) and last (END) records should be omitted from the NITAWL data.

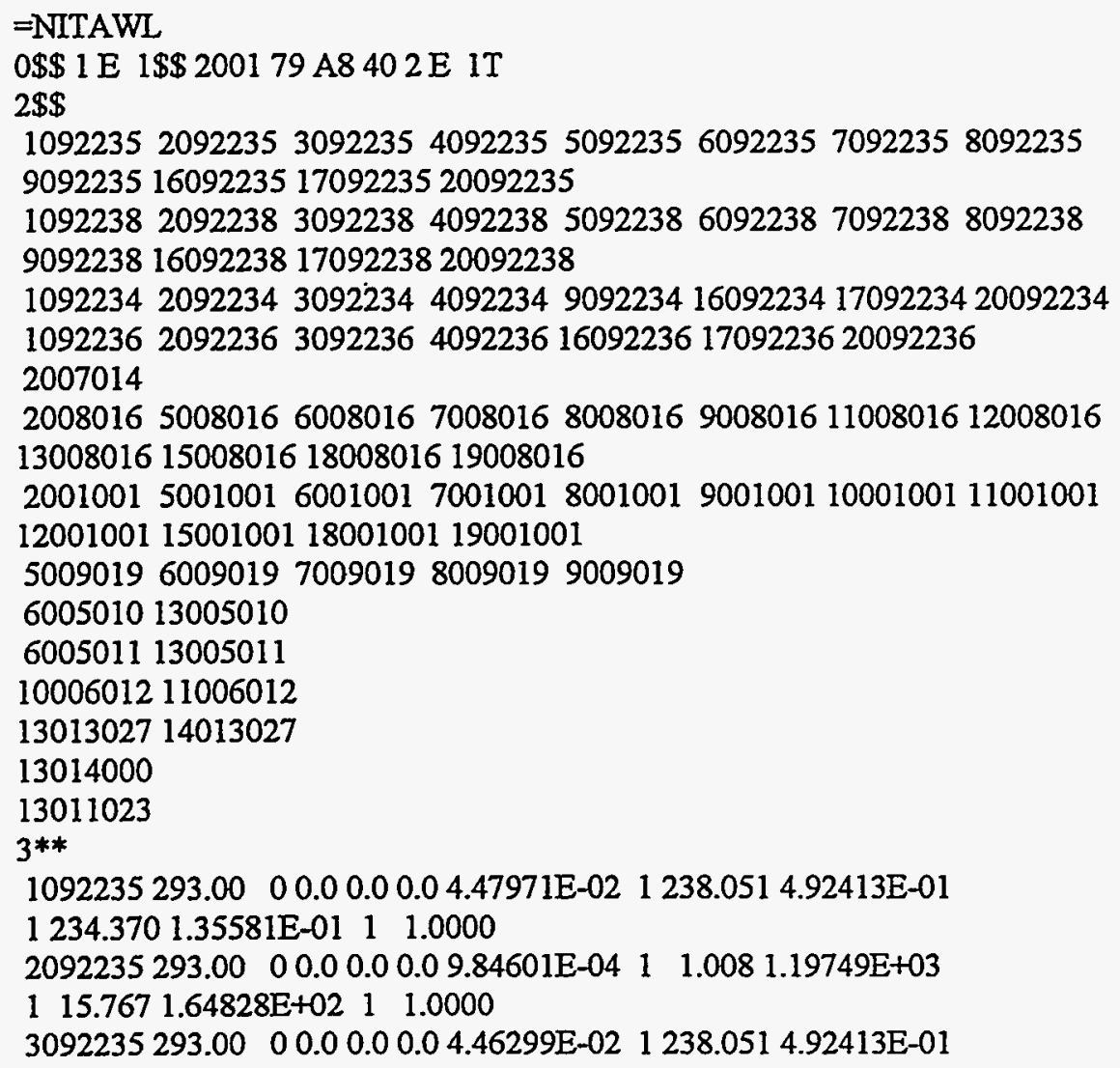




\author{
$1234.3701 .35581 \mathrm{E}-01 \quad 1 \quad 1.0000$ \\ $4092235293.00 \quad 00.00 .00 .04 .70211 \mathrm{E}-021234.0411 .26346 \mathrm{E}-01$ \\ $1237.6341 .03660 \mathrm{E}-0111.0000$

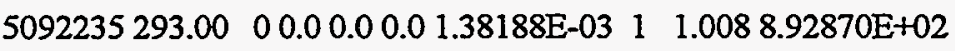 \\ $116.2949 .84222 \mathrm{E}+0111.0000$

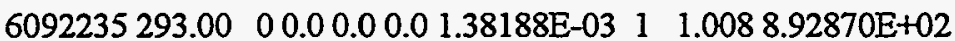 \\ $115.9511 .02996 \mathrm{E}+0211.0000$ \\ $7092235293.00 \quad 00.00 .00 .03 .16910 \mathrm{E}-04 \quad 1 \quad 1.0084 .21496 \mathrm{E}+03$ \\ $\begin{array}{llll}1 & 16.0584 .03814 \mathrm{E}+02 \quad 1 \quad 1.0000\end{array}$ \\ $8092235293.00 \quad 00.00 .00 .01 .37751 E-03 \quad 1 \quad 1.0088 .96007 \mathrm{E}+02$ \\ $116.2949 .87105 \mathrm{E}+01 \quad 1 \quad 1.0000$ \\ $9092235293.00 \quad 00.00 .00 .06 .18924 \mathrm{E}-05 \quad 1 \quad 1.0082 .02927 \mathrm{E}+04$ \\ I $17.3172 .32155 \mathrm{E}+03 \quad 1 \quad 1.0000$ \\ $16092235293.00 \quad 00.00 .00 .04 .47708 \mathrm{E}-02 \quad 1238.0515 .07281 \mathrm{E}-01$ \\ $1234.1101 .15394 \mathrm{E}-01 \quad 1 \quad 1.0000$ \\ $17092235293.00 \quad 29.14400 \mathrm{E}+00$ 4.10601E-03 3.30200E+00 9.49269E-04 \\ $1238.0514 .12036 \mathrm{E}+021235.5384 .29860 \mathrm{E}-02 \quad 1 \quad 1.0000$ \\ $20092235293.0015 .84200 \mathrm{E}+001.00000 \mathrm{E}+000.00000 \mathrm{E}+009.49269 \mathrm{E}-04$ \\ $1238.0514 .12036 \mathrm{E}+02 \quad 1235.5384 .29860 \mathrm{E}-02 \quad 1 \quad 1.0000$ \\ $1092238293.00 \quad 00.00 .00 .02 .65767 \mathrm{E}-03 \quad 1235.044$ 1.76985E+02 \\ $1234.3702 .28531 \mathrm{E}+00111.0000$ \\ $2092238293.00 \quad 00.00 .00 .06 .19414 \mathrm{E}-05 \quad 1 \quad 1.0081 .90349 \mathrm{E}+04$ \\ $116.6892 .77866 \mathrm{E}+03 \quad 1 \quad 1.0000$ \\ $3092238293.00 \quad 00.00 .00 .02 .64776 \mathrm{E}-03 \quad 1235.0441 .76985 \mathrm{E}+02$ \\ $1234.3702 .28531 \mathrm{E}+0011.0000$ \\ $4092238293.00 \quad 00.00 .00 .04 .65936 \mathrm{E}-041235.044$ 1.05963E+03 \\ $1234.3291 .49116 \mathrm{E}+01 \quad 1 \quad 1.0000$ \\ $5092238293.00 \quad 00.00 .00 .09 .95504 \mathrm{E}-05 \quad 1 \quad 1.008$ 1.23941E+04 \\ $1 \quad 17.8681 .50367 \mathrm{E}+03 \quad 1 \quad 1.0000$ \\ $6092238293.00 \quad 00.00 .00 .09 .95504 \mathrm{E}-05 \quad 1 \quad 1.008 \quad 1.23941 \mathrm{E}+04$ \\ $117.4271 .56716 \mathrm{E}+03 \quad 1 \quad 1.0000$ \\ $7092238293.00 \quad 00.00 .00 .02 .35521 \mathrm{E}-05 \quad 1 \quad 1.0085 .67151 \mathrm{E}+04$ \\ $1 \quad 16.4485 .56657 \mathrm{E}+03 \quad 1 \quad 1.0000$ \\ $8092238293.00 \quad 00.00 .00 .09 .92356 \mathrm{E}-05 \quad 1 \quad 1.008$ 1.24377E+04 \\ $117.8621 .50767 \mathrm{E}+03 \quad 1 \quad 1.0000$ \\ $9092238293.00 \quad 00.00 .00 .01 .18834 \mathrm{E}-03 \quad 1 \quad 1.0081 .05690 \mathrm{E}+03$ \\ $116.2451 .13160 \mathrm{E}+02 \quad 1 \quad 1.0000$ \\ $16092238293.00 \quad 00.00 .00 .02 .73631 \mathrm{E}-03 \quad 1235.0441 .71798 \mathrm{E}+02$ \\ $1234.1101 .88805 \mathrm{E}+00111.0000$ \\ $17092238293.00 \quad 29.14400 \mathrm{E}+00$ 4.10601E-03 3.30200E+00 4.71245E-02 \\ $1235.0442 .11511 \mathrm{E}-01 \quad 1235.5388 .65905 \mathrm{E}-04 \quad 1 \quad 1.0000$ \\ $20092238293.0015 .84200 \mathrm{E}+001.00000 \mathrm{E}+000.00000 \mathrm{E}+004.71245 \mathrm{E}-02$ \\ $1235.0442 .11511 \mathrm{E}-01 \quad 1235.5388 .65905 \mathrm{E}-04 \quad 1 \quad 1.0000$ \\ $1092234293.00 \quad 00.00 .00 .04 .82717 \mathrm{E}-04 \quad 1235.0449 .74421 \mathrm{E}+02$ \\ I $237.9634 .77791 \mathrm{E}+01 \quad 1 \quad 1.0000$ \\ $2092234293.00 \quad 00.00 .00 .01 .06784 \mathrm{E}-05 \quad 1 \quad 1.0081 .10414 \mathrm{E}+05$ \\ $116.7271 .61556 \mathrm{E}+0411.0000$ \\ $3092234293.00 \quad 00.00 .00 .04 .80915 E-04 \quad 1235.0449 .74422 E+02$ \\ $1237.9634 .77791 \mathrm{E}+01111.0000$ \\ $4092234293.00 \quad 00.00 .00 .05 .65802 \mathrm{E}-04 \quad 1235.044$ 8.72604E+02 \\ $1237.6348 .61464 \mathrm{E}+0011.0000$
}

NUREG/CR-0200,

Vol. 2, Rev. 5

F17.D.44 


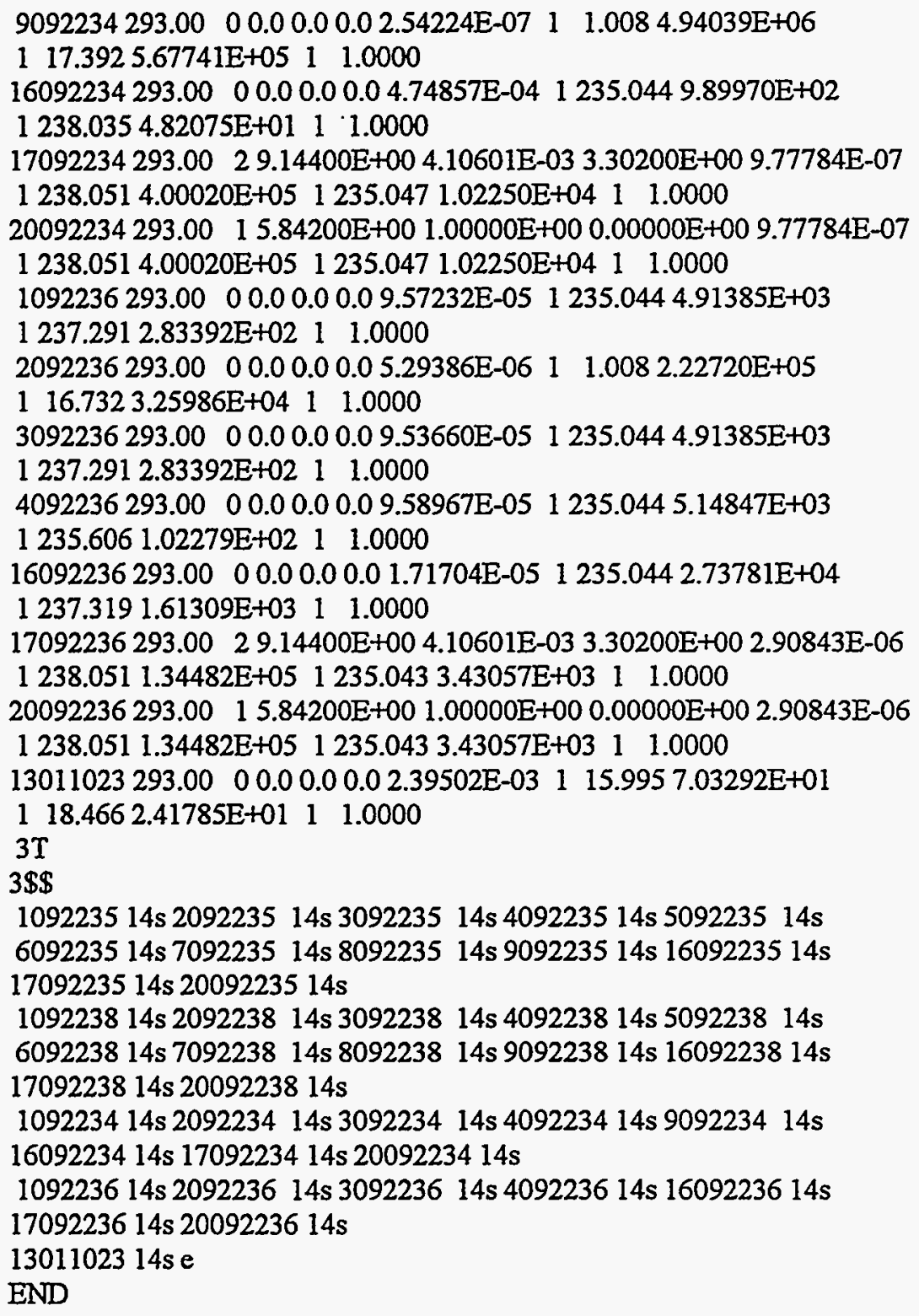

\section{F17.D.3 REFERENCES}

1. J. T. Thomas, "Critical Three-Dimensional Arrays of U(93.2)-Metal Cylinders," Nucl. Sci. Eng. 52, 350 (November 1973).

2. G. E. Whitesides and J. T. Thomas, "The Use of Differential Current Albedos in Monte Carlo Criticality Calculations," Trans. Am. Nucl. Soc. 12, 889 (November 1969).

3. J. T. Thomas, Critical Three-Dimensional Arrays of Neutron-Interacting Units, Part II, ORNL/TM868, Union Carbide Corp., Nucl. Div., Oak Ridge Natl. Lab. (July 1964). 
4. D. C. Irving and J. T. Mihalczo, "Monte Carlo Calculations for Enriched Uranium Metal Assemblies," Trans. Am. Nucl. Soc. 7, 284 (November 1964).

5. Cleo C. Byers et al., "Critical Measurements of a Water-Reflected Enriched Uranium Sphere," Trans. Am. Nucl. Soc. 27, 412 (November 1977).

6. J. T. Thomas, Critical Three-Dimensional Arrays of Neutron-Interacting Units, ORNL/TM-719, Union Carbide Corp., Nucl. Div., Oak Ridge Natl. Lab., 1963.

7. J. K. Fox, L. W. Gilley, D. Callihan, Critical Mass Studies, Part IX Aqueous U-235 Solutions, ORNL2367, Union Carbide Corp., Nucl. Div., Oak Ridge Natl. Lab., February 1958.

8. D. F. Cronin, Critical Mass Studies, Part XUranium of Intermediate Enrichment, ORNL-2968, Union Carbide Corp., Nucl. Div., September 1960. 


\section{F17.E SELECTED OUTPUT FROM KENO V.a SAMPLE PROBLEMS}

The computer output on the following pages is an example of the output for sample problems 4 and 19 described in Sect. F17.D. 

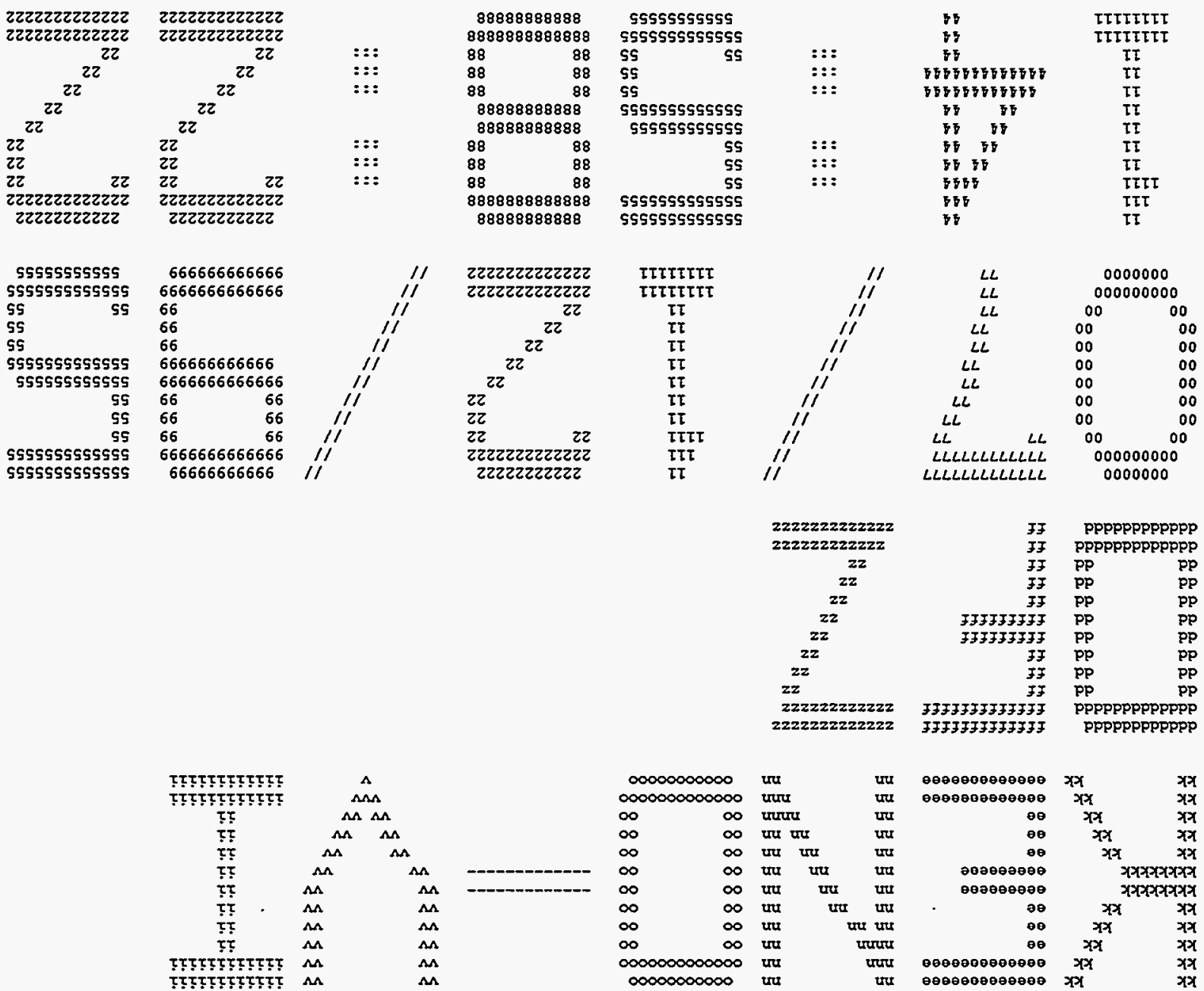


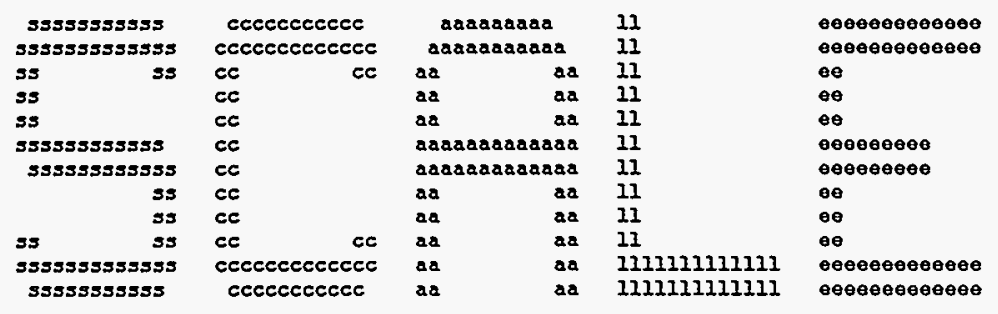

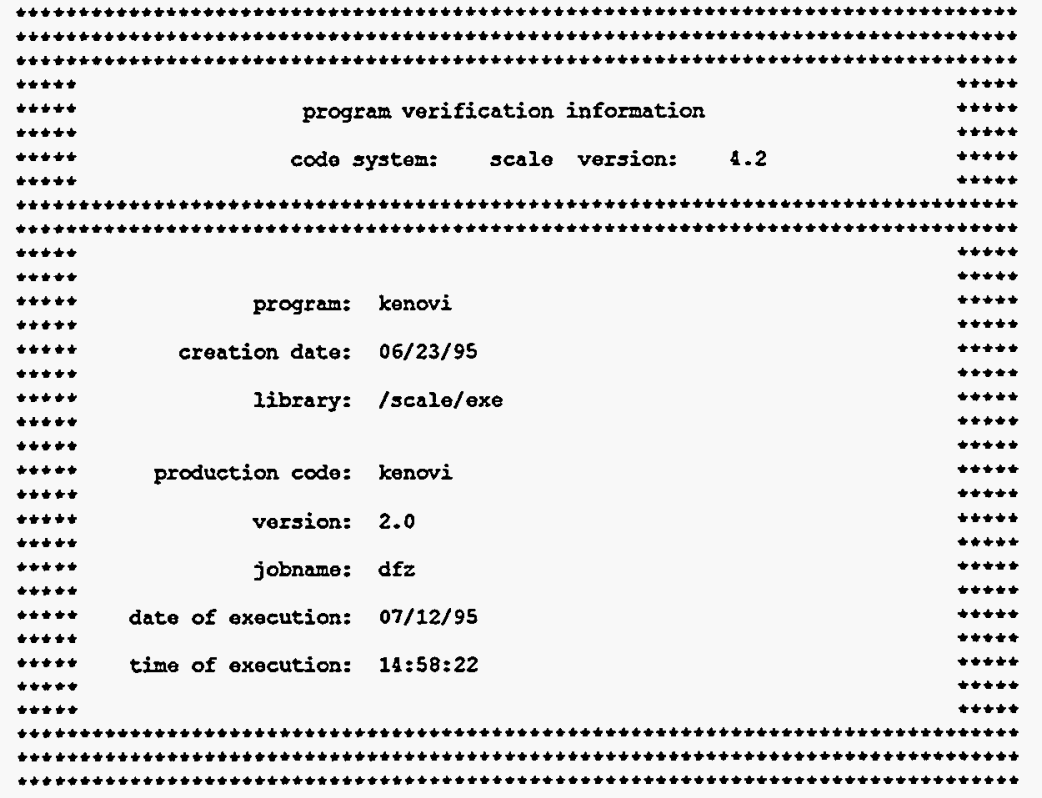




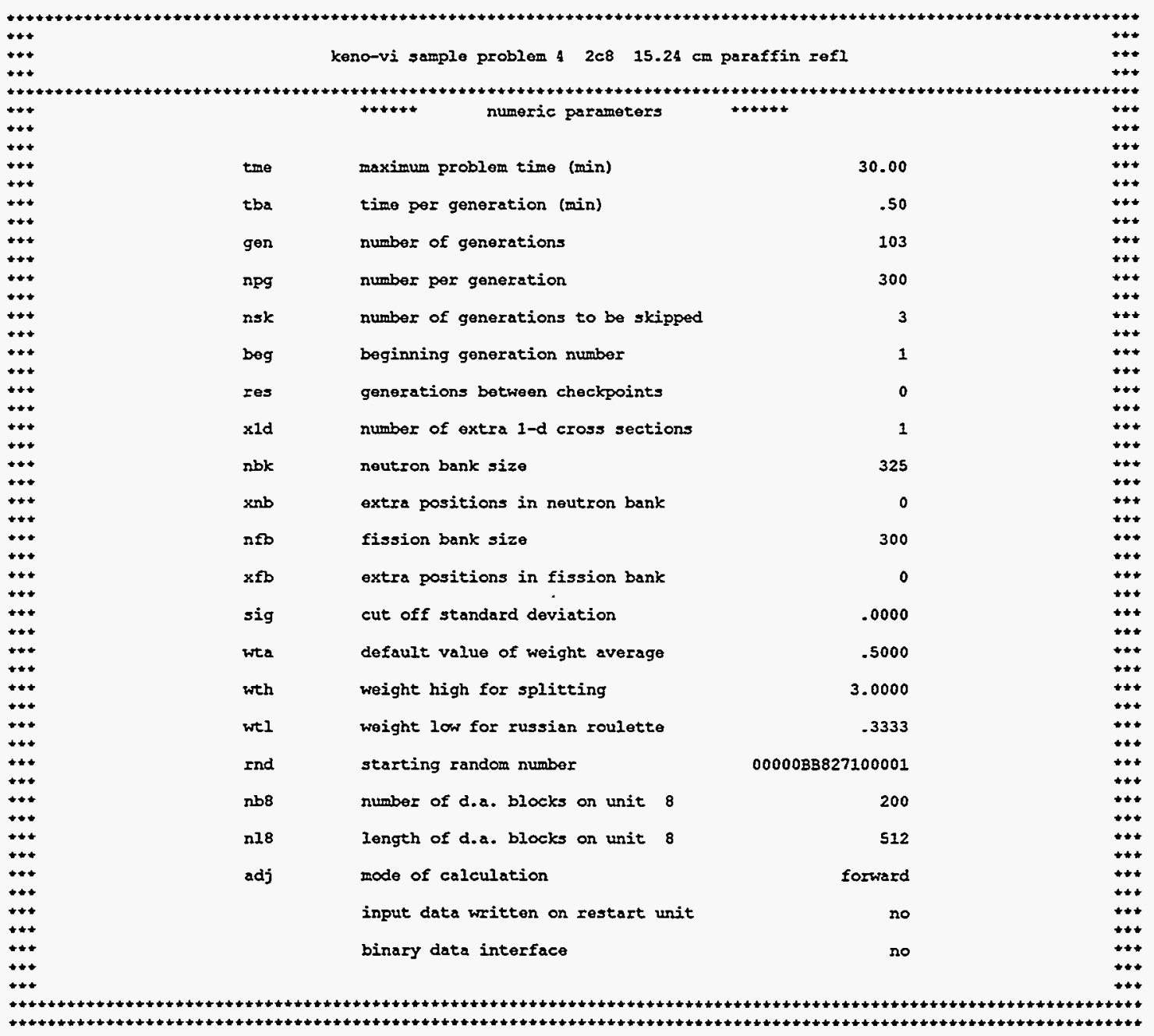

NUREG/CR-0200,

Vol. 2, Rev. 5
F17.E.4 


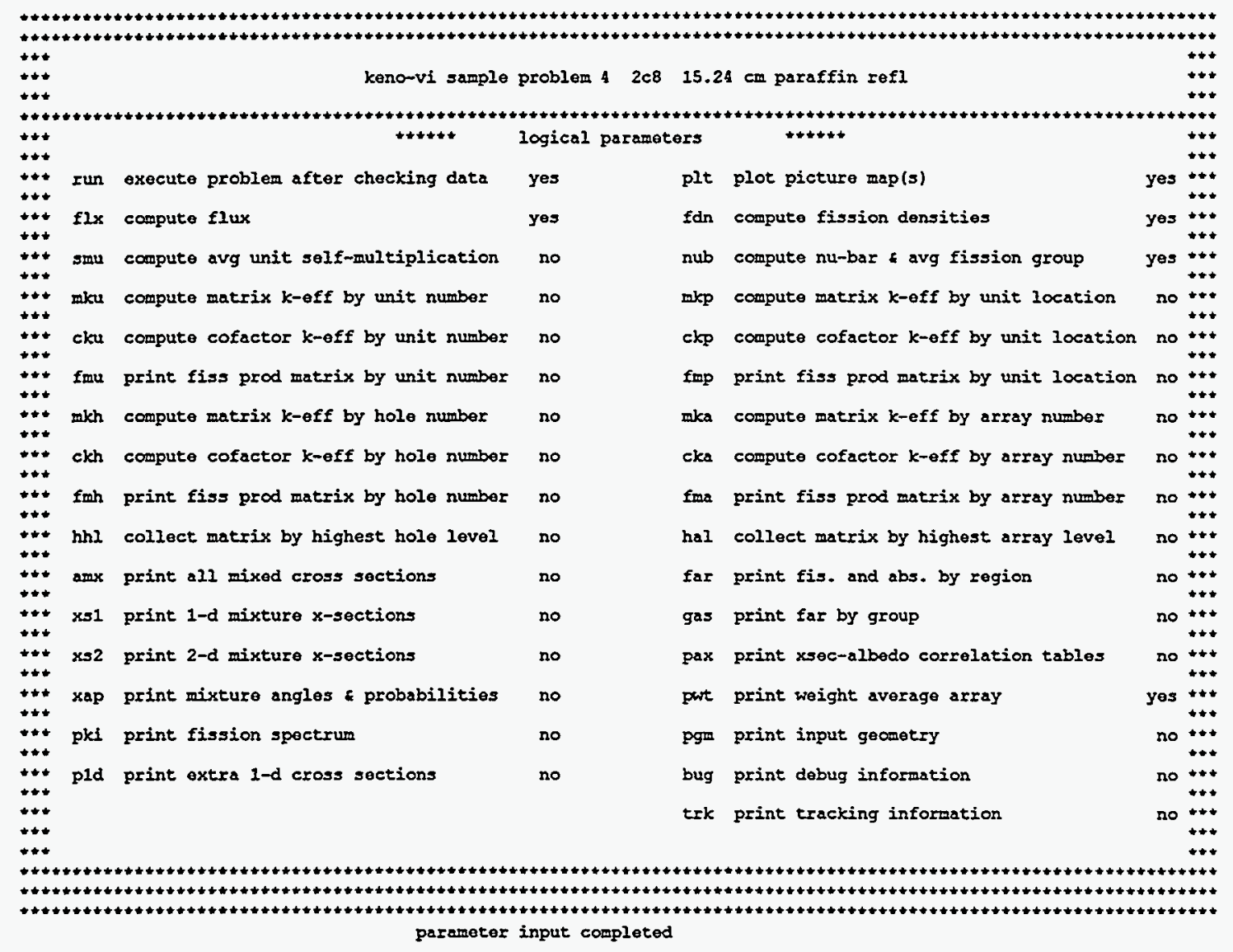

....... 0 io's were used reading the parameter data $\quad . . . .$.

$t+t+t+t+t+t+t+$ data reading completed $+t+t+t+t+t+t+t+$ 


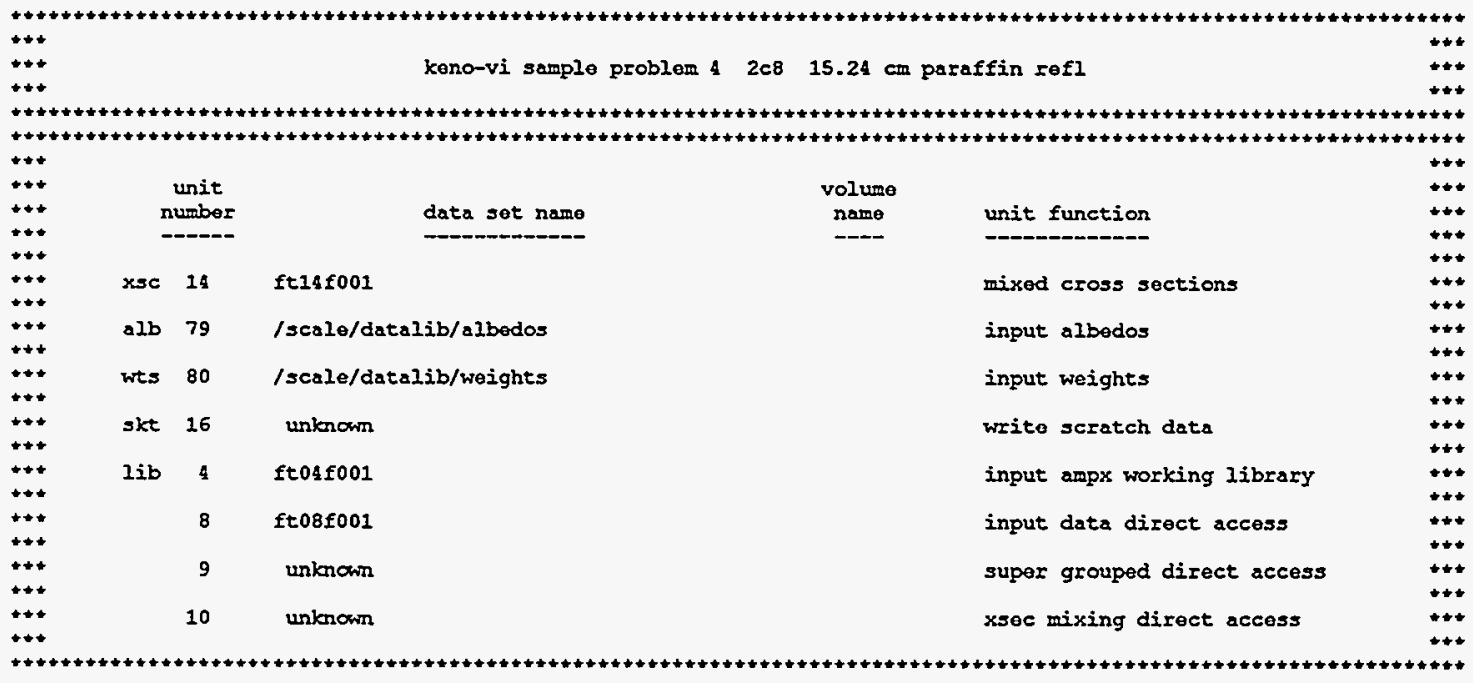

....... 0 io's were used preparing input data $\quad \ldots \ldots \ldots$

cross sections read from the ampx working library on unit 4 
keno-vi sample problem $42 c 8 \quad 15.24 \mathrm{~cm}$ paraffin refl

wixing table

number of scattering angles $=2$

cross section message threshold $=3.0 \mathrm{E}-05$

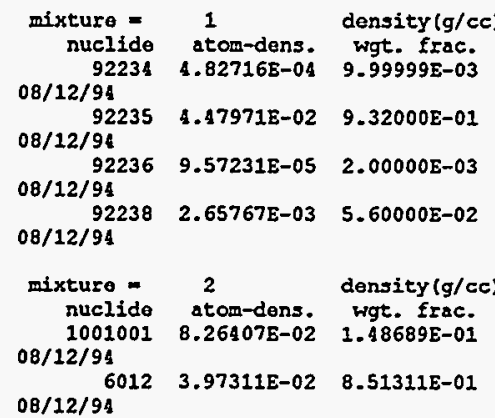

$92238 \quad 2.65767 \mathrm{E}-03 \quad 5.60000 \mathrm{E}-02$ $08 / 12 / 94$

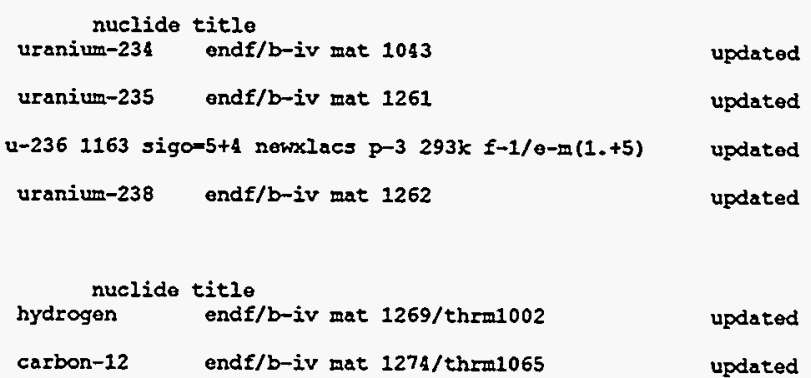

updated

updated

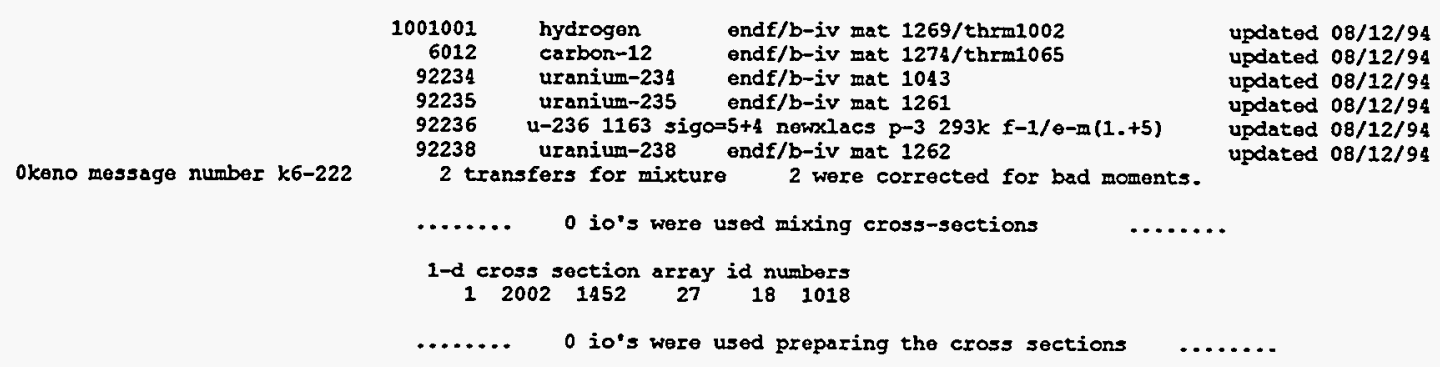




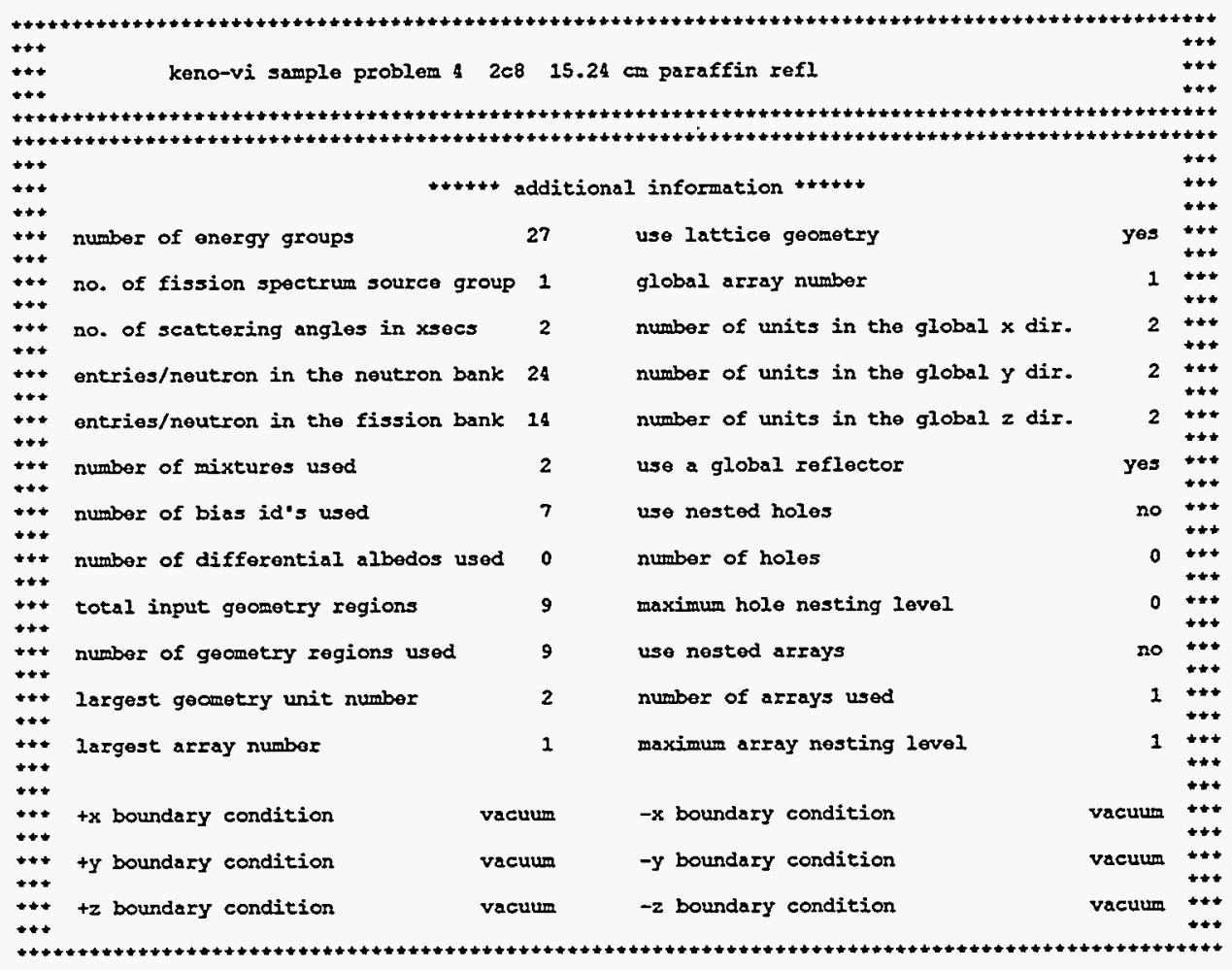

NUREG/CR-0200,

Vol. 2, Rev. 5

F17.E. 8 


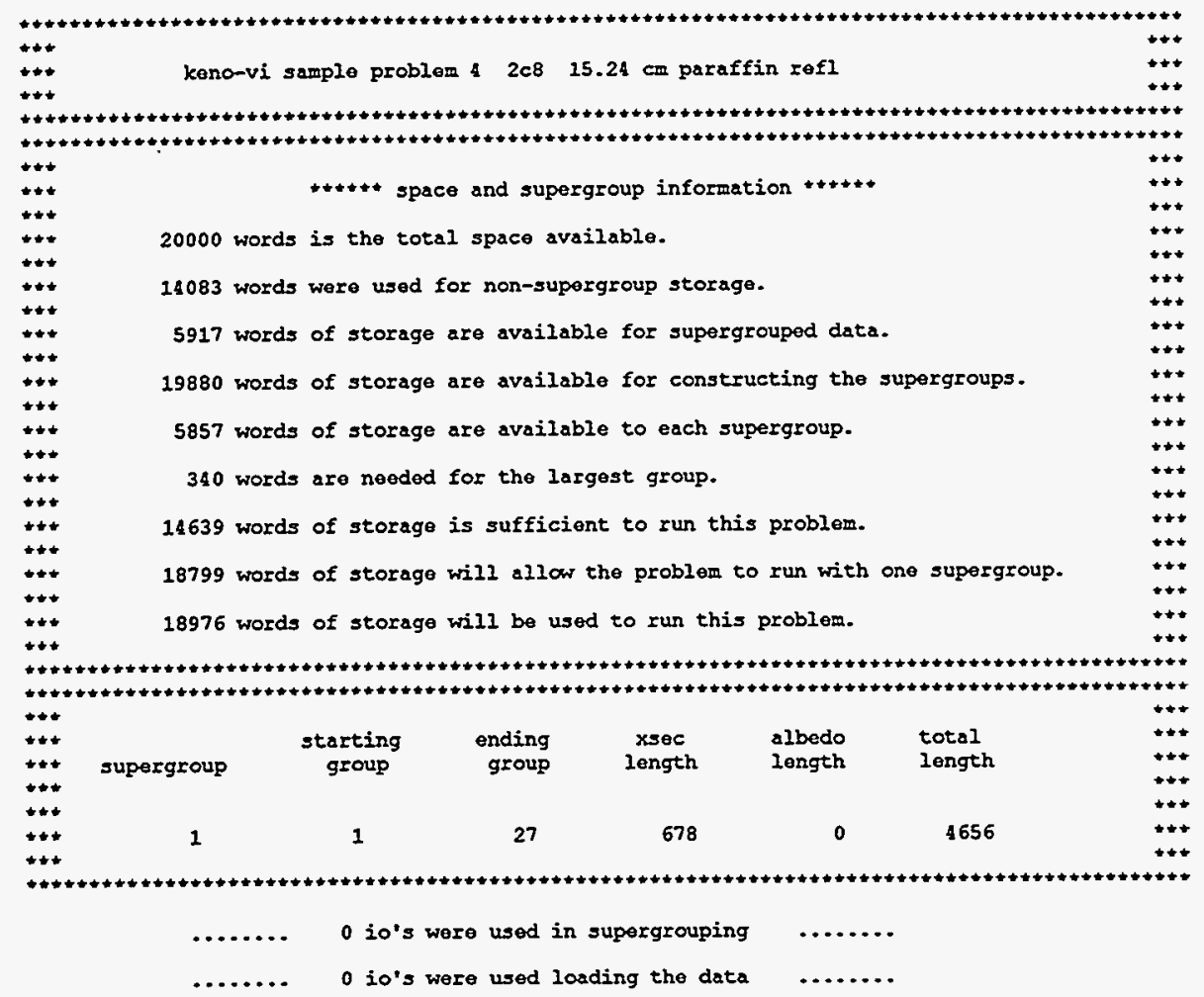




\begin{tabular}{|c|c|c|c|c|}
\hline$++\downarrow$ & & & & ++ \\
\hline$\cdots$ & $+\infty+\infty$ & $+\infty+$ & & $+\infty$ \\
\hline$+\infty$ & & geometry parameters & & $\pitchfork+$ \\
\hline$t+$ & & & & $\#+t$ \\
\hline+ & & & & $+\star$ \\
\hline$\infty$ & $\boldsymbol{\Omega I a I}$ & number of independent array references & 1 & +4 \\
\hline$+\star$ & ngblu & globsl unit number & 2 & 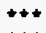 \\
\hline$t+t$ & & & & $\star+$ \\
\hline$\stackrel{+\infty}{+\infty}$ & nboxt & number of wits in the problem & 2 & $+\infty$ \\
\hline 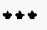 & nquad & number of quadratics in the problem & 26 & $\pitchfork+$ \\
\hline$+*$ & & & & $\pm+t$ \\
\hline$+*$ & ngwrds & number of geometry words read & 9 & $+t$ \\
\hline++ & maxald & maximum qeomety words in a unit & 7 & $\star+$ \\
\hline +t+ & & & & $+t$ \\
\hline$+*$ & maxsfu & largest number of surfaces in a unit & 21 & $\star *$ \\
\hline$\ldots$ & $\operatorname{maxreg}$ & largest number of modia in a unit & 7 & + \\
\hline$\star+$ & & 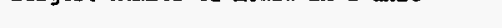 & & $\pitchfork+$ \\
\hline$t+t$ & regtot & number of spatial volumes defined & 9 & $+*$ \\
\hline 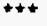 & & & & 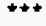 \\
\hline$+\infty$ & sectot & number of entries in the sector array & 53 & $+\infty$ \\
\hline W & & & & 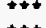 \\
\hline$+\infty$ & nuccm & number of coments in the geometry data & 2 & $\stackrel{++\infty}{++\infty}$ \\
\hline$+\infty$ & numbol & number of holes in the problem & 0 & $\leftarrow+$ \\
\hline
\end{tabular}

NUREG/CR-0200,

Vol. 2, Rev. 5 
keno-vi sample problem $42 c 8 \quad 15.24$ cm paraffin refl

geometry description for those units utilized in this problem

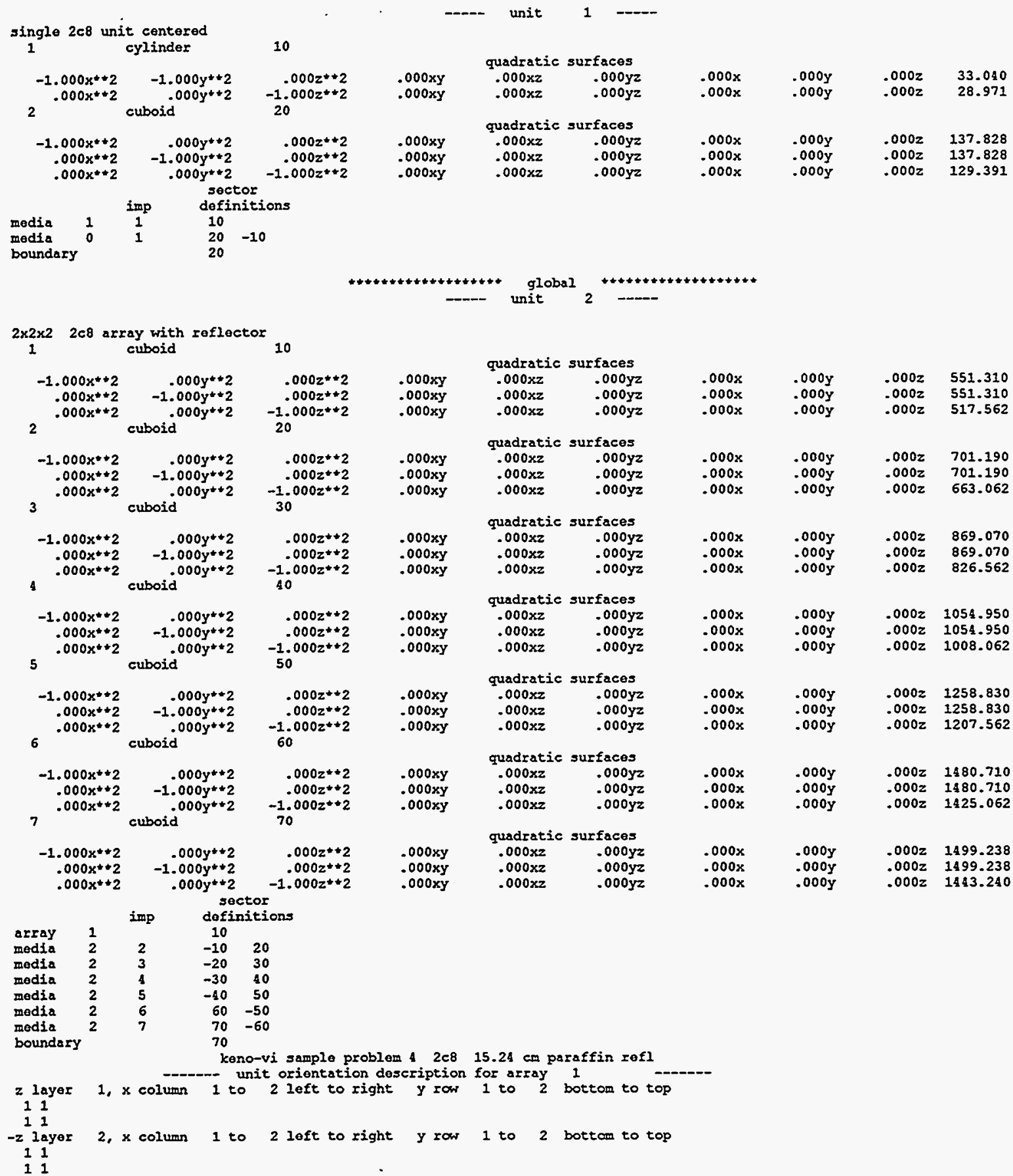

F17.E.11 


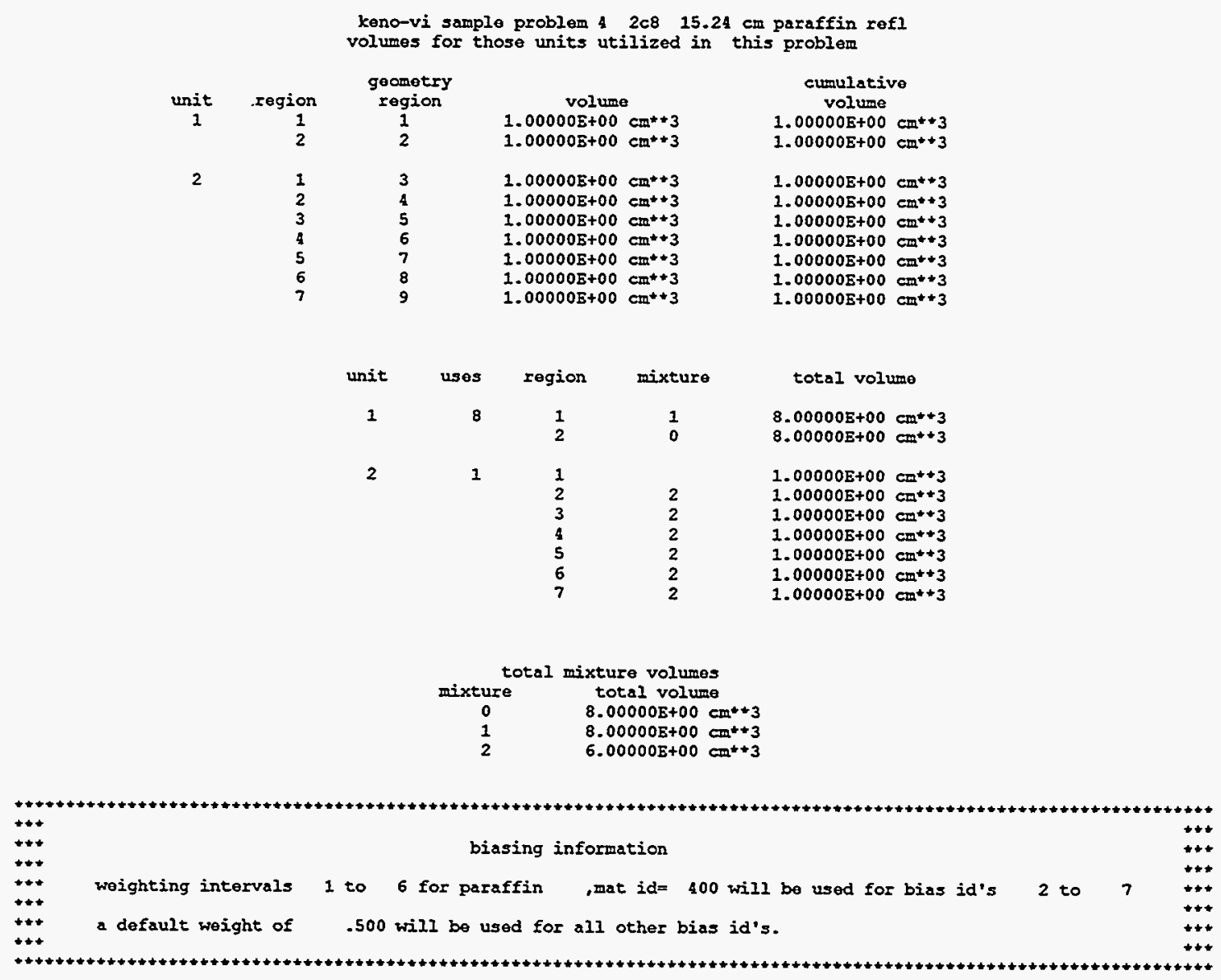

NUREG/CR-0200,

Vol. 2, Rev. 5

F17.E.12 
keno-vi sample problem $42 c 8 \quad 15.24$ cm paraffin refl

group dependent weights

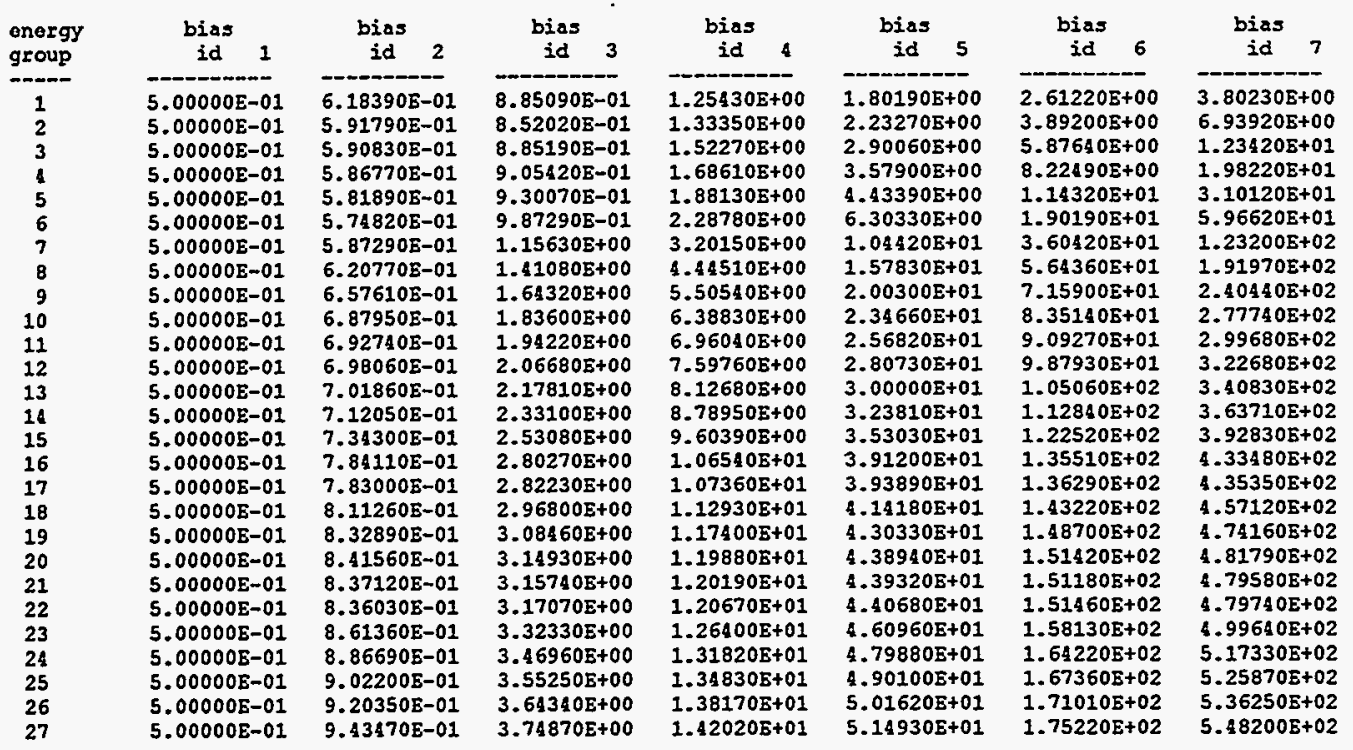

....... 0 io's were used in keno-v before tracking $\quad . . . . .$.

....... .00000minutes were used processing data.

volume fraction of fissile material in the system $.36364 \mathrm{E}+00$

start type 0 was used.

the neutrons were started with a flat distribution in a cuboid defined by:

$+x=3.87200 E+01-x=-3.87200 E+01+y=3.87200 E+01-y=-3.87200 E+01+z=3.79900 E+01-z=-3.79900 E+01$

.02133 minutes wore required for starting. total elapsed time is .02133 minutes.

F17.E.13

NUREG/CR-0200,

Vol. 2, Rev. 5 
keno-vi sample problem $42 c 8 \quad 15.24$ cm paraffin refl

\begin{tabular}{|c|c|c|c|}
\hline neration & $\underset{\text { genfertion }}{\text { generation }}$ & $\begin{array}{l}\text { elapsed time } \\
\text { minutes }\end{array}$ & $\begin{array}{c}\text { average } \\
k \text {-effective }\end{array}$ \\
\hline 1 & $1.05232 \mathrm{E}+00$ & $6.400005-02$ & $1.00000 \mathrm{E}+00$ \\
\hline 2 & $1.03003 E+00$ & $1.28000 E-01$ & $1.00000 \mathrm{E}+00$ \\
\hline 3 & $1.02401 \mathrm{E}+00$ & $1.92000 \mathrm{E}-01$ & $1.02401 \mathrm{E}+00$ \\
\hline 4 & $9.74890 \mathrm{E}-01$ & $2.13333 E-01$ & $9.99448 \mathrm{E}-01$ \\
\hline 5 & $1.02300 \mathrm{E}+00$ & $2.77333 E-01$ & $1.00730 \mathrm{E}+00$ \\
\hline 6 & $1.02899 E+00$ & $3.41333 E-01$ & $1.01272 E+00$ \\
\hline 7 & $9.791245-01$ & $3.84000 \mathrm{E}-01$ & $1.00600 \mathrm{E}+00$ \\
\hline 8 & $1.03230 E+00$ & $4.48000 E-01$ & $1.01038 \mathrm{E}+00$ \\
\hline 9 & $1.06259 \mathrm{E}+00$ & $5.12000 \mathrm{E}-01$ & $1.01784 \mathrm{E}+00$ \\
\hline 10 & $1.01395 E+00$ & $5.76000 \mathrm{E}-01$ & $1.01736 \mathrm{E}+00$ \\
\hline 11 & $9.02205 E-01$ & $6.18667 \mathrm{E}-01$ & $1.00456 \mathrm{E}+00$ \\
\hline 12 & $1.002245+00$ & $6.61333 \vec{b}-01$ & $1.00433 \mathrm{E}+00$ \\
\hline 13 & $9.62315 \mathrm{E}-01$ & $7.25333 \mathrm{E}-01$ & $1.00051 \mathrm{E}+00$ \\
\hline 14 & $9.77535 \mathrm{E}-01$ & $7.89333 \mathrm{E}-01$ & $9.98596 \mathrm{E}-01$ \\
\hline 15 & $9.46200 \mathrm{E}-01$ & $8.32000 E-01$ & $9.94565 \mathrm{E}-01$ \\
\hline 16 & $1.09511 E+00$ & $8.96000 \mathrm{E}-01$ & $1.00175 E+00$ \\
\hline 17 & $1.00 \$ 11.5+00$ & $9.60000 E-01$ & $1.001905+00$ \\
\hline 18 & $1.01688 E+00$ & $1.00267 \mathrm{E}+00$ & $1.002845+00$ \\
\hline 19 & $9.38776 \mathrm{E}-01$ & $1.04533 \mathrm{E}+00$ & $9.99072 \mathrm{E}-01$ \\
\hline 20 & $1.057535+00$ & $1.10933 E+00$ & $1.002325+00$ \\
\hline 21 & $1.00952 \mathrm{E}+00$ & $1.15200 \mathrm{~B}+00$ & $1.00270 \mathrm{E}+00$ \\
\hline 22 & $9.86390 \mathrm{E}-01$ & $1.19467 E+00$ & $1.00188 \mathrm{E}+00$ \\
\hline 23 & $9.47884 E-01$ & $1.25867 \mathrm{E}+00$ & $9.99312 \mathrm{E}-01$ \\
\hline 24 & $9.20649 \mathrm{E}-01$ & $1.32267 \mathrm{E}+00$ & $9.95736 \mathrm{E}-01$ \\
\hline 25 & $9.98392 \mathrm{E}-01$ & $1.36533 \mathrm{E}+00$ & $9.95852 \mathrm{E}-01$ \\
\hline 26 & $9.61672 \mathrm{E}-01$ & $1.40800 \mathrm{~B}+00$ & $9.94427 \mathrm{E}-01$ \\
\hline 27 & $9.72450 \mathrm{E}-01$ & $1.87200 \mathrm{E}+00$ & $9.93548 E-01$ \\
\hline 28 & $1.04718 E+00$ & $1.51467 E+00$ & $9.95611 \mathrm{E}-01$ \\
\hline 29 & $9.61118 E-01$ & $1.55733 \mathrm{E}+00$ & $9.94334 \mathrm{E}-01$ \\
\hline 30 & $1.01641 E+00$ & $1.62133 \mathrm{E}+00$ & $9.95122 \mathrm{E}-01$ \\
\hline 31 & $9.53034 E-0 I$ & $1.66400 \mathrm{E}+00$ & $9.93671 E-01$ \\
\hline 32 & $1.17266 \mathrm{E}+00$ & $1.70667 \mathrm{E}+00$ & $9.99637 \mathrm{E}-01$ \\
\hline 33 & $1.00927 \mathrm{E}+00$ & $1.77067 \mathrm{E}+00$ & $9.99948 \mathrm{E}-01$ \\
\hline 34 & $8.86708 \mathrm{E}-01$ & $1.81333 \mathrm{E}+00$ & $9.96409 \mathrm{E}-01$ \\
\hline 35 & $1.07850 \mathrm{E}+00$ & $1.87733 \mathrm{~B}+00$ & $9.98776 \mathrm{E}-01$ \\
\hline 36 & $9.36499 E-01$ & $1.92000 \mathrm{E}+00$ & $9.969445-01$ \\
\hline 37 & $9.47681 E-01$ & $1.96267 \mathrm{E}+00$ & $9.95536 \mathrm{E}-01$ \\
\hline 38 & $9.69118 \mathrm{E}-01$ & $2.02667 \mathrm{~B}+00$ & $9.94803 \mathrm{E}-01$ \\
\hline 39 & $1.04915 \mathrm{E}+00$ & $2.09067 \mathrm{E}+00$ & $9.96271 \mathrm{E}-01$ \\
\hline 40 & $1.06399 \mathrm{E}+00$ & $2.133335+00$ & $9.98053 \mathrm{E}-01$ \\
\hline 41 & $1.04602 \mathrm{E}+00$ & $2.19733 \mathrm{~B}+00$ & $9.99283 \mathrm{E}-01$ \\
\hline 42 & $9.65354 \mathrm{E}-01$ & $2.24000 \mathrm{E}+00$ & $9.98435 \mathrm{E}-01$ \\
\hline 43 & $9.73261 \mathrm{E}-01$ & $2.304005+00$ & $9.97821 E-01$ \\
\hline 44 & $1.06292 \mathrm{E}+00$ & $2.34667 \mathrm{E}+00$ & $9.993715-01$ \\
\hline 45 & $9.55318 \Sigma-01$ & $2.36933 \mathrm{E}+00$ & $9.98346 \mathrm{E}-01$ \\
\hline 46 & $1.06056 \mathrm{E}+00$ & $2.47467 \mathrm{E}+00$ & $9.99760 \mathrm{E}-01$ \\
\hline 47 & $1.03734 \mathrm{E}+00$ & $2.538675+00$ & $1.00060 \mathrm{E}+00$ \\
\hline 48 & $1.06522 \mathrm{E}+00$ & $2.581335+00$ & $1.00200 \mathrm{E}+00$ \\
\hline 49 & $9.893115-01$ & $2.624005+00$ & $1.00173 \mathrm{E}+00$ \\
\hline 50 & $1.074205+00$ & $2.688005+00$ & $1.00324 E+00$ \\
\hline 51 & $1.01924 \mathrm{~B}+00$ & $2.752005+00$ & $1.00357 \mathrm{E}+00$ \\
\hline 52 & $1.06604 \mathrm{~B}+00$ & $2.79467 \mathrm{E}+00$ & $1.00482 \mathrm{E}+00$ \\
\hline 53 & $1.04927 \mathrm{E}+00$ & $2.85867 \mathrm{~B}+00$ & $1.00569 \mathrm{E}+00$ \\
\hline 54 & $9.90373 \mathrm{E}-01$ & $2.944005+00$ & $1.005395+00$ \\
\hline 55 & $9.96628 \mathrm{E}-01$ & $2.98667 \mathrm{E}+00$ & $1.00523 E+00$ \\
\hline 56 & $9.35001 E-01$ & $3.05067 \mathrm{E}+00$ & $1.00393 E+00$ \\
\hline 57 & $9.95944 \mathrm{E}-01$ & $3.09333 \mathrm{~B}+00$ & $1.003785+00$ \\
\hline 58 & $1.10795 \mathrm{E}+00$ & $3.15733 E+00$ & $1.00564 \mathrm{E}+00$ \\
\hline 59 & $1.050065+00$ & $3.20000 \mathrm{E}+00$ & $1.00642 \mathrm{E}+00$ \\
\hline 60 & $9.19054 \mathrm{E}-01$ & $3.242675+00$ & $1.00492 E+00$ \\
\hline 61 & $9.65863 \mathrm{E}-01$ & $3.30667 \mathrm{E}+00$ & $1.004255+00$ \\
\hline 62 & $9.52853 \mathrm{E}-01$ & $3.37067 \mathrm{E}+00$ & $1.00340 \mathrm{E}+00$ \\
\hline 63 & $9.70607 \mathrm{E}-01$ & $3.41333 \mathrm{E}+00$ & $1.00286 \mathrm{E}+00$ \\
\hline 64 & $1.08541 \mathrm{E}+00$ & $3.47733 E+00$ & $1.00419 \mathrm{E}+00$ \\
\hline 65 & $1.01429 E+00$ & $3.54133 \mathrm{E}+00$ & $1.00435 E+00$ \\
\hline 66 & $9.28092 \mathrm{E}-01$ & $3.60533 \mathrm{E}+00$ & $1.00316 \mathrm{~B}+00$ \\
\hline 67 & $1.01887 \mathrm{E}+00$ & $3.66933 \mathrm{E}+00$ & $1.00340 \mathrm{~B}+00$ \\
\hline 68 & $1.02995 \mathrm{~B}+00$ & $3.71200 \mathrm{~s}+00$ & $1.00380 \mathrm{~s}+00$ \\
\hline 69 & $1.01593 \mathrm{E}+00$ & $3.75467 E+00$ & $1.00398 \mathrm{E}+00$ \\
\hline 70 & $1.08576 E+00$ & $3.81867 \mathrm{E}+00$ & $1.00519 \mathrm{E}+00$ \\
\hline 71 & $9.36529 E-01$ & $3.86133 E+00$ & $1.00419 B+00$ \\
\hline 72 & $1.03625 \mathrm{E}+00$ & $3.92533 \mathrm{E}+00$ & $1.004655+00$ \\
\hline 73 & $9.84095 \mathrm{E}-01$ & $3.98933 \mathrm{~B}+00$ & $1.00436 E+00$ \\
\hline 74 & $9.38039 \mathrm{E}-01$ & $4.01067 \mathrm{E}+00$ & $1.00344 \mathrm{E}+00$ \\
\hline 75 & $1.00237 \mathrm{E}+00$ & $1.074675+00$ & $1.00342 \mathrm{E}+00$ \\
\hline 76 & $1.04787 E+00$ & $4.13867 \mathrm{E}+00$ & $1.00403 E+00$ \\
\hline 77 & $9.60502 \mathrm{E}-01$ & $4.18133 \mathrm{E}+00$ & $1.00344 \mathrm{E}+00$ \\
\hline 78 & $9.76534 \mathrm{E}-01$ & $4.22400 E+00$ & $1.00309 \mathrm{E}+00$ \\
\hline 79 & $9.30093 \mathrm{E}-01$ & $4.30933 \mathrm{E}+00$ & $1.00214 \mathrm{E}+00$ \\
\hline 80 & $9.69117 \mathrm{E}-01$ & $4.352005+00$ & $1.00172 E+00$ \\
\hline 81 & $1.04409 E+00$ & $4.39467 \mathrm{E}+00$ & $1.00226 \mathrm{E}+00$ \\
\hline 82 & $8.846575-01$ & $4.45867 \mathrm{E}+00$ & $1.00079 \mathrm{E}+00$ \\
\hline 83 & $1.10813 E+00$ & $4.50133 E+00$ & $1.00211 E+00$ \\
\hline
\end{tabular}

avg $k$-eff

$0.000005+00$

0.00000 E +00

$0.00000 E+00$

$2.45582 \mathrm{E}-02$

1.62072E-02

1.62072802

1. 26783E-02

$1.18994 \mathrm{E}-02$

$1.16950 \mathrm{z}-02$

$1.01399 \mathrm{E}-02$

$1.56100 \mathrm{~S}-02$

1. $396395-02$

1.31957E-02

$1.219725-02$

$1.19217 \mathrm{E}-02$

$1.31684 \mathrm{E}-02$

$1.22601 \mathrm{E}-02$

$1.15064 \mathrm{E}-02$

$1.15064 \mathrm{z}-02$

$1.14665 \mathrm{E}-02$

$1.12699 \mathrm{E}-02$

$1.06670 \mathrm{~B}-02$

$1.01524 \mathrm{E}-02$
$9.99337 \mathrm{E}-03$

$1.01771 \mathrm{E}-02$

$9.72524 \mathrm{E}-03$

9.41950E-03

9.07753E-03

$8.96207 E-03$

$8.71787 \mathrm{~B}-03$

$8.43767 \mathrm{~B}-03$

$8.43767 \mathrm{~B}-03$
$8.26986 \mathrm{~B}-03$

9.97139B-03

9.64937E-03

$9.99069 \mathrm{E}-03$

$9.96814 \mathrm{E}-03$

9.84245E-03

$9.66019 \mathrm{E}-03$

9.41666 -03

$9.27565 \mathrm{E}-03$

$9.20244 \mathrm{E}-03$

$9.04735 E-03$

$8.85896 \mathrm{E}-0$

8. $66198 \mathrm{~B}-03$

8.59413E-03

$8.45420 \mathrm{E}-03$

8.37995E-03

8.23408E-03

$8.174705-03$

80345-03

$8.00344 \mathrm{E}-03$

$7.97905 \mathrm{~B}-03$

7. 821345-03

7.764515-03

7. $66050 \mathrm{E}-03$

$7.517515-03$

$7.376165-03$

7.35418E-03

7.220695-03

$7.330535-03$

$7.33053 \mathrm{E}-03$

7.242825-03

$7.27452 \mathrm{E}-03$

$7.18073 \mathrm{E}-03$
$7.11182 \mathrm{E}-03$

$7.11182 \mathrm{E}-03$
$7.01489 \mathrm{E}-03$

$7.02809 \mathrm{E}-03$

$6.917495-03$

$6.912025-03$

$6.80914 E-03$

$6.71723 \mathrm{E}-03$

$6.61869 \mathrm{E}-03$

6.63061E-03

$6.60914 \mathrm{E}-03$

$6.53012 \mathrm{E}-03$

$6.44400 \mathrm{E}-03$

6.420295-03

$6.33175 E-03$

$6.27 \$ 41 E-03$

6. $21733 \mathrm{E}-03$

$6.14518 \mathrm{E}-03$

$6.13850 E-03$

$6.07406 \mathrm{E}-03$

6. 02062E-03

$6.12393 \mathrm{E}-03$
$6.19136 \mathrm{E}-03$ matri

-effective

$.00000 \mathrm{E}+00$

$0.00000 \mathrm{~B}+00$

$0.00000 \mathrm{E}+00$

$0.00000 \mathrm{E}+00$

$0.00000 \mathrm{E}+00$

$00000+00$

$0.0000 E+00$

$.00000 E+00$

$0.00000 \mathrm{E}+00$

$0.00000 E+00$

$.00000 E+00$

$.00000 \mathrm{E}+00$

$0.00000 \mathrm{E}+00$

$0.00000 E+00$

$0.00000 E+00$

$0.000005+00$

.00000E+00

$0.00000 E+00$

.00000 Bt00

$.00000 E+00$

$0.00000 E+00$

$.000005+00$

$0.00000 \mathrm{E}+00$

$0.00000 \mathrm{E}+00$

$0.00000 \mathrm{E}+00$

$0.00000 \mathrm{E}+00$

00000

.00000E+00

.

$0.000005+00$

$.00000 E+00$

$.00000 \mathrm{E}+00$

$0.00000 E+00$

$.00000 \mathrm{E}+00$

$0.00000 E+00$

$0.00000 \mathrm{E}+00$

$0.00000 \mathrm{E}+00$

$.00000 \mathrm{E}+00$

$.00000 \mathrm{~B}+00$

$0.00000 B+00$

$0.00000 \mathrm{E}+00$

$0.000005+00$

$0.00000 \mathrm{E}+00$

$0.00000 E+00$

$0.00000 \mathrm{E}+00$

$0.00000 \mathrm{E}+00$

$0.000005+00$

$0.00000 E+00$

.0000

.0000E+00

$0.000005+00$

$0.00000 \mathrm{E}+00$

$0.00000 \mathrm{E}+00$

$0.000008+00$

$0.00000 E+00$

$0.00000 E+00$

$0.000008+00$

$0.00000+00$

$0.00000 E+00$

$0.00000 E+00$

$0.00000 E+00$

$0.00000 \mathrm{E}+00$

$0.00000 \mathrm{E}+00$

$0.00000 \mathrm{E}+00$

$0.000008+00$

$0.000005+00$

$0.00000 E+00$

$0.00008+00$

$0.0000 \mathrm{E}+00$

$0.00000 \mathrm{E}+00$

$0.00000 \mathrm{E}+0$

$0.00000 \mathrm{E}+00$

$0.00000 \mathrm{E}+00$

$0.00000 \mathrm{E}+00$

$0.00000 E+00$

$0.00000 E+00$

$0.00000 E+00$

$0.00000 \mathrm{E}+00$

$0.0000 \mathrm{~B}+00$

$0.0000 \mathrm{E}+00$

$0.00000 E+00$

$0.00000 E+00$

$0.00000 E+00$
$0.00000 E+00$ ratrix k-eff

doviation

$0.000005+00$

$0.00000 \mathrm{E}+00$

$0.00000 E+00$

$0.00000 E+00$

$0.00000 E+00$

$0.00000 \mathrm{~B}+00$

$0.00000 \mathrm{E}+00$

$0.00000 \mathrm{~B}+00$

$0.00000 E+00$

$0.00000 \mathrm{E}+00$

$0.00000 E+0.0$

$0.00000 \mathrm{E}+00$

$0.00000 \mathrm{E}+00$

$0.00000 E+00$

$0.00000 \mathrm{~B}+00$

$0.00000 \mathrm{E}+00$

$0.00000 \mathrm{E}+00$

$0.00000 E+00$

$0.00000 \mathrm{E}+00$

$0.00000 E+00$

$0.00000 E+00$

$0.00000 E+00$

$0.00000 \mathrm{~B}+00$

$0.00000 \mathrm{E}+00$

$0.00000 \mathrm{E}+00$

$0.00000 E+00$

$0.00000 \mathrm{E}+00$

$0.00000 \mathrm{E}+00$

$0.00000 \mathrm{E}+00$

$0.00000 \mathrm{E}+00$

$0.00000 E+00$

$0.000005+00$

$0.00000 E+00$

$0.00000 \mathrm{E}+00$

$0.00000 E+00$

$0.00000 E+00$

$0.000005+00$

$0.00000 E+00$

$0.00000 \mathrm{E}+00$

$0.00000 \mathrm{E}+00$

$0.00000 \mathrm{E}+00$

$0.00000 E+00$

$0.00000 E+00$

$0.00000 \mathrm{E}+00$

$0.00000 E+00$

$0.00000 E+00$

$0.00000 E+00$

$0.00000 E+00$

$0.00000 E+00$

$0.00000 E+00$

$0.00000 E+00$

$0.00000 E+00$

$0.00000 E+00$

$0.00000 \mathrm{E}+00$

$0.00000 E+00$

$0.00000 E+00$

$0.000005+00$

$0.00000 E+00$

$0.00000 \mathrm{E}+00$

$0.00000 E+00$

$0.00000 E+00$

$0.000005+00$

$0.00000 \Sigma+00$

$0.000008+00$

$0.000008+00$

$0.00000 E+00$

$0.00000 E+00$

$0.00000 E+00$

$0.000008+00$

$0.00000 \mathrm{E}+00$

$0.00000 \mathrm{E}+00$

$0.00000 \mathrm{E}+00$

$0.00000 \mathrm{~s}+00$

$0.000008+00$

$0.00000 E+00$

$0.00000 \mathrm{~B}+00$

$0.00000 \mathrm{~B}+00$

$0.00000 \mathrm{E}+00$

$0.00000 B+00$

$0.00000 \mathrm{E}+00$

$0.00000 \mathrm{~B}+00$

$0.00000 \mathrm{E}+00$

$0.00000 \mathrm{E}+00$

NUREG/CR-0200,

Vol. 2, Rev. 5

F17.E.14 


\begin{tabular}{|c|c|c|c|c|c|c|}
\hline $\begin{array}{l}84 \\
85\end{array}$ & $\begin{array}{l}9.57290 \mathrm{E}-01 \\
9.60983 \mathrm{E}-01\end{array}$ & $\begin{array}{l}4.544005+00 \\
4.60800 \mathrm{E}+00\end{array}$ & $\begin{array}{l}1.00156 \mathrm{E}+00 \\
1.00108 \mathrm{E}+00\end{array}$ & $\begin{array}{l}6.13977 E-03 \\
6.08502 E-03\end{array}$ & $\begin{array}{l}0.00000 \mathrm{~B}+00 \\
0.00000 \mathrm{~B}+00\end{array}$ & $\begin{array}{l}0.00000 E+00 \\
0.000005+00\end{array}$ \\
\hline 86 & $1.160508+00$ & $4.67200 \mathrm{E}+00$ & $1.00297 \mathrm{E}+00$ & $6.30458 \mathrm{E}-03$ & $0.000005+00$ & $0.000005+00$ \\
\hline $\begin{array}{l}87 \\
88\end{array}$ & $\begin{array}{l}9.75571 \mathrm{E}-01 \\
1.02697 \mathrm{E}+00\end{array}$ & $\begin{array}{l}4.71467 \mathrm{E}+00 \\
4.75733 \mathrm{E}+00\end{array}$ & $\begin{array}{l}1.00265 E+00 \\
1.00293 E+00\end{array}$ & $\begin{array}{l}6.23831 E-03 \\
6.17182 E-03\end{array}$ & $\begin{array}{l}0.00000 \mathrm{~B}+00 \\
0.00000 \mathrm{~B}+00\end{array}$ & $\begin{array}{l}0.00000 \mathrm{E}+00 \\
0.00000 \mathrm{E}+00\end{array}$ \\
\hline 89 & $9.38932 \mathrm{E}-01$ & $4.82133 E+00$ & $1.00220 \mathrm{E}+00$ & $6.14467 E-03$ & $0.00000 \mathrm{E}+00$ & $0.000005+00$ \\
\hline 90 & $1.03860 \mathrm{E}+00$ & $4.86400 \mathrm{E}+00$ & $1.00261 \mathrm{E}+00$ & $6.08851 E-03$ & $0.00000 \mathrm{E}+00$ & $0.00000 E+00$ \\
\hline 91 & $1.04515 E+00$ & $4.90667 \mathrm{~B}+00$ & $1.00309 \mathrm{E}+00$ & $6.03865 \mathrm{~B}-03$ & $0.00000 \mathrm{E}+00$ & $0.00000 \mathrm{~B}+00$ \\
\hline 92 & $9.97060 \mathrm{E}-01$ & $4.97067 \mathrm{E}+00$ & $1.00302 E+00$ & $5.97156 \mathrm{E}-03$ & $0.00000 \mathrm{E}+00$ & $0.00000 \mathrm{E}+00$ \\
\hline 93 & $1.04236 \mathrm{E}+00$ & $5.01333 E+00$ & $1.00345 E+00$ & $5.92137 \mathrm{E}-03$ & $0.000005+00$ & $0.000005+00$ \\
\hline 94 & $1.01219 E+00$ & $5.07733 E+00$ & $1.00355 E+00$ & $5.85743 \mathrm{E}-03$ & $0.00000 E+00$ & $0.00000 E+00$ \\
\hline 95 & $1.033878+00$ & $5.18133 E+00$ & $1.00388 E+00$ & $5.80327 \mathrm{E}-03$ & $0.00000 \mathrm{E}+00$ & $0.00000 E+00$ \\
\hline 96 & $9.71395 \mathrm{E}-01$ & $5.16267 \mathrm{E}+00$ & $1.00353 \mathrm{E}+00$ & $5.75159 \mathrm{E}-03$ & $0.00000 \mathrm{E}+00$ & $0.00000 \mathrm{E}+00$ \\
\hline 97 & $9.62189 \mathrm{~B}-01$ & $5.22667 \mathrm{E}+00$ & $1.00310 \mathrm{E}+00$ & $5.70734 \mathrm{E}-03$ & $0.00000 \mathrm{~B}+00$ & $0.00000 E+00$ \\
\hline 98 & $1.07200 \mathrm{E}+00$ & $5.29067 \mathrm{E}+00$ & $1.00381 E+00$ & $5.69300 \mathrm{E}-03$ & $0.00000 \mathrm{E}+00$ & $0.00000 \mathrm{E}+00$ \\
\hline 99 & $1.02765 \mathrm{E}+00$ & $5.33333 E+00$ & $1.00406 \mathrm{E}+00$ & $5.63936 \mathrm{E}-03$ & $0.00000 \mathrm{E}+00$ & $0.00000 \mathrm{E}+00$ \\
\hline 100 & $1.07155 \mathrm{E}+00$ & $5.37600 E+00$ & $1.00475 E+00$ & $5.62384 E-03$ & $0.00000 E+00$ & $0.00000 \mathrm{E}+00$ \\
\hline 101 & $1.05471 E+00$ & $5.44000 E+00$ & $1.00525 E+00$ & $5.58958 \mathrm{E}-03$ & $0.00000 E+00$ & $0.00000 \mathrm{~B}+00$ \\
\hline 102 & $1.01308 \mathrm{E}+00$ & $5.52533 E+00$ & $1.00533 E+00$ & $5.53395 \mathrm{E}-03$ & $0.00000 E+00$ & $0.00000 E+00$ \\
\hline 103 & $9.21325 E-01$ & $5.56800 \mathrm{E}+00$ & $1.00450 \mathrm{~B}+00$ & $5.54166 \mathrm{E}-03$ & $0.00000 \mathrm{~B}+00$ & $0.00000 \mathrm{E}+00$ \\
\hline
\end{tabular}


keno-vi sample problem $4 \quad 2 c 8 \quad 15.24 \mathrm{~cm}$ paraffin refl

lifetime $=2.68453 \mathrm{E}-04+$ or $-2.04323 \mathrm{E}-05$

nu bar $=2.56302 \mathrm{E}+00+$ or $-1.26827 \mathrm{E}-03$

- average fission group $=9.64538 \mathrm{E}+00+$ or $-6.51398 \mathrm{E}-06$ onergy (ev) of the average lethargy causing fission $=1.19057 \mathrm{E}+04+$ or $-6.65147 \mathrm{E}+02$ no. of initial
generations generations
skippod skippod

3

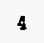

5

6

7

8

9

10

11

$57 \quad 1.00536+$ or -.00866

$62 \quad 1.00611+$ or -.00894

$67 \quad 1.00648+$ or -.00964

$721.00416+$ or - .01059

$77 \quad 1.00754+$ or - .01211

$82 \quad 1.01864+$ or - .01271

$87 \quad 1.01431$ + or - .01127

92 k-effoctive deviation

$1.00430+$ or -.00559

$1.00441+$ or -.00570

$1.00416+$ or -.00575

$1.00442+$ or - .00581

$1.00413+$ or - .00586

$.00350+$ or -.00589

1.00449 + or - .00591

$1.00452+$ or - .00598

$1.00495+$ or - .00617

$1.00514+$ or -.00646

$1.00655+$ or -.00669

$1.00925+$ or - .00674

1.00847 f or - .00712

$1.00764+$ or - .00753

$1.01657+$ or -.01438
67 per cont
confidence interval

.99871 to 1.00990

.99896 to 1.01024

.99872 to 1.01011

.99841 to 1.00991

.99862 to 1.01023

.99827 to 1.00999

.99762 to 1.00939

.99744 to 1.00934

.99858 to 1.01040

.99854 to 1.01049

.99878 to 1.01112

.99868 to 1.01161

1.00139 to 1.01481

.99986 to 1.01325

1.00251 to 1.01599

1.00136 to 1.01559

1.00010 to 1.01517

.99621 to 1.01217

.99669 to 1.01402

.99718 to 1.01505

.99684 to 1.01612

.99357 to 1.01474

.99543 to 1.01965

1.00593 to 1.03135

1.00305 to 1.02558

1.00220 to 1.03095
95 per cent confidence interval

.99312 to 1.01549

.99332 to 1.01589

.99302 to 1.01581

.99266 to 1.01566

.99281 to 1.01603

.99241 to 1.01584

.99173 to 1.01528

.99149 to 1.01529

.99267 to 1.01632

.99256 to 1.01647

.99261 to 1.01730

.99221 to 1.01807

.99468 to 1.02152

.99317 to 1.01994

.99577 to 1.02273

.99424 to 1.02271

.99257 to 1.02270

.98822 to 1.02015

.98803 to 1.02268

.98824 to 1.02398

.98720 to 1.02576

.98299 to 1.02533

.98332 to 1.03176

.99322 to 1.04406

.99178 to 1.03685

.98782 to 1.04533
99 per cent
conficonce interval

.98752 to 1.02109

.98767 to 1.02153

.98732 to 1.02151

.98691 to 1.02141

.98701 to 1.02184

.98655 to 1.02170

.98584 to 1.02117

.98554 to 1.02124

.98676 to 1.02223

.98659 to 1.02245

.98643 to 1.02347

.98575 to 1.02454

.98797 to 1.02823

.98647 to 1.02663

.98903 to 1.02947

.98713 to 1.02982

.98504 to 1.03023

.98024 to 1.02813

.97937 to 1.03134

.97930 to 1.03292

.97756 to 1.03540

.97240 to 1.03591

.97121 to 1.04387

.98051 to 1.05677

.98051 to 1.04812

.97344 to 1.05971 number of variance histories (por cent)

30000

14.5545

29700

14.5554

29400

14.5600

$29100 \quad 14.5881$

$28800 \quad 14.5742$

$28500 \quad 14.6166$

$28200 \quad 14.8415$

$27900 \quad 14.8228$

$27600 \quad 15.0389$

$27300 \quad 14.9985$

$25800 \quad 15.5482$

$24300 \quad 15.8499$

$22800 \quad 16.3120$

$21300 \quad 15.2633$

$19800 \quad 16.1417$

$18300 \quad 16.9725$

$16800 \quad 18.0166$

$15300 \quad 19.5567$

$13800 \quad 20.0210$

$12300 \quad 22.7493$

$10800 \quad 24.8960$

$9300 \quad 27.8887$

$7800 \quad 29.6757$

$6300 \quad 33.4440$

$4800 \quad 33.7550$

3300

42.7123

NUREG/CR-0200, 
keno-vi sample problem $42 c 815.24 \mathrm{~cm}$ paraffin refl

no. of initial

generations skippod

97 average k-effoctive

deviation

$1.02672+$ or -.02319
67 por cont confidenee interval

1.00352 to 1.04991
95 par cent

.98033 to 1.07311
99 per cent number of variance of variance
.95714 to 1.09630

1800

79.9852 


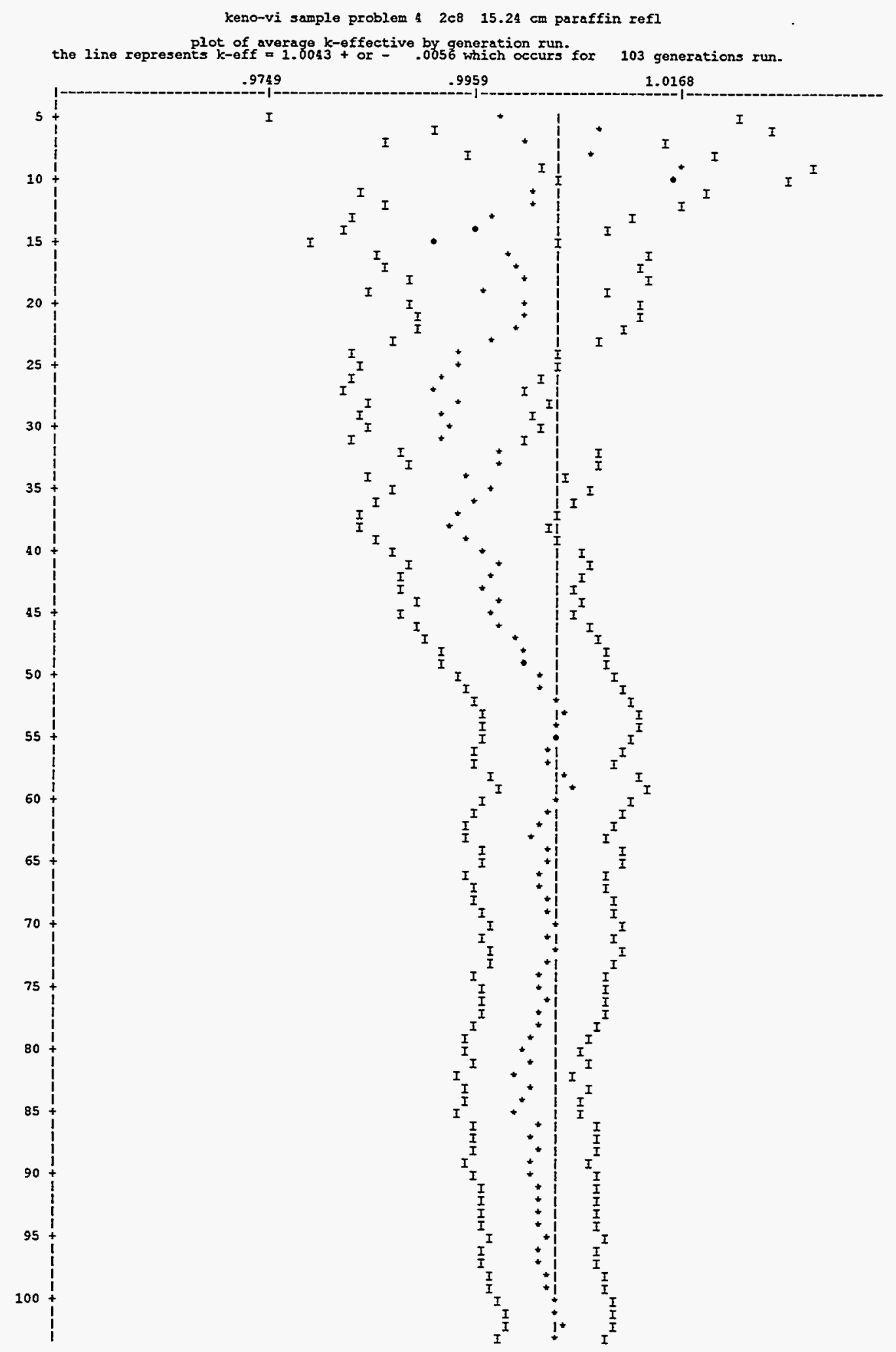

NUREG/CR-0200,

Vol. 2, Rev. 5

F17.E.18 


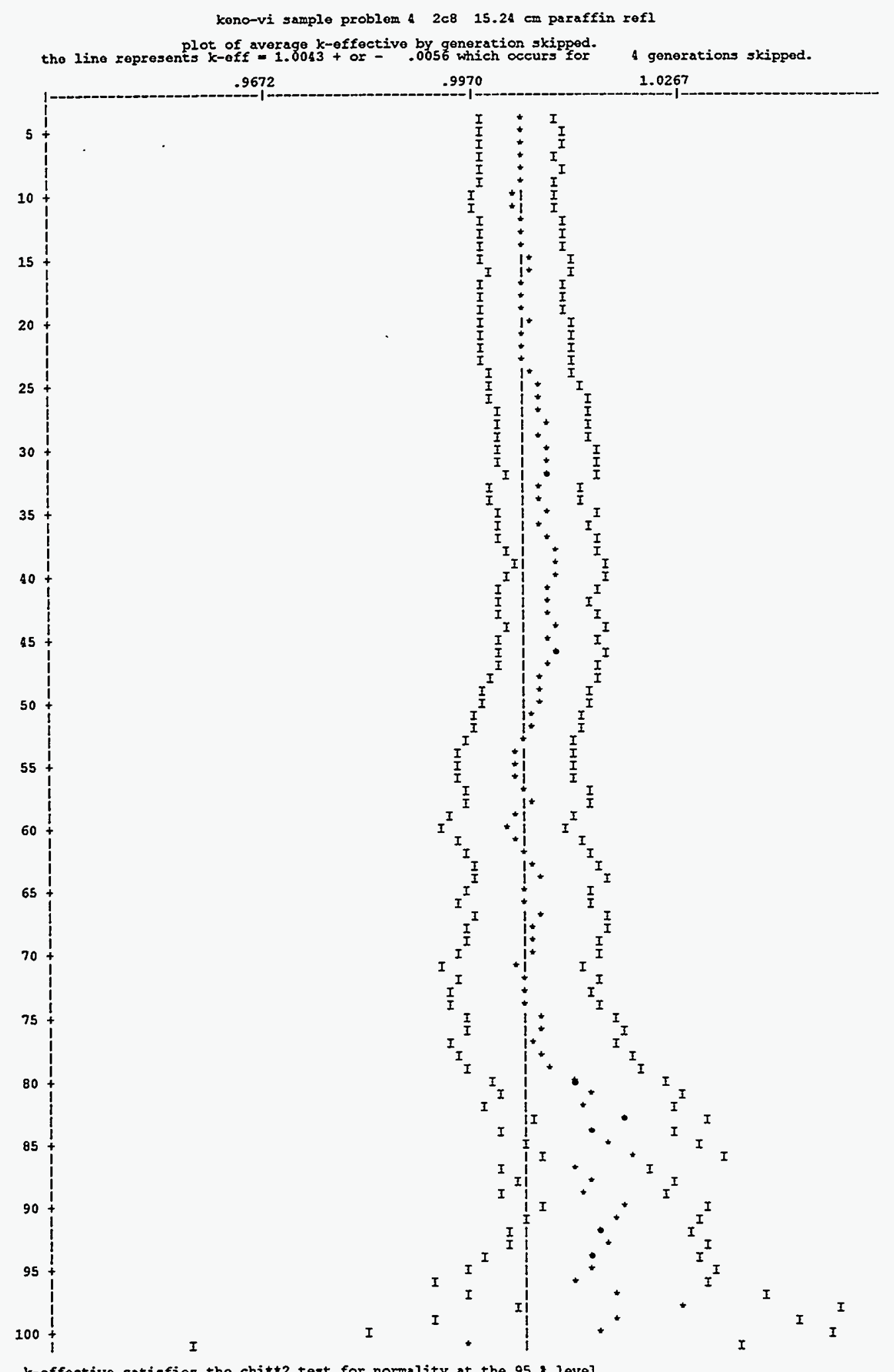

$k$-effective satisfies the chi**2 test for normality at the $95:$ level 
keno-vi sample problem $42 c 8 \quad 15.24 \mathrm{~cm}$ paraffin refl

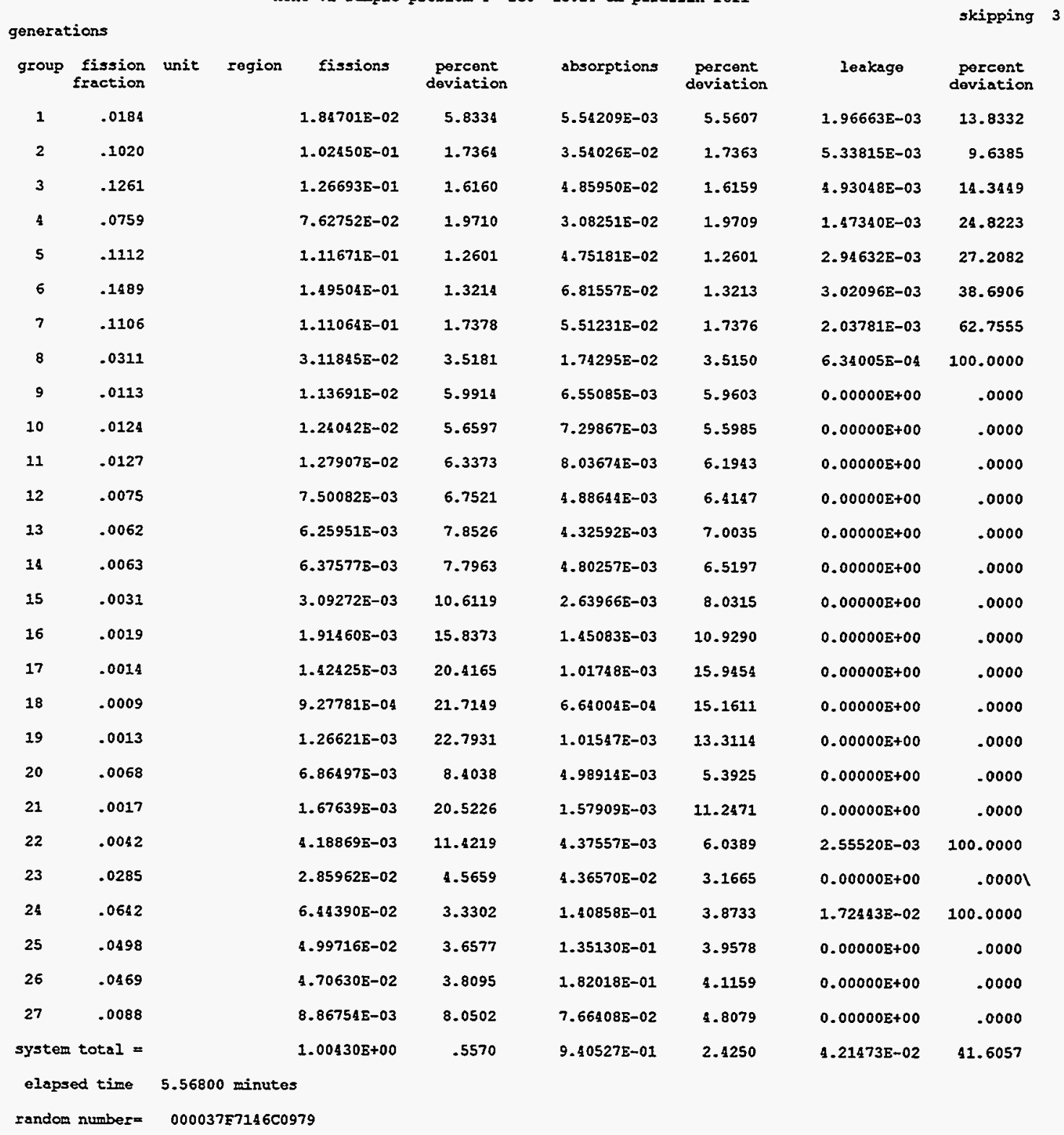

NUREG/CR-0200,

Vol. 2, Rev. 5

F17.E.20 
keno-vi sample problem 4 2c8 $15.24 \mathrm{~cm}$ paraffin refl

*** fission densities ***

$\begin{array}{rcccc}\text { unit } & \text { region } & \begin{array}{l}\text { fission } \\ \text { density }\end{array} & \begin{array}{c}\text { percent } \\ \text { deviation }\end{array} & \begin{array}{c}\text { total } \\ \text { fissions }\end{array} \\ 1 & 1 & 1.255 \mathrm{E}-01 & .56 & 1.004 \mathrm{E}+00 \\ & 2 & 0.000 \mathrm{E}+00 & .00 & 0.000 \mathrm{E}+00\end{array}$

global unit

$2 \quad 1 \quad 0.000 E+00$

$0.000 E+00$
$0.000 E+00$

$0.000 E+00$
$0.000 E+00$

$0.000 \mathrm{E}+00$

$0.000 E+00$

$0.000 E+00$

$0.000 E+00$

.00
.00
.00
.00
.00
.00
.00

$0.000 E+00$

$0.000 E+00$

$0.000 E+00$

$0.000 E+00$

$0.000 E+00$

$0.000 E+00$

$0.000 E+00$

F17.E.21

NUREG/CR-0200,

Vol. 2, Rev. 5 
keno-vi sample problem $42 c 8 \quad 15.24 \mathrm{~cm}$ paraffin ref1

\begin{tabular}{|c|c|c|c|c|}
\hline fluxes & $\begin{array}{l}\text { for unit } \\
\text { rogion }\end{array}$ & $\begin{array}{l}1 \\
1\end{array}$ & region & 2 \\
\hline group & flux & $\begin{array}{l}\text { percent } \\
\text { deviation }\end{array}$ & flux & $\begin{array}{l}\text { percent } \\
\text { deviation }\end{array}$ \\
\hline 1 & $9.598 \mathrm{E}-03$ & 5.20 & $2.838 \mathrm{E}-02$ & 5.33 \\
\hline 2 & $9.093 \mathrm{E}-02$ & 1.98 & $2.547 \mathrm{~B}-01$ & 1.91 \\
\hline 3 & $1.1375-01$ & 1.54 & $3.279 \mathrm{E}-01$ & 1.59 \\
\hline 4 & $7.125 \mathrm{E}-02$ & 2.15 & $2.000 \mathrm{~B}-01$ & 2.20 \\
\hline 5 & $1.110 \mathrm{~B}-01$ & 1.46 & $3.132 \mathrm{E}-01$ & 1.50 \\
\hline 6 & $1.664 \mathrm{E}-01$ & 1.35 & $4.523 \mathrm{E}-03$ & 1.26 \\
\hline 7 & $1.170 \mathrm{E}-01$ & 1.73 & $3.276 \mathrm{~B}-01$ & 1.83 \\
\hline 8 & $3.190 \mathrm{E}-02$ & 3.24 & $1.384 \mathrm{E}-01$ & 3.07 \\
\hline 9 & $1.389 \mathrm{E}-02$ & 6.06 & $8.608 \mathrm{E}-02$ & 3.35 \\
\hline 10 & $1.230 \mathrm{E}-02$ & 5.67 & $7.854 \mathrm{E}-02$ & 3.83 \\
\hline 11 & $1.1115-02$ & 6.23 & $7.1525-02$ & 4.57 \\
\hline 12 & $7.136 \mathrm{E}-03$ & 6.57 & 4.820E-02 & 4.79 \\
\hline 13 & $6.563 E-03$ & 7.85 & $4.301 \mathrm{E}-02$ & 5.40 \\
\hline 14 & $6.823 \mathrm{E}-03$ & 7.16 & $4.481 \mathrm{E}-02$ & 5.02 \\
\hline 15 & $3.015 E-03$ & 10.56 & $2.019 \mathrm{E}-02$ & 8.05 \\
\hline 16 & $1.618 \mathrm{E}-03$ & 15.07 & $1.223 \mathrm{E}-02$ & 10.51 \\
\hline 17 & $1.001 \mathrm{E}-03$ & 21.18 & $4.978 \mathrm{~B}-03$ & 14.14 \\
\hline 18 & $5.960 \mathrm{E}-04$ & 21.54 & $4.400 \mathrm{E}-03$ & 14.38 \\
\hline 19 & $6.735 \mathrm{E}-04$ & 23.66 & $8.777 \mathrm{E}-03$ & 12.93 \\
\hline 20 & $3.900 \mathrm{E}-03$ & 8.37 & $2.725 \mathrm{E}-02$ & 5.85 \\
\hline 21 & $1.152 \mathrm{E}-03$ & 21.40 & $7.493 \mathrm{E}-03$ & 11.52 \\
\hline 22 & $2.579 E-03$ & 11.28 & $1.858 \mathrm{E}-02$ & 8.83 \\
\hline 23 & $1.713 E-02$ & 4.94 & $1.293 \mathrm{E}-01$ & 3.72 \\
\hline 24 & $3.781 \mathrm{E}-02$ & 3.87 & $2.750 \mathrm{E}-02$ & 2.63 \\
\hline 25 & $2.923 \mathrm{E}-02$ & 3.93 & $1.943 \mathrm{~B}-01$ & 3.14 \\
\hline 26 & $2.738 \mathrm{E}-02$ & 3.77 & $1.864 \mathrm{E}-01$ & 3.20 \\
\hline 27 & $5.2315-03$ & 8.25 & $3.825 \mathrm{E}-02$ & 5.56 \\
\hline
\end{tabular}

NUREG/CR-0200,

Vol. 2, Rev. 5

F17.E.22 
keno-vi sample problem 4 2c8 $15.24 \mathrm{~cm}$ paraffin refl

\begin{tabular}{|c|c|c|c|c|c|c|c|c|c|c|c|c|}
\hline \multirow{2}{*}{$\begin{array}{l}\text { fluxes } \\
\text { group }\end{array}$} & \multicolumn{2}{|c|}{$\begin{array}{c}\text { for global unit } \\
\text { rogion } 1\end{array}$} & region & 2 & region & 3 & region & 4 & region & 5 & region & 6 \\
\hline & flux & $\begin{array}{l}\text { percent } \\
\text { doviation }\end{array}$ & flux & $\begin{array}{c}\text { porcent } \\
\text { deviation }\end{array}$ & flux & $\begin{array}{l}\text { percent } \\
\text { deviation }\end{array}$ & flux & $\begin{array}{c}\text { percent } \\
\text { deviation }\end{array}$ & flux & $\begin{array}{l}\text { percent } \\
\text { deviation }\end{array}$ & flux & percent \\
\hline \multicolumn{3}{|l|}{ doviat } & & & & & & & & & & \\
\hline 1 & $0.000 E+00$ & .00 & 4.946E-02 & 5.82 & $4.863 \mathrm{E}-02$ & 6.81 & 4.292E-02 & 7.91 & $3.245 \mathrm{E}-02$ & 11.04 & & \\
\hline 2 & $0.000 E+00$ & $\begin{array}{r}.00 \\
.00\end{array}$ & $\begin{array}{l}3.826 \mathrm{E}-01 \\
4.832 \mathrm{E}-01\end{array}$ & $\begin{array}{l}1.98 \\
1.55\end{array}$ & $\begin{array}{l}3.200 E-01 \\
3.605 E-01\end{array}$ & $\begin{array}{l}2.84 \\
2.16\end{array}$ & $\begin{array}{l}2.122 \mathrm{E}-01 \\
2.185 \mathrm{E}-01\end{array}$ & $\begin{array}{l}3.80 \\
3.14\end{array}$ & $\begin{array}{l}1.234 \mathrm{E}-01 \\
1.295 \mathrm{E}-01\end{array}$ & $\begin{array}{l}4.72 \\
4.60\end{array}$ & $\begin{array}{l}6.949 \mathrm{E}-02 \\
7.154 \mathrm{E}-02\end{array}$ & $\begin{array}{l}7.02 \\
7.37\end{array}$ \\
\hline 3 & $\begin{array}{l}0.000 E+00 \\
0.000 E+00\end{array}$ & $\begin{array}{l}.00 \\
.00\end{array}$ & $\begin{array}{l}4.832 \mathrm{E}-01 \\
3.078 \mathrm{E}-01\end{array}$ & $\begin{array}{l}1.55 \\
2.13\end{array}$ & $\begin{array}{l}3.603 E-01 \\
2.232 E-01\end{array}$ & 2.94 & $1.244 \mathrm{E}-01$ & $\begin{array}{l}3.14 \\
4.31\end{array}$ & $6.372 E-02$ & $\begin{array}{l}2.60 \\
7.22\end{array}$ & $3.538 \mathrm{E}-02$ & $\begin{array}{r}7.37 \\
10.04\end{array}$ \\
\hline 5 & $0.000 \mathrm{E}+00$ & .00 & $4.7388-01$ & 1.56 & $3.222 \mathrm{E}-01$ & 2.24 & $1.658 \mathrm{E}-01$ & 3.51 & $8.2315-02$ & 5.88 & $4.517 \mathrm{E}-02$ & 13.59 \\
\hline 6 & $0.000 E+00$ & .00 & $7.167 \mathrm{E}-01$ & 1.07 & $4.415 \mathrm{E}-01$ & 1.79 & $2.1135-01$ & 2.92 & $9.5645-02$ & 6.50 & $4.359 \mathrm{E}-02$ & 13.76 \\
\hline 7 & $0.000 E+00$ & .00 & $7.086 \mathrm{E}-01$ & 1.14 & $3.890 \mathrm{E}-01$ & 1.54 & $1.755 \mathrm{E}-01$ & 3.80 & $8.1065-02$ & 9.38 & $3.7185-02$ & 19.32 \\
\hline 8 & $0.000 E+00$ & .00 & $4.816 \mathrm{E}-01$ & 1.21 & $2.799 E-01$ & 1.75 & $1.347 \mathrm{E}-01$ & 4.93 & $5.375 E-02$ & 9.85 & $1.4045-02$ & 34.07 \\
\hline 9 & $0.000 E+00$ & .00 & $3.625 \mathrm{E}-01$ & 1.29 & $2.301 E-01$ & 2.25 & $9.696 \mathrm{E}-02$ & 4.65 & $4.055 \mathrm{E}-02$ & 16.04 & $2.3095-02$ & 41.29 \\
\hline 10 & $0.000 \mathrm{E}+00$ & .00 & $3.070 \mathrm{E}-01$ & 1.10 & $2.106 E-01$ & 1.95 & $9.619 \mathrm{E}-02$ & 5.30 & $3.9725-02$ & 17.72 & $2.659 \mathrm{E}-02$ & 49.87 \\
\hline 11 & $0.000 \mathrm{E}+00$ & .00 & $3.094 \mathrm{E}-01$ & 1.23 & $2.181 E-01$ & 2.20 & $9.780 \mathrm{E}-02$ & 5.61 & $2.9745-02$ & 15.34 & $1.4785-02$ & 47.03 \\
\hline 12 & $0.000 E+00$ & .00 & $2.043 E-01$ & 1.30 & $1.4975-01$ & 2.04 & $7.553 \mathrm{E}-02$ & 7.30 & $3.066 \mathrm{E}-02$ & 23.09 & $2.5425-02$ & 69.69 \\
\hline 13 & $0.000 \mathrm{E}+00$ & .00 & $1.862 \mathrm{E}-01$ & 1.56 & $1.450 \mathrm{E}-01$ & 2.86 & $6.045 \mathrm{E}-02$ & 7.16 & $4.0385-02$ & 33.65 & $1.393 \mathrm{E}-02$ & 60.73 \\
\hline 14 & $0.000 E+00$ & .00 & $1.937 \mathrm{E}-01$ & 1.49 & $1.4635-01$ & 3.06 & $6.938 \mathrm{E}-02$ & 7.91 & $4.053 \mathrm{E}-02$ & 22.42 & $2.274 E-02$ & 50.22 \\
\hline 15 & $0.000 E+00$ & .00 & $9.120 \mathrm{E}-02$ & 2.12 & $7.647 \mathrm{E}-02$ & 3.95 & $3.479 \mathrm{E}-02$ & 9.54 & $1.960 \mathrm{~s}-02$ & 26.88 & $8.887 E-03$ & 75.83 \\
\hline 16 & $0.000 E+00$ & .00 & $4.907 \mathrm{E}-02$ & 2.89 & $4.181 \mathrm{E}-02$ & 4.04 & $1.940 \mathrm{E}-02$ & 13.00 & $1.3765-02$ & 36.28 & $7.458 \mathrm{E}-03$ & 69.25 \\
\hline 17 & $0.000 E+00$ & .00 & $2.393 E-02$ & 4.50 & $1.925 E-02$ & 6.22 & $1.091 \mathrm{E}-02$ & 17.46 & $6.6395-03$ & 55.60 & $3.852 \mathrm{E}-03$ & 100.00 \\
\hline 18 & $0.000 E+00$ & .00 & $2.180 \mathrm{E}-02$ & 4.29 & $1.629 \mathrm{E}-02$ & 6.66 & $8.5765-03$ & 19.15 & $5.3435-03$ & 40.71 & $0.000 E+00$ & .00 \\
\hline 19 & $0.000 E+00$ & .00 & $4.040 \mathrm{E}-02$ & 3.29 & $3.075 \mathrm{E}-02$ & 4.65 & $2.177 \mathrm{E}-02$ & 33.54 & $1.263 \mathrm{E}-02$ & 34.07 & $3.264 E-03$ & 59.54 \\
\hline 20 & $0.000 E+00$ & .00 & $1.251 \mathrm{E}-01$ & 2.17 & $1.021 E-01$ & 3.88 & $5.595 \mathrm{E}-02$ & 10.61 & $3.647 \mathrm{E}-02$ & 22.66 & $1.139 \mathrm{E}-02$ & 48.07 \\
\hline 21 & $0.000 E+00$ & .00 & $4.095 \mathrm{E}-02$ & 3.30 & $3.260 \mathrm{E}-02$ & 6.78 & $1.742 \mathrm{E}-02$ & 14.26 & $9.322 \mathrm{E}-03$ & 34.90 & $5.610 \mathrm{E}-03$ & 59.47 \\
\hline 22 & $0.000 \mathrm{~B}+00$ & .00 & $9.799 \mathrm{E}-02$ & 2.68 & $8.628 \mathrm{E}-02$ & 3.97 & $5.807 \mathrm{E}-02$ & 13.34 & $4.736 \mathrm{E}-02$ & 26.54 & $7.647 \mathrm{E}-03$ & 50.54 \\
\hline 23 & $0.000 E+00$ & .00 & $8.213 E-01$ & 1.75 & $8.837 \mathrm{E}-01$ & 3.52 & $5.801 E-01$ & 6.99 & $3.5915-01$ & 15.67 & $9.286 \mathrm{E}-02$ & 32.52 \\
\hline 24 & $0.000 \mathrm{~B}+00$ & .00 & $1.934 \mathrm{E}+00$ & 1.66 & $2.215 B+00$ & 3.27 & $1.459 E+00$ & 6.98 & $9.681 \mathrm{E}-01$ & 16.72 & $2.871 \mathrm{E}-01$ & 29.99 \\
\hline 25 & $0.000 \mathrm{E}+00$ & .00 & $1.484 \mathrm{E}+00$ & 1.60 & $1.703 \mathrm{E}+00$ & 3.34 & $1.178 \mathrm{E}+00$ & 6.69 & $6.794 \mathrm{E}-01$ & 17.62 & $2.022 \mathrm{E}-01$ & 34.61 \\
\hline 26 & $0.000 E+00$ & .00 & $1.518 E+00$ & 1.65 & $1.749 B+00$ & 3.56 & $1.129 \mathrm{E}+00$ & 6.98 & $6.716 \mathrm{E}-01$ & 18.32 & $1.905 \mathrm{~B}-01$ & 35.44 \\
\hline 27 & $0.000 \mathrm{E}+00$ & .00 & $3.551 E-01$ & 1.80 & $4.016 \mathrm{E}-01$ & 3.86 & $2.596 \mathrm{E}-01$ & 7.50 & $1.794 \mathrm{E}-01$ & 20.93 & $5.211 \mathrm{E}-02$ & 42.35 \\
\hline
\end{tabular}

F17.E.23

NUREG/CR-0200, Vol. 2, Rev. 5 
fluxes for global unit

$\begin{array}{crr}\text { group } & \text { flux } & \begin{array}{c}\text { percent } \\ \text { deviation }\end{array} \\ 1 & 3.501 E-03 & 35.92 \\ 2 & 5.483 E-03 & 23.16 \\ 3 & 4.652 E-03 & 21.53 \\ 4 & 1.483 E-03 & 38.68 \\ 5 & 3.753 E-03 & 39.54 \\ 6 & 2.250 E-03 & 37.83 \\ 7 & 6.510 E-04 & 60.09 \\ 8 & 1.531 E-04 & 100.00 \\ 9 & 0.000 E+00 & .00 \\ 10 & 5.947 E-04 & 100.00 \\ 11 & 2.3625-03 & 100.00 \\ 12 & 8.608 E-04 & 100.00 \\ 13 & 0.000 E+00 & .00 \\ 14 & 0.000 E+00 & .00 \\ 15 & 0.000 E+00 & .00 \\ 16 & 0.000 E+00 & .00 \\ 17 & 0.000 E+00 & .00 \\ 18 & 0.000 E+00 & .00 \\ 19 & 0.000 E+00 & .00 \\ 20 & 0.000 E+00 & .00 \\ 21 & 0.000 E+00 & .00 \\ 22 & 1.001 E-03 & 100.00 \\ 23 & 0.000 E+00 & .00 \\ 24 & 4.139 E-03 & 100.00 \\ 25 & 2.1385-03 & 78.23 \\ 26 & 0.000 E+00 & .00 \\ 27 & 0.000 E+00 & .00\end{array}$

NUREG/CR-0200,

Vol. 2, Rev. 5

F17.E.24 
keno-vi sample problem $4 \quad 2 \mathrm{c} 8 \quad 15.24 \mathrm{~cm}$ paraffin refl

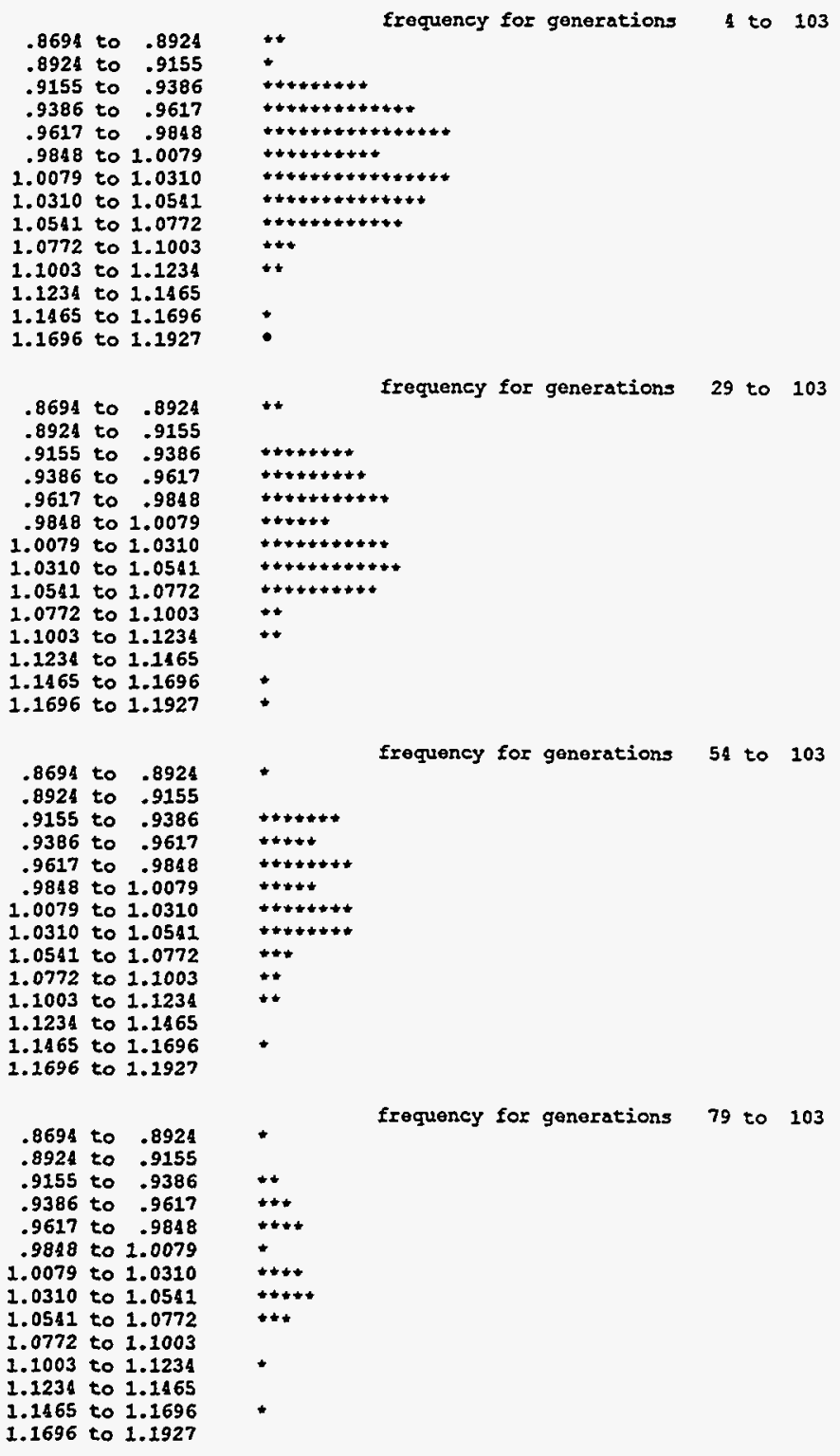

congratulations! you have successfully traversed the perilous path through keno vi in 5.56800 minutes

F17.E.25

NUREG/CR-0200,

Vol. 2, Rev. 5 

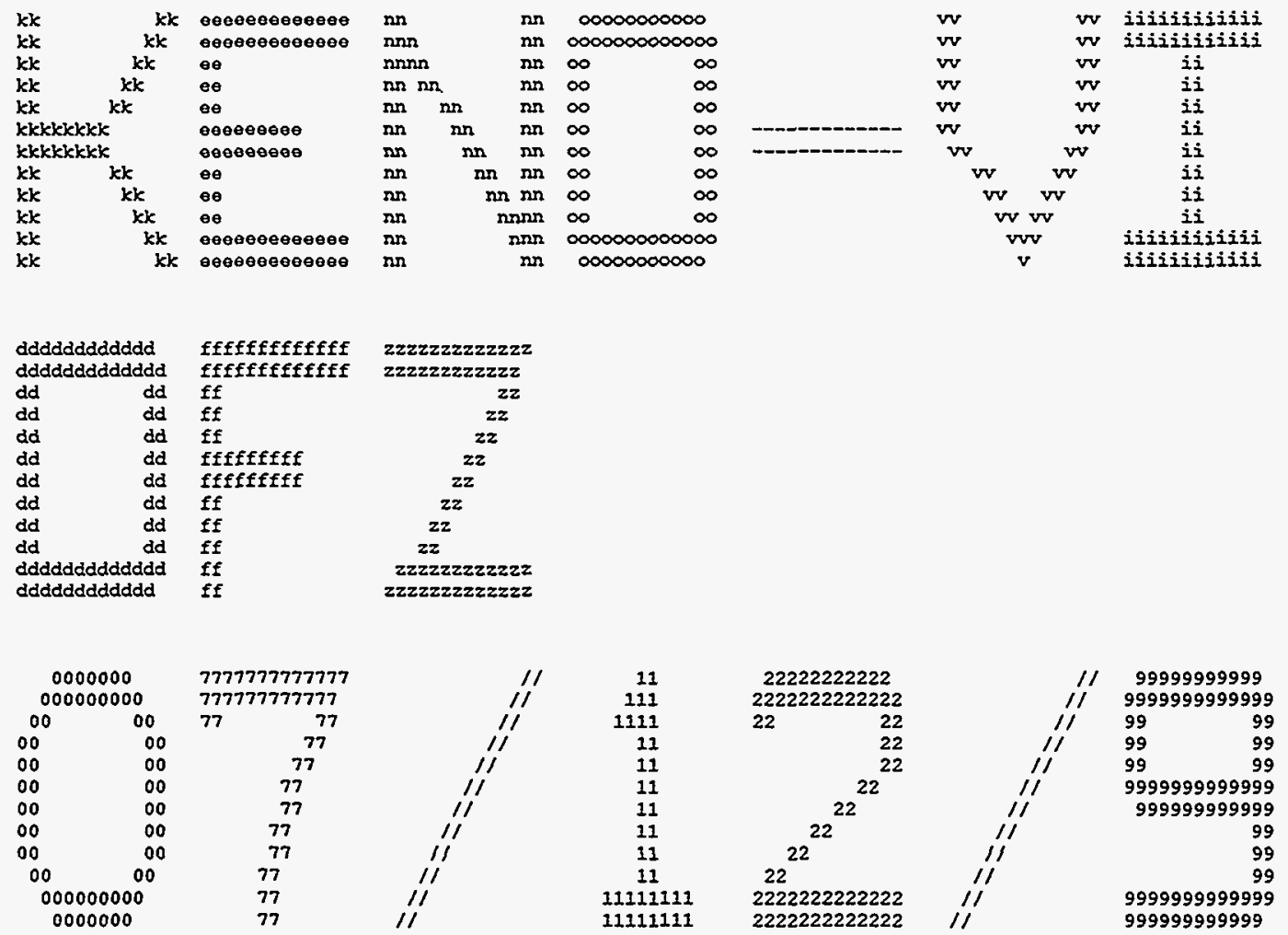

5555555555555 5555555555555

55

55

55 5555555555555 $\begin{array}{lr}\mathbf{5 5} \\ \mathbf{5 5} \\ \mathbf{5 5} & \mathbf{5 5} \\ \mathbf{5 5 5 5 5 5 5 5 5 5 5 5 5}\end{array}$ 999999999999

55555555555
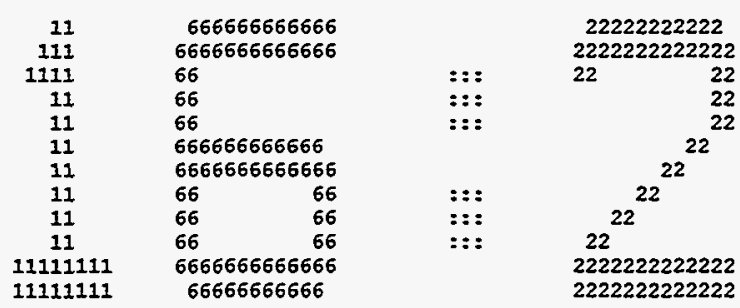

5555555555555 $\mathbf{5 5 5 5 5 5 5 5 5 5 5 5 5}$ 55

55
55

555555555555

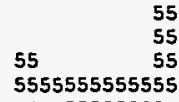

5555555555555
55555555555

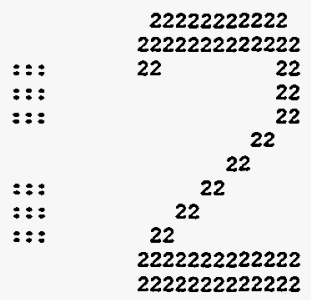

666666666666 ธ666666666666

66
66 666666666666 6666666666666

66
66
66 2222222222222 


\begin{tabular}{|c|c|c|c|c|c|}
\hline 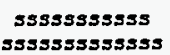 & $\begin{array}{c}\operatorname{ccccccccccc} \\
\operatorname{ccc} c \operatorname{cccccccc}\end{array}$ & \multicolumn{2}{|c|}{ 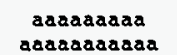 } & \multirow{3}{*}{$\begin{array}{l}11 \\
11 \\
11\end{array}$} & \multirow{2}{*}{ 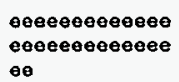 } \\
\hline ss & ce & aa & as & & \\
\hline ss & ce & aa & aa & & $\theta \theta$ \\
\hline$=3$ & $\mathrm{ce}$ & aa & as & 11 & ee \\
\hline s5s3sss3sss3 & ce & aas & asa & 11 & 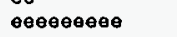 \\
\hline 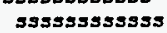 & cc & aas & aaa & 11 & 800000000 \\
\hline ss & cc & aa & aa & 31 & $\theta$ \\
\hline ss & $\mathrm{cc}$ & aa & aa & 11 & 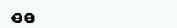 \\
\hline 53 & ce & aa & as & 11 & eo \\
\hline 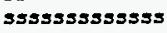 & cecececececee & aa & aa & 1111111111111 & eөee \\
\hline sssessssszes & ceccesceccc & as & aa & 1111111111111 & 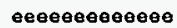 \\
\hline
\end{tabular}

program verification information 190




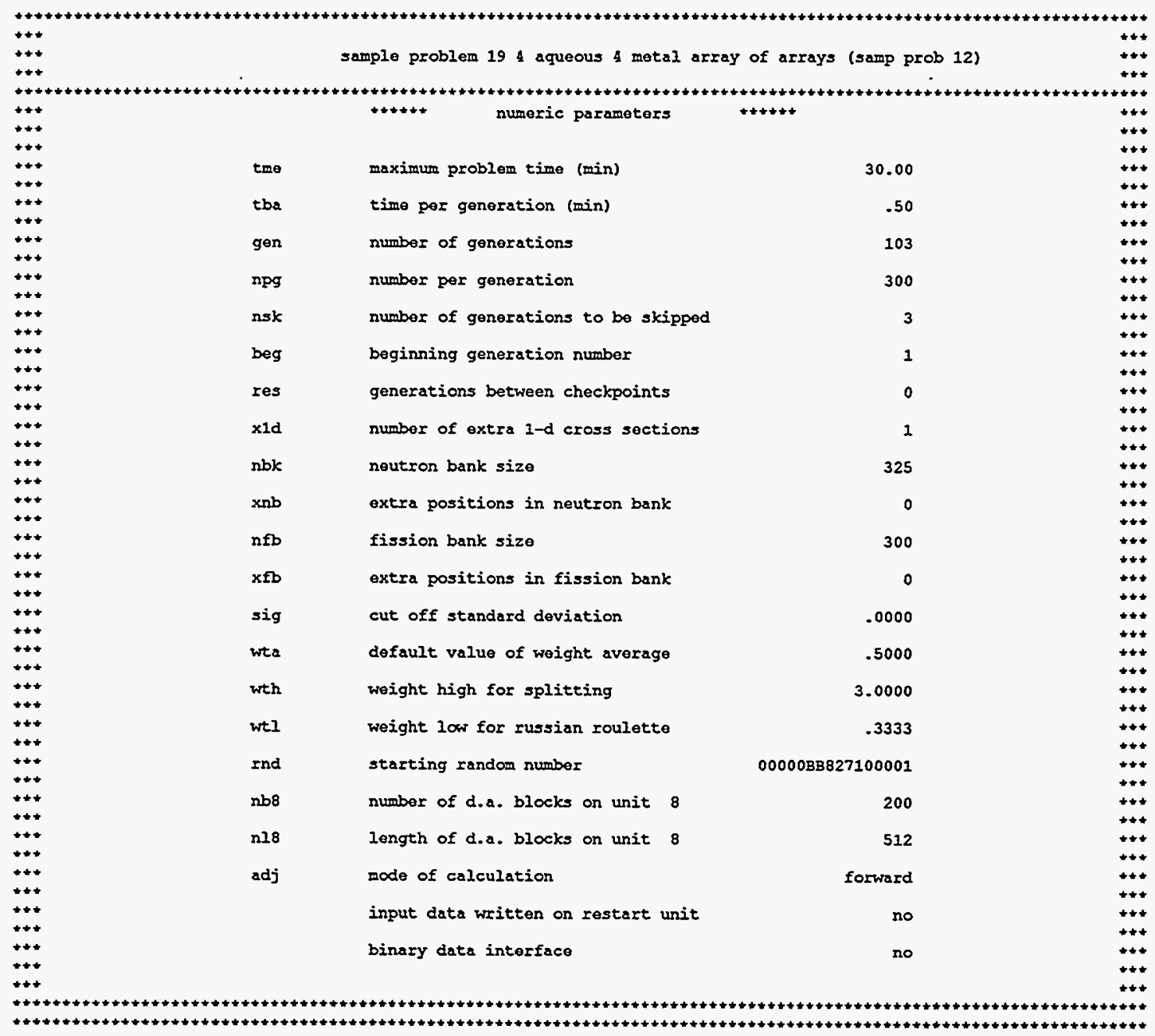

NUREG/CR-0200,

Vol. 2, Rev. 5

F17.E.28 


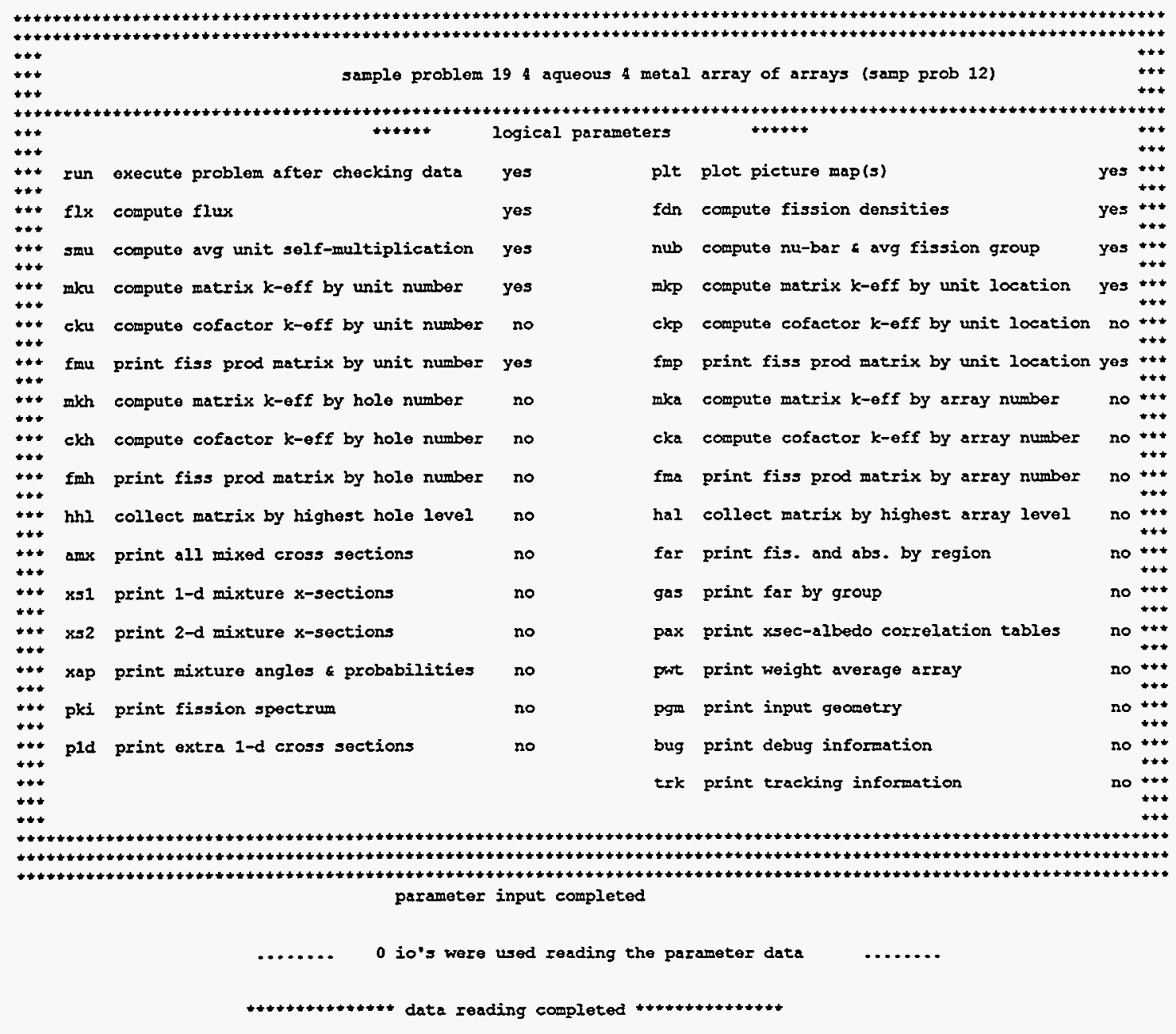




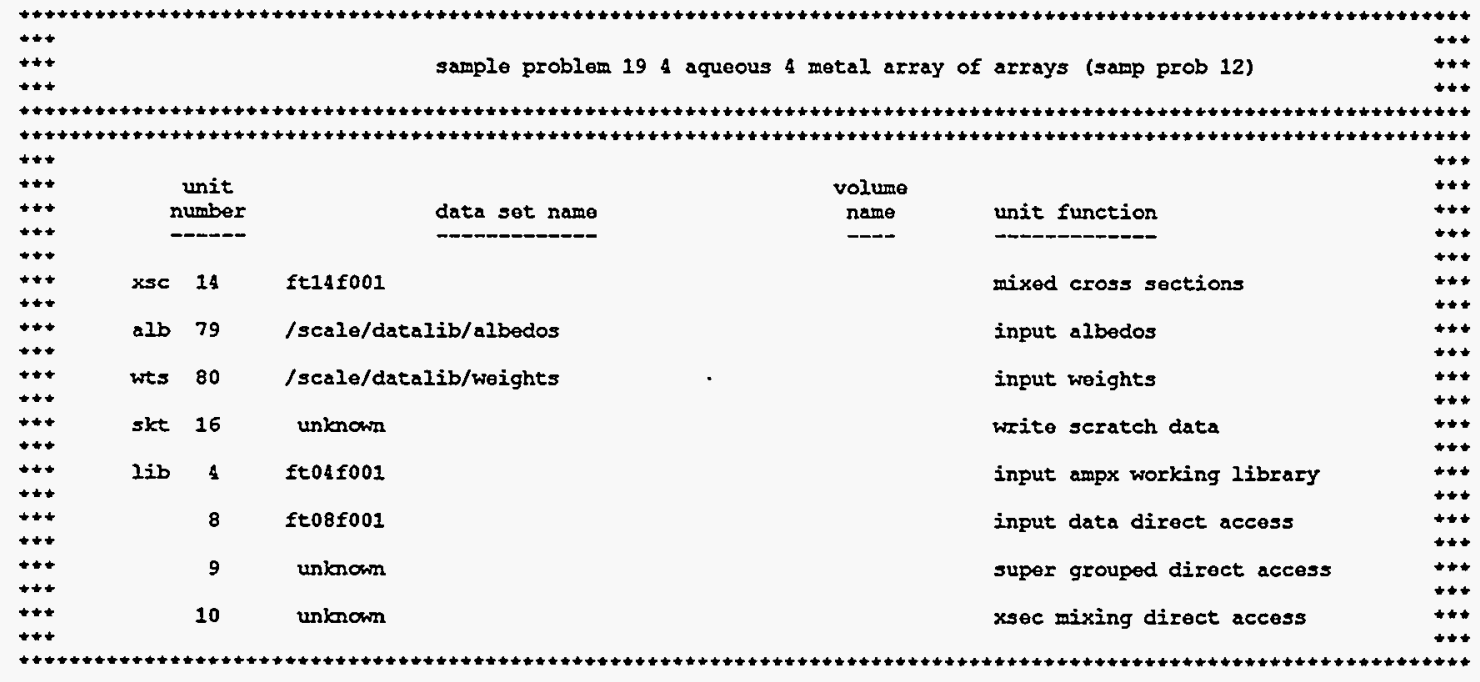

....... 0 io's were used preparing input data

cross sections read from the ampx working library on unit

NUREG/CR-0200,

Vol. 2, Rev. 5

F17.E.30 
sample problem 194 aqueous 4 metal array of arrays (satp prob 12)

mixing table

number of seatrering angles - 2

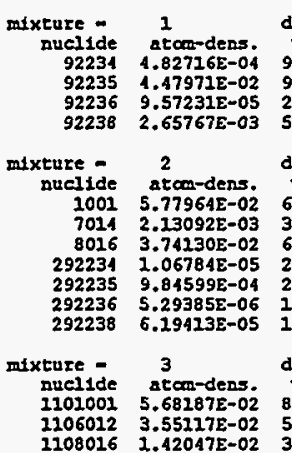

1108016 density $(g / c e)-18.760$

wyt. frac.

$9.99999 \mathrm{E}-0$

9.3200OE-OI

$\begin{array}{ll}92234 & 231.0405 \\ 92235 & 235.0441\end{array}$

$\begin{array}{ll}92236 & 236.045 \\ 92238 & 238.053\end{array}$

density $(g / c c)-1.5547$

wgt. frac.

$\begin{array}{cc}29 & \\ 1001 & 1.0077 \\ 7014 & 14.0033\end{array}$

11.0033
15.9904

801

$92234 \quad 234.0405$

$\begin{array}{lll}2.47284 E-01 & 92235 & 235.0441 \\ 1.334685-03 & 92236 & 236.0458\end{array}$

$\begin{array}{ll}92236 & 236.0458 \\ 92238 & 238.0510\end{array}$

igt. frac.

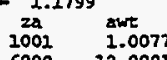

awt $6000 \quad 12.0001$

$.19672 E-0$

15.9904 nuelide title
uranium-234 endf/b-iv mat 1043
uranium-235 endf/b-iv mat 126

u-236 1163 sigo-5+4 newxlacs $p-3$ 293k $f-1 / \mathrm{e}-\mathrm{m}(2 .+5)$

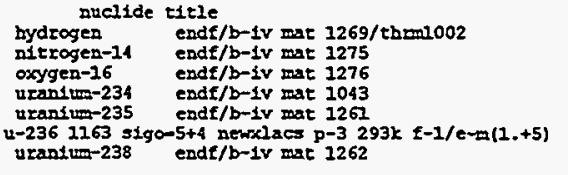

muelide title

bydrogen tuelide title endf/b-IV mat 1269/:henio02

carbon-12 endf/b-1V mat 1274/thnello65

$\begin{array}{ll}\text { carbon-12 } & \text { endf/b-1V mat } 1274 / \text { th } \\ \text { oxygen-16 } & \text { endf/b-1v mat } 1276\end{array}$ updated 08/12/94

updated 08/12/94

updated 08/12/94

updated 08/12/94

updated $08 / 12 / 94$

updated 08/12/94

updnted 08/12/94

updsted 08/12/94

updated $08 / 12 / 94$

updated $08 / 12 / 94$ updited $08 / 32 / 94$ keno message number $16-222$

keno message number $k 6-222$

1001
1101001
1106012
7014
8016
1108016
92234
292231
92235
292235
92236
292236
92238
292238

hydrogen bydzogen nttrogen-14 oxygen-16 oxygen -16
uxaniun-234 urantum-234 uranium -235 uranium-235 uranilum 235

esdf/b-IV mat 1269/thm-1002 exdf/b-iv mat $1269 /$ them endf/b-1v mat 1275 endf/b-iv mat 1276 exdt/b-iv mat 1276 endf/ -1v mat 1043 ende/b-ty mat 1043 ende/b-IV mat 126 sigo-5+4 newselacs p-3 $293 \mathrm{f} f-1 / \mathrm{e}-\mathrm{m}(1 .+5)$

$\begin{array}{ll}\text { urantum-238 } & \text { endf/b-iv mat } 1262 \\ \text { uranfum-238 } & \text { eadf/b-iv mat } 1262\end{array}$

2 transfers for mixture 2 were corrected for bad mocents.

3 transfers for mixture 3 were corrected for bad moments.

updated 08/12/94 updated 08/12/94 updated 08/12/94 updated 08/12/94 updated $08 / 12 / 94$ godnted 08/12/94 odated 08/12/94 updared 08/12/94 updated 08/32/94 updated $08 / 12 / 94$ podated 08/12/94 updated $08 / 12 / 94$

....... 0 10's were used mixiog cross-sections

$1-d$ cross section array 1 id numbers
$12002 \quad 1452 \quad 27 \quad 281018$

....... $010^{\prime}$ s were used preparing the cross sections $\ldots . . .$.

F17.E.31

NUREG/CR-0200,

Vol. 2, Rev. 5 


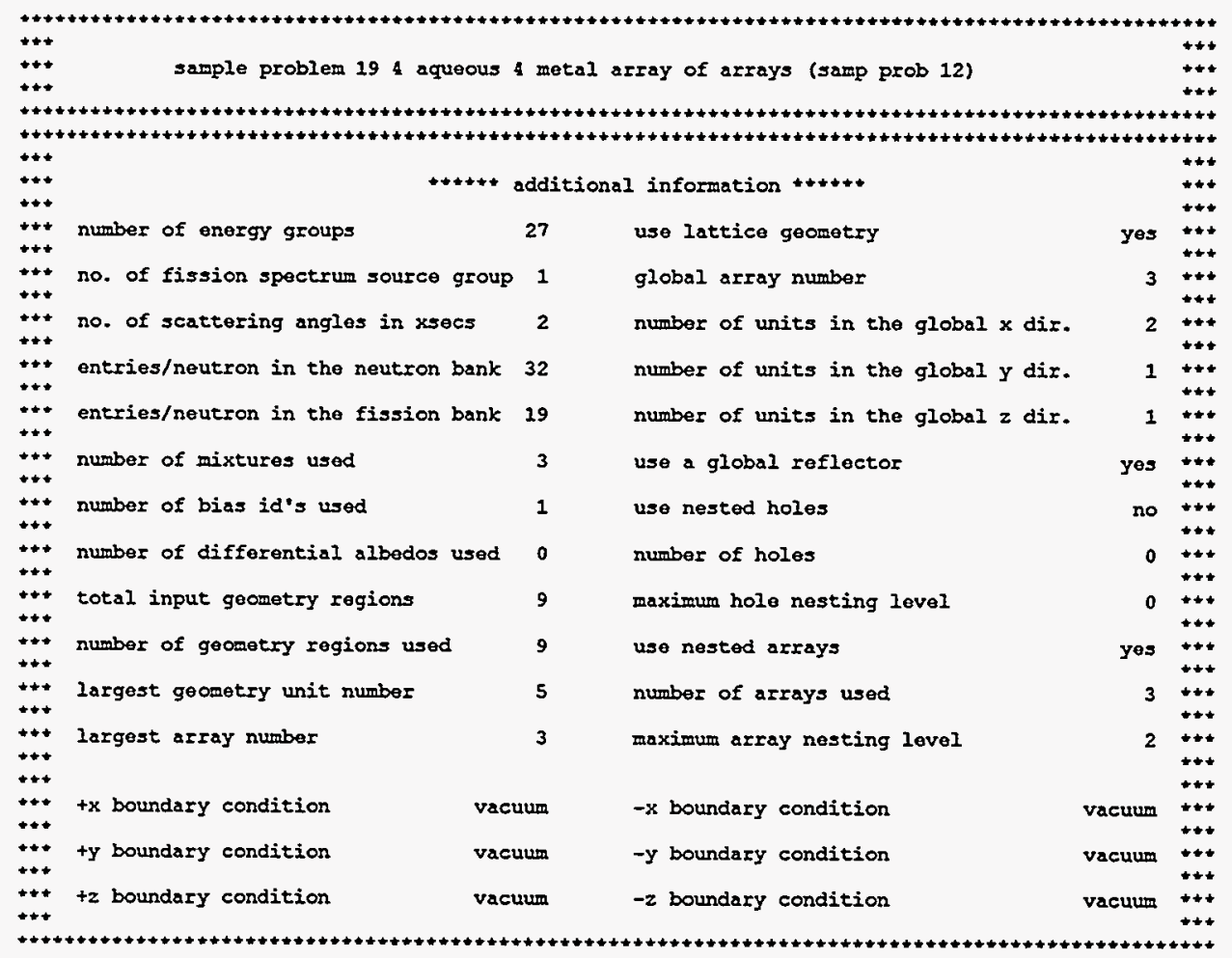

NUREG/CR-0200,

Vol. 2, Rev. 5

F17.E.32 


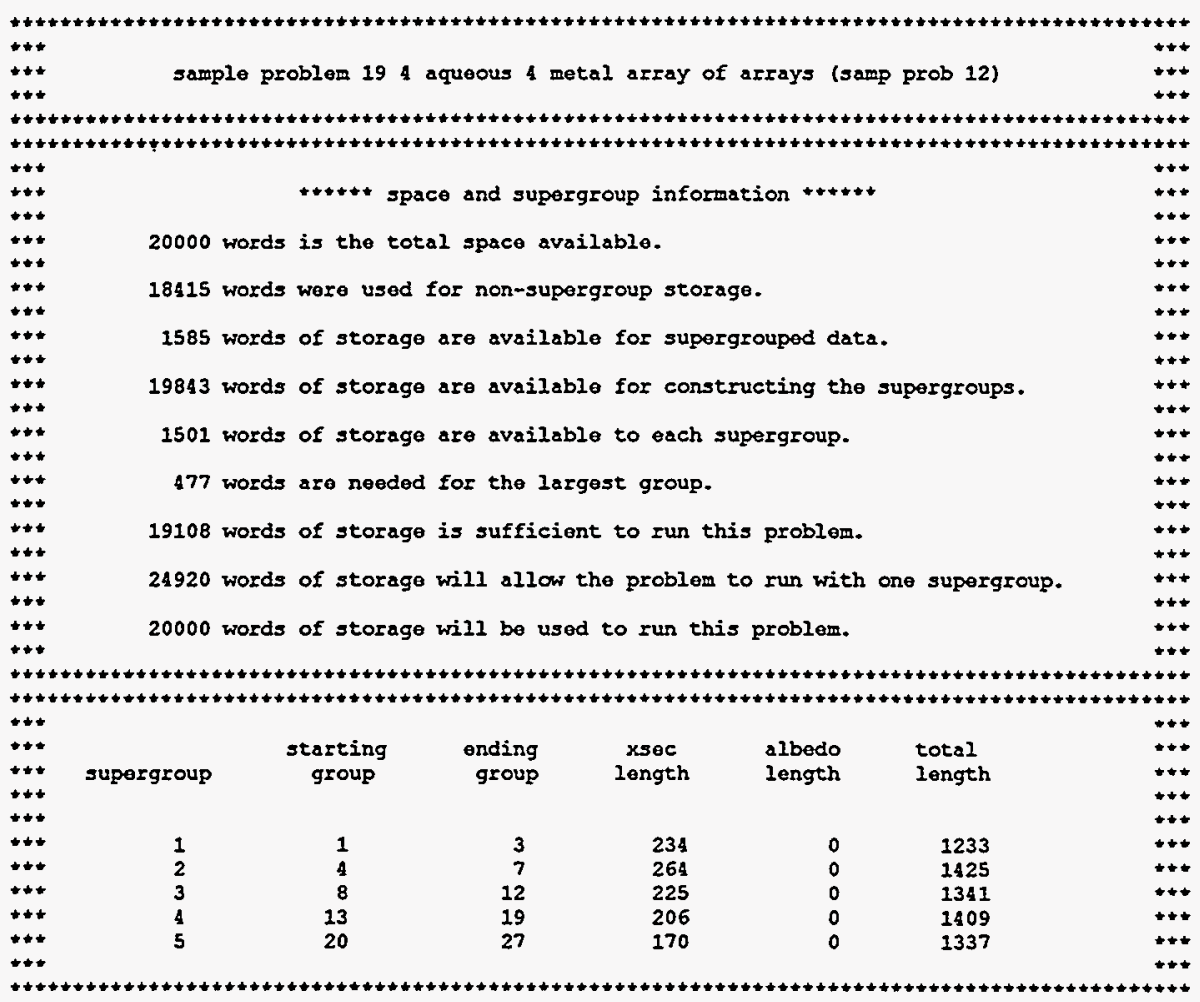

........ 0 io's were used in supergrouping $\quad \ldots \ldots \ldots$

\begin{tabular}{|c|c|c|c|c|c|}
\hline $\begin{array}{l}\text { array } \\
\text { number }\end{array}$ & $\begin{array}{l}\text { units in } \\
x \text { dir. }\end{array}$ & $\begin{array}{l}\text { units in } \\
y \text { dis. }\end{array}$ & $\begin{array}{l}\text { units in } \\
z \text { dis. }\end{array}$ & $\begin{array}{c}\text { nesting } \\
\text { level }\end{array}$ & + \\
\hline 1 & 1 & 2 & 2 & 2 & $\stackrel{+}{+}$ \\
\hline 2 & 1 & 2 & 2 & 2 & + \\
\hline 3 global & 2 & 1 & 1 & 1 & $\stackrel{*}{+\infty}$ \\
\hline
\end{tabular}

....... 0 io's were used losding the date $\ldots . .$. 


\begin{tabular}{|c|c|c|c|c|}
\hline$+* *$ & & & & $\stackrel{+\infty}{+\infty}$ \\
\hline$\bullet+\infty$ & \multicolumn{3}{|c|}{$+*$} & 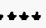 \\
\hline 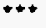 & & geometry parameters & & ++ \\
\hline$+\infty$ & & & & +* \\
\hline 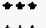 & & & & $\cdots$ \\
\hline++ & niar & number of independent array references & 3 & 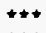 \\
\hline 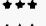 & & & & $\uplus \star$ \\
\hline$+*$ & ngblu & global unit number & $\mathbf{5}$ & ++ \\
\hline$\star \star \star$ & & thar of unit= in the nroblam & & $\because+$ \\
\hline 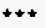 & Moxis & number of units in the problem & 5 & $\star \star$ \\
\hline +\$+ & nquad & number of quadratics in the problem & 24 & 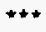 \\
\hline+ & & & & $\star \star$ \\
\hline$\because *$ & ngwrds & number of geometry words read & 9 & \#+ \\
\hline$+\infty$ & maxom $>0$ & & & 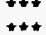 \\
\hline 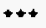 & mand & maxamum geometry words in a unit & $\mathbf{s}$ & $+\infty$ \\
\hline$+\infty$ & $\operatorname{maxsfu}$ & largest number of surfaces in a unit & 7 & 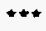 \\
\hline$\cdots$ & & & & 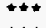 \\
\hline$\stackrel{+*}{*+*}$ & $\operatorname{maxreg}$ & largest number of media in a unit & 3 & $+*$ \\
\hline$+\infty$ & regtot & number of spatial volumes defined & 9 & $\star \star *$ \\
\hline$\bullet \bullet \bullet$ & & & & $\star \star$ \\
\hline 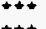 & sectot & number of entries in the sector array & 19 & $+\star \star$ \\
\hline$+\star+$ & & & & | \\
\hline$+\infty$ & rucom & numoer of coments in tne geowetry ada & $\mathbf{5}$ & $+\infty$ \\
\hline$t+t$ & numbol & number of holes in the problem & 0 & + \\
\hline
\end{tabular}

NUREG/CR-0200,

Vol. 2, Rev. 5

F17.E.34 
sample problem 194 aqueous 4 metal array of arrays (samp prob 12) geometry description for those units utilized in this problem

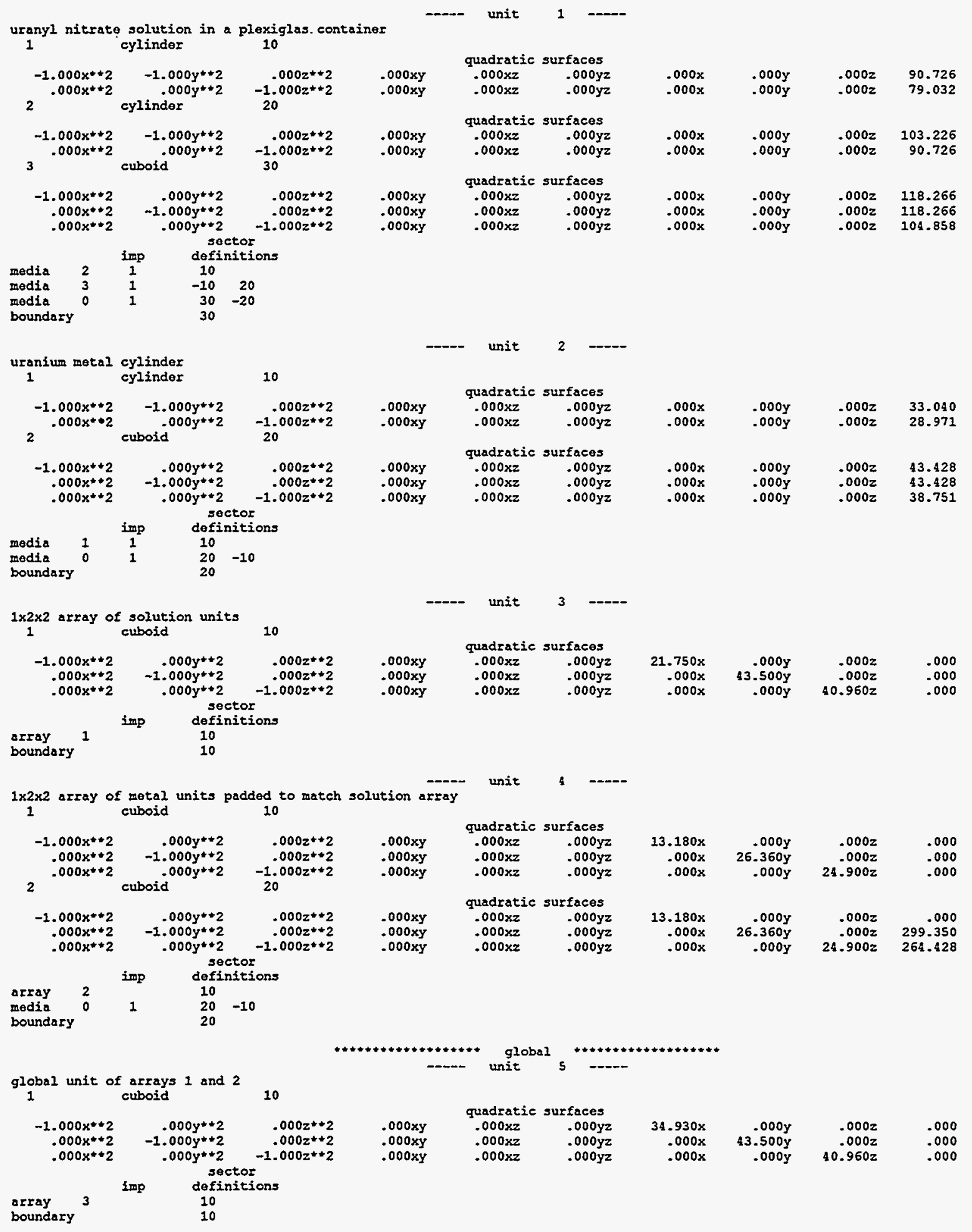

F17.E.35

NUREG/CR-0200,

Vol. 2, Rev. 5 
sample problem 194 aqueous 4 metal array of arrays (samp prob 12)

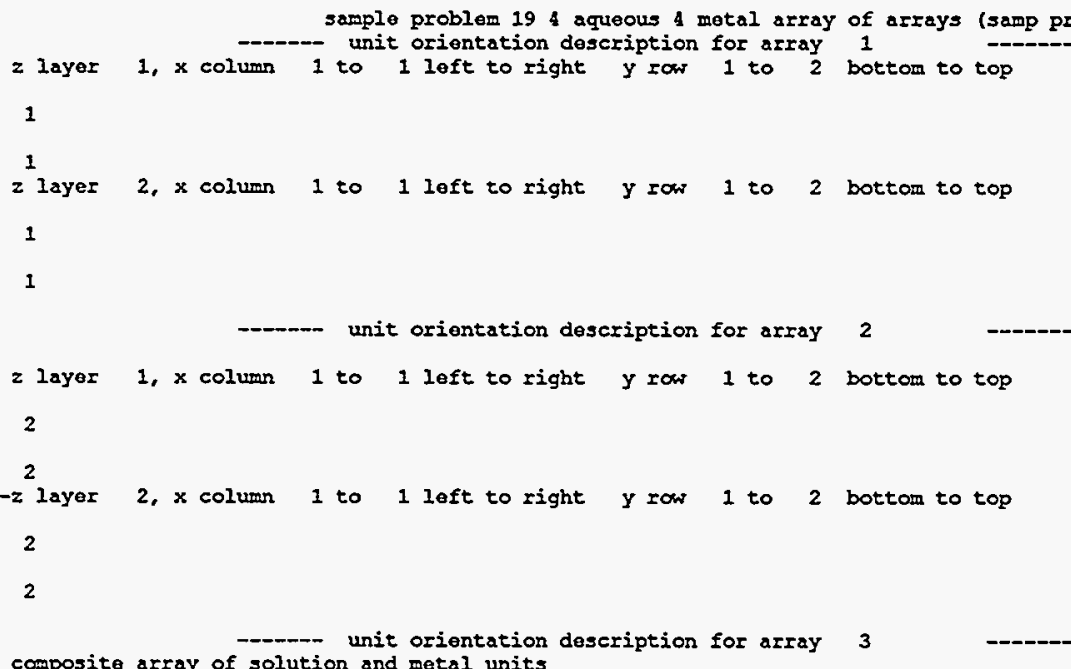
composite array of solution and metal units

$z$ layer $1, x$ colum 1 to 2 left to right $y$ row 1 to 1 bottom to top

43 


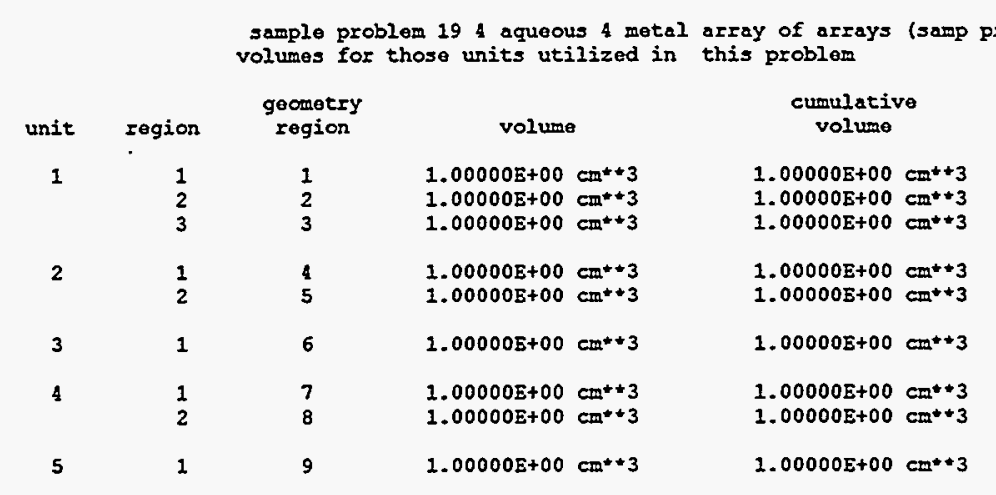

\begin{tabular}{|c|c|c|c|c|}
\hline unit & uses & region & mixture & total volume \\
\hline 1 & 4 & $\begin{array}{l}1 \\
2 \\
3\end{array}$ & $\begin{array}{l}2 \\
3 \\
0\end{array}$ & $\begin{array}{l}4.00000 \mathrm{E}+00 \mathrm{~cm}+* 3 \\
4.00000 \mathrm{E}+00 \mathrm{~cm}^{*+3} \\
4.00000 \mathrm{E}+00 \mathrm{~cm}^{*+3}\end{array}$ \\
\hline 2 & 4 & $\begin{array}{l}1 \\
2\end{array}$ & $\begin{array}{l}1 \\
0\end{array}$ & $\begin{array}{l}4.00000 \mathrm{E}+00 \mathrm{~cm}^{++3} \\
4.00000 \mathrm{E}+00 \mathrm{~cm}^{++3}\end{array}$ \\
\hline 3 & 1 & 1 & & $1.00000 \mathrm{E}+00 \mathrm{~cm} *+3$ \\
\hline 4 & 1 & $\begin{array}{l}1 \\
2\end{array}$ & 0 & $\begin{array}{l}1.00000 \mathrm{E}+00 \mathrm{~cm}^{++3} \\
1.00000 \mathrm{E}+00 \mathrm{~cm}^{t+3}\end{array}$ \\
\hline 5 & 1 & 1 & & $1.000005+00 \mathrm{~cm} * 3$ \\
\hline
\end{tabular}

\begin{tabular}{cc}
\multicolumn{2}{c}{ total mixture volumes } \\
mixture & total volume \\
0 & $9.00000 \mathrm{E}+00 \mathrm{~cm}^{++3}$ \\
1 & $4.00000 \mathrm{E}+00 \mathrm{~cm}^{++3}$ \\
2 & $4.00000 \mathrm{E}+00 \mathrm{~cm}^{+* 3}$ \\
3 & $4.00000 \mathrm{E}+00 \mathrm{~cm}^{+* 3}$
\end{tabular}

\begin{tabular}{|c|c|c|c|}
\hline$* * *$ & & & \\
\hline$\#+$ & & biasing information & $*$ \\
\hline 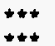 & a default weight of & .500 will be used for all bias id's. & \\
\hline
\end{tabular}

........ 0 io's were used in keno-v before tracking

....... .02133minutes were used processing data.

volume fraction of fissile material in the system $.38095 \mathrm{E}+00$

start type 0 was used.

the neutrons were started with a flat distribution in a cuboid defined by:

$t x=3.49300 \mathrm{E}+01-x=0.00000 \mathrm{E}+00+y=4.35000 \mathrm{E}+01 \quad-y=0.00000 \mathrm{E}+00 \quad+z=4.09600 \mathrm{E}+01 \quad-z=0.00000 \mathrm{E}+00$ .00000 minutes were required for starting. total elapsed time is .02133 minutes.

F17.E.37

NUREG/CR-0200,

Vol. 2, Rev. 5 
sample problem 194 aqueous 4 metal array of arrays (samp prob 12)

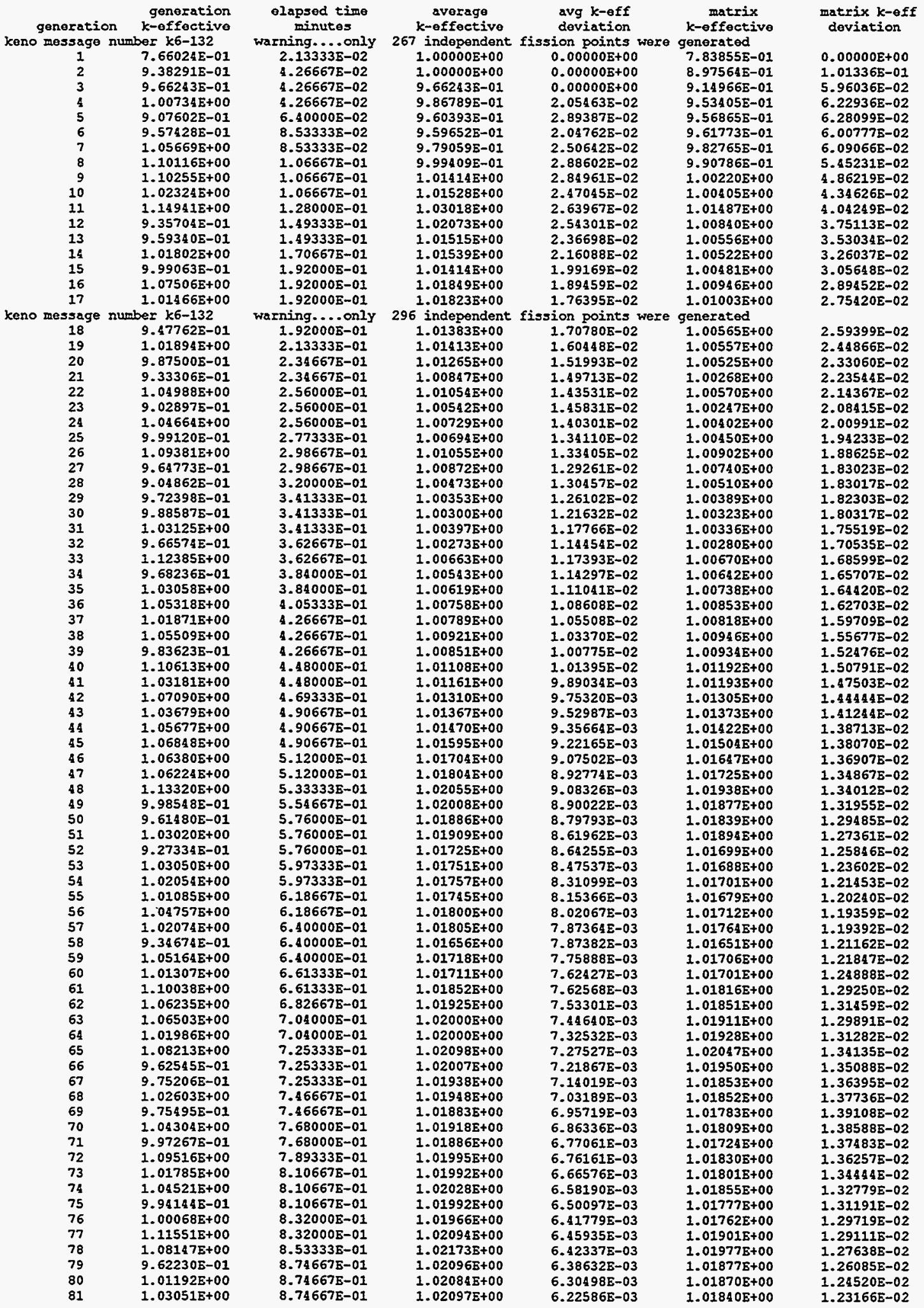

\section{NUREG/CR-0200,}




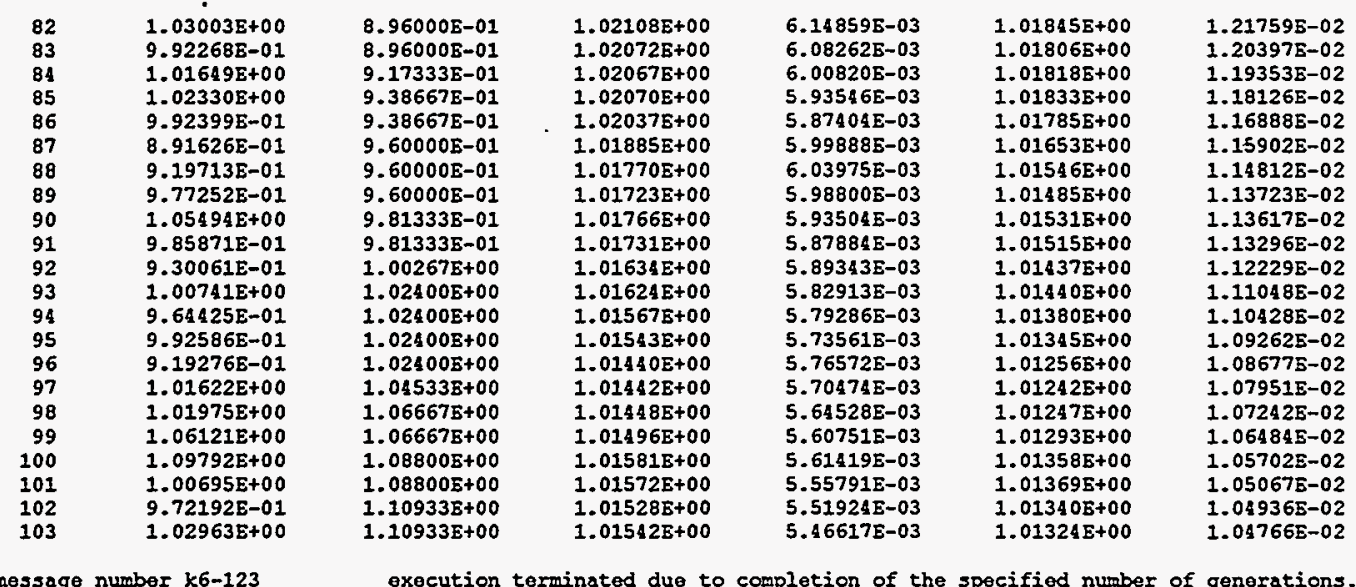

the matrix $k$-effective is the largest eigenvalue of the fission production by position index matrix. there are nbrmax * nbymax - nbzmax positions in an array. 


\begin{tabular}{|c|c|c|c|c|c|c|c|c|}
\hline \multirow{2}{*}{$\begin{array}{l}\text { l1fetsme }=4.4 \\
\text { gu bar }-2.5 \\
\text { no. of Initial } \\
\text { generations } \\
\text { shipped }\end{array}$} & $\begin{array}{r}7725-06+ \\
608 \mathrm{E}+00+ \\
\text { energy }\end{array}$ & $\begin{array}{l}o x=8 \\
\text { or }=1 \\
y(e v)\end{array}$ & $\begin{array}{l}8.99083 \mathrm{E}-08 \\
1.40421 \mathrm{E}-03 \\
\text { of the average }\end{array}$ & $\begin{array}{r}\text { sample problem } 194 \\
\text { generation } \\
\text { average fission } 9 \\
\text { e lethrgy causing fis } \\
\text { self multiplica }\end{array}$ & $\begin{array}{l}\text { aqueous } 4 \text { meeal arzay } \\
\text { time = } 5.31792 \mathrm{E}-06+ \\
\text { roup = } 1.41476 \mathrm{E}+01 \text { + } \\
\text { sion }=1.85333 \mathrm{E}+02+ \\
\text { tion }=1.01225 \mathrm{E}+00 \text { + }\end{array}$ & $\begin{array}{l}\text { of arrays (satep prob } \\
\text { or - } 1.24913 E-07 \\
\text { or - } 9.90757 E-02 \\
\text { or - } 1.6611 E+01 \\
\text { or - 5.92558E-03 }\end{array}$ & 12) & \multirow[b]{2}{*}{$\begin{array}{c}\text { eviation of } \\
\text { variance } \\
\text { (per cent) }\end{array}$} \\
\hline & $\begin{array}{l}\text { average } \\
k \text {-effective }\end{array}$ & & deviation & $\begin{array}{c}67 \text { per cent } \\
\text { contidence interval }\end{array}$ & $\begin{array}{c}95 \text { per cent } \\
\text { confidence interval }\end{array}$ & $\begin{array}{c}99 \text { per cent } \\
\text { confidence interval }\end{array}$ & $\begin{array}{l}\text { number of } \\
\text { alstories }\end{array}$ & \\
\hline 3 & 1.01592 & + or - & -.00550 & 1.01042 to 1.02141 & 1.00492 to 1.02691 & .99942 to 2.03241 & 30000 & 13.2575 \\
\hline 4 & 1.01600 & $+o r=$ & $=.00555$ & 1.02045 to 1.02156 & 1.00489 to 1.02711 & .99934 to 1.03266 & 29700 & 13.2262 \\
\hline 5 & 1.02711 & + or - & -.00550 & 2.02161 to 3.02261 & 1.00612 to 1.02811 & 1.00061 to 1.03360 & 29400 & 13.4186 \\
\hline 6 & 1.01772 & + or & -.00552 & 1.01220 to 1.02324 & 1.00668 to 2.02876 & 1.00116 to 1.03429 & 29100 & 13.5929 \\
\hline 7 & 1.01732 & + or & -.00556 & 1.01175 to 1.02288 & 1.00619 to 1.02844 & 1.00063 to 1.03401 & 28800 & 13.6570 \\
\hline 8 & 1.01644 & +or - & -.00555 & 1.01088 to 2.02199 & 1.00533 to 1.02754 & .99978 to 1.03309 & 28500 & 13.9239 \\
\hline 9 & 1.01552 & + or - & -.00553 & 1.00999 to 1.02105 & $1.00445=01.02659$ & 99892 to 1.03212 & 28200 & 14.2077 \\
\hline 10 & 1.01544 & $+05-$ & -.00559 & 1.00984 to 1.02103 & 1.00425 to 1.02662 & .99866 to 1.03221 & 27900 & 14.1736 \\
\hline 11 & 1.01398 & + or - & -.00546 & 1.00852 to 1.01941 & 1.00306 to 1.02490 & .99760 to 1.03036 & 27600 & 13.8415 \\
\hline 12 & 1.01484 & + or - & -.00545 & 1.00939 to 1.02029 & 1.00394 to 1.02574 & .99849 to 1.03119 & 27300 & 14.1486 \\
\hline 27 & 1.01493 & + or - & -.00569 & 1.00925 to 1.02062 & 1.00356 to 1.02631 & .99788 to 1.03199 & 25800 & 14.4451 \\
\hline 22 & 1.01663 & + or - & -.00586 & 1.01076 to 1.02249 & 1.00490 to 1.02836 & .99903 to 1.03422 & 24300 & 15.1754 \\
\hline 27 & 1.01763 & + or - & -.00592 & 1.01170 to 1.02355 & 1.00578 to 1.02948 & .99986 to 1.03540 & 22800 & 15.9821 \\
\hline 32 & 1.02079 & $+02-$ & -.00603 & 1.01476 to 1.02682 & 1.00872 to 1.03286 & 1.00269 to 1.03889 & 21300 & 16.7464 \\
\hline 37 & 1.01942 & + or - & -.00623 & 1.01319 E0 1.02564 & 1.00697 to 1.03187 & 1.00074 to 1.03809 & 29800 & 17.2931 \\
\hline 42 & 1.01695 & $+02-$ & -.00647 & 1.01048 to 1.02342 & 1.00402 to 1.02988 & .99755 to 1.03635 & 18300 & 18.2226 \\
\hline 47 & 2.01332 & + or - & -.00682 & 1.00650 to 1.02014 & .99967 to 1.02697 & .99285 to 1.03379 & 26800 & 19.2924 \\
\hline 52 & 1.01363 & + or - & -.00682 & 1.00681 to 1.02045 & 1.00000 to 1.02726 & .99318 to 1.03408 & 15300 & 20.3986 \\
\hline 57 & 1.01228 & + or - & -.00751 & 1.00477 to 1.01979 & .99726 to 1.02731 & .98974 to 1.03482 & 13800 & 20.2128 \\
\hline 62 & 1.00982 & + or - & -.00776 & 1.00207 to 1.01758 & .99431 to 1.02534 & .98655 to 1.03310 & 12300 & 22.7435 \\
\hline 67 & 1.00828 & + or - & -.00830 & .99998 to 1.01658 & .99168 to 1.02488 & .98337 to 1.03318 & 10800 & 25.4805 \\
\hline 72 & 1.00519 & + or - & -.00906 & .99614 to 1.01425 & .98708 to 1.02331 & .97803 to 1.03236 & 9300 & 27.6581 \\
\hline 77 & .99953 & + or - & -.00972 & 98981 to 1.00924 & .98009 to 1.01896 & -97038 to 1.02867 & 7800 & 28.2542 \\
\hline 82 & .99388 & + or - & -.01097 & .98291 to 1.00485 & .97194 to 1.01582 & .96097 to 1.02679 & 6300 & 31.7664 \\
\hline 87 & .99721 & + or - & -.01267 & .98454 to 1.00988 & .97187 to 1.02255 & .95920 to 1.03522 & 4800 & 33.3090 \\
\hline 92 & 1.00796 & + or - & -.01442 & .99354 to 1.02238 & .97912 to 1.03681 & .96469 to 1.05123 & 3300 & 49.1956 \\
\hline 97 & 1.03128 & + or - & -.01785 & 1.01343 to 1.04912 & .99558 to 1.06697 & .97773 to 1.08482 & 2800 & 60.5636 \\
\hline
\end{tabular}

NUREG/CR-0200, Vol. 2, Rev. 5 


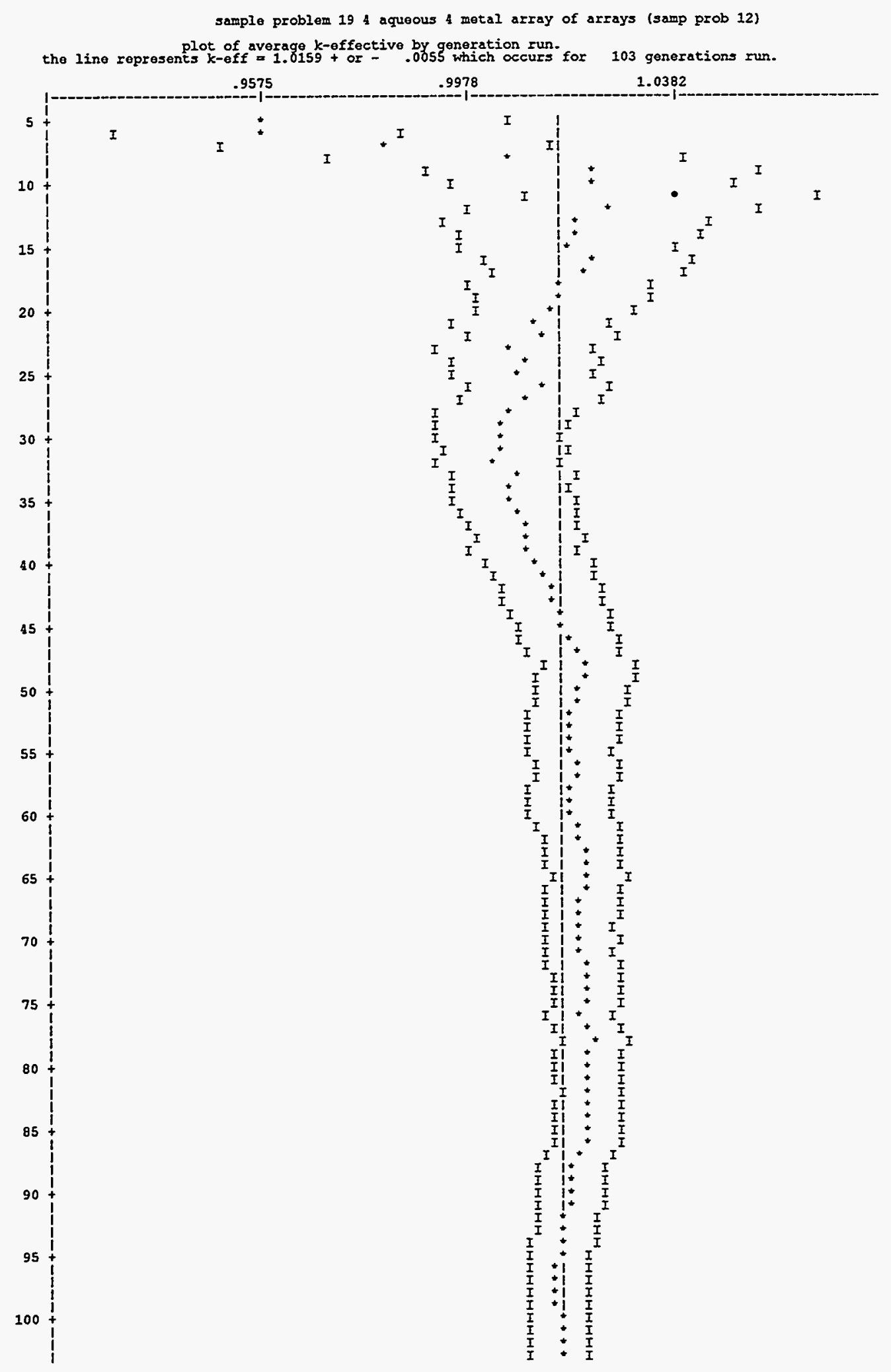

F17.E.41

NUREG/CR-0200,

Vol. 2, Rev. 5 


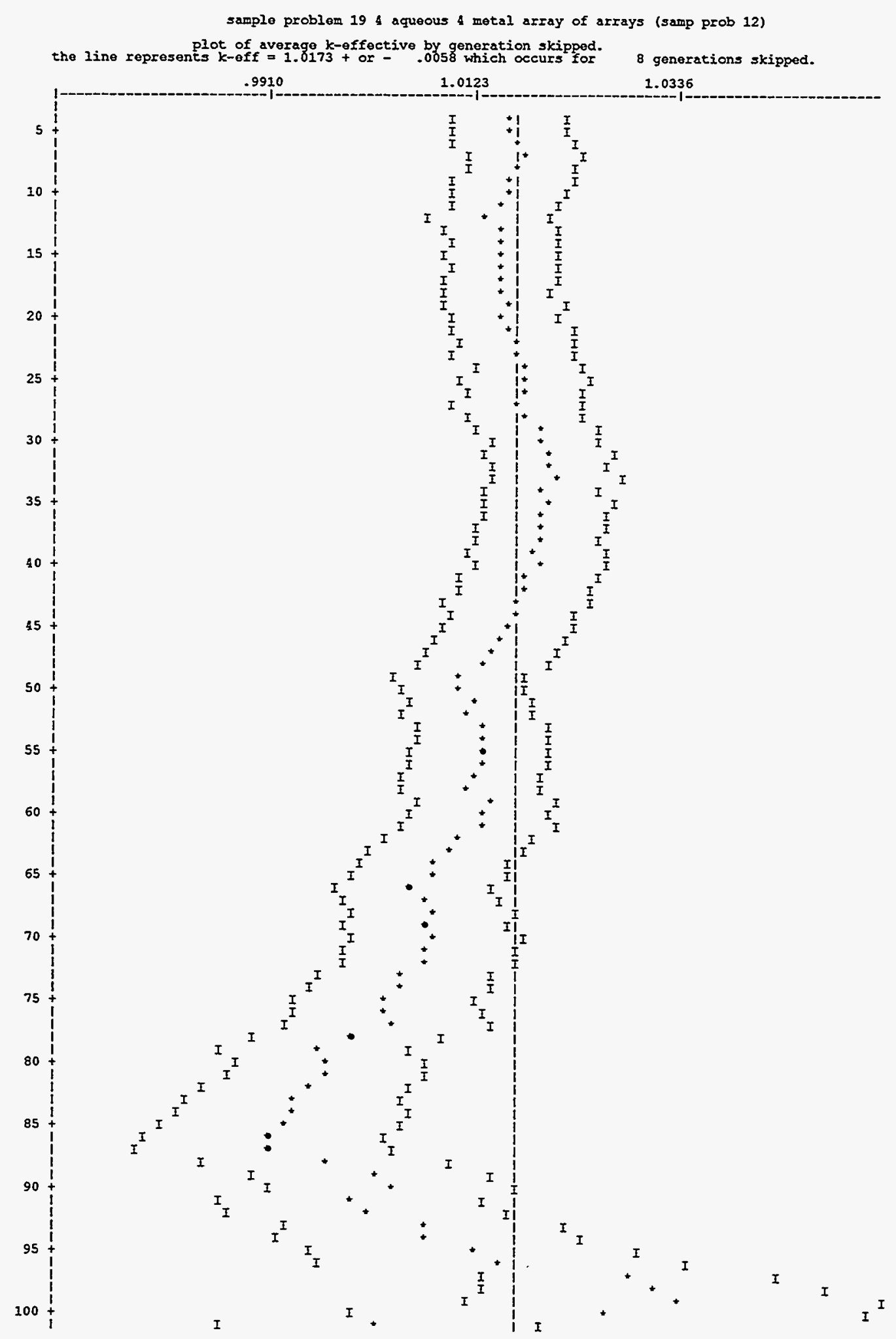

$k$-effective satisfies the chi*+2 test for normality at the 95 level 


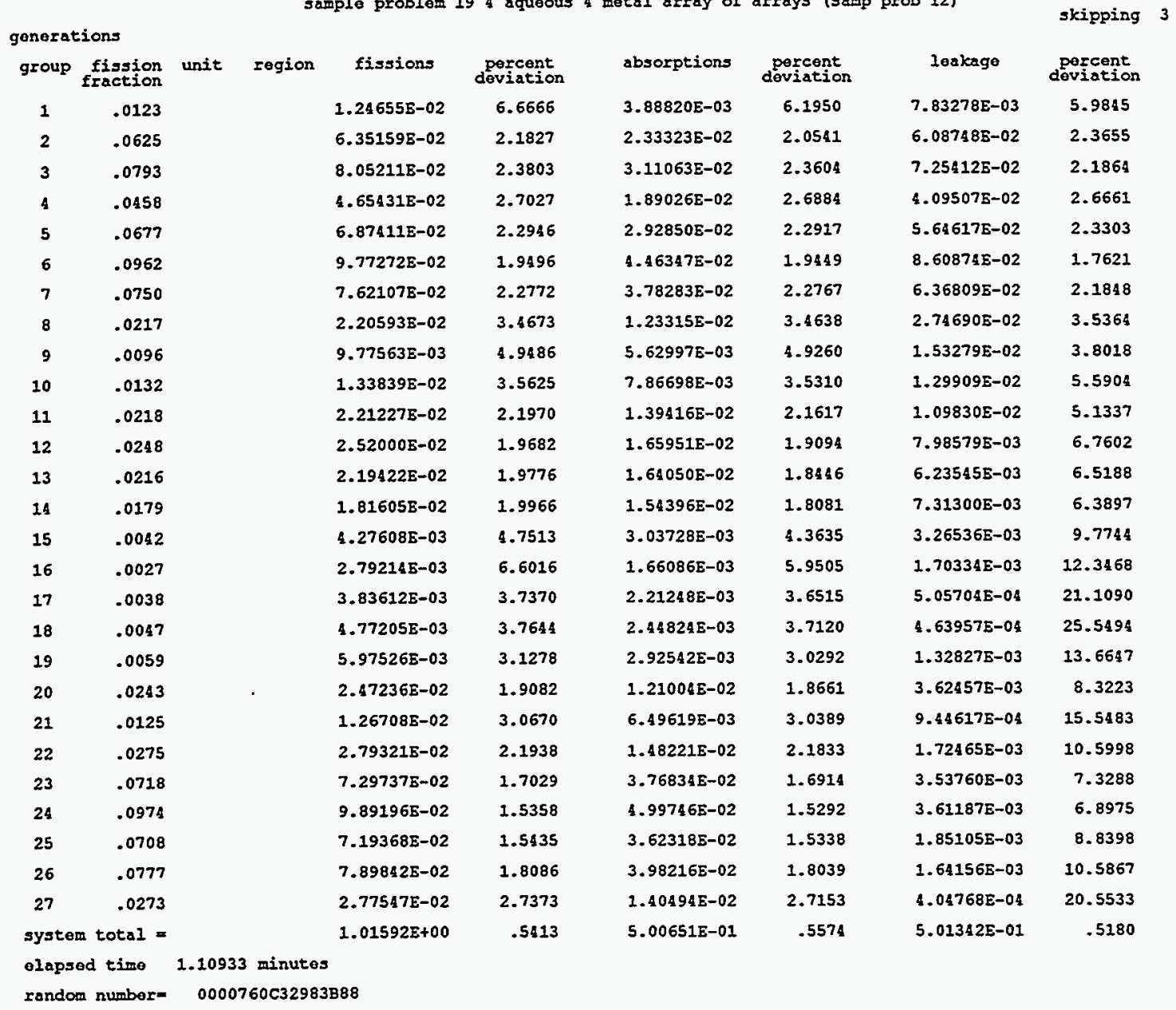


sample problem 194 aqueous 4 metal array of arrays (samp prob 12)

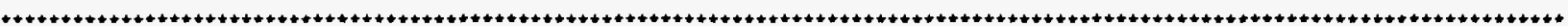

position k-effective $=1.01345 \mathrm{E}+00+$ or $-1.04790 \mathrm{E}-02$

the position k-effectivo is the largest eigenvalue of the fission production by position index matrix.

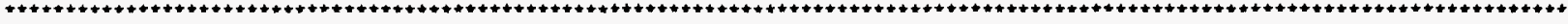

elapsed time 1.10933 minutes

fission production by position index matrix

$(i, j) p$ is the number of next generation neutrons produced at position index $j$ by a neutron born at position index $i$.

( 1, 1) $9.01 \mathrm{E}-01$ ( 1, 2) $1.86 \mathrm{E}-01$ ( 1, 3) $0.00 \mathrm{E}+00$

(2, 1) $1.04 E-01$ ( 2, 2) $8.42 \mathrm{E}-01$ (2, 3) $0.00 \mathrm{E}+00$

(3, 1) $0.00 E+00(3,2) 0.00 E+00(3,3) 0.00 E+00$

NUREG/CR-0200,

Vol. 2, Rev. 5

F17.E.44 
sample problem 194 aqueous 4 motal array of arrays (samp prob 12) source vector by position index

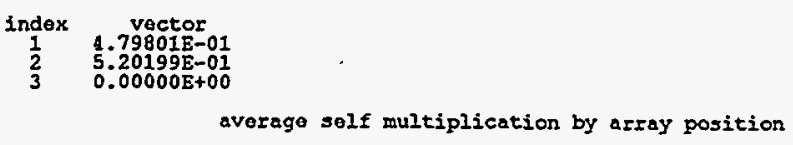

the numbor of next generation neutrons produced in a unit located at a given position in the array by 
sample problem 19 aqueous 4 metal array of arrays (samp prob 12)

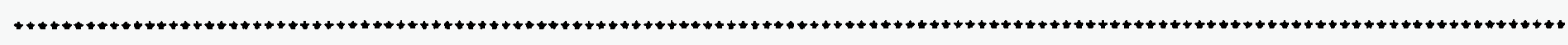

unit $k$-effective $1.01345 \mathrm{E}+00+$ or $-1.04790 \mathrm{E}-02$

the unit $k$-effective is the largest eigenvalue of the fission production by unit number matrix.

elapsed time 1.10933 minutes

fission production by unit number matrix

( 1,1$) 8.42 \mathrm{E}-01(1,2) 1.04 \mathrm{E}-01(1,3) 0.00 \mathrm{E}+00(1$, 4) $0.00 \mathrm{E}+00$ ( 1,5$) 0.00 \mathrm{E}+00$

(2, 1) $1.86 \mathrm{E}-01(2,2) 9.01 \mathrm{E}-01(2,3) 0.00 \mathrm{E}+00(2$, 4) $0.00 \mathrm{E}+00$ (2, 5) $0.00 \mathrm{E}+00$

(3, 1) $0.008+00(3,2) 0.00 E+00(3,3) 0.00 \mathrm{E}+00(3,4) 0.00 \mathrm{E}+00(3,5) 0.00 \mathrm{E}+00$

(4, 1) $0.00 E+00(4,2) 0.00 E+00(4,3) 0.00 E+00(4,4) 0.00 E+00(4,5) 0.00 E+00$

(5, 1) $0.00 E+00(5$, 2) $0.00 E+00(5,3) 0.00 E+00(5$, 4) $0.00 E+00$ ( 5, 5) $0.00 E+00$

NUREG/CR-0200,

Vol. 2, Rev. 5

F17.E.46 
sample problem 194 aqueous 4 metal array of arrays (samp prob 12) souree vector by unit

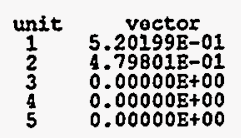

average self multiplication by unit

the number of next generation neutrons produced in a unit by
a noutron born in that some unit is $8.69919 E-01+$ or $-5.02814 E-03$ 
aple problem 194 aqueous 4 metal array of arrays (samp prob 12)

*t+ fission densities *t+*

\begin{tabular}{|c|c|c|c|c|}
\hline unit & region & $\begin{array}{l}\text { fission } \\
\text { donsity }\end{array}$ & $\begin{array}{l}\text { percent } \\
\text { deviation }\end{array}$ & $\begin{array}{l}\text { total } \\
\text { fissions }\end{array}$ \\
\hline 1 & $\begin{array}{l}\frac{1}{2} \\
3\end{array}$ & $\begin{array}{l}1.327 E-01 \\
0.000 E+00 \\
0.000 E+00\end{array}$ & $\begin{array}{r}1.20 \\
.00 \\
.00\end{array}$ & $\begin{array}{l}5.308 \mathrm{E}-01 \\
0.000 \mathrm{~B}+00 \\
0.000 \mathrm{E}+00\end{array}$ \\
\hline 2 & $\frac{1}{2}$ & $\begin{array}{l}1.213 E-01 \\
0.000 E+00\end{array}$ & $\begin{array}{r}1.26 \\
.00\end{array}$ & $\begin{array}{l}4.851 E-01 \\
0.000 E+00\end{array}$ \\
\hline 3 & 1 & $0.000 \mathrm{E}+00$ & .00 & $0.000 \mathrm{E}+00$ \\
\hline 4 & $\frac{1}{2}$ & $\begin{array}{l}0.000 E+00 \\
0.000 E+00\end{array}$ & $\begin{array}{l}.00 \\
.00\end{array}$ & $\begin{array}{l}0.000 E+00 \\
0.000 E+00\end{array}$ \\
\hline 5 & 1 & $0.000 \mathrm{E}+00$ & .00 & $0.000 \mathrm{E}+00$ \\
\hline
\end{tabular}

global unit

NUREG/CR-0200,

Vol. 2, Rev. 5

F17.E.48 


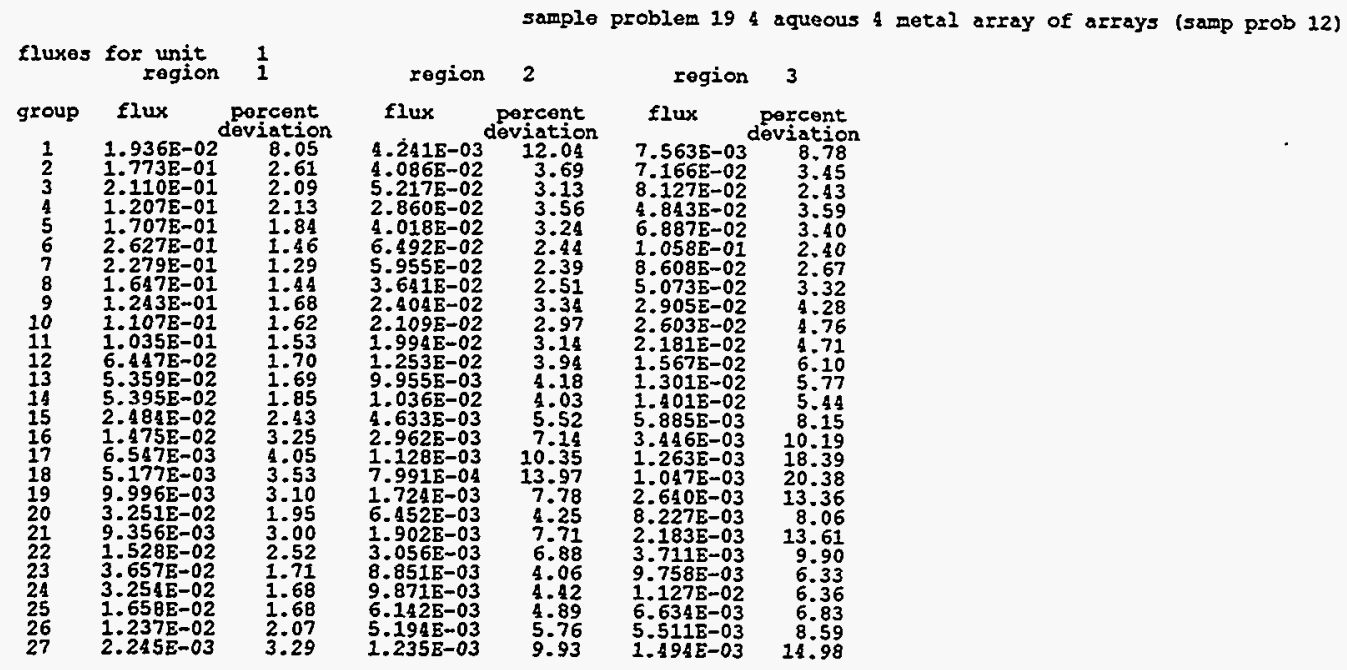

F17.E.49

NUREG/CR-0200,

Vol. 2, Rev. 5 


\begin{tabular}{|c|c|c|c|c|}
\hline uxes & 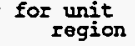 & $\frac{2}{1}$ & region & 2 \\
\hline group & flux & & flux & d \\
\hline $\begin{array}{r}1 \\
2 \\
3 \\
4 \\
5 \\
5 \\
7 \\
7 \\
8 \\
9 \\
10 \\
11 \\
12 \\
13 \\
14 \\
15 \\
16 \\
17 \\
19 \\
20 \\
21 \\
22 \\
23 \\
24 \\
25 \\
26 \\
27\end{array}$ & 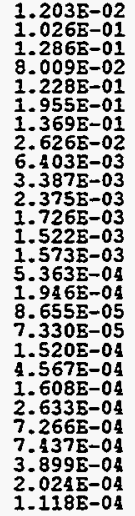 & $\begin{array}{r}6.25 \\
2.12 \\
2.42 \\
2.97 \\
2.36 \\
1.90 \\
2.19 \\
4.02 \\
8.48 \\
9.98 \\
9.92 \\
13.71 \\
13.74 \\
11.96 \\
11.51 \\
21.66 \\
36.75 \\
35.63 \\
43.54 \\
34.80 \\
17.72 \\
28.36 \\
22.37 \\
14.47 \\
15.44 \\
18.31 \\
26.95 \\
46.80\end{array}$ & 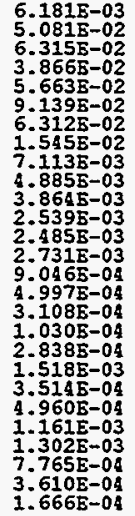 & $\begin{array}{r}3.26 \\
2.83 \\
3.42 \\
2.48 \\
2.17 \\
2.17 \\
2.64 \\
4.96 \\
8.48 \\
9.77 \\
10.79 \\
13.69 \\
14.62 \\
13.55 \\
13.60 \\
23.10 \\
26.74 \\
39.22 \\
52.15 \\
30.54 \\
16.56 \\
32.36 \\
28.56 \\
12.76 \\
14.52 \\
19.39 \\
22.70 \\
38.36\end{array}$ \\
\hline
\end{tabular}


sample problem 194 aqueous 4 metal array of arrays (samp prob 12)

\begin{tabular}{|c|c|c|}
\hline fluxos & for unit & $\begin{array}{l}3 \\
1\end{array}$ \\
\hline group & flux & percen \\
\hline $\begin{array}{l}1 \\
2 \\
3 \\
4 \\
5 \\
6 \\
7 \\
7 \\
8 \\
99 \\
10 \\
11 \\
12 \\
13 \\
14 \\
15 \\
16 \\
17 \\
19 \\
20 \\
21 \\
22 \\
23 \\
24 \\
25 \\
26 \\
27\end{array}$ & 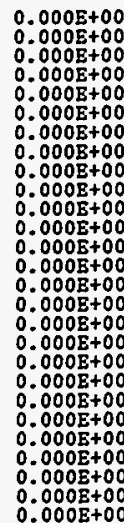 & $\begin{array}{l}00 \\
000 \\
000 \\
000 \\
000 \\
000 \\
000 \\
000 \\
000 \\
000 \\
000 \\
000 \\
000 \\
000 \\
000 \\
000 \\
000 \\
000 \\
000 \\
000 \\
000 \\
000 \\
000 \\
000 \\
000 \\
000\end{array}$ \\
\hline
\end{tabular}


sample problem 19 aqueous 4 motal array of arrays (samp prob 12)

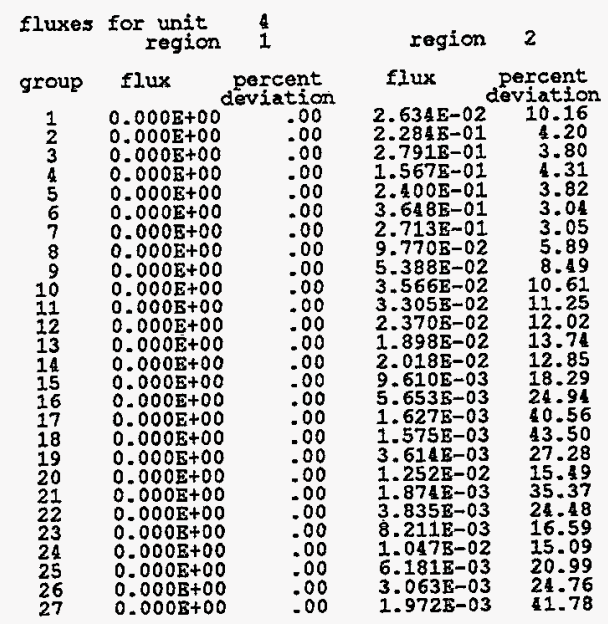


c.

'00Z0-\&ว/DGषกN
ESㅋㄴㄴㅕ

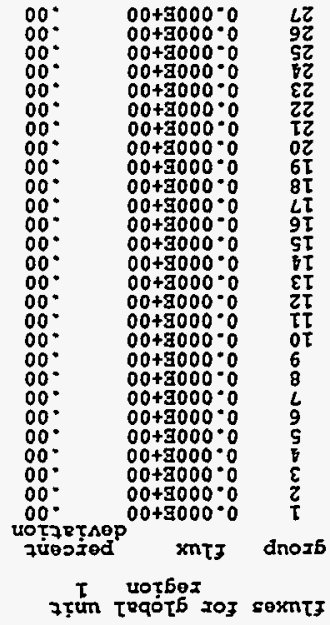


sample problem 19 aqueous 4 metal array of arrays (samp prob 12)

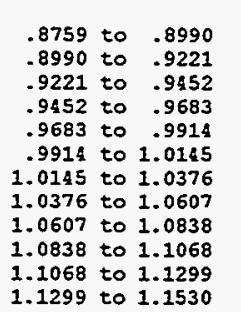

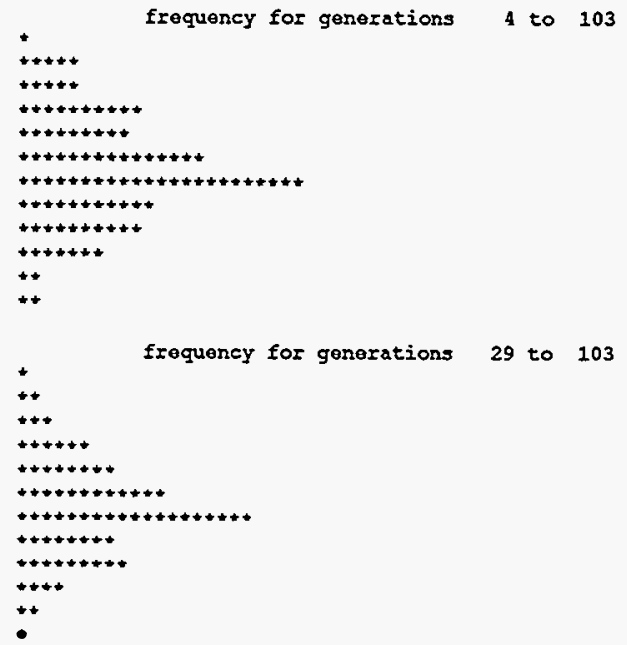




\section{F17.F. LIST OF KENO V.a VALIDATION REPORTS}

This section contains a list of $\mathrm{KENO}$ validation reports in reverse chronological order. This list includes validation reports for KENO V.a and older versions of KENO. These reports form the basis of the validation reports to be done on KENO-VI.

ORNL-6512

ORNL-6511

ORNL-6510

NEACRP-L-306

Y/DD-419

ORNL-6449
Validation Studies Based on Data From Criticality Experiments Performed With Mixed Oxide Fuel Pins Moderated by Plutonium-Uranium-Gadolinium Nitrate Solutions, G. R. Smolen, Martin Marietta Energy Systems, Inc., Oak Ridge Natl. Lab. (to be published).

Validation Studies Based on Data From Plutonium-Uranium Nitrate Critical Experiments Conducted in Annular Geometry, G. R. Smolen, Martin Marietta Energy Systems, Inc., Oak Ridge Natl. Lab. (to be published).

Validation Studies Based on Data From Plutonium-Uranium Nitrate Critical Experiments Conducted in Slab and Cylindrical Geometries, G. R. Smolen, Martin Marietta Energy Systems, Inc., Oak Ridge Natl. Lab., December 1989.

Standard Problem Exercise on Criticality Codes for Dissolving Fissile Oxides in Acids, OECD, Paris, France, 1989.

Validation Check Cases of SCALE77 on the ORGDP IBM-3083, W. C. Jordan, H. R. Dyer, J. C. Turner, Martin Marietta Energy Systems, Inc., Oak Ridge Y-12 Plant, January 1989.

Validation Studies Based on Data From Low Concentration Mixed Pu $+U$ Aqueous Critical Experiments," G. R. Smolen, Martin Marietta Energy Systems, Inc., Oak Ridge Natl. Lab., August 1988.

Notice: APPLIED TECHNOLOGY INFORMATION

Receipt of this report requires approval from:

D. E. Bailey

Director, Division of Fuels and Reprocessing

NE-551

U.S. Department of Energy

Washington, DC 20545 
Validation Studies Performed With Water-and Organic-Moderated and Reflected Mixed Oxide Fuel Pin Critical Experiments, G. R. Smolen, Martin Marietta Energy Systems, Inc., Oak Ridge Natl. Lab., June 1988.

Notice: APPLIED TECHNOLOGY INFORMATION

Receipt of this report requires approval from:

D. E. Bailey

Director, Division of Fuels and Reprocessing

NE-551

U.S. Department of Energy

Washington, DC 20545

ORNL/CSD/TM-242 Recalculation of a Few Bare Plutonium Critical Arrays, H. R. Dyer, Martin Marietta Energy Systems, Inc., Oak Ridge Nat1. Lab., April 1987.

ORNL/CSD/TM-238 Validation of KENO-V.a Comparison with Critical Experiments, W. C. Jordan, N. F. Landers, L. M. Petrie, Martin Marietta Energy Systems, Inc., Oak Ridge Natl. Lab., December 1986.

ORNL/TM-9668

Validation Studies for KENO-IV with Mixed Plutonium-Uranium Critical Experiments, R. T. Primm III, Martin Marietta Energy Systems Inc., Oak Ridge Natl. Lab., November 1985.

Notice: APPLIED TECHNOLOGY INFORMATION

Receipt of this report requires approval from

D. E. Bailey

Director, Division of Fuels and Reprocessing

NE-551

U.S. Department of Energy

Washington, DC 20545

ORNL/CFRP-84/20 Validation of the SCALE Code System and One Cross-Section Library for Plutonium and Gadolinium Solutions, R. L. Sanders, University of Tennessee, July 1985.

Notice: APPLIED TECHNOLOGY INFORMATION

Receipt of this report requires approval from

D. E. Bailey

Director, Division of Fuels and Reprocessing

NE-551

U.S. Department of Energy

Washington, DC 20545

ORNL/CSD/TM-223 Validation of KENO-Y.a and Two Cross-Section Libraries for Criticality Calculations of Low-Enriched Uranium Systems, M. E. Easter, Martin Marietta Energy Systems Inc., Oak Ridge Natl. Lab., July 1985.

ORNL/TM-9402

Validation of the SCALE Code System and Two Cross-Section Libraries for Plutonium Benchmark Experiments, M.E. Easter, University of Tennessee, R. T. Primm III, Martin Marietta Energy Systems Inc., Oak Ridge Natl. Lab., January 1985.

Notice: APPLIED TECHNOLOGY INFORMATION

F17.F.2 
Receipt of this report requires approval from

D. E. Bailey

Director, Division of Fuels and Reprocessing

NE-551

U.S. Department of Energy

Washington, DC 20545

ORNL/CSD/TM-224 Assessment of Computational Performance in Nuclear Criticality, L. M. Petrie, J. T. Thomas, Martin Marietta Energy Systems Inc., Oak Ridge Natl. Lab., January 1985.

ORNL/CSD/TM-221 Validation of the Monte Carlo Criticality Program KENO-V.a for Highly Enriched Uranium Systems, J. R. Knight, Martin Marietta Energy Systems, Inc., Oak Ridge Natl. Lab., November 1984.

CSNI Report No. 78 Standard Problem Exercise on Criticality Codes for Large Arrays of Packages on Fissile Materials, CSNI Working Group, OECD, Paris, France, August 1984.

Trans. Am.

Nucl. Soc.

"Validation of the NITAWL-KENO Methodology in Modeling New-Fuel V44, p. 291-293

(US) (1983)

CSNI Report No. 71

Storage Criticality," D. G. Napolitano, Dr. Harris, P.F. Rose, E. Schmidt E. Schmidt, M. Divadeennam, Yankee Atomic Electric Co., Framingham, Ma. 01701 (1983).

Standard Problem Exercise on Criticality Codes for Spent LWR Fuel Transport Containers, CSNI Group of Experts on Nuclear Criticality Safety Computations, OECD, Paris, France, May 1982.

NUREG/CR-1917

Validation of Three Cross-Section Libraries Used with the SCALE System for Criticality Safety Analysis," ORNL/NUREG/CSD/TM-19, A. M. Hathout et al., U.S. Nuclear Regulatory Commission, June 1981.

$\mathrm{Y}-2234$

Validation of the Monte Carlo Criticality Program KENO-IV and the Hansen-Roach "Sixteen-Energy Group Cross-Sections for High Assay Uranium Systems," G. R. Handley, L. C. Masters, R. V. Stachowiak, Union Carbide Corp., Nuclear Div., Oak Ridge Y-12 Plant, April 1981.

Trans. Am.

"Validation of Criticality Safety Broad-Group Library Using Uranium Systems," Nucl. Soc.

V27, p. 406-407

US (1977)

Y-1948 N. F. Cross, R. M. Westfall, K. R. Turnbull, P. B. Fox, Union Carbide Corp., Nuclear Div., Oak Ridge Natl. Lab. (1977).

Validation of the KENO code for Nuclear Criticality Safety Calculations of Moderated, Low-Enriched Uranium Systems," G. R Handley and C. M. Hopper, Union Carbide Corp., Nuclear Div., Oak Ridge Y-12 Plant, 1974.

Y-1858

Validation Checks of the ANISN and KENO Codes by Correlation with Experimental Data," G. R. Handley and C. M. Hopper, Union Carbide Corp., Oak Ridge Y-12 Plant, 1972.

F17.F.3 